THE MANHATTAN-ROCHESTER COALITION, RESEARCH ON THE HEALTH EFFECTS OF RADIOACTIVE MATERIALS, AND TESTS ON VULNERABLE POPULATIONS WITHOUT CONSENT IN ST. LOUIS, 1945-1970.

A Dissertation
presented to
the Faculty of the Graduate School
at the University of Missouri-Columbia
In Partial Fulfillment
of the Requirements for the Degree
Doctor of Philosophy
LISA MARTINO-TAYLOR
Dr. Clarence Y.H. Lo, Dissertation Supervisor
DECEMBER 2011


(C) Copyright by Lisa Martino-Taylor 2011

All Rights Reserved 
The undersigned, appointed by the dean of the Graduate School, have examined the dissertation entitled:

THE MANHATTAN-ROCHESTER COALITION, RESEARCH ON THE HEALTH EFFECTS OF RADIOACTIVE MATERIALS, AND TESTS ON VULNERABLE POPULATIONS WITHOUT CONSENT IN ST. LOUIS 1945-1970.

\author{
presented by Lisa Martino-Taylor, \\ a candidate for the degree of \\ Doctor of Philosophy,
}

And hereby certify that, in their opinion, it is worthy of acceptance.

Professor Clarence Y.H. Lo

Professor John Galliher

Professor Ibitola Pearce

Professor J. Sandy Rikoon 
To the victims of the Manhattan-Rochester Coalition, who each had a right to know.

To victims of warfare and war-related activities around the globe.

To my former work colleague, as well as my former neighbor, for asking questions about their victimization and entrusting me with their personal histories, which enabled me to know of, and explore this issue.

To three incredible men in my life: Steve, Drew, and Jake, who are a constant reminder of what is right and good in the world.

To my husband, who enthusiastically supported me throughout this project, and who was always willing to engage in discussions about chemical, biological, and nuclear weapons, over coffee and cornflakes. 


\section{ACKNOWLEDGEMENTS}

My deepest thanks goes to Clarence Lo, who has been extremely supportive during my entire time at University of Missouri-Columbia, and throughout this dissertation experience as my chair. You always provided a wonderful balance of intellectual provocation, unwavering support, and enthusiasm regarding this project. In what began as a tremendous amount of respect for you as a scholar, has only increased over these past five years. Your intellect, patience, insight, guidance, humor, and confidence in the abilities of this advisee, are deeply appreciated.

Thanks to Dr. John Galliher, who was an enthusiastic and early member on my committee, and who always added greatly to the discussions. I am very appreciative of your contributions and support, in regard to this work. Thank you for taking time to support this project, and for providing insight when insight was needed. It was such an extraordinary pleasure to have you seated on my committee.

Thank you to Dr. Ibitola Pearce, who so generously climbed on board this project during my final year, despite an incredibly busy work calendar. It was my hope that you would help me maintain a global perspective in what seemed like such a local issue, and you never disappointed. Your insightful comments and provocative questions pushed me to expand my horizon outwards. I will hear your words in future endeavors, and rest assured, that I am and will continue to be a better scholar because of you.

Professor Sandy Rikoon, you are a wonderful individual and have been a superb committee member. You posed thoughtful questions, and always offered excellent guidance and feedback. Your kindness and support was invaluable; I always felt incredible encouragement, and I so appreciated your guidance. I could not have asked for a more wonderful outside committee member than you.

To my entire committee: Thank you all. I was often awe-struck by the individual and collective knowledge around the table. What a humbling and outstanding experience it was, and I will be forever grateful to all of you, and for this experience.

A very special thanks goes to the esteemed Dr. Fred Emil Katz, who continues to be profoundly inspiring, and who offered supportive comments, kindness, and above all, a lovely friendship. 


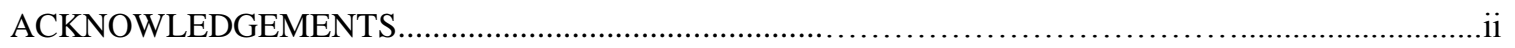

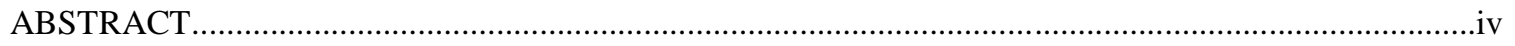

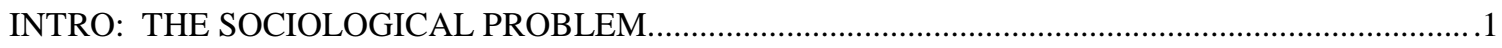

Chapter

1. METHODOLOGY

2. TARGET ST. LOUIS: MOSCOW AND AN AMERICAN "SLUM" IN THE

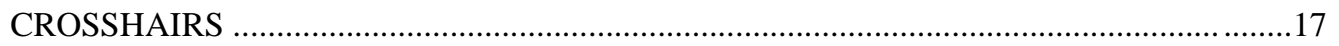

3. THE MANHATTAN-ROCHESTER COALITION ……….....................................................

4. SUNSHINE \& GABRIEL: ORGANIZATIONAL STRUCTURE .............................................105

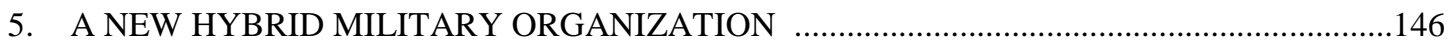

6. ETHICAL AND SOCIAL AUTISM: THE QUASHING OF INTERNAL AND EXTERNAL

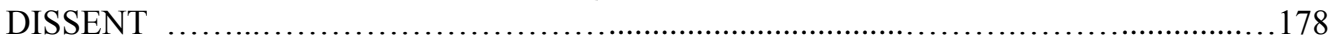

7. THE MANHATTAN-ROCHESTER COALITION AND A GLOBAL AMERICAN

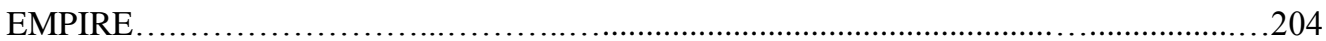

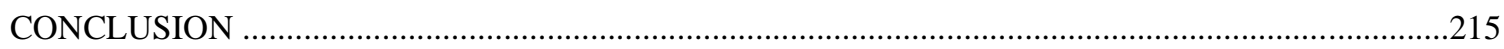

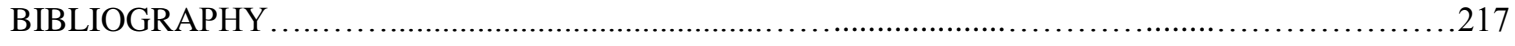

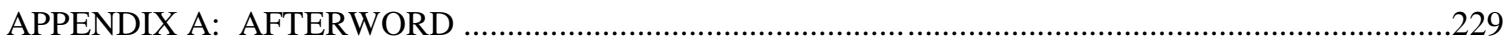

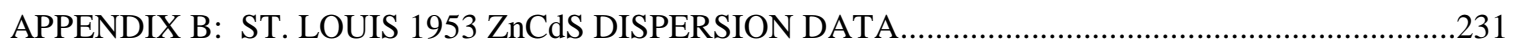

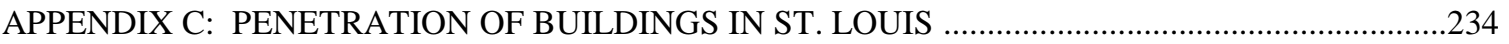

APPENDIX D: SYNOPSIS OF FINDINGS: GOVERNMENT ACCOUNTING OFFICE'S

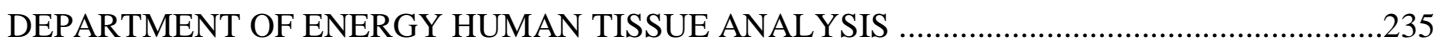

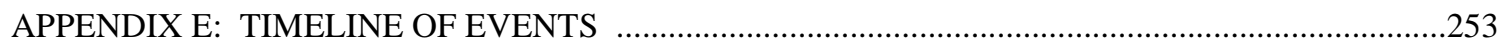

APPENDIX F: FOIA RESPONSE- ABERDEEN PROVING GROUND ............................................256

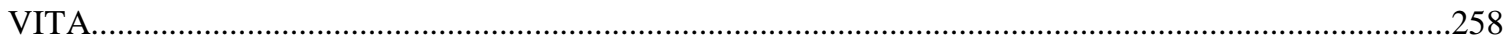

APPENDIX G: FOIA RESPONSE- DUGWAY PROVING GROUND: BEHAVIOR OF AEROSOL

CLOUDS WITHIN CITIES \& ST. LOUIS DISPERSION STUDY, VOL. II ANALYSIS .................259 


\title{
THE MANHATTAN-ROCHESTER COALITION, RESEARCH ON THE HEALTH EFFECTS OF RADIOACTIVE MATERIALS, AND TESTS ON VULNERABLE POPULATIONS WITHOUT CONSENT IN \\ ST. LOUIS, 1945-1970
}

\author{
Lisa Martino-Taylor
}

Dr. Clarence Y. H. Lo, Dissertation Supervisor

\begin{abstract}
This piece analyzes a covert Manhattan Project spin-off organization referred to here as the Manhattan-Rochester Coalition, and an obscure aerosol study in St. Louis, Missouri, conducted under contract by the U.S. military from 1953-1954, and 1963-1965. The militarysponsored studies targeted a segregated, high-density urban area, where low-income persons of color predominantly resided. Examination of the Manhattan-Rochester Coalition and the St. Louis aerosol studies, reveal their connections to each other, and to a much larger military project that secretly tested humans, both alive and deceased, in an effort to understand the effects of weaponized radiation. Through this case study, the author explores how a large number of participants inside an organization will willingly participate in organizational acts that are harmful to others, and how large numbers of outsiders, who may or may not be victims of organizational activities, are unable to determine illegal or harmful activity by an organization. The author explains how ethical and observational lapses are engineered by the organization through several specific mechanisms, in an effort to disable critical analysis, and prevent both internal and external dissent of harmful organizational actions. Through studying the process of complex organizational deviance, we can develop public policies that protect the public's right to know, and construct checks and methods to minimize the chance of covert projects that are contrary to societal norms.
\end{abstract}




\section{INTRODUCTION:}

\section{THE SOCIOLOGICAL PROBLEM AND THE "THOUSAND PEOPLE BELOW"}

The principle of medical and surgical morality...consists in never performing on man an experiment which might be harmful to him to any extent, even though the result might be highly advantageous to science, i.e., to the health of others...it is immoral, then, to make an experiment on man when it is dangerous to him, even though the result may be useful to others.

(French physician Claude Bernard, 1865) ${ }^{1}$

$$
\text { Z }
$$

Fifteen years ago, while I was working as a researcher in St. Louis, Missouri, a respected acquaintance and colleague shared a troubling story with me. This reserved woman opened up about her recent diagnosis of breast cancer, and a haunting question that pressed upon her. As a young girl living in the city of St. Louis, her neighborhood and school had been "sprayed by the military". My colleague was consumed by worry that this event as a child, had triggered decades later, her breast cancer as an adult. Since my research at that time was focused on toxic threats in communities, she asked me if I knew about this issue. I had to admit with some embarrassment, that I had no information or knowledge about the event. I was asked if I would be willing to look for any information that might help her determine to what she had been exposed. Disturbed by her story, I attempted to locate information on the event, to little avail. According to public records, it was as if the event was the figment of a wild imagination. I informed my colleague that

\footnotetext{
${ }^{1}$ U.S. House of Representatives, 1994: 118.
} 
there was no information in the literature, and only one brief, uninformative mention in the news media. She graciously took the little information that I had located, and did not mention it again. I continued to find her story troubling, however.

Approximately a week or two later, there was a knock on my front door at home. My neighbor asked if she could have a minute of my time, and next shared a personal story with me. Ten years prior, she had survived a brain tumor. She explained that she had come to me for a specific reason, however... she had been sprayed as a child while on the playground at school, by "something that the military was doing", and she had for a decade believed that her brain tumor was caused by that event. Mouth agape, I pointedly asked if I was the victim of a distasteful joke. Perhaps my colleague and neighbor knew each other, and were testing me. How otherwise could two acquaintances of mine, who did not know each other, have lived in the same area at the same time, and experienced the same thing? How could both women know me and coincidentally share with me virtually identical stories, one on the heels of the other? I thought it perversely unbelievable. Taken aback by my response, my neighbor informed me a bit tersely, that her story was no joke, and pointed to her head where the tumor had threatened her life. Her expression said the rest. I shared with her the story of my colleague, told to me days prior. My neighbor's expression turned dark, as she surmised that something had happened to people in the city of St. Louis, and she needed to know more...might I be willing to help? She handed me a manila envelope, and said that then-Congressman Richard Gephardt had made an official inquiry about the incident; inside the folder was information related to his findings. I shut the door in an utter daze, not believing the 
incredible coincidence of two acquaintances with their shared experience. The fact that a Congressional investigation had taken place, and that there was almost no information in the literature, turned it from mere conjecture, to a mysteriously shrouded and chilling historical event. I again did cursory searches in the literature, and found virtually nothing on the subject. I informed my neighbor of this. We all fell back into life's rhythms and demands, moving on. Their stories however, stayed in the back of my mind, filed away for a future date when my schedule was less lean, and time was more generous.

Photocopies of the file that my neighbor had provided to me were eventually lost after several moves (until a day not long after I had drafted this piece, when my husband insisted that I go through some old boxes, and lo!...there was the long-lost file.) I am indebted to both my colleague and my neighbor, for sending me down this meandering path of discovery and despair. If I can locate them, they will get a copy of this piece and hopefully, they will forgive me for the belated answers to questions that stumped us all. The victims above all, have a right to know what happened, and that is something that has never been acknowledged by those who coordinated and conducted the St. Louis aerosol studies.

This has been a long discovery of peeling back layers of deception and secrecy to locate historical accuracy in this complex case study. My challenge beyond uncovering how it was that the St. Louis aerosol studies came to be, and all that they entailed, was to also explain how over a long period of time (in this case decades), a large number of rotating personnel- seemingly normal people (defined here as those who don't desire to impose harm on others in general) can knowingly come to engage in harmful or criminal actions 
towards others, or in unethical actions for the benefit of their organization. How can this be explained through this case study as well as the existing literature? How is it that given such a scenario, that even larger numbers of people can have no knowledge that a long series of harmful historical events occurred, even when they themselves may have been victimized? How can the existing literature explain the element of complex organizational actions, which diffuse internal and external dissent by hundreds, thousands, or tens of thousand of people involved in or directly effected by an organization's actions? How does it come to be that normally ethical individuals, who may be highly educated, and ethical and moral in other spheres of their daily lives, would carry forth the work of an organization that is harmful to others? How do we explain the ordinary "thousand people below" (those working for the elite, decision-makers in an organization), who seem to have no ethical sense in their sometimes substantial contributions to harmful organizational actions?

This piece reveals the emergence of a secret post-Manhattan Project group, referred to here as the Manhattan-Rochester Coalition. Members of this elite group embraced their roles as scientists engaged in the war effort for the United States, but their work would take an ugly turn during the Cold War that followed Hiroshima and Nagasaki, when they engaged with breathtaking detachment and frequency in human subject testing of radioactive isotopes. I examine the efforts of this group from the springboard of a series of classified but seemingly innocuous-sounding military-sponsored studies targeting civilians in the city of St. Louis, Missouri, beginning in 1953. What is framed as a simple study of cloud dispersal in an urban area is in fact, a deliberate, menacing 
targeting of American civilians in a long series of experimental Cold War weapons research and development that would ultimately target Russian civilians. Furthermore and most disturbingly, evidence indicates that the St. Louis aerosol studies may have involved the spraying of unsuspecting vulnerable populations with pernicious radioactive isotopes.

In this case study, we see a convergence of military and corporate interests, supported by political elites that served as defenders and champions of the Manhattan-Rochester Coalition. Stretching over five decades, state-sponsored human subject testing undertaken by members of the coalition was systematic, coordinated, and involved humans of all ages, both alive and dead. The astoundingly vast, highly-coordinated efforts of the coalition, and the decades-long series of projects warranted a shifting in and out of personnel, who were all required to maintain the utmost of secrecy and deception towards those outside the organization. This piece attempts to explain 1) how large numbers of individuals (in this case thousands were involved in the highly-coordinated efforts of the Manhattan-Rochester Coalition) inside an organization, can maintain sustained actions in secret that deviate greatly from society's norms, particularly when those actions are harmful to outsiders. There are many threads in the literature that advance our understanding of organizational structure, elite deviance, crime, and bureaucracies, but none fully explain the activity of this vast network of elite scientists and support teams of tens of thousands of individuals, who advanced the mission of the Manhattan-Rochester Coalition, and who were involved in reprehensible acts of human experimentation over five decades of the Cold War. This analysis examines 
organizational motivations along with the inter-organizational dynamics inside the Manhattan-Rochester Coalition. Specific mechanisms are employed that control potential dissent, both inside and outside the organization, and allows for uninterrupted continuance of non-normative activity by the coalition. In regard to these elements or organizational dynamics, this piece is unique to the literature.

I look first at my original concept of ethical autism, defined here as the purposeful reduction or blockage of information inside an organization or group, intending to 1) distort the perceptions of insiders to ensure compliance and advancement of the organizational goals 2) minimize the awareness of collective illegal and/or unethical activity of the organization, 3) create a false sense of security to members within the organization from outside threats due to illegal or unethical activity, 4) to stifle opposition, critical analysis, and ensure conformity to the organizational goals. Ethical autism ensures that the significance of harmful organizational actions will be underestimated by an internal audience; the control of information in this case study was essential to generating ethical autism.

I next propose the original concept of social autism to explain how organizations can successfully, systematically, and purposefully impede meaningful information flow to an external audience, in order to manipulate public opinion, impede public debate and dialogue, and to ensure that the significance of harmful organizational actions will be unknown to or underestimated by an external audience. Three specific mechanisms 
(snipping, spinning ${ }^{2}$, and blizzarding), explained herein, are used towards this end.

Snipping and blizzarding are original concepts, and unique to the literature. The three mechanisms (along with stonewalling) are used to regulate information outflow in an effort to obfuscate, downplay, or deny damaging organizational information to various internal and external parties. The purposeful and strategic utilization of these mechanisms thereby create internal effects (ethical autism) and external effects (social autism) on various audiences, whereby insiders and outsiders are deceived as to potential dangers or harmful acts, and whereby full and open debate is strategically suppressed. In this way, we can explain how "ethical lapses" might occur inside large organizations or coalitions that employ hundreds or thousands of individuals who move in and out of the organization over extended periods of time, such as during the five decades of statesponsored human subject testing in the United States. Through strategic use of these mechanisms, organizational leaders can control opposition, resistance, and debate both inside and outside the organization, in an effort to advance uninterrupted, organizational goals. Thusly, as the control of information is essential to generating ethical autism internally, the control of information is also essential to generating social autism in the external community.

\footnotetext{
2 "Spinning" is a public relations term originally used by various newspapers such as the UK Guardian in the late 1970s, or early 1980s.
} 


\section{CHAPTER I}

\section{METHODOLOGY}

The principle of medical and surgical morality...consists in never performing on man an experiment which might be harmful to him to any extent, even though the result might be highly advantageous to science, i.e., to the health of others... it is immoral, then, to make an experiment on man when it is dangerous to him, even though the result may be useful to others.

(French physician Claude Bernard, 1865) ${ }^{3}$

Z

A complex case study requires a variety of research methods to adequately address the issue; one methodology will not suffice in this type of multi-layered, multi-dimensional, long-sustained problematic. In fact, no single methodological approach would come close to explaining, or even defining the problem. When we look to the existing literature, some theories can explain part of the organizational dynamics and actions that occur in this case study. We can examine contributing elements such obedience, group influence/groupthink, rationalization, compartmentalization, tapping into ordinary attributes and personal goals to harness enthusiastic participation, dehumanization of outsiders (victims in particular), and the climate of the times. All of these help us to understand the events herein, in part. Yet complex crimes or acts of harm by an organization over an extended period of time, involving the contributions of thousands of seemingly "normal" people (no ill-intent) require us to go further in our explanation. Do all of the participants even realize that they are participating in harmful acts? If the

\footnotetext{
${ }^{3}$ U.S. House of Representatives, 1994: 118.
} 
victims don't know a harmful act has occurred, should we assume that the internal organizational participants know? Certainly some participants have full and complete knowledge, but do all?

My task was to look at this complex phenomenon from the vantage point of this specific case study. The actions of participants are not sufficiently explained by existing theory. The medical model does not suffice to explain organizational dynamics here, because the individuals that supported and advanced the projects for the military-scientist elites, were likely not pathological or deviant. In fact, one could argue that behind the efforts of the Manhattan-Rochester Coalition were normal, high-functioning universities and other institutions in this particular case. Indeed, this helped in part, to conceal the activities of the organization. The human rights model does not explain what occurred, either. At the time that the Manhattan-Rochester Coalition emerged at the end of WWII and the beginning of the Cold War, American exceptionalism was at a peak. The elite decisionmakers of the Manhattan-Rochester Coalition felt justified for their actions, in that they believed that they must preserve American freedom, as the most important place freedom and rights, in order to preserve world freedom. This in fact, was the basis of Cold War ideology. Indeed, it was the suspension of the human rights model, that allowed for ethical and social autism. The criminology model perhaps best explains the actions seen herein, except it too, falls short. There was indeed, criminal behavior at the top of the decision tree in the Manhattan-Rochester Coalition, and state crime is certainly applicable here. Crimes against humanity could also be applied effectively in this context. Yet, we cannot explain the actions of the thousands of underlings - many of whom did not fully 
understand the role that they were playing in advancing the project as a whole, or even what the project was, in part because it was highly classified. The vast support staff beneath the decision-makers, advanced the harmful acts as ordered by the elites of the coalition, even if unbeknownst to that staff. The fundamental question here is however, how the thousands of underlings (seemingly good people and citizens in other spheres of their lives), who moved in and out of the organization over a period of many decades, came to participate in harmful actions on behalf of the organization.

Early reviews of secondary sources had all posited that the St. Louis aerosol study was related to bioweapons and/or chemical weapons. Primary sources - in this case Army documents-- also implied that the St. Louis tests were related to bioweapons, but evidence was in fact quite scant, and agencies were not forthcoming with information. I followed the chemical/biological direction set out by the earlier researchers and the Army, and as a result, found many imposing brick walls in my path, whereby I would reroute along another fissure to explore. There were vague mentions of the St. Louis study, but nothing substantive in the literature, anywhere. I initially spent many hours reviewing material related to radiation studies, but became nervous that I was burning time on the calendar that I could ill afford, so I abandoned that tract, and re-doubled my efforts towards chemical and biological weapons testing. My task of unveiling the facts of this case study was not an easy one. Through this painstaking process, I initially spent many hundreds of hours looking for a radioactive needle in a chemical-biological haystack. It was when I was well into researching chemical and biological weapons and not finding much substantive information on the St. Louis study, when I picked up Eileen 
Welsome's book The Plutonium Files. Her book had lingered on my bookcase for about a year, and I had no time for what was now relegated to recreational reading. As I drifted off to sleep each night however, I read bits of Welsome's book, and chords of familiarity slowly unfolded for me. Events and familiar names aligned in provocative ways with my own research. Pieces of the puzzle continued to fit together, and early one Sunday morning, I had the jarring realization that the St. Louis aerosol study was much more aligned with radioactive military testing than with bioweapons or chemical weapons projects, and that a network of Manhattan-Project related scientists seemed to be tied to the St. Louis study. I found this revelation literally breathtaking, and the daunting task of putting this information together even more so.

I sent out at least forty Freedom of Information Act requests to every agency that had potential involvement, and that in itself, was a test in fortitude as request after request came back with not a single sheet of data or information. The Army at Aberdeen Proving Ground finally came through, where paralegal Brian May provided me with a "blizzard" of documents in electronic format. This gave me more needles in more haystacks, along with concrete evidence confirming the blizzarding tactic as a response to public inquiry. I spent endless hours reading dry military data to find the hidden gems within the old military reports. Indeed, there were a few there. After some often-terse written communications with the Office of the Command Judge Advocate at the Department of the Army, Dugway Proving Ground, I was provided with another blizzard of documents at a nominal fee. Appreciative for anything through FOIA, I was nevertheless disappointed that Dugway continued to deny some documents to the public (and to 
researchers such as myself), by their own admission. In fact, some documents were available for distribution to government agencies only, including a very important, Behavior of Aerosol Clouds within Cities, Part 2; technical Summary, April 1954, which summarized the findings of the St. Louis study. Dugway refused to provide this crucial document to me, even after I appealed the decline. Nevertheless, I appreciate the hundreds of pages of documents that were provided to me by Kateni Leakehe, Major, U.S. Army, Command Judge Advocate at Dugway Proving Ground. The FOIA responses that I received varied from mostly blatant denial, to stonewalling, and blizzarding. Clearly, the control of information that played such a key role in the St. Louis aerosol study and the Manhattan-Rochester Coalition's work, and was essential to generating ethical and social autism, was impacting my own research as well. Information is still controlled through the same mechanisms, and this became quite obvious as I attempted to gather, declassify, and analyze government documents, a full six decades after the first aerosol experiment in St. Louis. The mechanisms that were used to maintain the lock on military information related to the St. Louis aerosol studies when I requested documents for this project, and the mechanisms used to control information outflow and thus public inquiry and critical analysis internally through the Manhattan Rochester Coalition during the past several decades while testing was ongoing, were identical. Thus, theory and methods were brought together in this study.

I pulled and reviewed hundreds of news articles from Lexis-Nexis, along with regional, national, and international newspaper searches, as related to chemical, biological, and nuclear weapons testing, hoping to find a mention about the St. Louis study. Some of the 
most fruitful finds came from Congressional reports, which discussed human subject testing overall. In the 1990’s, under the direction of President Bill Clinton, Hazel O'Leary cleared the way for release of tens of thousands of documents related to humansubject testing. Indeed, she played a heroic role in truth seeking for scholars, reporters, lawyers, and American citizens who were victimized by human subject tests. Unfortunately, despite the release of these many documents during the Clinton administration, the military continues to maintain a high level of secrecy related to the St. Louis study- something I found curious, given the release of official records that have revealed some extraordinarily revolting experiments by the military during the same time period. As in the 1950 s and 1960 s, today the St. Louis aerosol study still remains mostly hidden.

The National Research Council's (NRC) Toxicological Assessment of the Army's Zinc Cadmium Sulfide Dispersion Tests, proved to be one of the only resources for hard data, regarding actual release levels of the material sprayed in St. Louis and other cities in the United States. Notably, the NRC (who by Congressional and Army request, took on the task of gathering information related to aerosol dispersion tests in St. Louis and several other cities such as Minneapolis), found its own path stonewalled by the Army. Thus, even the NRC's official data had gaping holes and missing data, which I did my best to fill in from other sources, such as published articles in obscure science journals.

I spent a few days in the Library of Congress, in Washington D.C., where I had some assistance from wonderful library personnel who were willing to go the extra mile for an 
out of town researcher working on a tight deadline. Some excellent documents in their collection confirmed that I was moving in the right direction with my research, and provided key points to help understand the early formation of the Manhattan-Rochester Coalition, and industry's involvement. ${ }^{4}$

George Washington University's National Security Archives document collection, provided a useful collection of research material. The research institute and library collects and makes available online to researchers, declassified documents pertaining to a plethora of important topics. Invaluable information can and was found there. Personnel at Washington University's Rare Book Room generously opened some files for me, and I spent a day reading about tooth studies and other fateful events that turned out to be related to the St. Louis aerosol study, although I'm not sure I realized how useful those documents would be until much later, when I discovered Projects GABRIEL and SUNSHINE. Notably, data related to Monsanto was either removed from the file, or had never been added, which was surprising given their role in management and oversight of Oak Ridge National Laboratories during the 1940s.

I did not interview participants for this project. Many victims and participants have no knowledge of the St. Louis aerosol study, so to locate interview subjects would be extremely difficult and arduous, particularly given the level of secrecy of the project. That said, oral history transcripts of high-level participants in human-subject radiation studies have been made available to researchers such as myself, through the U.S.

\footnotetext{
${ }^{4}$ Word of advice, do not wander too far in the basement tunnels of the Library of Congress; you may never be seen again.
} 
Department of Health and Human Services, and I utilized those interview transcripts in this project. The Oral Histories project was a controversial one at the time, undertaken by President Clinton's Advisory Committee on Human Radiation Experiments, which examined hundreds of radiation studies on American populations by the military and its contractors. The committee, headed by physician Ruth Faden, along with a variety of experts in science, ethics, medicine, and history, painstakingly assembled this oral history archive of interviews with high-ranking scientists and medical personnel who had participated in human experiments or were members of the elite Manhattan-Rochester Coalition, in addition to their various written commission reports and online documents. The Presidential Advisory Committee's Oral History Project was a very valuable primary source, that filled in the interview gap.

The task for many research ventures, is to identify a gap in the literature and attempt to fill that gap, by way of theory and supporting evidence. There are other times that existing theory does not sufficiently explain events, and new theory, grounded in evidence, must be developed. This particular case study is not only instructive in understanding secrecy of the State and historical events involving the victimization of vulnerable populations, but in also understanding more about complex organizations, and how large organizations manage to effectively quash dissent internally to pursue-without interruption- harmful and/or illegal projects, and how the public can acquire no awareness of its own victimization at the hand of the State. Indeed, this case study opens up a Pandora's box with more questions than answers. Countless times, I would turn a rock to discover a sinister secret, and find many more layers to peel back to reveal 
another piece; I would have hundreds more rocks to sort through until finding the next hidden secret beneath. This project was a test of fortitude, and it gave me trust in my researcher's intuition. What initially presented as a singular, local, isolated event, burst into an issue that could have taken me down hundreds of "rabbit holes", and could have easily cost me a decade or more, in time. The more that I uncovered of this story, the more of an enigma the story became. Nevertheless, this complex case study required an equally complex methodological design to distinguish claims from events. It is my belief that this piece contributes to the literature in explaining complex organizational dynamics as it relates to large-scale and long-term internal participation in crime, harm, and unethical actions, and external responses or non-responses to harmful or unethical organizational actions. 


\section{CHAPTER II}

TARGET ST. LOUIS:

MOSCOW AND AN AMERICAN “SLUM” IN THE CROSSHAIRS

Z

Prompted by the dark and sinister Nazi war crimes involving human experimentation that were exposed during the Nuremberg trials, in August, 1947 The Nuremberg Code established a set of international research codes. Those including the following:

1. Voluntary consent of the human subject is absolutely essential.

2. The experiment must yield generalizable knowledge that could not be obtained in any other way and is not random and unnecessary in nature.

3. Animal experimentation should precede human experimentation.

4. All unnecessary physical and mental suffering and injury should be avoided.

5. No experiment should be conducted if there is reason to believe that death or disabling injury will occur.

6. The degree of risk to subjects should never exceed the humanitarian importance of the problem.

7. Risks to the subjects should be minimized through proper preparations.

8. Experiments should only be conducted by scientifically qualified investigators. 
9. Subjects should always be at liberty to withdraw from experiments.

10. Investigators must be ready to end the experiment at any stage if there is cause to believe that continuing the experiment is likely to result in injury, disability or death to the subject.

With World War II and the Nuremberg trials fresh on the minds of many, the Army Chief of Staff published in 1952 with approval by the Secretary of the Army, seven guidelines and conditions in which human subjects could be used in military research. A second policy statement titled, The Use of Human Volunteers in Experimental Research, aka the Wilson Memorandum, followed shortly thereafter in 1953, and it was supplemented in 1954 (U.S. House of Representatives, 1994: 125-27). The guidelines were published after "legal investigation and ethical review", according to military records. (U.S. Senate, 1977: 178). Early guidelines, which were approved by the Secretary of the Army (CS 385-30, June 30, 1952) presented the following protocol:

1. Voluntary consent is required. Written consent must be witnessed, and signed by the individual concerned.

2. No experimentation which could predictably lead to death or permanent disabling or injury will be investigated with the use of human volunteers.

3. Proper medical supervision and treatment capability will be immediately available to the subjects.

4. Experimentation must be expected to yield fruitful results for the good of society, not available by any other means.

5. Experimentation should avoid all unnecessary physical and mental suffering. 
6. The degree of risk taken should never exceed the importance of the experiment or the expectable benefits from it.

7. The volunteer may remove himself from the experiment at any stage if he feels that he has reached the limits of his physical or mental endurance.

The Wilson Memorandum also stated explicitly that a human subject involved in testing,

...should have legal capacity to give consent; should be situated as to be able to exercise free power of choice, without the intervention of any element of force, fraud, deceit, duress, overreaching, or other ulterior form of constraint or coercion... (U.S. House of Representatives: 126).

Deception in human subject testing is explicitly defined by the Department of the Army, as a form of constraint or coercion, which is strictly prohibited. According to Bernard Lo, physician and medical ethicist, deception includes, "all statements and actions that are intended to mislead the listener, whether or not they are literally true"; this would include the use of "technical jargon, ambiguous statements, or misleading statistics, not answering a question, and omitting important information" (Lo, B.: 50). Thus, according to Lo, deception does not necessarily employ an element of duress, force, restraint, or coercion, but it could occur covertly and subtly. The Wilson Memorandum instructs, ...before the acceptance of an affirmative decision by the experimental subject there should be made known to him the nature, duration, and purpose of the experiment; the method and means by which it is to be conducted; all inconveniences and hazards reasonable to be expected; and the effects upon his health or person, which may possibly come from his participation in the experiment. (U.S. House of Representatives: 126)

Here, the subject must provide consent before any testing begins, after being fully informed by those in charge of the study about the purpose, nature, method, means, risks, inconveniences, and health effects to that subject. In 1954, the Wilson Memorandum was supplemented to include the element of comprehension, whereby, "...the human 
subject should have sufficient knowledge and comprehension of the elements of the subject matter involved as to enable him to make an understanding and enlightened decision" (U.S. House of Representatives: 127). In fact, any proposals involving human subjects were required to be reviewed by June, 1953 by the Army Surgeon General with final approval by the Secretary of the Army. The Wilson Memorandum guidelines appeared to be based on, but nevertheless deviated from the Nuremberg Code in several ways. First, consent was "required" with the U.S., whereby it was "absolutely essential" per Nuremberg. The Army alludes to the requirement of written consent, without explicitly mentioning it, however when obtained, it needed to be signed and witnessed. The Army did not require animal experimentation prior to human experimentation, and did not stipulate that "injury must be avoided", or that the study is not "random and unnecessary in nature", as did Nuremberg. Although the Army stipulates in vague terms that experimentation must yield "results for the good of society", Nuremberg requires that the "degree of risk" should "never exceed the humanitarian importance of the problem". Volunteers could withdraw under either set of guidelines, however per Army, only "if he feels that he has reached the limits of his physical or mental endurance". There is no Army stipulation whereby the researcher could end the experiment at any stage if there is cause to believe there is harm, injury or death occurring. Most notably, where Nuremberg stipulates that experiments should be conducted by "scientifically qualified investigators", the U.S. military omitted this requirement, and thus, with the stroke of a pen, the U.S. Army deemed anyone qualified to perform human subject testing.

\footnotetext{
5 It is unclear as to who decides what is for "the good of society" in the Wilson memorandum.
} 


\section{SHIFT IN MISSION}

On a spring afternoon in 1945, a group of scientists, all highly educated young white men, affiliated with elite universities across the United States, met at their usual location in Rochester, New York. The building was secured, and the window shades were down and fixed. At the helm, sat Dr. Stafford Warren, Professor of Radiology and Chairman of the Department of Radiology at the University of Rochester School of Medicine and Dentistry. Dr. Warren had recently been commissioned colonel in the Army Medical Corps. J. Robert Oppenheimer, chairman of the Atomic Energy Commission's General Advisory Committee, and project director of the Manhattan Project, joined the other scientists at the conference table, next to Oppenheimer's close friend Louis Hempelmann. Colleagues Willard Libby from the University of Chicago (although he would later move to University of California, Los Angeles), Joseph Hamilton of Berkeley, Wright Langham, who had worked on biomedical research at the Manhattan Project, and John Lawrence, also from Berkeley, were also in attendance, or would soon arrive to take their places at the conference table. The group of scientists discussed a proposal to inject a hospital patient at Rochester or Chicago with radioactive material such as plutonium, and then analyze their excreta and body fluids. Oppenheimer submitted his approval to the experiment in writing, but the men wanted help from their superiors at Manhattan Headquarters for the design of the project. They had each been assigned by the top secret Manhattan Engineer District (aka Manhattan Project), to head ten secret spin-off divisions of the Manhattan Project. Each division, located in strategic locations throughout the United States, would be uniquely responsible for research and 
development of nuclear weapons; this included the testing of human bodies- both alive and dead- for the effects of, or exposure to radiation.

Human subject weapons testing led by this group, would not be limited to the nameless patient at Chicago or Rochester. Nor would testing be limited to military personnel at remote sites. Testing that involved chemical, biological, and radiation simulants and compounds criss-crossed clear, blue skies, touched down upon the breadbasket of America into the wheat fields of the Midwest, and moved stealthily from shoreline to shoreline. In some cities, hiding in beautiful blue skies lurked sinister clouds of death. On sparkling California shorelines dotted with white sails and lined with beachgoers, deadly spores sprayed from regal-looking battle ships. On busy urban sidewalks while passersby rushed to work, invisible, carcinogenic particles were drawn deeply into their lungs, by the design of a few, privileged enough to know it was happening. Under the sparkling stars and clear bright moon, as children, their parents, and grandparents, slept on their porches or beneath an open window to escape the blazing heat of a St. Louis summer, toxins drifted silently inside through open windows and settled into their lungs. The particulates were designed to be optimal size for deep inhalation by the sleeping, unsuspecting victims. It was the Cold War, and this was America.

\section{BACKGROUND}

...we have identified hundreds of radiological, chemical, and biological tests and experiments in which hundreds of thousands of people were used as test subjects. These tests and experiments often involved hazardous substances such as radiation, blister and nerve agents, biological agents, and lysergic acid diethylamide (LSD). In some cases, basic safeguards to protect people were either not in place or not followed. For example, some tests and experiments 
were conducted in secret; others involved the use of people without their knowledge or consent or their full knowledge of the risks involved. (U.S. House, 1994: 17). ${ }^{6}$

So began a Congressional Hearing in 1994, which could potentially reveal to Americans not simply ugly secrets of the historical past, but also a paradigm shift and a fundamental military strategy change, whereby the targets of military weapons were now civilians. The Army began an aggressive program in the 1940s to assess the defensive and offensive use of chemical, biological and nuclear weapons. Most Americans were familiar with the first major use of nuclear weapons in warfare-when nuclear bombs were dropped on Hiroshima, Japan on August 6, 1945, and three days later on the shipbuilding town of Nagasaki, Japan. In Nagasaki, the death toll from the atomic bomb reached approximately 75,000 , with twice that number of victims dying later from lingering effects. Many Americans believed that after this jarring use of new warfare technology, the American scientists who had worked at the Manhattan Engineering District (aka the Manhattan Project aka Project Y) had packed their belongings and returned to their quiet academic appointments at prestigious universities around the country, to resume their pre-war teaching and perfunctory research. The scientists had been called to serve their country in a time of war, and their mission was complete. In the minds of some, the scientists would be linked forever not just to Hiroshima and Nagasaki, but also to a town tucked away high in the red mesas of Los Alamos, New Mexico- a town that could not be more different from the Japanese port cities that bore the fiery, twisted wrath of the atomic blasts. Contrary to popular belief however, the Manhattan Engineering Project scientists did not slip back into an ordinary life after atomic bombs were dropped in

\footnotetext{
6 Testimony of Frank C. Conahan, Assistant Comptroller General, US Government Printing Office.
} 
Japan. In fact, their lives forever changed by their experience at Los Alamos, many of the top scientists from the Manhattan Project had permanently shifted career trajectory into the military realm, and would continue on this fateful new track for the rest of their lives.

As revealed in one of several U.S. Congressional hearings on the subject, the United States military did not pause after the atom bombs dropped; in fact, they ramped up production of every type of weapon technology they had in their potential arsenal. Because much of the technology that was developed during the aggressive military push of World War II was new and untested, the military would need to harness the efforts of thousands or tens of thousands of people, to play a contributing role in advancing new weapons of war. Many would come from various branches within the academy, others from military war schools or officer's clubs, yet others from inside dust-filled munitions factories, banks, and corporate boardrooms, and some would stand before the podium and microphone, in front of note-pad wielding reporters. Other roles needed to be fulfilled. To accomplish their lofty goal, the military needed not just labor and creativity, but a commodity much more precious: human test subjects, of all ages, whether willing or unwilling. The military was in fact able to very quickly harness wide swaths of human labor and ingenuity, if not genius, towards their goal to build the atom bomb, as goes the "official" story on the books. The military elites also needed the assistance of a complacent public that would accept military research and development as necessary, if not desirable. For a mission that included decades long human-subject testing without consent of the victims, full public support could not be obtained by convincing political 
oratory or simple fear-mongering. Indeed, those methods would be employed, but to see the mission through, an open public debate would need to be suppressed, secrecy employed, and all potential dissent quashed both internally (those directly involved in research, development, and testing of deadly weapons), and among those external to the effort- the general public and potential victims. There is thus, a dark and chilling parallel layer below the publicly discussed narrative. Indeed, it is a layer of deception attached like a parasite to the underbelly of "truth", involving a secret spin-off group of elite scientists from the Manhattan Engineering District, who would enjoy full freedom to pursue military-related scientific and medical inquiry with no accountability to their tens of thousands of human victims.

World War II had ended with victory for the Allies in 1945, but it had left in its wake what came to be known as the Cold War. The Cold War would linger dangerously for four decades as the United States and the Soviet Union clashed in their attempts to retain power, which resulted in icy political relations between the two countries. In August 1949, four years after WWII ended, President Truman announced that U.S. Intelligence officials discovered that the Soviets had tested an atomic bomb in Kazakhstan, and were developing nuclear technology for use in warfare. This Soviet capability came "years earlier than Western Intelligence services had predicted and radically shift[ed] the global balance of power" (Tucker: 123). This revelation virtually blind-sided political officials. It was predicted (and discussed in top secret memorandums) by high ranking military officials, that the Soviets would likely produce an atomic bomb by mid-1951, and that by 1953, the Soviets would likely have nuclear capability to the tune of 100 bombs (U.S. Air 
Force, 1954). ${ }^{7}$ In another 1949 military report, it was stated that the earliest possible date by which the U.S.S.R. might be expected to produce an atomic bomb was mid-1950, but more likely in 1953. The nuclear arms race was on, and American military officials did not waste a moment in searching for ways to advance military technology and capability, with looming reports that by 1953 Soviets might have full nuclear capability. While some military analysts pushed for a ramped up biological weapons strategy, others (Navy) likewise pushed for limited use of chemical weapons (Tucker, 127). By 1951 however, a Joint Chiefs of Staff report "concluded that the USSR had biological weapons and was using large-scale field tests that targeted human subjects" (Guilemann: 96).

This may in fact, have been mostly rhetoric to advance a specific military agenda.

According to Clarence Y. H. Lo,

after the outbreak of the Korean War, the Truman administration sought to use the rhetoric of national unity and military threat to mobilize the nation, including big business, into supporting the administration's extensive military buildup. Business executives reacted to these calls for national unity by offering their own rhetoric in support" (Lo, C. 1982: 433).

In fact, "time and again the administration had exploited the multifaceted 'menace' of Communism to mask America's postwar expansion into Europe and the world for reasons having little, if anything to do with bolshevism" (Kolko: 650). Truman and his secretary of state Dean Acheson, "keenly saw the need to maintain a sense of danger from Russia and Communism that was the prerequisite for mobilizing protracted

\footnotetext{
${ }^{7}$ General S. E. Anderson, Director, Plans and Operations, memo to Director of Intelligence, "Implications of Soviet Atomic Explosion," 5 October 1949, attached to memorandum from General C. P. Cabell, U.S. Air Force Director of Intelligence to Director Plans and Operations, "Implication of Soviet Atomic Explosion," 6 October 1949, Top Secret

Source: Record Group 341. Records of Headquarters, United States Air Force (Air Staff), Deputy Chief of Staff for Operations, Directorate of Intelligence, Top Secret Control \& Cables Section Jul 1945-Dec 1954, box 46, 9300 to 29399; as obtained electronically through George Washington University, National Security Archives; http://www.gwu.edu/ nsarchiv/nukevault/ebb286/index.htm\#11 on June 2, 2011.
} 
American efforts and high allocations" (Kolko: 650). In other words, in a move that was truly political in nature, Truman and his administration would instill a sense of urgency and fear of the Soviets and Communism to bolster the immediate need for increased military funding. During this time period, there was a "major increase in the growth of the U.S. national security establishment", and by the end of 1952, national security expenditures reached a high of \$64 billion a year (Lo, C., 1982: 427-28). Indeed, according to Kolko, et al., "the historian will look hard to find responsible men who thought the Russians were an immediate military threat to the United States or Western Europe" (Kolko: 664). A threat may indeed have been there, however, in this study we find that military and political elites have, through the use of various mechanisms, the ability to construct the level of a threat; as it is constructed higher and higher we may see greater losses of freedoms in society.

In 1953, after a long hiatus from political power, embattled Republicans gained control of the White House, when Dwight D. Eisenhower became President of the United States by an overwhelming majority. Although power had switched hands to the Republicans, Eisenhower in no way substantively changed foreign policy related to military strategy, and according to Army documents, military officials continued to explore the viability of a bio-weapons program. As Eisenhower stuck to the mission of a general arms buildup, other methods of warfare were also advanced in U.S. laboratories. Indeed, the Arms Race was heating up, and the Cold War was frosting U.S./Soviet relations. Officials argued that "field studies" would be necessary, to increase confidence in their new weapons technology that sprang out of World War II efforts (Guillemin: 101). In an 
echo of what American military officials charged of the Soviets two years earlier,

American military officials would use their own "field tests" in 1953 to target American

human subjects- indeed, civilians- in mid-sized cities on American soil, without the

consent or knowledge of their victims.

The Defense Department gave them colorful names, including Green Mist, Red Cloud, and Rapid Tan. Some borrowed from nature, as in Tall Timber and Swamp Oak. Others were ominous: Devil Hole and Night Train, for example. A few were stark, even cryptic, as in Deseret 69-75. They were all military exercises conducted in the cold war to assess how well American forces could fight while under attack from chemical or biological weapons (Shanker, 2002a: 36).

Despite clever or even glamorous names, they all represented something much more sinister and much closer to home, than the fringes of what seemed to be a very distant Cold War.

To accomplish the Army's goal of estimating munitions requirements for the strategic use of BW agents against cities, [the] researchers considered as test areas North American metropolitan areas that most closely matched the meteorologic, terrain, population, and physical characteristics of the Soviet cities of interest, such as Moscow and Leningrad (NRC, 1997b: 117).

With specific urban and climactic conditions in mind, officials considered several Midwest cities including Oklahoma City, Kansas City, Omaha, Toledo, Cincinnati, St. Louis, Chicago, Minneapolis, and also Winnipeg, Canada. Of those, St. Louis and Minneapolis were selected as they both "met the desired summer temperature range", desired population density, urban structural heights "in general not exceeding three stories", the presence of universities for obtaining personnel to work on the project, cooperation of local officials including the U.S. Weather Bureau and police departments, and all the Soviet features that the Army desired to simulate in an urban American area 
(NRC, 1997b: 118-19). ${ }^{8}$ Military officials told the few local officials that were notified about the studies, that the targeted testing was undertaken to advance military defense of American civilians located in these and other US cities, using what would be in effect a "non-hazardous simulant" "smokescreen".

\section{LIE AND DECEPTIONS IN ST. LOUIS}

Medical ethicist Bernard Lo defines lying as "statements that the speaker knows are false or believes to be false and that are intended to mislead the listener" (Lo, B.: 50). This is distinctive from deception, which is "broader than lying", in that it "includes all statements and actions that are intended to mislead the listener, whether or not they are literally true (Lo, B.: 50). Thus, intentionally false and misleading statements fall under Lo's definition of lie, which is a form of deception. We clearly see lying and deception occur in the Manhattan-Rochester Coalition case study.

On a chilly February night in St. Louis at 11:05 p.m., a young contractor for the United States Army turned the valve to release the particles into the frosty air just above the sidewalk. The plume was carried aloft, meandering its way up above the trees, and then dropping down to street level again, swept down by the wind. The worker stood silently for five minutes as the motor purred, ticking out twelve grams of the mysterious, fluffy powder into the air. He knew little about what he was doing, other than following the instructions given by his crew leader earlier that evening. The job came about after seeing an ad on the university's job-search bulletin board, and it seemed easy enough for a young student who wanted a non-demanding, part-time job. Most of the residents,

\footnotetext{
${ }^{8}$ St. Louis was in fact, Army officials' most favored city for the study.
} 
some just a few feet away, were tucked into bed or dozing, while a local newscaster droned on about everything except what was going on outside their century-old windows. The data from the evening's activities would ultimately be missing at the hands of the Army, in a familiar pattern of missing data and other obfuscation, that would be no better explained by military officials during Congressional hearings in the distant mid-1990s. The residents in that fateful neighborhood, and others that were also targeted in St. Louis, Minneapolis, and other U.S. cities, had no idea that they had been selected for military field tests. Indeed, they had not been informed by local, state, or federal authorities, that a test would even occur; nor, were they advised to take any precautions. The Army would continue the aerosol study in St. Louis, through January $20,1954 .{ }^{9}$

Four decades after the 1953-54 Army study, news began to stream into the press that those St. Louis residents, and tens of thousands of other victims in urban and rural areas throughout the country, had been used as unsuspecting test subjects by the U.S. military. Officials claimed that selected areas within the cities of St. Louis and Minneapolis had been doused in a "harmless" mixture of zinc cadmium sulfide ( $\mathrm{ZnCdS})$. Other parts of the country had been sprayed with other materials of varying toxicity.

Army officials lied to city leaders and residents, saying the tests were intended to see if smoke screens could protect the city from Russian bomber attacks. But recently released Army reports admit that was a 'cover story' for... secret biological and chemical warfare tests (Sawyer, 1994).

In fact, the aerosol studies were not as Army officials "admitted" during Congressional hearings in the 1990s, part of a defense strategy to envelop urban areas in a cloud of

\footnotetext{
99 The 1953-1954 test series in St. Louis appears to have paused between July and November-resuming again on November 9, 1953, for reasons unknown. Given the large gaps in Army data, however, these gaps may only reflect missing data, not a pause in testing.
} 
smoke, hiding civilians from Soviet attack. Technology had advanced beyond that; the use of radar in the military (both U.S. and Soviet) made such a plan preposterous. St. Louis was not the only city to experience this fateful selection inside the crosshairs of the military, but it is the subject of this case study of lies, deception and unchecked state power.

\section{ST. LOUIS IN THE CROSSHAIRS: 1953}

Three distinct narratives emerge regarding the St. Louis aerosol study of 1953 . The first was an "admission" by military officials that the aerosol studies were designed to test massive smoke clouds in which to hide U.S. cities from Soviet air attacks. The aerosol studies were thus described as defensive measures to protect civilians residing in the targeted city. A different narrative emerges internally however, from the official Air Force Biological Program historian, Dorothy Miller, in $1952^{10}$. According to Miller, the United States military wanted to understand the "predictable dispersal of aerosol clouds over the potential target areas" (Guillemin: 103). Although not terribly specific, Miller's Air Force version of events leading up to the aerosol releases, indicates a military project of an offensive nature, where chemical dispersal becomes the focus, rather than one of chemical coverage or blanketing to hide potential victims. On the heels of Miller's official report, the Army discussed the study in their own classified report, advising that the studies were in fact, "part of a continuing program designed to provide the field experimental data necessary to estimate munitions requirements for the strategic use of

\footnotetext{
10 Sociologist Jeanne Guilleman cites the following source: Dorothy L. Miller, "History of the Air Force Participation in Biological Warfare Program, 1944-1951", Historical Study No. 194, Wright Patterson Air Force Base, Office of the Executive Air Material Command, September 1952.
} 
chemical and biological agents against typical target cities" (U.S. Army, 1953a: 118). ${ }^{11}$

More specifically, officials outlined four "specific objectives" of the tests:

1. To determine the reproducibility of street level dosage patterns in an essentially residential area under given meteorological conditions;

2. To determine whether the street level dosage pattern from a point source is affected by the source position, that is, when the generator is located at an intersection, at a point midway between intersections, at a point within a block, or on a rooftop.

3. To determine the effect on dosage patterns of day and night meteorological conditions.

4. To obtain data on the penetration of the aerosol cloud into residences at various distances from the aerosol disperser, and to determine whether there is any residual background or lingering effect of the cloud within buildings (U.S. Army, 1953b: 119) ${ }^{12}$.

Despite military officials' claims that the aerosol release objectives were to test smoke screen defenses for American civilians, the studies were in fact, as Miller alluded, undertaken to advance offensive warfare tactics against civilians in similarly featured Soviet cities. The tests' objectives and selection of targeted areas were part of a vast, complex plan to advance use of chemical, biological and radiological agents in warfare against civilian populations in other countries. As the world recoiled in horror over the

\footnotetext{
11 This 1953 report was obtained by this author through FOIA from Dugway Proving Ground; it was originally a classified report, and thus, unavailable to the public; the report is stamped "REGRADED UNCLASSIFIED-JOD, DPG).

12 Unclassified document AD031508; Defense Documentation Center for Scientific and Technical Information; Classification changed to "unclassified" from "secret" per authority listed in ASTIA Tab No. U63-4-4, November 15, 1963; obtained through FOIA, June 2011 from Dugway Proving Ground, Dugway, Utah.
} 
events at Hiroshima, Nagasaki, and Nuremberg, what had occurred in Japan was an ugly foreshadowing of future warfare tactics, whereby the newest of weaponry and methods of warfare would aim squarely at civilians.

According to one researcher, officials overseeing this new covert project that targeted U.S. cities, would ultimately name it the St. Jo Program. ${ }^{13}$ "Tentative plans were made to conduct "tracer" tests in Minneapolis and St. Louis during the winter, spring and summer of 1953, and the winter of 1954. In addition according to the Army, it was planned to conduct "tracer" tests in various industrial complexes in and near St. Louis during the fall of 1953 (U.S. Army, 1953a). A similar study was planned for Winnipeg, Canada approximately ten days after the St. Louis studies, to accommodate rotation of the equipment that would be used at multiple test sites; the time delay would assist in transport, crew training, and arrangement of temporary accommodations for personnel (U.S. Army, 1953a: 51). One Air Force historian stated in reference to the study that, "any expenditure figures finally derived will refer to a completely unprotected target population", (this author's emphasis) "which is assumed to be exposed in the open in a city, during the whole time of passage of the biological cloud" (Guillemin: 103). The St. Jo offensive war "simulations" would begin in January 1953 in both Minneapolis and St. Louis.

The U.S. Army described the 1953-54 St. Louis study as a "fluorescent particle tracer experiment". Federal officials were however, not satisfied with nearly a year of

\footnotetext{
13 Although referred to by this name by sociologist Jeanne Guilleman, this author found no reference in any official report that referred to this study as the "St. Jo Program".
} 
aerosolized material dispersed over the city of St. Louis in 1953; they would return again to St. Louis in the 1960 s for additional aerosol tests. ${ }^{14}$

\section{TARGET ONE: MINNEAPOLIS}

According to the National Research Council (NRC), "a total of 160 tests using various simulants were conducted at 66 locations (both military and civilian targets) in the United States (including Alaska and Hawaii) and Canada" (NRC, 1997a). Aerosol testing would begin in Minneapolis, with St. Louis studies closely following. Problems occurred immediately in Minneapolis. Efforts to secure homes in which to locate samplers, was met with resistance and "field personnel encountered a considerable number of refusals to cooperate with requests for permission to locate sampling equipment in homes. As many as ten contacts were made for each acceptance" (U.S. Army, 1953a: 14). The Army obtained rosters of police and fire department personnel, and letters from the Minneapolis mayor, the Chief of Civil Defense, and the Minneapolis Air Pollution Control Engineer to serve as introductions to city employees and residents. The letters were delivered to field office personnel for use in securing access to private homes and buildings for equipment location. "Thus, 'official sanction' was given to otherwise questionable results", according to Army records (U.S. Army, 1953a: 28). Project personnel also canvassed door-to-door in their efforts. Nevertheless, during the initials tests in the residential areas, "the police received numerous calls from residents reporting strange activities in the area....for several evenings in succession, sampling equipment was molested by curious passers-by, and several sampling units were actually found missing from

\footnotetext{
14 The 1960s series of tests in St. Louis was held under the auspices of the U.S. Public Health Service, which was also concerned with chemical, biological, and radiological warfare. This may also have been used as another layer of deception to mask a military-sponsored study.
} 
stations" (U.S. Army, 1953a: 29). As the Army notified officials and press of the Minneapolis experiments (assuming their claim of notification is accurate), or as observant local citizens became aware of the tests on their own or through the canvassing efforts, the Army came to experience both open and clandestine public protest of the Minneapolis aerosol studies. The St. Louis study would begin immediately after the Minneapolis study, with some crossover between the two studies, but there would be a dramatic difference in how the two cities were approached, in regard to notification of the public and authorities.

\section{TARGET TWO: ST. LOUIS}

The Army contracted with Philip A. Leighton at Stanford Research Institute, and the Ralph M. Parsons Company in Pasadena, California, to design and oversee the St. Louis aerosol study, whereby two 25 -square block areas in downtown St. Louis would be sprayed with what was claimed to be "biological simulants". One formerly classified Army document outlines the 1953-54-test range as a five square mile area (U.S. Army, 1953b: 24) ${ }^{15}$. Additional Army documents note that officials specifically selected a "slum area" in downtown St. Louis (Sawyer, 1994).

Oblique references are made to problems encountered in Minneapolis-lack of cooperation by residents, vandalism of equipment, and theft. The testers wanted to encourage more cooperation by the public in St. Louis than had been the case in Minneapolis. How to achieve this? Concentrate the tests in a poorer section of town and increase police surveillance. The testers theorized that poor people were less likely to object to strange happenings in their neighborhood, and if they did, the police would be there to control them (Cole: 64).

\footnotetext{
15 Unclassified document AD031508; Defense Documentation Center for Scientific and Technical Information; Classification changed to "unclassified" from "secret" per authority listed in ASTIA Tab No. U63-4-4, November 15, 1963; obtained through FOIA, June 2011 from Dugway Proving Ground, Dugway, Utah.
} 
According to historian Leonard Cole, the specific neighborhoods were selected to "minimize chances of resistance to the performance of experiments"; thus, [Army officials chose] "a slum where residents are less likely to be educated, inquisitive, or to question authority", based on intensive local scrutiny in the earlier Minneapolis study (Cole: 64). But perhaps Cole's analysis is only partly accurate. There are indications that the military had other reasons to keep the St. Louis study secret.

\section{CHARACTERISTICS OF ST. LOUIS HOUSING: 1950}

Two specific St. Louis areas were selected for the 1953 study: 1) "The How Area" and 2) "The Item Area". The How Area was a "densely populated residential area including some commercial and manufacturing areas" near the center of St. Louis, located approximately two miles west of the Mississippi River and approximately one mile from the center of downtown St. Louis (U.S. Army, 1953b: 24) ${ }^{16}$. The How Area boundaries included Grand Boulevard (west), Montgomery St. (north), $22^{\text {nd }}$ (east) and Pine Boulevard (south). The Item Area was selected as a downtown area "encompassing most of the tall buildings in [downtown] St. Louis" (U.S. Army, 1953b: 24). The Item Area was bounded by the Mississippi River (east), Biddle St. (north), $18^{\text {th }}$ St. (west), and Spruce St. (south). Some of the studies during the 1953 test series targeted the entire city of St. Louis (Toxicologic Assessment, 1997b: 253; U.S. Army, 1953b: 24; Appendix A). Indeed, one area was just adjacent to, and the other cut right down the middle of the Pruitt Igoe Housing Project complex, which was a new, imposing housing structure of

\footnotetext{
16 Unclassified document AD031508; Defense Documentation Center for Scientific and Technical Information; Classification changed to "unclassified" from "secret" per authority listed in ASTIA Tab No. U63-4-4, November 15, 1963; obtained through FOIA, June 2011 from Dugway Proving Ground, Dugway, Utah
} 
eleven stories in the midst of a blighted, poverty-stricken area, populated by poor African-Americans. Pruitt-Igoe's population was also strictly African American, as St. Louis had legally-mandated segregated housing in 1953. The total population in St. Louis City in 1950 was 852,023 (Statistical Abstract, 1951). Thus, the "expanded" tests areas in 1953, indeed those that were citywide, targeted an estimated 852,000 individuals during each exposure, however the areas of concentration that were selected by those who designed the aerosol study, purposely targeted vulnerable populations in St. Louis city.

The How Area testing included six St. Louis city census tracts that covered hundreds of city blocks. Those tract areas included the following:

20A

20C

$21 \mathrm{~A}$

21B

21C

21D

The Item Area testing included four St. Louis city census tracts. Those tract areas included the following:

$25 \mathrm{~A}$

25B

$25 \mathrm{C}$

25D

Formerly classified Army documents confirm that, " the How Area consists primarily of a densely populated slum district", whereby "particular precautions" were taken to 
minimize the "loss of equipment", and to protect personnel (U.S. Army, 1953b: 27) ${ }^{17}$. Thus, the US Army purposely selected areas where primarily persons of color resided, and further the military anticipated that criminal activity would present particular challenges to staff and equipment because it was an area where "non-whites" primarily resided.

The 1950 United States Census of Housing, Block Statistics Data compared St. Louis city neighborhoods block by block. A total of $23,187 \mathrm{St}$. Louis residents were targeted in the combined How Area and Item Area studies. When the How Area alone is compared to untested and relatively affluent areas in St. Louis city, as determined by average home value in dollars, there are marked differences in housing and population characteristics. For example, in Census Tract 19A, non-white residents residing in occupied dwellings numbered 30 out of 4,020 persons, totaling $.75 \%$ of the population in that non-tested tract. In the How Area however, non-white residents in occupied dwellings varied between 67 persons and 4,106, depending on tract. Out of 19,213 total residents in the How Area, nearly 70\% or 13,366 were "non-white" (U.S. Department of Commerce, 1950: 4). In the Item Area, the number of non-white residents in occupied dwellings, varied between eight persons and 2,377, varying by census tract. Out of 3,974 total residents in the Item Area, 2,666 or 67\%, were" non-white" residents (U.S. Department of Commerce, 1950: 4). Because housing discrimination was an issue that limited availability to people of color to an extraordinary degree in St. Louis in the early 1950s, those areas that were targeted by the military were likely known by officials (and were

17 Unclassified document AD031508; Defense Documentation Center for Scientific and Technical Information; Classification changed to "unclassified" from "secret" per authority listed in ASTIA Tab No. U63-4-4, November 15, 1963; obtained through FOIA, June 2011 from Dugway Proving Ground, Dugway, Utah. 
certainly verifiable through census data), to be areas where persons of color were identified as heads of households. There is thus, a marked racial component to the 1953 aerosol study, whereby poor minority populations in St. Louis, were pointedly targeted for military-sponsored human subject testing.

Army reports were kept secret, and few local officials were notified before tests began, and only if they were essential to advance the project. The National Research Council later claimed that the Army and partner Stanford University needed to elicit cooperation from local authorities (at least those in Minneapolis, presumably) such as police and air pollution control officials, and local staff from the US Weather Bureaus to undertake the studies and avoid problems (NRC, 1997). Yet there is no evidence that any officials beyond the mayor's office were notified in St. Louis; in fact all evidence indicates that the fewest possible officials were notified of the study. Study coordinators, concocted a cover story to deceive and misinform local officials and not reveal the true nature and purpose of the studies. In fact, "...city officials were told that the work was to obtain data pertinent to smoke screening of cities to prevent aerial observation" (NRC: 118, 274).

In St. Louis, meetings were held with city officials...to outline the summer test program. Meetings were also held with officials of Monsanto Chemical Company, Socony-Vacuum Oil Company, Granite City Steel Corporation, and the Board of Alderman of Granite City, IL. Full cooperation of the industrial firms was obtained, and permission was granted for use of company properties for field-test sites (NRC: 274). 
The Army project successfully maintained relative secrecy throughout; this may have been due in part to resistance seen in the earlier Minneapolis study. ${ }^{18}$ It is likely, however, that the Army planned all along to maintain a higher level of secrecy in the St. Louis study, than they did in Minneapolis. The Army nevertheless claimed that, "although the St. Louis press was cognizant of the test program being conducted, only a few small articles were printed during the period" (U.S. Army, 1953b: 28) ${ }^{19}$. Purposeful efforts to strictly limit local awareness of the study, kept press attention, public awareness, and thus public protest, to a bare minimum. According to official documents, however, officials from two private companies- both defense contractors- had been informed about the study, even though local public officials, who were responsible for the health and wellbeing of citizens in their communities, were left uninformed. When later asked about the deception, one Army official explained that " "the army didn't really lie. They just didn't tell the whole truth"' (Cole, L., 1994: 5). Thus, officials in the tight-knit group who knew about the plan, including military officials, defense industry insiders, and select members of the scientific establishment, participated in a deception of local officials and the public about aerosol studies that targeted non-suspecting civilians. As a result, the public did not know to hold military officials to the Army's own protocol for human subject testing, as promulgated by the Army Chief of Staff in 1952 (U.S. House, 1977: 178). Indeed, given the existence of the Wilson Memorandum, the military circumvented their own protocol for human subject testing, by omitting

\footnotetext{
18 The Minneapolis experience does not fully explain the level of secrecy planned and maintained for the St. Louis study, however. There were other motivations at play involving the St. Louis study.

${ }^{19}$ Unclassified document AD031508; Defense Documentation Center for Scientific and Technical Information; Classification changed to "unclassified" from "secret" per authority listed in ASTIA Tab No. U63-4-4, November 15, 1963; obtained through FOIA, June 2011 from Dugway Proving Ground, Dugway, Utah.
} 
important information about the nature of the tests in St. Louis, and not notifying citizens. This important omission would fall under Lo's definition of deception (Lo, B.: 50).

\section{EQUIPMENT, METHODOLOGY, AND PERSONNEL}

Personnel at Stanford Research Institute/Stanford University designed an air-sampling unit to be used in the St. Louis and Minneapolis aerosol studies, and they also outlined the overall design of the experiments. Under military contract, Leighton, et al., were required to determine the following criterion:

- The point or line source of aerosol generation, elevation requirements, and the general release of the material to be dispersed.

- The number of tests to be conducted in each area, and the times of day to do so.

- Design of "certain special tests" (undefined in Army reports).

- Special requirements such as location of sampling equipment in residences and buildings (U.S. Army, 1953a: 12).

The sampling units were custom built specifically for the Minneapolis and St. Louis studies. All field and lab activities were the responsibility of the Ralph M. Parsons Company, which also held a contract with the U.S. Army for the project (U.S. Army, 1953a: 12). The metal sampling units were approximately 14 by 14 by 10 inches, with a metal nozzle that extended from the side of the box. A suction motor run by battery made a "ticking and purring" sound, according to a January 20, 1953 article in the Minneapolis Tribune. The article also noted that, in the Minneapolis study, "the Ralph Parsons Company name appear[ed] on the sides of the cars "from which guards watch the 
boxes" (Minneapolis Tribune, Jan 20, 1953, as cited by U.S. Army, 1953a: 14).

According to Army documents, "the first four tracer tests were planned and supervised jointly by Stanford and Parsons personnel. Subsequent planning and operational supervision were performed by the Parsons field office" (U.S. Army, 1953a: 32). Problems occurred throughout the process, however, and this affected both the scope of the study and the quality of the data. One secret Army report revealed that,

the tight labor market in St. Louis made it difficult to obtain adequate personnel, particularly responsible personnel. The scope of several of the tests were limited by failure of employees to report for duty. It was necessary to discard some data because of obvious poor quality and incompleteness. The rapid personnel turnover, coupled with the generally disinterested attitude, made it extremely difficult to retain even a nucleus of trained people (U.S. Army, 1953b: 22-23).

The Army acknowledged that it "discarded" data related to the St. Louis study, but we have no way of knowing if it was for reasons stated. We do know however, that incomplete and missing data was what the National Research Council had to work with, when they examined the process and effects of the St. Louis and Minneapolis studies in 1997.

According to official documents, fifty-three part-time employees worked on the 1953 study in positions related to administrative, meteorology, laboratory, and instruments needs. ${ }^{20}$ The Army reported that it was "difficult to obtain sufficient personnel of any description and in particular responsible people for balloon captain positions. Considering the tight labor market, this situation will undoubtedly continue throughout the period of the project in that city" (U.S. Army, 1953a: 24). The earliest tests were run

\footnotetext{
${ }^{20}$ It is uncertain if this includes the specially "security-cleared personnel" who are virtually unmentioned in the official documents.
} 
by "a small group of inexperienced part-time workers", according to official documents (U.S. Army, 1953a: 32). ${ }^{21}$

Prerequisites for hiring in both the Minneapolis and St. Louis studies, were that "men met minimum security requirements and that each man have a means of transportation" (U.S. Army, 1953a: 35). ${ }^{22}$ Many of those who were employed to participate were college students. Operators of the aerosol generators were selected from "those men possessing some mechanical aptitude and technical background", as operation of the equipment required "a reasonable degree of mature judgment” (U.S. Army, 1953a). Washington University in St. Louis, had conveniently hired four former Los Alamos scientists; they were likely useful contacts from which to recruit temporary student workers with some technical knowledge. According to official documents, local college students with lab experience were employed in the labs where exposed filters were attached to glass slides; some were civil engineering students from Washington University (U.S. Army, 1953a: 50). An operating manual prepared by Stanford University was used to train men in this capacity. Officials reported that this process went smoothly in Minneapolis, but, "one problem inherent with employment of students, however, is the general dearth of manpower during periods of final examinations and vacations...during this period tests were conducted with some difficulty” (U.S. Army, 1953a: 37). ${ }^{23}$

\footnotetext{
21 This may explain the omission of "scientifically qualified investigator" requirement when comparing the Wilson Memorandum to the Nuremberg Code.

${ }^{22}$ An additional team with higher security clearance were also involved in the study, but again they are not discussed in most of the official documentation.

23 This may explain the gap in data between July and November, 1953.
} 
It is noted repeatedly in official documents that there were concerns related to contamination of the field office and laboratory by equipment used in the field, and measures were taken to avoid this, including storage of equipment at a remote location. In Minneapolis, for example, the contaminated equipment was stored at the home of the "chief of the disperser crew". "The panel truck used for transportation of the generator and crew during test operations [was] procured from a rental agency also remotely located from the field office" (U.S. Army, 1953a: 41). Even the radios, and batteries used to power the remote generator were segregated from other equipment after use, tested for contamination, decontaminated if necessary outside, and stored away from all the other equipment, "to eliminate any possibility of contamination of field office premises from this source" (U.S. Army, 1953a: 42). The Army claimed that the material sprayed in St. Louis was zinc cadmium sulfide $(\mathrm{ZnCdS})$, with a "fluorescent additive" for ease in lab analysis. Notably, the "fluorescent additive" is left unidentified in official records.

For their tasks, all available men would meet prior to testing in a field office several hours in advance, to obtain directions and field data sheets for the daily operation. The field office for the 1953 tests in St. Louis was at a building in the 5500 block of Pershing Avenue, just north of Forest Park, that served as the temporary headquarters for the Army's aerosol tests (“Cancer Coincidence”, 1995). Three of the men that served as technicians in the aerosol tests in St. Louis claim that they never knew the nature of the tests, nor to their knowledge, was any other worker informed as to the true nature of the 
tests. The Army was thus maintaining secrecy down to the lab and field workers conducting the experiments.

After a demonstration, the men and their equipment were then dispatched to various field test areas within the city. From this group, crew captains were selected to train new workers, disseminate instructions and equipment to a small team of workers, and receive information by phone as to location, date, hours, and number of men required at specific tests. Crew captains met in advance of the other men and were given maps that indicated the locations where each field crew worker would set up between one and three sampling units. Radio equipment was issued to crew captains and field crews. ${ }^{24}$ According to official records, the tests started with reports from meteorological stations regarding wind direction and velocity, which was tracked via weather balloons and instruments, prior to "tracer" release. Adjustment of equipment location might occur due to outcome of the wind direction tests. Once test personnel were in place, filters were exposed, samplers were started, and the aerosol generator dispersed the aerosolized material from stationary sources or the backs of slowly moving vehicles.

Philip Leighton, a Stanford University chemist, and the primary author of the study who contracted with the Army on the aerosol project, focused intently on perfecting a certain particulate size for the studies. Leighton required that the fluorescent particles in the aerosol studies be in the 1-5 $\mu$ size range" (Leighton, et al., 1965: 334). Fluorescent particles and the optimal sizes were selected in part, because they were easy to observe under a microscope and offered "a very sensitive method of detection and quantitative

\footnotetext{
24 Conditions did not always cooperate with their plans. In open test areas around Minneapolis, snow became a
} challenge, thus, sampling equipment was delivered via sleds and toboggans. 
estimation", according to a report published by Leighton (Leighton, et al., 1965: 335). Particulate size would take on grave importance to those targeted victims who inhaled the dosages, and Leighton's true purpose for selection of a specific sized particle may not align with his public narrative. The National Research Council, who was provided data on the St. Louis aerosol study by the Army decades later, noted that, "no reports on the toxicity of inhaled $\mathrm{ZnCdS}$ are available in the literature. Because the $\mathrm{ZnCdS}$ particles used in the Army's dispersion studies were so small, the particles could probably be inhaled and deposited deep in the lung..." (NRC, 1997b: 7).

The material (claimed to be zinc cadmium sulfide) that was sprayed by the Stanford labs in the St. Louis study was referred to internally as "FP2266". ${ }^{25}$ FP2266 was manufactured by the New Jersey Zinc Company and the United States Radium Corporation. The United States Radium Corporation, located in New Jersey, had been in legal hot water decades prior, for producing luminescent paint that was used by girls and young female factory workers to paint watch dials in the 1920s. The young women were instructed to lick the paint-brushes prior to painting the hands onto the watches, in order to refine the point of the brush. As a result, the radioactive material in the paint sickened and killed many of the young women (Frame: 1). Radium 226 was mixed with zinc sulfide to make the radioactive powder that the workers used to paint the watch dials, and the compound was used in manufacturing until the 1970s (Frame: 1). It is unknown if "FP2266" was also known as or incorporated Radium 226, the radioactive radium product produced by United States Radium Corporation. Typically, the manufacturer is reflected in the "name" of the compound, whereby the compound might also be referred

\footnotetext{
${ }^{25}$ It is also possible that FP2267 may have been used in St. Louis; documents are unclear.
} 
to as NJZ2266. In the St. Louis study however, Leighton refers to "FP2266" ${ }^{26}$ FP2266 had a "maximum number of particles between $0.75 \mu$ and $3.0 \mu$ in diameter" (Leighton, et al., 1965: 335; NRC, 1997b: 141). The fluorescent, fluffy powder varied between yellow and green due to an unidentified additive, and the material glowed brightly under ultraviolet light. Silicate was also added to facilitate dispersal of what was claimed to be 80\% ZnS and 20\% CdS (NRC, 1997b: 32-3). In an environment with high humidity such as St. Louis, it was often necessary to heat the powder in advance of use to obtain a fluff quality, which made dispersion easier utilizing a blower generator.

After release of the aerosolized material by a blower generator, "a low trajectory freeflight balloon [was] released from the location during tracer dispersal to further define the local wind direction" (U.S. Army, 1953a: 44). "As some scientists launched weather balloons to track wind direction, others sprayed the particles into the air using aerosol generators at street corners and rooftops" (Sawyer, 1994). The particles moved downwind, and some were collected on sampling plates that were placed outdoors and inside buildings, including private homes. Workers would place the black sampling boxes downwind of the aerosol test, stay in their vehicles to watch the boxes, and obtain the necessary data, which would be processed later off-site. Thus, the Army could measure how the cloud of chemical moved through the air in the community, and into structures (Sawyer, 1994). Each release of material was typically one hour long (Venkatram, et al.: 20), and often at night (McElroy, 1997: 1027). Later studies of the releases in St. Louis noted an increase in the "initial size of the plume" immediately after the release of the aerosolized material (McElroy, 1997: 1028).

\footnotetext{
${ }^{26}$ Reasons for this distinction are discussed later in this paper.
} 
Machine "operators were furnished chains and locks with which the sampling equipment could be secured to trees, lamp poles, or similar permanent objects", which limited tampering or theft of equipment by local citizens. One woman in St. Louis recalled the "mysterious black boxes chained to trees just down the block" from her house where she and her four children, as well as hundreds of her neighbors often spent the hot summer evenings outdoors to avoid the interior heat of the house. "I can remember saying, "what are they doing there?'...we went up next to them to see if they were ticking” (“Cancer Coincidence, 1995). Indeed, many residents even slept outside to avoid the oppressive summer heat of the tall brick structures that dotted the urban landscape of St. Louis in 1953.

After release of the aerosolized material, the sampling equipment was packed up and removed from the site. According to official Army documents, lab technicians would visually identify and count illuminated microscopic fluorescent particles on the filters using a microscope. The results were documented on "exposure data sheets", and plotted on a test area map. "The final total dosage data, in addition to virtual wind track vectors, balloon track directions, and aerosol release information, are then plotted on maps of the test area in preparation for more detailed analysis of the test results" (U.S. Army, 1953a: 50). In all, St. Louis "tracer" personnel worked more than 3,000 hours in February and more than 2,500 hours in March 1953. The April-June tests alone totaled 7,511 
personnel hours for field and a portion of the laboratory labor (U.S. Army, 1953b: 25) ${ }^{27}$.

According to Army reports, the 1953 tests totaled 25,896 personnel hours from the rented field office in St. Louis. According to official records, staff members included a Division Chief, an Office Manager, and a Field Foreman (U.S. Army, 1953a: 14).

\section{TWO DEGREES OF SECRECY: A PARALLEL ST. LOUIS STUDY}

A once-classified 1953 Army report ${ }^{28}$ stated that, "all work of a possibly classified nature was performed by cleared personnel away from the St. Louis office, and no special measures incident to handling of classified material were required" (U.S. Army, 1953b: 31). ${ }^{29}$ Here, Army officials hint to a secret parallel study in tandem with the ZnCdS study - indicating additional testing of an even more classified nature, beyond that which is included in the official record. This parallel study required special security clearance for personnel, and a separate, distant location for data analysis than that provided for the initial study. ${ }^{30}$ What is by appearances an off-handed note buried within a lengthy, dry, and formerly classified report, brings up several points and questions ${ }^{31}$, some of which will be discussed here.

\footnotetext{
27 Unclassified document AD031508; Defense Documentation Center for Scientific and Technical Information; Classification changed to "unclassified" from "secret" per authority listed in ASTIA Tab No. U63-4-4, November 15, 1963; obtained through FOIA, June 2011 from Dugway Proving Ground, Dugway, Utah.

28 The document was obtained by this author through FOIA from Dugway Proving Grounds, is currently stamped "unclassified", with the notation from the Defense Documentation Center that "classification changed to "unclassified' from "secret"'. In fact the initial stamp listed "SECRET-SECURITY INFORMATION" in duplicate at the top and bottom of each page of the report. Date of reclassification is not indicated on either the report or the cover letter.

29 Author's emphasis.

30 This is a good example of blizzarding or "paper whiteout".

31 Among those not mentioned are also the following questions: Were the labor hours of these specially "cleared" personnel calculated into the tally of labor hours? Where and how were these classified samples analyzed? Did the Monsanto and other company officials fall into this tiny group of notified officials, because they would play a role in processing some of the lab results, or provide additional test materials to the Army? Given that scenario, were there different chemicals utilized in this classified portion of the study? If so, what were those chemicals? Who was targeted? How often?
} 
First, it was argued (and continues to be argued by some official sources ${ }^{32}$ ) that the St. Louis study was defensive, rather than offensive in nature, when official records indicate otherwise. Likewise, it has been argued that military officials in 1953 did not officially recognize the toxicity of $\mathrm{ZnCdS}$ (NRC, 1997b). Indeed, officials refer to $\mathrm{ZnCdS}$ as a harmless "simulant". ${ }^{33}$ Were it the case that Army officials believed that ZnCdS was a harmless simulant, than there would have been no discernable need on their part to: 1) suppress press attention 2) notify only a few select local officials on the apparent "need to know basis", and 3) maintain information related to the study and the results of the study as "classified" (or in this case more accurately, "secret"), which would exempt the information and data from Congress, the public, media, victims, legal interests, and other interested parties, unless there was a separate reason to maintain secrecy. Second, the “special measures" utilizing "special personnel" at a "special, off-site location", were assigned a higher level of classified secrecy by the Army, than was the rest of the secret study.

Given the large gaps in data (gaps to which the Army admits), and given their own official statement that there was more data and information than is discussed in official documents at that time, it becomes clear that crucial elements of the St. Louis study were omitted in official records. What possible additional aspects of this study are too secret to be classified as "Secret" in official military documents? In other words, what type of

\footnotetext{
32 And frequently repeated by non-official sources.

33 This is surprising given the long list of toxicological studies in the literature prior to 1953, which notes a high level of toxicity, particularly related to cadmium, which is a known carcinogen.
} 
research took place in St. Louis that rose to a level classified above "Secret- Security Information"?

\section{THE NATIONAL RESEARCH COUNCIL REVIEWS THE AEROSOL STUDIES}

In 1997, The National Research Council (NRC) ${ }^{34}$ compiled and published the aerosol dispersal data of several U.S. cities including St. Louis and Minneapolis, as a result of Congressional and public pressure.

Upon learning of the dispersion tests in the early 1990s, government officials and citizens in cities where the tests had occurred raised concerns about the thousands of people who might unknowingly been exposed to $\mathrm{ZnCdS}$. After some information on the tests became public, people living in areas where the tests had been conducted attributed various illnesses, including cancer and reproductive difficulties, to exposure to the chemical (NRC: 2).

The Army denied any public health risks associated with the studies, but public and Congressional pressure (including Senator Ted Kennedy, Senator Paul Wellstone and Congressman Richard Gephardt) forced the hand of the Army to release information to concerned citizens. In response, “...the U.S. Army Environmental Hygiene Agency (AEHA) prepared reports that retrospectively assessed the health risk to humans who had been exposed to ZnCdS in those cities" (National Research Council: 2). Again, the Army re-affirmed negative health effects from testing. Later the review was expanded to include public meetings in three cities where $\mathrm{ZnCdS}$ was reportedly sprayed, to review Environmental Protection Agency and Centers for Disease Control risk-assessment reports on $\mathrm{ZnCdS}$, and identify gaps in research regarding $\mathrm{ZnCdS}$ exposure. The National Research Council "assigned the project to the Committee on Toxicology of the

\footnotetext{
34 The NRC may also refer to the Nuclear Regulatory Commission; in this piece however, it refers only to the National Research Council.
} 
Board on Environmental Studies and Toxicology in the Commission on Life Sciences" (NRC: 3). St. Louis was omitted from the list of meeting locations. The NRC subcommittee ultimately issued two reports: one for public distribution which included the subtitle, "Answers to Commonly Asked Questions", and consisted of approximately 15 pages total, and another "technical report" (no subtitle) that comprised 358 pages. The shorter, public distribution report is available through any Internet search by the title, Toxicologic Assessment of the Army's Zinc Cadmium Sulfide Dispersion Tests: Answers to Commonly Asked Questions. The longer technical report (Toxicologic Assessment of the Army's Zinc Cadmium Sulfide Dispersion Tests) is referenced through a general Internet search, however it must be purchased online. ${ }^{35}$ Not only are the titles identical, other than the subtitle included on the short report whereby one might easily confuse the short report for the long, but those interested in obtaining the report might infer that a particular party is selling a report that can be obtained online for free, and thus, they would likely obtain only the free, short report. The difference between the reports regarding data is dramatic. The short report provides very little information, and glosses over the tests themselves, health information related to zinc cadmium sulfide exposure, and offers very little (and often conflicting) data.

The 1997 NRC technical report noted that the 1953-54 releases were conducted at the Army designated locations of "How" and "Item" areas in St. Louis (NRC, 1997b: 26061). Some of the dispersant came from a single point source, and others were dispersed over a length from one point to another (presumably by vehicle), for up to 10,750 yards.

35 Cost for the technical report for this author was approximately \$45 USD in 2010. 
(See Appendix A). In the short, public-distributed report, the NRC subcommittee states that "the highest estimated cadmium intake from the zinc cadmium sulfide dispersion tests was 24.4 [micrograms] in St. Louis", based on a cadmium content of $15 \%$ of the ZnCdS compound (NRC, 1997a). The subcommittee also acknowledged, that "the $\mathrm{ZnCdS}$ used in the Army studies was composed of about $80 \%$ zinc sulfide ( $\mathrm{ZnS})$ and 20\% cadmium sulfide (CDs) (NRC 1997b: 6; 32). It is unclear whether the NRC should have adjusted their calculation to account for a higher cadmium level.

Conflicting data emerged from the NRC report. There are discrepancies in the report; they note for example, an estimated cadmium exposure in St. Louis of 19.2 micrograms "maximal exposure per person" (NRC, 1997b: 77). Yet, the subcommittee also refers to a calculated "highest estimated potential exposure dose" of $156 \mu$ (micrograms) in St. Louis (NRC, 1997a). The $156 \mu$ level disputes the NAS' own technical report of 1997, that indicates a level of 1,898 micrograms per cubic meter, as dispersed on Saturday, June, 20, 1953. This level exceeds the levels used in the subcommittee's calculations in the public report (NRC, 1997a; 1997b). These combined errors indicate a cadmium exposure level of not $24 \mu$, but rather roughly $38 \mu$ on just that one individual date in St. Louis. ${ }^{36}$

The 1953 raw data for St. Louis, was not provided in full to the National Research Council when they compiled an Army-supported study on cities sprayed with zinc cadmium sulfide. The NRC acknowledged in their 1995 technical report that complete

\footnotetext{
36 The NRC notes that this is general exposure data, not specific or individual data. Individual cadmium levels are essential for determining specific health effects from exposure, per epidemiological study guidelines, but environmental exposure can indicate general causation of health effects based on overall ambient exposure to a population.
} 
data had not been provided to them, or that there were errors in calculations. The following statements all appear in the NRC technical report regarding the military's aerosol studies:

- "There should be much more information about this test in files..." (NRC, 1995b).

- The paper has some graphs of "concentrations" in particles... and "maximum concentrations", although the basis for these graphs is not given....However, no raw data were provided in the paper, and much of the information needed for accurate estimates is missing" (NRC, 1995b: 192).

- "It was noted that the conversion from $\mathrm{ZnCdS}$ to cadmium concentration [was] in error" (NRC, 1995b: 325).

- Terms used in the toxicity-assessment portions of the documents include "inconclusive studies", "limited data", "not generally associated", and “inconclusive data"-all vague and left unexplained (NRC, 1995b: 330).

- "A technical summary of the data from these studies was to be published by Stanford, but it is not available for this report" (NRC, 1995b)

- "A final administrative and operational report was to be published by the Ralph M. Parsons Company, giving an enumeration of all field tests, but it is not available for this report (NRC, 1995b).

- "No complete summary of all the tests performed in any city is available, and the results of some tests were not reported anywhere in the series of Army-issued Joint Quarterly Reports [JQRs]. Critical pages of some of the JQRs are missing, so that certain details (particularly the amounts of material released) are not 
available for some tests. There are occasional slight differences in details between the available summary tables and the detailed information in the appendices of the JQRs...” (NRC, 1995b)

- "Individual digits of some of the numbers might be incorrect, because of unreadable script in the available reports" (NRC, 1995b).

Various parties have requested the data from the Army: House and Senate subcommittees; several members of Congress such as now deceased Senator Paul Wellstone; the National Research Council; and researchers (including this one), yet the full and complete data seems elusive to requestors, being declared either missing, unavailable, or of classified status. During the Clinton administration, the military was ordered to open their books on past human subject testing, and to embrace a new era of transparency. This extraordinary effort, under the direction of President Clinton's Secretary of Energy, Hazel O'Leary, ushered in unprecedented transparency related to state-sponsored human subject testing. In response to President Clinton's mandate, the military came forward with thousands of pages of formerly classified studies of a notably sinister nature, involving civilians, children, infants, prisoners, commuters in public spaces, and pregnant women. Yet for all the revolting revelations, information involving the St. Louis aerosol studies continues to be "missing" and withheld, particularly data from the 1953 study. Indeed, we know little of what took place in 1953. This begs further scrutiny, and suggests that something dark took place that military officials, still believe warrants secrecy. The first series of tests in this St. Louis test study concluded on January 20,1954, but a decade later and before the shroud of secrecy had been partially lifted, federal officials would once again land in St. Louis to conduct additional studies. 


\section{TRACER STUDY}

A second series of "tracer studies" began in 1963 in St. Louis, and those involved in this subsequent study included the United States Public Health Service, and the U.S. Department of Health, Education, and Welfare in Cincinnati, Ohio. According to one insider who worked for the Public Health Service, in the early 1950's, the U.S. Public Health Service was interested in the public health effects of radiation, and thus, planned at that time to establish a... large radiobiological research unit” (U.S.DOE, 1995).

In the 1963 study, several sites were set up with instruments to measure the levels of aerosolized material that were released into the air. One set of four instruments was attached to a radio tower at KMOX-TV in central downtown St. Louis. The aerosol was released in the "southeast corner of Forest Park" (Pooler, 1966: 677), roughly at the corner of Clayton and Faulkner Roads, according to the 1997 NRC technical report. According to the St. Louis Post-Dispatch, the Forest Park releases were located at a pond east of the Planetarium in the park (Sawyer, 1994). The Knights of Columbus Building was located near the intersection of South Grand Boulevard and Gravois Road, where aerosol releases were dispersed from the rooftop of the "three story building in the midst of buildings and trees of comparable height" (Pooler, 1966: 677) "Those two sites [were] approximately 2.8 miles apart" (National Research Council, 1997b: 188). Sampling sites surrounded both release sites in circles or arcs up to five miles away to the Mississippi River. "The tracer was generally released for a period of $1 \mathrm{hr}$ " in the 1963 study (Pooler, 1966: 678). 
Up to twenty workers were needed to conduct the St. Louis experiments in 1963. A cadre of approximately ten student workers were recruited from the Department of Civil Engineering at Washington University, where Engineering professor Ed Edgerly provided "on-call student help" to the study personnel working on the tests. (Pooler, 1966: 678). Many of the tracer levels were much higher than what they had found in open-air emission tests in the countryside (Pooler, 1966: 681). The author of the study discusses how the "tracer" emissions would rise in a plume, "meandering back and forth in the crosswind direction,... selectively carried aloft by convective motions until finally, when most of the plume has removed from near the ground", the tracer once again dropped down to ground level (Pooler, 1966). Air levels of zinc cadmium sulfide were measured as high as 7,400 micrograms over a 40 square mile area in a populated area of St. Louis (NRC, 1997b: 127). ${ }^{37}$ A report at the time noted that there were 42 experiments conducted, but only 32 of the experiments, "yielded usable dispersion data". The report stated that, "many of the excluded experiments yielded usable data for which analysis could not be made in the conventional manner used here. A separate publication is planned to report analyses of these data" (McElroy and Pooler, 1968: 5) ${ }^{38}$.

\section{POST-STUDY CLAIMS BY OFFICIALS}

In July 1994, the military released official documents to Senator Paul Wellstone (DMinneapolis) and Congressman Richard Gephardt (D-St. Louis), after Senator Wellstone began receiving individual inquiries related to the Minneapolis study from adults who

\footnotetext{
37 This release level was revealed in a graph, according to the National Research Council, in a presentation to the Air Pollution Control Association, which noted that the information was incomplete- that there "should be more information available somewhere (National Research Council, 1997b: 140).

38 Clasification is not noted on this document; obtained through FOIA, June 2011 from Dugway Proving Ground, Dugway, Utah.
} 
had been targeted in aerosol studies sponsored by the military, and who were convinced that health issues had been caused by those events. Documents provided to the Congressmen confirmed that,

Army officials [had] concocted a 'cover story' to win approval for the aerosol tests from the few city officials that they disclosed the information to prior to the study. The Army claimed the tests were intended to see if smoke screens could protect the city from Soviet bomber attacks (Allen and Best, 1994).

"The smokescreen explanation was concocted to allay suspicions about the strange equipment and activities that passersby might notice. The misinformation effort included planting false news stories" (Cole: 61). Thus, officials involved did not simply engage in secrecy and covert actions targeting specific communities of disenfranchised citizens, but they went beyond that, by issuing false information to media, to deflect criticism and inquiry. The same day as the release of documents to Congressman Wellstone, Army Chemical Division officials claimed in a St. Louis press conference, that the "tests did not present a long-term health risk to the area" (Allen, et al 1994). Army Colonel John Doesburg also stated that, "the tests were aimed at understanding how the atmosphere carried the particles and not at how they affect humans" (Allen, et al., 1994). What the public did not know, however, was that the ZnCdS particulate size was specifically selected by Leighton to ensure optimal human lung absorption. Leighton's careful selection of particulate size for the St. Louis aerosol studies was considered at length, based on properties such as inhalation rate and depth. "One Army report notes that the small size of the particles was chosen because it "approximates that which is considered 
most effective in penetrating into the lungs" (Sawyer, 1994). Yet through the 1990s, the Army has continued to" maintain that the tests harmed no one" (Cole, 1997: 28). ${ }^{39}$ We can examine through a pre-1954 literature search however, whether information related to human toxicity and health effects from cadmium existed when officials began the St. Louis study.

\section{CADMIUM TOXICITY IN THE OPEN LITERATURE (PRE-1954)}

“As early as 1656 , Stockhusen described what is perhaps the first data on industrial cadmium poisoning", whereby he found that "cadmium fumes cause gastrointestinal disturbances in foundry workers, these disturbances being accompanied by diarrhea and vomiting" (USPHS: 604). An 1858 study documented cadmium poisoning in three people via inhalation (Sovet, as cited by USPHS: 604), and other studies in 1888, 1893, and 1897 confirmed the Sovet study regarding the toxicity of cadmium, noting digestive and "metabolic disturbances". Also in the mid 1800s (1865), well-known French physician Claude Bernard wrote An Introduction to the Study of Experimental Medicine, where he outlined medical ethics thusly:

The principle of medical and surgical morality...consists in never performing on man an experiment which might be harmful to him to any extent, even though the result might be highly advantageous to science, i.e., to the health of others...it is immoral, then, to make an experiment on man when it is dangerous to him, even though the result may be useful to others...(U.S. House, 1994: 118.)

After the turn of the century, cadmium research continued whereby "investigations of poisoning caused by human exposure to cadmium" were reported in the literature by

39 The Army continues today to maintain their position that the aerosol studies were "harmless". 
Chajes (1929), Fisher (1926), Lewin (1929), Gadamer (1934), Schwarz and Otto (1925), Starkenstein, Rost, and Pohl (1929), Otto (1925), and Leschke (1934), among others. Many other investigations that involved animal studies (too numerous to mention here), bolstered the human studies related to the toxicological effects of cadmium. A 1923 report of a fatal case of cadmium exposure, noted that the victim experienced "dryness of the throat, headache, rapid pulse, nausea, and shivering, with brown discoloration of the urine" prior to death (Legge, as cited by Bridge, 1929: 1144). A number of other studies around the same time, noted similar symptoms as well as influenza-like symptoms.

By 1929, Lewin and others found that exposure to cadmium was related to increased salivation, choking attacks, persistent vomiting, abdominal pain, diarrhea, and tenesmus. "These are the symptoms, according to most investigators, which occur most frequently in cases of poisoning due to cadmium" (USPHS, 1942: 605). One investigator noted that "respiration was retarded" due to exposure, and that attacks of vertigo and loss of consciousness occur. "According to Athanasiu and Langlois, "cadmium paralyses the central nervous system" (USPHS, 1942: 605). Another 1929 study of cadmium toxicity in the workplace echoed Lewin et al's findings: "the part played by inhaled dust in the etiology of cancer of the bladder cannot be ignored.... a few fatal cases of cancer of the bladder have also been noted among pitch workers. Their occurrence may be of importance" (Bridge, 1929: 1146). Leon Prodan argued in 1932 that "cadmium is a dangerous substance and that the type of damage to be expected is of such critical nature as to indicate the avoidance of the inhalation or ingestion of even small amounts of 
cadmium" (Prodan, 1932; as cited by Cole, 1997: 26). Cadmium was found to cause serious lung damage and according to Prodan, "one may conclude that cadmium, no matter how small the amount taken in the lungs, causes pathologic changes...there is, therefore, no permissible amount of cadmium" (Prodan, 1932; as cited by Cole, 1997: 27).

A 1937 study outlined two human fatalities from cadmium poisoning in Canada (Bulmer, as cited in The British Medical Journal: 33). Several years later in 1942, Hubert Smith of the Harvard Law and Medical Schools wrote that "ethical and legal principles required 'full disclosure of material facts' and the securing of the 'enlightened consent' of the human subject" thusly,

...subjecting a patient to experimental remedies without disclosure and consent is contrary to the customs of surgeons and thus negligent... The surgeon should make a full disclosure of material facts to the patient, including risks and alternative treatments, and obtain his enlightened consent before applying any novel or experimental treatment (U.S. House: 1994: 119).

By 1942, the United States Public Health Service (USPHS) described the symptoms of cadmium poisoning specifically through inhalation:

The first symptoms of industrial cadmium poisoning are usually dryness of the throat, cough, headache, vomiting, and a sense of constriction of the chest. Later symptoms are predominantly referable to the respiratory system and are characterized by cough, pain in the chest, severe dyspnea, and prostration. These symptoms result from a pneumonitis, which in many instances is followed by bronchopneumonia.

The USPHS study noted numerous fatalities involved from cadmium exposure, which included liver and kidney effects, as well as degenerative changes leading to necrosis. 
In 1947, Barrett, et al., affirmed the earlier cadmium toxicity studies, and found cadmium inhalation to be fatal to humans. Barrett's animal studies (also 1947), supported the human studies, determining that mortality in animals was "proportional to the product of the duration of exposure and the concentration of inhaled cadmium" (ATSDR: 19). In 1948, The British Medical Journal described the toxicological pathways of cadmium that leads to death in animals and humans alike. Notably, lesions in the lungs and pulmonary edema which lasts for approximately three days, progresses into pneumonitis for ten days, and then the exposed individual will exhibit a string of symptoms which continue for reportedly four years or more. Permanent lung damage is the result of cadmium exposure in animal studies. The long-term symptoms described by the journal includes "vague motor difficulties, pain in the lower limbs, pelvis, and groin, and [by] striae in the long bones...loss of appetite and weight, constipation, fatigue, headache" and perhaps most notably, "a yellow cadmium ring on the teeth" (The Toxicity of Cadmium: 33$).{ }^{40}$ If medical personnel are aware that a patient has been exposed to cadmium, they can not only see indicators of toxicity in terms of not only symptomology, but also the visual cue of a yellow cadmium line on the teeth. As well, cadmium was at that time, measurable in blood and urine. ${ }^{41}$ This was outlined in the medical literature as early as 1919 , in The Journal of Pharmacology (The Toxicity of Cadmium: 33).

By 1950, L. Friberg published a study regarding the poisoning of workers in a cadmium battery factory (ATSDR: 17). In that toxicological study, exposure occurred through inhalation of fumes or cadmium dust, and a resultant pneumonia was the direct cause of

\footnotetext{
40 The cadmium ring presents an interesting finding as it parallels a similar blue ring on the gum line to persons exposed to high levels of another heavy metal, notably lead.

${ }^{41}$ Today, cadmium can also be measured in hair, fingernails, and teeth.
} 
death. The American Medical Association published various articles in the 1950s, and a list of principles in 1957, that echoed the earlier calls for full disclosure of human experimentation, voluntary consent and agreement of those being tested as a requirement, ability of the patient to terminate the experiment at any time, avoidance of conflict of interest by the physician/experimenter, that the "danger of each experiment must have been investigated previously by means of animal experimentation", and the provision that the test must be performed under "proper medical protection and management"( U.S. House, 1994: 124).

Beton, et al. (1966) using a technique similar to Barrett's earlier study, calculated fatal human doses of cadmium in the air. A 1976 study by Patwardhan and Finckh "prompted Elinder (1986b) to estimate that an exposure of $1-5 \mathrm{mg} / \mathrm{m} 3$ for 8 hours could be immediately dangerous. (ATSDR: 18). Even the United States Public Health Service (USPHS) which would run their own studies of ZnCdS in St. Louis in the 1960s, despite that they reported at least two decades prior in their own literature, a high number of cadmium toxicity cases and studies in the literature (they reference 109 such studies). In fact, the USPHS argued that cadmium exposure should be prevented at all costs. Their report tracked "all the known cases of cadmium poisoning which have been reported up to the present time" between 1858 and 1941, which resulted in 346 reported poisoning incidents, and 58 inhalation poisoning events. Yet, the USPHS would engage in a $\mathrm{ZnCdS}$ study in St. Louis in 1963, just one decade after the Army completed their study. 
Later studies (Friberg 1950; Bonnell 1955; Adams, et al. 1969; Liu, et al. 1985; Rose et al. 1992) found that workers exposed to cadmium report "chronic rhinitis and impairment or the loss of the sense of smell" (ATSDR: 44). In animal studies, not only has respiratory injury been reported, but also persistent damage has been reported "from a single acute exposure" (ATSDR: 45). According to the Agencies for Toxic Substances and Disease registry, the arm of the federal Centers for Disease Control that studies and addresses issues of toxins and public exposure to toxins, inhalation of cadmium can intensely irritate lung tissue, with delayed or latent effects. Initial exposure (up to two hours), produces symptoms including coughing, and throat and mucosa irritation. Symptoms thereafter become progressively worse:

From 4 to 10 hours post exposure, influenza-like symptoms...appear, including cough, tight chest, pain in chest on coughing, dyspnea, malaise, ache, chilling, sweating, shivering, and aching pain in back and limbs. From 8 hours to 7 days post exposure, more advanced stages of pulmonary response included severe dyspnea and wheezing, chest pain and precordial constriction, persistent cough, weakness and malaise, anorexia, nausea, diarrhea, nocturia, abdominal pain, hemoptysis, and prostration. Acute, high-level exposures can be fatal (ATSDR: 21).

Immediate and delayed (one week) post exposure symptoms thus present as flu-like symptoms, and include pulmonary problems that may advance to pneumonia. Long-term symptoms of workers exposed to cadmium through inhalation, revealed "progressive pulmonary fibrosis", emphysema, and impaired respiratory function, unimproved even nine years after exposure (ATSDR: 21).

L. Arthur Spomer, a former researcher with the Army Chemical Corps, who conducted atmospheric tracer studies at Deseret Test Center as a meteorologist, reportedly appealed 
to the officers in charge of the experiments about the hazards related to its use, and was ignored (Cole, 1997). Later, as a professor in the School of Agriculture at the University of Illinois, Spomer published a study arguing that $\mathrm{ZnCdS}$ was a dangerous compound to use in field experiments, saying that it presented a 'potential health hazard to experimenters and other humans exposed to it"' (Spomer, 1973; as cited by Allen and Best and Allen, 1994). Spomer explained the nature of symptoms related to cadmium exposure to military officials with an appeal to stop its use in military field studies.

Although Cd [cadmium] toxicity is well-established and FP [zinc cadmium sulfide fluorescent particles] is commonly used as a tracer in atmospheric studies, no case of CD poisoning resulting from the use of FP has been reported in the literature. This may be because none has occurred; however it is more likely that such poisoning has been of a low-level chronic nature and its symptoms are less dramatic and more difficult to recognize than in the case of acute $\mathrm{Cd}$ poisoning. A general ignorance of the toxicity of FP and of the symptoms of $\mathrm{Cd}$ poisoning also contribute to the failure to recognize FP poisoning. [Spomer, 1973 as cited in Cole, 1997: 27).

Given Spomer's study and supported by the majority of the other toxicology studies related to cadmium, if exposed persons are not notified in advance of potential exposure to $\mathrm{ZnCdS}$, and medical personnel are uninformed of acute $\mathrm{ZnCdS}$ exposure through inhalation, it will likely result in incorrect treatment for the misdiagnosed illness, which by all appearances presents as flu, pneumonia, or other respiratory ailments. Not only might this create additional complications for the patient, but also it would not address the initial episode of toxicity. Although the issue of consent is not analyzed at length in this paper, it is an element of importance in this and hundreds of other military-sponsored studies on humans during the Cold War, and thus, the issue warrants some attention. One thing is clear, published health studies addressed the severe human toxicity of cadmium at least one hundred years prior to the secret US Army aerosol studies in St. Louis. 


\section{STANDARDS OF THE TIMES}

One argument that surfaces in testimony and contemporary sources regarding militarysponsored human subject testing during the Cold War, asserts that ethical standards were either non-existent or unclear in 1953. In light of the highly publicized Nuremberg Code that resulted from the trials of German physicians who engaged in atrocious human experimentation, most familiar with the issue of human experimentation at least have a limited appreciation of the Nuremberg Code. Other international codes followed Nuremberg, such as the Geneva Protocol. Nevertheless, in 1994, in a testimony before a Congressional investigative committee, David J. Rothman of Columbia University, challenged the assumptions that ethical standards in 1953 were non-existent.

The idea that the 'standard of the times was different' is not correct. The ethical precepts were clearly formulated and well understood. What is now more clearly established is that investigators transgressed the standards not out of ignorance, but out of a commitment to advancing scientific knowledge and Cold War strategies. In effect, they were prepared to transgress the principles to serve these other ends (U.S. Congress, 1994: 117).

In other words, according to Rothman, officials chose to ignore Nuremberg. In 1942, Hubert Smith of the Harvard Law and Medical Schools wrote that, "ethical and legal principles required 'full disclosure of material facts' and the securing of the 'enlightened consent' of the human subject":

...subjecting a patient to experimental remedies without disclosure and consent is contrary to the customs of surgeons and thus negligent...The surgeon should make a full disclosure of material facts to the patient, including risks and alternative treatments, and obtain his enlightened consent before applying any novel or experimental treatment (U.S. House, 1994: 119). 
Four years later (1946), the American Medical Association adopted an ethical code recognizing a voluntary consent requirement in research, along with disclosure regarding the danger of the study, and the necessary provision of proper medical protection and management of the individuals tested (U.S. House, 1994: 120). Indeed, in the 1940s and 1950s, "the ethical requirements for obtaining consent prior to experimentation were also widely recognized in scholarly publications" (U.S. House, 1994: 122). In 1949, Louis John Reagan wrote in Doctor and Patient and the Law, that,

The physician must keep abreast of medical progress, but he is responsible if he goes beyond the usual and standard procedures to the point of experimentation. If such treatment is considered indicated, it should not be undertaken until consultation has been had and until the patient has signed a paper acknowledging and assuming the risk (U.S. House, 1994: 122).

In 1950, Carl Wiggers, Dean of Case Western Reserve Medical School, an academy that would ultimately be involved with human subject testing on behalf of the military, published Basic Ethical Principles for the Conduct of Human Experimentation, where he noted that,

The voluntary consent of the human subject must be obtained...All unnecessary physical and mental suffering should be avoided...The human subject should be at liberty to terminate the experiment at any time (Western Reserve University [sic], 1950: 60-65, as cited in U.S. House, 1994: 118). ${ }^{42}$

What is clear, is that 1) health studies emphasizing the high level of human toxicity of cadmium, 2) consistent flow of reports in the literature emphasizing a fundamental need for informed consent, along with 3) established international guidelines for human health

421950 Alumni Bulletin, School of Medicine, Western Reserve University, 60-65, as cited in US House, 1994; Also cited in Beecher; Research and the Individual; pgs., 238-39. 
studies in Nuremberg and Geneva, and 4) the military's own Wilson Memorandum, all have a notable presence either in the literature of the times or was a recognized policy within the military structure itself. Thus, Rothman's assertion seems correct, in that American government scientists engaged in human subject experimentation without consent of the victims, did so knowingly, and chose to violate published ethical standards and codes. Indeed, “...the voluntary consent requirement was a well-established medicolegal obligation of physicians", according to Rothman (U.S. House, 1994: 119). In other words, government officials placed military goals above the health of targeted citizens, and above the laws of the times. St. Louis residents would come in the 1990s to find out the partial truth of the military tests that targeted their neighborhoods, and officials once again assured them that there was no concern.

It would appear by military claims that the St. Louis study was less dramatic than many other studies conducted by the military and its contractors, as military officials assured the public that a "harmless" ZnCdS had been sprayed. St. Louis would, by all accounts scarcely receive mention in the literature and formal investigations that discuss militarysponsored chemical tests involving civilians. Although St. Louis shared a brief, albeit ugly experience with a few cities such as Minneapolis, and Ottawa, Canada, in 1953 (and again in 1963), what occurred in St. Louis was much more than meets the eye, and it is deserving of its own case study and analysis. Yet officials are still tight-lipped, six decades later, about events in St. Louis.

St. Louis was but a sliver-albeit an important one- of a massive, complex, and coordinated top secret effort to expand military technology exponentially, to a degree 
unmatched in U.S. history. St. Louis was, in fact, tied to an extraordinary militaryindustrial-academic complex and an exceedingly powerful, top-secret network referred to here as the Manhattan-Rochester Coalition- a professional group that secretly sprang out of World War II. The St. Louis study may have involved far more than biological "simulants", per the official military talking point. There is indication of a secret study conducted in tandem to the "official" military-sponsored St. Louis aerosol study. ${ }^{43}$ The second study, which for some reason warrants even more secrecy than its parallel study, appears to have been connected to a new type of deadly nuclear weapon, one of many being developed by the coalition, to be tested on unsuspecting residents of St. Louis, Missouri, at the urging of Manhattan-Rochester Coalition member Joseph G. Hamilton.

\footnotetext{
${ }^{43}$ This would not be the only time that the military used the tactic of hiding one study beneath another during this time period. See: "M.D. Anderson Played Role in Radiation Testing"; The Houston Chronicle, June 28, 1994, where 95 "previously hidden nuclear bomb detonations at the Nevada Test Site"... went undetected because they were set off with reported tests". Hidden beneath publicly disclosed tests, were secret tests.
} 


\section{CHAPTER III}

\section{THE MANHATTAN-ROCHESTER COALITION}

It was spring of 1945 . World War II would soon come to an end with the culmination of extraordinary efforts of virtually the entire population in Los Alamos, New Mexicoassigned either by Army or marriage, to the Manhattan Project. Indeed, the U.S. dropped the first-ever atomic bombs on both Hiroshima and Nagasaki, Japan, and as a result, Japan would surrender to the Allies in September. But rather than recognize the soon-tobe fait accompli, the Manhattan Engineer District ${ }^{44}$ pushed for much more from its scientists. The District created ten top-secret spin-off divisions, to be headed by some of the world's most brilliant scientists, who had directly or indirectly contributed to the creation of the atomic bomb. Biophysicist Cornelius A. Tobias recalled later that,

The war ended with victory. The Manhattan Project told us - that included both Hamilton and Lawrence - that we could become part of the rejuvenated Manhattan Project, and we were told that basic medical research with radiation and radioisotopes would be A-okay (U.S. DOE, 1995b).

The men would enter a top secret, life-time partnership with high-ranking military officials, and "captains" of the defense industry, and would play major roles in a sometimes grotesque underworld of twisted science and medicine, for the benefit of a

\footnotetext{
44 This is the official name of the atomic bomb project, known commonly as the Manhattan Project. The organization was originally controlled from New York, NY (Madison Square area), which is where the name was derived prior to moving to the newly built Los Alamos District in New Mexico.
} 
vast and powerful war machine. In doing so, the men would also enter a world of duplicity, and thus, engineer one of the greatest and most sordid feats in modern history. The elite scientists in the inner ring of the Manhattan-Rochester Coalition formed a lifetime bond of secrecy and intrigue. They were each given extraordinary freedom by their military superiors, to pursue the most diabolical of research that they could conjure, but the military officials also insisted on extraordinary constraints of secrecy. Indeed, the generals and colonels were willing to destroy careers to that end. The men of science and medicine in the coalition learned to work and thrive in this perverse closed world, where "body-snatching”, and plutonium injections became a norm. This chapter identifies many of those scientists who comprised the secretive inner ring of the ManhattanRochester Coalition (the spin-off group from the Manhattan Project), as well as the military contractor who led the St. Louis aerosol study in 1953.

\section{LOUIS H. HEMPELMANN (1914-1993)}

Louis Hempelmann was born in St. Louis, Missouri, on March 5, 1914 and attended Washington University in St. Louis as both an undergraduate, and student of medicine. Hempelmann completed a residency at the Peter Bent Brigham Hospital in Boston (Moss and Eckhardt: 183). He "had many friends and well-established acquaintances in St. Louis. His wife, Elinor Wickham Pulitzer, was the daughter of Joseph Pulitzer, publisher of the St. Louis Post-Dispatch, for whom the Pulitzer Prizes are named" (Welsome: 31). Hempelmann accepted a fellowship at the RAD (radiation) Lab in Berkeley to gain experience with cyclotrons and radiation "therapy" alongside John Lawrence and Robert Stone (other core members of the coalition). "After four months in Berkeley, 
Hempelmann went to Memorial Hospital in New York [where Manhattan-Rochester colleague Hymer Friedell had just trained] and spent another month studying radiation physics. Then he returned home to St. Louis.” (Welsome: 31). In St. Louis he accepted a supervisory position for a new Washington University cyclotron, funded in part by the Rockefeller Foundation and Monsanto, which would be used to produce plutonium for the Manhattan Engineering District. Monsanto also donated \$300,000 for a radiochemistry building, which would house the engineering department (Morrow: 430). According to journalist Eileen Welsome, Hempelmann also began injecting patients several times per week, with radioactive material produced by the Washington University cyclotron. "He soon grew uneasy when some of the patients developed dangerously low blood counts and even hemorrhages" (Wellsome: 39). Hempelmann was later handpicked by Lawrence to become the medical director of the Los Alamos Manhattan project, and he arrived in Los Alamos in March of 1943. At Los Alamos, Hempelmann "was in charge of the stricken scientists when they arrived at the hospital...[where] the doctors would have a chance to observe what would happen to a healthy person exposed to radiation from an atomic weapon without the confounding effects of blast or burn" (Welsome: 185). In other words, Hempelmann poked, prodded, observed, and "collected data" as those scientists unfortunate enough to be exposed to deadly radiation accidents, died painful and agonizing deaths within hours or days of exposure.

Although he began his affiliation with Rochester in the 1940s, "in 1950, Hempelmann joined the faculty at the University of Rochester as an Associate Professor of Experimental Radiology and served as Chairman of the Department of Radiology, from 
1960 through 1971" (Moss, et al., 203). Hempelmann and his wife were for decades, very close friends to J. Robert Oppenheimer, who headed the Manhattan Project. In fact, Hempelmann briefly employed Oppenheimer's wife Kitty, who had a background in biology, in the medical lab at Los Alamos. ${ }^{45}$ As one of the core scientists inside the inner circle of the Manhattan-Rochester coalition, Hempelmann supported and engaged in human subject testing of radioisotopes. Decades after some eleven patients had been injected with plutonium under his supervision, "Hempelmann told investigators that 'a deliberate decision was made not to inform the patient of the nature of the product that was injected" (Welsome: 127). Hempelmann continued his participation with radiation and human subject tests, over much of his professional career. He retired in Rochester, NY, which was the heart of the Manhattan-Rochester Coalition.

\section{WRIGHT HASKELL LANGHAM (1911-1972) aka "MR. PLUTONIUM"}

Originally from Texas, Langham earned his M.S. in chemistry at Oklahoma A\&M College and his Ph.D. in biochemistry at the University of Colorado (1943). Langham joined the "Plutonium Project" at Chicago's MetLab, and left for the Manhattan Project in Los Alamos in 1944, where he became Associate Division Leader for Biomedical Research. Langham led the Health Division's Radiobiology group from 1947 until his death in 1972 (U.S. DOE, 1995b). Langham helped develop procedures for estimating body burden doses of plutonium, and developed the "Langham Equation" for plutonium excretion in the human body. "He was active in stimulating and correlating nearly all of the toxicological work on plutonium and related elements for Los Alamos, Argonne

\footnotetext{
45 Hempelmann would later recall Kitty Oppenheimer as being “awful bossy” (Bird \& Sherwin: 257).
} 
National Lab, Rochester, and later, the programs at Utah and other laboratories" (Moss, et al, 206). Langham also derived standards for plutonium exposure through air and water. One former colleague of Langham's described him as a young Ph.D. reluctantly participating in human subject testing, but refusing to inject patients himself; another colleague (H. Friedell) described Langham as very enthusiastic about the human radiation studies, however (U.S.DOE, 1995b). Langham's widow Julie Langham Grilly described him as an excellent speaker, very well connected in Washington, DC, and "very good friends" with Stafford Warren (U.S.DOE, 1995b). Langham died in 1972 in an airplane crash (Moss, et al, 206)

\section{JOSEPH G. HAMILTON ( 1907-1957)}

Born in Santa Barbara, California, Joseph Hamilton studied chemistry and medicine, where he eventually focused on the health effects from radiation exposure as a professor of Medical Physics and manager of the University of California-Berkeley’s Crocker Laboratory aka RAD Lab. Eileen Welsome describes Hamilton as cold, sober, seriousminded, but with a streak of recklessness. "To the casual observer, Hamilton seemed like any other affluent urbane doctor; he enjoyed fine wine, drove a convertible, played poker. But documents written by Hamilton himself as well as recollections of his colleagues, reveal a suspicious and brooding side to his personality" (Welsome: 27). Welsome describes how Hamilton "immersed himself in radiation", gulped "radioactive cocktails", and flew threw radioactive clouds "during the postwar years" (Welsome: 29). "But where he really pushed his luck was around the cyclotron. He raced into the bombardment area to grab samples while the room was still radioactive and slouched 
against the hot, ticking parts of the machine..." (Welsome: 29). The scientists were all later instructed by the AEC to not use radioactive materials on themselves, according to one insider (USDOE, 1995b). Hamilton engaged with similar abandon in human subject testing with radiostrontium and plutonium at the University of California Hospital-San Francisco, and it was later revealed that he did not obtain consent from patients to administer radioactive cocktails to them, or to inject them with plutonium, actions in which he and his research team engaged. Robert Stone at the MetLab in Chicago hired Hamilton under contract, but Hamilton would not move to Chicago; "instead he remained in Berkeley, where he did his research and then forwarded his reports to Stone" (Welsome: 43). Hamilton studied how radioactive isotopes killed rats, and the isotope distribution in the deceased rats at Crocker Laboratory.

With chilling implications, Hamilton had been recruited for his expertise to "investigate the possibilities of using...fission products as a weapon..." in radiological warfare (Welsome: 43). In fact, Hamilton seemed to reserve his greatest scientific ingenuity for inventing uses of radioactive material in warfare.

Hamilton advised Robert Stone in a May 26, 1943, report that radioactive isotopes sprayed from aircraft 'offer the possibility of infecting to dangerous levels, large areas such as cities'. He added [that], the poisoning of water supplies such as reservoirs, wells, etc., and food must be kept in mind (Welsome: 43).

Hamilton pushed his colleagues at the Manhattan-Rochester Coalition, and the AEC for studies to develop radioactive smoke for use in warfare. His idea involved,

...'radioactive smoke' [that] could be designed to maximize the absorption of radioactive material in the lungs and the subsequent deposition of the 
material in the bones. Such a preparation... would be 'well adapted for producing fission product aerosols to subject urban populations to fission product poisoning' (Grover: 43).

Hamilton's "radioactive smoke" field test idea, was intended to target urban populations, and in doing so, particle size would become particularly important, as his colleague Louis Hempelmann would later argue. The word "product" was used by most of the researchers in the coalition, because the word "plutonium" was in fact, classified. It is unclear in this case, however, if Hamilton was referring specifically to plutonium or another fission-related material. Nevertheless, he was advocating the testing and use of radioactive smoke, clouds, or airborne radioactive material in urban areas for warfare. In January 1945, Hamilton continued his push for,

further study of the metabolic behavior of product oxide smokes with particular reference to the correlation between particle size and pulmonary retention, and a continuation of the investigation of the rates of elimination of product deposited in the lungs for protracted intervals after exposure ranging up to one year (Hamilton, 1945).

Hamilton noted at the time that, "considerable information has already been acquired concerning the behavior of fission products when distributed in the air in the form of a smoke" (Hamilton, 1945). Hamilton's recommendations of fission products with short half-lives included cadmium, and he advocated the testing of a radioactive spray or dust. According to Hamilton, "the distribution in the body of fission products following inhalation as a spray or dust of water soluble compounds would seem to be worthy of devoting some effort by our group here at Berkeley...” (Hamilton, 1945). Hamilton advocated use of Berkeley's cyclotron to produce radioactive materials for testing on animals and human subjects through tracer studies, and he sent a letter advocating these warfare research projects to Manhattan-Rochester Coalition colleagues Louis 
Hempelmann, Wright Langham, J.W. Kennedy, Capt. J. Nolan, and A.C. Wahl. Both Louis Hempelmann and Joseph Kennedy were affiliated with Washington University in St. Louis.

In his own radiation experiments, Hamilton and his colleagues often targeted patients who were "uneducated, had poor education, low IQs, and...[had] brain dysfunction because of their disease" (U.S. House, 1994: 108). He wrote to Shields Warren about his work, which included injecting patients with 'many times the so-called lethal textbook dose' of plutonium"; Hamilton described this experiment as a little bit of the 'Buchenwald touch"” (U.S. House, 1994 :108; Herken \& David, 1994). According to the New York Times, "Dr. Hamilton also continued experimenting long after the war. By the late 1940s, he had helped persuade the Army to carry out 'pilot experiments on a fairly large scale' of his radioactive aerosol idea (Herkin \& David, 1994). Hamilton- one of the Manhattan-Rochester Coalition's most valued young scientists - may have been the impetus for the St. Louis aerosol study just a few years later. There is a strong indication, particularly given the level of extreme secrecy surrounding the St. Louis study, and the involvement of Monsanto, that radioactive materials were sprayed in the St. Louis test series.

While Hamilton secretly advocated the most sinister of radionuclide weaponry to his colleagues in science and the military, in public he boasted about the safety of nuclear weapons. Despite this, Hamilton grew sick and died from a fatal form of leukemia in the 1950s, which was believed to be occupational-related. 


\section{ROBERT SPENCER STONE (1895- 1966)}

Robert Stone was one of four children of Flora and Spencer Stone. He was born in 1895 in Ontario, Canada, and served in the Canadian Air Force. Stone received his BS, MA, and MD degrees all from the University of Toronto, and trained with his uncle in Detroit, Michigan at Grace Hospital. He moved to the University of California School of Medicine, and he remained affiliated with the University of California for his entire life. Stone became director of the Plutonium Project human test series at the Metallurgical Laboratory (MetLab) aka the Chicago Health Division. According to one source, along with "Dr. Joseph Hamilton, he first administered a therapeutic dose of an artificially produced radioisotope to a human being, in March 1936" (Howell). Stone was also head of Project SUNSHINE, and in his position as head of The Plutonium Project, "he organized and directed the Health Division which consisted of medical, health-physics, and biological research sections... it was for this work that in 1946 he was awarded the Medal of Merit" from President Truman; this is the highest civilian award" (Howell). Stone also worked at the Oak Ridge National Laboratory (aka Clinton Laboratory) for Monsanto, according to the Chatham Daily News (October 9, 1945). Stone was administrator of many of the human studies projects involving radioisotope research, and appears to have screened and routed reports from Rochester to appropriate individuals, if secrecy allowed (U.S. DOE, 1995b). The term "acute radiation syndrome" (a disease related to excessive doses of radiation) was a term coined by Robert Stone. Stone was fascinated by Geiger counters much of his professional life. About his work at MetLab, he one wrote in a secret letter that, "the whole clinical study of the personnel is one vast 
experiment. Never before has so large a collection of individuals been exposed to so much irradiation" (Welsome: 45). His experiments with human subjects and radioactive materials continued at Chicago and in California, where he was giving full body $\mathrm{x}$-rays to patients, which came under fire. Stone "defended the radiation experiments on the grounds that he and his colleagues...had the right to select the patients and choose the type of therapy" (Herkin \& David, 1994). Even after much criticism Dr. Stone, funded by the University of California, continued his work at a "county-run home for the elderly in San Francisco" (Herkin \& David, 1994). Stone pushed the limits of research related to human effects from radiation, and was an essential member of the core team that coordinated and extended the AEC/military sponsored human-related studies of radioactive materials.

\section{WILLARD FRANK LIBBY (1908-1980)}

Born in Colorado, Willard Libby earned his degrees at the University of CaliforniaBerkeley in chemistry. Libby worked on the Manhattan Project through Columbia University, with enriched uranium-235, and he was also interested in the development of Geiger counters, tracer techniques, and isotope tracers (Nobelprize.org). Libby was closely affiliated with the University of Chicago, and was later appointed as the head of the Atomic Energy Commission by President Eisenhower, where he remained for four years, until he resigned to accept a teaching position at the University of California-Los Angeles. In 1960, Willard Libby was awarded the Nobel Prize for Chemistry. According to his Nobel Prize biography, "Libby has performed a wide range of scientific advisory and technical consultant work with industrial firms associated with the Institute 
for Nuclear Studies, as well as with defence [sic] departments, scientific organizations and universities" (Nobelprize.org). At the University of Chicago, Libby worked with tritium, and carbon-14 (radioactive carbon).

STAFFORD LEAK WARREN (1896-1981)

Stafford L. Warren attended University of California at Berkeley and received an M.D. from University of California Medical School at San Francisco (1922). He became assistant professor and later department chair of radiology at the University of Rochester School of Medicine and Dentistry. In November 1942, Brigadier General Leslie R. Groves (head of the Manhattan Engineer District, and superior to J. Robert Oppenheimer), through an Eastern Kodak intermediary, visited the office of Stafford Warren in Rochester. Warren explained in a 1966 interview that,

'they wanted to know what I was doing in radiation. So I discussed the cancer work and some of the other things... we got upstairs and they looked in the closet and they closed the transom and they looked out the window... Then they closed and locked the door and said, 'Sit down.' Soon thereafter, Dr. Warren was made a colonel in the U.S. Army and the medical director of the Manhattan Project (U.S.DOE, 1995a). ${ }^{46}$

In 1943, Warren became a consultant to the Manhattan Project at the Rochester, NY location, and he later became medical director of the Manhattan Project in Oak Ridge. He was commissioned as a colonel in the Army Medical Corps (Moss, et al: 183). In 1971, both Stafford and Shields Warren were both awarded the DOE's Lifetime Enrico Fermi Award. Dr. Warren later became dean of the University of California, Los

\footnotetext{
46 Stafford Warren, interview by Adelaide Tusler (Los Angeles: University of California), 23 June 1966 in An Exceptional Man for Exceptional Challenges, Vol. 2 (Los Angeles: University of California, 1983) (ACHRE No. UCLA-101794-A-1), 421-422, as cited in US DOE Openness: Human Radiation Experiments: Roadmap to the Project; ACHRE Report.
} 
Angeles, School of Medicine (U.S. DOE, 1995b). Hymer Friedell, a colleague of Warren's, noted that Warren had frequent contact with General Groves, who oversaw the entire Manhattan Engineering District (U.S. DOE, 1995b).

JOHN LAWRENCE (1904-1991)

John Lawrence was born in South Dakota, and was the younger brother of famed physicist Ernest Lawrence. He earned his B.A. in South Dakota, and graduated from Harvard with a degree in medicine. He was an instructor in the School of Medicine at Yale, before he move to the University California-Berkeley, where he joined his brother and began with other doctors exploring "whether neutrons and radioisotopes could be used to treat cancer patients" (Welsome). The RAD lab at Berkeley was instrumental in creating the atom bombs used during World War II, under the supervision of his brother, Ernest, who won the Nobel Prize. Under Ernest's supervision the lab discovered Carbon14, Iodine-131, and tritium (Berdahl, 2001). John Lawrence raised money to build the Donner Lab of Nuclear Medicine, where he became Director of the Division of Medical Physics. In 1935, John Lawrence performed the first biological experiments with neutrons (Berdahl, 2001). Lawrence "injected his first leukemia patient with radiophosphorus on Christmas Eve on 1937" (Welsome: 25). This was the first use of radioisotopes on humans (Berdahl, 2001). After Ernest died in 1959, John became the associate director of the RAD Lab aka Lawrence Berkeley Lab. He retired in 1970. In 1983, Lawrence was awarded the DOE's Lifetime Enrico Fermi Award; he died in 1991. 
HYMER FRIEDELL (1911-2002)

Hymer Friedel was born in 1911 in St. Petersburg, Russia; in 1915, his family moved to Minneapolis, MN. He earned his MD and Ph.D. in Physics from University of Minnesota, when he left for the National Cancer Institute's Memorial Hospital, and the University of California-San Francisco. Friedell joined the US Army and was assigned to work at MetLab in Chicago. From MetLab,

...he was transferred to Clinton Laboratories (now called the Oak Ridge National Laboratory) in mid-1943, where he worked as the Executive Officer of the Manhattan Engineer District (MED) Medical Division. In this role, he assisted in determining dose tolerances for new radioactive isotopes, was involved in reviewing applications for use of these isotopes, and witnessed the first test of the atomic bomb at Alamogordo, New Mexico (Dewey, 2007).

At the time that Friedell was Executive Officer of the Medical Division at Clinton Labs the laboratory was under the direction of Monsanto. Along with Stafford Warren, Friedell "went frequently to Rochester, New York, to confer with scientists at a topsecret biomedical research facility, called the 'Manhattan Department' or 'Manhattan Annex'. Located at the University of Rochester medical school and formally established in April of 1943 by the Manhattan Project" the Rochester facility was strictly concerned with health-related issues related to radiation (Welsome: 64). "After the war, Friedell taught and conducted research at the University of California and at Western Reserve University [sic] in Cleveland, Ohio" (Dewey, 2007). Friedell retired in 1979 and died on May 10, 2002 in Ohio. 


\section{SHIELDS WARREN (1898-1980)}

Shields Warren was grandson of William Fairfield Warren, the first president of Boston University, and son of William Marshall Warren, Dean of the College of Arts and Sciences, Boston University. Shields (no relation to Stafford Warren) graduated from Boston University, and Harvard Medical School. He was pathologist at New England Deaconess Hospital in Boston, and professor of pathology at Harvard University. After World War II, Warren became director of the Atomic Energy Commission's Division of Biology and medicine, and was commissioned as colonel. At Los Alamos, Warren was in charge of determining the amount of radiation that would cause death in a person (U.S.DOE, 1995b). Warren was "an expert on the effects of radiation on the human body. But even more important, he had the sophistication to navigate Washington's political waters" (Welsome: 198). Wellsome calls Warren "probably the most influential biomedical scientist in AEC history and one of the enigmas of the Cold War" (Welsome: 198). Warren traveled to the Manhattan Engineering District's laboratories and production facilities routinely, and was aware that patients were being injected with plutonium at Rochester, Chicago, California, and Oak Ridge (Welsome 203). It was under his leadership that that AEC cobbled together,

a vast network of national laboratories, universities, and hospitals that would investigate every imaginable effect of radiation" for over three decades... through grants, fellowships, contracts, construction projects, and the funding of huge machines, the AEC created a new industry and became one of the largest sponsors of scientific research in the United States (Welsome: 198-99).

As a result of this vast, top-secret myriad of projects Shields Warren was an enigma and not well understood, even by his colleagues whose opinions of Warren varied from hero 
to untrustworthy political operative. Indeed, Warren's shrewdly-constructed public

persona varied quite a lot from his private persona. He frequently,

...suppressed information that might provoke lawsuits or harm the AEC's image, and dealt brutally with outsiders. Yet documents declassified in 1994 and 1995 also reveal a courageous scientist who spoke out in secret meetings against proposed radiation experiments... but his enemies saw an opportunist who shifted with the political wind" and was perhaps untrustworthy (Welsome: 200).

In 1971, both Shields Warren and Stafford Warren were awarded the DOE's Lifetime Enrico Fermi Award.

\section{J. ROBERT OPPENHEIMER (1903-1967)}

Julius Robert Oppenheimer was born on March 23, 1903 in New York City. As a child of privilege, Oppenheimer was surrounded by opulence and fine art in the family home; the Oppenheimers had three live-in maids and a chauffeur. Robert and his younger brother Frank, grew up basking in luxury and advantage (Bird, et al: 12). Oppenheimer was recognized as precociously brilliant in science at an early age, and earned a scholarship to Harvard University, which he attended as an undergraduate. ${ }^{47} \mathrm{He}$ graduated summa cum laude in three years, with a degree in chemistry, but he quickly left to study physics at Cambridge, where he was tutored by Patrick Blackett, a future Nobel Prize winner. He later accepted a Rockefeller Foundation-funded fellowship to study at CalTech. His work in theoretical physics was internationally recognized at that point, and he had sixteen publications related to continuum wave functions, an original theory of field emission, and "breakthroughs in the calculation of the absorption

\footnotetext{
${ }^{47} \mathrm{He}$ would refuse the scholarship money however, and in lieu of the money, Harvard presented Oppenheimer with a book of Galileo's early writings (Bird, et al: 29).
} 
coefficient of x-rays" (Bird, et al: 78). The constructed public persona of Robert J. Oppenheimer was markedly different from that of the Manhattan-Rochester Coalition insider and leader, who approved and advanced weaponized radiation technology to a chilling degree, and who authorized radiation exposure tests on populations without their consent. Indeed, Oppenheimer (along with Shields Warren) appeared to have mastered the art of image-making, creating a public persona of thoughtful, if not distraught and conflicted project leader/historical figure who regretted his own participation in the profound devastation of nuclear war (Bird, et al: 114). That constructed public image, and Oppenheimer's actions on behalf of the Manhattan-Rochester Coalition as outlined in private correspondence, clash markedly.

Oppenheimer accepted a position at Berkeley where he was known to be an inspiring lecturer, but was often impatient, arrogant, and intimidating, as well as charismatic, magnetic, enthusiastic, and intellectually versatile (Conant: 24-25). At age thirty-seven, Oppenheimer was "summoned to the office of Arthur Compton", director of the University of Chicago's Metallurgical Laboratory (aka MetLab-which was a name selected to hide their purpose) (Conant: 29). "Compton needed Oppenheimer...to take charge of a division of the MetLab and organize a group to study the physics of an explosive chain reaction- or bomb" (Conant: 29). Meetings began with the top theoretical physicists in the country, under enormous secrecy and the head of General Leslie R. Groves, from the Army Corps of Engineers. "This sent a clear signal that the scientists and army officers would have to put aside their natural suspicions and work together. Under Groves, the scientists would have to accept life under a military regime, 
with army representatives becoming a constant presence in their lives, laboratories, and meetings" (Conant: 34). Oppenheimer, as director of this new Manhattan Engineering project, would oversee this cooperative effort, and he did so with great vigor and skill. In stark contrast to Oppenheimer's professed concerns related to social ills, he slipped by all accounts, quite easily into bomb-making, and became an enthusiastic proponent of creativity in warfare. For example, Oppenheimer and Enrico Fermi once debated whether to use radioactive strontium to poison food supplies:

'I think that we should not attempt a plan unless we can poison food sufficient to kill a half a million men, since there is not doubt that the actual number affected will, because of non-uniform distribution, be much smaller than this', Oppenheimer wrote in a May 25, 1943 letter to Fermi (Welsome: 43).

Oppenheimer as the high-profile overseer of the Manhattan Project, would bear the weight of the project's weighty legacy more than anyone, and had ample cause to reconstruct his historical image in a positive light. Indeed at the end of his tenure with the Manhattan Project, he claimed publicly—in a reaffirmation of his public persona as bomb-builder- that nuclear energy should come under international control in order to prevent the spread of nuclear weapons. This notion was by most accounts, met with an icy response by the military and industrial arms of his extended coalition, who recognized the influence that Oppenheimer had over his colleagues. As a result, in December 1953, the Atomic Energy Commission filed formal charges against their own lead operative, Oppenheimer, alleging that his continued employment on AEC contracts would endanger defense and security, based on alleged associations with "known and unknown communists" — charges of which Oppenheimer had been absolved, prior. The charges were more a censorship regarding Oppenheimer's potential influence on other scientists 
to not work on a new hydrogen bomb project. The AEC's charges alleged that, "the opposition to the hydrogen bomb, of which you are the most experienced, most powerful, and most effective member, has definitely slowed down its development" (Bird, et al: 487). If this portion of Oppenheimer's constructed image is in fact, valid, Oppenheimer's political indictment was a show of brazen power by the AEC and its chairman at the time, Lewis L. Strauss, to force Oppenheimer, and the other scientists to comply with AEC's aggressive plan to rapidly develop a hydrogen bomb, and a show that nuclear power would remain in the hands of the U.S. military and industry. The 1954 trial did not go well for Oppenheimer. His security clearance was revoked, and AEC's head Strauss "had the AEC staff highlight the most damaging testimony for reporters" (Bird, et al: 546). Oppenheimer's "public transformation from Washington insider to exiled intellectual was complete" (Bird, et al: 558). Nevertheless, he received the Lifetime Enrico Fermi award in 1963. Oppenheimer, who had long been a chain-smoker, was diagnosed with throat cancer, and died on February 18, 1967 at age 62.

\section{JOSEPH W. KENNEDY (1916-1957)}

Joseph Kennedy was born in 1916 in Texas. In 1935, he received his BA from Stephen F. Austin State Teachers College. He then attended the University of Kansas, earning an MA, and acceptance into the University of California, Berkeley. In 1939, he was awarded a Ph.D. in chemistry (Los Alamos National Labs). According to his official Los Alamos Laboratory biography, Kennedy taught at the University of California's radiation lab, where with colleagues he "discovered plutonium".

Kennedy, on the verge of his 27 th birthday, was among the first wave of 
Project Y recruits, coming to Los Alamos in March 1943 to head the Chemistry and Metallurgy division. Ironically, Kennedy's greatest achievements were managerial rather than technical: 'The amount of technical work involved has been very small; the principal problem has been to establish and maintain a sufficiently strong laboratory to handle the jobs supplied by other divisions.' These... jobs included purifying plutonium, fabricating plutonium and uranium metal, and handling polonium and radiolanthanum (Los Alamos National Labs).

Kennedy left Los Alamos in 1946 for the Chemistry Department at Washington

University in St. Louis, when Arthur H. Compton (Chancellor at Washington University, 1945-1953 and discoverer of the "Compton Effect") hired six scientists from the Manhattan Project. ${ }^{48}$ (Washington University, 2011). In 1955, the Atomic Energy Commission awarded $\$ 40,000$ to Compton and his co-discoverers of plutonium. "Unfortunately, Kennedy would have little time to enjoy his prize. After a battle with cancer lasting little more than half a year, he died on May 5, 1957" (Los Alamos National Labs).

\section{THE MILITARIZATION OF THE ACADEMY}

World War II and the establishment of the Manhattan Engineer District ushered in an unprecedented partnership between the U.S. military and the scientific establishment, and that partnership did not end during the emergence of the Cold War. Infusion of defenserelated money became exceedingly seductive to those inside the academy, and a burgeoning of growth in many universities took place over several decades. "Beginning at the end of the 1950s and in the early 1960s, before the major wave of the postwar baby boom created a huge demand for places in colleges, there began a major expansion in the

\footnotetext{
48 Other faculty brought to Washington University from the Manhattan Project included Lindsay Helmholtz, David Lipkin, Herbert A. Potratz, Arthur C. Wahl, and Samuel I. Weissman (http://www.chemistry.wustl.edu/research).
} 
size of university faculties, especially in science, as a result of the inflow of money from the state" (Lewontin, R.C., 29). In fact, Stanford University's engineering school's faculty expanded from thirty-two in the late 1930s, to forty-one in the next decade (Lowen, Rebecca: 118). Universities in fact, had lobbied for Department of Defense support, in the form of grants and capital to support various programs in their institutions.

Stanford University and Massachusetts Institute of Technology (MIT) were two universities that realized extraordinary growth from defense contracts. According to Seymour Hersh, by the 1960s, MIT awarded "about 20 Masters' and Doctoral degrees for classified research" per year (Hersh, Seymour: 198). Defense contracts with faculty members are not without controversy among peers, staff, and students, however. In California, lab and support personnel clashed with administrators over the support staff's refusal to participate in weapons-related experiments proposed by Lawrence Livermore National Laboratory. The Faculty Committee considered the case and determined that, "since the protesting... personnel were involved not by choice, but by their functions in the laboratory; attempts should be made to find them other positions..." (Kistiakowsky, V., 1989: 152). The lead investigator who accepted a contract with the Department of Defense, was not working solely on a project; indeed, that individual usually required a team of technical people that served as support staff, postdoctorates, and students, all supported by the research grant. "These individuals, like the SLAC personnel, may disagree with the end use of research in which they are involved, but will have only the options of acquiescing or quitting unless the institution takes responsibility for finding them other places internally" (Kistiakowsky: 152). In other words, support staff 
typically have no choice as to their assignments, and if they have moral or ethical concerns regarding a research assignment, they have few options of recourse if the university does not provide them with a lateral move or alternative assignment. In the 1980s, a decision by CalTech to establish a think tank for Army-related problems, led to "a heated debate between the faculty and the administration, followed by a reversal of that decision. The concluding event embodies the most prevalent attitude, which is that the requirements of excellence in education and research at universities are incompatible with classification" (Kistiakowsky, 1989: 148). Some find it troubling that within a militarized academy, "matters of justice, ethics, and equality...[were] exiled to the margins of politics" (Giroux, 2011: 118). Indeed, there were even punitive actions taken against faculty members who did not support the military mission on their campuses. For example, it was found that "earth scientists who did not conform (or were perceived not to conform) to the secrecy policies of the national security state often did not receive research opportunities or ship time (Doel, Ronald: 654). Other scientists remained unaware that their colleagues were even involved in classified research on behalf of the military, which suggests "a degree of partitioning familiar in military research programs (Doel, 2003: 642). If classified military projects are known inside the academy however, there may be internal resistance by faculty, students, and support staff who are professionally, morally, or ethically opposed to being associated with or contributing to military-sponsored projects, and this is something with which the principal researcher as well as the Department of Defense, must contend. 
"In fiscal year 1966, fifty-seven U.S. universities and their affiliated non-profit research arms were listed among the top 500 defense research contractors...heading the list was Johns Hopkins University with more than $\$ 50$ million in research contracts" (Hersh, Seymour: 188). By the following year, the Pentagon had in place a plan to bring more universities and academic researchers into contractual work with the military. In fiscal year 1968, military contractors included Johns Hopkins University (\$57.6 million), the University of California (\$17.4 million), Stanford University (\$16.4 million), the University of Rochester (\$13.1 million), Pennsylvania State University (\$10.5 million), Columbia University (\$9.9 million), Michigan State University (\$9.5 million), and the University of Illinois (\$8.6 million), among others (Kaufman, R.F., 1970: 187). "The Navy alone awards about 1,100 contracts each year to colleges and universities. In 1968, 143 colleges and universities were occupied, if not preoccupied, with Air Force research projects" (Kaufman, R.F: 187). The financial bonanza helped to create a massive buildup of newly militarized Cold War universities; the free-flowing money was both seductive and toxic.

It hardly seems necessary to document in detail the immense increase that has occurred in the size of the academic enterprise in the United States since the end of World War II. In constant dollars, the total budgets of colleges and universities increased by twenty times between 1946 and 1991 and the value of their physical plants by a factor of six in the same period (Lewontin, R.C., 1997: 24).

For example, Case Institute and Western Reserve University, both in Cleveland, (and later to be combined into Case Western Reserve University) were strongly shaped by military-funded and controlled research grants. "When the community of funders began to doubt the wisdom of supporting parallel scientific-technical establishments on adjacent 
sites, they pressured the two schools to unify their science departments and then to federate, an eventuality that provides a convenient terminus to the story" (Stapleton, D., 1993: 304). In other words, military funders essentially forced the two institutions to combine, because it was more convenient for the state, who was holding the purse stings. "At Case Institute, the total research budget in the last prewar academic year was $\$ 26,510$; in the last year of the war, only four years later, it was $\$ 392,860$, almost 15 times larger" (Stapleton, D., 1993: 305). By 1962, Case Institute's federal portion for research was approximately 75\% (Stapleton, D., 1993: 307). Western Reserve also held government contracts that totaled $\$ 2,000,000$ by $1942-1945$ (Stapleton, D., 1993: 305). This did not come without strings, however. One of the stipulations imposed by the U.S. Navy upon Western Reserve, was that military research on campus be infused into their educational programs (Stapleton: 306). This was conceivably to create a next generation of military scientists. As well as the military control of coursework for students, publication of results was restricted.

The influence of the military and the state, quickly permeated most of the sciences ${ }^{49}$ during the early Cold War, and it immediately altered the focus of research in the academy, thus, creating a "militarization of knowledge" (Giroux, H., 2007: 54).

Like all influential patrons, U.S. military funds helped create a landscape of research programs-an ecology of knowledge- that reflected this patron's particular interests and needs. Civilian earth scientists who assembled lists of critical 'unsolved problems' in oceanography, seismology, atmospheric sciences, and geography in Pentagon conference rooms in the late 1940s and early 1950s understood that their assessment of what problems mattered most ultimately reflected their patron's utilitarian needs (Doel, R.: 655).

\footnotetext{
${ }^{49}$ Some departments have their hands deeper in the State's military pockets than do others. The robotics program at MIT for example, received 75\% of its funds from the Department of Defense (Giroux: 54).
} 
Henry Giroux argues that not only does military funding within the university have a long history, but higher education's willingness to "ingratiate itself to the national security state" continues today, with a massive influx in funding to universities after 9/11. He describes not only a "growing and chilling collaboration between higher education and the sixteen national intelligence agencies that make up the national security state, but also the breathtaking spread of corporate policies, values, and modes of governance throughout the realm of higher education" (Giroux, 2011: 125). The result of military and corporate influence on the academy according to Giroux, is a myriad of disturbing changes throughout education, including restrictions on academic freedom, reduction in faculty rights, demoralization of academics, devaluing of critical thought and engaged scholarship for both students and faculty, faculty refusal to address urgent social problems, etc. As well "undergraduate teaching received short shrift as professors, not surprisingly, showed more interest in and loyalty to their patrons outside the university than to their own institutions and students" (Lowen, Rebecca: 3). "More striking still is the slow death of the university as a center of critique, vital source of civic education, and crucial public good. Or, to put it more specifically, the consequence of such dramatic transformations has been the near-death of the university as a democratic public sphere", whereby the university is "increasingly reduced to an adjunct of the growing national security state" (Giroux, 2011: 125; 130).

Some students took note of the negative impacts and implications however, and "called for an end to war-related research on university campuses and a severing of the relationship between the university and the Defense Department; these calls were ignored 
by university administrators" for the most part (Lowen, Rebecca: 234). In response to the public and student pressure however, several academic institutions did create satellite institutes near campus, in a thinly veiled attempt to continue Defense Department work, yet these institutions were often staffed by faculty from the university. Thus, university officials could (and did) claim that military research was not connected to the university. For example, Stanford University created Stanford Research Institute (SRI) in nearby Menlo Park, California.

\section{STANFORD UNVIVERSTY, SRI, AND THE ST. LOUIS AEROSOL STUDIES}

Stanford University opened officially in 1891, and in the 1930s, the small private university included a few hundred faculty members and several thousand students. The university had been founded by Jane and Leland Stanford. Leland Stanford was a former California senator, and one of four major partners in the Central Pacific Railroad, from which he had amassed a fortune (Lowen, Rebecca: 18). Stanford's personal largess did not prevent the university from financial problems, however. Nevertheless, the small university hosted students who would move up far through industrial and political ranks. Herbert Hoover was one of the first graduates from Stanford, and he later became trustee of the university in 1912. The trustees, made up mostly of conservative businessmen, allowed Hoover's "interests to prevail" when he selected an old friend and mentor as Stanford's new president during World War II (Lowen, Rebecca: 20). Under his leadership by mid-1947, "the engineering school was receiving more money from military contracts than from the university's own operating budget. A year later, the school had approximately $\$ 500,000$ in military contracts" (Lowen, Rebecca: 118). 
In 1946 however, Stanford University had spun off Stanford Research Institute (SRI), a research center that "would work closely with major business powers in the western United States"; SRI took over a former Army hospital complex near the university (Krueger, 1A). This was no spontaneous decision; it was in response to the criticism by students of Stanford's uncomfortably close relationship with the Pentagon. Eventually, "he institute dropped the name Stanford Research Institute, and became SRI International, the name it uses today" (Krueger, 1A). SRI was accused in the 1960s however, of attempting to defraud the federal government of $\$ 250,000$, based on the "separation" of the university from SRI. A lawsuit charged that the federal government had been billed by SRI for,

depreciation on buildings that the government had donated to Stanford University, and which the university had later given to SRI...the institute had acknowledged 'that the close ties with Stanford University are clear cut and unmistakable as evidenced by the fact that the trustees of the University are the general members of the Institute and elect the Institute's Board of Directors... and are in a position to exercise control of the Institute as well of the University regardless of the Institute's statement to the contrary' (Hersh, S., 1969: 214).

SRI was in fact, deriving lucrative funding from the public coffers. During the second year of SRI's operations, " $70 \%$ of SRI's revenue was derived from contracts with the federal government" (Lowen, Rebecca: 17). By 1978, SRI had become the "biggest government research contractor", and they maintained strict secrecy on behalf of their clients, denying to a Congressman in the 1970s, a list of contractors (Richards: A1). In fact, in 1978, 68\% of SRI's funding still came from government contracts; this amounted to approximately $\$ 72$ million (Richards: A1). 
SRI was a spin-off corporation from Stanford University, but there was ample personnel crossover with the Department of Chemistry, where SRI researchers were also faculty members. Philip Leighton served as chairman of the Department of Chemistry at Stanford University from 1940-1951, and he was the principal researcher at SRI, in charge of the 1953-54 St. Louis aerosol studies. Just two years after leaving the chair position at Stanford, Leighton was contracted by the U.S. military to design, coordinate, and oversee the tests, and to analyze data from the St. Louis aerosol studies. Under Leighton's oversight, the Stanford University Chemistry Department had earlier developed a program whereby the department actively partnered with private industry; this program was called the "Industrial Affiliates Program". In the program, each company assigned to the university,

a staff member or two as representatives for liaison purposes, and a member of the [Chemistry] Departmental faculty similarly serves as a means of maintaining close communication with one or two companies... the financial support provided to the Affiliates has been invaluable in enabling the Department to pursue a vigorous research program during times of rapidly rising costs and diminishing government grants (Stanford: 35 ).

Some of the "industrial affiliates" that held unprecedented influence over Stanford University's Department of Chemistry included the following:

- Allied Chemical Corporation

- Chevron Research

- DuPont de Nemours \& Co.

- Exxon

- Haldor

- Hoffman LaRoche

- Monsanto Company (St. Louis)

- Syntex (Palo Alton, CA) 
Many of the corporations listed as members of Stanford's Industrial Affiliates Program were and still are, defense contractors. "The program provided the participating companies with privileged and early access to technical information in a field of increasing interest to the military" (Lowen, Rebecca: 131). This blurring between private industry, universities, and government agencies is problematic, in that at the very least, it can become a tool for insider industries to gain market advantage. ${ }^{50}$ "The relationship between the university and local industry seems not to have bothered Stanford's professors, administrators, or military patrons... [and] the development of close university-industry ties went unquestioned at the time (Lowen, R.: 135).

SRI also contracted with the military related to radiation and nuclear-test studies, such as the detonation of nuclear bombs. As well as analyzing airborne radiation samples related to military nuclear tests Tumbler/Snapper and Ivy Operations, (RAND: 36), SRI, along with the New York Operations Office of the Atomic Energy Commission (AEC aka NYOO), were in the early 1950s, developing a new analytical method for radioactive Strontium-90 (Sr90), using electrostatic precipitation. Thus, SRI was working with NYOO on a new type of analysis for aerosolized radioactive Sr90, at the same time that SRI was in charge of the St. Louis aerosol studies. NYOO's role was central to the efforts of the Manhattan-Rochester Coalition.

\footnotetext{
50 Perhaps the most alarming example resulting from such a partnership, occurred when private company Quaker Oats sponsored a study in Massachusetts in the 1940s, whereby MIT researchers fed radioactive strontium-90-laced-oatmeal to orphans. The children were not informed, nor did they consent to the study. There were instead, told that their participation would distinguish them as members of a new "Science Club". Thus, industry-funded research in partnership with the State, allowed private citizens, indeed parentless children in this case, to be used as unwitting test subjects for the profit of the corporation.
} 
Official records and testimony indicate that $\mathrm{SRI}^{51}$ contracted with the US military from at least 1953 through 1966; other documents indicate that their contractual work began much earlier and likely continues today [RAND, 1953; U.S. Senate, 1977: 97). It was during that well-documented contract window with the military, that SRI set up and coordinated the St. Louis and Minneapolis dispersion studies. Notably, in the year preceding the SRI-headed St. Louis aerosol study, Congress "had passed legislation that provided for Defense Department indemnification of private contract researchers in cases where human experiments resulted in injury to subjects" (Advisory Committee, 1996: 236).

Ten years after the St. Louis study, Leighton, et al., continued to work with the fluorescent particulate material FP2266 used in St. Louis, and manufactured by New Jersey Zinc. The FP2266 provided to SRI in a subsequent 1963 report, had been produced by New Jersey Zinc. The FP2266 was sent to Dugway Proving Ground by New Jersey Zinc, where it was retained for several years, before providing it to SRI for their "tracer" studies (U.S. Army Chemical Corps, 1963: 27-28). It is unclear whether the FP226 had been altered at Dugway, but it is referred to in Leighton's study as "FP2266", rather than the standard "NJZ2266", which indicates a formalized name change from New Jersey Zinc's production of the material. Because it was held at Dugway for some two years, and the name was changed when Dugway had the material

\footnotetext{
51 According to Seymour Hersh, the General Accounting Office "accused SRI of attempting to defraud it of \$250,000 by charging the government for depreciation on buildings that the government had donated to Stanford University, and which the university later gave to SRI" (Hersh: 214). Hersh noted that Stanford University and SRI have very close ties; in fact, trustees were also "general managers" of SRI. Other members of the SRI Board of Directors include business leaders from the defense industry such as General Dynamics, Northrup, McDonnell-Douglas and others.
} 
in its possession, it is plausible that the material may have been altered, and the new name reflected the change. It is also unclear whether the FP226 referenced in Leighton's 1964 study is the material used in St. Louis, but there is some indication that it is. Leighton, et al., noted in the report that the tracer can "be stored as permanent original records", and those samples can be re-examined as much as ten years later (Leighton, et al., 1965: 336) ${ }^{52}$. Leighton's subsequent study was completed approximately ten years after the original St. Louis study. SRI's relationship with Dugway Proving Ground at the time of the St. Louis studies is disturbing, particularly in that SRI obtained FP226 from Dugway, rather than directly from New Jersey Zinc. A 1994 Congressional investigation found that in the 1950s, while SRI was conducting the St. Louis study, Dugway also conducted at least 68 open-air trials that included the scattering of radioactive dust (Davidson, 1994). ${ }^{53}$ Given this information, it is plausible that the material provided by Dugway, and used in St. Louis for the aerosol studies, was "enhanced" at Dugway with a radioactive component. The St. Louis study may have in fact been the "urban equivalent" of the open-air studies done by Dugway in Utah at approximately the same time.

The Manhattan-Rochester Coalition was a Cold War spin-off research and weapons development group that emerged from the original Manhattan Project. Military funded and coordinated, the scientists who played central roles in the coalition had nearly all worked on the Manhattan Project in some capacity, either directly or indirectly.

\footnotetext{
${ }^{52}$ It is referred to herein as Leighton's 1964 study because the manuscript was submitted in 1964, although the publication date was in 1965 .

53 Also, Dugway dropped radioactive pellets in open-air tests. It is unclear but seems plausible that the glass beads or cork particles that were reportedly dropped by the military in various cities in the 1950s, are likely these radioactive pellets.
} 
Concentric rings of personnel surrounded the ultra-secret military core; the inner circle included among others, those elite scientists listed earlier in this chapter. The scientists brought expertise, knowledge, enthusiasm, ingenuity, and academic resources to the military endeavor. In return, they were part of a secret, elite fraternity of young, white males - the best and the brightest minds that free-flowing military money could buy. The St. Louis aerosol studies are linked to the Manhattan-Rochester Coalition, along several lines. First, Louis Hempelmann and David Kennedy- two core members of the coalition, both lived in St. Louis and held supervisory positions at Washington University that involved the cyclotron and the production of fission materials. Hempelmann had been the medical director of the Manhattan Project, at Los Alamos, and studied the health effects of radiation exposure in workers at the site. Monsanto would play one of the most central roles as a defense contractor, coordinating to a great extent, military efforts during the time period just preceding the St. Louis aerosol studies. Monsanto's world headquarters was located in the city of St. Louis, adjacent to the test areas. Monsanto was one of only two companies to be notified in advance of the St. Louis studies, while the targeted public was left uninformed of the top secret military-sponsored actions that would directly impact them. Philip Leighton, the coordinator of the St. Louis aerosol studies, worked closely at that time with the AEC's NYOO, who also played a major role in human radiation studies and military Projects GABRIEL and SUNSHINE. 


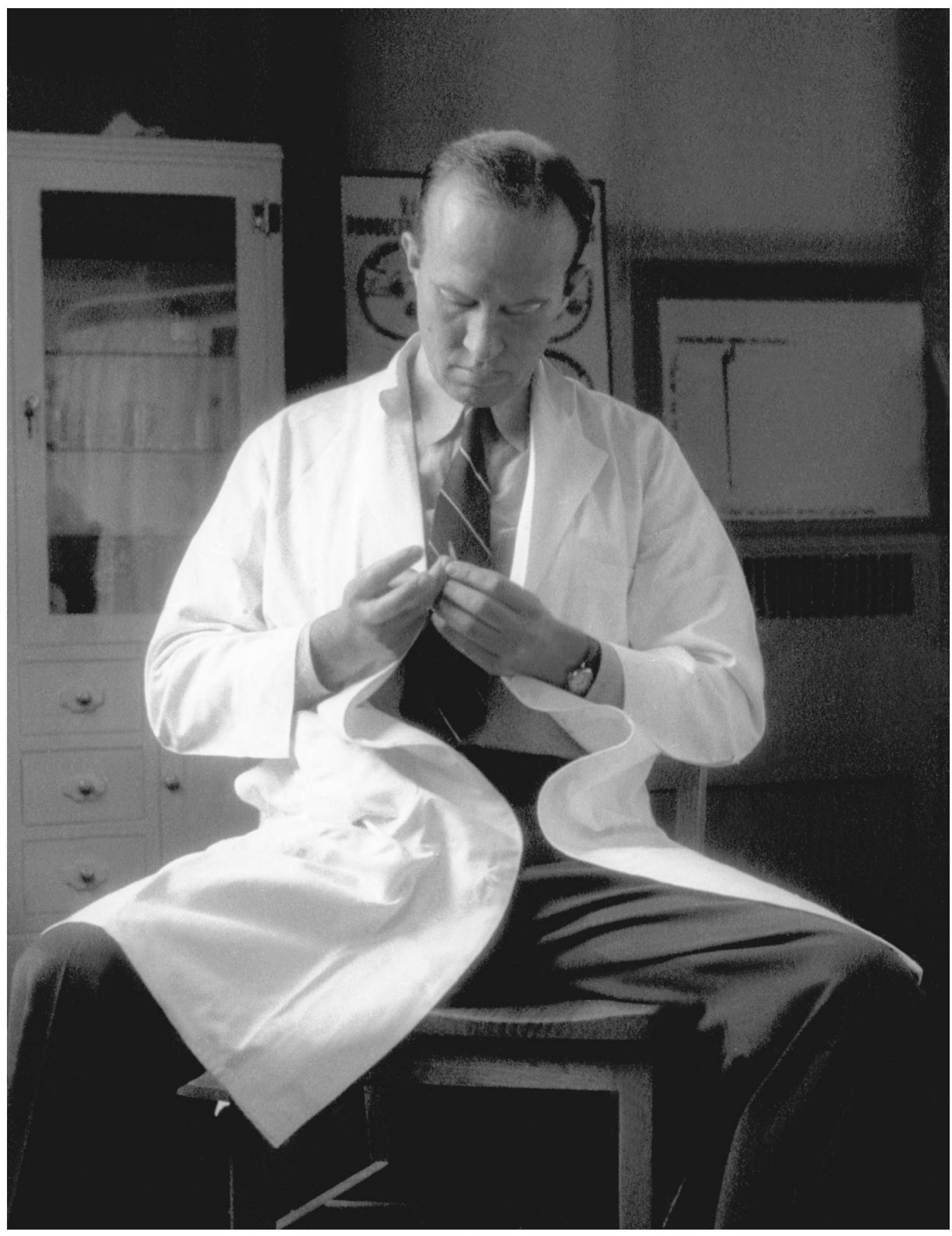

John Lawrence- Courtesy of University of California, Lawrence Berkeley National Laboratory. 


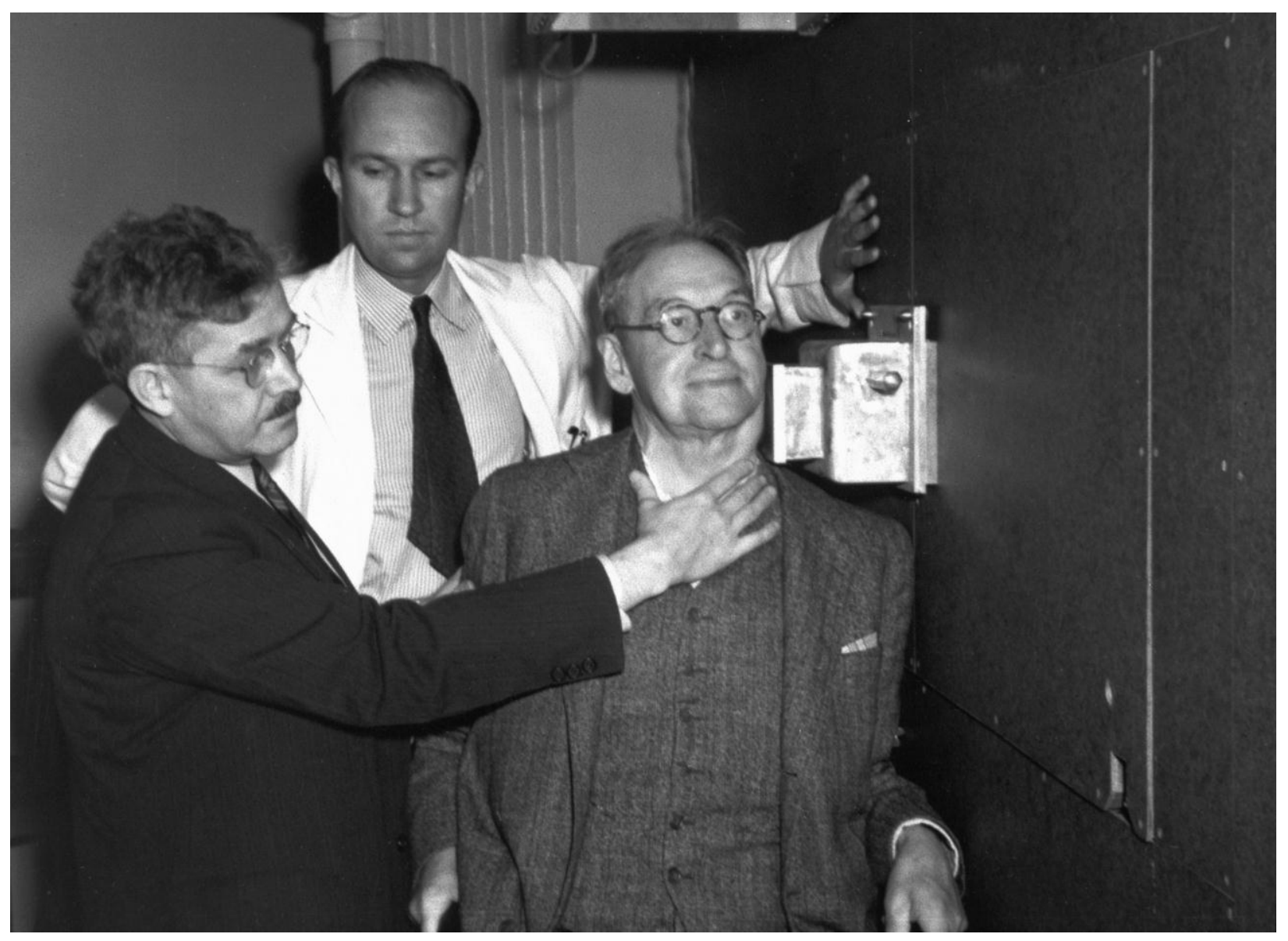

Robert Stone (left) and John Lawrence "treat" patient Robert Penny with 60-inch neutron port. Photo courtesy of University of California, Lawrence Berkeley National Laboratory. 


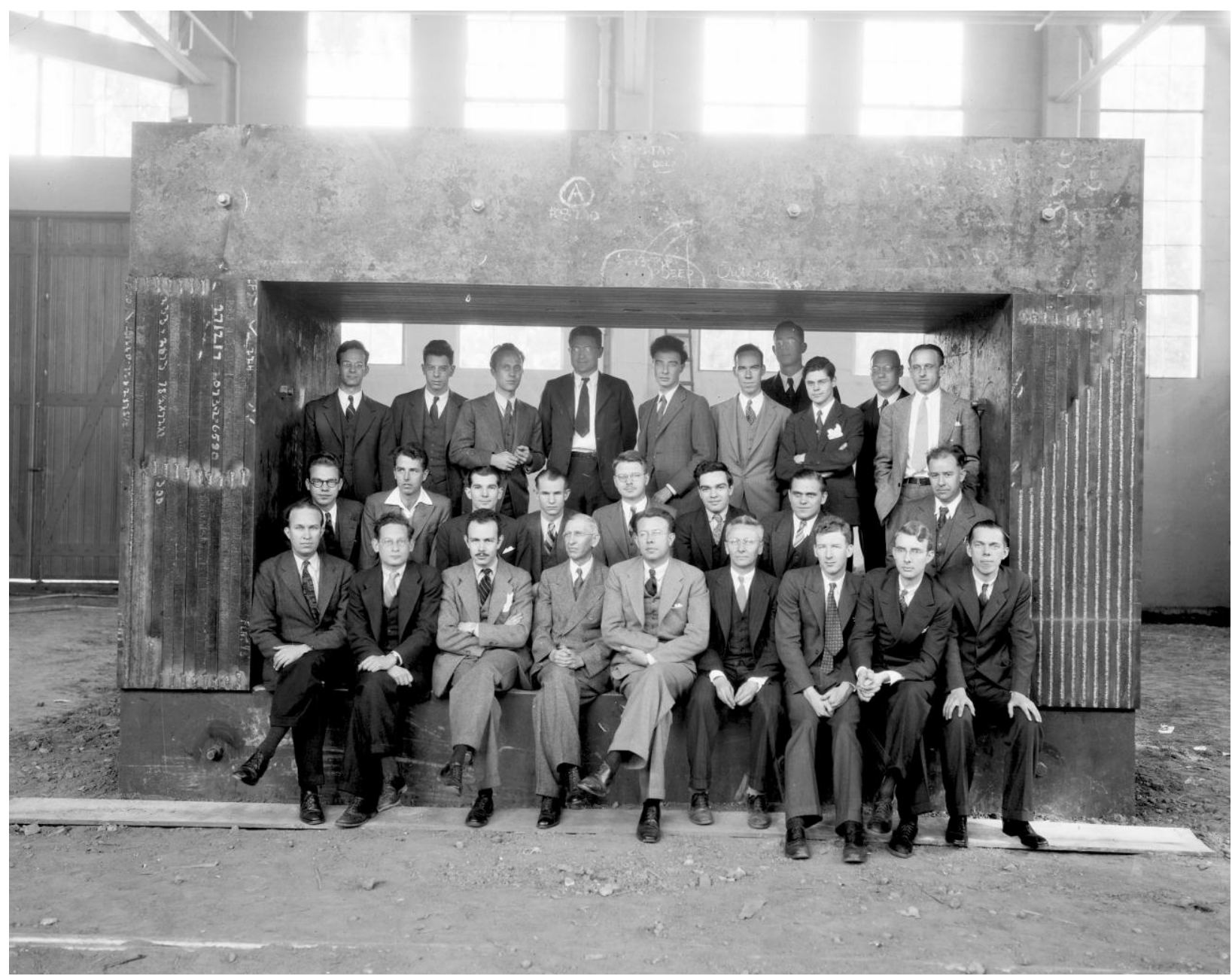

Early Radiation Laboratory staff framed by the magnet for the 60-inch cyclotron in 1938 . Front row, left to right: John H. Lawrence, Robert Serber, Franz N.D. Kurie, Raymond T. Birge, Ernest O. Lawrence,

Donald Cooksey, Arthur H. Snell, Luis W. Alvarezz, Philip H. Abelson. Second row: John Backus, Wilfred B. Mann, Paul C. Aebersold, Edwin M. McMillan, Ernest Lyman, Martin D. Kamen, D.C. Kalbfell, W.W.

Salisbury. Back row: Alex S. Langsdorf, Jr., Sam Simmons, Joseph G. Hamilton, David H. Sloan, J.

Robert Oppenheimer, William Brobeck, Robert Cornog, Robert R. Wilson, Eugene Viez, J.J. Livingood. Photo courtesy of University of California, Lawrence Berkeley National Laboratory.

Three colleagues from the Manhattan-Rochester Coalition appear in this photo: John Lawrence, J. Robert Oppenheimer, and Joseph G. Hamilton. 


\section{PREFACE TO CHAPTER FOUR}

The following chapter outlines the emergence of the Atomic Energy Commission, and information related to the appointed chairs of the commission. Several chairmen of the AEC were closely affiliated with the Manhattan-Rochester Coalition, and the organization of that group is outlined in this chapter. Connections and influence abounded among the elites affiliated with agencies and committees related to defense, as well as the defense contractors who were intimately involved in advancing classified military goals involving weapons research and development, including the development of airborne particles for warfare.

Military projects GABRIEL and SUNSHINE, which were a major focus of the Manhattan-Rochester Coalition, are outlined and discussed in this chapter, along with their connection to the St. Louis aerosol studies. This chapter reveals how some ultraclassified defense projects were embedded deeply within legitimate projects, to avoid public scrutiny and diffuse potential dissent. Thus, military projects were not simply labeled as "classified', but rather they were layered with secrecy, which allowed the elite scientists of the coalition to undertake covert human subject research related to radioactive materials, without risk of public knowledge of their activity. 


\title{
CHAPTER IV
}

\author{
SUNSHINE AND GABRIEL: \\ Organizational Structure of the \\ Manhattan-Rochester Coalition During the Cold War
}

After much Congressional debate, the Atomic Energy Commission (AEC) was officially established in August 1946, when President Harry Truman signed the McMahonDouglass/Atomic Energy Act. Prior to the formation of this agency, the military had maintained control over atomic energy and research, and much of the decision-making related to such issues were addressed by the Manhattan Project's General Groves. "The AEC was composed of five members, each appointed by the President and confirmed by the Senate. The JCAE consisted of 18 members, nine from each house of Congress, and was to function as 'watchdog' over the AEC. The Act granted the AEC complete ownership of all nuclear facilities, research, development, fissionable materials, and information related to nuclear energy" (Clarke: 475-76). The Act stipulated that all patents would be owned by the commission so that classified intelligence be maintained..."government ownership of patents meant that the AEC was the only means of access to nuclear technology" (Clarke: 476). Lee Clarke argues that there was no 
compelling economic reason for private interests to invest in nuclear technology. (The US military would later strike a deal that would change industry's perception that nuclear technology could not be profitable.) David Lilienthal was the first person appointed to chair the AEC. In contrast to the impressive scientific credentials of other persons considered for the position, Lilienthal was a rather unremarkable civil servant who had been involved in the establishment of the Tennessee Valley Authority. Lilienthal served in the capacity as chairman for four years before submitting his resignation; he was replaced for the next three years by Gordon Dean ("The Atom"). Dean, a lawyer and a former lieutenant in Naval Intelligence, was also a senator and the author of the Atomic Energy Act of 1946, and chairman of the Joint Atomic Energy Committee of Congress. According to the U.S. Department of Energy’s official historian Alice L. Buck, beginning in October 1950 the Commission embarked on a vast expansion program. During the next three years the construction of huge plants increased capacity at each step in the production chain...the threebillion-dollar expansion program represented one of the greatest federal construction projects in peacetime history (Buck: 2).

Lewis Strauss was next appointed as chairman of the AEC in July 1953. Strauss was President Eisenhower's special assistant for atomic energy and supported an expeditious nuclear expansion program (Buck: 3). Following Strauss as chairman, were John McCone (1958-1961), Berkeley chemist Glenn Seaborg (1961-1971), James Schlesinger (1971-1973), and Dixy Lee Ray (1973-1975). Ray was a graduate of Stanford University where she studied marine biology, and was the only woman to serve as chair of the AEC. She later became the governor of the state of Washington, and was a staunch advocate of nuclear power. John McCone, an industrialist who had been the founder of defense contractor Bechtel-McCone, left the Atomic Energy Commission to become director of 
the CIA from 1961 to 1965 , under presidents Kennedy and Johnson. Nobel-Prize winning chemist and AEC chairman Seaborg had worked on the Manhattan Project, was closely affiliated with Chicago's MetLab, the University of California-Berkeley, and the Manhattan-Rochester Coalition.

\section{A COALITION OF ELITE SCIENTISTS}

Robert S. Stone, Joseph Hamilton, Louis Hempelmann, Wright Langham, and the other scientists - all had worked directly or indirectly on the Manhattan Project, and led an elite corp of scientists/physicians in the newly formed Manhattan-Rochester Coalition. Their task was to develop new nuclear or radiation-based weapons, and examine human health effects from radiation exposure. The men all either knew each other by attending the same elite colleges, or they had mutual acquaintances that recommended them for posts. This coalition of elites, were involved in human experiments that were planned and coordinated at the highest levels of secrecy by the Manhattan Engineering District, and funded by the Atomic Energy Commission. On the rare occasions when one or two of the studies slipped into the literature despite the careful eye of General Groves and other gatekeepers, the studies were explained away as the work of rogue researchers, or they appeared in journals obscure enough to not draw attention. For example, hospital officials at Strong Memorial Hospital in Rochester initially expressed regret about human radiation studies that took place on their premises. "But the repentant attitude hardened into a defensive posture as debate over the experiment raged. Hospital spokesman Robert Loeb described the plutonium injections as a 'covert extracurricular activity' of which the university was not aware and did not approve" (Welsome: 478). Regardless of false 
revisionist statements, the ten men of the Manhattan-Rochester Coalition, were intimately linked to the top levels of the military war machine, and the coalition harnessed the same creativity that produced the atom bomb, to determine what would be the next area of radiation weapons-related research.

The men were assigned to particular regions of the United States- Lawrence and Hamilton on the west coast (University of California-Berkeley), Stone in Chicago (University of Chicago aka MetLab), Hempelmann transferred from St. Louis to Los Alamos as medical director, and back to Washington University (St. Louis) in 1951 and 1952. Wright Langham, was the coordinator at Oak Ridge and Rochester, and General Stafford Warren, was the medical director at Los Alamos. Hempelmann and Oppenheimer were very close friends at Los Alamos, and later when Hempelmann would move to Rochester, they would care for the Oppenheimer children as "Oppie" went through trial (Bird, K., and Sherwin, 2006) ${ }^{54}$.

The coalition's work was measured, calculated and highly coordinated, and part of a larger effort of the newly extended post-war Manhattan Engineer District. In this newly extended effort, "ten autonomous but mutually interdependent divisions were established...[whereby] experiments were discussed and organized on a cooperative basis through a system of "planning sessions"' or conferences, coordinated by and held at the University of Rochester (Fink: xi) ${ }^{55}$. The dozen or so military/academic elites traveled frequently from their respected assignments throughout North America, to meet, plan,

\footnotetext{
54 The Atomic Energy Commission, to take control and oust him from his position, brought forth lawsuit.

55 Document obtained at the Library of Congress, Washington, DC.
} 
and attend the University of Rochester's "conferences", which were held every few weeks, and were often completely classified. Rochester was a place where the men felt comfortable; in fact, Hempelmann would ultimately retire there.

The U.S. military made a deliberate decision to contract out much of their Research and Development work to private companies in the 1940s. Private companies thus, had unprecedented power over the direction and production of chemical, biological and nuclear weapons programs and use in warfare. External advisory committees headed by individuals from academia and/or industry that were central to this effort included the following:

- The US Biological Warfare Committee (aka Merck Committee; headed by George W. Merck, president of Merck Corporation; 1940s).

- Committee on Biological Warfare of the National Military Establishment Research and Development Board (aka Baldwin Committee; 1940s).

- The Ad Hoc Committee on BW Testing (aka Scheele Committee; mid 1950s)

- The Interagency Survey Committees on BW Testing (aka Price Committee; late 1950s).

- Deseret Test Center Medical Advisory Committee (aka Davis Committee; 1962-1969)

According to Army documents, "these committees did in fact make strong recommendations for safety/medical requirements and specified certain pathogenic microorganisms which should be utilized for open-air testing. Indeed, St. Louis was not 
the only city to experience open-air field tests. Microorganism "simulants" were sprayed in many U.S. cities; this included (but is not limited to) BG (Bacillus Globigii), SM (Serratia Marcescens), Bacillus subtilis, and Aspergillus funigatus. In fact, the Army released SM and Bacillus subtilis into the San Francisco and New York subway systems (NRC, 1997b :119).

The Army considered the industry recommendations binding (U.S. House, 1994: 107), and as a result at least one American corporation (Merck) made the selection of which pathogens would be sprayed over which cities of unsuspecting civilians. Perhaps the Army had agreed to let their selections stand, due to conflicts of interest. The Merck Corporation for example, had contracts with Fort Detrick between 1955 and 1961- during the time that Detrick was fully in charge of biological research and development (U.S. House, 1994: 91). It is also certainly possible that Merck and Company held a contract with Fort Detrick or the Department of Defense prior to 1955.

It is interesting nevertheless that the agency in charge of at least the biological weapons program deferred to industry interests, and allowed private companies to decide what safety measures would be taken for citizens, what chemical or microorganisms would be tested on people. Clearly, industry was at the helm.

\section{SCHEELE COMMITTEE}

The Scheele Committee takes its name by committee chair Dr. Leonard Scheele, Surgeon General of the U.S. Public Health Service. The Scheele Committee seated nine members in 1953. The Scheele committee emphasized to Dugway Proving Ground in 1953, "the 
importance of continuing and expanding meteorological investigations" and they recommended that "numerous small and large scale tests be done with viable biological simulants...and inert particulates (FP) to determine cloud travel and deposition" (U.S. House, 1994: 156). Although Army officials reviewed minutes of the Scheele Committee meeting discussing field trials, they did not provide those minutes or the names of committee members to a Congressional committee investigating human subject testing in 1994. The Army did however, readily admit in 1977 to another investigatory Congressional committee, that "all of these recommendations were immediately and fully implemented" (U.S. House, 1994: 156). The information provided to the Congressional Committee is listed below; the names of committee members were redacted for Congress, however, titles and affiliations remain.

\section{Scheele Committee Membership (1953):}

Leonard A. Scheele, MD, Chairman

Surgeon General-US Public Health Service

Department of Health, Education, and Welfare

Washington DC

Chief, Bureau of Animal Industry

US Department of Agriculture

Washington, DC

State Director of Public Health

Utah State Department of Health

Salt Lake City, Utah

Operations Research Office

The Johns Hopkins University

6410 Connecticut Ave.

Chevy Chase, MD

Chief, Biological Warfare Branch

Research and Development Division 
Office of the Chief Chemical Officer

Washington, DC

Assistant to the Secretary of Defense

(Health and Medical)

Washington, DC

Professor of Bacteriology

College of Agriculture

University of Wisconsin

Madison, Wisconsin

Health \& Special Weapons Defense Office

Federal Civil Defense Administration

Washington, DC

President, Armed Forces Epidemiological Board

Professor of Microbiology

College of Medicine

New York University

$4771^{\text {st }}$ Ave

New York, NY

\section{Advisors to the Scheele Committee (1953):}

Chief, Office of Health Emergency Planning

Public Health Service

Department of Health, Education and Welfare

Washington, DC

Director, Microbiological Institute

National Institutes of Health

Public Health Service

Department of Health, Education and Welfare

Bethesda, Maryland

The Scheele Committee also recommended that 'appropriate state officials' be

continually informed of tests to be conducted with pathogenic agents in order that their cooperation may be obtained..." (U.S. House, 1994: 156). The committee did not 
however, recommend that local officials or citizens be notified of pending experiments on humans.

\section{DAVIS COMMITTEE}

The Deseret Test Center Medical Advisory Committee (aka “The Davis Committee”), was chaired by Dr. Dorland G. Davis, Director of the National Institute of Allergy \& Infectious Diseases, and served between 1962 and 1969. All committee members were public health officials, and some had formerly served on the Price and Scheele committees. The membership made recommendations based on agent use and test sites, and committee members sometimes visited proposed test sites. The Davis Committee is of interest because several St. Louis studies took place during the time this committee made recommendations. In all likelihood, it was the Scheele Committee (1953 series) and the Davis Committee (1963-65 series) that recommended that St. Louis be tested with ZnCdS. This does not however, omit the possibility that either Dugway Proving Ground or Philip Leighton, altered the recommendation to include an additional test material in the St. Louis study. As in testimony related to the Scheele Committee, military officials, from a list provided to the investigating Senate Subcommittee, redacted names of committee members. Titles and/or affiliations remain.

\section{Davis Committee Membership (1963-1965):}

Dr. Dorland J. Davis, Chairman

Direction, National Institute of Allergy and Infectious Diseases

National Institute of Health

Bethesda, Maryland

Assistant Chief, Ecological Investigations Program

U.S. Public Health Service, CDC

Colorado State University

Fort Collins, Colorado 
Senior Staff Veterinarian

Emergency Animal Diseases

Animal Health Division

Agriculture Research Service

Hyattsville, Maryland

Associate Dean, Graduate School

University of Wisconsin

Madison, Wisconsin

Chief, Section of Wildlife Disease and Parasite Studies

Patuxent Wildlife Research Center

US Fish and Wildlife Service

Laurel, Maryland

Chief, Epidemiology Branch

Communicable Disease Center

Atlanta, Georgia

Principal Medical Entomologist

Rocky Mountain Laboratory

Hamilton, Montana

Yale University

Hartford, Connecticut

\section{MONSANTO}

In the fall of 1953, Army officials prepared for their upcoming aerosol dispersion study in St. Louis. Limited meetings were held with only a select few St. Louis city officials, in advance of the summer test series. Military documents note that, "minor difficulties with the Park Commissioner were ironed out with the completion of the change in city administration" (U.S. Army Chemical Corps, 1953b: 18) ${ }^{56}$. In other words, any internal resistance by city officials was met with replacement of that individual. For some reason

56 Unclassified document AD031508; Defense Documentation Center for Scientific and Technical Information; Classification changed to "unclassified" from "secret" per authority listed in ASTIA Tab No. U63-4-4, November 15, 1963; obtained through FOIA, June 2011 from Dugway Proving Ground, Dugway, Utah. 
not identified in the very limited official reports, meetings were also arranged with officials of Monsanto Chemical Company, Socony-Vacuum Oil Company, Granite City Steel Corp., and the Board of Aldermen of nearby Granite City, IL (National Research Council, 1997b: 274; U.S. Army, 1953b: 27). ${ }^{57}$ Monsanto and Socony had worked together previously on U.S. Forest Service and Air Force contract projects, involving petroleum hydrocarbons and herbicide use. ${ }^{58}$ Monsanto officials had curiously, been one of only a few persons apprised in advance of the St. Louis aerosol study by military officials (NRC, 1997b). The company's world headquarters is located in St. Louis, but their involvement in the aerosol tests was not a matter of a courtesy call by the U.S. military. Military documents from 1953 note that "tests are planned at a Monsanto plant located in St. Louis proper, representing a large chemicals manufacturing complex; at the Socony-Vacuum refinery in East St. Louis, Illinois ${ }^{59}$, representing a large petroleum refining complex; and at the Granite City Steel Corporation, representing a large steel manufacturing complex, including blast furnaces, open hearth furnaces, and blooming and rolling facilities" (U.S. Army, 1953b: 27) ${ }^{60}$. Indeed, Monsanto had a powerful role in the military network and in decision-making circles; they were also under contract with the Atomic Energy Commission, along with other companies such as General Electric, Westinghouse, Union Carbide, Dow, Eastman Kodak and St. Louis’ Mallinckrodt. Monsanto also had close connections to Washington University in St.

\footnotetext{
57 Granite City, Illinois was in the 1950s primarily a steel-mill town, and is located just across the Mississippi River from the city of St. Louis, Missouri.

58 Hull, Herbert M. Studies on Herbicidal Absorption and Translocation in Velvet Mesquite Seedlings. Weeds, v. $4,1$. January, 1956: 22-42. Zengel, Lander, Scribner, Warren (1964, March). An Examination of Methods for Calculating Vapor Pressure of Petroleum Hydrocarbon. Air Force Aero Propulsion Laboratory, Research and Technology Division, Air Force Systems Command, Wright-Patterson Air Force Base, Ohio. Project No. 3048, Task No. 30-1801.

59 East St. Louis, IL is located directly across the river from the city of St. Louis, MO.

60 Unclassified document AD031508; Defense Documentation Center for Scientific and Technical Information; Classification changed to "unclassified" from "secret" per authority listed in ASTIA Tab No. U63-4-4, November 15, 1963; obtained through FOIA, June 2011 from Dugway Proving Ground, Dugway, Utah.
} 
Louis, with many Monsanto executives in key positions of fund-raising and other roles at the university (Morrow, 1996).

In the 1940s and 1950s, Monsanto officials were deeply interested in nuclear weapons technology, and had been a financial contributor to a cyclotron at St. Louis' Washington University in the 1940s. Washington University and many of its faculty would become an integral part of the military machine that was the Manhattan Project, and the cyclotron was instrumental in providing plutonium for the atomic bomb at Los Alamos.

Washington University faculty member Louis Hempelmann became a key member of the spinoff Manhattan-Rochester Coalition, which led human-subject radiation research projects of every type, across the United States. Indeed, Hempelmann had a long history of human subject testing with radioactive materials, and collection of data related to radiation exposure at Los Alamos. The cyclotron at Washington University, would be used for studies related to human effects of radiation and to produce radioactive tracers, and Monsanto provided grants for Washington University to operate the "atom smasher". Washington University would later provide engineering faculty and students as a labor force for the St. Louis aerosol studies. "Beginning with the third series, on-call student help was obtained from Washington University through the assistance of Professor E. Egerly of the Department of Civil Engineering. The students constituted more than half of the test personnel during the last four series" (Pooler: 678).

The company also held a spot in Stanford University Department of Chemistry's "Industrial Affiliates Program", where Philip Leighton was faculty member and the 
former chair, when he took on the role of principal researcher of the St. Louis aerosol studies. Presumably, through this Industrial Affiliates Program, Leighton worked closely with Monsanto who had unprecedented access to faculty and influence over Stanford's chemistry department.

Monsanto was already as deeply embedded within the defense network as was possible, by the time they were "notified" of a pending aerosol study in St. Louis. The company had in fact been in charge of the military's Oak Ridge National Laboratory, since 1945 (fka Clinton Labs; aka Clinton Engineer Works; aka "X-10" Plant) (ORNL: 2) ${ }^{61}$. When Monsanto's vice-president Charles Thomas took over the supervision and project directorship of Oak Ridge, he retained his main office at Monsanto's corporate headquarters in St. Louis (ORNL: 2). Monsanto's Oak Ridge National Laboratories was known as "one of the three major nuclear research labs in the United States" (ORNL: 3). In fact, Monsanto ran Oak Ridge on 56,000 remote acres in Tennessee, under contract with the Department of Defense, where its official name was Clinton Engineer Works. "Several vast factories where uranium-235 would be produced also were located in the rolling hills and valleys. The bomb builders, still unsure whether enough uranium or plutonium could be produced to make a weapon, were hedging their bets and pursuing several ways to produce enriched uranium, as well as plutonium" (Welsome: 41). Clinton/Oak Ridge was designed to above all, develop methods for plutonium recovery, however General Groves concluded that the pilot plant site was not sufficient for plutonium production, in part due to the need for isolation and a large power supply, so

\footnotetext{
61 Heretofore, referred to as Oak Ridge National Laboratories (or Oak Ridge) for purposes of clarity and uniformity.
} 
that task would later transfer to Hanford Engineer Works (Smyth, H.: 112). The Clinton plant would eventually house a gaseous diffusion plant, an electromagnetic separation plant, and a thermal diffusion plant, and started operations in 1945 (Smyth: 184). According to the U.S. Department of Energy, Oak Ridge was the nation's "largest supplier of radioisotopes for medical, industrial, and physical research, as well as a regional center or research in chemistry, physics, metallurgy, and biology. The laboratory also conducted the largest radiation genetics program in the world" (Buck, 1982: 2).

By the summer of 1946, Monsanto was deeply entrenched in the nucleus of the "war effort", and had also provided radioactive carbon-14 to "a cancer research hospital in St. Louis",62 (ORNL: 5). Monsanto's vice-president and head of Oak Ridge Charles Thomas, also held sway over his professional colleagues around the world, as president of the American Chemical Society (Forrestal: 193). Indeed, some insiders might have posited that Monsanto was at that time, at the core of the chemical, biological, and radiological research and development effort.

In the summer of 1950, officials from the Monsanto Company, approached the newly formed Atomic Energy Commission (AEC) and proposed that the company design, construct and operate at least one nuclear reactor to produce plutonium for military use, as well as provide a profitable distribution of energy to the public during peace time.

\footnotetext{
62 Presumably, Washington University. This long-standing relationship would continue; in 1976 Monsanto revealed plans to construct a $\$ 12$ million toxicology lab adjacent to Washington University (Forestall:189), and donated $\$ 100,000,000$ to the School of Medicine in 1982 for research into the effects on proteins and peptides on cell behavior (Morrow: 623).
} 
Monsanto was still overseeing activities at Oak Ridge aka Clinton Labs at that time, and thus, had insider status with the agency. Other companies including Dow, Union Electric, and Bechtel, sought a similar arrangement with the AEC, and the agency asked the companies to provide written proposals for dual-purpose reactors to be submitted within one year. "More than 100 engineers and scientists of the 8 firms were cleared for access to restricted data. These men devoted full or part time to examining reports, visiting AEC installations, and talking with people working in the reactor field" (AEC, 1953: iv). Monsanto officials visited "the principal AEC installations... and certain fundamental information was obtained through conferences scheduled at the various sites" (AEC: 52). The AEC would share with Monsanto officials that "enriched uranium would be made available" to the companies in their production of plutonium for military use (AEC: 52). In other words, if the AEC funded the building of a major facility to be owned by Monsanto, the company would in turn, produce radioactive plutonium for military use, and provide for sale nuclear power during times of peace. With this proposal, government (and thus, taxpayers) would fund a nuclear facility to be owned and run by a private company, for corporate profit. This agency/industry arrangement would not only be lucrative to industry, and advance military goals, but it also extended an unprecedented level of shared classified data and highly restricted weapons materials, to private industrial interests.

In classic "Revolving Door" fashion, Charles Thomas left Oak Ridge in 1951, when Monsanto submitted their written proposal to the AEC, and he was promptly promoted from vice-president to president of Monsanto (ORNL: 13). The AEC had at that time, a 
policy "for dissemination of unclassified and declassified atomic energy information" (AEC, 1953: iv). They also wanted to secure "greater industrial participation in reactor development" as prompted in part, by the corporations' proposals to build nuclear reactors (AEC, 1953: iv). To this end, the AEC contracted with two insider consultants who were "representatives of the industrial participation contractors", both editors (or managers) of industry-related publications. The two members took the classified reports and prepared "declassified versions" for public issue. ${ }^{63}$ The resultant public-issued reports do "not present a balanced picture of the original reports, owing to security limitations", according to the AEC (AEC, 1953: v). Thus, the information placed in the public domain was a distorted and fragmented image of the issue, packaged as a "value to industry" argument, rather than the actual military goals (while omitting social and economic costs). In other words, the military was making a sales pitch for American companies to invest in plutonium production for military use, while selling them on the potentially lucrative nature of consumer power-production during peacetime, in this plan of "dual-use" technology. UCLA's Lee Clarke agrees that "the government promoted the nuclear industry for the purpose of advancing military technology" and thus, the state became a central player shaping development of what is now the nuclear power industry (Clarke: 474). Hooks and McLauchlan argue that,

under 'dual-use' policy the path of technological development is bounded by the requirement of demonstrating military applications. Thus scientific and technological advancement is being led by military agencies to complement the existing military technology base and to serve the Department of Defense's emerging technological agenda (Hooks, G. and G. McLauchlan: 163).

63 AEC would also do the same for Project Sunshine, and retroactively for Project Gabriel. 
This strategy by the military to lure industry involvement in military research and development projects, may have served other purposes as well. "Dual-use" may have been a tactic to mask defense-related activity under a blanket of industrial research, production, and add additional layers of secrecy through intellectual property laws. Hooks and McLauchlan also argue that, "instead of converting federal and private facilities from military to civilian applications, critics contend the dual-use strategy constitutes a 'Trojan Horse' that perpetuates the overemphasis on defense production and underinvestment in civilian-oriented initiatives" (Hooks, et al., 163). ${ }^{64}$

A secret Army document outlining the St. Louis aerosol project notes that "as a result of these meetings, the full cooperation of these industrial firms was extended to The Ralph M. Parsons Company in the prosecution of the testing program, with permission being granted by all firms for use of company properties for field test sites" (U.S. Army, 1953b: 27). “Tests were planned" with Monsanto ${ }^{65}$; Socony-Vacuum (aka Rockefeller's Standard Oil Company of New York, which eventually became ExxonMobil), which was located near Monsanto, was also involved, but to what degree is unknown. This vague statement implies either that 1) The company's military or corporate lab facilities, which were admittedly sophisticated enough to even analyze for radioactive materials, were to analyze samples associated with the study, or 2) that the Monsanto facility itself would be utilized as a target area where additional tests would be done. Monsanto's headquarters at that time were located in downtown St. Louis, on South Second Street. Monsanto also had a "central research lab" in Ohio, where Charles Thomas head of Clinton/Oak Ridge

\footnotetext{
64 This critique was in response to President Bill Clinton's reorientation towards dual-use strategy, but is applicable to similar early programs.

65 According to the Army, Monsanto was at that time, located in "St. Louis proper".
} 
Laboratory in the early 1950s, had begun his career. Monsanto's AEC-sponsored laboratory that had been proposed in 1950, was built in Miamisburg, Ohio. Called "Mound Lab", Monsanto employees researched radioactive materials and polonium for the Atomic Energy Project; the lab was located less than fifty miles from Cincinnati (Forrestal: 103).

By the time military officials visited St. Louis in 1953 to set up the aerosol study, the former chief of Oak Ridge National Laboratories (one of the largest nuclear research labs in the country), Charles Thomas, was the president of Monsanto. (Thomas would remain in that position for a dozen more years, which also includes the timeframe of the second aerosol study, in 1963 - the same year that he also became chair of the trustee's committee on planning and development at Washington University). Under Thomas' watch, a new subsidiary was officially established in 1960, called Monsanto Research Corporation. The subsidiary was charged with the responsibility of handling contract research for the government, and for supervising Mound Laboratories, which some sources report that Monsanto had been operating under contract for the Atomic Energy Commission since 1943, rather than 1950 as indicated in AEC records. Mound Lab also developed plutonium capsules, polonium, and other radioactive isotopes (Forrestal: 163; $181 ; 193 ; 214) .{ }^{66}$ Some official reports indicate that the later aerosol studies in St. Louis were sent to Cincinnati, Ohio for analysis, and Monsanto's role in the St. Louis studies

\footnotetext{
66 Their coalition partners at the University of Rochester adapted the "Mound Laboratory procedure" for polonium urinalysis in 1953, to detect "the accidental ingestion, inhalation, or incision of amounts of polonium" in humans. These procedures were adapted for Rochester by Mound Laboratory's Ruth Kennedy Scherberger (Krebs, C.A., and Whipple, G. H.: 2-3).
} 
and as an approved defense contractor, indicate that it was at Mound City, that at least some of the aerosol data was analyzed.

By 1965, Charles Thomas had stepped down as president of Monsanto, but stayed on as chairman of the board for five years and then as a retired board member until 1970 (Forrestal: 203; 256). Records indicate that Monsanto's deeply embedded militaryindustrial contractual relationship continued through 1969, and into the 1970s when they provided the US military with Agent Orange and other chemical weapons, under contract with the Department of Defense for use in the Vietnam War.

Several decades after the St. Louis aerosol studies, a local attorney investigating Monsanto found that corporate officials decades earlier, had secretly tested human tissues from deceased St. Louis residents (Francis, 1994; Downs, 1998; Martino-Taylor, 2006: $44)^{67}$. It is quite plausible that this secret testing of cadavers by a defense contractor involved in the St. Louis aerosol studies, was a follow-up study to measure radiation exposure in residents in the city of St. Louis. In fact, that is exactly what occurred under Project GABRIEL and Project SUNSHINE.

\section{IN THIS HOUSE: PROJECTS GABRIEL \& SUNSHINE}

In an effort to gather what they claimed was radiation fallout data, the Atomic Energy Commission began Project GABRIEL, Project AUREOLE, and Project SUNSHINE. Project GABRIEL was initiated at Oak Ridge, when Monsanto was in charge of the

${ }^{67}$ See Kemner v. Monsanto; Saint Clair County, Illinois; Filed by plaintiffs' Attorney Rex Carr, Esquire. 
facility. ${ }^{68}$ A presidential commission in 1994 located military documents which indicated that, "as early as 1947 the Atomic Energy Commission had a policy in place for conducting radiation experiments on humans" (U.S. Proposed Nuclear: 12A). A U.S. Senate-requested Government Accounting Office (GAO) study found that as early as 1943, radioactive polonium had been injected into hospital patients to test for human absorption of the isotope (GAO: 35$)^{69}$. Polonium was in fact, produced at Monsanto's Mound City facility. In 1945, "at the request of the Manhattan Engineer District", a metabolic ward had been 'activated' at Rochester's Strong Memorial Hospital to carry out 'certain tracer studies' with long-lived radioisotopes" (Welsome: 125). According to documents that were not released to the public until 1995, the experiment sprang out of a Rochester meeting discussion, as well as 'numerous' conversations with Colonel Warren, Colonel Friedell, and Dr. L. H. Hempelmann' (Welsome: 126). Hempelmann later told investigators that a "'deliberate decision was made not to inform the patient[s] of the nature of the product that was injected"' (Welsome: 127). As a result of this secret project, between October 16, 1945 and July 16, 1946, eleven hospital patients in Rochester were injected with plutonium. In 1946, radioactive zirconium-95 was injected into at least one patient at the University of San Francisco, and the University of California, Berkeley at the behest of the AEC (GAO: 37). A newspaper reported that Robert Stone, “exposed 32 dying patients to powerful X-rays to examine radiation's effect on the body" at the University of California Hospital in San Francisco (Herken, G. and David, J., 1994). Thus, several independent entities provide evidence of a

\footnotetext{
68 Official correspondence indicates that Project Gabriel may have begun as early as 1944, on or about the secret Manhattan meetings in Rochester, although the official name GABRIEL may not have been assigned to the project yet.

69 See Appendix D for a synopsis of the GAO's findings.
} 
coordinated human subject studies prior to those initiated through Project GABRIEL, Project AUREOLE, and the subsequent Project SUNSHINE.

Project GABRIEL was the responsibility of the Division of Biology and Medicine within the AEC, and the focus of the project was the study of radioactive isotopes, particularly Strontium 90 (Sr90) in the environment. The narrative that rationalized the studies, was that they were necessary as a result of international nuclear weapons testing. At least three major labs coordinated analyses for soil, alfalfa, animal, dairy products, rain water, drinking and surface water, along with human bones from the United States and 20 foreign countries for Sr90: University of Chicago, under W.F. Libby; Columbia University, under J.L. Kulp; and the New York Operations Office of the AEC [heretofore referred to as NYOO] (U.S. AEC, 1954: 2). All samples, taken from over 100 sampling locations in the U.S. and the twenty or so foreign countries, were "sent to NYOO for measurement of activity" (U.S. AEC, 1954: 2). Thus, the primary responsibility of the sampling analysis for exposure to radioisotopes came under the purview of the AEC's NYOO. Air sampling throughout the United States for Sr90 had already begun before 1951 (U.S. AEC, 1954: 8).

One AEC report regarding GABRIEL, notes the results of human thyroid tests from cadavers in Chicago and New York with a disturbing tone of indifference; particularly since the study measured body burden levels in individuals both purposely and "accidentally" exposed to radionuclide. The authors of the report discuss another study that included spectrographic analyses on the bones of 26 individuals-- including 12 
cadavers preserved since 1914, and also the testing of a number of fetuses (AEC, 1954: 14). The test data was startlingly comprehensive in scope, and included radiation studies on mice, rats, rabbits, dogs, steers, monkeys, goats' milk, cheese, lambs, and calves. Human stillborns had been "collected" from Utah, S. India, and Massachusetts, and at least six human cadavers were obtained at a University of California hospital. An AEC Project GABRIEL report indicates that prior to death, the six patients had been administered doses of Strontium-89 (AEC, 1954: 39). Two other humans had been administered doses of Strontium-89, but they both survived. Another eleven humans were given " $\mathrm{x}$ and gamma irradiation of bone" (AEC, 1954: 41). A Clinton presidential commission in the 1990s reviewed a formerly classified 1954 Project GABRIEL report as part of an effort towards transparency regarding human subject radiation testing. The Project GABRIEL update reported with surprising detachment and candor, that "55 human stillborn infants had been collected in Chicago, and analyzed by Drs. Kelp of Columbia and Libby of Chicago, and that Dr. Libby had done analyses of [a] stillborn infants from Utah, three stillborn from Vellore, South India, and three 'human legs (adult)' from Massachusetts" (Advisory Committee: 4). A separate GAO report notes that during Project GABRIEL, "stillborn babies were cremated to determine the content, in their ashes, of [radioactive] strontium that resulted from atmospheric nuclear weapons testing" (GAO, 1995: 3). In a 1995 interview of Merril Eisenbud, the former head of the NYOO, Eisenbud discussed Projects GABRIEL and SUNSHINE, and how in his capacity as director of the Heath \& Safety Division of NYOO, it was his division's task to obtain autopsy specimens. Eisenbud described how the NYOO obtained bodies (or body parts such as thyroids, lungs, etc.), from Bellevue morgue, which was run by the 
city of New York (U.S. DOE, 1995c: 85). He wistfully recalled the slogan on the building of Bellevue morgue:

I've forgotten the words; it was in Latin. And in the translation underneath, something to the effect that, 'In this house'-it's a quotation from classical Latin- 'In this house, we, the dead, live for the living'- something like that, meaning that there were lessons to be learned (U.S. DOE, 1995c: 85)

Eisenbud, like many of the other scientists involved in Projects GABRIEL and SUNSHINE, thus viewed the poor as a resource for the wealthy elites who were focused on not simply military advancement, but also career advancement, while framing it in terms of "public health". Much as the residents in the city of St. Louis- an American "slum"- were purposefully targeted, those who were poor and predominantly of color were used again without notification or approval, to test the effects of new weapons for use ultimately in similar populations around the world. In addition, what the studies, reports, and communications do not reveal, is that most (if not all) of the nuclear test/radiation exposures in the American population came from state-sponsored testing and exposure of civilians, in a highly coordinated effort to advance warfare and weaponry. In other words, victims- both alive and dead, many of them poor people of color, were used as human test subjects for weapons testing, without their consent or knowledge.

Willard Libby, head of Project GABRIEL (as well as Project SUNSHINE), himself tested "radioactive tracers" as early as 1947 (Libby, 1947), and also tested thyroids from cadavers for radiation exposure. Libby also tested Mississippi River water for the presence of radiostrontium, at the same time the St. Louis study was in commission. 
(U.S. AEC, 1954: 9). ${ }^{70}$ At the University of Chicago during GABRIEL, Libby tested at least 59 stillborn babies for levels of radioactive strontium-90. Libby was central in the coalition of scientists assigned by the Manhattan Engineer District to secretly advance the military effort of increased chemical, biological, and nuclear weapons post World War II. $^{71}$ Dr. Libby was also the president of the Atomic Energy Commission, and he worked at great length to coordinate all types of radiation studies, including those related to human health. At Libby's MetLab, he measured radionuclide contamination in "sunshine units" (AEC, 1954: 25). ${ }^{72}$ A 1993 GAO report indicated that the US military had been engaging in secret radiation tests on humans since the 1940s. Prompted by the blind goal to rapidly develop offensive radiation warfare, the Government engaged in deliberate acts of deception to cover their acts, and to advance the nuclear arms race, according to the New York Times. Indeed,

...the Government was considering two types of radiation weapons. The first would have exposed enemy soldiers to nuclear materials so intensely radioactive that they would have died or been severely injured. These battlefield materials would have lost their radioactivity in hours or days, so that American troops could have entered the area (Schneider, Keith, 1983a).

At least a dozen or more experiments that exposed civilians to radiation took place, where researchers "released thousands of times the radiation that would be considered safe today" (Schneider, K., 1983b). At least one study was planned to test "a type of radiation weapon" that "would have spread longer-lived radioactive particles, rendering the land unfit for human habitation for as long as the materials remained radioactive"

\footnotetext{
70 The St. Louis study aligned the Mississippi riverfront.

71 Libby was also Commissioner of the Atomic Energy Commission, and would later win a Nobel Prize for research related to carbon dating in 1960. See http://nobelprize.org/nobel_prizes/chemistry/laureates/1960/libby-bio.html

72 One might suggest that this is where Libby derived the name for Project Sunshine.
} 
(Schneider, K., 1983a, 1983b). Thus, researchers affiliated with the Manhattan-

Rochester Coalition were developing radioactive airborne particulates for use in warfare.

As if the scientists involved in Project Gabriel had an insatiable thirst for the macabre, their bold and vast repertoire of experiments under the banner of Project GABRIEL, only opened the door for further studies. The studies also represented a sharp turn from a focus on defensive use of weapons, to offensive. In 1952, the AEC and US Air Force contracted with the RAND Corporation to study the findings of Project GABRIEL.

\section{THE RAND REPORT}

In the summer of 1953, RAND held a short conference of selected consultants to make an over-all review of GABRIEL. The conference recommended that studies then current be supplemented by a worldwide assay of the distribution of $\mathrm{Sr} 90$ from the nuclear detonations that have occurred. This assay has been designated Project SUNSHINE (U.S.AEC, 1954: 2).

Project SUNSHINE began in $1953^{73}$ as a continuance of Project GABRIEL. Like GABRIEL, it was a top-secret project headed by William Libby. A July, 1953 RAND conference regarding SUNSHINE, included a large number of key players involved in defense and the MIA complex, including scientists, AEC officials, defense lab analysts including Los Alamos and MetLab, Air Force research center personnel, officials from the Armed Forces Special Weapons Project, and individuals from private defense firms such as TracerLab, General Electric, and SRI (Stanford Research Institute) ${ }^{74}$. The conference had an "invitation only" status, and members were notified that, "the

\footnotetext{
${ }_{73}^{73}$ Coincidentally or not, Project SUNSHINE began same year as the St. Louis aerosol study.

74 At least two people attended from Stanford Research Institute (SRI), which designed and provided oversight to the 1953-54 St. Louis study, as well as analyzed the data from the study.
} 
existence of the project and the conference itself should not be revealed to anyone other than those who have been contacted officially in connection with the project" (Advisory Committee, 1995: 1). In fact, conference invitees were told to return their classified invitations by registered mail to a particular confidential address (Advisory Committee, 1995: 2).

During the RAND conference, RAND officials discussed preliminary research data, which indicated Sr90 has a "high carcinogenic capability"... "fixed in the bone [it] will cause a certain average percentage of the population to die of bone cancer comparable with that observed in victims of radium poisoning" (RAND: 4). RAND subsequently issued a report on some of the findings, and they acknowledge that children are particularly vulnerable to the carcinogenic effects of Sr90. The danger to children is not limited to bone deposition of the radioactive material; “...we must also bear in mind that young growing tissue is more radiosensitive than adult tissue having lower rates of cell division" (RAND: 42-43). "As strontium follows a similar metabolic pathway [to calcium], our chief items of concern will be deposition and accumulation of radioactivity in bone" (RAND: 38). Although RAND acknowledged that these studies were already undertaken through Project GABRIEL, RAND nevertheless recommended additional "urgent" and secretive studies including soil, food, and water monitoring systems, as well as biological and cancer studies regarding ingested and inhaled radioactive materials (RAND: 8). 
RAND recommended that the secret "pilot study", evolve into a full-scale secret investigation. Project GABRIEL was already deeply involved in multiple Sr90 studies not just domestically, but internationally, however, and military studies that are now declassified reveal the vast scope of studies that were underway prior to the 1953 RAND perfunctory recommendation. RAND recommended that the scope of studies include water (drinking, rain, and surface), livestock, milk, baby teeth, soil, human biological effects, atmospheric studies, and they stressed that "whole human skeletons" were "essential" to the studies (RAND: 53). Indeed, every recommendation (from types of tests to methods of sampling) that RAND made in their 1953 Project SUNSHINE report, was already long underway. The RAND report only reaffirmed, albeit a bit less secretively, the earlier top-secret studies already underway during Project GABRIEL. The RAND report appears to be a retroactively issued report, as does the now-available Project GABRIEL report. The GABRIEL report was "issued" by AEC in 1954, one year AFTER the RAND report, which notes that, the former GABRIEL report had been destroyed and was no longer available (RAND, 1953). Yet rather mysteriously, a GABRIEL report became available one year later.

RAND officials reported problems related to sampling and analysis of radioactive materials, particularly Sr90, and they discussed available options. They noted that SRI and the New York Division of the AEC (NYOO) were developing a process to measure radioactive $\mathrm{Sr} 90$ in airborne material and, "it appears that the electrostatic precipitation process, being extremely efficient for the collection of very small-diameter particles, will 
be adequate for the task" (RAND: 48). RAND's Project SUNSHINE report of $1953^{75}$ discussed at length the variety of test sampling methods and equipment for Sr90 tests. Geiger counters were the most effective sampling instrument, and a modified Geiger counter could also be constructed in the laboratory, but the shield should be made of steel and "would require special construction" to accommodate the Sr-90 aerosol spray (RAND: 66). It is notable that the same year that RAND was recommending a custom steel casing for strontium-90 aerosol studies, the St. Louis aerosol study was underway, that two specific companies seemingly related to the effort--Monsanto and Granite City Steel, were some of the few officials notified of the St. Louis aerosol project.

Earlier, in February 1944, an official from Monsanto’s Mound City “Central Research Department" had written a letter to Colonel John R. Ruhoff in New York. Ruhoff was the former director of research at Mallinckrodt Chemical Works in St. Louis, and a ranking officer in the Manhattan Project at Oak Ridge in its earliest days. He later moved to NYOO, where he was in charge of basic materials related to uranium production. Under his supervision, the NYOO tested the bulk of food, vegetation, soil, and even human bone samples for Sr-90 during Project GABRIEL (AEC, 1954: 29). The letter, from W.C Fernelius at Mound City, asks that Colonel Ruhoff surreptitiously obtain for Monsanto, "materials" from the Bartol Research Foundation in Pennsylvania, (aka the Franklin Institute) in order for Monsanto to remain anonymous. Fernelius states, "Inasmuch as any inquiry directly to the Foundation would of necessity reveal a good deal about the nature of the things we are doing here, we believe that such inquiry had

\footnotetext{
75 RAND acknowledges on the title page and introduction page that this 1953 report had been prepared specifically for public use, and all classified information had been deleted from the paper.
} 
best come through your office" (Fernelius, 1944). Perhaps more interestingly however, is the equipment that Monsanto was attempting to obtain. "We would like to secure 4 Geiger counters with thin glass windows for counting soft beat rays and 2 Geiger counters of usual design and thickness...for beta and gamma rays" (Fernelius, 1944). In an echo of the later RAND report related to instruments required for Sr-90 aerosol tests, Fernelius asks, "what is the possibility of making glass sealed counters with very thin windows for alpha particles-either making them at the Foundation or giving us directions for construction here?” (Fernelius, 1944). Monsanto was attempting to secure Geiger counters of a specific design, to determine nuclear signatures.

Indeed, Monsanto's Oak Ridge was long a partner in Project SUNSHINE when RAND noted that Oak Ridge's labs conducted "tests on various filters" to measure atmospheric strontium-90 (RAND: 58). Project SUNSHINE's worldwide data collection activities were to operate in a cloak of secrecy, particularly in relation to collecting foreign samples. According to a Presidential Advisory Committee, the AEC undertook a plan of deception "which involved the personal and professional contacts of researchers, and the use of an elaborate cover story", to obtain samples from India, through the Rockefeller Foundation (Advisory Committee: 2). The cover story was concocted as follows:

The stated purpose of the collection is to be for a survey of the natural $\mathrm{Ra}$ [radium] burden of human bones...there are still enough uncertainties regarding threshold dose for injury...to provide a plausible explanation for further surveys...As for the emphasis on infants, we can say that such samples are easy to obtain here, and that we would like to keep our foreign collections comparable (Advisory Committee: 3 ). 
Libby noted in a 1956 study that since 1953, human bones had been analyzed for strontium-90 content, and the bones were from across the nation including Massachusetts, Ohio, Maine, California, New Hampshire, Rhode Island, Louisiana, Chicago, and from other countries such as Brazil, Chile and England (Libby, 1956). The rationalization offered to justify the need for "samples" was that the researchers were conducting studies related to radium exposure. The cover story was partially true. Radium, a naturally occurring substance, would not raise the same scrutiny than would a study involving plutonium or strontium-90 in human bodies. Thus, embedded beneath a seemingly legitimate request for a radium study, was a concurrent top-secret AEC study for radioactive strontium. In a letter from one researcher to another at the AEC Rochester office, Robert A. Dudley of the Biophysics Branch of the AEC Division of Biology and Medicine, told his colleague, "we actually are providing for the measurement of Ra as well as Sr-90 in many or all of the samples, so that the Ra story is merely incomplete, not false" (Advisory Committee: 4). In addition, "mobile teams" were often used to collect samples (AEC: 2), and that method of sampling was discreet, as their presence was limited and would not draw attention to the various activities.

Thus, the Manhattan-Rochester Coalition involved in the human subject studies through Projects GABRIEL and SUNSHINE, layered studies while publicly admitting to one, while keeping the parallel, concurrent study classified. Similarly, in 1994, the Department of Energy released "stacks of documents" that revealed "95 previously hidden nuclear bomb detonations" at a Nevada test site; "the blasts went undetected because they were set off simultaneously with reported tests" (M.D. Anderson, 1994: 
A1). Military officials thus embedded secret nuclear radiation tests, within less innocuous tests that were publicly known, in a lie by omission. A pattern of deception by omission regarding embedded studies not revealed to the public, becomes apparent here. Likewise, a 1954 memorandum from the Chief of the Armed Forces Special Weapons Project (a leadership group to the "fallout network") revealed a cover story for the animal studies related to Project SUNSHINE:

The actual data obtained are SECRET and the sample collection should be discreetly handled. It is suggested that a statement be included in the instructions to the effect that these samples are being collected for nutritional studies (Advisory Committee: 5).

In 1995, President Clinton's Advisory Committee on Human Radiation Experiments, analyzed official Project SUNSHINE documents that had been recently declassified. One document originally stamped "Secret" was particularly revealing. The report stated that "considerable thought had been devoted to best ways to establish channels to procure 'human samples', and the impact of secrecy on the effort...Willard Libby explained the great value of 'body snatching' and noted that the AEC had even employed an 'expensive law firm' to 'look up the law of body snatching'” (Advisory Committee Staff, 1995: 1). Dr. Libby lamented the difficulty of obtaining human bodies legally, but stated in a 1955 conference that Project SUNSHINE was the agency's top priority. He stated:

By far the most important [gap] is human samples. We have been reduced to essentially zero level on the human samples. I don't know how to get them but I do say that it is a matter of prime importance to get them and particularly in the young age group...we were fortunate, as you know to obtain a large number of stillborns as material. This supply, however, has now been cut off also, and shows no signs, I think of being rejuvenated. (Advisory Committee Staff, 1995: 2). 
Libby further urged the group of the importance of Project SUNSHINE: "so human samples are of prime importance and if anybody knows how to do a good job of body snatching, they will really be serving their country" (Advisory Committee Staff, 1995: 2). Dr. J. Laurence Kulp, a Columbia University geo-chemist, and Willard Libby's protégé, was present at the meeting, and Kulp updated them regarding the acquisition of human bodies for testing.

We have the channels in these places where we are getting everything. We Have three or four other leads where we could get complete age range samples from different other geographic localities. These three are Vancouver, Houston, and New York. We could easily get them from Puerto Rico and other places. We can get virtually everyone that dies in this age range...the channels are there and the samples are flowing in (Advisory Committee Staff: 3 ).

By this time, the expanded Manhattan satellite program that coordinated nuclear weapons health effects on humans, had nearly burst at the seams. Money seemed to be flowing everywhere:

By 1955 the program was receiving 8,000 applications a year, including hundreds from abroad...there were now 100 companies in the radiation instrument business, two dozen suppliers of commercially labeled compounds, pharmaceutical companies, hundreds of isotope specialists, a half-dozen waste disposal firms, and ten safety monitoring companies. Also, 2,693 U.S. institutions had received isotope authorization, including 1,126 industrial firms, 1,019 hospitals and private physicians, 220 colleges and universities, 244 federal and state laboratories, and 47 foundations (DOE Openness).

Despite the incredibly vast network that had been arranged with astounding speed, the AEC tissue-sampling program operated through a network of personal and professional informal contacts in order to maintain top secrecy. Even the closest of contacts-relatives and friends- were not apprised of the purpose of the secret program. Some principle 
researchers did not even know the true purposes of their own studies. Most disturbingly, areas of poverty were targeted for body snatching, according to J. Laurence Kulp, who was an insider:

Down in Houston they don't have all these rules. They claim that they can get virtually and they intend to get virtually every death in the age range we are interested in that occurs in the City of Houston. They have a lot of poverty cases and so on... (Advisory Committee Staff: 3).

Libby called the project, "a delicate problem in public relations", particularly given his pointed interest in infant remains, but some researchers argued that the networks of friends and families, who were professionals in their field, would trust that the request was for legitimate, albeit secret military purposes, and would therefore comply without asking many questions. Others argued for the need to adjust the description of the project, such as calling the study a "trace elements program as we have discussed" to deal with the "public relations problem" (Advisory Committee Staff: 5). Thus, by renaming what was called behind the scenes "body snatching", to a "tracer study", they would avoid scrutiny and suspicion. The public would continue to be in the dark, as planned. Coincidentally or not, the St. Louis tests were often referred to externally as "a tracer study". ${ }^{76}$ By describing atmospheric or aerosol studies over populated areas as tracer studies, they would avoid requirements related to informed consent and other restrictions that protect those individuals involved in human health studies.

76 See Leighton, P., W. Perkins, S. Grinnell and F. Webster (1965). The fluorescent particle atmospheric tracer. Journal of Applied Meteorology, 4: 334-48; Pooler, Francis. (1966). A Tracer Study of Dispersion Over a City. Journal of the Air Pollution Control Association, 16: 677-81; McElroy, James L. (1996, August). Diffusion from Low-Level Urban Sources: Reexamination using Recently Available Experimental Data. Journal of the American Meteorological Society, 36: 1027; Johnson, Warren B. (1983, January). Meteorological Tracer Techniques for Parameterizing Atmospheric Dispersion. Journal of the American Meteorological Society, 22: 931- 46; Venkatram, Jing Yuan, Tao Zhan and David Pankratz; Proceedings of the $10^{\text {th }}$ International Conference on Harmonisation within Atmospheric Dispersion Modelling for Regulatory Purposes. 
According to investigative reporter Eileen Welsome "between 1959 and 1985 the body parts of 1,712 human beings, including nearly a dozen whole cadavers, were shipped to Los Alamos and analyzed for their plutonium content" (Wellsome: 312). Body parts were solicited from around the world, and analyses of men, women, children, and infants' remains "helped scientists estimate how much plutonium the American people were accumulating from the bomb tests" (Wellsome: 312). But other news sources contradict that amount, and argue that approximately " 6,000 bodies were taken from hospitals in Australia, Britain, Canada, Hong Kong, the United States, and South America over 15 years without the permission of parents" (Reuters, 2001: A04). A study released in 2001 by the Australian Radiation Protection and Nuclear Safety Agency notes that "the bones of infants who died at a few weeks of age, as well as the bones of children 5 to 19 years old and adults up to 39 years, were cremated and sent overseas to be tested for strontium 90" (Perry, M., 2001). The head of the Australian agency claimed in 2001, that the tests were not secret "and was on the public record in scientific and government documents" (Perry, 2001). Another source claimed that the Australian "federal government has received expert advice on how to tell more than 21,000 people- including 3,078 in South Australia- that bones from their children or adult relatives were burned to ash" in relation to Project SUNSHINE (James, 2002: 2). To the Australian official's charge that the project was made public, the project itself was deemed top secret by officials, a few obscure scientific journals reported highly-edited "for the public" information, but the source(s) of the deceased bodies (if they were even discussed) were kept secret. Indeed, the few government documents about Project SUNSHINE were highly classified 
(Advisory Committee Staff: 1). Few insiders even knew the purpose of the project or that it was connected to the US military's own secret chemical, biological, and radiation tests on unsuspecting Americans, and those defense agencies wanted to covertly measure the effects in the environment, and in humans-alive or dead. In fact, one presidential panel "uncovered records of more than 4,000 secret tests" (Perlman, A1). A GAO report also noted that, "between 1940 and 1974, experiments were performed on at least half a million individuals, including 210,000 people exposed to radiation" (Army Exposed: 13A). Historian Leonard Cole however, estimates that "tens of millions of Americans may have inhaled the army's test agents" (Cole, L., 1994: 5).

Despite the wide range of activity related to exposure studies in developing chemical and biological weapons, and the "feverish pace of weapons testing", particularly nuclear weapons, the first open-literature paper did not appear until 1957 (Willis, J: 9). As the newly coined concept of "radioactive fallout" trickled out into government reports and scientific journals, Congress began discussing radioactive fallout in the atmosphere. In June, 1957, the National Institutes of Health (NIH) proposed a study whereby children's milk teeth would be collected to measure Strontium-90. The idea had actually been proposed as part of their all-encompassing Project SUNSHINE recommendation in 1953. Atomic Energy Commissioner Libby supported the project, but was again concerned about the public finding out the reason behind the study. According to Libby,

...I would not encourage publicity in connection with the program. We have found that in collecting human samples publicity is not particularly helpful. We could get the teeth by having investigators make their own collections. The samples need not be too large. Dentists would help. (Advisory Committee Staff: 6). 
The St. Louis aerosol study of 1953 was part of an organized network of assigned tasks and divisions working through the Manhattan-Rochester Coalition, the massive spin-off network that came from the Manhattan Project. In 1953, a select group of St. Louis city residents were sprayed with an unknown agent, perhaps $\mathrm{ZnCdS}$, or more likely, a radioactive $\mathrm{ZnCdS}$. There are at least twenty radioactive isotopes of cadmium, and eight radioactive isotopes of zinc; radioisotope Zn65 was in fact, used in biological tracer studies. Officials and scientists involved in the Manhattan-Rochester Coalition had plentiful access to at least radiozinc; by 1939 , radioactive isotopes of zinc had been isolated at University of California-Berkeley and Harvard University (Livingood, J. and G. Seaborg: 457). By 1961, General Electric was extracting a high-yield radioactive zinc from reactor cooling water at the Hanford atomic facility (Silker: 233).

\section{BABY TOOTH STUDY}

What methodology was used besides mechanical means, to potentially measure radiation exposure in the population of St. Louis? Although some baby "milk teeth" had already been tested under Project GABRIEL, the baby tooth study under the banner of Project SUNSHINE was officially launched in 1953 the same year as the earliest aerosol study in St. Louis. The project would hone in specifically, on St. Louis, Missouri.

In 2009 , researchers discovered 85,000 baby teeth in cardboard boxes in a dusty ammunition bunker in St. Louis. According to one report "each was in its own manila envelope, with an index card identifying the donor. These 85,000 baby teeth were 
collected in the late 1950s and early 1960s to study the effects of radioactive fallout in the environment" ("85,000 Radioactive Baby Teeth": IN01). More than 300,000 children sent their teeth to the Greater St. Louis Tooth Survey where Washington University and St. Louis University researchers "analyzed most of the teeth for strontium-90" (McGuire: 2009). Children in turn, received a button that proclaimed, "I Gave My Tooth to Science". "The study concluded that St. Louis children born in 1964 had about 50 times more strontium-90 in their baby teeth than those born in 1950, before the start of atomic testing" (McGuire: 2009). The baby tooth study that targeted St. Louis was one of many studies coordinated by the network of coalition members that made up the ManhattanRochester Coalition, but because it measured radioactivity in babies at the same time that a secret aerosol study was undertaken in St. Louis, the alignment of test/health study indicates a troubling possibility, that the tests were measuring "fallout" from the St. Louis study.

The 1953 RAND study that officially introduced the launch of Project SUNSHINE, incorporated a number of recommendations for studies that were already in place through Project GABRIEL. RAND officials discuss SR-90 "incasement [sic] in glass beads" (RAND, 1953: 56). Whether a byproduct of nuclear weapons testing, or laboratoryinduced encasement, it is clear that there were plans to drop radioactive glass beads in urban areas, where bones would be later collected to confirm exposure. ${ }^{77}$ A 1977 Department of the Army report on the U.S. biological warfare program, listed locations where "simulant/agents" were used in military-related tests throughout the U.S.

77 Recall that all other recommendations that appear in the RAND study were already underway. 
Although the list is hardly complete, military officials confirm that "glass beads", along with "fluorescent tagged cork" were dropped in Victoria, Texas in the summer of 1966, as well as in East Central Texas in 1967 (U.S. Army, 1977: 133). In fact, "the Army dropped 22 tons of tiny glass beads and fluorescent-treated cork particles over a 4,800square-mile area of Texas in 1966 in simulated chemical and biological warfare, according to Army documents made public in 1981" ("Chemical Warfare Tests", 1981: A18). An "Air Force Transport plane dropped the beads and cork particles from altitudes of 6,500 to 9,800 feet", whereby crews "collected" them ("Chemical Warfare Tests", 1981: A18). Because Dugway Proving Ground had secretly dropped radioactive pellets in the air by airplane in the 1950s (Davidson, 1994), there is some indication that the cork and bead drop, also tested a radioactive substance, per the RAND recommendation. Dugway had conducted their tests with cork and beads, and other radioactive dust and particles secretly, and the studies were not revealed until 1994.

The foodstuffs test portion of RAND's Project SUNSHINE recommendations also progressed quickly. On December 16, 1954, Major General A. R. Luedecke, United States Air Force and Chief of the Armed Forces Special Weapons Project (AFSWP), sent a letter, marked "secret" to the Surgeon General, Department of the Air Force. The Armed Forces Special Weapons Project's responsibility was to also study human effects of radiation exposure. Luedecke's letter instructed Army veterinary personnel in St. Louis to collect, ship, and analyze samples for radiation exposure, noting that "data from studies of these samples is classified SECRET" (Luedecke: 2). The chief of AFSWP added that "the samples collected from the local slaughterhouses should consist of one 
complete thyroid and one rib", and that milk samples should also be taken for sampling, which were to be shipped to Oak Ridge, Tennessee, at intervals between January and June, 1955. Clearly, the secret memorandum reveals that the Army did in fact direct personnel to complete a radiation "fall-out study" in animals from the St. Louis region that year.

\section{HEMPELMANN AND THE ST. LOUIS AEROSOL STUDY}

Louis Hempelmann had strong personal and professional ties to St. Louis, and was back at Washington University in St. Louis for two years prior to the 1953 aerosol study, before permanently leaving for Rochester. In 1945, before moving back to St. Louis, Hempelmann wrote to his boss, J. Robert Oppenheimer stating, "the very important and difficult problem of detection of alpha active material in the lungs has been studied only at this project and here only on a very limited scale. This problem should be given much higher priority here and at other projects" (Hempelmann, as cited by ACHRE: 164; sic declassification date not provided). Indeed, Hempelmann pushed for radioactive inhalation studies, and continued to do so in 1951 when he again discussed airborne radiation studies with his Rochester colleagues, arguing that radioactive aerial studies had incomplete risk assessments. He insisted to colleagues that specific particulate sizes were necessary for an accurate study. Hempelmann stated,

One point makes me unhappy... all the discussion of particle size indicated that we had absolutely no idea whether breathing these things in was serious or not. I think we should at least have some philosophy or basis for saying that we think people twenty miles downwind would be safe (Welsome: 258-59).

Welsome points out that Hempelmann would not let the issue go, even the following day, but his argument was eventually shut down by Shields Warren. Perhaps Hempelmann's 
concern was related to the tests that would soon occur in his hometown of St. Louis. 


\section{PREFACE TO CHAPTER FIVE}

The following chapter outlines bureaucracies, and elements of insular localized groups, which can create a moral myopia, internal group pressure for participation, and the harnessing of individual autonomy, to carry out activities that may result in harm. The emergence of the Manhattan-Rochester Coalition ushered in a newly hybridized organization, whereby the scientific community partnered with military elites and industry, to create a goal-oriented, militarized, clandestine community. Elements from all three subgroups were apparent in the new hybrid, however the military (sometimes directly and other times through the Atomic Energy Commission) presided over and directed all of the group's covert activities. Insiders of this new organizational model were not immune to the pressures of conformity. The various motivations for the individuals involved indicate that the membership was made up of men who were willing participants; indeed, they also benefitted personally and professional from their efforts, which included secretive human subject testing. Many, except the core members of the group, did not have awareness of the full scope of and social effects from the project; indeed, their tasks- however sordid they were- were in fact, compartmentalized at the directive of the head of the Manhattan Project, General Groves, in an effort to advance uninterrupted, the goals set by military elites. 


\section{CHAPTER V}

\section{A NEW HYBRID MILITARY ORGANIZATION}

Z

\section{BUREACRACIES \& MORALITY}

Max Weber described in his treatise Economy and Society, the distinct characteristics of the modern bureaucracy. The modern bureaucracy can be equated to a machine, and the individual bureaucrat the "single cog in an ever-moving mechanism which prescribes to him an essentially fixed route of march" (Weber, as cited in Gerth \& Mills, 228). Weber outlined how the characteristics of a modern bureaucracy encompassed rationalization as the basis for bureaucratic domination, which can conflict with democracy (Weber: 977; 985).

When fully developed, bureaucracy...is welcomed by capitalism, develops the more perfectly the more the bureaucracy is 'dehumanized', the more completely it succeeds in eliminating from official business love, hatred, and all purely personal, irrationally, and emotion elements which escape calculation. This is the specific nature of bureaucracy and it is appraised as its special virtue (Weber, as cited in Gerth, et al., 215-16).

Jurgen Habermas extended Weber's work to add an element of technological domination as a function of the modern bureaucracy. This newly technocratic model aggressively seeks increasing rationality, while whispering that technical progress is a natural phenomenon. Like Weber, Habermas pointedly reasons that rationality in course of action accompanies irrationality regarding values, goals and needs (Habermas, 63). In addition, such elements lead to increased technological and political domination 
(Habermas, 82-83). Thus, the modern bureaucracy according to some, is rife not just for internal dysfunction, but also extends its reach towards external domination and control-not strictly domestic control, but also global control through imperialism, etc. These characteristics not only allow, but encourage and reward, systematic failures related to moral responses to its actions. Indeed, the "flaw" is intentionally exploited within the organizational structure, and a moral response may be considered a failure within a model bureaucratic organization.

\section{THE BUREAUCRATIC MODEL: FOSTERING ETHICS OR DEVIANCE?}

In a modern society, organizations, like citizens, must adhere to laws. Legal constraints differ from ethical constraints, however and the criterion for ethical lapse is less than that of legal violation. A focus on legal obligations within an organization may result in a distinct loss of focus on, or the jettisoning of ethical obligations. "In the corporate era, economic relations become impersonal-and the executive feels less personal responsibility. Within the corporate worlds of business, war-making and politics, the private conscience is attenuated-and the higher immorality is institutionalized" (Mills, 1956: 343). In other words, diffusion of responsibility and a multi-directional fingerpointing blame game is built into the system of bureaucracies and organizations; this may be in part, by design. Adams and Balfour suggest that, "within a culture of technical rationality, a model of professionalism that drives out ethics and moral reasoning offers all to fertile soil for administrative evil to emerge" (Adams \& Balfour: 2009: 38). Thus, prescribed ethical behavior in the context of scientific rationality, becomes mere windowdressing (Adams \& Balfour, 2004: 35). In other words, there is a semblance of ethics 
that those inside an organization may rationalize as genuine. Other factors related to organizations can prompt ethical or legal failures. For example, "the sprawling character of the American health care system... whether in organ transplants or intensive care units, [also] allows a great number of actors to share in decisions without assigning clear responsibility to any particular actor (Zussman citing Fox \& Swazey, 1997: 182). Thus, the inherent quality of working together in a work team can create a diffusion of responsibility. In the Manhattan-Rochester coalition, teamwork was an essential component of goal-oriented classified research (Sutton: 205). There too, diffusion of responsibility was an element that contributed to a lack of personal and professional accountability for a collective action.

A diffusion of responsibility allowed avoidance of stigmatization and other negative sanctions to those who engaged in reprehensible actions during Nazi Germany. Indeed, "it has long been recognized that the Nazis used bureaucratic organizations to help implement the mass production of death. In many ways the concentrations camps were run like modern factories" (Katz, F. 1993: 135). The 'euthanasia' program allowed the Reich, assisted by scientists, chemists, and doctors, to perfect methods of efficient killing while murdering those found unworthy of living” (Geiderman, J.M., 2002: 228). Rationality, efficiency, even a bureaucracy of killing occurred not just at extermination camps, but at esteemed hospitals and medical facilities, where "medical personnel were at the heart of the operation" (Geiderman, 2002: 228). Human subjects research was also carried out at major universities and hospitals throughout Germany, and likewise, “Germany's most important universities were also quite willing to accept anatomic 
material taken from victims" (Geiderman, citing Seidelman, WE: 229). Indeed, many respected professionals played a critical role in state-sponsored genocide during Hitler's reign. After the war, many German physicians who were directly responsible for the killing of Jews during the Holocaust, were acquitted or were "restored to positions of prominence and respect" in the community, but according to Seidelman, others were so effective in their work within the bureaucratized mass murder scheme, that they were "recruited to provide their expertise to pharmaceutical companies as well as to the U.S. government" (Geiderman: 230). Indeed, many scientists were moved to protected academic posts in the United States under Project PAPERCLIP, after World War II.

According to Jurgen Habermas, the rationality of bureaucracies can also create a moral myopia. "Rationality in the choice of means accompanies avowed irrationality in orientation to values, goals, and needs" (Habermas, 1970: 63). The very structure of the modern rationalized bureaucracy creates an institutionalized platform for diffusion of responsibility, denial of responsibility, moral myopia, and ethical autism. For example, citing Robinson and Darley (2004), James Lager notes that deterrence is ineffective, "in organizational cultures where an individual might be 'caught up in... social pressures of the group' which is likely to occur frequently in organizations since group based loyalty can supersede loyalty to society" (Lager, 2010: 217). Rather than deterrence, Lager cites internal controls and monitoring that increase individuals' perceptions that they are more likely to get caught, as the method most likely to reduce ethical misconduct in organizations. Rational, bureaucratic models, which stress organizational efficiency and high performance to the point where executives' compensations are tied to the company's performance, can without strong internal controls, encourage fraud and dishonesty. 
Nevertheless, organizations often focus on (often minimal) compliance with law, rather than ethics per se, and this can quickly devolve into methods to skirt existing law. "Unethical but compliant leaders can behave similarly, but rather than attend required training, they instead engage attorneys, accountants, and other experts [to] find ways around ethics, tax, and other laws to meet their objectives" (Lager, 2010: 218). In other words, access to experts that work in and on behalf of the organization, allow leaders to engage in unethical behaviors that skirt the very edge of the law, and perhaps violate the outside majority's view of acceptable ethical boundaries. In a political/military organization, access to experts is just one door or a phone call away. Indeed, military tribunals are full of lawyers parked at the defense table, who will swiftly argue "just following orders", "he may be a cad, but he is no murderer", or finally, "it may not have been ethical, but it was legal".

Social pressures from inside the organization can be seen in other ways with far more dramatic, negative outcomes. Fred Emil Katz argues that autonomy can be harnessed to contribute to not just crime, but also genocide, as took place in Nazi Germany:

First, it was made possible by autonomy. Auschwitz officials were not mere robots. They did not carry out orders precisely as directed. They added to the orders. They detracted from the orders. They went around orders. They interpreted. They invented. To be able to do these things they, like other bureaucrats, used their own autonomy. They used it not only to invent evil deeds, but to invent justifications for evil deeds with which they, individually, could live. In their minds they constructed an appropriate reality (Katz, 1993: 95).

Bureaucracies can thus, harness positively-defined human attributes to carry out the most evil of deeds, while convincing those engaged in the activity that they were making a 
valuable or great moral contribution to the group or society, perhaps even at great sacrifice to themselves. In this closed community, with its own set of "locally-generated standards of morality, loyalty, and decency", a personal obligation to the group and its mission prevails, even regarding obligations that are repugnant and wholly deviant to larger society (Katz, 2009: 38).

Carrying out this obligation underscored one's good standing in this communityas a good soldier, who can be counted on to do his share of the task. It also added to one's stature. Precisely because it was onerous, one was making a noble contribution, demonstrating moral virility. It was but a short step to demonstrating zeal in the fine art of killing (Katz, 2009: 39).

The powerful influence of the localized group (particularly when partnered with a distinct separation from larger society, as we saw in the clandestine coalition that was the Manhattan-Rochester Coalition), prompts members to favor the group's mission, norms, and expectations, even if that means rejecting the morals and ethics shared by most of society (and perhaps shared by the organizational members prior to entering the group). These "closed worlds" as Katz refers to them, escalate their own uniqueness and thus contribute to their increasing estrangement from their surrounding world, where “eventually alienated responses from that world will accumulate" (Katz, 2009: 42-43). This does not however, according to Fred Emil Katz, negate a person's culpability. When one does not recognize or see their own autonomy in any given situation, "this blindness can serve as a mechanism for obscuring, even to oneself, one's contributions to horrendous deeds" (Katz, 2004: 105).

We see the escalation of uniqueness that Katz describes, also reflected in Daniel Ellsberg's analysis, whereby he described his loss of respect for outsiders who were 
misled or deceived by those inside the inner circle (Ellsberg, 44). There is no doubt that the men inside the unique circle of power called the Manhattan-Rochester Coalition, believed that their group was unique and part of a special mission for "mankind". Likewise, Edwin Sutherland's differential association theory asserts that behavior (including criminal behavior) is learned in association with those who define such behaviors favorably, and in isolation from those who define it unfavorably (Sutherland, 240). An isolated, insular organization can become distinct and separate from larger society, incorporating its own norms and moral code, which those involved are expected to follow, using paradoxically, their own autonomy. During the same decade whereby the Manhattan-Rochester Coalition first became active, Sutherland explained the dynamics surrounding corporate crime that prove relevant here.

In their confidential relations businessmen speak with pride of their violations of law, and regard the enactment of the law rather than the violation as reprehensible. Their consciences do not ordinarily bother them, for they have the support of their associates in the violation of the law. The feeling of shame at their business practices is probably found more frequently among younger businessmen who have not thoroughly assimilated the culture and rationalizations of business (Sutherland, 232).

Sutherland makes an interesting side point about the role of age in criminal activity and group dynamics, as many of the scientists brought into the fold of the ManhattanRochester Coalition were young men with newly-minted Ph.D.s. However, they quickly learned from their older colleagues such as Robert Stone, how to navigate this exclusive new world outside the academy. 


\section{TEAMWORK AND SANCTIONS FOR NON-COMPLIANCE}

Professional organizations can mask hostile internal group pressure to conform to organizational goals. Diamond and Adams note that, "oppressive organizational cultures are institutions of dominance and submission, even though the rhetorical patina may be characterized by pronouncements of teamwork or ethical action" (Diamond, M. and G. Adams, 1999: 254). This type of organizational culture is "often characterized by topdown retribution, intimidation, and punishment" (Diamond, et al., 254). Diamond's description of an oppressive organizational culture is also accurately descriptive of the military structure, which is hierarchical and dualistic. Like the culture which is fostered in the military, Volkan describes how a typical organization can become divided internally into "a culture of enemies and allies" (Volkan, 1988, cited by Diamond, et al., 255). Such a dualism of enemies versus allies or "us versus them" is also both explicitly stated and reinforced on a daily basis inside the military organization. In a typical organization dualism is dysfunctional, and prompts dehumanization, abuse, disrespect. It can also "justify an attack" within the organization, even under a patina of ethics and teamwork (Diamond, et al., 255). According to the military model, the fundamental underpinning of effective training requiring acceptance of obedience, hierarchy, coercion, dualistic thinking, dehumanization, and attack, conflicts with a code that reinforces ethical actions, as defined by those outside the institution. In fact, according to this model, these are not -in regards to military culture-, ethical lapses, but are rather part of the model traits in a "successful" modern military. 


\section{A NEW HYBRIDIZED ORGANIZATION}

The 1940s and 1950s realized an "increasing dependence of a new class of intellectuals and academics on the government" as the universities became militarized during World War II (Barnet: 304). As a result of earlier military efforts, the U.S. saw a merge between private industry and powerful military leadership, creating a "military-industrial complex". During World War II, a new entity was brought officially into the fold-one that heretofore, had been reluctant to breeching the final lines in the sand that divided the entities. The U.S. government enlisted the help of top scientists in physics and chemistry, to permanently halt Hitler and Mussolini, who were advancing on the Allies.

Government-university relationships changed dramatically during this time, and a partnership was created, whereby the most prestigious assignments and recognitions were reserved for "responsible" academics. According to Barnet,

The state helped to set intellectual fashions for thinkers who never had any contact with the Department of Defense or the CIA or, for that matter, the Communist Party. The mobilization of the university in war led to a reassessment of the very purposes of the intellectual effort (Barnet: 305).

In fact, intellectuals found their roles changing, in mostly abandoning to some degree the freedom to select research problems related to science, to a revamped role of one "supporting and rationalizing power" (Barnet: 305). There was by all accounts, a sense of teamwork, mission, and overall camaraderie in the newly formed Manhattan-Rochester Coalition, which combined military, select industry, and elites from the scientific community. Each secret spin-off division became an extremely goal-oriented team, as was the military model at the time. There was however, room for continued competition between the men, to a limited degree inside their closed community. This highly 
specialized, elite group shared elements with military battalions or teams overseas during times of war, whereby commitment to group and the group's goal superseded all, as was true when most of the men had worked on the Manhattan Project. The military was a barely perceptible underpinning of this vast network, but they were ever present, and officers consistently pressed and often aggressively reaffirmed their goals to the scientists and industry executives inside the coalition.

When people become a part of a closed institutionalized setting where the members are encouraged to take actions that outsiders would find repugnant or abhorrent, insiders can often effectively convince the other group members to engage in all manners of terrible acts. The men of the Manhattan-Rochester Coalition were highly competitive and very successful, but this did not free them from group conformity, as Milgram and other researchers have revealed in a number of studies (Milgram, 1974). Conformity can also lead to crimes of obedience, as characterized by Kelman and Hamilton. A crime of obedience is an "act performed in response to orders from authority that is considered illegal or immoral by the larger community (Kelman, et al., 46; 51). When legitimacy and authority are given to destructive authority, automatic, unquestioned crimes of obedience may occur. Although acknowledging that people willingly surrender to legitimate authority due to commitment and loyalty to the group, Kelman and Hamilton fail to see the autonomy that is often available to people in those situations (Kelman, et al., 91). Individual autonomy remains, although it is utilized in a number of ways inside the organization. Indeed, in the Manhattan-Rochester Coalition, individual autonomy 
was used to creatively identify potential advanced weapons, and to advance individual careers through military/scientific advancement.

When there is a blurring between the academy and the military-indeed a morph into a militarized academy, then participation may require proving ones allegiance to group and country, by engaging in activities (in this case research) that may or may not harm others. As Milgram and Soloman Asch revealed individual behavior can be influenced by one's group-however temporary- to the degree that one will willingly harm others simply because they are asked to do so by an authoritative or influential member of one's team (Milgram 1974; Asch, 1951). This can help explain how people with no apparent illintent can engage with others in a collective action that is harmful. In addition, as Katz pointed out, individual autonomy is often used quite willingly and creatively by the individual, to advance the causes of the group or organization, rather than to challenge authority. When this element of individual autonomy is acknowledged, it too, opens up the possibility that ordinary people may engage in deviant or criminal acts on behalf of their organization or “closed world”. Katz's theory (which adds to that of Sutherland and Milgram) seems to fill the most gaps in explaining historical events where "decent" people have readily engaged in (and heartily justified) acts, that years later were wholly rejected under moral and ethical grounds by the general public, when the event became known.

Beyond the closed circle of the Manhattan-Rochester Coalition, state-sponsored weapons testing during the Cold War involved a large number of personnel and insiders of varying 
levels of knowledge and skill, and testing extended over five or six decades. Presumably, given the decades-long effort, old staff rotated out, and new staff moved into the organizational structure at all facilities that were involved in testing. Thus, new internal staff had to be "brought into the fold", and somehow convinced that harmful acts were warranted, desirable, and justified. Given the great number of civil servants, scientists, and military and medical personnel involved in such a vast military project, would indicate that at least some percentage of personnel had no ill intent towards the victims. Thus, we must examine motivations that could prompt a wide range of people with varying skill sets, varying levels of status or rank, levels of insider knowledge, varying personality types, etc., to consistently engage in ethical lapses or purposeful harmful acts over an extended length of time, when there is no personal mal-intent involved. Upon examination, various motivations crystallize for the different subgroups that comprise the Manhattan-Rochester Coalition.

\section{MOTIVATIONS FOR INDUSTRY}

Profit motives for the company

Power

Individual profit and status in the community

Positive public relations in the community

Elevation of public view of industry

Perceived national security threat

Careerism

\section{MOTIVATIONS FOR THE SCIENTIFIC COMMUNITY}

Dependable sources of funding (particularly during lean economic times)

Large funding amounts

Prestige/Status

Careerism/Job security 
Intellectual stimulation $^{78}$

Release from teaching loads

Scientific advancement

Perceived national security threat

\title{
MOTIVATIONS FOR MILITARY ${ }^{79}$
}

\author{
Culture of obedience ${ }^{80}$ \\ Dehumanization/Zones of exclusion (an underpinning factor) \\ Careerism/Promotion/Rank \\ Salary \\ Group/peer attachment \\ Military structure \\ Desire to serve country/self-sacrifice \\ Prestige \\ Avoidance of routine/specialized activity and training \\ Defense paradigm \\ Perceived national security threat
}

Notably, all three groups share some personal or professional motivational triggers that may encourage individual participants to engage in human subject testing:

\section{1) PROFIT/FUNDING/PROMOTION-SALARY INCREASE:}

In 1957, the New York Times announced that grants totaling \$1,500,000 were

awarded to three universities by the Rockefeller Foundation "to further education

\footnotetext{
78 In 1959, Dr. Shields Warren Professor of Pathology at Harvard University, and insider in the cabal for CBN weapons human subject research, advocated for radiation studies on humans. Shields was quoted, "you could study in the laboratory a million mice, and it would just be mice. You have to study men". See New York Times, January 7, 1959: "Radiation Study in U.S. Proposed".

79 A great number of military personnel have also engaged as both willing and unwilling test subjects.

80 One revealing example of obedience informing the actions of military personnel who contributed to the Nazi Holocaust, appears in The Nuremberg Interviews, p. 296. When Rudolf Hoess explained why he could not protest to orders to kill millions of men, women and children, Hoess responded: “... when Himmler told us something, it was so correct and so natural we just blindly obeyed it.” (Goldensohn, Leon. 2004. The Nuremberg Interviews. Vintage Books: New York.) See also Hannah Arendt's Eichman in Jerusalem; pgs. 92 and 247, where Eichman's last words included the claim that "his guilt came from his obedience, and obedience is praised as a virtue", a virtue that had been "abused by Nazi leaders"- thus, Eichman believed that he himself was a victim. It must also be added here that Arendt doubts the obedience defense (p. 175). William McNeill also discusses military obedience, which allows for no personal responsibility of low-ranking personnel, and freedom from decision-making (see: McNeill, William; The Pursuit of Power.) Also, as the Stanley Milgram study (Yale University) showed us, some people will engage in harmful acts just by being politely asked to do so.
} 
in health hazards of nuclear radiation" (“1.5 Million”, 1957). ${ }^{81}$ The three universities included Harvard, Johns Hopkins, and University of Pittsburgh, and “each would receive $\$ 500,000$ over a ten-year period” (“1.5 Million”, 1957).

Clearly, there is a great financial motive for researchers affiliated with institutions to accept grants requiring military-related human subject testing, particularly during periods when federal and state funding of educational institutions is lacking. This also adds a measure of security for non-faculty personnel at such institutions. A study at Lawrence Livermore Laboratories found that weapons researchers are somewhat sheltered from the funding process, however, and this distance from the process "was significant compensation for working on an applied agenda" in defense (Sutton, 214). In addition, Sutton found that governmental support in the form of advanced technology and equipment, creates a concentration of resources that not only attracts excellent personnel, but it “clearly expands the parameters of the laboratory's research capabilities in a quantitative sense"; researchers interviewed in Sutton's study found this to be "a particularly attractive feature" (Sutton: 218).

\section{2) PRESTIGE/STATUS:}

A 1957 New York Times article announcing grants of $\$ 1,500,000$ to three universities, quoted the president of the Rockefeller Foundation; the foundation had recently distributed research money to be used for human-subject testing. Foundation President Dean Rusk (who had previously worked for the War Department and Department of 
State, and was later to become Secretary of State under Presidents Kennedy and Johnson) stated, "highly qualified experts are needed who can bridge the gap between the conventional public health area and that of the engineers, physicists and chemists, and who can contribute to the direction these developments take in their earlier phases" ("1.5 Million”, 1957). Rusk appeals to the desire for prestige from potential scientific participants, as well as funding needs. In 1962, Senator John Carroll announced that, "the federal government had chosen Colorado State University at Fort Collins as the site for a $\$ 2,500,000$ long-range laboratory to study the effects of low-level nuclear radiation" ("Radiation Study", 1962). ${ }^{82}$ Not only was money granted to the university, but the Senator who made the announcement earned accolades and prestige (along with political capital) with his constituents, which equates to political power. Other benefits embedded within this announcement are free and positive media coverage for all involved, and an enhanced ability for the Senator to gain funding for future political campaigns, and for the university to gain future grants and gifts. A researcher that brings in large government grants, particularly if they do so regularly, are valued in their institution, and often promoted accordingly. This relates to other careerism, as well. Professional autonomy also played a role in job satisfaction, whereby researchers were inclined to continue their affiliation. For example, radiologist Hymer Friedell who worked as a core member of the "Health Division" described his colleagues and the working environment, for the researchers involved in human subject testing of radioactive materials such as plutonium, uranium, and polonium.

Dr. Hamilton's interest in patients was rather modest, clinically. He

\footnotetext{
82 The purchasing power of $\$ 2,500,000$ as of 2010 is $\$ 18,000,000.00$. Source: Measuring Worth; http://www.measuringworth.com/ppowerus/result.php.
} 
was doing research more than anything. But exactly what research he was doing, I wasn't particularly aware of. At that time, it was very interesting. There was real freedom, as we extol the virtues of freedom. Everybody did anything they wanted to do. There wasn't any real surveillance. The only surveillance that I had was from Dr. Stone. If I told him I wanted to do something and I outlined it in general, he would say, 'Go ahead, do it.' I don't think John Lawrence really had a kind of committee to take a look and see whether this was an appropriate approach as far as over here, for example (U.S. DOE, 1995b).

Sutton's examination of Lawrence Livermore Laboratory found a lack of autonomy at the defense lab, but he identified three types of compensation for the loss of freedom to select research problems. He noted that satisfaction of the visible group goal; the attraction of group collaboration and a resultant reduction of competition (and hence stratification); and 'scientists' perceived freedom from the practical constraints of academic research, especially personal involvement in fund-raising" (Sutton: 213). Clearly, although Sutton found a reduction in traditional notions of autonomy (ie: selection of research topics), there was marked autonomy in other areas of their work. Indeed, at Lawrence Livermore Lab, "scientists from all areas of the laboratory interpreted autonomy not as an issue of what to study, but of how to study a given problem" (Sutton: 214). According to Fred Katz however, the autonomy of members in a powerful local universe, is limited. "There are zones of behavior in which one may not exercise any autonomy at all. Most notably, one is not permitted to question the sanctity or authority of the leader (Katz, 2009). The military arm under General Groves, was often quietly in the background, but always in full control of the Manhattan-Rochester Coalition. If a participant forgot that point of order, then military officials were willing to shatter the career of the oppositional party, thus, stigmatizing resistant scientists, who were promptly labeled "enemy", and treated accordingly according to the dualistic military model. The military/AEC used J. Robert 
Oppenheimer as a symbol of their willingness to serve extremely negative formal sanctions to the scientists and industrial leaders, for not complying with military goals.

\section{3) CAREERISM:}

Careerism is defined here as valuing success in career above all else, and seeking to advance it by any possible means, including unethical, illegal, or immoral actions. ${ }^{83}$ Welsome describes the aggressive careerism that took place within the insular military-academic war machine, and the scientists' desire to publish new research on nascent, cutting edge technology, at the cost of the patient and ironically, the interests of the general public for whom they claimed to be working (Welsome: 212). "With the expansion in medical research came a new breed of physicians who were interested not in treating patients but in finding cures that would benefit mankind. Original research and frequent publication put physicians and scientists on the fast track to academic advancement" (Welsome: 211). According to Beecher, "every young physician knows that he will never be promoted to a tenure post, to a professorship in a major medical school, unless he has proved himself as an investigator" (Beecher, 1970: 16). Thus, there was a shift from physician to researcher (and thus, patient to subject), whereby the objective became original research and proving oneself to colleagues.

Professional medical ethics were thereby subordinated to scientific ethics, which are far less concerned with the well-being of patients. Welsome quotes William Silverman, a retired Columbia University physician and researcher in the 1940s to

${ }^{83}$ Taken in part from the World English Dictionary. 
1960s: "Some of my peers were quite immoral or perhaps amoral. I realize many would do anything for scientific advancement" (Welsome: 212). Although publication is in itself not a measure of anything unethical, immoral or illegal, it does represent a commitment to professional growth, and contribution to the field. Sutton notes that at Lawrence Livermore Laboratory, "despite structural obstacles to publication, limited interaction, and some degree of alienation from academic science, LLL scientists do not display markedly inferior rates of productivity by academic standards" (Sutton: 204). This is impressive considering that almost half of their reports are of a classified nature, and reflects a high level of productivity in the area of publication.

\section{CASE IN POINT: JOHN RUNDO}

John Rundo Ph.D., D.Sc., was a principal investigator in human subject radiation testing in Chicago. In the 1990s, Rundo offered testimony to the U.S. House of Representatives regarding human subject radiation testing, and described how some of his work involved exhuming the bodies of people who were subjected to plutonium studies in the 1940s at MetLab in Chicago. Rundo vehemently defended human subject testing involving radiation in his testimony, and he presented as evidence the following:

...by 1973, I had more than 70 publications in the open literature...by 1974 , I was promoted to Senior Biophysicist, a title I held until my retirement in 1991; by that time I had roughly doubled the amount of publications. In 1980, I was awarded the degree of D. Sc. (a 'higher doctorate', not an honorary degree) by the University of London, based on my published work in the field of low-level Radioactivity in man. I must emphasize that I am not a physician... (U.S. House, 1994: 204-06).

Dr. Rundo mentioned publications at least sixteen times in his testimony, revealing that he holds publishing research in some regard. Clearly, Rundo focused his career on 
original research submissions for publication, and this would include follow-up studies on victims of plutonium injections (U.S. House, 1994: 204-06). Thus, he aligned his personal and professional goals to accommodate that of the military's goals. Yet Rundo's desire to publish original research in prestigious journals conflicted with the extraordinary secrecy of the Manhattan spin-off program. Therefore, Rundo like his colleagues, would adjust his goal to accommodate the secrecy in exchange for the unique prestige involvement in the program would offer to him and others. The new local moral universe was a tightly closed world, but this sealed universe was one that was quite large indeed, involving thousands of respected scientists and physicians. This new "local moral universe" as defined and outlined by F.E. Katz, became their world in which to compete with top scientists, and to share research results and successes (Katz, F.E., 1993). It also allowed the scientists to explore morbid new horizons not otherwise available to them, not unlike soldiers who were likewise "serving their country". Katz's description of Reserve Battalion 101, German police reservists during World War II who engaged in a series of brutal innocents, serves us here:

They molded into a cohesive moral community; an increasingly Closed World. This was achieved through their common training and association with one another...by their relatively constant membership...they formed an enclave of their own.... a new moral community could and did flourish. It developed its own local system of community- its system of where each man fits (Katz, 2009: $38)$.

Oak Ridge scientist Karl Morgan once stated that, "weapons scientists worked in a closed society where the same ideas were passed from researcher to researchers" (Welsome: 211). Sutton notes that Lawrence Livermore Labs is also a closed community, where "recognition in the outside community of science is irrelevant to 
success within the organization" (Sutton: 206). Indeed, closed worlds escalate their uniqueness and become increasingly estranged from the surrounding world, whereby "participants believe they are making a moral contribution to a morally justified cause"

(Katz, 2009: 27; 42). We see this occur in the Manhattan-Rochester Coalition programs.

\section{4) PERCEIVED NATIONAL SECURITY THREAT:}

Participation in the satellite Manhattan-Rochester Coalition projects, may have been based in part on a perceived national security threat, and inflammatory rhetoric used by military and political elites. The message and language emerged from the military, was echoed by other high-profile political allies. According to Mills, motives and actions originate not from within, but from the situation in which individuals find themselves (Mills, 1940: 906). In this case, the perception of external threat may have motivated people to join the organization and maintain membership. Katz discusses how an individual's personal desire to participate in the defeat of an external threat can be a powerful motivator to join an effort:

I believe there is indeed one highly seductive core message, one that makes the recruitment process work. It is that a Zarqawi- just as a Hitler, or a leader of a cult- identifies the Ultimate, the very greatest good and the very greatest evil, and declare that this Ultimate is within your own reach. You, personally can make a profound impact on it (Katz, 2009: 41).

In the case of the Manhattan satellite program, there were at least two perceived threats at hand. The original impetus to contribute to a Manhattan program was the rise of Hitler's power in Germany, and the joining of forces with Japan and Italy (presented as a dehumanized greatest evil) against the Allies (presented as the greatest good). The 
second threat was that of the Soviet rise of military power during the Cold War. By harnessing "good science", the greatest evil could be halted, and the greatest good would prevail over its enemies. Everyone's contribution was needed, and there was a moral justification for all to sacrifice and contribute, no matter how much it would prevail upon their personal convictions. Regarding Reserve Battalion 101, Katz states, "at the heart of the tragedy is that the majority of participants came to regard their actions as morally justified, at least at the time of their participation" (Katz, 2009: 39). The actions of the scientists engaged in human subject testing during and post WWII, posed little difference from the soldiers of Battalion 101, in terms of morality or depravity. Both were willingly serving their countries against a terrible perceived threat, and both groups were engaging in harmful acts under a banner of morality and righteousness.

It is notable that the Cold War military-sponsored tests described here continued postWorld War II-- beyond the immediate threat of war-- in Chicago, by Robert Stone's group...in San Francisco by Joseph Hamilton's group; and also in Rochester (Welsome: 123). Indeed, the United States has at least a fifty-year history of radiation experiments on humans, which extends long past World War II (U.S. House, 1994: 109). Thus, the fear of immediate threat was not the only factor to propel scientists and troops to engage in harmful acts under the auspices of national security. Because human subject testing continued decades after the conclusion of World War II, immediate threat to a nation is not necessarily the impetus behind participation in harmful acts against ones' fellow citizens in the name of defense. The perception of a Cold War threat by the USSR in the form of the atom bomb, as painted by a powerful military-industrial complex, was a 
plausible tale, however. Other factors may have also motivated internal participants in harmful military-sponsored Cold War experimentation, including fear of treason (U.S. House, 1994: 109), institutional loyalty (U.S. House, 1994: 69) and even "administrative convenience" (U.S. Senate, 1994: 53).

\section{CROSS-OVER AND THE REVOLVING DOOR}

Many of the scientists who fell within the most intimate ring of secrecy inside the clandestine Manhattan-Rochester Coalition, were associated with more than one of the groups discussed here. For example, Dr. Shields Warren was a member of the Naval Reserves, but also affiliated with Harvard University, where he engaged in militarysponsored human-subject research. Warren was also director of the Atomic Energy Commission's biomedical programs, and in that role, he made "regular loops to the Manhattan Project's laboratories at Los Alamos, Chicago, Berkeley, and its monolithic uranium and plutonium-producing factories in Oak Ridge, Tennessee, and eastern Washington State" (Welsome: 197-209; 201). In 1947, Shields and his colleague Joseph Hamilton (Berkeley) began “discussing 'isotope injection’ when Hamilton made an oblique reference to the 'utilization of plutonium'. Hamilton described for his friend, "details of... three plutonium injection cases in California" that Hamilton had conducted (Welsome: 202-03). Shields Warren claimed that he later learned that "additional patients had been injected with plutonium by his colleagues in Rochester, Chicago, and Oak Ridge" (Welsome: 203). Warren was in fact, not simply an individual research scientist engaging in human subject testing, but he was leader of this clandestine Manhattan spin-off coalition, whose members were secretly injecting hospital patients with plutonium, and engaging in all forms of human subject testing of radionuclides. In 
fact, Warren and his staff were the individuals to approve such tests (Wellsome: 204$){ }^{84}$ According to Eileen Welsome, the reporter who in the 1990's, broke the case of human subject research involving radioisotopes, “under Shield Warren's steady hand, a vast new empire devoted to radiation research sprang up in the United States" (Welsome: 207). Warren was just one individual at the peak echelon of a top-secret human-subject research machine, that enlisted the help of some of the world's top researchers to test chemical, biological, and radiological weapons for the U.S. military.

\section{AN EMERGENT HYBRID ORGANIZATION}

What emerges from the union of military, scientific community, and industry (with politician-advocates in the background or foreground as appropriate for political cover), is a new structural dynamic with clearly defined military goals, driven by scientific legitimacy. The nascent organization incorporated transformative and hybridized elements from the three individual entities (military, industrial, scientific community) that formed the organization. This included:

- Aggressive industrial competition not against (industrial) competitors, but against State-determined military and political enemies.

- Fiercely competitive research, not to advance science and society, but to advance the goals of the military. ${ }^{85}$

\footnotetext{
84 According to Welsome, Shields thrived in the culture of secrecy at the AEC, and fearing lawsuits and bad publicity, he quashed efforts by other researchers in the cabal when they attempted to publish findings of their human-subject studies (Welsome: 205).

${ }^{85}$ This does not exclude benefits to science and society; those are merely viewed as potentially lucrative asides, external to the central goal of military superiority.
} 
- Rapid military growth, as thousands of persons join the military war machine through military contractual agreements with universities and industry. Satellite military institutions emerge all over the country, and are particularly desirable to the military arm, because classified military activity can be disguised under the guise of typical industrial activity.

- The military becomes the focus of lobbying interests and industry, as it becomes a source of funds to private interests. Thus, competition between industrial entities over military resources becomes tied to industrial growth, which is thus, claimed by some groups as a mark of "successful" industrial capitalism. In turn, economic and military power gained, may be leveraged world-wide by political and military elites in the U.S., in a show of imperialism.

- Military-sourced funds can determine which academic institutions have more resources, are viewed as prestigious, and which have the financial capital towards physical growth. Thus, competition between academic institutions over military resources becomes an emphasis to advance growth and prestige in the academy. This becomes particularly relevant during lean economic times.

- A triangulation of power occurs, whereby leaders (military, industrial, scientific community) from each side of the partnership develop close fraternity, viewing many others in the partnership as partners or potential equals ${ }^{86}$. From this, emerges the Revolving Door phenomena, and an overall expansion of what C. Wright Mills refers to as "the Power Elite".

\footnotetext{
86 I use the term "potential" here because some scholars argue that scientists are viewed as "hired hands" in this arrangement, and indeed, the military views their role as overseer and director, above the coalition (see "Politics of Research Ethics in a Federal Bureaucracy", in Deviance and Decency: The Ethics of Research with Human Subjects (1979); Sage Annual Reviews of Studies in Deviance: Beverly Hills.
} 
The unique compact between military, industry, and the scientific community that makes up the military-industrial-academic complex and the Manhattan-Rochester Coalition, allows for non-normative behavior that far exceeds the bounds of any actions that any individual component alone could manage. In this synergistic compact, each element has decision-making capability, indeed some autonomy, over the direction of whatever need they fill in this hybridized group. Each element in this coalition can advance their own varied goals under a shroud of secrecy and protection, in this clandestine effort of military superiority. They are thus, able to press their own agendas in new and unique ways that heretofore, had been unavailable to them given the constraints outside the compact, which include compliance requirements related to criminal and administrative laws, transparency, and public accountability. Citizens will accept to a great degree some level of secrecy and activity generally not acceptable, in efforts to assure national safety. But because of the covert nature of military activity, indeed of the military-industrialacademic complex, the same social agreement that allows some secrecy in exchange for national security, can also allow exploitation. In the case of the Manhattan-Rochester Coalition, this exploitation in fact, led to morbid and clandestine body-snatching during Project SUNSHINE. Were any individual component within this compact to engage in the same type of activity, without the protection of the other components, they would likely be exposed and viewed as rogue or criminal. Thus, the compact itself is of great import, as it brings a collective autonomy unrealized otherwise. This unique arrangement brings cover and rationale for actions that would otherwise be viewed as perhaps 
criminal; it gives, as one individual stated, "another set of fingers for people to point with", and indeed, another set of players for insiders to point towards.

How then, does each individual component of this compact benefit from this arrangement? For scientists in the Manhattan-Rochester Coalition, the arrangement brings an expansion of autonomy whereby they can explore scientific horizons heretofore left unexplored; it brings a new layer of protection to the scientists for those explorations; it allows for a legitimate rationale to engage in research that may be otherwise deemed unacceptable, unethical, or illegal. The compact is seen as advantageous (and perhaps desirable) to the scientist and their affiliated institution, as it brings direct access to seemingly endless funds, which also lends prestige to the scientists and to their institutions. The scientists themselves are able, through this extra layer of secrecy and the rationale of "national security", to shift ethical burdens and delegitimize accountability. In one interview, Hymer Friedell, who was a core member of the Health Division, discussed how like cogs in a machine or playing cards, the University of Rochester made a deal to trade one of their faculty members to the coalition, in exchange for project funding and capital:

I think that President Vallentine, who was then in charge of the University of Rochester, probably made a hard bargain with the Army, saying, 'You can have Stafford Warren'...they probably made an agreement to have a research program going on in Rochester, and to build the building then for them to do it. That was, I don't think, a [hard] bargain, but it was a bargain: 'You can have Warren if you'll do this'. I think the Army probably felt that we needed the research program anyway, and so, they did it. Undoubtedly, in the contract someplace, it probably outlined some of the studies that could be done-I know that I visited many times there before the building was built - and what the general program might be like. FISHER: At Rochester? FRIEDELL: At Rochester (U.S.DOE, 1995). 
In an equally beneficial exchange, back-room deals were made between corporations and universities such as Rochester. They provided highly qualified faculty members to the military, in exchange for capital funds and lucrative project funding contracts for years to come. Rochester certainly was fully engaged in the effort of the coalition; the university slipped quickly and silently into the sinister military-driven efforts of human radiation studies.

The industrial component of the Manhattan-Rochester Coalition benefitted from this arrangement in several ways. Clearly, industry obtained access to extraordinary capital that may not otherwise have been within reach. Indeed, during the Cold War, the Department of Defense and other military-related agencies such as the AEC, funded industrial plants for military production during major times of war, but those plants were to be privately owned. This arrangement was of enormous benefit to industry, as it allowed them capital to build enormous new industrial complexes to produce products, both for sale to the U.S. military (a committed customer), and to the private sector around the world ${ }^{87}$. This capital investment allowed for unrivaled growth of the defense industry in the United States. Many of the "captains of industry" from the defense sector ${ }^{88}$ became significant industrial figures on the world stage, whereby they leveraged power in other countries to their own financial gain. This also provided to them unprecedented access to key players at the top levels of government and science, as well as

${ }^{87}$ Including sometimes, sales to persons or governments from "hostile nations". This creates a conflict of interest. There are laws to prevent corporations from selling defense weaponry to hostile nations, but how much those laws are implemented and enforced, is anyone's guess, and not the subject of this paper.

88 Such as John McDonnell from McDonnell Douglas, or Henry Kaiser who was linked to ship-building, automobiles, steel, and now healthcare through the Kaiser Foundation. 
unprecedented access to classified information. With this came domestic and international power, prestige, status, and generations of vast wealth and advantage. It could certainly be argued that industry benefitted the most from this Cold War compact.

The military component of the Manhattan-Rochester Coalition also benefitted in a number of ways. Their "partnership" with the scientific community brought legitimacy and credence to the military's efforts. The military effort instantly gained industryinsider support, and labor support. It infused into the military-industrial complex, a legion of new scientists with vast intellectual capability, a never-ending supply of bright and up-and-coming scientists, and access to prestigious academic laboratories and resources, to work on behalf of a very focused, intense, clandestine military agenda. The military shifted to scientists the burden of definition of what risks are "acceptable" in the pursuit of advanced weaponry and methods of warfare. Both the ethical burden and accountability likewise shifted from the military, and public scrutiny was instead directed towards prestigious, respected, and a somewhat invisible "scientific body". A questioning public will be in general, less suspicious of "good science" than they would be of stated or perceived military goals which may or may not, enhance national security or defense. Science, in turn could push this agenda out of normative bounds, justifying actions based on the military's claim of a national security risk, in a somewhat symbiotic relationship that increases risk taking overall. Risk taking and exploitation increased dramatically, from the synergistic efforts of those within the compact, with an unsuspecting public not knowing much of the details of the matter, except for that which 
had been framed by President Truman and his cabinet. Indeed, a risky shift took place within the Manhattan-Rochester Coalition.

According to Walzer,

When a state like this commits itself to a campaign of aggression, its citizens (or many of them) are likely to go along, as Americans did during the Vietnam War, arguing that the war may after all be just; that it is not possible for them to be sure whether it is just or not; that their leaders know best and tell them this or that, which sounds plausible enough; and that nothing they can do will make much difference anyway...by citizens seeking to avoid the difficulties that might follow if they thought about the war for themselves (Walzer: 301).

Incorporation of the scientific community squarely into the fold of secret military endeavors, provided legitimacy for military-guided actions that the public may respond to differently, when believed to be conducted by scientists rather than military elites.

Weber notes that "the belief in the specific legitimacy of political action can, and under modern conditions actually does, increase to a point where only certain political communities, viz., the 'states' are considered to be capable of 'legitimizing', by virtue of mandate or permission, the exercise of physical coercion by any other community" (Weber: 904). Thus, the state has legitimacy to engage in physical coercion. In the realm of defense, this basic function of the state falls to a military administration, which offers “organized armed protection against outside attack" (Weber: 905). Physical coercion by the state is thus viewed as legitimate, while political colleagues present salient rationales, sound bytes, and political cover for the actions of their military colleagues, to a sometimes uninformed and collectively gullible public. ${ }^{89}$ (Indeed, politicians control the

\footnotetext{
89 We will discuss the constructed framework of public rationale, in the section entitled "Social Autism".
} 
resources of the military, so the military had better be willing to routinely provide them with positive stories to placate constituents and critics.) Human experimentation however, is generally not viewed as legitimate action by the state, particularly on the heels of the Nuremberg trials, which involved American prosecutors. Human experimentation may however, be plausibly argued as potential treatment for disease, when presented as such by the medical community. Experimentation was also easier to mask when under the auspices of the scientific or medical community, rather than that of the military.

Philip Morrison, who had also worked on the Manhattan Project, warned about the danger of the military co-opting the academy however, whereby "science itself will have been bought by war on the installment plan" (Welsome: 211). Indeed, the fusion of the military and the academy became not a scientific military, but rather militarized science. Once co-optation was complete, inside the Manhattan-Rochester Coalition, there was essentially no oversight. All "oversight" was internal; "oversight” was provided by military commander General Leslie Groves, and the chairman of the AEC, who would advance above all, the interests of the military war machine.

On the heels of a world war, and in an era of hostile McCarthyism, the general public was already very careful in their public- and even private- criticism of public officials. This served to silence a citizenry en masse, and allowed acceleration of activity that might otherwise had realized vocal critics. Civilians viewed the 1950 s as a time of peace, and were therefore, not vigilant for activity that smacked of war. Although, according to 
Walzer, a great number of citizens did not wish to be bothered with what they considered to be the minutia of war and peace, in the climate of the 1950s, there were other matters at stake. 


\section{PREFACE TO CHAPTER SIX}

The following chapter outlines the use of secrecy and how the dissemination of information- both internally and externally from the Manhattan Rochester Coalition was used to control dissent, targeting both internal participants, and the external public. Two concepts are identified and defined in this chapter. Ethical autism is the use of tactics by organizational elites to control internal dissent and create "ethical lapses" inside the organization. This minimizes awareness of collective activities, such as crimes, unethical actions, or other organizational activity that may result in internal resistance by participants. Social autism is the use of tactics by organizational elites to control external dissent in an outside audience (ie: the general public). The intention is to stifle debate in the public square, to distort the reality of harmful, unethical, or illegal actions by the organization, and to create a false sense of security in the external audience. Both ethical and social autism are induced through mechanisms called snipping, spinning, and blizzarding, which are each defined in this chapter. Through ethical autism, we can come to understand how harmful ethical lapses by a large number of individuals, over a long period of time can occur inside an organization, without extensive internal dissent and opposition that might otherwise suspend the deviant activity. Through social autism, we can come to understand how the public at large can be kept in the dark about harmful organizational actions involving hundreds or thousands of participant insiders. Through specific mechanistic triggers, dissent both internally and externally can thus be quashed, allowing the organization to continue with unethical, harmful, or illegal actions, undetected and unchallenged. 


\title{
CHAPTER VI
}

\section{ETHICAL AND SOCIAL AUTISM: \\ THE QUASHING OF INTERNAL AND EXTERNAL DISSENT}

\begin{abstract}
Z
Just as secrecy protects such abuses of power, so it also gives those who employ it successfully more power, thus increasing their susceptibility to corruption, and in turn a still greater need for secrecy. In the absence of accountability and safeguards, the presumption against secrecy when it is linked with power is therefore strong.
\end{abstract}

(Sisella Bok, 1989)

The 1950s was a turbulent time. A peace-shattering World War II had ushered in the decade, which would precede the beginning of a passionate Civil Rights Era. It fell squarely within the vulgar snarl of McCarthyism, when Wisconsin Senator Joseph McCarthy boldly accused statesmen, celebrities, and public officials of being active communists, and so ruined careers and personal lives. Richard Barnet suggests that a climate of coerced conformity and blindness ensued.

There is no doubt that the climate of fear, which the...senator capitalized upon and helped to promote produced ideological conformity, self-protective blindness, and the prudent avoidance of controversy. But what was it about the intellectual climate of America, that permitted McCarthyism to flourish and caused his attackers to question only his 'methods' and not his 'objectives'? (Barnet, 1971: 304).

In the era of the communist blacklist, many social scientists and media sought silent refuge in the safe corners of the magnifying glass, tacitly accepting those engaged in a 
vicious political witch-hunt and blossoming romance between military, industry and science (Barnet: 304). Between 1950 and 1954, Senator Joseph McCarthy accused among others, the Atomic Energy Commission of ignoring the communist leanings of scientists (Wellsome: 323). This frightening witch-hunt may have served as impetus for reluctant scientists to tacitly support secret military efforts related to human subject tests of radioactive materials. Indeed, secrecy was a crucial element in advancing the military project, and most of the human radiation studies undertaken during the Cold War would in fact, remain secret for decades.

\section{SECRECY AND POWER}

Secrecy can be defined at the most basic level, as the intentional practice of concealment or hiding of information. Secrecy can also be viewed as a practicing or leveraging of control and power, through withholding of information. Some degree of secrecy is desirable and warranted, however. Bok argues that ,"with no capacity for keeping secrets and for choosing when to reveal them, human beings would lose their sense of identity and every shred of autonomy" (Bok: 282). Thus, secrecy can be both beneficial and harmful. This dualism presents a challenge:

Not only must we reject definitions of secrecy that invite approval or disapproval; we cannot even begin with a moral presumption in either direction. This is not to say, however, that there can be none for particular practices, nor that these practices are usually morally neutral. But it means that it is especially important to look at them separately, and to examine the moral arguments made for and against each one (Bok: 27).

Because some secrecy can be positive for individuals or society, acts or events involving secrecy must be scrutinized to determine what level of secrecy is warranted, and what the 
effect is on others. Secrecy is often used to remove accountability, and to avoid negative sanctions that would otherwise arise to address purposeful norm violations. In the case of the Manhattan-Rochester Coalition and the St. Louis aerosol study, avoidance of accountability was one motivation behind acts embedded within a framework of military secrecy.

\section{STATE AND MILITARY SECRECY}

State secrecy in general, applies to the withholding of information from the public or other entities or nations, by the government of any given nation-state. This is particularly true regarding the military and state matters of "defense". Military secrecy is a highly compartmentalized subset of a class of restricted information held by the state. Through the state, military secrecy is invoked. It is often argued that secrecy is an essential element in the military defense of a nation-state and thus, state preservation. Military secrecy includes not only secrets from enemies, but also secrecy from a state's own citizens, as an extension of the former (keeping secrets from enemies). There must exist however, an element of public trust in the state that such power will not be abused. "The public is asked to take on faith the need for secrecy on the grounds that an open debate of the reasons for such a need might endanger national security (Bok, 202).

There is thus, a tension between necessary secrecy for reasons of defense, versus the need for transparency, the desire to prevent abuses, and to uphold individual rights in society. "Because a degree of military secrecy is so fundamental to survival, it can call on greater sacrifices than all other rationales for secrecy", thus, citizens can "lose ordinary democratic checks on precisely those matters that can affect them most strongly", (Bok, 
191-92). In addition, not only will one nation's secrecy often prompt a response in kind from other nations, but military secrecy holds a particular danger in that, "misapplied or excessive secrecy can be equally dangerous in causing hostile nations to respond inappropriately to one another" (Bok, 196). Thus, there is danger in state secrecy, as it relates to international diplomacy and political-military response. Adding to such events is the additional issue that, "under conditions of crisis, when nations feel beleaguered, military secrecy is likely to spread, invite abuse, and undermine the very security it is meant to uphold" (Bok, 194).

The military is not the only institution where secrecy is a norm. Daniel Ellsberg, author of The Pentagon Papers, described how "people on the inside of the government become convinced that they are acting for the good of the country, develop a contempt for those who do not have the secrets, and come to consider them really unfit to participate 'in determining who shall run the country"" (Dorsen: 20). Ellsberg also describes the various and complex levels of secrecy that are unknown to the general public, noting that "top secret" is not the most classified category within the upper echelons of the executive branch. According to Ellsberg:

I shared the universal ethos of the executive branch, at least of my part of it: that for the Congress, the press, and the public to know much about what the president was doing for them, with our help, was at best unnecessary and irrelevant. At worst, it was an encouragement to uninformed (uncleared), shortsighted, and parochial individuals and institutions to intervene in matters that were too complicated for them to understand, and to muck them up (Ellsberg, 44).

There was clearly, a culture of secrecy in the administration. It went however, beyond secrecy, and entered the realm of misinformation and arrogance, according to Ellsberg:

Once I was inside the government, my awareness of how easily and pervasively 
Congress, the public, and journalists were fooled and misled contributed to a lack of respect for them and their potential contribution to better policy. That in turn, made it easier to accept, to participate in, to keep quiet about practices of secrecy and deception that fooled them further and kept them ignorant of the real issues that were occupying and dividing inside policy makers. Their resulting ignorance made it all the more obvious that they must leave these problems to us (Ellsberg, 44).

Patrick Moynihan likewise argues that by the 1940s and 1950s in the United States, secrecy had become a norm in the political realm (Moynihan, 1998). This was true in defense laboratories, such as Lawrence Livermore Labs, where classified research "restricts the number of institutions engaged in it, limits communication generally, and particularly restricts publication of findings" (Sutton: 207). Likewise, in the ManhattanRochester Coalition, secrecy was a deeply embedded norm that sprang from the military structure that organized the group, funded, and oversaw their projects. Indeed, a culture of secrecy emerged. The very bureaucracy that was the state, supported this culture of secrecy. Daniel Ellsberg describes the "local moral world" (Katz, 2009) of a presidential cabinet that relied heavily on institutionalized secrecy to cover their actions:

...the regular classification system could be regarded as a mere cover for a much higher category of secrets, available only to an inner group of officials who amount to a government within a government. They carry on covert operations that never become known except by some fluke of political history such as Watergate (Dorsen: 18-19).

In fact, the Freedom of Information Act process is a highly regulated system of secrecy, in that one must know specific information to obtain a document; general inquiries are typically not met with document returns. Thus, in an ironic twist, Freedom of Information in effect, reflects institutionalized secrecy that sustains a certain level of ignorance in society, at the hands of those in power to determine what, who, and how 
individuals obtain information about their government, while projecting an aura of openness and transparency. Institutionalized secrecy may also reflect an abuse of power. Indeed, Sissella Bok argues that those who employ secrecy to protect abuse of power, gain more power and thus can become even more corrupt, which advances the need for additional secrecy (Bok: 106). Thus, there is according to Bok, a strong need to institute checks and safeguards to increase transparency and debate in the public domain.

\section{SECRECY \& THE MANHATTAN-ROCHESTER COALTION}

Hymer L. Friedell who had worked on the human subject studies involving radioactive materials for the Atomic Energy Commission's Health Division, recalled the importance of secrecy in the radiation projects:

We didn't want anybody to know that we were working on radiation. Work on animals was secret, because we didn't want anyone to be aware of this. As a matter of fact, publications in the literature, once they came into our office, were stamped 'secret'. Throughout the literature-it wasn't to be discovered by anybody that we were looking at data in the literature. All of this, then, had to be handled in a secret fashion. That was obvious. Secrecy probably made a big difference (U.S. DOE, 1995).

Secrecy was used as a tool of power to control the reaction of the public to human subject research of atomic weapons, but secrecy was an important element of internal control, as well. Dr. Friedell worked at the Chicago Division MetLab, under Dr. Robert Stone; MetLab was at that time creating a "pile" on site. ${ }^{90}$ Decades later, Friedell described the way he and other researchers backhandedly deduced information on various projects at the lab.

\footnotetext{
${ }^{90}$ A "pile" is a pile of bricks of a particular material, which retains uranium, and produces plutonium through fission activity.
} 
Because of secrecy, there was a considerable compartmentalization. Often, we weren't told everything. But my understanding was: that they were going to see whether they could build an experimental pile. Then we knew that they needed a moderator. We learned a lot about the nuclear science by the fact that they looked at moderators, and they decided that carbon [(graphite)] was a very good one. And we used to see carbon blocks around there and machining of carbon blocks... (U.S.DOE, 1995).

Former pathologist Clarence Lushbaugh, who had worked at the Chicago Toxicity Lab, which was closely aligned to MetLab, recalled the following event decades later:

I almost got fired by the secretary of our Chicago Toxicity Lab group who was there, and she also knew about the metallurgy project at the University of Chicago. I had come to the conclusion from listening around, that the University of Chicago was somehow associated with the pathology of radiation damage, and that this pathology of radiation damage involved bone marrow, and therefore they were interested in anemia! I mentioned this to her one day, that the focus of the metallurgy [project] was on the pathology of radiation damage. For that reason, she accosted me for having broken the secret and had threatened to fire me. I explained that I had arrived at those conclusions all on my own, and that I did not have to be fired at that point (U.S. DOE, 1994).

Secrecy was thus used internally to limit any one persons knowledge of projects that were being conducted, and formal sanctions were built into policy to deal with violations. This use of power through secrecy, extended not only inside the organization, but outside as well.

Although information on the human radiation experiments occasionally made its way into obscure journals, the scientists managed to pursue their studies without drawing much public attention to their projects. This was due in large part, of course, to the deliberate efforts on the part of the researchers and their government funders to keep the experiments quiet (Welsome: 403).

According to Welsome, "the culture bred by the Manhattan Project caused a blanket of secrecy to be thrown over everything related to atomic weapons. The secrecy was essential during the Manhattan Project, but it hardened into a protective and impenetrable shell after the war" (Welsome: 484). Hymer Friedell discussed the secrecy and 
deception extended by the military arm of the Manhattan-Rochester Coalition, to obtain equipment and supplies for the Manhattan Engineering District laboratories.

Obviously, all of the shots were really being called by General Groves from Washington. Often, General Groves would call on me to do things. One of the anecdotes is that-I have written it up —was that he asked me to go to Boston to Harvard [University] to buy their cyclotron. The reason for asking me to do it - and I was still at Chicago - the reason for asking me to do it was: they wanted to camouflage the idea that the Army was buying a cyclotron-well, that the Manhattan Engineer District was buying a cyclotron. Ostensibly, the cyclotron - actually - the cyclotron was being purchased for Los Alamos. We used the facade of my representing the [Army's] Medical Corps, which wasn't true, and that I wanted it for medical purposes (U.S. DOE, 1995).

Secrecy extended from the military leadership and was a requirement for insiders within the Manhattan-Rochester Coalition, as part of a highly coordinated effort to deceive parties outside the coalition. The military, the scientific community insiders, and industry insiders all benefitted and derived power from this pact of secrecy, a pact that Eviatar Zerubavel might refer to as a "conspiracy of silence". Zerubavel highlights how, “each conspirator's actions are symbiotically complemented by the others'...pressure toward silence gains momentum as the number of those who conspire to maintain it increases, the longer it lasts, and when the very act of denial is itself denied" (Zerubavel: 15). Conspiracies of silence might indeed rest squarely on employee loyalty, a trait that is revered in both politics and industry. As an example, Daniel Ellsberg describes the culture of "supersecrecy", whereby a loyal administration employee was expected to, "do what's good for your boss, the man who hired you; put that above what you think is best for the country, above giving the president or the secretary of defense your best advice if that would embarrass your boss (Ellsberg: 53). In other words, loyalty to superiors above all — indeed, above ones own beliefs and values, and even perhaps above national 
interests, can create or sustain conspiracies of silence. Ellsberg notes that many top administration officials personally criticized and disagreed with continued involvement in the Vietnam War, yet they went along without objection, out of loyalty to higher level officials (Ellsberg, 57).

"The concept of the 'official secret' is the specific invention of bureaucracy and nothing is so fanatically defended by the bureaucracy as this attitude, which cannot be substantially justified beyond these specifically qualified areas" (Weber, et al., as cited in Gerth, et al., 233). According to Weber, the secret is a means of power in a bureaucracy, and we see how that power is leveraged in the Manhattan-Rochester Coalition. Indeed, the realm of "politically-convenient" official secrets, expands as decisions become "more fateful" (Mills: 355). Secrets are used as a tool of manipulation by political elites (Mills, 1956), military elites, (Habermas, 1968; Arendt, 1963), and corporate elites (Sutherland, 1983), and the union of the three groups in the Manhattan-Rochester Coalition magnified the use of official secrets. This administrative barrier locks out information to citizens, "disturbs the flow of communication on the most basic level", and creates an inability to form ethical and just discourse (Habermas, 76). According to Habermas however, moral decision-making requires open debate and discourse, including the airing of differences of opinion (Edgar, 28), where members of society can reflect upon social norms, rights, and collective goals (Edgar, 25). Indeed, domination arises from distorted and incomplete communication (Habermas, 112), which also serves to hide ideology (Habermas, 110), and manipulate public response. 


\section{DISSEMINATION OF INTERNAL INFORMATION \& THE HYBRID}

\section{ORGANIZATION}

The reorganization of duties by the Manhattan Engineering District aggressively

advanced weapons technologies, added layers of secrecy, and divided responsibilities into approximately ten satellite divisions that made up the Manhattan-Rochester Coalition.

"The program expanded from the base of the Manhattan Project research sites such as

Oak Ridge, Hanford, Chicago, and the Universities of California, Chicago, and Rochester

to take in a growing portion of the university research establishment” (U.S. DOE, 1995a).

The program was indeed, an ambitious one. Expansion would focus on the following

research areas: “...the physical measurement of radiation, the biological effects of

radiation, the methods for the detection of radiation damage, methods for the prevention

of radiation injury, and protective measures" (U.S. DOE, 1995a). But lingering under a

legitimate list of concerns during an age of nuclear war, was a more sinister list, whereby

the tasks of secretive weapons testing on American civilians, were to be divided up

between the following facilities: MetLab (aka Argonne National Lab), Los Alamos,

Monsanto (Oak Ridge), Columbia University, and the Universities of Rochester,

Michigan Tennessee, California, and Virginia. All would take on these tasks, to be

funded to a great extent by the Atomic Energy Commission, with Rochester taking the

largest slice of the project pie.

The University of Rochester was to be the largest contractor, receiving more than $\$ 1$ million, followed by the University of California (about one-half million for UCLA, where Stafford Warren was dean of the new medical school, and Berkeley, to which [Robert] Stone had returned to join Hamilton, Western Reserve (to which Warren's deputy Hymer Friedell was headed), and Columbia (more than \$100,000). Argonne [MetLab] received an amount comparable to 
Rochester; other labs, including Los Alamos National Laboratory and Clinton Labs (now Oak Ridge National Laboratory), were scheduled for $\$ 200,000$ or less (DOE). ${ }^{91}$

All of the divisions were clandestine, and all communications were rigorously controlled and screened. Meetings were strictly confidential and held "by invitation only". Hymer L. Friedell, who was in charge of the AEC's Health Division, described the circulation of information inside the Manhattan-Rochester Coalition thusly:

Dr. Hamilton made all his reports to the University of Chicago; possibly because it was considered The Plutonium Project. But nevertheless, all other groups like [the University of] Rochester, and so on, always reported directly: made their own reports and submitted them somewhere to the Manhattan Project someplace. It wasn't known as the Manhattan Project, so it came to the Manhattan Corps of Engineers. And then, the reports from the University of Chicago all then came to us, once it was organized. It was always interesting that the reports came under the general (General Groves). First of all, it always identified Compton as the director, Stone as the director of the biomedical studies, and then Dr. Hamilton as the director of the studies, which were being done on fission products. It was an illogical, in a way, thing to do. And it was obviously the best place to do it because they had the cyclotron working there. They would then go ahead and do these studies. The reports were always made through Chicago, and then, in turn, we would receive it.

\section{FISHER: In Oak Ridge?}

FRIEDELL: Oak Ridge. For a while, while I was in Chicago, I would receive it. (U.S. DOE; Friedell; 1995b).

Friedell describes a strict screening process, and a controlled regulation of internal communications. Sutton describes a similar process at the defense lab Lawrence Livermore; "two mechanisms exist for the more general dissemination of information within the laboratory: a constant flow of seminars given by local and visiting scientists, and in-house publications" (Sutton: 208). The description of Lawrence Livermore

\footnotetext{
91 Cited in DOE Openness Report: www.hss.energy.gov/healthsafety/ohre/roadmap, but attributed to Stafford Warren, Interim Medical Committee, proceedings of 23-24 January 1947 (ACHRE No. UCLA-111094-A-26).
} 
Laboratory's communication as "highly compartmentalized" whereby "communication outside the immediate task group is only occasional", aligns with the communication procedures described by Friedell in the Manhattan-Rochester Coalition. The ManhattanRochester Coalition which focused on highly compartmentalized group tasks and goals, held larger discussions in the form of regular, classified conferences, held usually at Rochester. Regardless of all other elements, secrecy was the primary distinctive feature throughout the entire process, both internally as well as externally, by the organization.

\section{COMPARTMENTALIZATION}

Within an organization, information is often provided to employees on a need-to-know basis. This enables employees (and/or military personnel) to complete their assigned tasks, duties, or mission, without always understanding how their tasks contribute to an end or final outcome. Thus, there may be no knowledge of the organization's engagement in crime or unethical actions, even if that individual played a role in the outcome. In some situations, were employees to be fully apprised of their own contribution to the larger whole, some may decide to become non-participants. This can create dissention and division in the organization, as well as a situation where the final goal is unattainable. Because of this, participants are often restricted to limited bits of information, but not enough to have a full understanding of their organization's actions. They are provided the information that they need to know to complete their tasks, and often no more. This withholding or parsing of information restricts the ability of workers to think critically or ask critical questions. It disengages organized response, and can be used to rationalize actions and deflect criticism. Thus, the organization is not a 
community where protest can occur (Walzer: 315). The purposeful regulation of information becomes then, a tool in military, bureaucratic, and hierarchical systems, to manage potential dissent. In the military-industrial-academic complex where military has the highest authority, this is particularly relevant. "Civil protest and disobedience usually arise out of community of values. But the army is an organization, not a community, and the communion of ordinary soldiers is shaped by the character and purposes of the organization, not by their private commitments" (Walzer: 315$).{ }^{93}$ Thus, participants are expected to compartmentalize their own personal beliefs, and adopt those of the larger organization. ${ }^{94}$ As an extra assurance to maintain compliance however, this may be engineered for organizational participants (without their knowledge). For example, General Leslie Groves, the military head of the Manhattan Project, operated by the principle, "that workers should know only what they need to know to do their jobs and nothing more" (Wellsome: 423). Groves saw this as an important element to retain secrecy and so that no one person knew enough information to piece together the enormous potential of the project, and perhaps also to avoid a response of moral repugnancy and outrage, whereby workers might refuse to contribute to the project. In the MIA complex, Groves' operating principle becomes a very important tool that contributes to non-normative behavior, and according to some scholars, it is also inherently dangerous. Hannah Arendt refers to the purposeful compartmentalization of tasks in government as "Rule by Nobody".

\footnotetext{
92 In the private sector, too, open protest is rarely, if ever, allowed.

93 The same argument might be advanced regarding industry.

94 If the participants are able to incorporate their personal goals into those of the larger organization, than all the better for the organization.
} 
If in accord with traditional political thought, we identify tyranny as government that is not held to give account of itself, rule by Nobody is clearly the most tyrannical of all, since there is no one left who could even be asked to answer for what is being done. It is this state of affairs, making it impossible to localize responsibility and to identify the enemy, that is among the most potent causes of the current worldwide rebellious unrest, its chaotic nature, and its dangerous tendency to get out of control and run amuck (Arendt: 1972, 138).

According to Arendt, responsibility and accountability are jettisoned when compartmentalization is employed in an organization or state, and the result is a tyrannical or despotic abuse of authority. Arendt's argument is supported in the case of the Manhattan-Rochester Coalition.

\section{CONTROL OF DISCOURSE}

When information is transmitted from organizations, it is often in the form of messages to define events, and also to manipulate public opinion (Mills, 221). The messages are often the product "of those with the power to define what is to be taken as "factual"" (Taylor, 26). Often, a message is wrapped in seductive discourse that make people believe they have the same goals (Mouffe \& Chantal, 184; 191), or it is repackaged as a positive misrepresentation that conceals the nature of the issue (Walzer, 326). According to Flyvbjerg, "success in rhetoric is associated...with distortion", and this is related to issues of power (Flyvbjerg, Bent: 216). In the concept of moral inversion as expressed by Adams and Balfour where, "something evil has been redefined convincingly as good... [this] allows ordinary people to easily engage in acts of administrative evil while believing that what they are doing is not only correct, but in fact, good" (Adams, et al., 4). Moral inversion occurred during the German Holocaust, whereby the SS placed official language requirements on particularly offensive terms, in order to purposely mask 
the daily evil tasks of genocide (Arendt, 46; 84-85). Indeed, during the early part of the Cold War, the Manhattan-Rochester Coalition could not use the word "plutonium" in communications, as the word itself had been classified. Through the control of language and communication, an organization can thus systematically develop a methodology to avoid responsibility and an ethical or moral response to its own actions. Thus, internal ethical lapses can be purposely engineered by officials inside the organization.

\section{ETHICAL AUTISM-DEFINED}

Secrecy, compartmentalization, and the strategic use of communication and rhetoric were used by the Manhattan-Rochester Coalition to contain internal dissent and create "ethical lapses" inside the organization. Manufactured ethical lapses purposely created by an organization in an effort to control internal dissent, is referred to here as "ethical autism". More specifically, ethical autism is defined as the purposeful reduction, manipulation, or blockage of information inside an organization or group, intended to 1) distort reality 2) minimize awareness of collective illegal or unethical activity 3) create a false sense of security to members of the organization from outside threats due to illegal or unethical activity 4) to stifle opposition, open debate, and ensure conformity to the organizational goals. Ethical autism is a reflection of a systemic problem that allows unethical or criminal behavior within an organization to go unchecked, unchallenged, whereby the significance of events are underestimated or misinterpreted by an internal audience. It impairs the ability for those involved, to fully understand or appreciate their contribution towards unethical or illegal actions by the organization. 


\section{ETHICS AND ETHICAL LAPSES}

Henry Beecher, one of the earliest twentieth century scholar/physicians to address the ethics of human subject testing in the medical literature, argued that, "a particularly pernicious myth is the one that depends on the view that the end always justifies the means. A study is ethical or not at its inception; it does not become ethical merely because it turned up valuable data" (Beecher, 1970: 25). As we have seen, secrecy played a major role in the cover-up of the Manhattan-Rochester Coalition projects, including the St. Louis aerosol study. We have seen certain individual and group-related elements that could inspire the highly accomplished men of the Manhattan-Rochester Coalition to engage in acts that most outside the group would consider immoral, unethical and perhaps criminal. Indeed, the men planned and carefully coordinated these actions through a complex network that reinforced and hid their actions - actions that in a larger context would meet criteria of "ethical lapse". Ethical lapse is defined here as:

- Intent to mislead

- Withholding the truth

- Concealing information from stakeholders

- Fabricated, omitted, or falsified data

- Failure to credit work of others

- Violation of confidentiality

- Mistake in judgment by an otherwise ethical person

- Participation in actions that contribute to or directly harm: psychological, physical, financial, cultural

- Non-disclosure of information

- Allowing self-interest to override principles 
In the case of the scientists involved in the Manhattan-Rochester Coalition, ethical lapses most assuredly occurred, but they became to the core circle of participants, institutionalized research norms that were outside standard norms of the time. Norms are fluid and can change rapidly and dramatically, particularly in response to dramatic or traumatic events such as war or other events of significance. Norms can also vary from group to group, and particularly so in a "closed world" (Katz, 2009: 26), such as in the Manhattan-Rochester Coalition, which had virtually no external oversight or imposition of external norms, that might challenge ethical lapses.

Part of controlling actors both inside and outside the organization, involves the regulation of information. There are three distinct tactics or mechanisms regulating information outflow both within and outside the organization that produce ethical (and social) autism. These mechanisms shut down or impair open communication, discourse and debate in the organization, and eschew ethically responsible actions due to calculated organizational manipulations. Snipping, Spinning, and Paper Whiteout/Digital Dumping, all operate beyond legitimate claims of military or political classification and privilege. Using these mechanisms, information is molded, shaped, and parsed to assure that internal participants will comply with demands that may conflict with personal values or criminal laws.

\section{SOCIAL AUTISM-DEFINED}

Similar to ethical autism, social autism also results from particular activities designed to engineer complacency. Targeting external audiences, the intention is to 1) distort reality 
2) minimize awareness of an entity's illegal or unethical activity 3) create a false sense of security to the general public in an effort to hide illegal or unethical activity 4) to stifle opposition, open debate, and insure uninterrupted organizational goals in an external audience. A social autism will occur when political, military, and/or economic organizations systematically and purposefully impede meaningful information flow, which manifests as a public misunderstanding of reality and potential danger, and suppression of full and open debate related to particular organizational actions and their effects on society or groups (Martino-Taylor, 48).

\section{MECHANISMS \& SOCIAL AUTISM: SNIPPING, SPINNING \& BLIZZARDING}

If military or government officials believe that they cannot present plausible arguments to civil society that testing of chemical, biological, or radiological weapons on citizens, is reasonable and warranted, then secrecy assumes an ever-greater role in asserting power and control. Human subject testing may become covert, and a social autism can be engineered by a series of actions. When availability, transparency, and access to information by parties external to the organization is examined, three distinct mechanisms regulating information outflow emerge, that can produce social autism.

1) Snipping: Snipping occurs when information is parsed, abbreviated, or otherwise limited, and it thereby takes on an innocuous-sounding form. Snipping is defined as selectively revealing bits of information to an audience, in an effort of false transparency, intended to create a false sense of security in the either internal or external audience. Employees within a bureaucracy 
where snipping is employed, and who are involved in an unethical or illegal tasks, are told only as much as they need to know to be productive in their role as employee. When snipping is used (either inside or outside the organization) in an effort to obfuscate, information is limited to the degree that a harmful activity or outcome sounds unimportant, routine, mundane, and non-harmful to the audience, both inside and outside the organization.

\section{SNIPPING \& THE MANHATTAN-ROCHESTER COALITION}

In 1953, the aerosol studies in Minneapolis and St. Louis were part of a larger, coordinated effort related to offensive military weapons testing. While the aerosol dispersants were sprayed over neighborhoods in St. Louis, various state agencies, including the Atomic Energy Commission, were collecting human and animal tissues from around the world. Officials claimed that they were conducting a study related to a naturally occurring source of radiation in the environment-radon, when in reality, they were analyzing for exposure to strontium-90, radioactive iodine, and other radioactive contaminants that emerged in people due to military tests. The radon claim was a halftruth, a cover story to purposely deflect public scrutiny. One internal document justified that officials were "providing for the measurement of Ra (radium) as well as Sr-90 (strontium-90) in many of all of the samples, so that the Ra story is merely incomplete, not false', [as] Robert A. Dudley of the Atomic Energy Commission Biophysics Branch wrote on Dec. 9, 1953" (Davidson, 1995). 
Snipping is apparent in a National Academy of Sciences (NAS, 1997) report related to the aerosol spraying in St. Louis and other U.S. cities. A subcommittee of the NAS produced three reports. Firstly, an interim report, published in September 1995, contains the subcommittee's preliminary toxicity assessment of $\mathrm{ZnCdS}$ exposures; secondly, a final technical report published in 1997 (National Academy of Sciences, 1997b); and thirdly, a separately published nontechnical report for the general public (National Academy of Sciences, 1997a). The (second) final technical report includes 356 pages of text and data, excluding final references. The (third) public nontechnical report was issued in the form of "Answers to Commonly Asked Questions", and comprised a total of 14.5 pages of text and data, including one page dedicated to answering the question, "where can I go for more information?" The public report includes at least one full page of irrelevant information related to cadmium in the ambient environment or from other sources. In all, without the additional sources page, the third, public report includes twelve pages of information relevant to the $\mathrm{ZnCdS}$ study, produced for public consumption. The abbreviated public report also notes that the committee "based its conclusions on two basic sources of information", including information gathered at public meetings, and toxicity and exposure data on $\mathrm{ZnCdS}$, cadmium, and cadmium compounds from the open scientific literature and other technical reports" (National Academy of Sciences, 1997a: 3). The report issued for the public was an example of purposeful snipping, whereby 356 pages of technical data was snipped down into a convenient 14.5 pages of non-specific information related to cadmium in the general environment, which served to diffuse public protest and dissent regarding the studies. Another example of snipping in the Manhattan-Rochester Coalition activity, occurred 
when military officials secretly embedded dangerous nuclear detonation tests within concurrent, less innocuous tests that had been in fact, announced to the public. Thus, information was limited and parsed to the degree that it provided a false sense of security to the public, whereby the tests sounded routine, mundane and non-hazardous.

2) Spinning: Spinning occurs when information is carefully packaged to send a specific, planned, and strategic message to an audience, in an effort to control their response. Verbal rationalizations are used that present as plausible to the audience. Spinning is used by officials to alter, fashion, repackage or reframe information in an effort to make an action or actions sound less threatening or coercive, but instead as positive, justified, legal, and ethical.

Spinning is similar to snipping in that the desired outcome is to make an action or actions sound positive, justified, and ethical. Moral inversion for example, would be a spinning mechanism. Spinning utilizes verbal rationalizations, which are made to sound plausible to an audience. For example, when scientists argued that "no one was harmed" by radiation studies, or that "we should all sacrifice for the war effort", these were examples of spinning used as a mechanism to control the message, and thus, the response. When officials initiated an "aggressive propaganda campaign about 'friendly atoms' (Welsome: 485), this was an example of spinning to control the message, and thus, control public response. When scientists argued (or continue to argue) that the human subject tests occurred at a time when the "standards of the day" allowed such activity; this was (and is) spin. In 1947, during the time when the Manhattan-Rochester Coalition was in thick 
of planning and implementing their many studies involving human subject testing with radioactive materials, state officials changed the name of the "Department of War" to the "Department of Defense". This name change reflects a purposeful public relations spin to control the public perception from that of American aggressors to that of American defenders.

3) Blizzarding: Paper Whiteout/Digital Dumping: The third mechanism of blizzarding is often used by officials in a public display of transparency without meaningful revelation of significant data, and it takes two forms. Paper Whiteouts bury the public or audience with voluminous paperwork, research, undifferentiated documents, and/or highly complex technical materials, to the point where it is impossible to glean anything meaningful from the combination of a) the sheer volume of documents and b) the overlytechnical language of the documents. This can also take the alternative form of "Digital Dumping", which is similar to Paper Whiteout, except documents are provided in an electronic format with the marked absence of a search feature, or a search feature that is difficult to utilize effectively. Digital Dumping is particularly disabling and tedious when attempting to locate factual information. It occurs when officials provide a great number of documents, many unrelated or vaguely related, in response to a request for specific information, through either the FOIA or legal discovery process. Each document must be individually viewed by the recipient, and are typically not sorted or categorized in any way. Documents or lengthy reports (or 
portions of those reports) may be repeated (sometimes many times) at random intervals, which adds to the overwhelming volume of pages. Because the viewer will typically not choose to print thousands of documents and images that may appear on an electronic file, they must manually view (and perhaps enlarge to make legible) each individual page, which results in timeconsuming, tedious work. The United States Government Printing Office produces millions of pages of information per year, which is "made available" to the general public, in an effort to comply with the public's right to know. Seemingly borrowed from the playbooks of defense attorneys, paper whiteout and digital dumping seem to imply that "if you must make it available, bury them in a blizzard of documents", so creating a blinding "paper whiteout", and thus, quite effectively reducing the visibility of meaningful information, while creating the impression of compliance. This tactic is the opposite of another well-known tactic called, stonewalling. Stonewalling occurs when for example, "over a period of months the Secretary of State...tells the Senate Foreign Relations Committee that he is too busy to testify on some subject. Or the Defense Department takes months to answer a letter... with reasonable hope that the request will eventually be forgotten" (Dorsen: 15). Stonewalling is a well-known attempt to block meaningful information to a recipient who has requested an action or information.

As researchers in the Manhattan-Rochester Coalition discussed plutonium injection studies in humans, Shields Warren had an interesting suggestion for the clandestine group; he recommended that all such studies be declassified and published. Stating that 
openness was important for such studies, he argued, “'I think it very important in something of this sort that there be no suspicion that anything is being hidden or covered up, that it is all being done openly and straightforwardly...We don't have to advertise it, but at the same time it doesn't want to be concealed"' (Welsome: 319). In other words, top officials of this secret group, conducting top-secret human subject research on topsecret weapons, would quietly bury reports in obscure journals. Thus, they could claim they were hiding nothing, but yet the technical, jargonistic reports would be lost among the thousands of other technical studies published each year.

In the case of the St. Louis studies, a long, declassified 1953 Army report indicated that additional tests beyond those identified, took place in St. Louis, and that the "extra studies" required special, security-cleared personnel, as well as special data analysis, at a separate location, due to an elevated classification of that portion of the study (U.S Army, 1953b: 31$)^{95}$. Noting the elevated security efforts involved in this otherwise unidentified aspect of the St. Louis tests, the Army used the obscure military report to mention in one succinct sentence, that a highly classified additional study had taken place. There was no other mention in any official documents of this additional test series that rose to a level above the "SECRET" military classification that the rest of the project was assigned. By burying this short statement of admission within the context of mundane jargon, in a long, obscure report that itself had been marked "SECRET", officials presented a semblance of candor, while avoiding scrutiny, in an example of blizzarding. This is supported particularly when combined with study officials' efforts to minimize public

95 Unclassified document AD031508; Defense Documentation Center for Scientific and Technical Information; Classification changed to "unclassified" from "secret" per authority listed in ASTIA Tab No. U63-4-4, November 15, 1963; obtained through FOIA, June 2011 from Dugway Proving Ground, Dugway, Utah 
and media scrutiny through other efforts such as notifying only a few key local officials, targeting citizens who had access to fewer resources, and purposely not notifying the press and public, before, during, and immediately after the study concluded.

Three tactics or mechanisms (snipping, spinning, and blizzarding) are used by officials to regulate information output to the public, so that a controlled amount of information is made available to their audience. Using these mechanisms (along with stonewalling) information is molded, shaped, and/or withheld to retain layers of secrecy from outsiders (thereby purposefully creating social autism). These tactics are intended to control public discourse, critique, opposition, and potential public protest. They are used to limit transparency and accountability, while creating a semblance of transparency to outsiders.

Snipping, spinning, and blizzarding are mechanisms that regulate information in an effort to obfuscate, downplay, or deny potentially damaging information to various parties, both internal to and external to the organization. The tactics can lead to ethical autism, whereby the significance or totality of certain actions become unchecked, unchallenged and misunderstood by internal participants of organization. This allows officials to diffuse potential internal dissent or refusal to participate in the organization's actions. Ethical autism impairs targeted internal audiences from critical inquiry within the organization, and it disengages negative responses. When these mechanisms are systematically instituted outside the organization in an attempt to deceive, manipulate public opinion, or hide information related to criminal activity or improper behavior such as harmful acts, the result is a social autism, whereby outsiders are unaware or are deceived as to potential dangers, and a suppression of full and open public debate 
regarding organizational actions (and resultant effects), is manifested. We can thus explain through ethical autism, how ethical lapses that may harm outsiders can occur within an organization, at the hand of a large number of "normal" internal participants, over an extended period of time such as decades. We can explain as well, how resistance is kept in check internally, through mechanisms that are implemented to trigger ethical autism that suppresses potential opposition and noncompliance. We can explain through social autism, how outsiders may have no knowledge of major events that may directly impact or harm them, or how potential public opposition and public debate is diffused or jettisoned through manipulative tactics from inside the organization. These additions to the literature, are helpful to understand how organizational leadership employs specific mechanisms internally and externally to control opposition, resistance and debate, and thus, trigger ethical and social autism, which allows them to pursue a project or line of action, that might otherwise be rejected by individuals either inside or outside the organization. 


\section{CHAPTER VII}

\section{THE MANHATTAN-ROCHESTER COALITION \\ AND \\ A GLOBAL AMERICAN EMPIRE}

The Manhattan-Rochester Coalition aggressively used a framework of deception to control the type and amount of information to which the general public had access. This served the interests of the men professionally, along with the financial interests of the industrial members of the organization. The military's interests subjugated all others in this group, and however deeply embedded beneath the surface their presence seemed, they would make their presence known when their interests were challenged or threatened. The studies in which the coalition engaged were vast and all encompassing, as they related to nuclear weapons and their human health effects. The limit of their military progress, was that of imagination of the bright, young scientists involved.

The claim by the Manhattan-Rochester operatives who presented as credible and successful scientists, and who legitimized the work of the military, was one that necessitated, in a hostile world, defenses new and foreign to civilians. It would be necessary, they claimed to the few who knew about the study, to envelope a low-income urban area, where people of color predominantly resided, in a heavy layer of smoke in an 
attempt to hide them from hostile foreign (read Soviet) attack. Were that argument plausible, one could logically conclude that the neighborhoods selected in St. Louis, were the same neighborhoods that officials would protect in event of a Soviet air strike. Were the argument plausible, it would benefit all involved to notify all public officials so that they might use the occasion as a "dress rehearsal" in which to modify and implement their own coordinated actions in anticipation of such an attack. Were the argument plausible, than we would have to deny the existence of radar. Indeed, the military's official narrative pre and post-testing, was simply a deception to cover military actions of which outsiders, particularly those persons who were targeted, would presumably strongly disapprove.

We find too, that the St. Louis aerosol study was just one single sliver of a vast network of studies, in a new military spin-off endeavor, conceived and installed by the generals of the Manhattan Project, and coordinated and advanced by a covert Manhattan-Rochester Coalition. The work of the coalition was mostly offensive in nature, rather than defensive as they would claim. Defensive work suggests protection at home, but offensive work suggests something quite different; it suggests the development and testing of devastating new weapons for use in other countries. Moreover, given the types of weapons being developed under the direction of the coalition, it suggests the targeted use of the weapons on civilian populations overseas. This smacks of imperialism.

Indeed, imperialistic military underpinnings of the vast new complex headed by the group referred to here as the Manhattan-Rochester Coalition, supported, directed, and 
financed the network through the U.S. military, to develop new weapons technology for use overseas. After World War II, deeply embedded in the military and political discourse, was a shift in focus to the development of weapons by the Soviets. Surprisingly, this topic does not find its way into the documentation or narratives of scientists in the Manhattan-Rochester Coalition. It was clearly not used as a motivator in which to engage the scientists in their military endeavor (it was however, used as public rationale). Yet, there was a silent global context looming at the edges, that the men in the Manhattan-Rochester Coalition were perhaps unwilling to discuss from their isolated seats inside. They understood all too well, given their participation in the atomic bombs dropped at Hiroshima and Nagasaki, the implication that these highly deadly weapons would ultimately be used in warfare to target non-American civilians.

\section{THE CONSTRUCT OF DEHUMANIZATION}

Dehumanization is one key element that scholars agree constitutes the underpinning of victimization. It is connected in the literature to a host of social ills, ranging from and including discrimination and racism, to the ultimate violence of genocide (Adams, G.; Agamben, G.; Arendt, H.; Hooks, G.; Katz, F. Kelman; Pilisuk, M). Arendt recounts how certain groups in Germany were set up for dehumanization; this "set up" included early abandonment by peers (Arendt, 1994: 125). Guy Adams discusses dehumanization in combination with rationalization (Adams, Guy, and Danny Balfour: 9; 41; 60). Dehumanization can occur through distancing, whether physical or psychosocial. The sheer physical distance between countries can create a buffer in which to deny social action for atrocities that occur far away. "It's their problem"; "We have other problems 
right here"; "It doesn't affect me or 'us", placate inaction of distant, although otherwise concerned citizens. Yet, Cohen argues that the "boundaries of 'moral impingement' have been widened due to an increased access to information through international humanitarian agencies, internet availability, and global televised news (Cohen, 2001: 290). 'For a premodern 'morality of proximity' to acknowledge the plight of distant strangers demands some leap of identification. This in turn...assumes a natural or universal human identity, at least 'in the basic fraternity of hunger, thirst, cold, exhaustion, loneliness or sexual passion" (Cohen, 2001: 290 and Cohen quoting Zygmunt Bauman: 290.) In sum, "there is only one way to include the distant stranger: to define the threshold of the intolerable as exactly the same for everybody" (Cohen, 2001: 293). Yet, distance can be created any number of ways. Most obviously, distance can begin through physical distance, as in global placement. When partnered with poverty, a nameless dehumanized "other" can become invisible. Distance can be created through cultural difference that is reinforced. If it is reinforced that a particular group is fundamentally different from ones own, than they can become dehumanized, and distance is created and/or increased. Rhetoric or plausible arguments can then be effective in further dehumanizing, or in justifying harmful actions against a targeted group. According to Kellman and Hamilton,

As long as victims are out of sight, it is easier to forget that there are real human beings who are being harmed by one's actions. Thus, it is easier to kill people by dropping a bomb on a distant target or pushing a button at a missile-launching station than it is to kill face to face (Kelman, Herbert \& V. Lee Hamilton: 163).

Distance can be incorporated during war situations through strategic weaponry-trigger from afar, computer programs, standoff munitions capability, and even through official 
chain of command. ${ }^{96}$ Thus, a social-psychological distancing is created for soldiers in battle, which allows them even less discomfort for fighting and killing an already-vilified and dehumanized enemy. In a unique situation such as war, norms are suspended or annulled, according to Georgio Agamben (Agamben: 34). This can create a state of exception, or zone of indifference whereby victims are viewed as dehumanized nonentities. This results in the "suspension of...those constitutional norms that protect individual liberties" (Agamben: 5). In other words, laws that accord protection and rights to citizens, are annulled in regard to a particular group of victims, whereby they experience involuntary exclusion. The creation of a state of exception is a particularly useful tool for those in power during a state of war. One example of an attempt to establish a state of exception during the time period of creation of the ManhattanRochester Coalition stands out:

In 1944 and 1945, two periodicals with very different audiences published similar images. Both showed half-human, half-insect creatures, talked of the 'annihilation' of these vermin, and touted modern technology as the means to accomplish that end. One piece, a cartoon in the United States Marines' magazine Leatherneck, showed a creature labeled 'Louseous Japanicas' and said its 'breeding grounds around the Tokyo area...must be completely annihilated. A month after the cartoon appeared, the United States began mass incendiary bombings of Japanese cities, followed by the atomic blasts that leveled Hiroshima and Nagasaki (Russell, E., 1996: 1505).

The second image, according to Russell, was an illustration in a chemical industry journal that promoted perfumes to mask new insecticides such as DDT. The advertisement text led with the provocative phrase, "speaking of annihilation".

\footnotetext{
${ }^{96}$ Distancing is even engaged during execution by firing squad, where one person out of eight has a live round capability and is thus the executioner. This strategy creates an emotional distancing where each person has a social-psychological buffer of seven other potential executors, and the odds are that the executioner is another individual.
} 
The accompanying image showed three creatures with insect bodies, each with a stereotypical head representing a national enemy. The Italian creature lay on its back, an allusion to Allied victory over the Italian army. The German and Japanese creatures remained standing, as guns blasted all three with chemical clouds (Russell, 1996: 1505).

Household and agricultural chemicals were often one and the same as those for use in chemical weapons. Russell points out that,

the science and technology of pest control sometimes became the science and technology of war, and vice versa. Chemists, entomologists, and military researchers knew that chemicals toxic to one species often killed others, so they developed similar chemicals to fight human and insect enemies. They also developed similar methods of dispersing chemicals to poison both (Russell, 1996: 1509).

Shared metaphors, images, and terms (i.e. exterminate) helped support a militaryindustrial developed claim that advancement of warfare techniques would make for a better world, as these undesirable "pests" would be eliminated. For example, Monsanto "advertised that "chemical warfare defeats moths and larvae" (Russell, 1996: 1523). These arguments served the ends of industry and the military quite effectively, and scientists could find a chemical, biological or nuclear "solution" to this problem, as well as add legitimacy to their effort. "By dehumanizing enemies, animal metaphors reduced the sense of guilt about killing human beings in battle" (Russell, 1996: 1512). Dehumanization thus creates justification, and a moral distancing from the targeted victims of warfare. This moral distancing allows for annihilation with greater emotional ease, for troops and civilian supporters. According to Russell, "describing war as an exercise in control of nature helped define war as not just morally permissible, but morally necessary” to gain support for military goals (Russell, 1996: 1513). Dehumanization that creates psychological or moral distancing occurs when victims are 
"categorized as inferior or dangerous beings and identified by derogatory labels- so that they are excluded from the bonds of human empathy and protection of moral rules" (Kelman: 336). ${ }^{97}$

\section{MILITARISM, IMPERIALISM, AND EMPIRE}

One cannot recognize that deadly weapons were researched, developed, and intended for use on non-American civilians in the Manhattan-Rochester Coalition story, without recognizing the looming cloud of war, and the lingering contribution of American imperialism. Chalmers Johnson argued that, "wars and imperialism are Siamese twins joined at the hip. Each thrives off the other. They cannot be separated. Imperialism is the single-greatest cause of war, and war is the midwife of new imperialist acquisitions" (Johnson: 187). Richard Kaufman echoes Johnson, agreeing that militarism and imperialism are distinctive, and that militarism is a tool for imperialism. "Imperialism looks to increase size and territory; militarism covets more men and more money. The former is outward looking, the latter inward looking. An imperialistic nation seeks to dominate foreign peoples. A militaristic nation seeks to control its own people" (Kaufman, 171). Indeed, we see both features in the St. Louis aerosol case study, and within the larger context of the Manhattan-Rochester Coalition. Kaufman looks to sociologist Joseph Schumpeter, who examined Rome as a classic example of imperialism (through militarism). The historical scene is described vividly, whereby Rome,

\footnotetext{
97 Kelman, et al., points out that often 'neutralized' (or forgotten) victims can gain salience only by overtly complaining: by engaging in legal conflict or publicity. Regarding the deconstruction of dehumanization, Kelman recommends programs and efforts to promote social norms against dehumanization, to individualize victims wherever possible, and to be "critically alert to dehumanizing messages conveyed by ideologies that glorify and romanticize violence" (p. 336-37).
} 
...pretends to aspire to peace, but unerringly generates war, the policy of continual preparation for war, the policy of meddlesome interventionism. There was no corner of the known world where some interests were not alleged to be in danger or under actual attack. If the interests were not Roman, they were those of Rome's allies; and if Rome had no allies, then allies would be invented. When it was utterly impossible to contrive such an interest- why, then it was the national honor that had been insulted. The fight was always invested with an aura of legality. Rome was always being attacked by evilminded neighbors, always fighting for a breathing space. The whole world was pervaded by a host of enemies, and it was manifestly Rome's duty to guard against their indubitably aggressive designs. (Schumpeter ${ }^{98}$, as cited by Kaufman, 171).

Indeed, we may see Roman design in Western policy. "Since the end of World War II, American governments have offered many rationales for the bases they were collecting around the world, including containing Communism, warding off the 'domino theory', fighting 'ethnic cleansing', and preventing the spread of 'weapons of mass destruction' (Johnson: 188). Militarism is thus publicly presented or justified as moral, or at least more moral than one's (dehumanized) enemy. "The 'just war' is effectively supported by the 'moral police', just as the validity of imperial right and its legitimate functioning is supported by the necessary and continuous exercise of police power (Hardt and Negri, 2000: 37-38). "Over time, if a nation's aims become imperial, the bases form the skeleton of an empire (Johnson: 187).

Hardt and Negri drew however, a significant contrast between imperialism and empire. Imperialism is defined as "an extension of the sovereignty of the European nation-states beyond their own boundaries", whereby "all the world's territories could be parceled out and the entire world map could be coded in European colors..." (Hardt \& Negri: xii). Yet, imperialism is thus, a phenomenon of the past, replaced by a flexible, decentralized

98 Schumpeter, Joseph (1951). Imperialism and Social Classes. New York: Augustus M. Kelly, p. 66. 
apparatus of rule that is highly networked and with no traditional center of power. This new "order", which emerged from Eurocentric roots, is according to Hardt and Negri, known as empire.

Empire presents its rule not as a transitory moment in the movement of history, but as a regime with no temporal boundaries and in this sense outside of history or at the end of history...empire not only manages a territory and a population but also creates the very world it inhabits. It not only regulates human interactions but also seeks directly to rule over human nature. The object of its rule is social life in its entirety, and thus Empire presents the paradigmatic form of biopower (Hardt, et al., xv).

Rather than competing empires, Hardt and Negri envisioned a network of empire. Yet Johnson's view of a network of military bases, "vaguely legitimized through alliances and mutual security pacts" as the new "institutional form" that the new imperialism took (Johnson: 193). Johnson's view is close to Hardt and Negri's vision.

Who benefits most from this network of empire? First, in addition to political elites, career military personnel and economic elites such as defense contractors, stand to benefit greatly. "Wars... promote the growth of the military and are a great advertising medium for power and effectiveness of our weapons- and the companies that make them, which can then more easily peddle them to others" (Johnson: 214). When closely examined, evidence indicates that the military benefitted greatly from the ManhattanRochester Coalition, as they quietly controlled the actions and activity of the group. A pattern emerges of purposeful layering of deception beneath a public narrative by the Manhattan-Rochester Coalition, however. This can be seen in 1) the claimed ZnCdS study in St. Louis; 2) the claimed radium-only study in Project SUNSHINE, and 3) the 
secret spraying of radioactive dust, beads, and other radioactive materials, concurrent with publicly acknowledged studies by Dugway.

It is apparent through close examination, that the military assumed control of the Manhattan-Rochester Coalition and thus, represented the silent belly of the beast. Like their well-worn tactic of layering secrets below secrets, however, it leads one to question whether hiding under the belly of a militarized beast, is in fact, another layer of deception and raw power, in the form of an industrial behemoth. Was in fact, the military serving as a tool for economic interests in this case? One can certainly envision that military domination can and does open a door for economic exploitation, global expansion of territory, market opportunities, industrial base expansion, as well as provide to economic interests, access to resources including raw materials, and cheap labor. In this case study, one can see a plausible argument that industry could in fact, have been the secret underbelly of the Manhattan-Rochester Coalition's efforts, and it absolutely served industry's interests in many ways to quietly orchestrate from the underbelly of the beast.

Empire benefits the most powerful people within the most powerful nation-states- those entities within the military-industrial complex, and more tenuously, those in the highlevel political realm. A military-backed push by economic and political elites towards the frontiers of "free markets", ensures more growth and thus, more global power, under the vanguard of a westernized vision of "modernization" that is often ill fitting, and in all regards, insulting. "It is critically important to understand that the doctrine of globalism is a kind of intellectual sedative that lulls and distracts its Third World victims while rich 
countries cripple them, ensuring that they will never be able to challenge the imperial powers" (Johnson: 261). In combination with militarism, that constitutes a power that seemingly cannot be challenged. One could argue with some plausibility from all evidence included in this paper, that the covert targeting by the military of civilians anywhere by any given nation-state, opens up the door to the targeting of that country's own civilians with military weaponry. 


\section{CONCLUSION}

No single theory explains how organizational members systematically fail to develop a moral response or reject immoral, unethical, illegal, or harmful activities. Many good theoretical explanations have been advanced, and all present a reasonable contribution towards understanding this complex phenomenon. Indeed, it appears that a number of factors 1) inherent to bureaucracies, 2) found in group dynamics, 3) that occur through social distancing, dehumanization, states of exception, and zones of exclusion, 4) through human attributes that are commonly viewed as positive and desirable, and 5) through efforts of packaging favorable information while withholding other substantive information, organizations routinely fail to develop moral responses to its own actions. When partnered with manipulative organizational tactics that actively suppress information so that internal dissent is diffused, we can thus explain through ethical autism, why a large number of "normal" persons inside an organization engage willingly in acts that are harmful to others. When officials manipulate (through various tactics) information outflow to those outside the organization in an effort to deceive, manipulate, or impede understanding of events related to organizational activity, a social autism is engineered and constructed. Social autism blocks the ability of outsiders to determine or fully understand ethical failures, and illegal or harmful activity by an organization. Through a variety of factors previously identified by various scholars, along with mechanisms that bring about ethical and social autisms, we can understand how unethical, illegal, or harmful organizational acts can occur that involve a large number of participants, and rotation of personnel over time, without public knowledge or debate, or 
either internal or external dissent. Secrecy and mechanisms are used purposely to initiate ethical autism within the organization, and social autism external to the organization, so that the organization's goals will be met unchallenged by insiders and by outsiders in the larger arena of public discourse. Indeed, these mechanisms have been utilized to undermine responsive action in a show of internal/external control and power. Social and ethical autisms were engineered internally and externally in the case of the ManhattanRochester Coalition, so the U.S. military and economic interests could engage in nonnormative actions that benefitted them, and presumably would have been rejected by targeted populations, the general external population, and perhaps as well by internal participants.

The role of social and ethical autism was crucial to test without interruption, offensive military weapons on uninformed and misinformed civilians in St. Louis. Officials both inside the Manhattan-Rochester Coalition and within their vast and complex network, layered secrets upon secrets, to protect their goal of advancing military and industrial interests. In turn, world power and imperialism were also advanced, induced by the mechanisms that produced ethical and social autism. Thus, deceived and dehumanized civilians both home and overseas, became victims caught in the crosshairs of empire. 


\section{BIBLIOGRAPHY}

Adams, Guy and Danny Balfour (2004). Unmasking Administrative Evil. Revised Ed. New York: M.E. Sharpe.

Advisory Committee Staff (1995, February 8). Documentary Update: Fallout Data Collection. [Electronic copy obtained on June 27, 2011 through George Washington University, National Security Archives. http://www.gwu.edu.]

Advisory Committee Staff (1995, June 9). Memorandum to Members of the Advisory Committee on Human Radiation Experiments, re: Documentary Update on Project Sunshine "Body Snatching". [Electronic copy obtained on June 23, 2011 through George Washington University, National Security Archives. http://www.gwu.edu.]

Agamben, Giorgio (2005). State of Exception. Translated by Kevin Attell. Chicago: University of Chicago Press.

Allen, William and Kathleen Best. (1994, July 16). St. Louis Post Dispatch; "Spraying of Chemicals in 1953 Not Dangerous, Army Officials Assert".

Arendt, Hannah (1972). Crises of the Republic. New York: Harcourt Brace Jovanovich.

Arendt, Hannah (1994 ). Eichman in Jerusalem: A Report on the Banality of Evil. Penguin Classics.

Arendt, Hannah (1970). On Violence. Orlando: Harcourt.

Army Exposed Public to Harmful Chemicals: Cities were sprayed in study of wind dispersal. (1994, September 29). San Jose Mercury News: 13A.

Bacevich, Andrew (2002). American Empire: The Realities and Consequences of U.S. Diplomacy. Cambridge: Harvard University Press.

Barnet, Richard J. (1973). Roots of War: The Men and Institutions behind U.S. Foreign Policy. Baltimore: Penguin Books.

Beecher, Henry K. (1970). Research and the Individual: Human Studies. Boston: Little Brown.

Berdahl, Robert M. (2001, December 10). The Lawrence Legacy. Lawrence Symposium: University of South Dakota, Vermillion. [Electronic version] http://cio.chance.berkeley.edu/chancellor/sp/lawrence_legacy.htm. 
Bird, Kai and Martin J. Sherwin (2006). American Prometheus: The Triumph and Tragedy of J. Robert Oppenheimer. New York: Vintage Press.

Bok, Sissela. (1989). Secrets: On the Ethics of Concealment and Revelation. New York: Vintage Press.

Buck, Alice (1982, August). A History of the Atomic Energy Commission. Office of the Executive Secretary, History Division, U.S. Department of Energy. DOE/ES-0003

Cancer Coincidence Spurs Questioning of Army Aerosol Tests." St. Louis PostDispatch, July 25, 1995.

Carrington, Tim. (1985, May 2). Commission Urges Lawmakers to Fund Production of New Chemical Weapons. The Wall Street Journal. [Electronic edition.]

"Chemical Tests Did Not Harm Health." The New York Times, May 15, 1997.

[Electronic Edition, printed on March 24, 2011.]

“Chemical Warfare Tests by Army are Disclosed.” (1981, March 19). The New York Times. [Electronic Edition.]

Clarke, Lee (1985, June). The Origins of Nuclear Power: A Case of Institutional Conflict. Social Problems; 32, 5: 474-87.

Cole, Leonard A. (1994). Clearing the Air in Minneapolis. The Bulletin of the Atomic Scientists. November/December, 1984: 5-6.

Cole, Leonard. (1988). Clouds of Secrecy. Rowman \& Littlefield: Lanham, Maryland. Cole, Leonard (1997). The Eleventh Plague: The Politics of Biological and Chemical Warfare. New York: W.H. Freeman.

Conant, Jennet (2005). 109 East Palace: Robert Oppenheimer and the Secret City of Los Alamos. New York: Simon \& Schuster.

Davidson, Lee (1994, July 22). At Least 68 Dugway Tests Involved Radioactive Dust: Documents show Army conducted 35 more trials than previously disclosed. Deseret News. [Electronic edition.]

Davidson, Lee. (1995, February 16). Skullduggery Used to Collect Human Tissue for Fallout Tests. Deseret News. [Electronic Retrieval, May 27, 2011.]

Dewey, Will (2007). Finding Aid for the Hymer Friedell Papers. Knoxville: University of Tennessee. 
Diamond, Michael and Guy Adams (1999). "The Psychodynamics of Ethical Behavior in Organizations", American Behavioral Scientist, vol. 43, no. 2, Oct. 1999: 245-263.

Doel, Ronald E. (2003, October). Constituting the Postwar Earth Sciences: The Military's Influence on the Environmental Sciences in the USA after 1945. Social Studies of Science; 33: 635-66.

Dorsen, Norman and Stephen Gillers (1974). None of Your Business: Government Secrecy in America. New York: Penguin Books.

Downs, Peter (1998, May). Post Misleads Readers During Dioxin Litigation. The St. Louis Journalism Review; 28: 1, 8.

--------. "85,000 radioactive baby teeth. Now that we have your attention...Forgotten about for 50 years, an odd stash yields clues about aboveground nuclear tests and cancer". (2009, April 26). The Toronto Star. [Electronic edition.]

Ellsberg, Daniel (2002). Secrets: A Memoir of Vietnam and the Pentagon Papers. New York: Viking Press.

Fink, Robert M., ed. (1950). Biological Studies with Polonium, Radium, and Plutonium. New York: McGraw-Hill.

Forrestal, Dan J. (1977). Faith, Hope, \& \$5,000: The Story of Monsanto, the Trials and Triumphs of the First 75 Years. New York: Simon \& Schuster.

Foucault, Michel (1995). Discipline and Punish: The Birth of the Prison. $2^{\text {nd }}$ edition; New York: Vintage Press.

Frame, Paul (1999). "Radioluminescent Paint". Oak Ridge Associated Universities. Electronic Copy:

http://www.orau.org/ptp/collection/radioluminescent/radioluminescentinfo.htm.

Francis, E. (1994, September/October). "Conspiracy of Silence". Sierra Magazine. [Electronic version; http:..www.planetwaves,net/silnce2.html].

Geiderman, Joel Martin, MD (2002, March). "Ethics Seminars: Physician Complicity in the Holocaust: Historical Review and Reflections on Emergency Medicine in the $21^{\text {st }}$ Century, Part I"; Academic Emergency Medicine, v. 9, no. 3: 223-31.

Giroux, Henry A. (2007). The University in Chains: Confronting the MilitaryIndustrial-Academic Complex. Boulder: Paradigm Publishers.

Giroux, Henry A. (2011). Once More, With Conviction: Defending Higher Education as a Public Good. Qui Parle; 20, 1: 118-35. 
Government Accounting Office (1995, May). Information on DOE's Human Tissue Analysis Work. GAO/RCED-95-109FS.

Grover, Will. "All the Easy Experiments: A Berkeley Professor, Dirty Bombs, and the Birth of Informed Consent." Berkeley Science Review, 9: 41-45 [Electronic edition: sciencereview.berkeley.edu/articles/issue9/plutonium.pdf].

Habermas, Jurgen (1970). Toward a Rational Society: Student Protest, Science and Politics. Boston: Beacon Press.

Hamilton, J.G. (1945, January 11). Letter, re: Proposed Biochemical Program at University of California. National Security Archives; George Washington University [Electronic edition:

http://www.gwu.edu/ nsarchiv/radiation/dir/mstreet/commeet/meet2/brief2/tab_m/br2m1 gl.txt].

Hart, Michael and Antonio Negri (2000). Empire. Cambridge, MA: Harvard University Press.

Hempelmann, L.H., Los Alamos Laboratory (1945, March 15). Medical Research of Manhattan District concerned with plutonium; as cited by the Advisory Committee on Human Radiation Experiments, Final Report of the Advisory Committee, 1996. Oxford University Press.

Herken, Gregg and James David. (1994, January 11). "Doctors of Death." The New York Times. [Also included in U.S. House of Representatives, Hearing before the Subcommittee on Administrative Law and Governmental Relations of the Committee on the Judiciary; Government-Sponsored Testing on Humans. February 3, 1994]. As included in U.S. House of Representatives, Hearing before the Subcommittee on Administrative Law and Governmental Relations of the Committee on the Judiciary. Government-Sponsored Testing on Humans. February 3, 1994.

Hersh, Seymour M. (1969). Chemical \& Biological Warfare: America's Hidden Arsenal. Garden City, NY: Anchor.

Hooks, Gregory and Clayton Mosher (June, 2005). "Outrages Against Personal Dignity: Rationalizing Abuse and Torture in the War on Terror." Social Forces, 83 (4): 1627-46.

Hooks, Gregory and Gregory McLauchlan (1998). "Big Missions and Big Business: Military and Corporate Dominance of Federal Science Policy". Social Policy and the Conservative Agenda; Clarence Y.H. Lo and Michael Schwartz (eds). Blackwell: Malden, Massachusetts.

Howell Family Geneology Page [Electronic edition] http://www.jhowell.com/tng/getperson.php?personID=I129\&tree= 
James, Colin. (2002, April 15). "Day of Reckoning on Baby Bones.” The Advertiser. [Electronic edition.]

Johnson, Chalmers (2004). The Sorrows of Empire: Militarism, Secrecy, and the End of the Republic. New York: Henry Holt \& Company.

Katz, Fred Emil (2004). Confronting Evil: Two Journeys. New York: State University of New York Press.

Katz, Fred Emil (1993). Ordinary People and Extraordinary Evil. New York: State University of New York Press.

Katz, Fred E. (2009). Our Quest for Effective Living: How We Cope in Social Space- A Window to a New Science. Bloomington, IN: Authorhouse Press.

Kaufman, Richard F. (1970). The War Profiteers. Indianapolis: Bobbs-Merrill.

Kelman, Herbert C. and V. Lee Hamilton. (1989). Crimes of Obedience: Toward a Social Psychology of Authority and Responsibility. New Haven: Yale University Press.

Kistiakowsky, Vera (1989). Military Funding of University Research. Annals of the American Academy of Political and Social Science; 502: 141-54.

Kolko, Joyce and Gabriel Kolko ( 1972). The Limits of Power: The World and United States Foreign Policy, 1945-1954. New York: Harper and Row.

Krueger, Curtis. (2006, February 9). “SRI's Path: Innovation or Death”. St. Petersburg Times. [Electronic Edition].

Ladd, J., (1980). "The Quest for a Code of Professional Ethics"; AAAS Professional Ethics Project, AAAS: 154-159. Washington, D.C. (As cited in Rappert, B. (2003), "Coding Ethical Behavior: The Challenges of Biological Weapons", p. 456 in Science and Engineering Ethics; vol. 9, 4.

Leighton, Philip A., William A. Perkins, Stuart W. Grinnell, and Francis X. Webster (1965, February 24). "The Fluorescent Particle Atmospheric Tracer." Journal of Applied Meteorology, 4: 334-348).

Libby, W.F. (1947, January). Measurement of Radioactive Tracers: Particularly C14, S35, T, and Other Longer-Lived Low-Energy Activities". The Journal of Analytical Chemistry.

Libby, W.F. (1956, October 17). Current Research Findings on Radioactive Fallout. United States Atomic Energy Commission, Washington, DC. Proceedings of the National Academy of Sciences of the United States of America, 42; 12: 945-62. 
Livingood, J.J. and G. T. Seaborg (1939). Radioactive isotopes of zinc. Physical Review; 55, 5: 457-63.

Lo, Bernard. (2009). Resolving Ethical Dilemmas: A Guide for Clinicians; $4^{\text {th }}$ edition. Baltimore: Lippincott Williams \& Wilkins.

Lo, Clarence (1982, April). Theories of the State and Business Opposition to Increased Military Spending. Social Problems; 29, 4: 424-38).

Los Alamos National Laboratory. Some Staff Biographies. [Electronic edition; viewed on July 8, 2011]. http://www.lanl.gov/history/people/J_Kennedy.shtml.

Lowen, Rebecca S. (1997). Creating the Cold War University: The Transformation of Stanford. Berkeley: University of California Press.

Luedecke, A. R. (1954, December 16). Letter to the Surgeon General, Department of the Air Force, Washington 25, D.C. Attention: Brigadier General H.H. Twitchell, Director of Professional Services. Published by George Washington University, National Security Archives. [Electronic edition.]

http://www.gwu.edu/ nsarchiv/radiation/dir/mstreet/commeet/meet8/brief8/tab_f/br8fli.t $\mathrm{xt}$

McElroy, James L. (August, 1997). "Diffusion from Low-Level Urban Sources: Reexamination Using Recently Available Experimental Data". Journal of the American Meteorological Society, v. 36: 1027-1030.

McElroy, James and Pooler, Francis Jr. (1968, December). St. Louis Dispersion Study Volume II- Analysis. U.S. Department of Health, Education, and Welfare, Public Health Service. National Air Pollution Control Administration; Arlington, VA.

McGuire, Kim. (2009, October 21). "St. Louis Baby Teeth Yield New Findings on Nuclear Fallout". St. Louis Post-Dispatch.

M.D. Anderson played role in radiation testing. (1994, June 28). The Houston Chronicle. [Electronic edition.]

Milgram, Stanley (1974). Obedience to Authority: An Experimental View. New York: Harper \& Row.

Mills, C. Wright. (1940). "Situated Actions and Vocabularies of Motives". American Sociological Review, 5: 906-13.

Mills, C. Wright (2000). The Power Elite. New York: Oxford University Press.

Minneapolis Called Toxic Test Site in '53. The New York Times; June 11, 1994. [Electronic edition, printed on March 24, 2011.] 
Morrow, Ralph E. (1996). Washington University in St. Louis: A History. St. Louis: Missouri Historical Society Press.

Moss, William and Roger Eckhardt (1995). "The Human Plutonium Injection Experiments". Los Alamos Science, 23.

Moynihan, Daniel Patrick (1998). Secrecy: The American Experience. New Haven: Yale University Press.

National Research Council (NRC) (1997a). Toxicologic Assessment of the Army's Zinc Cadmium Sulfide Dispersion Tests: Answers to Commonly Asked Questions. Subcommittee on Zinc Cadmium Sulfide; Committee on Toxicology; Board on Environmental Studies and Toxicology, Commission on Life Sciences. Washington, D.C. National Academy Press.

National Research Council (NRC) (1997b). Toxicologic Assessment of the Army's Zinc Cadmium Sulfide Dispersion Tests. Subcommittee on Zinc Cadmium Sulfide; Committee on Toxicology; Board on Environmental Studies and Toxicology, Commission on Life Sciences. Washington, D.C. National Academy Press.

Nobel Prize.org. The Nobel Prize in Chemistry 1960- Willard F. Libby. [Electronic edition] http://www.nobelprize.org/nobel_prizes/chemistry/laureates/1960/libbybio.html

"1.5 Million to Aid Radiation Study: 3 Universities Get Grants from Rockefeller Fund for Health Research”. (1957, December 13). The New York Times. [Electronic edition.]

"ORNL: The First 50 Years". Oak Ridge National Laboratory Review [Electronic edition]. http://www.ornl.gov/info/ornlreview/rev25-34/net325.html (see also Oak Ridge National Laboratory Review, v. 25, 3-4).

Perlman, David. (1995, October 3). Panel Urges Damages for 'Immoral' Tests: Secret radiation trials by U.S. during the '40s. The San Francisco Chronicle. [Electronic Edition.]

Perry, Michael. (2001, June 7). Bones of Australian infants used in nuclear tests. Reuters Health Medical News. [Electronic edition].

Pilisuk, Marc (2008). Who Benefits from Global Violence and War: Uncovering a Destructive System. Series in Contemporary Psychology; Praeger Security International.

Pooler, F. Jr. (1966). "A Tracer Study of Dispersion Over a City." Journal of the Air Pollution Control Association, 16: 677-81. 
"Radiation Study in Colorado". (1962, May 15). The New York Times. [Electronic edition].

Rand Corporation. (1953, August 6). Worldwide Effects of Atomic Weapons. Report R251-AEC (Amended. US Atomic Energy Commission, Contract AT(11-1)-135; US Air Force Project RAND (Contract AF 33(038)-6413.

Ransom, Harry Howe (1970). The Intelligence Establishment. Cambridge: Harvard University Press.

Reuters (2001, June 5). Did U.S. use infant bodies to test levels of N-fallout? Deseret News. [Electronic edition.]

Richards, Bill. (1978, February 20). "Interest Conflicts Feared in Studies by Testing Labs; Conflicts Feared in Safety Research". The Washington Post. [Electronic edition].

Richards, Bill and Tom Carrington (1986, September 17). "Controversy Grows Over Pentagon's Work on Biological Agents: The Attraction of Big Money". The Wall Street Journal: 1. [Electronic edition.]

Russell, Edmund P. (1996, March). 'Speaking of Annihilation': Mobilizing for War Against Human and Insect Enemies, 1914-1945". The Journal of American History, 82; 4: $1505-1529$.

Sawyer, Jon. (1994, June 14). St. Louis Post Dispatch. "Military Sprayed Chemicals, Fungus to Test Dispersal".

Schneider, Keith. (1983b, December 17). "Secret Nuclear Research on People Comes to Light." The New York Times. [Electronic Edition.]

Schneider, Keith. (1983a, December 16). "Trying to Build Secret Weapons, U.S. Spread Radiation in 1950s." The New York Times. [Electronic Edition.]

"Scientist Dies in 'Cold Fusion' Test”. (1992, January 4). The Independent (London). [Electronic Edition].

Shanker, Thom. (2002, October 10). "Defense Department Offers Details of Toxic Tests Done in Secret." The New York Times. [Electronic edition, obtained on January 17, 2011].

Silker, W.B. (1961, February). Separation of Radioactive Zinc from Reactor Cooling Water by an Isotope Exchange Method. Analytical Chemistry; 33, 2: 233-35.

Smyth, Henry D. (1946). Atomic Energy for Military Purposes: A General Account of the Scientific Research and Technical Development that went into the making of Atomic Bombs. Princeton: Princeton University Press. 
Stapleton, Darwin H. (1993). Dilemmas of Funded Research at Case Institute and Western Reserve, 1945-1965. Science, Technology, \& Human Values; 18, 3: 303-14.

Statistical Abstract of the United States (1951). Electronic version http://www.census.gov. Obtained on May 31, 2011.

Sutherland, Edwin (1983). White Collar Crime: The Uncut Version. New Haven: Yale University Press.

Sutton, John R. (1984, May). "Organizational Autonomy and Professional Norms in Science: A Case Study of the Lawrence Livermore Laboratory." Social Studies of Science, 14; 2: 197-224.

Tabucki, Hiroko (2011, April 9). "Worries Grow as Experts Argue About Nuclear Dangers at Japan Plant." The New York Times.

--- "The Atom: A Friendly Favor". (1950, July 24). Time. [Electronic Edition: http://www.time.com/time/printout/0,8816,812797,00.html\#].

----- "The Toxicity of Cadmium." (1948, July 3). The British Medical Journal, v. 2, no. 4565: $33-34$.

Treaster, Joseph B. (1975, August 9). “Test of Lethal Gas on Unwitting G.I.'s is Confirmed". The New York Times. [Electronic edition].

Tucker, Jonathan B. (2006). War of Nerves: Chemical Warfare from World War I to AlQaeda. Random House: New York.

U.S. Army Chemical Corps (1963, February 18). Final Report No. 543-14: Summary of Investigations. Aerosol Laboratory, Metronics Associates, Palo Alto, CA. Contract No. DA 42-007-CML-543.

United States Army Chemical Corps. (1953a). Joint Quarterly Report No. 3: Behavior of Aerosol Clouds Within Cities.

United States Army Chemical Corps. (April-June 1953b). Joint Quarterly Report No. 4: Behavior of Aerosol Clouds Within Cities.

U.S. Department of Commerce, Bureau of the Census. (1950). United States Census of Housing, St. Louis, MO, Block Statistics.

U.S. Atomic Energy Commission; Division of Biology and Medicine (1954, July). Report on Project Gabriel. [Electronic edition; obtained from George Washington University; National Security Archives.] 
U.S. Atomic Energy Commission, Division of Biology and Medicine (1954, July). Report on Project Gabriel. Washington, DC.

U.S. Atomic Energy Commission (1953, May). Reports to the U.S. Atomic Energy Commission on Nuclear Power Reactor Technology. Washington, D.C. United States Government Printing Office.

U.S. Department of Energy (DOE) Openness (1995). Human Radiation Experiments: Roadmap to the Project. ACHRE Report: Introduction Endnotes. [Electronic format]; www.hss.energy.gov/healthsafety/ohre/roadmap/achre/intro.html

U.S. Department of Energy, Office of Human Radiation Experiments (1995).

OralHistories Project. [Electronic edition.] http://www.hss.energy.gov/healthsafety/ohre/roadmap/histories

U.S. Department of Energy (1995a). Introduction: The Manhattan Project: A New and Secret World of Human Experimentation. [Electronic edition.] http://www.hss.energy.gov/healthsafety/ohre/roadmap/achre/intro_3.html

U.S. Department of Energy, Office of Human Radiation Experiments (1995b). Oral Histories Project. Human Radiation Experiments: Roadmap to the Project [Electronic edition.] http://www.hss.energy.gov/healthsafety/ohre/roadmap/histories Endnotes, and Oral Histories of Biochemist William D Moss; Julie Langham Grilly; Clarence Lushbaugh; Cornelius Tobias, and Radiologist Hymer L. Friedell, MD, PhD and Henry Kohn, $\mathrm{PhD}$ [Electronic Edition]; http://www.hss.energy.gov/healthsafety/ohre/roadmap/histories

U.S. Department of Energy, DOE Openness (1995c). Human Radiation Studies: Remembering the Early Years: Oral History of Merril Eisenbud. Office of Human Radiation Experiments, May, 1995. [Electronic edition].

U.S. House of Representatives Committee on Government Operations (1994, September 28). Cold War Era Human Subject Experimentation. Washington, D.C. U.S. Government Printing Office.

U.S. House of Representatives (1994, February 3). Hearing before the Subcommittee on Administrative Law and Governmental Relations of the Committee on the Judiciary. Government-Sponsored Testing on Humans. One Hundred Third Congress, Second Session. Washington, D.C. U.S. Government Printing Office.

"U.S. Proposed Nuclear Tests on Humans in '51" (1994, July 6). San Jose Mercury News: 12A.

United States House of Representatives, Subcommittee on Administrative Law and Governmental Relations of the Committee on the Judiciary. (1994, April 11). One Hundred Third Congress, Second Session. Radiation Experiments Conducted by the 
University of Cincinnati Medical School with Department of Defense Funding. Washington, D.C. U.S. Government Printing Office.

U.S. Senate, $95^{\text {th }}$ Congress, First Session (1977). Biological Testing Involving Human Subjects by the Department of Defense; Hearings before the Subcommittee on Health and Scientific Research of the Committee on Human Resources (Includes US Army Activity in the U.S. Biological Warfare Programs). Washington, D.C. U.S. Government Printing Office.

United States Senate (1994, January 13). Human Subjects Research: Radiation Experimentation. Hearing of the Committee on Labor and Human Resources; One Hundred Third Congress, First Session. Washington, D.C. U.S. Government Printing Office.

Venkatram, et al. Proceedings of the $19^{\text {th }}$ Int. Conf. on Harmonisation within Atmospheric Dispersion Modeling for Regulatory Purposes: 20-24.

Venkatram, Akula, Jing Yuan, Tao Zhan, David Pankratz. "Comparison of Results from Three Urban Tracer Experiments". Proceedings of the $10^{\text {th }}$ International Conference on Harmonisation within Atmospheric Dispersion Modeling for Regulatory Purposes: 2024.

Wallerstein, Immanuel (2000). The Essential Wallerstein. New York: The New Press.

Walzer, Michael. (1977). Just and Unjust Wars: A Moral Argument with Historical Illustrations. New York: Basic Books.

Washington University. Department of Chemistry profile. [Viewed on July 8, 2011]; http://www.chemistry.wustl.edu/research.

Weber, Max (1978). Economy and Society: An Outline of Interpretive Sociology. Berkeley: University of California Press.

Wells, Ken (1985, March 5). "Utah Town Likes Its Nerve-Gas Bombs because they Help the Local Economy. The Wall Street Journal: 22. [Electronic edition.]

Welsome, Eileen (1999). The Plutonium Files: America's Secret Medical Experiments in the Cold War. New York: Random House.

Willis, Jay C. (1979, June 1). Report on The History of Fallout Prediction. Prepared for NE 6.99 Special Study (Fallout Modeling). School of Engineering, Air Force Institute of Technology, Ohio: Wright Patterson Air Force Base.

Zerubavel, Eviatar (2006). The Elephant in the Room: Silence and Denial in Everyday Life. New York: Oxford University Press. 
Zussman, Robert. "Sociological Perspectives on Medical Ethics and Decision Making", Annual Review of Sociology, 1997, v. 23: 171-89. 


\section{APPENDIX A}

\section{AFTERWORD}

This piece is an extension of my Master's thesis, which focused on the chemical weapon Agent Orange, and what I believe was the improper and reckless disposal of that agent all over eastern Missouri. Initially, I believed that the spraying of zinc-cadmium-sulfide in St. Louis to be an issue of a hazardous toxin being sprayed without consent. I had no inkling whatsoever that the St. Louis aerosol study might be related to a vast project undertaken by a clandestine group of Manhattan Project scientists developing the most sinister weapons of war in the form of radionuclide materials such as radioactive dust, beads, pellets, and smoke.

There came a brief period of time when I felt overwhelmed by some of the revelations related to the human-subject tests, and was not sure if I had the fortitude to continue this project. I felt physically ill as I read about how radioactive oatmeal was fed to institutionalized children (and moreover, sponsored by Quaker Oats); stolen cadavers including infants; radioactive injections into ill and/or pregnant patients without their consent or knowledge, etc. The blatant and cavalier targeting of vulnerable populations by some of the nation's top scientists and physicians, backed by the U.S. military, was a chilling and gross violation of human rights.

Ultimately revealed, was a complex network in a vast military-industrial-scientific machine of war, encircled with deception and manipulations to maintain secrecy and allow continuance of their quest for an unrivaled global empire. This required dehumanization of certain groups, lying by omission, layering of secrets, internal and external controls of information, threat, engaging particular qualities in individuals that aligned with the group's goals, and the quashing of dissent, inside and out. Secrecy, rhetoric, and other machinations were purposely used to undermine 
responsive actions inside the organization, and outside in the larger arena of public discourse. This is absolutely connected to power, and there was no existing theory that I could find to explain the types and levels of manipulation used internally and externally by the elites involved in the coalition, to avoid internal dissent and public opposition. The large support staff who completed the daily tasks at the behest of the Manhattan-Rochester Coalition elites, who themselves appear to have engaged in outright criminal actions, may not even have been aware of the larger project in which they participated. The "thousand people below" those elite decisionmakers were likely ordinary, patriotic, and moral in other spheres of their lives. Indeed, we would consider most of them to be good citizens and members of the community, and fine family members. When the thousand people below contributed to the Manhattan-Rochester Coalition's wide-scale projects, such as SUNSHINE, many of them likely did not have an ethical sense, in that it had been purposely disengaged through the elite's use of mechanisms (described herein) to create ethical autism. In this way, educated, moral, and ethical individuals below the top decision makers (who bear much of the legacy and responsibility here), were induced to contribute to unethical, harmful, and/or criminal actions in which they might never ordinarily play a part, given full knowledge of the project. As well, the general public and the targeted vulnerable populations were also disengaged from critical analysis through social autism, which was also induced through the use of the mechanisms described in this study. 

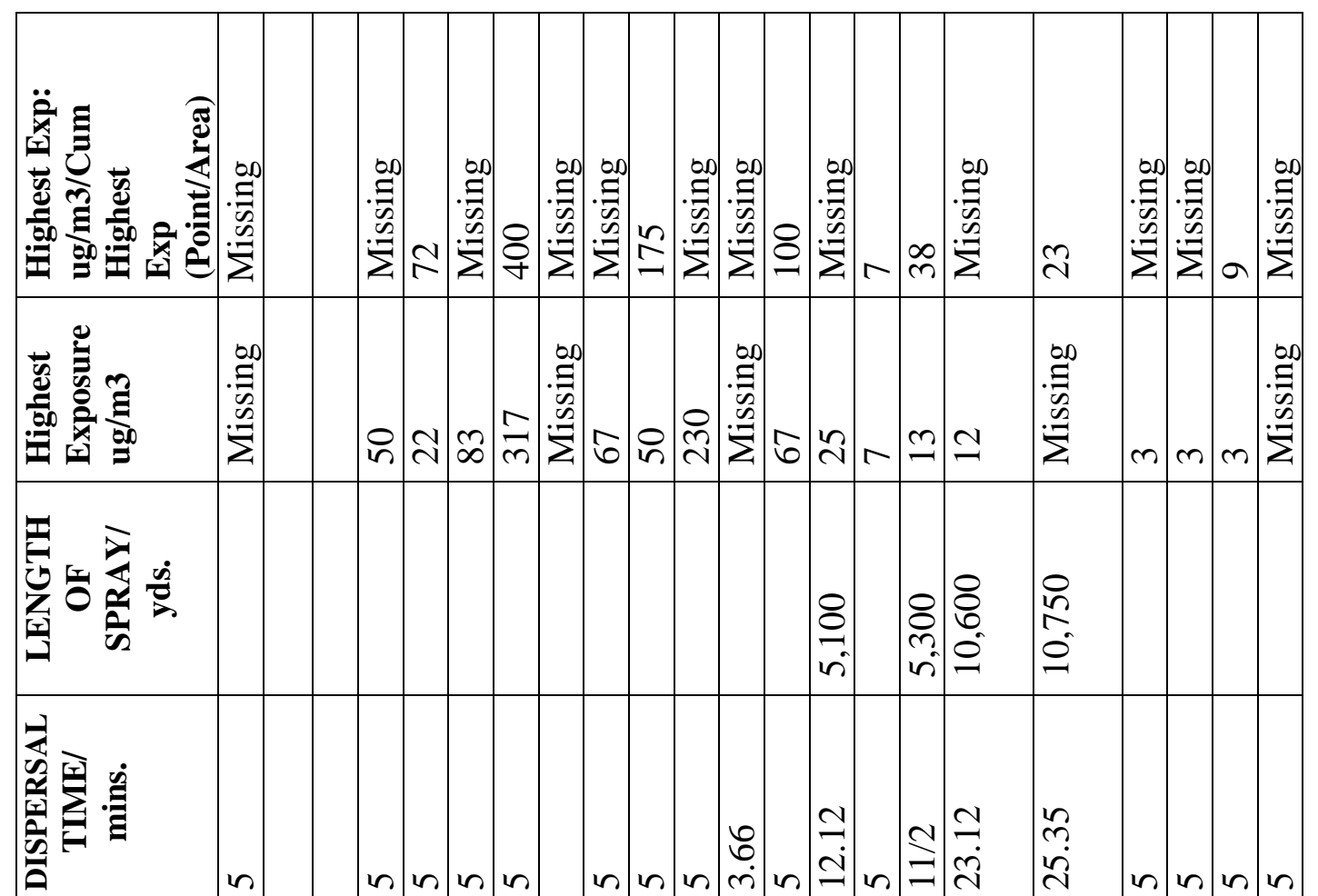

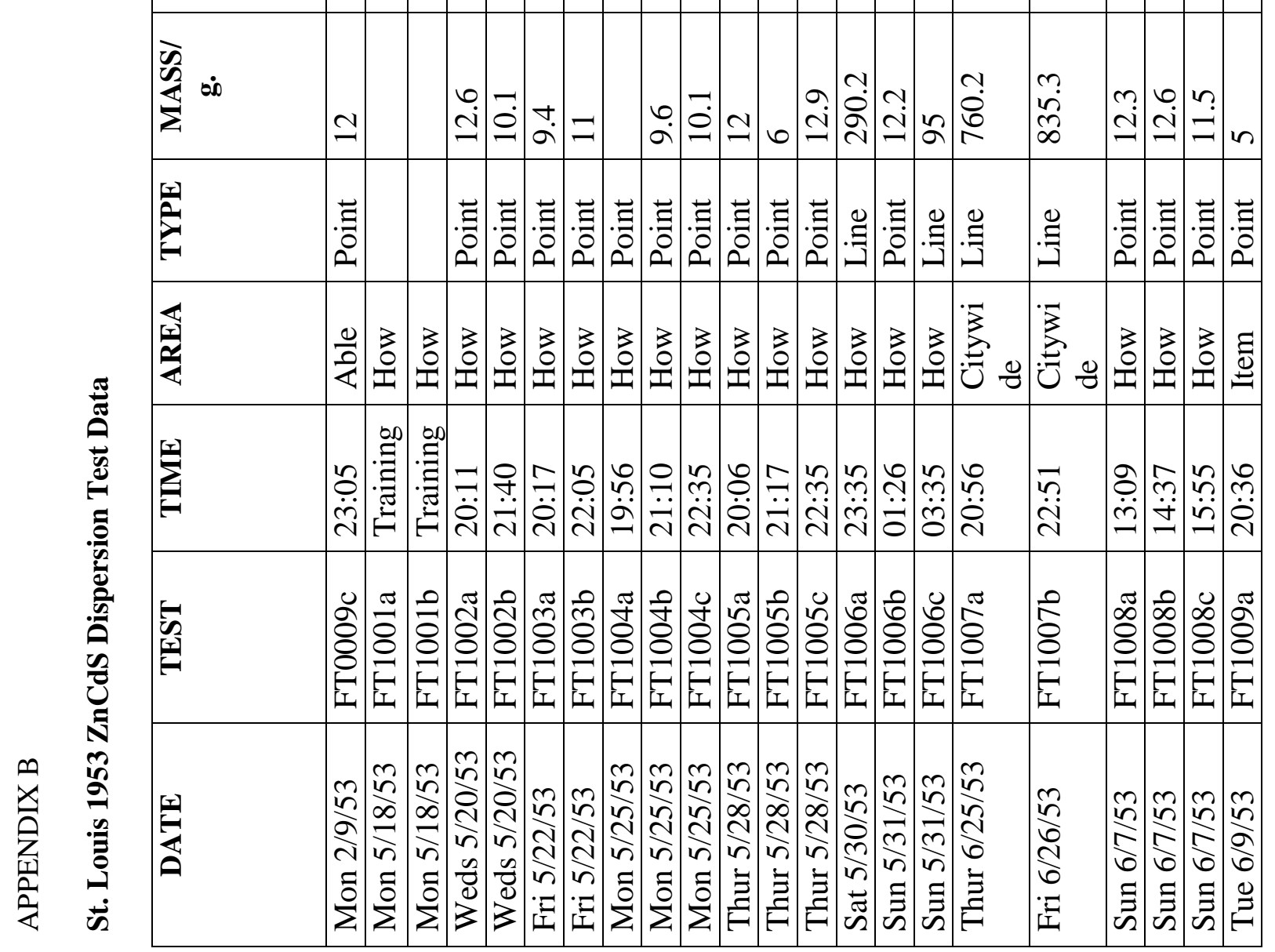




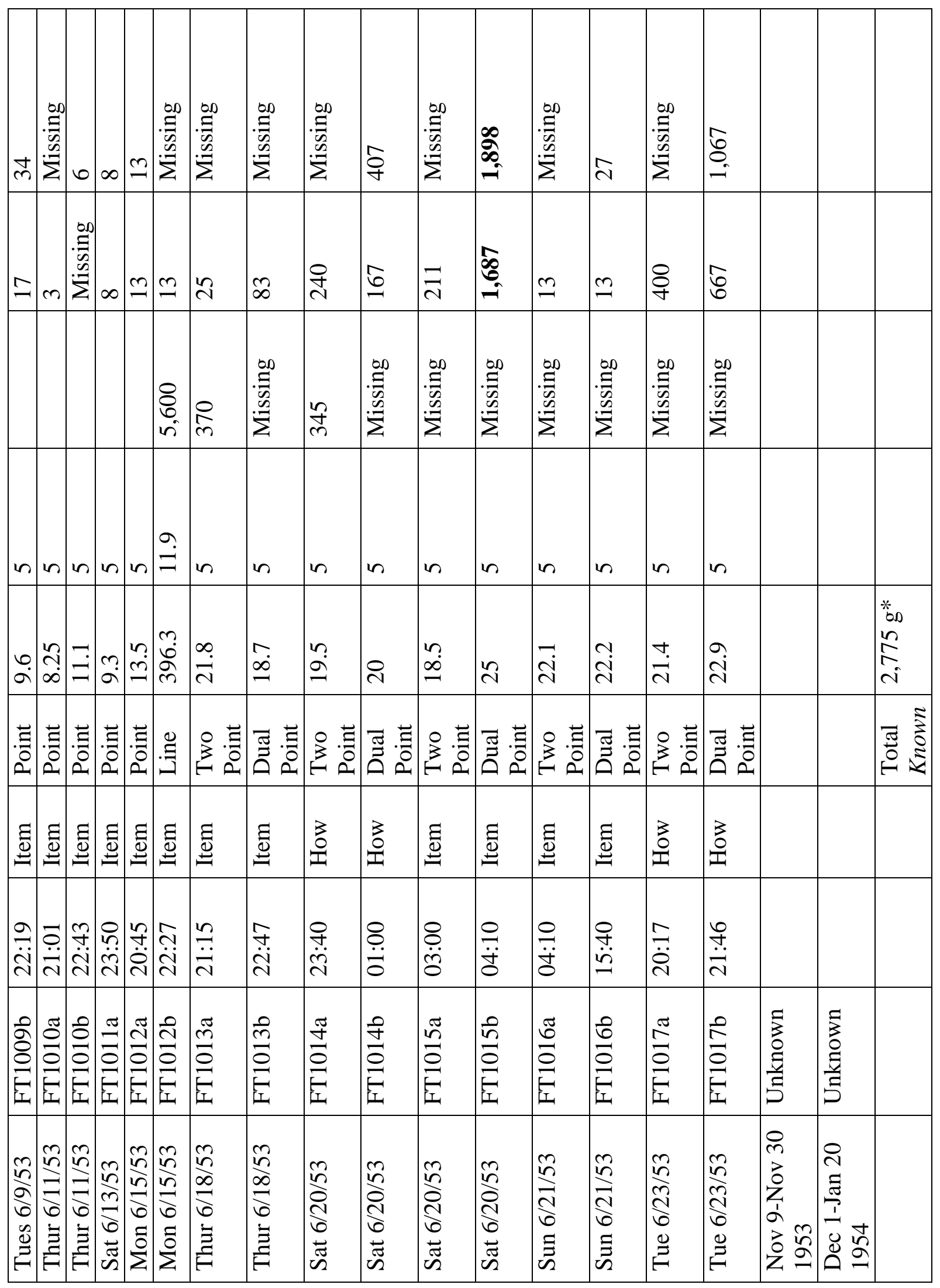




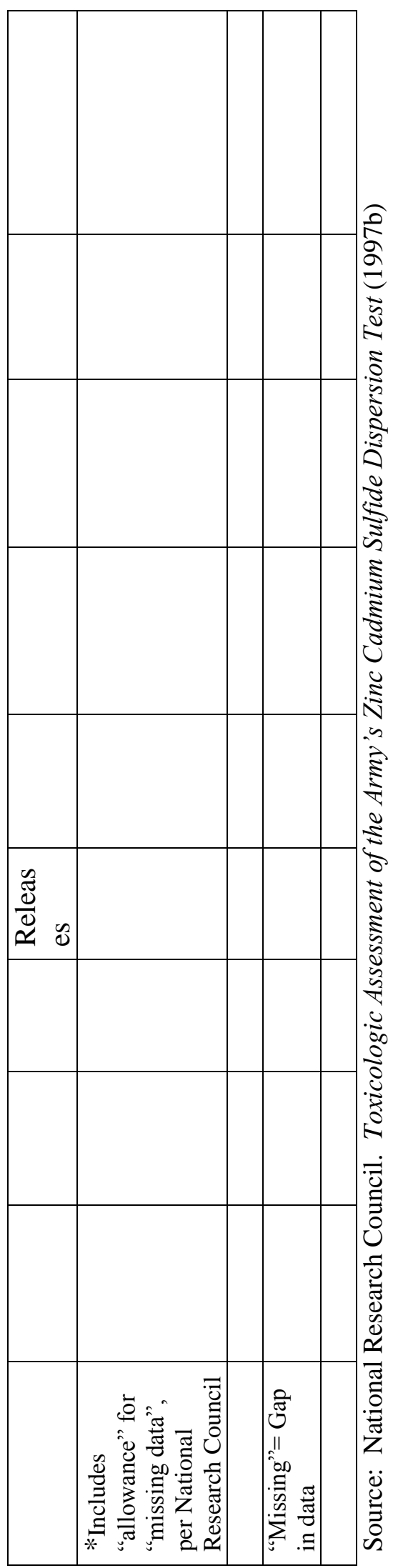


APPENDIX C

PENETRATION OF BUILDINGS IN ST. LOUIS (MAY-JUNE 1953)

\begin{tabular}{|l|l|l|l|l|l|}
\hline & & RELATIVE & DOSES & & \\
\hline $\begin{array}{l}\text { HEIGHT } \\
\text { RANGE } \\
\text { (ft) }\end{array}$ & $\begin{array}{l}\text { NO. OF } \\
\text { SAMPLES }\end{array}$ & MEDIAN \% & $\begin{array}{l}\text { INTERQUARTILE } \\
\text { RANGE \% }\end{array}$ & $\begin{array}{l}\text { EXTREME } \\
\text { RANGE \% }\end{array}$ & \\
\hline Basement & 53 & 33 & $14-100$ & $0-1,800$ & \\
\hline $6-50$ & 26 & 42 & $16-100$ & $1-1,250$ & \\
\hline $51-100$ & 37 & 45 & $16-78$ & $0-175 \%$ & \\
\hline $101-200$ & 26 & 26 & $3-77$ & $0-877$ & \\
\hline GROSS & 142 & 34 & $13-93$ & $0-1,800$ & \\
\hline
\end{tabular}

Source: National Research Council; Toxicologic Assessment of the Army's Zinc Cadmium Sulfide Dispersion Tests. (1997b: 277).

The National Research Council qualifies the building penetration information with the following addendums: "No complete summary of all the tests performed...is available, and the results of some tests were not reported anywhere...critical pages...are missing... so that certain details (particularly the amounts of material released) are not available for some tests". As well, "individual digits of some of the numbers might be incorrect, because of unreadable script in the available reports" (National Research Council, 1997b: 278.) "Some required pages of the available documents were not reproduced in their entirety in the available copies"..."exposures are primarily estimates based on contours visible on the fold-out pages for... St. Louis" (National Research Council, 1997b: 279). 


\section{APPENDIX D}

SYNOPSIS OF FINDINGS OF GAO'S DOE'S HUMAN TISSUE ANALYSIS (As prepared for Senator John Glenn, Committee on Governmental Affairs, May 24, 1995 by the US General Accounting Office). The following represents AEC-sponsored human tissue tests only; all are related to the testing and effects of radioactive isotopes in the human body. The information was compiled by the GAO from May, 1994 to March, 1995.

\section{1) PROJECT SUNSHINE-Strontium 90 in Man (Based on World-wide sampling)}

Description: Festuses, single bone samples, and whole medical skeletons of subjects who had been autopsied were procured from medical scientists worldwide. The study's objective was to determine the strontium-90 content in humans.

\section{DURATION OF STUDY: $1950 \mathrm{~s}$}

PERFORMING ORGANIZATIONS: Primarily 17 stations worldwide, including New York City, Boston, Houston, and Denver.

NUMBER OF SUBJECTS: 9,000 samples of human bone were procured, including fetuses, single bone samples from individuals of all ages, and whole skeletons. Samples from 584 whole fetuses were collected between 1954 and 1959.

\section{2) LOS ALAMOS GENERAL POPULATION STUDY}

Description: Tissue was obtained during autopsies performed at various hospitals throughout the country, and were tested for plutonium levels.

DURATION OF STUDY: 1959 to 1985

PERFORMING ORGANIZATIONS: Los Alamos National Laboratory

NUMBER OF SUBJECTS: 1,712

\section{3) THYROID COLLECTION PROGRAM}

Description: Thyroid glands were obtained at autopsies nationwide and sent to Oak Ridge for analysis. The study's objective was to measure radioactive iodine introduced in the body.

DURATION OF STUDY: 1954 to 1958

PERFORMING ORGANIZATIONS: Oak Ridge Institute for Nuclear Studies 
NUMBER OF SUBJECTS: 1,165

4) UNITED STATES TRANSURANIUM AND URANIUM REGISTRIES Description: Analysis of tissues and whole bodies, from volunteers. Some tissue solutions and related materials are stored for future study in a national tissue repository.

DURATION OF STUDY: 1968 to present.

PERFORMING ORGANIZATIONS: Washington State University

NUMBER OF SUBJECTS: 726-383 living and 343 deceased

\section{5) TRACE ELEMENTS IN HUMAN TISSUE}

Description: Tissues and organ were collected from autopsy subjects within Africa, the Near and Far East, Switzerland, and the United States. The U.S. cities participating in the study included San Francisco, Cal.; Denver, Colorado; Miami, Florida; Atlanta, GA; Baltimore, MD; Dallas, TX;

Richmond, VA; Seattle, WA; Tacoma, WA. The study's objective was to determine the chemical element content of many tissues and organs from members of the general population.

DURATION OF STUDY: 1950s to 1970s

PERFORMING ORGANIZATIONS: University of Tennessee and Oak Ridge National Labs

NUMBER OF SUBJECTS: 450

6) TISSUE SAMPLING FOR PLUTONIUM THROUGH AN AUTOPSY PROGRAM (HANFORD).

Description: Researchers obtained various tissue samples at autopsy from deceased persons from two groups: those who had resided locally or some distance from Hanford (344 people), and those who were employed at the Hanford facility, and may have been exposed to plutonium at work (77 people).

DURATION OF STUDY: 1949 to 1975

PERFORMING ORGANIZATIONS: Hanford Site, Richland, Washington NUMBER OF SUBJECTS: 421 


\section{7) ARGONNE RADIUM STUDY}

Description: Tissue was obtained from living and deceased persons who were exposed to radium, either through the workplace or purposely.

DURATION OF STUDY: Mid 1940s to early 1990s

PERFORMING ORGANIZATIONS: Argonne National Labs

NUMBER OF SUBJECTS: 293

\section{8) LOS ALAMOS STUDY OF OCCUPATIONALLY-EXPOSED WORKERS}

Description: Tissue was taken from former lab workers during autopsies performed at local hospitals and sent to Los Alamos National Lab.

DURATION OF STUDY: 1959 to 1978

PERFORMING ORGANIZATIONS: Los Alamos National Laboratory

NUMBER OF SUBJECTS: Approximately 254

\section{9) LUNG CANCER IN URANIUM MINERS: PILOT INVESTIGATION}

Description: Lung tissues taken from people through biopsies of uranium miners and from the general population; samples were analyzed and stored for future study.

DURATION OF STUDY: 1991 to 1995

PERFORMING ORGANIZATIONS: New Mexico Tumor Registry, Cancer Research and Treatment Center, Albuquerque, NM.

NUMBER OF SUBJECTS: 150

10) EVALUATION OF RESIDUAL RADIOACTIVITY IN HUMAN TISSUE ASSOCIATED WITH WEAPONS TESTING AT THE NEVADA TEST SITE

Description: The University of Utah obtained tissues at autopsy or surgery from 44 subjects in northern Utah and 31 subjects in southern Utah.

DURATION OF STUDY: 1981 to 1986

PERFORMING ORGANIZATIONS: University of Utah (funded by the Defense Nuclear Agency through DOE). 
NUMBER OF SUBJECTS: 115

\section{1) REVIEW OF PATIENTS WITH CANCER OF THE OVARY}

Description: Tissue samples were obtained from ovarian cancer patients, who was given radioisotopes.

DURATION OF STUDY: 1950 to 1961

PERFORMING ORGANIZATIONS: ORINS

NUMBER OF SUBJECTS: 95 women, 65 received a radioisotope.

12) STUDY OF BONE MARROW FIBROSIS IN CERTAIN PATIENTS

Description: Specimens of bone marrow were obtained at autopsy from patients with bone marrow disorders who were admitted to ORINS hospital during the study period.

DURATION OF STUDY: 1950 to 1967

PERFORMING ORGANIZATIONS: ORINS

NUMBER OF SUBJECTS: 90

\section{3) TESTICULAR IRRADIATION OF INMATES AT OREGON STATE} PRISON

Description: Tissue samples were obtained from prisoners who were subjected to testicular irradiation by x-rays. Each test subject agreed to have a vasectomy post irradiation.

DURATION OF STUDY: 1963 to 1971

PERFORMING ORGANIZATIONS: Pacific Northwest Research Foundation NUMBER OF SUBJECTS: 67

\section{4) TESTICULAR IRRADIATION OF INMATES AT WASHINGTON STATE PRISON}

Description: Tissue samples were obtained from prisoners who were subjected to testicular irradiation by x-rays. The study was reportedly proposed after a radiation accident at DOE's Hanford facility. 
DURATION OF STUDY: 1963 to 1970

PERFORMING ORGANIZATIONS: University of Washington

NUMBER OF SUBJECTS: 64

\section{5) PROJECT GABRIEL}

Description: The bodies of stillborn babies were cremated and the amount of strontium-90 in their remains was measured. Two adult legs were also analyzed during this study.

DURATION OF STUDY: Early to mid-1950s

PERFORMING ORGANIZATIONS: University of Chicago

NUMBER OF SUBJECTS: 59

\section{6) CHOLESTEROL METABOLISM IN CORONARY PATIENTS}

Description: The University of Chicago hospital performed autopsies on several people and later provided tissue samples to the Los Alamos National Laboratory to be analyzed for tritium.

DURATION OF STUDY: 1955

PERFORMING ORGANIZATIONS: Los Alamos National Laboratory/University of Chicago

NUMBER OF SUBJECTS: Approximately 34

17) RADIUM CONTENT OF INDIVIDUALS (ADULTS AND STILLBORN INFANTS) WITH NO KNOWN OCCUPATIONAL EXPOSURE

Description: Radium analyses were made on the bodies of adults and stillborn babies. The bodies were, for the most part, embalmed and had been used for instruction purposes in an anatomy course. Note: Stillborn infants had an "appreciable concentration of radium in their body ash."

DURATION OF STUDY: Approximately 1950

PERFORMING ORGANIZATIONS: University of Rochester

NUMBER OF SUBJECTS: 25 adults and 6 stillborn infants 


\section{8) NONREGISTRY URANIUM WORKERS}

Description: Tissue samples were obtained at autopsies from employees at the Fernald Plant whose deaths were unrelated to their occupations and from subjects not employed at the plant who died at a neighboring hospital.

DURATION OF STUDY: 1956 to mid-1960s

PERFORMING ORGANIZATIONS: Feed Materials Production Center, Fernald, Ohio

NUMBER OF SUBJECTS: 22

19) PLUTONIUM INJECTION CASES

Description: Tissue samples were obtained through biopsy or autopsy from hospital patients who had been injected with plutonium.

DURATION OF STUDY: 1945 to 1947

PERFORMING ORGANIZATIONS: Los Alamos National Laboratory; Manhattan Engineer District Hospital, Oak Ridge, Tennessee; the University of Rochester; the University of Chicago; and the University of California.

NUMBER OF SUBJECTS: 18 (at least 10 were biopsied or autopsied).

\section{0) ABORTED FETUS STUDY}

Description: Aborted fetuses from 22 weeks old to 26 weeks old —obtained from the University of Kansas Medical Center-were analyzed for plutonium, americium, uranium, and thorium. The analyzed tissue parts included the fetal head, body, placenta, and cord. ${ }^{99}$

DURATION OF STUDY: 1982

PERFORMING ORGANIZATIONS: Los Alamos National Laboratory

NUMBER OF SUBJECTS: 17

\section{1) SODIUM-24 CHROMATE USED TO MEASURE RED CELL SURVIVAL TIMES IN SUBJECTS WITH LIVER DISEASES}

Description: Tissue was obtained through biopsy of patients with liver disease who were administered sodium-24.

\footnotetext{
99 The rationale for obtaining the fetuses was that "the women had signed abortion consent forms, which automatically transferred custody of the aborted bodies (including the placenta, cord, and other parts), to the hospital, whereby the parts were transferred or sold to Los Alamos. Also note that some of the aborted fetus studies involved injection of the mother with radionuclides to measure placenta barrier rate to the festus.
} 
DURATION OF STUDY: 1953

PERFORMING ORGANIZATIONS: Argonne Cancer Research Hospital

NUMBER OF SUBJECTS: 15

22) AUTOPSY STUDIES OF DISTRIBUTION OF GALLIUM-72.

Description: Tissue samples were obtained at autopsy from subjects given therapeutic or tracer doses of gallium-72.

DURATION OF STUDY: 1950 to 1953

PERFORMING ORGANIZATIONS: ORINS

NUMBER OF SUBJECTS: 14

23) RADIUM-226 AND LEAD-210 IN HUMAN TEETH AND BONES

Description: Bone and tooth materials were extracted from a group of bodies donated for anatomical study; the subjects ranged in ages from 40 to 90 years with a median age of 63 .

DURATION OF STUDY: mid-1960s

PERFORMING ORGANIZATIONS: University of Rochester

NUMBER OF SUBJECTS: 13

\section{4) STRONTIUM AND CALCIUM INJECTED IN TERMINAL CANCER}

PATIENTS

Description: Tissue was obtained from terminal cancer patients who had been injected with radioactive strontium or calcium. The patients were chosen because they could be autopsied "fairly soon after injection". Patients ranged in age from 49 to 72 .

DURATION OF STUDY: $1950 \mathrm{~s}$ 
PERFORMING ORGANIZATIONS: Columbia University and Montefiore HospitalNew York

NUMBER OF SUBJECTS: 12

\section{5) LUNG AND ABDOMINAL INJECTION OF RADIOACTIVE GOLD}

Description: Tissue was obtained at autopsy from patients with tumors who had been injected with radioactive gold.

DURATION OF STUDY: Early 1950s

PERFORMING ORGANIZATIONS: ORINS

NUMBER OF SUBJECTS: 12

26) INECTIONS IN PATIENTS FOLLOWING TOTAL-BODY IRRADIATION

Description: Tissue was obtained at autopsy from patients who had received high doses of radiation to the whole body.

DURATION OF STUDY: Early 1960s

PERFORMING ORGANIZATIONS: ORINS

NUMBER OF SUBJECTS: 12

\section{7) ARSENIC-76 BIODISTRIBUTION AND EXCRETION STUDIES}

Description: Tissue was obtained through either biopsy or autopsy from patients with various type of cancers who had been injected with radioactive arsenic.

DURATION OF STUDY: 1947

PERFORMING ORGANIZATIONS: Argonne National Laboratory NUMBER OF SUBJECTS: 12

28) BOSTON-OAK RIDGE INTRAVENOUS INJECTIONS 
Description: Tissue was obtained from patients with terminal brain tumors who had been injected with uranium. Using terminal subjects provided the "advantage", according to one scientific paper, that the distribution of uranium in the body could be determined after autopsy.

DURATION OF STUDY: 1953 to 1957

PERFORMING ORGANIZATIONS: Massachusetts General Hospital (injections performed) and Oak Ridge National Laboratory (uranium solution prepared and tissue analyzed.)

NUMBER OF SUBJECTS: 11

29) PATHOLOGIC CHANGES IN NORMAL HUMAN THYROID TISSUE FOLLOWING LARGE DOSES OF IODINE-131

Description: Thyroid tissue was obtained from patients who had received large doses of radioactive iodine-131.

DURATION OF STUDY: 1950 to 1953

PERFORMING ORGANIZATIONS: ORINS

NUMBER OF SUBJECTS: 10

30) DEVELOPMENT OF IODINE-131 LABELED FLUORESCEIN AS A BRAIN TUMOR IMAGING AGENT

Description: Tissue was obtained through either biopsy or autopsy from patients suspected of having brain tumors who had been injected with fluorescein, a radioisotope.

DURATION OF STUDY: 1960

PERFORMING ORGANIZATIONS: Argonne Cancer Research Hospital

NUMBER OF SUBJECTS: 10

31) MOLECULAR MECHANISMS IN RADIATION-INDUCED BREAST CANCER

Description: Tissue was removed during breast reduction surgery on "certain patients".

DURATION OF STUDY: 1993 to 1994 
PERFORMING ORGANIZATIONS: University of Texas, Galveston

NUMBER OF SUBJECTS: 10

32) STUDY OF THE ORIGIN OF STERIOD HORMONES USING TRITIUM AND CARBON-14 LABELED COMPOUNDS

Description: Tissue was obtained through surgery from patients who were to have their adrenal glands removed or were scheduled to have a therapeutic abortion. Aborted fetuses, removed adrenal glands, and other biopsy tissue samples were analyzed. The patients were administered a radioactive tritium compound before surgery and a carbon-labeled compound during surgery.

DURATION OF STUDY: 1955

PERFORMING ORGANIZATIONS: Argonne Cancer Research Hospital and Los Alamos National Laboratory

NUMBER OF SUBJECTS: 7

\section{3) LOS ALAMOS NATIONAL LABORATORY CORONERS' CASES}

Description: Tissue was obtained at autopsy from various subjects who had been declared coroners' cases. The coroner's "ultimate objective was to determine whether the subject's exposure to radioactivity was sufficient to have contributed to the cause of death".

DURATION OF STUDY: 1973 to approximately 1985

PERFORMING ORGANIZATIONS: Los Alamos National Laboratory

NUMBER OF SUBJECTS: At least 5.

\section{4) UTAH STRONTIUM-85 METABOLISM STUDY}

Description: Tissue was obtained through biopsy or autopsy on patients who had been injected with strontium- 85 . The study's objective was to study the uptake, retention, and excretion of strontium- 85 in humans.

DURATION OF STUDY: 1956

PERFORMING ORGANIZATIONS: University of Utah Radiobiology 
NUMBER OF SUBJECTS: 5

\section{5) UPTAKE OF TRITIATED THYMIDINE BY TUMORS IN CANCER PATIENTS}

Description: Tissue was obtained from four cancer patients scheduled for surgery who had been given radioactive tritiated thymidine.

DURATION OF STUDY: 1962

PERFORMING ORGANIZATIONS: Northwestern University Medical School;

Veterans Administration Research Hospital; and Argonne National Laboratory

NUMBER OF SUBJECTS: 4

\section{6) DISTRIBUTION OF THOROTRAST IN THE BODY}

Description: Tissue was obtained at autopsy from patients who had been injected with thorotrast, a naturally occurring radioactive material used for medical diagnosis.

DURATION OF STUDY: 1950 s

PERFORMING ORGANIZATIONS: University of Rochester and the US Naval Hospital-Bethesda, MD

NUMBER OF SUBJECTS: 4

37) STUDIES OF THE DISTRIBUTION OF RADIOLABLED LEWISTE AND MUSTARD GAS ON SKIN

Description: Tissue was obtained through biopsy from subjects who had small areas of their skin exposed to two chemical-warfare gases- lewisite and mustard gas.

DURATION OF STUDY: 1947

PERFORMING ORGANIZATIONS: Crocker Radiation Laboratory, University of California at Berkeley, and the University of California Medical School in San Francisco.

NUMBER OF SUBJECTS: 4 
38) METABOLISM OF STRONTIUM-85 IN HUMAN BEINGS

Description: Tissue was obtained via autopsies from patients who had received tracer doses if strontium-85.

DURATION OF STUDY: 1955

PERFORMING ORGANIZATIONS: ORINS

NUMBER OF SUBJECTS: 4

39) STUDIES ON THE METABOLISM OF GLYCINE LABELED WITH CARBON-14

Description: Tissue was obtained at autopsy form terminally ill patients who had been injected with glycine labeled carbon-14.

DURATION OF STUDY: 1952 to 1953

PERFORMING ORGANIZATIONS: University of California-Berkeley

NUMBER OF SUBJECTS: 4

40) CARBON-14 LABELED DIGITOXIN ADMINISTRATION TO PREGNANT WOMEN TO DETERMINE FETAL DISTRIBUTION

Description: Tissue, including fetal organs, was obtained from women who had therapeutic abortions and one woman who delivered a baby having no brain. The women had been given carbon-14 labeled digitoxin, a drug used in the treatment of cardiac failure. "When the total radioactivity in the maternal and fetal body was calculated on an equivalent body weight basis, it was found that the near-term fetus had almost twice the concentration of the maternal body".

DURATION OF STUDY: mid-1950s

PERFORMING ORGANIZATIONS: Argonne Cancer Research Hospital

NUMBER OF SUBJECTS: 4

41) DISTRIBUTION OF RADIOACTIVE CHROMIC PHOSPHATE AFTER LUNG AND ABDOMINAL ADMINISTRATION 
Description: Tissue was obtained at autopsy form patients who had received medical treatment using radioactive chromic phosphate.

DURATION OF STUDY: Early 1950s

PERFORMING ORGANIZATIONS: ORINS

NUMBER OF SUBJECTS: 3

\section{2) RADIUM APPLIED TO HUMAN SKIN}

Description: Irradiated tissues were surgically removed from patients who had received thorium-X, along with electrical currents to "cause greater penetration of the skin".

DURATION OF STUDY: 1955

PERFORMING ORGANIZATIONS: New York University

NUMBER OF SUBJECTS: 3

\section{3) BLOOD LEVEL STUDIES WITH CARBON-14 DIGITOXIN}

Description: Tissue was obtained at autopsy from terminal patients who had been injected with digitoxin.

DURATION OF STUDY: mid-1950s

PERFORMING ORGANIZATIONS: Argonne Cancer Research Hospital

NUMBER OF SUBJECTS: 3

\section{4) IODINE-131 ANALYSIS IN FETAL AND MATERNAL THYROIDS}

Description: Thyroid tissue was obtained at autopsy from fetuses, stillborn babies, young infants, and mothers to analyze for Iodine-131.

DURATION OF STUDY: $\quad$ early 1960s

PERFORMING ORGANIZATIONS: Brookhaven National Laboratory, Argonne National Laboratory, Argonne Cancer Research Hospital, Donner Laboratory, University of California Medical Center, Los Alamos National Laboratory, Oak Ridge Institute for 
Nuclear Studies, New York University, University of Rochester, and Hanford Laboratories Operation.

NUMBER OF SUBJECTS: Unknown, however a mother and her full-term child both of whom died during deliver were test subjects.

\section{5) POLONIUM ADMINISTERED TO HUMANS}

Description: Tissue was obtained from a hospital patient with an incurable disease who had been injected with radioactive polonium. The subject died 6 days later and was autopsied to determine which organs absorbed the polonium.

DURATION OF STUDY: 1943 to 1947

PERFORMING ORGANIZATIONS: University of Rochester

NUMBER OF SUBJECTS: 1

\section{6) STUDY OF PLUTONIUM METAL DEPOSITS IN SKIN}

Description: The accidental deposition of plutonium metal particles in a person's finger subsequently led to the amputation of the finger at a particular institution. The finger was sent to Oak Ridge to evaluate changes in the skin.

DURATION OF STUDY: 1966

PERFORMING ORGANIZATIONS: ORISE

NUMBER OF SUBJECTS: 1

47) HUMAN SKIN DECONTAMINATION FROM RADIOACTIVE SILVER Description: Skin samples were obtained from a researcher after a selfinduced contamination.

DURATION OF STUDY: 1963

PERFORMING ORGANIZATIONS: Oak Ridge National Laboratory NUMBER OF SUBJECTS: 1 
48) PLUTONIUM CONTENT OF SEVERAL INTERNAL ORGANS FOLLOWING OCCUPATIONAL EXPOSURE (ROCKY FLATS)

Description: Various tissue samples were obtained at autopsy from a subject who had died of a heart attack at the Rocky Flats Plant, and declared a coroner's case by the County Coroner's office. One DOE report noted that Rocky Flats "asked the pathologist if we [Rocky Flats] could analyze some tissue samples for plutonium as a logical extension to the autopsy.

DURATION OF STUDY: 1967

PERFORMING ORGANIZATIONS: Rocky Flats

NUMBER OF SUBJECTS: 1

49) COMPARISON OF THE UPTAKE OF ZIRCONIUM-95 IN TUMOR AND NORMAL TISSUE

Description: Tissue was obtained following a mid-thigh amputation of the cancerous leg of a patient who had been previously injected with zirconium95 .

DURATION OF STUDY: 1946

PERFORMING ORGANIZATIONS: University of California at San Francisco, and the Crocker Radiation Laboratory, University of California, Berkeley

NUMBER OF SUBJECTS: 1

50) INJECTION OF AMERICUM-241

Description: Tissue was obtained from the amputated left thigh of a patient with malignant tumors who had been previously injected with americium-241, to determine the distribution of the radioactive isotope.

DURATION OF STUDY: 1947

PERFORMING ORGANIZATIONS: University of California at San Francisco NUMBER OF SUBJECTS: 1

51) METABOLISM OF ZINC-65 IN HUMAN LEUKEMIA 
Description: Tissue was obtained at autopsy from a patient with chronic leukemia to whom zinc-65 had been administered.

DURATION OF STUDY: 1961

PERFORMING ORGANIZATIONS: Los Alamos Scientific Laboratory

NUMBER OF SUBJECTS: 1

52) THE METABOLISM AND FATE OF TRITIATED THYMIDINE IN MAN

Description: Tissue was obtained at autopsy form a patient with a brain tumor who had been injected with radioactive tritiated thymidine.

DURATION OF STUDY: 1959

PERFORMING ORGANIZATIONS: Brookhaven National Laboratory

NUMBER OF SUBJECTS: 1

\section{3) ANALYSIS OF RADIOACTIVITY IN ANIMAL TISSUES AND HUMAN} BONE

Description: Samples of human bone obtained at surgery or autopsy from local hospitals were analytically compared with measurements of radioactivity in animals located at the Reactor Testing Station (currently the Idaho National Engineering Laboratory). The human bone samples appear to have been analyzed for two radioactive elements, strontium and yttrium.

DURATION OF STUDY: 1954 to 1955

PERFORMING ORGANIZATIONS: Idaho National Engineering Laboratory

NUMBER OF SUBJECTS: The number of subjects is unknown, however five human bone samples were used.

54) PERMEATION OF IODINE THROUGH HUMAN EPIDERMIS EXPERIMENT

Description: Skin from amputated limbs or other surgical procedure was obtained from various hospitals. The study's ultimate objective was to apply 
radioactive iodine to the human skin to evaluate the hazards caused by iodine permeation.

DURATION OF STUDY: 1968 to 1970

PERFORMING ORGANIZATIONS: Idaho National Engineering Laboratory

NUMBER OF SUBJECTS: Unknown

\section{5) DISTRIBUTION OF PHOSPHORUS-32}

Description: Tissue was obtained from patients who received phosphorus-32 to evaluate the distribution of phosphorus-32 in cancerous bone cells.

DURATION OF STUDY: 1956 to 1957

PERFORMING ORGANIZATIONS: ORINS

NUMBER OF SUBJECTS: Unknown

\section{6) UPTAKE OF RADIOIODINE IN HUMAN EMBRYOS}

Description: Embryos were analyzed from pregnant women who were scheduled for therapeutic abortion and had been given radioiodine. The study's objective was to determine the uptake of iodine-131 in human embryo thyroids.

DURATION OF STUDY: 1953

PERFORMING ORGANIZATIONS: University of Iowa

NUMBER OF SUBJECTS: Unknown

57) POSTMORTEM STUDIES OF RADIONUCLIDES IN MAN

Description: Tissues or organs were obtained at autopsy from patients who had received radionuclides. The studies' objective was to obtain information on the distribution and metabolism of radionuclides in human tissue.

DURATION OF STUDY: $\quad$ 1950s to mid-1960s

PERFORMING ORGANIZATIONS: ORINS

NUMBER OF SUBJECTS: Unknown. 
58) RADIONUCLIDE STUDIES TO DETERMINE BONE MARROW DISTRIBUTION IN MAN

Description: Tissue was obtained through either biopsy or autopsy from hospital patients and normal volunteers, including children, who had been administered radionuclides.

DURATION OF STUDY: $\quad$ early 1960s

PERFORMING ORGANIZATIONS: Donner Laboratory and the Lawrence Radiation Laboratory, University of California at Berkeley

NUMBER OF SUBJECTS: Unknown

\section{9) STUDIES ON THE INTERACTIVE EFFECTS OF A DRUG THAT INDUCES HYPERTHYROIDISM ON X-RAY IRRADIATION}

Description: Tissue was obtained at autopsy from patients with advanced cancer who could tolerate an elevated metabolic rate caused by oral doses of triliodothyronine in combination with x-rays.

\section{DURATION OF STUDY: Late 1960s}

PERFORMING ORGANIZATIONS: Argonne Cancer Research Hospital

NUMBER OF SUBJECTS: 421

Author's note: Some of the information regarding the stated objective of the study, and the results of the studies, were purposely omitted here. As argued here, those claims were often intended to misguide the public and local officials. Any results gained from these studies may be interpreted as creating the impression that the study was of value to the medical community and the American public. As well, the "duration of study" has been included here, but the dates identified in official documents may have been purposely altered to mislead the general public. The original GAO report includes information related to consent. Because consent is not of concern to this analysis, it is not included here.

\section{APPENDIX E \\ TIMELINE OF EVENTS}


June 17,1925

1944

April 10, 1945

April 26, 1945

May 14, 1945

October 1945-July 1946

1947

1947

January, 1947

March, 1947

August, 1947
Stockhusen study noting human health effects of cadmium

Sovet study notes cadmium poisoning via inhalation

The Geneva Protocol (aka Protocol for the Prohibition of the Use in War of Asphyxiating, Poisonous or Other Gases, and of Bateriological Methods of Warfare), is signed in Geneva.

Chajes, Lewin, and Pohl studies confirm cadmium toxicity

Leschke and Gadamer studies confirm cadmium toxicity

Army Medical Corps authorize Rochester to study polonium exposure on humans (Moss, et al, 196)

The first human plutonium injection occurs in Oak Ridge; three others were "approved" for Chicago, Berkeley/San Francisco, and Los Alamos by Dr. Friedell at Oak Ridge (under Langham's instruction), Hamilton, and Warren. (Moss, et al, 195)

Second human plutonium injection takes place in a 68-year old man at Billings Hospital in Chicago (Moss, et al, 197).

Third person injected with plutonium at the University of California Hospital in San Francisco (Moss, et al, 197).

Eleven patients were injected with plutonium at Strong Memorial Hospital in Rochester, NY; this included seven men and four women ranging in age from 18 years through 68 years old. The 18 -year old died approximately 1.5 years later (Moss, et al, 205).

Barrett, et al., find inhalation of cadmium fatal to humans

US Army Corps of Engineers issues internal statement that says, "It is desired that no document be released which refers to experiments with humans and might have adverse effect on public opinion or result in legal suits. Documents covering such work should be classified 'secret"' [Welsome, 1993, as cited in Congressional Hearing Government-Sponsored Testing on Humans, 1994: 250].

The Manhattan Project is officially transferred to the newly formed Atomic Energy Commission (Moss et al: 213).

The legal department of the Atomic Energy Commission acknowledges that human subject experimentation should include informed consent

The Nuremberg Code is established. US recommends that within the definition of mass destruction, the following be added: "lethal chemical and biological weapons"; Australia's response was a proposal to delete the word "lethal" in the text.* 
1950

June, 1952

August 27, 1952

1952

1953

January 15-16, 1953

January 19-Oct 18, 1953

January-March, 1953

Feb 9, 1953

March, 1953

April, 1953

May 18, 1953

May 20-July 1, 1953

July 10-Aug, 1953

Aug 18-Sept 15, 1953

Nov 9-Nov 30, 1953

Dec 1-January 20, 1954

1954

Jan 27, 1954-Feb 12, 1954

1957-1958

1960

1962
University of California researcher Joseph Hamilton proposes to the US military, inhalation experiments with radioactive iodine, and calls the study "a touch of Buchenwald".

The Wilson Army Memorandum is written which mirrors The Nuremberg Code.

Government officials/agents met with St. Louis city officials including Lawrence F. Wood, representing then-ill Mayor Darst.**

Preliminary meteorological tests taken in Minneapolis, St. Louis.

The Wilson Memorandum is published with guidelines regarding human subject military research.

Equipment check and training for $\mathrm{ZnCdS}$ Experiments- Minneapolis.

Army ZnCdS Tracer Experiments-Minneapolis.

Preparations/training for Army Aerosol tests in St. Louis.

Aerosol dispersal by Army contractors in St. Louis.

US DOD Tests Radioactive cloud studies across US; St. Louis

Army holds meetings with St. Louis city officials, and representatives from Monsanto Chemical Co., Socony-Vacuum Oil Co., Granite City Steel Corp., and the alderman of Granite City, IL.**

Training for Army contractor personnel-St. Louis.

Army Tracer Experiments-St. Louis; 54 releases (Note: may have concluded on 6/23).

Army Tracer Experiments-Minneapolis; 36 releases.

Army Tracer Experiments-Minneapolis; 36 releases.

Army Tracer Experiments-St. Louis; 27 releases.

Army Tracer Experiments-St. Louis; 60 releases.

The Wilson Memorandum is revised to include knowledge and comprehension of the study and effects on the part of the patient.

Army Tracer Experiments-Minneapolis; 36 releases.

Large area aerial study with allegedly ZnCdS from Detroit to Springfield, to Goodland, KS.

Natanson v. Kline is filed in court in Kansas, related to un-consented cobalt irradiation tests on cancer patient Irma Natanson.

US proposes that the Geneva Protocol include language that disallows field testing of $\mathrm{CB}$ weapons of mass destruction. 
May 27-Sept 18, 1963

1964

April 1-Oct 21, 1964

March 6- March 17, 1965

1966

July, 1969

Nov 25, 1969

1970

Feb 14, 1970

April, 1972

December 16, 1974

January 22, 1975

1997
Army Tracer Experiments- St. Louis; 43 experiments.

Helsinki Accords regulating human subject experiments are issued by the World Health Organization.

Army, USPHS Tracer Experiments-St. Louis, Forest Park.

Army, USPHS Tracer Experiments-St. Louis, Forest Park.

Beton, et al., calculate fatal doses of cadmium exposure by air.

United Nations urges all countries to sign on to the Geneva Protocol.

President Nixon renounces first-use of lethal and incapacitating chemicals; renounces use of lethal biological agents and weapons and "all methods of biological warfare". Biological research was restricted to "defensive measures". Nixon states he will resubmit the Geneva Protocol to the Senate for ratification.

U.S. proposes that the use of riot-control agents, napalm, tear gas, and chemical herbicides in war should be excluded from prohibition. The Netherlands and Norway respond that all CB agents including tear gas and herbicides should be banned.*

White House announces extension to Nixon's policy to include biological toxins.

U.K. and Russia sign on to the Geneva Protocol; United States Senate does NOT adopt the Geneva Protocol.

U.S. Senate approves the Geneva Protocol.

President Ford signs the Geneva Protocol.

National Research Council releases several versions of the

"Toxicological Assessment of the Army's Zinc Cadmium Sulfide

Dispersion Tests".

- Source: The Problem of Chemical and Biological Warfare, Stockholm International Peace Research Institute

** Source: National Research Council, Toxicological Assessment of the Army's Zinc Cadmium Sulfide Dispersion Tests, Final Technical Report.

Moss, William and Roger Eckhardt (1995). The Human Plutonium Injection Experiments. Los Alamos Science, 23. 
Although documents sent to this author in response to a 2011 Freedom of Information Act request to Aberdeen Proving Ground had been declassified years earlier, Aberdeen prohibits the publication of those documents. The following warning was stamped on the documents:

\section{"Reproduction of this document in whole or in part is prohibited except with permission of the issuing office."}

Furthermore, the documents are heavily redacted. The sheer number of documents provided in this FOIA response is an example of blizzarding. The titles of the documents are as follows:

U.S. Army Chemical Corps; Major Problems and Events: FY 1953 (Regraded unclassified May, 1992 by DAMD-SWC; Col. [REDACTED], Chief Chemical NBC Defense Division; 32 pages.

U.S. Army Chemical Corps; Summary of Major Events and Problems, FY 1954 (Parts One and Two). (Declassified by CBDCOM Security Classification Review Board, 24 August 95 (Part One). Document is excluded from Automatic downgrading.

United States Chemical Corps; Summary of Major Events and Problems for Fiscal Year 1955 (1955, December). Secret/Restricted/Data declassified by DNA and CBDCOM Security Classification Review Board 24 Aug 95; with the exception of SECRET/RESTRICTED Data, material is downgraded unclassified. Authority: DAMOSWC, January, 1990 signed by Document was excluded from automatic regarding. Reclassified from "SECRET" to "Unclassified"; 164 pages.

United States Chemical Corps Historical Office; Summary of Major Events and Problems for Fiscal Year 1956 (1956, November); 199 pages.

NOTE: U.S. Army Chemical Corps, Major Problems and Events, FY 1957 was requested, however FY 1967 was provided.

United States Army Chemical Corps Historical Office; Summary of Major Events and Problems: Fiscal Year 1967 (August, 1967); 186 pages.

U.S. Army Chemical Corps Historical Office; Summary of Major Events and Problems, FY 1958 (March, 1959), 201 pages. 
U.S. Army Chemical Corps; Summary of Major Events and Problems, FY 1959 (January, 1960); 192 pages. Document regarded unclassified order Army; downgraded at 12 year intervals but not automatically declassified.

U.S. Army Chemical Corps Historical Office; Summary of Major Events and Problems, FY 1960 (April, 1961); 332 pages.

U.S. Army Chemical Corps Historical Office; Summary of Major Events and Problems, FY 1961-1962 (JUNE, 1962). UNCLASSIFIED DOCUMENT; 400 pages. 


\section{VITA}

Lisa Martino-Taylor was born in Newington, Connecticut, where she spent many summer days lingering in the stacks at the local public library, until her family relocated to St. Louis, Missouri. She received her bachelor's and master's degrees in sociology at Southern Illinois University at Edwardsville. Martino-Taylor worked for over a decade as a senior paralegal involving several high-profile cases such as light cigarettes, and a large toxic-tort case involving hundreds of children who had been poisoned with heavy metals by a local Missouri company, which resulted in an historic verdict of $\$ 38.5$ million dollars for the plaintiffs. It was while working on these large lawsuits, which involved hundreds to thousands of plaintiffs, that Ms. Martino-Taylor earned both her master's and doctorate degrees in sociology. Her master's thesis, Times Beach and Beyond: The Politics and Pollution of Dioxin and Agent Orange, focused on the complex history of chemical weapons production, reckless contamination, and problematic cleanup of Missouri dioxin sites within the context of State-Corporate Crime theory. In 2007, Martino-Taylor appeared in the German Public Television documentary, Auslandsreporter, regarding chemical weapons production in the U.S. Martino-Taylor is married with two children. As a sociologist, she acknowledges that education is never an individual endeavor, and therefore recognizes the support of all family, friends, and colleagues who helped her along the long, arduous journey to Ph.D. 
APPENDIX G

\section{FOIA RESPONSE FROM DUGWAY PROVING GROUND}

Includes in part, the following documents:

Behavior of Aerosol Clouds within Cities

St. Louis Dispersion Study, Volume II- Analysis 


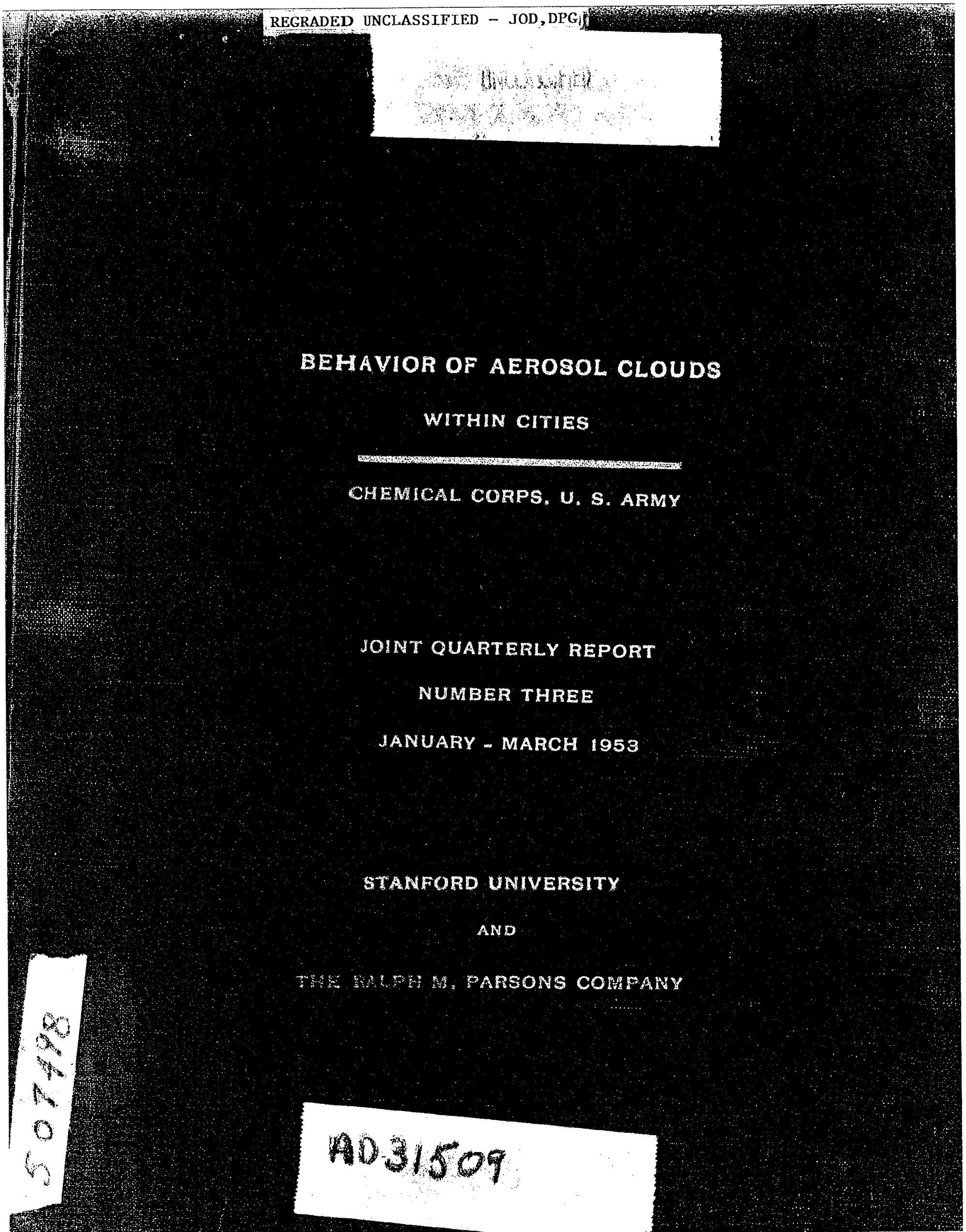




\title{
DISCLAIMER NOTICE
}

\author{
This document is \\ Best Quality Available. \\ The copy lurnished to \\ JOD DPG contains \\ a number of pages \\ which do not \\ reproduce legibly.
}


REGRADED UNCLASSIFIED - JOD, DPG
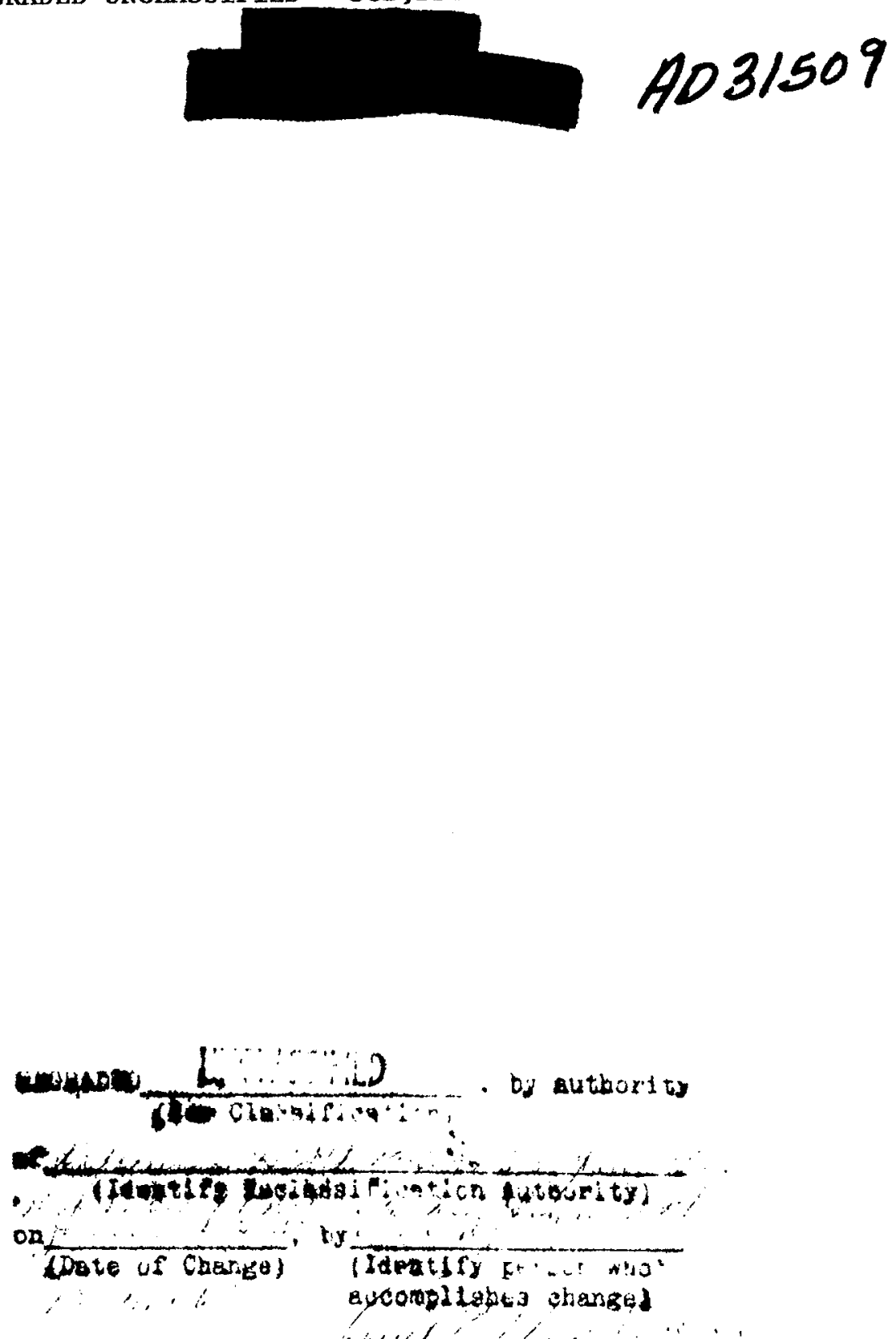

$$
\begin{aligned}
& \infty \\
& 0 \\
& 0
\end{aligned}
$$
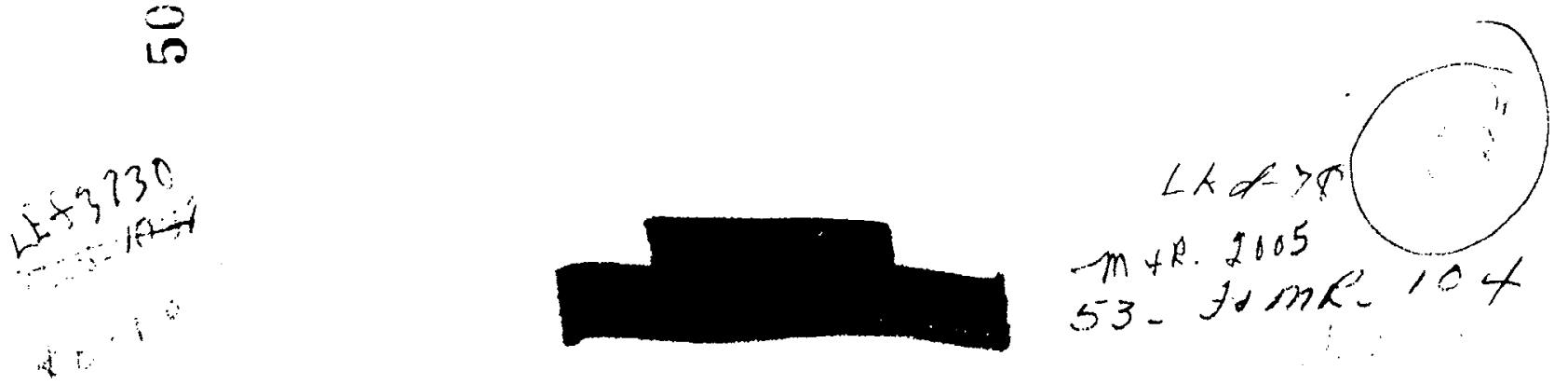
Copy 8 of $30_{2}$ Series A

This document consists of 218 pages

CHEMICAL CORPS, U. So. ARMY

BEHAVIOR OF AEROSOL CLOUDS WITHIN CITIES

Joint Quarterly Report No. 3

January - March 1953

Submitted by:
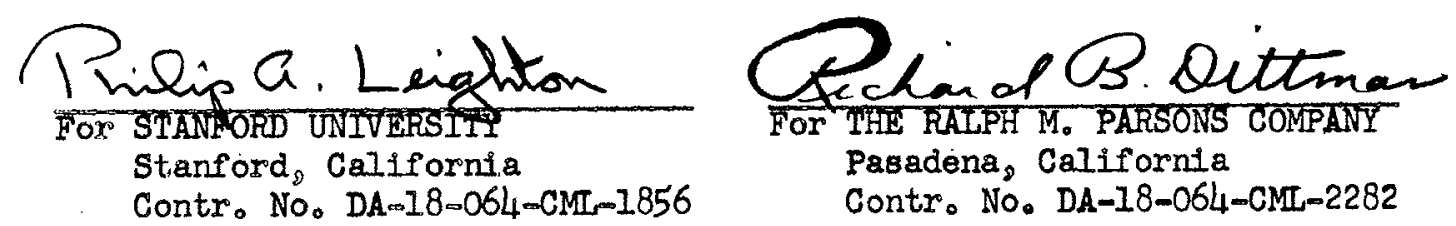

"This material contains information affecting the national defense of the United States within the meaning of the espionage laws, Title 18 , J.S.C. Sec. 793 and 794 , the transmission or revelation of wich in any manner to an unauthorized person is prohibited by law."

Page 1 
C ONTENTS

Page No.

TITLE PAGE

CONTENTS

LIST OF TABLES

LIST OF TEXTUAL ILUUSTRATIONS

I. SUMMARY

A. Operational and Administrative Progress

B. Preliminary Evaluation of Winter Program

II. FIELD OPERATIONS AND MANAGEMENT
A. Introduction
B. Administration
C. Meteorological Tests
D. Tracer Tests (Minneapolis)
E. Schieduled Operations

III. INSTRUMENTATION

A. Ceneral

B. Field Oservations on Equipment Performance

C. Portable Membrane Filter Sampler and Accessories

D. Modified Alnor Velometer, Jr. for Monitoring Battery Operated Samplers

E. Wiresonde Thermistor Air Temperature Measuring Equipment

IV. TEMPERATURE SURVEYS IN ST. LOUIS

A. C City Structure and Terrain

B. Summary of Results

C. Characteristics of Horizontal Temperature Patterns

D. Vertical Temperature Gradients

E. Selection of Site for Aerosol Cloud Studies

V. AEROSOL TRACER TESTS IN MINNEAPOLIS

A. Scope of Operations ' 118

B。 Test Site 120

C. Equipment and Procedures 122

D. Summary of Results 132

E. Preliminary Comments on Aerosol Cloud Behavior 135

APPENDIXES

A. St. Louis Surveys and Soundings 163

B. Minneapolis Winter Field Tests, Able Area 175 
II-3 Mesometeorological Surveys, St. Louis

II 4 . Summary of Data on Minneapolis Tracer Tests

IV -1

Sumnary of Data from Selected Temperature Surveys

V-3 Penetration Data Expressed in Percentages of Outside Dosages 


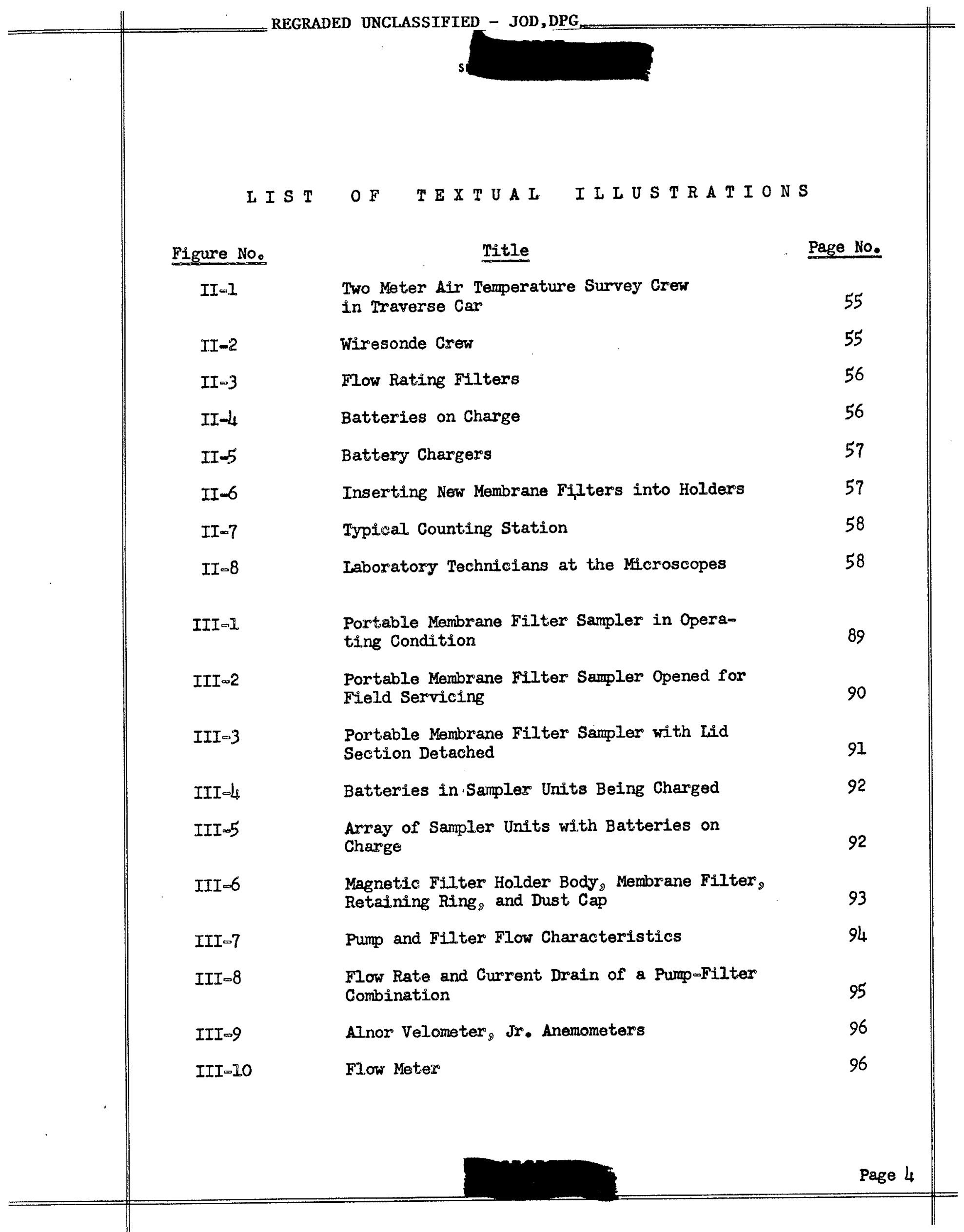


IIST OF TEXTUAL ILUUSTRATIONS (Continued)

Figure No.

III 11

$\operatorname{III} 12$

III $\square 13$

III -14

III $=15^{\circ}$

III 16

III-I7

$\operatorname{III}-18$

IV -1

VuI

$\mathrm{V}=2$

$\nabla-3$

$\nabla-4$

$\nabla \curvearrowleft 5$

$\mathrm{V}=6$

$\forall=7$

$V=8$
Title

Western Electric D-17690 Bead Type Thermistor

Protective Cage for Bead Thermistor

Simplified Schematic Wiresonde Bridge

Circuit

Wiresonde Bridge with Case Opened

Interior View of Wiresonde Bridge

Wiresonde Reel

Method of Attachment of Balloon Cord and Thermistor Cage to Wiresonde Cable

Kytoon and Reserve Helium Supply

Topographic Map, St. Loui,s

Topographic Map, Minneapolis, Able Area

Aerial Photograph, Minneapolis, Able Area

Typical Two Story Frame Residences in Able Area

Clinton Avenue School Viewed from the Southwest Quarter

Aerosol Dispersal Crew Checking Equipment Prior to a Field Test

Aerosol Dispersal Equipment in Truck as Arranged for Field Test

Typical Roof Top Iocation of Aerosol Disperser

Sampler Chained to Post, with Filter at Box Level
113

Page No.

140

InI

142

142

143

144

144 
LIST OF TEXTUAL IILUSTRATIONS (Continued)

Figure No.

$\nabla=9$

$\nabla=10$

$\mathrm{V}-11$

$\mathrm{V}-12$

$\mathrm{V}=13$

$\mathrm{V}=14$

$\mathrm{V}=15$

V..16

$\nabla=17$

$\operatorname{Vol8}$

$\nabla=19$

$\nabla=20$

$\mathrm{V}-21$
Mitle

Sampler Chained to Post, with Filter

Five Feet above Ground

145

Typical Arrangement of Sampler Location in Car

145

Typical Roof Top Sampler Location

Sampler Installation Inside Private

Residence

146

Typical Indoor Sampler Installation with Filter Exposed Outside

14 ?

Mothod of Obtaining Flow Rate of a

Filter

147

Wind Direction Unit Mounted on Field

Meteorological Station Automobile

148

Wind Direction Recording Equipment, Showing Esterline Angus Recorder in Meteorological Station Automobile

Meteorological Station on Roof of Clinton School.

Field Meteorological Team Reporting Wind Velocity and Balloon Track by Radio and Surface Temperatures

Five Selected Aerosol Tracer Tests

Average Dosage-area Relationships for Daytime Tracer Tests in Minneapolis and in Salisbury, England 
LIST OF TEXTUAL ILUUSTRATIONS (Continued)

Figure No.

$\nabla-22$

V -23

$\operatorname{Vo} 24$

$V=25$

V×26

V०27

$\mathrm{V}-28$

$\nabla-29$

$V 0.30$

$\nabla=31$
Title

Average Crosswind Integrated Dosages at Downwind Distances from Source

for Six Selected Aerosol Tracar Tests

Dosages Obtained in House A

Dosages Obtained in House $B$

Dosages Obtained in House $\mathrm{C}$

Dosages Obtained in House D

Dosages Obtained in House $\mathrm{E}$

Clinton School Sampler Array and Results FT 0008

3 February 1953

Clinton School Samplex Array and Results FT 0009

9 February 1953

Clinton School Sampler Array and Results FT 0010

$$
11+1,2 \text { February } 1953
$$

Clinton School Sampler Array and Results FT 0011
15 February 1953
Page No.

153

154

155

256

157

158

159

160

161

162 


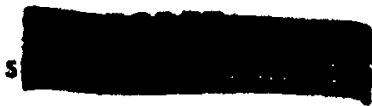

Io SUMMARY

\section{A. OPERATIONAL AND ADMINISTRATIVE PROGRESS}

1. Winter Program in St。 Louis and Minneapolis

Between January and March 1953, 18 temperature surveys, in addition to the 17 reported for the preceding quarterly period, were made in Sto Louis preparatory to selecting a provisional site for studying aerosol cloud bee havior. Though no measurements were taken of the vertical temperature gradient within the city $y_{9}$ the associated raob sounding obtained at Columbia Airport is presented with each horizontal air temperature survey described in this report。

In Minneapolis, aerosol cloud study has been started, based on the results of 61 separate releases of fluorescent tracer material in four selected areas. Complementary information was provided from measurements of the horizontal and vertical temperature gradients, the St. Cloud raob soundings, and observations reported by auxiliary field meteorological stations before and during individual tracer tests. In addition, studies were made of the penetration of the aerosol cloud into structures to determine the ratio of inside to outside dosages obtainable. Penetration data were obtained from 29 sampling units placed in houses, and from 88 units located at various levels within a school building.

2. Field and Laboratory Operating Procedures

Detailed descriptions are given of the St. Louls and Minneapolis activities, in which 15 full-time and 233 part-time employees are currently 
engaged. Considerable attention is given to procedures for conducting mesometeorological surveys, including temperature traverses, wiresonde operations, and data analysis. Tracer test operations are also detailed, including test planning, preparation of equipment, aerosol generation sampling, and filter analysis.

\section{Instrumentation}

The selfcontained, portable filter sampling unit especially developed for this project embodies a number of desirable features and characteristics which are described in the current report. Also presented is the design of a suitable flow meter for use in conjunction with the unit. The wiresonde equipment now in successful operation for obtaining vertical aix temperature profiles is discussed from the standpoint of design and field operation。 


\section{B. PRELIMINARY EVALUATION OF WINTER PROGRAM}

I. St. Louis Temperature Surveys and Aerosol Site Selection

of the 35 two-meter air temperature surveys conducted in St. Louis since the inception of the current program, four surveys are fully evaluated. From seven selected isotherm charts, and the associated raob soundings and winds-aloft data, a characteristic temperature structure has been determined. As in other cities in which comparable studies have been made, highest temperatures are found in or near the built-up area, while lower temperature readings are obtained near the large parks or undeveloped regions. The horizontal temperature gradient, however, is much flatter in St. Louis than in Minneapolis. Though a considerable horizontal gradient is generally evident to the east of the downtown district, the gradient to the west-northwest is quite weak. The reproducibility of the temperature pattern seems likely, since the same gradient was obtained under varying weather conditions. The flatness of this gradient was the factor chiefly responsible for the selection of a five-square mile test area within the west-northwest region. The area, which is densely built-up and sparsely

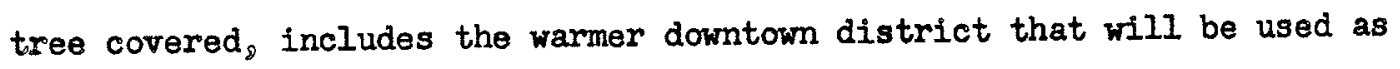
one test site and is large enough so that a number of one-square mile test sites of intermediate building density can subsequently be chosen.

\section{Aerosol Cloud Behavior in Minneapolis}

Preliminary evaluation of aerosol cloud behavior is based on results obtained from six tracer tests; comprising a total of 18 releases, which 
were conducted in Able Area. Except for one daytime operation, all tests were performed at night using a point-source operated for a five-minute period either from a vehicle or from a roof-top position.

From currently available data, three tentative conclusions may be drawn:

a. Under given meteorological conditions, street-level dosage patterns are reproducible in an essentially residential area.

b. The position of the point-source aerosol generator has little influence in the street-level dosage pattern; similar patterns are obtained when the source is located at a street intersecm tion, on a roof top, or in the middle of a block. As a result, the point-source data may be combined to estimate the dosage-area relationship, which might be obtained from multiple-potnt or line sources.

c. Of the penetration studies conducted in residences and in the Clinton School, greater dosages were obtained in the basements of houses than in the upper levels; in the school bullding, howerer, there was little difference in vertical distribution of the inside dosages. 


\section{FIELD OPERATIONS AND MANAGEMENT}

\section{A. INTRODUCTION}

Section II summarizes all field and laboratory activities for the current period for which the Ralph M. Parsons Company is primarily responsible.

Complete resumes of tracer tests conducted in Minneapolis, including related laboratory activities, and meteorological survoys conducted in Minneapolis and St. Louis are presented in tabular form.

The breakdown of tracer tests and meteorological surveys includes the manhours expended on various phases of field and laboratory operations. Methods of procurement, training, scheduling, and use of part-time help for conducting field work are presented. This Section includes such aspects. of field procedure as have been influenced by the cities and climate in which tests have been conducted and the availability and capabilities of manpower. Actual field operating procedures for conducting tracer tests are covered in Section $\nabla$. The section is concluded with a resume of test operations scheduled for completion during the balance of the contract period. 


\section{B. ADMINISTRATION}

\section{Organization}

The organization of thirteen full-time field office employees remains substantially as described in JQR 2, the only additions during the current period being a full-time typist and a full-time draftsman at Minneapolis. These two additions make a total of 15 full-time employees, with 14 at Minneapolis, and one at St. Louis.

There was considerably more activity during the current period in the parttime personnel hires and terminations. At Minneapolis the year started with 62 part-time employees, and during the following three months, some 174 new people were employed, and 55 were terminated, leaving the total number of part-time employees approximately 180 as of $31 \mathrm{March}$. As of 1 January there were 32 part-time employees at st. Louis, and during the current period 29 additional were hired with only 8 terminations, leaving a total of 53 part-time employees on the St. Louls force at the close of the quarter. The above part-time figures include personnel for the adminm istrative, meteorological, tracer, laboratory, and instrument divisions.

Table II-1 shows both full-time and part-time manhours expended for the current period, broken down by months and activities. 
TABIE II-I

FIEID OFFICE MANHOURS

\begin{tabular}{|c|c|c|c|c|c|}
\hline & & January & February & March & $\begin{array}{c}\text { Total for } \\
\text { Period }\end{array}$ \\
\hline \multirow[t]{2}{*}{ Admintstration } & Full-time & 565 & 643 & 807 & 2015 \\
\hline & Part-time & 0 & 52 & 0 & 52 \\
\hline \multirow[t]{2}{*}{ Meteorological } & Full-time & 993 & 868 & 997 & 2858 \\
\hline & Part-time & 1148 & 3280 & 4256 & 8684 \\
\hline \multirow[t]{2}{*}{ Tracer Test } & Full-time & 674 & 616 & 764 & 2054 \\
\hline & Pert-time & 1176 & 3169 & 2512 & 6857 \\
\hline \multirow[t]{2}{*}{ Laboratory } & Full-time & 64 & 410 & 365 & 839 \\
\hline & Part-time & 0 & 510 & 969 & 1479 \\
\hline \multirow[t]{2}{*}{ Instrumentation } & Full-time & 176 & 160 & 183 & 519 \\
\hline & Part-time & 0 & 249 & 290 & 539 \\
\hline \multirow[t]{3}{*}{ Totals } & Full-time & 2472 & 2697 & 3116 & 8285 \\
\hline & Part-time & 2324 & 7260 & 8027 & 17611 \\
\hline & & & & & 25896 \\
\hline
\end{tabular}

The Division Chiefs requisition part-time employees by the number and type required. The office Manager conducts the inftial interviews and effects the hiring of the part-time employees.

\section{Training}

Training of part-time personnel is undertaken by each Division. In general, the Division Chief, with the assistance of the Field Foreman, explains the 
functions and operations of the equipment, the detailed requirements for handling equipment in the field, precautions to be observed, manner of completing fleld data records, and manner of submitting time and mileage records. In the current period at $\mathrm{St}$. Louis only meteorological tests were involved, and employees engaged in this work were instructed by the Field Foreman。

\section{Facilities}

The rental space at $\mathrm{St}$. Louis and Minneapolis, as described in QQR 2, proved adequate during the current perlod. However, because of the increased space required at Minneapolis for layout of sampling equipment and assembly of personnel prior to tests, it was found necessary to install all meteorological instruments on automobiles while outside the building instead of in the garage area as had been previously planned. 4. Security

No special security measures have been instituted in connection with the St. Louis operation inasmuch as all computing and data analysis for $\mathbf{S t}$. Iouis tests are performed in Minneapolis.

The arrangement of restricted areas and the security precautions talien at Minneapolis, as described in JR 2 have proven satisfactory during the current period, and have been adequate even for the relatively large. number of part-time employees requiring access to the unrestricted portions of the building. Uncleared personnel enter restricted areas only for approved purposes and then only under the supervision of cleared 
personnel. Drafting of meteorological data, computing of meteorological data, laboratory analysis of filters, and other phases of the project work performed by uncleared personnel are performed in separate areas in order to isolate these functions. Thus idle exchange of information relative to the various phases of the project is prevented as far as is practicable。 Restricted areas are kept locked at all times and visitors requiring admittance to restricted areas are required to sign a log.

A fireproof safe with combination lock is located within the restricted area for storage of rough field data of a classified nature and other important records.

Fire protection facilities have been installed and include pump type water cans in the office area where records are located, and $\mathrm{CO}_{2}$ fire extinguishers in the shop area for protection of equipment and instruments. 


\section{METEOROLOGICAL TESTS}

\section{General}

The purpose of the mesometeorological tests conducted during the current period was to determine the horizontal and vertical temperature patterns to serve as a basis for the selection of tracer test sites in St. Louls and to obtain data required for determining the effect of these patterns on the diffusion of an aerosol cloud in Minneapolis.

In order to provide the necessary information for accomplishing the above purposes, traverse routes in both cities for two-meter air temperature surveys were designed to include the urban area, most of the residential area, and sufficient mural area to enable the establishment of characteristic patterns of any area which might possibly affect aerosol diffusion. Normally, five cars and occasionally as many as ten cars, when equipment was available, were used for the temperature traverses in Minneapolis. Normally, four circuits were made on each route. On those nights coinciding with tracer tests in Minneapolis, 5 to 12 traverses were completed. Wiresonde ascents in either one or two locations, usually one urban and one rural, were made each hour during the period of the traverse operation. Operations for the period represent a total of 4,681 hours for traverses, 964 hours for wiresondes, and 2,913 hours for data reduction.

\section{Test Data}

Table II-2 Ilsts all mesometeorological surveys conducted in Minneapolis in the current period and gives pertinent statistics on the number of 
routes, runs, wiresonde ascents, maps obtained and man-hours expended for the vartous phases of the operation. Table II-3 provides like information for St. Louis surveys.

\section{Public Relations}

The advance meetings with city officials of Minneapolis are discussed elsewhere in this Section. Meetings with city officials of St. Louis are scheduled for the purpose of completing arrangements for forthcoming mesometeorological surveys involving wiresonde operations. In both St. Louis and Minneapolis little interest has been evidenced in the operation of the traverse cars, and in Minneapolis, the removal of the two wiresonde sites from normal public traffic patterns has served to reduce public curlosity in these operations.

\section{Traverse Route Planning}

The purpose of the traverse routes is to provide a grid of air-temperature readings taken at the two-meter level which are adequate for establishing characteristic temperature patterns over the required area with a mintmum of equipment. It is necessary that the routes cover such areas of interest as urban heat islands, rural heat lows, the tracer test area in use, and any surrounding areas that may possibly affect the diffusion of an aerosol cloud.

The length of each traverse route will vary between 12 and 20 miles, depending on traffic conditions characteristic of the city, street patterns, and street conditions. In current operations in Minneapolis, routes were 
GENERAL

\begin{tabular}{|c|c|c|c|}
\hline $\begin{array}{l}\text { Survey } \\
\text { No. }\end{array}$ & $\begin{array}{l}\text { Date } \\
1953\end{array}$ & $\begin{array}{l}\text { Map } \\
\text { Times } \\
\text { CST }\end{array}$ & $\begin{array}{l}\text { Tracer } \\
\text { Test } \\
\text { No. }\end{array}$ \\
\hline 434 & $16 \mathrm{Jan}$. & $2000-2200$ & m 0002 \\
\hline M35 & $19 \mathrm{Jan}$ & $2000-2200$ & $\mathrm{~T} 0003$ \\
\hline M36 & 21 Jan. & $n$ & $\mathrm{~T} 0004$ \\
\hline M37 & 22 Jan. & $n$ & \\
\hline M38 & $26 \mathrm{Jan}$. & $n$ & ₹ 0005 \\
\hline บ39 & 27 Jan. & $n$ & \\
\hline MLO & $28 \mathrm{Jan}$. & 1 & $\mathrm{T} 0006$ \\
\hline MLI & 30 Jan. & $n$ & $\mathrm{~T} 0007$ \\
\hline ML2 & 2 Feb. & n & \\
\hline $\mathrm{ML3}$ & 3 Feb. & $2000-2300$ & $\mathrm{~T} 0008$ \\
\hline 144 & 4 Feb. & $2000-2200$ & \\
\hline$M 45$ & 5 Feb. & $n$ & \\
\hline v46 & 9 Feb. & $1900-2400$ & T 0009 \\
\hline 347 & $11 / 12 \mathrm{Feb}$. & $2200-0500$ & 10010 \\
\hline Mh8 & 13/14 Feb. & $2000-0600$ & \\
\hline M49 & $15 \mathrm{Feb}$. & $1200-1900$ & $\mathrm{~T} 0011$ \\
\hline$M 50$ & $16 \mathrm{Feb}$. & $1800-0100$ & T 0012 \\
\hline M51 & $18 \mathrm{Feb}$. & $1900-0100$ & $\mathrm{~T} 0013$ \\
\hline$M 52$ & 23 Feb. & $1900-2400$ & T 0018 \\
\hline M53 & 24. Feb. & $1900-2300$ & $\mathrm{~T} 0015$ \\
\hline M54 & $27 \mathrm{Feb}$. & $1900-2400$ & 10016 \\
\hline 455 & 3 Mar. & $\pi$ & T o014 \\
\hline M56 & 4 Mar. & n & T 0019 \\
\hline$M 57$ & $6 / 7$ Mar. & $1900-0600$ & T 0017 \\
\hline$M 58$ & 18 Mar. & $1900-2400$ & T 0020 \\
\hline 155 & 20/21 Mar. & $2100-0600$ & $\mathrm{~T} 0021$ \\
\hline n60 & 24 Mar. & $1900-0000$ & T 0022 \\
\hline
\end{tabular}

2 METER TEMPERATURE SURVEYS

$\begin{array}{lllllll}\text { No. } & \text { No. Kuns } & \text { No. } & & \text { Traverse Total } & \text { Traverse } & \text { N } \\ \text { Routes } & \text { Per } & \text { Traverse No. Car } & \text { Traverse MHrs per } & U \\ \text { Used } & \text { Route } & \text { Men } & \text { Cars Miles } & \text { MHrs.(P) Run (P) } & S \\ & & & \end{array}$

$\begin{array}{rrrrrrr}5 & 4 & 15 & 5 & 245 & 72 & 3.6 \\ 5 & 4 & 15 & 5 & 264 & 88 & 4.4 \\ 5 & 4 & 15 & 5 & 297 & 72 & 3.6 \\ 5 & 4 & 15 & 5 & 279 & 72 & 3.6 \\ 5 & 4 & 15 & 5 & 245 & 78 & 3.9 \\ 4 & 4 & 12 & 4 & 247 & 58 & 3.6 \\ 5 & 4 & 15 & 5 & 243 & 68 & 3.4 \\ 5 & 4 & 15 & 5 & 288 & 83 & 4.2 \\ 5 & 4 & 15 & 5 & 310 & 78 & 3.9 \\ 5 & 5 & 15 & 5 & 324 & 102 & 4.0 \\ 5 & 4 & 15 & 5 & 308 & 83 & 4.1 \\ 10 & 4 & 30 & 10 & 637 & 172 & 4.3 \\ 5 & 6 & 15 & 5 & 440 & 119 & 4.0 \\ 5 & 10 & 30 & 10 & 744 & 176 & 3.5 \\ 2 & 12 & 12 & 4 & 371 & 88 & 3.7 \\ 5 & 7 & 25 & 5 & 563 & 120 & 3.4 \\ 7 & 7 & 35 & 7 & 735 & 144 & 3.0 \\ 7 & 7 & 35 & 7 & 727 & 208 & 4.2 \\ 5 & 7 & 25 & 5 & 540 & 120 & 3.4 \\ 5 & 7 & 25 & 5 & 425 & 110 & 3.1 \\ 5 & 7 & 25 & 5 & 503 & 112 & 3.2 \\ 5 & 7 & 25 & 5 & 531 & 128 & 3.7 \\ 5 & 7 & 25 & 5 & 514 & 124 & 3.5 \\ 5 & 13 & 30 & 5 & 920 & 212 & 3.3 \\ 5 & 7 & 25 & 5 & 509 & 171 & 4.9 \\ 5 & 11 & 30 & 5 & 566 & 192 & 3.5 \\ 5 & 7 & 25 & 5 & 620 & 180 & 5.1\end{array}$

PART 1 of 3 


\begin{tabular}{|c|c|c|}
\hline $\begin{array}{l}\text { SURVEYS } \\
\text { iraverse } \\
\text { iar } \\
\text { I1les } \\
\end{array}$ & $\begin{array}{l}\text { Total } \\
\text { Traverse } \\
\text { MHrs. (P) }\end{array}$ & $\begin{array}{l}\text { Traverse } \\
\text { MHrs per } \\
\text { Run (P) } \\
\end{array}$ \\
\hline 245 & 72 & 3.6 \\
\hline 264 & 88 & 4.4 \\
\hline 297 & 72 & 3.6 \\
\hline 279 & 72 & 3.6 \\
\hline 245 & 78 & 3.9 \\
\hline 247 & 58 & 3.6 \\
\hline 243 & 68 & 3.4 \\
\hline 288 & 83 & 4.2 \\
\hline 310 & 78 & 3.9 \\
\hline 324 & 102 & 4.0 \\
\hline 308 & 83 & 4.1 \\
\hline 637 & 172 & 4.3 \\
\hline 440 & 119 & 4.0 \\
\hline 744 & 176 & 3.5 \\
\hline 371 & 88 & 3.7 \\
\hline 563 & 120 & 3.4 \\
\hline 735 & 144 & 3.0 \\
\hline 727 & 208 & 4.2 \\
\hline 540 & 120 & 3.4 \\
\hline 425 & 110 & 3.1 \\
\hline 503 & 112 & 3.2 \\
\hline 531 & 128 & 3.7 \\
\hline 514 & 124 & 3.5 \\
\hline 920 & 212 & 3.3 \\
\hline 509 & 171 & 4.9 \\
\hline 566 & 192 & 3.5 \\
\hline 620 & 180 & 5.1 \\
\hline
\end{tabular}

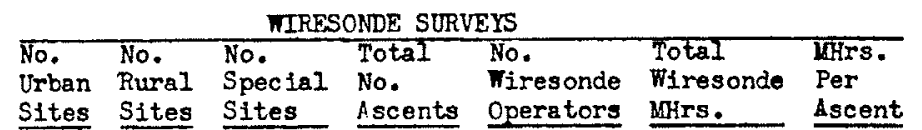

$\begin{array}{lllll}1 & 0 & 0 & 1 & 6\end{array}$

$\begin{array}{llllll}0 & 0 & 1 & 3 & 3 & 30\end{array}$

$0 \quad 0 \quad 1$

100

$0 \quad 0 \quad 1$

100

$0 \quad 0 \quad 1$

$0 \quad 01$

100

$0 \quad 0 \quad 1$

100

000

$0 \quad 0 \quad 1$

$0 \quad 01$

1210

$0 \quad 01$

010

110

100

110

110

110

101

110

000

000

010

PART 2 of 3

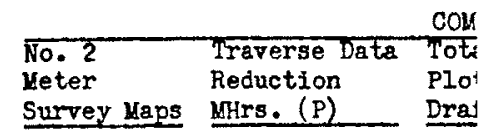

$25 \quad 25$

3

30

30

33

37

27

27

35

35

33

38

33

68

45

68

35

65

65

65

10

45

50

55

55

50

55

40

30 
REGRADED UNCLASSIFIED - JOD,DPG

\begin{tabular}{ll}
\hline Total & MHrs. \\
\hline nde Wiresonde Per & Pers \\
ars MHrs. & Ascent \\
\hline
\end{tabular}

\begin{tabular}{|c|c|}
\hline 25 & 25 \\
\hline 30 & 10 \\
\hline 16 & 5.3 \\
\hline 16 & 5.3 \\
\hline 32 & 10.7 \\
\hline 16 & 5.3 \\
\hline 21 & 7.0 \\
\hline 21 & 7.0 \\
\hline 31 & 10.3 \\
\hline 35 & 8.8 \\
\hline 26 & 5.3 \\
\hline 0 & - \\
\hline 33 & 6.6 \\
\hline 51 & 6.4 \\
\hline 61 & 6.1 \\
\hline 31 & 6.2 \\
\hline 30 & 7.5 \\
\hline 61 & 6.8 \\
\hline 58 & 5.3 \\
\hline 51 & 5.7 \\
\hline 88 & 8.0 \\
\hline 56 & 6.2 \\
\hline 56 & 8.0 \\
\hline 84 & 3.5 \\
\hline 0 & - \\
\hline 0 & - \\
\hline 45 & 15.0 \\
\hline
\end{tabular}

\begin{tabular}{|c|c|c|c|c|c|}
\hline $\begin{array}{l}\text { No. } 2 \\
\text { Meter } \\
\text { Survey Maps }\end{array}$ & $\begin{array}{l}\text { Traverse Data } \\
\text { Reduction } \\
\text { MHrs. (P) } \\
\end{array}$ & $\begin{array}{l}\text { COMPUTING AND ANA } \\
\text { TotalYap } \\
\text { Plotting \& } \\
\text { Drafting MHrs. (P) }\end{array}$ & $\begin{array}{l}\text { YSIS } \\
\text { 2 Meter Survey } \\
\text { Analysis } \\
\text { MHrs. (F) }\end{array}$ & $\begin{array}{l}\text { No. } \\
\text { Wiresonde } \\
\text { Charts } \\
\end{array}$ & $\begin{array}{l}\text { Wresonde Data } \\
\text { Reduction \& } \\
\text { Drafting MHrs. (P) }\end{array}$ \\
\hline 3 & 30 & $10 *$ & * & 1 & 3 \\
\hline 3 & 30 & 28 & 14 & 1 & 8 \\
\hline 3 & 33 & 26 & 15 & 1 & 8 \\
\hline 3 & 37 & $12 *$ & * & 1 & 8 \\
\hline 3 & 27 & 26 & 18 & 1 & 10 \\
\hline 3 & 27 & $7 *$ & * & 1 & 9 \\
\hline 3 & 35 & 28 & 16 & 1 & 9 \\
\hline 3 & 35 & $10 *$ & \# & 1 & 10 \\
\hline 3 & 33 & 10* & * & 1 & 9 \\
\hline 4 & 38 & $10 *$ & * & 1 & 7 \\
\hline 3 & 33 & $10 *$ & * & 1 & 8 \\
\hline 3 & 68 & $2 L_{*}$ & * & 0 & 0 \\
\hline 5 & 45 & $12 *$ & * & 1 & 8 \\
\hline 9 & 68 & $15 *$ & * & 1 & 16 \\
\hline 11 & 35 & 3* & * & 5 & 16 \\
\hline 6 & 65 & 28 & 30 & 1 & II \\
\hline 6 & 65 & 33 & 30 & 1 & 7 \\
\hline 6 & 65 & 33 & 18 & 6 & 26 \\
\hline 6 & 10 & 35 & 27 & 7 & 22 \\
\hline 6 & 45 & $7 *$ & * & 7 & 23 \\
\hline 6 & 50 & $12 *$ & * & 7 & 20 \\
\hline 6 & 55 & $10 *$ & * & 6 & 20 \\
\hline 6 & 55 & $8 *$ & * & 5 & 15 \\
\hline 12 & 50 & 8* & * & 18 & 33 \\
\hline 6 & 55 & 28 & 30 & 0 & 0 \\
\hline 10 & 40 & 48 & 35 & 0 & 0 \\
\hline 6 & 30 & 27 & 24 & 1 & 12 \\
\hline
\end{tabular}

TABLE II-2

MESOMETEOROLOGICAL SURVEYS MINNEAPOLIS

COMPUTING AND ANALYSIS 
GENERAL

\begin{tabular}{|c|c|c|}
\hline $\begin{array}{l}\text { Survey } \\
\text { No. } \\
\end{array}$ & $\begin{array}{l}\text { Date } \\
1953 \\
\end{array}$ & $\begin{array}{l}\text { Map } \\
\text { Times } \\
\text { CST }\end{array}$ \\
\hline M1018 & $5 \mathrm{Jan}$ & $2000-2200$ \\
\hline M1019 & 6 Jan. & " \\
\hline M1020 & $8 \mathrm{Jan}$ & $"$ \\
\hline M1021 & $12 \mathrm{Jan}$ & $"$ \\
\hline MIO22 & $13 \mathrm{Jan}$ & $"$ \\
\hline M1023 & 4 Mar. & $"$ \\
\hline M1024 & 5 Mar. & $"$ \\
\hline M1025 & 6 Mar. & $"$ \\
\hline M2026 & 11 Mar. & $n$ \\
\hline M1027 & 12 Mar. & $n$ \\
\hline M1028 & 13 Mar. & $n$ \\
\hline M1029 & 16 Mar. & " \\
\hline M1030 & 18 Mar. & $"$ \\
\hline M1031 & 19 Mar. & $"$ \\
\hline M1032 & 24 Mar. & $n$ \\
\hline M1033 & 25 Mar. & $n$ \\
\hline $\mathrm{M} 2034$ & 26 Mar. & $"$ \\
\hline$M 1035$ & 27 Mar. & $"$ \\
\hline
\end{tabular}

2 METER TEMPERATURE SUF

\begin{tabular}{|c|c|c|c|c|}
\hline $\begin{array}{l}\text { No. } \\
\text { Routes } \\
\text { Used } \\
\end{array}$ & $\begin{array}{l}\text { No. } \\
\text { Runs Per } \\
\text { Route } \\
\end{array}$ & $\begin{array}{l}\text { No. } \\
\text { Traverse } \\
\text { Men } \\
\end{array}$ & $\begin{array}{l}\text { No. } \\
\text { Cars }\end{array}$ & $\begin{array}{l}\text { Trav } \\
\text { Car } \\
\text { Mile }\end{array}$ \\
\hline 3 & 4 & 9 & 3 & 208 \\
\hline 3 & 4 & 9 & 3 & $21 C$ \\
\hline 4 & 4 & 12 & 4 & $28 \mathrm{C}$ \\
\hline 5 & 4 & 15 & 5 & 297 \\
\hline 4 & 4 & 12 & 4 & $28 \varepsilon$ \\
\hline 4 & 4 & 12 & 4 & 284 \\
\hline 5 & 4 & 15 & 5 & 344 \\
\hline 5 & 4 & 15 & 5 & $40 \approx$ \\
\hline 5 & 4 & 15 & 5 & 334 \\
\hline 5 & 4 & 15 & 5 & $38 \mathrm{C}$ \\
\hline 5 & 4 & 15 & 5 & 373 \\
\hline 5 & 4 & 15 & 5 & 397 \\
\hline 5 & 4 & 15 & 5 & 393 \\
\hline 5 & 4 & 15 & 5 & 390 \\
\hline 5 & 4 & 15 & 5 & 373 \\
\hline 5 & 4 & 15 & 5 & 392 \\
\hline 5 & 4 & 15 & 5 & 390 \\
\hline 5 & 4 & 15 & 5 & 373 \\
\hline
\end{tabular}

(P) Part-time personnel

(F) Full-time personnel

* Work not completed as of 31 March 1953. 


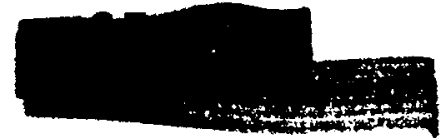

TABLE II-3

MESOMETEOROLOGICAL SURVEYS

ST. IOUTS

E SURVEYS

\begin{tabular}{|c|c|c|c|c|c|c|}
\hline $\begin{array}{l}\text { Traverse } \\
\text { Car } \\
\text { Miles } \\
\end{array}$ & $\begin{array}{l}\text { Total } \\
\text { Traverse } \\
\text { MHrs.(P) } \\
\end{array}$ & $\begin{array}{l}\text { Traverse } \\
\text { MHrs. Per } \\
\text { Run (P) }\end{array}$ & $\begin{array}{l}\text { No. } 2 \\
\text { Meter } \\
\text { Survey Maps } \\
\end{array}$ & $\begin{array}{l}\text { Traverse } \\
\text { Data Re- } \\
\text { duction } \\
\text { MHrs.(P) } \\
\end{array}$ & $\begin{array}{l}\text { Total } \\
\text { Map Plotting } \\
\text { \& Drafting } \\
\text { MHrs.(P) } \\
\end{array}$ & $\begin{array}{l}2 \text { Meter } \\
\text { Survey } \\
\text { Analyses } \\
\text { MHrs. (F) } \\
\end{array}$ \\
\hline 208 & 50 & 4.2 & 3 & 24 & $7 *$ & * \\
\hline 210 & 50 & 4.2 & 3 & 26 & 24 & 12 \\
\hline 280 & 86 & 5.4 & 3 & 29 & 24 & 15 \\
\hline 297 & 101 & 5.0 & 3 & 30 & 22 & 12 \\
\hline 288 & 72 & 4.5 & 3 & 33 & 23 & 15 \\
\hline 284 & 62 & 3.9 & 3 & 25 & $*$ & * \\
\hline 344 & 84 & 4.2 & 3 & 25 & 22 & 12 \\
\hline 402 & 77 & 3.9 & 3 & 23 & $9 *$ & * \\
\hline 334 & 72 & 3.6 & 3 & 23 & $7 *$ & * \\
\hline 380 & 81 & 4.1 & 3 & 26 & * & * \\
\hline 373 & 72 & 3.6 & 3 & 23 & * & * \\
\hline 397 & 109 & 5.5 & 3 & 28 & * & * \\
\hline 393 & 87 & 4.4 & 3 & 25 & * & * \\
\hline 390 & 82 & 4.1 & 3 & 22 & * & * \\
\hline 373 & 83 & 4.2 & 3 & 28 & * & * \\
\hline 392 & 109 & 5.5 & 3 & 27 & * & * \\
\hline 390 & 85 & 4.3 & 3 & 24 & * & * \\
\hline 373 & 89 & 4.5 & 3 & 26 & * & * \\
\hline
\end{tabular}

Part 2 of 2 
reduced to 8 to 12 miles because of the loy street condition prevailing during this winter period. Each route is designed to take approximately 55 minutes in route coverage time, observing maximum speed regulations of 30 miles per hour or less. Time is allowed on certain routes for the procurement of supplementary data, such as wind direction and velocity, and lake water temperatures. Normally, three men comprise the craw of a traverse car (Fig. II-I).

Design of the traverse routes has required careful consideration of traffic patterns, shopping nights, sporting events, left-turn restrictions and the necessity for avoiding dangerous intersections not controlled by signal lights. Because of inaccuracies found prevalent in the available street maps of both Minneapolis and St. Louis, it has been found necessary to conduct a trial run on each route prior to its use in a test.

\section{Traverse Scheduling}

Traverses are normally scheduled during the evening to cover a period of four hours at the rate of one each hour. When tracer tests are in progress, traverses are so scheduled as to provide maps beginning one hour prior to the tracer tests and ending one hour after completion of the tests. Tracer tests are also conducted from time to time during the early morning hours and during daytime in order to determine the effect of these times on the aerosol diffusion pattern. Testing thes are Iimited to some extent by the availability of the part-time personnel used in the operations. 


\section{Selection of Wiresonde Sites}

In order to obtain the vertical temperature structure over the heat island and the heat low, wiresonde sites are selected as close as possible to the center of the urban area and to the normally coldest surface point. It is further required that the sites selected be relatively free of surface obstacles and be accessible to vehicles. It is important in establishing any wiresonde site that the location be sufficiently removed from trees, tall buildings, and in particular, high tension power lines, to constitute a minimum hazard to operating personnel and to preclude loss of equipment at times when balloons are blown to low elevation angles. In Minneapolis the urban site is on top of a one-story building adjacent to the field office and just outside the area of tall buildings. The rural site is 10cated in Wirth Park near Wirth Lake, a location which has proved to be a consistent low point in the temperature pattern. In St. Louis it is considered that a location on one of the many two-story buildings in the vicinity of 9 th Street and Del Mar (on the periphery of the tall building area) will be near the heat island. The only feasible rural site adequate for the purpose in Sto Louis is along the banks of the stream in Forest Park. It is anticipated that permission will be extended by city officials for the use of such a site.

\section{Wiresonde Scheduling}

Wiresonde ascents are so scheduled that the peak of the first run is reached simultaneously with the start of the second auto traverse. Ascents are then scheduled for each hour with the last peak being reached at the 
start of the last auto traverse. This procedure provides a wiresonde ascent coinciding with each horizontal temperature survey map. An experienced crew will normally complete one ascent to the maximum altitude of 1000 feet in a total period of 50 minutes.

\section{Mobile Meteorological Stations}

Mobile meteorological stations are set up for each tracer test to determine meteorological conditions existing in the area during diffusion of the aerosol cloud. Their function and type of data recorded are discussed under Meteorology in Section $\mathrm{V}-\mathrm{C}-4$.

\section{Data Refuction and Analysis}

Data reduction is nomally accomplished by part-time personnel within four or five days after each test. The instrument readings are converted to actual temperatures by means of tables obtained from calibration curves: made for each thermistor-bridge set. Interpolation to a common map time is accomplished in accordance with the procedure detailed in Stanford Quarterly Report 1856-3 Appendix A. These data are next plotted on area maps to provide temperatures along traverse $r$ outes at the points at which readings were originally taken. Wiresonde temperatures are plotted on standard graph paper. Analysis of the surface charts, consisting of determination of isothermal contours, is accomplished by the Chief Meteorologist. Analysis of individual maps takes between one-half hour and five hours depending on the degree of complexity of the thermal patterns. A summary of meteorological conditions prevaling during the test period 
is then prepared from examination of the analyzed horizontal temperature maps, the wiresonde curves, the raob from the nearest Weather Bureau raob station, the applicable hourly weather observations, and the surface and $700 \mathrm{mb}$ charts.

\section{Personnel}

An adequate number of part-time personnel has been available in Minneapolis. It has, however, been difficult to obtain a sufficient number of responsible men to act as balloon crew captains for wiresonde operations (Fig. II-2)。 For this purpose young engineers in the first years of their career have proven the most reliable. In St. Louis it has been difficult to obtain sufficient personnel of any description and in particular responsible people for the balloon captain positions. Considering the tight labor market, this situation will undoubtedly continue throughout the period of the project in that city. 


\section{TRACER TESTS (NTMNEAPOLIS)}

\section{General}

During the current period, tests to determine the behavior of aerosol clouds in cities were conducted in Minneapolis only. Four areas were used for the tests as described in $\mathrm{RR} 2$. The areas consisted of a residential section (Able Area), an area traversed by a river course (Baker Area), an open and relatively flat area (Charlie Area), and a downtown section (Dog Area). The last tests in the winter series were city wide in scope. Plans for conducting similar tests in other cities will be found in a subsequent portion of this Section.

A total of 65 separate field tests were conducted in which fluorescent material was released in 61. The other four tests were performed in the process of training operating personnel, checking equipment operation in the field, and obtaining background particulate samples in the kinneapolis area. Fluorescent tracer material was released in 24 tests in the rosidential area, in $山_{1}$ tests in the river area, in 12 tests in the open area, and in 9 tests in the downtown area. Two releases were made on a city-wide basis.

Operations for the period represent a total of 81 field experiment hours and 11,170 man-hours, including full-time and part-time personnel in the field and laboratory. Experiments were conducted predominantly in the evening hours between 2000 and 2400 , with several supporting experiments being conducted in the early morning hours between midnight and 0600 and in the afternoon hours between 1300 and 1700 . 


\section{Test Data}

Table II-4 enumerates all field tests conducted in the current period and gives pertinent statistics for the several main phases of a field operation. These phases consist of test preparations, aerosol generation, samo pling, and analysis. Additional data are given for field moteorological station activities. Total man-hour expenditure figures for various operations are listed and a basis for comparison of tests is shown by man-hours per unit operation.

\section{Public Relations}

Advance meetings with the Mayor of Minneapolis, the Minneapolis City Council, and the Public Utilities Committee were held in August and September of 1952 as previously outlined in $\mathrm{RR}$ 1. The result of these meetings was the extension of the full cooperation of various city departments to the field of fice during the test program.

Prior to starting the tracer test program in January, representatives of the field office were invited to meet with the Chief of Police and the Fire Marshall to apprise these departments of the areas and hours of operation. It was the desire of these departments to be prepared to dispel the anticipated concern of citizens calling to report unusual activities at unusual hours. At the suggestion of police officials, identification placards reading "Official Test Car" were printed. These cards are issued to personnel involved in the use of automobiles for temperature traverses and 


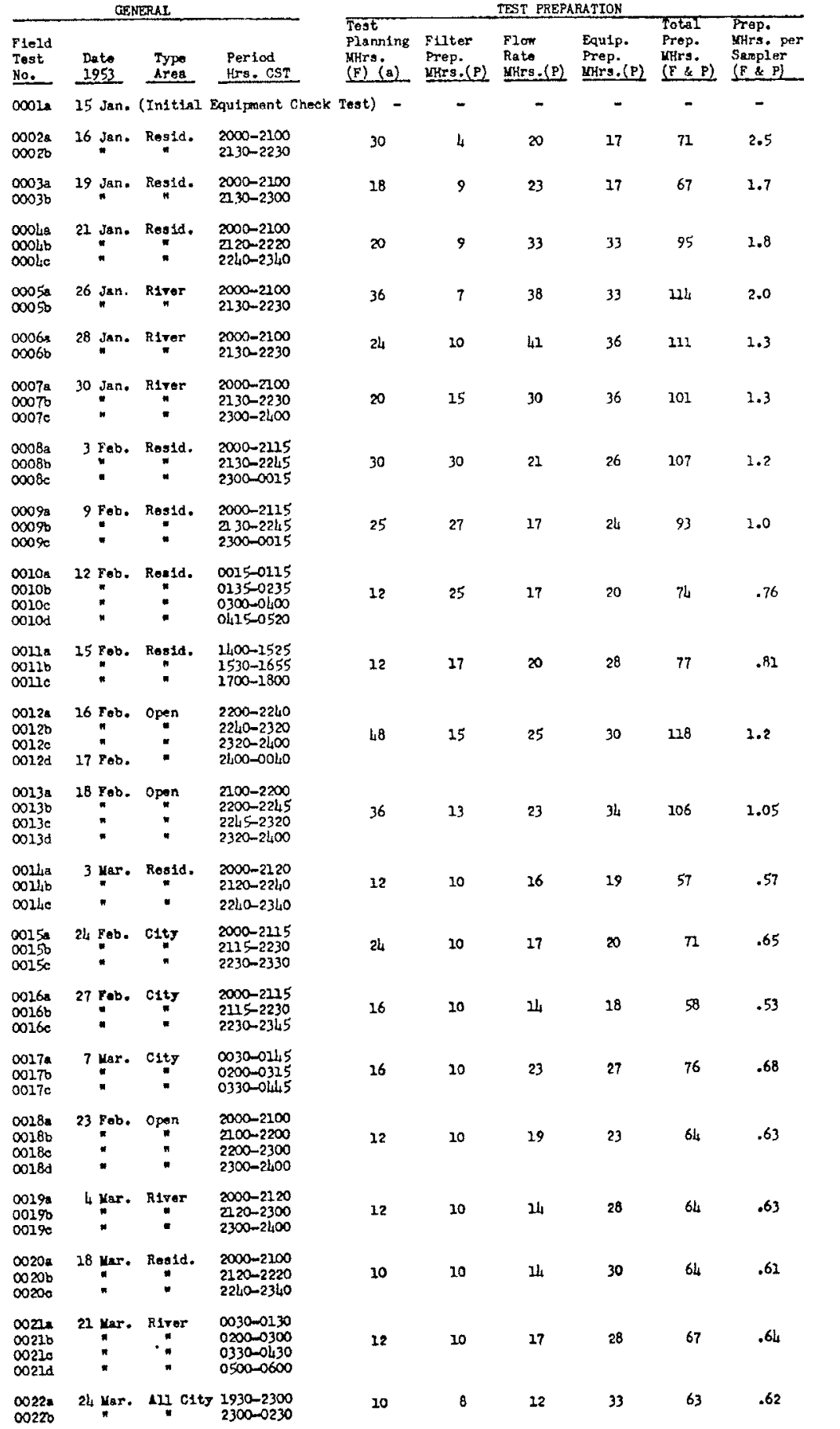

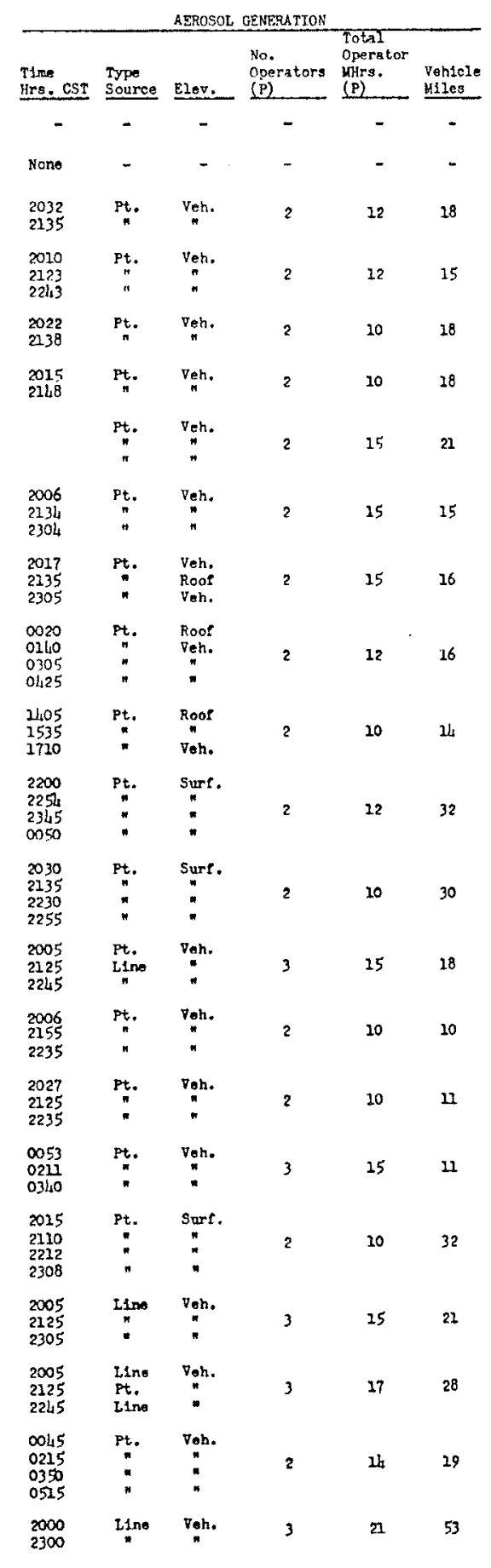

(b) Includes training hours 

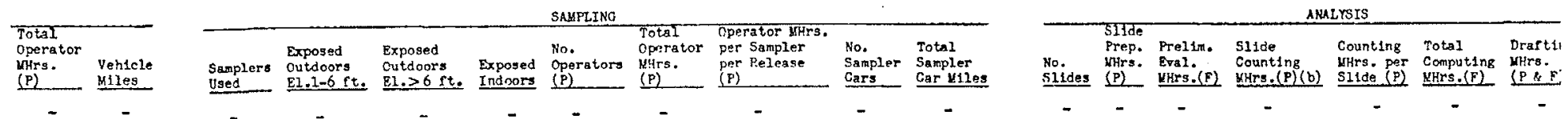

uHrs. Yehicle
(P) Used El.1-6 ft. El.>6 ft. Indoors (P) (P)

\begin{tabular}{|c|c|c|c|c|c|c|c|c|c|c|c|c|c|c|c|c|c|}
\hline- & - & 28 & 28 & 0 & 0 & 16 & 54 & .96 & 12 & 270 & 55 & 10 & - & N.c. & - & - & 8 \\
\hline 12 & 18 & 140 & 40 & 0 & 0 & 28 & 96 & 1.20 & 11 & 161 & 120 & 17 & 8 & 90 & .75 & 10 & 24 \\
\hline 12 & 15 & 52 & 47 & 2 & 3 & 23 & 132 & .85 & 17 & 248 & 11,6 & 27 & 8 & 95 & .65 & 12 & 24 \\
\hline 10 & 18 & 56 & .53 & 3 & 0 & 29 & 160 & 1.43 & 20 & 344 & 116 & 12 & 7 & 65 & .56 & 10 & 30 \\
\hline 10 & 18 & 83 & 77 & 5 & 1 & 42 & 24,0 & 1.45 & 33 & 584 & 166 & 38 & 8 & 90 & . 5 & 17 & 27 \\
\hline 15 & 21 & 75 & 70 & 4 & 1 & 33 & 200 & .89 & 27 & 694 & 248 & 25 & 10 & 101 &.$h 1$ & 20 & 22 \\
\hline 15 & 15 & 92 & 68 & 4 & 20 & 1,9 & 293 & 1.06 & 40 & 701 & 365 & 50 & 12 & 182 & .50 & 27 & 16 \\
\hline 15 & 16 & 93 & 72 & 4 & 17 & 47 & $32 \mathrm{~h}$ & 1.16 & 36 & $62 h$ & 387 & 48 & 10 & 170 & . Wh & 30 & 20 \\
\hline 12 & 16 & 97 & 87 & 3 & 7 & 39 & 305 & .79 & 36 & 667 & 407 & 35 & 11 & 158 & .38 & 31 & 27 \\
\hline 10 & 14 & 96 & 82 & 5 & 9 & 40 & 269 & .95 & 38 & 6luh & 339 & 33 & 8 & 121 & .35 & 27 & 25 \\
\hline 22 & 32 & 101 & 101 & 0 & 0 & 32 & 281 & .70 & 30 & 1182 & 399 & 28 & 8 & 150 & .38 & 30 & 46 \\
\hline 10 & 30 & 101 & 101 & 0 & 0 & 45 & 321 & .79 & L1 & $14: 26$ & Lols & 23 & 9 & 173 & .43 & 28 & 40 \\
\hline 25 & 18 & 100 & $\infty$ & 4 & 6 & 37 & 258 & .86 & 35 & 653 & 367 & 24 & 7 & 215 & .31 & 25 & 27 \\
\hline 10 & 10 & 110 & 54 & 24 & 32 & 40 & 274 & .83 & 33 & 521 & 412 & 20 & $B$ & 135 & .33 & 30 & 28 \\
\hline 10 & $1 x$ & 110 & 50 & 25 & 35 & Lo & 292 & .89 & 33 & 528 & 420 & 19 & 8 & 126 & .30 & 30 & 28 \\
\hline 15 & 11 & 110 & 60 & 25 & 25 & 39 & 268 & .80 & 36 & 636 & 422 & 21 & 8 & 127 & .30 & 28 & 25 \\
\hline 10 & 32 & 101 & 101 & 0 & 0 & Wh & 320 & .79 & 38 & 2357 & LOL & $n$ & 8 & 204 & .50 & 25 & 40 \\
\hline 15 & 21 & 100 & 95 & 2 & 3 & 48 & 333 & 1.11 & 33 & 748 & 319 & 26 & 7 & 105 & .33 & $2 \hat{q}_{4}$ & 20 \\
\hline 17 & 28 & 104 & 103 & 1 & 0 & 31 & 236 & .76 & 26 & 633 & 312 & 16 & 7 & 117 & .38 & 20 & 32 \\
\hline 14 & 19 & 104 & 104 & 0 & 0 & 31 & 280 & .68 & 27 & 721 & 403 & 16 & 8 & 133 & .33 & 20 & 29 \\
\hline 21 & 53 & 302 & 88 & $\mathrm{di}_{4}$ & 0 & 42 & 374 & 1.90 & 32 & 15,06 & 219 & 12 & 6 & 75 & .34 & 13 & 26 \\
\hline
\end{tabular}

PART 2 of 3 


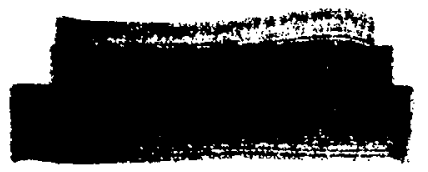

TABLE IIT-4

SIMUARY OF DATA ON MTNAEAPOLIS TRACEA TESTS

Total Operator yHrs.

- verator par Sampler No. Totol

ro UHrs. per Release Sampler Sampler

- 1

$96 \quad 1.20 \quad 11 \quad 161$

$\begin{array}{llll}132 & .85 & 17 & 248\end{array}$

$\begin{array}{lll}160 & 1.43 \quad 20 & 34\end{array}$

$240 \quad 1.45 \quad 33 \quad 584$

$\begin{array}{llll}200 & .89 & 27\end{array}$

32

305

269

281

$\begin{array}{llll}258 & .86 & 35 & 653\end{array}$

$274 \quad .83 \quad 33 \quad 5$

$292 \quad .89 \quad 33 \quad 52$

$268-.80-36$

$\begin{array}{llll}320 & .79 & 38 & 1357\end{array}$

$333 \quad 1.21 \quad 33$

$\begin{array}{llll}236 & .76 & 26 & 639\end{array}$

$\begin{array}{lll}380 & .68 & 27\end{array}$

374

1.90

$32 \quad 1506$

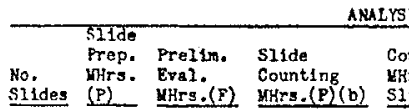

\section{Count ing}

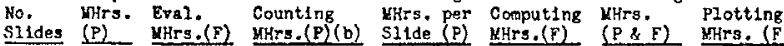

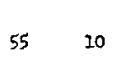

$120 \quad 17$

$2166 \quad 17 \quad 8 \quad 95$

$116 \quad 12$

$166 \quad 18$

$248 \quad 25 \quad 10 \quad 101$

$365 \quad 50 \quad 12 \quad 182$

$387 \quad 48 \quad 10 \quad 170$

$407 \quad 35 \quad 11 \quad 156$

$\begin{array}{llll}339 & 33 & 8 & 121\end{array}$

$\begin{array}{llll}399 & 28 & 8 & 150\end{array}$

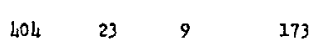

$\begin{array}{llll}367 & 24 & 7 & 115\end{array}$

$\begin{array}{llll}422 \quad 20 & 8 & 135\end{array}$

$420 \quad 19 \quad 8 \quad 126$

$\begin{array}{llll}422 & 22 & 8 & 127\end{array}$

LOL $22 \quad 8 \quad 204$

$\begin{array}{llll}319 & 16 & 7 & 105\end{array}$

$\begin{array}{llll}312 & 16 & 7\end{array}$

$\begin{array}{llll}403 & 16 & 8 & 133\end{array}$

$219 \quad 12 \quad 6 \quad 75$

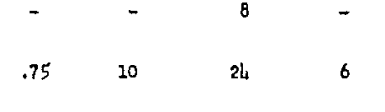

$$
.65 \quad 22 \quad 24 \quad 8
$$$$
\begin{array}{llll}
.56 & 10 & 30 & 6
\end{array}
$$$$
\text { .5 } 27 \quad 27 \quad 8
$$

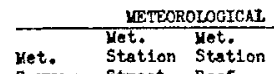

Het. Station Station

Roor- Field

No. LereI Top Test No.

None - - $0001 \mathrm{a}$

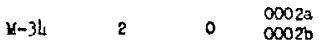

$x-35 \quad 2 \quad 2 \quad 0003 a$
$0003 b$

$\begin{array}{lll}0,36 & 2 & 000 \mathrm{La}\end{array}$

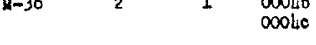

$u-38 \quad 3 \quad 0 \quad 0055$
00056

$u-4,0 \quad 3 \quad 0 \quad 0006 \mathrm{a}$

$x-412 \quad 3 \quad 0007 \mathrm{a}$
$0007 \mathrm{~b}$

$\begin{array}{lll}1-43 \quad 2 \quad & 0008 \mathrm{a}\end{array}$

$0008 \mathrm{e}$
$0009 \mathrm{a}$

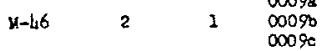

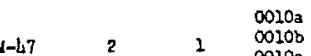

$\begin{array}{ll}1.17 \quad 2 \quad & \text { coloc } \\ & \text { colod }\end{array}$

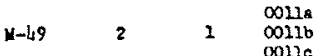

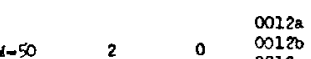

$\infty$
$\infty 12 \mathrm{c}$
$\infty$

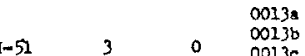

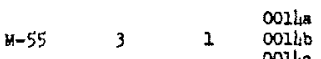

$-53-0015$

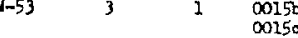

u-5h $3 \quad 2 \quad 0016$

0016

$\begin{array}{llll}4-57 & 3 & 2 & 0017 \\ & 0017\end{array}$

$x-52 \quad 4 \quad 0 \quad \begin{aligned} & 0018 a \\ & 0018 b \\ & 0018 c\end{aligned}$
$0018 d$

$0018 \mathrm{~d}$

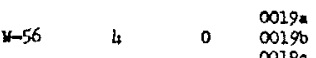

$4, \quad 0020$

o020b

(0)20

$\begin{array}{lll}4-59 \quad 3 \quad 0 \quad \begin{array}{l}00216 \\ 0021 b \\ 00210\end{array} & 00210\end{array}$

$\begin{array}{lll}w-60 \quad 3 \quad & \begin{array}{c}0021 d \\ 0022 a \\ 0022 b\end{array}\end{array}$ 
field meteorological stations, and to sampler operators using parked iutomobiles for sampler stations. The cards are prominently displayed on windshields while the automobiles are in such use.

In connection with the phase of the program concerned with the penatration of aerosols into residences and buildings, city officials were advised of a subsidiary requirement for determining the degree of infiltration of smoke screens into a few representative residences. At the request of field representatives, complete rosters of personnel in both the police and fire departments were furnished. It was anticipated that omployees in these departments could be contacted in each of the test areas regarding location of equipment in homes. A letter of introduction to Minneapolis city employoes and to citizens in general was prepared by the Mayor requesting the cooperation of persons contacted in connection with the test program. This letter was later augmented by similar documents from the Minneapolis Air Pollution Control Engineer and the Chief of Civil Defense. This portfolio was delivered to the field office and was of great help to personnel in the process of securing use of private homes, buildings, and land for equipment locations. Thus "official sanction" was given to otherwise questionable requests. Even so, field personnel encountered a considerablo number of refusals to cooperate with requests for permission to locate sampling equipment in homes. As many as ten contacts were made for each acceptance. only two city employees were found to reside in the tost areas selected, and it was necessary, therefore, to resort to house-to-house canvassing to obtain the necessary residences. The Northwestern Bell Telephone Company, the Northwestern National Bank, and other large and small building 
owners in the city proper have cooperated fully in permitting sampling equipment to be located throughout these structures. Likewise, little difficulty was exporienced in obtaining use of farm land for the openarea tests. For this operation some half dozen owners granted permission to the field office to survey a grid systom, and to erect stakes for some 100 sampler locations. Permission was granted for full run of the land by operating personnel in the tests involving use of this area.

During the first several field tests in the residential area, the police roceived numarous calls from residents reporting strange activities in the area. The sampling phase in particular aroused considerable curiosity. For several evenings in succession, sampling equipment was molested by curious passers-by, and several sampling units were actually found missing from stations. All of these were eventually recovered, however, either being returned by citizens in the area or by the police to whom the samplers had been turned in.

The local press has been cognizant of the proposed operations in Minneapolis, having been represented at a city council meeting early in the program in which the purported nature of the program was presented. As a result of the general interest stimulated by the appearance of equipment in the first field tests, the Minneapolis Tribune carried the following article on 20 Jenuary 1953:

"In summer it was flying saucers. In winter it's little gray boxes that just sit on street corners, ticking and purring. 
"Several Minneapolis residents phoned police Monday about 'ticking boxes' sitting in the snow in front of their homes. Most of the reports came from the vicinity of Clinton Avenue between Twenty-seventh and Lake Streets.

"I am not at liberty to say what these boxes are,' said E. I. (Pat) Walling, inspector of untformed police, 'but they are nothing for citizens to get alarmed about.'

"One observer indicated the boxes are being used in a series of tests intended to help the Army learn to throw smoke screens over American cities. They could be used to measure the concentration in the air of a fine, harmless powder blown over the city.

"The Minneapolis Tribune learned in November that The Ralph M. Parsons Company of Los Angeles, California, would conduct some 40 tests for the Army Chemical Corps in the Twin Cities area. This firm's name appears on cars from which guards watch the boxes.

"Government research has shown that even in an age of radarbombing, it may be desirable to hide cities with smoke screens in event of atomic attack. It is not known if any smoke has been released over Minneapolis. Several other cities also are involved in the tests.

"The metal boxes are about $\Psi_{4}$ by $\Psi_{4}$ by 10 inches in dimension. A small metal nozzle extends from the side. The notse coming from the boxes may be from a small battery-operated suction motor. 
Worried guards at Trenty-seventh Streat and Clinton Avenue conducted a fruitless search for a missing box last night. Another one of the machines disappeared at Lake Street and clinton. A guard said they are worth ia couple of hundred dollars."

"The Parsons company has offices at 918 Third Avenue South and employp 10 full-time people and some 65 part-time workers. Many of these workers place and guard the boxes at city intersections. Guards park their cars so they can watch two boxes at one time on a corner. Nothing on or near the box indicates: their purpose.

"They need changing every three hours,' one guard remarked, but he would not allow a Tribune reporter to look beneath the lid."

Other local newspapers followed with reports of simizar content. Public curiosity diminished rapidly following these press releases. However, to prevent further idle tampering or actual loss of equipment by theft, operators were furnished chains and locks with which the sampling equipment could be secured to trees, lamp poles, or similar permanent objects. Few molestations of consequence occurred during the balance of the program.

\section{Test Planning}

Both general and specific requirements for the Minneapolis winter tests were outlined for the field office by Stanford University. Such plans have specified: 
a. The point or line source type of aerosol generation, elevation requirements, and general order of the quantity of tracer material to be released for each type of generation,

b. The approximate number of tests to be conducted in each area and the operating hours such as early orening, early morning, and afternoon,

c. The general extent of the sampler array for certain special tests,

d. Sppcial requirements, such as location of sampling equipment in residences and buildings.

The first four tracer tests were planned and supervised jointly by Stanford and Parsons personnel. Subsequent planning and operational supervision were performed by the Parsons fleld office.

The actual planning of the test is undertaken with specific objectives in mind such as area to be used, meteorological conditions required, period of operation, types and relative locations of serosol generation, and spem cial locations of sampling equipment. The inftial test arrays involved a limited number of samplers consistent with the small group of inexperienced part-time workers then available. These test arrays were essentially rectangular in shape. As the operating force increased in profieiency and number, it became possible to place a greater number of units in the field, and consequently the areal extent of the arrays was increased to meet more nearly the specific objectives of the winter test program. 


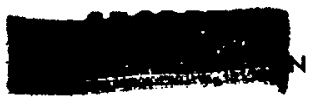

It was found expedient, however, in planning larger tests later in the program, to continue to define a generally rectangular grid of samplers in the center of the test area. This basic core, then, can be planned 24 hours or more in advance, and the necessary mapping and preparation of operator instructions for this arrangement can be scheduled prior to the peak effort period just preceding the test. The permanent core normally includes any residences or buildings to be used for sampling or aerosol generating stations. Therefore, time-consuming arrangements for use of such premises may be scheduled well in advance of the test.

The field office meteorological group, in close llaison with the weather Bureau at Wold-Chamberlain Airport, furnishes progressively more accurate forecasts of weather and wind conditions to be expected at the time of the test, beginning with a five-day advance forecast and carrying through to the conclusion of the actual test. Six hours prior to the test the meteorological group prepares a final forecast, based on the most recent weather information available at the Weather Bureau and upon data furnished by field office instruments. Design of the final test grid is undertaken at this time, with sampler locations being prepared as an adjunct to the basic grid system, consistent with test objectives and the anticipated wind direction.

The sarpler array represents a compromise between two requirements. First, sufficient equipment must be provided within the area anticipated to be covered by the cloud, to determine such parameters as the axis of travel, regions of constant concentration, and behavior of the cloud on the 
dowmind side of buildings. Second, some equipment must be located outside the anticipated region of cloud coverage to define a line of some minimum effective concentration. Since the very nature of these results is the object of the experiments, and is not specifically known, the array must be designed with sufficient "safety factor" to ensure accomodation of the aerpsol cloud while it is being diffused from the source while under the influence of winds which may vary in direction and velocity. For a point-source experiment an array of samplers within an included angle of approximately 60 to 90 degrees, with the aerosol generator just inside the apex, has been found to constitute a sultable system for the initial. test program。

Refinements or modifications of the initial plan of a given test may be made in the field prior to a release to accommodate any significant change in wind direction. The aerosol generator may be relocated or sampler positions may be changed to form a more adaptable grid. The extent of such maneuvers is controlled by the time available for moving the equipment, the adequacy of field commications, and the degree to which some specific test objective, such as determination of the effect of generator location on diffusion of the cloud, may be altered.

The scheduling of operating personnel for a test is given in a subsequent portion of this Section.

\section{Sampling}

The University of Minnesota has been the principal source of men for part-time employment as sampler operators. A small percentage of the 
field crew represents men employed in various private and civil occupations. Prerequisites for hire are that men meet minimum securlty requirements and that each man have a means of transportation. The net increase in parttime employees assigned to the Tracer Test Division for the current period is approximately 60 men.

As the test program progressed, methods of scheduling personnel, training of operating crews, disseminating test plan information, performing certain pre-test operations such as flow rating filter units to be used in the samplers, dispatching men into the field, and maintaining contact with and control over the crew while in the field were steadily improvod.

The scope of initial tests was limited to permit determination of basic personnel capabilities and to establish methods for training crews with a minimum of confusion. For the first half dozen operations, all available men were scheduled to report to the fleld office approximately two hours prior to the time planned for the first tracer release. This small force, averaging less than 20 in number, was assembled to receive operating and special test instructions. A standard operating procedure formed the basis for discussion. After a question-and-answer period, each man was issued the necessary field data sheets, completed with respect to sampler location and exposure requirements for the evening's operations. Each operator was then assigned a number of sampling units, and the test directors demonstrated the initial filter flow rating procedure with the assistance of the field supervisors. The men and their equipment were then dispatched to field positions. Contact with men in the field and 
checking of sampler locations were accomplished by the test command car makin a circuit of the whole test area. The crew was again used for final flow rating of filters after equipment had been returned to the field office at the end of the test period.

As the operating force became proficient, several lead men were selected to act as crew captains, and the balance of the force was divided into groups and assigned under these men. Each crew presently consists of about eight to ten men. The crew captains are delegated the responsibility for training of new men assigned to the crews, disseminating special test instructions, dispatching men to the field with proper equipment, and checking to ensure proper location and operation of sampling equipment in the field, all under the guidance of field office supervisors. The system of decentralizing supervision of a large number of men has been successful and has increased the operting efficiency of the test organization as a whole.

A time and availability chart is now prepared for the entlre field force. This schodule serves as the basis for hiring additional personnel for scheduling of part-time employees for work in the field office prior to a test and for the actual field tests.

A tentative operating schedule is prepared and posted regarding the activities to be conducted for the following several weeks. This information includes dates of tests, and areas and hours of operation. Crew captains are contacted by telephone when a test has been established definitely as to date, hours of operation, and number of men required. Crew chiefs then 
schedule men in their crews for the operation and report in advance of test time regarding availability of manpower. The total part-time force is necessarily established at a lpvel exceeding the maximum manpower requirement for the largest operation in order to ensure that a full working crew is available for any given test. Relatively few manpower scheduling problems were encountered during the current period, and the working force for tracer tests was stabilized in the neighborhood of $60 \mathrm{men}$, including crew chiefs. One problem inherent with omploywient of students, however, is the general dearth of manpower during periods of final examinations and vacations. This shortage was experienced just prior to and during the University of Minnesota's spring vacation. During this period tests were conducted with some difficulty.

Under present procedures, flow rating of filter units is performed well in advance of the time that the operating crew is scheduled to report for a test. Several part-time workers generally can be scheduled to perform this work during the day preceding the test. A discussion of the flow rating procedure is included in Section $\nabla$ of this report.

Samplers are arranged in the equipment assembly area of the field office in separate groups for sach field crew. Loaded filter holders are arranged in perforated trays in the laboratory, and these are transported on small castered tables along lanes between samplers so arranged for flow rating (Fig. II-3). Filter holders are selected in the proper quantity for each sampler, and flow rates and holder numbers, together with the sampler identification number, are recorded on data sheets which are then stored in 


\section{$+\sin x+2$}

the sampler box. Sampling equipment is completely prepared for service and arranged for the most officient dispatching into the field prior to arrival of the operating crew. Stand-by time of a large number of men is thereby reduced to a minimum since the field-crew time schedule permits only sufficient time in advance of the test to receive necessary instructions and equipment and to take positions in the field.

The crew captains alone are assembled prior to the arrival of the general crew at which time special instructions are given relative to the forthcoming operations. Each man is provided with a map showing the locations of men and equipment under his cognizance. These instructions are then disseminated as necessary to each crew. The crow chief dispatches men to field locations with proper equipment and performs the necessary function of checking locations and operations in the field during the experiment.

Each man in the initial tests was assigned to operate one or two sampling units. Where two units wore assigned, one was located in the operator's automobile and the other not farther than onemalf block distant. As operator proficiency increased, it was found that the optimum number of samplers to be operated by one man was three when located one-tenth of a mile or more apart. Based on the performance of average employees handling from two to five sampling units each, this three-unit standard was established primarily because frequent inspections of remote equipment were necessary to discourage tampering by curious people. A greater number of samplers may be tended by one man if located in an unpopulated 
area or in a building where relative security is assured. Where flexibility of the grid system is an important factor, it was found that as a general rule one man can relocate a meximum of three samplers from one side of a one-half mile spmare grid to the opposite side in the 30 minutes generally allotted between test periods. Subsequent relpases are delaybd where time required for transporting and setting up equipment in other locations exceeds the normally scheduled interval.

During a field test the crew chiefs not equipped with portable radio are contacted by the command car. Radio equipment is normally issued to crew supervisors cognizant of samplers which are located in areas of the samm pler array most likely to be "deactivated" by a significant shift in wind direction. With radio communication facilities, the instructions for revision of sampler locations can be issued to field crews in the shortest possible time by having the crew chief contact the operators so affected。

After a field test the samplers are returned to the equipment assembly area and arranged in the groups from which they were originally taken. Those samplers which were located within a radius of 150 foet downwind of the aerosol disperser are segregated into a special group and marked for examination of the exterior of the box under ultraviolet light to determine the presence of fluorescent particles. If such examination indicates the presence of excessive amounts of the tracer material, the cases are washed with a detergent to eliminate a possible source of contamination within the premises. All final flow rating is undertaken by 
a small crew immediately after each test to provide for release of sampling equipment to battery charging crews. Exposed filter holders are then arranged on small trays in an ordered sequence suitable for preliminary examination on the following day (see Section:V).

While field operations in the residential, river, and downtown areas were not materially hindered by deep snow, this was not the case for the open test area. High drifts and the general inaccessibillty of sampler stations made operations in this area extremely difficult. Transportation of sampling equipment for long distances over the open area was facilitated by use of sleds and toboggans. During the first open-area field test, the temperature dropped to well below zero degrees Fahrenheit, and under this condition it was first perceived that small ice crystals formed on some of the filters. With a small starting nucleus, many formations grew so large as to cover half of the top of the filter. The origin of these crystals is belleved to be from several sources such as from moisture in the breath of operators and from small air-borne ice and snow crystals. The effect of this phenomenon on the analysis of filters will be discussed in a subsequent JQR dealing with the field tests involved.

\section{Aerosol Generation}

Because of the nature of the equipment, part-time employees assigned to the aerosol generator crew were selected from those men possessing some mechanical aptitude and technical background. Operation of the dispersal equipment requires a reasonable degree of mature judgement and the ability to 
follow a multiple step operating sequence. Three men are presently assigned to this crew. A discussion of the operating procedure for the aerosol generator is included in Section $\nabla$.

An operating manual prepared by Stanford University for the blower type aerosol generator with mechanical feeder was the basis for training men assigned to this crew. The initial tralning procedure included a practice run in the New Brighton, Minnesota, area in which personnel performed all operations incident to the aerosol generator phase of a field test, including placement of equipment, preparation of the bulk material for dispersal, initial and final weighing, and actual dispersal of tracer material over a representative period of time.

It was recognized at the beginning of the field project that in order to ensure validity of results obtained from tests using the fluorescent tracer technique, the control of contamination of office and laboratory facilities by tracer material was of paramount importance. In order that contamination of the premises in which the analytical work is performed be reduced to an absolute minimum, it was planned that bulk tracer mater ial and all equipment used in connection with the aerosol generation process be stored at a location remote from the field office. A convenient arrangement was made with the chief of the disperser crew for storage of all of this equipment at his home in New Brighton, Minnesota, some eight miles distant from the field office. The panel truck used for transportation of the generator and crew during test operations is procured from a rental agency also remotely located from the field office. The pick up 
and return of this vehicle are arranged for entirely by members of the generator crew. Under present procedures the lead-acid aircraft batteries comprising the power pack for the generator are stored and charged at the field office because of the avallability of battery charging facilities there. The power pack is segregated from other equipment upon its return from a field operation, however, and is examined under ultraviolet light and imdiately decontaminated, if required, by scrubbing with a detergent and water outside the building. Thts power pack is to be charged and stored elsewhere during all forthicoming test periods to eliminate any possibility of contamination of field office premises from this source.

Other sources of contamination such as the generator operating personnel, portable radio equipment used by this crew, and field operation data sheets are excluded from the field office premises. The miniature lead-acid batteries for the radio are charged there, however, and the radio is stored at the remote location. Dispersal operation notes are transcribed to clean sheets in the fleld, and contaminated sheets are then destroyed.

For a typical field experiment, the dispersal crew on the truck reports to the field office sufficiently in advance of release time to recelve special instructions and batteries. The crew is then dispatched to the test area, where radio contact is maintained at all times with the test director. At the dispersal point, after the tracer material has been released, necessary welghing and loading operations in preparation for the subsequent release are performed in the vehicle. 


\section{Test Direction}

During an operation the Field Test Director, either the Chief of the Tracer Test Division or the Assistant Project Engineer, is assisted by the Chief of the Meteorological Division, or his assistant. Field test operations are either directed from a command car, which is provided with a 30 watt mobile transmitter and receiver, or from the field office which is provided with a 60 watt main base transmitter and receiver. The command car is used as a base of operations particularly in the remote test areas which are beyond the effective transmltting range of the small portable radio equipment.

Street level and roof top meteorological stations begin to report local wind direction and velocity, as observed from instruments and from the track of small helium-filled free-flight balloons, an hour before the time scheduled for the first tracer release. These reports are continued at 15 minute intervals, or as otherwise required, to furnish the Test Director with a complete mesometeorological picture of the test area. Where a shift or trend in wind direction significantly different from the planned direction is noted, relocation of sampling or generator equipment may be required. Such revisions in test plans are issued to field crews either prior to leaving the equipment assembly area, or are issued to crew captains in the field by the main base or command car radio.

When reports are recelved that final equipment positions have been taken, and that filters are exposed and samplers started, the command car proceeds to the location of the aerosol generator for the start of the test. 
Final reports are received from remote field meteorologlcal stations, and when all conditions are satisfied, the aerosol generator crew is instructed to procepd with dispersal. A low trajectory free-flight balloon is released from the disperser location during tracer dispersal to further define the local wind direction.

Several spare sampling untts, complete with flow rated filters, are carried In the cormand car for replacement of any units found to be malfunctioning in the field.

\section{Equipment Preparation}

\section{a. Sampling Equipment}

As soon as samplers are returned from the field and flow rating of filter holders is accomplished, preparation of the equipment is begun for the subsequent operation. The purms are removed from the cases and are stored on shelves adjacent to the equipment assembly area. Any pumps that did not operate properly in the field are segregated in preparation for checkup in the instrument shop.

Servicing and charging the lead-acid aircraft type batteries used in the samplers represent the major item of equipment preparation for a test operation. Three hours of operation of the sampler pump depletes the capacity of a fully charged battery, represented by an initial specific gravity of 1.295 or more, to a condition in which the battery is unreliable for further extensive service. Specific gravity readings after such a period of service average less than 1.225 , indicating the need for a full recharge. 
Representative cells in each battery are checked with a hydrometer and the average reading noted. Electrolyte lovel is checked and a carefully measured charge of distilled water is added as required. Sampler cases with batteries are then arranged on racks in the battery charging room, and connections are made to the charging circuits (Fig. II- 4 ).

Charging facilities consist of two Lincoln Electric taper rate generators with a rated charging capacity of 700 ampere hours each (Fig. II-5). Positive and negative direct current busses are installed directly on the charging racks. Male electrical plugs are permanently wired in series botweon these busses, and connection of a biattery for charging is accomplished by inserting a plug into the mating receptacle in the sampler case. Thus, hookup work required for connection of batteries for charging is reduced to a minimum. All batteries in a series string are arranged to be in essentially the same condition of discharge, or specific gravity level, to ensure equal charging of all. The present racks accommodate a total of 36 batteries for each charger, and it is found that all except extremely discharged batteries are adequately charged in an eight hour period.

Charging racks were constructed in six foot sections to facilitate their handling, loading, and transportation botween the field offices in the several cities to be used for the project tests.

After a full complement of samplers has been charged, each battery is again checked by a hydrometer or a wide scale voltmeter. Batteries failing to come to an acceptable charge are reseryed for recharge. Sampler cases are then arranged in rows in the equipment area in the order in which 


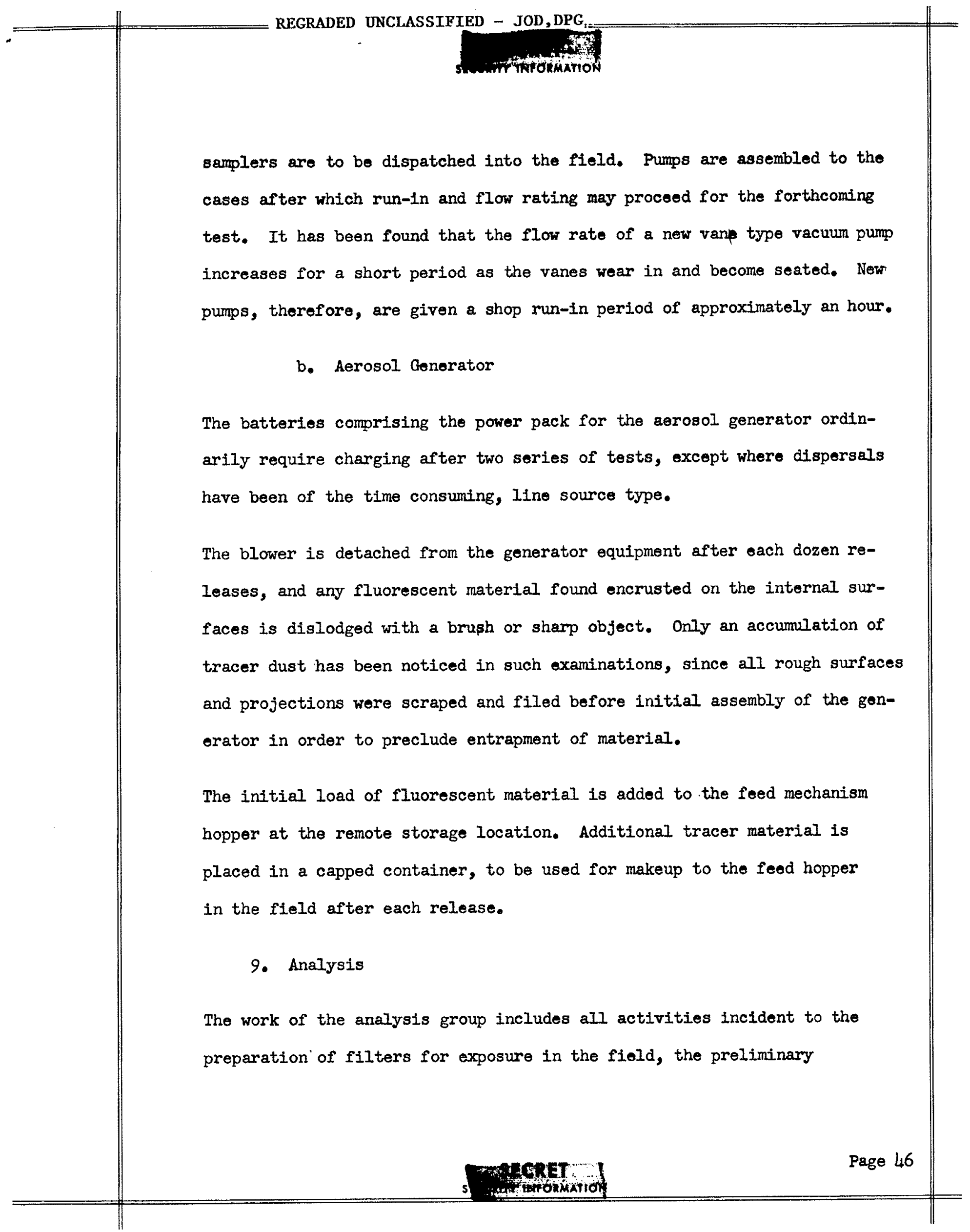


evaluation of exposed filters after a test, the mounting of exposed filters on slides, the counting by microscopic techniques of fluorescent particles, computations relative to determination of concentrations of the tracer simulant at the various sampler stations, and plotting of these values on the test area maps. This work is performed by members of full-time field office force and part-time employees as described hereinafter.

Personnel hired for part-time work in the particle counting laboratory are required to have had microscope or related laboratory experience at the college level. The major source of these workers is the University of Minnesota, from which women in the dental and nursing schools and men in the graduate technical schools have been recruited. Several of the men employed in this work are otherwise employed as technicians in various State of Minnesota agriculturil, dairy, and drug laboratories. The laboratory force numbers approximately 20, of which approximately 75 per cent are women.

Newly hired technicians are required to read a detailed manual outlining all pertinent operating phases of the work, after which familiarity with equipment and procedures is gained by counting standard slides. It has been found that an acceptable counting proficiency is obtained on the average after some ten counting hours, although workers normally employed at work requiring the use of a microscope become familiar with specific techniques in a shorter time.

Several part-time technicians have been trained in the work of filter holder proparation (Fig II-6) and mounting of exposed filters on slides. 
Because of the great volume of filter analysis resulting from performance of a large tracer test program, and the requirement that analysis of a field test be completed as soon as possible after the test, the laboratory counting facilities must be staffed as completely as possible during working hours. Five counting stations are available, (Figs. II-7 and II-8), and it has been considered necessary to schedule use of all these facilities from the start of each weok day until 2100 or later, with a full eight hour use of the facilities on Saturdays, to reduce the large backlog of counting work resulting from the concentrated Minneapolis testing program.

Personnel are scheduled in relays throughout the day, with a two hour counting period representing the average time a person can spend in concentrated analysis without experiencing eye fatigue. In many cases, however, technicians accustomed to using a microscope regularly find it possible to count for four to five hours by taking a short break every hour or oftener. Less experienced operators are given calculation or computing work to perform for an hour between counting periods. The morning hours of the day have been found to be the most difficult in which to schedule personnel for counting operations, since those hired are predominately students. Facilities are generally well staffed during the afternoon hours, and evening hours are well taken up by personnel who are employed elsowhere during the day. Operation of the laboratory factlities requires the supervision of qualified full-time technicians during all hours that the facilities are in use. 
In preparation for a tracer test, several laboratory technicians are assigned to prepare filter holders. Metal holders and plastic dust caps are washed in a detergent solution to remove any traces of fluorescent material remaining from a previous test. After drying, holders are arranged on perforated trays, and membrane filters are inserted into the holders. Trays of prepared filter holders are then stored in a dust-free cabinet in the laboratory until such time as filters are required for flow rating in the equipment assembly area.

After the tracer test, exposed filter holders are arranged on small racks in an ordered manner in preparation for preliminary examination and evaluation of results. The method of preliminary evaluation is discussed in Section V. All preliminary examination work, in which fleld location and exposure data sheets are identified with the respective filter holders, is performed by cleared full-time laboratory technicians to preclude compromise of results. After preliminary evaluation work, holders are returned to the preparation laboratory where membrane filters are mounted on glass slides. This work is performed by part-time techniclans. In this process, glass slides are thoroughly cleaned in a detergent solution and then dried. A coded slide number, assigned by cleared full-time technicians, is given to each slide by means of a gummed label. Exposed filters are carefully applied to the slides with a thin rubber cement. Mounted slides are stored in slide boxes in an ordered manner and are sent to the counting room. The full-time technician in charge of the laboratory 
operations supervises all of the filter and slide preparation work. All instrument setups as well as any repairs or adjustments of the equipment are made by the full-time laboratory supervisor.

With results of the preliminary evaluation of test-exposed filters, the Test Director prepares a plot of tracer material concentrations at the sampler locations for each release. In this manner, preliminary results of a test can be determined within 24 hours after the operation. These preliminary plots form the basis for design of subsequent tests by providing an indication both of the adequacy of the previous sampler array and the effectiveness of maneuvers taken to encompass the aerosol cloud.

From final fluorescent particle count data the total particle population of a filter is calculated, and based on the known average flow rate through the filter, the total dosage of tracer simulant is calculated in particle minutes per liter. All computations of this nature are performed by cleared full-time personnel in the restricted area of the field office. The final total dosage data, in addition to virtual wind track vectors, balloon track directions, and aerosol release information, are then plotted on maps of the test area in preparation for more detailed analysis of the test results. A discussion of results of certain tracer tests conducted during the current period will be found in Section $\nabla$. 


\section{E. SCHEDULED OPERATIONS}

At the beginning of the project, tentative plans were made to conduct tracer tests in Minneapolis and St. Louis during the winter of 1953, the surmer of 1953, and the winter of 1954. In addition, it was planned to conduct tracer tests in various industrial complexes in and near St. Louis during the fall of 1953. Prior to conducting tracer tests, mesometeorological surveys were to be made for several months duration in order to determine the general thermal structure prevailing in these areas to serve as a basis for choice of tracer test areas. It was also recognized that meteorological surveys and tracer tests in Winnipeg during the summer of 1953 would be of scientific interest and would provide useful information by virtue of the long days and short nights prevailing there during the summer. The tentative 1952-1953 winter test schedule represented an optimum program which would be difficult to meet because of problems involved in designing and fabricating instrumentation in sufficient time for a full program:

The actual program of tests conducted to date includes meteorological surveys in Minneapolis and St. Louis to establish meteorological patterns. In addition to the meteorological surveys, tracer tests were conducted in Minneapolis for a period of approximately ten weeks. Because of the late start of tests in Minneapolis, it was considered desirable to obtain as much complete data on that city as possible rather than attempt to divide a short test period between Minneapolis and St. Louis. 
Tentative plans have been made for future testing, based on experience to date and a desire to obtain as much useful information as feasible during the remainder of the program. Current planning is based on the assumption that it will be possible to operate in Winnipeg during the summer of 1953. From experience gained thus far in conducting field office operations, it is indicated that a minimum period of ten days would be required between completion of tracer tests in St. Louis and commencement of tests in Winnipeg. The performance of tracer tests in St. Louis or Winnipeg involves equipment transportation, procurement of temporary quarters, training test crews, and making arrangements to initiate tests. On the other hand, it appears that such a move could be made to Minneapolis from either Winnipeg or St. Louis in approximately seven days, since the facilities for tracer tests there are well established.

Table II-5 shows the proposed tracer test schedule through February 1954. Based on experience to date, three tests per week, consisting of three releases per test, represent the maximum rate at which tests can be conducted and data analzed to permit planning of subsequent tests. The actual number of tests conducted in a locality would in all probability fall short of these optimum operations if unsuitable weather conditions, a shortage of part-time personnel, transportation problems, or other unforeseen difficulties were encountered.

It is planned that mesometeorological surveys will be conducted continur ously in both Minneapolis and St. Louis. Such surveys in Minneapolis will 
be interrupted late in May or early in June in order to use the meteorological equipment in Winnipeg prior to and during tracer tests there.

TABLE II - 5

TRACER TEST SCHEDULE THROUGH FEBRUARY 1954

St. Louis -- Summer 1953

20 May - 1 July -- 18 Tests, 54 Releases

Winnipeg - Summer 1953

$10 \mathrm{July}$ - 10 August -- 12 Tests, 36 Releases

Minneapolis -- Sunmer 1953

18 August - 15 September -- 12 Tests, 36 Releases

St. Louis -- Fall 1953 - Industrial Areas

9 November - 30 November -- 9 Tests, 27 Releases

St. Louis -- Winter 1954

1 December - 20 January -- 20 Tests, 60 Releases

Minneapolis -- Winter 1954

27 January - 26 February -- 12 Tests, 36 Releases

A trip is to be made to Ottawa, Canada, in May to meet with the Defense Research Board to discuss all phases of the proposed program in Winnipeg. It is anticipated that this trip will furnish information regarding operation of a business in Canada, including requirements for customs inspection and employment of Canadians by a U.S. company. If tests in Winnipeg 
are assured, it is planned that representatives of The Ralph M. Parsons Company will go to Winnipeg late in Kay to obtain operating space, hire, and train personnel, and begin the meteorological phase of the program. These surveys will continue through the tracer test program. Specific test sites will be chosen from the analysis of the initial meteorological surveys. Arrangements will be made for the transportation of exposed filters to Minneapolis for analysis.

In the event that Winnipeg tests are not authorized by the Chemical Corps or approved by the Canadian Defense Research Board, or if for any other reason the tests cannot be arranged to be conducted during the desired summer season, the summer tests in St. Louis and Minneapolis may be extended accordingly. 


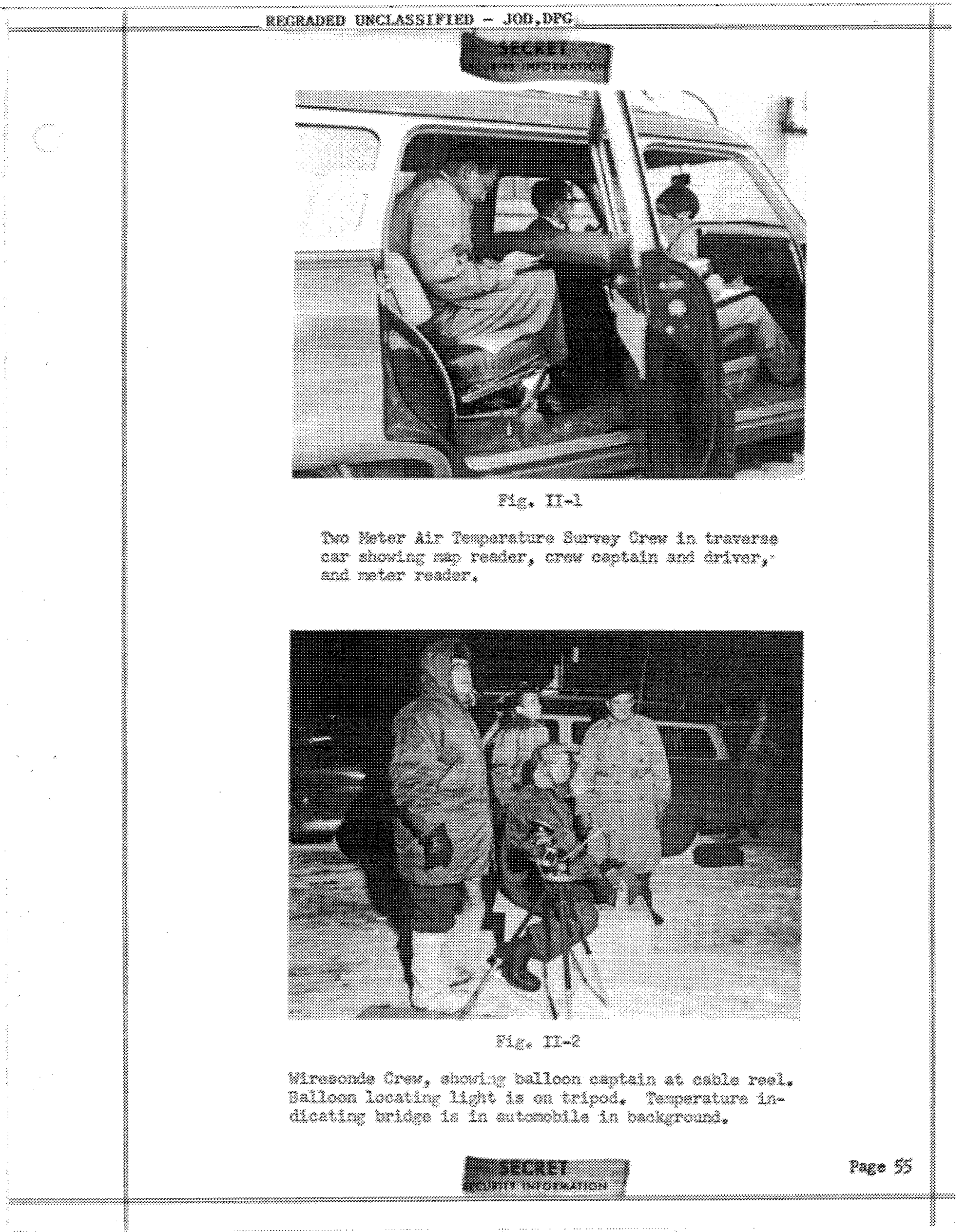




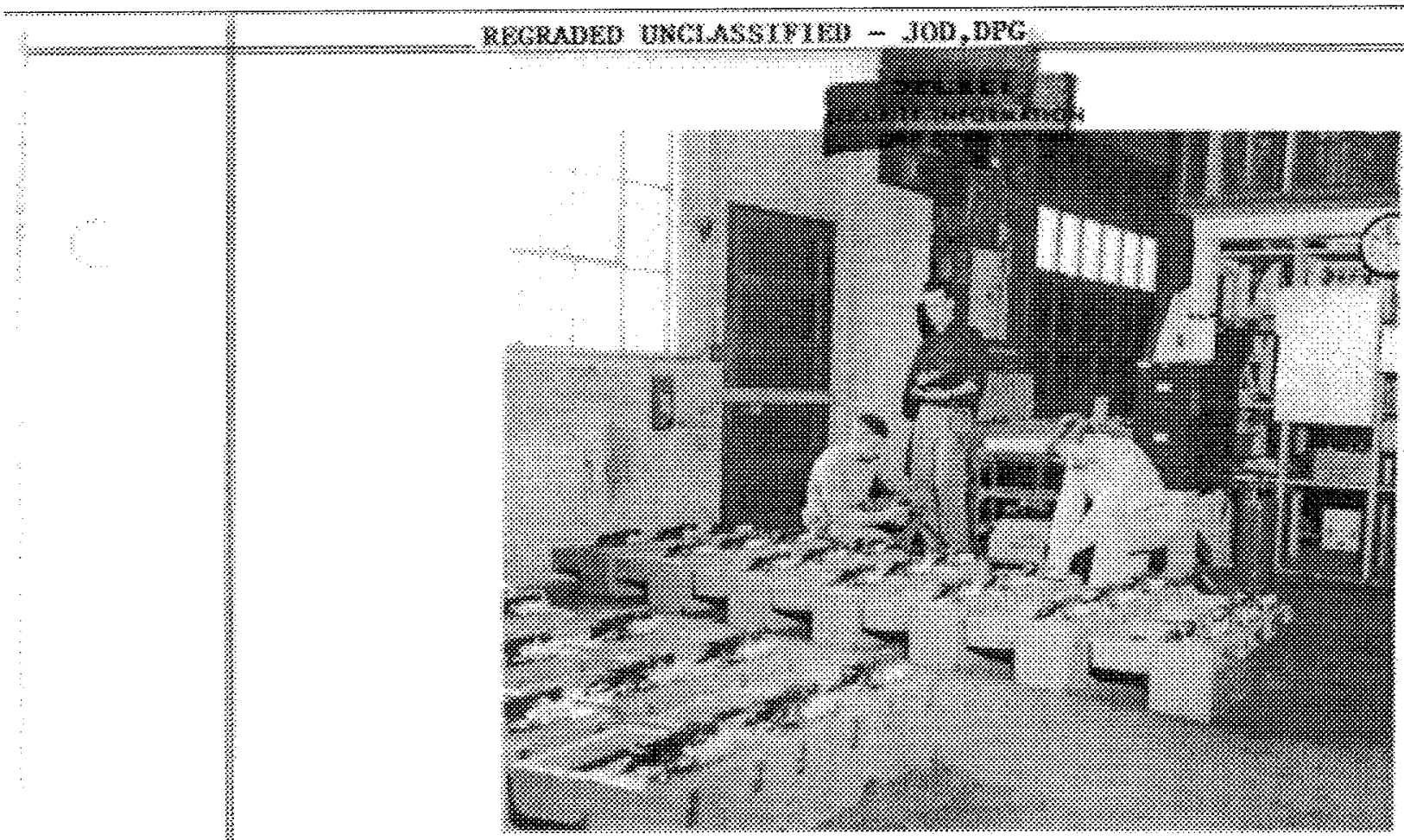

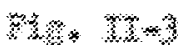

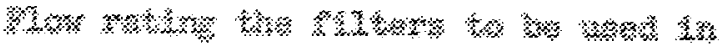

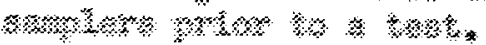

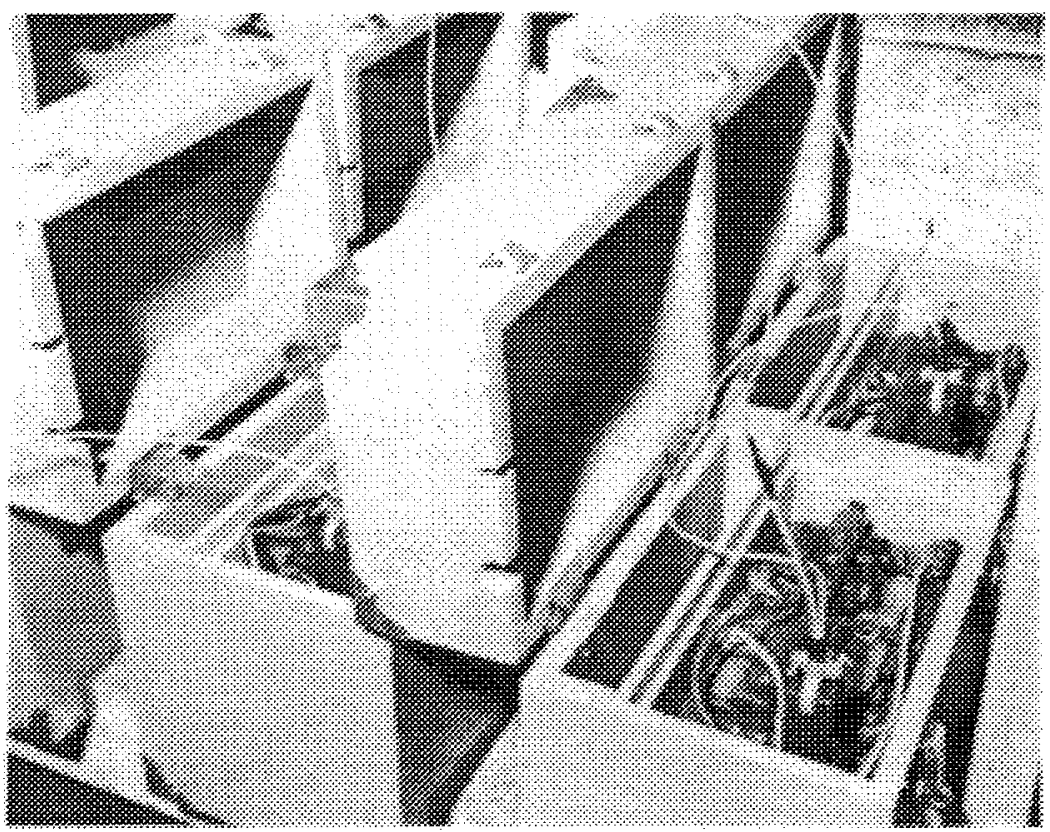

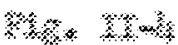

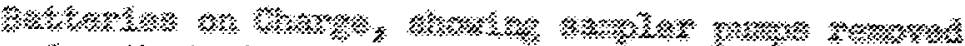

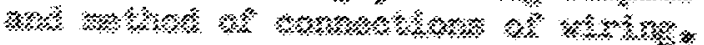




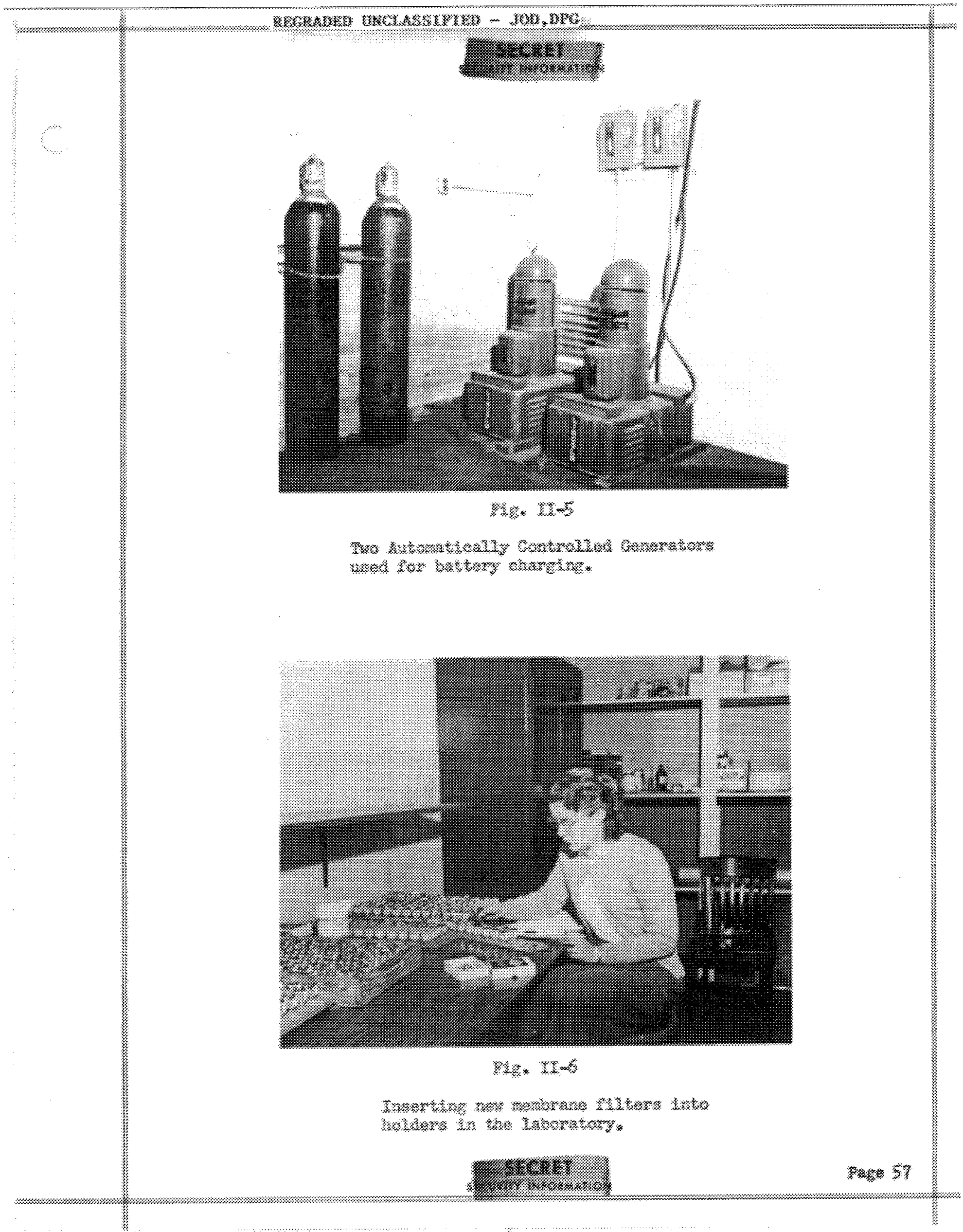




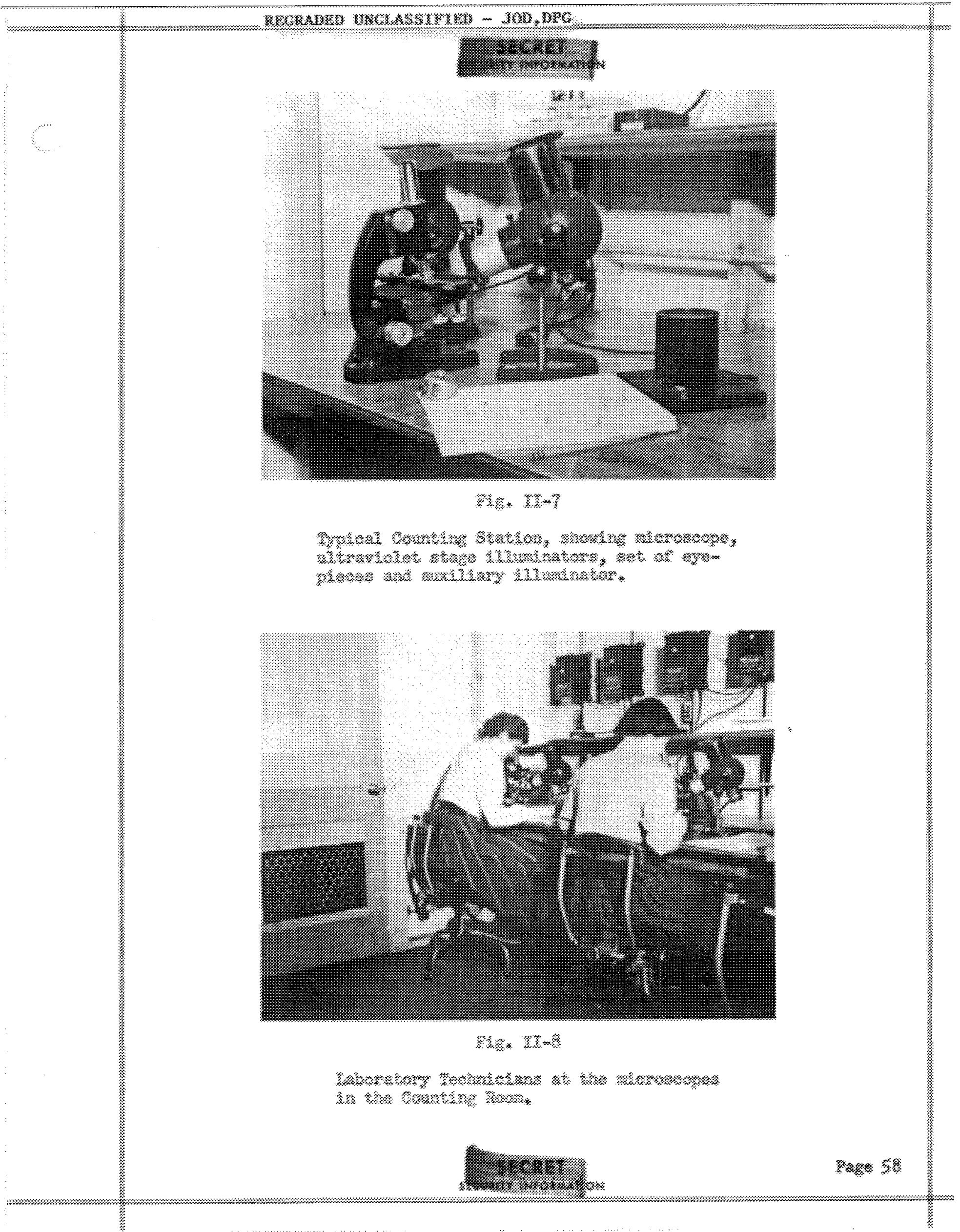




\section{INSTRUMENTATION}

\section{A. GENERAL}

At the end of the period covered by this report, practically all instrumentation has been completed and delivered to the fleld. The only exceptions to the above statement are the time sequential drum impactor and the wind velocity recording units. Both of the latter items are now in the production stage and the first deliveries are scheduled so that some quantities of these items will be available for summer operations in the St。 Louis area。

Continuing the practices established in previous Joint Quarterly Reports, two additional items of instrumentation are written up in following sections. These are the wiresonde temperature bridges and the portable membrane filter sampler including the pertinent accessories. Also included below is a section covering the observations on equipment performance by field personnel, the data for which have been obtained during the winter test program in the city of Minneapolis.

Future reports will continue to contain detailed write-ups on individual instruments, including laboratory and analytical equipment and techniques。 These reports will also contain observations recelved from personnel in the field regarding operation and evaluation of instruments, in addition to a description of problems encountered and their solution. 


\section{B. FIELD OBSERVATIONS ON EQUIPMENT PERFORMANCE}

The following represents a summary of the information received from the field office regarding the performance of instrumentation throughout the winter test period in Minneapolis. The pertinent data regarding each type of instrument are given under separate captions below.

\section{Portable Membrane Filter Air Samplers}

A quantity of 150 MF samplers were produced and shipped to Minneapolis in time for the winter test period. Operational experience with these units indicates that they are entireiy suitable for their intended use, and actual reliability in the field averaged better than $97 \%$ under all conditions. During the severest conditions encountered which comprised an open area test at an ambient temperature of $-16^{\circ} \mathbf{F}_{2}$ a total of 3 out of 120 samm plers set out failed because of mechanical or electrical malfunction. This represents an actual reliability of $98.5 \%$, which can be considered as a conservative estimate due to the fact that some data were obtained prior to the complete failure of the three units mentioned. In general, all components selected for these units proved reliable, and every evidence was given that this equipment will continue to operate with a minimum of maintenance throughout the entire test program.

The major difficulty encountered was in the malfunction of certain of the Gast type AD 440-2 vacuum pumps. A total of 27 pump malfunctions occurred during the winter tests, the majority of which proved to be the result of foreign material getting into the pump body. Because of the nature of the 
foreign material, which generally proved to be small pleces of aluminum or iron, it was impossible to determine whether the failures were due to improper or incomplete inspection on the part of the pump manufacturer or to carelessness in handling during the assembly of the sampler units. In none of the cases mentioned above was the damage serious. A pump exchange service was arranged with the Gast Manufacturing Company of Benton Harbor, Michigan, which will assure prompt repair of defective units, a maintenance supply of spare pumps, and, therefore, the availability of a full complement of samplers for any test.

The 6 volt DC Kendrick-Davis motor used to power these pumps operated with $100 \%$ reliability throughout the winter tests. However, in view of possible future contingencies, a repair and exchange arrangement was established with the Kendrick-Davis people on a bisis similar to that arranged with Gast. The Willard 12 volt aircraft batteries providing prime power for these units also performed admirably and no operational casualties occurred.

During a typical field experiment at Minneapolis, a group of 188 pump filter combinations involving 94 pumps was flow rated both before and after a 4 hour operating period. The mean change between the initial and final rates amounted to a decrease of $3 \%$, and only 11 of the pump filter combinations deviated by more than $10 \%$ from their initial flow rates, which altogether averaged 10.4 liters per minute.

Some slight difficulty was encountered with the plastic dust covers used for the protection of the filter holders. The original filter holder design had a knurled body over which the plastic caps fitted, thereby 
offering both mechanical protection and assuring freedom from contamination of the filter. Under low temperature conditions, it was found that the plastic dust caps tended to contract to the place where the removal from the filter holders was extremely difficult. A further complication ensued when it was determined that in the removal of the caps small shreds of the plastic were scraped off. In several cases minute pieces of the dust cap material fell on the face of the filter and exhibited fluorescent properties under ultraviolet illumination. This phenomenon created some difficulty in the counting of particles although not to the degree that the accuracy of the count was impaired. This condition was alleviated by a redesign of the filter holder which eliminated the knurling and slightly reduced the outside diameter. This minor design change now permits easy removal of the dust cover under conditions of low temperature and eliminates any possibility of scraping extraneous material on the filter face.

The magnetic filters themselves and the quick-connect couplings used in the sampling unit proved to be both reliable and operationally desirable. As a result of tests made on the first filter holders produced, which indicated some air leakage around the ring magnet, all subsequent models have the magnet imbedded in a sealing compound which successfully prevented the recurrence of this difficulty. The provisions made for charging batteries without necessitating their removal from the sampler case, and the battery charging equipment itself, proved satisfactory in every respect, and a complete recharge of all batteries may be made in time to permit the running of a complete sampler array on alternate days. 


\section{Portable Temperature Indicating Bridges}

Sipteen of the portable temperature indicating bridges were completed, as well as the 22 aspirated automobile mountings and 4 aspirated aircraft thermistor mountings. The temperature bridges themselves were operationally satisfactory with the exception of several minor features. A plywood writing panel was substituted for the aluminum panel originally provided because of the difficulty encountered in handling metal parts at below zero temperatures. The only other modification required was the substitum tion of 6 volt DC automobile power for the 3 volt internal batteries originally used for both instrument and chartboard illumination. Personnel in the field found that the use of 6 volt light bulbs provided and arranged for power for the higher voltage lamps by the simple expedient of plugging the circuit into the cigarette lighter on the automobile instrument panel, thereby eliminating the necessity of increasing the size and weight of the battery required in the portable equipment.

As of the end of the current period, no flight test has been conducted in the field using the aircraft thermistor mountings. Laboratory tests at Stanford University, however, indicated that some slight modification in design would be desirable in order to provide better radiation shielding for the thermistor elements. Therefore, the aircraft mountings in the field were recycled through stanford and modified to incorporate this latest change in design.

As mentioned in JQR 2, the original automobile aspirated thermistor mountings, of which six were constructed, failed to withstand the structural 
shocks imposed on the equipment by the extremely rough streets and inclement weather conditions prevalent in the Minneapolis area, even though exact duplicates of this equipment had been found satisfactory for use in Palo Alto. Therefore, 16 additional units of heavier mechanical construction were produced. These modified units withstood the rigors of the winter test program in excellent fashion and appear to have eliminated any possibility of future difficulties. The remaining problem with the automobile mountings resulted from factors which are not under the control of operating personnel. These include the infinite variety of bumpers and bumper guards encountered on the automobiles of part-time personnel. A serious problem thus arises, due to the need for obtaining a large number of various types of bumper brackets and trafler hitches. Another problem in this connection was the somewhat fragile bumper-attaching brackets provided on late model automobiles. The excessive flexure of the automobile bumper and its attaching brackets resulted in tilting the aspirator mast from vertical.

\section{Wiresonde Temperature Measuring Equipment}

The wiresonde temperature measuring equipment consists of the temperature measuring bridge, the thermistor elements and protective cage, the cable reel, and the lifting device which, in the case of Minneapolis, was a Kytoon. The only serious equipment problems were the freezing of the wiresonde batteries and the reel bearings. The former problem was capable of easy solution by actually operating the bridge itself either within a building or a heated automobile or truck. The latter problem was 
successfully solved by reaming the bearings somewhat oversized and by the use of low temperature lubricants such as Prestone 200 or Yukon oil.

The major problem in wiresonde operation was the result of high wind conditions which effectively prevented the use of this equipment during many of the tests. Some thought has been given to a practical solution to this problem, but no feasible answer has appeared which would allow use of the wiresonde equipment under conditions of high winds or extreme turbulence. With respect to turbulence, the rapid temperature fluctuations which occurred during wiresonde observations under such conditions posed several questions. In many cases temperature readings could not be taken because of violent meter fluctuations. In other cases the average temperature changes reversed without any apparent cause. In a series of tests conducted in Minneapolis during the winter months it was definitely established that both the fluctuations and temperature reversals were true measurements of an actual phenomenon caused by the inhomogeneity of the upper air under turbulent conditions. The test results are considered conclusive and indicate that in every case the equipment was performing in its specified manner and within its established limits of accuracy. Field evaluation of the balance of the instrumentation will be included in future reports. 


\section{PORTABLE MEMBRANE FILTER SAMPLER AND ACCESSORIES}

One of the primary pieces of equipment required for conducting tracer tests was a rugged, portable piece of air sampling equipment for obtaining quantitative measurements of the simulant materials. The fundamental design criteria for this equipment were established by personnel at Stanford University, based on their theoretical and experimental background and on the results of tests in the Palo Alto and San Francisco areas. The general requirements as established included the following:

1. The pumping unit must be capable of providing a minimum flow of 7 liters per minute of free air through a 16 millimeter diameter deposition area of a membrane filter。

2. The holder for the filter must be constructed so as to permit ready loading and unloading of the filters and must provide a secure air seal of a type which could not result in damage to the filter membrane itself.

3. The equipment must be capable of satisfactory performance over an ambient temperature range of $-40^{\circ} \mathrm{F}$ to $\$ 115^{\circ} \mathrm{F}$.

4. The final design of the equipment should represent the maximum in portpbility and ruggedness and must be capable of operation by relatively unskilled part-time personnel.

5. Provisions should be made for the rapid interchange of filter holders to permit multiple testing to be accomplished by a single unit.

6. The entire equipment should be packaged in a rugged case capable of withstanding extremely rough usage and having provision for 
locking the equipment cover and securing it by means of a chain to prevent theft.

7. The equipment should be inconspicuous in appearance so that use of large numbers of these units in heavily populated urban areas will not excite undue attention.

The equipment as finally designed and produced has successfully met all of the above requirements. As seen in Figs. III-I, III-2, and III-3, the portable membrane filter samplers consist essentially of a vacuum pump and battery mounted in a $3 / 4$ inch thick marine plywood box. The box dimensions are 14 inches in height, 13 inches in width, and 9 inches in depth, with the complete equipment woight including a fully charged battery being in the neighborhood of 35 pounds. The equipment is built in three sections as shown in Fig. III-3. The pumping unit, the control panel, the filter holder, and vacuum hose are contained in a single unit which plugs into the top section of the lower half of the case. The bottom of the case contains a battery compartment and a hose storage compartment. The lid section is attached to the lower half of the case by slip hinges which permit its easy removal for maintenance. The entire box is finished in two coats of a durable, weatherproof enamel of an inconspicuous neutral. gray color. Metal corners are provided for the protection of the box, and the lid is secured by means of two trunk type latches which contain provision for locking by use of a padlock chain combination. The pump deck contains a Gast AD 440-2 vacuum pump which is powered by a KendrickDavis 6 volt DC motor. This unit is shock mounted on two Iord vibration mounts and is equipped with both an input and output filter unit. The 
purpose of the Iord mountings is to minimize mechanical noise rather than for any vibration protection of the unit. If the pump were mounted directly on the panel, the sounding board effect would raise the noise level to an objectionaple value.

The input filter section is a safety device to prevent abrasive or foreign material from entering the pump chamber when the unit is operated without a filter holder and membrane filter. The output filter section acts as an acoustical mafler and is very efficient in the reduction of the high frequency acoustical sound level. A manual petcock is provided on the output of this acoustical maffler as a means of regulating the air flow as desired. The control section contains a DPST on/off switch, a standard cartridge type fuse for battery protection in case of a direct short, and a polarized accessory outlet which can be used to provide 6 volt DC power for either lights or the operation of other units as required. Provision is also made in the deck for the storage of four filter holders. This entire unit fits into a recessed section in the lower half of the case and connects with the battery by means of a four prong Jones plug. The vacuum hose is permanently attached to the pumping section and is stored in a separate compartment immediately adjacent to the battery when the unit is assembled.

There are no mechanical or electrical devices contained within the lid other than a sponge-rubber covered hold-down block which secures the filter holders in position when the lid is closed, and two openings with 
metal closures which permit the hose and an electrical line to be brought out from the box with the lid closed and locked.

The battery chosen for this untt is a willard aircraft type AW 12-25, The batteries as ordered from the Willard Battery Company were specially constructed in the form of two 6 volt cell groups which are connected in parallel to provide power for the operation of the pump. This battery was chosen because of its desirable form factor, relatively high efficiency, and physical characteristics. It is of the spillproof typo which is necessary to prevent damage to any of the equipment from battery acid should the sampler case be overturned. Further protection is provided by a manifold which conducts the battery gases from each cell to the outside of the box through a small grilled opening in the side of the case. As arranged, the battery may be charged without the need for removing it from the samplex case as shown in Figs. III-4 and III-5. This procedure is accomplished by equipping a battery charging bus with male Jones plugs corresponding to the type installed on the pump unit. This feature saved considerable time in the field as it permits the pump and hose to be removed and the caso and battery to be taken directly to the charging room.

One of the most critical parts of this equipment is represented by the filter holders. The membrane filters used are a cellulose ester membrane and are extremely fragile mechanically. Experience proved that any rotational force applied to this type of filter may result in tearing of the filter and making it unusable. Also, this mechanical weakness requires that a secure backing be provided which will have the dual capability of 
providing mechanical support for the filter without introducing any undue violent disturbance of the incoming air stream.

The two factors mentioned above, combined with the necessity of maintaining an air seal around the periphery of the filter to assure that all air drawn through the pump passes through the 16 millimeter diameter active filter area, resulted in considerable study being expended on the design of the final configuration arrived at are shown in Fig. III-6. The essential parts of the filter holder as shown in this photograph are the filter holder body, the membrane filter, the motal retaining ring, and a plastic dust cap.

The filter holder body consists of an inner section surrounded by an Alnico Number 5 cast magnet which is covered by a protective aluminum outer sleeve. The top surface of the magnet is ground flat and is positioned .002 inch above the surface of a 100 mesh monel screen which acts as a backing for the filter. In operation the filter is placed on the magnet and screen surface, and the soft iron washer is laid on the filter face. The surface of the washer is ground flat, and the magnetic attraction between the magnet and the washer provides an air seal around the periphery of the filter. A slot is milled in each side of the outer sleeve to allow easy removal of the washer. The plastic dust cover can be placed over the entire assembly giving both mechanical and contamination protection to the filter. The base of the filter holder was machined to fit a Wiggins quick-connect vacuum coupling. This permits filter holders to be connected and disconnected from the Wiggins fitting provided at the end of the vacuum hose in a matter of ten seconds or less. The ability to make rapid changes of 
filter holders in the field proved to be extremely valuable. The use of the magnetic principle for the provision of an air seal also permits rapid loading and unloading of filter holders in the laboratory and minimizes damage to the filter media itself either before or after exposure. The maximum pressure drop through the entire vacuum system including the filter holder without filter, the vacuum hose, and the input filter to the purmp averaged less than one inch of mercury at $I_{4}$ liters per minute free flow.

Representative purm flow and fllter flow characteristics are shown in Fig. III-7. The flow rate and pressure drop corresponding to the point where the two curres cross represents the expected values for the combination of filter and pump; other units will have a similar but not identical curves.

Fig. III-8 shows how the flow rate and current drain of the complete sampling unit changes with battery voltage. Over the useful battery life, nominally 50 ampere hours at voltages varying from 6.6 to 5.4 volts, it will be seen that about nine hours of operation may be expected, with the flow rate varying from 9.6 to 8.4 liters per minute. At low battery temperatures, of course, the performance will not be as good but will still be satisfactory.

In operation the amount of hose required may easily be fed out through the port provided in the side of the box. In many cases only the filter holder itself is exposed as indicated in Fig. V-8. Where the filter 


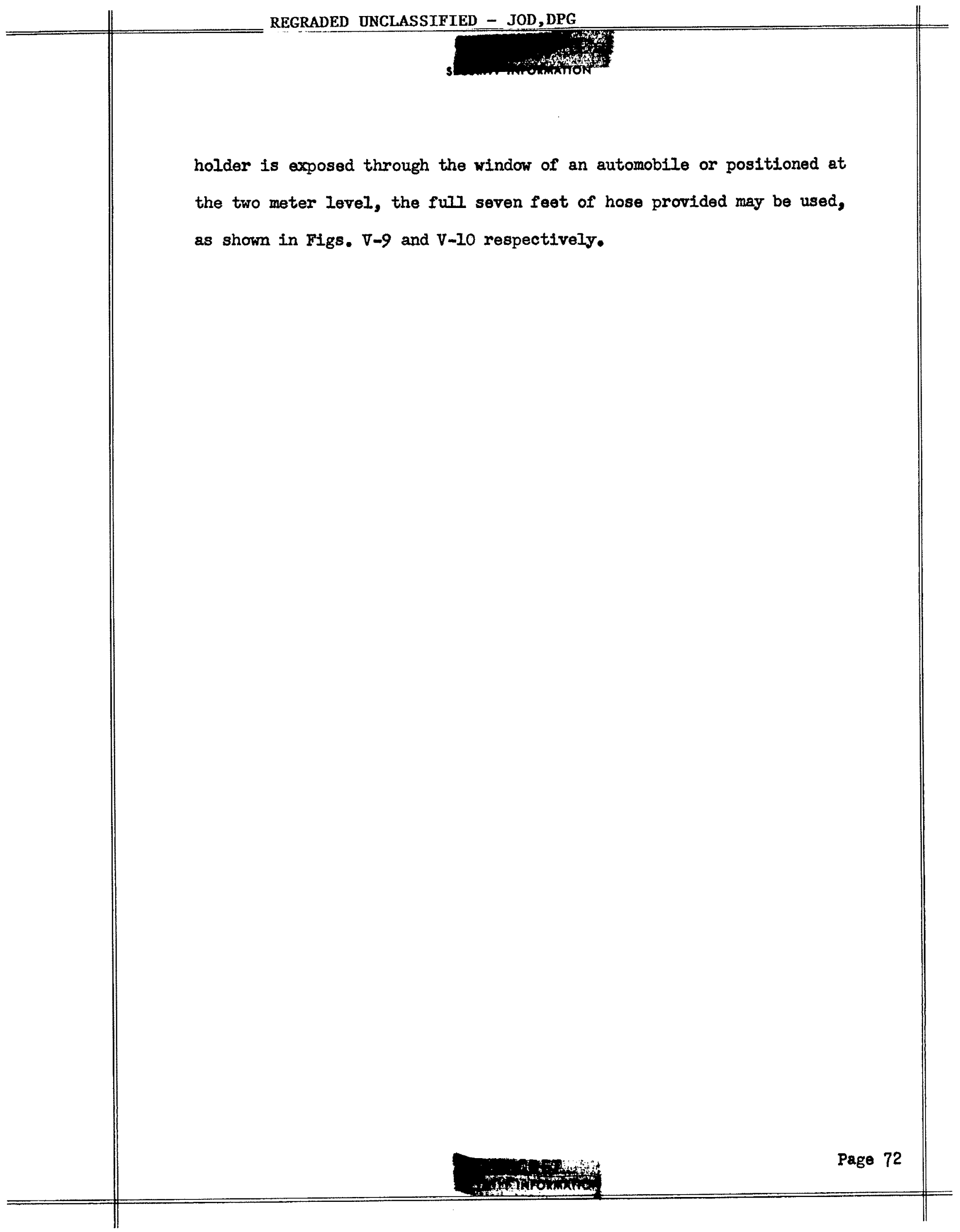


D. A MODIFIED ALNOR VELOMETER, JR. FOR MONITORING BATTERY OPERATED SAMPLERS

Since the battery operated sampling units were designed in the interests of portability with no automatic means of regulating the air flow to a standard value, it is necessary to keep track of the flow through each individual filter in order to enable calculation of total dosages from filter counts. The Alnor Velometer, Jr. (IIlinois Testing Laboratorles, Chicago, Illinois) furnishes a good basic instrument capable of responding to a moderate pressure drop across the intake and outlet apertures, and hence may be modified to form a compact flow meter.

This instrument, see Fig. III-9, is used to measure wind speeds by facing the inlet port into the wind, thus allowing an air flow through the instrument. This air flow impinges on a pivoted vane and deflects it to a position where the restoring force provided by a coiled hair spring is equal to the deflecting force. The design of the vane housing permits the instrument to be read as an almost linear function of wind speed over most of the scale. Therefore, when modified, the instrument is capable of being used as a flow meter having a quite linear scale deflection as a function of rate of flow. The instrument can be held in any position, and it is well danped because of the lightweight construction of the balanced vane and pointer.

This flow meter, illustrated in Fig. III-10, is provided with an adapter head which fits over the filter to be flow rated. A cemented rubber ring making contact with the hold-down ring of the filter gives a leakproof 
connection. The air drawn in through the filter enters from the outside through the inlet holes in the crosspipe and the stream divides, mostly flowing through the orifice between the crosspipe and the adapter head. The remaining fraction of the air flows through what was formerly the inlet port of the Velometer to produce the deflection corresponding to the measured flow rate, and then enters the adapter head through what was formerly the outlet port.

Because of the use of common inlet holes in the crosspipe, the reading is not affected by high ambient wind speeds. The holes are made so large that even if the outer one is accidentally blocked, such as by the operator's gloves, the reading will be practically unaffected.

The size of the metering orifice is chosen so that the useful range of the flow meter will be from 2 to 15 liters per minute, graduated at intervals of .5 liter per minute. Since these graduations are quite open, the flow rate may easily be read to the nearest. I liter per minute and the absolute calibration at $70^{\circ} \mathrm{F}$ is considered to be good to plus or minus 0.2 liter per minute. Since the pressure drop across the flow meter at 10 liters per minute is only $.25 \mathrm{~cm}$ of mercury, an estimated $1 \%$ change in flow rate will be occasioned by addition or removal of the flow meter from the pump filter system.

In the preparation of the direct reading scale, each instrument is calibrated at a number of fixed points (determined by a set of critical orifices) against a Fischer-Porter Triflat Flowrater, and a smooth plot is 
made of the deflection in terms of the original 0 to $40 \mathrm{mph}$ scale as a function of flow rate. From this plot a new scale is hand drawn with lines at the 1 liter per minute and .5 liter per minute intervals. The modified Alnor Velometer, Jr. flow meter, which may be reforred to as a shunted vane flow meter, gave very satisfactory performance and offered a more rapid and reliable means of checking large numbers of filter-purp combinations (see Section IV) than the Ilquid type flow meters previously used. FIgures II-3 and $\nabla-14$ show the flow meter in actual use at Minneapolis during flow rating of a large group of samplers. 


\section{E. WIRESONDE THERMISTOR ATR TEMPERATURE MEASURING BQUIPMENT}

\section{Requirements and Features}

In the present mesometeorological studies, the vertical temperature profile of the air at various localities plays an important part as an indicator of the expected rate of diffusion of gas and aerosol clouds. The equipment described below fulfills the need for a measuring unt which may be readily moved from place to place. Under ideal conditions it will give readings signiflcant to the nearest tenth degree Fahrenhelt and will cover a range of altitudes from a few inches to nearly 1000 feet above the ground.

The device consists of a cage-protected Wistern Electric Number D176980 bead type thermistor element, a hand operated cable reel with provision for suspending the cable and thermistor from a Kytoon or cluster of $100 \mathrm{gm}$ meteorological balloons, and a deflection indicating wheatstone bridge unit containing a stable battery operated vacuum tube amplifier. In the interests of portability and simplicity, automatic recording is not employed. Therefore, at least two operators are required; one man attends to the balloon cable, varyling the altitude of the thermistor, and the other reads the bridge and records the indicated temperatures as a function of height and time.

The following characteristics of the 0176980 thermistor make it well suited for this type of measurement: bead diameter, .013 inches; resistance, 75,000 ohms at $25^{\circ} \mathrm{C}$; temperature coefficient, $4.3 \%$ resistance change per 
degree Centigrade at $25^{\circ} \mathrm{C}$; dissipation constant in st1ll air, $0.12 \mathrm{mfll1}-$ watts per degree Centigrade rise in still air; thermal time constant, 0.5 seconds.

Photographs of the unmounted thermistor bead and the protective cage are given in Figs. III-1I and III-12, respectively. Becsuse of the samll physIcal size of the bead itself, the rate of response is rapid as compared to other temperature sensing elements of equal ruggedness and stability. The small size also enhances the unit area heat-transfer characteristics of the bead and hence permits it to be relatively free from radiational heating and cooling even when used unshielded and without aspiration. The fact that aspiration of the sensing element is not used in the present equipment greatly simplifies the cable and balloon requirements since only a minimum load need be supported by the balloons.

The lift required from the balloons is further reduced by the use of a lightweight balloon cable: 1000 feet of Plastoid fiber glass insulated three strand Number 30 copper, capable of supporting 100 pounds. This small copper size is made permissible by virtue of the comparatively high resistance and large temperature coefficient of the thermistor bead.

The high resistance of the thermistor bead does offer one drawback in that a film of condensed moisture on the end of the glass stem between the supporting wires (see Flg. III-II) will offer a shunting path across the bead and cause the instrument to read incorrectly. Therefore, it is intended for use only at less than $100 \%$ relative humidity. 
Although the internal temperature of the dry cells constituting the power supply to the bridge circuit and amplifier should not be allowed to fall below about $20^{\circ} \mathrm{F}$, the calibration ranges of the instrument extend from a nominal $-10^{\circ} \mathrm{F}$ to $+120^{\circ} \mathrm{F}$.

2. Additional Characteristics of the Thermistor Sensing Element and its Means of Support

The mechanical means of supporting the thermietor bead, involving four $1 / 8$ inch sections of .001 inch diameter platinum wire, make it essential to protect it during handling and use from any possible contact with the lead wires, balloon cable, or leaves and twigs near the ground. The weight of the bead Itself, however, is so small that the sensing element is not vulnerable to transmitted mechanical shocks。

The protective cage consists of a six sided piano wire framework ending In a loop at the top for attaching the balloons and silver soldered to a brass sleeve at the bottom for holding the lucite adapter in which the glass stem of the thermistor unit and extemal flexible leads are held by casting resin. The wire spacing is sufficiently open to avoid spurious effects from radiational heating or cooling of wires. These effects, of course, would be most pronounced under still air conditions.

Although relatively fow beads have become casualties in the field either from mechanical damage or from escape by balloon, this possibility together with the extent of the individual variations in resistance temperature characteristics of the beads led to the decision that it would not 
be worthwhile to attempt to make the bridges accurately direct reading. At the present stage of development, this would require an undue amount of time for individually adjusting the resistors for a particular thermistor bridge. Moreover, because of the limitations of the allowablo measuring current which may be passed through the thermistor without exceeding the permissible temperature rise, some sacrifice in the desired linear relationship between bead temperature and bridge indication must be made or the voltage sensitivity of the vacuum tube amplifier must be increased to the point where the zero drift is apt to become great onough to interfere with maximum ease of use under rigorous field conditions.

Therefore, although the direct readings give an approximate idea of the course of the indicated temperature changes, these readings must be subsequently referred to calibration tables before the true temperatures are obtained, and two or three thermistors used with a single bridge may differ in direct readings by several degrees Fahrenheit before the corrections are made.

The fast response time of the bead thermistor is considered desirable in vertical traverse work where the altitude of the thermistor varies rapidly, although the naturally occurring temperature fluctuations at any constant level may cause greater apparent difficulty in assigning a definite air temperature to that level than if a more slowly responding sensing element were used. The extent and rapidity of these fluctuations are in themselves an indication of the mesometeorological conditions and, even though gtated qualitatively, are a useful addition to the temperature-height data。 


\section{Bridge Circuit.}

The simplified bridge circuit of Fig. III-13 has a number of features in common with the bridge circuit developed for the $14-\mathrm{B}$ aspirated thermistor air temperature indicator described in Section III, JQR 2. The VTVM (vacuum tube voltmeter, $i_{0} e_{0}$, the amplifier plus the Weston Model 301 0 to 50 microameter) may be switched (Sw2) across $R_{9}$ and adjusted to a 45.0 1 a indication by $R_{\text {adjo }}$ in order that the ratio 'of bridge current to VTVM sensitivity may be kept constant. This feature is even more important in the case of the wiresonde bridge than in the case of the aspirated thermistor bridge since the sensitivity of the unbalance indicator, now the combination of the 0 to 50 microammeter and the vacuum tube amplifier, is more likely to show variations with time and instrument temperature and among the different units due to manufacturing variations in the vacuum tubes.

The purpose of the voltage-dividing resistor series $R_{51} R_{52}, R_{31}, R_{32}$ etc., Is to recuce the bridge current to fulfill the following two conditions:

a. That the $I^{2} R$ thermistor heating at any temperature on any range not exceed $.25^{\circ} \mathrm{F}$ in still air and

b. That on Ranges $I_{2} 2,3$, and 4 , the temperature difference. corresponding to a deflection change from 0 to 50 microamperes be close to $25^{\circ} \mathrm{F}$, and that on Range 5 a temperature difference corresponding to the 0 to 50 microampere range be close to $50^{\circ} \mathrm{F}$. 
Fulfilling these conditions allows the bridge to be nearly direct reading in conformation to the 0 to 50 graduated meter scale on all ranges, and also, for Range 5 permits the thermistor heating current to be kept small enough to fulfill requirement "a".

The balancing resistor series $R_{1}$ through $R_{5}$ is so chosen that the bridge will give zero deflection at, respectively, $-10^{\circ},+10^{\circ}, 30^{\circ}, 50^{\circ}$, and $70^{\circ} \mathrm{F}$, based on the expected $200 \mathrm{ohm}$ cable resistance and the design mean temperature-resistance function curve of the group of thermistors originally ordered.

The VTVM unit is a balanced two tube circuit enploying a pair of dry cells operated Raytheon CK 502 AX hearing aid tubes; in Fig. III-13 it is merely denoted by a block symbol. The absolute sensitivity varies from .55 to .65 volts required for a full scale reading and the plot of applied emf against meter deflection in microamperes is not quite linear, but is fairly reproducible despite variations in battery voltage.

Before the bridge is put into operation, and at suitable intervals thereafter, the zeroing button Sw3 is depressed and the VTVM indication set at zero by means of an internal variable voltage source controlled by $a$ zeroing knob on the panel. The rates of drift of the VTVM unit and of the bridge battery $B_{1}$ supply voltage, are so small, especially above freezing ambient temperatures, that the zeroing procedure (which must obviously be done first) and the bridge current adjusting procedure need be repeated only at 15 minute intervals or greater after the bridge has been in operation for the first five mimutes. 
The finished bridge unit, with the case opened into operating position, is shown in Fig. III-I4. The upper hinge on the control panel allows it to be raised for battery changing. It will be observed that there are three pairs of terminals for attachment of thermistors; pair No. I is normally connected to the bridge, and pairs No, 2 and No, 3 are temporarily connected by pressing the appropriate buttons. This allows similtaneous observations of air temperature at the balloon altitude, at the base level, and, if the equipment is operated on a roof top, of temperatures down to ground level. Figure III-15 shows an interior view of the instrument case with the batteries in place but not connected. The space under the clipboard is available for storing the thermistors in their cages as well as the panel lights.

\section{Wiresonde Reel and Balloon Attachment}

The wiresonde reel (see Fig. III-16) is operated by mean of a hand crank, and wraps the cable around a 6 inch diameter flanged drum. The fixed ond of the cable terminates at an outside connector block connected to well insulated brass slip rings from which silver contact brushes make connections to the bridge terminals. This provision onables the thermistor bead resistance to be read at any time during ascent or descent of the balloons as well as when the reel is stationary by the cam-operated brake shown at the lower right. Terminals under the slip ring housing provide electrical connections to the three cable wires.

In normal operation one lead of the balloon cable is connected to the balloon reel stand which is in turn connected to a good electrical ground 
and also to the grounded side of the thermistor bridge instrument case. This procedure reduces the shock hazard occasioned by nearby power lines and in addition reduces the sometimes large effects of radio frequency pickup from nearby broadcasting and television transmitters. For certain cable lengths this effect has, on occasion, completely vitiated the bridge readings until proper grounding wes Installed; strong radio frequency voltages, despite the presence of bypass capacttors across the bridge input terminals and across the grid circuit of the vacuum tube amplifier, have in these cases blocked the amplifier so that it would no longer respond properly to the D.C. unbalance emf from the bridge circuit, This condition has been easily detected by the peculiar and fluctuating behavior of indications, and has not jeopardized the reliability of the temperature profiles.

The manner in which the thermistor cage is inserted between the cable and the balloon cord is shown in Fig. III-17. The cable strain is transferred by means of grooved Bakelite rings around which the cable is wrapped sereral times and then secured with tape and string. A heavy clamping pressure is not applied to the cable because it has been found that there is danger of distorting the interior plastic insulation and short-circuiting the copper wires.

The peripheries of the Bakelite spools also tend to distribute the points on the cable at which the copper is most subject to continual flexing. To safeguard against parting of the cable at the point of strain, the lower spool is attached to a jurper wire which bypasses the thermistor 
cage and is attached independently to the balloon cord. Thus, it is only the upper spool, to which the looped thermistor leads are attached, that normally takes the strain, while the lower spool and jumper act as a standby.

A Kytoon, which is normally used with the wiresonde equipment rather than balloons, is shown in Fig. III-18. The KJtoon, being a special form of airfoil balloon, has better lift characteristics and stability at high wind speeds and offers less horizontal drag than round balloons. The one 1llustrated, a Dewey and Alny Kytoon "8000", displaces 82 cubic feet, is 126 inches long by 51 inches in diameter, and has 4 to 6 pounds of lift at a $5 \mathrm{mph}$ wind speed.

\section{Calibration and Accuracy}

Since the bead type thermistor and its leads are directly exposed, the bead thermistors are not calibrated by direct immersion in liquid baths but are mounted in a liquidproof brass tube container which is immersed in the constant temperature bath. The reference temperature is read by means of frequently calibrated Mo. 30 copper-constantin thermocouples mounted close to the beads. A slow strean of helium (for better temperature equilibration) is passed through a colled copper tubing heat exchanger surrounding the brass container, then through the bottom of the container, and finally out through the one-half inch lucite tube which also brings out the thermistor and thermocouple leads. This tube extends from the top of the brass container, kept about two inches below the level of the bath, to a height of ten inches above the surface. In this way appreciable 
heat exchange between the interior of the container and the room air is prevented, and by virtue of the approximately equal response times of the thermocouples and themistor beads, accurate caltibrations are possible even if slow drifts occur at the low temperature when the bath is not thermostatically controlled.

Termerature resistance data are generally taken at $115^{\circ}, 90^{\circ}, 32^{\circ}$, about $0^{\circ}$, and about $-20^{\circ} \mathrm{F}$ and translated into resistance values for even $5^{\circ} \mathrm{F}$ intervals from $-40^{\circ}$ to $+115^{\circ} \mathrm{F}$. The method is similar to that deacribed In Section III of JQR 2 for the $\Psi_{4-B}$ thermistor aspirated air temperature indicator. The bridge unit is then calibrated by substituting for the thermistor a precision dial resistance box which is set in turn to the known thermistor resistance values at the $5^{\circ} \mathrm{F}$ intervals. The deviation of the bridge indicated temperature from the even $5^{\circ} \mathrm{F}$ intervals is recorded and translated into a correction curve.

Since no attempt is made to equalize the temperature resistance characteristics among a group of thermistors and since the VTVM sections of the different bridge units have characterlstics which may depend on the individual tubes used, each bridge indication of temperature must, for translation into air temperature, be referred to a correction curve applying to the particular thermistor and the particular bridge used.

In the field, frequent comparisons between the corrected bridge readings and concurrent readings taken with a sling psychrometer will insure against 
serious inaccuracies due to failing batteries, moisture, and contemination on the thermistor bead and its support, stray electrical leakage, and partial component failures in the bridge indicating unit.

\section{Performance in the Fleld}

It is possible for a two man crew in favorable weather to unload the entire equipment from a station wagon or walk-in van and to make the wiresonde runs. For the sake of more rapid operation, for operation in gusty winds, and when the ambient temperature gets below $20^{\circ} \mathrm{F}$, a larger crew is desirable.

At low temperatures all operations become more difficult, especially with gloves on, and the bridge itself must be kept in a heated car to provent the batteries from freezing. By making use of a larger crew successful operations have been conducted at Minneapolis down to the limt of the lowest range, $-10^{\circ} \mathrm{F}$, of the bridge, and several of the bridges were subsequently modified to extend the range down to $-25^{\circ} \mathrm{F}$. Figure II-2 illustrates the cold weather operation of the wiresonde by a four man crew.

In the interests of safety both of operating personnel and of chance finders of escaped balloons, only helium, not hydrogen, is used for filling the balloons. Since this is rather expensive, it is standard practice to store and handle the Kytoons in the inflated or at least partially inflated condition.

Also for reasons of safety, certain electrical hazards in the operation of the wiresonde equipment must be recognized and dealt with. Before setting 
up the equipment at a new location, a thorough survey is made to locate any high tension wires in the vicinity, and if these are present the maximum allowable balloon altitude is set at very conservatite safe limits, dependent upon anticipated variations in wind speed and direction.

If the balloon cable should break so as to leave the balloon pulling its lead wire across country, there would be the danger of someone innocently taking hold of the trailing wire while it is draped across a high tension line. Therefore, the maximum tension to which the cable will be:subjected is kept well below the rated 100 pound minimum breaking strength, and operation in strong winds is avoided, particularly when the temperature profile is of secondary interest.

In practice, it is found that the altitude may usually be determined with sufficient accuracy from an experimentally determined table in which the balloon altitude is given as a function of the elevation angle of the balIoon measured at the reel location and the length of cable paid out as indicated by coded markings on the cable. Allowance is made, of course, for the distance beneath the balloon at which the thermistor cage is suspended. In daylight the balloon's vertical angle is measured by a simple clinometer reading to the nearest degree, and at night an automobile spotlight mounted with altitudemazimuth dials is centered on the Kytoon。

Additional reference to the wiresonde operations is made in Section II of this report, and some of the wiresonde data are presented in Section $\nabla$. On 


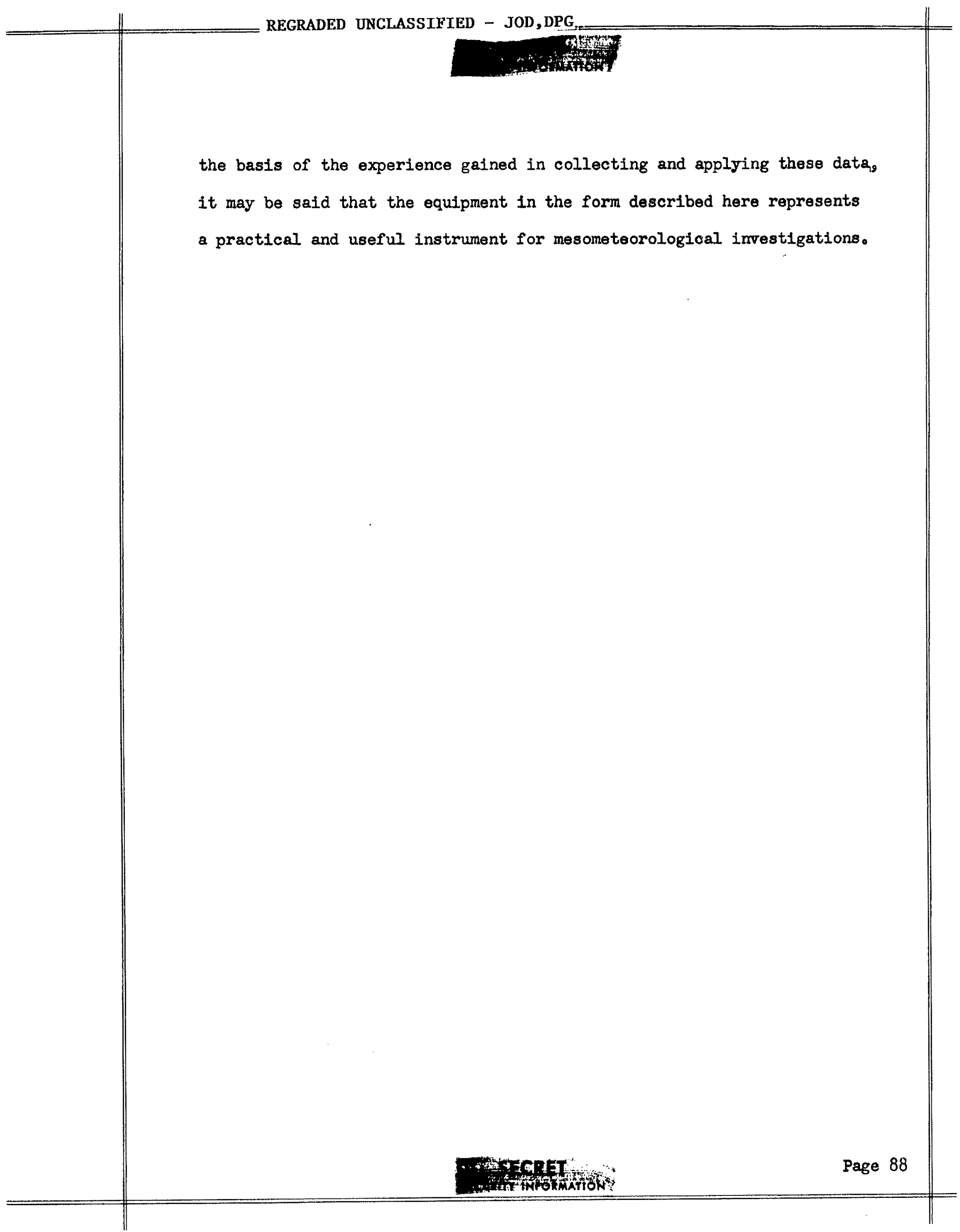




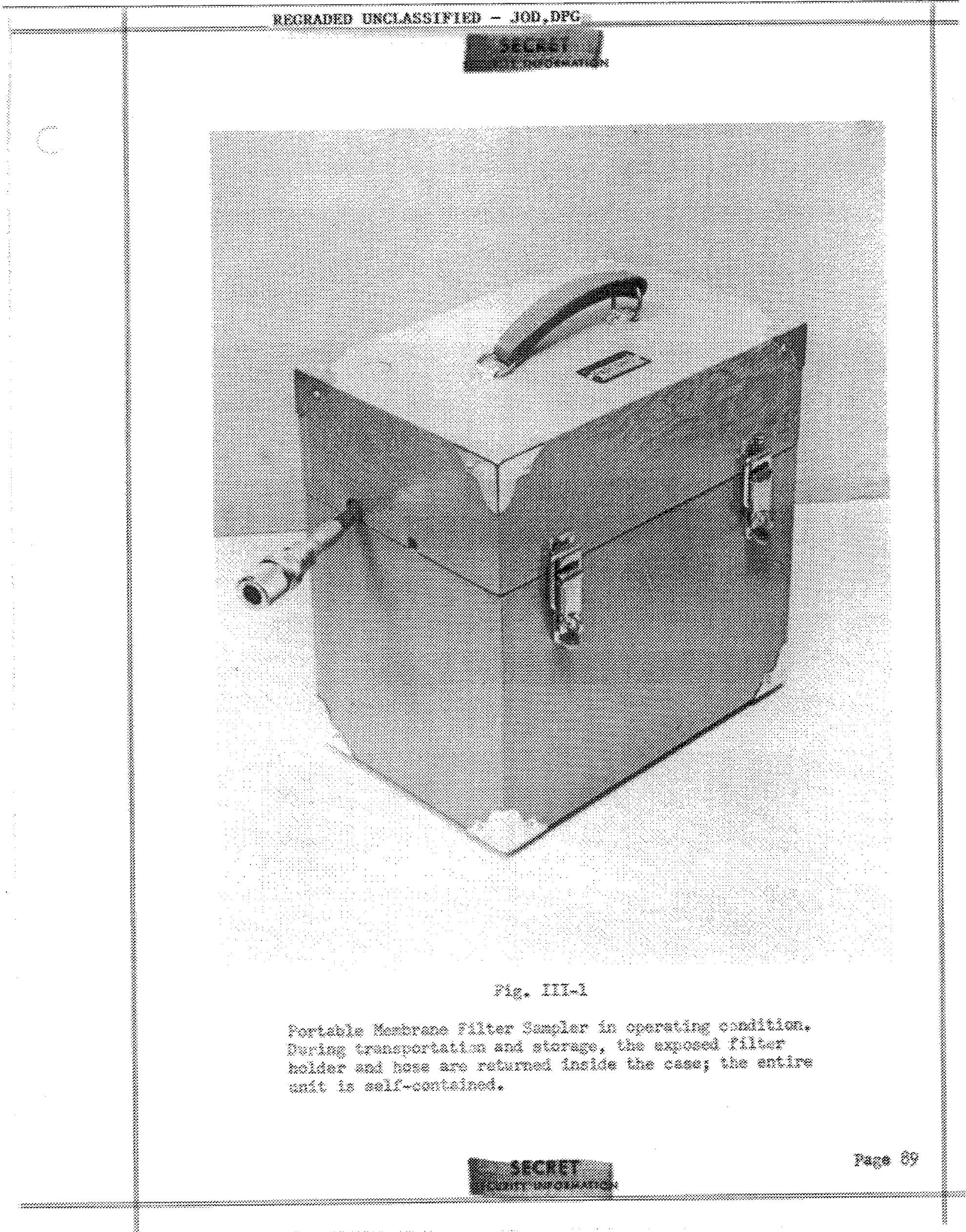




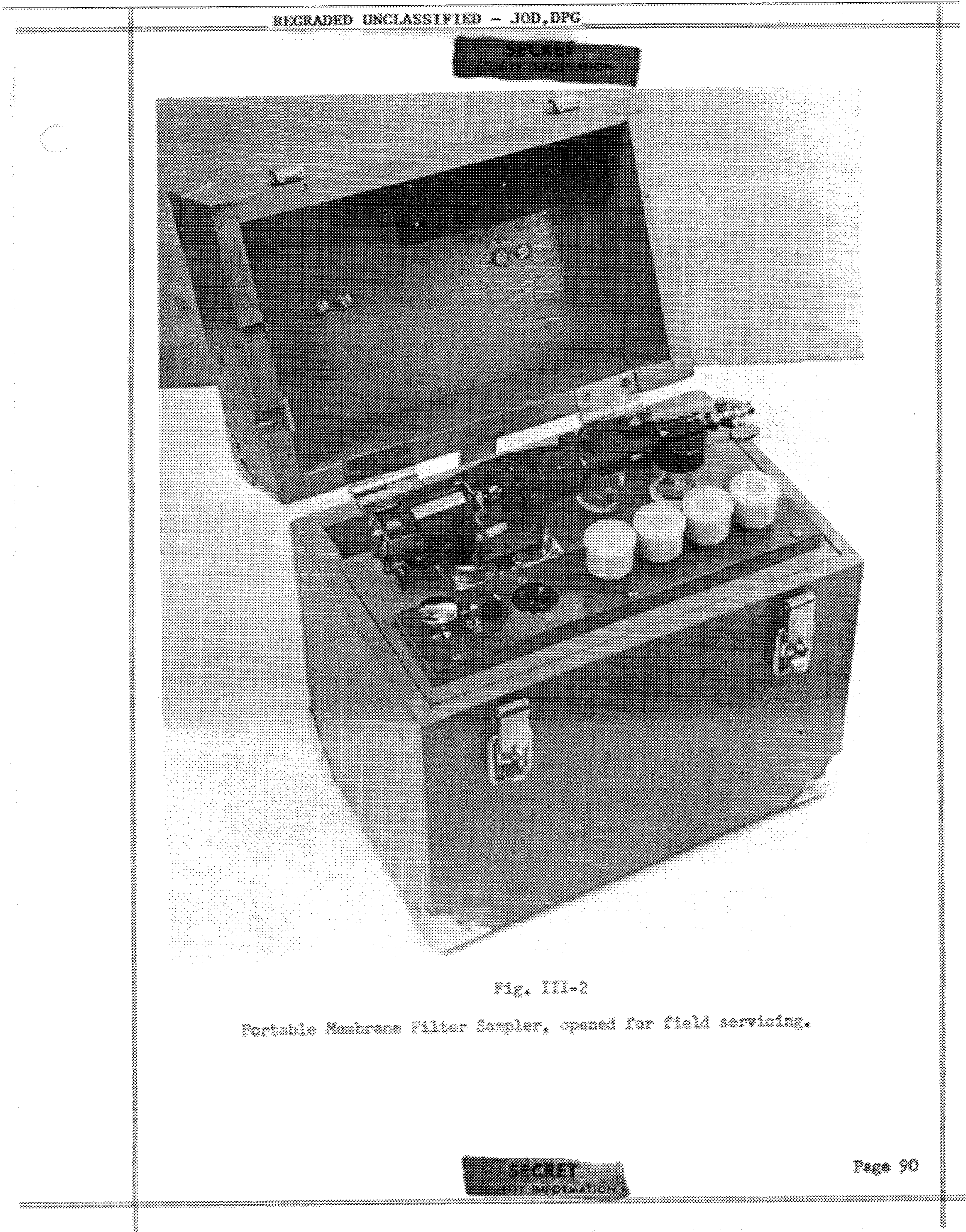




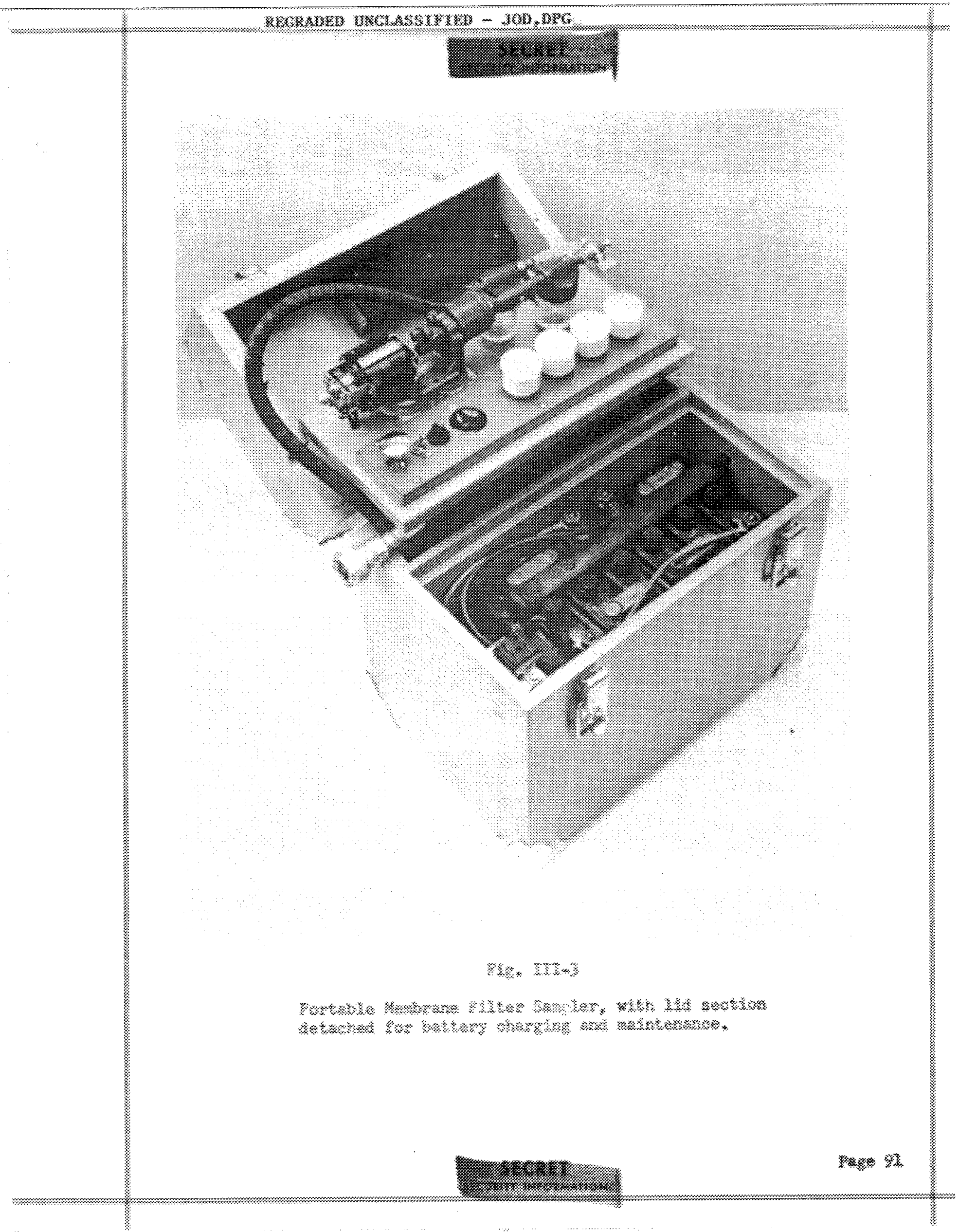




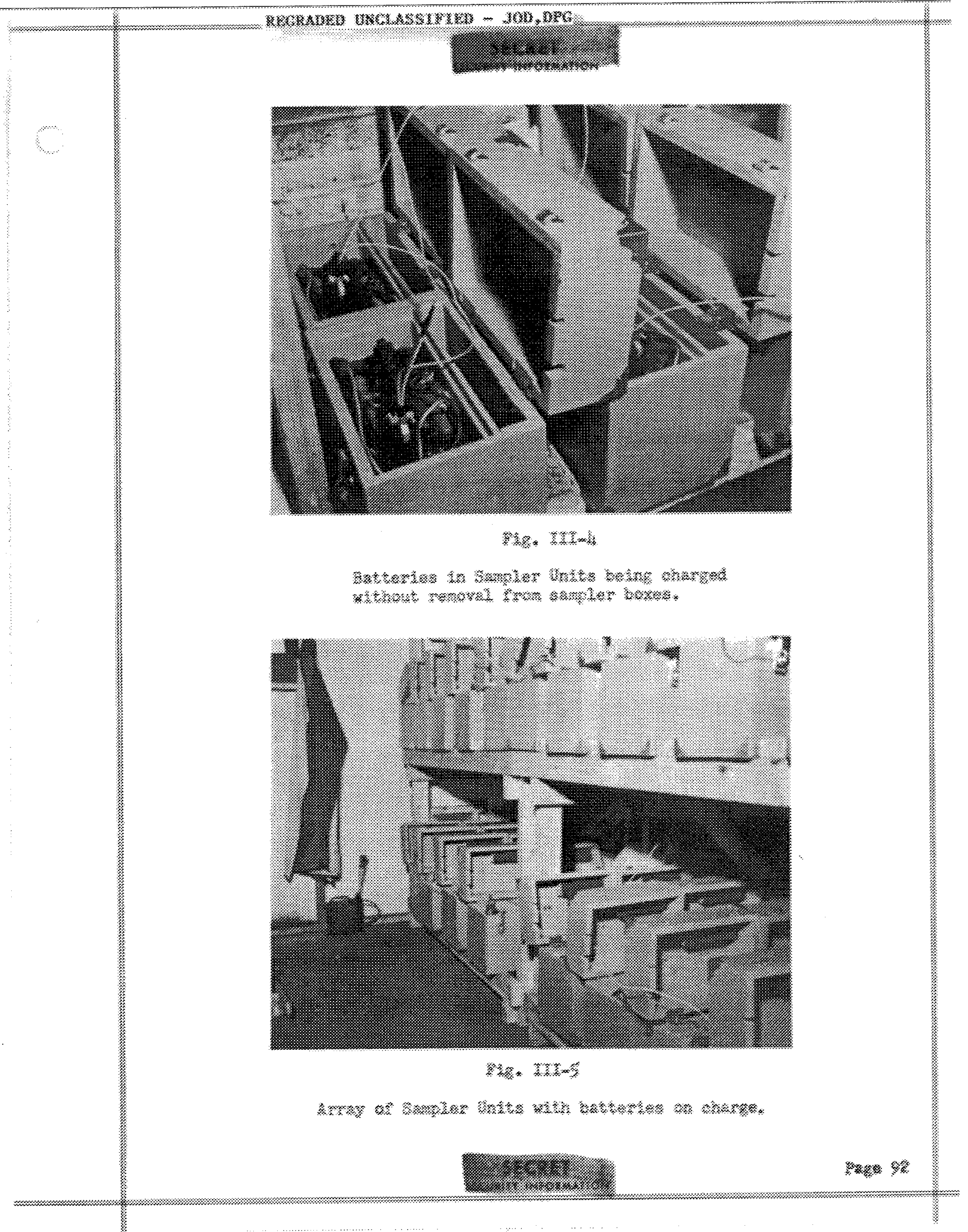




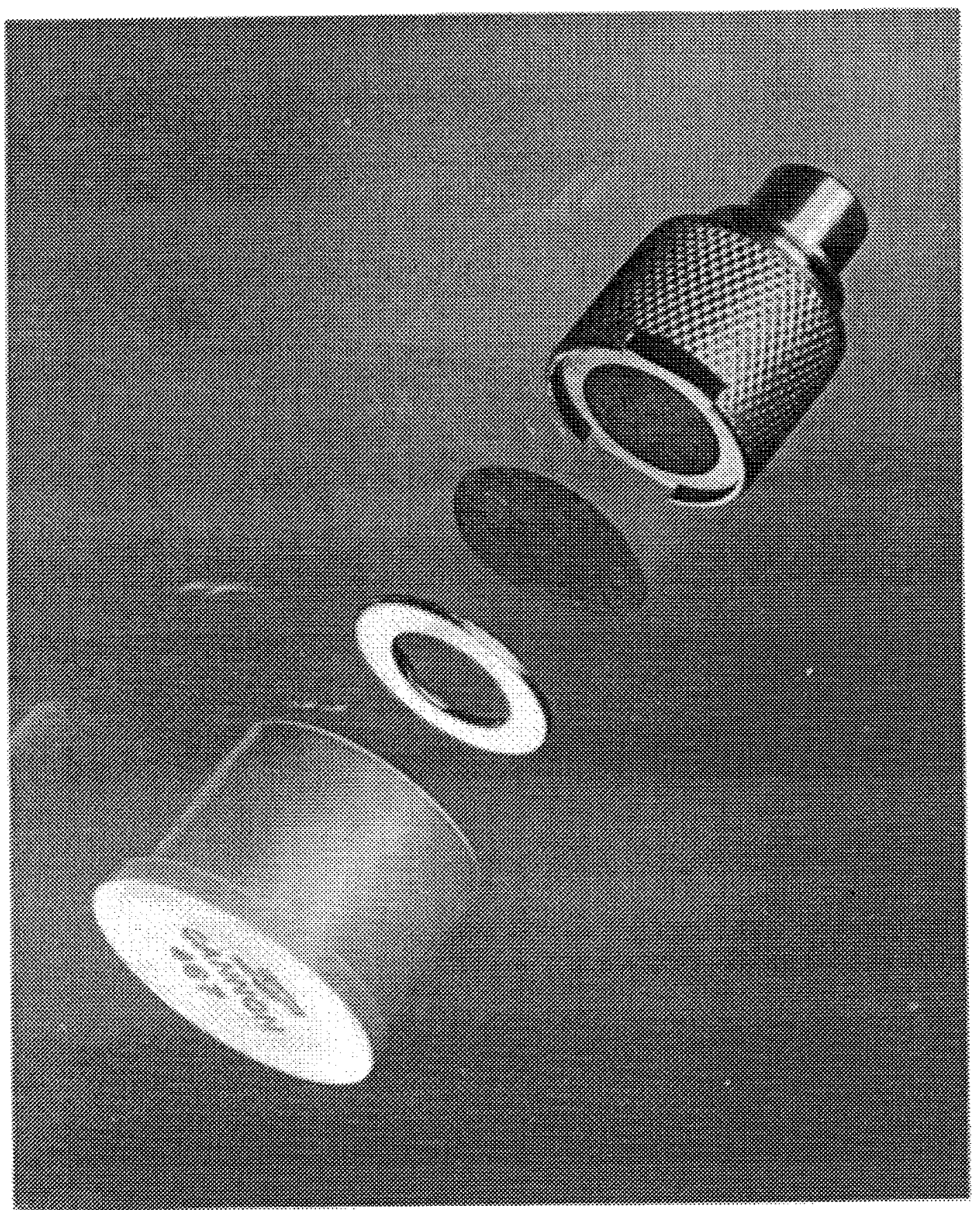

ख.. $. \mathrm{H}, \mathrm{H}$

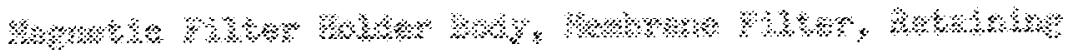

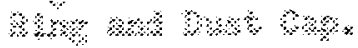


FIGURE III-7

PUMP FLOW CHARACTERISTICS AND FILTER

FLOW CHARACTERISTICS AS MEASURED ON PARTICULAR UNITS

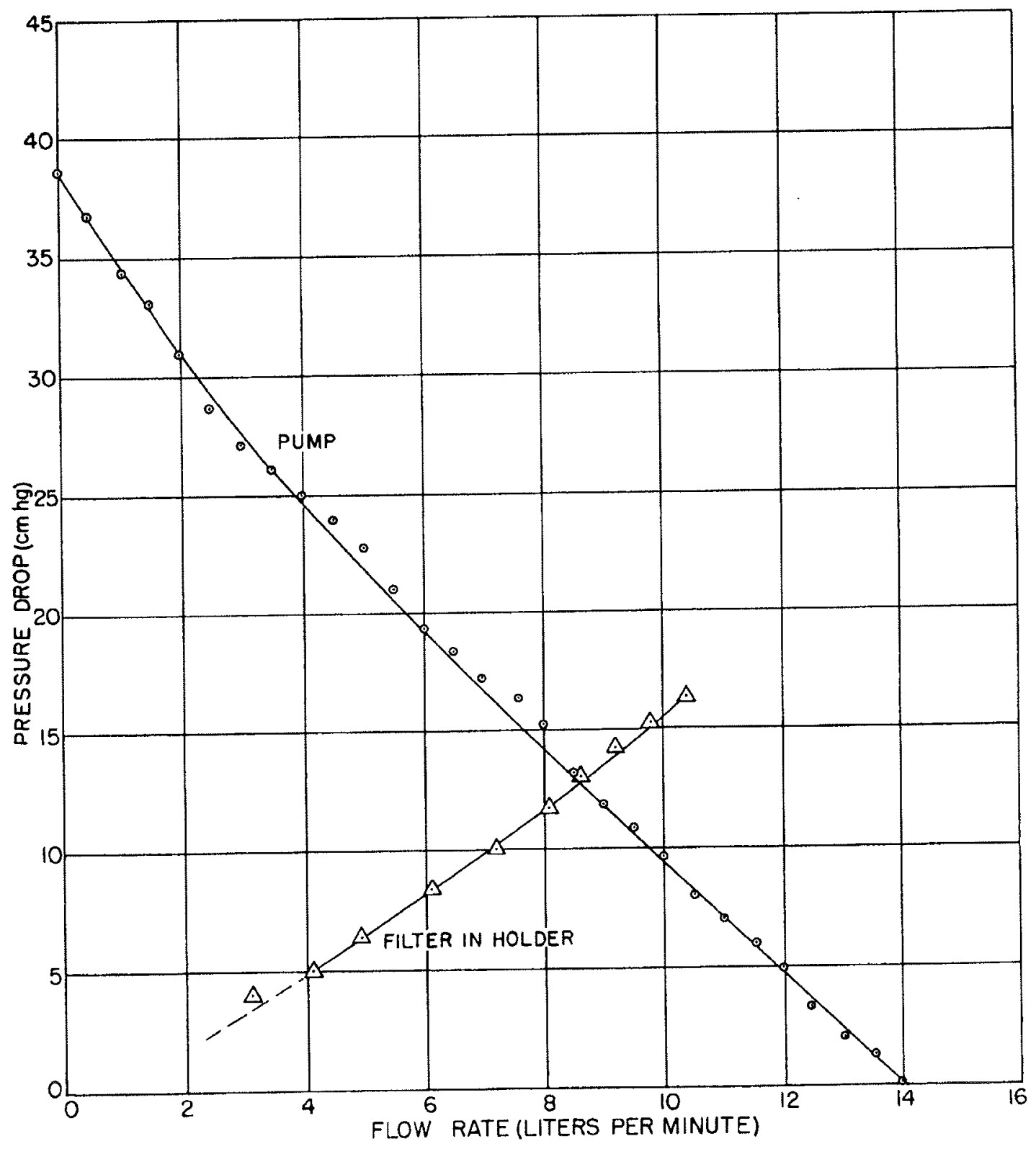




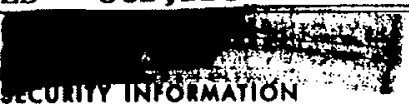

FIGURE III-8

FLOWRATE AND CURRENT DRAIN OF A PARTICULAR PUMP - FILTER COMBINATION AS A FUNCTION OF BATTERY VOLTAGE

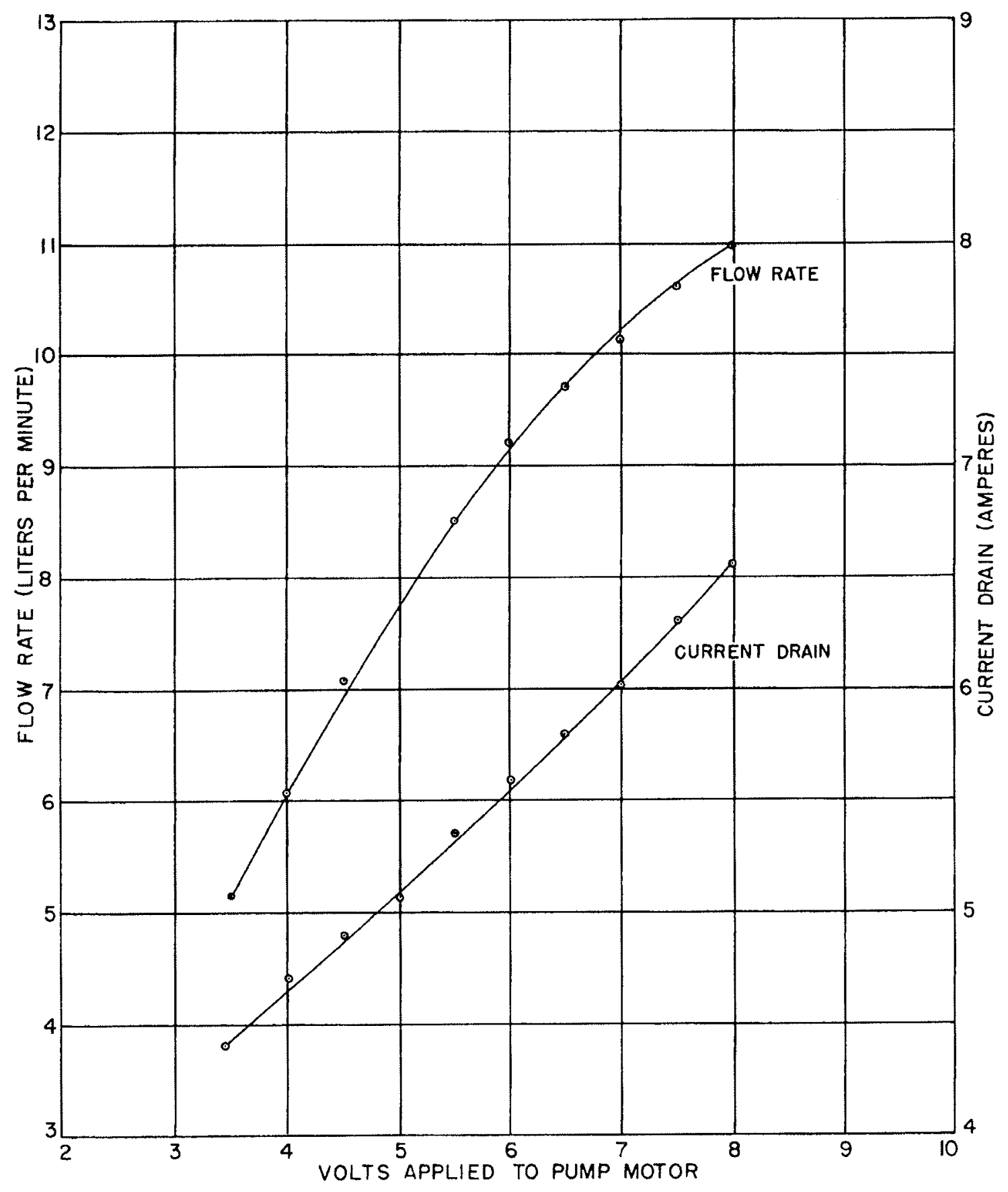




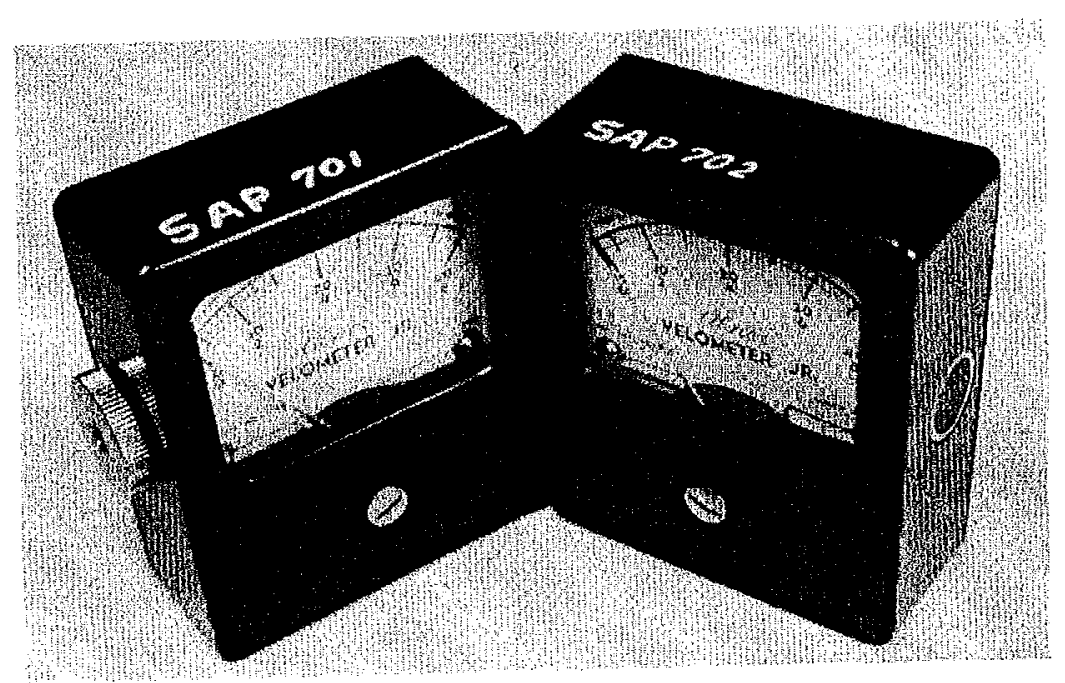

Fig. III-9

Alnor Velometer $\mathrm{Jr}$. Anemometers, showing inlet port, left, and outlet port, right.

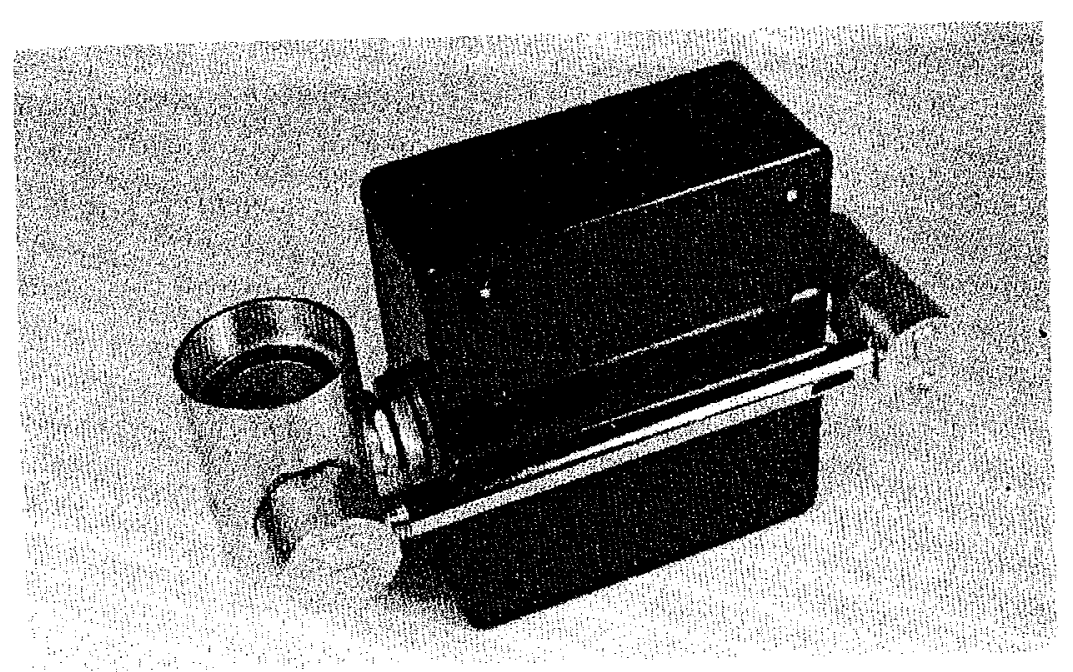

Fig. III-10

Back view of Shunted Vane Flowmeter, consisting of modified Alnor Velometer Jr. Anemometer.

Right; communication to former outlet port, and common inlet hole in crosspipe. Left; adapter head, with communication to crosspipe and former inlet hole. Meter in inverted position to show details of adapter head. 


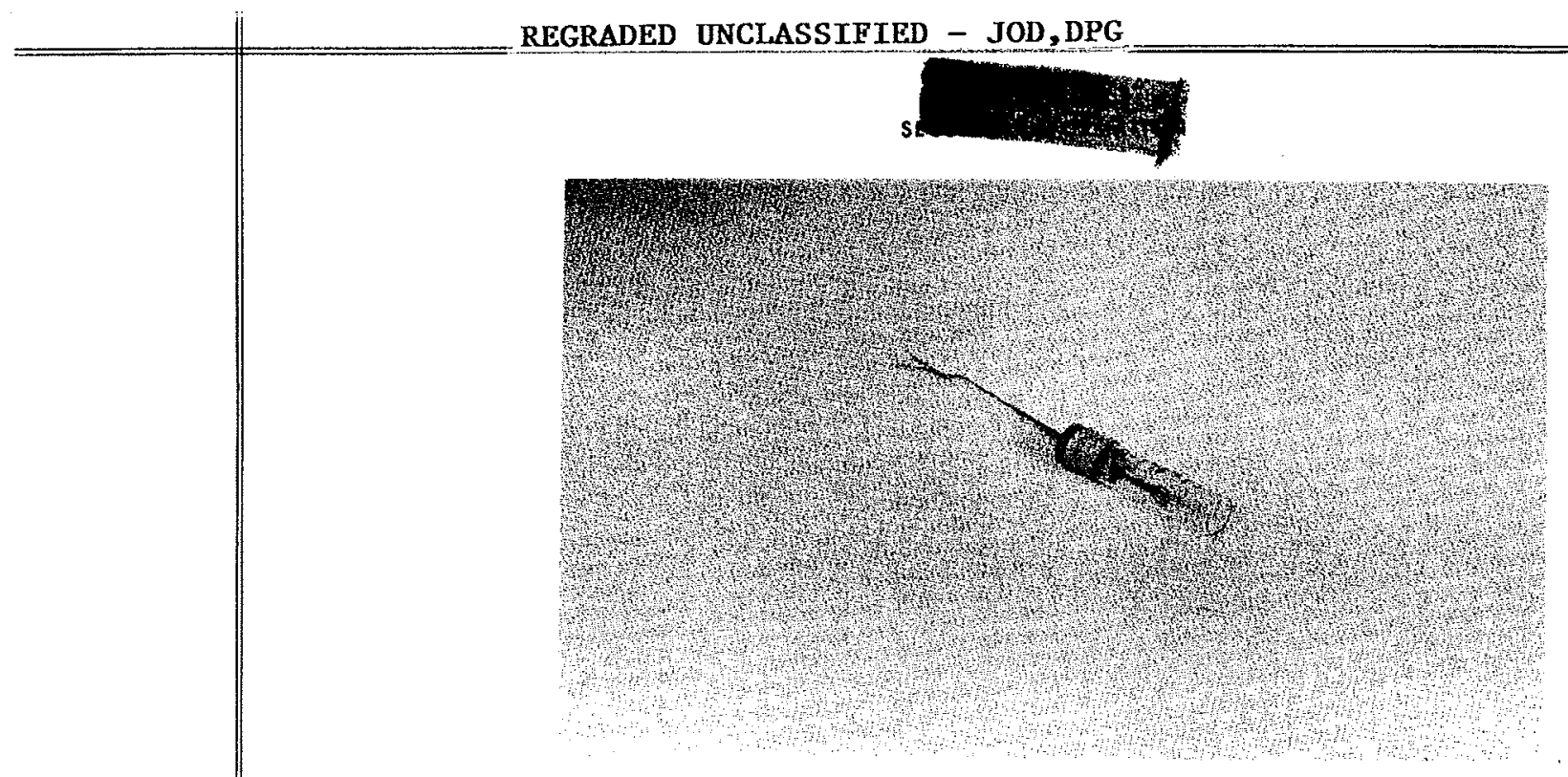

Fig. III-1I

Western Electric D-17690 Bead Type Thermistor, used as wiresonde temperature sensing element (shown in shipping container).

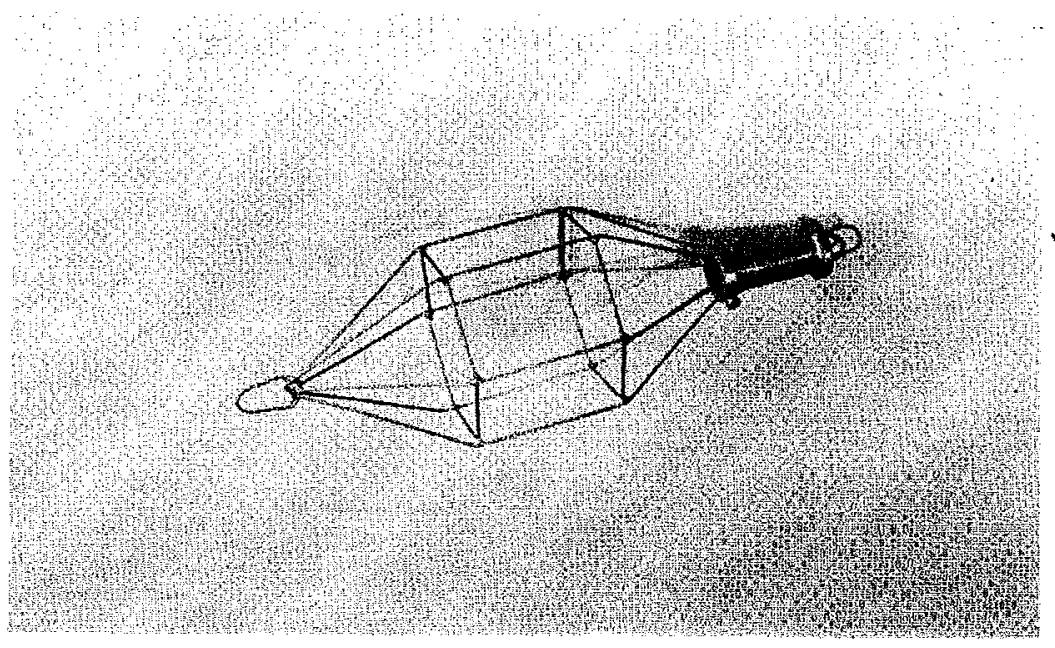

Fig. III-12

Protective Cage for Bead Thernistor, to be inserted in balloon line. 
REGRADED UNCLASSIFIED - JOD,DPG

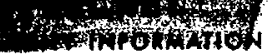

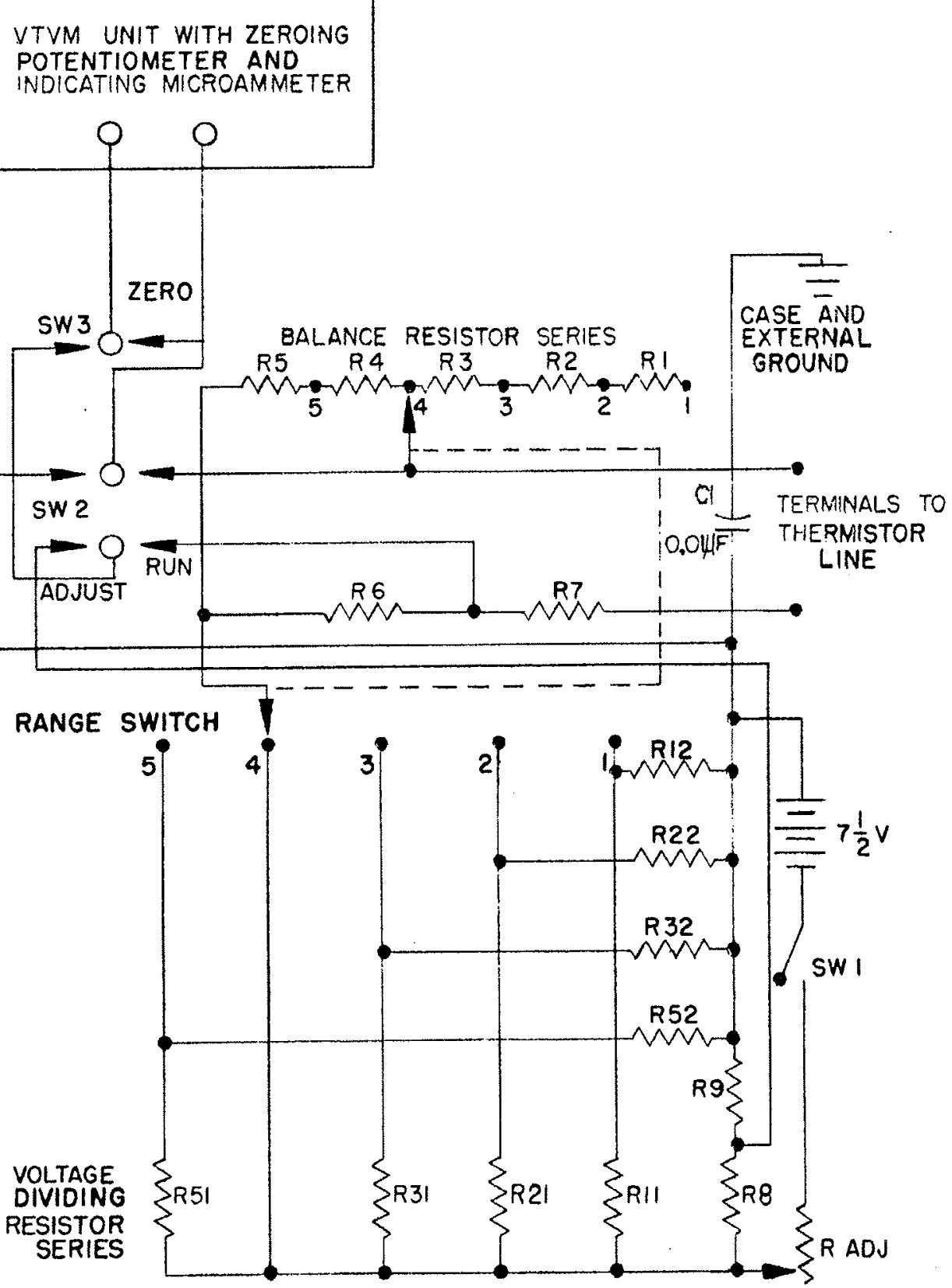

FIG III-13

SIMPLIFIED SCHEMATIC WIRESONDE BRIDGE CIRCUIT 


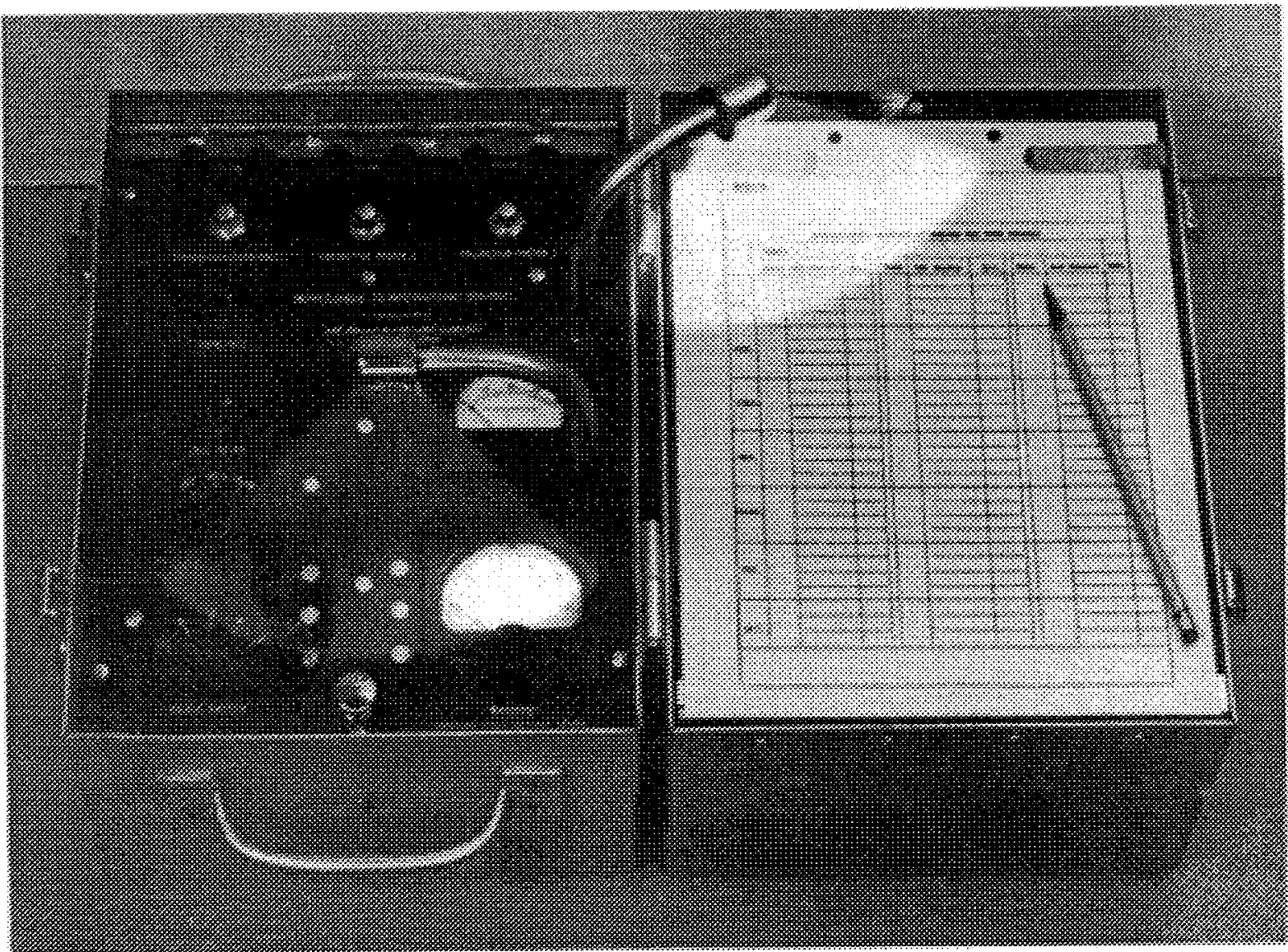

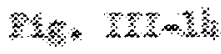

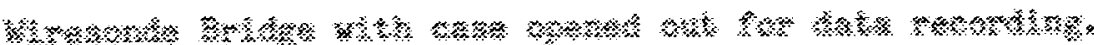

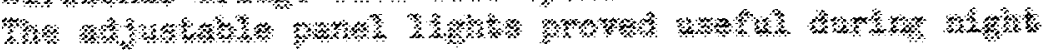

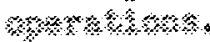




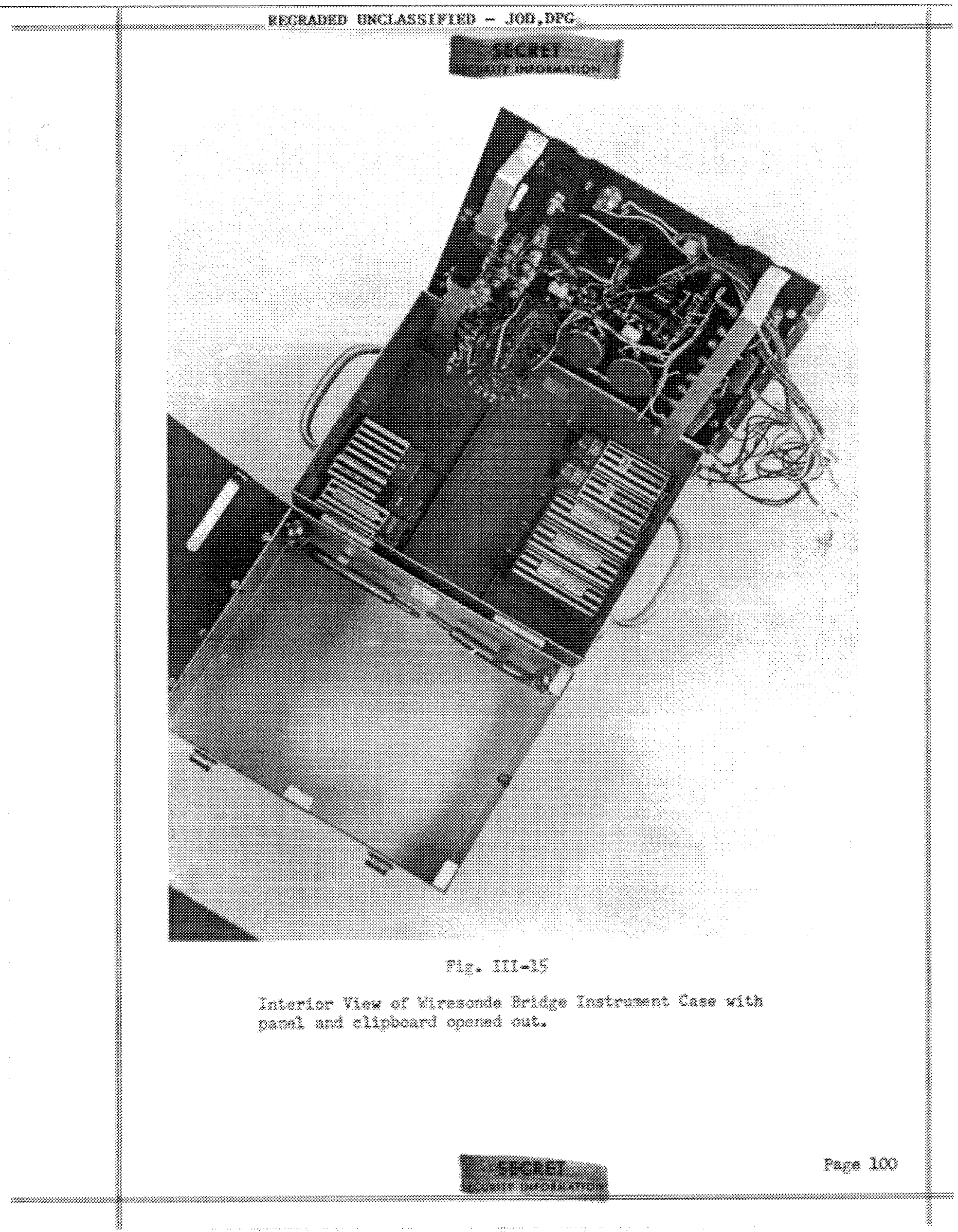




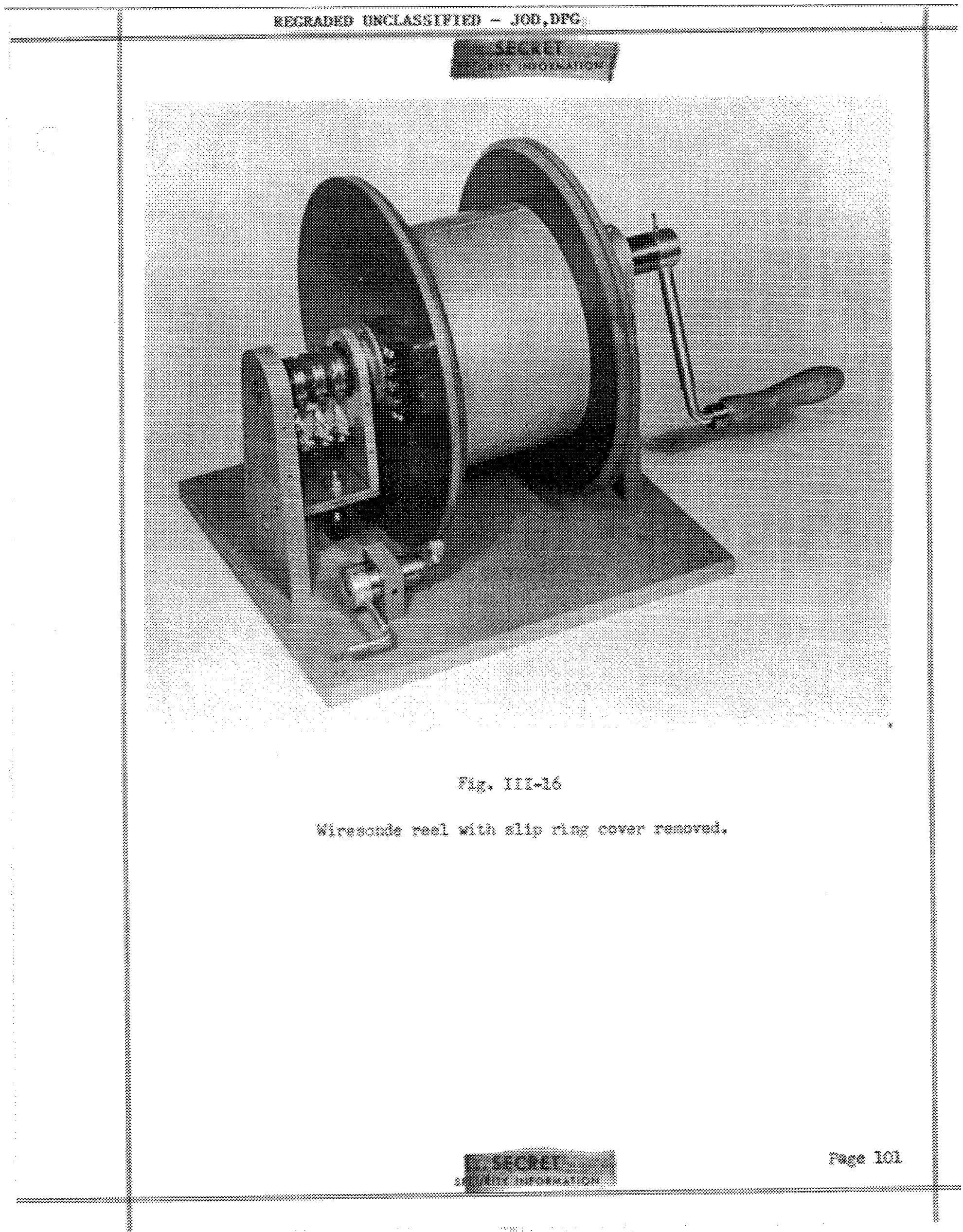




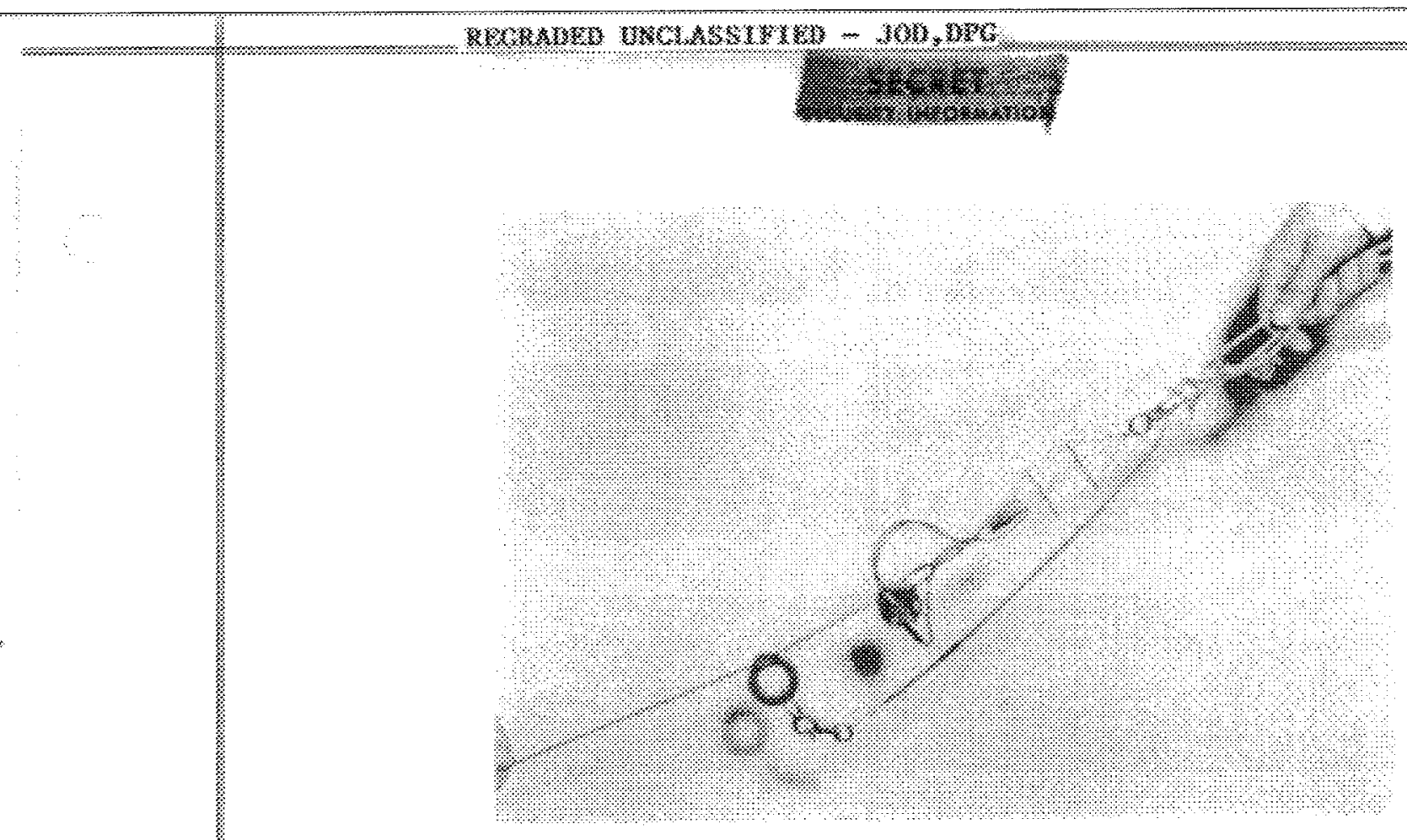

K.

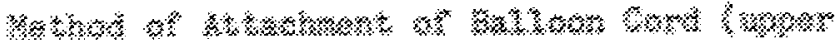
r.

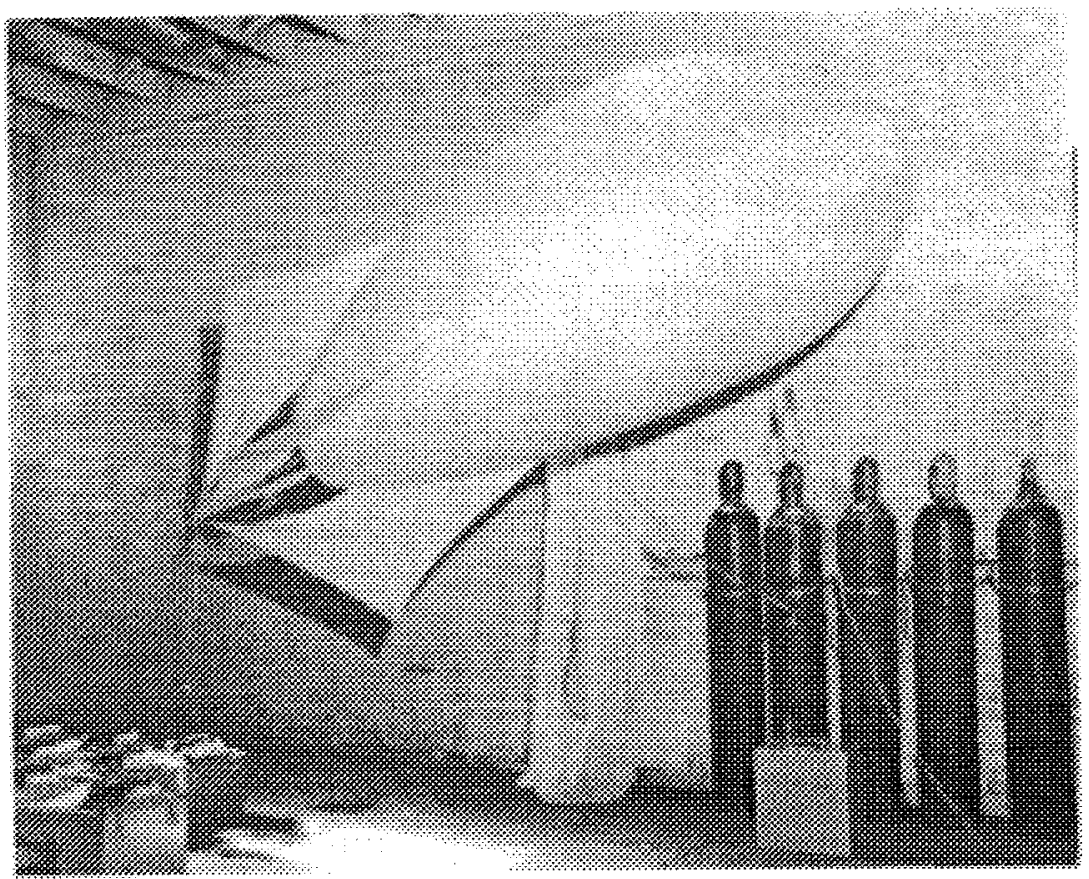

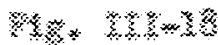

类

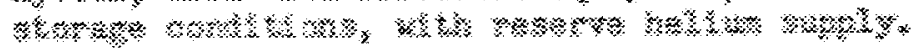




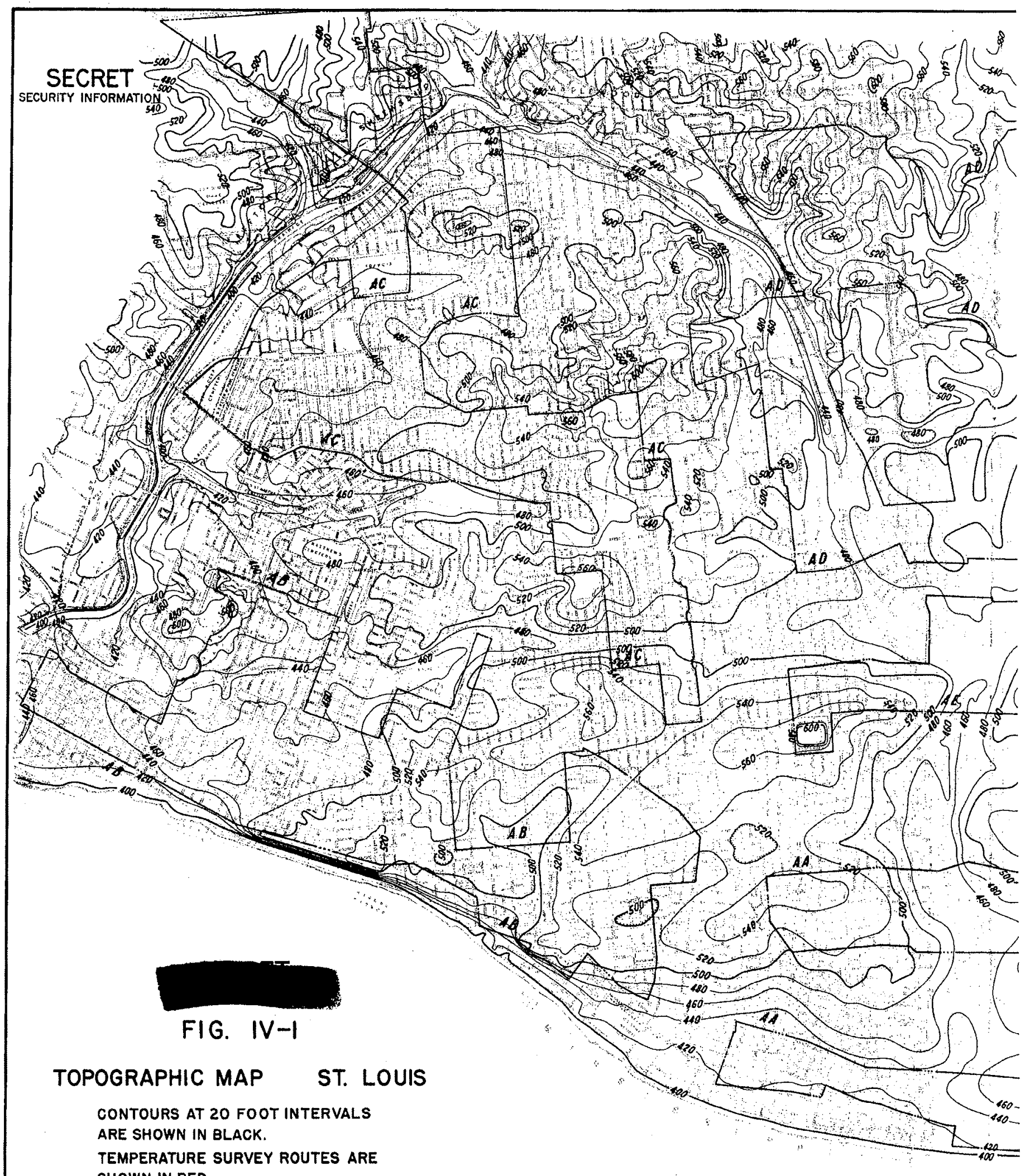

SHOWN IN RED. 


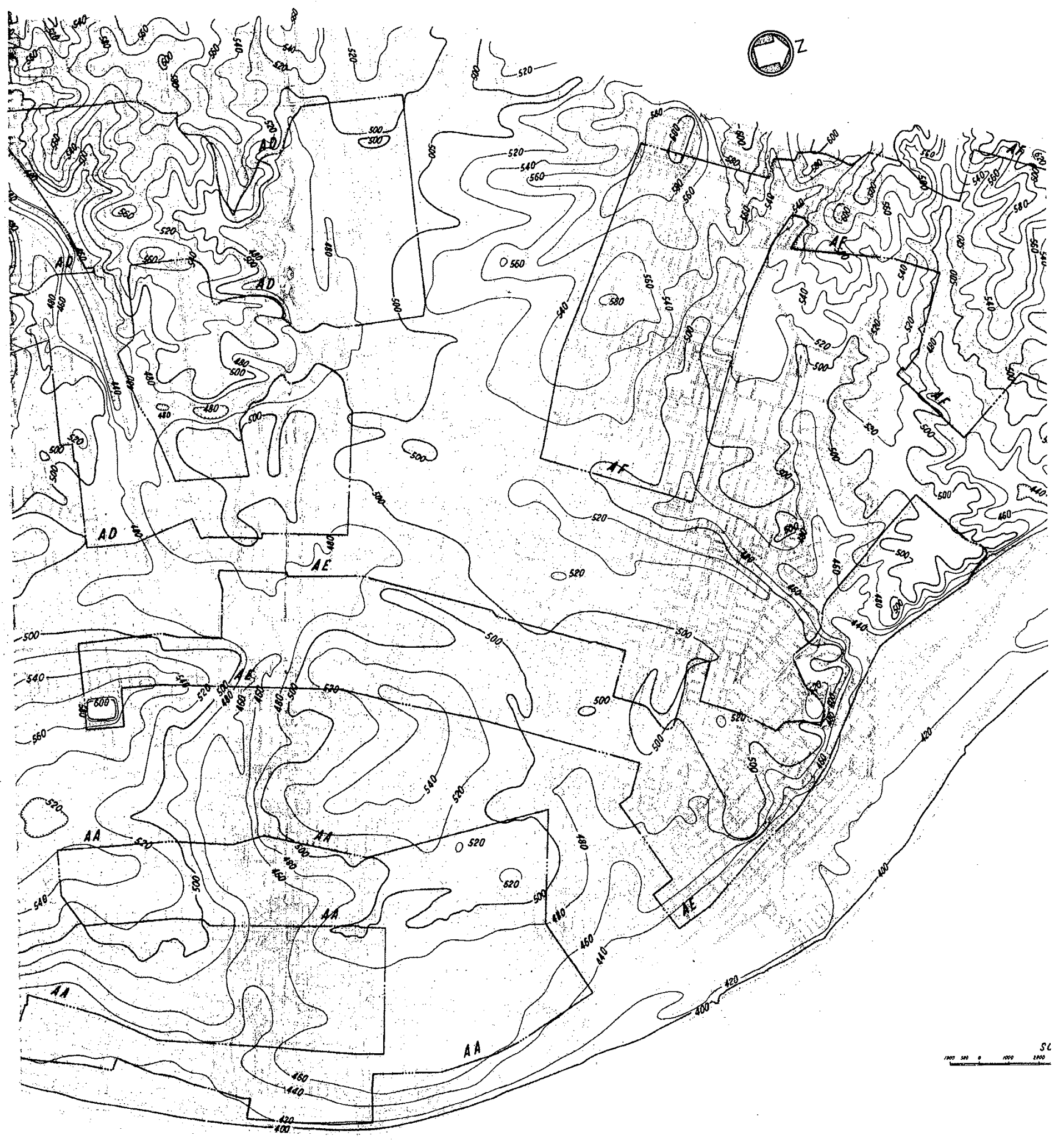

PART 2 of 3 


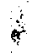

2

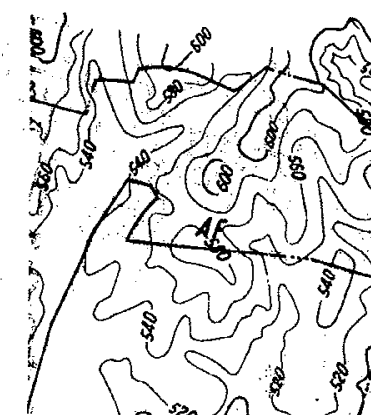

(1)
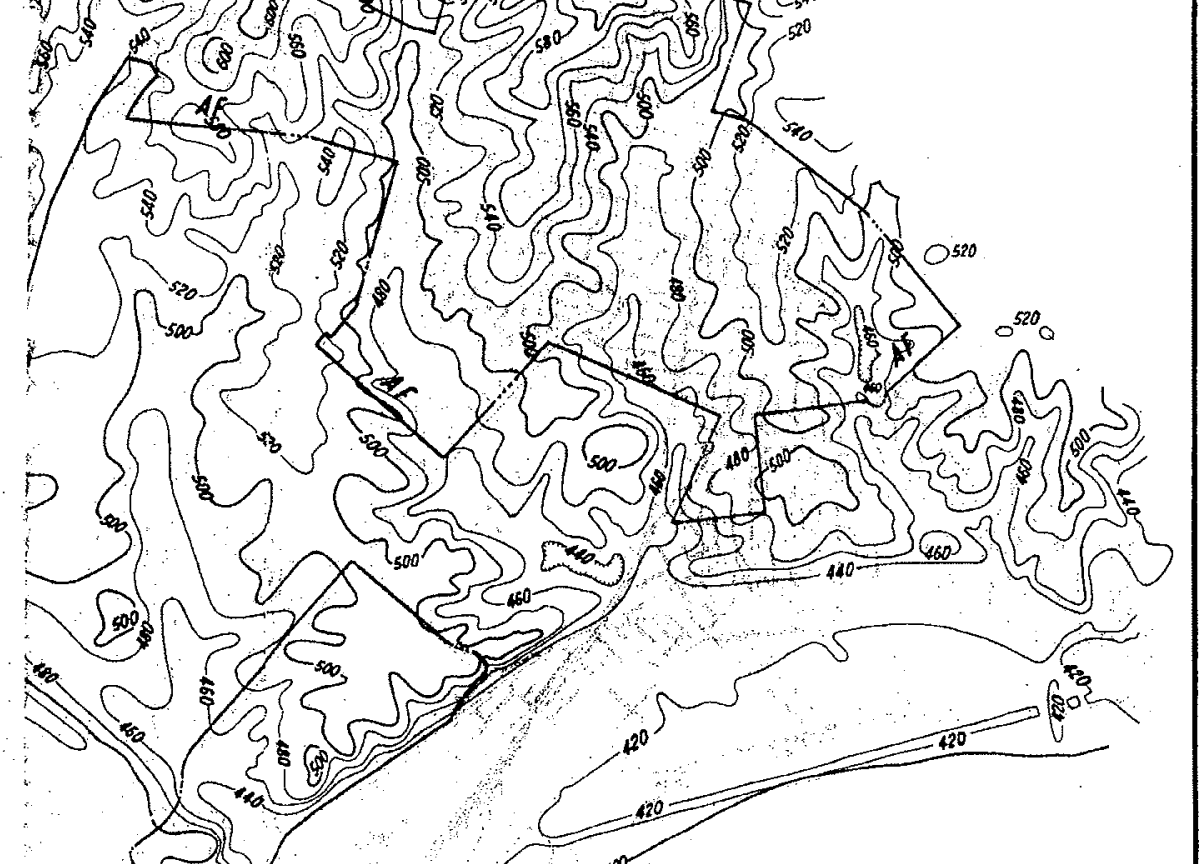

PART 3 of 3

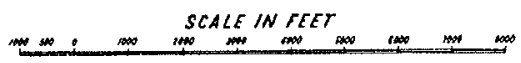




\section{TEMPERATURE SURVEYS IN ST。 LOUIS}

\section{A. CITY STRUCTURE AND TERRAIN}

St. Louis, with a population of more than 856,000 , is located on the western side of the Mississippi River, near its conjunction with the Missouri River. Running parallel with the river, from north to south, are the railroad tracks and yards. Also running from north to south between the river and Broadway, is the heavy industrial complex. The Monsanto Chemical Company, for example, is located in this area. As one approaches the river, going east from Broadway, the ground drops moderately. Throughout the city the elevation varies from 400 to 605 feet above sea level.

Covering an area of approximately 61 square miles, St. Louis contains about four square miles of inland water. Lakes and rivers are thus not as prominent within the City as they are in Minneapolis. Forest Park, covering an area of two square miles in the west-central section, is the largest of the 79 city-owned parks. South of the railroad tracks to Jefferson Memorial National Park, which faces the river on the east, is light industry from one to six stories high. Beyond the park the area becomes densely residential.

The downtown district is well defined. It consists of an area of 0.86 of a square mile, bounded by Delmar Boulevard on the north just above Jefferson Park, by railroad yards on the south, by Third Street adjoining Jefferson Park on the east, and by Twentieth Street on the west. It consists of maltistoried buildings. No trees are found here except in the parks, and in this respect, too, St, Louis differs from Minneapolis. 


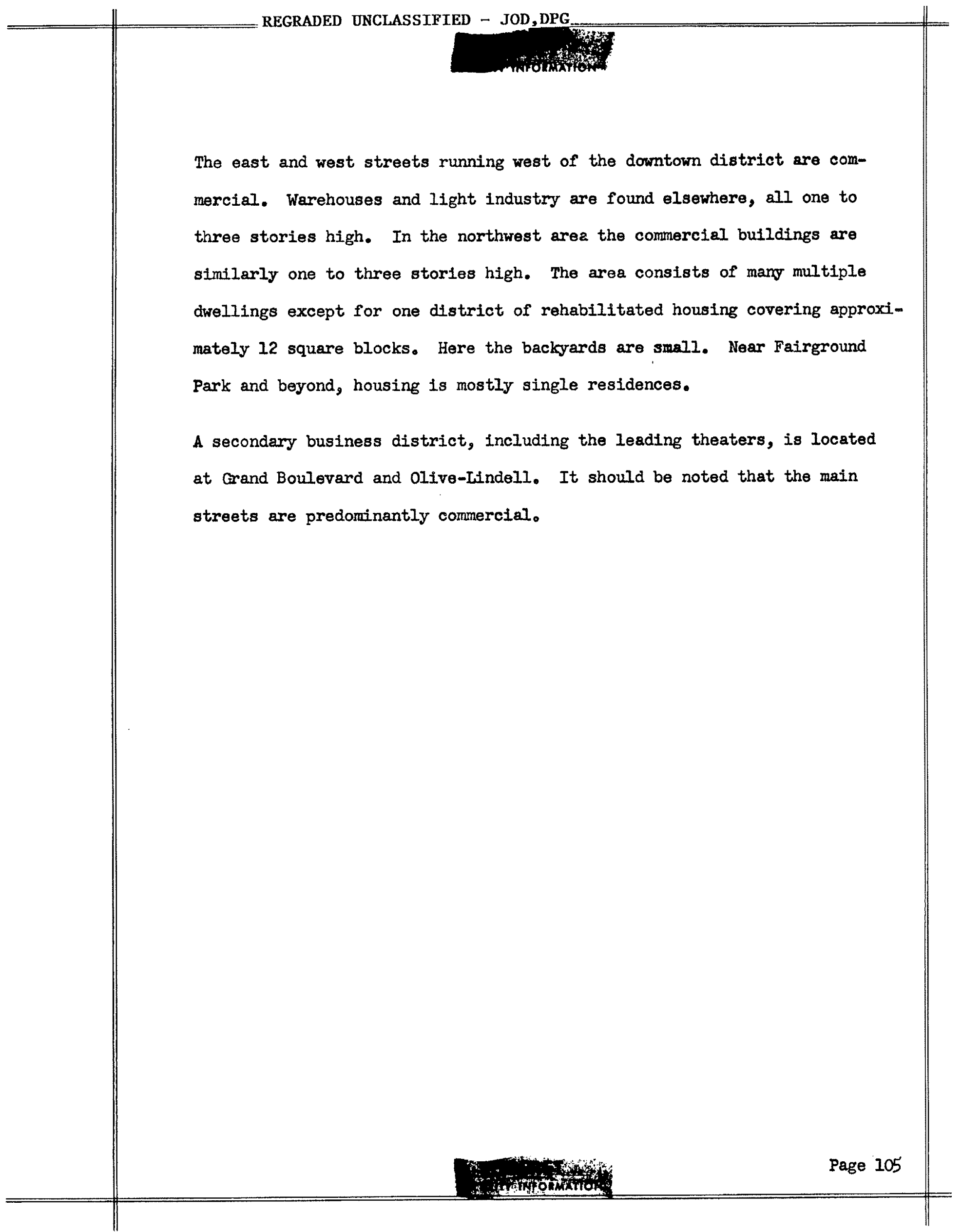


B. SUMMARY OF RESULTS

Between January and March 1953, 18 temperature surveys, in addition to the 17 reported for the preceding quarterly period, were made in St. Louls preparatory to selecting a provisional site for studying aerosol cloud behavior. The procedures and instruments for measuring the horizontal temperature gradient are detailed in JQR 2. Because of the major testing effort expended in Minneapolis and the resulting diversion of a limited supply of necessary meteorological equipment, no measurements were taken of the vertical temperature gradient. A summary of the 18 two-meter temperature surveys is included in Table II-3, Section II.

of the 35 temperature surveys conducted in St. Louis since the inception of the current program, full evaluative attention is given in this report to four: to surveys $M-1010$ and $M-1016$, both of which were merely cited in $J Q R$ 2, and to surreys $M-1020$ and $M-1024$. In each survey, resulting in isotherm charts for 2000,2100 , and $2200 \mathrm{CST}$, an adequate network of representative data was obtained, although the area south of Tower Grove Park was not traversed. The first three surveys employed four cars each; the last survey, an additional car. Routes covered in the surveys are indicated in FIg. IV-I; they are based on the results of preliminary muns in this city and on the findings obtained in similar surveys of other cities, particularly Minneapolis. Since intensive coverage was not achieved, certain regions of uncertainty remain. Isotherms for such regions, as for comparable Minneapolis isotherms, have been drawn on the basis of experience gained from surveys conducted elsewhere and are indicated as dashed rather than solid lines. 
For each of the four surveys, the applicable raob sounding obtained at Columbia Municipal Airport, the summary of the synoptic situation, and the isotherm chart or charts are presented in Appendix A. Of the twelve isotherm charts obtained from these surveys, seven are reproduced in the appendix, three for $M-1010$, two for $M-1016$, and one each for $M-1020$ and M-1024.

These particular isotherm charts were chosen for their comprehensive representation of the City under varying meteorological conditions. M-1010, for example, was selected to present a corplete series of three traverses for one night, 5 December 1952, which was characterized by clear skies and relatively light winds. Survey $M-1016$, conducted eleven nights later, showed an extremely high temperature differential at 2100 hours, and a marked decrease one hour later. Whereas the 2100 isotherm map for M-1020 (8 January 1953) shows the influence of adverse weather such as cloudy skies with moderate winds and precipitation, the corresponding map for M-1024 (5 March 1953) shows an average typical night characterized by clear skies and light winds.

The prevailing meteorological conditions described above are listed in Table IV-I, which, for purposes of correlation, defines horizontal gradient measurements in numerical terms. The symbols used to describe the chart situations are defined in JQR 2 (pp. 68-69). Entries for other meteorological data, including survey clouds and diurnal temperature range, are 


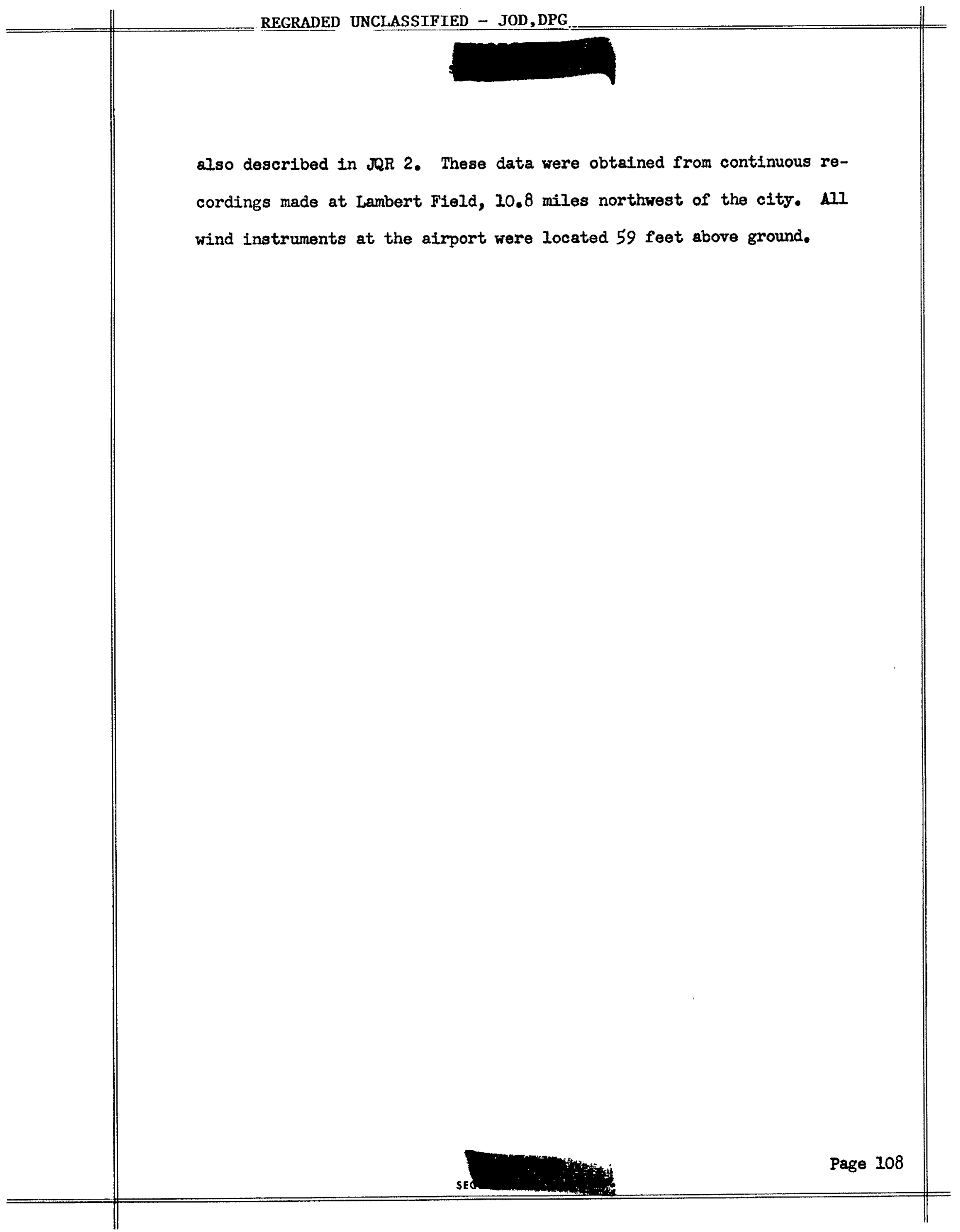


REGRADED UNCLASSIFIED - JOD,DPG
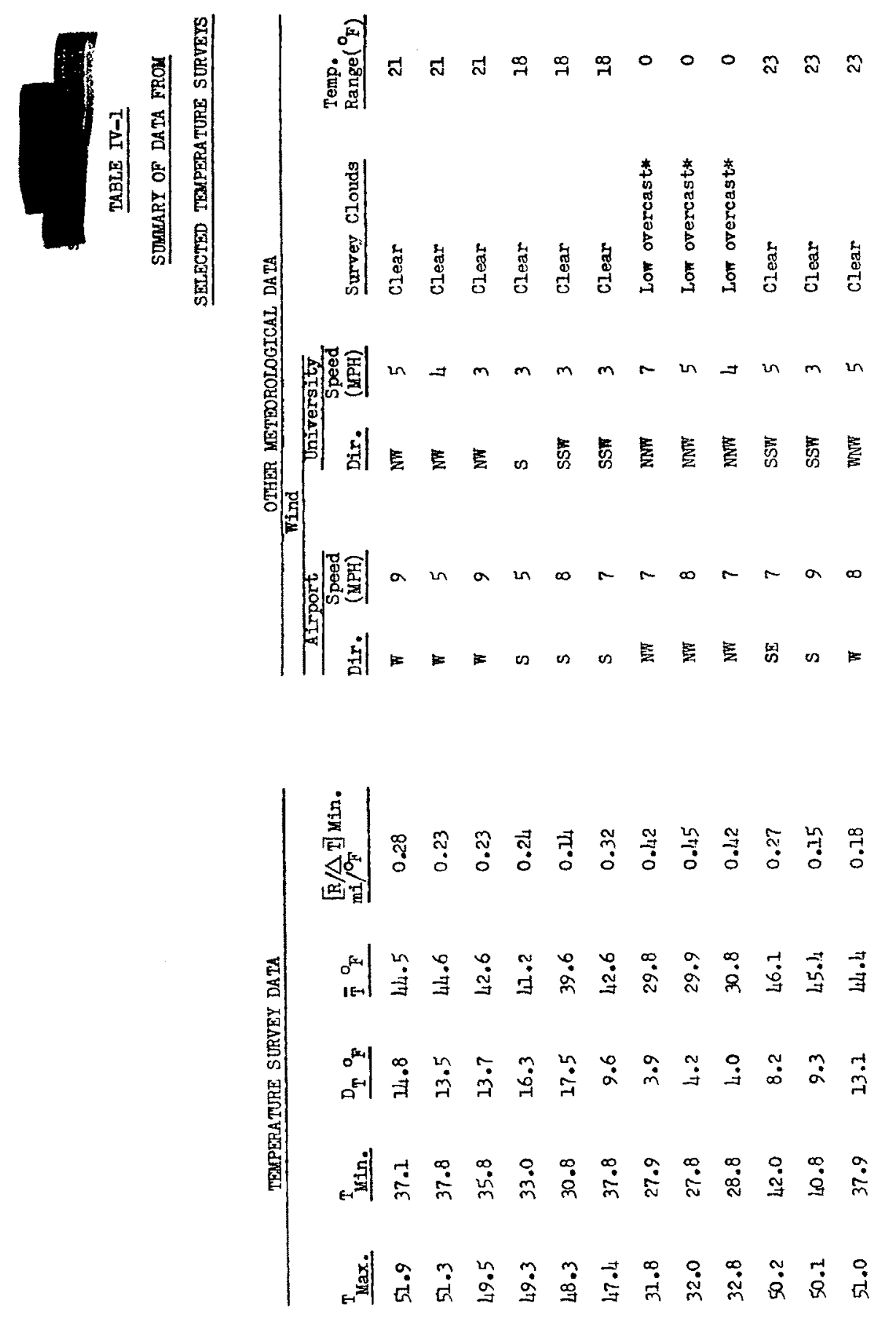

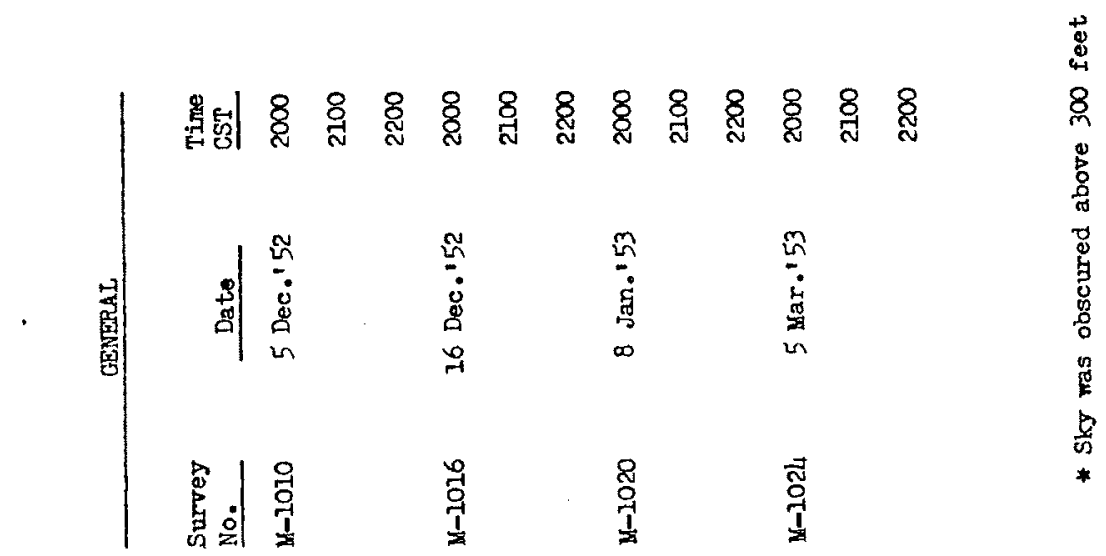

4 


\section{CHARACTERISTICS OF HORIZONTAL TEMPERATURE PATTERNS}

\section{Isotherm Patterns and their Reproducibility*}

The two-meter isotherms over St. Louls show a consistent pattern on all nights. With clear skles and light winds the pattern is sharp and intense as shown by the 2100 CST map from M-1016 (F1g. 1-6). Under adverse weather conditions the pattern fades as shown by the map from M-1020 (Fig. A-9). The warmest air is generally over the downtown district just west of the Jefferson Memorial, while the coolest air 1s over Forest Park and the outlying areas to the northwest of the city limits. The horizontal temperature gradients in the vicinity of the downtown heat island are frequently quite pronounced on the east or river side but are weak to the northwest. As indicated by the map from survey M-1024 (FIg. A-II), the gradient to the east was in excess of $6^{\circ} \mathrm{F}$ and only 1 to $2^{\circ} \mathrm{F}$ to the northwest. The temperature gradients in the colder areas are frequently quite intense on all sides. An extreme instance is shown by the 2100 CST map from M-1016, where horizontal temperature changes in excess of $10^{\circ} \mathrm{F}$ per 2000 feet were measured in the vicintty of Forest Park.

Although the termerature differential (In) varies markedly with the weather, the basic pattern persists under a considerable range of meteorological conditions and is therefore considered to be reproducible. In particular, the weak gradients in the tentatively selected test sites (see Section IV-E) are reproducible.

* All figures cited in this and the succeeding portions of the present Section are found in Appendix A. 


\section{Effect of Meteorological Parameters on the Isotherm Patterns}

The primary effect of cloud cover and the secondary effect of wind speed are clearly illustrated by comparing the 2100 CST date from surveys M-1016 and $\mathrm{M}-1020$ (Figs. $\mathrm{A}-6$ and A-9). In the first case, on 16 December 1952, a near maximum value of $D_{T}$ in excess of $17^{\circ} \mathrm{F}$ was obtained with clear skies and local wind speeds of 2 to $3 \mathrm{mph}$. But in survey $\mathrm{K}-1020$, conducted on 8 January 1953, a near minimum value of $4^{\circ} \mathrm{F}$ was obtained with cloudy skies, precipitation, and local wind speeds of 4 to $7 \mathrm{mph}$. The $[\mathrm{E} / \Delta \mathrm{r}]$ min values for the two surveys are also affected. Under clear skies and an average wind speed of $2.5 \mathrm{mh}$, a value of only 0.1 mile per degree Fahrenheit was obtained, but with cloudy skies the value exceeds 0.5 mile per degree Fahrenheit and wind speeds average $5.5 \mathrm{mph}$.

Since no survey has yet been made with clear skies and moderate to strong winds, it is impossible to evaluate completely the singular effects of wind speed on temperature. However, currently available data do not contradict previous conclusions that the city temperature differential decreases with increasing wind speed. The evaluation of wind speed effect is also complicated by the wide range in values obtained on a given night from the continuously recording instruments located at different sites and at relatively high elevations. In survey $\mathrm{K}-1016$, for instance, varying wind speeds were reported for the following helghts: 2 mh at ground level, 3 mph at roof top height in the University area, 6 mph at the 59 foot hed ght (Lambert Field), and $18 \mathrm{mph}$ at 303 foot height (Weather Bureau, city office). 
Qualitative indications are that wind speed changes both the shape and location of the heat island. In N-1010 the warm area was quite elongated by the westerly winds, and weakening of the usual riverside gradient is largely explained by advection of warmer air eastward.

The immediate effect of a small change in weather conditions is clearly demonstrated by comparing the 2100 and 2200 CST maps from surrey M-1016 (Figs. A-6 and A-7). On the 2100 map an intense $D_{T}$ of $17.5^{\circ} \mathrm{F}$ existed; on the following map the $D_{T}$ dropped sharply to $9.6^{\circ} \mathrm{F}$. This decrease of nearly $8^{\circ} \mathrm{F}$ was occasioned by a decrease of $2^{\circ} F$ in the warm areas and by a varming of nearly $6^{\circ} \mathrm{F}$ in the cold areas. Associated with this warming of the colder areas was a gradual increase in wind speeds at the airport and at the Weather Bureau, city office. It would thus appear that the wind shear of $12 \mathrm{mph}$, as evidenced between the 60 and 300 foot observations, was sufficient to weaken the strong but shallow inversion established early In the evening. This hypothesis is supported by the twofold increase in visibility at the airport, from five miles in smoke to ten miles unrestricted, and a local shift in wind direction from southeast to south-southwest.

\section{Effects of Terrain}

St. Louls terrain may be described as gently rolling country. From a low contour of appraximately 400 feet paralleling the river, the land slopes upward to the west at a maximum rate of 100 feet in 4000 (FIg. IV-1). The highest spots in the city are a few knolls which just exceed 600 feet. With an elevation range of only 200 feet, It would thus seem that terrain effects are at a minimum. Such is the case in the downtown district and 
the associated area to the northwest, both lying mostly between the 450 and 550 foot elevations. In the Forest Park area, however, there are definite indicatipns that on inversion nights the cold atr favors the lowest ground even though the elevation differentials are only 50 to 100 feet. Another noticeable terrain influence is along the river's edge just east of the downtown district. These two effects are exemplified by the 2100 CST map from $\mathrm{M}-1016$.

Within the city limits there are no lakes comparable in size to those of Minneapolis, although the City does include some four square miles of water area mostly east from the Mississippi River. Considerable water and marshy area on the eastern side of the river may have some influence under conditions of weak easterly winds.

4. Comparison with Other Cities

A comparison of St. Louis with Minneapolis or with the western cities studied earlier by the Stanford project shows that for 1ts size, St. Louis has comparable intensities of horizontal temperature differential and temperature gradient. As Table IV-2 indicates, there is considerable similarity in the basic temperature patterns of St. Louis and San Francisco. Each has a downtown district less than a mile awray from the water, and a large park approximately four mlles to the west. Both also compare favorably in population density and maximum temperature differential. In one respect, however, St. Louis is unique. It is the only city so far studied that has such a high percentage of flat gradient area. The overall 
differentials persist, but even under the extreme cases of $D_{T}$, as in M-1016, the area to the northwest of the dorntown district is relatively homogeneous.

TABLE IV -2

HORIZONTAL TEMPERATURE PATTERN CHARACTERISTICS

COMPARED WITH

VARIOUS INDEXXS OF CITY SIZE

\begin{tabular}{|c|c|c|c|}
\hline & St. Iouis & San Francisco & Minneapoli: \\
\hline Population & 857,000 & 784,000 & 522,000 \\
\hline $\begin{array}{l}\text { Incorporated Land Area, } \\
\text { square miles }\end{array}$ & 57.0 & 45.1 & 53.5 \\
\hline $\begin{array}{l}\text { Population Density, } \\
\text { persons/square mile }\end{array}$ & 15,000 & 17,300 & 9,700 \\
\hline $\begin{array}{c}\text { Maximum Temperature Differ- } \\
\text { ence }\left(D_{\mathrm{T}}\right) \mathrm{O}_{\mathrm{F}}\end{array}$ & 17.5 & 20.0 & 18.0 \\
\hline Minimum $R / \Delta T\left(m i /{ }^{0} \mathrm{r}\right)$ & .14 & .18 & .14 \\
\hline
\end{tabular}

Page 174 


\section{VERTICAL TEMPERATURE CRADTENTS}

No measurements of vertical temperature gradients were made with wiresonde equipment because of the greater need at Minneapolis for the avatiable equipment. Iocal wiresondes are scheduled for the next quarterly pertod.

The nearest radiosonde station 18 at Columbia, Kissourl, about 115 miles to the west. There are no major topographic discontinulties between CoIumbia and st. Louts. Therafore, in the absence of frontel systems, the Columbla raob data should indicate reasonably well the degree of atmospherlc stability over the open lands surrounding St. Iouis. Thus for each of the four surveys reported here, Columbia raob soundings and winds-aloft data for the first 4000 feet above the surface are given for $2100 \mathrm{CST}$, corresponding to a selected isotherm chart, and for the preceding and following mornings at $0900 \mathrm{CST}$ (F1gs. A-1, A-5, A-8, and A-10).

A comparison of the four low-level vertical temperature gradients at Columbia with the four corresponding temperature differentials at St. Louls shows a close agreement between the strength of the inversion and the intensity of the St. Louis $D_{T}$ (see Table IV-2). With strong inversions of $9.8^{\circ} \mathrm{F}$ per 400 feet, as in M-1016 (FIg. A-5), there is a maximum $D_{\mathrm{T}}$ of $17.5^{\circ} \mathrm{F}$, but with a lapse of $0.8^{\circ} \mathrm{F}$ per 400 feet as in M-1020 (F1g. A-8), the intermediate values decrease on a nearly straight line relationship, reaching a minimum $D_{\mathrm{T}}$ condition of $4.2^{\circ} \mathrm{F}$. More data are needed to establish a definite relationship. However, some evidence of such a 


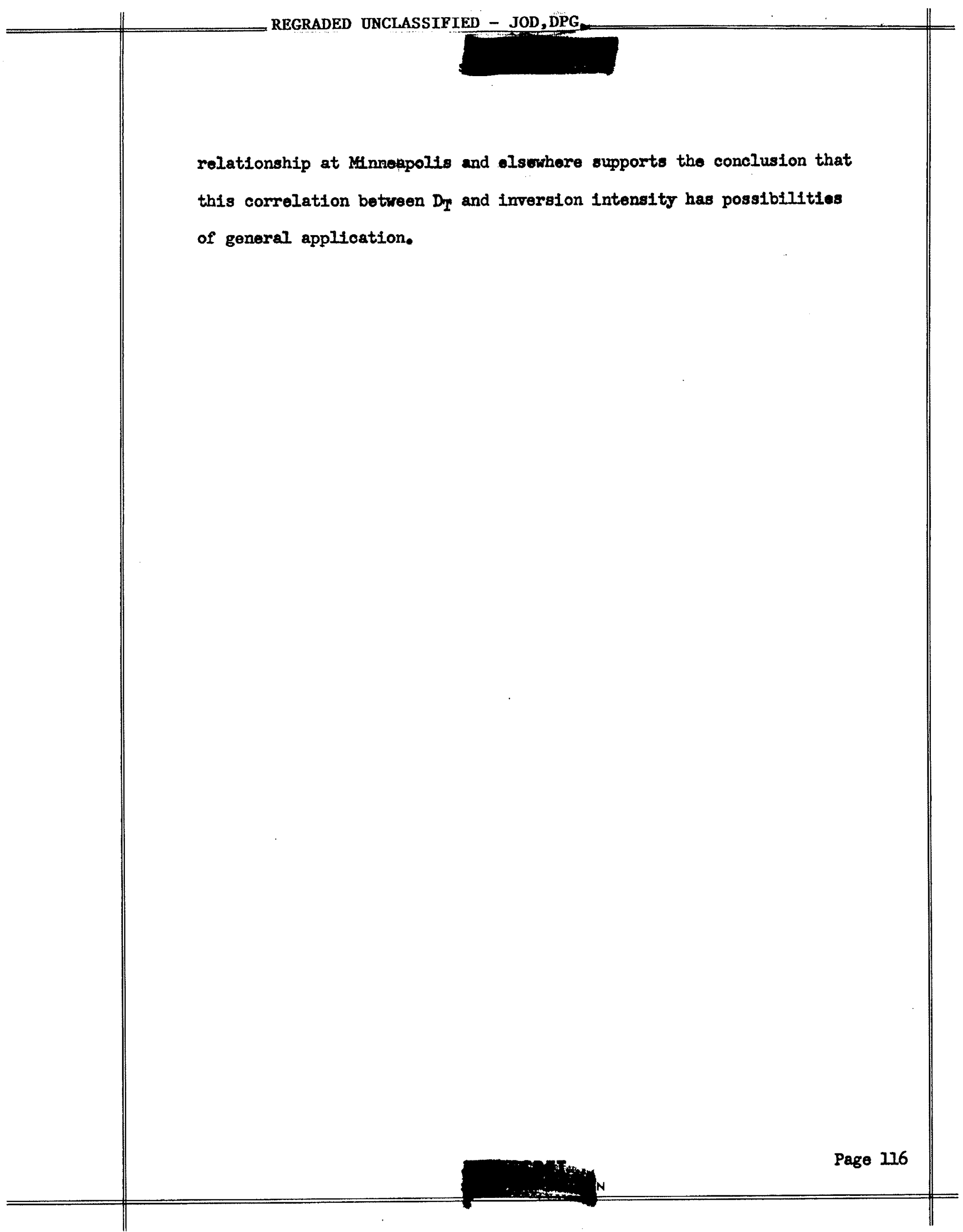




\section{E. SELECTION OF SITE FOR $\angle E R O S O L$ CLOUD STUDITS.}

The criteria for selecting sites suitable for aerosol cloud studies employing the fluorescent tracer tochntque were discussed in JQR 2. It was noted that of the areas ranging from a quarter to a mile on a side, one area should be typical of the major built-up portion of the oity, including comerciel and residential structures, and that other areas enabling comparative studies should have relatively similar population densities and land use characteristics. Additional requirements of an appropriately selected test site are a minimum horizontal temperature gradient across 1t, reasonable level terrain, and a unfform building density also in the surrounding region.

Based on considerations of the foregoing criteria, mosometeorological survey results, personal inspection, and examination botb of topographic maps and aerial photographs, a fire square mile test area was selected. It is bounded by Grand Boulevard on the west, Palm Stroet on the north, Chouteau Arenue on the south, and Broadway and Third Streets on the east. Relatively flat, densely built up, and sparsely tree covered, this area Includes the downtown district which will be used as one test and 18 large enough so that a number of one square mile test sites of intermediate building density can be selected. 


\section{ARROSOL TRACER TESTS IN MILMEAPOLIS}

\section{A. SCOPE OF OPERATIONS}

The fluorescent tracer studies described here are part of a continuing program designed to proflde the field experimentel date necessary to estimate munitions requirements for the atrategic use of chenical and biological agents against typical target cities. The principal factors affecting such munitions requirements, the climatological and topographical requisites of a test city, and the characteristics of a suitable simulant agent were described in SQR 1. 1180 presented in the report was a general description of the city test planning required to obtain information which is applicable to any agent and type of muition and is dependent of the munition diatribution on the target.

From past field experience it has been found that selected urban areas should be about one-half mile on a side and that approximately ten grams of the tracer material should be released from a fixed point source over a period of approximately five minutes. Dispersal of such duration minimizes the effect of transient fluctuations in local meteorological conditions and yields more reproducible as well as representative dosage patterns.)

Iisted below are the spectfic objectives of the tests described in this report. These tests were conducted in $1 b l e$ area (see Section $V-B$ "Test Site") and involved point-source releases and in some instances included sequential sampling. 
1. To determine the reproducibility of atreet level dosage patterns in an essentially residential area under given meteorological conditions;

2. To determine whether the street level dosage pattern from a point source is affected by the source position, that 18, when the generator is located at an intersection, at a point midway between intersections, at a point within a block, or on a roof top.

3. To determine the effect on dosage patterns of day and night meteorologicel conditions.

4. To obtain data on the penetration of the aerosol cloud into residences at various distances from the aerosol disperser, and to determine whether there is any residual background or lingering effect of the cloud within butldings. 


\section{B. TEST SITE}

Able srea, tentatively selected by 31 December 1952 as a desirable area for conducting aerosol cloud studies aploying the fluorescent tracer technique, was the site for the fleld tests described in the present report. Approximately one and a half miles south of the central business district, the area is bounded by 25 th Street, 35 th Street, lot dremas South, and Chicago Aveme. It is reasonable flat although the terrain slopes gently to a 20-foot depression in the center (F1g. V-I). PrimariIy a residential area, it consists predominantly of two story frame houses (Fig. V-3). The area is bisected by an esst-west railroad which runs 2long an underpass cut below the level of all streets except the one street crossing the sink at the 48-foot elevation. Thus, all north-to-south oriented streets except 5 th Avemue span the railroad by bridges which are somewhat arched; the west and east embankments are 20 and 18 feet, respectively, at the highest points.

Along the railroad artery a moderately sized industrial complex has grown (Fig. V-2). Only to the north, along 4th Avemse between 27 th and 28 th Streets, are the manufacturing buildings from four to nine stories high. These constitute Kinneapolis-Honeywell Regulator Corporation. Nlong Lake Street to the south, a commercial center has developed consisting predominantly of one and two story bufldings.

Clinton School (FIg, $\mathrm{V}-4$ ) the two story brick elomentary school at Clifton Areme and 28 th Street, was used for a roof top meteorological station, 


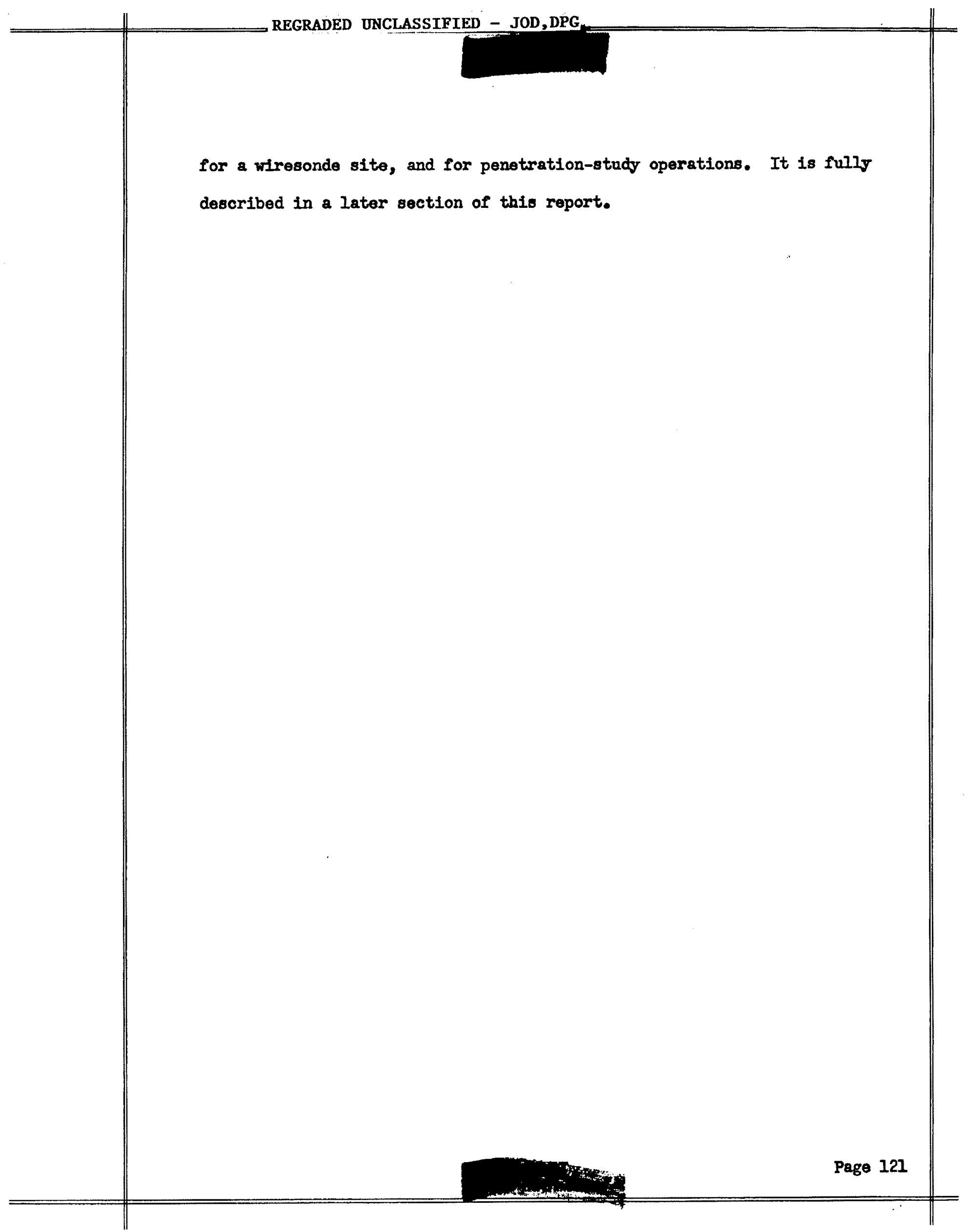




\section{DQUIPAENT AND PROCEDURRS:}

\section{Aerosol Cenoration}

A contimous blower-type aerosol generstor* is used in each test to disperse the tracer materiel WJZ 2266 as an aerosol. The generator components Include a small hopper for the dry poudared pigment, a high speed centrifugal blower to generate the aerosol, a feed mechantim to provide a controlled rate of powder delivery from the hopper to the blower, and a battery powered supply and control box. Recent modifications of the feed mechanism** permit delivery of approdmatoly 1 to $3 \frac{7}{2}$ grams per minute for a period of at least ten minutes and with an average deviation of less than $3.5 \%$ from the moan discharge rate. By weighting the removable plexiglass hopper before and after a test, the precise amount of material dispersed can be detarmined.

The aerosol generating unit, supported by a motal frame, is operated either from the rear of a truck (Figs. $\nabla-5$ and $\nabla-6$ ) or from a roof top (Fig. V-7). Exact locations of the disperser during the ourrently reported tests are found in the respective isodosage charts in Appendix B. The first dispersing position for a given test involving several releases: Is established at the last minute so that optimum coverage of the sampler array is achiered by the aerosol cloud. In later releases during the night the generator is relocated on a roof top or at another position

* For description see SBRR $147-11$ and $U_{4}$, and SQR 1856-3.

* Full details will be found in SQR 1856-5. 
within a block of the first, provided there is no substantial wind shift. Dispersal starting time is fixed not only by a predetermined schedule but by work received on the radio network from the Test Director.

Upon completion of a test the generating untt is 1solated for separate housing and maintenance at a location remote from the field office. Full precautions are taken to avold accidentally introducing contamination into the fleld office premises which would reduce the accuracy and reliability of particle counts.

\section{Sampling}

\section{a. Deployment and Exposure of Samplers}

Membrane filter samplers, described and illustrated in Section III, were used exclusively in the currently roported series of tests. Units were deployed at a predetermined set of positions which included car, ground, roof, and inside installations (Figs, $\nabla-8$ through $\nabla-13$ ).

The basic array or grid pattern may be modified up to 20 minutes prior to the aerosol release. The samplers are dispatched to the most favorable positions based on meteorological dats obtained during the preceding hour. Should the wind shift after the initial release has been made, instructions are given either by direct contact or by radio to redistribute certain samplers. Should a preassigned location not be reached or become available, the sampler is placed as close as possible to that location and the exact Iocation and mothod of exposure recorded. 
Though there is no specific orientation of filter surfaces, they are generelly faced downrard in the erent of rain, and to the atreet side of cars and away from the objects to which the holders are tied. To approximate a man's height, surface-sampling holders are normally placed at or about the fire foot lovel (Fig. V-9).

\section{b. Sampling Period}

Samplers are atarted on or before a scheduled sero time and are turned off several times after the duration calculated to be required for passage of the aerosol cloud. Each operator is instructed to check his sampler or samplers perlodically and to cap all holders not in use. For each succesoive release he inserts a new filter-loaded holder, taking care not to change the sampler position. Between releases there is a 20 to 30 minute off-sanpling period during which time pumps are not in operation.

\section{c. Sequential Sampling}

To check the time of cloud passage and the adequacy of sampling time, two filters are sequentially exposed during a given relesse. At a prescheduled time at selected stations primarily inside buildings and at a few outside positions dowmind of the aerosol source, the ioperators remove an already exposed holder and insert another holder into the connective coupling of the same pump. The change is made quickly so that the off-sampling period Is limited to a few seconds. 


\section{d. Flow Rating}

A flow rate through each exposed filter is necessary for calculation of the total dosage which is defined as the number of particles deposited on the entire filter divided by the average flow rate. This flow rate for a given filter-purp combination can be predicted only approximately.

In practice particularly since the purps (described in Section III) are not equipped with regulating devices, the actual flow rate is not necessar1ly constant during the sampling period and differs among the individual pump units. It is also determined by variations in permeability anong the filters. During a normal exposure not enough material is collected on the filter aurface to change its permeability. The flow rate used in the total dosage calculations is the mean between easurements made at the beginning and the end of the sampling period. This is currently accomplished by the modified llnor Velometer Jr. described in Section III (Fig. V-14).

Flow rating can be done conventently within satisfactory limits of accuracy inside the laboratory rather than at the site of operations at outdoor temperatures.*

* In Minneapolis a number of direct flow rate measurements were taken to determine the effect of the ambient atr temperature or the temperature of the equipment on the capacity of the sampling pumps. These measurements were made in a room at $74^{\circ} \mathrm{F}$ and out-or-doors at $7^{\circ} \mathrm{F}$. The flow rate was mosured inmediately after all equipment, including the flow moter, was transferred to the warm room from out-of-doors and yielded a high value of 8.7 liters per minute. On the other hand, a low value of 7.6 liters per minute was obtained when measurement was taken immediately upon removal of the equipment from the room to the outdoors. in extreme 145 change in flow rate was thus observed. Under a more normal or usual situation, however; the change was found to be in the range of 0.3 to 0.5 ilters per mimute, or an average of $5 \%$ higher out-of-doors. 
A standard filter-loaded holder has been used recently to eliminate the need for flow rating of exposed filters after the release. Since this holder remains in the laboratory, its use as a standerd, in preference to an exposed holder, lessens the possibility of cross contamination in the handling of filter units. Before a tracer test the filter-loaded holders belonging to the same sampling group, that is, those operated by the same pump, are flow rated; firat, the holders that are to be exposed during the test, and next the holder consldered as the standard. After the experiment flow rate measurement is taken of the standard holder only. The resulting relationship between the initial and finel readings of the standard is used to extrapolate the expected flow rate change for the other holders.

Bata gathered during the current period from test FT 0009 indicate that this extrapolation method of determining the final flow rates of the exposed filters is a valid procedure. These data provide a comparison between the extrapolated final flow rate and actual flow measurements made on a group of 95 exposed filters distributed among 30 puxps, each pump being tested with a filter used only as a standard.

The mean deviation between the extrapolated and the measured flow rates was found to be 3.3\%, and 90 out of the 95 filturs shown maan deviations of less than 10\%. Two filters showing a $30 \%$ deviation, probably due to gross exrors in the flow rating technique, were not included in the above figures, although they formed a part of the same group of samplers employed in an actual field experiment. 
It should be noted that the foregoing figures reflect not only the expected validity of the extrapolation mothod, but also all of the additional errors entailed in the flow rate measurements. Koreover, if the flow rate used in calculating total dosages is taken to be the average of the initial and the extrapolated final flow rates, then the effect of the above deviations on the accuracy of the total dosages are even less, and st1ll greater is the justification for dispensing with the procedure of actually measuring the final flow rates of the exposed filters.

\section{Filter Analysis}

The lárge number of samplers used in the aerosol hour tests and the fact that tests are run in rapid succession requires that the results be evaluated as quickly as possible in order to plan subsequent tests. Therefore, a comparison technique, briefly described below, has been established for obtaining a preliminary evaluation (preval) of the filter count. When plotted, the prevals provide a preliminary estimate of the test result within a few hours after the release is made. In the course of the preval operation, the filters are segregated according to estimated particle count after which they are mounted on microscope slides and counted for final evaluation.

Prevals are made after exposed holders have been flow rated and placed in racks, 24 at a time, but before the filters are removed from their holders for microscopic examination. Estimates are made of particle concentration by moving the racks alongside an array of standard filters containing previously determined counts of varying particle dengities. The comparison 


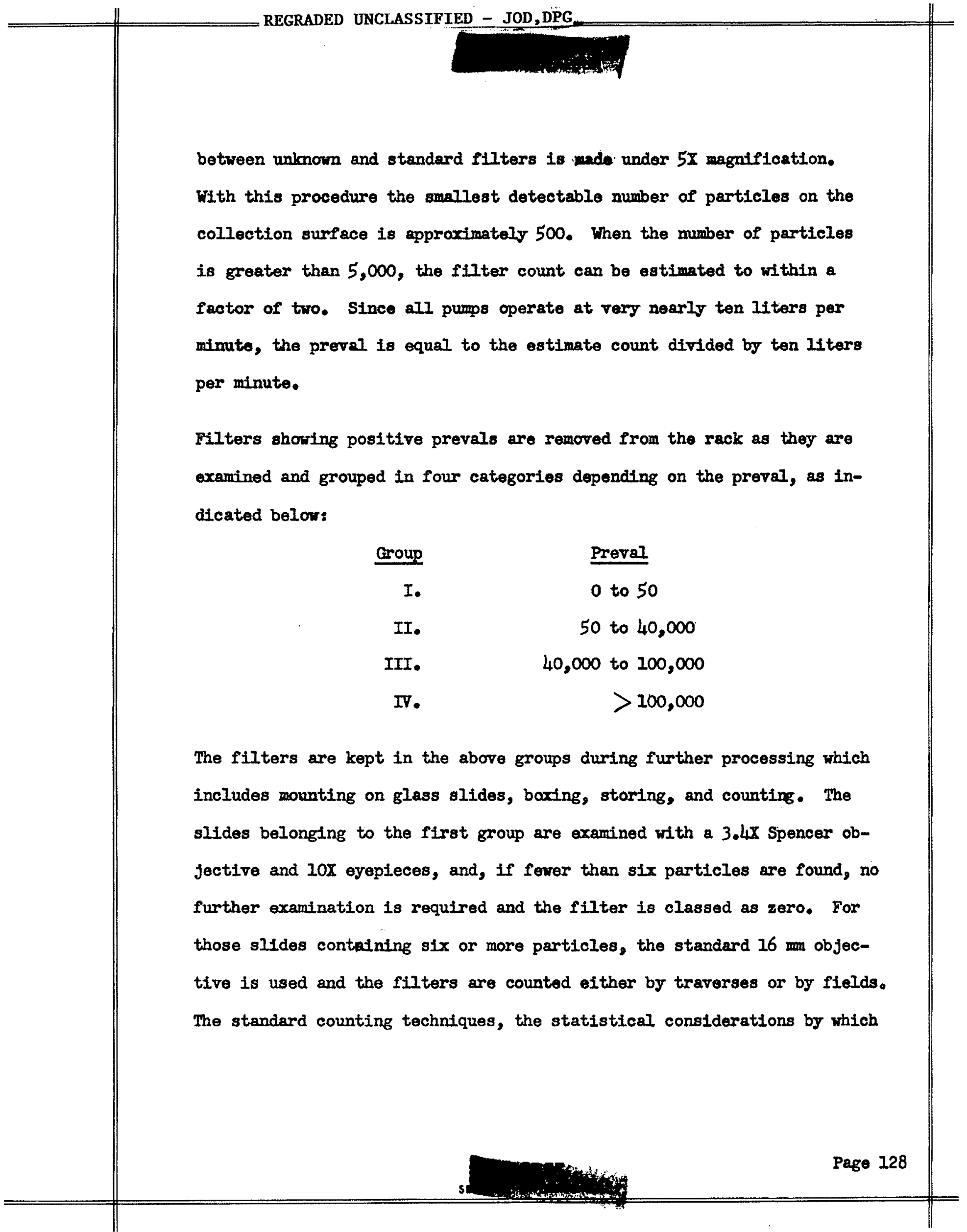


the minimum representative count of 270 was determined, and the respective formulas for estimating total particle counts are described in SQR 1856-4.

\section{Mateorology}

It was seen in JQR 2, and reiterated by the temperature survers reported above in Section IV, that measurements of horizontal and vertical temperature gradients in urban and peripheral areas are prerequisite to a selection of proper sites for conducting aerosol tracer tests. So that correlations can subsequentIy be made with the dosage distribution data, complementary two-meter atr temperature surreys are made including rartical temperature soundings. In addition, audliary meteorological observations must be made within the selected areas before and during the individual tracer tests. Tro types of field meteorological stations are responsible for these observations: the surface leval and the roof top stations.

The first type consists of two to three automobiles, each equipped with

a. A sensitive microtorque wind vane mounted on the automobile top at approximately two motors (FIg. V-15);

b. An Esterline-Angus miliameter placed Inside the car for contimuous recording of street level wind direction (Fig. $\nabla-16)$; and

c. An Alnor Velometer for measuring wind velocities at ten mimute intervals.

Measurements are taken while the cars are parked at predetermined locations: one approximately a half block ( 150 feet) upwind of the aerosol 
source, and another along the general axis of the serosol cloud at the dowmind edge of the test grid. One hour before the first release at 2 time, the cars are parked generally on the dowmind side of a street, not in the lee of a building but preferably on the downrind side of an intersection or facing an open ares. During this one hour period, personnel prepare balloons and keep in constant communication with the rest Director for recelving or supplying pertinent information.

The roof of the Clinton School (Fig. V-17.), 35 feet above street level, is similarly equipped with a wind vane which is set three feet higher on the parapet at the farthest uprind edge of the building. At ten minute intervals wind velocity is likewise measured with a hand held Alnor Velometer.

Various procedures are common to the auxiliary meteorological stations. at a specified time immediately prior to release time, toy balloons, inflated with helium and weighted to give a long low angle trajectory, are released at all points ( $\mathrm{FIg} \cdot \mathrm{V}-18$ ), and additional wind drift observations are thereby obtained. At ten minute intervals all dry bulb thermometers are checked as are the wet bulb thermometers when the occasion warrants. In addition pyrometers are used to obtain representative measurements of typical bujlding, snow, and road surfaces in the general vicinity of the meteorological stations (Fig. V-19).

Al: measurements, including observations of cloud cover, gustiness, and precipitation, are taken during all releases. As noted above, trends or sudden changes are immediately reported by radio to the Test Director. 


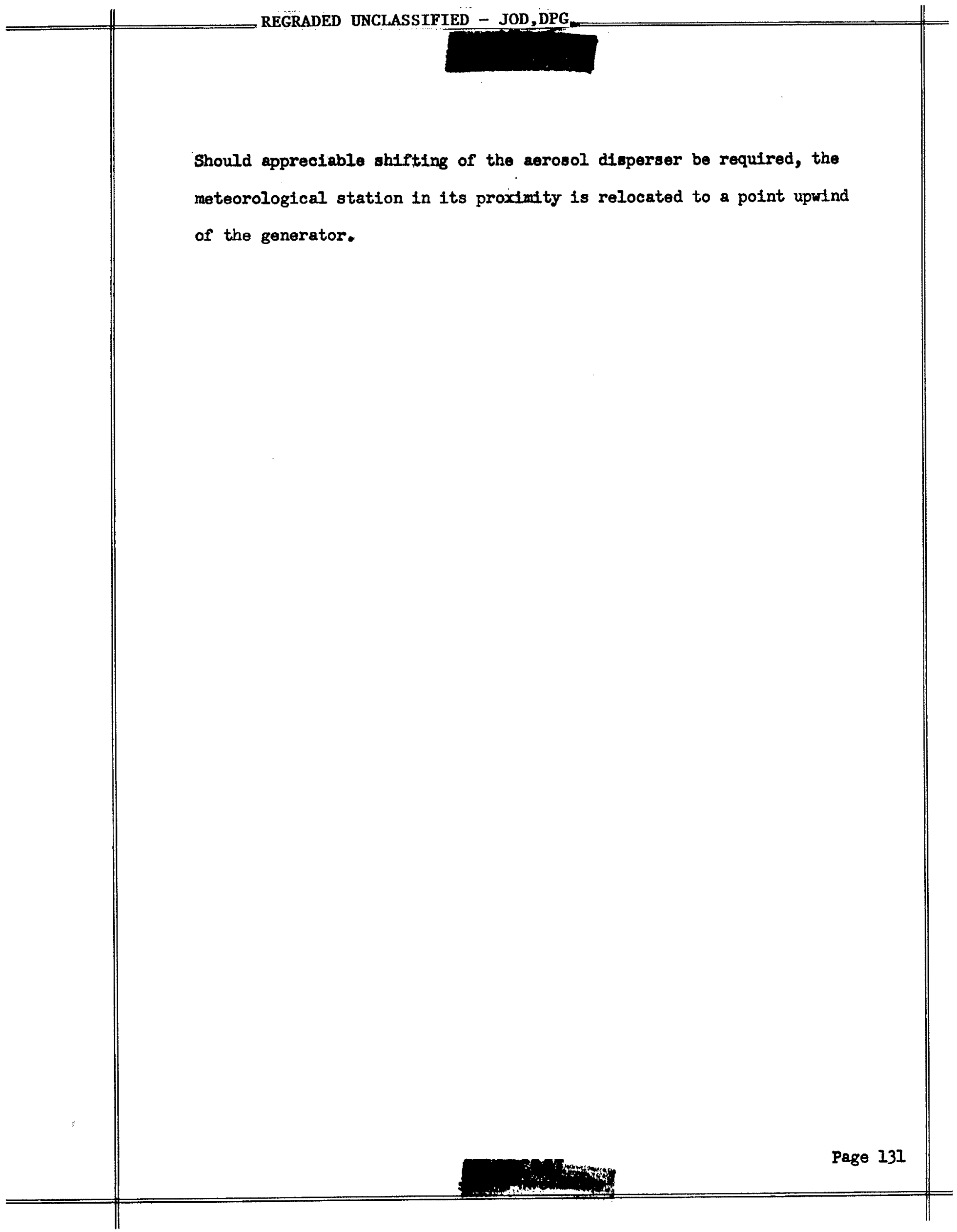




\section{SUMMARY OF RESULTS}

During the present quarterly perlod 24 tracer teste involving 61 relesses of fluorescent particulate material were conducted in four selected areas. of these tests six are fully evaluated in this report: FT's 0003, 0004, 0008, 0009, 0010, and 0011 . Each test, comprising two to four point-source releases from vehicle or roof top position, was conducted in Able Area which earlier descriptions have identffied as representative of the city with respect to meteorological and land use factors and which in all likelihood will be the standard by which other test areas and the results obtained in them wlll be considered.

of the point-source releases sumarized in Table $\nabla-1$ in termas of aerosol source, meteorological, and area-dosage information, 11 were made at night, three in the afternoon, and four in the early morning hours. The early morning releases comprising FT 0010 are considered as nighttime operations since they were completed before dawn. In four tests, FT's 0008, 0009, 0010, and 0011 , sampling unt ts were placed both within and outside Clinton School. In some Instances the samplers nominally considered outside were actually placed within the butlding with noszles extending beyond the windows. House penetration studies were also made in FT's 0008 , 0009 , and 0011 , and samplers were operated sequentially at selected residences.

For each test the applicable isodosage charte, area-dosage relationships, sumary of house penetration and Clinton School results, 1sotherm map for an associated temperature survey, St. Cloud raob soundings, wiresonde 


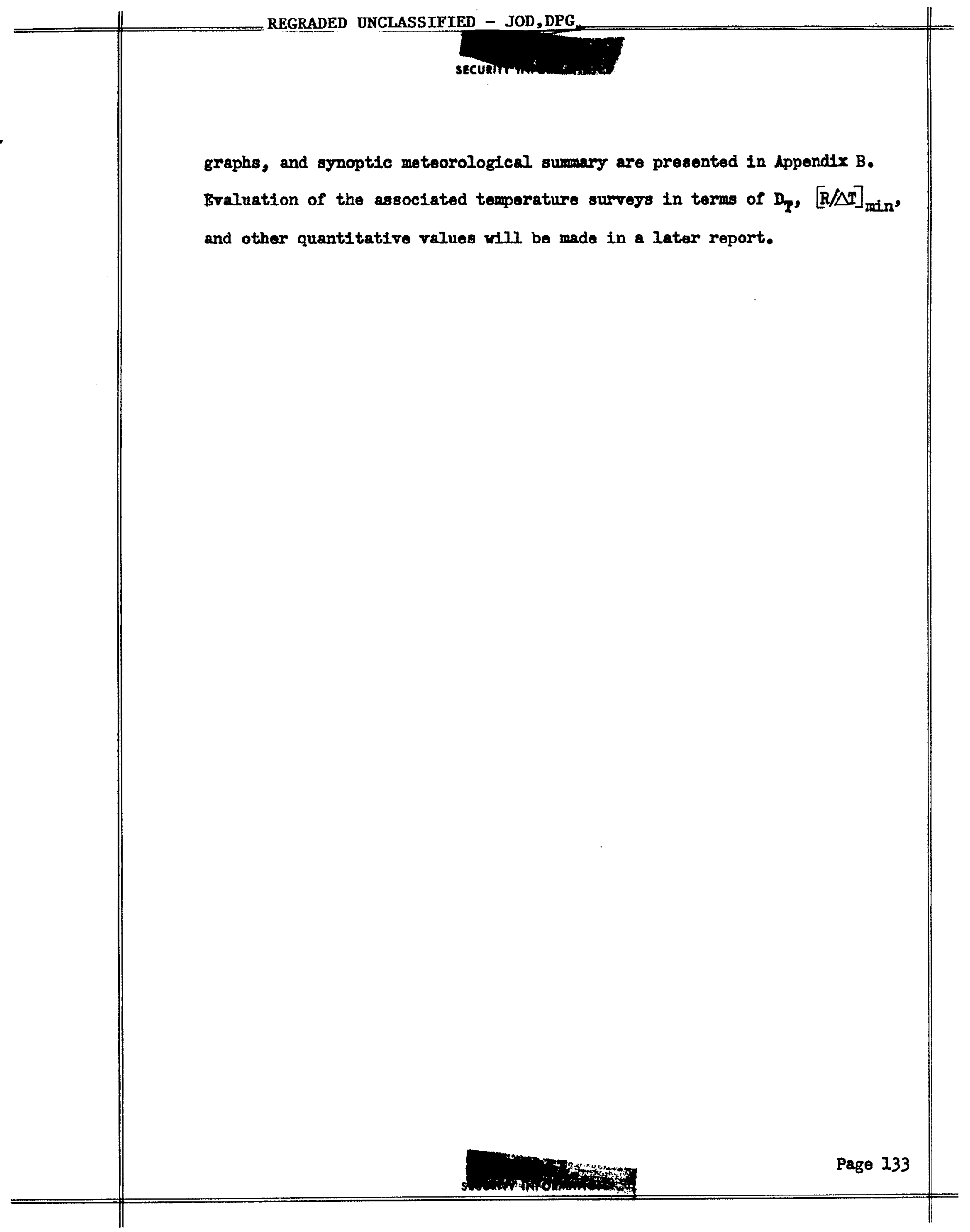


REGRADED UNCLASSIFIED - JOD,DPG

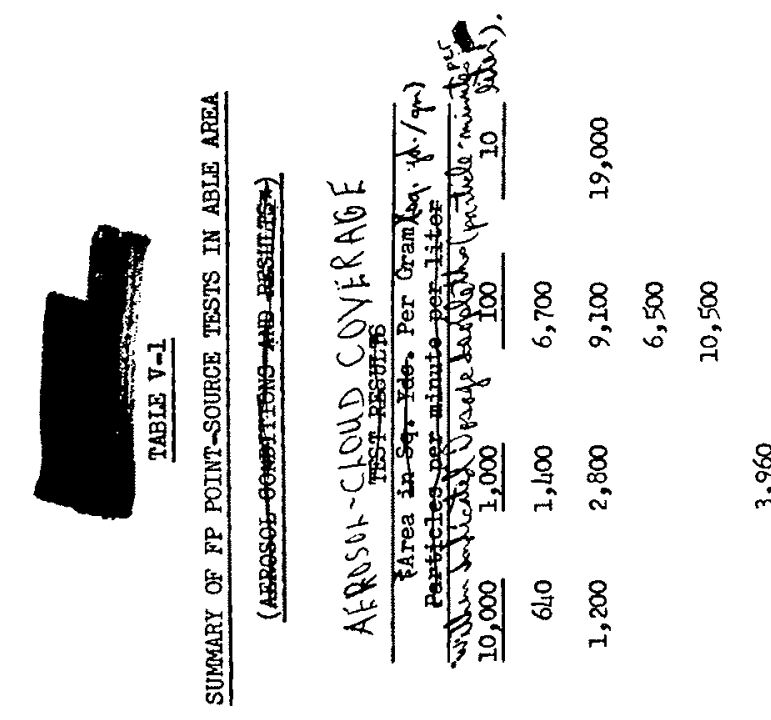

. 


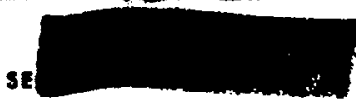

E. PRELIMTINARY COMAENTS ON AEROSOL CLOUD BEHAVIOR

\section{Dosage Areas}

The six tests in Able Area involving eighteen reloases were conducted under wind conditions which ranged from an avorage of 0.7 mph for one test night to $5.5 \mathrm{mph}$ on another night. Vertical temperature gradients ranged from $1.5^{\circ} \mathrm{F}$ lapse to $2.5^{\circ} \mathrm{F}$ inversion in 200 feet.

The areas within given dosage 1soplbths, when adjusted for the amount of material released, were at a maximum on the night with inversion conditions existing. They were at a mintmum for the daytime test. Based on an average of all releases during a given test, the areas within the 1000,500 , and 100 isodosage contours were greater under inversion conditions (FT 0008) by factors of $\Psi_{4}, 8$, and 11 , respectively, than for daytime lapse conditions (FT 0017 ). If the areas are further adjusted for wind speed, the factors become $21 / 2$ and $11 / 2$ and 3 .

For each test a presentation of dosage values versus enclosed areas in square yards is shown in Appendix B (FIgs. B-4, B-10, B-17, B-24, B-31, and B-39). The averages for each sertes of releases on a single night or afternoon are shown in FIg. $\nabla-20$. In all cases the areashacheemadficted

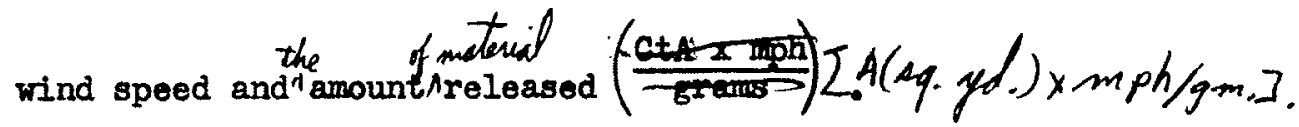

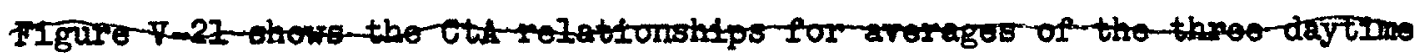

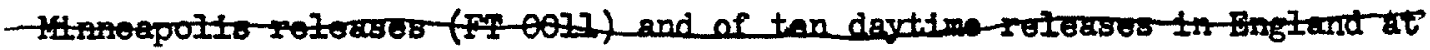
Setiobuto

* C. J. M. Lanensen, Diffusion of Smoke in a Built-up Area, Porton Technical Paper No. 193, 1950. 
These are based on areas per gram of material released and are not corrected for wind Bince in Kinneapolis the yind-was messured in the test area, but in Salisbury It yes finewered in an open area outside the tost area. If adjustiments for wind trexe made, the difference betreen the tro would probably be greater than showm

2. Cross Wind Integrated Dosages (CWID)

Maximum adjusted cross wind integrated dosages were obtained on FT's 0008 , 0009, and 0010. In general CWID values for these tests were about four times greater than for FT's 0003, 0004, and 0011. FT 0008 was mun under ground inversion conditions; FT's 0009 and 0010 were run under slight inversions or 30 to 40 foot 1sothermal layers with bases at or below 50 feet (FIgs. $B-16, B-23, B-30$ ).

Two of the three tests wich showed low CWID values were performed at night with lapse conditions existing to at least 160 feet. The other was a dajtime test with lapse conditions prevaliing.

Figure V-22 shows the average CWID distance relationship for each series of releases with the CWID's adjusted for wind speed and amount released $\left(\frac{\text { CwrD } \times \text { mph }}{\text { grams }}\right)$

3. Reproducibility of Dosage Patterns

When wind conditions were relatively constant throughout the succession of releases of a given test period, similar dosage patterns were obtained on all releases. Even when slight wind ahfets moved the axis of the 
dosage pattern, the resulting change was primarily a change in orientation; the width and length of the pattern remained essentially the same.

The calculation of dosage patterns obtained from multiple source releases, based only on single source releases, can be reasonably accurate only if the variations of the single source dosage patterns with horizontel and vertical displacements of the source are considered. In these Hinneapolis tests displacement of the source horisontally or vertically on successive releases caused no observable significant effect. However, since none of the four roof top releases were made under strong inveralon conditions, it cannot yet be concluded that under all conditions those elements of a cluster which function on roofs will contribute to the total dosage at ground level to the same extent as those which function on the ground. 4. Variation of Dosages with Height

Vertical samples taken outside windows of the first and second floors of the Clinton School, with other samples being taken on the roof, indicate a slight drop-off of dosage with altitude. A total of 48 samples were taken during 12 releases. Expressed as per cents of the dosages obtained at a sampler on the ground nearby, the median values for the first floor, second floor, and roof as shown in Table V-2 were 93\%, 88\%, and $61.5 \%$, respectively. 
TABLE $\nabla-2$

CLINTON SCHOOL VERTICAL ATTENUATION DATA EXPRESSED IN PERCENTAGES OF GROUND LEVELL DOSACES

\begin{tabular}{|c|c|c|c|c|c|c|}
\hline & $\begin{array}{r}\text { No. of } \\
\text { Relonses } \\
\end{array}$ & $\begin{array}{r}\text { Ho. of } \\
\text { Sarples }\end{array}$ & $\begin{array}{l}\text { No. of Values } \\
\text { Trace or Zero }\end{array}$ & $\begin{array}{l}\operatorname{Min} x \\
(\mathscr{D})\end{array}$ & $\begin{array}{l}\text { Min } \\
(\%) \\
\end{array}$ & $\begin{array}{c}\text { Kodian } \\
(\$) \\
\end{array}$ \\
\hline First Floor & 8 & 21 & 0 & 158 & 33 & 93 \\
\hline Second Floor & 12 & 13 & 0 & 272 & 35 & 88 \\
\hline Roof & 12 & 24 & $\underline{I}$ & 272 & 0 & 61.5 \\
\hline GROSS & 12 & 48 & 1 & 272 & 0 & 81.5 \\
\hline
\end{tabular}

\section{Penetration}

Penetration into the interior of the Clinton School showed somewhat lower values. For 71 dosages obtained during the same 12 releases, the modian values for the ground floor, first floor, and second floor were $23.5 \%, 27 \%$, and 22.5\%, respectively. The rentilating system of the school was not in operation during the tests.

Penetration into houses differed markedly from that at the school. Based on only 42 dosages obtained during seven releases, the medians for basement, first floor, and second floor were 13\%, 11\%, and 2\%. Until further data are obtained it is difficult to account for the low value on the second floor. A sumary of penetration values at Clinton School and at several residences are given in Table $\nabla-3$. 


\section{TABIS V-3}

PENETRATION DATA EXPRESSED IN PERCENTACHS OF OUTSIDE DOSAGES:

\begin{tabular}{|c|c|c|c|c|c|c|}
\hline Houses & $\begin{array}{l}\text { No. of } \\
\text { Releases }\end{array}$ & $\begin{array}{r}\text { No. of } \\
\text { Samples } \\
\end{array}$ & $\begin{array}{l}\text { No. of Values } \\
\text { Trace or Zero }\end{array}$ & $\begin{array}{l}\operatorname{sax} \\
(\$)\end{array}$ & $\frac{14 n}{(8)}$ & $\begin{array}{c}\text { Kodian } \\
(\$) \\
\end{array}$ \\
\hline Basement & 7 & 19 & 7 & 58 & 0 & 13 \\
\hline First Floor & 7 & 13 & 4 & 200 & 0 & 11 \\
\hline Second Floor & 7 & 10 & 4 & 41 & 0 & 2 \\
\hline CROSS & 7 & 42 & 15 & 200 & 0 & 27.5 \\
\hline
\end{tabular}

Clinton School

$\begin{array}{lrrrrrc}\text { Cround Floor } & 12 & 36 & 4 & 100 & 0 & 23.5 \\ \text { First Floor } & 9 & 13 & 0 & 43 & 11 & 27 \\ \text { Second Floor } & 12 & 22 & 2 & 100 & 0 & 22.5 \\ \text { CROSS } & 12 & 71 & 6 & 100 & 0 & 23\end{array}$

Five houses in which penetration studies were conducted are described and illustrated in Figs, V-23 through $\nabla-27$. With each of these figures is given a sumary of the dosages obtained at or wlthin the particular residence. No positive counts were obtained from outdoor and indoor samplers at a sixth house, F, located at 2722 Portland Avenue. The sampler arrays at Clinton School for FT's 0008, 0009,0010 , and 0017 are shown in Figs. $\nabla-28$ through $\nabla-31$, respectively. Each figure includes dosage sumaries: for all releases of the given test. 


\section{REGRADED UNCLASSIFIED - JOD,DPG}

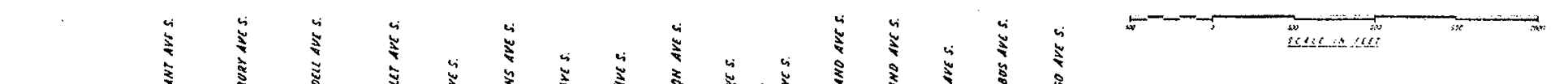

N
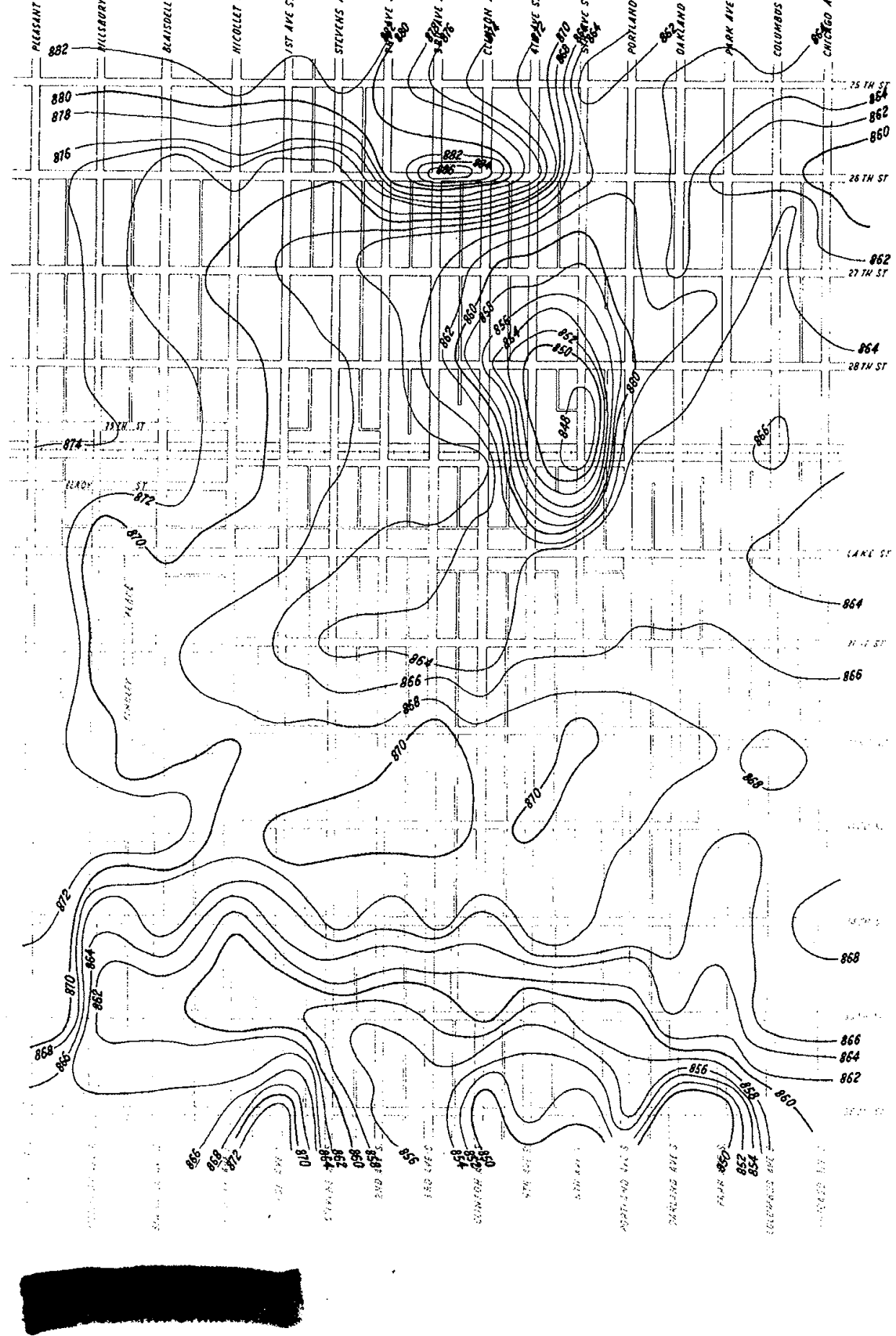

FIG. V-I

TOPOGRAPHIC MAP

MINNEAPOLIS

ABLE AREA

PAGE 140 


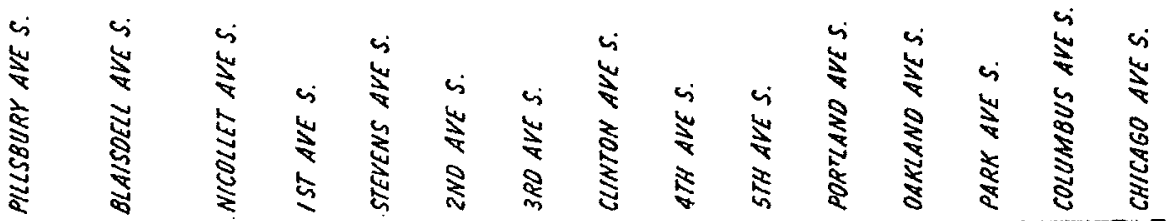

25 TH ST.

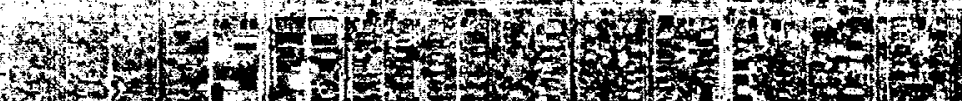

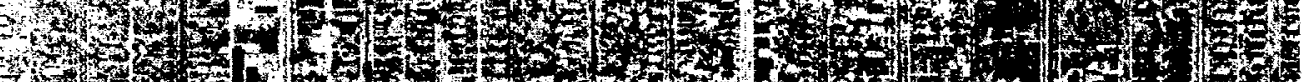

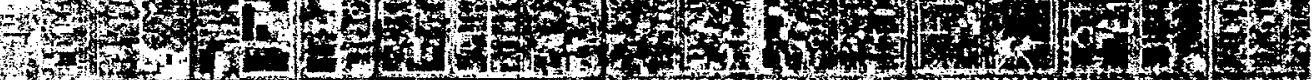

26 TH ST.

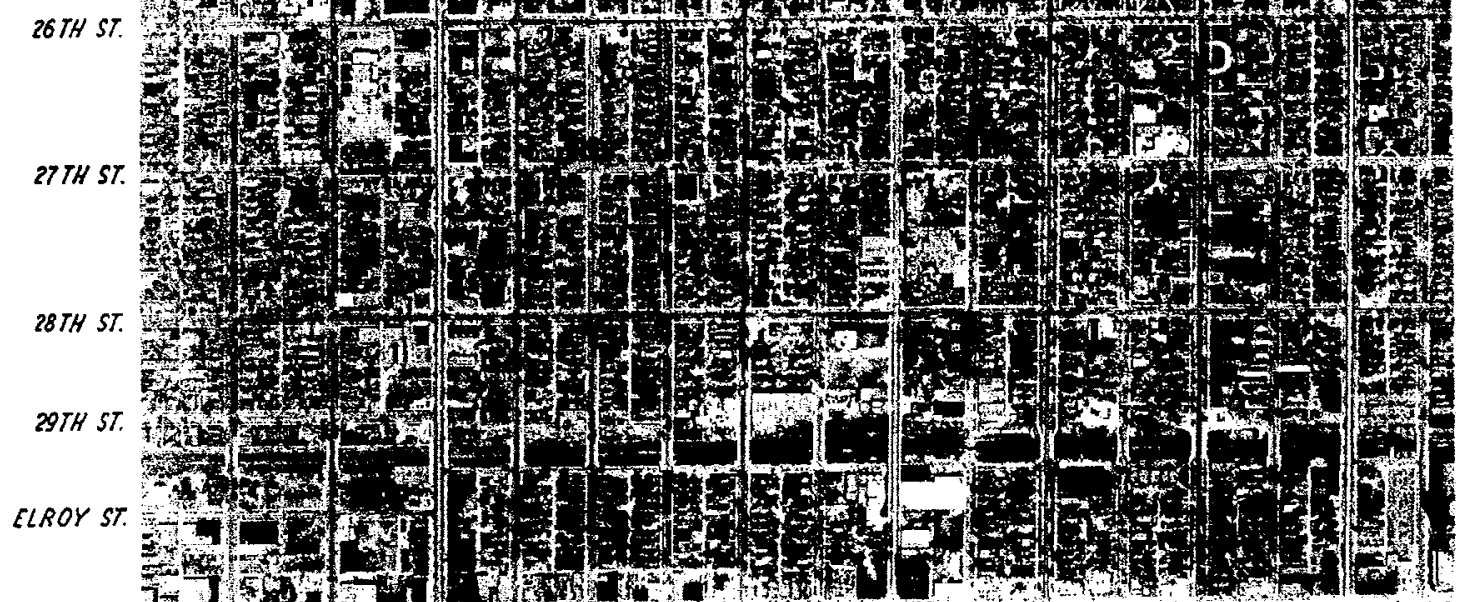

LAKE ST. 1.

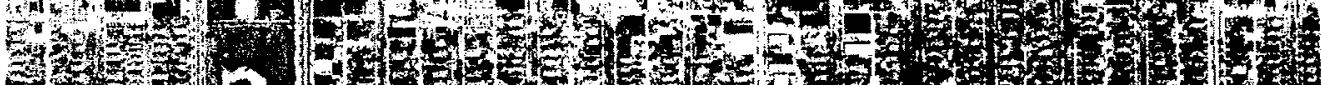
3 (6)

3IST ST.

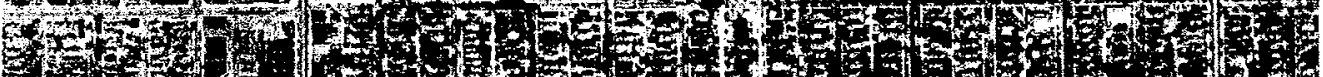
6.

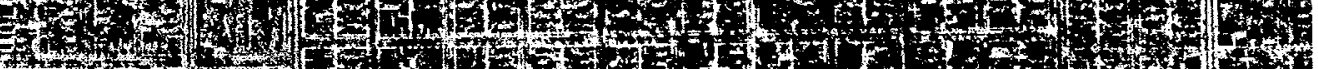
32ND ST.

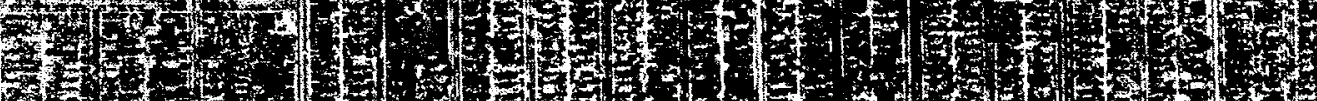

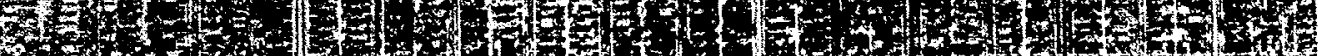

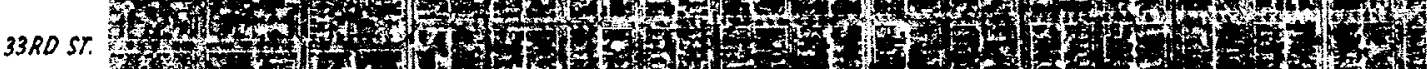

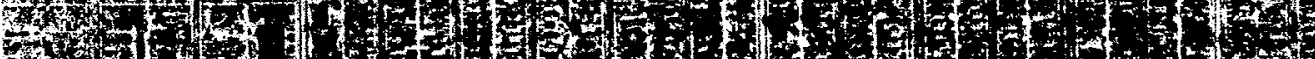

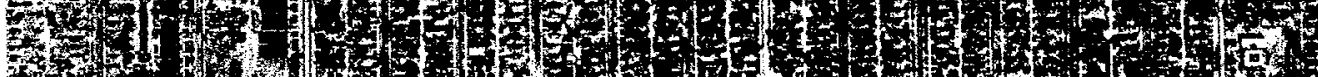

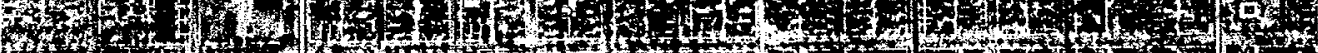

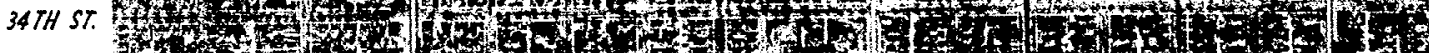

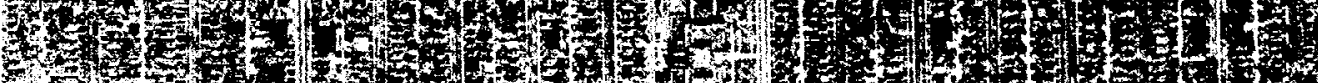

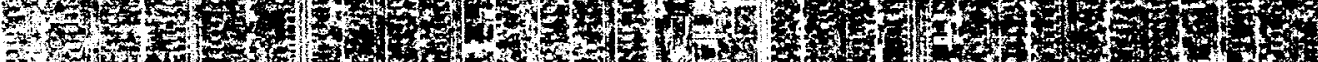

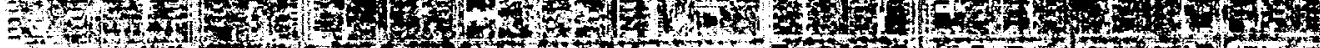

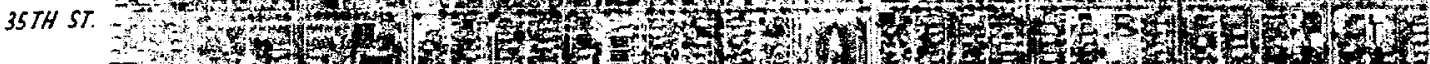
:3,

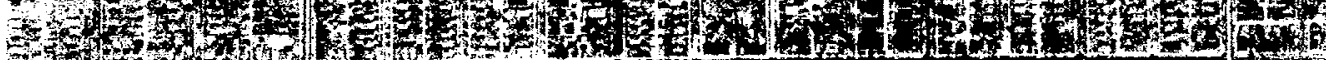
36 TH ST. 7\%t.

FIG. $V-2 \quad$ MINNEAPOLIS ABLE AREA

PAGE 141 


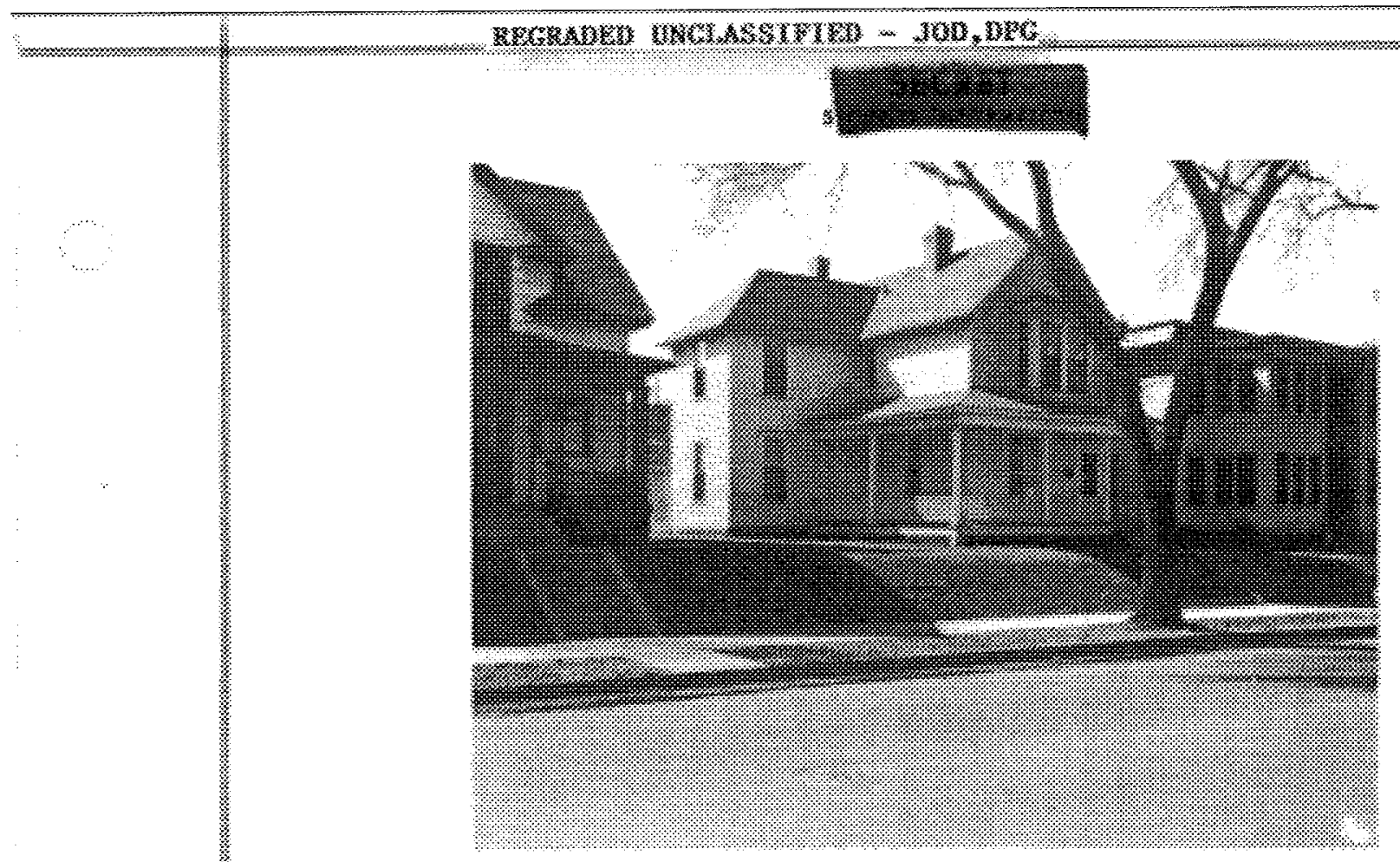

F** * * $* \cdots$

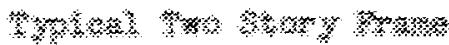

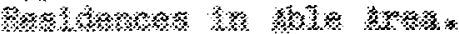

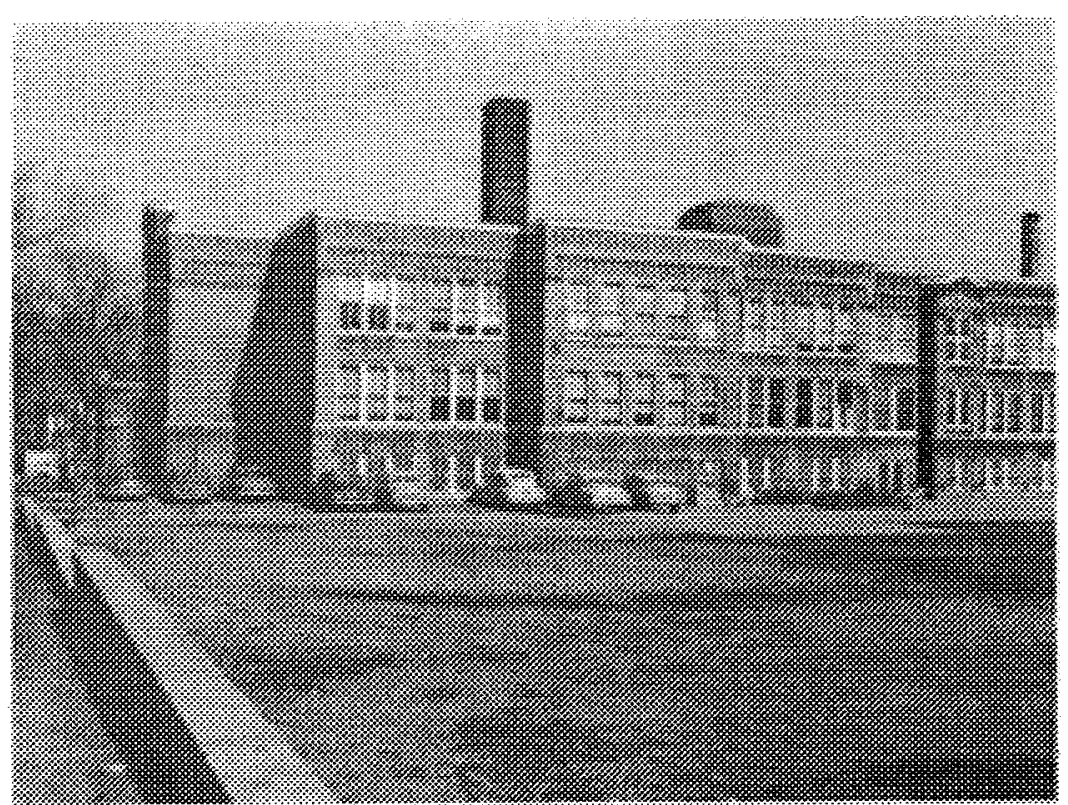

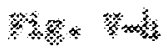

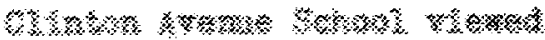

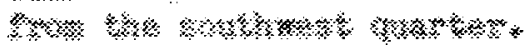

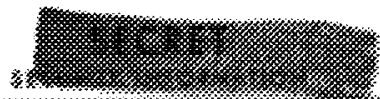

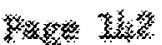




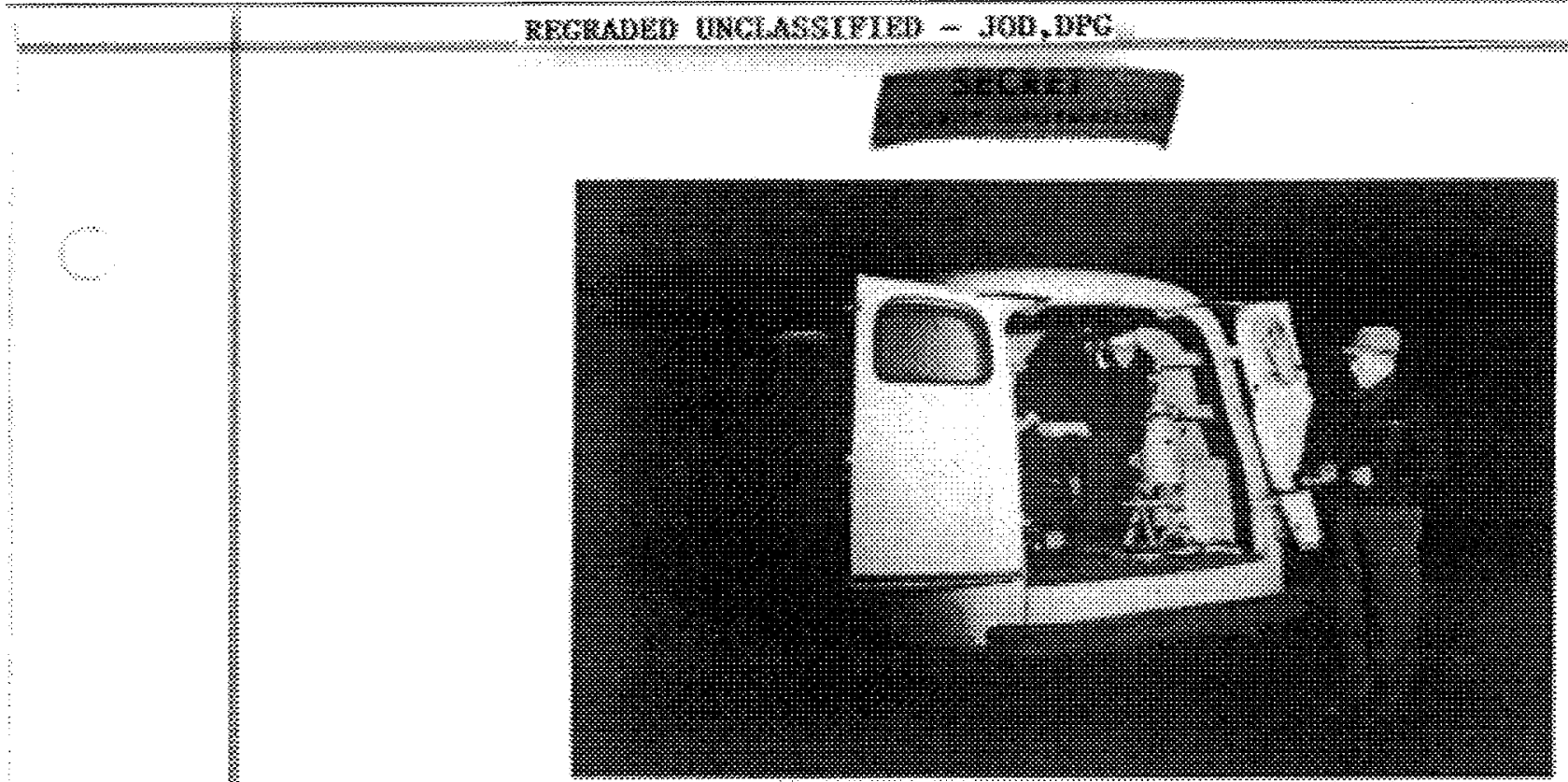

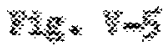

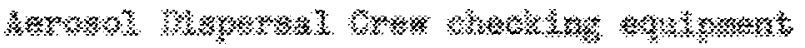

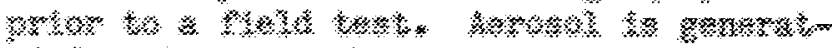
喓

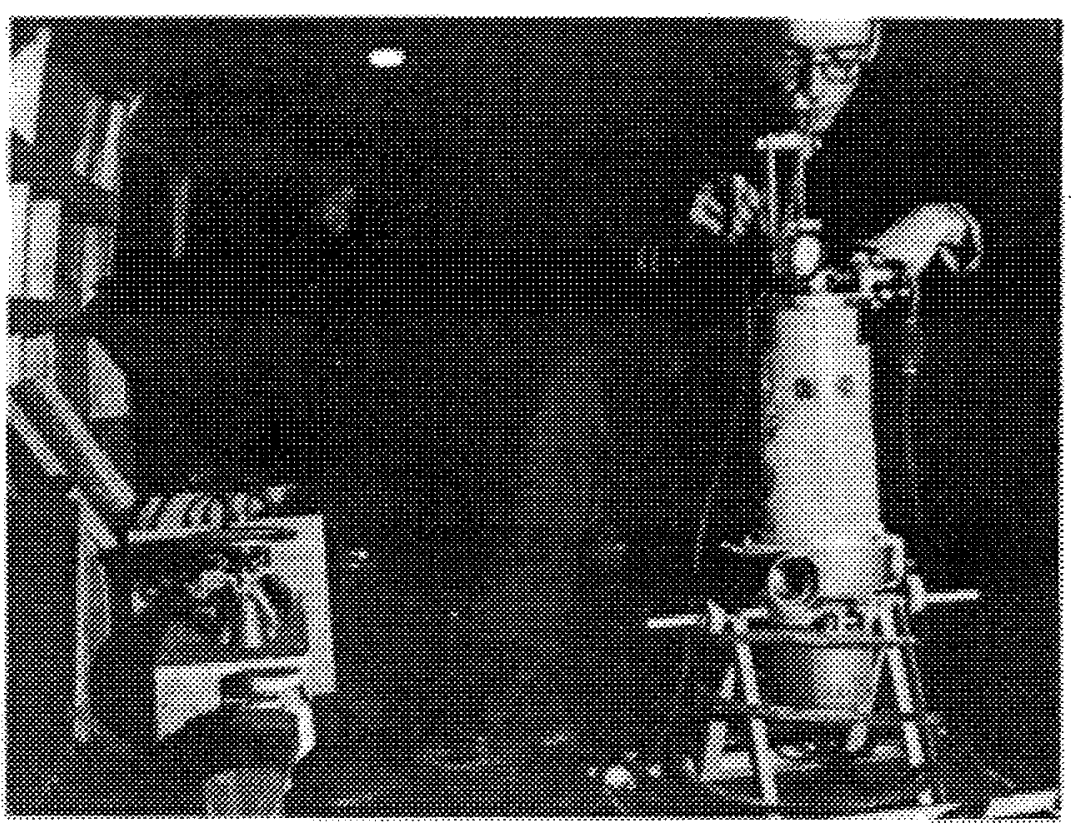

\%

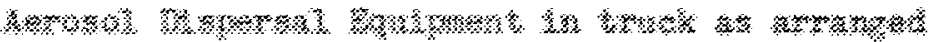

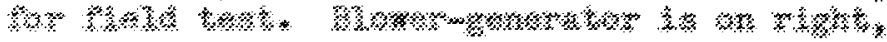

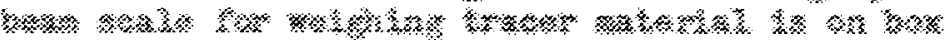

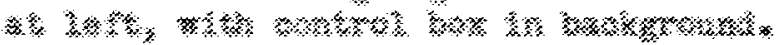




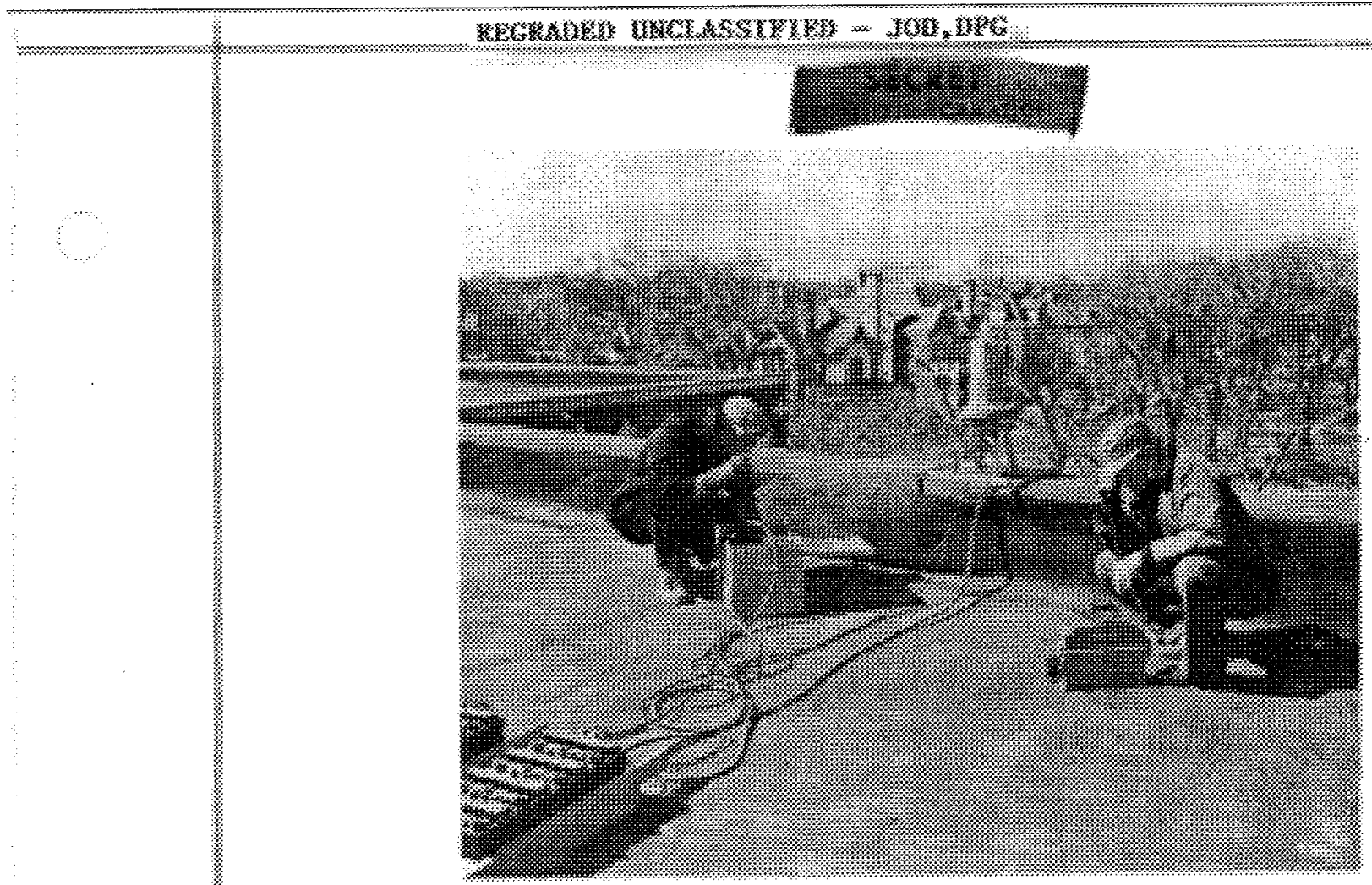

V)

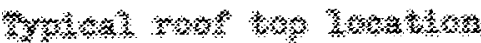

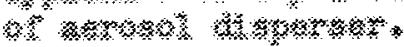

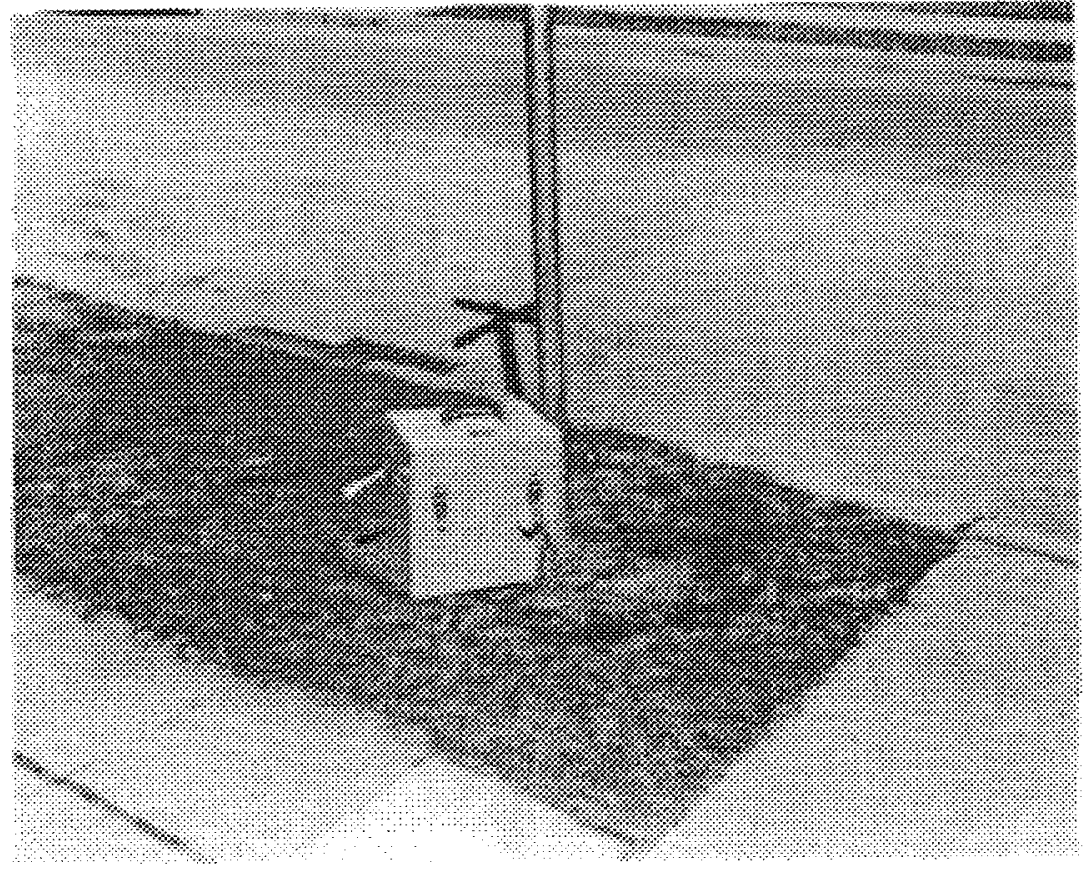

\%

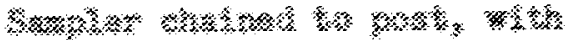

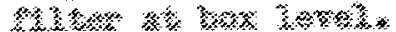




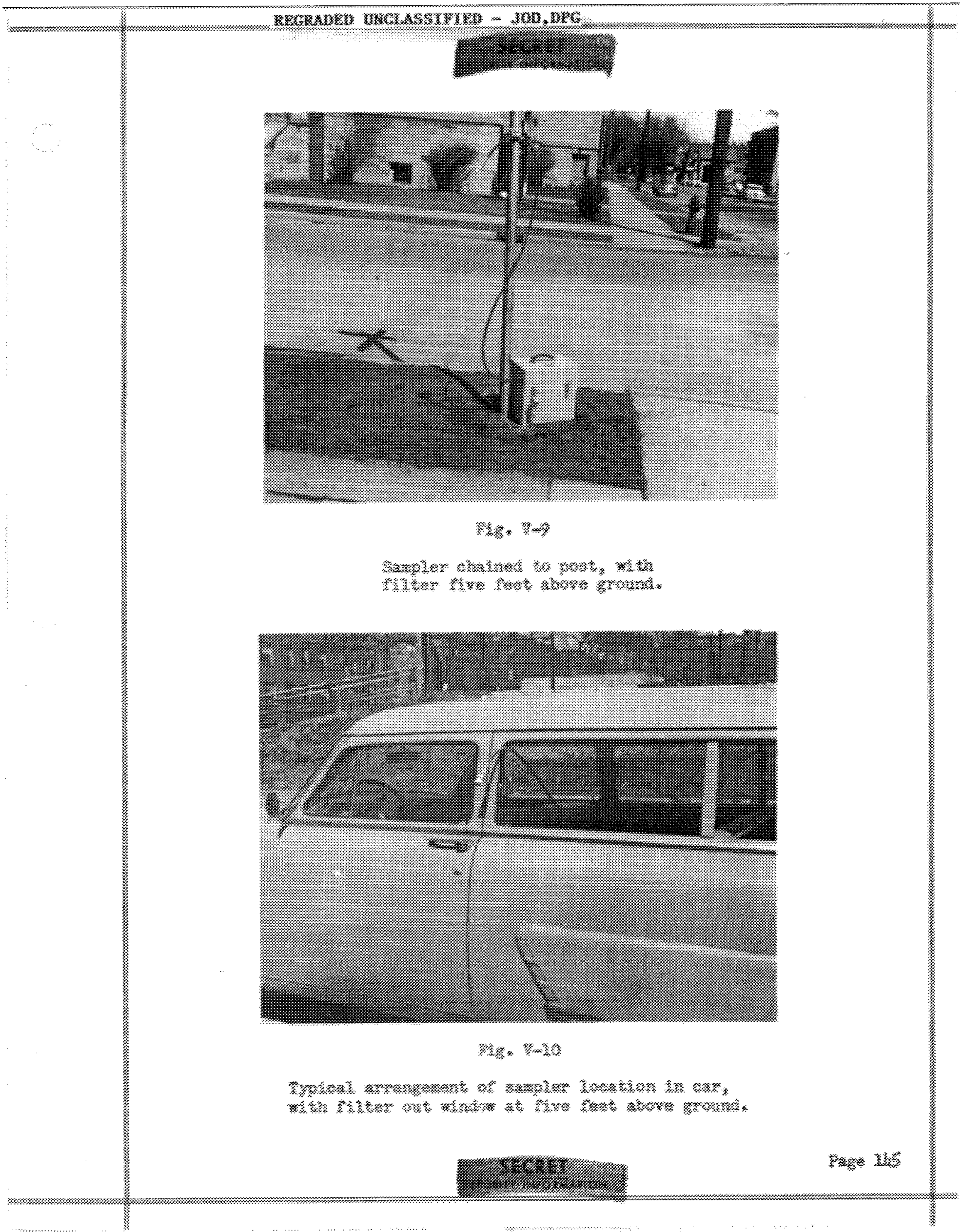




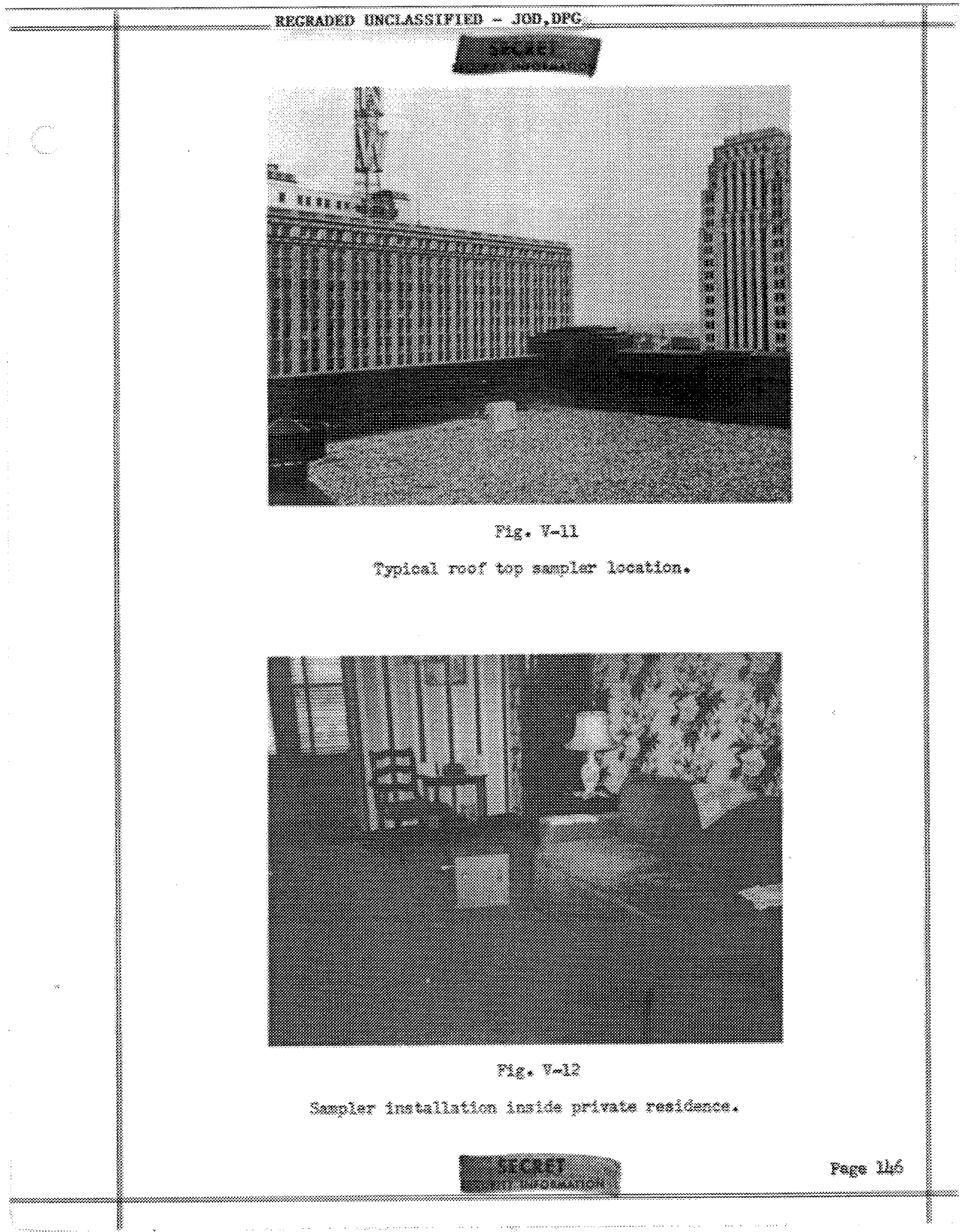




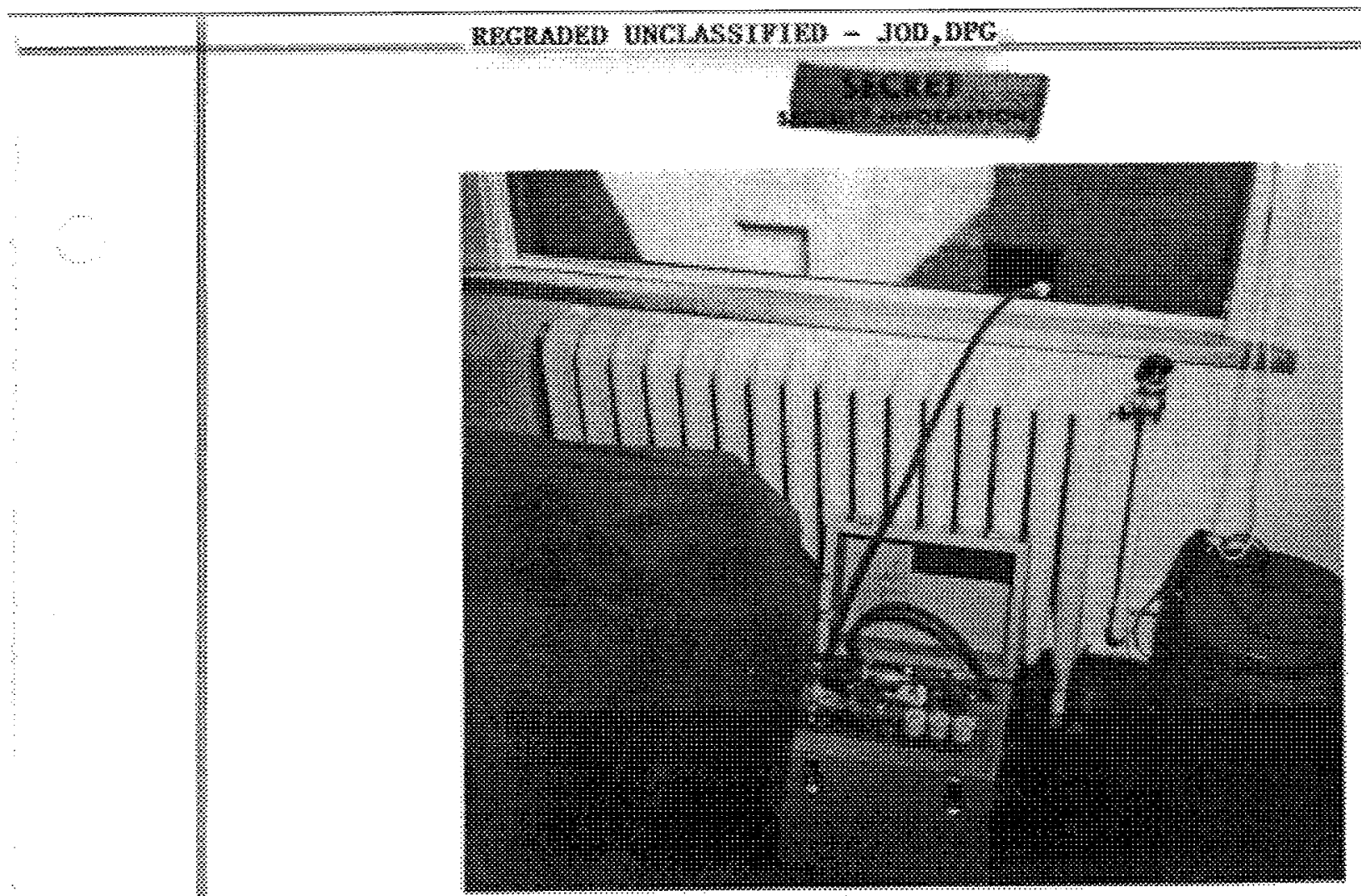

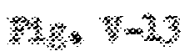

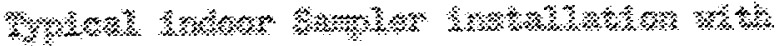

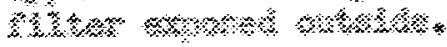

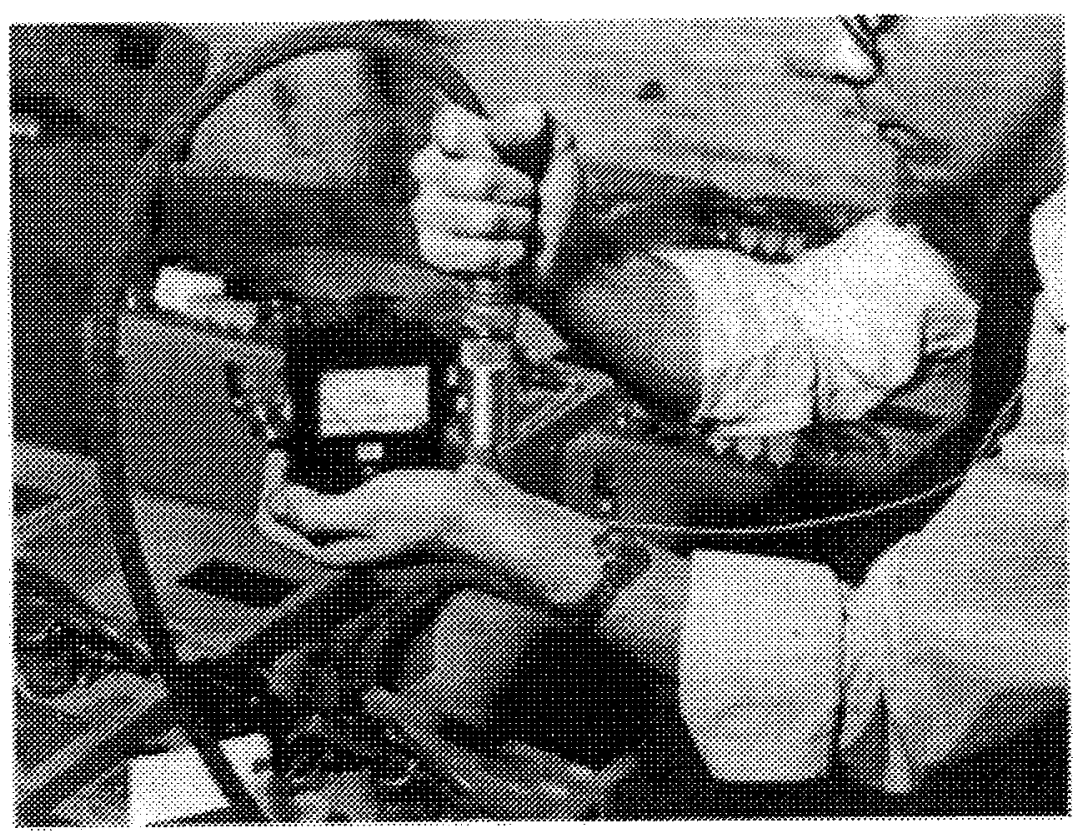

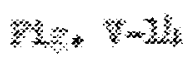

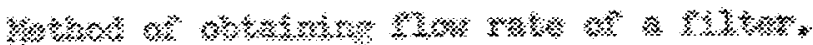




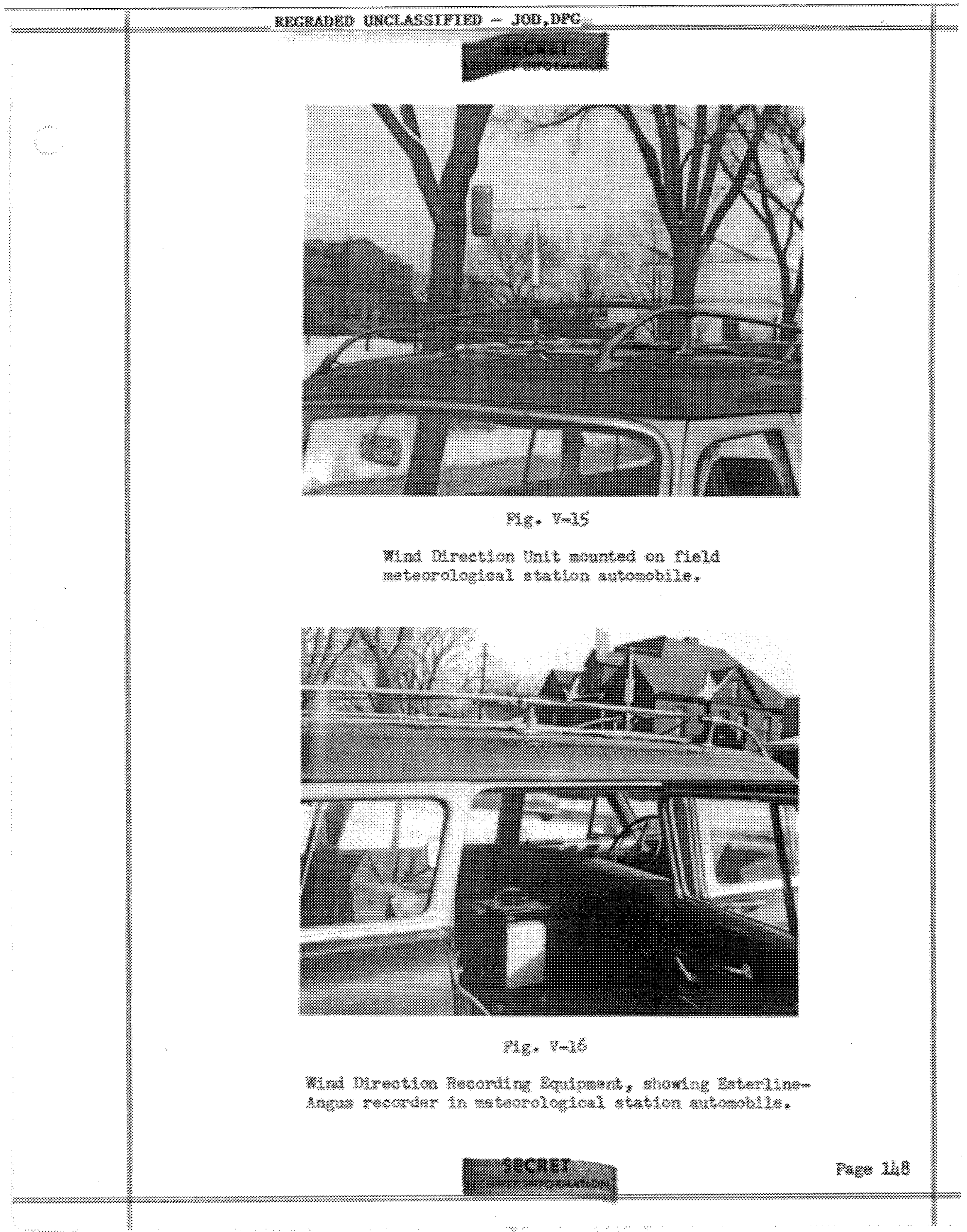




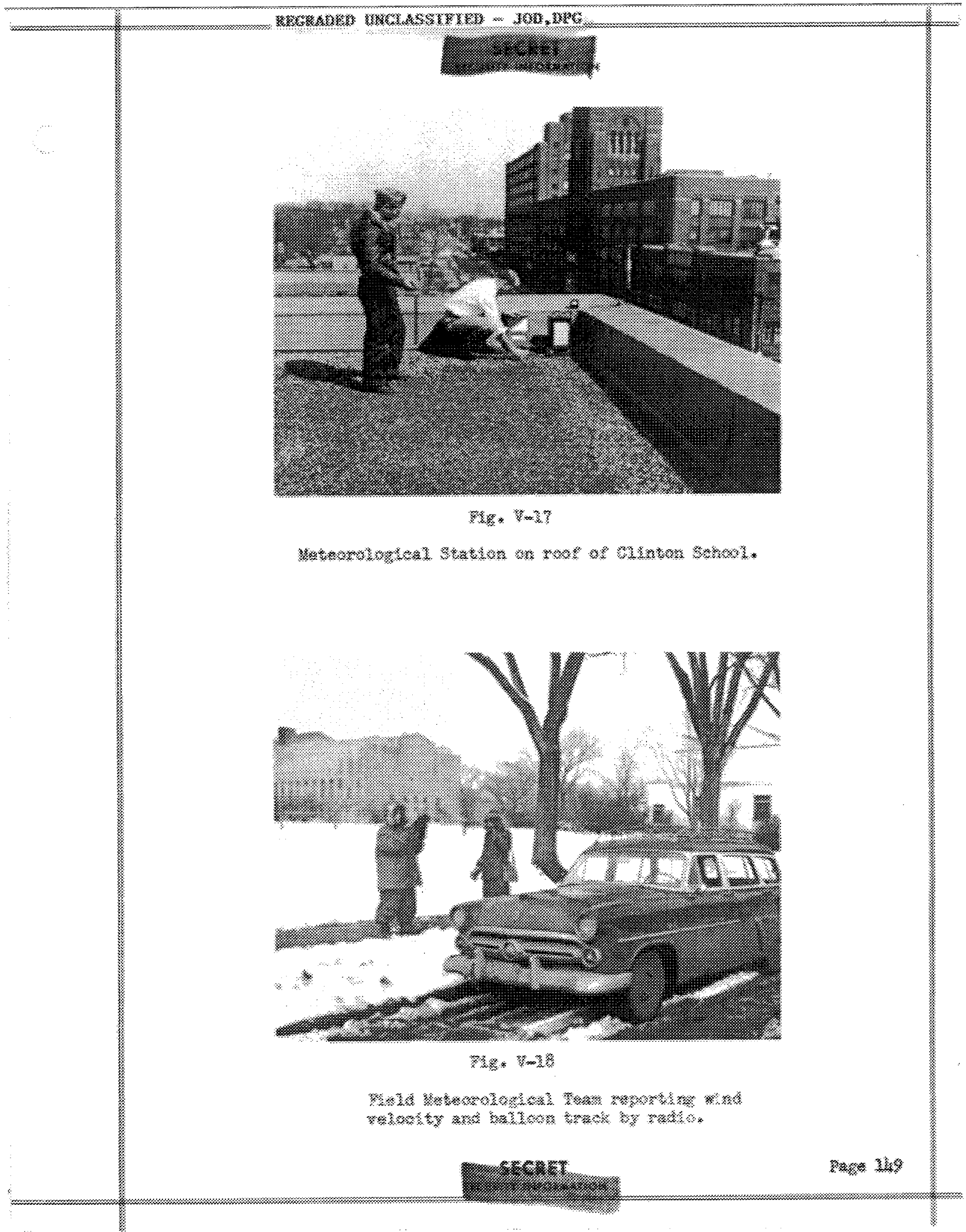




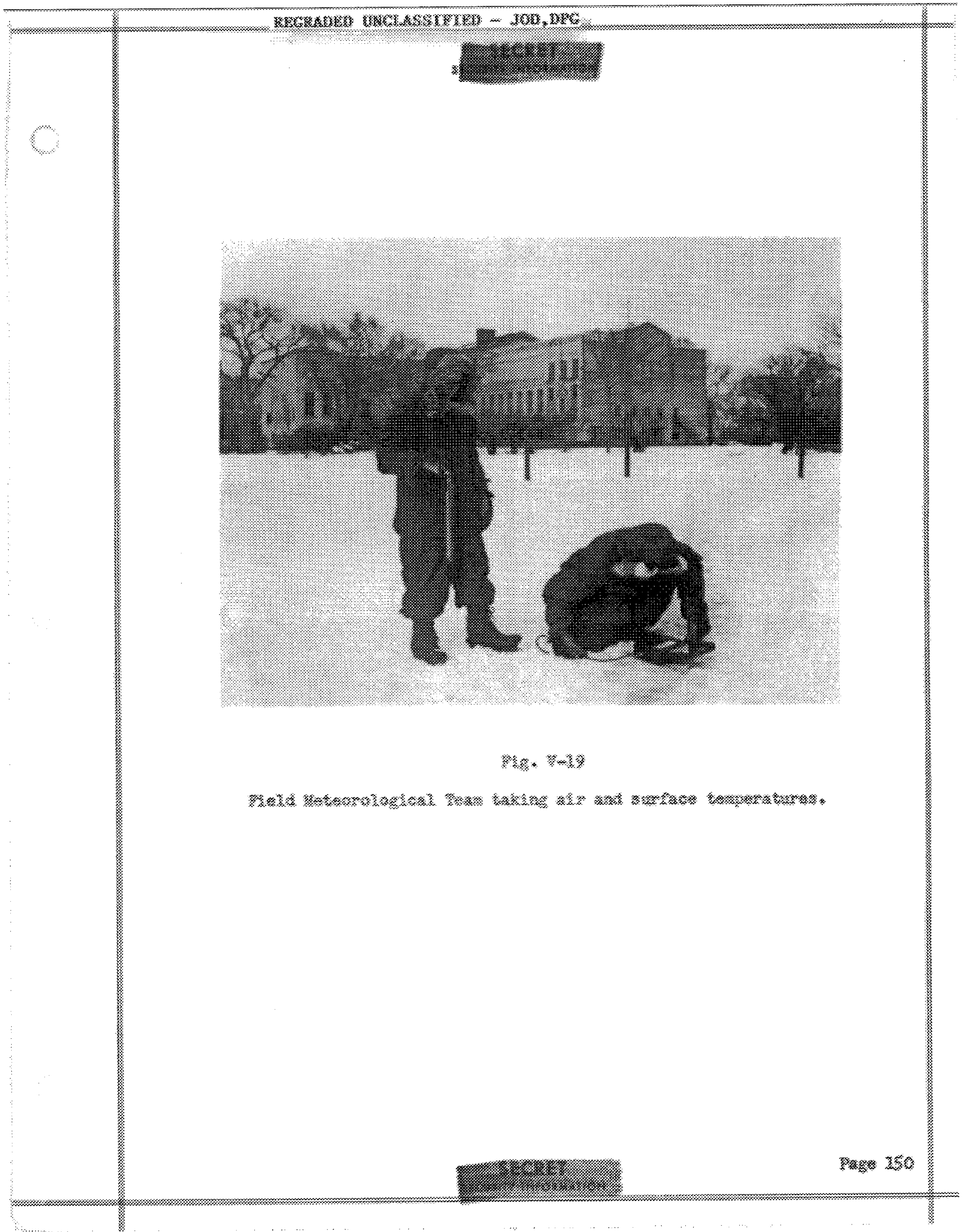




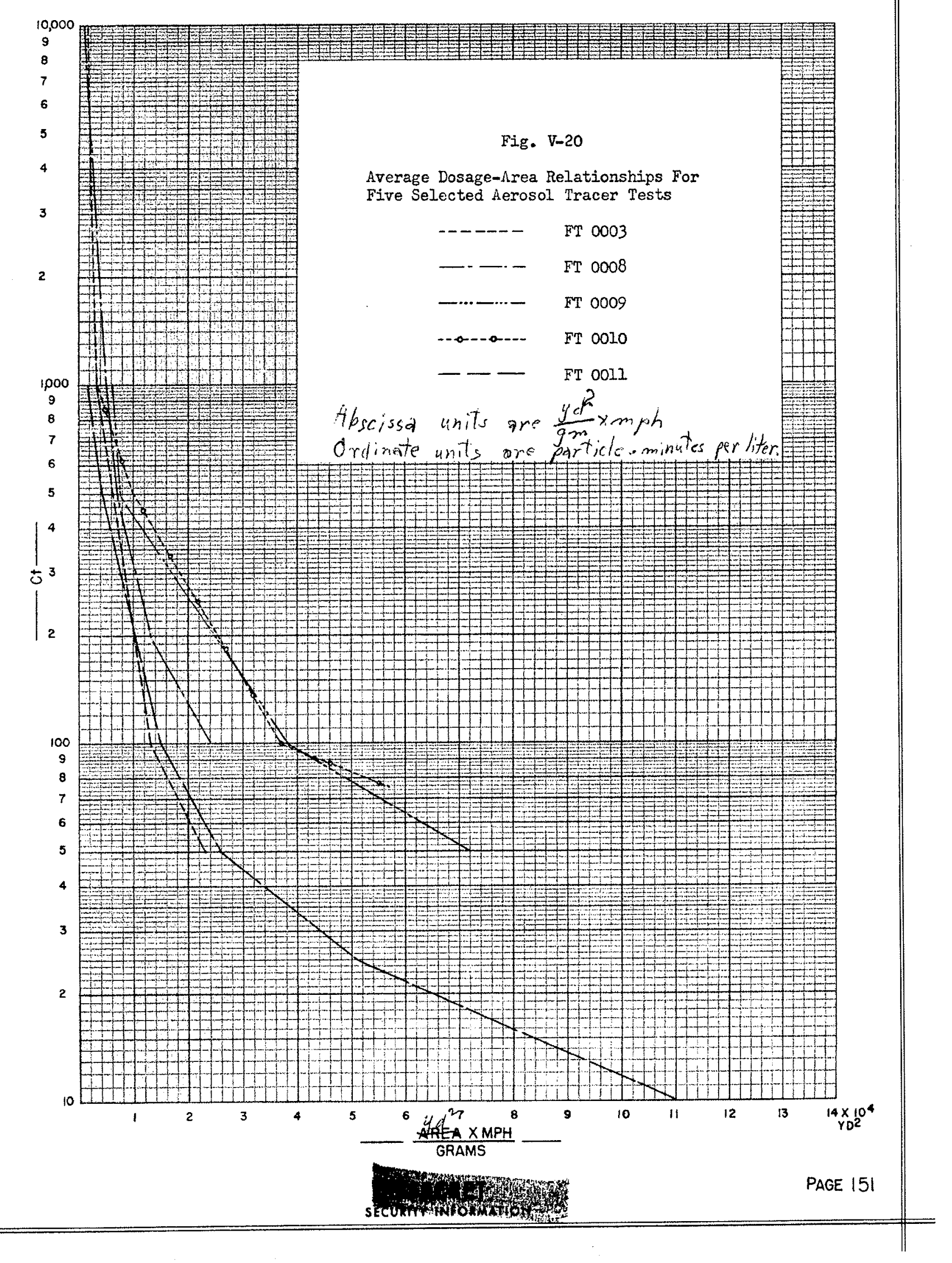




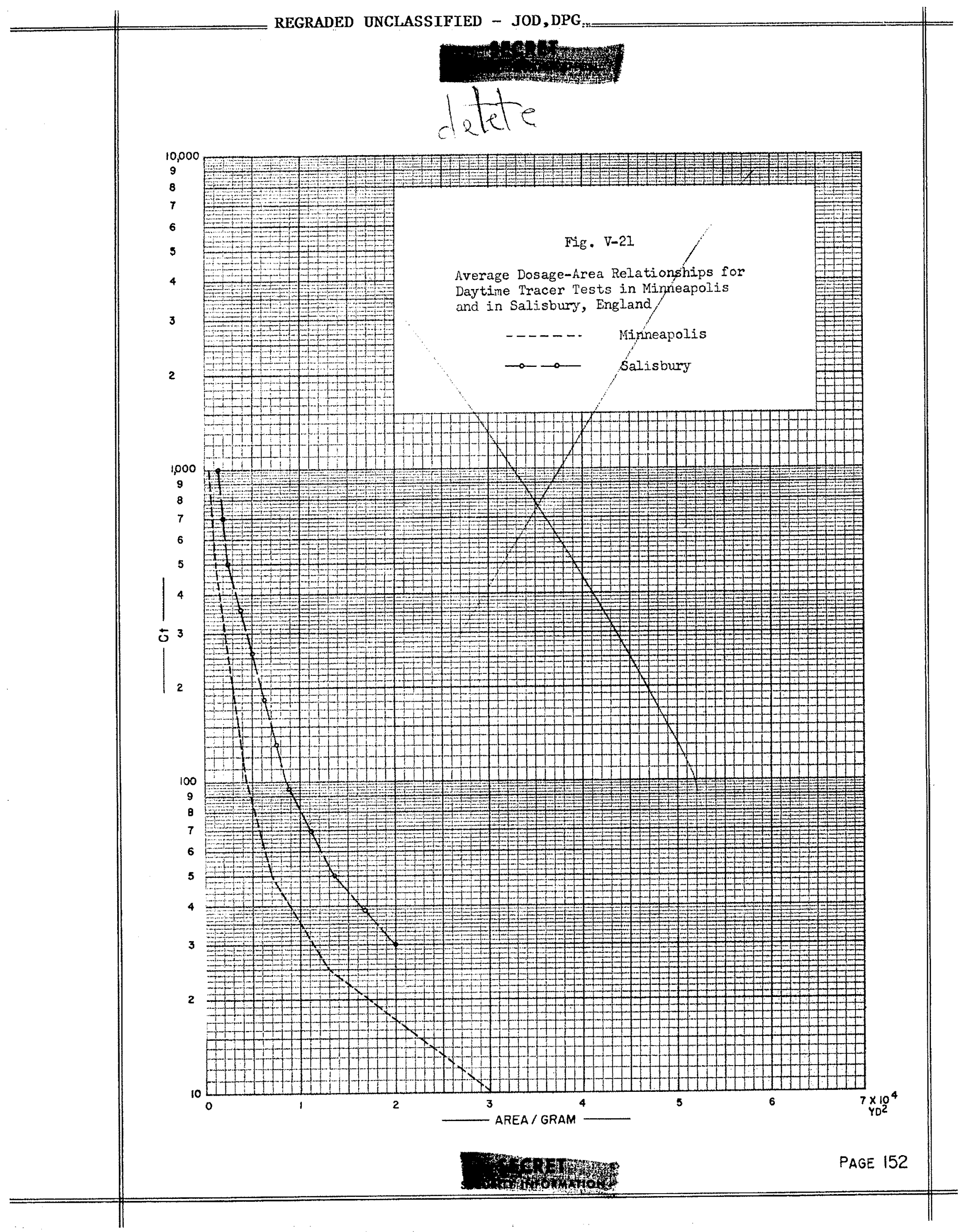




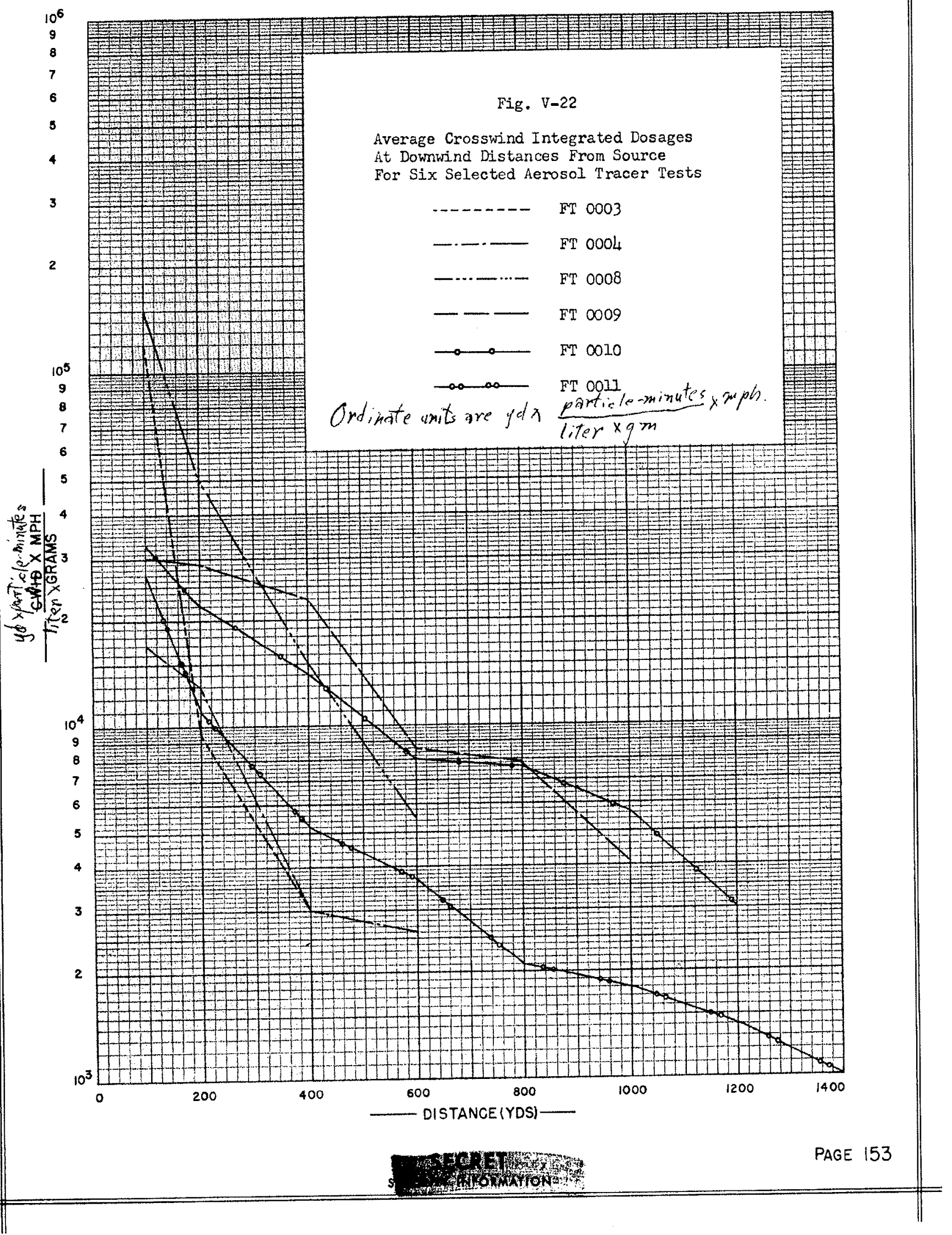




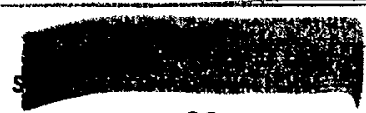

Fig. $\nabla-23$

HOUSE A
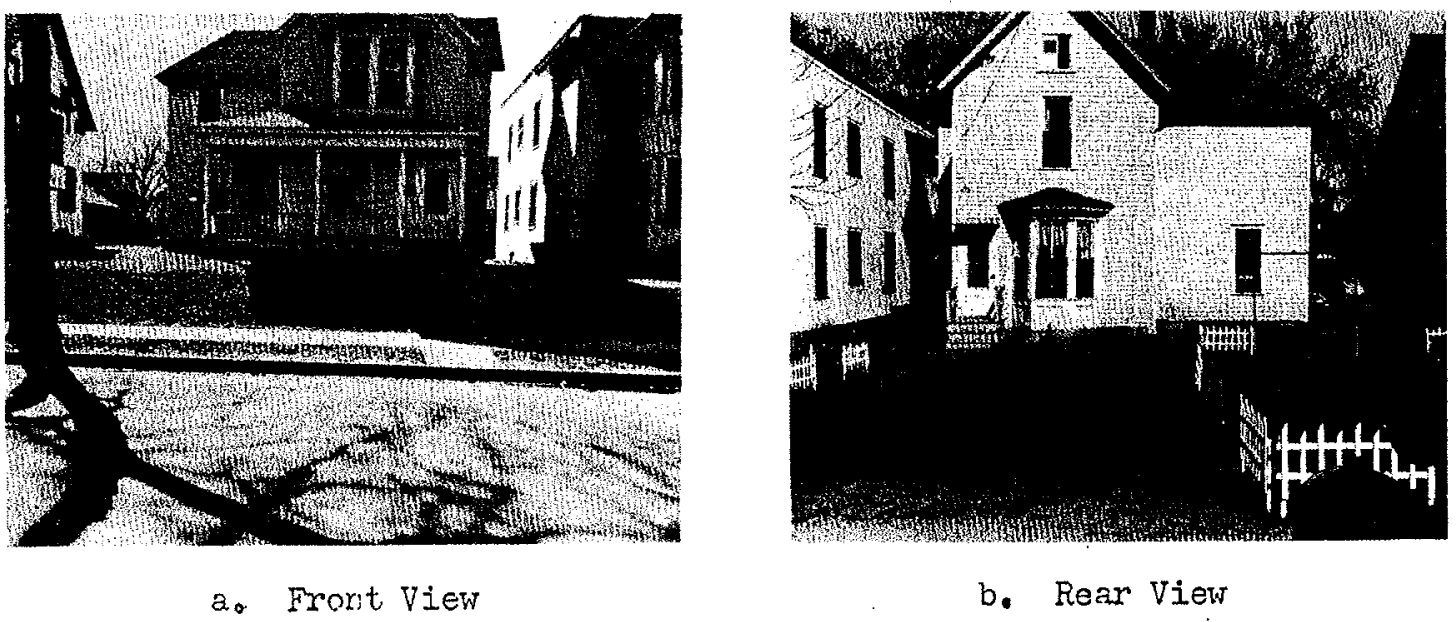

House $A$, at 2814 Third Avenue South, is a two stcry wooden frame structure, equipped with storm wirdows of the wooden frame type. It has no basement and is insulated only in the attic. On each floor are gassoace heaters which lack fans for circulating heat.

Dosages Obtained ir. House A*

\begin{tabular}{|c|c|c|c|c|c|c|}
\hline Release*t* & Outside & Basement & \multicolumn{2}{|c|}{ First Floor } & \multicolumn{2}{|c|}{ Second Flcor } \\
\hline 000 & 15 & 0 & $\mathrm{~T}$ & 0 & 0 & 0 \\
\hline 00083 & $26 \quad 152$ & & 3 & 17 & 0 & 3 \\
\hline
\end{tabular}

*Dosages are expressed in particle-minutes per liter; T represents trace dosage, i.e., a count not exceeding 15 fluorescent particles. Double entries for a given column represent incremental dosages obtaired with sequentially exposed filter units.

**Releases are listed only when positive counts were obtained outside. For the indicated releases, Figs. B-18 and B-19, Appendix $B$, show the house in relation to the grid complex and the dosage pattern. 
Fig. V-24

HOUSE B

House B (not illustrated), at 2739 Second Avenue South, is a two story stucco building, equipped with storm windows of the wooden frame type. Its walls and attic are completely insulated. A gas-fired, hot-water boiler is located in the one-quarter basement.

Dosages Obtained in House B*

\begin{tabular}{|c|c|c|c|c|c|c|c|c|}
\hline Release** & \multicolumn{2}{|c|}{ Outside } & \multicolumn{2}{|c|}{ Basement } & \multicolumn{2}{|c|}{ First Floor } & \multicolumn{2}{|c|}{ Second Floor } \\
\hline FT $0008 \mathbf{a}$ & 0 & 3 & 0 & $\mathrm{~T}$ & 0 & $\mathrm{~T}$ & 0 & 0 \\
\hline FT $0008 \mathrm{~b}$ & 17 & 110 & 3 & 31 & 3 & 5 & 0 & 3 \\
\hline FT $0009 b$ & 4 & 0 & $\begin{array}{l}\mathrm{T} \\
\mathrm{T}\end{array}$ & $\begin{array}{l}0 \\
0\end{array}$ & $\mathrm{~T}$ & 0 & 0 & 0 \\
\hline
\end{tabular}

*Dosages are expressed in particle-minutes per liter; $\mathrm{T}$ represents trace dosage, i.e., a count not exceeding 15 fluorescent particles. Double entries, for a given column represent incremental dosages obtained with sequentially exposed filter units. When more than one sampler is involved, values are listed on separate lines.

$\ldots$ Releases are listed only when positive counts were obtained outside. For the indicated releases, Figs. B-18, B-19, and $\mathrm{B}-26$, Appendix $B$, show the house in relation to the grid complex and the dosage pattern. 


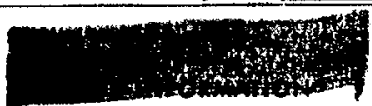

Fig. V-25

HOUSE C

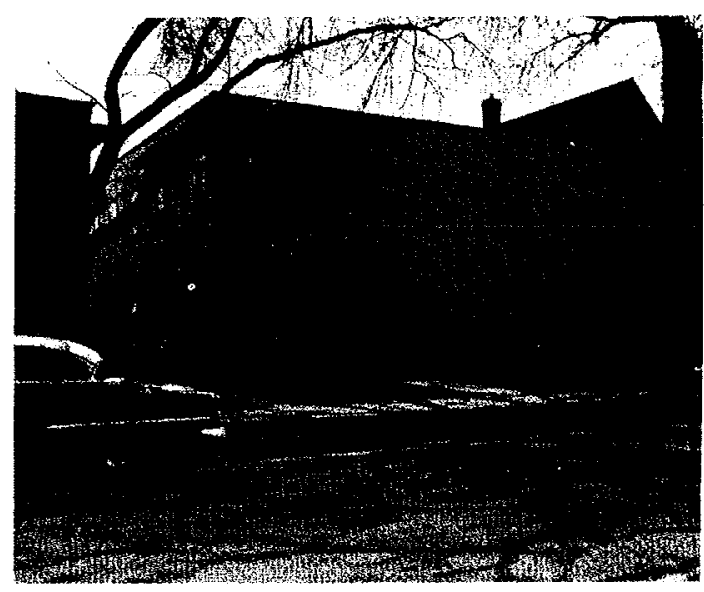

a. Oblique View

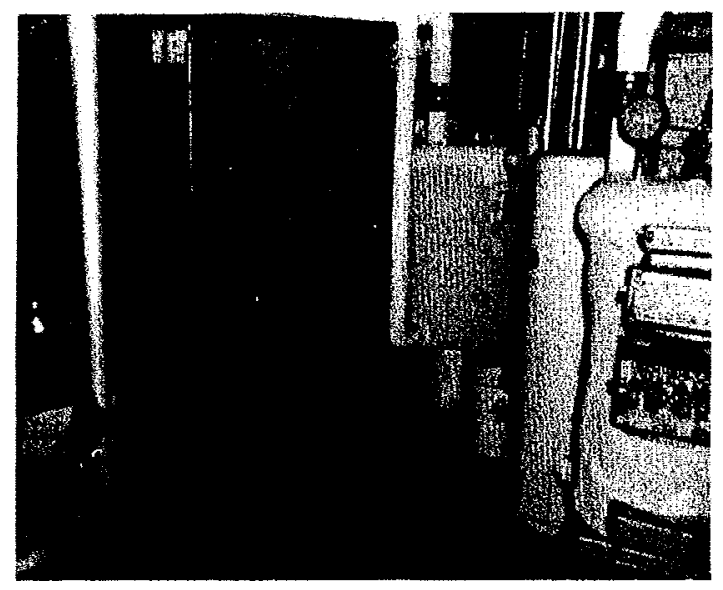

b. Sampler 15 feet from east wall of basement, with holder at box level.

House C, at 3021 Third Avenue South, is a completely insulated two story stucco building, equipped with storm windows of the aluminum type in the rear, and of the wooden frame type on the sides and front. A gas-fired, hot-water boiler is located in the basement.

Dosages Obtained in House $\mathrm{C} *$

$\frac{\text { Releasex: }}{\text { FT 0008b }} \frac{\text { Outside }}{4410 \quad 390} \frac{\text { Basement }}{1000493} \frac{\text { First Floor }}{141} \quad \frac{\text { Second Floor }}{160} \quad \frac{83}{117}$

*Dosages are expressed in particle-minutes per liter. Double entries for a given column represent incremental dosages obtained with sequentially exposed filter units.

* * Releases are listed only when positive counts were obtained outside. For the indicated release, Fig. B-19, Appendix B, shows the house in relation to the grid complex and the dosage pattern. 


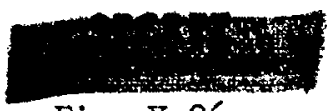

Fig. $\nabla-26$

HOUSE $D$

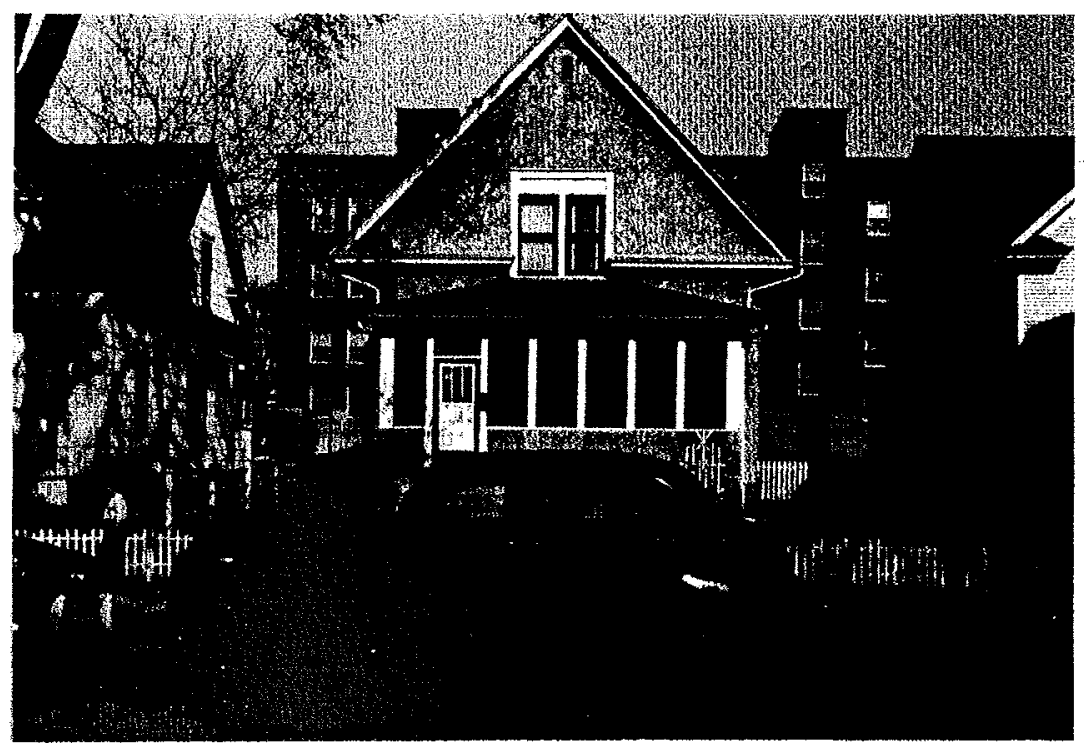

House $D$, at 2813 Fifth Avenue South, is a two story stucco frame structure, equipped with storm windows of the wooden frame type. Its upper story and attic are completely insulated. A gas-fired, hot-water boiler is located in the basement.

Dosages Obtained in House $D *$

\begin{tabular}{|c|c|c|c|c|c|c|c|}
\hline Release**: & \multicolumn{2}{|c|}{ Outside } & \multicolumn{2}{|c|}{ Basement } & \multicolumn{2}{|c|}{ First Floor } & Second Floor \\
\hline $\mathrm{FT} 0009 \mathrm{a}$ & 79 & 0 & 12 & 2 & 13 & 9 & \\
\hline FT $0009 b$ & 395 & $\mathrm{~T}$ & $\begin{array}{l}31 \\
39\end{array}$ & $\begin{array}{r}10 \\
8\end{array}$ & 52 & 13 & \\
\hline
\end{tabular}

*Dosages are expressed in particle-minutes per liter; $T$ represents trace dosage, i.e., a count not exceeding 15 fluorescent particles. Double entries for a given column represent incremental dosages obtained with sequentially exposed filter units. When more than one sampler is involved, values are listed on separate lines.

**Releases are listed only when positive counts were obtained outside. For the indicated releases, Figs. B-25 and B-26, Appendix $B$, show the house in relation to the grid complex and the dosage pattern. 
Fig. V-2?

HOUSE E

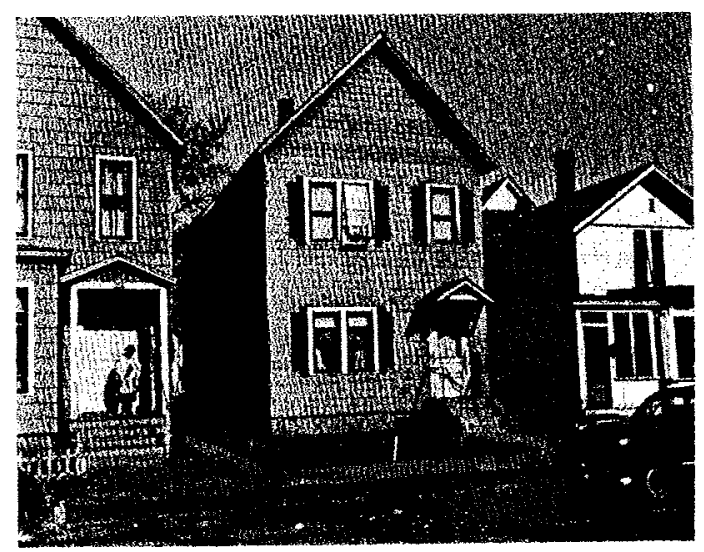

a. Oblique View

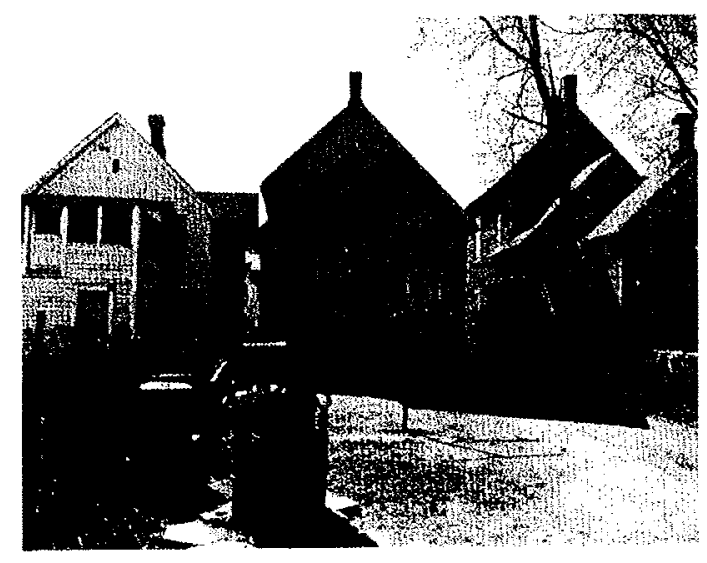

b. Rear View

House $E$, at 2625 Stevens Avenue South, is a two story wooden frame structure, equipped with storm. windows of the wooden frame type. Its walls and attic are completely insulated. The first floor is heated by a coal furnace located in the three-quarter basement; the heating system is of the hot-air gravity type. The second floor is heated by an oil-space heater located in the living room.

Dosares Obtained in House $E *$

\begin{tabular}{|c|c|c|c|c|c|c|c|}
\hline Releaser & Outsido & \multicolumn{2}{|c|}{ Basement } & \multicolumn{2}{|c|}{ First Floor } & \multicolumn{2}{|c|}{ Second Floor } \\
\hline FT 001la & 643 & 341 & 30 & 302 & 18 & 218 & 27 \\
\hline & & 284 & $\begin{array}{l}12 \\
77\end{array}$ & 708 & 32 & 409 & 36 \\
\hline FT $0011 \mathrm{~b}$ & 1040 & $\begin{array}{l}412 \\
506\end{array}$ & 11 & 100 & $x$ & 407 & \\
\hline FT OOL1c & 1970 & $\begin{array}{l}996 \\
85.1\end{array}$ & $\begin{array}{l}25 \\
48\end{array}$ & 1060 & 54 & 750 & 63 \\
\hline
\end{tabular}

*Dosages are expressed in particle-minutes per liter. Double entries for a given column represent incremental. dosages obtained with sequentially exposed filter units. When more than one sampler is involved, values are listed on separate lines.

**Releases are listed only when positive counts were obtained outside. For the indicated releases, Figs. B-40, B-4I, and $B-42$, Appendix $B$, show the house in relation to the grid complex and the dosage pattern. 
REGRADED UNCLASSIFIED - JOD,DPG

CLINTON SCHOOL DOSAGES*

\begin{tabular}{|c|c|c|c|c|c|c|}
\hline \multirow{3}{*}{$\frac{\text { Sampler }}{A}$} & \multicolumn{3}{|c|}{ Test } & \multicolumn{3}{|c|}{ Number } \\
\hline & \multicolumn{2}{|c|}{ FT $0008 \mathrm{a}$} & \multicolumn{2}{|c|}{ FT $0008 \mathrm{~b}$} & \multicolumn{2}{|c|}{ FT $0008 \mathrm{c}$} \\
\hline & $\mathrm{T}$ & $\mathrm{T}$ & 50 & 104 & 110 & 7 \\
\hline B & \multicolumn{2}{|c|}{0} & \multicolumn{2}{|c|}{$\mathrm{T}$} & \multicolumn{2}{|c|}{33} \\
\hline C & \multicolumn{2}{|c|}{0} & \multicolumn{2}{|c|}{0} & \multicolumn{2}{|c|}{35} \\
\hline D & 0 & $\mathrm{~T}$ & 0 & 33 & 15 & 3 \\
\hline $\mathbf{E}$ & 0 & $T$ & 22 & 89 & 51 & $\mathrm{~T}$ \\
\hline$F$ & 0 & 0 & 3 & 14 & 19 & 12 \\
\hline G & 0 & 0 & 14 & 40 & 50 & $\mathrm{~T}$ \\
\hline $\mathrm{H}$ & 0 & 0 & 0 & 8 & 16 & 8 \\
\hline I & \multicolumn{2}{|c|}{0} & \multicolumn{2}{|c|}{16} & \multicolumn{2}{|c|}{43} \\
\hline$J$ & 0 & 0 & 27 & 50 & 50 & $\mathrm{~T}$ \\
\hline K & \multicolumn{2}{|c|}{0} & \multicolumn{2}{|c|}{33} & \multicolumn{2}{|c|}{59} \\
\hline
\end{tabular}

*Dosages are expressed in particle-minutes per llter; $T$ represents trace dosage, i.e., a count not exceeding 15 fluorescent particles. Double entries for a given column represent incremental dosages obtained with sequentially exposed filter units. Sampling periods for a given release are listed in the respective isodosage charts appearing in Appendix. B.

LEGEND

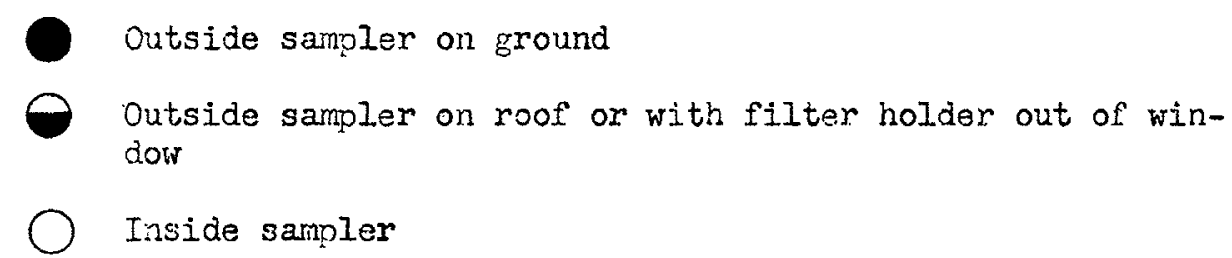

part / of 3 

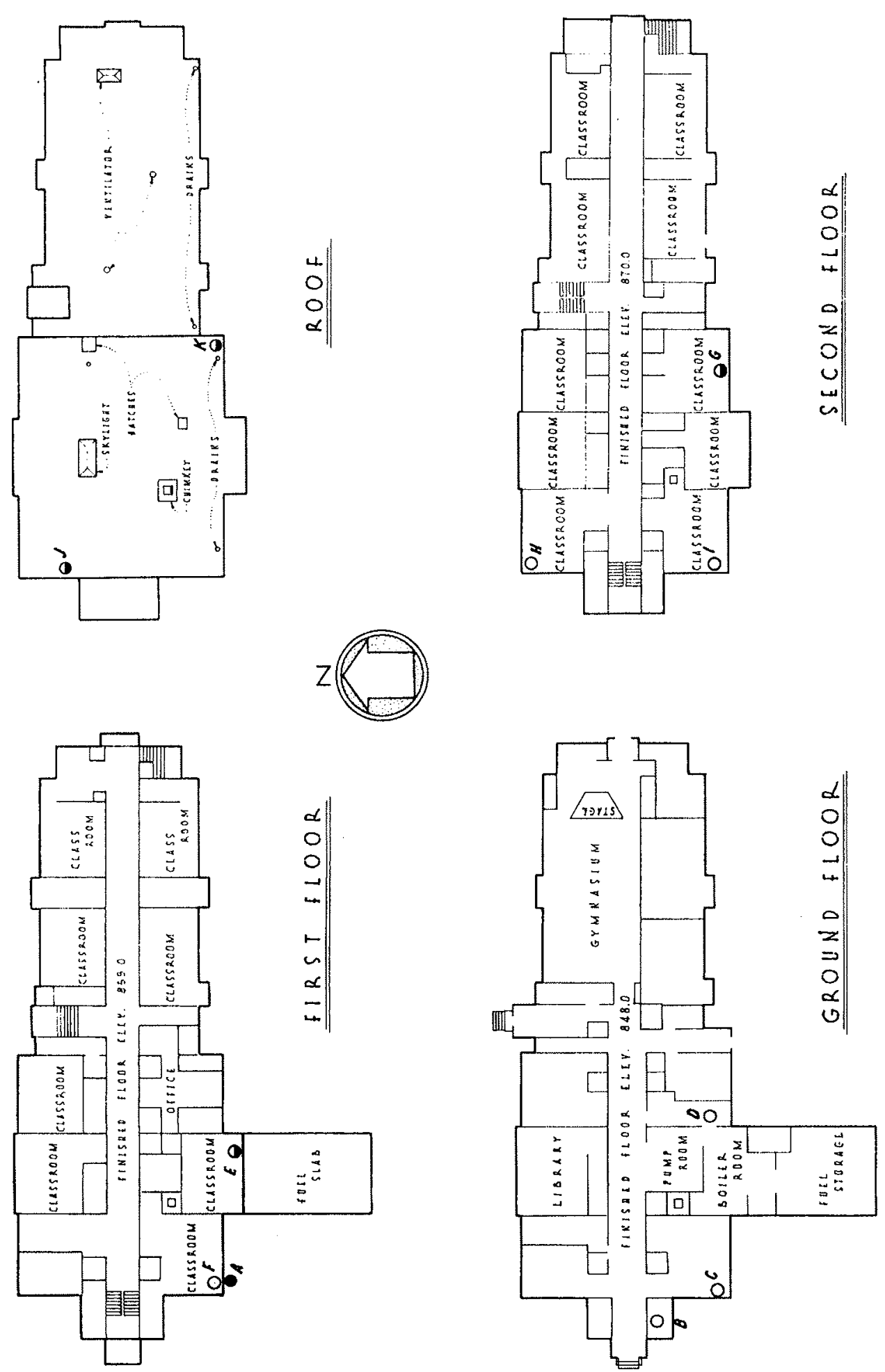

part 2 of 3 


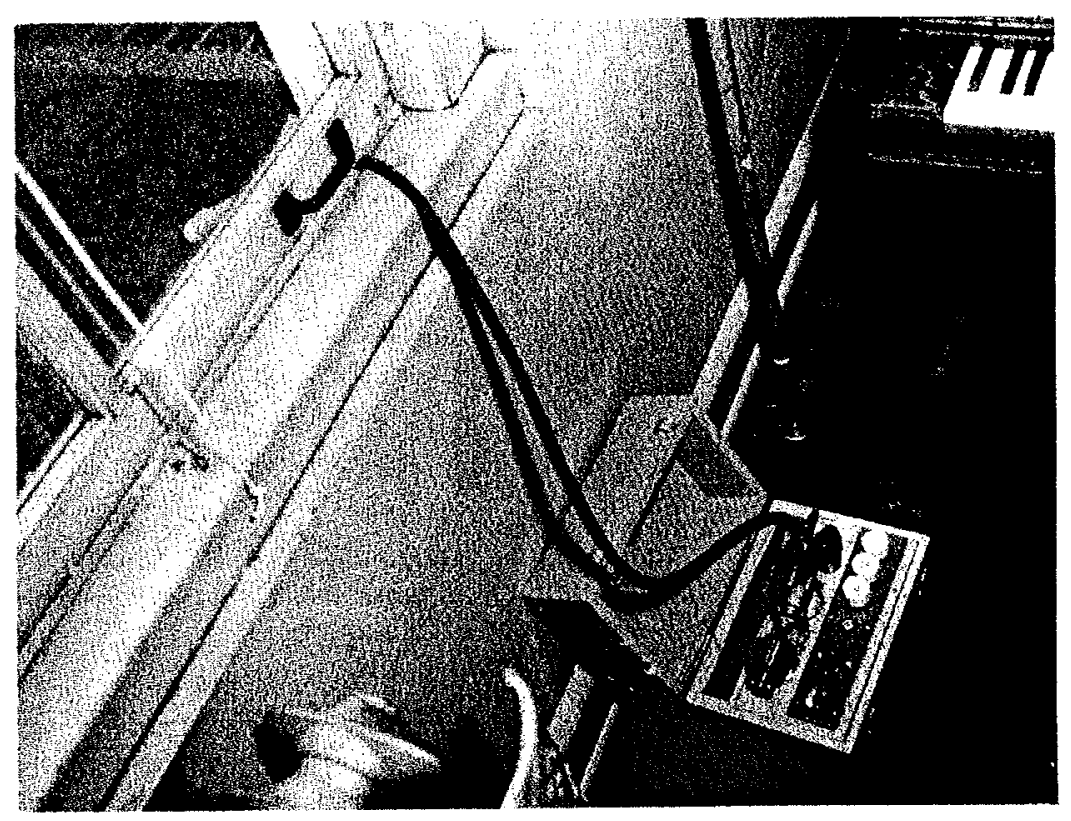

TYPICAL SAMPLER IN CLASSROOM WITH FILTER HOLDER OUT OF WINDOW

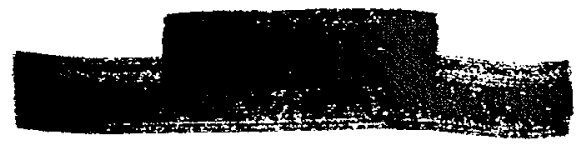

FIGURE Z-28

CLINTON SCHOOL SAMPLER ARRAY AND RESULTS

FT 0008

3 FEBRUARY 1953

PAGE 159

$$
\text { part } 3 \text { of } 3
$$




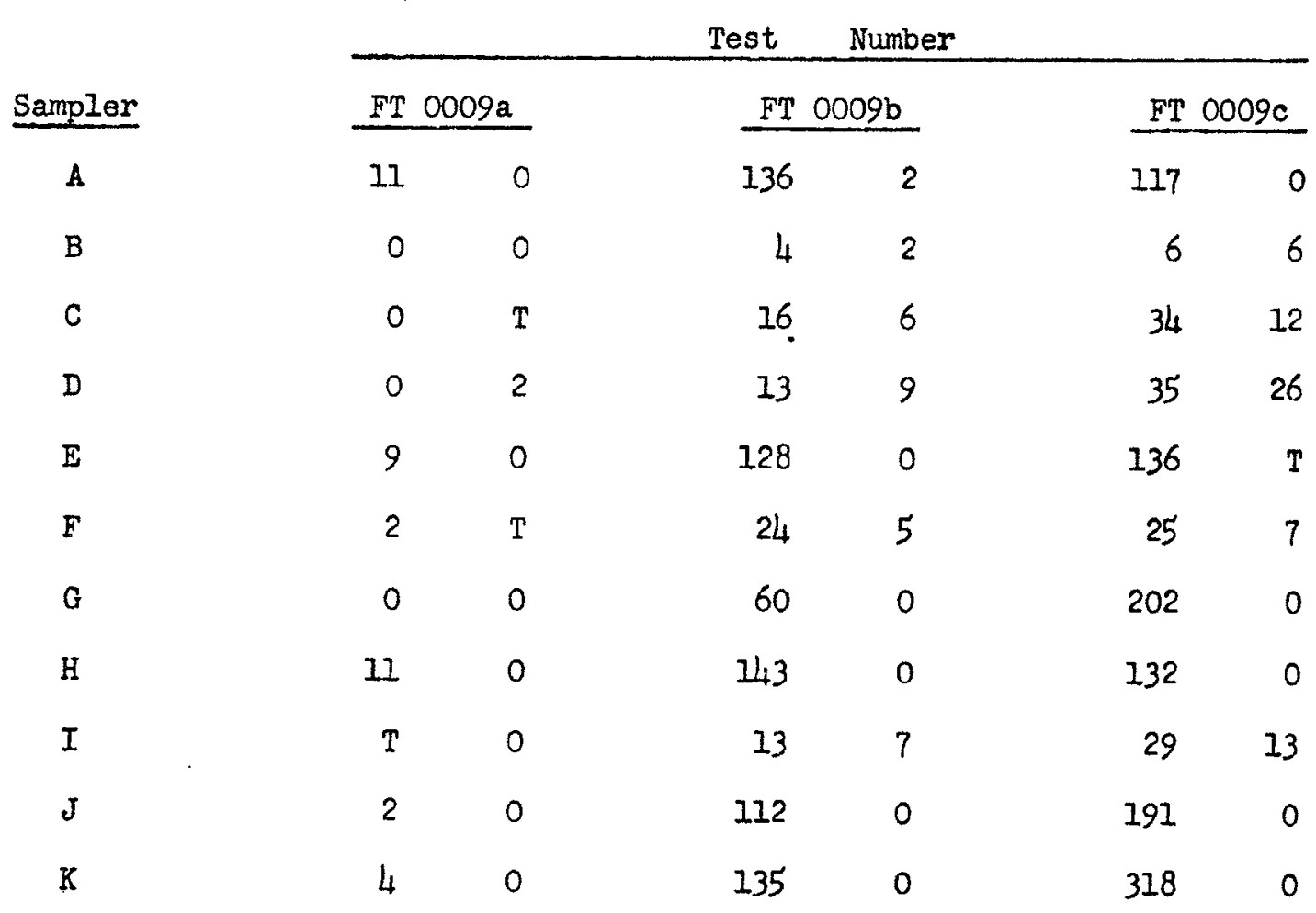

*Dosages are expressed in particle-minutes per liter; $T$ represents trace dosage, i.e., a count not exceeding 15 fluorescent particles. Double entries for a given column represent incremental dosages obtained with sequentially exposed filter units. Sampling periods for a given release are listed in the respective isodosage charts appearing in Appendix B.

IEGEND
Outside sampler on ground
Outside sampler on roof or with filter holder out of win-
dow
Inside sampler

part / of 3 

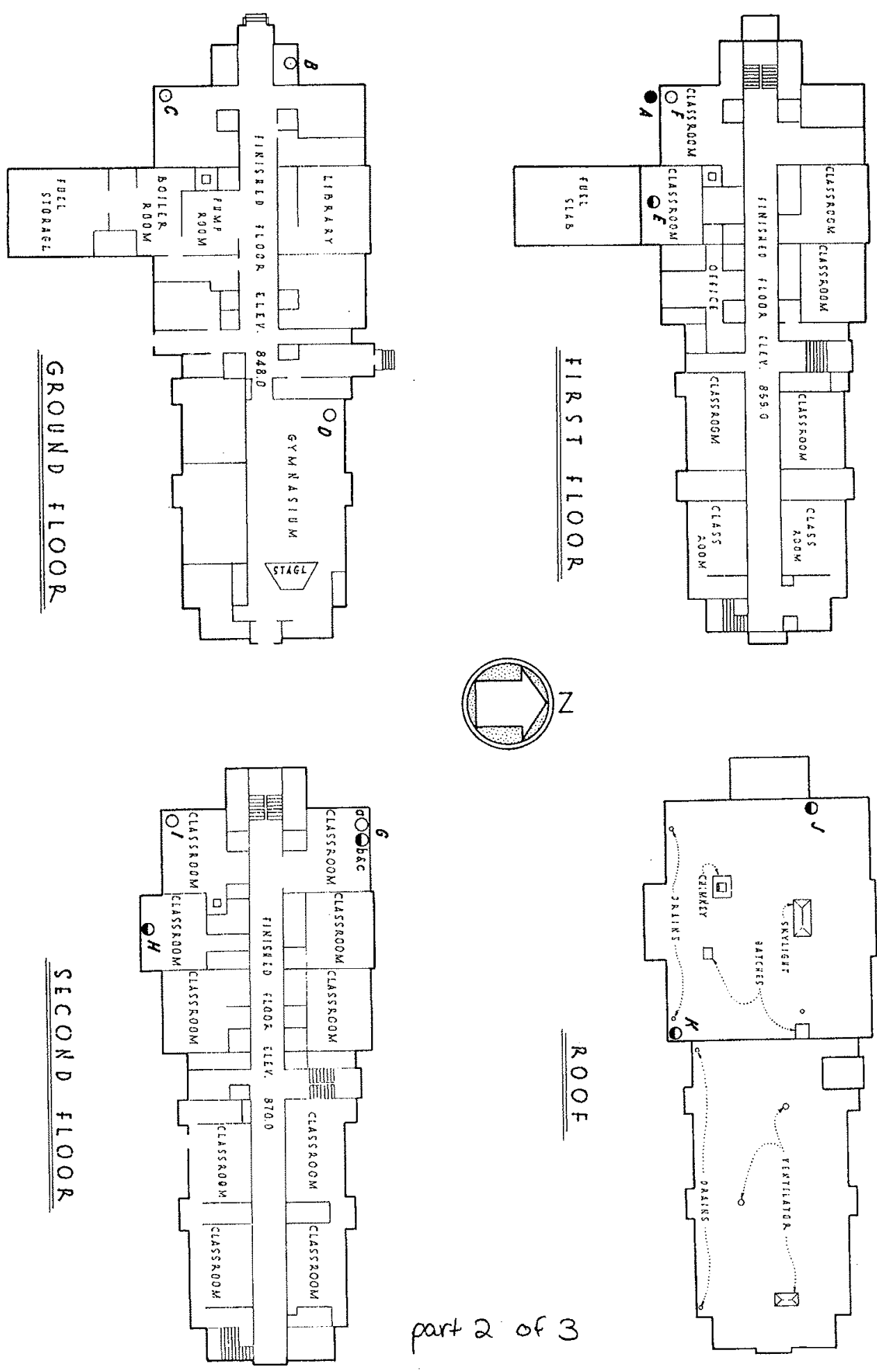

part 2 of 3

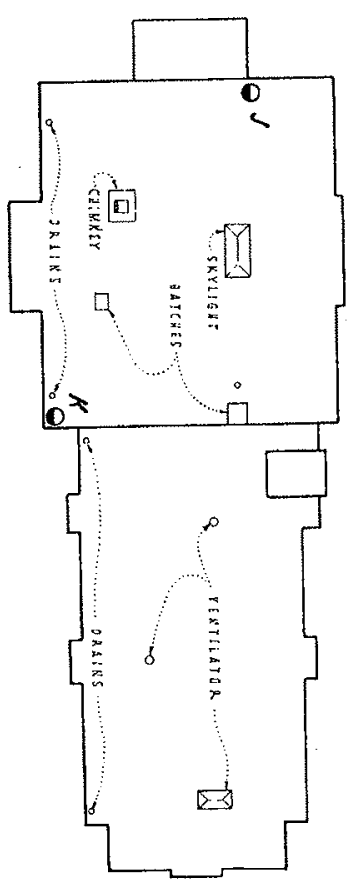




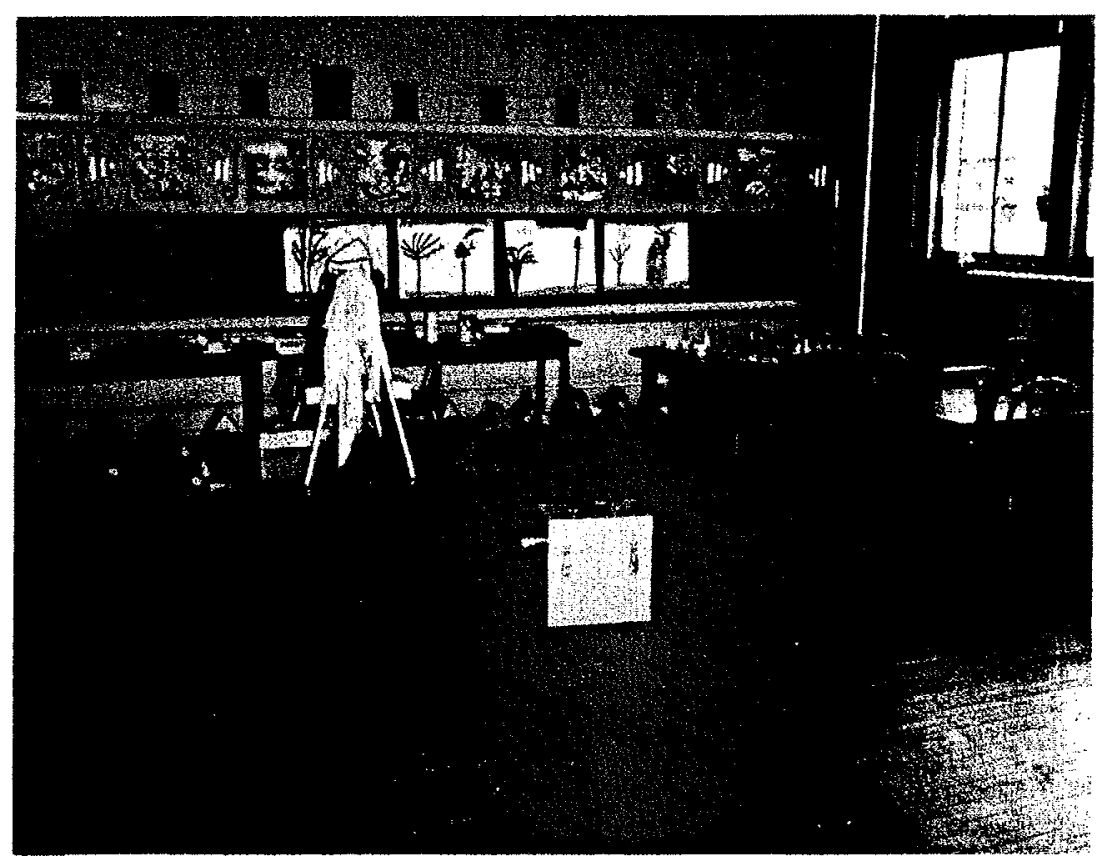

TYPICAL SAMPLER IN CLASSROOM WITH FILTER HOLDER AT BOX LEVEL

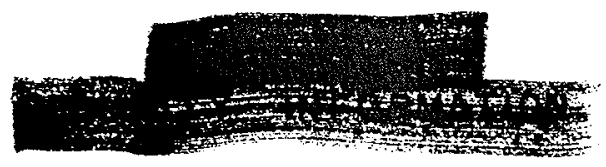

FIGURE Z-29

CLINTON SCHOOL SAMPLER

ARRAY AND RESULTS

FT 0009

7 FEBRUARY 1953

PAgE 160

$$
\text { part } 3 \text { of } 3
$$


CLINTON SCHOOL DOSAGES*

\begin{tabular}{|c|c|c|c|c|}
\hline \multirow[b]{2}{*}{ Sampler } & \multicolumn{2}{|r|}{ Test } & \multicolumn{2}{|l|}{ Number } \\
\hline & ET 0010a & FT $0010 \mathrm{~b}$ & FT $0010 \mathrm{c}$ & FT $0010 \mathrm{~d}$ \\
\hline A & 192 & 96 & 181 & 223 \\
\hline B & 51 & 22 & 23 & 28 \\
\hline $\mathrm{C}$ & 172 & 30 & 64 & 34 \\
\hline D & 68 & 33 & 61 & 38 \\
\hline $\mathrm{E}$ & 82 & 37 & 34 & 41 \\
\hline$F$ & 51 & 31 & 51 & 52 \\
\hline G & 303 & 61 & 208 & 163 \\
\hline $\mathrm{H}$ & 61 & 31 & 41 & 31 \\
\hline$I$ & 74 & 21 & 30 & 25 \\
\hline $\mathrm{J}$ & 244 & 32 & 93 & 93 \\
\hline $\mathrm{K}$ & 129 & 92 & 247 & 226 \\
\hline
\end{tabular}

*Dosages are expressed in particle-minutes per liter; T represents trace dosage, i.e., a count not exceeding 15 fluorescent particles. Double entries for a given column represent incremental dosages obtained with sequentially exposed filter units. Sampling periods for a given release are listed in the respective isodosage charts appearing in Appendix B.

LEGEND
Outside sampler on ground
Outside sampler on roof or with filter holder out of win- dow
Inside sampler

fart $/$ of 3 


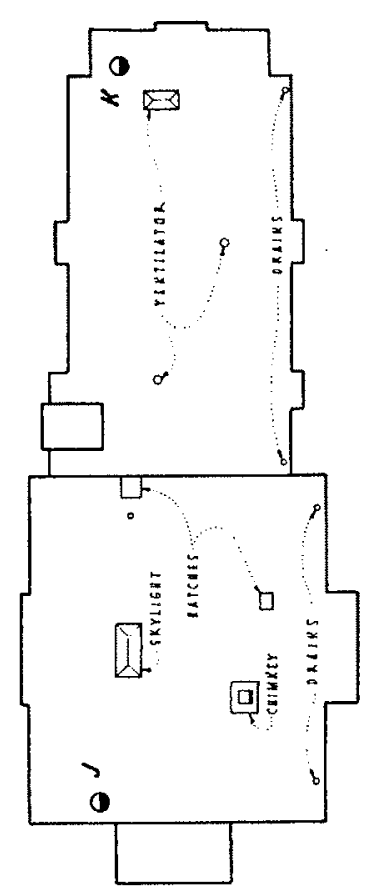

4
0
0
$\alpha$
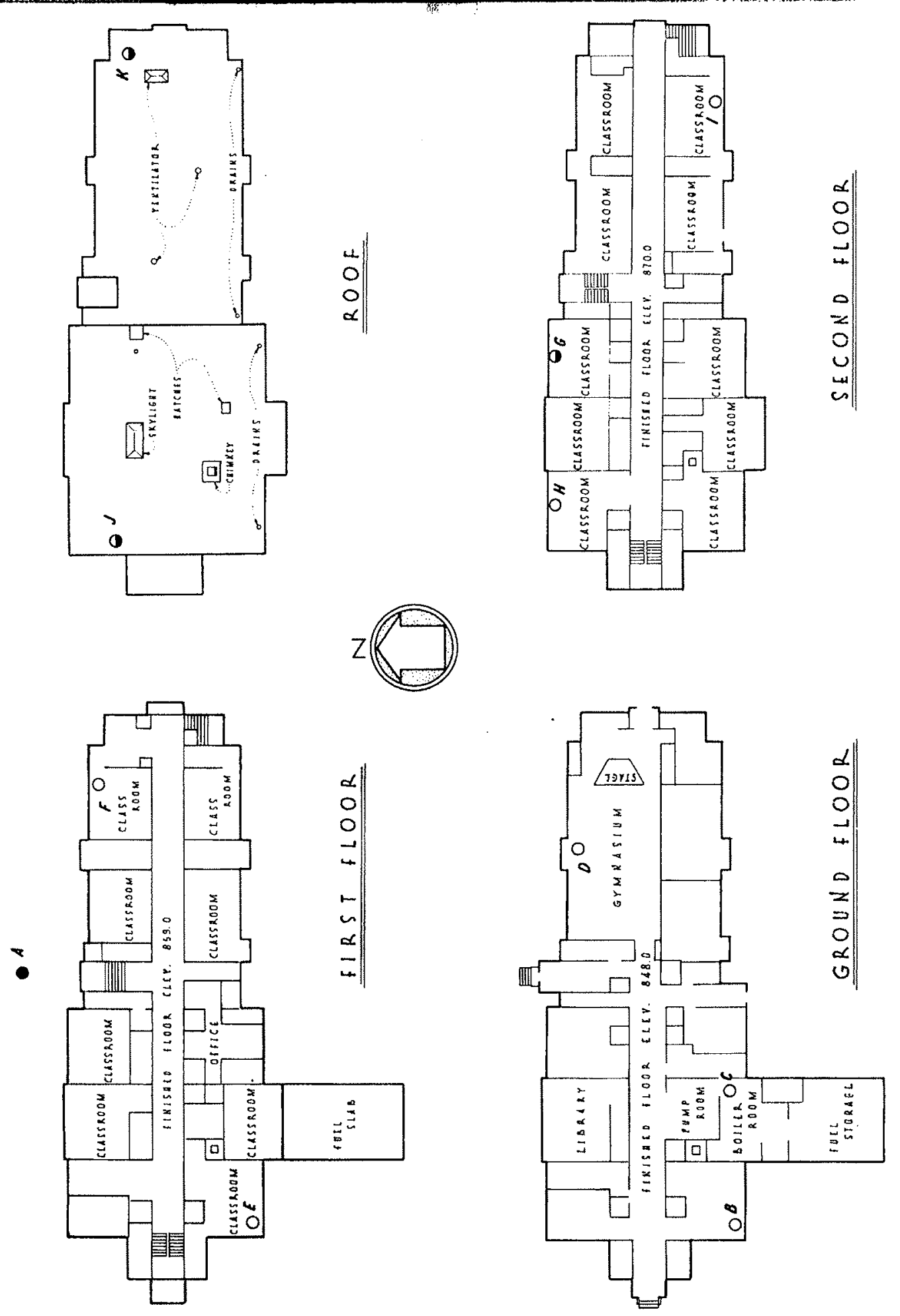

part 2 of 3 


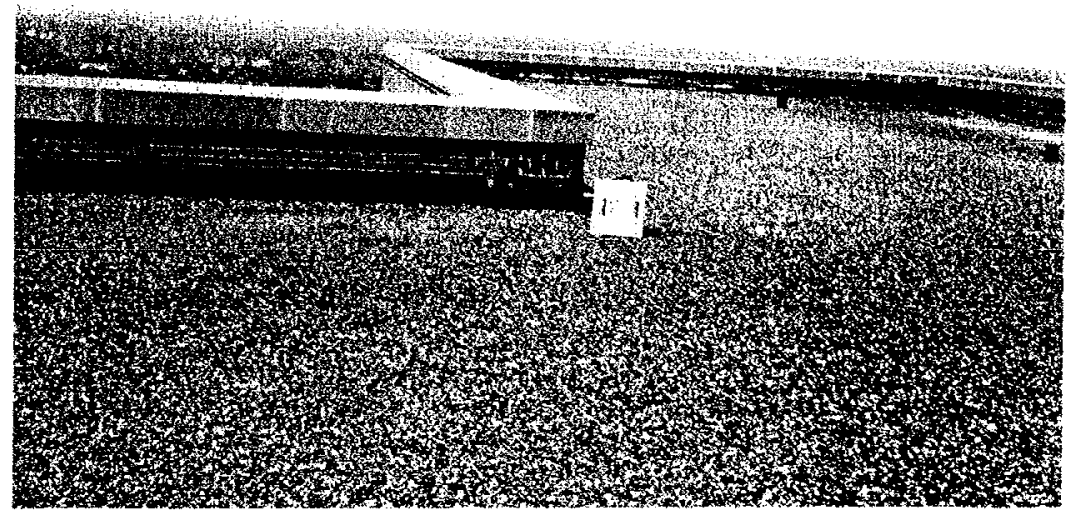

TYPICAL SAMPLER ON ROOF

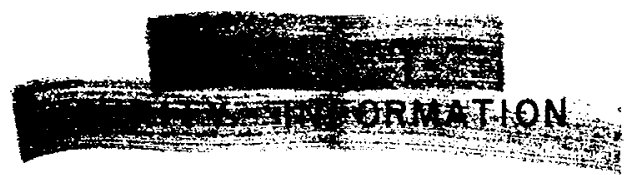

FIGURE $\nabla-30$

CLINTON SCHOOL SAMPLER

ARRAY AND RESULTS

FT OOIO

II-12 FEBRUARY 1953

PAGE $|6|$ 
REGRADED UNCLASSIFIED - JOD,DPG

CLINTON SCHOOL DOSAGES*

Test Number

\begin{tabular}{|c|c|c|c|c|c|c|}
\hline Sampler & \multicolumn{2}{|c|}{ FT 00112} & \multicolumn{2}{|c|}{ FT $0011 \mathrm{~b}$} & \multicolumn{2}{|c|}{ FT OOIIc } \\
\hline A & \multicolumn{2}{|c|}{8} & \multicolumn{2}{|c|}{41} & \multicolumn{2}{|c|}{0} \\
\hline B & \multicolumn{2}{|c|}{4} & \multicolumn{2}{|c|}{0} & \multicolumn{2}{|c|}{12} \\
\hline C & $\mathrm{T}$ & 8 & 6 & 2 & 19 & $\mathrm{~T}$ \\
\hline D & 3 & $\mathrm{~T}$ & 23 & $\mathrm{~T}$ & 7 & 3 \\
\hline $\mathrm{E}$ & 4 & 3 & 19 & 10 & 5 & $\mathrm{~T}$ \\
\hline $\mathrm{F}$ & 8 & $T$ & 41 & 17 & 19 & $\mathrm{~T}$ \\
\hline G & 11 & $T$ & 31. & $\mathrm{~T}$ & $\mathrm{~T}$ & 4 \\
\hline $\mathrm{H}$ & \multicolumn{2}{|c|}{$M$} & \multicolumn{2}{|c|}{36} & \multicolumn{2}{|c|}{7} \\
\hline$I$ & 3 & $\mathrm{~T}$ & 5 & 8 & 4 & $\mathrm{~T}$ \\
\hline $\mathrm{J}$ & 6 & 2 & 6 & 4 & 2 & $\mathrm{~T}$ \\
\hline K & \multicolumn{2}{|c|}{7} & \multicolumn{2}{|c|}{23} & \multicolumn{2}{|c|}{4} \\
\hline $\mathrm{I}$ & \multicolumn{2}{|c|}{11} & \multicolumn{2}{|c|}{36} & \multicolumn{2}{|c|}{$\mathbf{T}$} \\
\hline
\end{tabular}

*Dosages are expressed in particle-minutes per liter; $T$ represents trace dosage, i.e., a count not exceedirig 15 fluorescent particles; $M$ indicates data missing or equipment malfunction. Double entries for a given colum represent incremental dosages obtained with sequentially exposed filter units. Sampling periods for a givon release are listed in the respective isodosage charts appearing in Appendix B.

LECEND

Outside sampler on ground

Outside sampler on roof or with filter holoer out of window

Inside sampler

pact $/$ of 3 

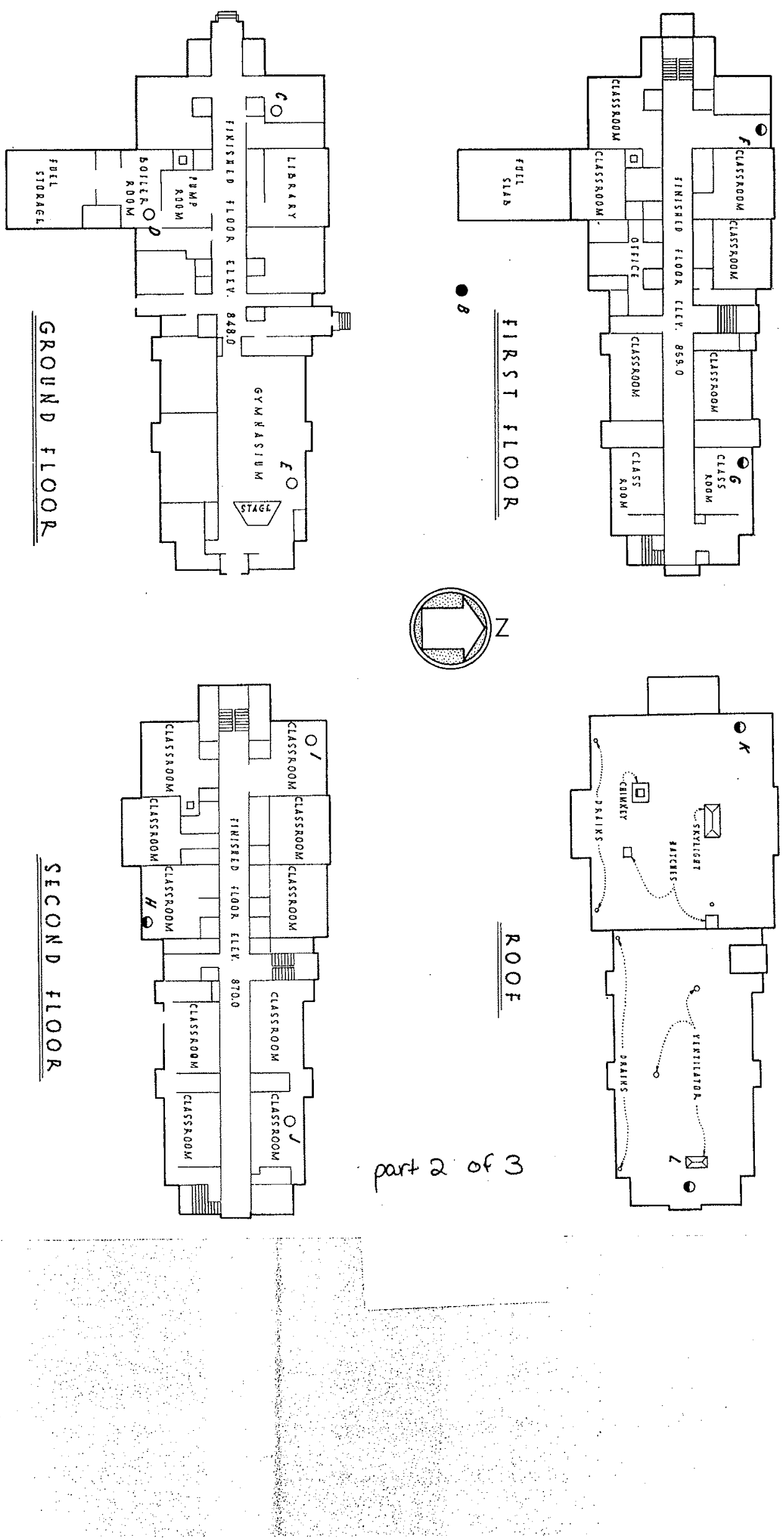


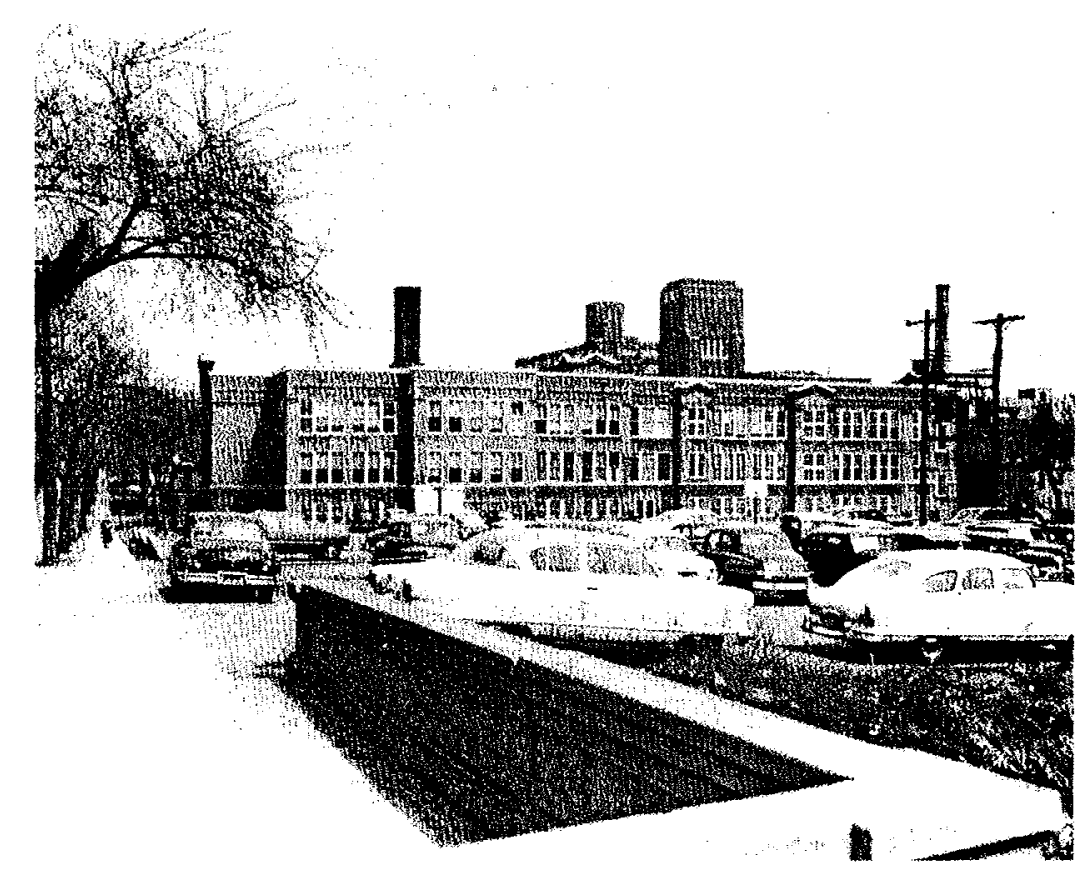

CLINTON SCHOOL, LOOKING NORTH FROM $29^{\text {th }}$ STREET

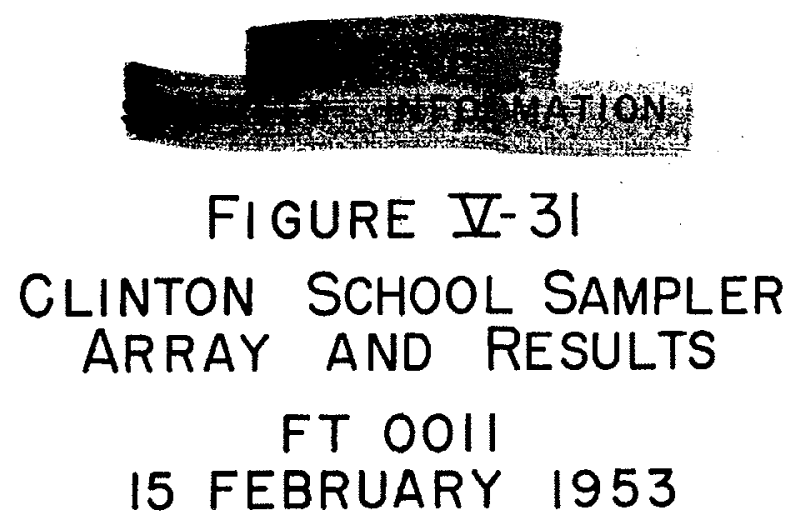

PAgE 162 


\section{A P P E D I X "}

Flgure No.

Title

Page No.

A-1 Tenperature Soundings, Columbia Raob, K-1010 164

1-2 Two Hater Air Temperature Survey, M-1010, 2000 CST

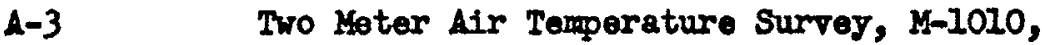
2100 CST

A-4 Two Meter Air Temperature Survey, M-1010, $2200 \mathrm{CST}$

A-5 Tamperature Soundings, Columbia Raob, K-1016

A-6 Two Meter Air Temperature Survey, M-1016, $2100 \mathrm{CST}$

A-7 Two Meter Air Termerature Survey, M-1016, 2200 CST

1-8 'Temperature Soundings, Columbia Raob, 4-1020

171

1-9 Tro Hoter Air Temperature Surrey, $\mathrm{K}-1020$, 2100 CST

1-11 Two Heter Air Temperature Survey, M-1024, $2100 \mathrm{CST}$ 
FIGURE A-I

TEMPERATURE SOUNDINGS

COLUMBIA RAOB 5 DEC 1952

(SUPPLEMENTAL TO SURVEY M-IOIO)

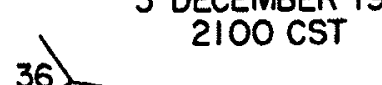

COLUMBIA

(KNOTS) 4000

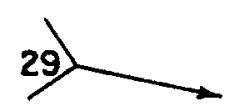

3000

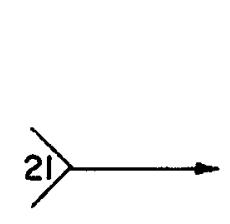

4000
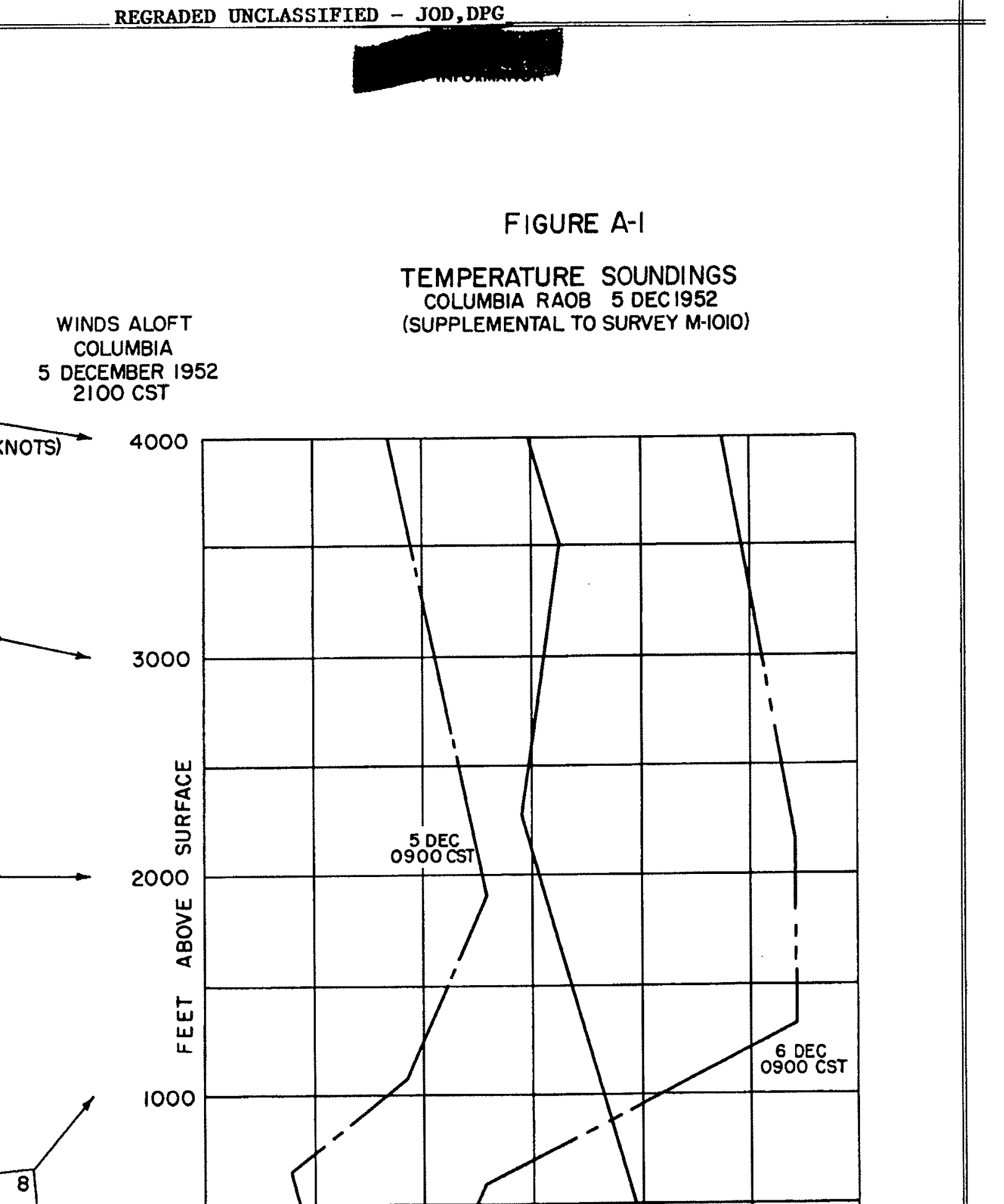

㟧

2000

安

岁

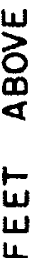

峁
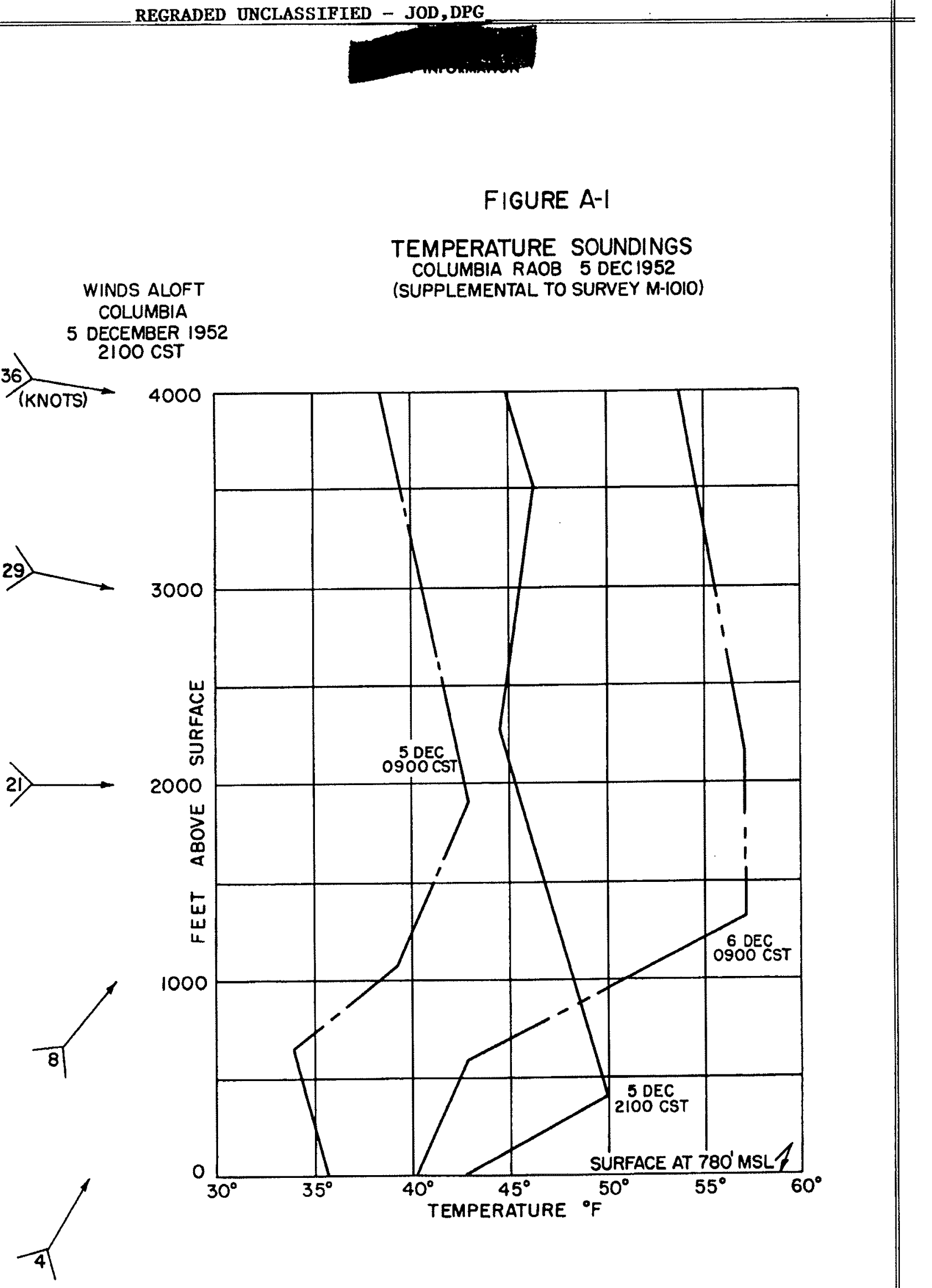

PAGE 164 


\section{SUMMARY OF REGIONAL AND LOCAL WEATHER \\ Survey M-1010, 5 December 1952}

\section{Synoptic Situation}

No fronts had passed St. Louis within the previous 36 hours, and the closest frontal activity at survey time was warm frontogenesis occurring some 400 miles to the wèst. A polar high-pressure cell of $1027 \mathrm{mb}$ extended from western New Mexico to southeast Texas. A major low-pressure area of $996 \mathrm{mb}$ was moving northeastward from the Great Lakes. Surface wind flow was southwest $4-7 \mathrm{mph}$. Air flow at the $700-\mathrm{mb}$ level was westerly at $40 \mathrm{mph}$.

Weather Reports from Lambert Field (st. Louis Airport)

\begin{tabular}{|c|c|c|c|c|c|c|c|c|c|c|}
\hline \multirow[b]{2}{*}{$\begin{array}{l}\text { Time } \\
\text { CST } \\
\end{array}$} & \multirow[b]{2}{*}{$\begin{array}{l}\text { Cloud } \\
\text { Height } \\
\text { (feet) }\end{array}$} & \multirow[b]{2}{*}{$\begin{array}{c}\text { Sky } \\
\text { Cover }\end{array}$} & \multirow[b]{2}{*}{$\begin{array}{c}\text { Visibility } \\
\text { (miles) }\end{array}$} & \multirow[b]{2}{*}{ Weather* } & \multirow[b]{2}{*}{$\begin{array}{l}\text { Temp } \\
\left({ }^{\circ} \mathrm{F}\right) \\
\end{array}$} & \multirow[b]{2}{*}{$\begin{array}{c}\text { Dew } \\
\text { Point } \\
\end{array}$} & \multicolumn{4}{|c|}{ Wind } \\
\hline & & & & & & & $\begin{array}{l}\text { Airp } \\
\text { Dir }\end{array}$ & $\begin{array}{l}\text { Sprt } \\
\text { Speed } \\
\text { (mph) } \\
\end{array}$ & $\begin{array}{l}\text { Univ } \\
\text { Dir. }\end{array}$ & $\begin{array}{l}\text { versity } \\
\text { Speed } \\
\text { (mph) }\end{array}$ \\
\hline 1830 & & Clear & 15 & & 46 & 32 & $W$ & 12 & - & - \\
\hline 1930 & & Clear & 15 & & 45 & 31 & $W$ & 11 & $\mathrm{NW}$ & 7 \\
\hline 2030 & & clear & 15 & & 44 & 31 & $W$ & 9 & $\mathrm{NW}$ & 4 \\
\hline 2130 & & Clear & 15 & & 42 & 31 & W & 5 & NW & 3 \\
\hline 2230 & & Clear & 15 & & 41 & 31 & W & 9 & - & - \\
\hline 2330 & & Clear & 15 & & 40 & 32 & WSW & 6 & - & - \\
\hline * An & for rest & ction & to visibilit & ty & & & & & & \\
\hline & el pres & re ( $\mathrm{La}$ & umbert Field, &, $2130 \mathrm{CS}$ & $: 1$ & $8.1 \mathrm{mb}$ & & & & \\
\hline & & : Bar & $e$ and dry & & & & & & & \\
\hline
\end{tabular}




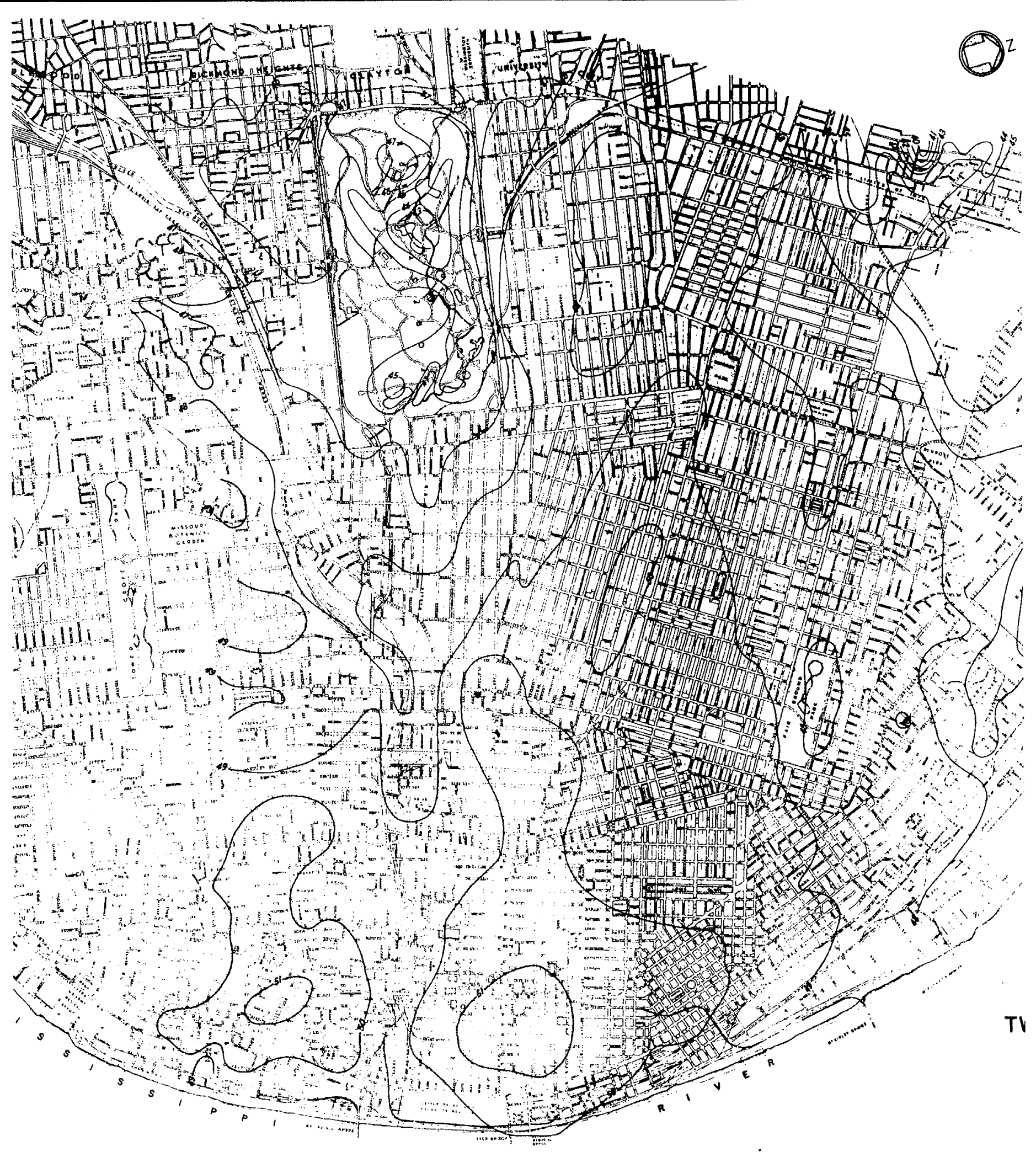




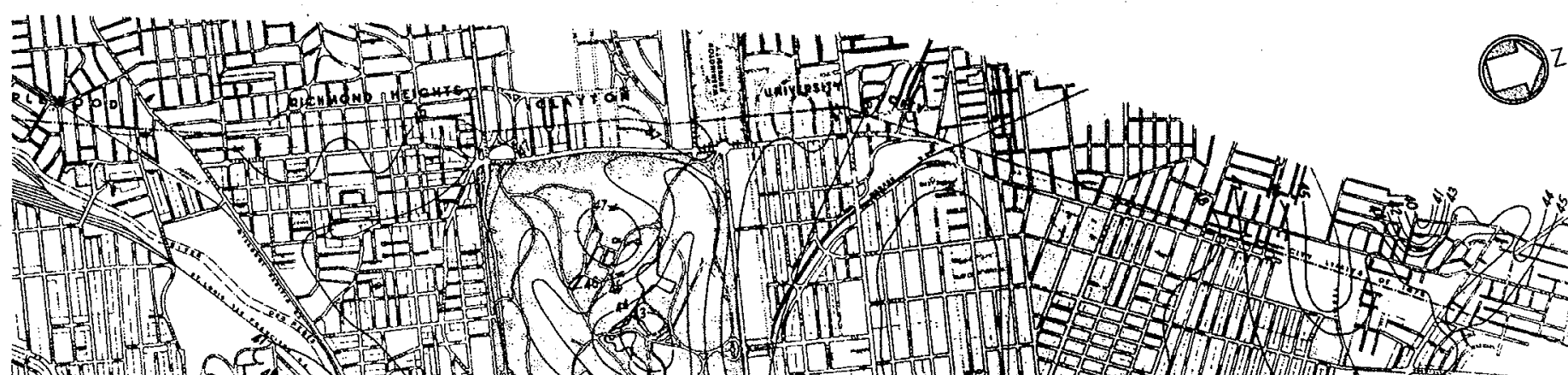

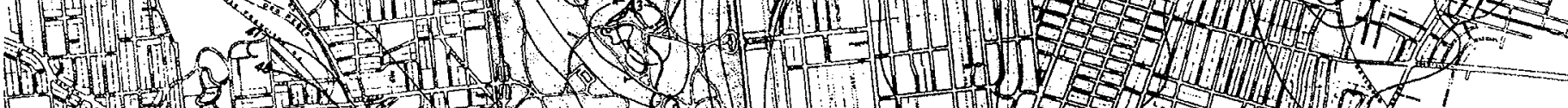

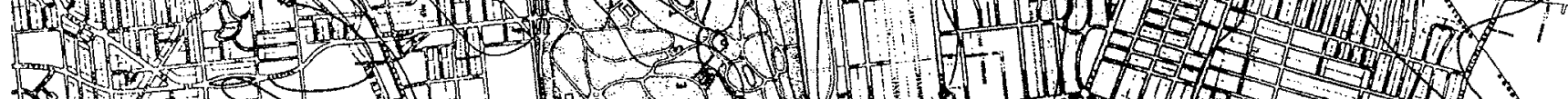

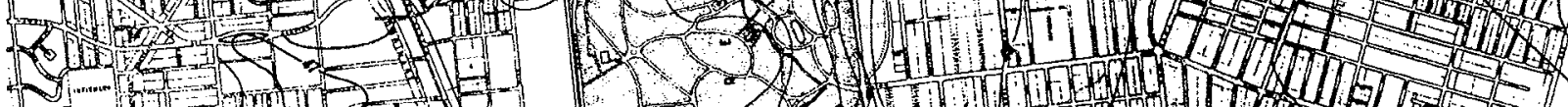

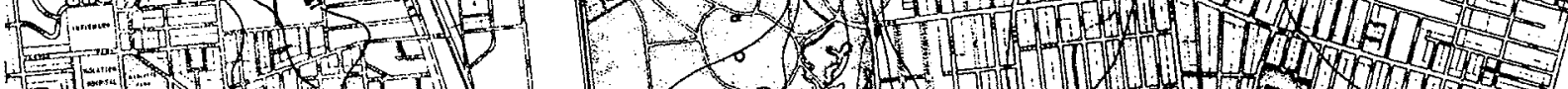

(5).

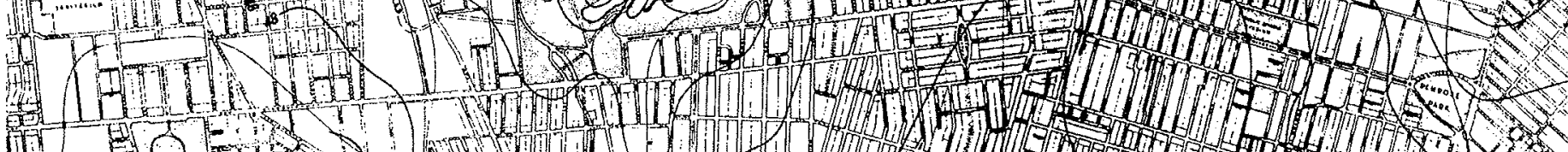

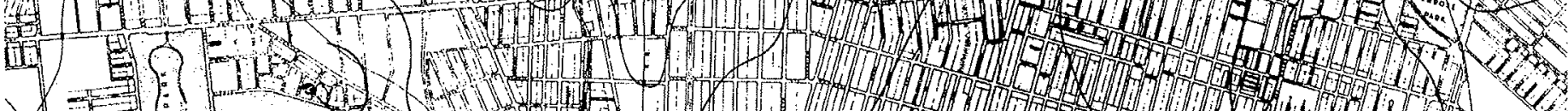
DTI

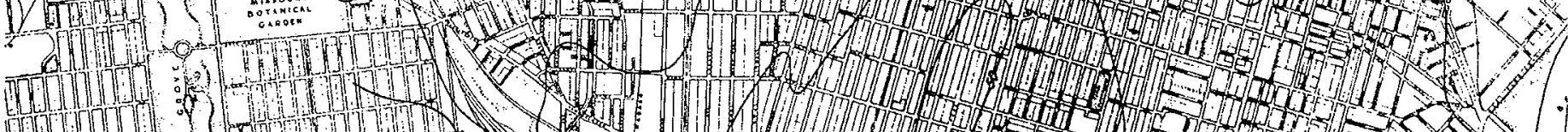

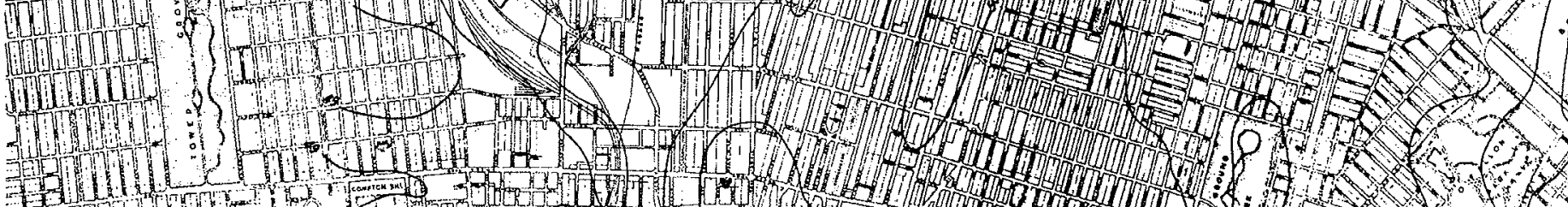

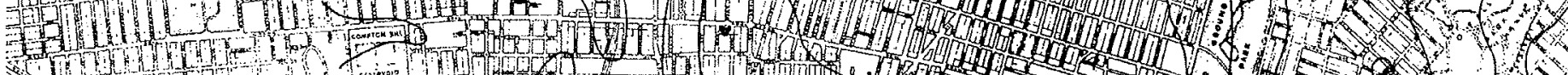

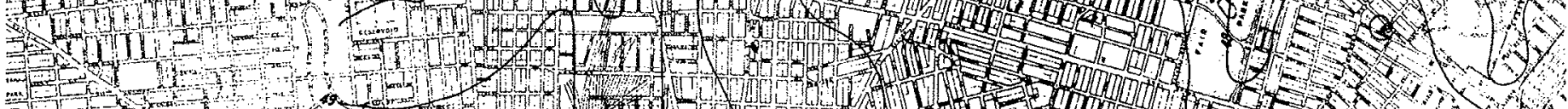

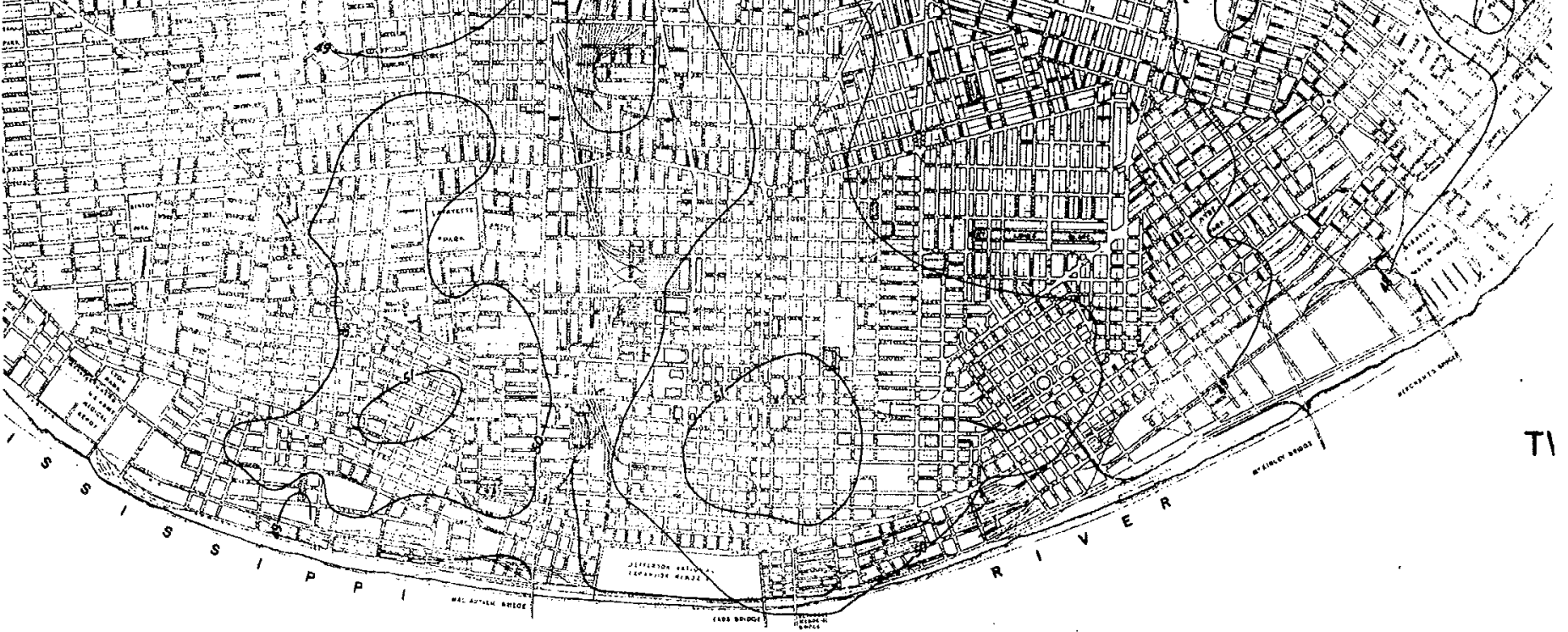




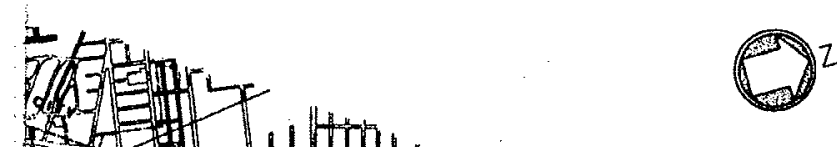

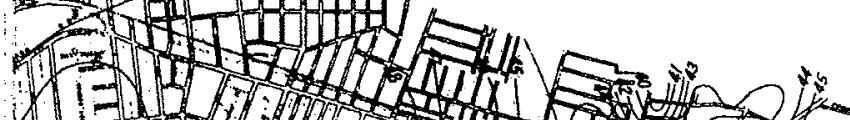
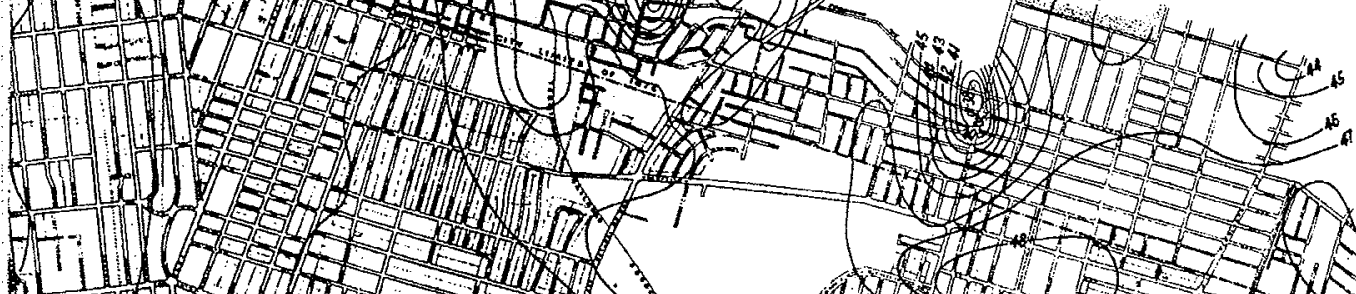

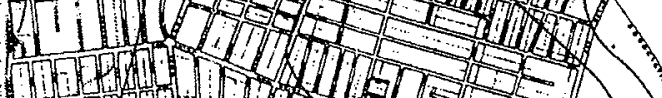

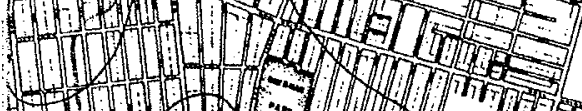

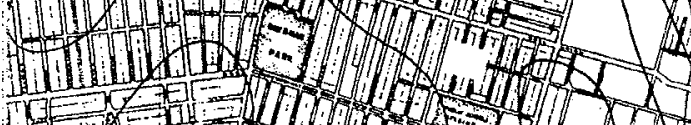

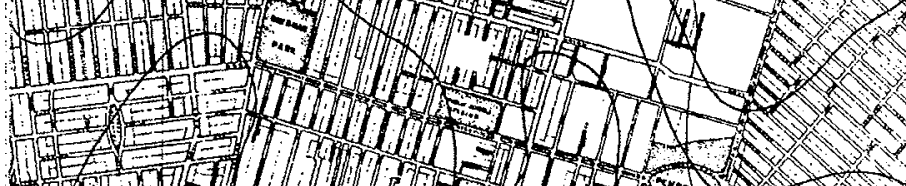

U.

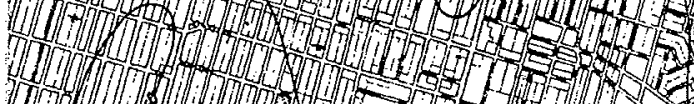

IJ)

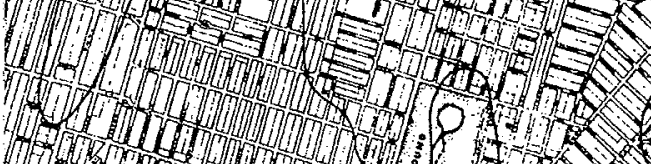

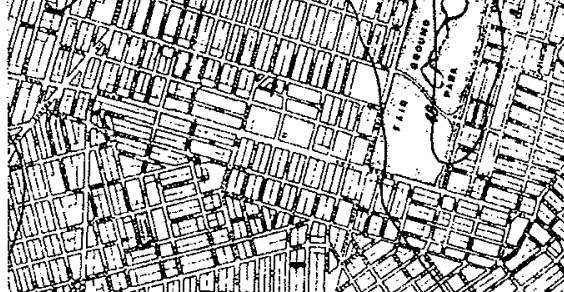

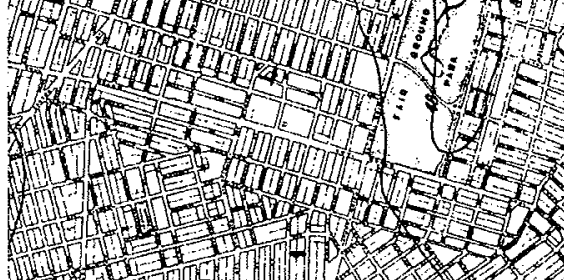

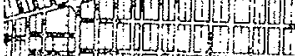

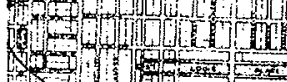

5,507070

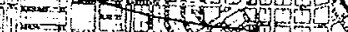

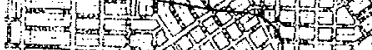

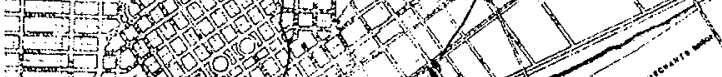

trom 1010

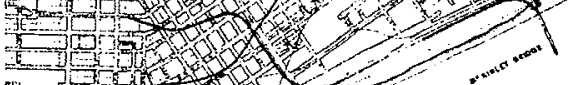

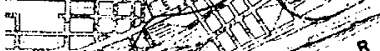

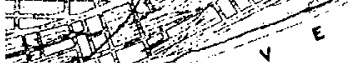

H.

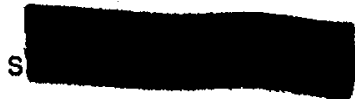

FIG. $A-2$

TWO METER AIR TEMPERATURE SURVEY
$M-1010$
2000 C ST
5 DECEMBER 1952 
SUMMARY OF REGIONAL AND LOCAL WEATHER

Survey M-1010, 5 December 1952

\section{Synoptic Situation}

No fronts had passed St. Louis within the previous 36 hours, and the closest frontal activity at survey time was warm frontogenesis occurring some 400 miles to the west. A polar high-pressure cell of $1027 \mathrm{mb}$ extended from western New Mexico to southeast Texas. A major low-pressure area of $996 \mathrm{mb}$ was moving northeastward from the Great Lakes. Surface wind flow was southwest $4-7 \mathrm{mph}$. Air flow at the $700-\mathrm{mb}$ level was westerly at $40 \mathrm{mph}$.

Weather Reports from Lambert Field (St. Louis Airport)

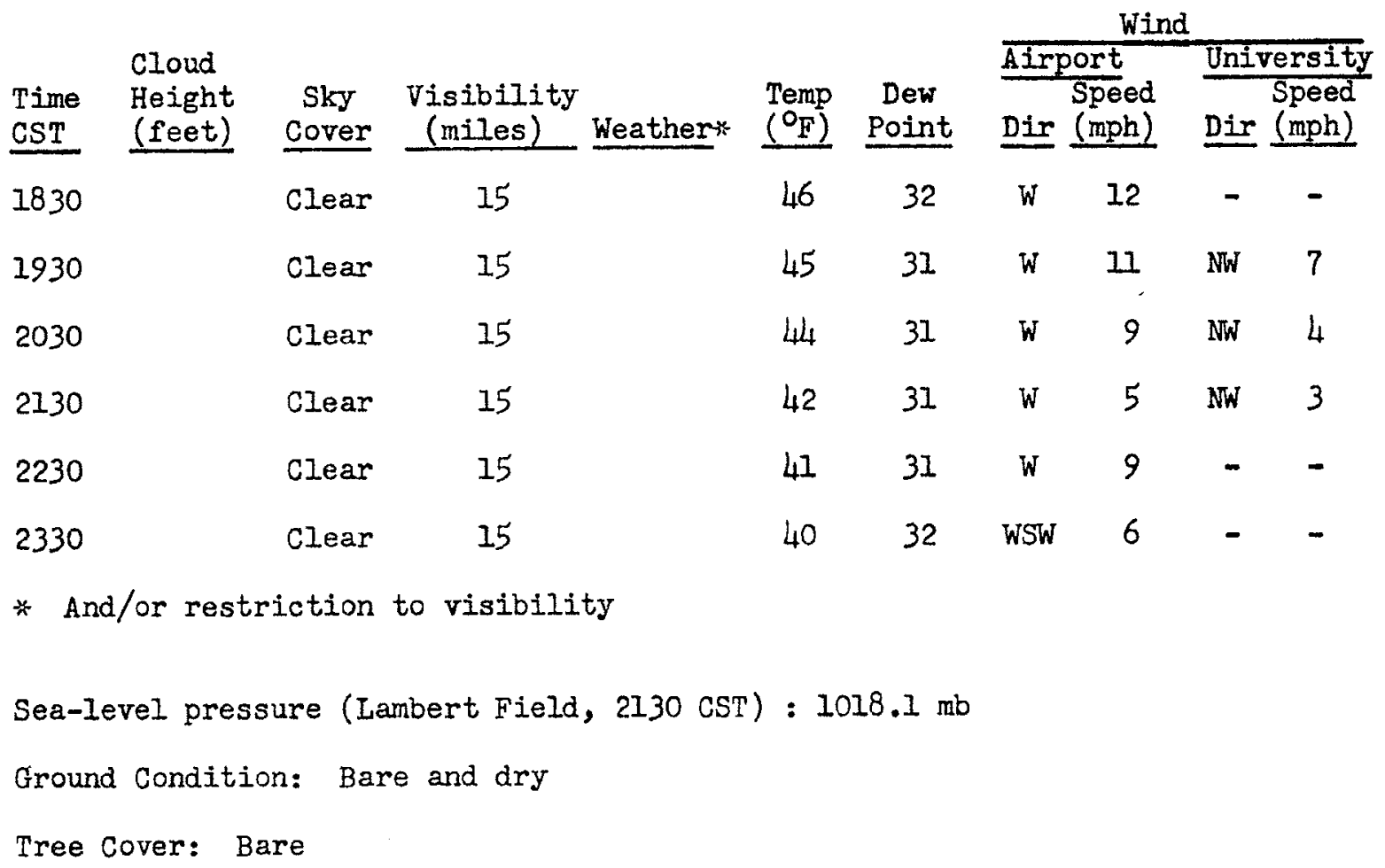



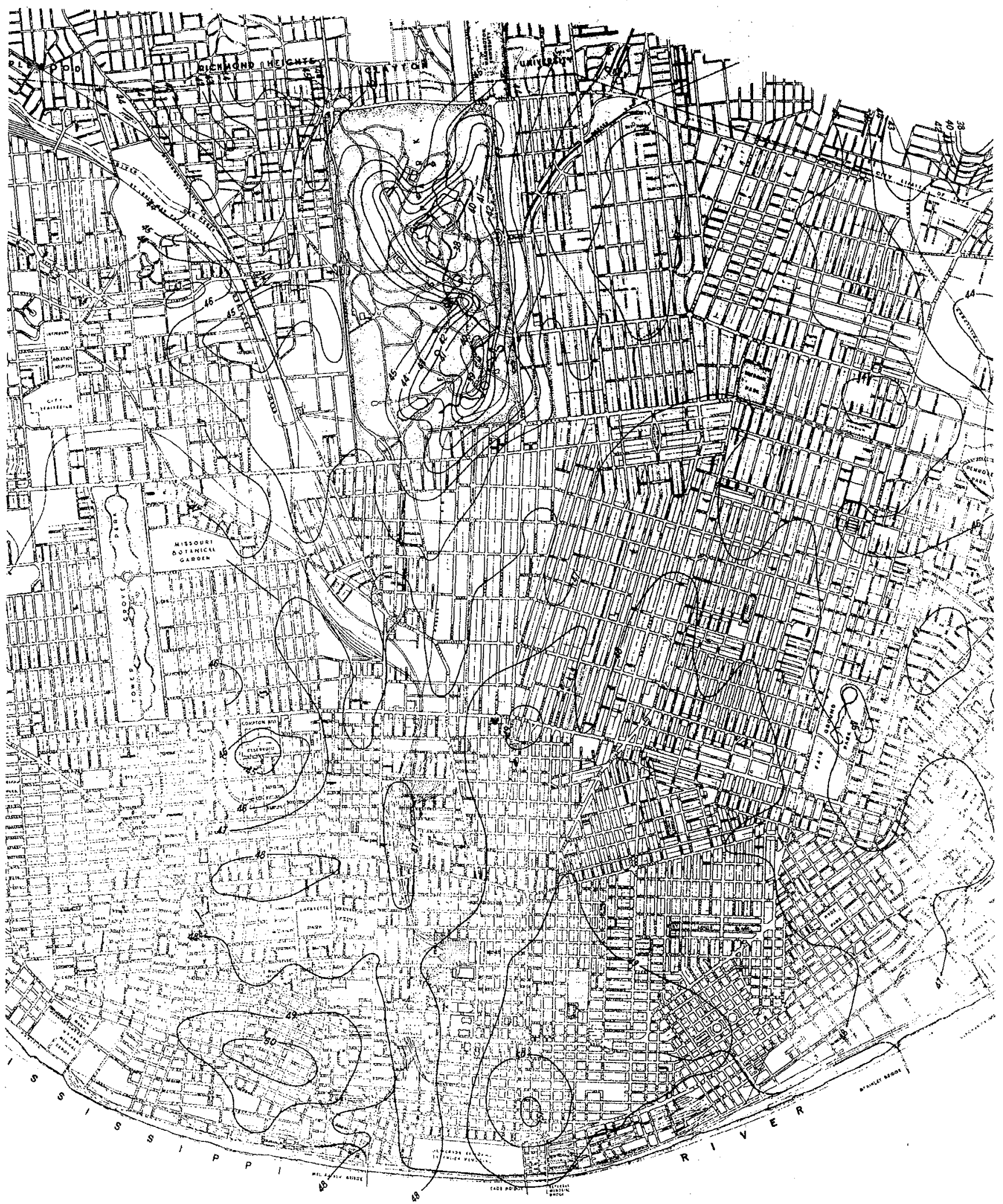


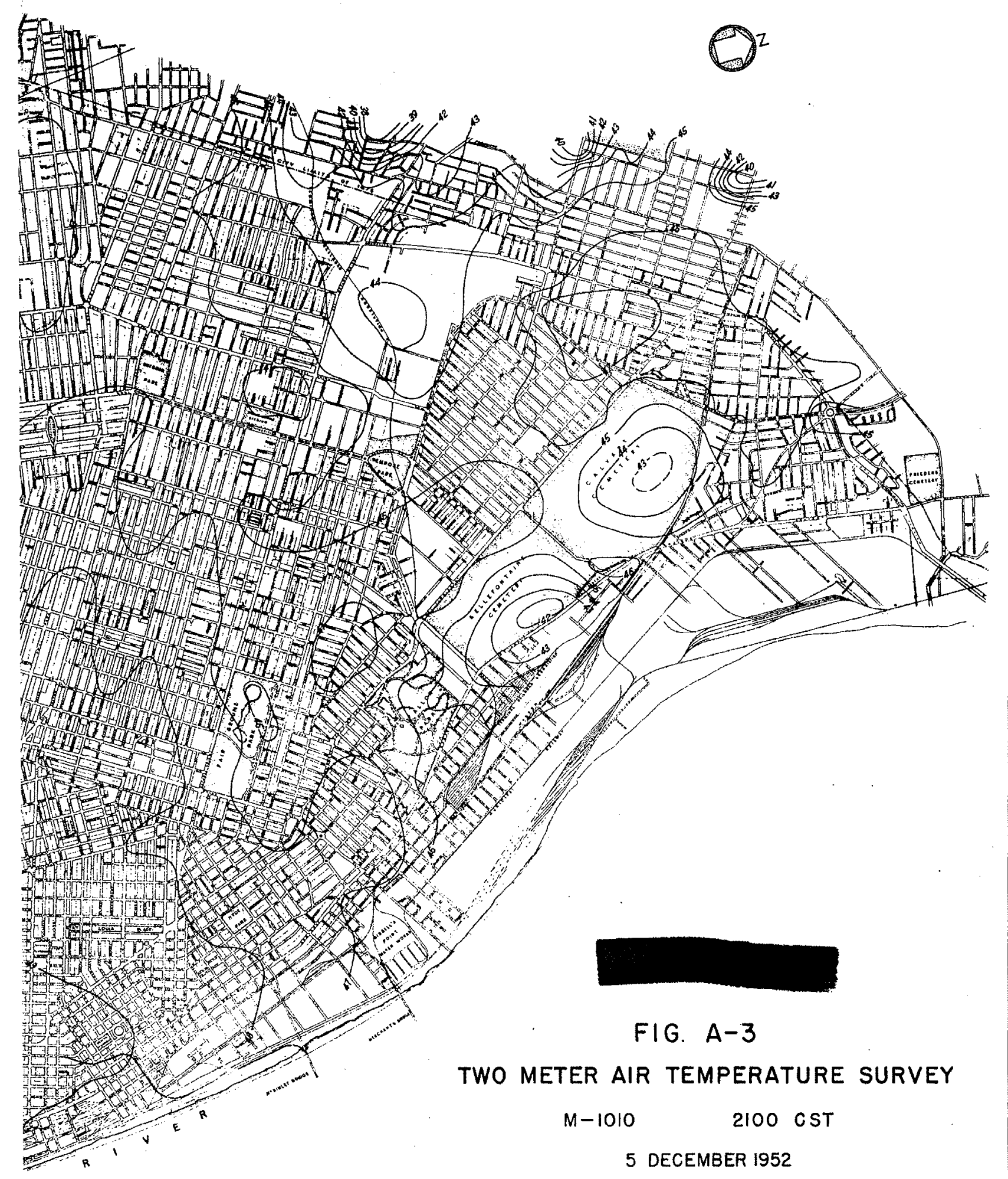




\section{SUMMARY OF REGIONAL AND LOCAL WEATHER \\ Survey M-1010, 5 December 1952}

\section{Synoptic Situation}

No fronts had passed St. Louis within the previous 36 hours, and the closest frontal activity at survey time was warm frontogenesis occurring some 400 miles to the west. A polar high-pressure cell of $1027 \mathrm{mb}$ extended from western New Mexico to southeast Texas. A luajor low-pressure area of $996 \mathrm{mb}$ was moving northeastward from the Great Lakes. Surface wind flow was southwest 4-7 mph. Air flow at the 700-mb level was westerly at $40 \mathrm{mph}$.

Weather Reports from Lambert Field (St. Louis Airport)

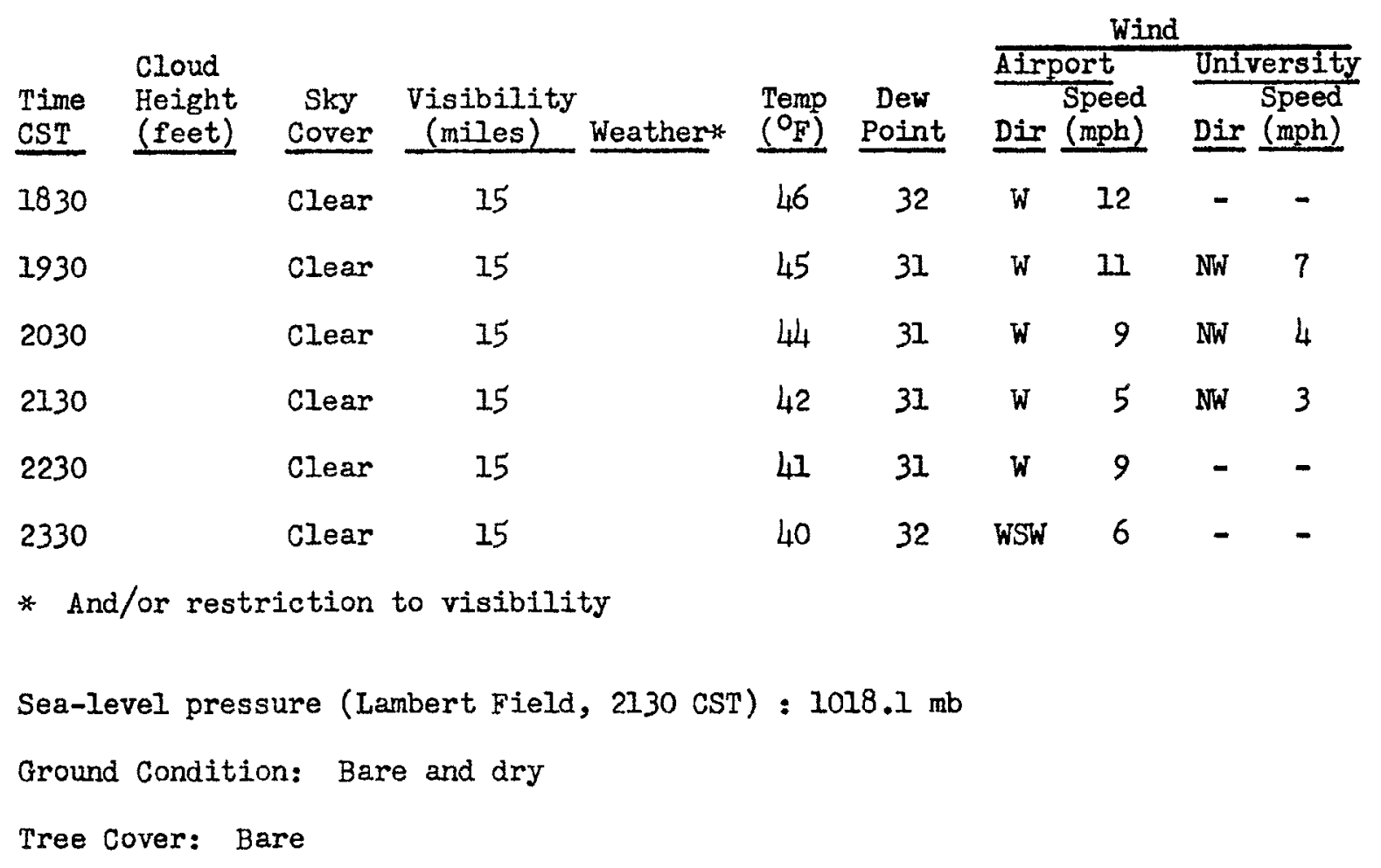




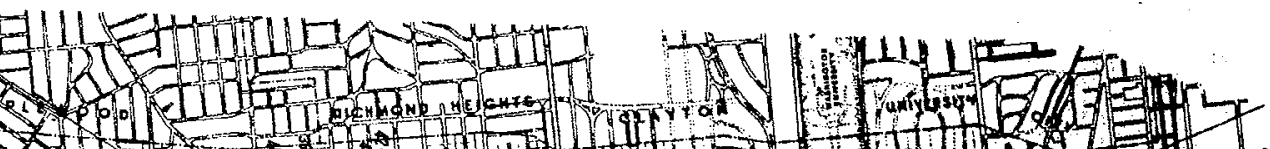

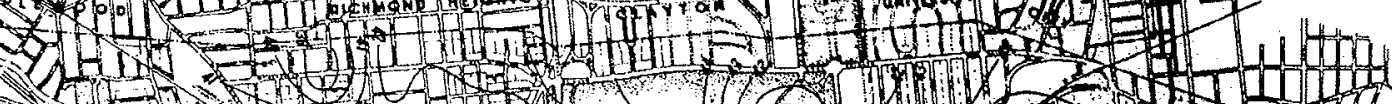

IJ

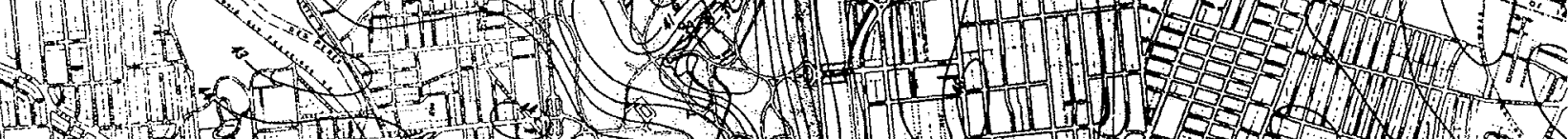

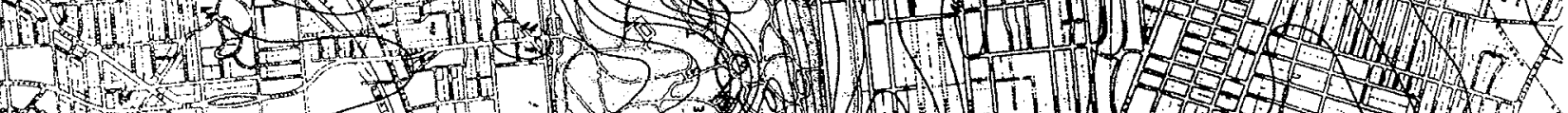

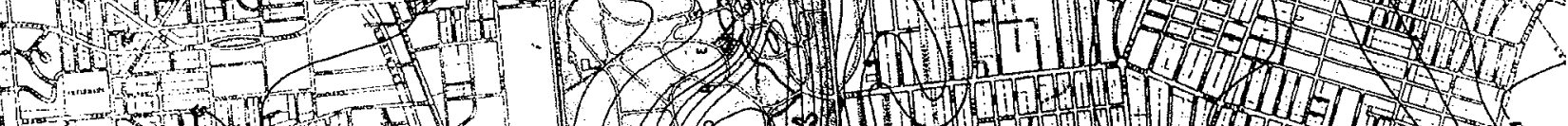

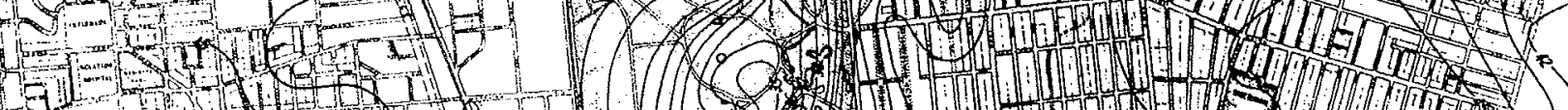

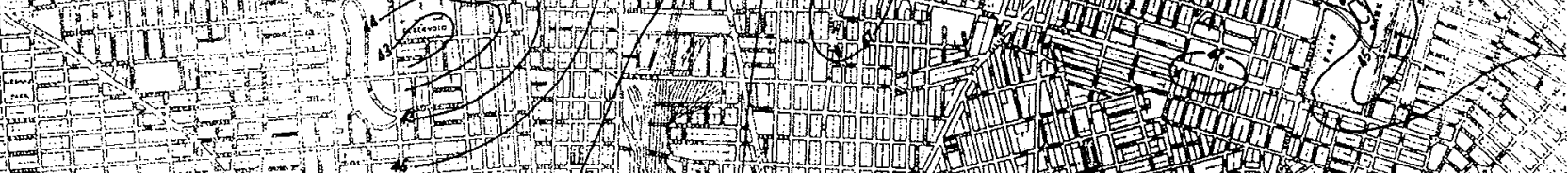

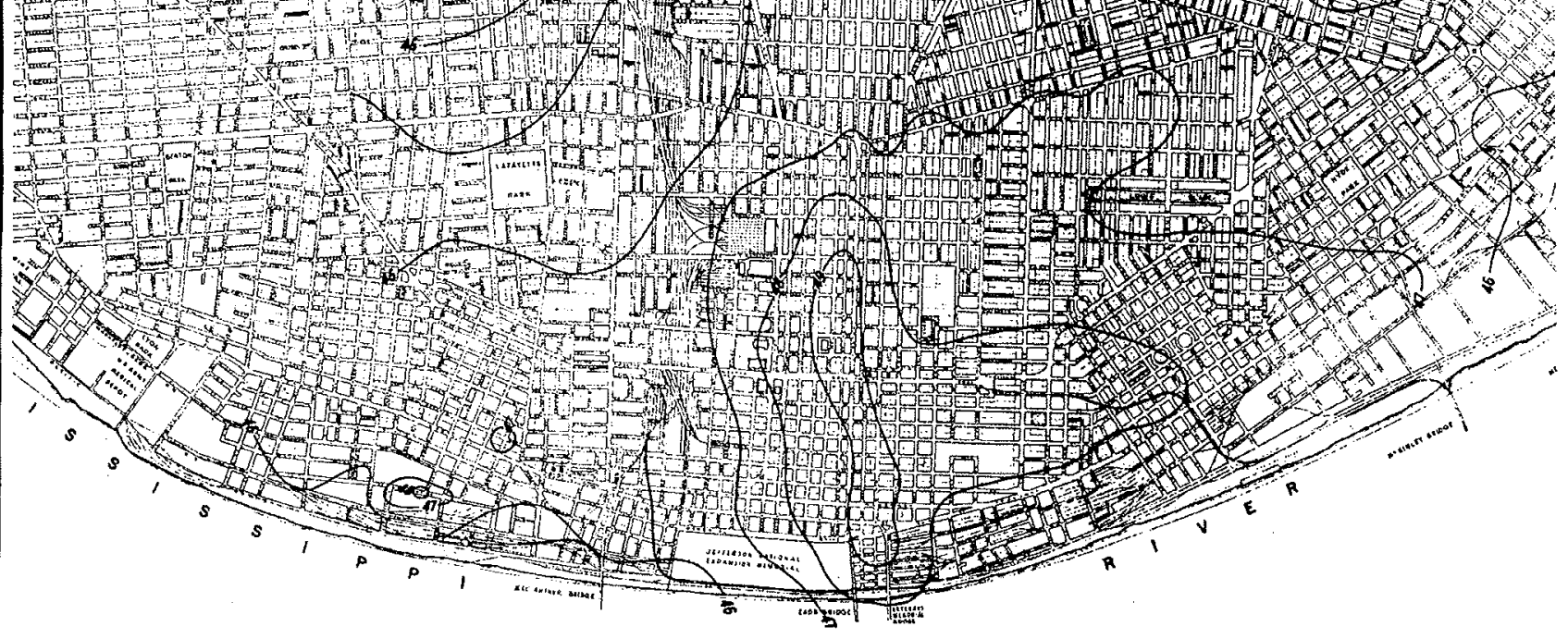




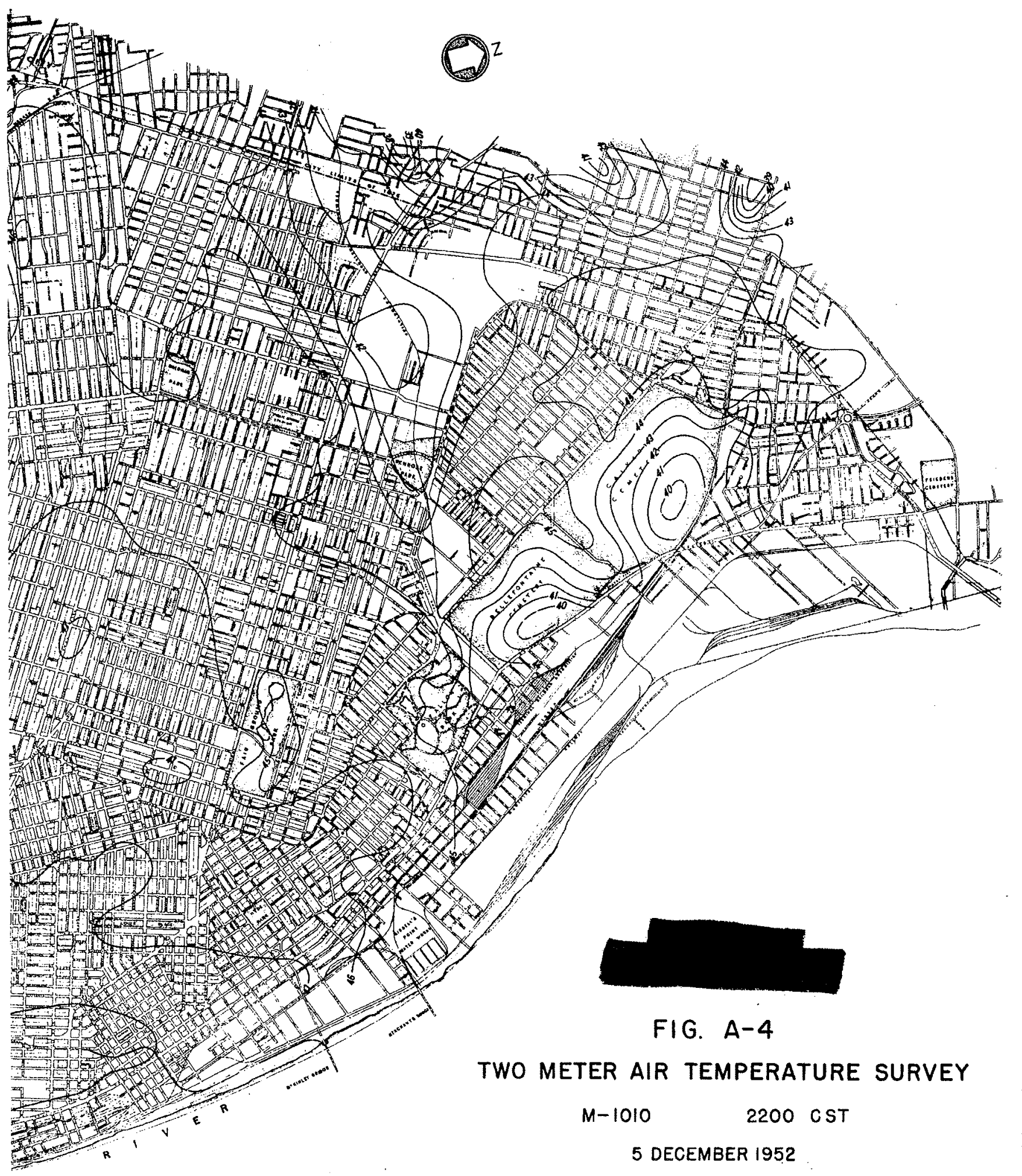

PAGE 167 
FIGURE A-5

TEMPERATURE SOUNDINGS

COLUMBIA RAOB 16 DEC 1952

WINDS ALOFT

COLUMBIA

(SUPPLEMENTAL TO SURVEY M-IO16)

16 DECEMBER 1952

$2100 \mathrm{CST}$

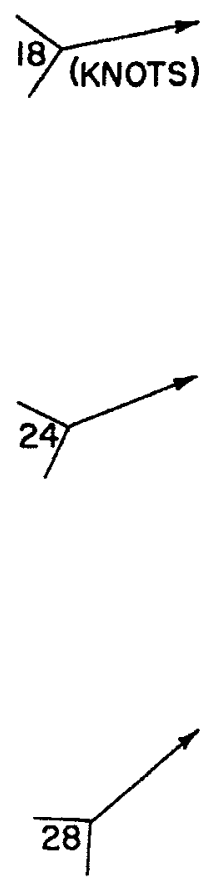

4000

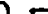

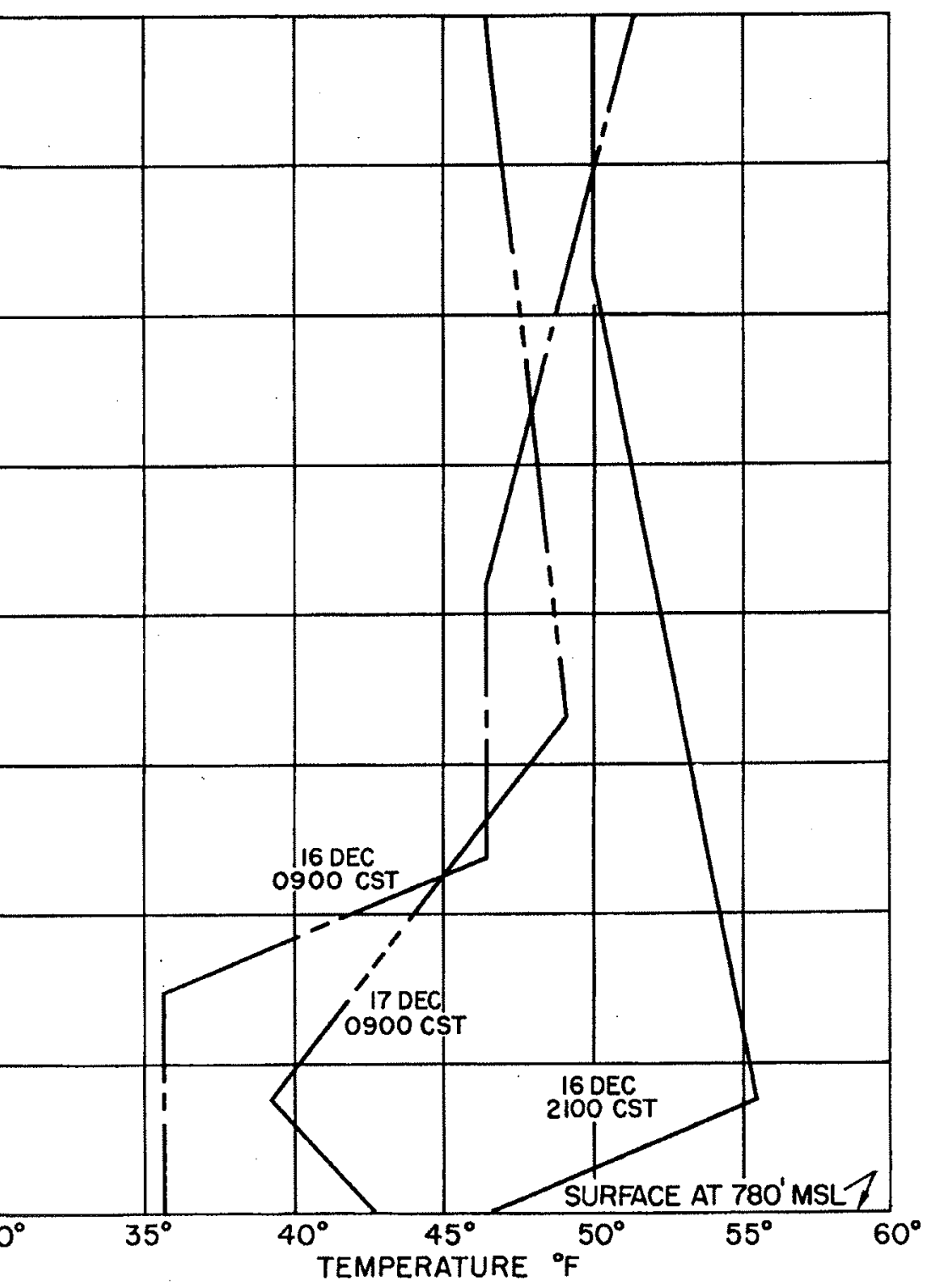

1

3000

岂

2000

岁

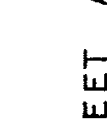

$\pi$

1000

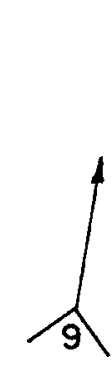

TEMPERATURE ${ }^{\circ}$

PAGE 168 
SUMMARY OF REGIONAL AND LOCAL WEATHER

Survey M-1016, 16 December 1952

\section{Synoptic Situation}

A weak cold front oriented ENE-WSW was located approximately 300 miles to the north of St. Louis. This front was moving slowly southward and did not pass St. Louis until late the next day. A very weak warm front was approaching the station from the west and undergoing frontolysis. North of Edmonton a continental high-pressure cell of $1034 \mathrm{mb}$ was centered and to the south of Mobile lay a maritime high of $1026 \mathrm{mb}$. A weak and inactive low of $1010 \mathrm{mb}$ was located over northern Texas. Surface wind flow was generally southsouthwest from $8-12 \mathrm{mph}$. At the $700 \mathrm{mb}$ level the air flow was westerly at $20 \mathrm{mph}$.

Weather Reports from Lambert Field (St. Louis Airport)

\begin{tabular}{|c|c|c|c|c|c|c|}
\hline $\begin{array}{l}\text { Tine } \\
\text { CST }\end{array}$ & $\begin{array}{l}\text { Cloud Ht. } \\
\text { (feet) }\end{array}$ & $\begin{array}{c}\text { Sky } \\
\text { Cover }\end{array}$ & $\begin{array}{c}\text { Visibility } \\
\text { (miles) }\end{array}$ & Weather* & $\begin{array}{l}\text { Temp } \\
\left(\mathrm{O}_{\mathrm{F}}\right) \\
\end{array}$ & $\begin{array}{c}\text { Dew } \\
\text { Point }\end{array}$ \\
\hline $\begin{array}{l}1830 \\
1930 \\
2030 \\
2130 \\
2230 \\
2330\end{array}$ & & $\begin{array}{l}\text { Clear } \\
\text { clear } \\
\text { Clear } \\
\text { Clear } \\
\text { Clear } \\
\text { Clear }\end{array}$ & $\begin{array}{r}10 \\
8 \\
5 \\
5 \\
6 \\
10\end{array}$ & $\begin{array}{l}\text { Smoke } \\
\text { Smoke } \\
\text { Smoke }\end{array}$ & $\begin{array}{l}45 \\
45 \\
42 \\
42 \\
39 \\
39\end{array}$ & $\begin{array}{l}30 \\
31 \\
30 \\
30 \\
29 \\
27\end{array}$ \\
\hline
\end{tabular}

Wind Direction and Speed (mph)

\begin{tabular}{|c|c|c|c|c|c|}
\hline $\begin{array}{l}\text { Time } \\
\text { CST }\end{array}$ & $\begin{array}{l}\text { Federal } \\
\text { Building } \\
\text { (303 ft) }\end{array}$ & $\begin{array}{l}\text { Lambert } \\
\text { Field } \\
\text { (59ft) }\end{array}$ & $\begin{array}{l}\text { St. Louis } \\
\text { University } \\
\text { (Rooftop) }\end{array}$ & $\begin{array}{l}\text { Special Obse } \\
1200 \mathrm{ft} . \mathrm{S} .\end{array}$ & $\begin{array}{l}\text { vation } \\
\text { ads Bridge }\end{array}$ \\
\hline $\begin{array}{l}1830 \\
1900 \\
1930 \\
2000 \\
2030 \\
2100 \\
2130 \\
2200 \\
2230 \\
2300\end{array}$ & $\begin{array}{ll}\text { SW } & 18 \\
\text { SW } & 20 \\
\text { SW } & 20\end{array}$ & $\begin{array}{ll}\mathrm{S} & 4 \\
\mathrm{~S} & 4 \\
\mathrm{~S} & 4 \\
\mathrm{~S} & 5 \\
\mathrm{~S} & 5 \\
\mathrm{~S} & 6 \\
\mathrm{~S} & 8 \\
\mathrm{~S} & 6 \\
\mathrm{~S} & 7 \\
\mathrm{~S} & 8\end{array}$ & $\begin{array}{ll}\text { SE } & 2 \\
\text { S } & 3 \\
\text { S } & 3 \\
\text { SSW } & 3 \\
\text { S } & 3 \\
\text { SSW } & 3\end{array}$ & $\begin{array}{l}\text { SSW } \\
\text { SW }\end{array}$ & $\begin{array}{l}2 \\
5\end{array}$ \\
\hline
\end{tabular}

* And/or restriction to visibility

Sea level pressure (Lambert Field $2130 \mathrm{CST}$ ) : $1017.4 \mathrm{mb}$ Ground Condition: Bare and dry

Tree Cover: Bare 


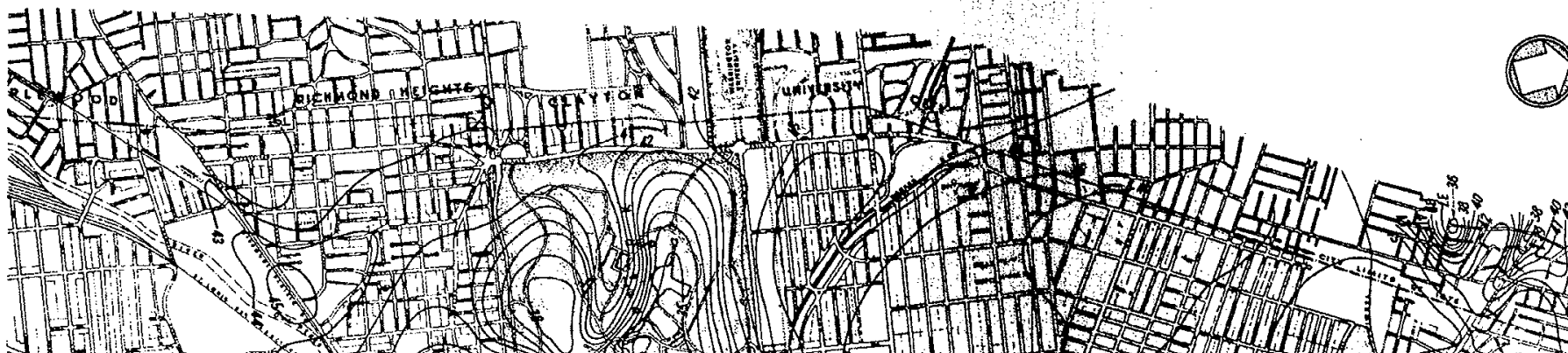
*.

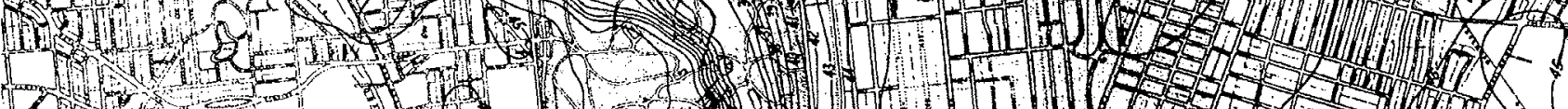
mo

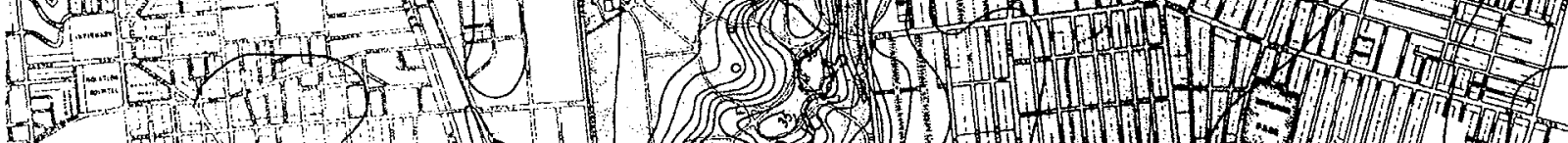

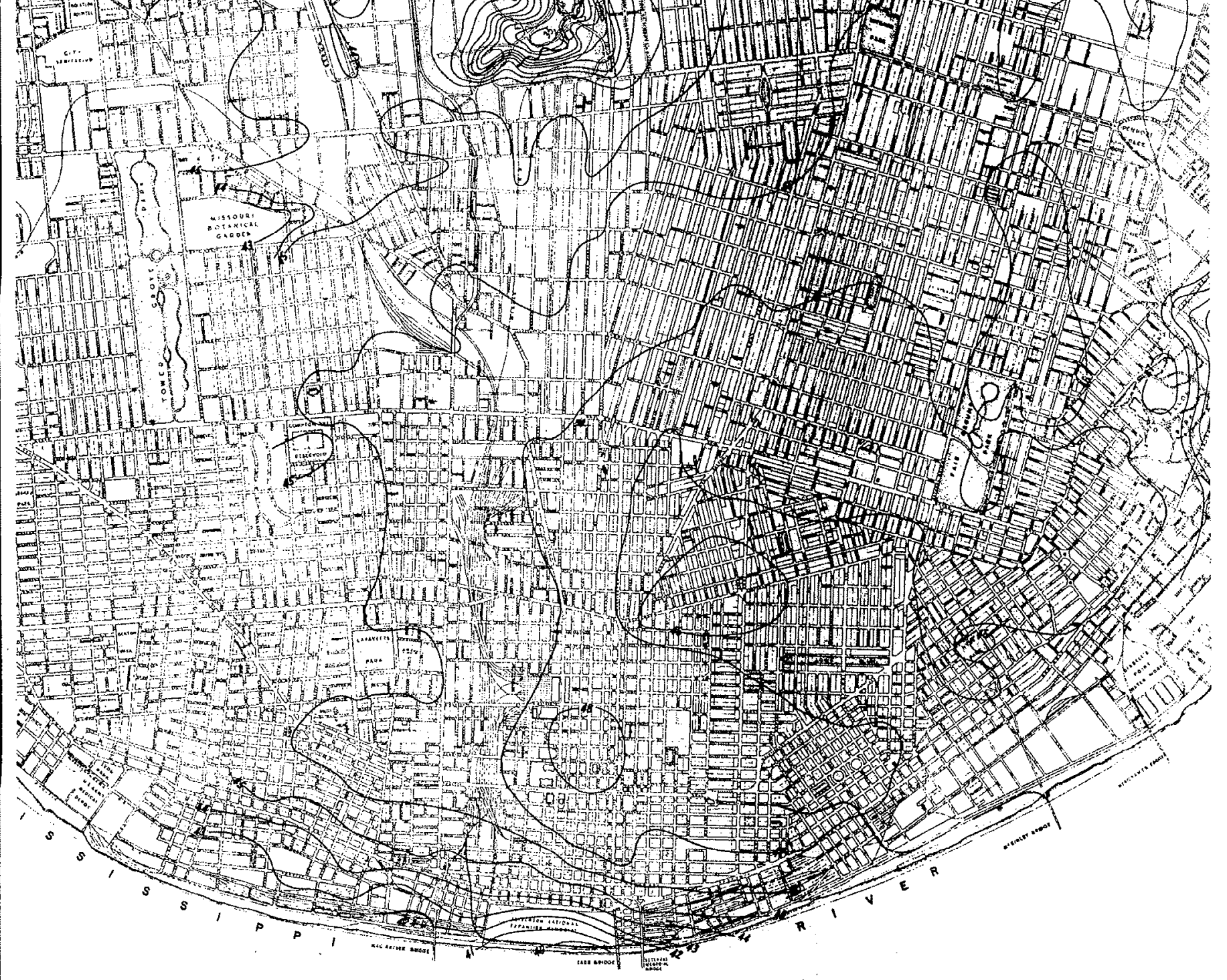




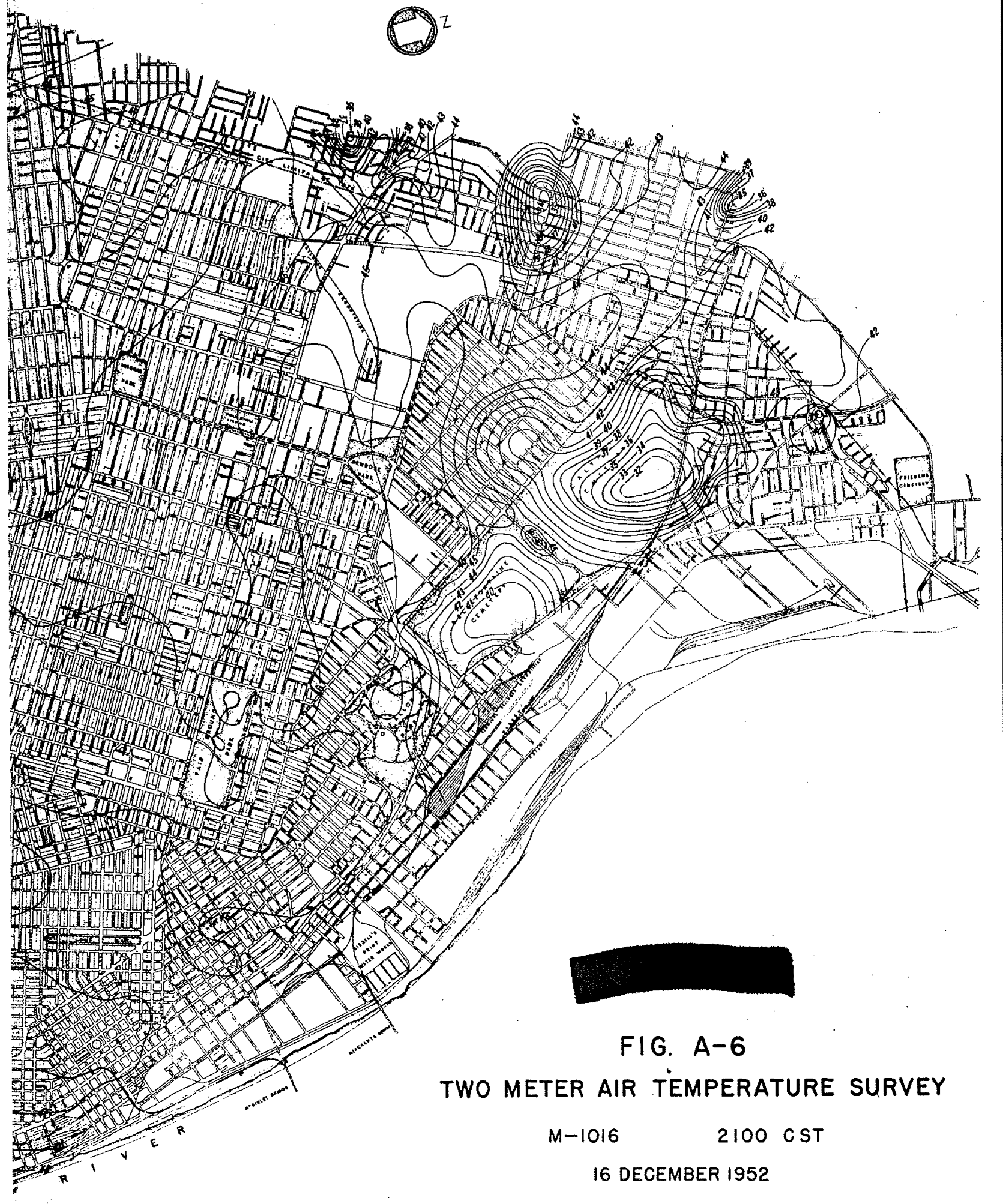

PAGE 169 
SUMMARY OF REGIONAL AND LOCAL WEATHER

Survey M-1016, 16 December 1952

Synoptic Situation

A weak cold front oriented ENE-WSW was located approximately 300 miles to the north of St. Louis. This front was moving slowly southward and did not pass St. Louis until late the next day. A very weak warm front was approaching the station from the west and undergoing frontolysis. North of Edmonton a continental high-pressure cell of $1034 \mathrm{mb}$ was centered and to the south of Mobile lay a maritime high of $1026 \mathrm{mb}$. A weak and inactive low of $1010 \mathrm{mb}$ was located over northern Texas. Surface wind flow was generally southsouthwest from 8-12 mph. At the $700 \mathrm{mb}$ level the air flow was westerly at $20 \mathrm{mph}$.

Weather Reports from Lambert Field (St. Louis Airport)

\begin{tabular}{|c|c|c|c|c|c|c|}
\hline $\begin{array}{l}\text { Time } \\
\text { CST }\end{array}$ & $\begin{array}{c}\text { Cloud Ht. } \\
\text { (feet) }\end{array}$ & $\begin{array}{c}\text { Sky } \\
\text { Cover }\end{array}$ & $\begin{array}{c}\text { Visibility } \\
\text { (miles) }\end{array}$ & - Weather* & $\begin{array}{l}\text { Temp } \\
(\mathrm{F}) \\
\end{array}$ & $\begin{array}{l}\text { Dew } \\
\text { Point }\end{array}$ \\
\hline $\begin{array}{l}1830 \\
1930 \\
2030 \\
2130 \\
2230 \\
2330\end{array}$ & & $\begin{array}{l}\text { Clear } \\
\text { Clear } \\
\text { Clear } \\
\text { Clear } \\
\text { Clear } \\
\text { Clear }\end{array}$ & $\begin{array}{r}10 \\
8 \\
5 \\
5 \\
6 \\
10\end{array}$ & $\begin{array}{l}\text { Smoke } \\
\text { Smoke } \\
\text { Smoke }\end{array}$ & $\begin{array}{l}45 \\
45 \\
42 \\
42 \\
39 \\
39\end{array}$ & $\begin{array}{l}30 \\
31 \\
30 \\
30 \\
29 \\
27\end{array}$ \\
\hline
\end{tabular}

Wind Direction and Speed (mph)

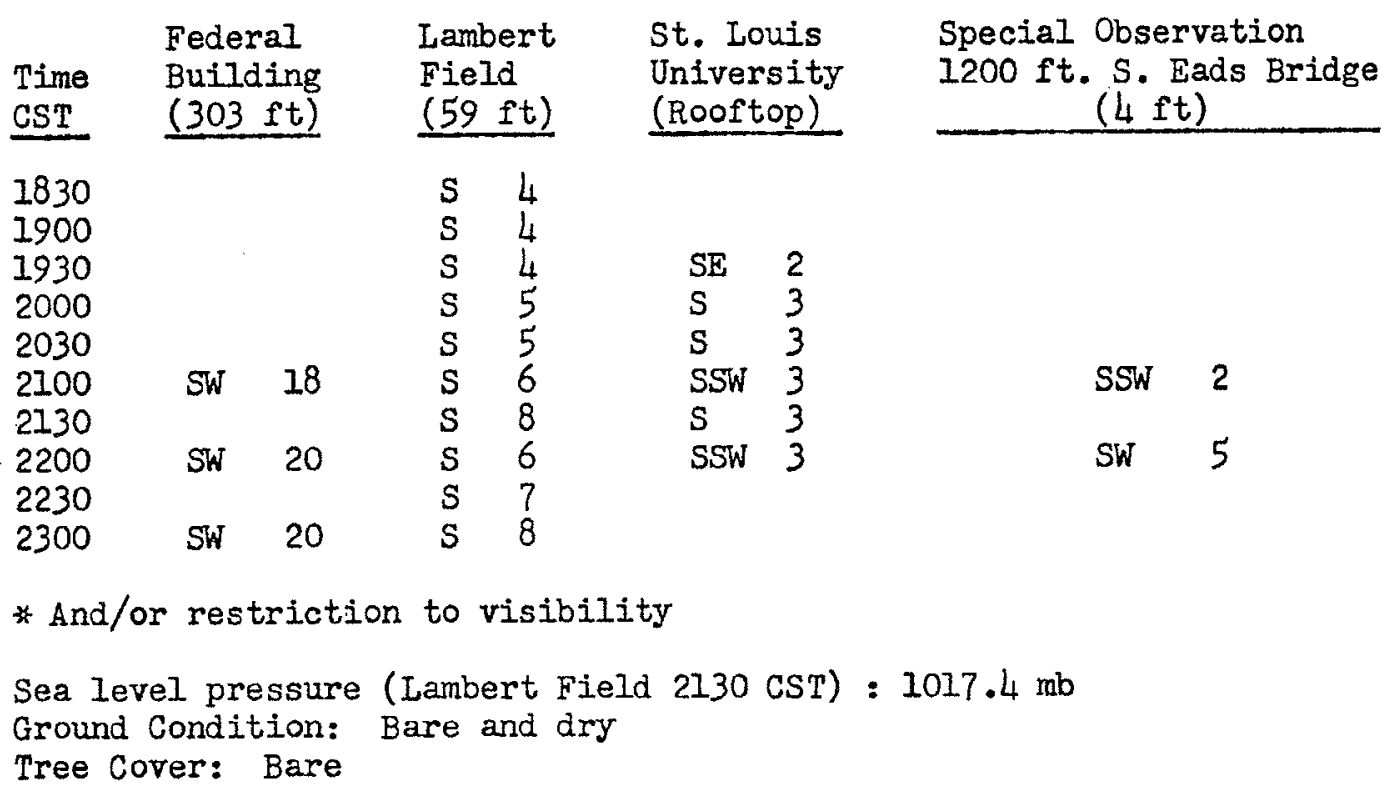




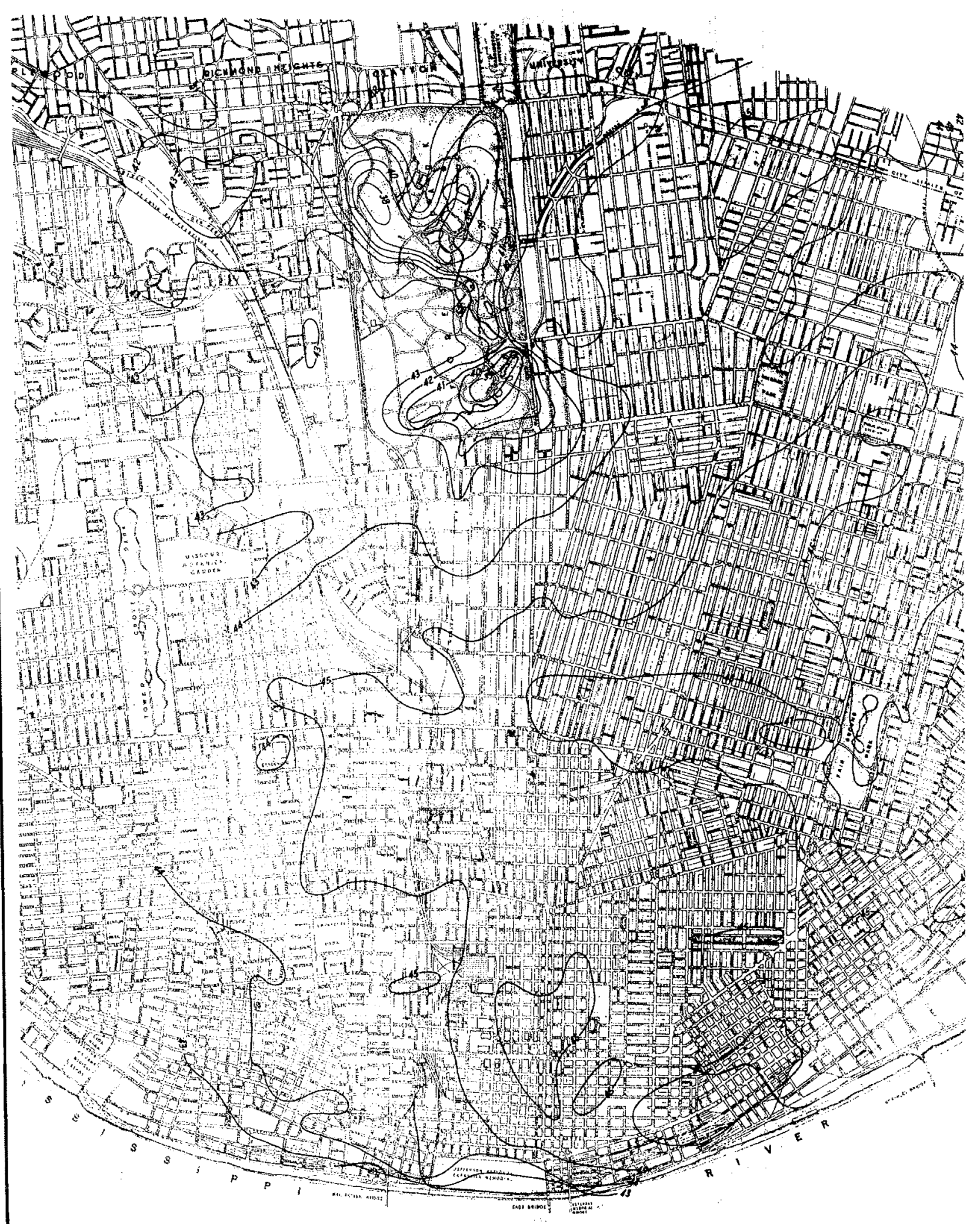




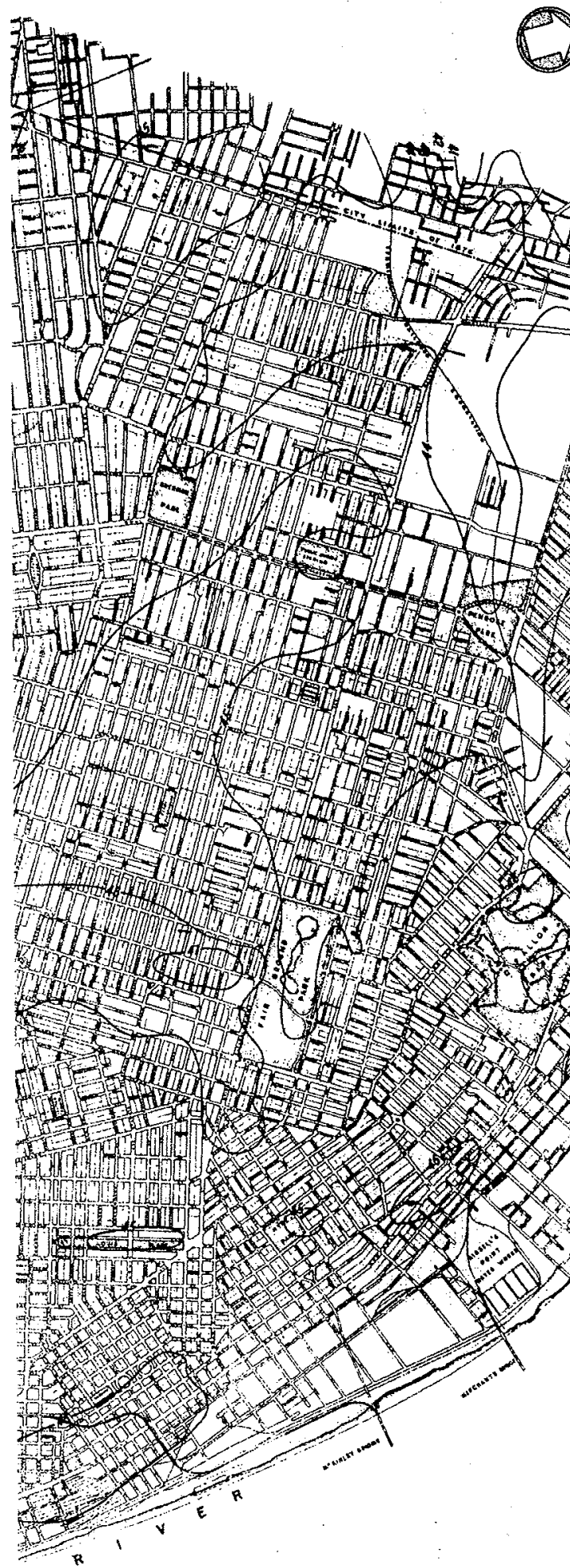

2

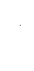


FIGURE A-8

TEMPERATURE SOUNDINGS

COLUMBIA RAOB 8 JAN 1953

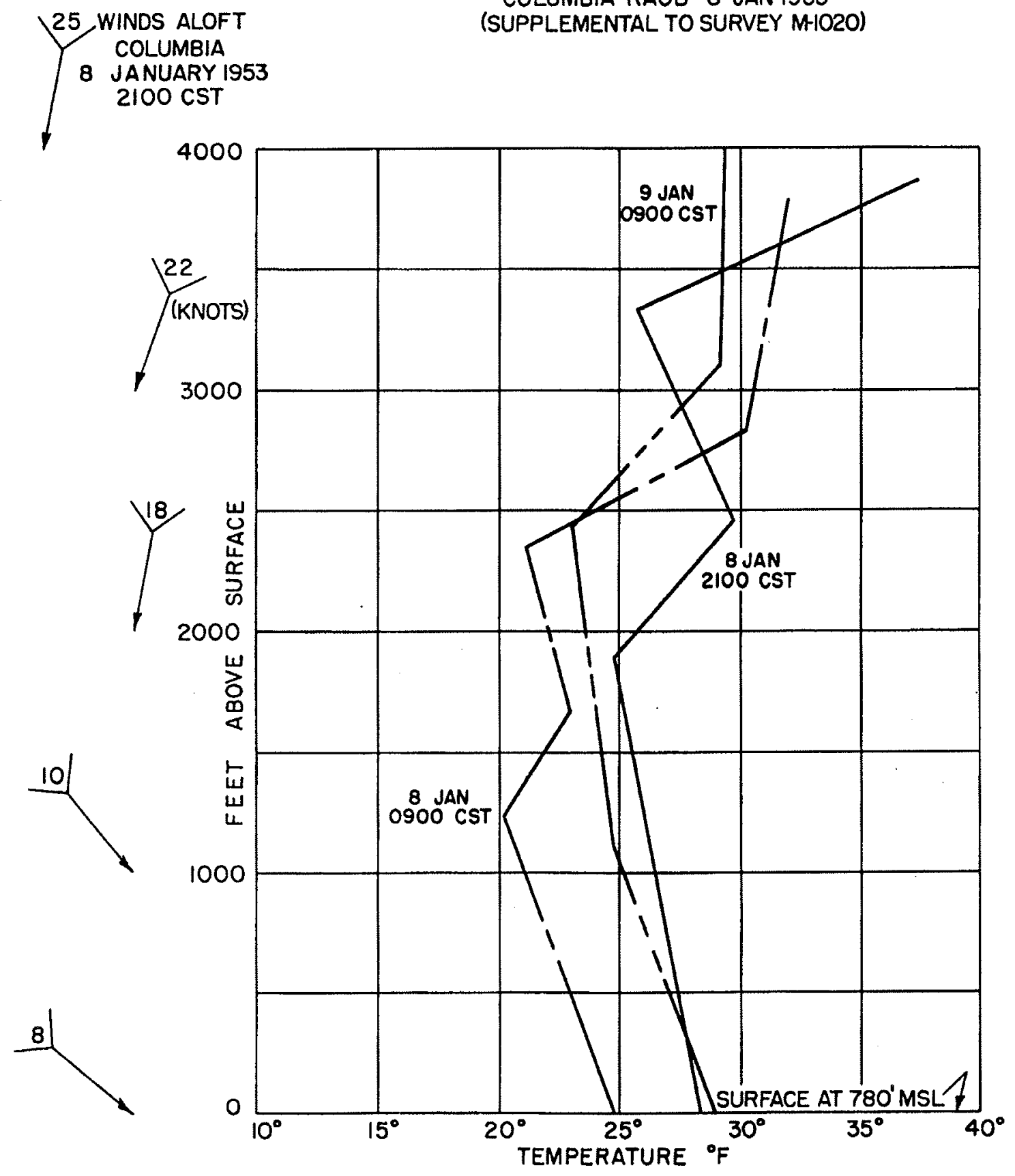

PAGE 171 
SUMMARY OF REGIONAL AND LOCAL WEATHER

Survey M-1020, 8 January 1953

\section{Synoptic Situation}

An active front existed approximately 300 miles to the east of St. Louis with a $1000 \mathrm{mb}$ low center in southern Alabama and the system was moving eastward. Considerable post-frontal weather observed throughout Illinois and Missouri was associated with an upper trough over this area. A Great Basin high-pressure cell of $1037 \mathrm{mb}$ was located just southeast of Salt Lake. Surface wind flow was north $8-12 \mathrm{mph}$ while at $700 \mathrm{mb}$ the air flow was northwesterly at $25 \mathrm{mph}$.

Weather Reports from Lambert Field (St. Louis Airport)

\begin{tabular}{|c|c|c|c|c|c|c|c|c|c|c|}
\hline \multirow[b]{2}{*}{$\begin{array}{l}\text { Time } \\
\text { CST }\end{array}$} & \multirow[b]{2}{*}{$\begin{array}{l}\text { cloud } \\
\text { Height } \\
\text { (feet) }\end{array}$} & \multirow[b]{2}{*}{$\begin{array}{r}\text { Sky* } \\
\text { Cover } \\
\end{array}$} & \multirow[b]{2}{*}{$\begin{array}{l}\text { Visibility } \\
\text { (miles) }\end{array}$} & \multirow[b]{2}{*}{ Weather*** } & \multirow[b]{2}{*}{$\begin{array}{l}\text { Temp } \\
\left({ }^{\circ} \mathrm{F}\right) \\
\end{array}$} & \multirow[b]{2}{*}{$\begin{array}{l}\text { Dew } \\
\text { Point }\end{array}$} & \multicolumn{4}{|c|}{ Wind } \\
\hline & & & & & & & $\begin{array}{l}\text { Airp } \\
\text { Dir. }\end{array}$ & $\begin{array}{l}\text { Speed } \\
\text { (mph) }\end{array}$ & $\begin{array}{l}\text { Univ } \\
\text { Dir. }\end{array}$ & $\begin{array}{l}\text { versity } \\
\text { Speed } \\
\text { (mph) } \\
\end{array}$ \\
\hline 1830 & 400 & $\begin{array}{l}\text { Over- } \\
\text { cast }\end{array}$ & $11 / 2$ & $\begin{array}{l}\text { Freezing, } \\
\text { drizzle }\end{array}$ & 29 & 28 & $\mathrm{NW}$ & 9 & - & - \\
\hline 1930 & 400 & $n$ & $11 / 2$ & $n$ & 29 & 28 & $\mathrm{NW}$ & 9 & $\mathrm{NW}$ & 6 \\
\hline 2030 & 400 & $n$ & $11 / 2$ & $"$ & 29 & 28 & NW & 7 & NNW & 6 \\
\hline 2130 & 300 & $"$ & $11 / 2$ & $"$ & 29 & 29 & $\mathrm{NW}$ & 8 & $\mathrm{NNW}$ & 4 \\
\hline 2230 & 300 & $n$ & $11 / 2$ & " & 29 & 29 & NW & 7 & - & - \\
\hline 2330 & 300 & $"$ & 1 & $n$ & 30 & 29 & NW & 10 & - & - \\
\hline \multicolumn{2}{|c|}{ *Average cloudiness sunrise to sunset (Lambert Field): } & \multicolumn{7}{|c|}{$*$ And/or restriction to visibility } & & \\
\hline \multicolumn{11}{|c|}{ Sea level pressure (Lambert Field $2130 \mathrm{CST}$ ): $1014.4 \mathrm{mb}$} \\
\hline \multicolumn{11}{|c|}{ Ground condition: Snow and ice on ground. Lakes in Forest Park frozen. } \\
\hline
\end{tabular}




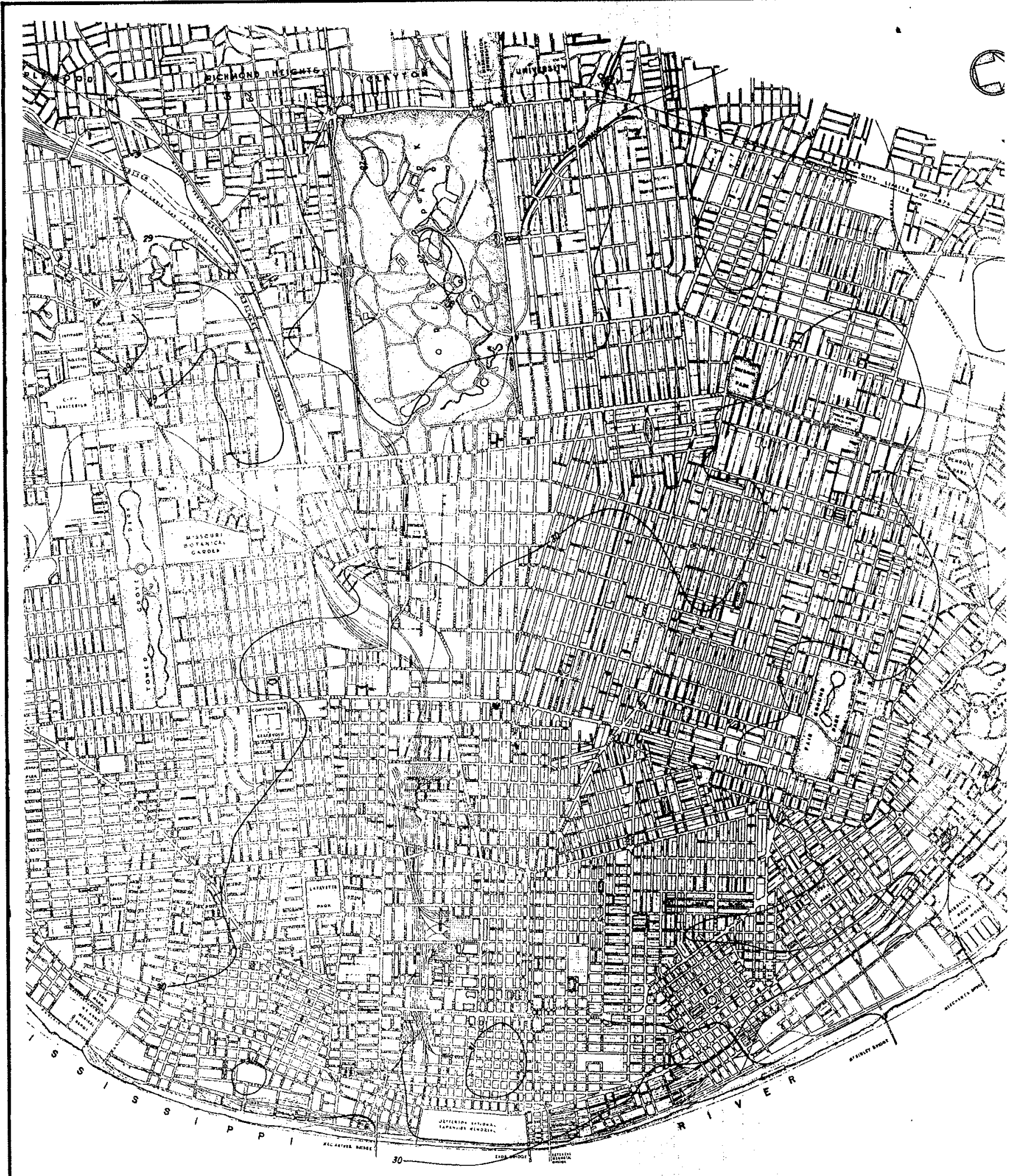




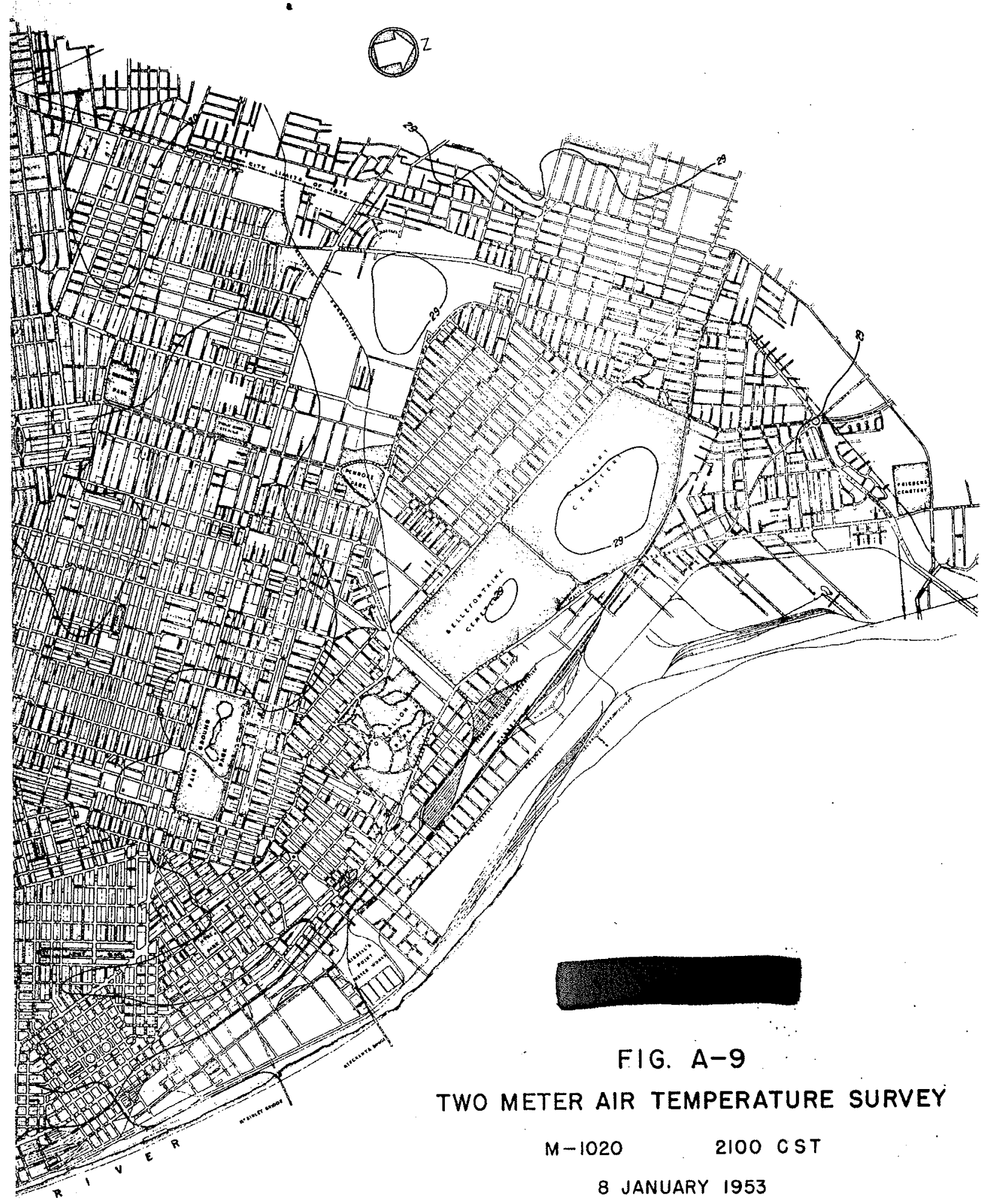

PAGE 172 
FIGURE A-1O

TEMPERATURE SOUNDINGS

COLUMBIA RAOB 5 MAR 1953

WINDS ALOFT

(SUPPLEMENTAL TO SURVEY M-1024)

COLUMBIA

5 MARCH 1953

$2100 \mathrm{CST}$

32)

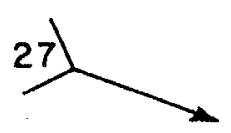

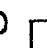
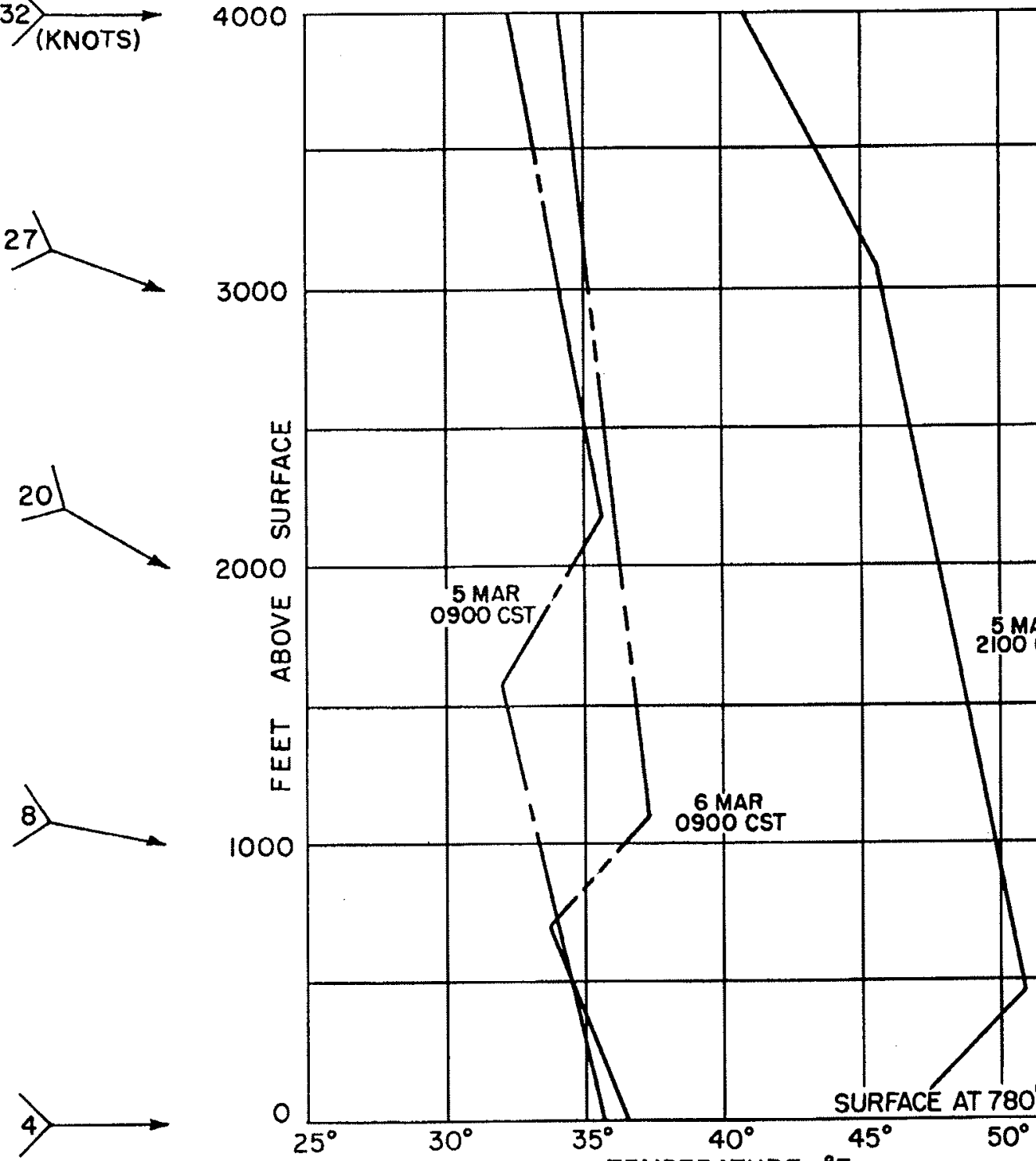

3000

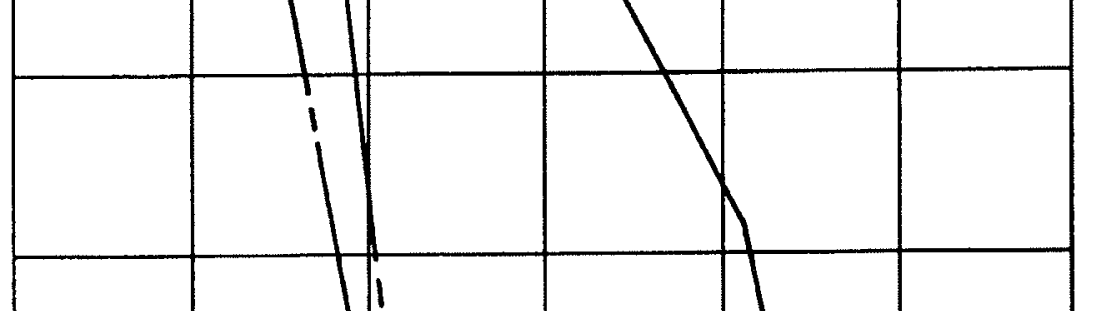

岕
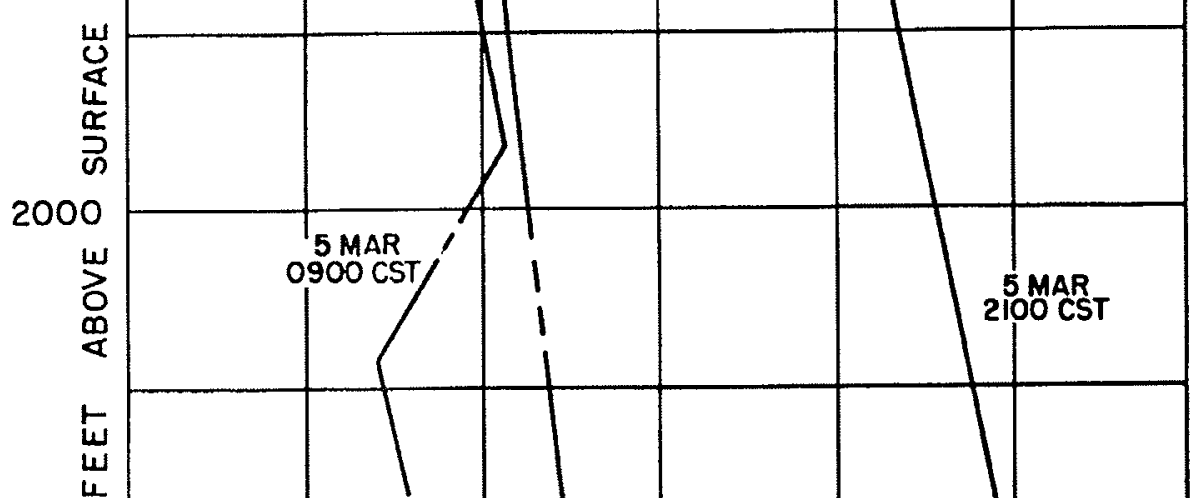
SUMMARY OF REGIONAL AND IOCAL WEATHER

Survey M-1024, 5 March 1953

Synoptic Situation:

Just north of St. Louis a weak stationary front was oriented east-west. Nearly clear skies prevailed to the south of the front, while light snow was falling from 100 - 200 miles to the north. High pressure dominated the Southeastern U.S. with central pressure of $1027 \mathrm{mb}$ in the vicinity of Montgomery. An inactive low of $1015 \mathrm{mb}$ was located over northern Texas. A strong polar high of $1036 \mathrm{mb}$ was pushing southward through the Dakotas. Surface wind flow at st. Louis was west-southwest $8-12 \mathrm{mph}$. Wind flow at $700 \mathrm{mb}$ was westerly at $45 \mathrm{mph}$.

Weather Reports from Lambert Field (St. Louis Airport)

\begin{tabular}{|c|c|c|c|c|c|c|c|c|c|c|}
\hline \multirow[b]{2}{*}{$\begin{array}{l}\text { Time } \\
\text { CST }\end{array}$} & \multirow[b]{2}{*}{$\begin{array}{l}\text { Cloud } \\
\text { Height } \\
\text { (feet) }\end{array}$} & \multirow[b]{2}{*}{$\begin{array}{l}\text { Sky\% } \\
\text { Cover }\end{array}$} & \multirow[b]{2}{*}{$\begin{array}{l}\text { Visibility } \\
\text { (miles) }\end{array}$} & \multirow[b]{2}{*}{ Weather** } & \multirow[b]{2}{*}{$\begin{array}{l}\text { Temp } \\
\left(\mathrm{O}_{\mathrm{F}}\right) \\
\end{array}$} & \multirow[b]{2}{*}{$\begin{array}{l}\text { Dew } \\
\text { Point }\end{array}$} & \multicolumn{4}{|c|}{ Wind } \\
\hline & & & & & & & $\begin{array}{l}\text { Airp } \\
\text { Dir }\end{array}$ & $\begin{array}{l}\text { port } \\
\text { Speed } \\
\text { (mph) } \\
\end{array}$ & $\begin{array}{l}\text { Uni } \\
\text { Dir }\end{array}$ & $\begin{array}{l}\text { Spersity } \\
\text { (mph) } \\
\end{array}$ \\
\hline 1830 & 12000 & Scattered & 4 & Smoke & 48 & 35 & ESE & 8 & - & - \\
\hline 1930 & & clear & 5 & Smoke & 47 & 36 & $\mathrm{SE}$ & 8 & SW & 7 \\
\hline 2030 & & Clear & 6 & Smoke & 46 & 36 & $\mathrm{SE}$ & 7 & $S$ & 2 \\
\hline 2130 & & Clear & 8 & & 47 & 35 & $s$ & 9 & SW & 3 \\
\hline 2230 & & clear & 8 & & 46 & 34 & $W$ & 8 & - & - \\
\hline 2330 & & Glear & 10 & & 43 & 34 & $W$ & 9 & - & - \\
\hline \multicolumn{11}{|c|}{ * Average cloudiness sunrise to sunset (Lambert Field) } \\
\hline \multicolumn{11}{|c|}{ ** And/or restriction to visibility } \\
\hline \multicolumn{11}{|c|}{ Sea level pressure (Lambert Field $2130 \mathrm{CST}$ ) : $1018.1 \mathrm{mb}$} \\
\hline \multicolumn{11}{|c|}{ Ground Condition: Bare and dry } \\
\hline Tree & cover: & are & & & & & & & & \\
\hline
\end{tabular}




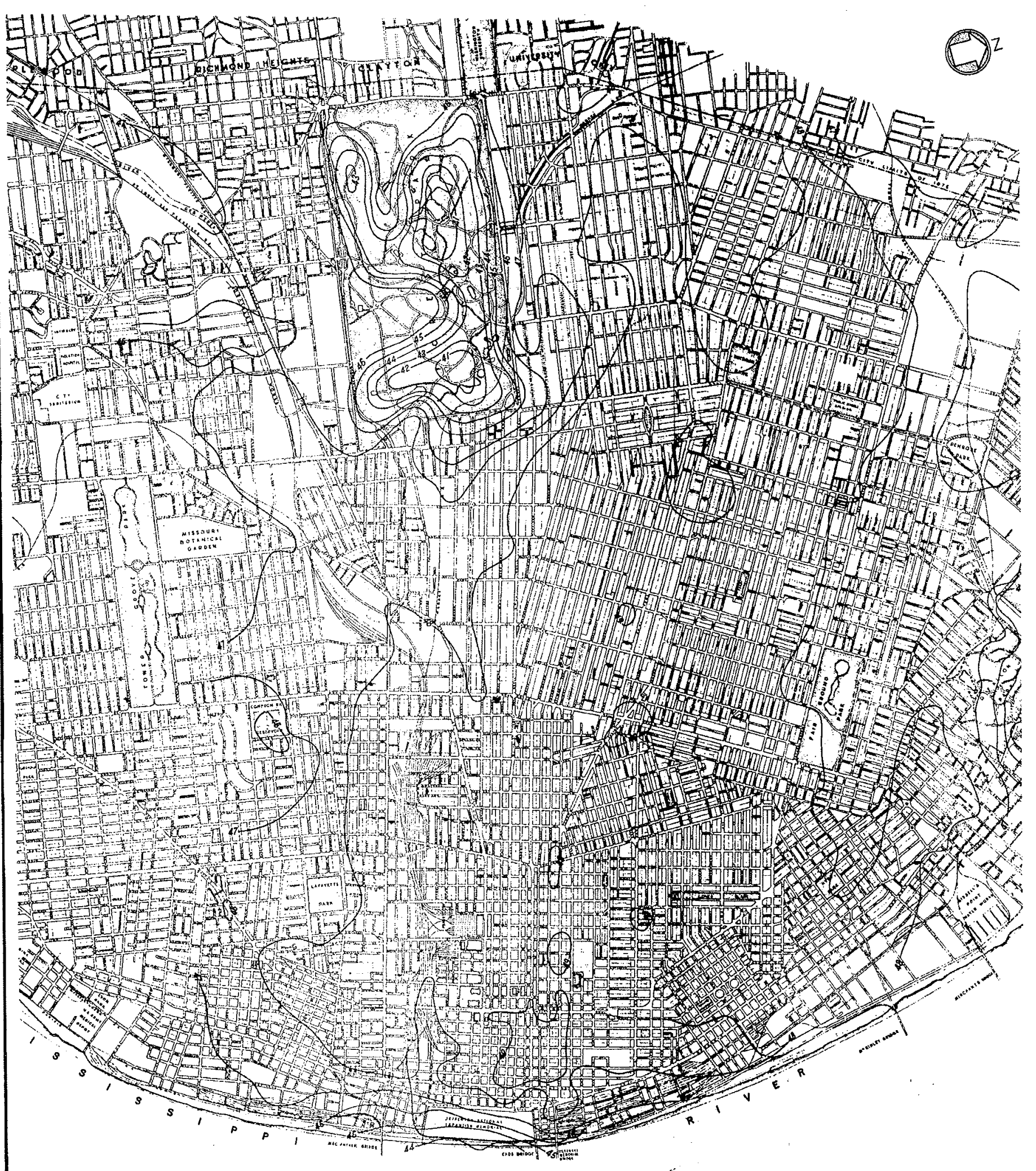




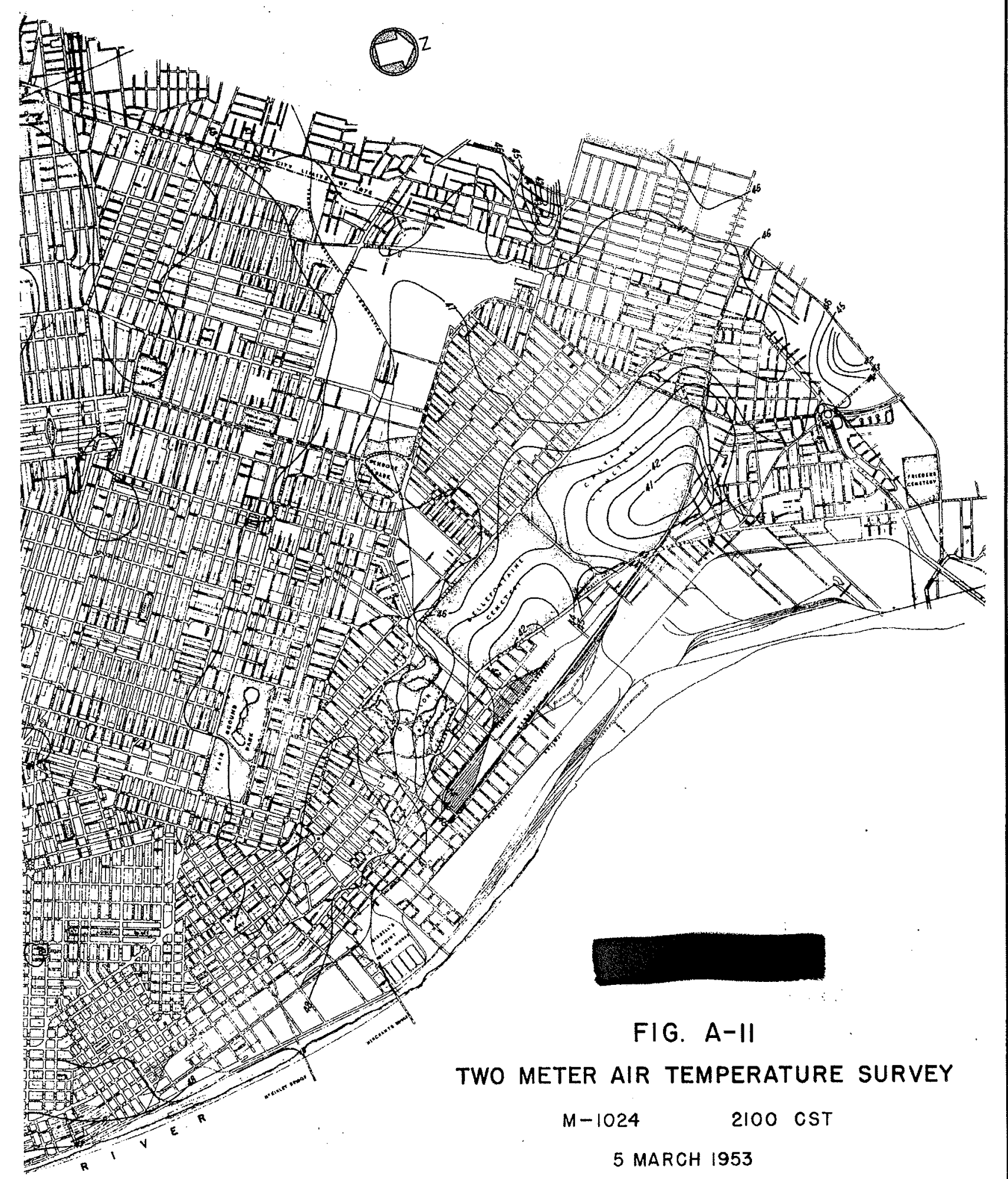

PAGE 174 
Figure No.

B-1

B-2

$B-3$

$B-4$

$B-5$

$B-6$

$B-8$

B-9

$B-10$

$B-11$

B-12

B-13

FIELD TEST 0003

19 January 1953

Page No.

Two Meter Air Temperature Survey, M-35, and Summary of Reglonal and Local Weather

177

Temperature Soundings, st. Cloud Raob, M-35

178

Temperature Soundings, Minneapolis Residential

Wiresonde, $M-35$

Dosage-Area Relationship, FT 0003

Test Array and Results, FT 0003a

Test Array and Results, FT 0003b

FIELD TEST $00 \mathrm{O}_{4}$

21 Jamary 1953

Two Meter Air Temperature Survey, M-36, and Summary of Regional and Local Weather

Termerature Soundings, St. Cloud Rzob, M-36

184

Temperature Soundings, Rinneapolis Residential Wiresonde, M-36

Dosage-Area Relationship, FT 0004

Test Array and Results, FT $00 \alpha_{4 a}$

Test Array and Results, FT 0004b

Test Array and Results, FT 0004c

FIEID TEST 0008

3 February 1953:

B-14

Two Moter Air Temperature Survey, M-43, and Summary of Regional and Local Weather

190

$B-15$

Temperature Soundings, St. Cloud Raob, $\mathrm{M}-43$

191

$\mathrm{B}-16$

Temperature Soundings, Minneapolis Residential Wiresonde, $\mathrm{M}-43$

192

B-17 Dosage-Area Relationshtp, FT 0008 193

B-18

Test Array and Results, FT 0008a

194

B-19

Test Array and Results, FT $0008 \mathrm{~b}$

195

B-20
196

Page 175 
Figure No. FIEID TEST OOd

Two Meter Air Temperature Survey, K-46, and Summary of Regional and Iocal Weather

Temperature Soundings, St. Cloud Raob, $M-46$

B-23 Temperature Soundings, Minneapolis Residential Wiresonde, $\mathrm{M}-46$

$B-24$

Dosage-drea Relationshtp, FT 0009

200

B-25

Test Array and Results, FT 0009a

201

B-26

Test Array and Reșults, FT 0009b

202

Test Array and Results, FT 0009c

203

FIELD TEST 0010

11 - 12 February 1953

Tro Meter dir Temperature Survey, 4-47, and Summary of Regional and Iocal Weather

204

B-29

Temperature Soundings, St. Cloud Raob, $\mathrm{K}-47$

205

B-30 Temperature Soundings, Minneapolis Residential

Wiresonde, $\mathrm{M}-47$

Dosage-Area Relationship, FT 0010

207

B-32

Test Array and Results, FT $0010 \mathrm{a}$

208

B-33

Test Array and Results, FT OOlOb

209

B-34

Test Array and Results, FT 0010c

210

$B-35$

Test Array and Results, FT 0010d

211

FTELD TEST 0011

15 February 1953

B-36 Two Meter Air Temperature Survey, M-49, and Summary of Regional and Local Weather

Temperature Soundings, St. Cloud Raob, $\mathrm{M}-49$

Temperature Soundings, Minneapolis Residential Wiresonde, $\mathrm{K}-49$ 


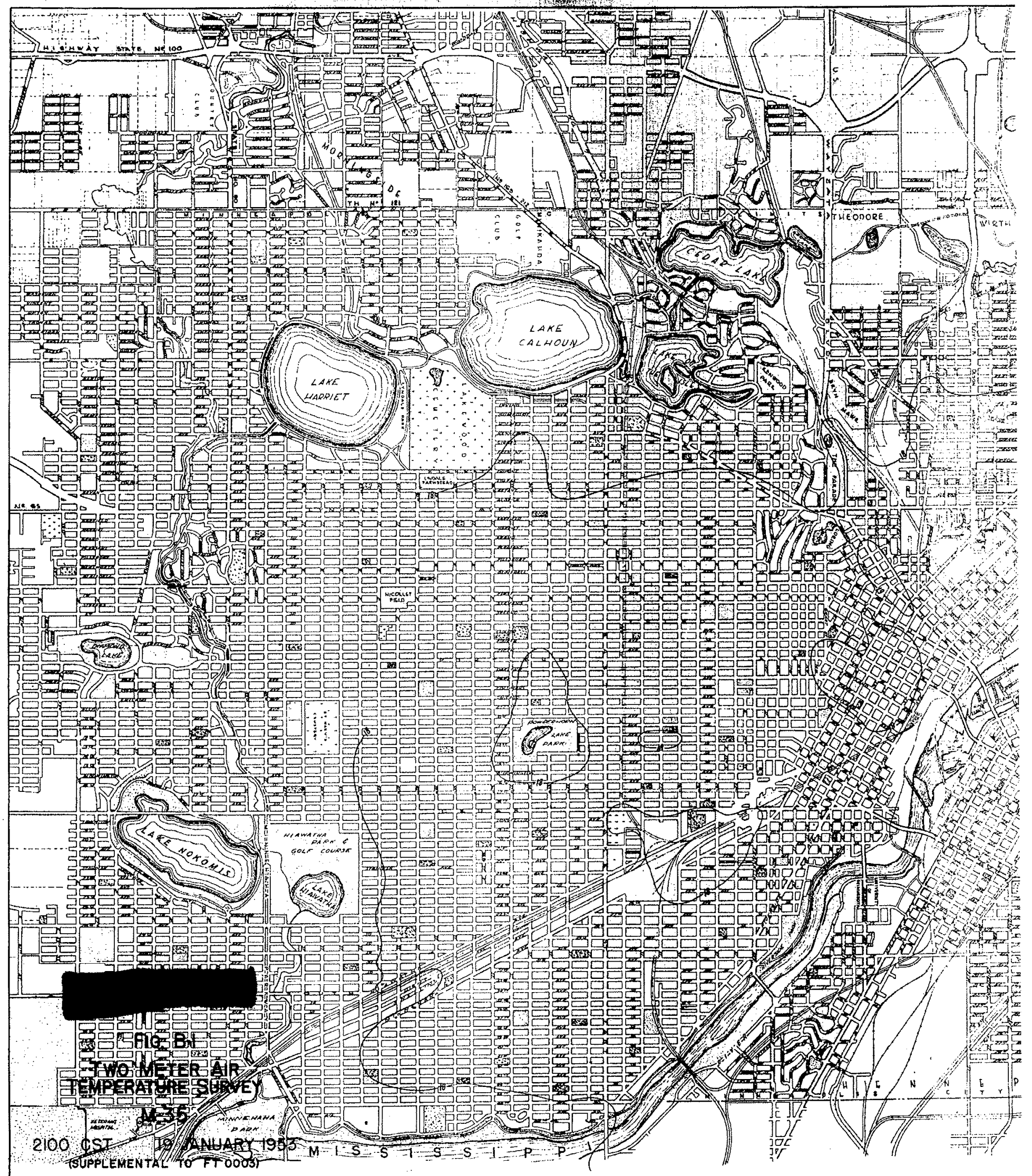

PAGE 177 


\section{REGRADED UNCCASSIFIED - JOD,DPG}
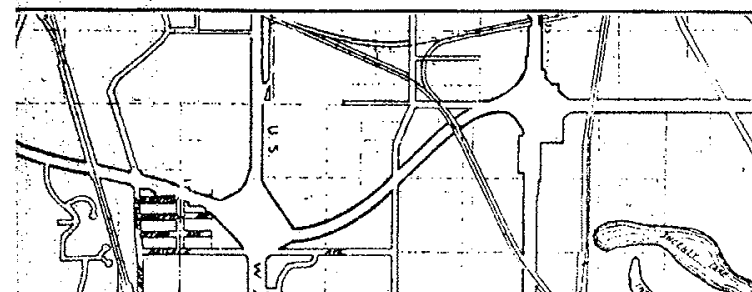

Sol con
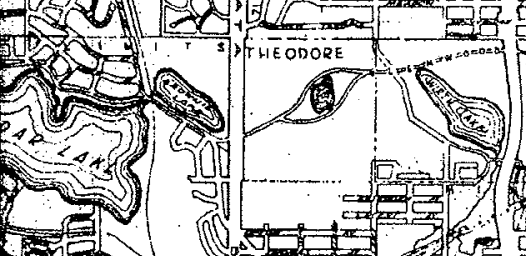

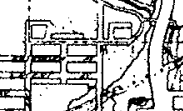

Non

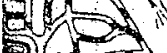

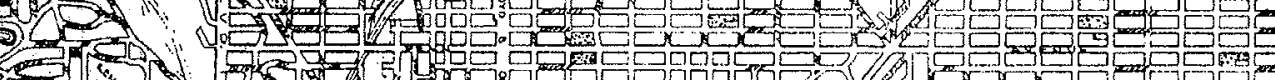

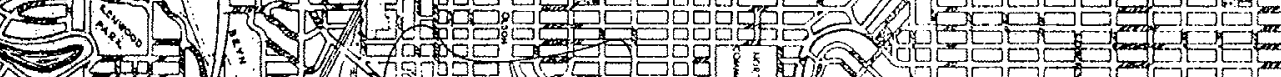

Socos

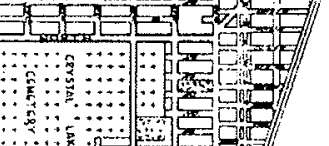

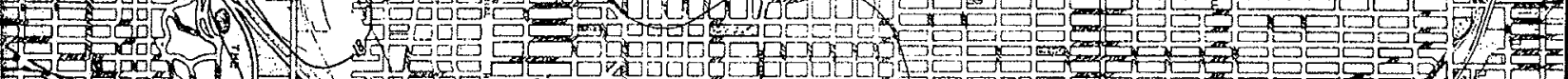

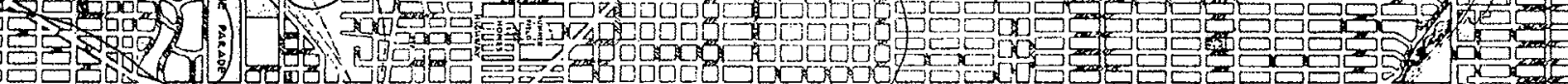

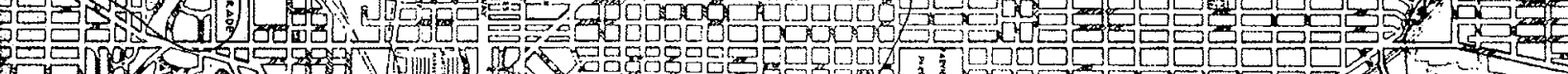

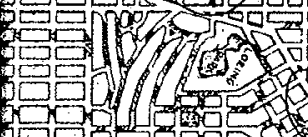

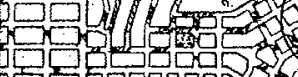

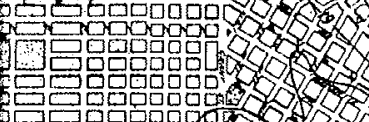
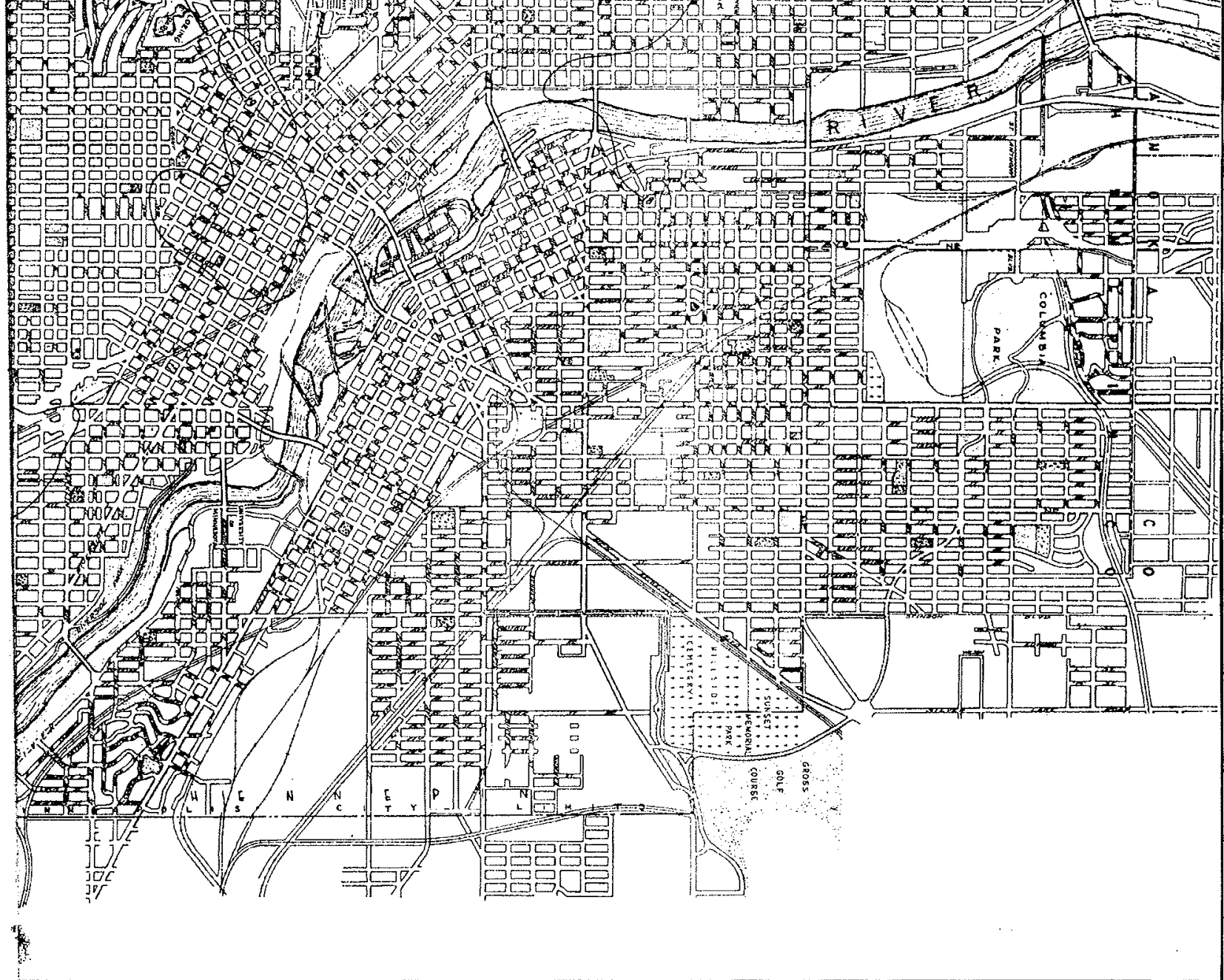

PART 2 of 3 
SUMMARY OF REGIOIAL AND LOCAL WEATHER

FT 0003 Survey M-35 19 Jan 1953

\section{Symoptic Situation}

A cold front lay some 400 miles to the south of Minneapolis through southern Missouri and Indiana. Snow flurries had occurred at Minneapolis and surroundings several hours before test time. An artic high cell of $1025 \mathrm{mb}$ was centered approximately 400 miles to the northeast of International Falls. The nearest major low pressure area was inactive. It was located in eastern Texas with central pressure of $1006 \mathrm{mb}$. Surface wind flow was northerly at 8 to $12 \mathrm{mph}$. The air flow at the $700 \mathrm{mb}$ level was from the west-northwest at $35 \mathrm{mph}$.

Weather Reports from Wold Chaniberlain Field (Minneapolis)

\begin{tabular}{|c|c|c|c|c|c|c|c|c|}
\hline & Cloud & & & & & & & ind \\
\hline $\begin{array}{l}\text { Time } \\
\text { CST }\end{array}$ & $\begin{array}{l}\text { Height } \\
\text { (feet) }\end{array}$ & $\begin{array}{r}\text { Sky\% } \\
\text { Cover } \\
\end{array}$ & $\begin{array}{c}\text { Visibility } \\
\text { (miles) }\end{array}$ & Weatheris & $\begin{array}{l}\text { Temp } \\
(\mathrm{O} F)\end{array}$ & $\begin{array}{l}\text { Dew } \\
\text { Point }\end{array}$ & Dir & $\begin{array}{l}\text { Speed } \\
\text { (nph) }\end{array}$ \\
\hline 1830 & 2100 & $\begin{array}{l}\text { Over- } \\
\text { cast }\end{array}$ & 7 & & 19 & 14 & $\mathrm{N}$ & 10 \\
\hline 1930 & 1900 & $\begin{array}{l}\text { Over- } \\
\text { cast }\end{array}$ & 10 & & 18 & 13 & $\mathrm{~N}$ & 10 \\
\hline 2030 & 1600 & $\begin{array}{l}\text { Over- } \\
\text { cast }\end{array}$ & 10 & & 18 & 13 & $\mathrm{~N}$ & 10 \\
\hline 2130 & 1500 & $\begin{array}{l}\text { Over- } \\
\text { cast }\end{array}$ & 10 & & 18 & 12 & $\mathrm{~N}$ & 8 \\
\hline 2230 & 1600 & $\begin{array}{l}\text { Over- } \\
\text { cast }\end{array}$ & 10 & & 18 & 12 & NNE & 8 \\
\hline 2330 & 1500 & $\begin{array}{l}\text { Over- } \\
\text { cast }\end{array}$ & 12 & & 18 & 12 & NNE & 10 \\
\hline
\end{tabular}

Sea level pressure at $2130 \mathrm{CST}: 1018.6 \mathrm{mb}$ Ground condition: Conplete coverage 6" snow pack Lakes frozen with snow Tree cover: None cover

* Average cloudiness sunrise to sunset: $100 \%$

* and/or restrictions to visibility 
FIGURE B-2

TEMPERATURE SOUNDINGS

(KNOTS) $\begin{gathered}13 \quad \begin{array}{l}\text { WINDS ALOFT } \\ \text { ST CLOUD } \\ 19 \text { JAN } 1953 \\ 2100 \mathrm{CST}\end{array} \\ 4000\end{gathered}$

ST CLOUD RAOB 19 JAN 1953

(SUPPLEMENTALTO SURVEY M-35)

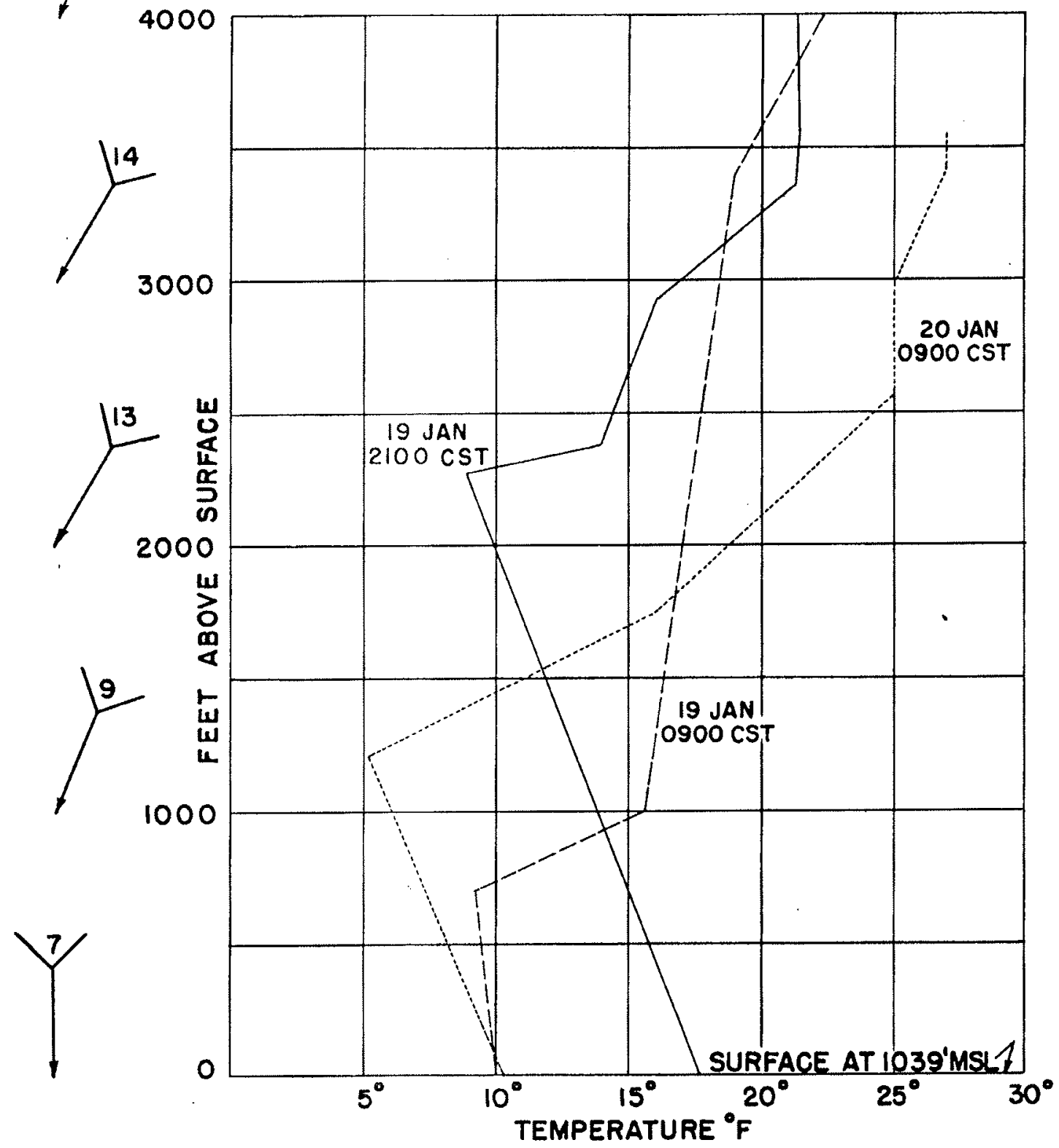

PAGE 178 

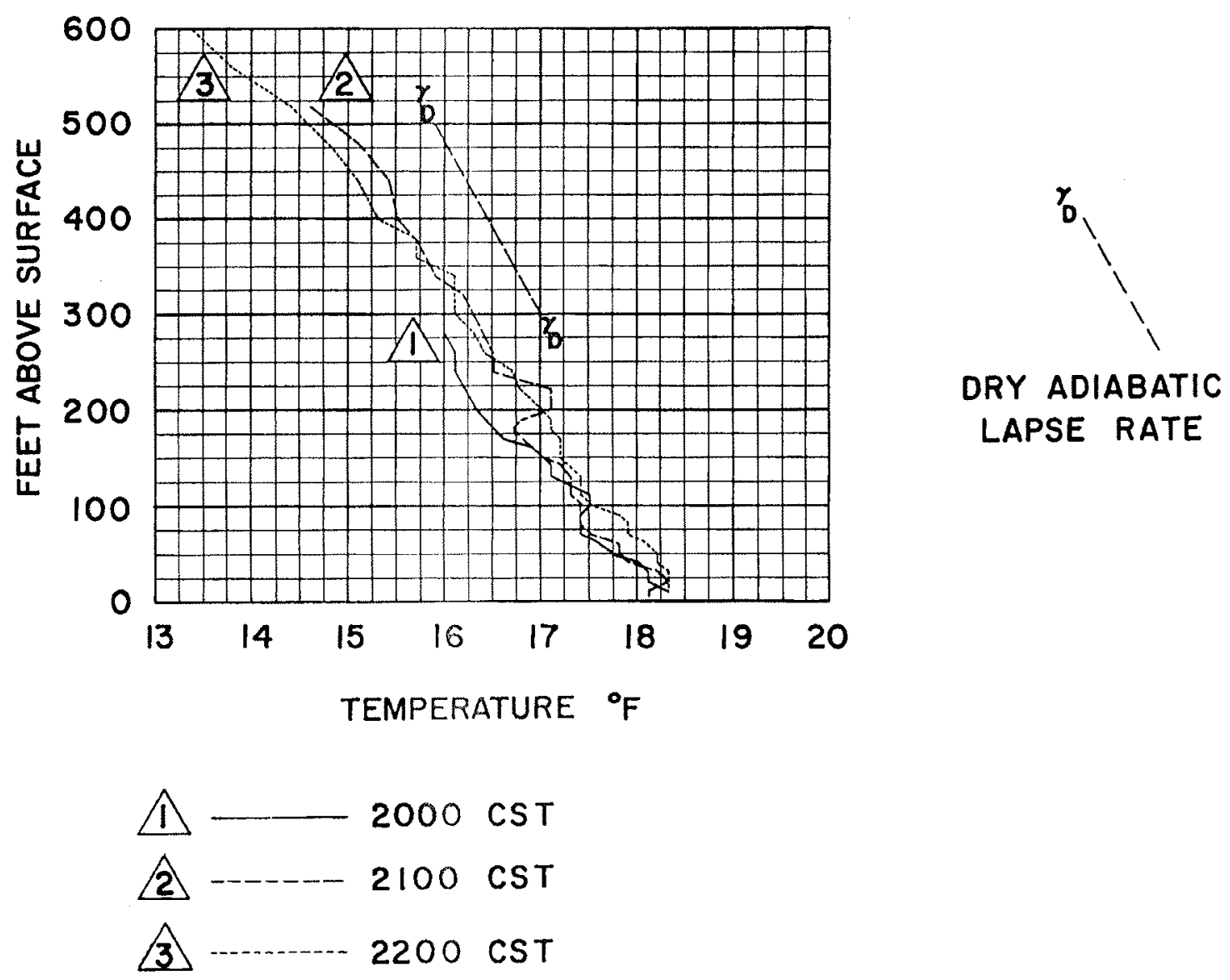

FIGURE B-3

TEMPERATURE SOUNDINGS MINNEAPOLIS RESIDENTIAL WIRESONDE SURVEY M-35 19 JAN. 1953

PAge 179 


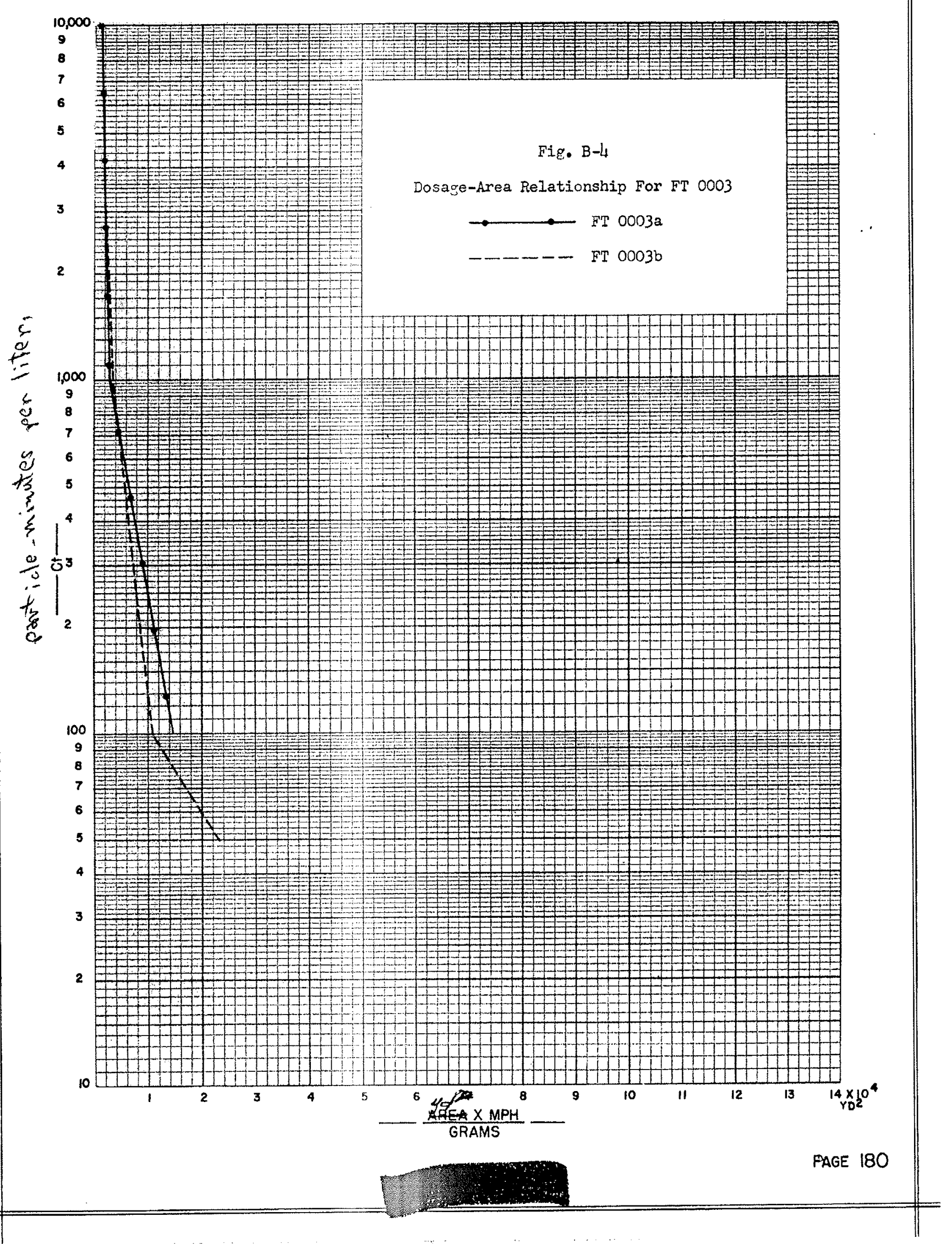




\section{AEROSOL GENERATION}

Point-source release of 7.7 gris of $\mathrm{NJZ} 2266$ over a period of 5 minutes starting at 2032 CST from a vehiclemounted blower disperser located at point 14

\section{SAMPL ING}

\section{Location and Exposure}

Kembrane-filter sampling equipment located at 40 stations as show on test-array map by following symbols:

Outdoor sampler at height between 1 and 6 feet.

Outdoor sampler at helght above or below general terrain level as indicated by note.

$O$ Indoor sampler at location indicated by test-array map or text.

Results

AII samplers operated to measure total dosages.

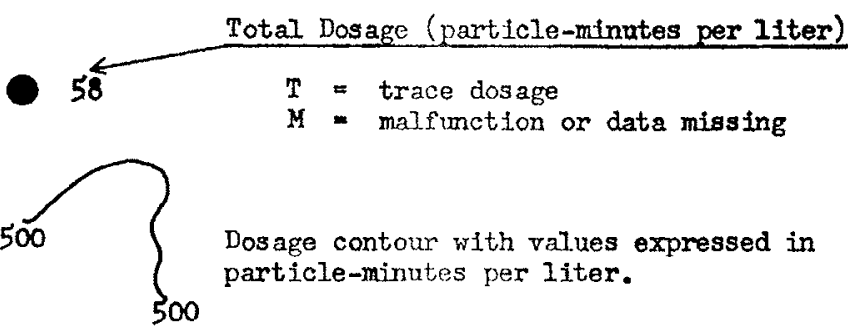

\section{METEOROLOGY}

\section{Equipment and Measurement}

At street level, wind direction continuously recorded, and air and surface temperatures, wind veloeity, and other meteorological observations taken at stations designated as (MI) and (M2).

Similar observations at rooftop level ( 35 feet above surface) and wiresonde ascents made at meteorological station (13) .

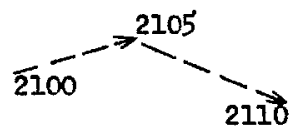

Virtual wind track, the length (drawn to map scale) and direction of each arrow representing the virtual wind travel between the times indicated.

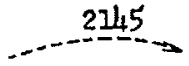

Balloon track representing wind-drift observation at the time indicated.

Winds

Estimated roof-level winds westerly at $2-3 \mathrm{mph}$; street-level winds northwesterly at $2.2 \mathrm{mph}$.

\section{Stability}

$2.2^{\circ} \mathrm{F}$ lapse from $6-300 \mathrm{ft}$.

$\underline{\text { Sky }}$

Overcast low clouds with base $1600 \mathrm{ft}$ above the surface.

Temperature

$18^{\circ} \mathrm{F}$ at 2 meters in the test area.

\section{Moisture}

Mixing ratio of $1.7 \mathrm{gra} / \mathrm{kgm}$ ary air. 

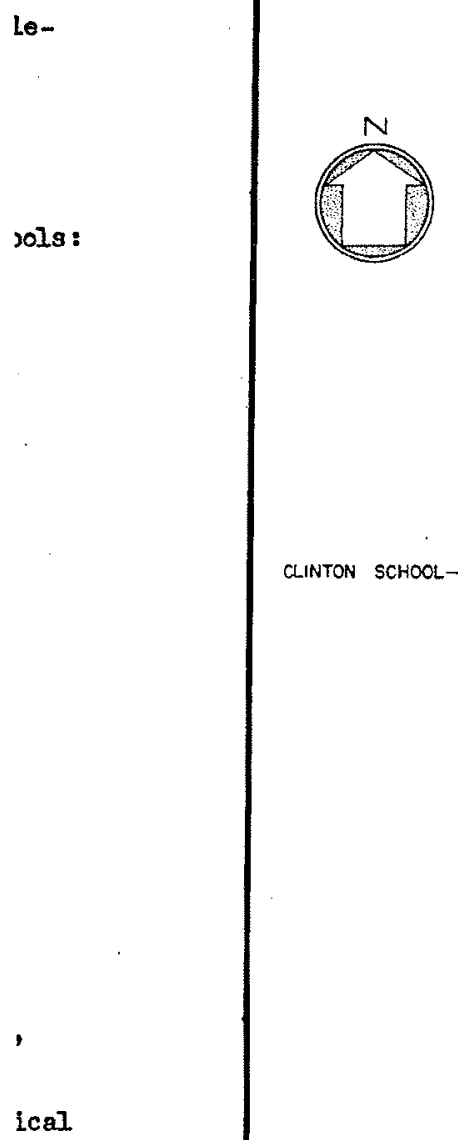

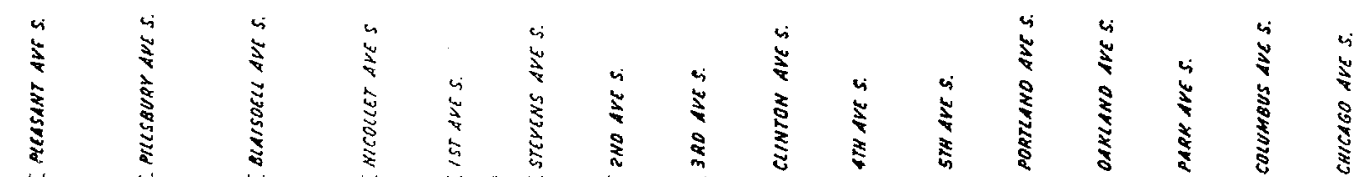

201s :

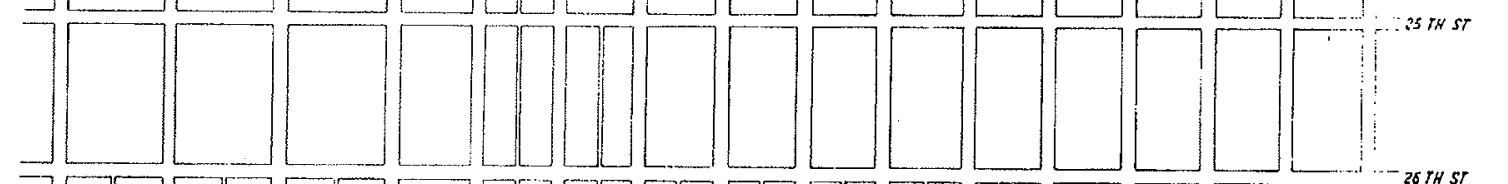

CLINTON SCHOOL
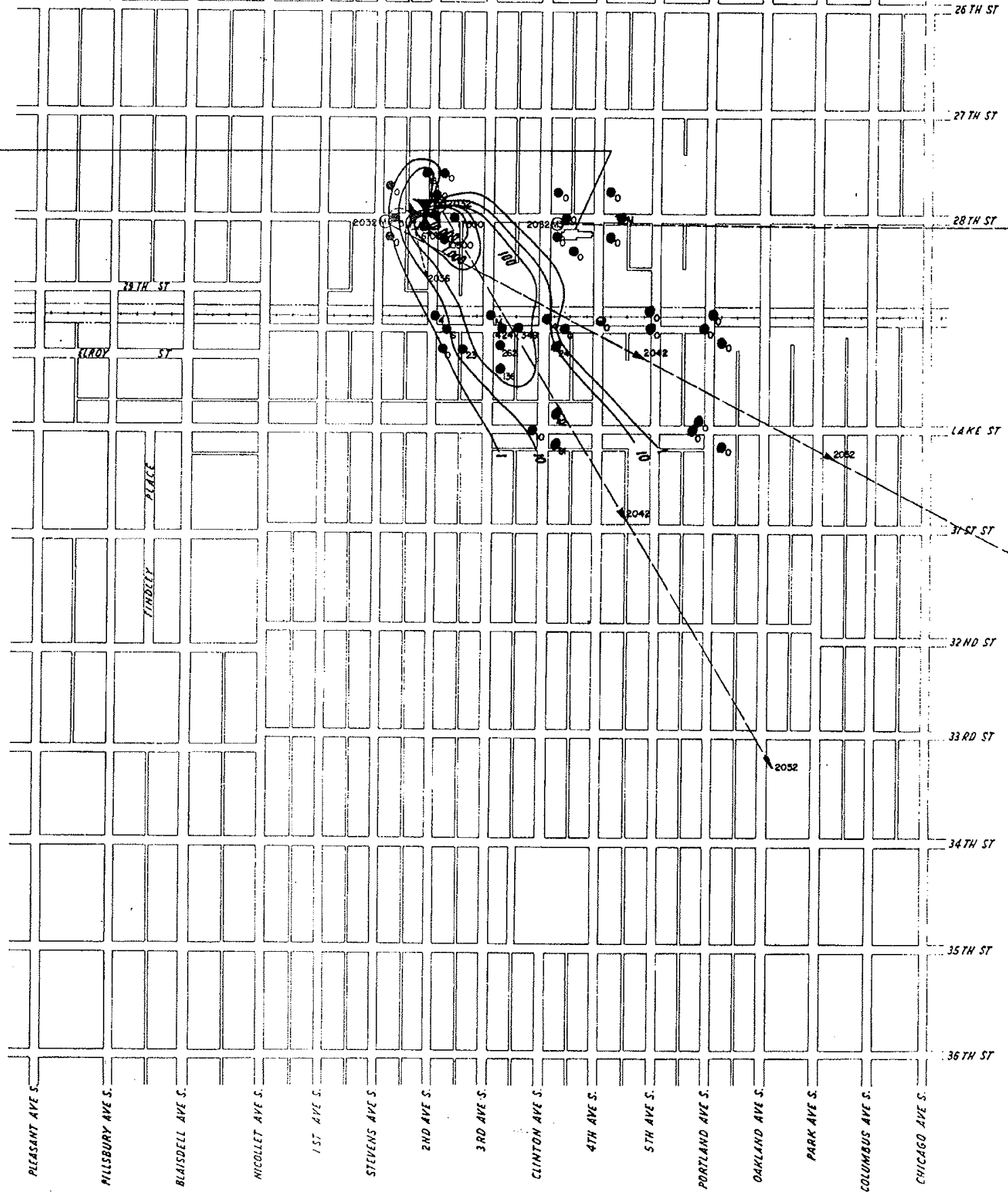

PART 2 of 3 


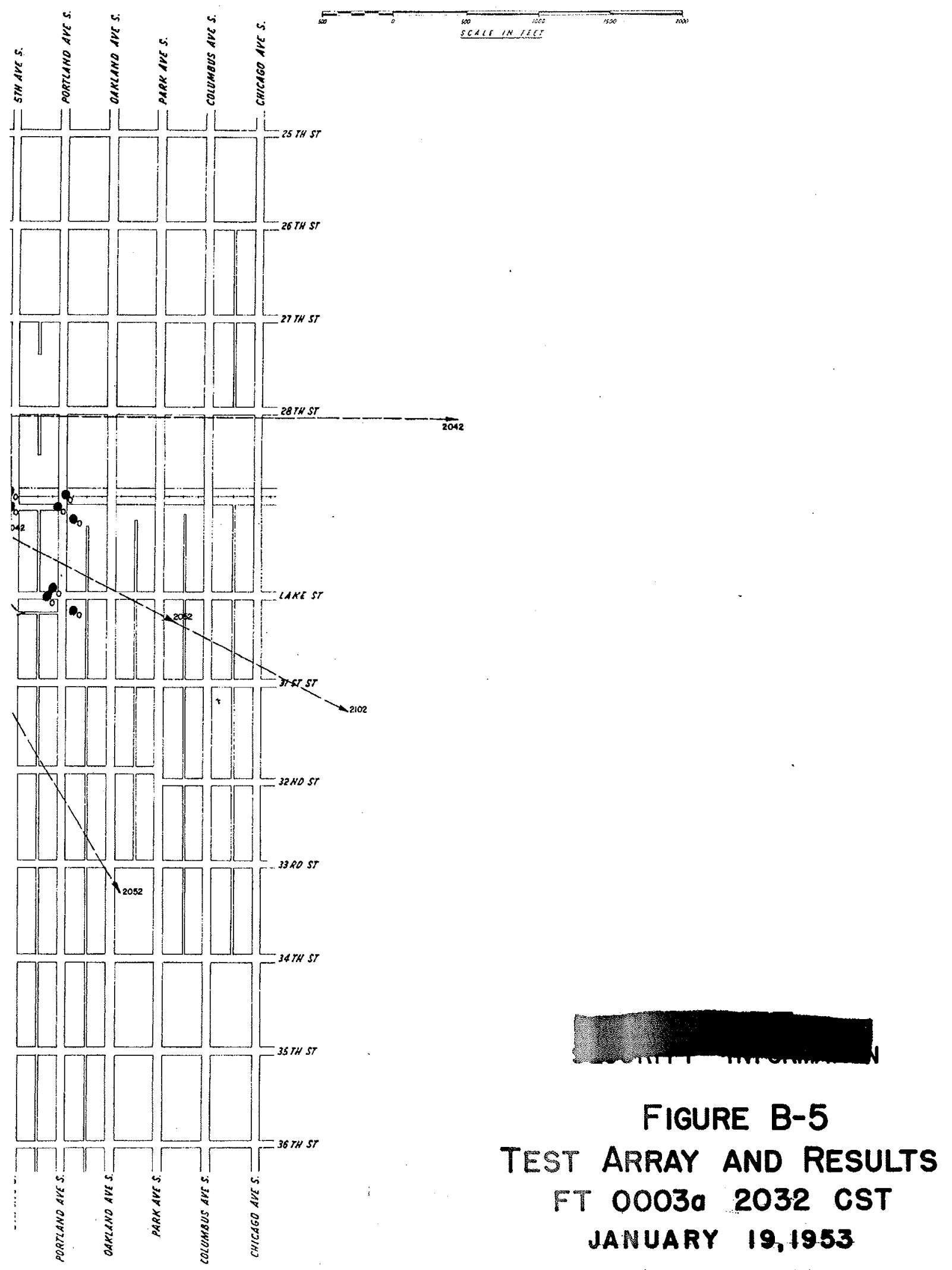

PAge 181 


\section{REGRADED UNCLASSIFTED - JOD,DPG}

AEROSOL GENERATION

Point-source release of 6.9 gms of $N J Z 2266$ over a period of 5 minutes starting at 2125 CST from a vehiclemounted blower disperser located at point

\section{SAMPLING}

Location and Exposure

Membrane-filter sampling equipment located at 40 stations as show on test-array map by following symbols:

Outdoor sampler at height between 1 and 6 feet.

Outdoor sampler at height above or below general terrain level as indicated by note.

0 Indoor sampler at location indicated by test-array map or text.

Results

All samplers operated to measure total dosages.
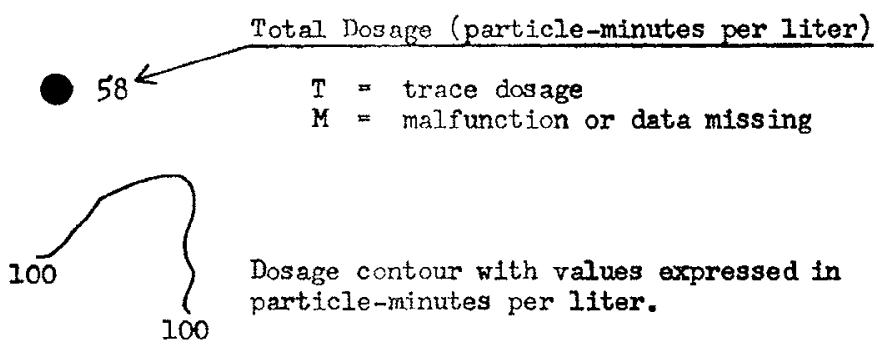

\section{METEOROLOGY}

Equipment and Measurement

At street level, wind direction continuously recorded, and air and surface temperatures, wind velocity, and other meteorological observations taken at stations designated as (M7) and (1/2)?

Similar obgervations at rooftop level ( 35 feet above surface) and wiresonde ascents made at meteorological station (M3) .

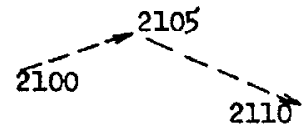

Virtual wind track, the length (drawn to map scale) and direction of each arrow representing the virtual wind travel between the times indicated.

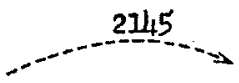

Balloon track representing wind-drift observation at the time indicated.

Winds

Estimated roof-level winds westerly at $2-3 \mathrm{mph}$; street-level winds northwesterly at $1.2 \mathrm{mph}$.

\section{Stability}

2.1. F lapse from 6-300 ft.

Skr

Orercast low clouds with base $1600 \mathrm{ft}$ above the surface.

Temperature

$28^{\circ} \mathrm{F}$ at 2 meters in the test area.

Moisture

Mixing ratio of $1.7 \mathrm{gm} / \mathrm{kgm}$ dry air. 


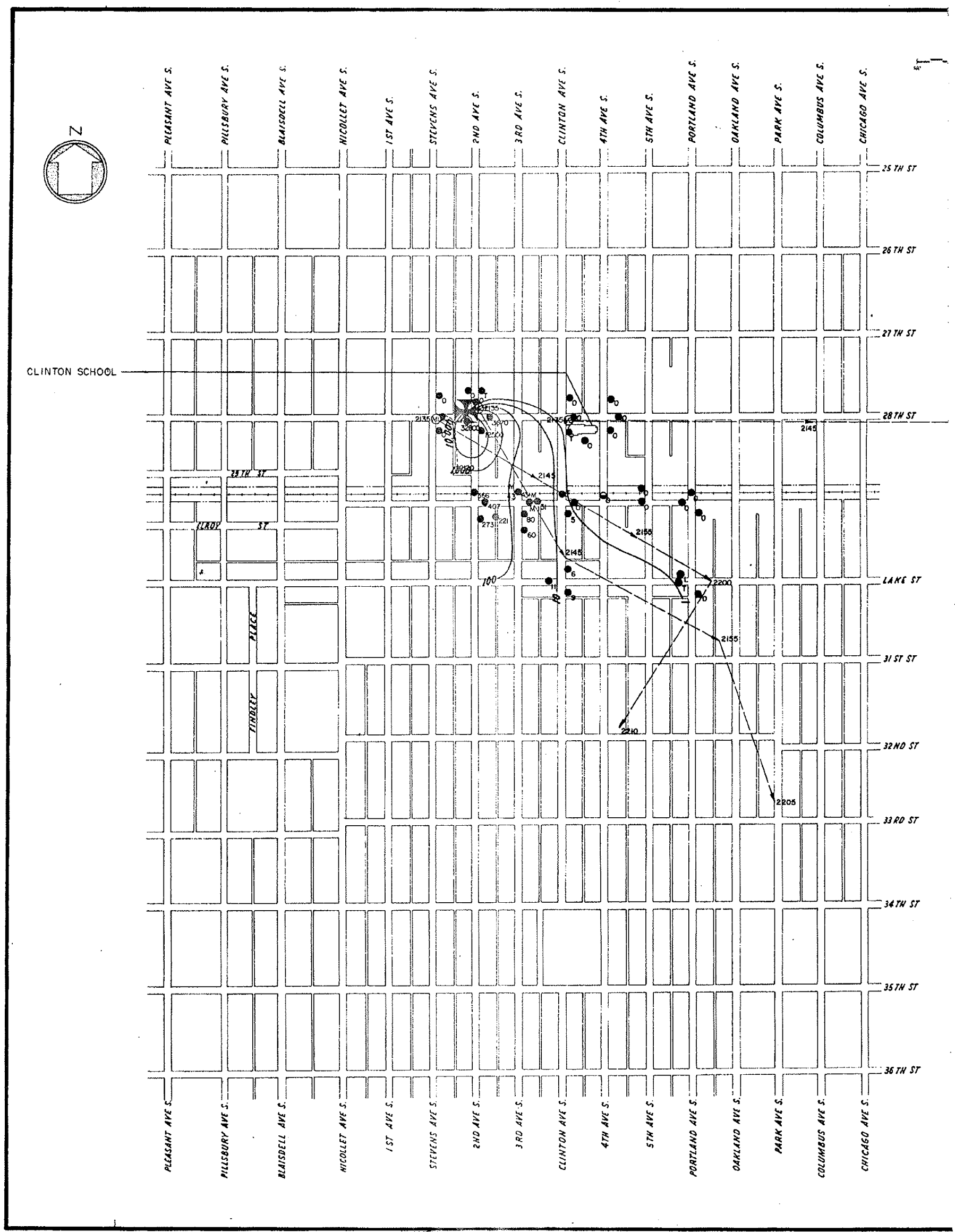

PART 2 of 3 

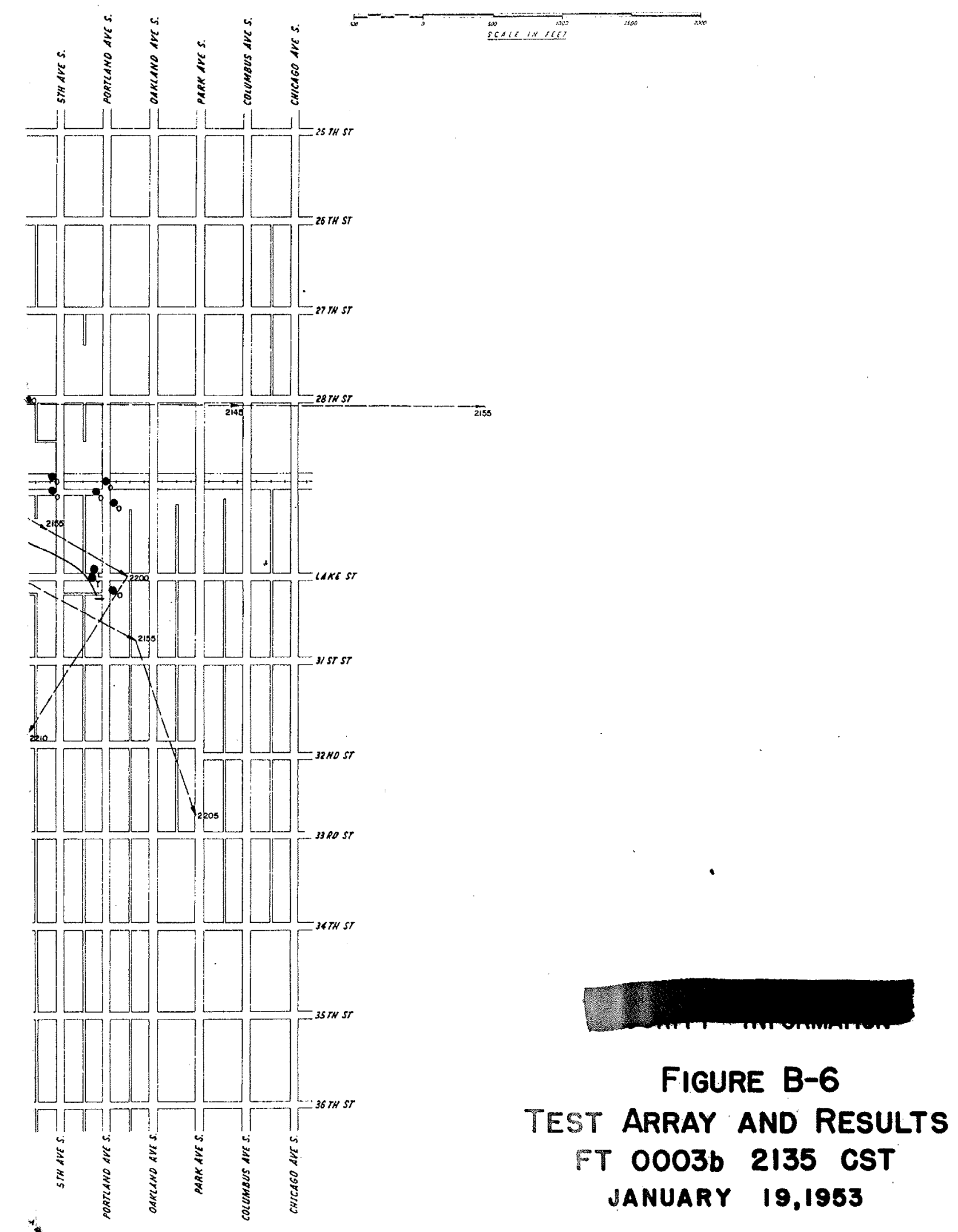

PAge 182 


\section{REGRADED UNCLASSTFIED - JOD,DPG}

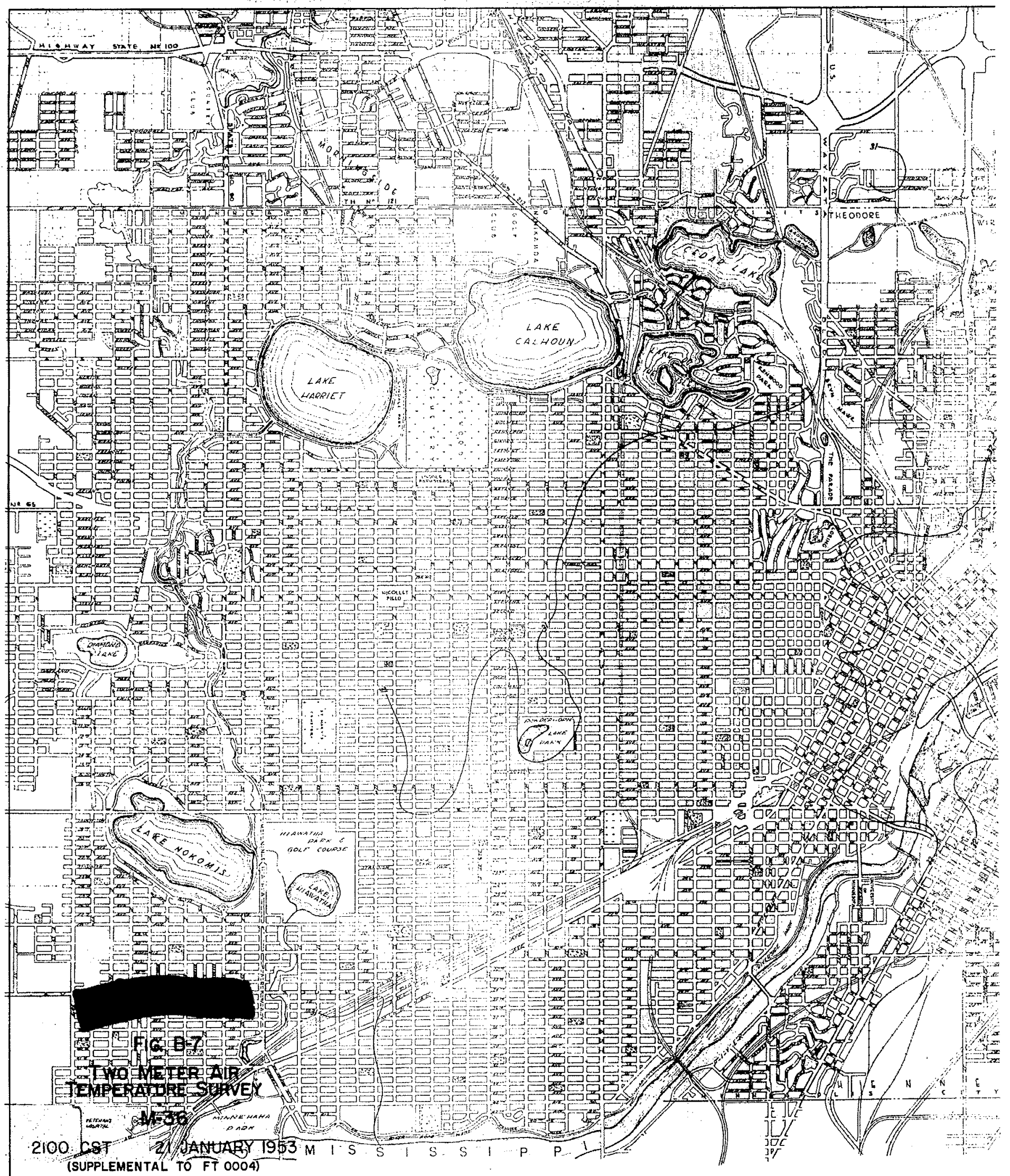

PAGE 183 


\section{REGRADED UNCLASSTFTED - JOD,DPG}

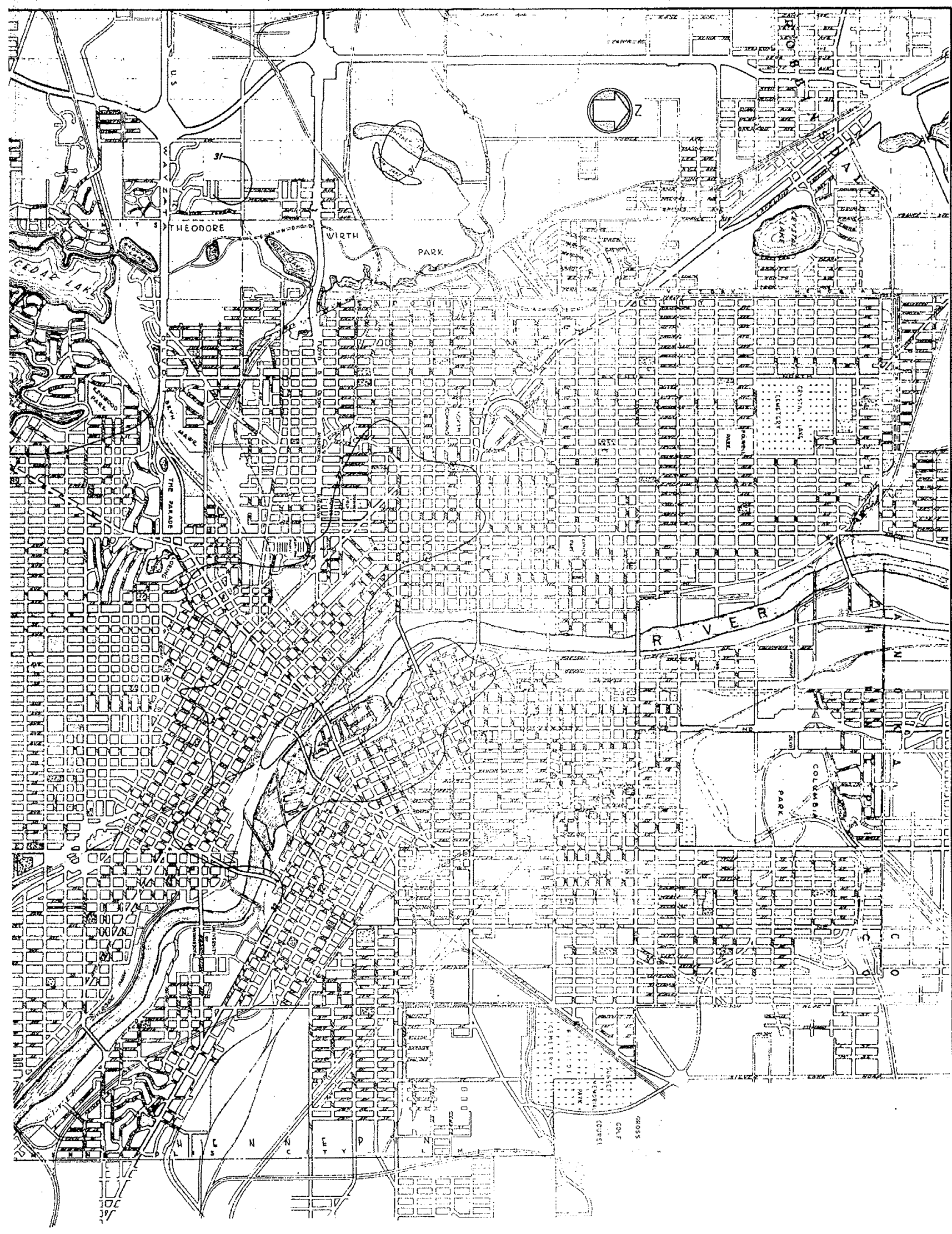


SUMMARY OF REGTONAL AND LOCAL WEATHER

FT 0004 Survey M-36 21 Jan 1953

\section{Symoptic Situation}

A weak semi-stationary front was oriented northeast - southwest just to the west of Minneapolis. This front was associated with a 1000 mb low center over northwestern Texas. Snow flurries generally accompanied this front. Surface flow was easterly at 8 to $12 \mathrm{mph}$. Air flow at 700 mb was southwesterly at 15 to $20 \mathrm{mph}$.

Weather Reports from Wold-Chamberlain Field (Minneapolis)

\begin{tabular}{|c|c|c|c|c|c|c|c|c|}
\hline & Cloud & & & & & & & nd \\
\hline $\begin{array}{l}\text { Time } \\
\text { CST }\end{array}$ & $\begin{array}{l}\text { Height } \\
\text { (feet) }\end{array}$ & $\begin{array}{l}\text { Skys } \\
\text { Cover }\end{array}$ & $\begin{array}{c}\text { Visibility } \\
\text { (miles) }\end{array}$ & Weather & $\begin{array}{l}\text { Temp } \\
\left({ }^{\circ} \mathrm{F}\right) \\
\end{array}$ & $\begin{array}{l}\text { Dew } \\
\text { Point } \\
\end{array}$ & Dir & $\begin{array}{l}\text { Speed } \\
\text { (mph) }\end{array}$ \\
\hline 1830 & 1200 & Over- & 3 & Fog & 30 & 28 & ESE & 6 \\
\hline 1930 & 1500 & over- & 5 & Fog & 30 & 29 & $\mathbf{E}$ & 11. \\
\hline 2030 & 1500 & $\begin{array}{l}\text { Brok- } \\
\text { en }\end{array}$ & 5 & Fog & 31 & 29 & ESE & 11 \\
\hline 2130 & 1300 & $\begin{array}{l}\text { Scat- } \\
\text { tered }\end{array}$ & 5 & Fog & 31 & 29 & ESE & 11 \\
\hline 2230 & 1300 & $\begin{array}{l}\text { Scat- } \\
\text { tered }\end{array}$ & 6 & Fog & 30 & 29 & ESE & 9 \\
\hline
\end{tabular}

Sea level pressure at 2130 CST: $1013.9 \mathrm{mb}$ Ground condition: 6" snow pack Ice and dirty snow on streets Lakes frozen and snow covered

Tree cover: None

* Average cloudiness sunrise to sunset: $100 \%$

** and/or restriction to visibility 
FIGURE B-8

TEMPERATURE SOUNDINGS

ST CLOUD RAOB 21 JAN 1953

WINDS ALOFT

ST CLOUD

(SUPPLEMENTALTO SURVEY M-36)

2 I JAN 1953

$2100 \mathrm{CST}$

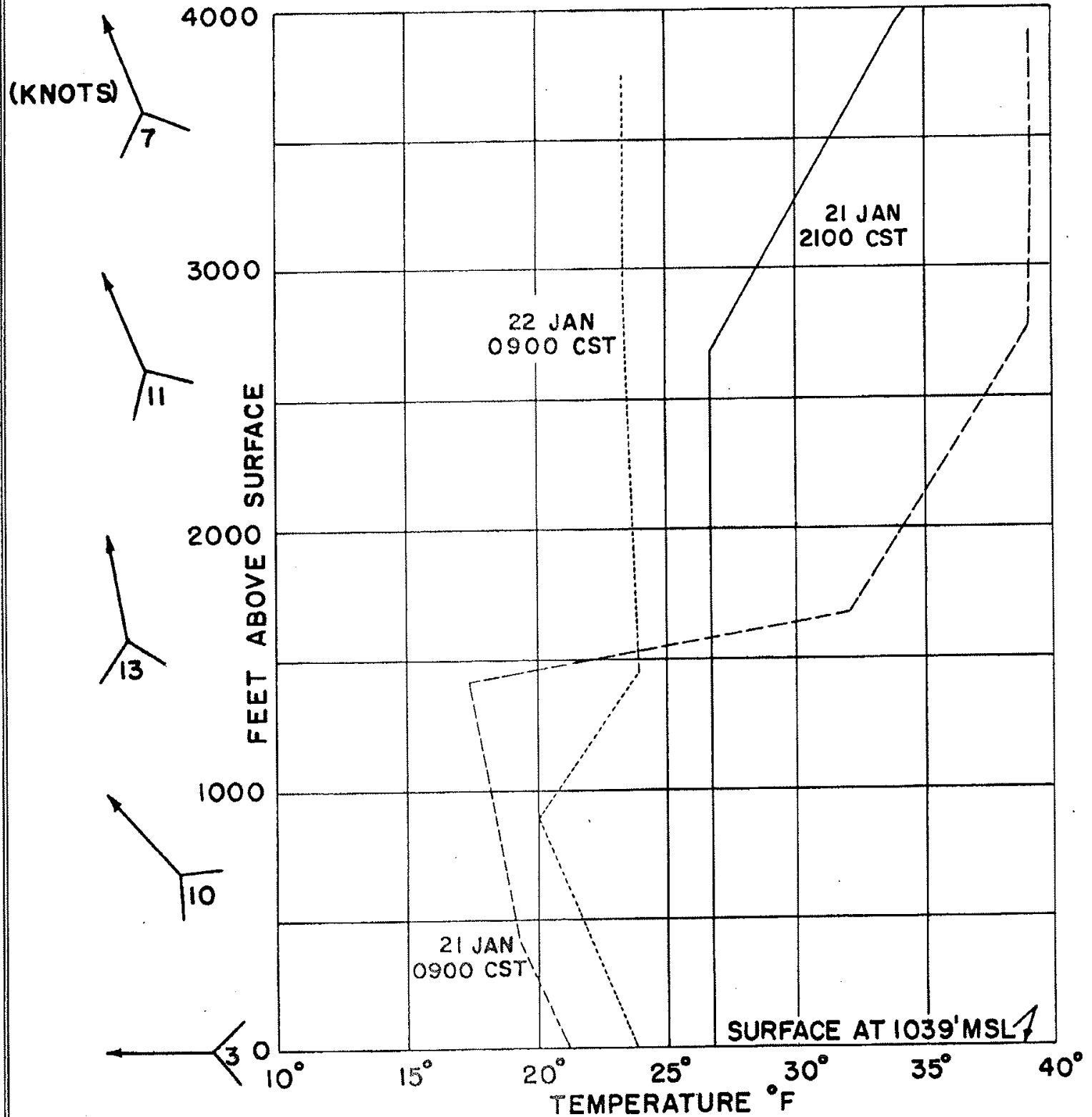




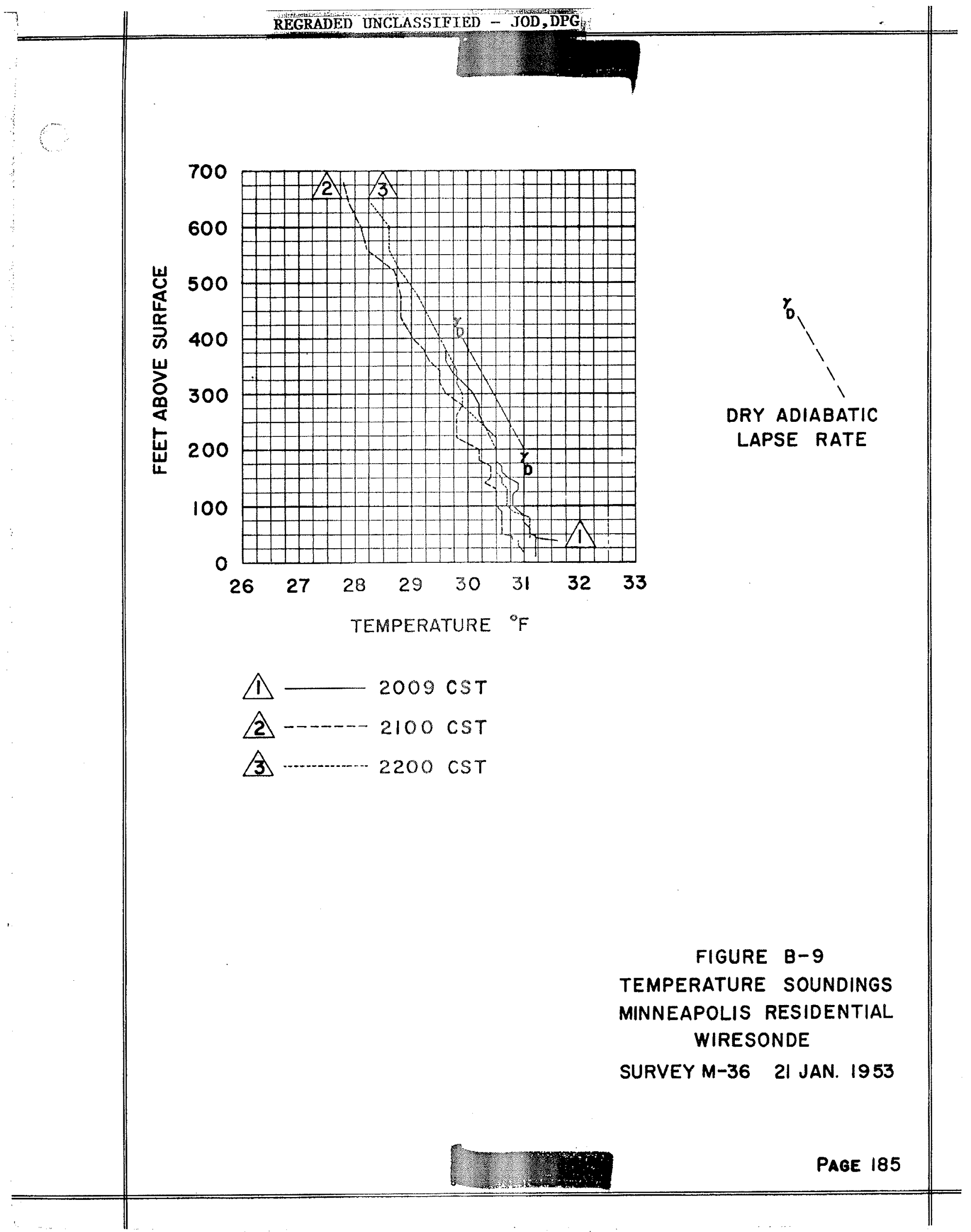




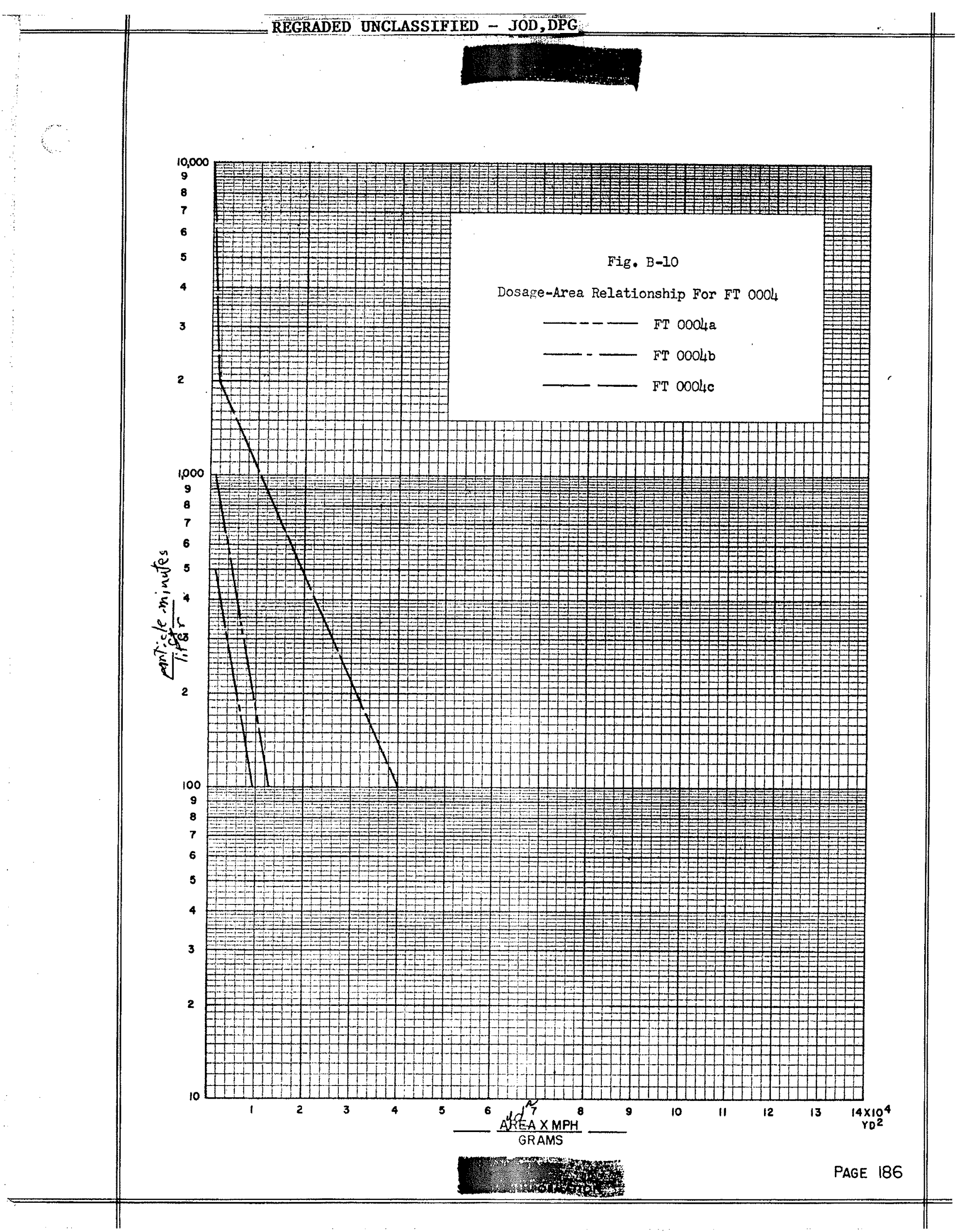


Point-source release of 5.8 gas of NJZ 2266 over a period of 5 minutes starting at 2010 CST from a vehiclemounted blower disperser located at point

\section{SAMPLING}

Location and Exposure

Membrane-filter sampling equipment located at 52 stations as show on test-array map by following symbols:

Outdoor sampler at height between 1 and 6 feet.

Q Outdoor sampler at height above or below general terrain level as indicated by note.

O Indoor sampler at location indicated by test-array map or text.

Results

All samplers operated to measure total dosages.

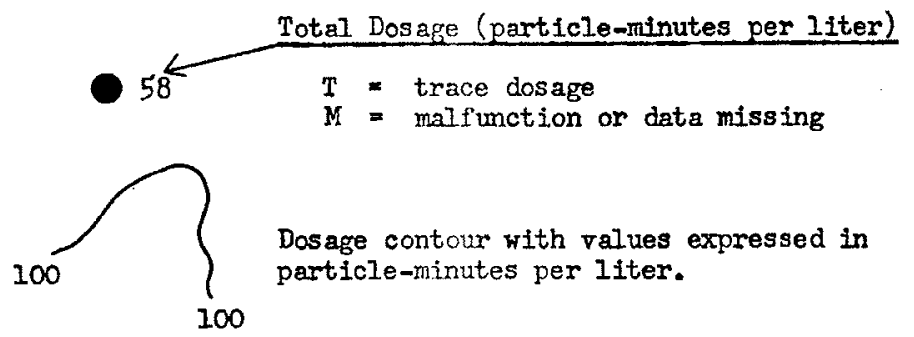

\section{METEOROLOCT}

Equipment and Mossurement

At street level, wind direction continuously recorded, and air and surface temperatyres, wind velocity, and other meteorological. observations taken at stations designated as (197) and.

Similar observations at rooftop level ( 35 feet above surface, at SW corner of the school building) and wiresonde ascents made at meteorological station (M3).

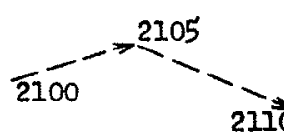

Virtual wind track, the length (drawn to map scale) and direction of each arrow representing the virtual wind travel between the times indicated.

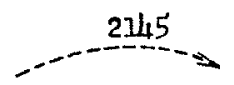

Balloon track representing wind-drift observation at the time indicated.

Winds

Roof-level winds easterly at $4.5 \mathrm{mph}$; street-level winds easterly at $2.0 \mathrm{mph}$.

\section{Stability}

I.1. F Iapse from $6-300$ ft.

\section{$\underline{s k}$}

The low overcast at $1930 \mathrm{CST}$, with base near $1500 \mathrm{ft}$ above surface, became broken at 2030 CST, then scattered at $2130 \mathrm{CST}$. A broken-to-overcast middle cloud deck with base 7,000 to 9,000 ft above the surface persisted thronghout the sampling period.

\section{Temperature}

$31^{\circ} \mathrm{F}$ at 2 meters in the test area.

\section{Notsture}

Mixing ratio of $3.4 \mathrm{gm} / \mathrm{kgm}$ dry air.

$\operatorname{PART} 1$ of 3 


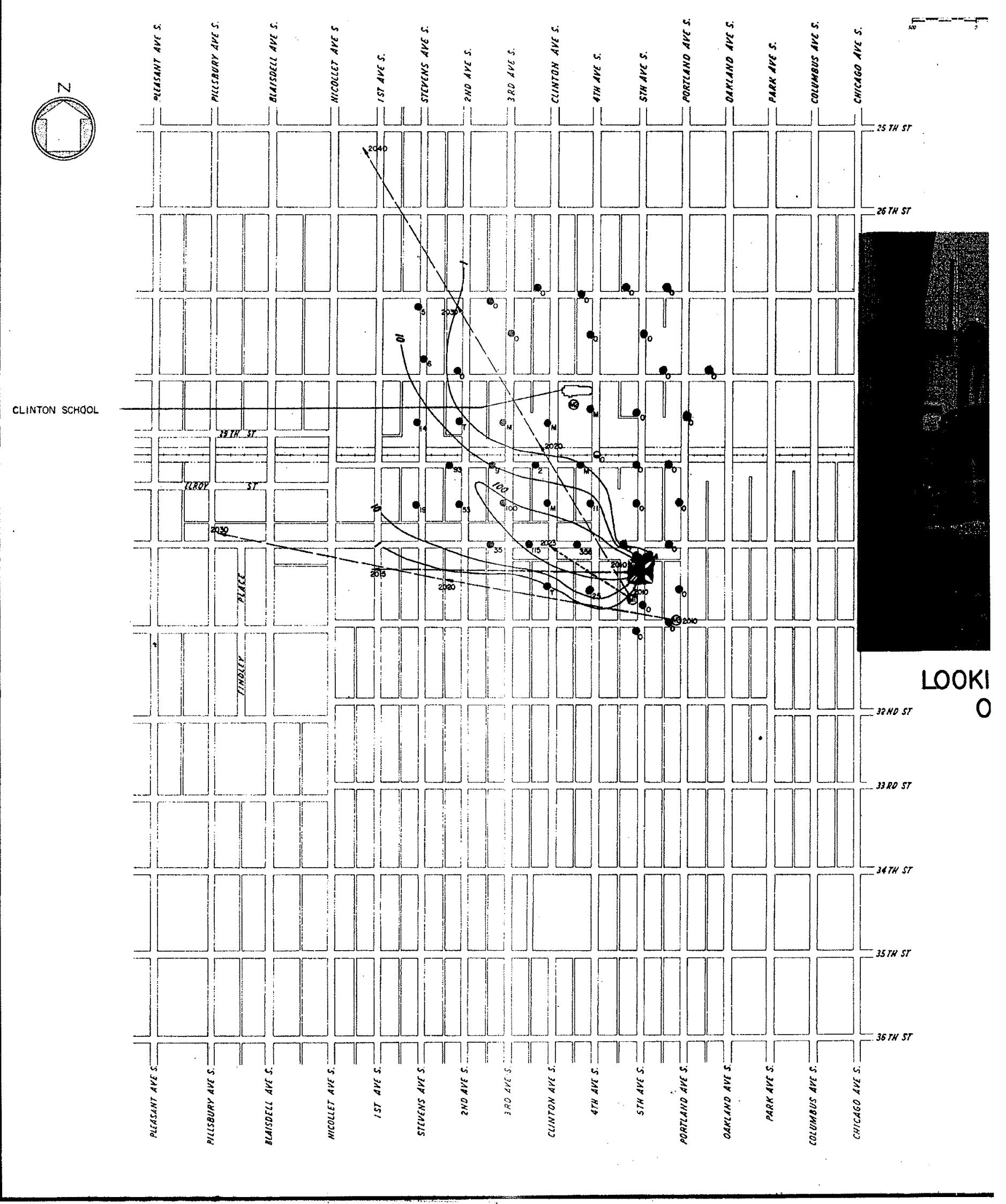




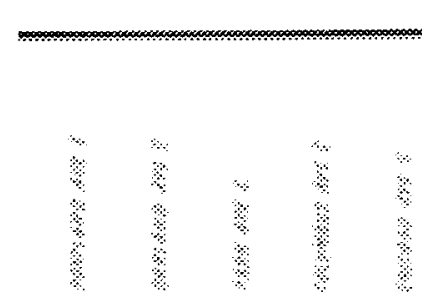
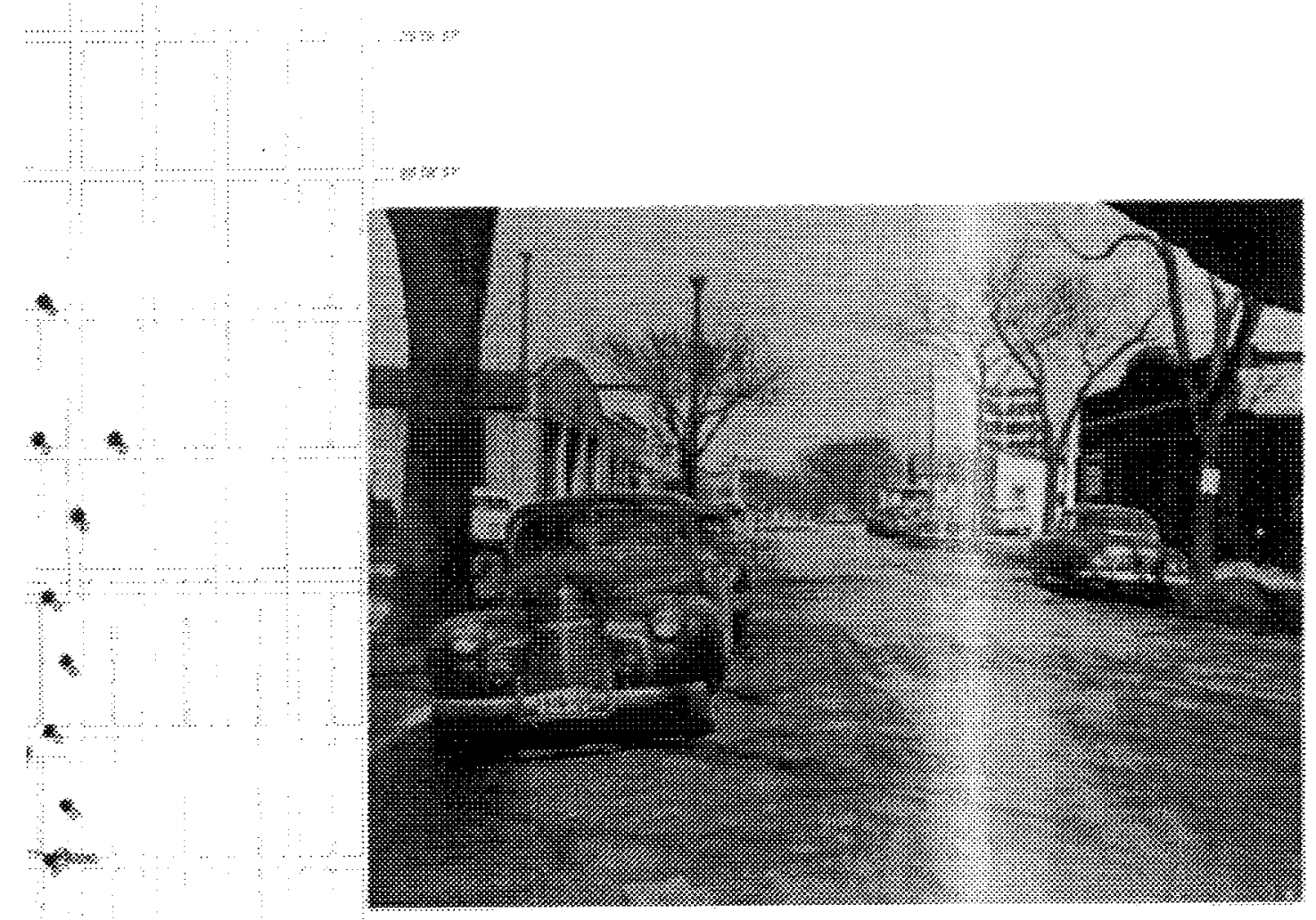

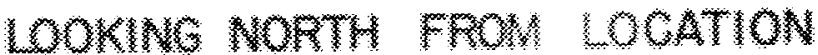
ow ARROSOL oNERHW \\ FIGURE B-11 \\ TEST ARKAY AND RESULTS \\ FT 0004a 2010 CST

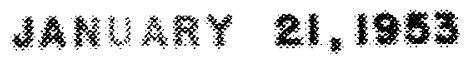




\section{AEROSOL GENERAT TON}

Point-source release of 6.7 gns of $\mathrm{NJZ} 2266$ over period of 5 minutes starting at 2123 CST from a vehiclemounted blower disperser located at point 1 .

SAMPL ING

Location and Exposure

Membrane-filter sampling equipment located at 52 stations as shown on test-array map by following symbols:

Outdoor sampler at height between 1 and 6 feet.

- Outdoor sampler at height above or below general terrain level as indicated by note.

0 Indoor sampler at location indicated by test-array map or text.

Results

All samplers operated to measure total dosages.
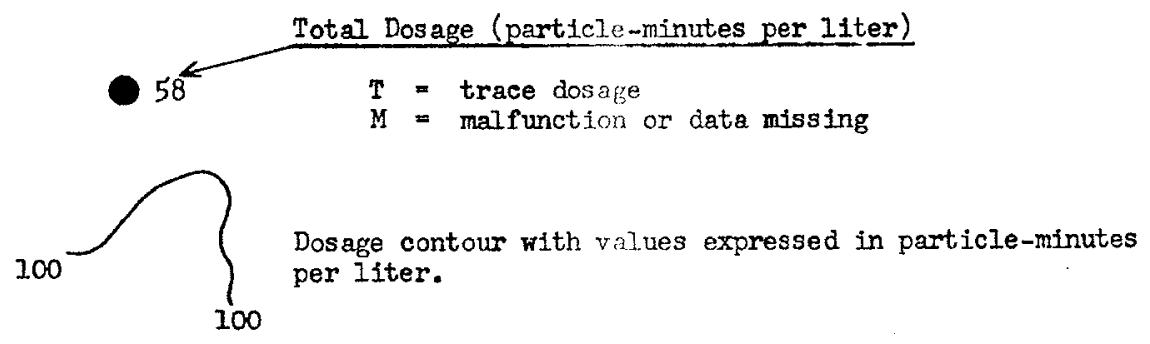

MEIEOROLOGY

Equipment and Measurement

At street level, wind direction continuously recorded, and air and surface temperatures, wind velocity, and other meteorological observations taken at stations designated as (MI) and (Mi2).

Similar observations at rooftop level ( 35 feet abovg surface, at SW corner of the school building) and wiresonde ascents made at meteorological station (M3).

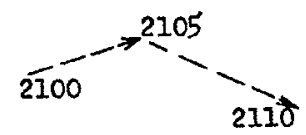

Virtual wind track, the length (drawn to map scale) and direction of each arrow representing the virtual wind travel between the times indicated.

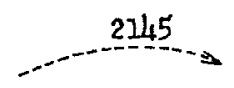

Balloon track representing wind-drift observation at the time indicated.

Winds

Roof-level winds easterly at $4.5 \mathrm{mph}$; street-level winds easterly at 0.9 mo

\section{Stability}

1.2. F lapse from 6-300 $\mathrm{ft}$.

\section{$\underline{\text { sky }}$}

The low overcast at $1930 \mathrm{CST}$, with base near $1500 \mathrm{ft}$ above surface, became broken at 2030 CST, then scattered at $2130 \mathrm{CST}$. A broken-to-crercast middle cloud deck with base 7,000 to 9,000 ft above the surface persisted throughout the sampling period.

\section{Temperature}

$31^{\circ} \mathrm{F}$ at 2 moters in the test area.

\section{Molsture}

Mixing ratio of $3.4 \mathrm{gm} / \mathrm{kgm}$ dry $\mathrm{air}$. 

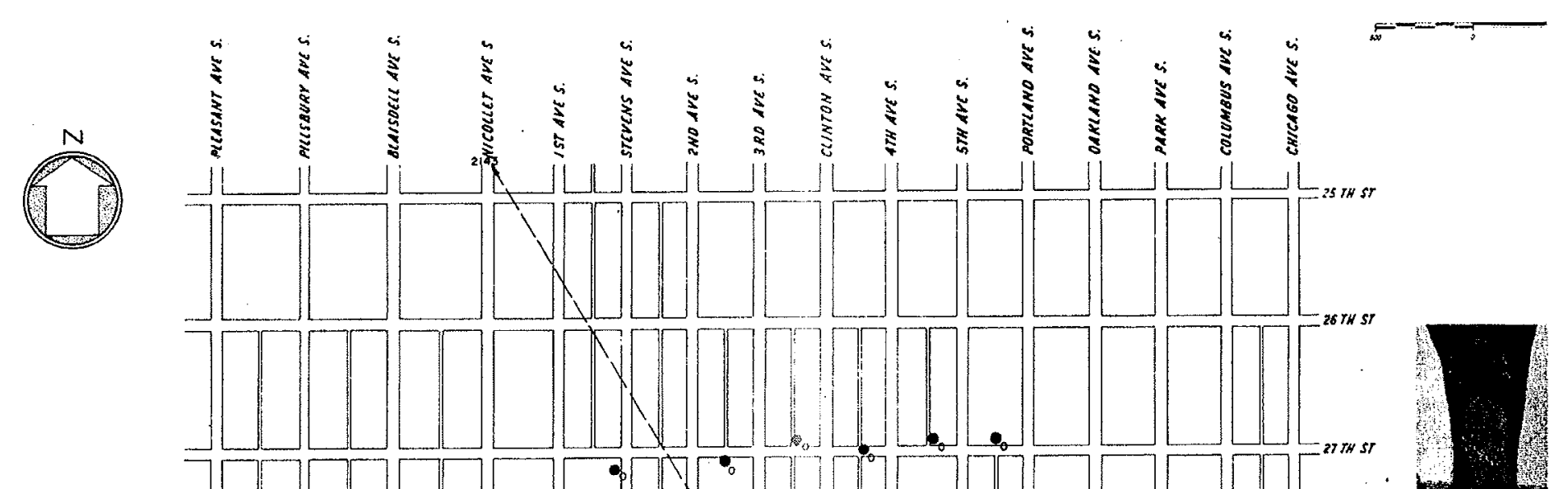

CLINTON' SCHOOL
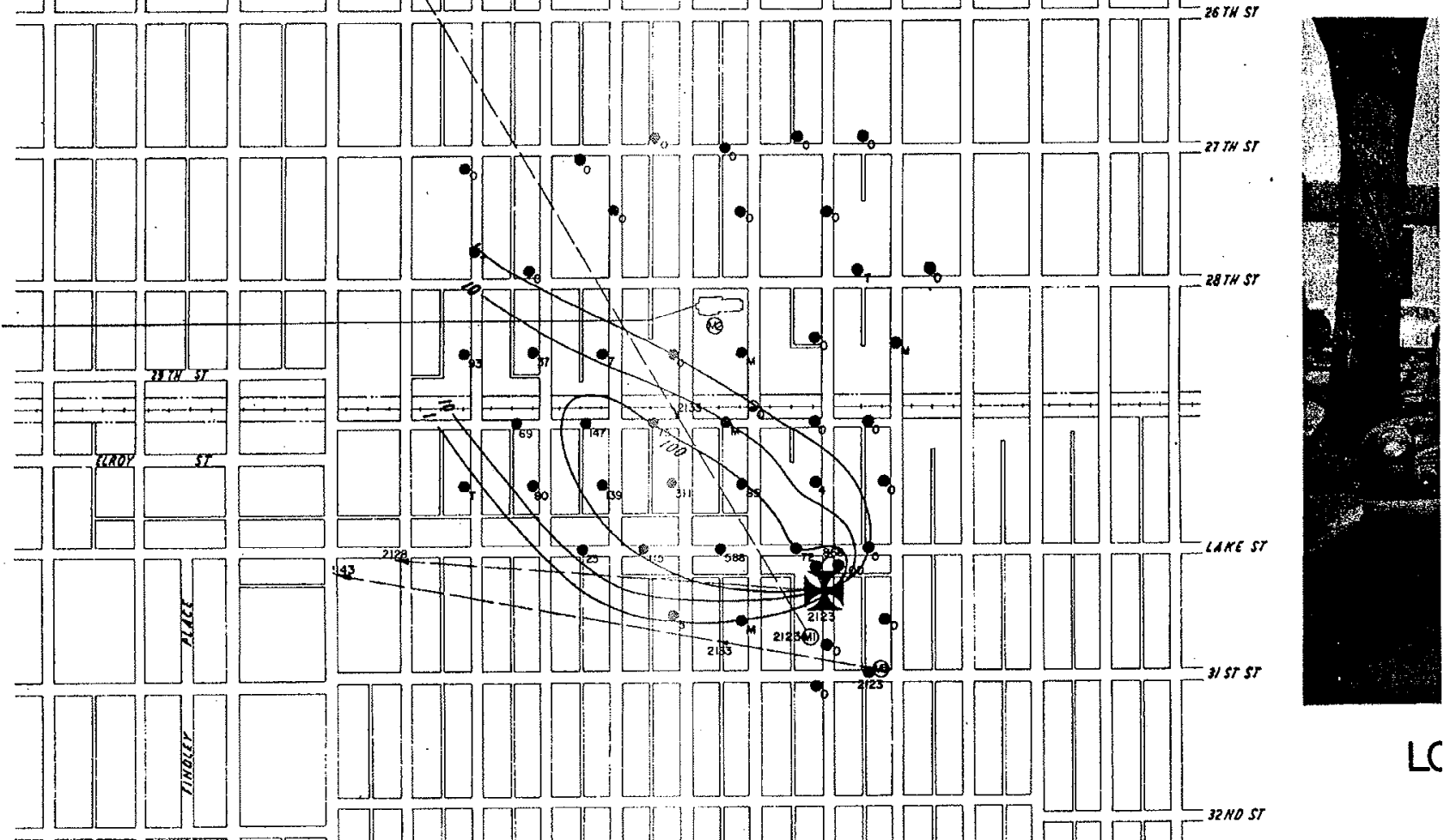

LC

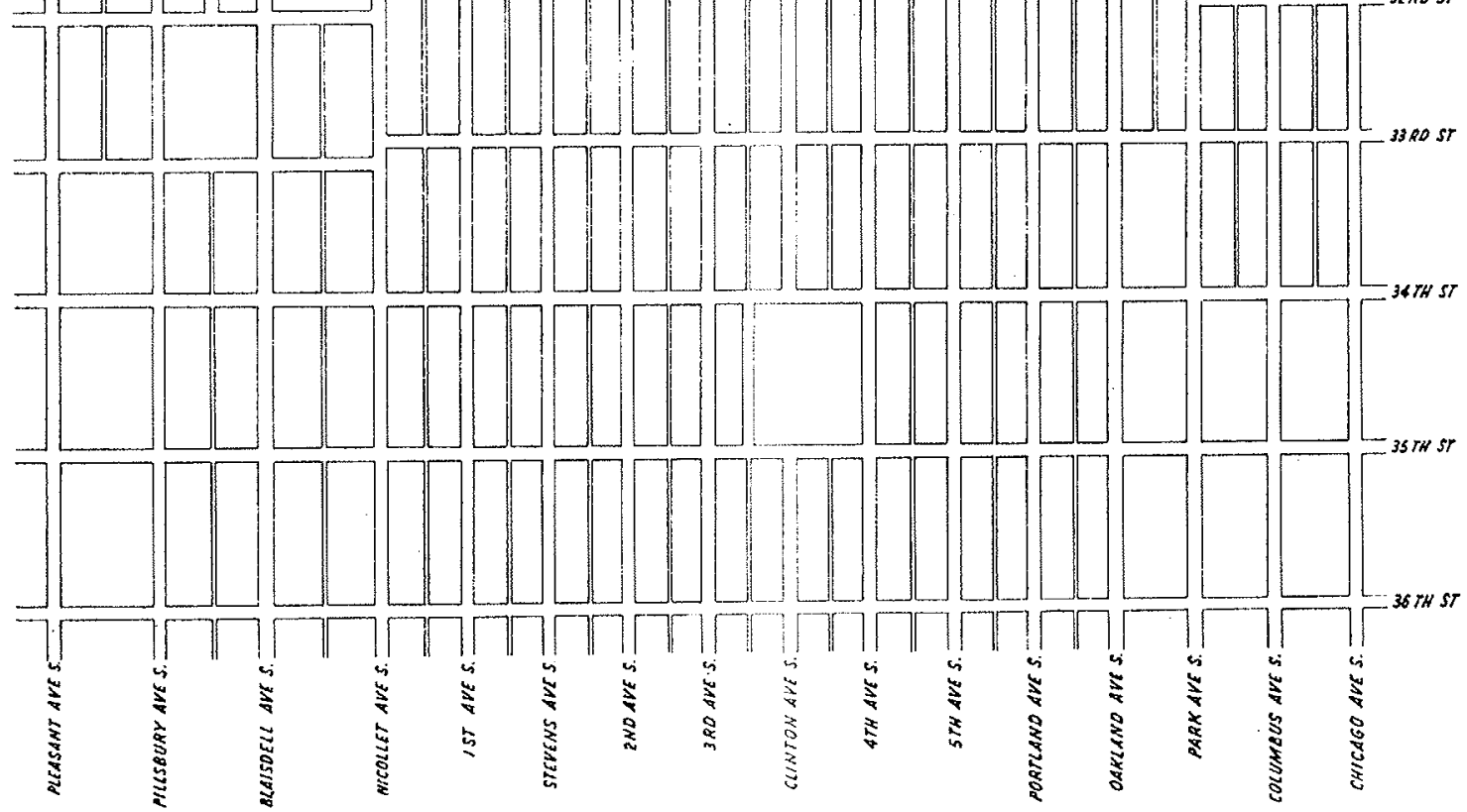



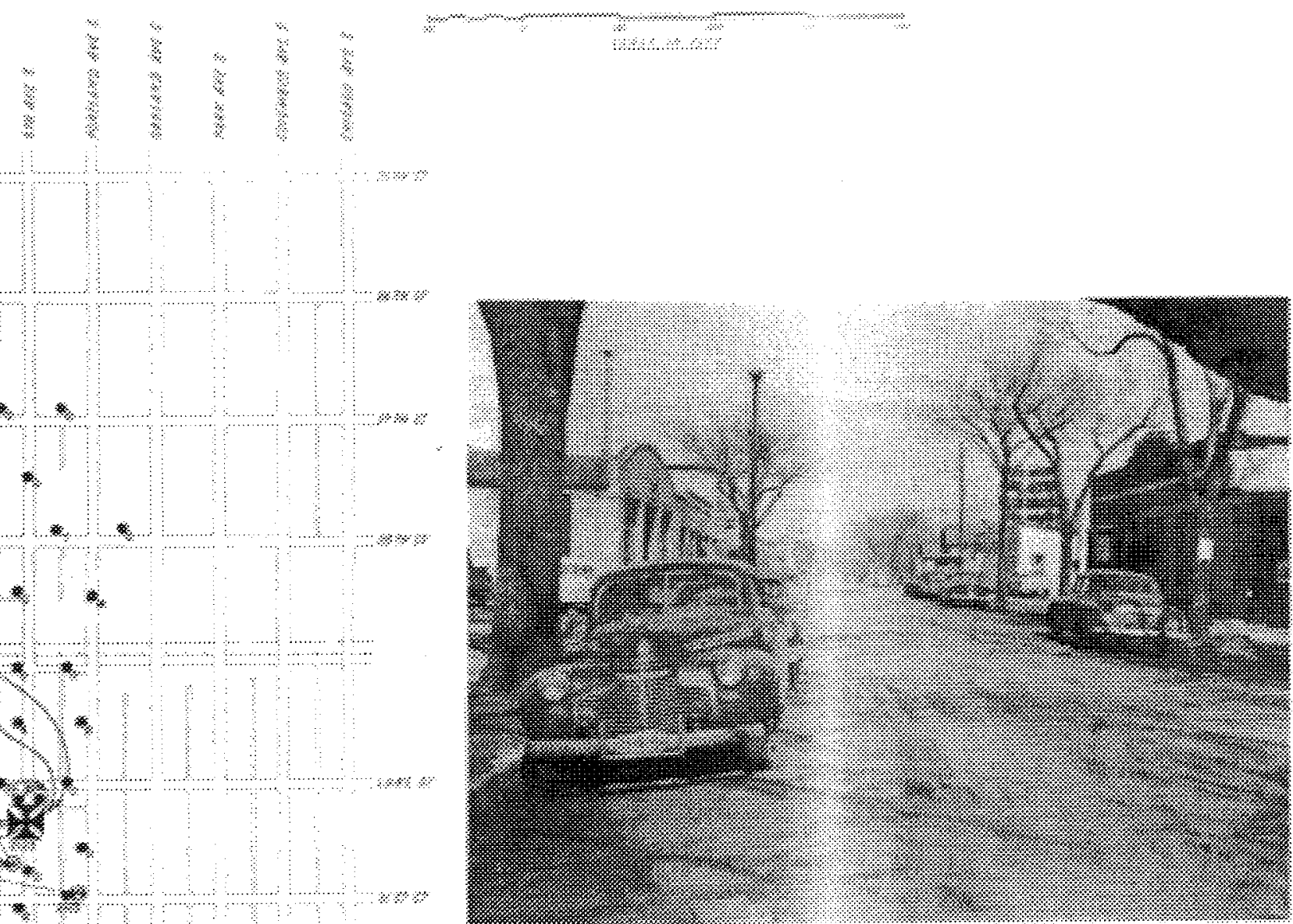

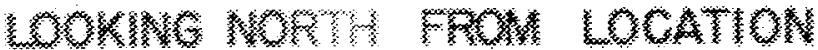

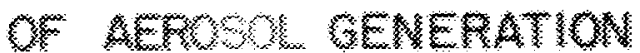

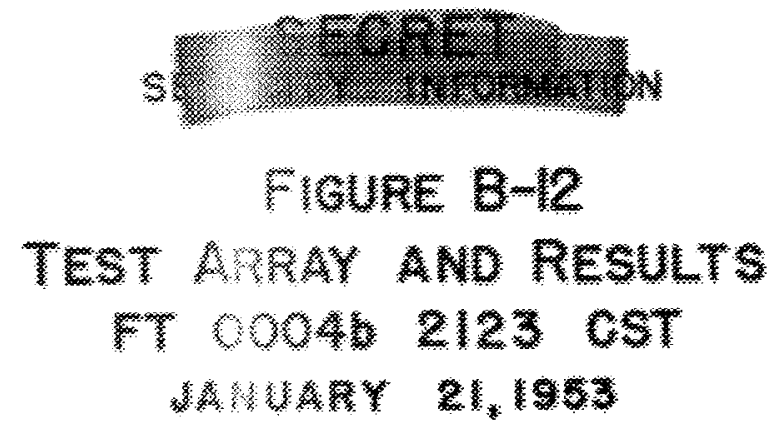

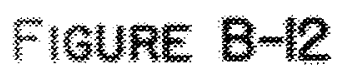

PkE 


\section{REGRADED UNCLASSIFIED - JOD, DPG}

\section{AEROSOI GENERAT ION}

Point-source release of 9.1 gms of $\mathrm{NJZ} 2266$ over a period of 5 minutes starting at 2243 CST from a vehiclemounted blower disperser located at point 2 .

SAMPLING

Location and Exposure

Membrane-filter sampling equirment located at 52 stations as show on test-array map by following symbols:

Outdoor sampler at height between 1 and 6 feet.

Outdoor sampler at height above or below general terrain level as indicated by note.

Indoor sampler at location indicated by test-array map or text.

Results

All samplers operated to measure total dosages.

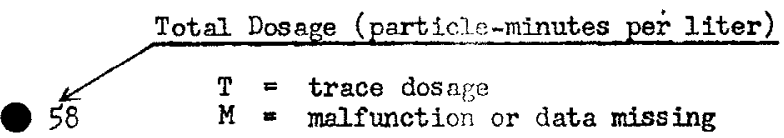

\section{METEOROLOGY}

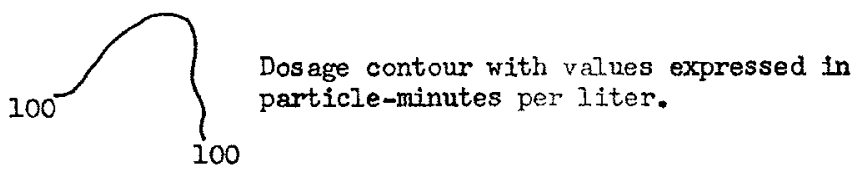

\section{Equipment and Measurement}

At street level, wind direction continuously recorded, and air and surface temperstures, wind velocity, and other meteorological observations taken at stations designated as (Mi) and (M2) .

Similar observations at rooftop level ( $35^{\prime}$ feet above surface, at SW corner of the school building) and wiresonde ascents made at meteorological station (M3).

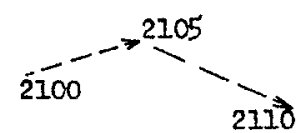

Virtual wind track, the length (drawn to map scale) and direction of each arrow representing the virtual wind travel between the times indicated.

Balioon track representing wind-drift observation at the time indicated.

Winds

Roof-level winds easterly at $7.5 \mathrm{mph}$; street-level winds easterly at $1.0 \mathrm{mph}$.

\section{Stability}

1.1. F lapse from $6-300 \mathrm{ft}$.

$\underline{S k y}$

The low overcast at $1930 \mathrm{CST}$, with base near $1500 \mathrm{ft}$ above surface, became broken at 2030 CST, then scattered at $2130 \mathrm{CST}$. A broken-to-overcast middle cloud deck with base 7,000 to 9,000 ft above the surface persisted throughout the sampling period.

\section{Temperature}

$31^{\circ} \mathrm{F}$ at 2 meters in the test area.

\section{Moisture}

Mixing ratio of $3.4 \mathrm{gm} / \mathrm{kgm}$ dry air. 


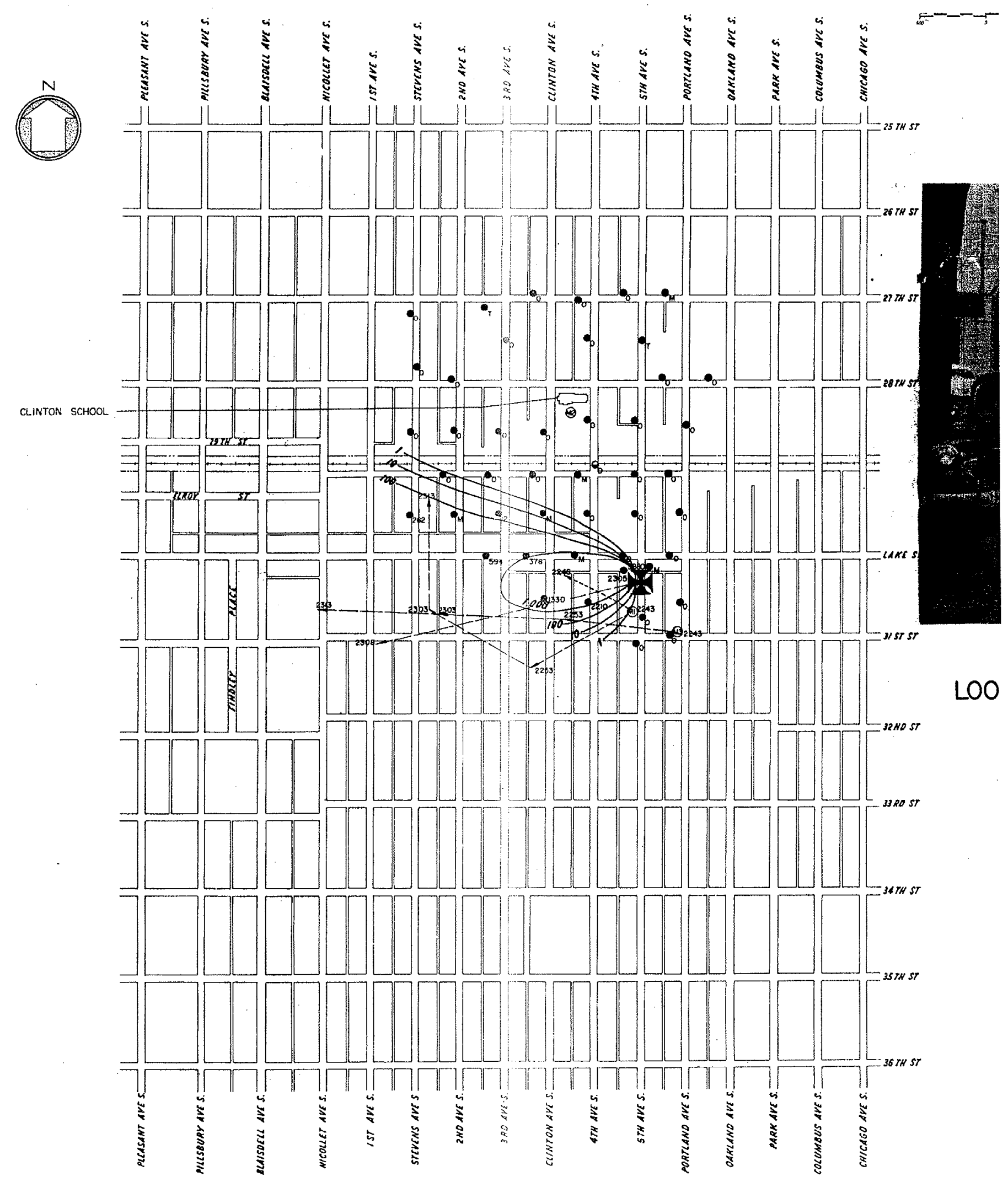




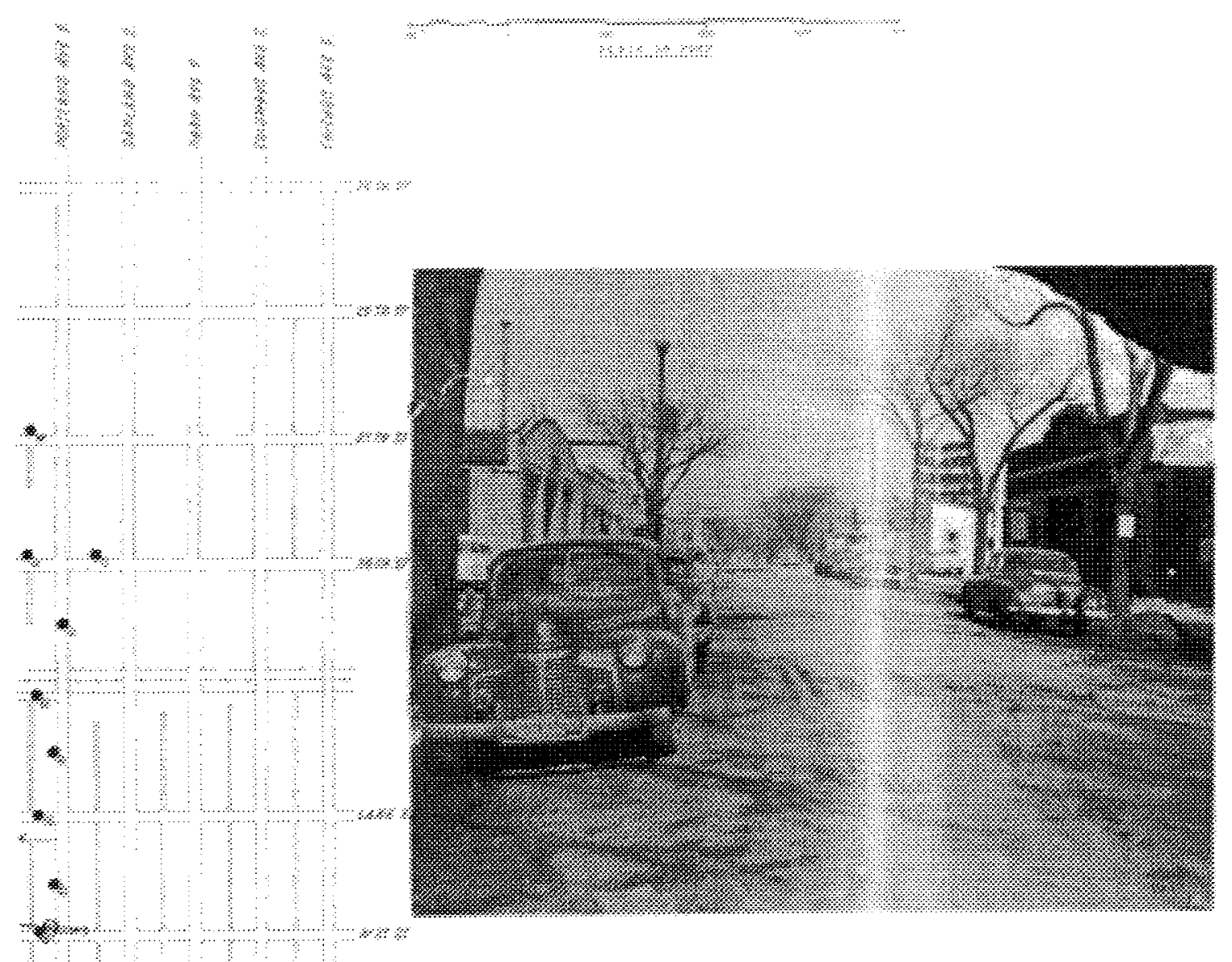

WOKNG WOFTH FRO LOCATON or Anosol orVerATlO

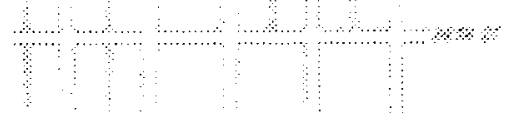




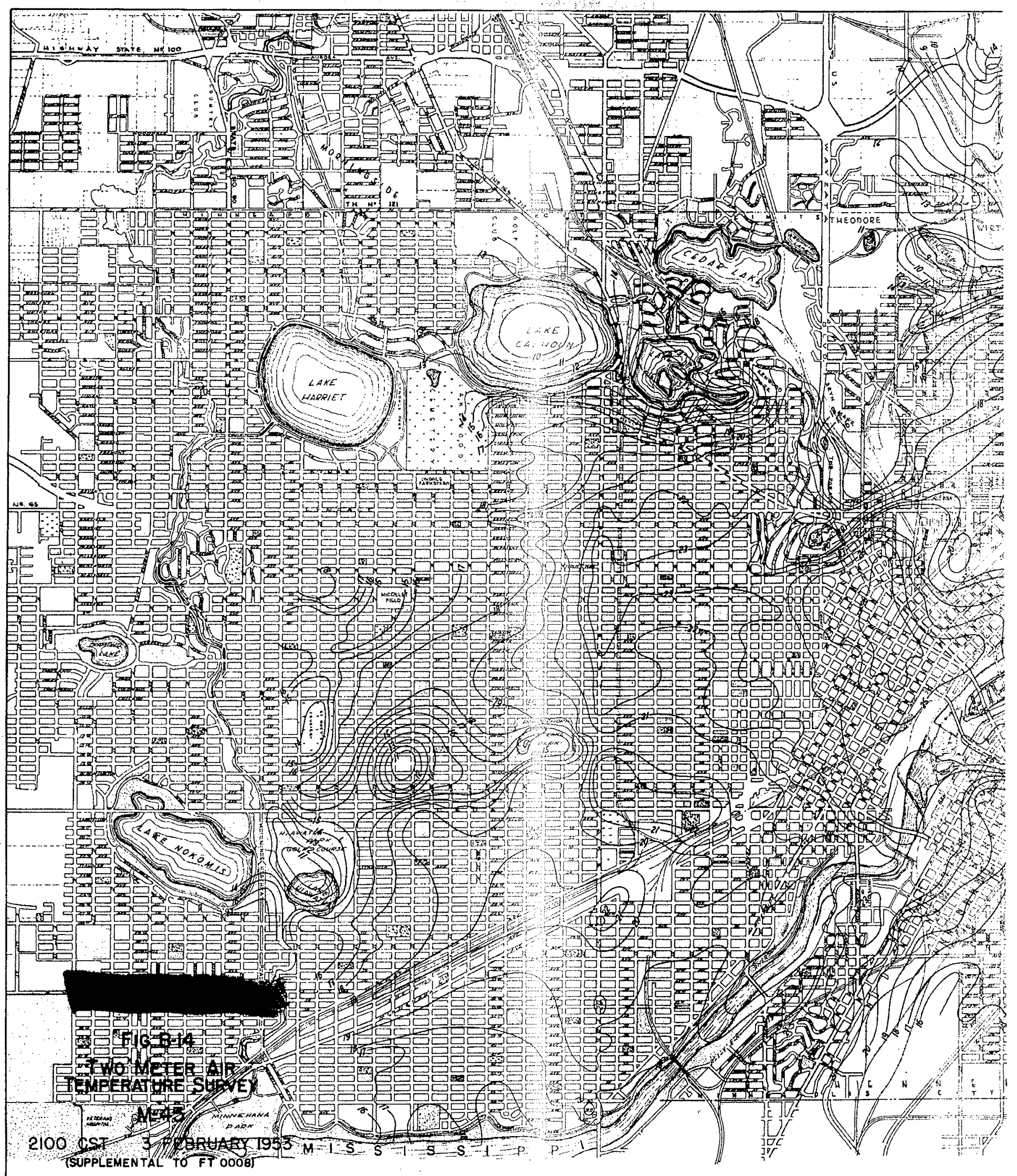

PAGE 190 


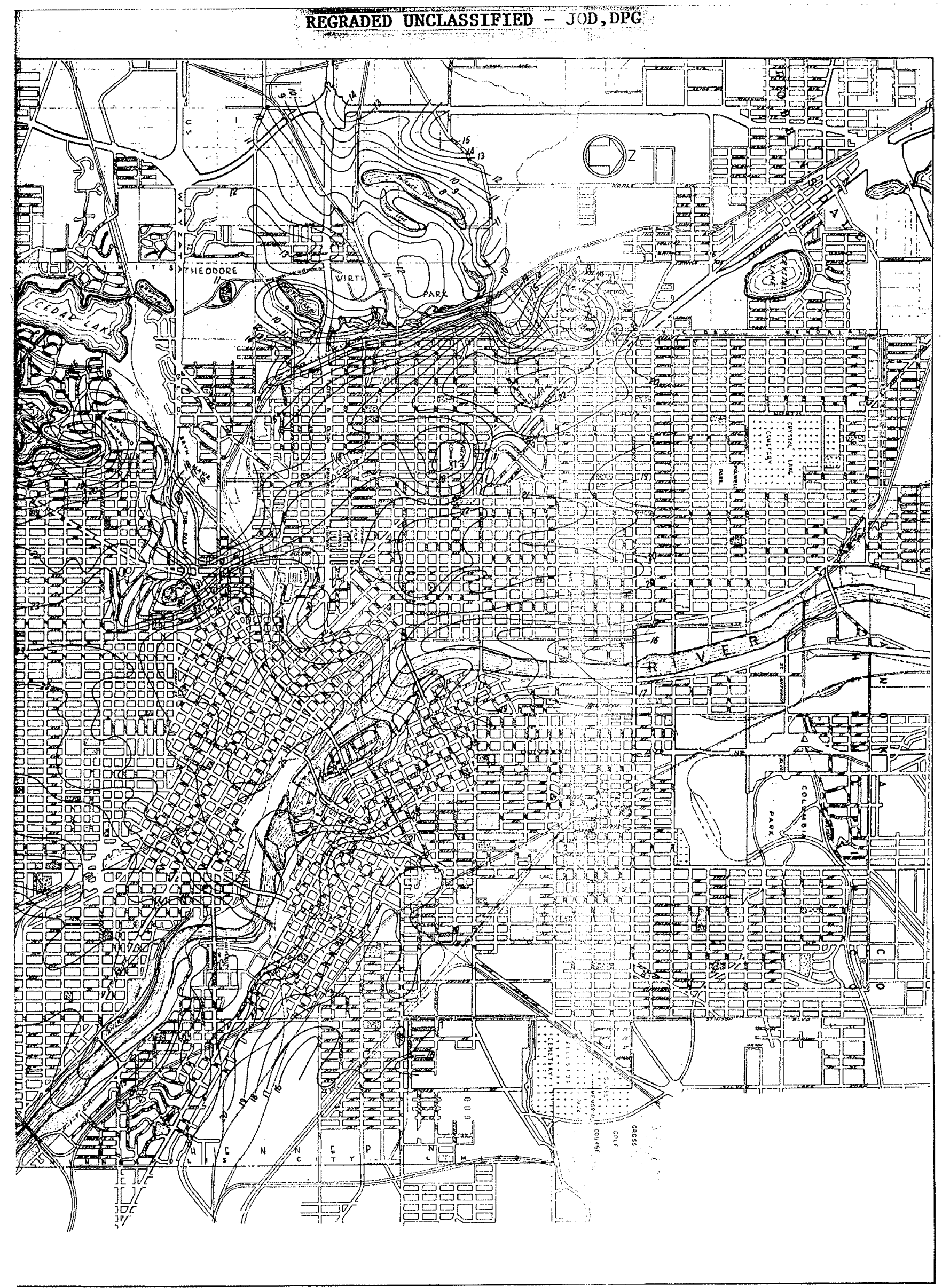


SUMMARY OF REGIONAL AND LOCAL WEATHER

FT 0008 Survey $\mathrm{M}-43 \quad 3$ Feb 1953

\section{Synoptic Situation}

A cold front had passed Minneapolis on the previous day leaving $2 \frac{1}{2}$ inches of fresh snow. A warm front was located about 300 miles to the west. A $1011 \mathrm{mb}$ low cell was located north of the creat lakes. A weak high cell with pressure $1021 \mathrm{mb}$ was centered over northwestern IIlinois. Surface wind flow was southeasterly 2 to $5 \mathrm{mph}$. Air flow at $700 \mathrm{mb}$ was from the west-northwest at $30 \mathrm{mph}$.

Weather reports from Wold-Chamberlain Field (Minnsapolis)

\begin{tabular}{|c|c|c|c|c|c|c|c|c|}
\hline \multirow[b]{2}{*}{$\begin{array}{l}\text { Time } \\
\text { CST }\end{array}$} & \multirow[b]{2}{*}{$\begin{array}{l}\text { Cloud } \\
\text { Height } \\
\text { (feet) }\end{array}$} & \multirow[b]{2}{*}{$\begin{array}{l}\text { Sky* } \\
\text { Cover }\end{array}$} & \multirow[b]{2}{*}{$\begin{array}{l}\text { Visibility } \\
\text { (miles) }\end{array}$} & \multirow[b]{2}{*}{ Weather } & \multirow[b]{2}{*}{$\begin{array}{l}\text { Terpp } \\
(\mathrm{F})\end{array}$} & \multirow[b]{2}{*}{$\begin{array}{c}\text { Dew } \\
\text { Point }\end{array}$} & \multicolumn{2}{|c|}{ Wind } \\
\hline & & & & & & & Dir & $\begin{array}{l}\text { Speed } \\
\text { (mph) }\end{array}$ \\
\hline $\begin{array}{l}1830 \\
1930 \\
2030 \\
2130 \\
2230 \\
2330 \\
0030\end{array}$ & & $\begin{array}{l}\text { Clear } \\
\text { Clear } \\
\text { Clear } \\
\text { Clear } \\
\text { Clear } \\
\text { Clear } \\
\text { Obs- } \\
\text { cured }\end{array}$ & $\begin{array}{r}12 \\
12 \\
12 \\
7 \\
2 \frac{1}{2} \\
1 \frac{1}{2} \\
\frac{1}{4}\end{array}$ & $\begin{array}{l}\text { Ground Fog } \\
\text { Ground Fog } \\
\text { Ice Fog }\end{array}$ & $\begin{array}{l}27 \\
21 \\
22 \\
21 \\
20 \\
18 \\
16\end{array}$ & $\begin{array}{l}22 \\
21 \\
19 \\
18 \\
18 \\
17 \\
14\end{array}$ & $\begin{array}{c}S \\
\text { ESE } \\
S E \\
S S E \\
S E \\
S \\
\text { SSE }\end{array}$ & $\begin{array}{l}3 \\
5 \\
4 \\
5 \\
4 \\
2 \\
3\end{array}$ \\
\hline
\end{tabular}

Sea level pressure at $2130 \mathrm{CST}: 1017.6$

Ground condition: $3^{\prime \prime}$ packed snow Side streets slippery Lakes were frozen

Tree cover: none

$*$ Average cloudiness sunrise to sunset: $80 \%$

$*$ and/or restrictions to visibility 
FIGURE B-15

TEMPERATURE SOUNDINGS

ST CLOUD RAOB 3 FEB 1953

(SUPPLEMENTALTO SURVEY M-43)

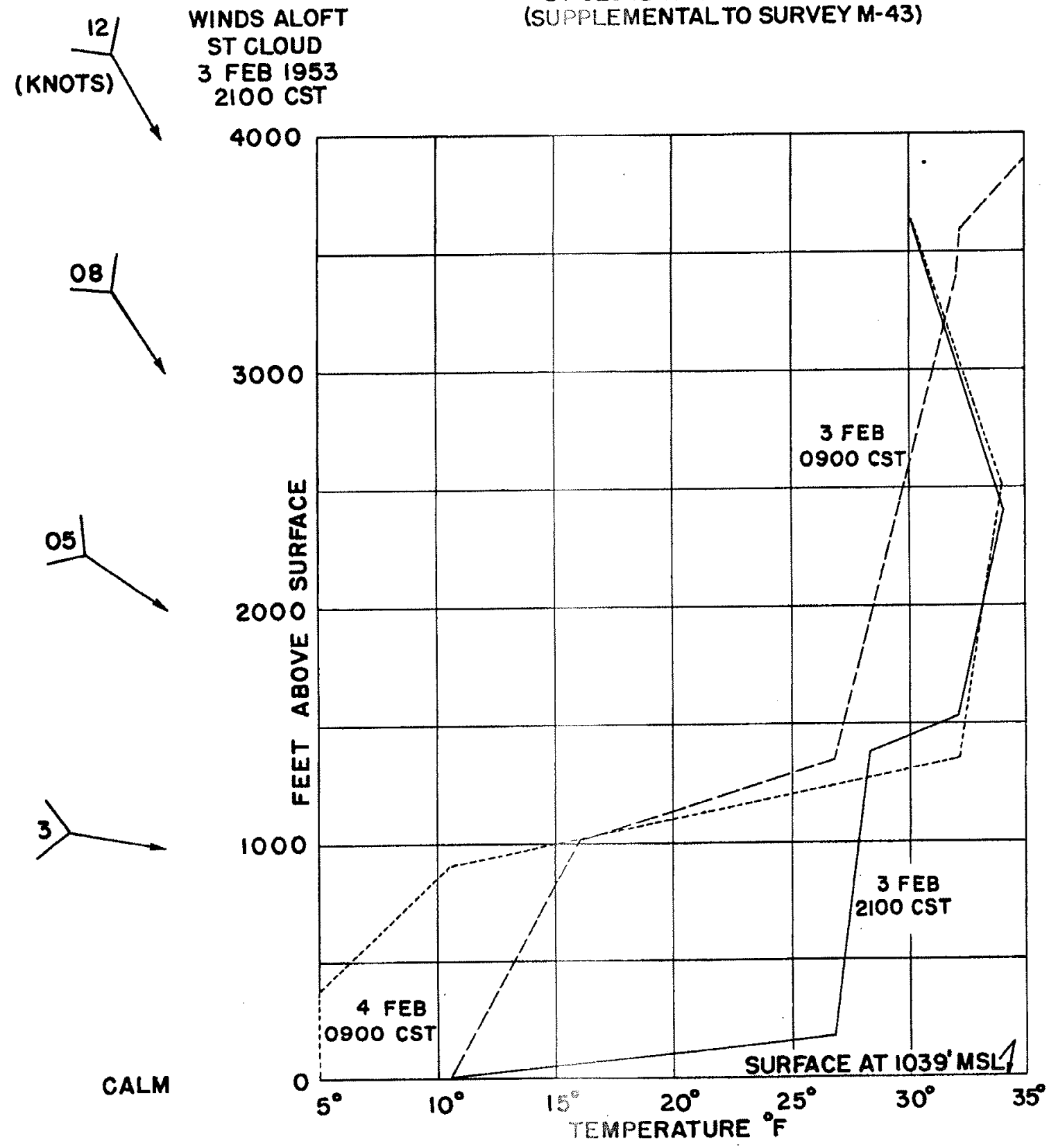

PAGE $19 \mid$ 

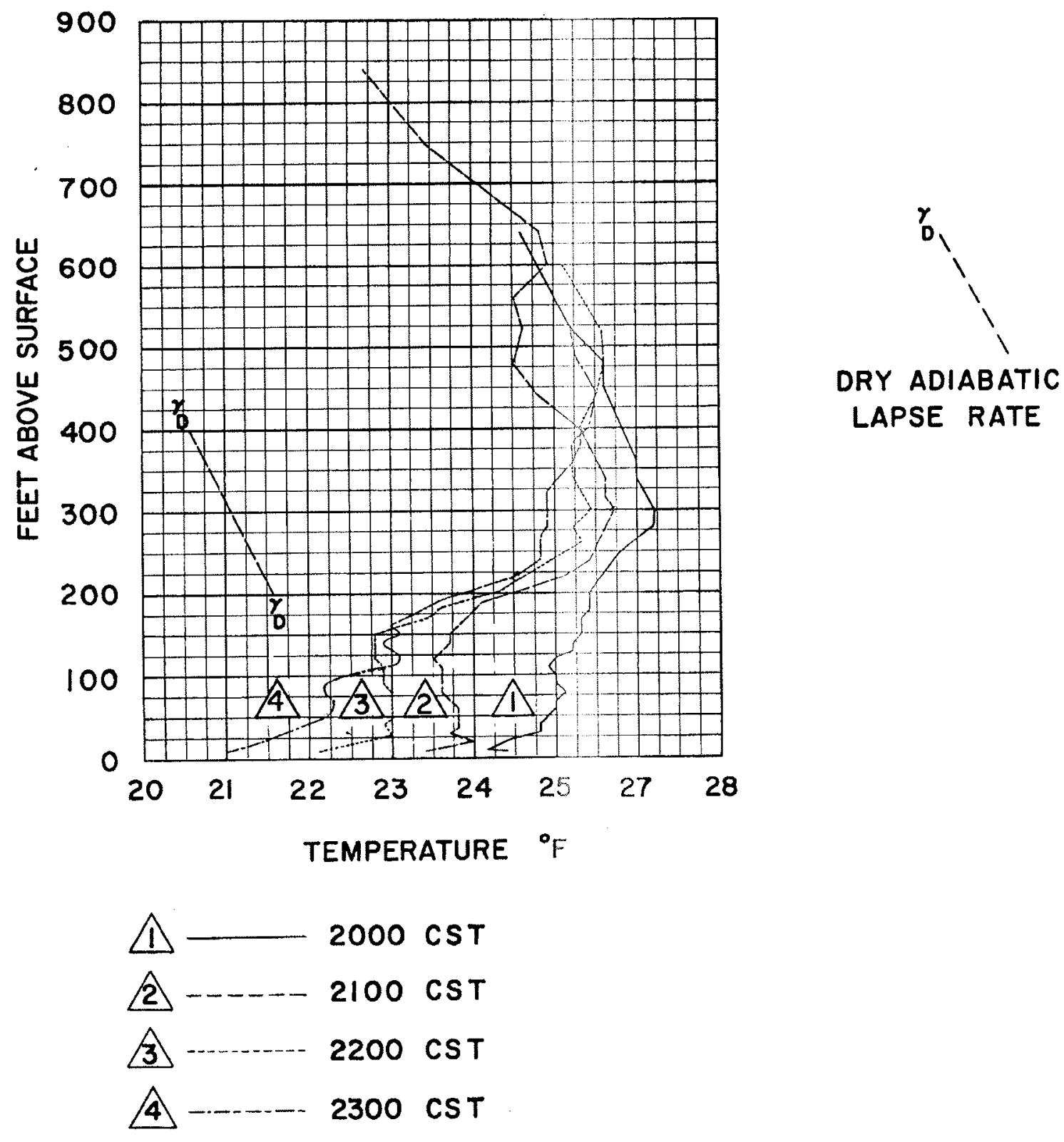

FIGURE B-16

TEMPERATURE SOUNDINGS MINNEAPOLIS RESIDENTIAL WIRESONDE SURVEY $M-43 \quad 3$ FEB. 1953

PAge 192 


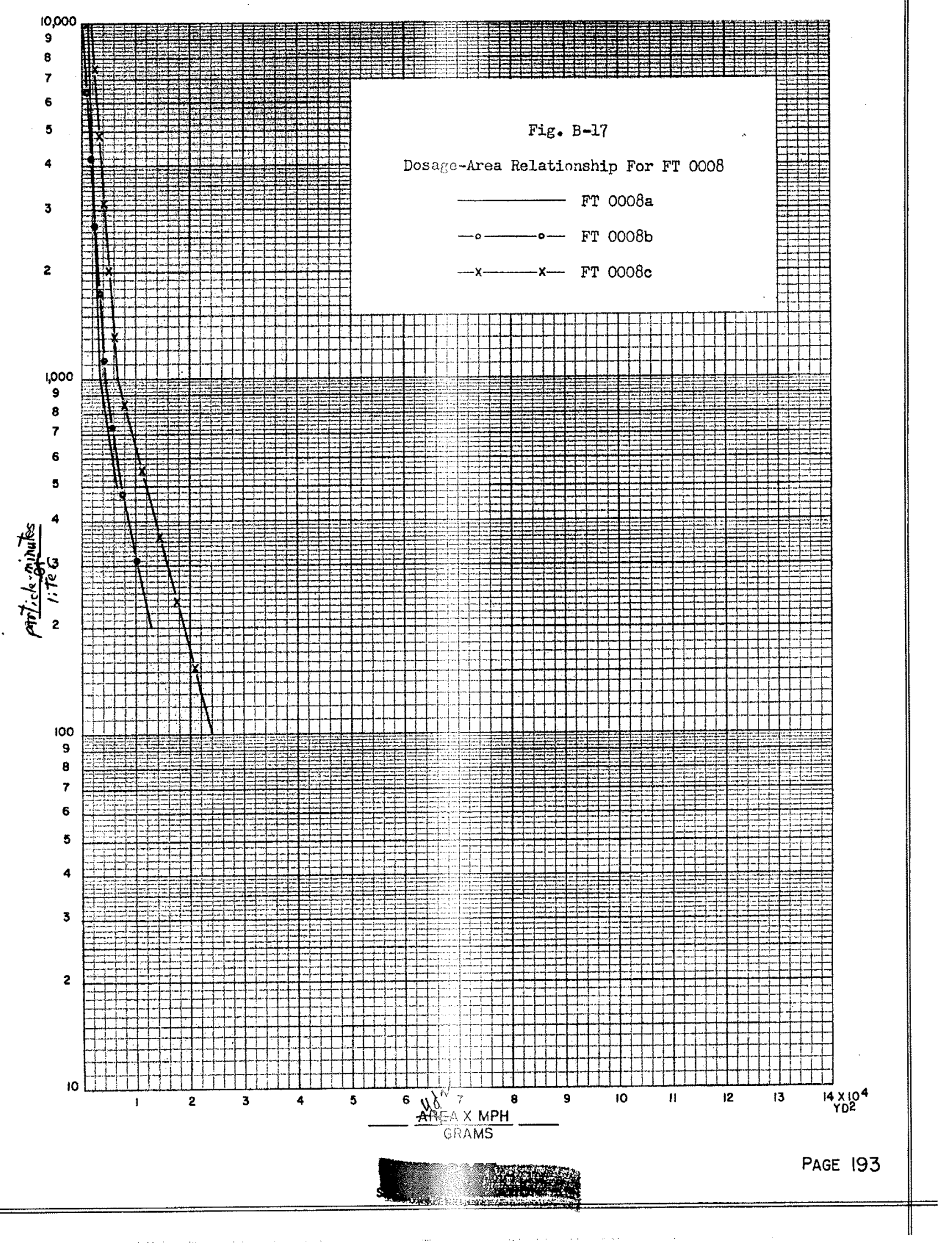


SUMMARY OF HOUSE-PENETRATION AND CLINTON SCHOOL DOSACES* FT 0008a

3 February 1953

\section{RESIDENCES}

\begin{tabular}{|c|c|c|c|c|}
\hline House & Outside & Basement & First Floor & Second Floor \\
\hline A & 158 & $0 T$ & $\mathrm{~T} 0$ & 00 \\
\hline
\end{tabular}

\begin{tabular}{|c|c|c|c|c|c|c|}
\hline & Ground & Ground Floor & Eirst Floor & Second & Floor & Roof \\
\hline Outside & $\mathrm{T} T$ & & $0 T$ & 0 & 0 & 0 \\
\hline
\end{tabular}

Inside

O T

00

00

0

0

* Dosages are expressed in particle-minutes per liter; T represents trace dosage, i.e., a count not exceeding 15 fluorescent particles. When more than one sampler is involved, values are listed on separate lines. Double entries for a given column represent incremental dosages obtained with sequentially exposed filter units.

* Individual residences are described in Section $V-E$. With the illustration of a given house (see Figs. V-23 through V-27) is given the summary of all dosages obtained at that house.

H* The sampler array for this and other tests is found in Figs。 $\mathrm{V}-28$ through $\nabla-31$.

Part 1 of 4 
Point-source release of 8.1 gms of $\mathrm{NZ} 2266$ over a period of 5 winutes starting at $2006 \mathrm{CST}$ from a vehiclemounted blower disperser located at point 1

\section{SAMPLING}

\section{Location and Exposure}

Membrane-filter sampling equipment located at 92 stations shown on test-array map by fol1owing symbols:

$$
\begin{aligned}
& \text { Outdoor sampler at height between } 1 \text { and } 6 \text { fect. } \\
& \text { Outdoor sampler at height above or below geners } 1 \text { terrain } 1 \text { evel as indicated by note. } \\
& \text { Indoor samplor at location indicated by test-aray map or text. }
\end{aligned}
$$

Results

A11 samplers operated to measure total dosages. In addition, samplers at selected stations were operated

\begin{tabular}{|c|c|c|c|}
\hline Sampling Period & Increment Dosage & Tota1 & Dosage (particle-minutes per 1iter) \\
\hline
\end{tabular}
incrementaliy, as shown by the sampling period and the corrosponding increment dosage given to the left of the station symbol.

Since sampling period was not continuous, the actual total dosage in some cases is probabiy more than indicated.

\section{METEOROLOGY}

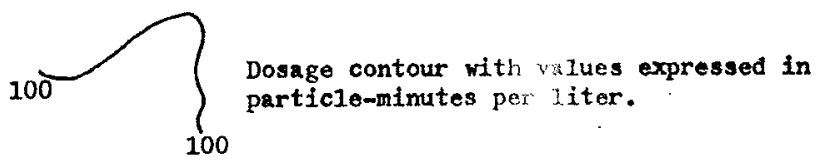

Equipment and Measurement

At street level, wind direction continuousiy recorded, and als and surface temperatyres, wind velocity, and other meteorological observations taken at stations desigrated as (41) and (M2)"

Similar observations at rooftop level ( 35 feet abovesurf ace, at SW corner of school building) and wiresonde ascents made at meteorological station (13).

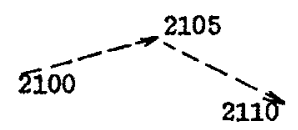

Virtual wind track, the length (drawn to map scale) and direction of each arrow representing the virtual wind travel between the times indicated.

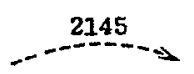

Balloon track representing wind-drift observation at the indicated time.

HInds

Roof-1ovel winds east-southeasterly at $0.5 \mathrm{mph}$; street-level inds southeasterly at $1.0 \mathrm{mph}$.

Stability

$1.8^{\bullet} \mathrm{F}$ inversion from $6 \mathrm{~m}-300 \mathrm{ft}$.

Sky

Clear; ground fog, which was forming about 2200 CST, changed to ice fog and obscured sky from view at approximately $0000 \mathrm{CST}$.

Temperature

$21-24^{\circ} \mathrm{F}$ at 2 meters in the test area.

Moisture

Mixing ratio of $2.1 \mathrm{gm} / \mathrm{kgm}$ dry air.

$$
\text { Part } 2 \text { of } 4
$$




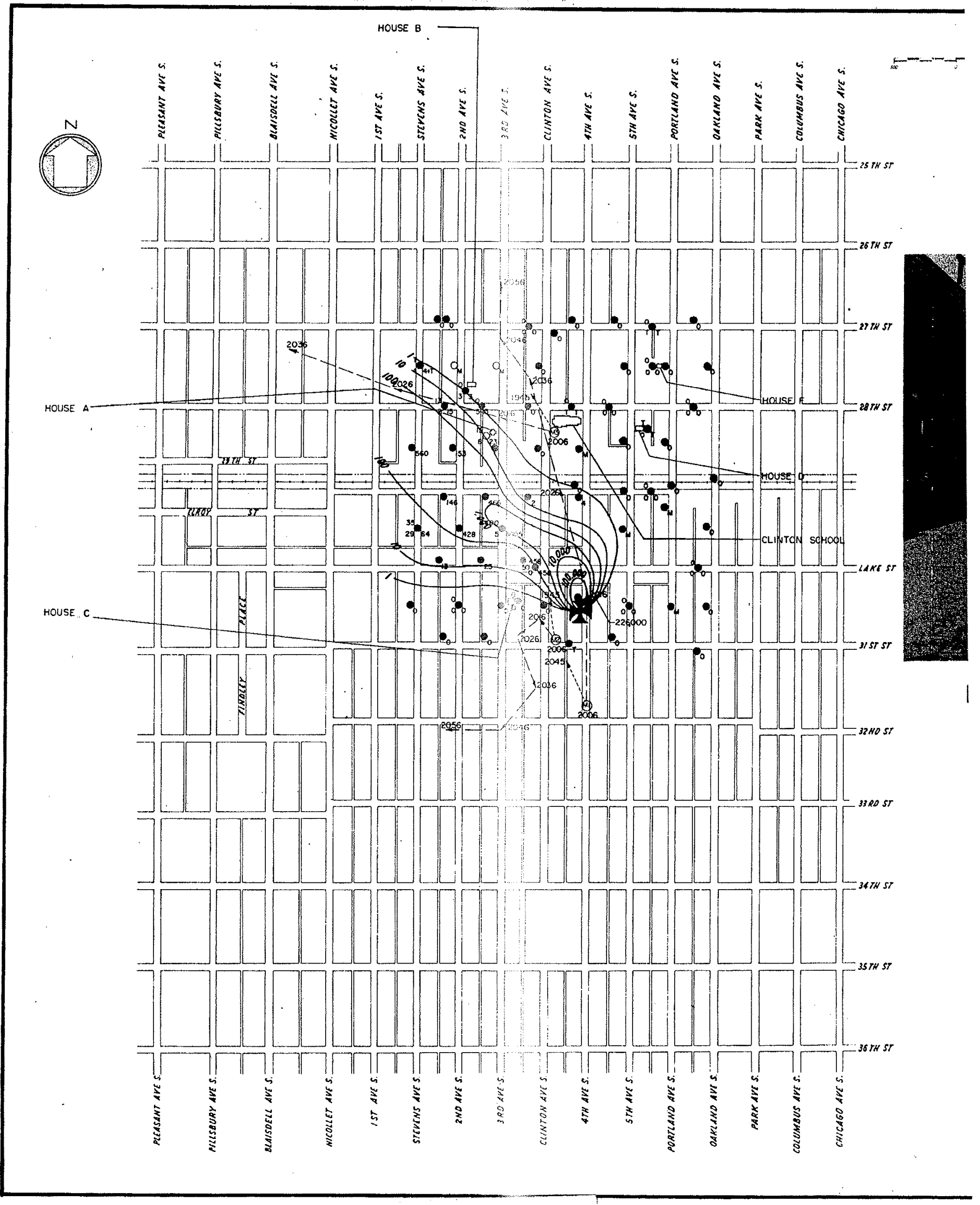



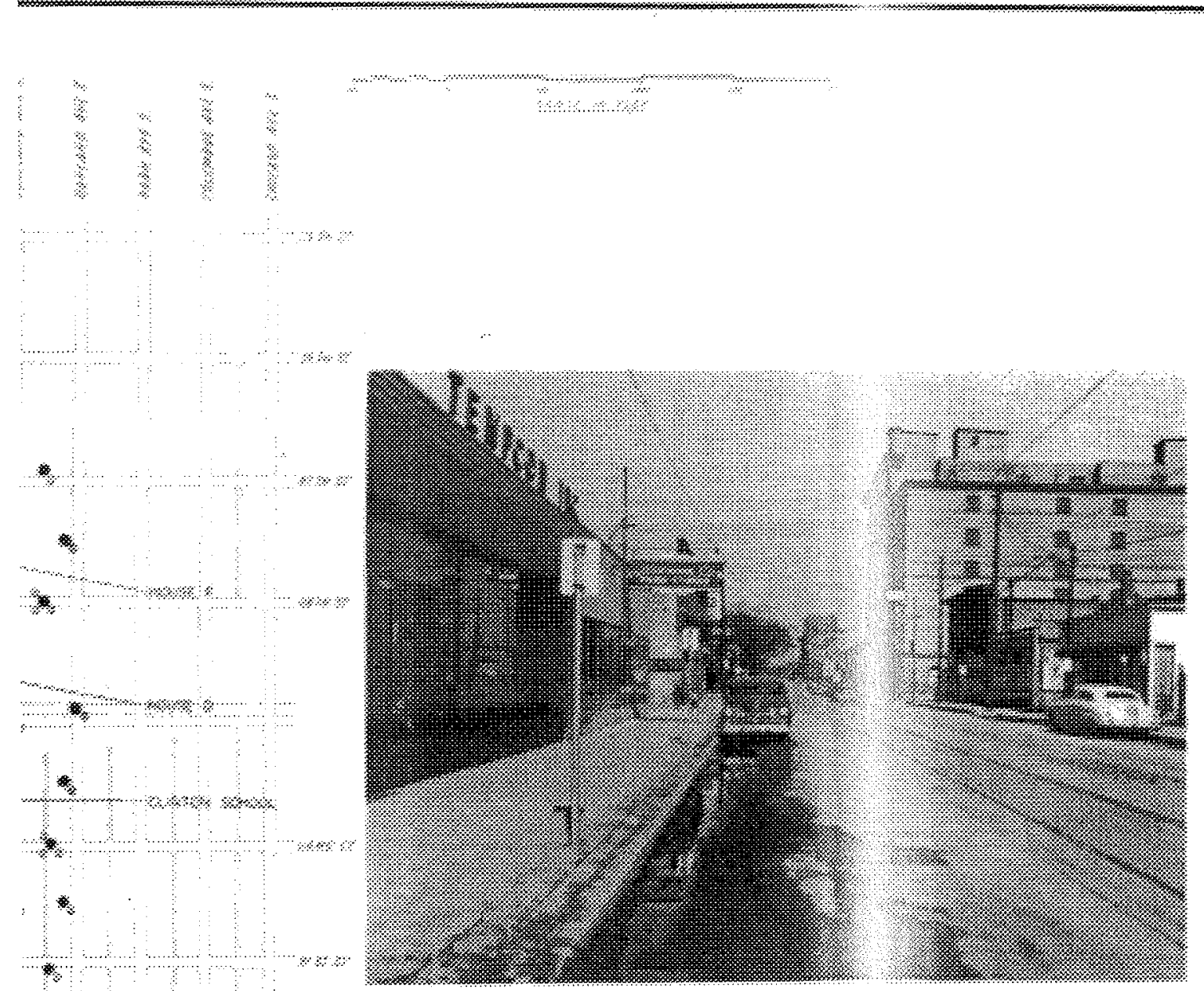

HOKWE WORTH FRO LOCATON or Abrosol GEVERTION
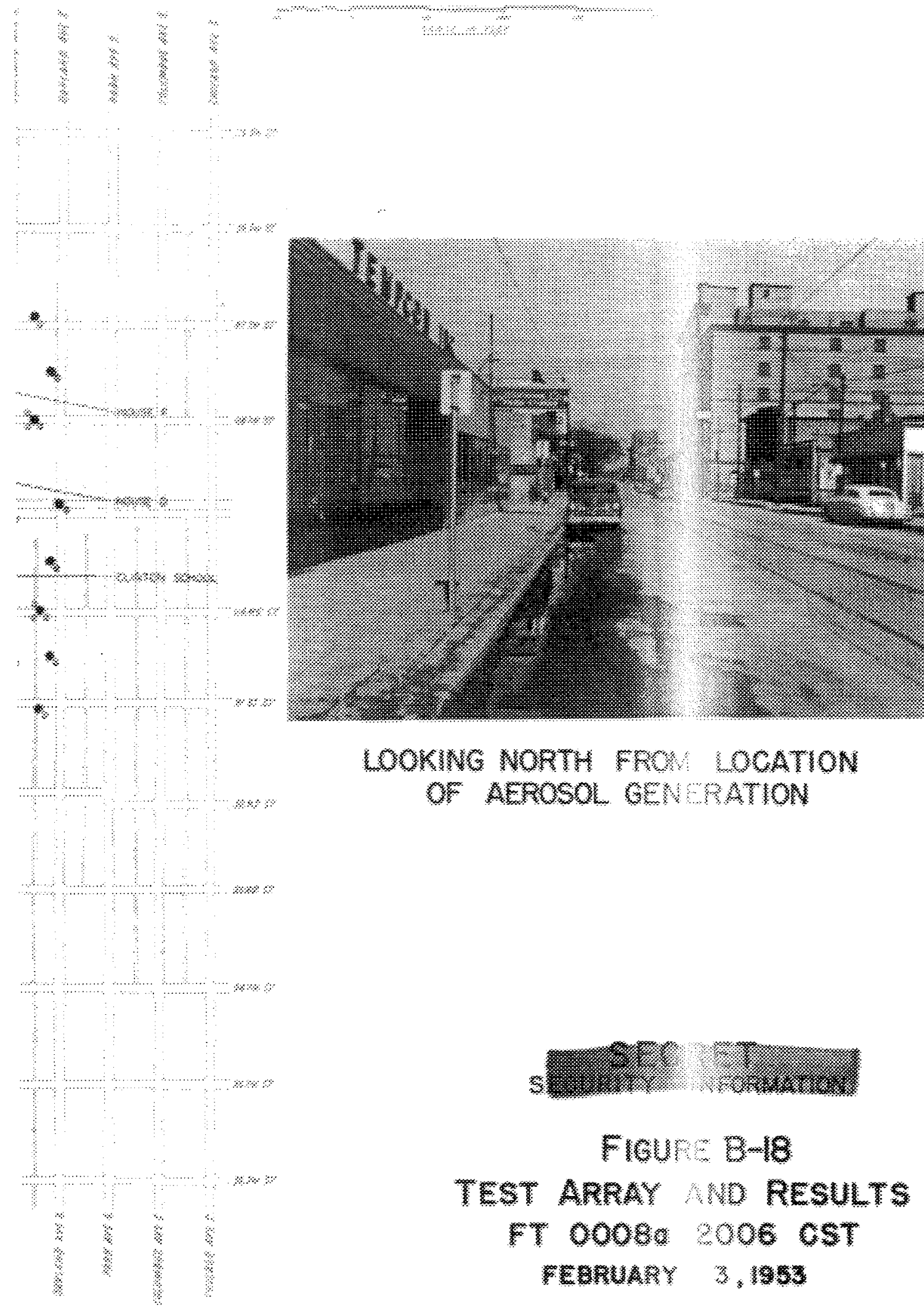

Pate 194 
SUMMARY OF HOUSE-PENETRATION AND CLINTON SCHOOL DOSAGES* FT $0008 b$

3 February 1953

RESIDENCES $* \because *$

\begin{tabular}{|c|c|c|c|c|c|c|c|c|}
\hline House & \multicolumn{2}{|c|}{ Outside } & \multicolumn{2}{|c|}{ Basement } & \multicolumn{2}{|c|}{ First Floor } & Second & Floor \\
\hline A. & 26 & 152 & & & 3 & 17 & 0 & 3 \\
\hline B & 17 & 110 & 3 & 31 & 3 & 5 & 0 & 3 \\
\hline C & Wilo & 390 & 1000 & 493 & 141 & 160 & 83 & 117 \\
\hline
\end{tabular}

CLINTON SCFOOL $* * *$

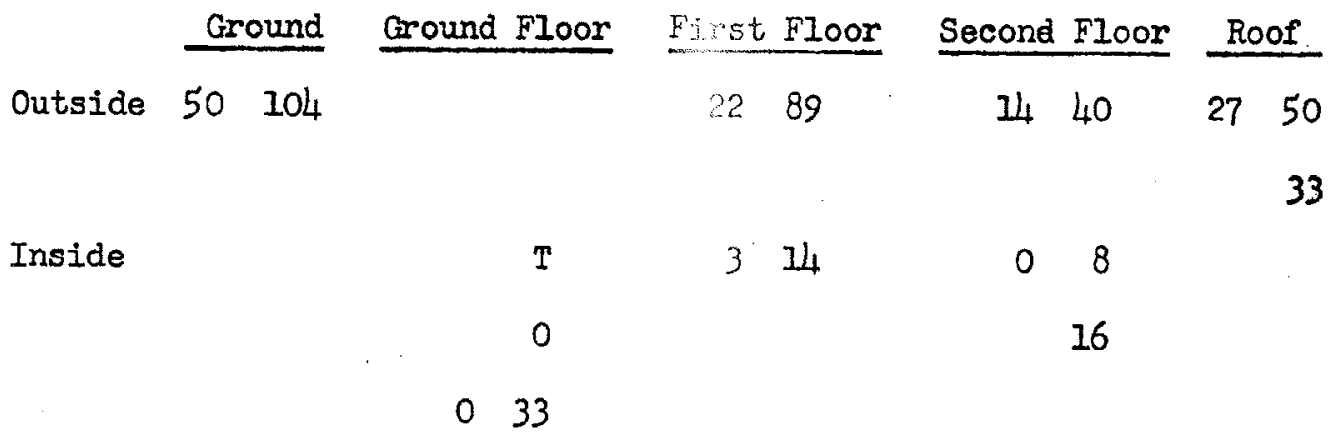

* Dosages are expressed in particle-minutes per liter; T represents trace dosage, i.e., a count not exceeding 15 fluorescent particles. When more than one ampler is involved, values are listed on separate lines. Double entries for a given column represent incremental dosages obtained with sequentially exposed filter units.

** Individual residences are described in Section $\nabla-E$. With the illustration of a given house (see Figs. V-23 through V-27) is given the summary of all dosages obtained at that house.

* The sampler array for this and other tests is found in Figs. $\mathrm{V}-28$ through $\mathrm{V}-3 \mathrm{l}$. 
Point-scurce release of 5.0 gms of $\mathrm{NJZ} 2266$ over a period of 5 minutes starting at 2134 CST from a vehiclemounted blower disperser located at point

\section{SAMPLING}

\section{Location and Exposure}

Membrane-filter sampling equipment located at 92 stations as show on test-array map by fo1lowing symbols: Outdoor sampler at height between $I$ and fect.

- Outdoor sampler at height above or below general terrain level as indicated by note.

0 Indoor sampler at location indicated by lest-array map or text.

$\underline{\text { Resu1ts }}$

Al1 samplers operated to measure total dosages. In addition, samplers at selected stations were operated incrementally, as shown by the sampling period and the corresponding increment dosage given to the left
of the station symbol.

Sampling Period
$2130-2215 \mathrm{CST}$
$2230-2245 \mathrm{CST}$$\underbrace{\text { Increment Dosage }}_{-50}$
Since sampling period was not continuous, the actual total dosage in some cases is probably more than
indicated.

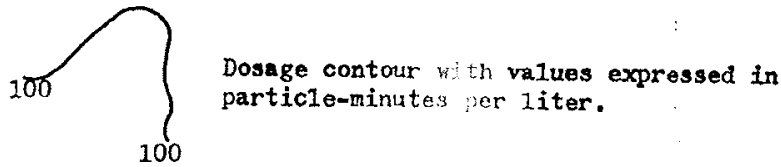

METEOROLOGY

\section{Equipment and Measurement}

At street level, wind direction continuously recorded, and air and surfage temperatures, wind velocity, and other meteorological observations taken at stations dasignated as (1) and (M2)"

Similar observations at roof top level ( 35 feet above surface, at SW corner of the school building) and wiresonde ascents made at meteorological station (M3).

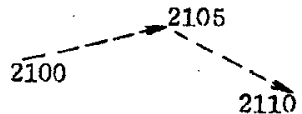

Virtual wind track, the length (drawn to map scale) and direction of each arrow representing the virtual wind travel between the times indicated.

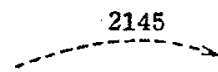

Balioon track representing wind- $d$, if t observation at the time indicated.

Winds

Roof - - level winds east-souther $1 \mathrm{y}$ at $1.2 \mathrm{mph}$; street-level winds southerly at $0.5 \mathrm{mph}$.

\section{Stability}

$3.0^{\circ} \mathrm{F}$ inversion from $6-300 \mathrm{ft}$.

\section{Sky}

Clear; ground fog, which was forming about $2200 \mathrm{CST}$, changet to ice fog and obscured sky from view at approximately $0000 \mathrm{CST}$.

Temperature

$21-24^{\circ} F$ at 2 meters in the test area.

\section{Moisture}

Mixing ratio of $2.1 \mathrm{gm} / \mathrm{kgm}$ dry air. 


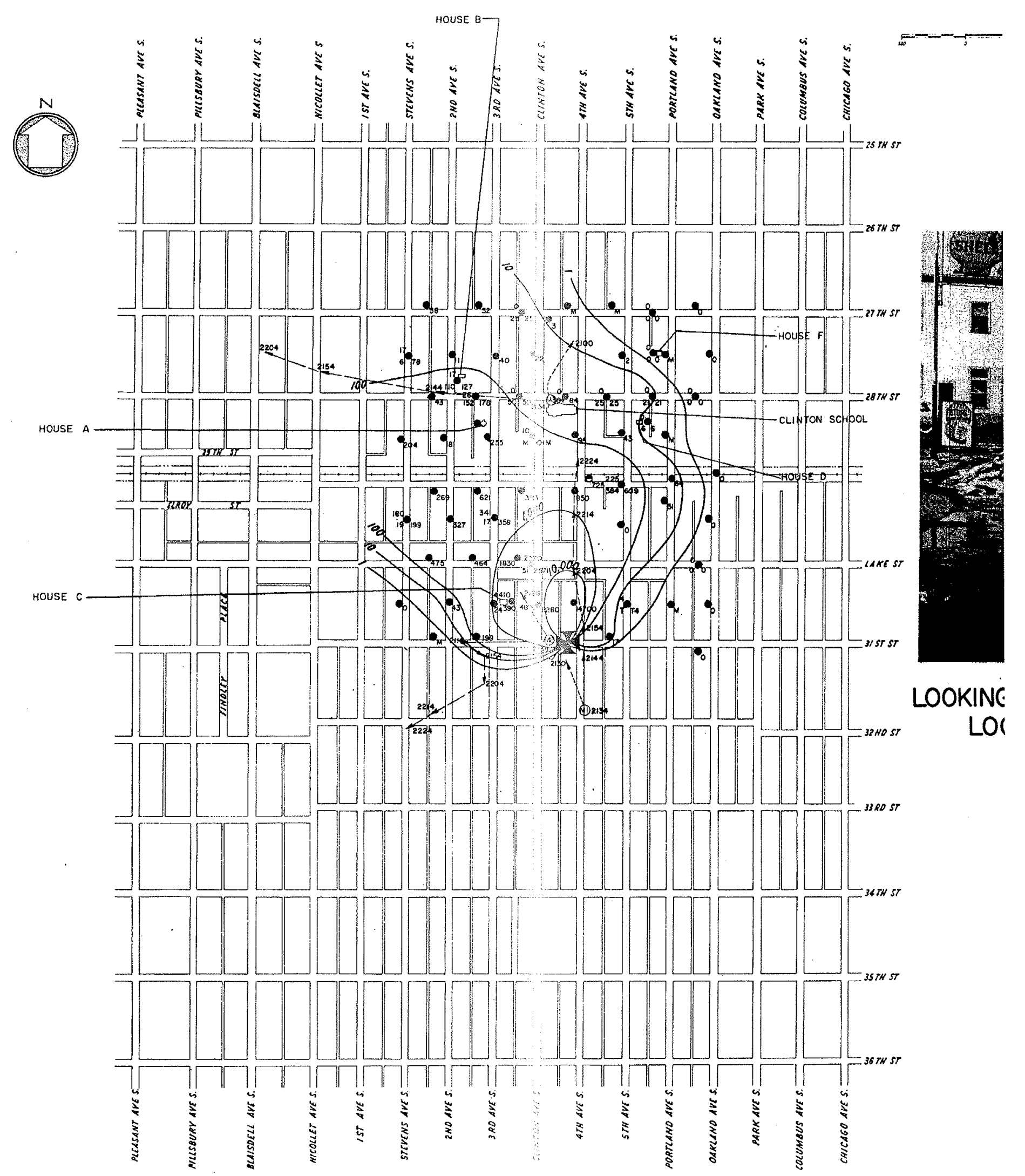




\section{$|1|$}
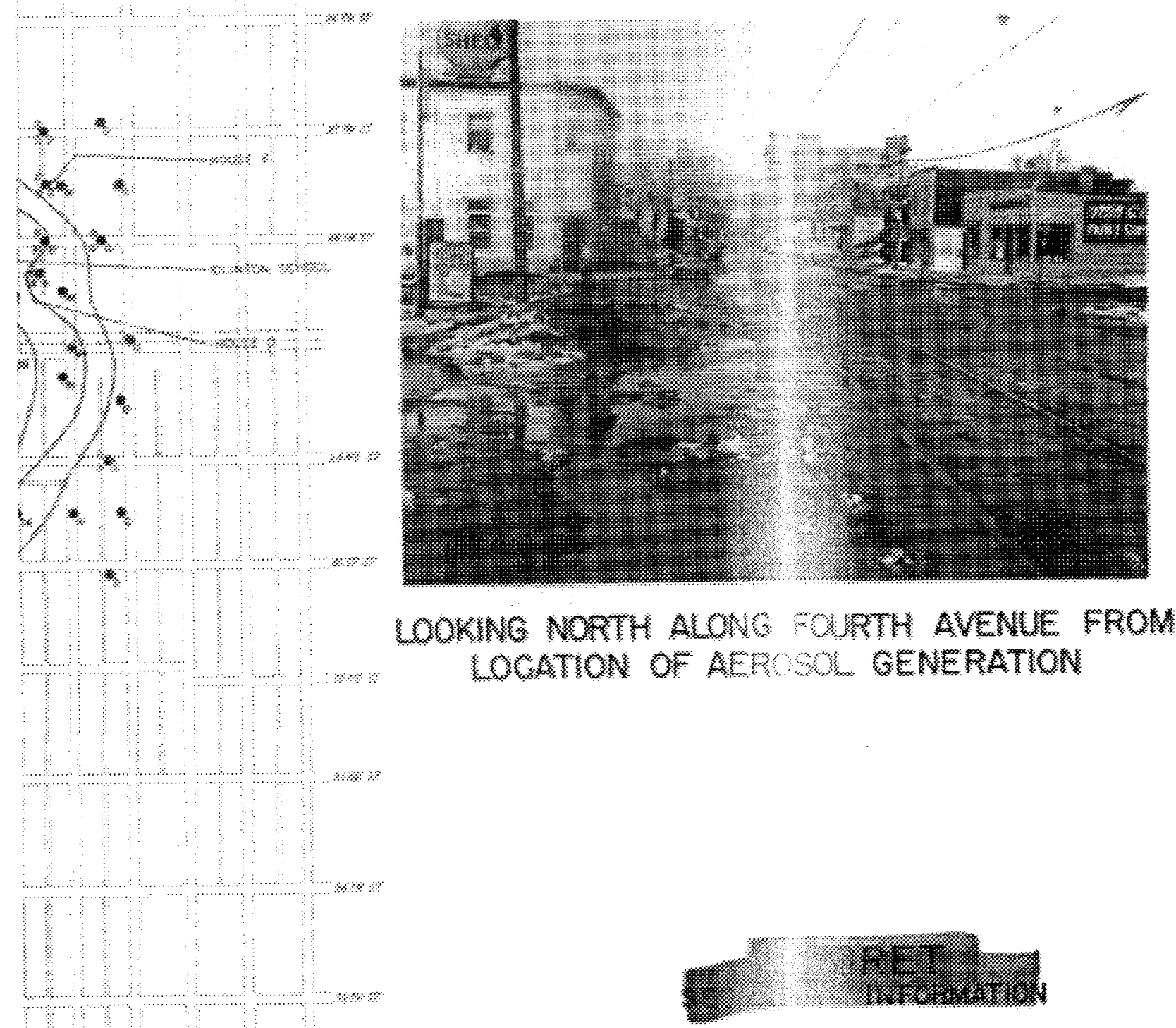

FIOURE B-19 
SUMMARY OF CLINTOI SCHOOL DOSACES *

FT 0008c

\begin{tabular}{|c|c|c|c|c|c|c|c|c|c|}
\hline \multirow[b]{2}{*}{ Outside } & \multicolumn{2}{|c|}{ Ground } & \multicolumn{2}{|c|}{ Ground Floor } & \multicolumn{2}{|c|}{ First Floor } & \multicolumn{2}{|c|}{ Second Floor } & Roof \\
\hline & 110 & 7 & & & 51 & $\mathrm{~T}$ & 50 & $\mathbf{T}$ & 50 \\
\hline Inside & & & 15 & 3 & 19 & 12 & 16 & 8 & \\
\hline & & & & 33 & & & & 43 & \\
\hline & & & & 35 & & & & & \\
\hline
\end{tabular}

* Dosages are expressed in particleminutes per Iiter; T represents trace dosage, i.e., a count not exceeding 15 fluorescent particles. When more than one sampler is involved, values are listed on separate lines. Double entries for a given column represent incremental dosages ontained with sequentially exposed filter units.

** The sampler array for this and other tests is found in Figs. $\mathrm{V}-28$ through $\mathrm{V}-31$. 
Point-source release of 7.4 gms of $\mathrm{NJZ} 2266$ over a period of 5 minutes starting at 2304 CST from a vehiclemounted blower disperser located at point

SAMPLING

\section{Location and Exposure}

Membranewilter sampling equipment located at 92 stations as shown on test-array map by following symbols:

Outdoor sampler at height between 1 and 6 feet.

Outdoor sampler at height above or below geneial terrain level as indicated by note.

Indoor sampler at location indicated by test-array hap or text.

Resu1ts

A11 samplers operated to measure total dosages. In addition, samplers at selected stations were operated incrementally, as shown by the sampling period and the corresponiting incremont dosage given to the left of the station symbol.

Sampling period

$2300-2345$ CST

$2400-0015$ CST

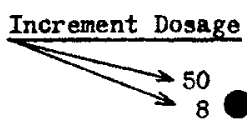

Total Dosage (particle-minutes per liter)

$T=$ trace dosage

$H=$ maliunction or data missing

Since sampling period was not continuous, the actual total dosage in some cases is probably more than indicated.

\section{METEOROLOGY}

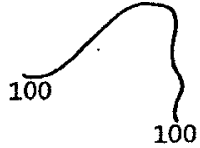

Dosage contour with values expressed in particle-minutes per litor.

Equipment and Measurement

At street level, wind direction continuously recorded, and air and surface temperatyres, vind velocity, and other metoorological observations taken at stations designated as (M1) and (M2) .

Sinilar observations at roof top level (35 feet above surface, at SW corner of the school building) and wiresonde ascents made at meteorological station (K3) .

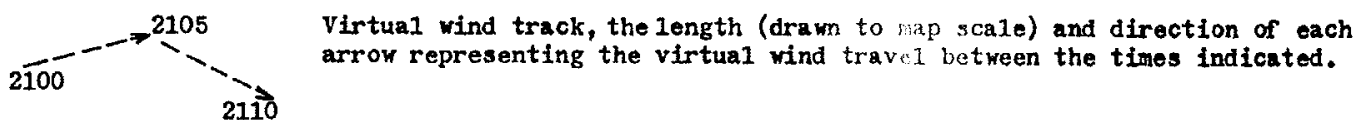

Balloon track representing wind-drift observation at the tine indicated.

Winds

Roof -level winds southeaster $1 \mathrm{y}$ at $1.9 \mathrm{mph}$; street-1evel winds 30 therly at 0.5 aph.

\section{Stability}

$3.8^{\circ} \mathrm{F}$ inversion from $6-300 \mathrm{ft}$.

Sky

Clear; ground fog, which was forming about $2200 \mathrm{CST}$, changed to $i c e$ fog and obscured sky from view at approximately $0000 \mathrm{CST}$.

Temperature

$21-24^{\circ} \mathrm{F}$ at 2 meters in the test area.

Moisture

Hixing ratio of $2.1 \mathrm{gm} / \mathrm{kgm}$ dry air. 

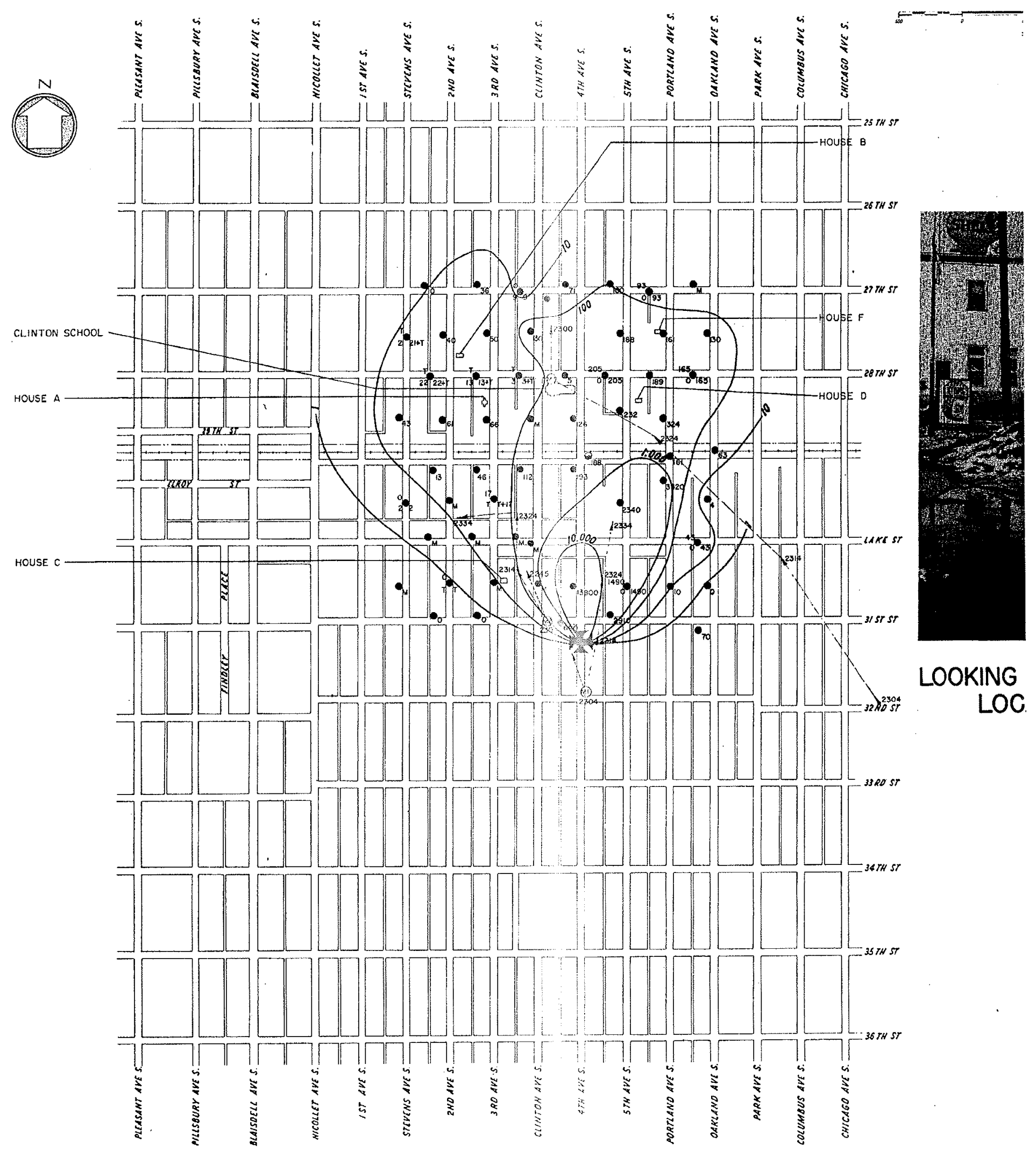

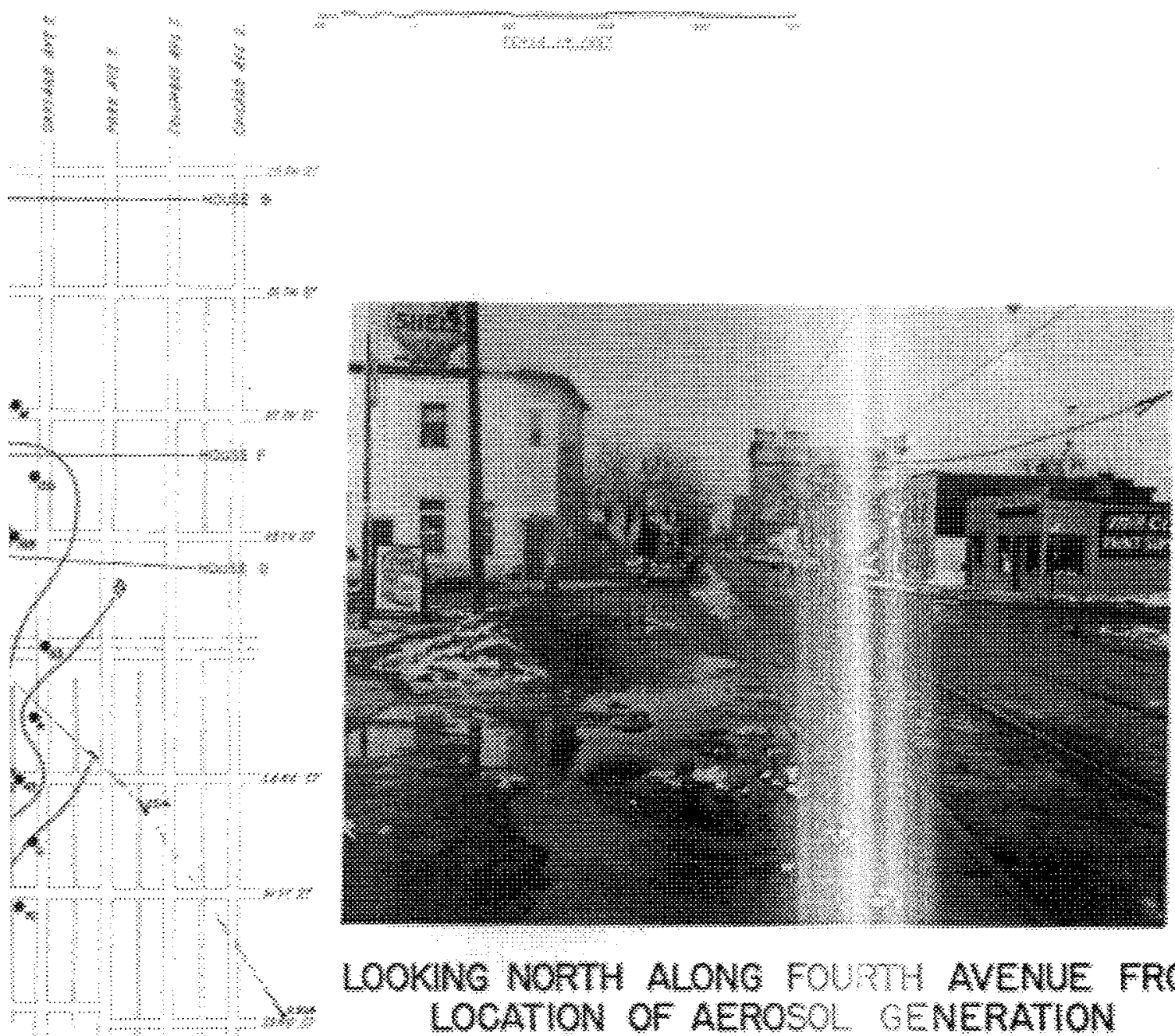

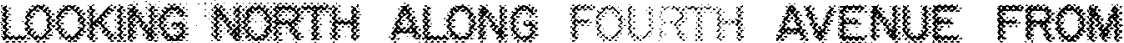 Lomatok oF AEOSW
}

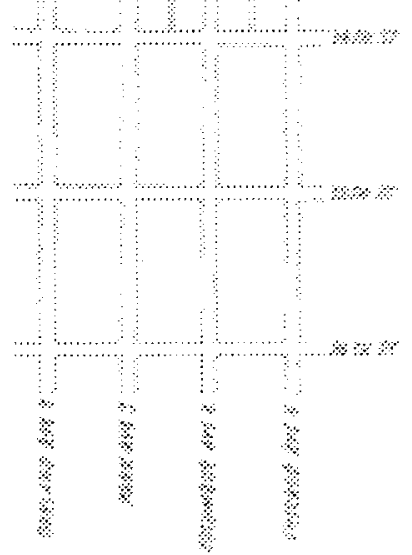

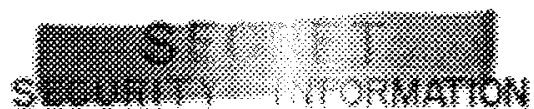 \\ woure $3-20$ \\ TEST ARRAY MVO RESULTS \\ FT 0008. 2804 CST

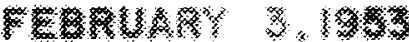




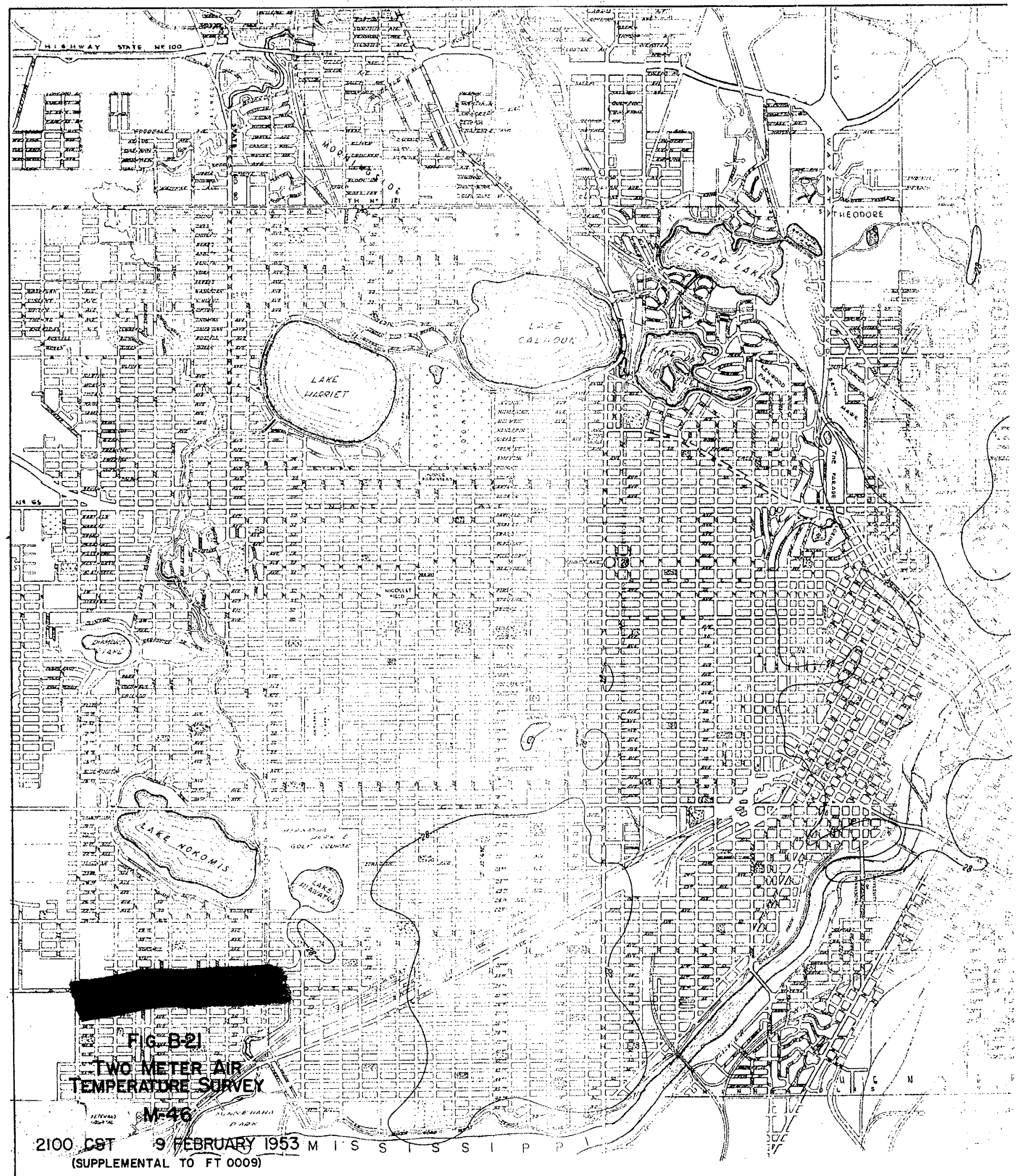

PAGE 197 
REGRADED UNCLASSIFIED - JON,DPG

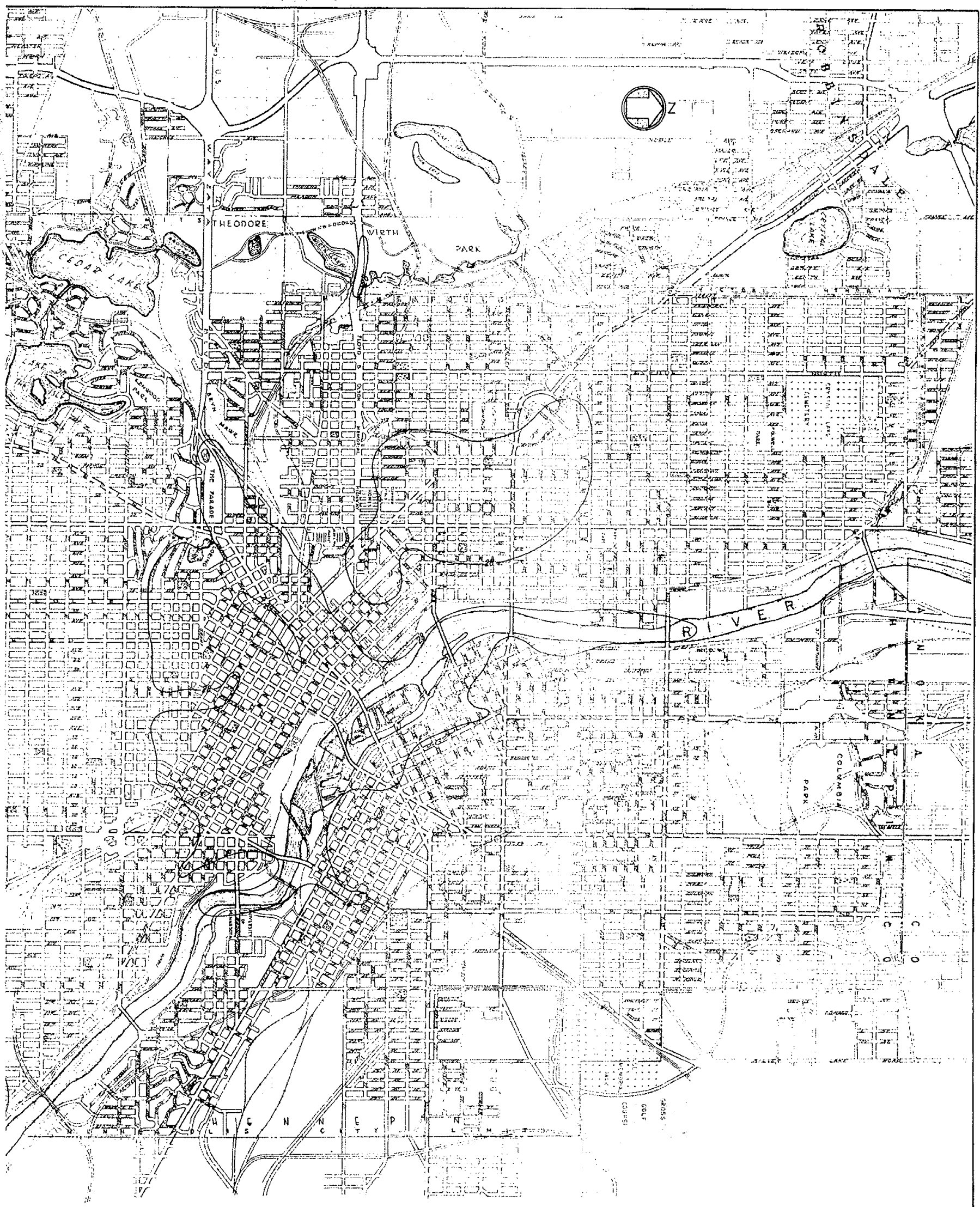


SUMMARY OF REGIONAI AND LOCAL WEATHTR

FT 0009 Survey M-46 9 Feb 1953

Synoptic Situation

A warm front through southern Iowa associated with a $1019 \mathrm{mb}$ low center near Omaha was moving toward Minneapolis. Light snow was occurring far ahead of this system and reached Minneapolis at the enc of the test. A $1046 \mathrm{mb}$ high was located over 300 miles northeast of International Falls. Surface wind flow was easterly $18 \mathrm{mph}$. Air flow at the $700 \mathrm{mb}$ level was south-southwesterly at $42 \mathrm{mph}$.

Weather reports from Wold-Chamberlain Field (Minneapolis)

\begin{tabular}{|c|c|c|c|c|c|c|c|c|}
\hline \multirow[b]{2}{*}{$\begin{array}{l}\text { Time } \\
\text { CST }\end{array}$} & \multirow{2}{*}{$\begin{array}{l}\text { Cloud } \\
\text { Height } \\
\text { (foet) }\end{array}$} & \multirow[b]{2}{*}{$\begin{array}{l}\text { Sky* } \\
\text { Cover }\end{array}$} & \multirow[b]{2}{*}{$\begin{array}{c}\text { Visibility } \\
\text { (miles) }\end{array}$} & \multirow[b]{2}{*}{ Weatherts } & \multirow[b]{2}{*}{$\begin{array}{l}\text { Temp } \\
\left(O_{F}\right)\end{array}$} & \multirow[b]{2}{*}{$\begin{array}{c}\text { Dew } \\
\text { Point } \\
\end{array}$} & \multicolumn{2}{|c|}{ Wind } \\
\hline & & & & & & & Dir & $\begin{array}{l}\text { Speed } \\
\text { (mph) } \\
\end{array}$ \\
\hline 1830 & 3800 & $\begin{array}{l}\text { Brok- } \\
\text { en }\end{array}$ & 15 & None & 26 & 16 & ENE & 14 \\
\hline 1930 & 4000 & $\begin{array}{l}\text { Scat- } \\
\text { tered }\end{array}$ & 15 & None & 26 & 16 & ENE & 16 \\
\hline 2030 & 4000 & $\begin{array}{l}\text { Scat- } \\
\text { tered }\end{array}$ & 15 & None & 27 & 18 & ENE & 17 \\
\hline 2130 & 3600 & $\begin{array}{l}\text { Over- } \\
\text { cast }\end{array}$ & 15 & None & 27 & 17 & $\mathrm{E}$ & 18 \\
\hline 2230 & 3600 & $\begin{array}{l}\text { Over- } \\
\text { cast }\end{array}$ & 15 & Light Snow & 27 & 19 & $\mathrm{E}$ & 18 \\
\hline 2330 & 4000 & $\begin{array}{l}\text { Over- } \\
\text { cast }\end{array}$ & $15^{\prime}$ & None & 28 & 18 & $\mathrm{E}$ & 19 \\
\hline 0030 & 2200 & $\begin{array}{l}\text { Obs- } \\
\text { cured }\end{array}$ & 3 & Light Snow & 27 & 18 & $E$ & 23 \\
\hline
\end{tabular}

Sea level pressure at $2130 \mathrm{CST}: 1033.2 \mathrm{mb}$ Ground condition: $3^{\prime \prime}$ to $4^{\prime \prime}$ packed snow Main streets clear Secondary Streets $2 "$ packed snow and ice Lakes were frozen

Tree cover: None

* Average cloudiness sunrise to sunset: 100\%

* and/or restrictions to visibility 
FIGURE B-22

TEMPERATURE SOUNDINGS

WINDS ALOFT

STCLOUD RAOB 9 FEB 1953

ST CLOUD

(SUPPLEMENTAL TO SURVEY M-46)

9 FEB 1953

$2100 \mathrm{CST}$

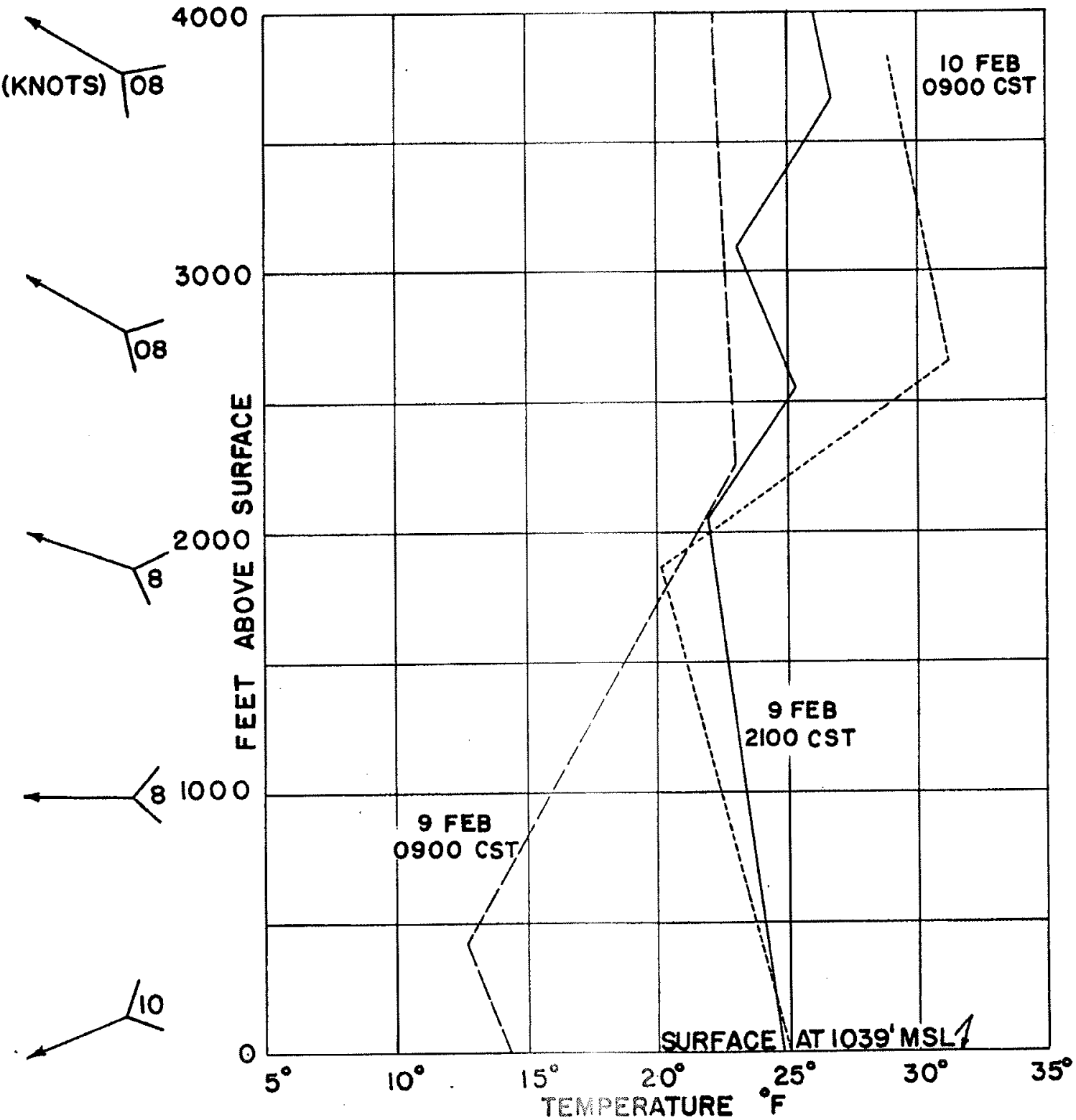

PAGE 198 


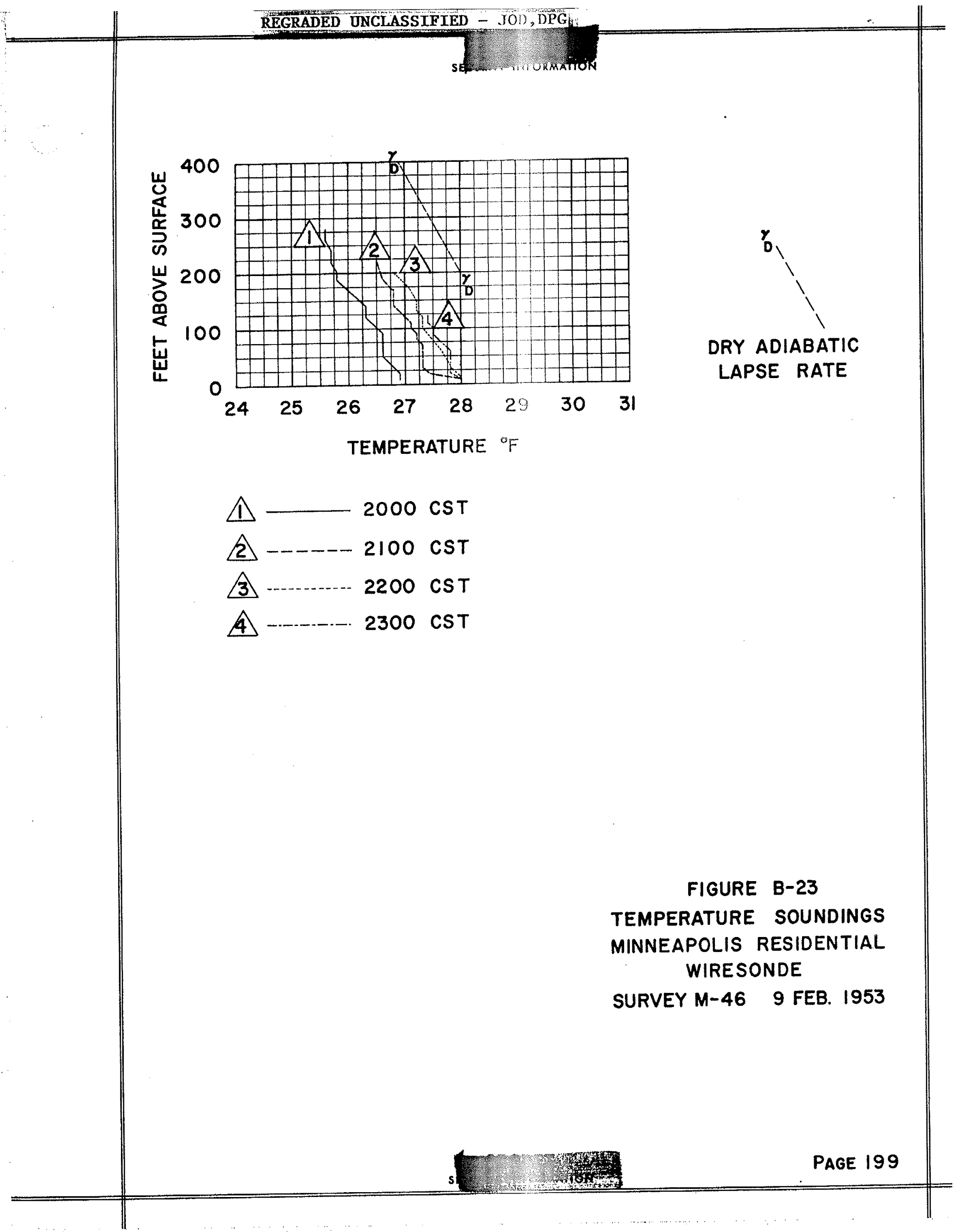




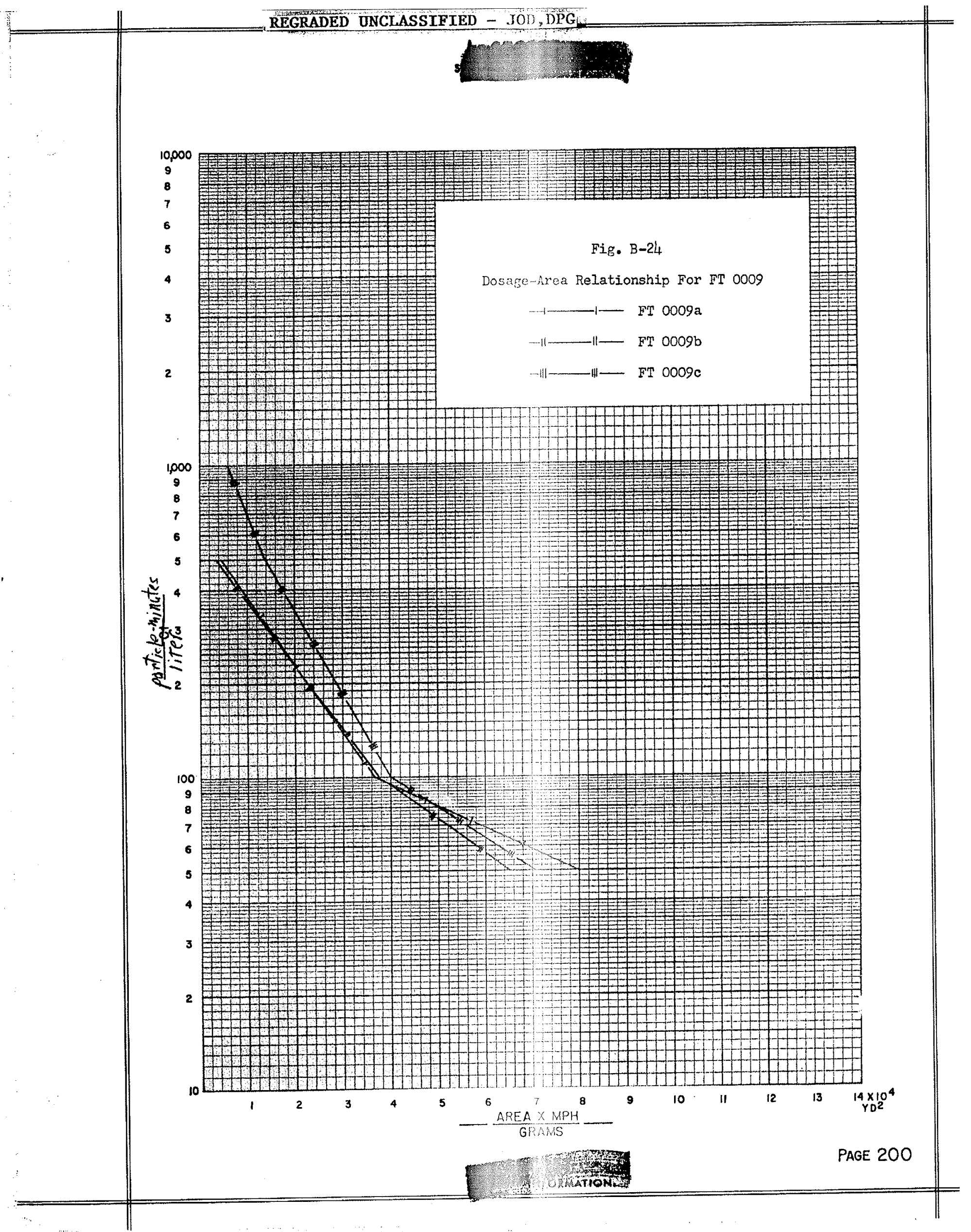


SUMMARY OF HOUSE-PENETRATION AND CLINTON SCHOOL DOSAGES*

FT $0009 a$

9 February 1953

\begin{tabular}{|c|c|c|c|c|}
\hline \multirow[b]{2}{*}{ House } & \multicolumn{3}{|c|}{ RESIDENCESWH } & \multirow[b]{2}{*}{ Second Floor } \\
\hline & Outside & Basement & First Floor & \\
\hline D & 790 & 122 & 139 & \\
\hline & & 55 & & \\
\hline
\end{tabular}

CLINTON SC:IOOLKKK

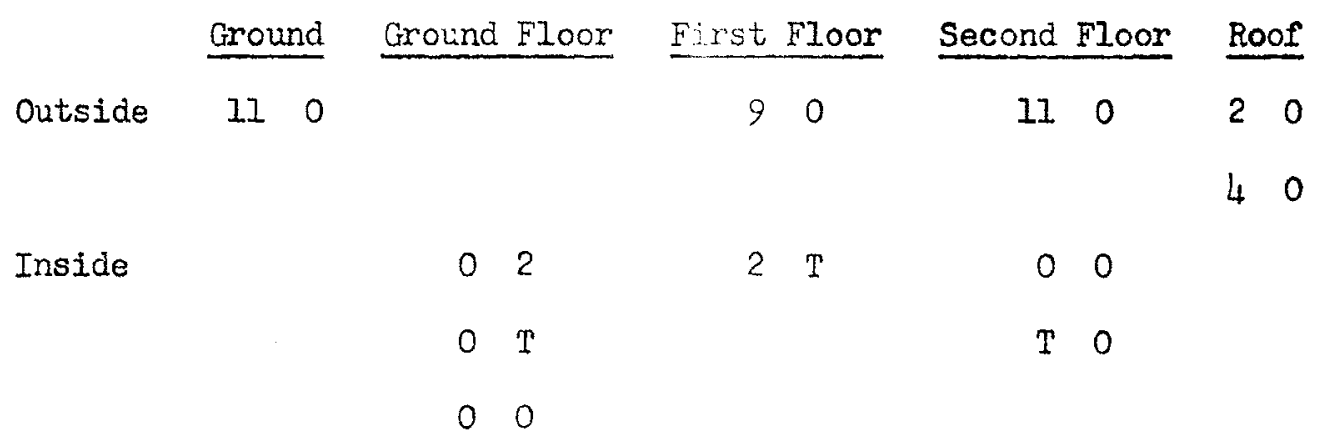

* Dosages are expressed in particle-minutes per liter; T represents trace dosage, i.e., a count not exceeding 15 fluorescent particles. When more than one sampler is involved, values are listed on separate lines. Double entries for a given column represent incremental dosages obtained with sequentially exposed filter units.

* Individual residences are described in Section V-E. With the illustration of a given house (see Figs. V-23 through V-27) is given the sumary of all dosages obtained at that house.

* The sampler array for this and other tests is found in Figs. $\mathrm{V}-28$ through $\mathrm{V}-3 \mathrm{I}$.

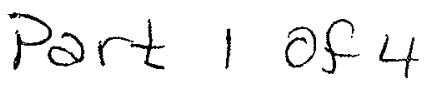


Point-source release of 12.2 gms of NJZ 2266 over a period of 5 minutes starting at 2017 CST from a vehiclemounted blower disperser at point is.

\section{SAMPLING}

Location and Exposure

Membrane-filter sampling equipment located at 93 stations as shown on test-array map by following symbols:

Outdoor sampler at height between 1 and 6 feet.

O Outdoor sampler at height above or below genoral terrain level as indicated by note.

Indoor sampler at location indicated by test-array map or text.

\section{Results}

All samplers operated to measure total dosages. In addition, samplers at selected stations were operated incrementally, as shown by the sampling period and the corresponding increment dosage given to the left of the station symbol.

Sampling Period

$2000-2045$ CST

2045-2115 CST
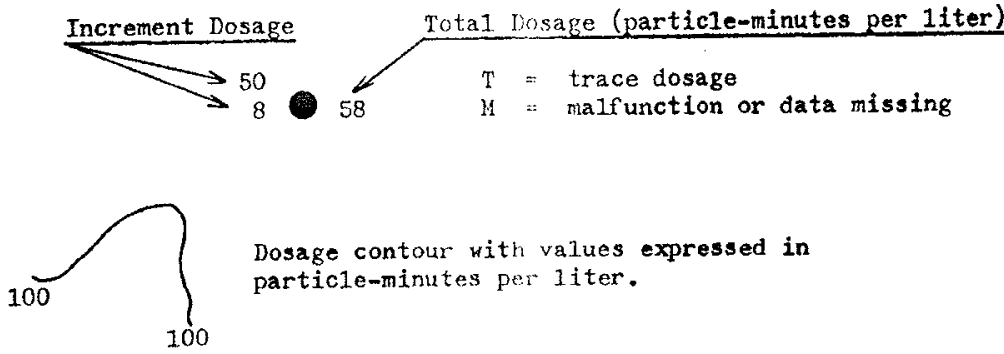

Dosage contour with values expressed in particleminutes per liter.

METEOROLOGY

\section{Equipment and Measurement}

At street level, wind direction continuously recorded, and air and surface temperatures, wind velocity, and other meteorological observations taken at stations designated as (Mi) and (M2).

Similar observations attempted at roof top level ( 35 feet above surface, at NE corner of school building) and wiresonde ascents made at meteorological station (M3). (No wind data obtained because of recorder malfunction.)

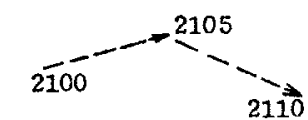

Virtual wind track, the length (drawn to map scale) and direction of each arrow representing the virtual winl travel between the times indicated.

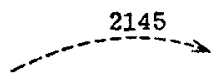

Balloon track representing wind-drif t observation at the time indicated.

\section{Winds}

Winds at treetop level estimated northeast to easterly at $16-20 \mathrm{mph}$; street-1evel winds northeaster $1 \mathrm{y}$ at $5 \mathrm{mph}$.

\section{Stability}

$1.4^{\circ}$ F lapse from $6-300 \mathrm{ft}$.

$\underline{5 k y}$

Low scattered clouds at $2000 \mathrm{CST}$, with base about $4000 \mathrm{ft}$, ahove the surface, became overcast at $2130 \mathrm{CST}$. A middle deck with bases 9,000 to $11,000 \mathrm{ft}$. above the surface persisted throughout the test period.

\section{Temperature}

$27-28^{\circ} \mathrm{F}$ at 2 meters in the test area.

\section{Moisture}

Mixing ratio of $2.1 \mathrm{gm} / \mathrm{kgm}$ dry air. 


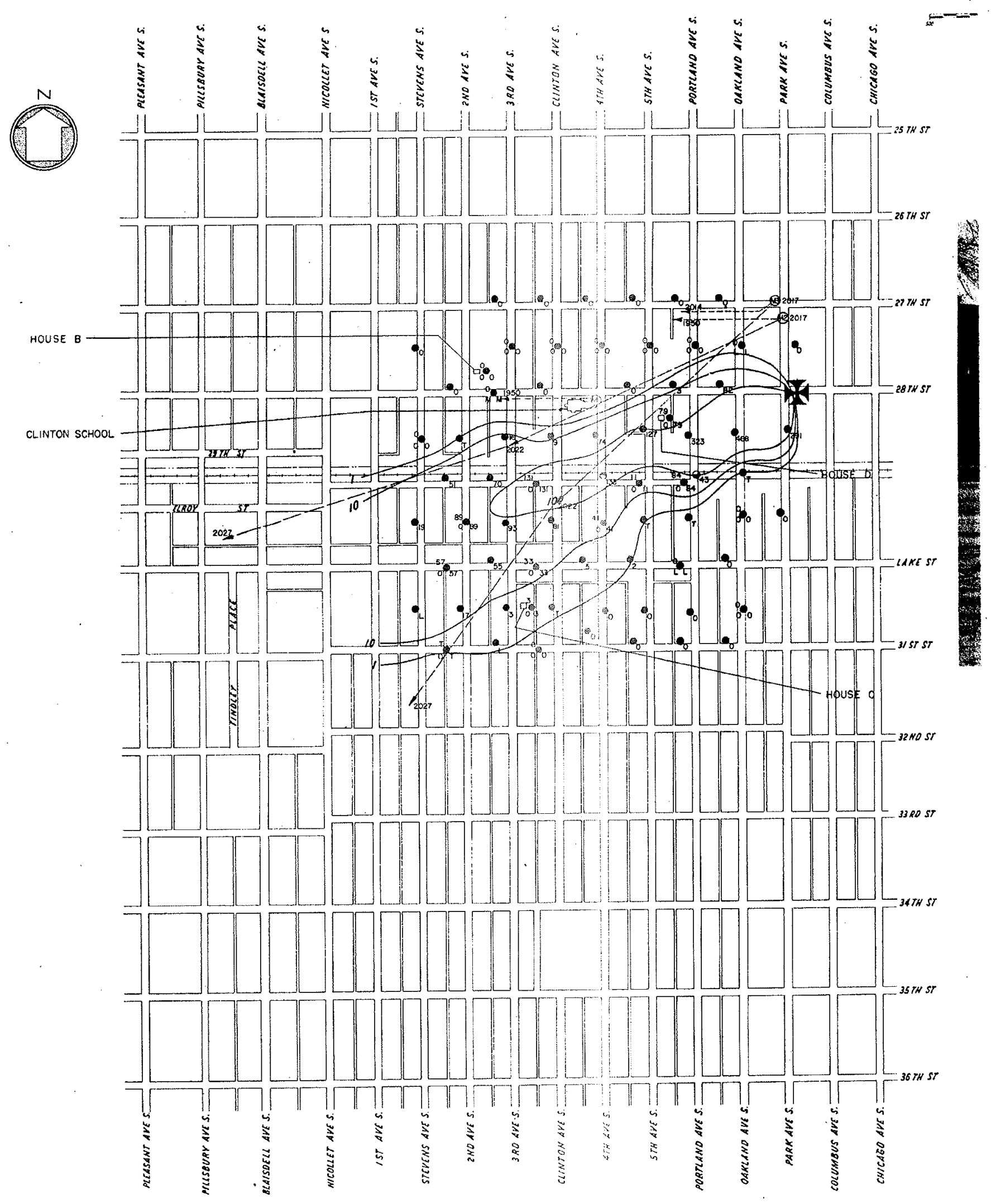




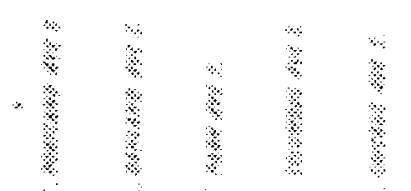

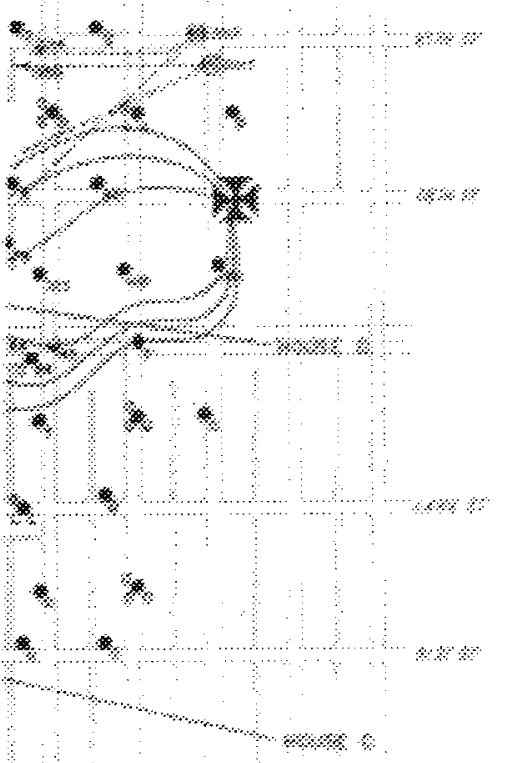

at

at

ж)

से

अ

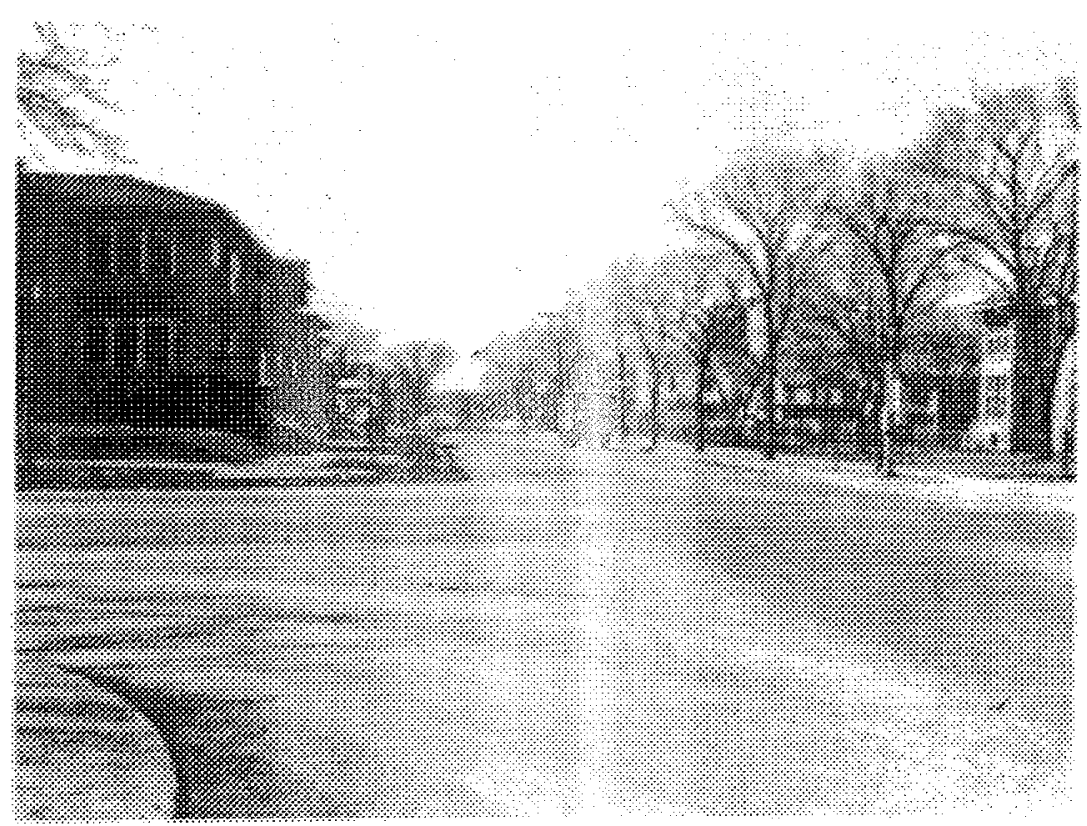

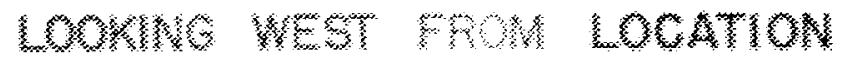

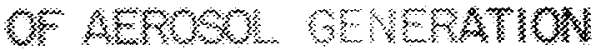

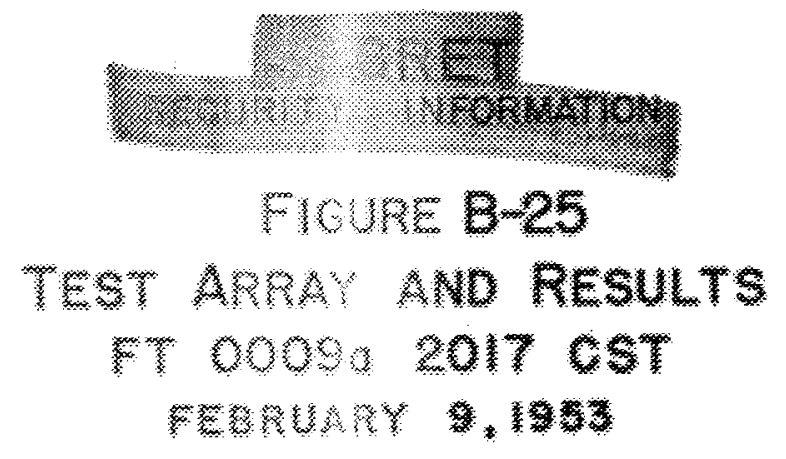

Pack 20 
SUMMARY OF HOUSE-PENETRATION AND CLINTON SCHOOL DOSAGES* FT $0009 \mathrm{~b}$

9 February 1953

\begin{tabular}{|c|c|c|c|c|}
\hline \multirow[b]{2}{*}{ House } & \multicolumn{3}{|c|}{ RESIDENCES } & \multirow[b]{2}{*}{ Second Floor } \\
\hline & Outside & Basement & First Floor & \\
\hline D & $395 \mathrm{~T}$ & $31 \quad 10$ & $\begin{array}{ll}52 & 13\end{array}$ & \\
\hline & & 398 & & \\
\hline
\end{tabular}

\section{CLINTON SCHOOLF:* *}

\begin{tabular}{|c|c|c|c|c|c|c|c|c|c|}
\hline \multirow[b]{2}{*}{ Outside } & Ground & \multirow[t]{2}{*}{ Ground } & Floor & \multicolumn{2}{|c|}{ First Floor } & \multicolumn{2}{|c|}{ Second Floor } & \multicolumn{2}{|c|}{ Roof } \\
\hline & 1362 & & & 3.28 & 0 & 60 & 0 & 11.2 & 0 \\
\hline & & & & & & 1143 & 0 & 135 & 0 \\
\hline Inside & & 4 & 2 & 24 & 5 & 13 & 7 & & \\
\hline & & 16 & 6 & & & & & & \\
\hline & & 13 & 9 & & & & & & \\
\hline
\end{tabular}

* Dosages are expressed in particle-minutes per liter; T represents trace dosage, i.e., a count not exceeding 15 fluorescent particles. When more than one sampler is involved, values are listed on separate lines. Double entries for a given column represent incremental dosages obtained with sequentially exposed filter units.

** Individual residences are described in Section $V-E_{0}$. With the illustration of a given house (see Figs. V-23 through V-27) is given the summary of all dosages obtained at that house.

**** The sampler array for this and other tests is found in Figs. $V-28$ through $V-3 I$.

Part 1 of 4 


\section{AEROSOL GENERATION}

Point-source release of 12.3 gms of $\mathrm{NJZ} 2266$ over a period of 5 minutes starting at 2135 CST from a roof mounted blower disperser ( $35 \mathrm{ft}$. above street level) located at point

\section{SAKPLING}

Location and Exposure

Kembrane-filter sampling equipment located at 93 stations as shown on test-array map bollowing syrabols:

Outdoor sampler at height between 1 and 6 feet.

- Outdoor sampler at height above or below general terrain level as indicated by note.

$O$ Indoor sampler at location indicated by test-array map or text.

\section{Results}

A11 samplers operated to measure total dosages. In addition, samplers at selected stations were operated incrementally, as shown by the sampling period and the corresponding increment dosage given to the left of the station symbol.

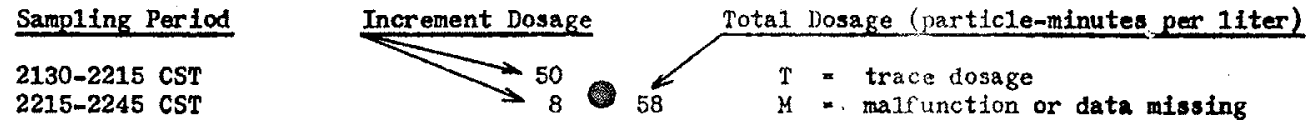

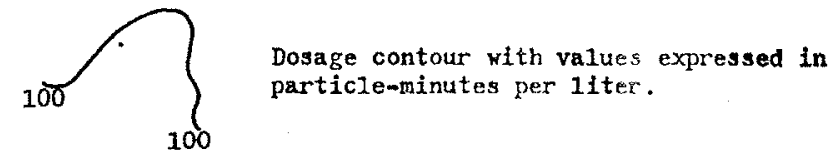

\section{YETEOROLOGY}

\section{Equipment and Measurement}

At street level, vind direction continuously recorded, and air and surface temperatuces, wind velocity, and other meteorological observations taken at stations designated as. (MI) and (43).

Similar observations attempted at roof top level ( 35 feet above surface, at NE corner of school bullding) and viresonde ascents made at meteorological station (183). (No wind data obtained because of recorder malfunction.)

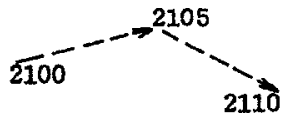

Virtual wind track, the length (dran to map scale) and direction of each arrow representing the virtual wind travel between times indicated.

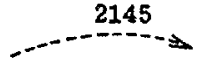

Balloon track representing wind-drift observation at the time indicated.

\section{Winds}

Winds at treetop 1evel estimated northeast to easterly at $15-20 \mathrm{mip}$; street-1evel winds northeasterly at $5 \mathrm{mph}$.

\section{Stability}

$1,9^{\circ} F$ lapse from $6-300$ feot.

\section{Sky}

Low scattered clouds at 2000 CST, with base about $4000 \mathrm{ft}$. above the surface, became overcast at 2130 CST. A middle deck with bases 9,000 to $11,000 \mathrm{ft}$, above the surface pexsisted throughout the test period.

\section{Temperature}

$27-28^{\circ} \mathrm{F}$ at 2 meters in the test area.

\section{Molsture}

Mixing ratio of $2.1 \mathrm{gm} / \mathrm{kgm}$ dry air.

$$
\text { Part } 2 \text { of } 4
$$




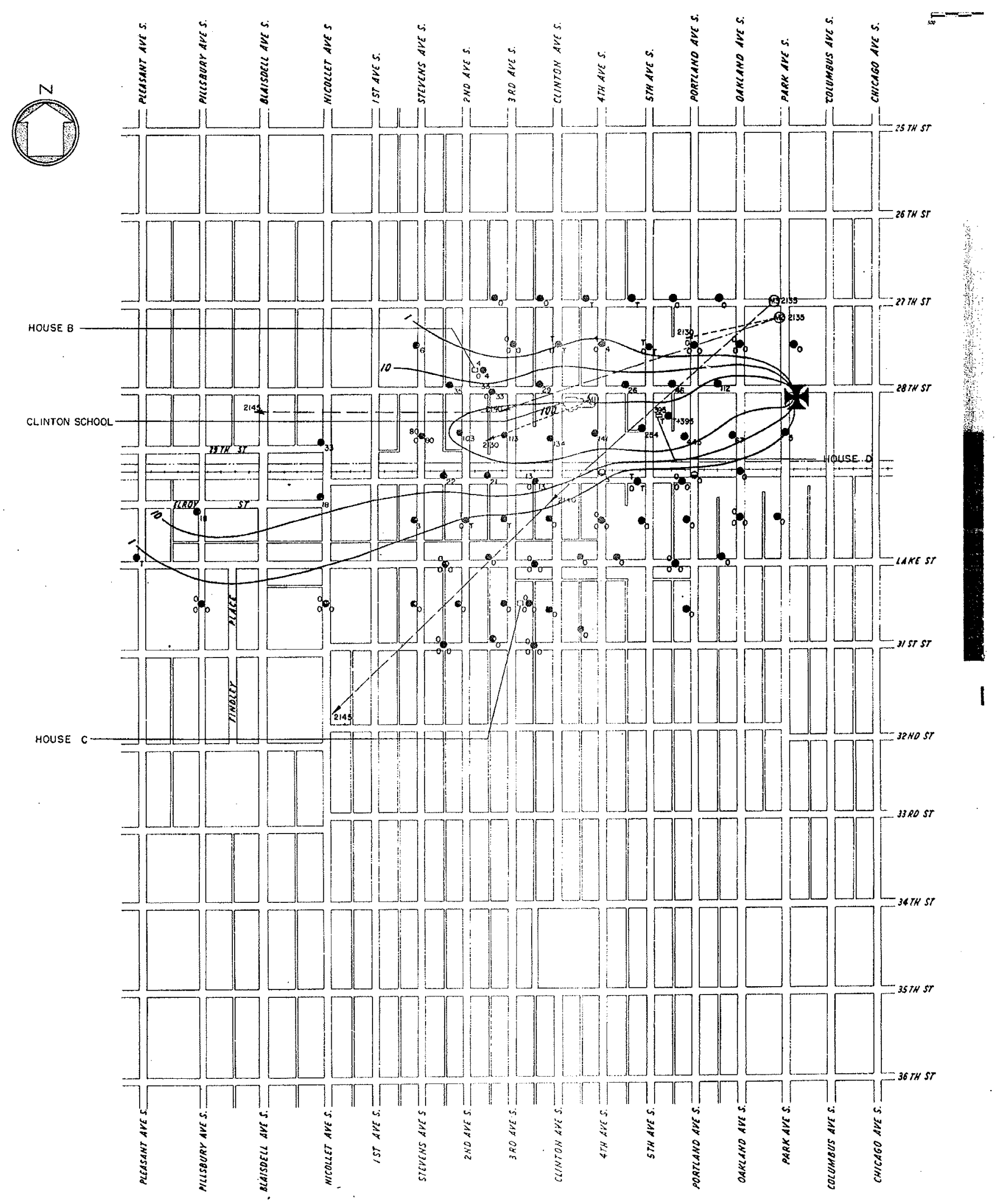

Part 3 of 4 

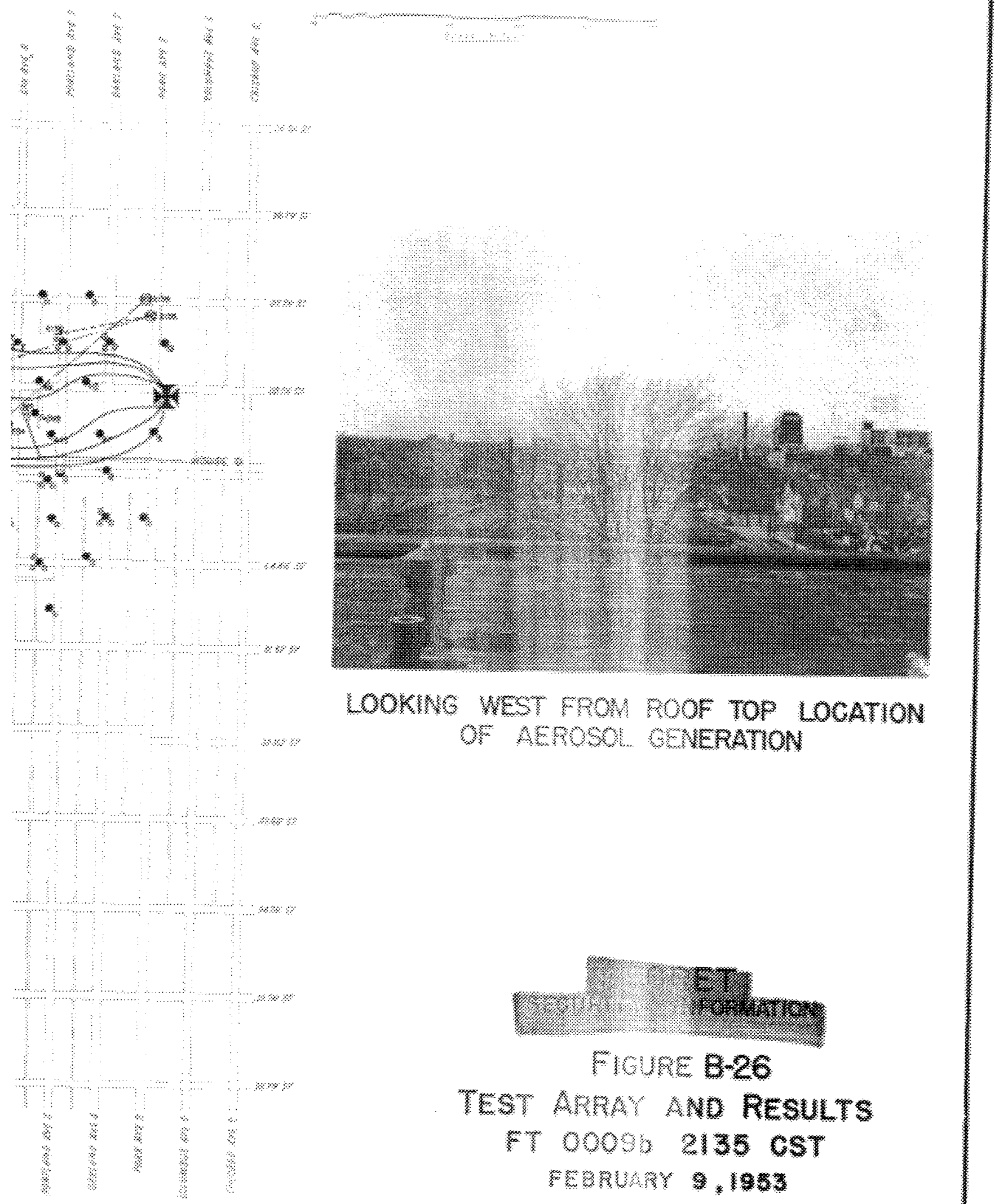
OF A moS" onERATWN

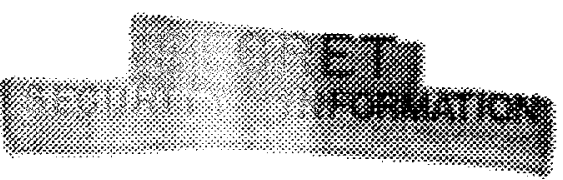

Foune B-26 TEST MRRA AND RESULTS FT 000कs $2135 \mathrm{csT}$ grentwh 1953 


\section{SUMMARY OF CLINTON SCHOOL DOSAGES* \\ FT 0009a然 9 February 1953}

\begin{tabular}{|c|c|c|c|c|c|c|}
\hline & Ground & Ground Floor & Fisst Floor & Secono & Floor & Roof \\
\hline \multirow[t]{2}{*}{ Outside } & 1170 & & $136 \mathrm{~T}$ & 202 & 0 & 1910 \\
\hline & & & & 132 & 0 & 3180 \\
\hline \multirow[t]{3}{*}{ Insicie } & & $34 \quad 12$ & 257 & 29 & 13 & \\
\hline & & 66 & & & & \\
\hline & & $35^{\prime} \quad 26$ & & & & \\
\hline
\end{tabular}

* Dosages are expressed in particle-minutes per liter; $\mathrm{T}$ represents trace dosage, $i, e_{\circ}$, a count not exceeding 15 fluorescent particles. When more than one sampler is involved, values are listed on separate lines. Double entries for a given column represent incremental dosages obtained with sequentially exposed filter units.

** The sampler array for this and other tests is found in Figs. $\mathrm{V}-28$ through $\mathrm{V}-3 \mathrm{I}$. 
AEROSOL GENERATION

Point-source release of 12.0 gms of NJZ 2266 over a period of 5 lnutes atarting at 2305 CST from a vehiclemounted blover disperser located at point 1 .

SAMRLING

Location and Exposure

Membrane-filter sumpling equipment located at 93 stations as shown on test-array map by following symbols: Outdoor sampler at helght between 1 and $6 \mathrm{fect}$.

outdoor sampler at height above or belov general terrain lovel as indicated by note.

Indoor sampler at location indicated by test-crray map or, text.

\section{Results}

A11 samplers operated to measure total dosages. In addition, samplers af selected stations were operated incrementally, as show by the sampling period and the corresponding incremont dosage given to the left of the station symbol.

Sampling Period

2300-2345 CST

2345-0015 CST

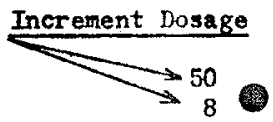

58 Tota1 Dosage (particle-minutes per liter)

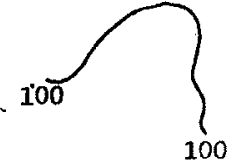

Dosage contour with values expressed in

$T$ trace dosage

$M$ * malfunction or data missing

\section{METEOROLOGY}

Equipinent and Measurement

At street level, wind direction continuously recorded, and air and surface temperatures, wind velocity, and other meteorological observations taken at stations designated as (III) and (in2).

Similar observations at rooftop level ( 35 feet above surface, at NE corner of school bullding) and wresonde ascents made at meteorological station (K3) -

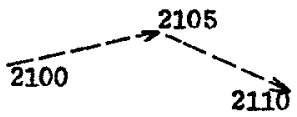

Virtual wind track, the length (drawn to map scalo) and direction of each arrow representing the virtual wind travel between indicated times.

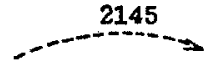

Balloon track representing wind-drift observation at the time indicated.

Winds

Roof-level winds northeasterly at $10 \mathrm{mph}$; street-level winds ast-northeasterly at $6.5 \mathrm{mph}$.

\section{Stability}

$1.9^{\circ} \mathrm{F}$ lapse from 6-300 ft.

Sky

Low scattered clouds at $2000 \mathrm{CST}$, with base about $4000 \mathrm{ft}$. above the surface, became overcast at $2130 \mathrm{CST}$.

A midd1e deck with hases 9,000 to $11,000 \mathrm{ft}$. above the surface persisted throughout the test period.

\section{Temperature}

$27-28^{\circ} F$ at 2 meters in the test area.

Moisture

Mixing ratio of $2.1 \mathrm{gm} / \mathrm{kgm}$ dry air. 

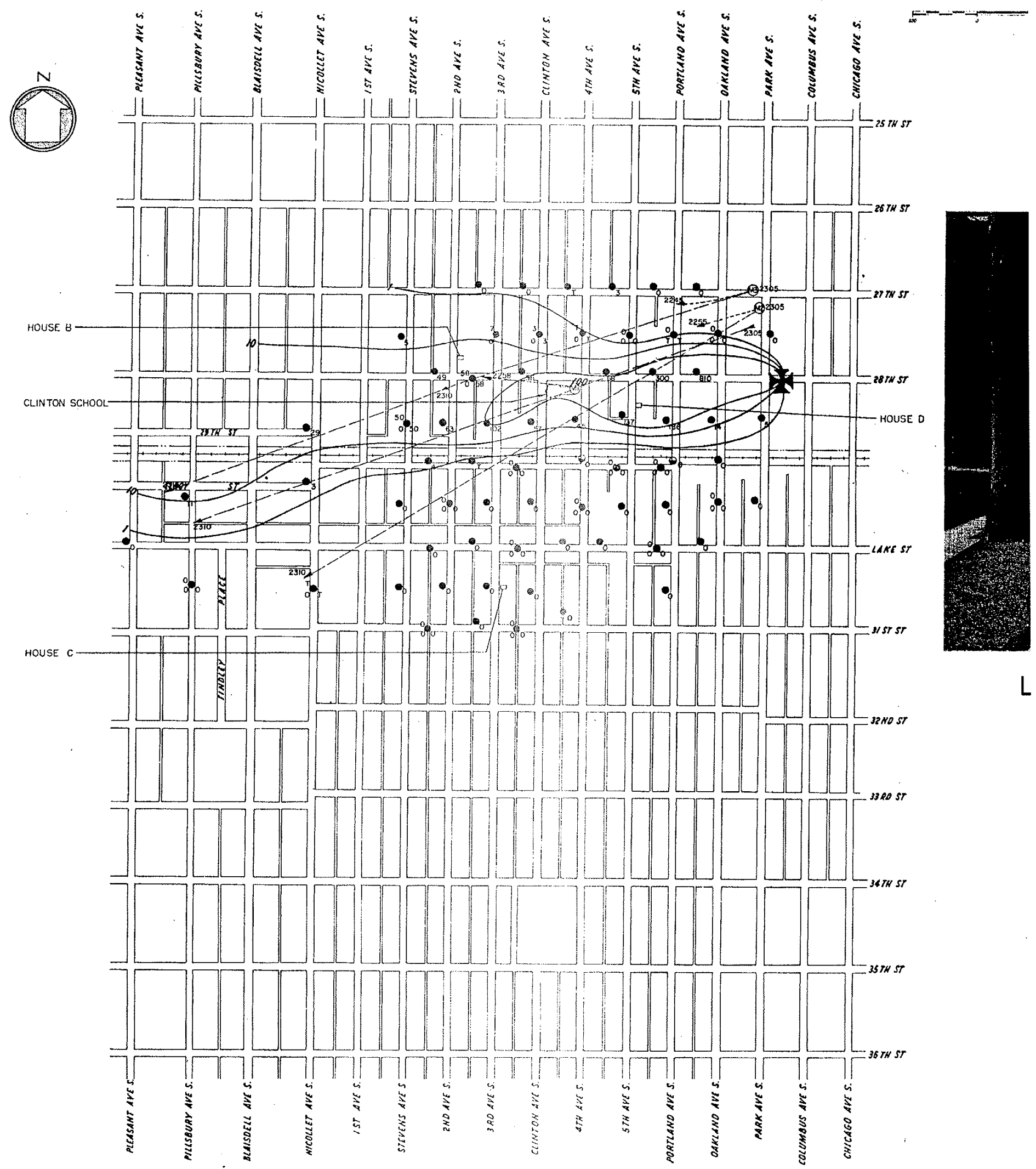

Part 3 of 4 


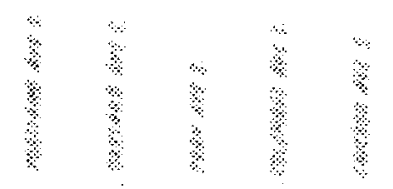

क्ष
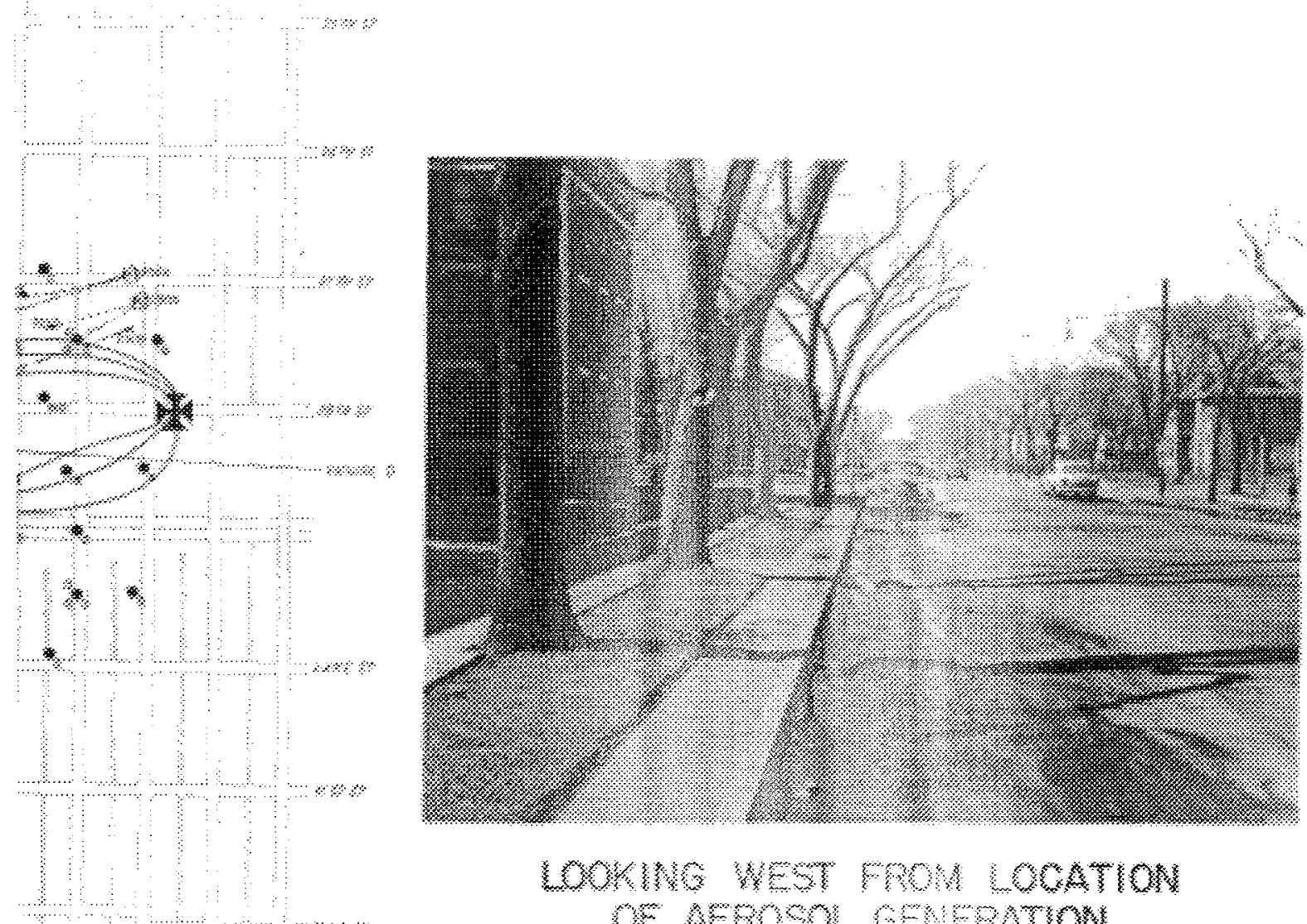

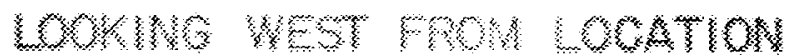

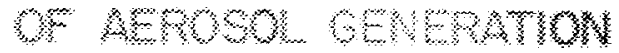




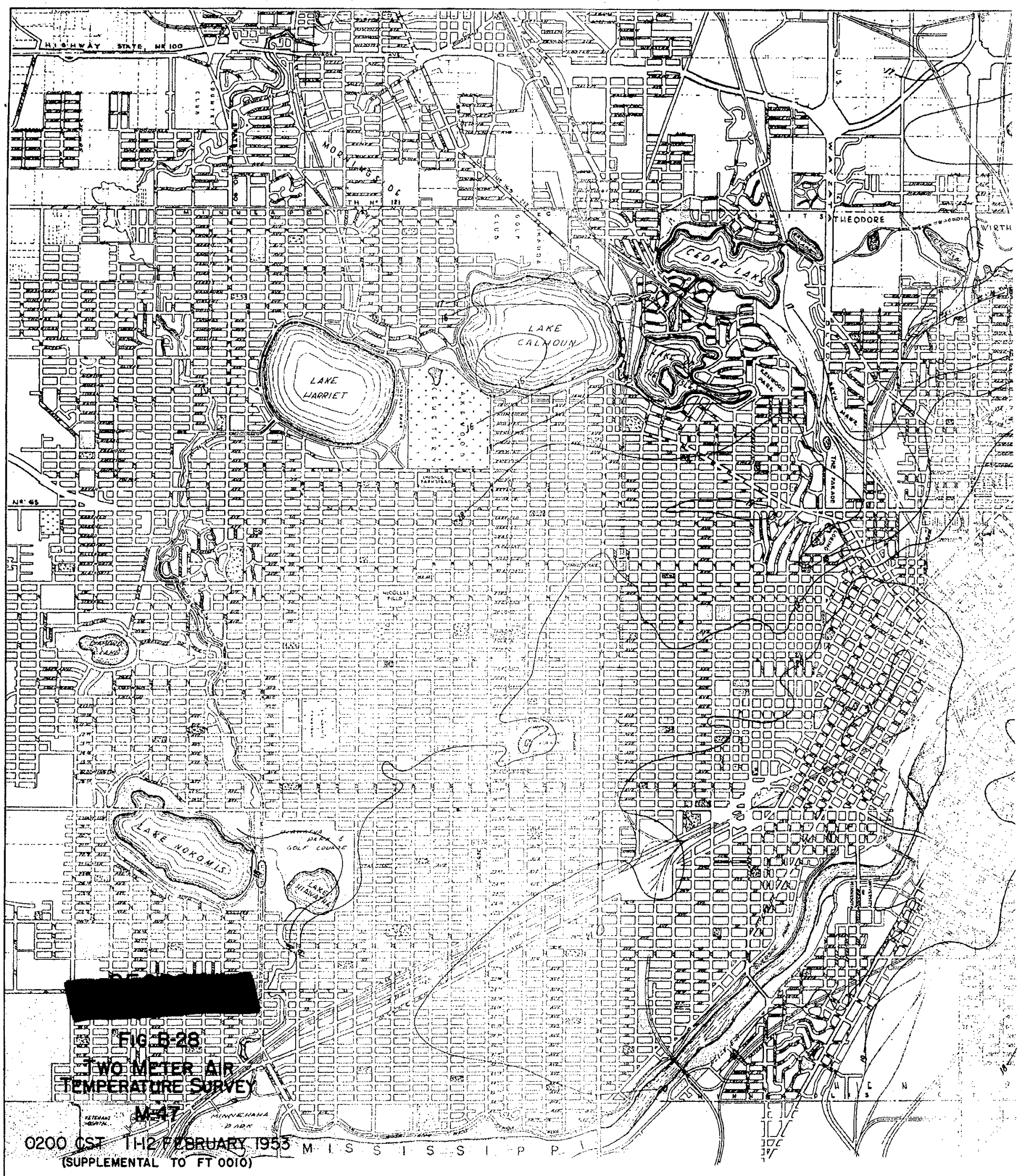

PAGE 204

PART 1 of 3 


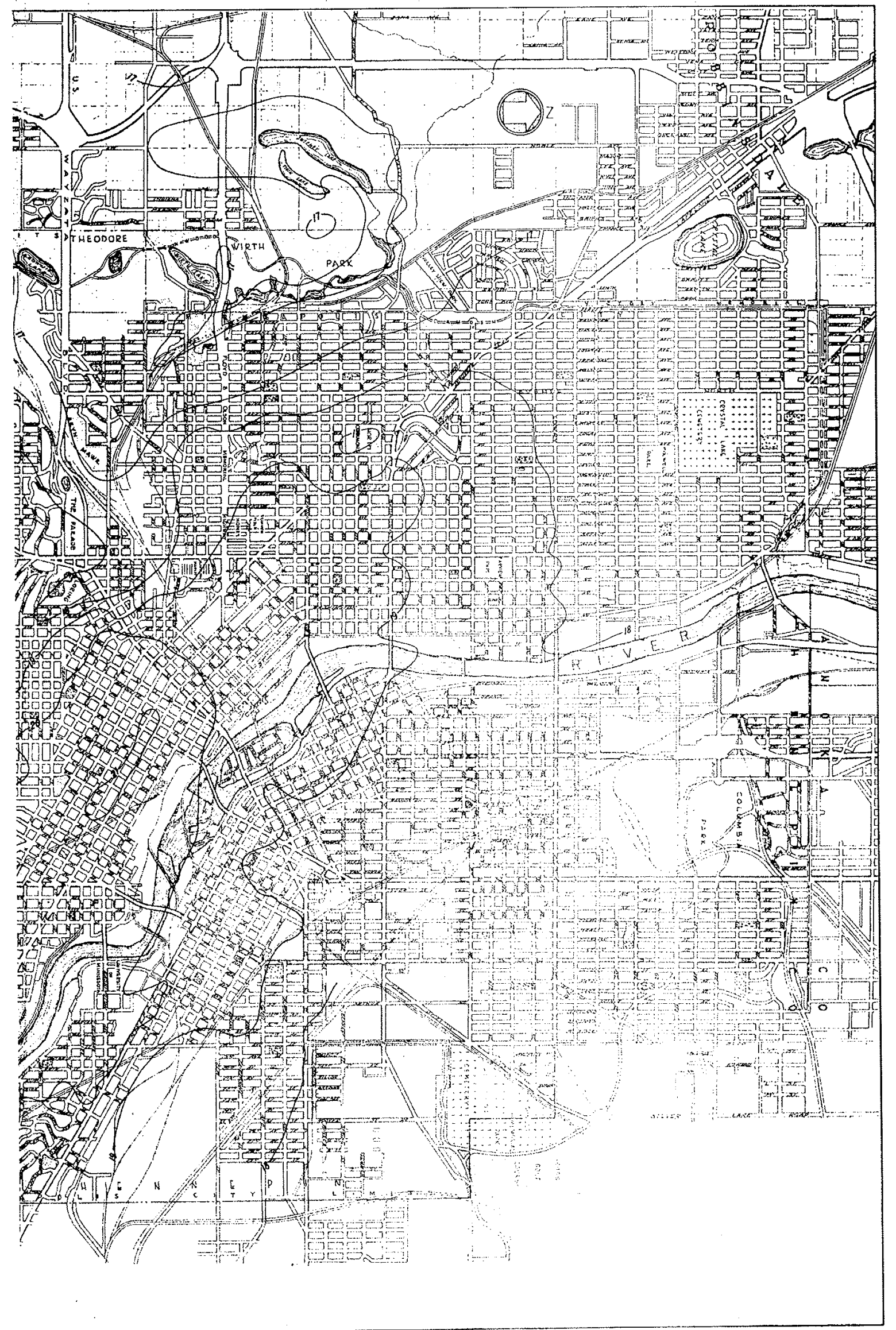

Synopti

A cold

of snow

front d

winds $w$

was fro.

Weather

Time

CST

2230

2330

0030

0130

0230

0330

0430

0530

0630

Sea lev

Ground ।

Tree co

* Aver

th: and/1 
SUIMARY OF REGIONAL AND LOCAL WEATHER

FT 0010 Survey $M-47 \quad 11-12$ Feb 1953

\section{Synoptic Situation}

A cold front had passed Minneapolis the night before leaving a 4 "layer of snow. Another cold front was approaching from the northwest. This front did not pass the station until well after this test. Surface winds were generally from the northwest at 8 to $12 \mathrm{mph} .700 \mathrm{mb}$ air flow was from the northwest at $25 \mathrm{mph}$.

Weather Reports from Wold Chamberlain Field (Minneapolis)

\begin{tabular}{|c|c|c|c|c|c|c|c|c|}
\hline & Cloud & & & & & & Wi & \\
\hline $\begin{array}{l}\text { Time } \\
\text { CST }\end{array}$ & $\begin{array}{l}\text { Helght } \\
\text { (feet) }\end{array}$ & $\begin{array}{l}\text { Sky* } \\
\text { Cover }\end{array}$ & $\begin{array}{c}\text { Visibility } \\
\text { (miles) }\end{array}$ & Weather* & $\begin{array}{l}\text { Termp } \\
(\mathrm{OF}) \\
\end{array}$ & $\begin{array}{l}\text { Dew } \\
\text { Point }\end{array}$ & Dir & $\begin{array}{l}\text { Speed } \\
\text { (mph) }\end{array}$ \\
\hline 2230 & & Clear & $15+$ & & 22 & 19 & WNW & 10 \\
\hline 2330 & & Clear & $15+$ & & 20 & 16 & W & $?$ \\
\hline 0030 & & Clear & $15+$ & & 19 & 15 & NW & $\begin{array}{l}9 \\
0\end{array}$ \\
\hline 0130 & & Clear & $15+$ & & 19 & 15 & NW & 8 \\
\hline 0230 & & Clear & $15+$ & & 18 & 14 & WNW & 7 \\
\hline 0330 & 9000 & $\begin{array}{l}\text { Scat- } \\
\text { tered }\end{array}$ & $15+$ & & 18 & 114 & $\mathrm{NW}$ & 10 \\
\hline 0430 & 3100 & $\begin{array}{l}\text { Over- } \\
\text { cast }\end{array}$ & $15+$ & & 20 & 17 & NW & 11 \\
\hline 0530 & 3000 & $\begin{array}{l}\text { Over- } \\
\text { cast }\end{array}$ & $15+$ & & 20 & 17 & WNW & 8 \\
\hline 0630 & 3300 & $\begin{array}{l}\text { Over- } \\
\text { cast }\end{array}$ & 15 & & 21 & 18 & WNW & 11 \\
\hline
\end{tabular}

Sea level pressure at $0230 \mathrm{CST}: 1015.6 \mathrm{mb}$

Ground condition: Packed snow with layer fresh snow on top Lakes were

Tree cover: None frozen

* Average cloudiness sunrise to sunset: $100 \%$

* and/or restrictions to visibility 
FIGURE B-29

TEMPERATURE SOUNDINGS

ST CLOUD RAOB II FEB 1953

(SUPPLEMENTAL TO SURVEY M-47)

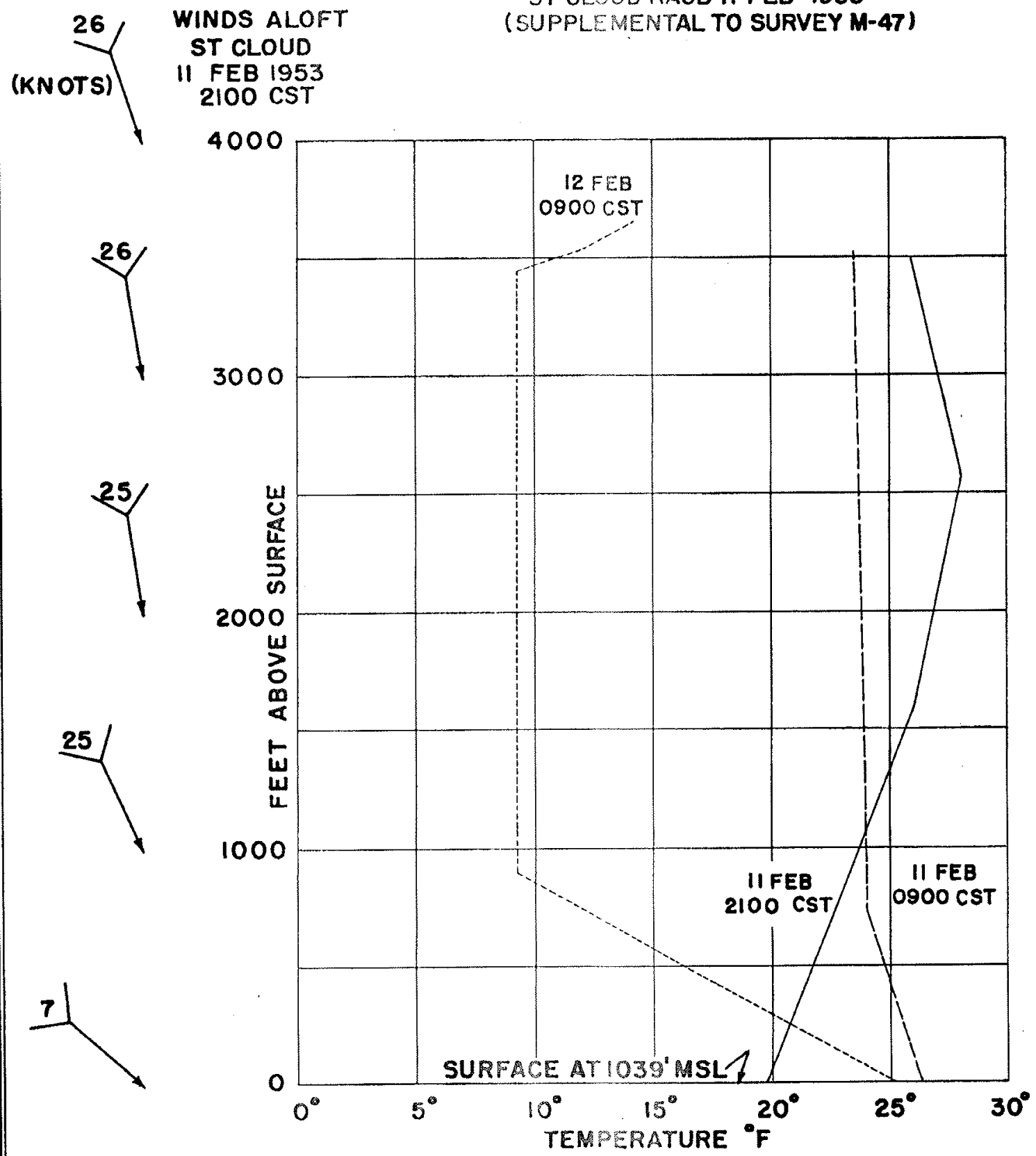

PAGE 205 


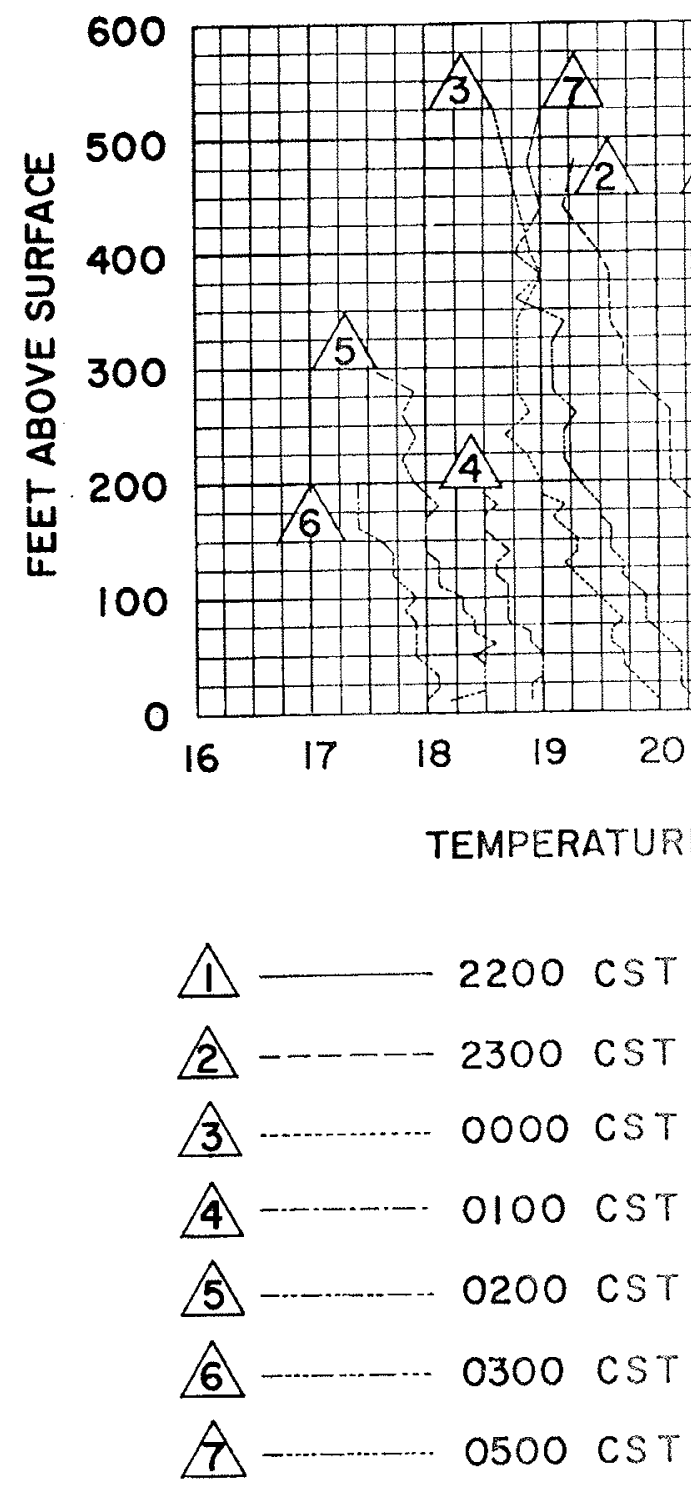

FIGURE B-30

TEMPERATURE SOUNDINGS MINNEAPOLIS RESIDENTIAL WIRESONDE SURVEY M-47 II FEB. 1953

PAge 206 


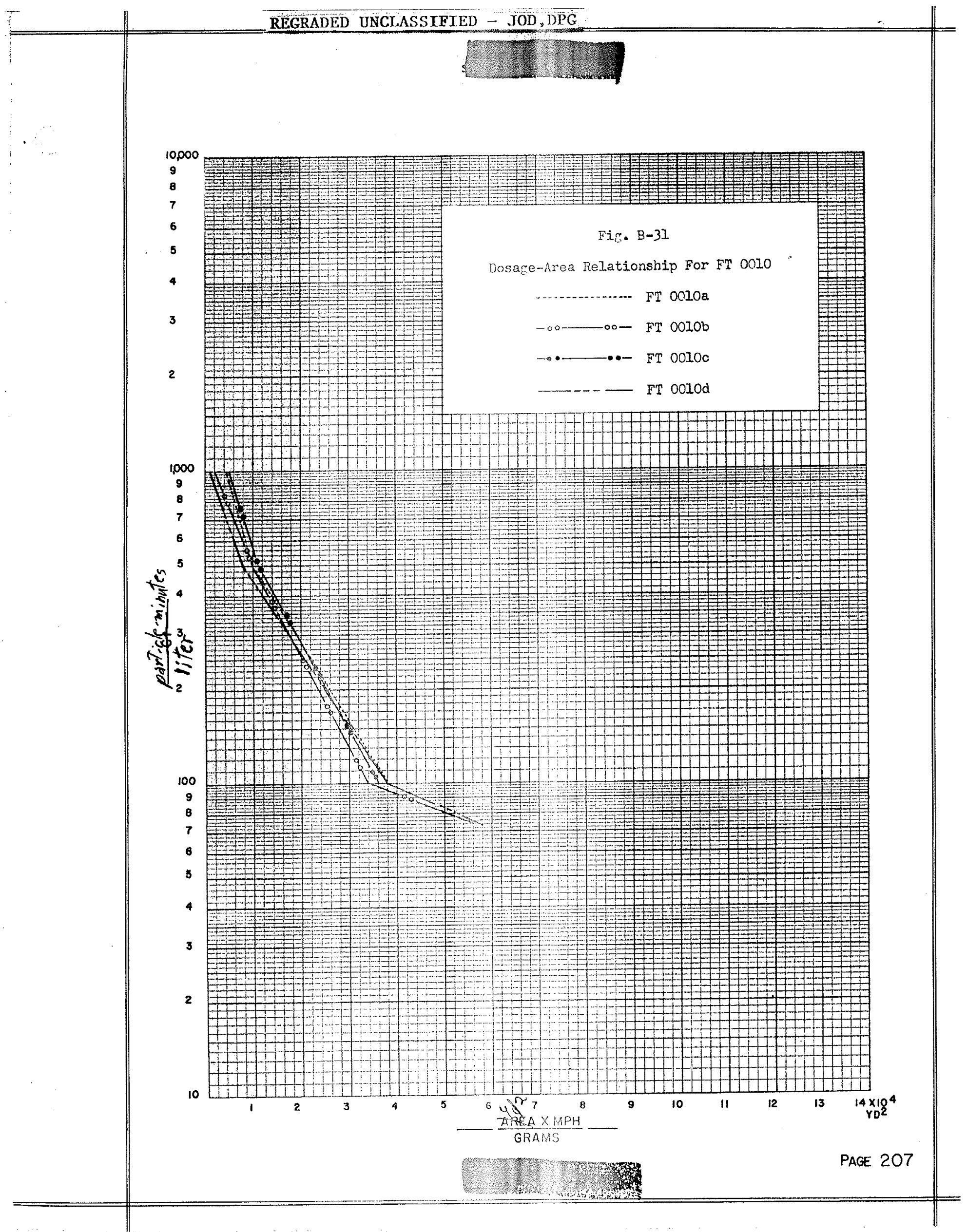


REGRADED UNCLASSTFXED - JOD, DPG

\section{SUTHARY OF CI.TNION SCHOOL DOSAGEStK \\ FT OOIOak* $\quad 12$ February 1953}

\begin{tabular}{|c|c|c|c|c|}
\hline & Ground & Ground Floor & First Floor & Second Floor \\
\hline Outside & 192 & & & 303 \\
\hline
\end{tabular}

Inside

51

82

61

$68 \quad 51$

172

* Dosages are expressed in particle-minutes per liter. When more than one sampler is involved, values are listed on separate lines.

* The sampler array for this and other tests is found in Figs. $\mathrm{V}-28$ through $\mathrm{V}-3 \mathrm{I}$.

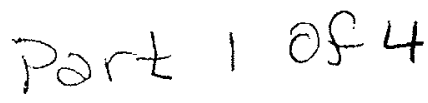


AEROSOL GENERATION

Point-source release of $13.3 \mathrm{gms}$ of NJZ 2266 over a period of 5 minutes starting at 0020 CSI from a roofmounted blower disperser ( 30 feet above street level) located at point 1 .

SAMPL ING

\section{Location and Exposure}

Nembrane-filter sampling equipment located at 97 stations as show on test-array map by following symbols:

Outdoor sampler at height between 1 and 6 feet.

Outdoor sampler at height above or below general terrain level as indicated by note.

Indoor sampler at location indicated by test-array map or text.

Results

AII samplers operated to measure total dosages. In addition, samplers at selected stations were operated ing increment dosage given to the left the station symbol.

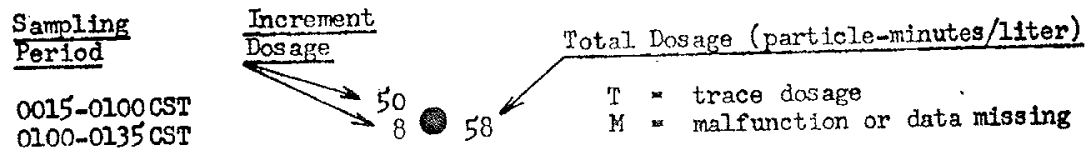

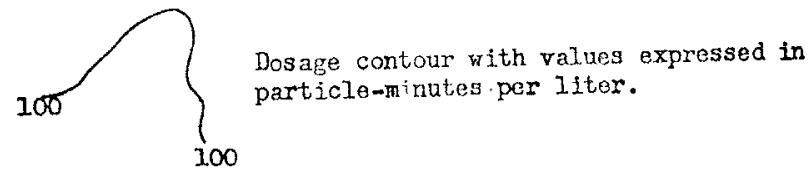

\section{METEOROLOGY}

Equiprent and Neasurement

At street level, wind direction continuously recorded, and air and surface temperatures, wind velocity, and other meteorological observations taken at stations designated as (11) and (112) -

Similar observations at rooftop level ( 35 feet ghove surface, at NW corner of the school building) and wiresonde ascents made at meteorological station (13).

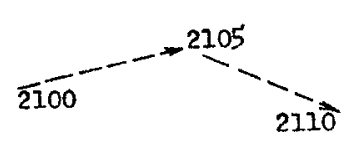

Virtual wind track, the length (drawn to map scale) and diraction of each arrow representing the virtual wind travel between the times indicated.

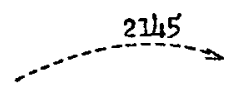

Balloon track representing wind-drift observation at the time indicated.

Winds

Roof-level winds northwesterly at $6.0 \mathrm{mph}$; street-level winds northwesterly at $3.8 \mathrm{mph}$.

\section{Stability}

$1.0^{\circ}$ F. Iapse from $6-300 \mathrm{ft}$.

Skr

Clear at start of test period but becoming scattered at $0330 \mathrm{CST}$ and low overcast at d430; bases were $3000 \mathrm{ft}$ above the surface.

\section{Temperature}

$18-20^{\circ} \mathrm{F}$ at 2 meters in the tert area.

\section{Molsture}

Mixing ratio of $1.9 \mathrm{gm} / \mathrm{kgm}$ dry air.

$$
\text { Part } 2 \text { of } 4
$$




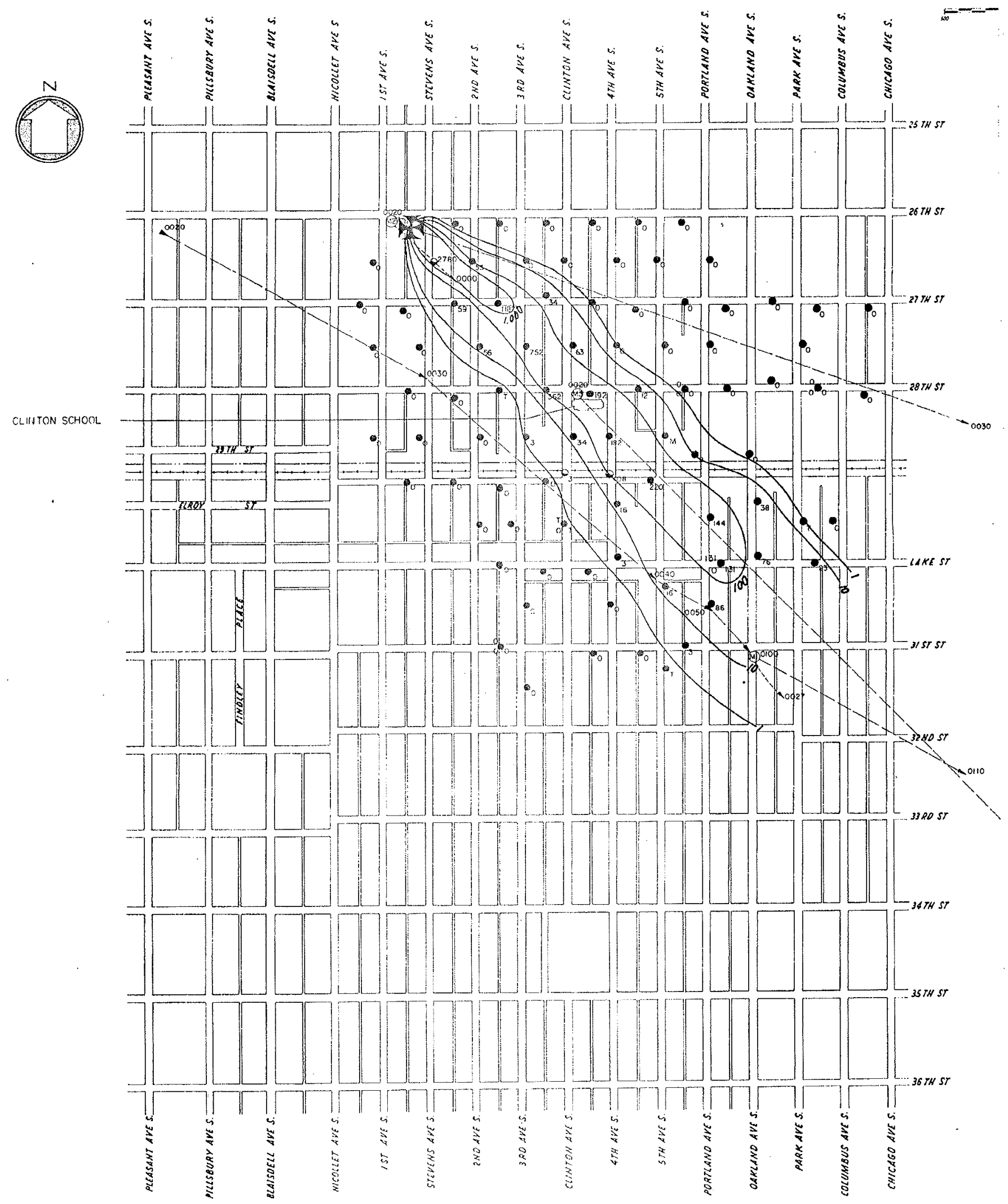



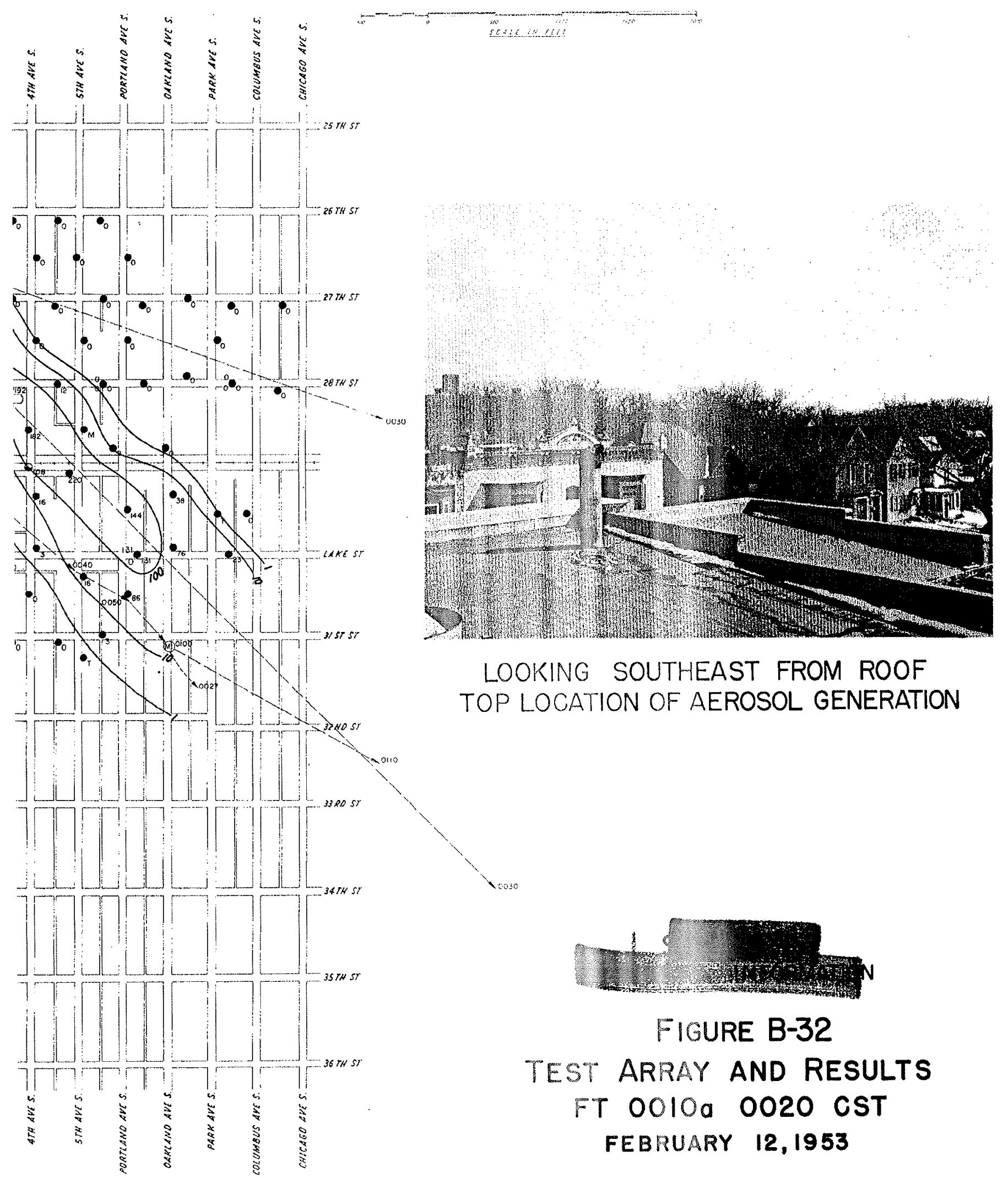

PAgE 208 


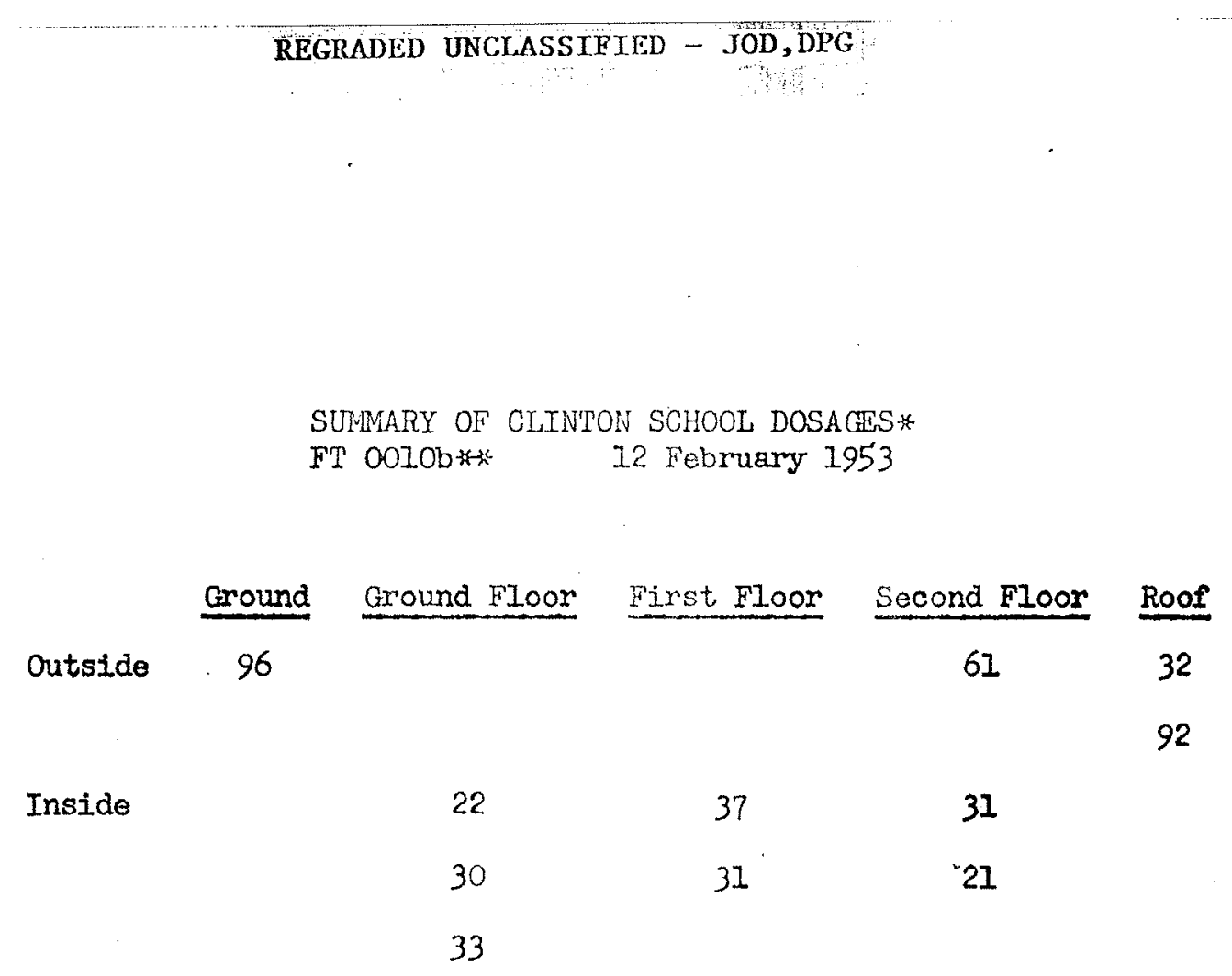
more than one sampler is involved, values are listed on separate lines.

** The sampler array for this and other tests is found in Figs. $\mathrm{V}-28$ through $\mathrm{V}-3 \mathrm{l}$.

Part 1 of 4 
Point-source release of 12.1 gms of $\mathrm{NJZ} 2266$ over a period of 5 minutes starting at ollo CST from a vehiclemounted blower disperser located at point

\section{SAMPLING}

Location and Exposure

Membrane-filter sampling equipment located at 97 stations as shown on test-array map by following symbols

$$
\begin{aligned}
& \text { Outdoor sampler at height between } 1 \text { and } 6 \text { feet. } \\
& \text { Outdoor sampler at height above or below general terrain level as indicated by note. } \\
& 0 \text { Indoor sampler at location lndicated by test-array map or text. }
\end{aligned}
$$

Results

All samplers operated to measure total dosages. In addition, samplers at selected stations were operated Incrementally, as shown by the sampling period and the corresponding increment dosage given to the left of the station symbol.

Sampling Period

0135-0220 CST

0220-0300 CST

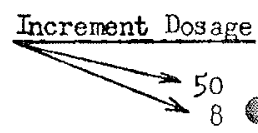

8
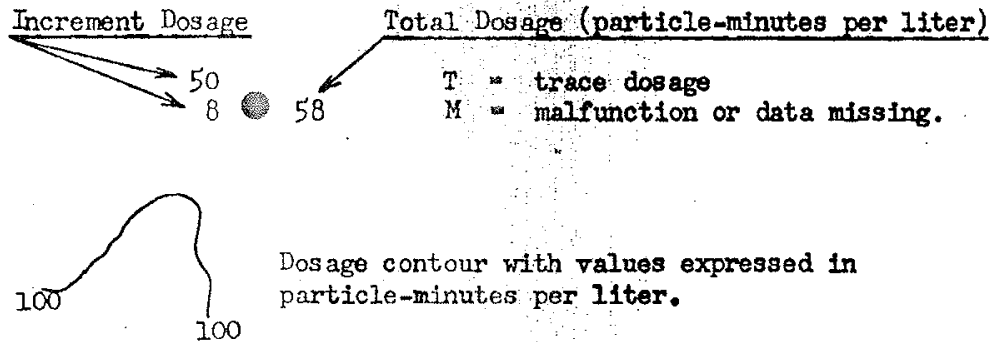

Dos age contour with values expressed in particle-minutes per liter.

\section{METEOROLOGY}

Equipment and Measurement

At street level, wind direction continuously recorded, and atr and surface temperatyies, wind velocity, and other meteorological observations taken at stations desfenated as (10) and (10).

Similar observations at rooftop level ( 35 feet above surface, at wh comer of the sohool building) and wiresonde ascents made at meteorological station.

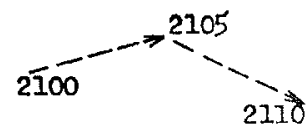

Virtual wind track, tha length (dram to map scale) and direction of each arrow representing the virtual wind travel between the times indicated.

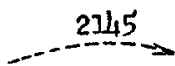

Balloon track representing wind-drift observation the time indicated.

Winds

Roof-level winds west-northwesterly at $8 \mathrm{mph}$; street-level wind northwesterly at $4 \mathrm{mph}$.

\section{Stability}

$0.8^{\circ} \mathrm{F}$ lapse from $6-300 \mathrm{rt}$.

\section{$\underline{s k y}$}

Clear at start of test period but becoming scattered at 0330 CST and low overcast at 0430 ; bases were $3000 \mathrm{ft}$ above the surface.

\section{Temperature}

18-20 $\mathrm{F}$ at 2 moters in the test area.

\section{Moisture}

Mixing ratio of $1.9 \mathrm{gm} / \mathrm{kgm}$ dry air.

$$
\text { Part } 2 \text { of } 4
$$




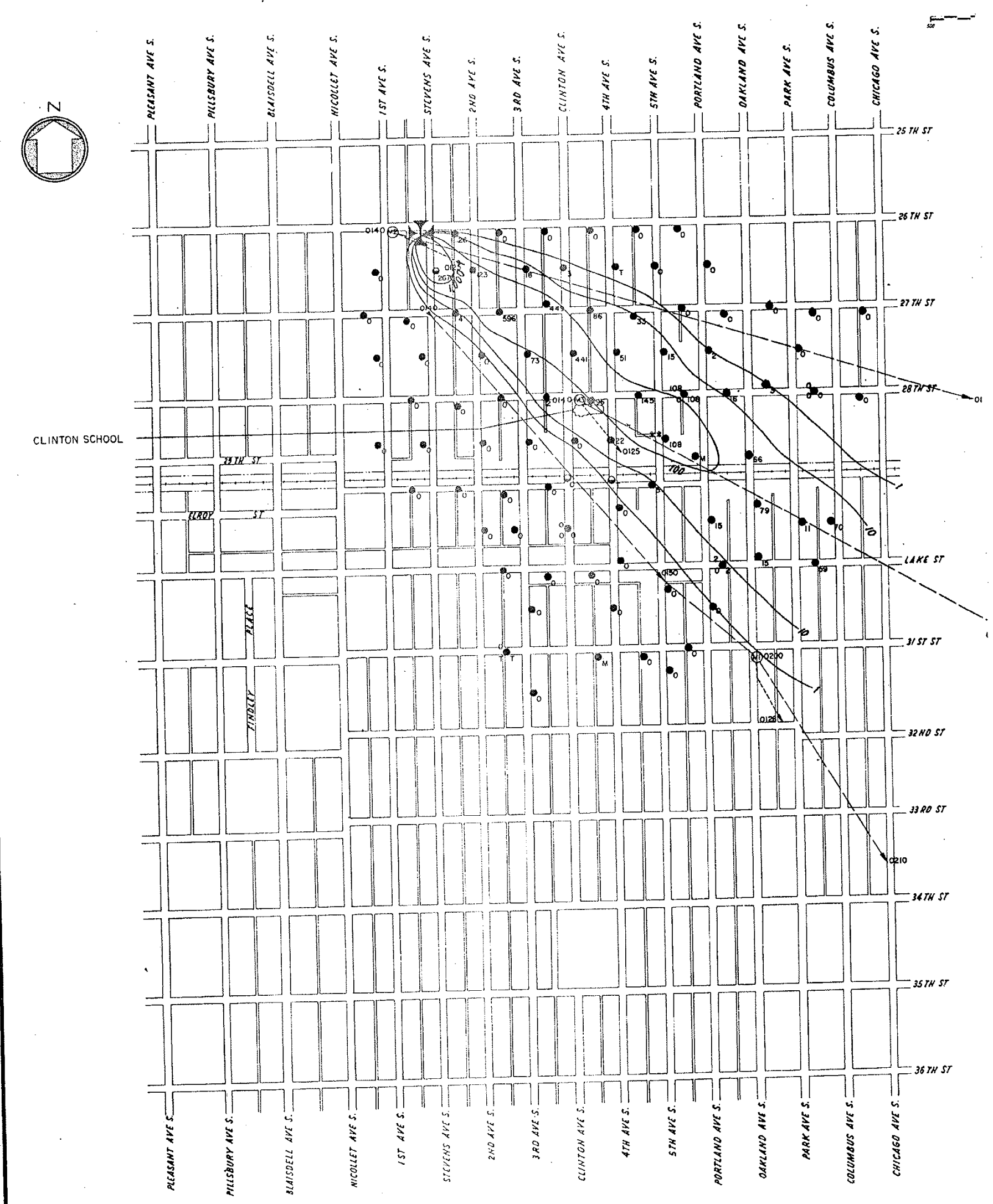

Paxt 3 of 4 

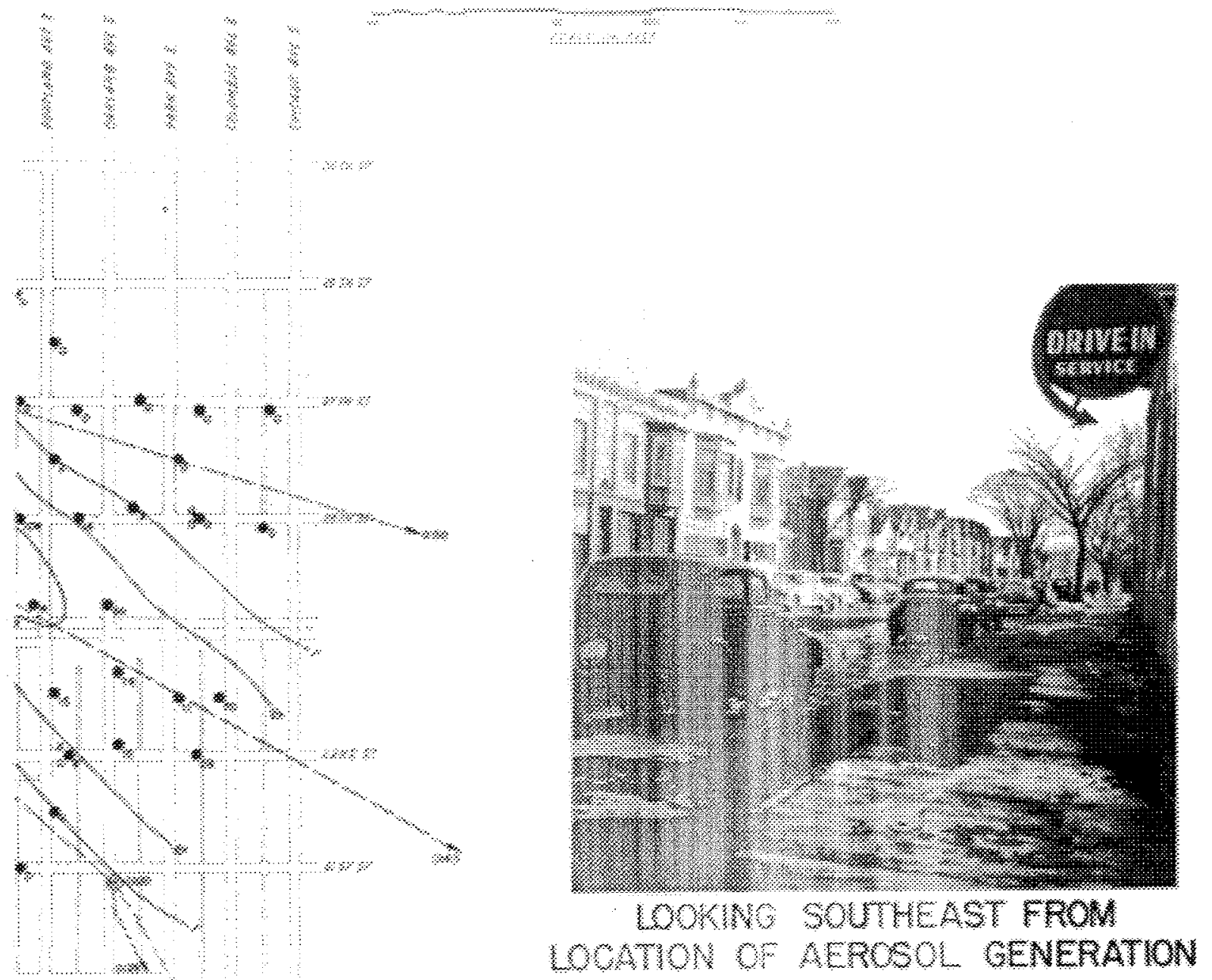

\%)

\%

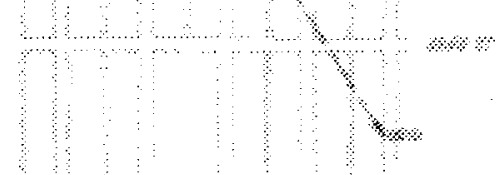

....
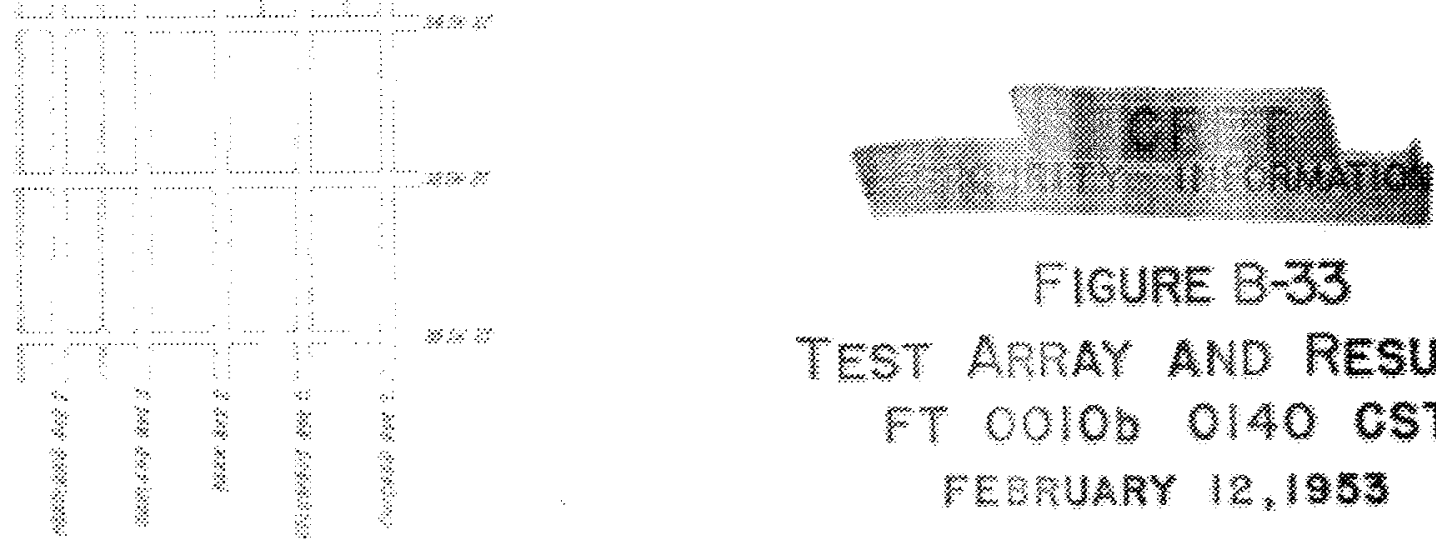

FlaURE $3-33$

TEST ARRAY WUD RESULTS

FT OOlOW Ola cst

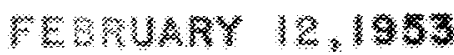

MACE 209 
SUMMARY OF CLINTON SCHOOL DOSACESH

FT 0010c\%*t 12 February 1.953

Ground Ground Floor First Floor Second Floor Roof

Outside. $\quad 181$

208

93

247

Inside

23

34

41

64

51.

30

61

* Dosages are expressed in particle-minutes per liter. When more than one sampler is involved, values are listed on separate lines。

* The sampler array for this and other tests is found in Figs. $\mathrm{V}-28$ through $\mathrm{V}-3 \mathrm{I}$.

Part 1 of 4 
AEROSOL, GENTRAT ION

Point-source release of $11.5 \mathrm{gms}$ of $\mathrm{NJZ} 2266$ over a period of 5 minutes starting at 0305 CST from a vehiclemounted blower disperser located at point

SAMPLING

Location and Exposure

Nembrane-filter sampling equipment located at 97 stations as show on test-array map by following symbols:

- Outdoor sampler at height between 1 and 6 feet.

- Outdoor sampler at height above or below general terrain level as indicated by note.

$O$ Indoor sampler at location indicated by test-array map or text.

Results

All samplers operated to measure total dosages. In addition, samplers at selected stations were operated incrementaliy, as shown by the sampling perlod and the corresponding increment dosage given to the left of the station symbol.

\begin{tabular}{|c|c|c|}
\hline Sampling Period & Increment Dosage & Total Dosage (particle-minutes per liter) \\
\hline
\end{tabular}

\section{METEOROLOOY}

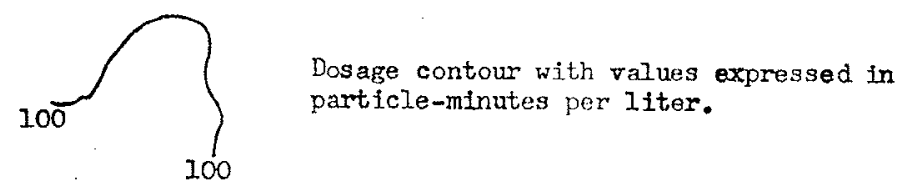

\section{Equipment and Measurement}

At street level, wind direction continuously recorded, and air and surfgce temperatyres, wind velocity, and other meteorological observations taken at stations designated as (117) and (1/2).

Simtlar observations at rooftop level ( 35 feet above 3 urface, at NW corner of the school building) and wiresonde ascents made at meteorological station (113).
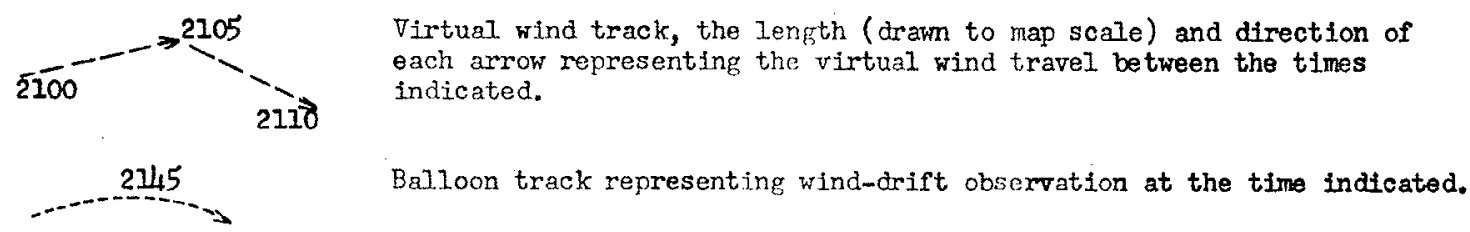

Winds

Roof-level winds west-northwesterly at $4.5 \mathrm{mph}$; street-level winds west-northwesterly at $3.0 \mathrm{mph}$.

Stability

$0.9^{\circ}$ F lapse from $6-300 \mathrm{ft}$.

$\underline{S \mathbf{r y}}$

Clear at start of test period but becoming scattered at 0330 CST and low overcast at 0430 ; bases were 3000 ft above the surface.

Temperature

28-20 $\mathrm{F}$ at 2 meters in the test area.

\section{Motsture}

Mixing ratio of $1.9 \mathrm{gm} / \mathrm{kgm}$ dry air.

Part 2 of 4 


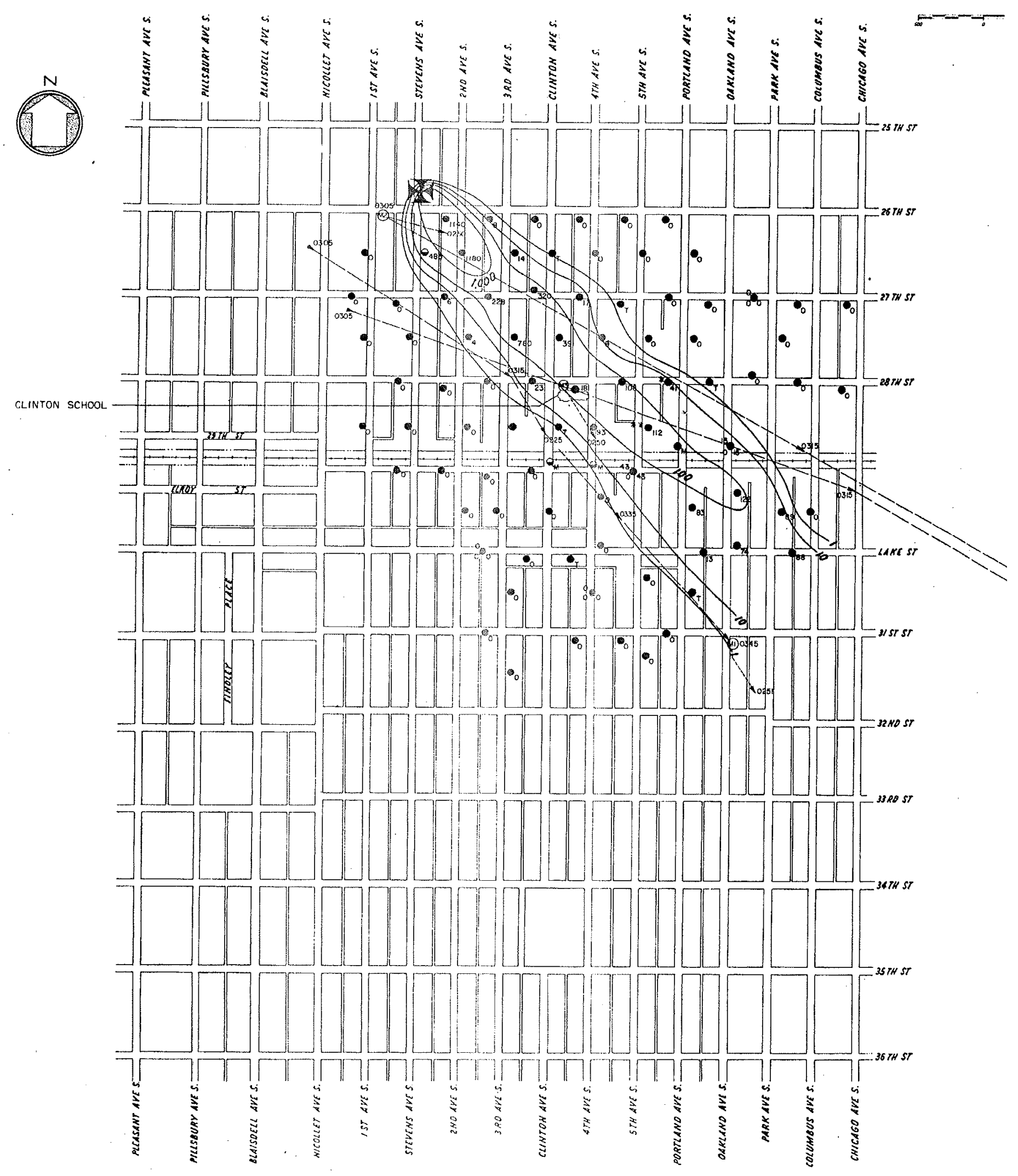



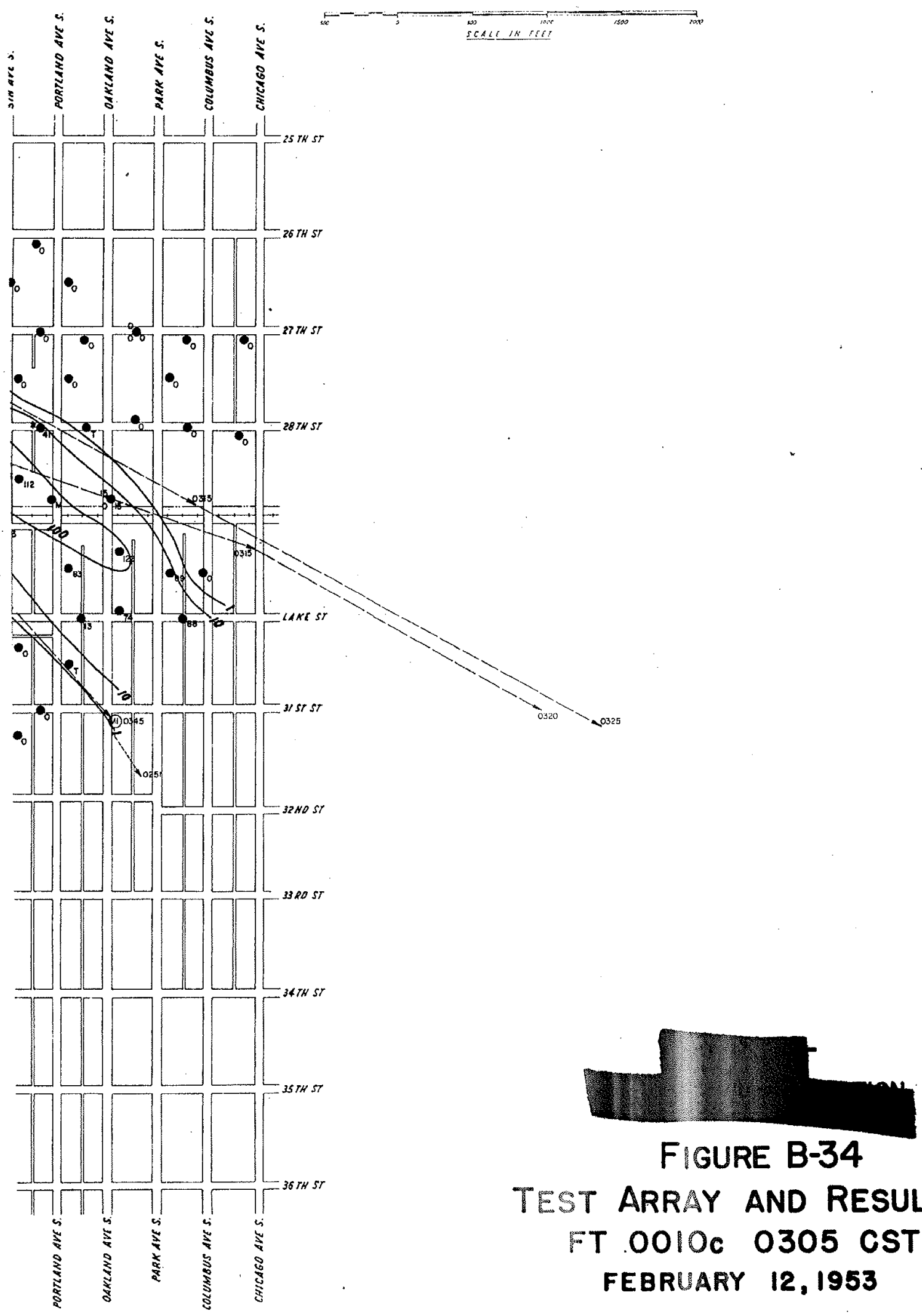

FIGURE B-34 TEST ARRAY AND RESULTS

FT .0010C 0305 CST FEBRUARY 12,1953 
SUMMARY OF CLINTON SCHOOL DOSAGES*

FT O010d:- $\quad 12$ February 1953

$\begin{array}{lllll}\text { Ground } & \text { Ground Floor First Floor } & \text { Second Floor } & \text { Roof } \\ \text { Outside } & 223 & & \\ 93 & & \\ & & \end{array}$

Inside $\quad 28 \quad 47$

$3452 \times 25$

38

* Dosages are expressed in particle-minutes per liter. When more than one sampler is involved, values are listed on separate lines.

** The sampler array for this and other tests is found in Figs. $\mathrm{V}-28$ through $\mathrm{V}-31$.

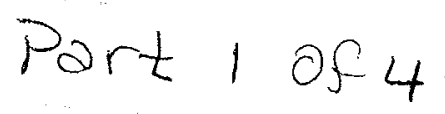




\section{AEROSOL GENERAT TON}

Point-source release of 12.2 gms of NJZ 2266 over a period of 5 minutes starting at d 425 CST from a vehiclemounted blower disperser located at point 1 .

\section{SAMPLTIG}

\section{Location and Exposure}

Nembrane-filter sampling equipment located at 97 stations as shown on test-array map by following symbols:

Outdoor sampler at helght between 1 and 6 feet.

- Outdoor sampler at height above or below general terrain level as indicated by note.

Indoor sampler at location indicated by test-array map or text.

Results

All samplers onerated to measure total dosages. In addition, samplers at selected stations were operated incrementaliy, as shown by the sampling period and the corresponding increment dosage given to the left of the station symbol.

\section{Sampling Period \\ Q $420-0505$ CST $0505-0520$ CST}
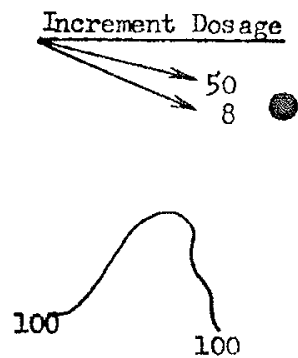

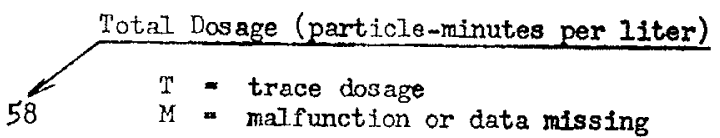

Dosage contour with values expressed in particle-minutes per liter.

\section{METEOROLOGI}

Equipment and Measurement

At street level, wind direction continuously recorded, and air and surface temperatyres, wind velocity, and other meteorological observations taken at stations designated as (MI) and (M2),

Similar observations at rooftop level ( 35 feet abovg surface, at NW comer of the school butlding) and wiresonde ascents made at meteorological station (M3).

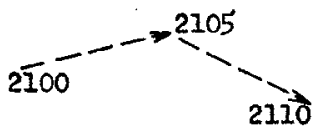

Virtual wind track, the length (drawn to map scale) and direction of each arrow representing the virtual wind travel between the timex indicated.<smiles>CC[AsH2]</smiles>

Balloon track representing wind-drift observation at the time indicated.

Winds

Roof-level winds north-northwesterly at $2.0 \mathrm{mph}$; strect-level winds northwesterly at 3.2 mp.

\section{Stability}

1.3. F lapse from $6-300 \mathrm{ft}$.

Sky

Clear at start of test period but becoming scattered at $0330 \mathrm{CST}$ and Iow overcast at d430; bases were $3000 \mathrm{ft}$ abore the surface.

\section{Temperature}

18-20 $\mathrm{F}$ at 2 meters in the test area.

\section{Molsture}

Mixing ratio of $1.9 \mathrm{gm} / \mathrm{kgm}$ dry air.

Part 2 of 4 


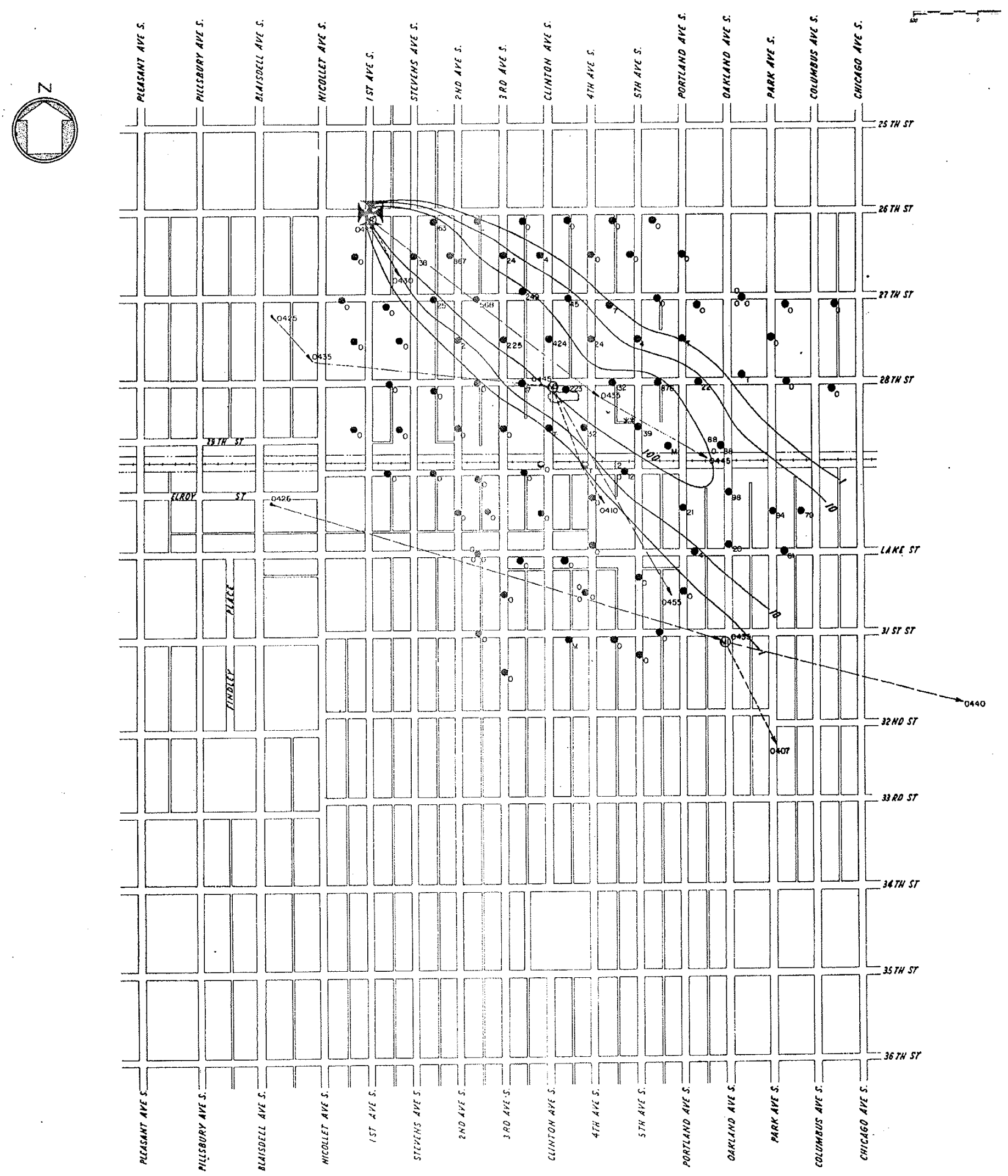

part 3 of 4 

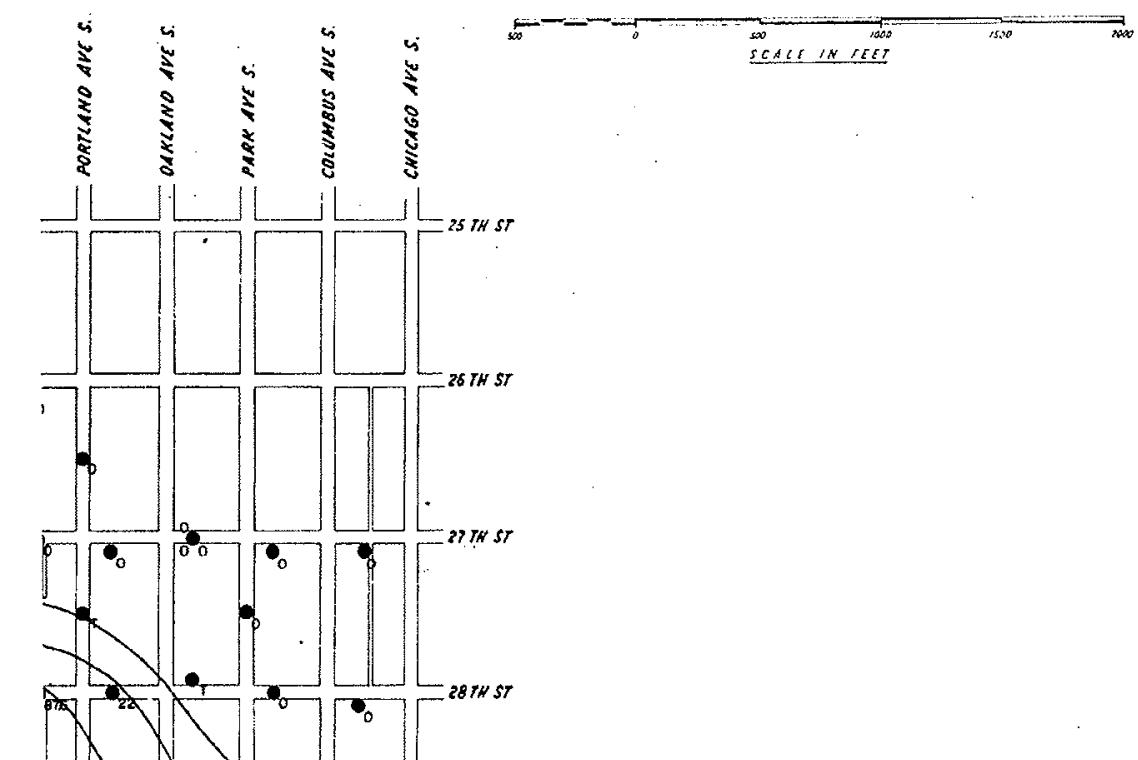

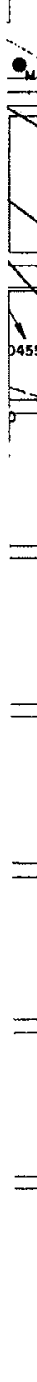
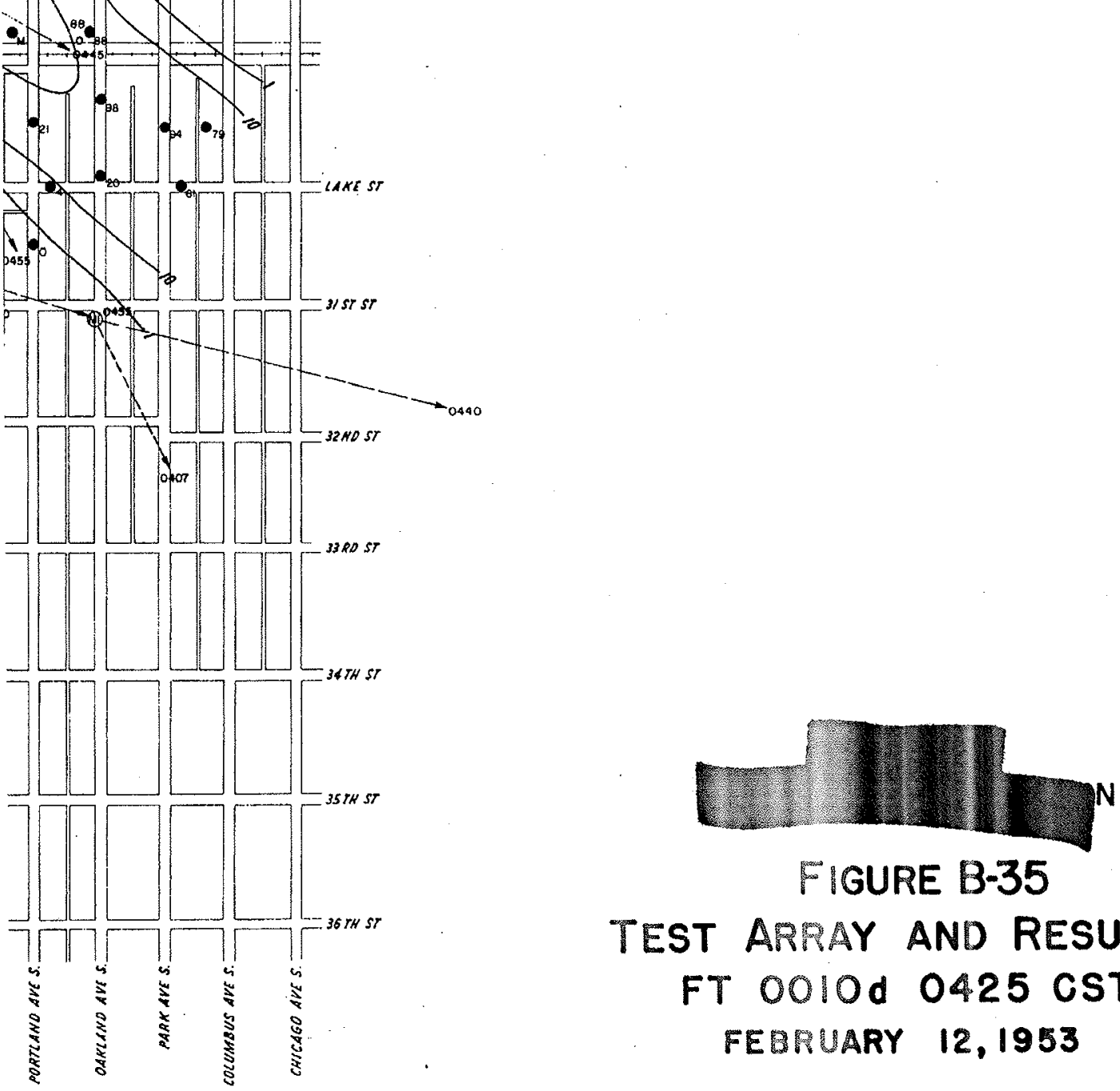

FIgURE B-35

TEST ARRAY AND RESULTS

FT OOIOd 0425 CST FEBRUARY 12,1953

PAGE 2II 


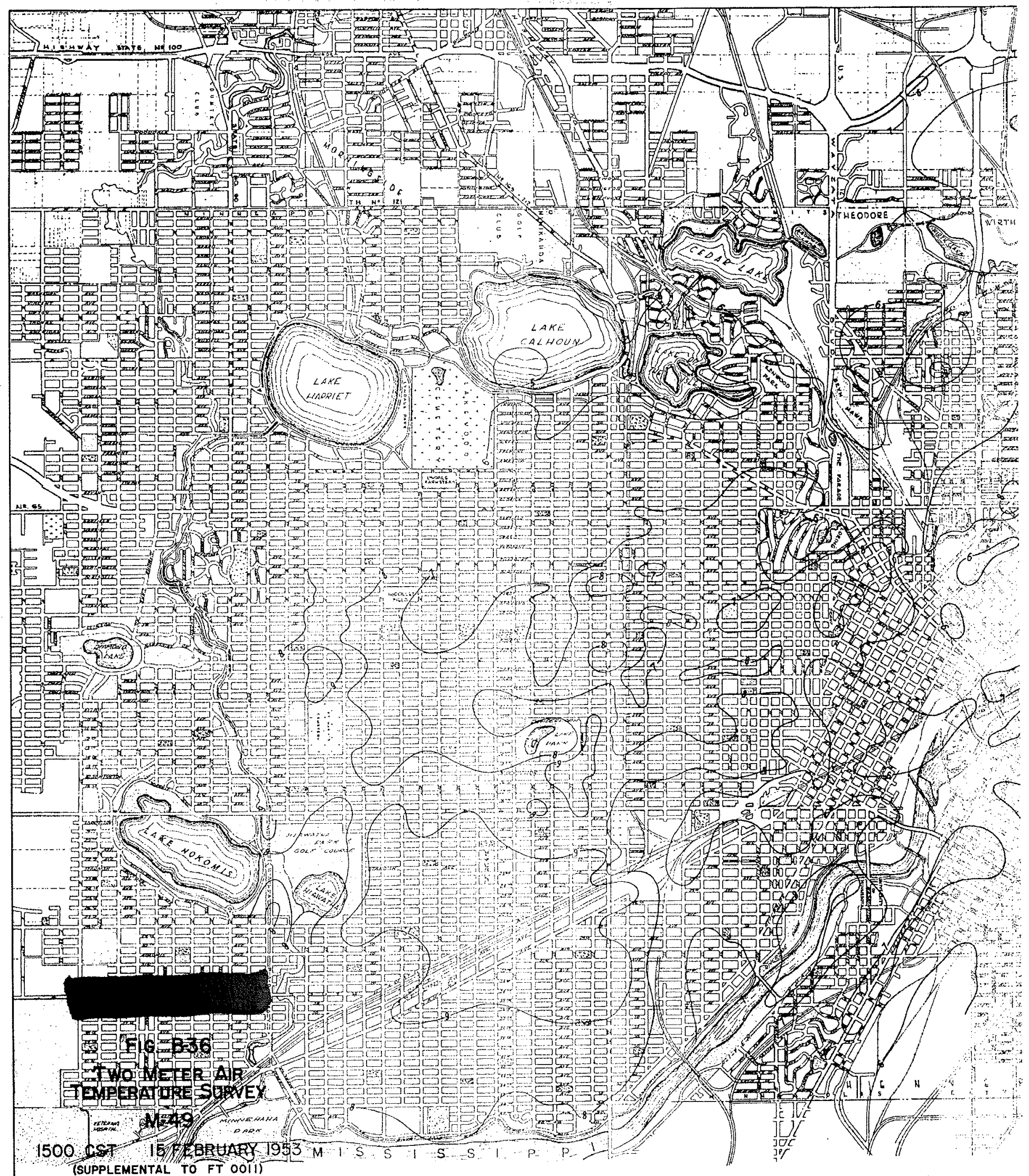

PAge 212

part I of 3 


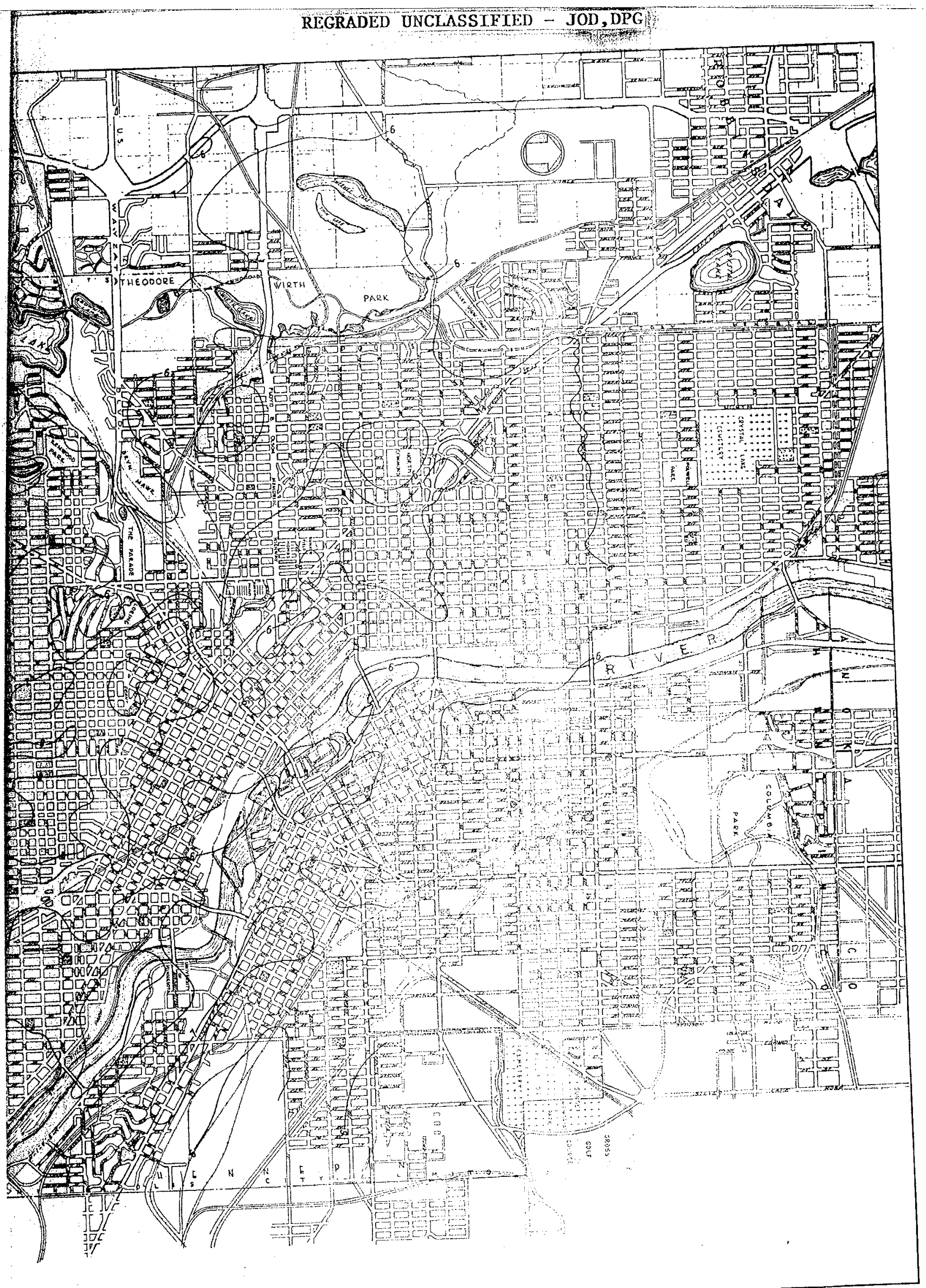

part 2 of 3 
SUMMARY OF REGIONAL RND LOCAL WEATHER

FT 0011 Survey $\mathrm{M}-49^{\circ} \quad 15$ Feb 1.953

\section{Synoptic Situation}

The closest front to Minneapolis was a warm front 350 miles to the south which extended through northern Missouri. A deepening low with pressure $1001 \mathrm{mb}$ was associated with this frontal system. An arctic high with pressure $1029 \mathrm{mb}$ was located over Saskatchewan. This high was the dominating weather influence in Minnesota. Surface wind flow was northwesterly at 8 to $12 \mathrm{mph}$. Air flow at 700 mb was from the northwest at $50 \mathrm{mph}$.

Weather Reports from Wold Chamberlain Field (Minneapolis)

\begin{tabular}{|c|c|c|c|c|c|c|c|c|}
\hline \multirow[b]{2}{*}{$\begin{array}{l}\text { Time } \\
\text { CST }\end{array}$} & \multirow{2}{*}{$\begin{array}{l}\text { Cloud } \\
\text { Height } \\
\text { (feet) }\end{array}$} & \multirow[b]{2}{*}{$\begin{array}{l}\text { Sky* } \\
\text { Cover }\end{array}$} & \multirow[b]{2}{*}{$\begin{array}{c}\begin{array}{c}\text { Visibility } \\
\text { (miles) }\end{array} \\
\end{array}$} & \multirow[b]{2}{*}{ Weather场 } & \multirow[b]{2}{*}{$\begin{array}{l}\text { Temp } \\
\left({ }^{\circ} \mathrm{F}\right) \\
\end{array}$} & \multirow[b]{2}{*}{$\begin{array}{l}\text { Dew } \\
\text { Point } \\
\end{array}$} & \multicolumn{2}{|c|}{ Wind } \\
\hline & & & & & & & Dir & $\begin{array}{l}\text { Speed } \\
\text { (mph) }\end{array}$ \\
\hline 1330 & 25,000 & $\begin{array}{l}\text { Scat- } \\
\text { tered }\end{array}$ & 15 & & 8 & -7 & NW & 9 \\
\hline 1430 & 25,000 & $\begin{array}{l}\text { Scat- } \\
\text { tered }\end{array}$ & 15 & & 10 & -5 & NW & 11 \\
\hline 1530 & 25,000 & $\begin{array}{l}\text { Scat- } \\
\text { tered }\end{array}$ & 15 & & 10 & -5 & NW & 10 \\
\hline 1630 & 25,000 & $\begin{array}{l}\text { Scat- } \\
\text { tered }\end{array}$ & 15 & & 8 & -5 & NNW & 10 \\
\hline 1730 & 25,000 & $\begin{array}{l}\text { Scat- } \\
\text { tered }\end{array}$ & 15 & & 7 & -8 & $\mathrm{NNW}$ & 10 \\
\hline $\begin{array}{l}1830 \\
1930\end{array}$ & $\begin{array}{l}25,000 \\
25,000\end{array}$ & $\begin{array}{l}\text { Clear } \\
\text { Clear }\end{array}$ & $\begin{array}{l}15 \\
15\end{array}$ & & $\begin{array}{l}5 \\
1\end{array}$ & $\begin{array}{l}-10 \\
-10\end{array}$ & $\begin{array}{l}\text { NNW } \\
\text { WNW }\end{array}$ & $\begin{array}{l}6 \\
8\end{array}$ \\
\hline
\end{tabular}

Sea level pressure at $1630 \mathrm{CST}: 1014.6 \mathrm{mb}$ Ground Condition: Streets clear 4 " packed snow on ground Lakes frozen Tree Cover: None

* Average cloudiness sunrise to sunset: $10 \%$

$* *$ and/or restrictions to visibility 
SUMMARY OF HOUSE-PENETRATION AND CLINTON SCHOOL DOSAGES*

FT 0011a

15 February 1953

\begin{tabular}{|c|c|c|c|c|c|c|c|c|}
\hline \multirow{3}{*}{$\frac{\text { House }}{E}$} & \multicolumn{6}{|c|}{ RESIDENCES $* *$} & \multirow[b]{2}{*}{ Second } & \multirow[b]{2}{*}{ Floor } \\
\hline & Outside & \multicolumn{2}{|r|}{ Basement } & \multicolumn{3}{|c|}{ First Floor } & & \\
\hline & 643 & & 34130 & & 302 & 18 & 218 & \multirow[t]{2}{*}{27} \\
\hline & & & $284 \quad 1$ & & & & & \\
\hline \multicolumn{9}{|c|}{ CLINTON SCHOOL*** } \\
\hline & Ground & Ground & Floor & First & Floor & Second & Floor & Roof \\
\hline \multirow[t]{2}{*}{ Outside } & 8 & & & 8 & $T$ & & & 7 \\
\hline & & & & 11 & $T$ & & & 11 \\
\hline \multirow[t]{3}{*}{ Inside } & & $\mathrm{T}$ & 8 & & & 3 & $\mathrm{~T}$ & \\
\hline & & 3 & $T$ & & & 6 & 2 & \\
\hline & & 4 & 3 & & & & & \\
\hline
\end{tabular}

* Dosages are expressed in particle-minutes per liter; T represents trace dosage, i.e., a count not exceeding 15 fluorescent particles. When more than one sampler is involved, values are listed on separate lines. Double entries for a given column represent incremental dosages obtained with sequentially exposed filter units.

** Indivicual resicences are described in Section $V-E$. With the illustration of a given house (see Figs. V-23 through V-27) is given the sumnary of all dosages obtained at that house.

\# The sampler array for this and other tests is found in Figs. $\mathrm{V}-28$, through $\mathrm{V}-3 \mathrm{I}$. 


\section{REGRADED DNCLASSTFIED - JOD,DPG}

\section{AEROSOL GENERATION}

Point-source release of $11.8 \mathrm{gms}$ of NJZ 2266 over a period of 5 minutes starting at 1405 CST from a roofmounted blower disperser ( 35 feet above street level) located at point

\section{SAMPLING}

\section{Location and Exposure}

Membrane-f11ter sampling equipment located at 96 stations as shown on test-array map by following symbols:

- outoor sampler at height between 1 and 6 feet.

- Outdoor sampler at height above or below general terrain level as indicated by note.

Indoor sampler at location indicated by test-array map or text.

\section{Results}

A11 samplers operated to measure total dosages. In addition, samplers at selected stations were operated incrementally, as shown by the sampling period and the corresponding increment dosage given to the left of the station symbol.

Sampling Period

$1400-1445$ CST

$1445-1530 \mathrm{CST}$
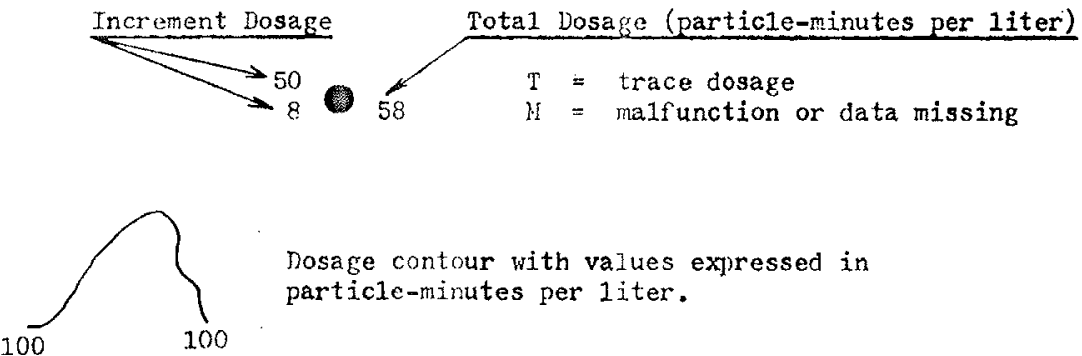

Dosage contour with values expressed in particle-minutes per liter.

\section{METEOROLOGY}

Equipment and Measurement

At street level, wind direction continuously recorded, and air and surface terperatyres, wind velocity, and other meteorological observations taken at stations designated as (MI) and (M2).

Similar observations at roof top level ( 35 feet above surface) and wiresonde ascents made at meteorological station (13).
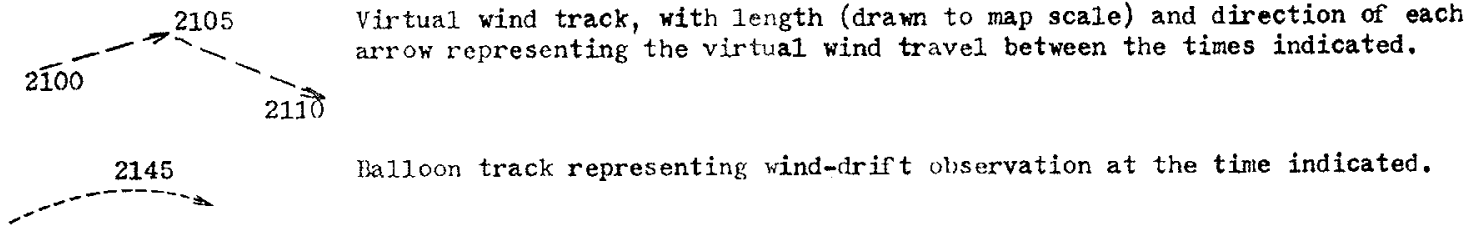

\section{Finds}

Roof-1evel winds westerly at $5.0 \mathrm{mph}$; street-1evel winds west-rorthwesterly at $3.7 \mathrm{mph}$.

\section{Stability}

$3.0^{\circ}$ F lapse from $6-300 \mathrm{ft}$.

\section{Sky}

High scattered clouds with base over $20,000 \mathrm{ft}$. from the surface.

\section{Temperature}

$3-7^{\circ} \mathrm{F}$ at 2 meters in the test area.

\section{Moisture}

Mixing ratio of $0.7 \mathrm{gm} / \mathrm{kgm}$ dry air.

$$
\text { part } 2 \text { of } 4
$$




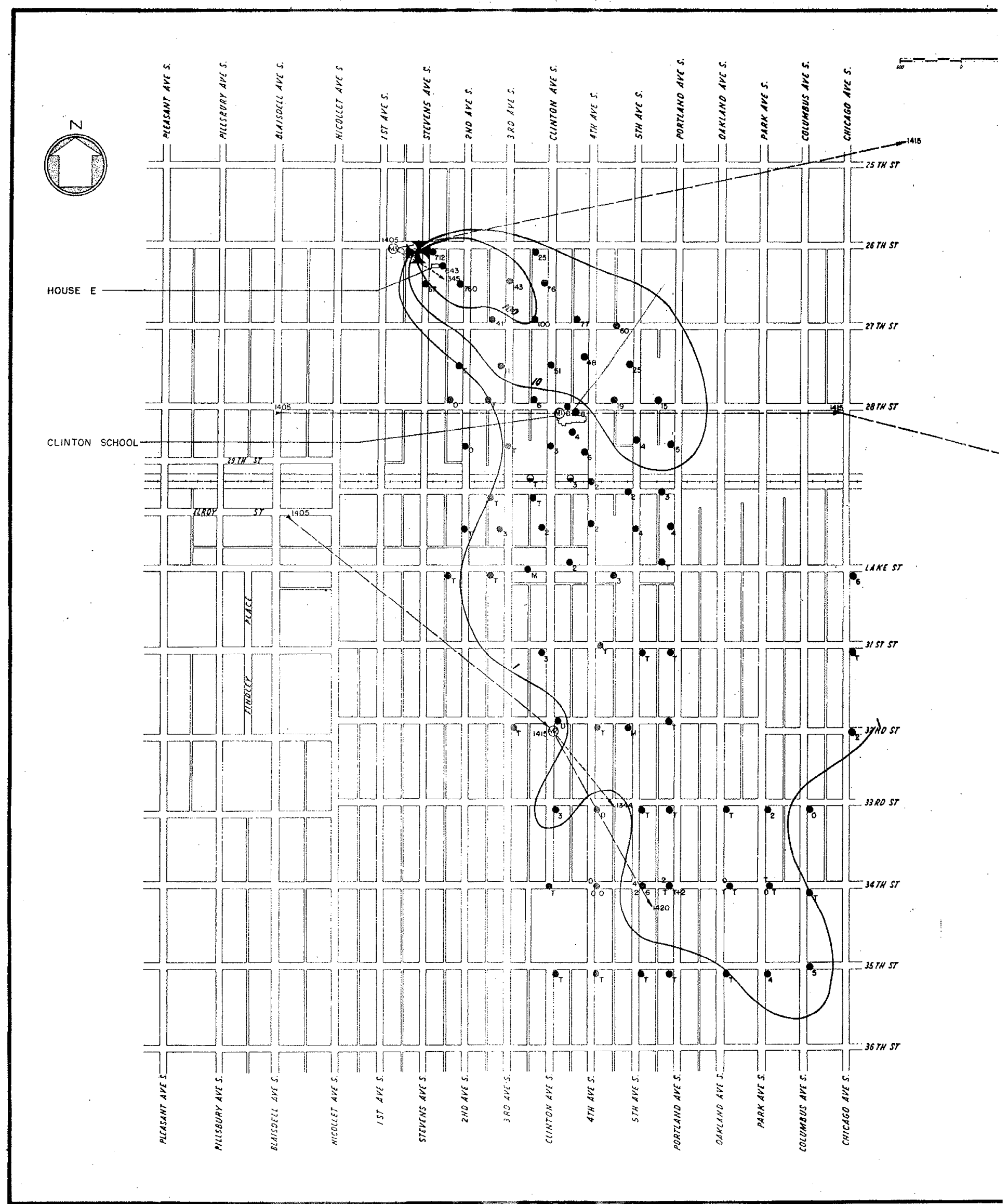

part 3 of 4 


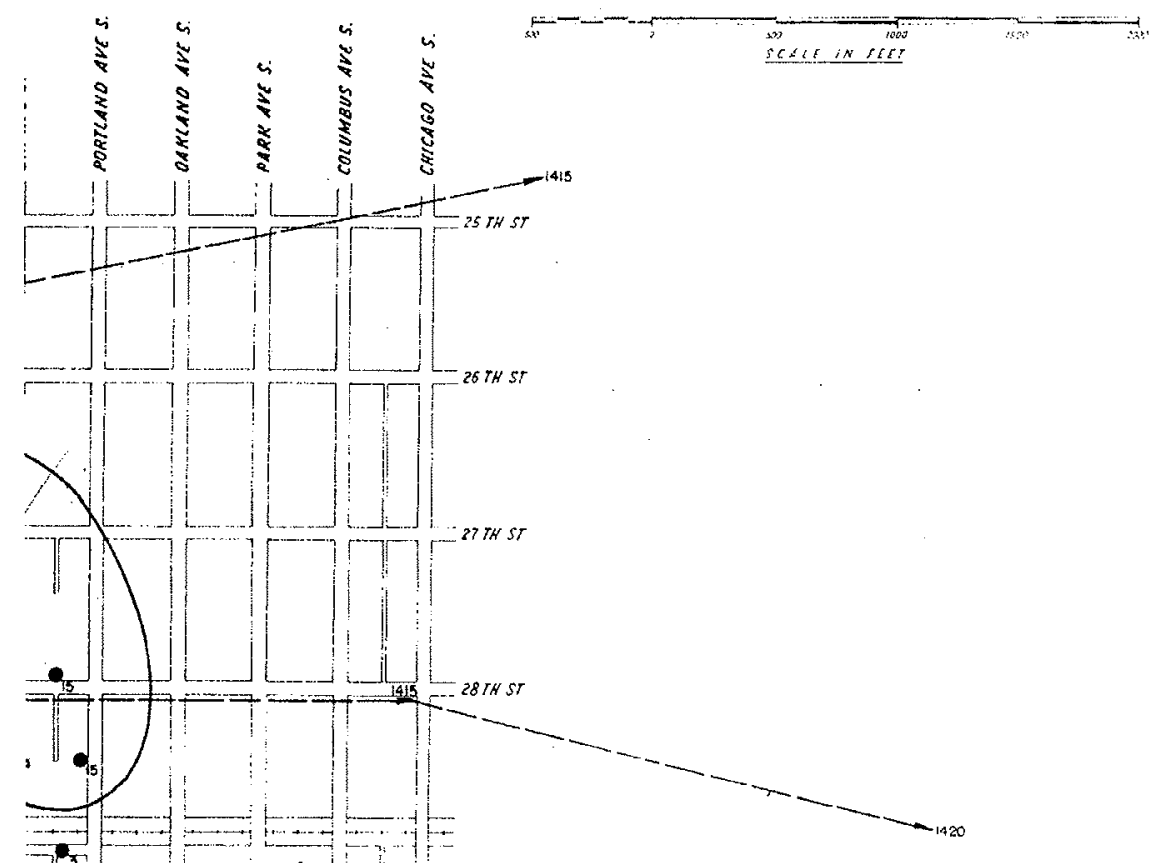

PHOTOGRAPH OF RELEASE POINT SAME AS FOR FT-OOIOa, FIG. B-32
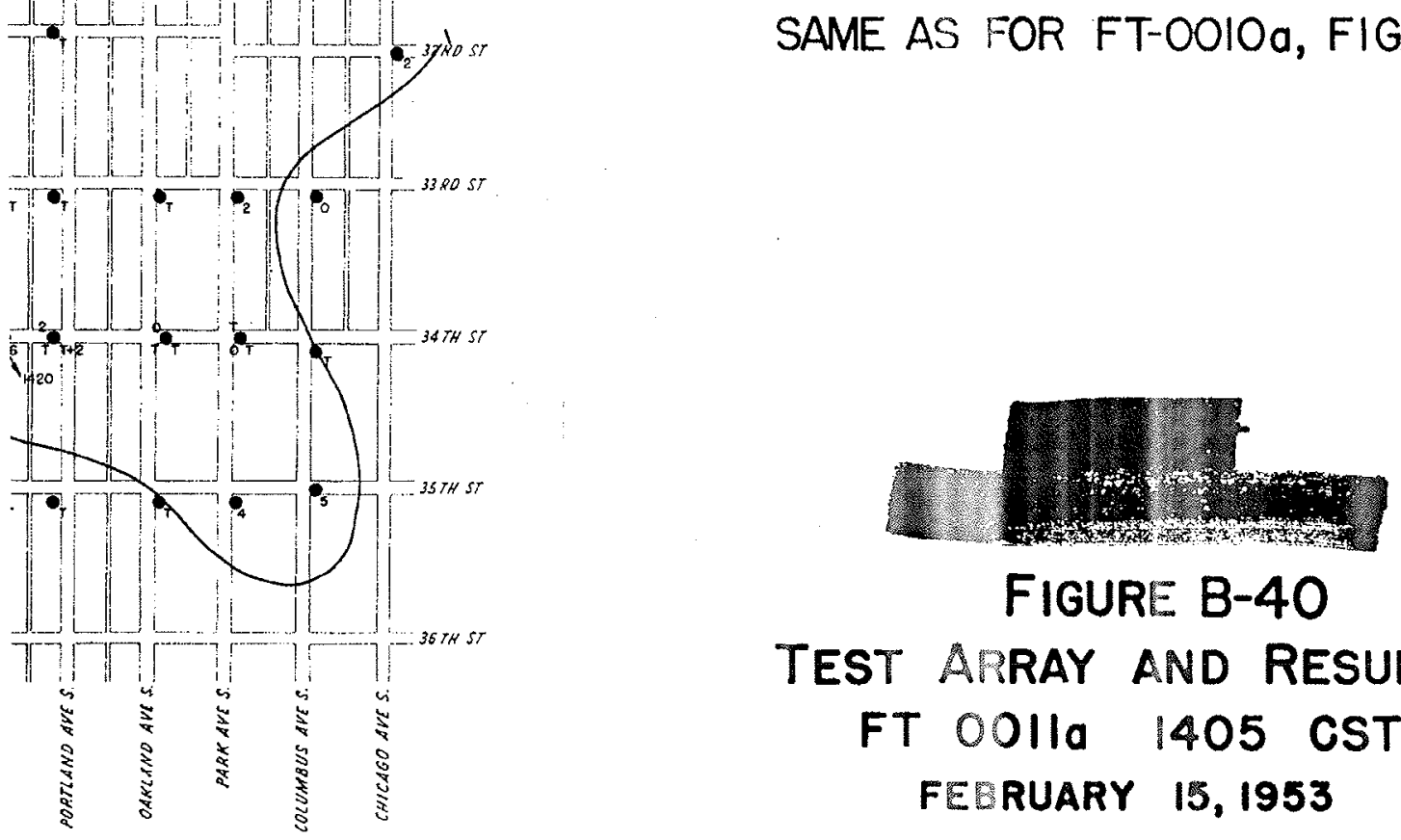

FIGURE B-40

TEST ARRAY AND RESULTS

FT OOlla 1405 CST

FEBRUARY 15, 1953

PAGE 216 
SUMMARY OF HOUSE-PENETRATION AND CLINTON SCHOOL DOSAGES* FT OOIIb

15 February 1953

\begin{tabular}{|c|c|c|c|c|c|c|c|c|}
\hline \multirow{3}{*}{$\frac{\text { House }}{E}$} & \multicolumn{6}{|c|}{ RESIDENCES $*-\not K$} & \multirow[b]{2}{*}{ Second } & \multirow[b]{2}{*}{ Floor } \\
\hline & \multirow{2}{*}{$\frac{\text { Outside }}{1040}$} & & \multicolumn{2}{|c|}{ Basement } & \multicolumn{2}{|c|}{ First Floor } & & \\
\hline & & & 4751 & & 708 & 32 & 409 & \multirow[t]{2}{*}{36} \\
\hline & & & 5061 & & & & & \\
\hline \multicolumn{9}{|c|}{ CLINTON SCHOOL } \\
\hline & Ground & Ground & Floor & First & Floor & Second & Floor & Roof \\
\hline Outside & 41 & & & 41 & 17 & & 36 & 23 \\
\hline . & & & & 31 & $T$ & & & 36 \\
\hline \multirow[t]{3}{*}{ Inside } & & 6 & 2 & & & 5 & 8 & \\
\hline & & 19 & 10 & & & 6 & 4 & \\
\hline & & 23 & $\mathrm{~T}$ & & & & & \\
\hline
\end{tabular}

* Dosages are expressed in particla-minutes per 11ter; T represents trace dosage, i.e., a count not exceeding 15 fluorescent particles. When more than one sampler is involved, values are listed on separate lines. Double entries for a given column represent incremental dosages obtained with sequentially exposed filter units.

* Individual residences are described in Section $V-E$. With the illustration of a given house (see Figs. V-23 through V-27) is given the summary of all dosages obtained at that house.

*** The sampler array for this and other tests is found in Figs. $\mathrm{V}-28$ through $\mathrm{V}-3 \mathrm{I}$.

$$
\text { part } 1 \text { of } 4
$$




\section{AEROSOL GENERATION}

Point-source release of 11.6 gms of $\mathrm{NJZ} 2266$ over a period of 5 minutes starting at 1535 CST from a roofmounted blower disperser ( 35 feet above street leve1) located at point 2 .

\section{SAMPLING}

\section{Location and Exposure}

Membrane-filter sampling equipment located at 96 stations as shown on test-array map by following symbols:

- Outdoor sampler at height between 1 and 6 feet.

- Outdoor sampler at height above or below general terrain leves as indicated by note.

$O$ Indoor sampler at location indicated by test-array map or text.

\section{Results}

A11 samplers operated to measure tota1 dosages. In addition, samplers at selected stations were operated incrementa11y, as shown by the sampling period and the corresponding increment dosage given to the left of the station symbol.

Sampling Period

1530-1615 CST

$1615-1655$ CST
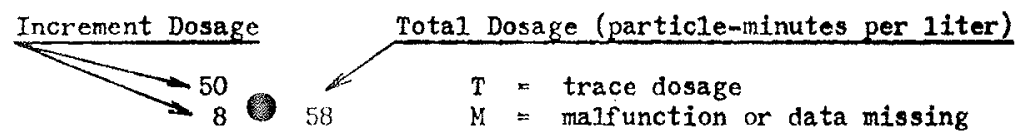

\section{METEOROLOGY}

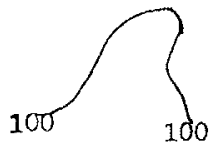

Dosage contour with values expressed in particleminutes per liter.

\section{Equipment and Measurement}

At street leve1, wind direction continuously recorded, and air and surface temperatyres, wind velocity, and other meteorologica1 observations taken at stations designated as (MI) and (M2).

Similar observations at roof top leve1 (35 feet above surface) and wiresonde ascents made at meteorological station (133).
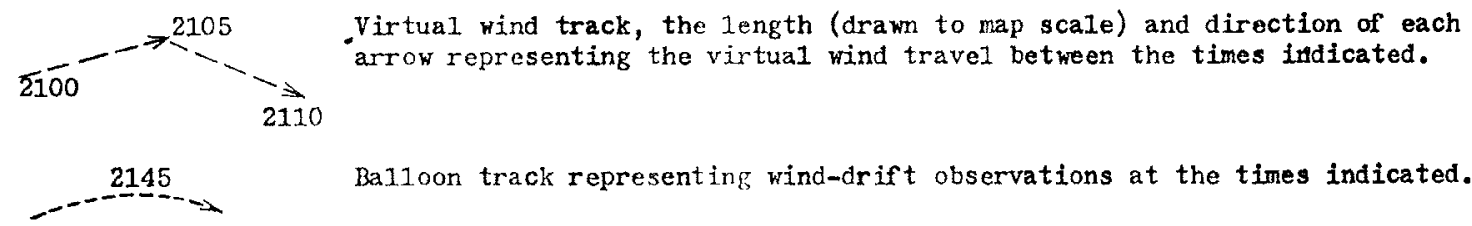

\section{Winds}

Roof-1evel winds west-northwesterly at $5.0 \mathrm{mph}$; street-1evel winds north-northwesterly at $3.9 \mathrm{mph}$.

\section{Stability}

$3.3^{\circ}$ F lapse from $6-300 \mathrm{ft}$.

Sky

High scattered clouds with base over 20,000 ft. above the surface.

\section{Temperature}

3-7 $F$ at 2 meters in the test area.

\section{Moisture}

Mixing ratio of $0.7 \mathrm{gm} / \mathrm{kgm}$ dry air.

$$
\text { part } 2 \text { of } 4
$$




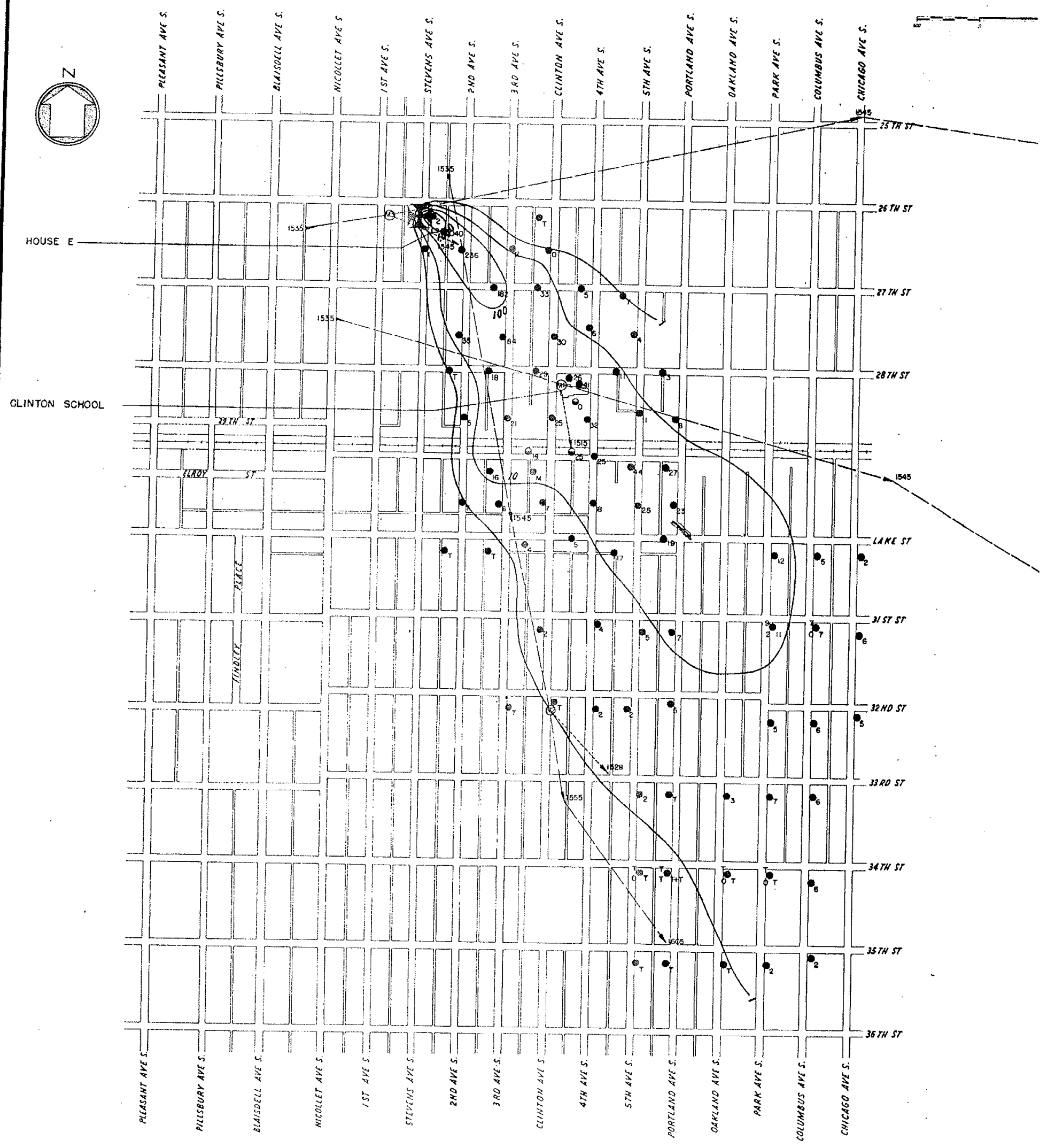



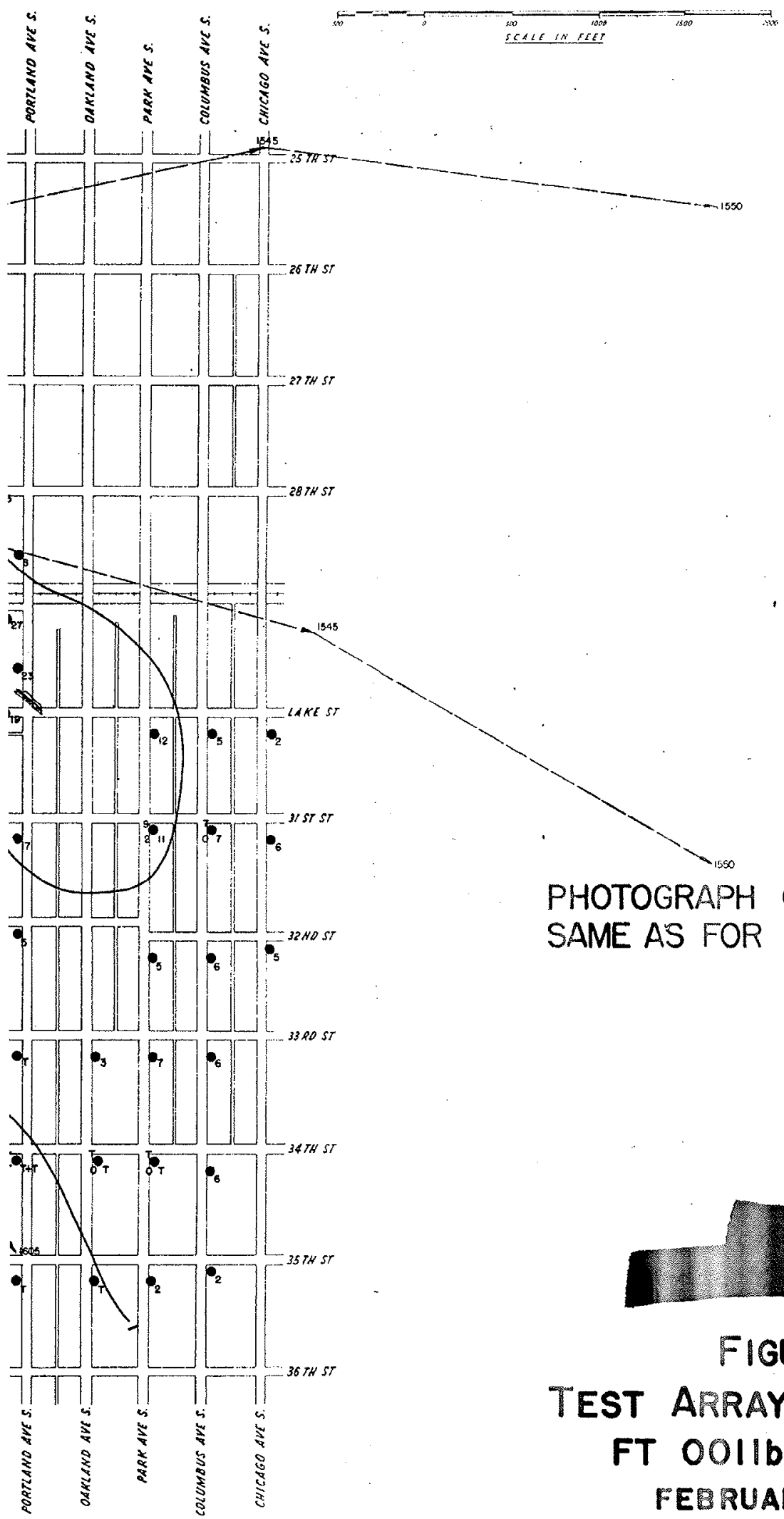

PHOTOGRAPH OF RELEASE POINT SAME AS FOR FT-OOIOa, FIG.B-32

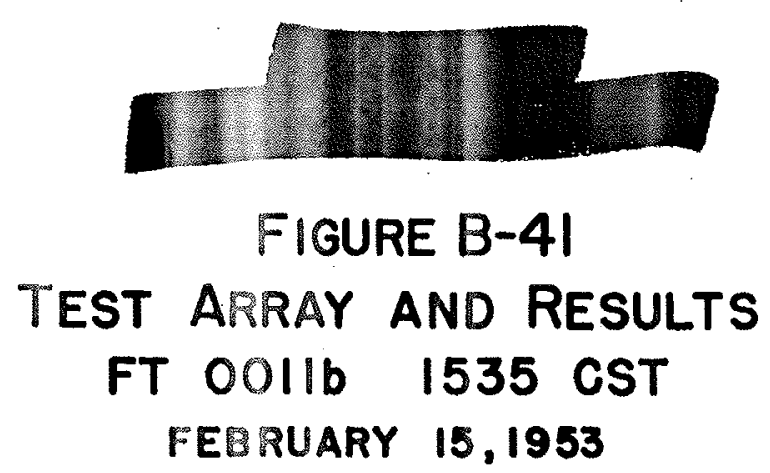

PAGE 217 
SUMMARY OF HOUSE-PENETRATION AND CLINTON SCHOOL DOSAGES* FT O011c

15 February 1953

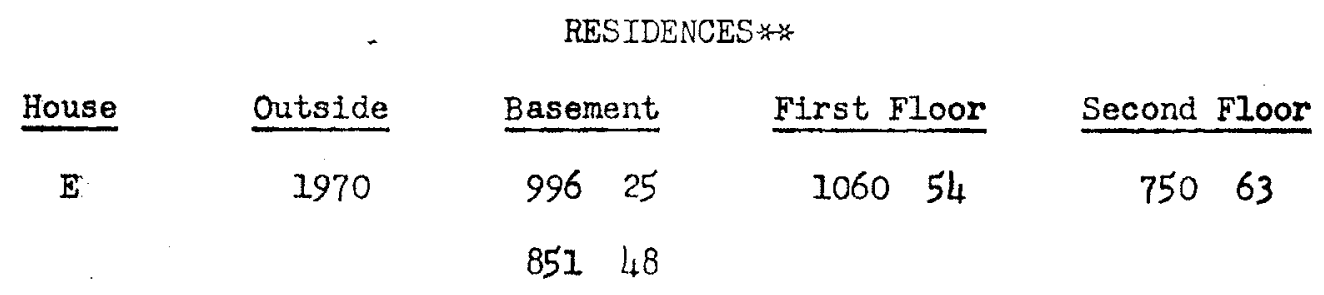

CIINTON SCHOOL

\begin{tabular}{|c|c|c|c|c|c|c|c|c|}
\hline & Ground & Ground & Floor & First & Floor & Second & Floor & Roof \\
\hline \multirow[t]{2}{*}{ Outside } & 12 & & & 19 & $T$ & & 7 & 4 \\
\hline & & . & & $\mathrm{T}$ & 4 & & & $T$ \\
\hline \multirow[t]{3}{*}{ Inside } & & 2 & $\mathrm{~T}$ & & & 4 & $\mathrm{~T}$ & \\
\hline & & 7 & 3 & & & 2 & $T$ & \\
\hline & & 5 & $\mathrm{~T}$ & & & & & \\
\hline
\end{tabular}

* Dosages are expressed in particle-minutes per liter; $T$ represents trace dosage, i.e., a count not exceeding 15 fluorescent. particles. When more than one sampler is involved, values are listed on separate lines. Double entries for a given column represent incremental dosages obtained with sequentially exposed filter units.

* Individual residences are described in Section V-E. With the illustration of a given house (see Figs, V-23 through V-27) is given the summary of all dosages obtained at that house.

*H* The sampler array for this and other tests is found in Figs. $\mathrm{V}-28$ through $\mathrm{V}-3 \mathrm{I}$. 
Point-source release of 10.9 gms of NJZ 2266 over a period of 5 minutes starting at 1710 CST from a vehic1emounted blower disperser located at point 2 .

\section{SAMPLING}

Location and Exposure

Membrane-filter sampling equipment located at 96 stations as shom on test-array map by following symbols:

- outdoor sanpler at height between 1 and 6 feet.

- Outdoor sampler at height above or below general terrain level as indicated by note.

0 Indoor sampler at location indicated by test-array map or text.

Results

A11 samplers operated to measure total dosages. In addition, samplers at selected stations were operated incrementaliy, as shown by the sampling period and the corresponding increment dosage given to the left of the station symbol.

Sampling Period

1700-1745 CST

$1745-1800$ CST
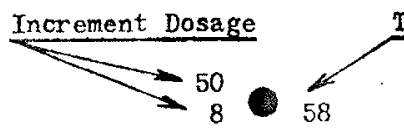
Total Dosage (particle-minutes per 1iter)

$T=$ trace dosage

$M=$ malfunction or data missing

Dosage contour with values expressed in

particle-minutes per liter.

\section{METEOROLOGY}

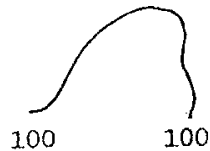

Equipment and Measurement

At street level, wind direction continuously recorded, and air and surface temperatures, wind velocity, and other meteorological observations taken at stations designated as (MI) and (4).

Similar observations at roof top level (35 feet above surface) and wiresonde ascents made at meteorological station (M3).

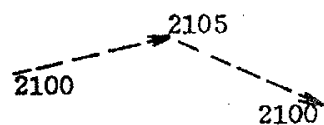

Virtual wind track, the length (drawn to map scale) and direction of each arrow representing the virtual wind travel between the times indicated.

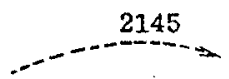

Balloon track representing wind- $d$ rift observation at the time indicated.

Winds

Roof-level winds northwesterly at $4 \mathrm{mph}$; street-1eve1 winds north-northwesterly at $3 \mathrm{mph}$.

\section{Stability}

$2.2^{\circ}$ F lapse from 6-300 feet.

$\underline{\text { Sky }}$

High scattered clouds with lase over 20,000 ft. above the surface.

\section{Temperature}

$3-7^{\circ} \mathrm{F}$ at 2 metors in the test area.

Moisture

Mixing ratio of $0.7 \mathrm{gm} / \mathrm{kgm}$ dry air. 


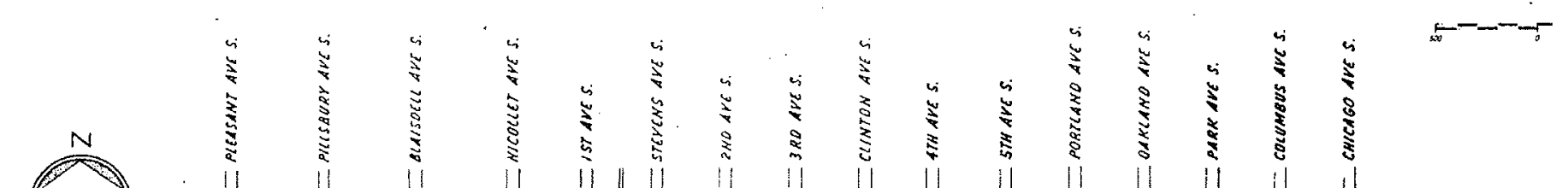

HOUSE E
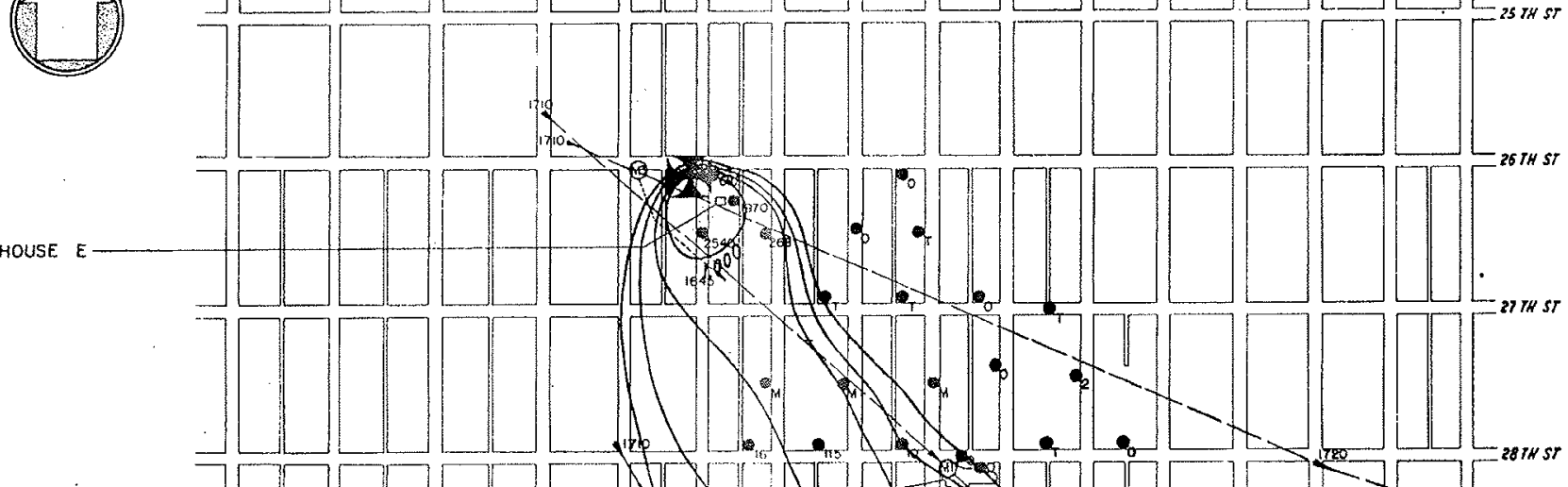

CLINTON SCHOOL
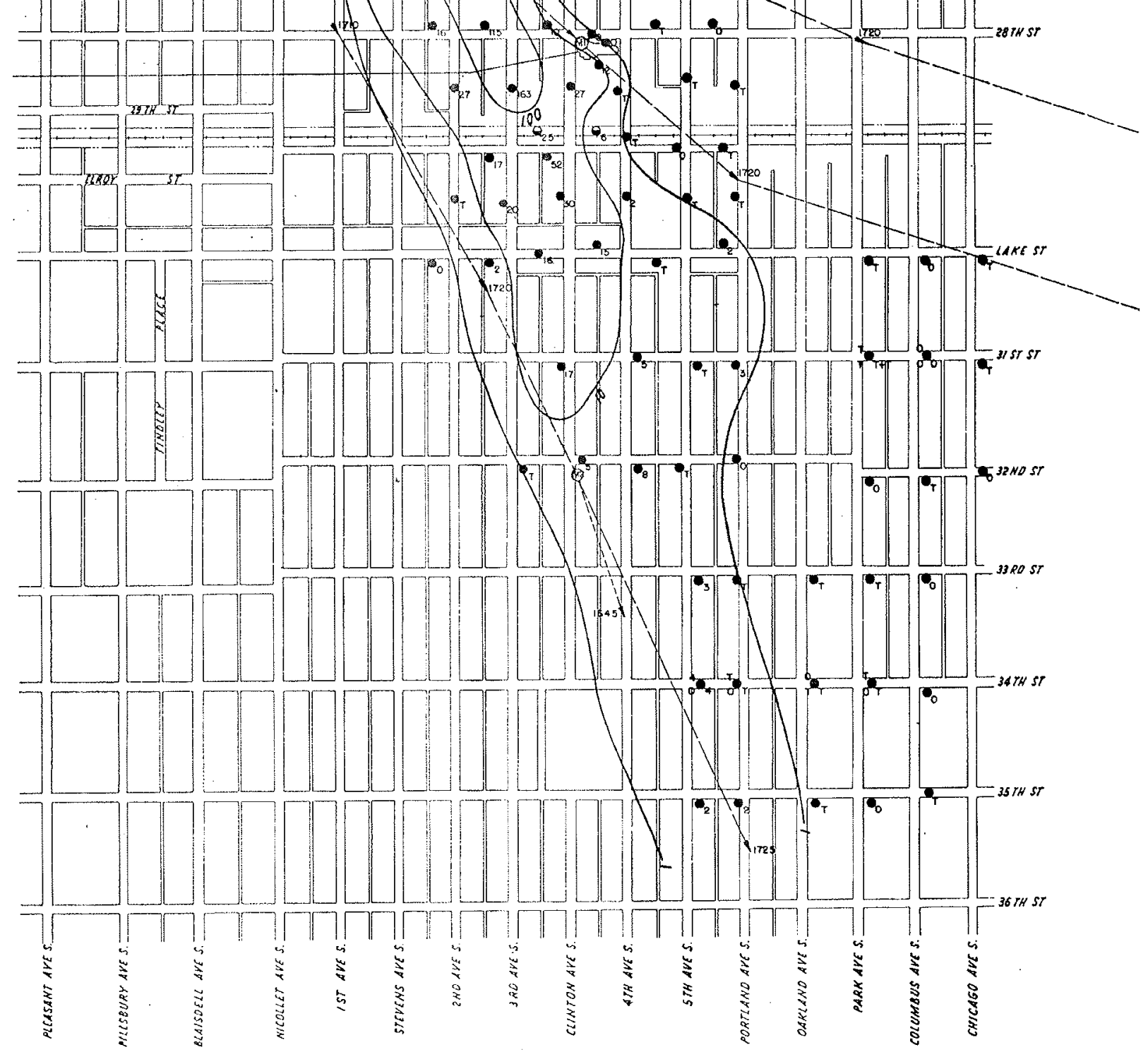

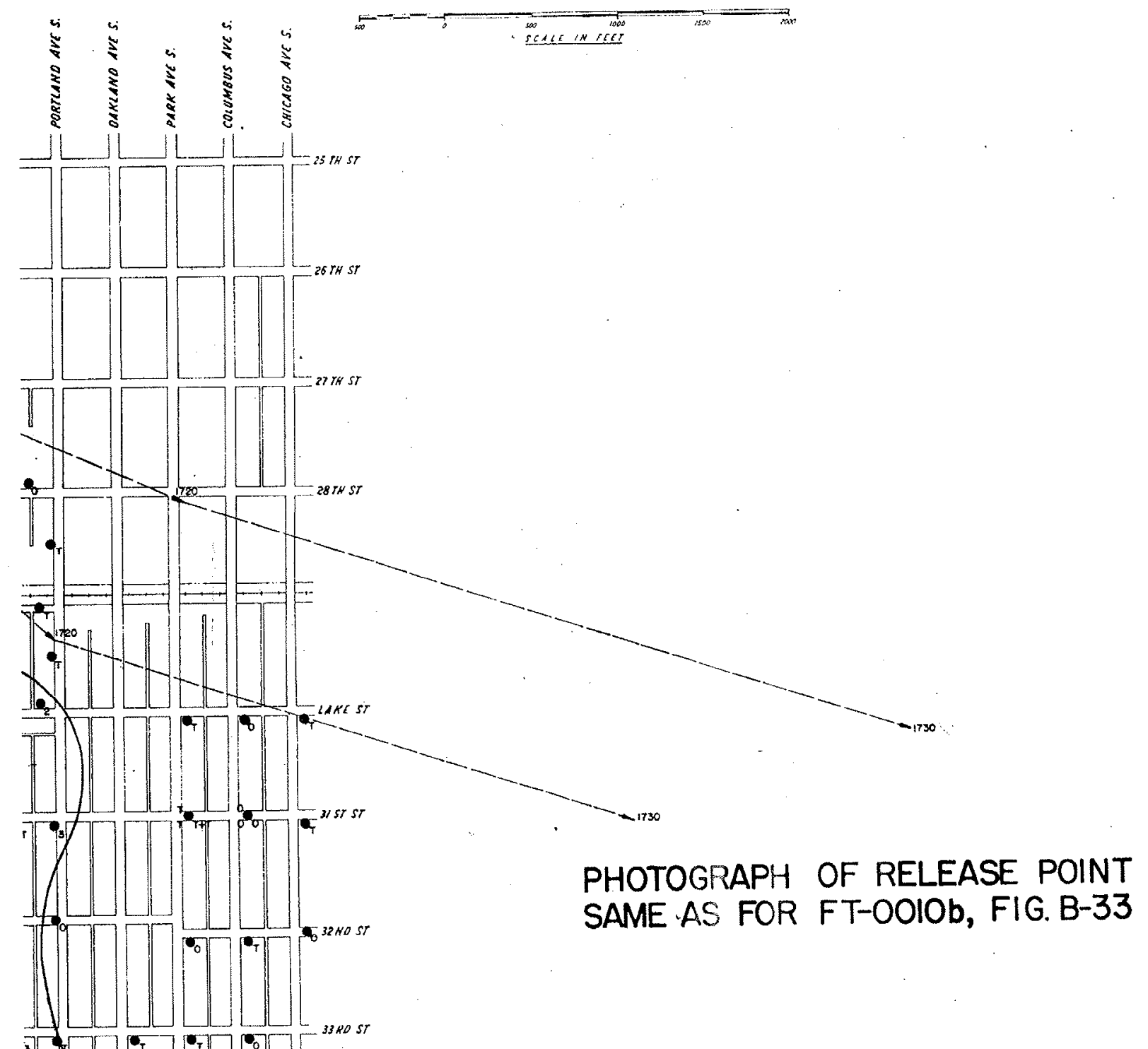
SAME AS FOR FT-OOIOb, FIG. B-33

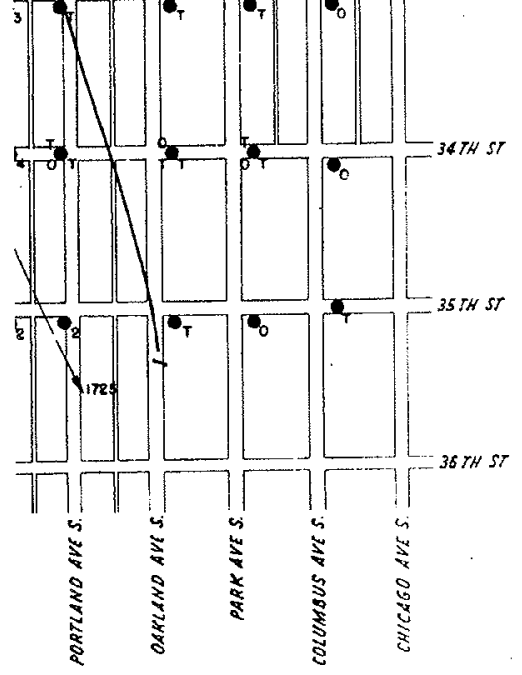

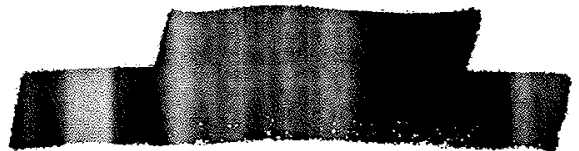

FIGURE B-42 TEST ARRAY AND RESULTS FT OOIIC 1710 CST FEBRUARY 15,1953

PAGE 218 
FIGURE B-37

TEMPERATURE SOUNDINGS

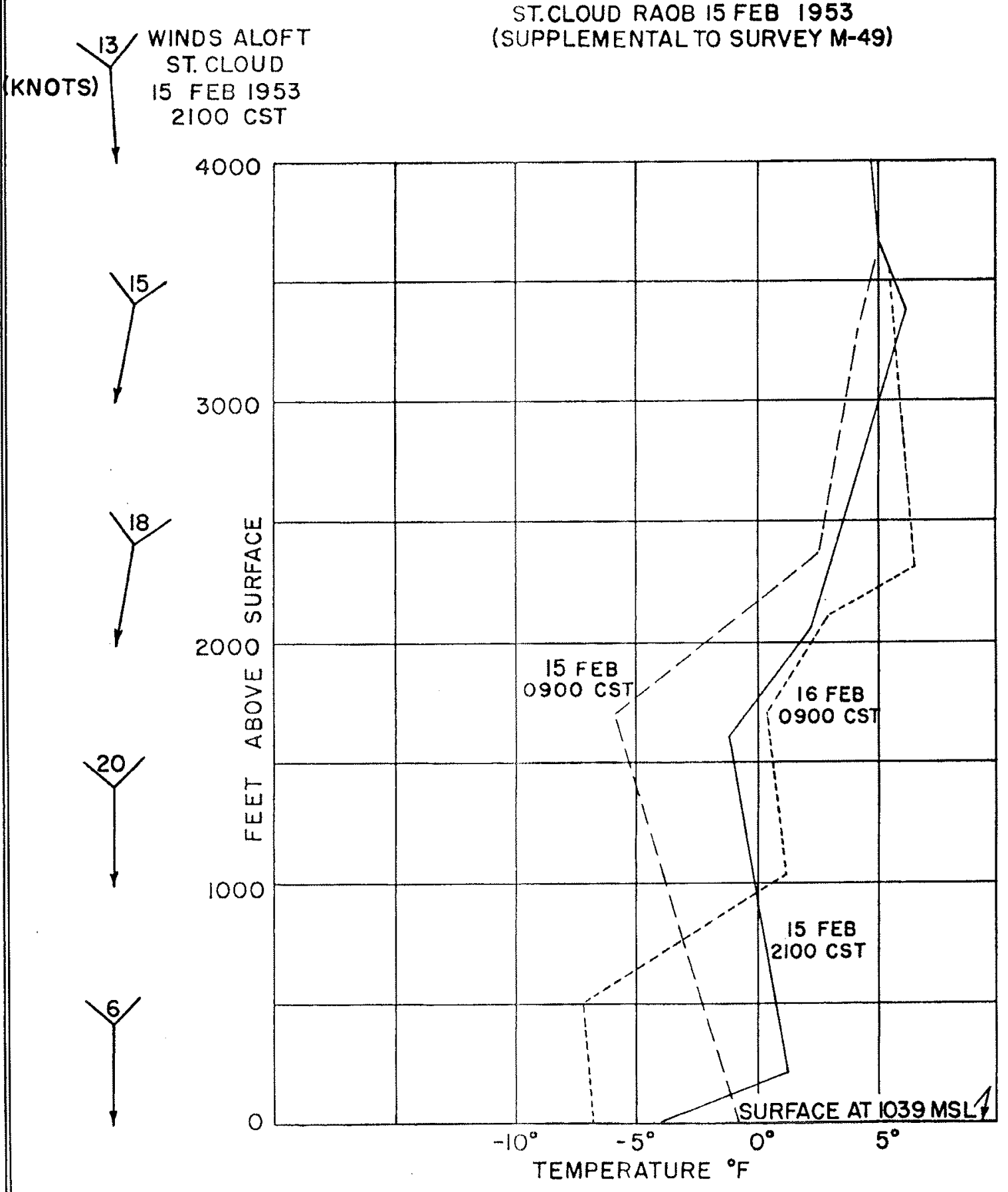

(SUPPLEMENTAL TO SURVEY M-49) 


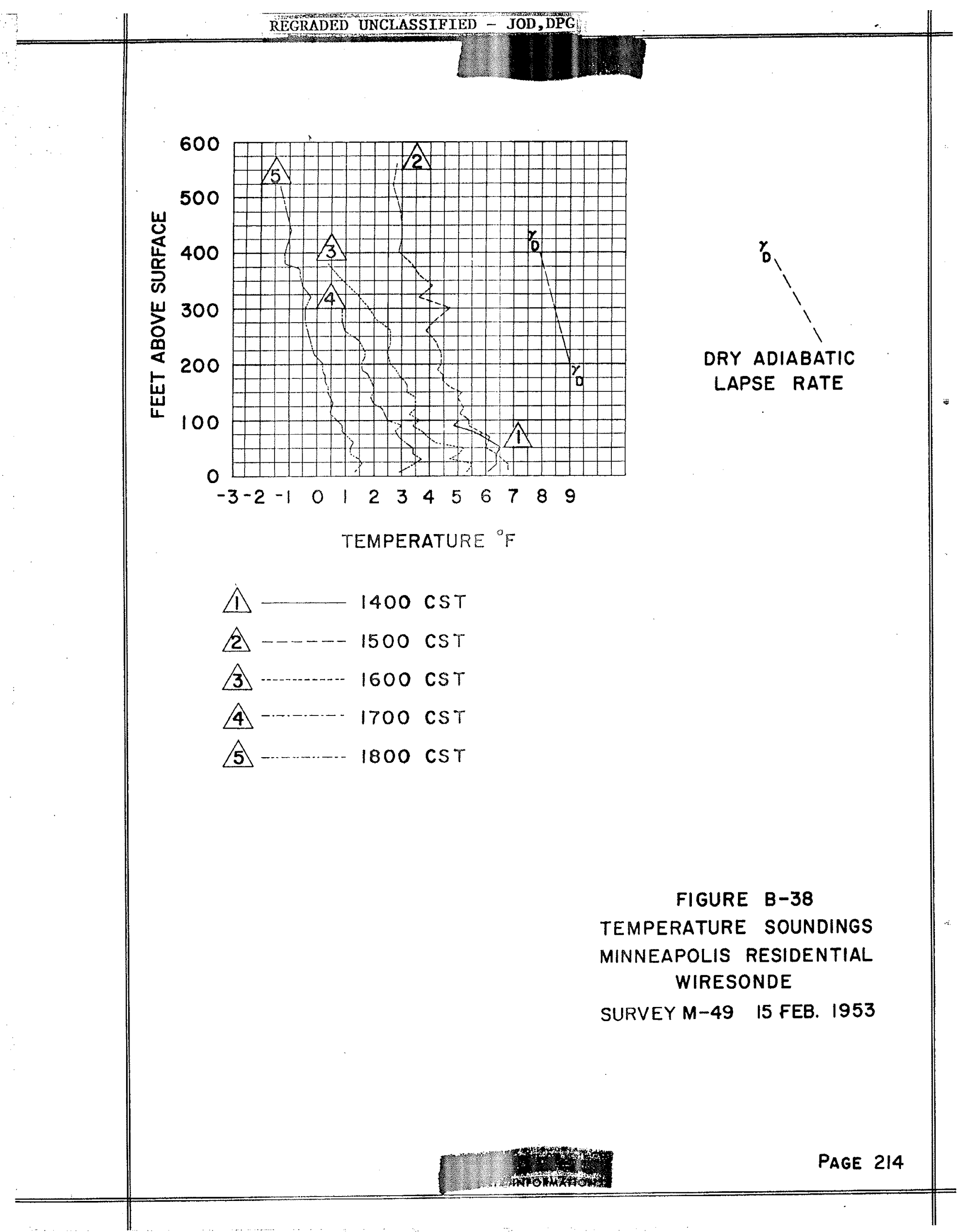




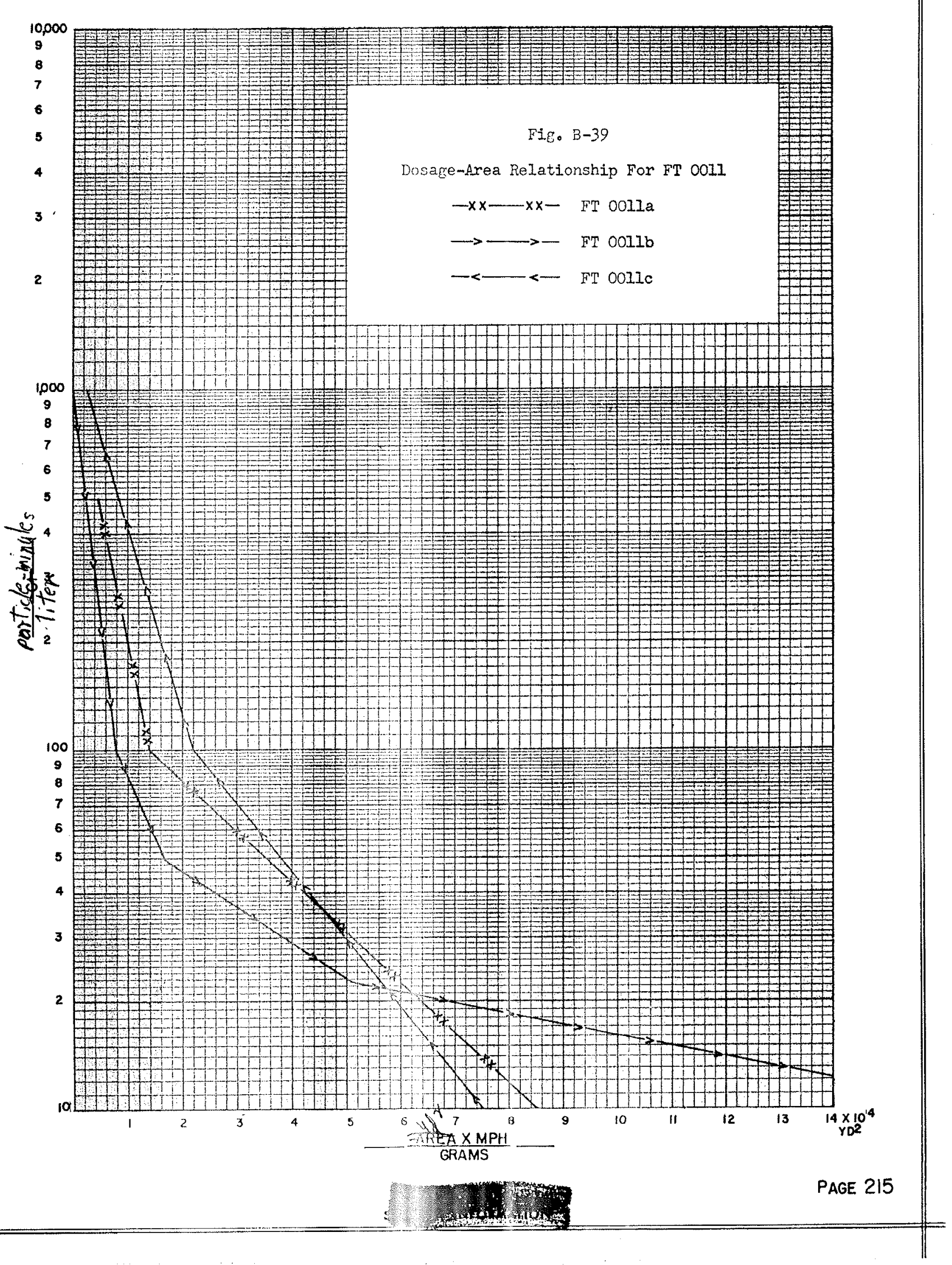




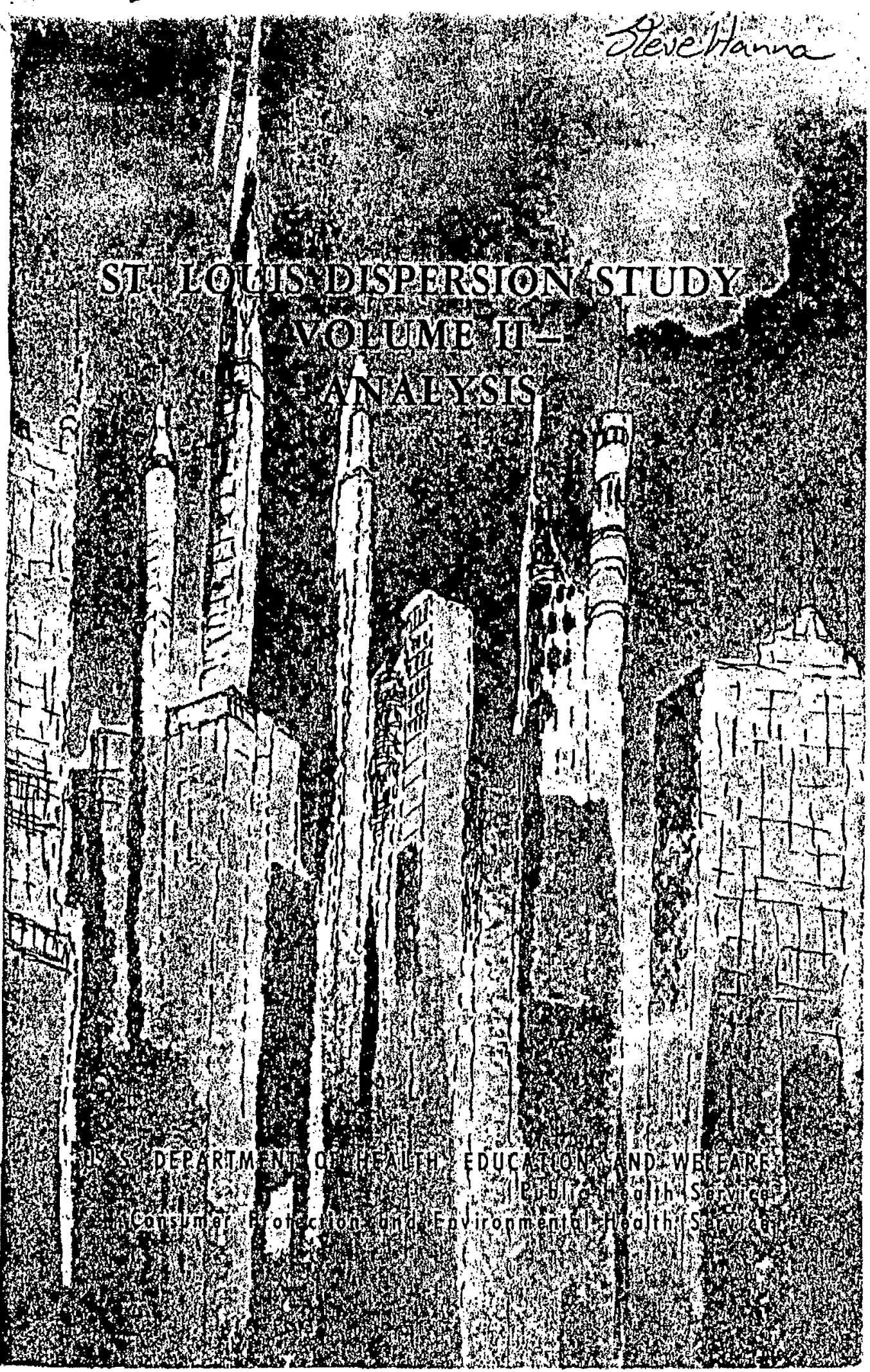

Obtained through FOIA-

Dugway 2 of 3 


\title{
ST. LOUIS DISPERSION STUDY VOLUME II -
}

\author{
ANALYSIS
}

James L. McElroy and Francis Pooler, Jr, Bureau of Engineering and Physical Sciences Division of Meteorology

U.S. DEPARTMENT OF HEALTH, EDUCATION, AND WELFARE Public Health Service

Consumer Protection and Environmental Health Service

National Air Pollution Control Administration Arlington, Virginia

December 1968 


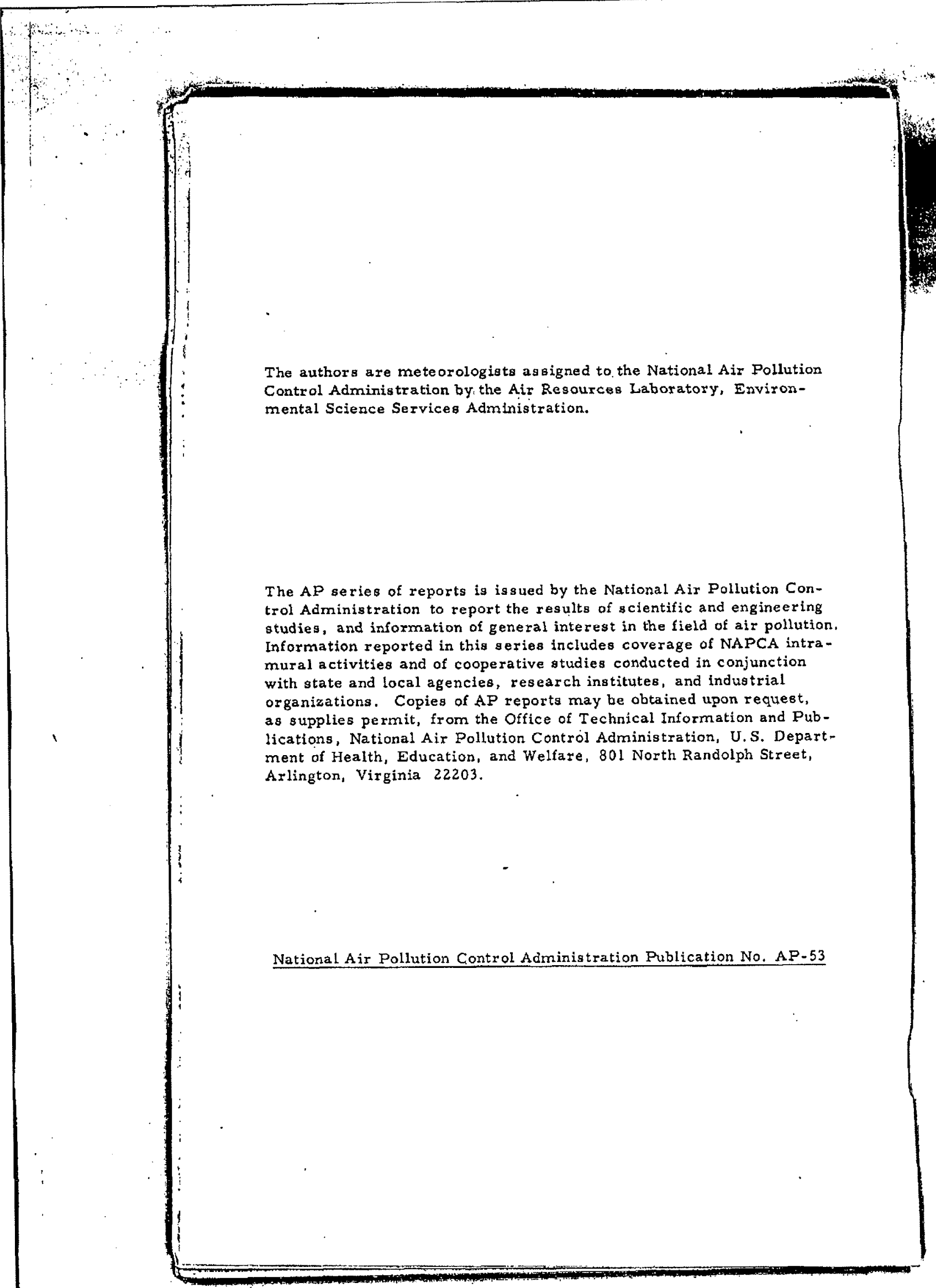


ABSTRACT . . . . . . . . . . . . . . . . iv

INTRODUCTION . . . . . . . . . ............ . 1

DESCRIPTION OF TRACER DATA . . . . . . . . . . . . 3

Total Dosage at Surface. . . . . . . . . . . . . . . 3

Sequential Dosage at Surface . . . . . . . . . . . . . . 3

Total Dosage in the Vertical . . . . . . . . . . . . . . 4

DISPERSION PARAMETERS. . . . . . . . . . . . . . . . 5

Normalized Axial Concentration. . . . . . . . . . . . . 5

Cross-Wind Parameters... . . . . . . . . . . . . . 5

Vertical Parameters.................. 6

Tabulation of Results. . . . . . . . . . . . . . . . . 9

Loss of Tracer Material :. . . . . . . . . . . . . . 9

Effective Transport Wind Speed, . . . . . . . . . . . 10

METEOROLOGICAL INDICES OF TURBULENCE . . . . . . . 15

Pasquill-Turner Stability Classes . . . . . . . . . . . 15

Modified "Brookhaven" Gustiness Classes... . . . . . . . 15

Horizontal Wind Direction Fluctuations and Conditions of

Vertical Stability . . . . . . . . . . . . . 16

Tabulation of Results . . . . . . . . . . . . . . . . 17

RELATION OF DISPERSION PARAMETERS TO METEORO-

LOGICAL INDICES OF TURBULENCE . . . . . . . . . . 19

COMPARISONS WITH OTHER EXPERIMENTAL PROGRAMS . . . 21

INITIAL DIMENSIONS OF TRACER CLOUD. . . . . . . . . . 23

CONCLUSIONS AND RECOMMENDATIONS . . . . . . . . . . . 45

ACKNOWLEDGMENTS . . . . . . . . . . . . . . . . . 47

REFERENCES ... . . . . . . . . . . . . . . 49 


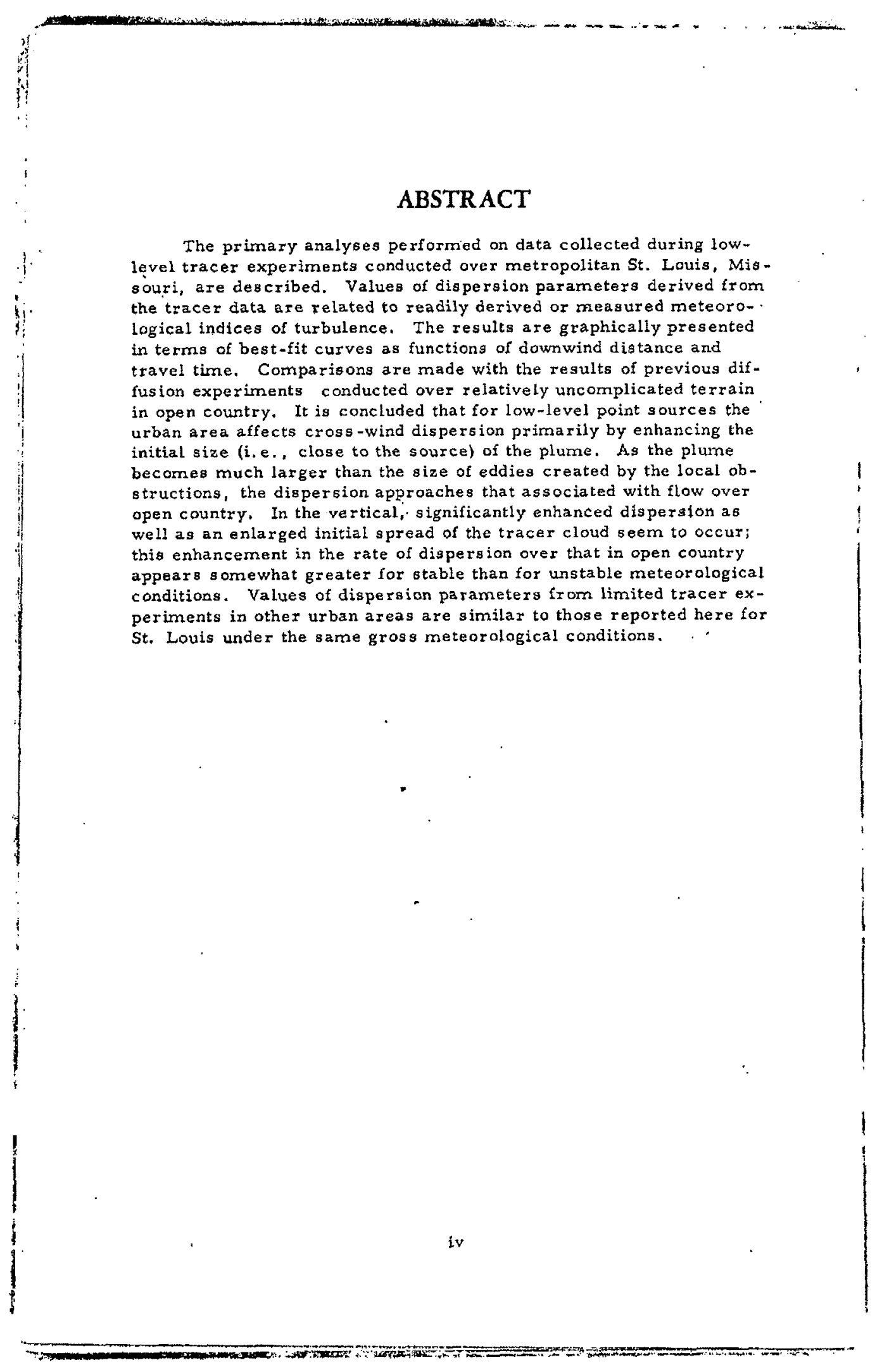




\title{
ST. LOUIS DISPERSION STUDY VOLUME II -
}

\author{
ANALYSIS
}

\section{INTRODUCTION}

The St. Louis Dispersion Study consisted of a series of experiment in which fluorescent zinc cadmium sulfide particles were released and traced across the relatively flat urban area of metropolitan St. Louis. The measurement program began in the spring of 1963 and ended in the spring of 1965 . Over this 2 -year period 26 daytime and 16 evening experiments were conducted in seven series. Dissemination of fluorescent particles from either of the two pre-selected sites near ground level was usually 1 hour long. For each experiment, measurements of total dosage at the surface were obtained on three nearly circular arcs at distances between $1 / 2$ and 10 miles from the dissemination site. The use of particular arcs varied, usually depending on appropriate forecasts of wind direction and speed. In addition, time-sequential measurements of dosage at the surface wexe made on each arc at a few locations near the anticipated mean centerline of the tracer cloud. During nine experiments, total dosage was measured at several heights along the tether of a balloon flown at a single site. The site was usually a park or vacant lot between the inner and outer sampling arcs and as near as possible to the anticipated mean centerline. Also, a mesometeorological network composed of three stations an the periphery of the urban a rea and an instrumented television tower (KMOX) in the downtown area provided continuous records of wind, temperature, and relative humidity. The TV tower was instrumented at three levels to provide information on the vertical gradients of wind and temperature. Single-theodolite (pibal) observationg of winds aloft and measurements of winds near the surface were made at the tracer dissemination site; free or tethered radiosonde ascents were made from the roof of a building in the downtown area; and transponder-equipped tetroons were released near the dissemination site. The tetroons were tracked by radar located at Lambert Field, northwest of the metropolitan area. 
Volume I of this report (APTD-68-12) presents a detailed description of the experimental equipment and procedures employed in the study, and provides in tabular form the dispersion and related meteorological data collected during the tracet experiments. Because Volume $I$ is mainly data tables, it is not being given general distribution.

Volume II describes the primary analyses performed on the dispersion and related meteorological data collected during the tracer experiments. The main objectives of the analyses were to obtain at least gross estimates of (1) the values of dispersion parameters over urban areas and (2) the relation of these parameters to meteorological indices of turbulence. A secondary objective was to compare the results of the St. Louis Dispersion Study with those of past experimental programs, especially those conducted over relatively "open" country. 


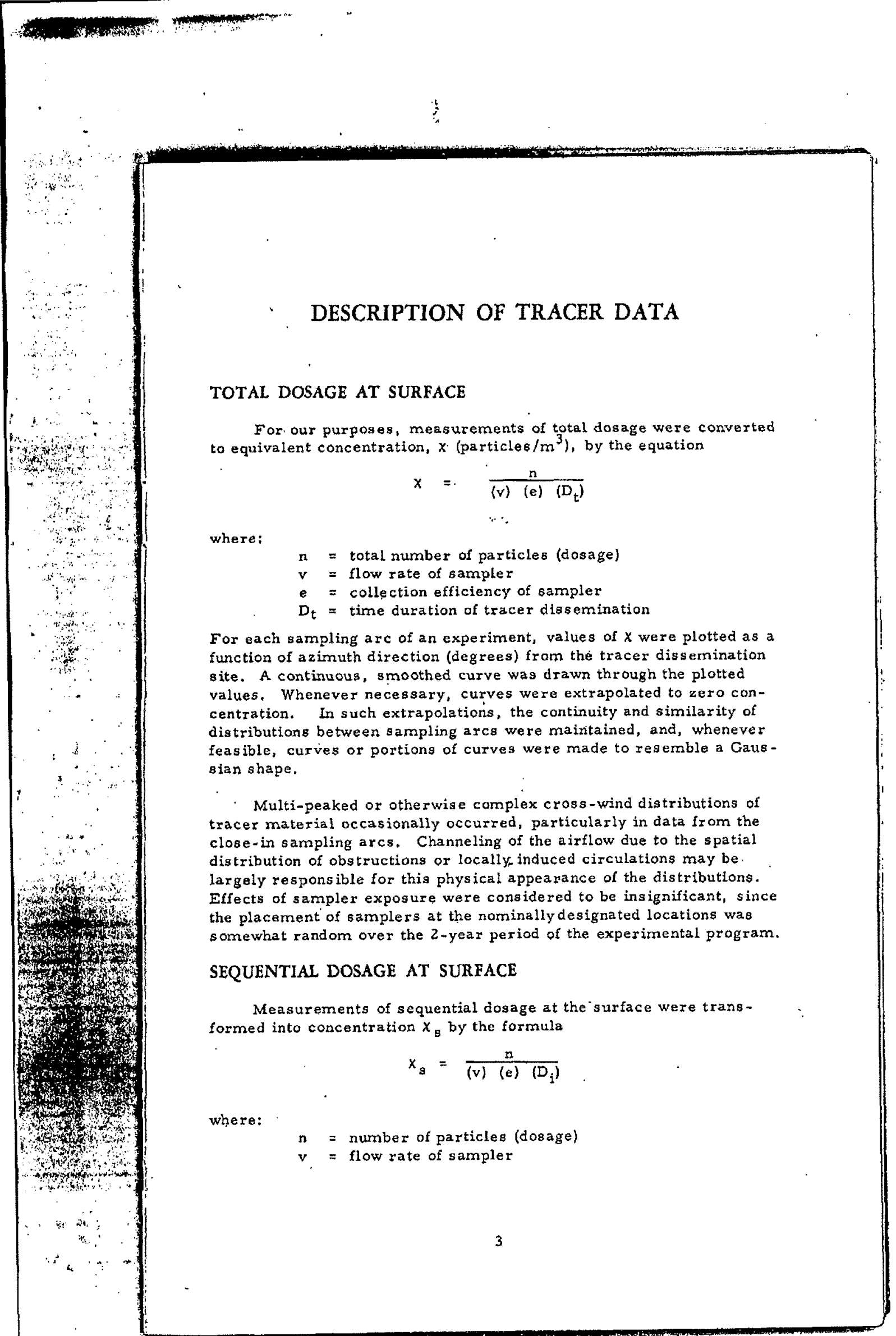




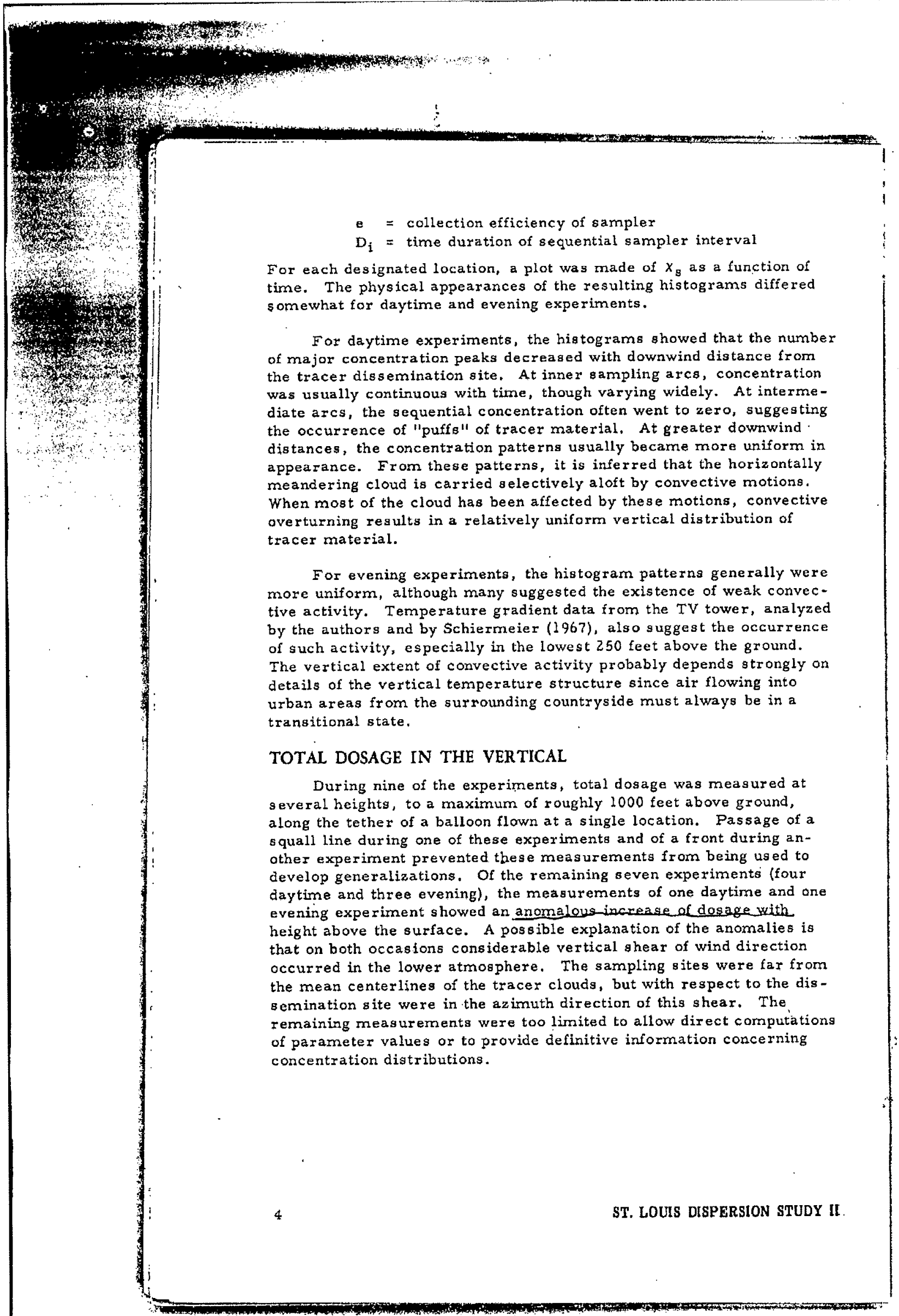




\section{DISPERSION PARAMETERS}

For the purposes of this report, 32 of the 42 experiments yielded usable dispersion data; 22 of these were conducted in the daytime and 10 in the evening. Many of the excluded experiments yielded usable data for which analysis could not be made in the conventional manner used here. A separate publication is planned to report analyses of these data.

\section{NORMALIZED AXIAL CONCENTRATION}

From the plots of equivalent concentration at the surface, $X$, (particles/meter ${ }^{3}$ ) vergus azimuth (degrees), $\theta$, from the tracer dissemination site for each sampling arc of an experiment, peak or axial values, $x_{p}$, were determined. These values were converted to normalized peak concentrations, $(x / \Omega)$ (seconds/meter $\left.{ }^{3}\right)$, through division by the tracer emission rate, $Q$ \{particles/second\}.

\section{CROSS.WIND PARAMETERS}

From each plot of $X$ versus 8 , values of $X$ were read at equally spaced azimuth intervals, beginning at an edge of the tracer cloud. The intervals were equivalent to the tracer measurement resolution. Measures of the statistical cross-wind standard deviation, $\sigma_{y}$ (meters), and the cross-wind integrated concentration, CIC (particles/meter ${ }^{2}$ ), were then computed from these values.

The equation for the root-mean-square standard deviation, $\sigma$, rewritten from Panofsky and Brier (1963), was modified to allow calculations of $\sigma_{y}$ :

$$
\sigma=\left[\frac{N \Sigma f_{i}\left(I_{i}\right)^{2}-\left(\Sigma f_{i} I_{i}\right)^{2}}{N^{2}}\right]^{1 / 2} \Delta
$$

where:

$$
\begin{aligned}
& \Delta= \text { frequency class interval } \\
& I_{i}= \text { deviation of class midpoint } i \text { from the assumed mean } \\
& \text { in terms of class intervals } \\
& f_{i} \approx \text { frequency of the distribution for class interval } 1 \\
& N=\text { total } f_{i}, \text { i. e., } \Sigma f_{i}
\end{aligned}
$$

When a plot of $x$ versus $\theta$ is considered to be a frequency histogram of $X$ in terms of $\theta$, the values of $X$ at the equal azimuth increments may be taken as the mean values of increments for which they are the midpoints. Thus, $x_{i}=f_{i}$ and $\Sigma x_{i}=N$. The proper $\Delta$ is not $\Delta_{\theta}$ (azimuth degrees) but rather $\Delta_{y}$ (arc length) written 


$$
\sigma_{y}=\left(\Delta_{Q}\right)(\bar{x})(\pi / 180)
$$

where $\vec{x}$, mean arc radius, is defined by $\frac{\Sigma x_{j} x_{j}}{\Sigma x_{j}}$ and $x_{j}$ is the equivalent

- concentration at a given sampling site along the arc located a distance $x_{j}$ from the dissemination site.

With thesedefinitions equation (1) may be rewritten as

$$
\sigma_{y}=\left[\frac{\Sigma x_{i}\left(\Sigma x_{i} i_{i}^{2}\right)-\left(\Sigma x_{i} I_{i}\right)^{2}}{\left(\Sigma x_{i}\right)^{2}}\right]^{1 / 2}\left[\Delta_{\theta}\right]\left[\frac{\Sigma x_{j} x_{j}}{\Sigma x_{j}}\right]\left[\frac{\pi}{130}\right]
$$

Surface cross-wind integrated concentration, CIC $\mathrm{C}_{3}$, defined as $\int_{-\infty}^{\infty} x(y) d y$ was approximated by $\Sigma x_{i} \Delta_{y}$, when $\Delta_{y}$ from equatio Surface cross-wind integrated concentration, cic $s$ defined as

$$
C I C_{s}=\sum\left[\left(x_{i}\right)\left(\Delta_{\theta}\right)\left(\frac{\Sigma x_{j} x_{j}}{\Sigma x_{j}}\right)\left(\frac{\pi}{180}\right)\right]
$$

\section{VERTICAL PARAMETERS}

Estimates of vertical dispersion parameters were based on the surface tracer measurements and hence represent only "effective" values. As previously noted, the measurements of tracer material in the vertical were too limited for direct computation of vertical parameter values. The rationale for describing dispersion in the vertical differed for daytime and evening experiments.

\section{Daytime Experiments}

For each arc of a daytime experiment, a derived estimate of the vertical standard deviation, $\sigma_{2}$ (metera), was computed from the appropriate mass continuity equation, assuning no loss of tracer in transit, uncorrelated horizontal and vertical tracer distributions, and a Gaussian distribution of material in the vertical. This equation may be written as

$$
Q=\int_{0}^{\infty} \int_{-\infty}^{\infty} \bar{u} x(y) \quad x(z) d y d z
$$

where:

$$
\begin{aligned}
& Q=\text { quantity of tracer material disseminated per unit time } \\
& \overline{\mathbf{u}}=\text { effective transport wind speed }
\end{aligned}
$$

Since $\bar{u}$ is assumed to be independent of $y$ ard $z$ and $\int_{\infty}^{\infty} x(y) d y$ is CIC $_{s}$,

$$
\frac{Q}{\overline{\mathrm{u}} \operatorname{CIC}_{\mathrm{s}}}=\int_{0}^{\infty} x(z) d z
$$




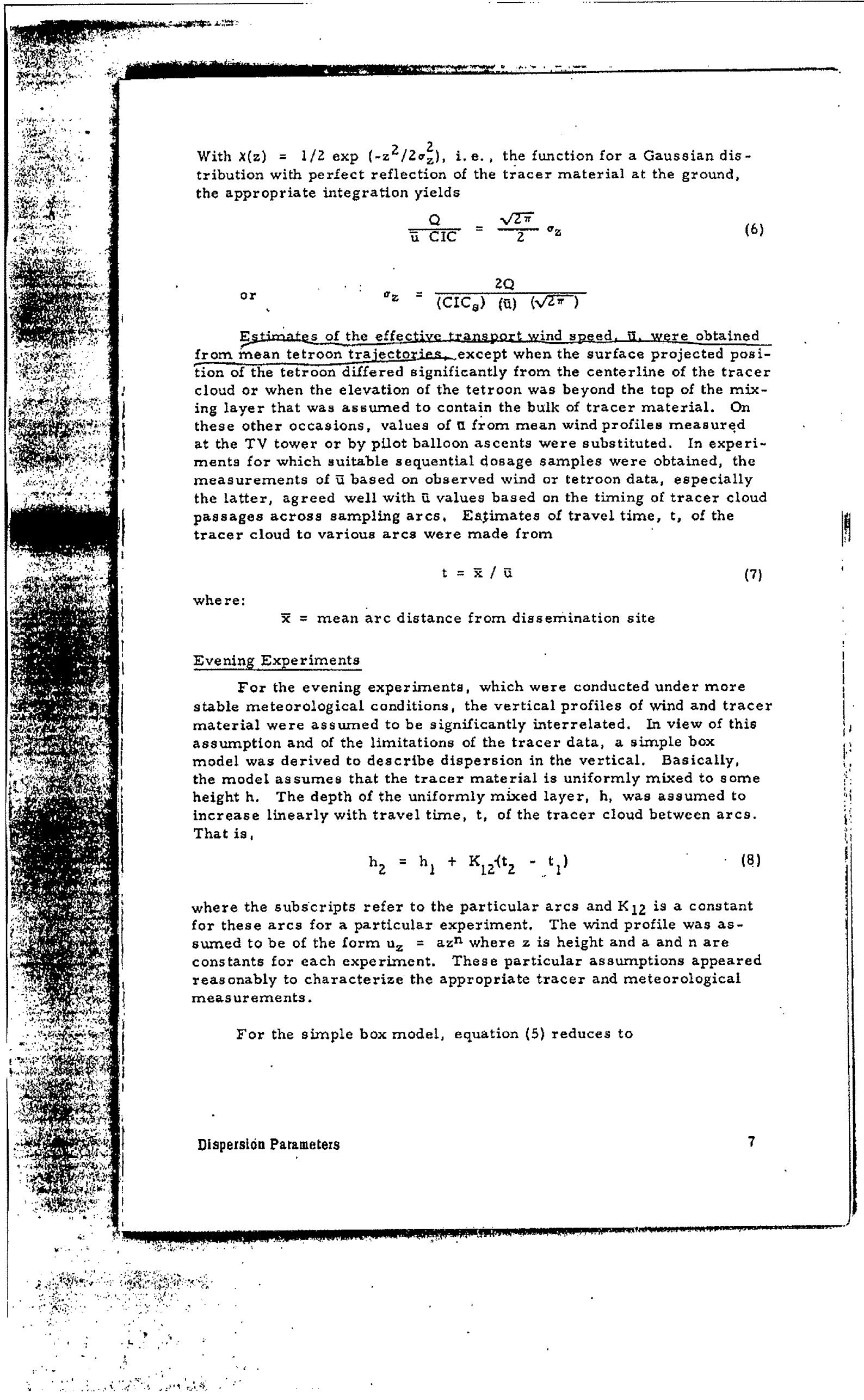


where $\widetilde{u}_{h}$ is the effective mean transport wind through depth, $h$, at a particular arc. The appropriate $\bar{u}_{h}$ for $h$ at each arc was defined by the relation

$$
\bar{\sigma}_{h}=\frac{\int_{0}^{h} x(z) u z d z}{\int_{0}^{h} x(z) d z}
$$

where $x(z)$ in thia case is a constant, $C$.

Integration of this equation with the substitutions $u_{z}=a z^{\text {n }}$ and $x(z)=C$ yields

$$
\pi_{h}=\frac{a h^{n}}{n+1}
$$

When this value for $\mathrm{t}_{\mathrm{b}}$ is substituted into equation (8), the relation becomes

$$
h=\left[\begin{array}{ll}
\frac{n+1}{a} & \frac{Q}{C I C_{B}}
\end{array}\right]^{\frac{1}{n+1}}
$$

Now it is necessary to determine horizontally and vertically averaged travel speeds, $\overline{\tilde{H}}_{h}$, based on the horizontal variation of vertically averaged speeds, $\bar{u}_{h}$. Since $h$ from equation ( 8 ) has been defined as a function of $t$,

$$
\overline{\bar{u}}_{h}=\frac{\int_{t_{1}}^{t_{2}} \bar{u}_{h}(t) d t}{\int_{t_{1}}^{t_{2}} d t}
$$

where $t_{1}$ and $t_{2}$ are travel times from the dissemination site to particular arcs. From equations (11) and (8),

$$
\bar{u}_{h}=\frac{\int_{t_{1}}^{t_{2}}\left[h_{1}+k_{12}\left(t_{2}-t_{1}\right)\right]^{n} d t}{\int_{t_{1}}^{t_{2}} d t}=\frac{a\left(\begin{array}{c}
n+1 \\
h_{2}
\end{array} h_{1}^{n+1}\right)}{(n+1)^{2}\left(h_{2}-h_{1}\right)}
$$

where, again, the subscripts indicate particular arcs. 


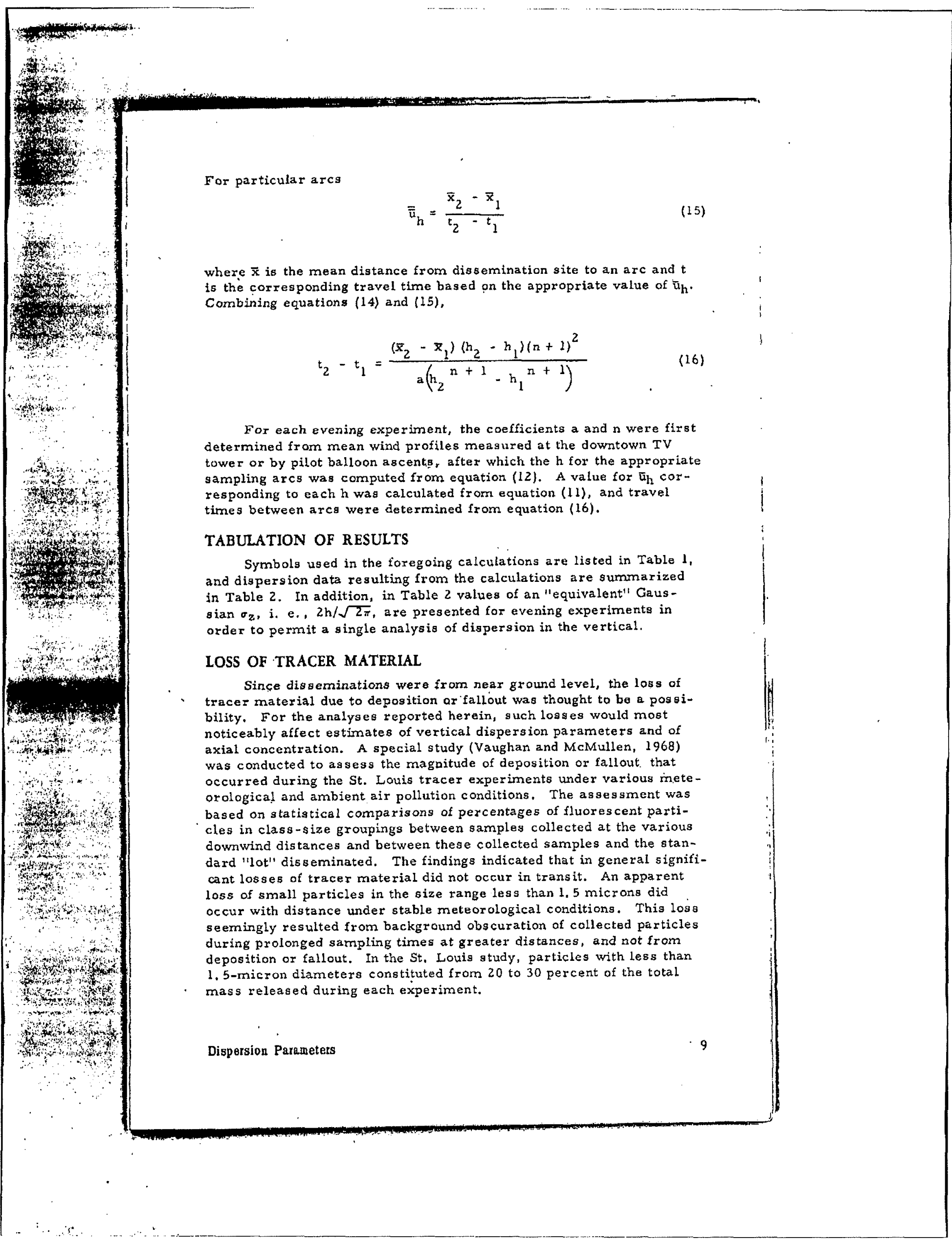




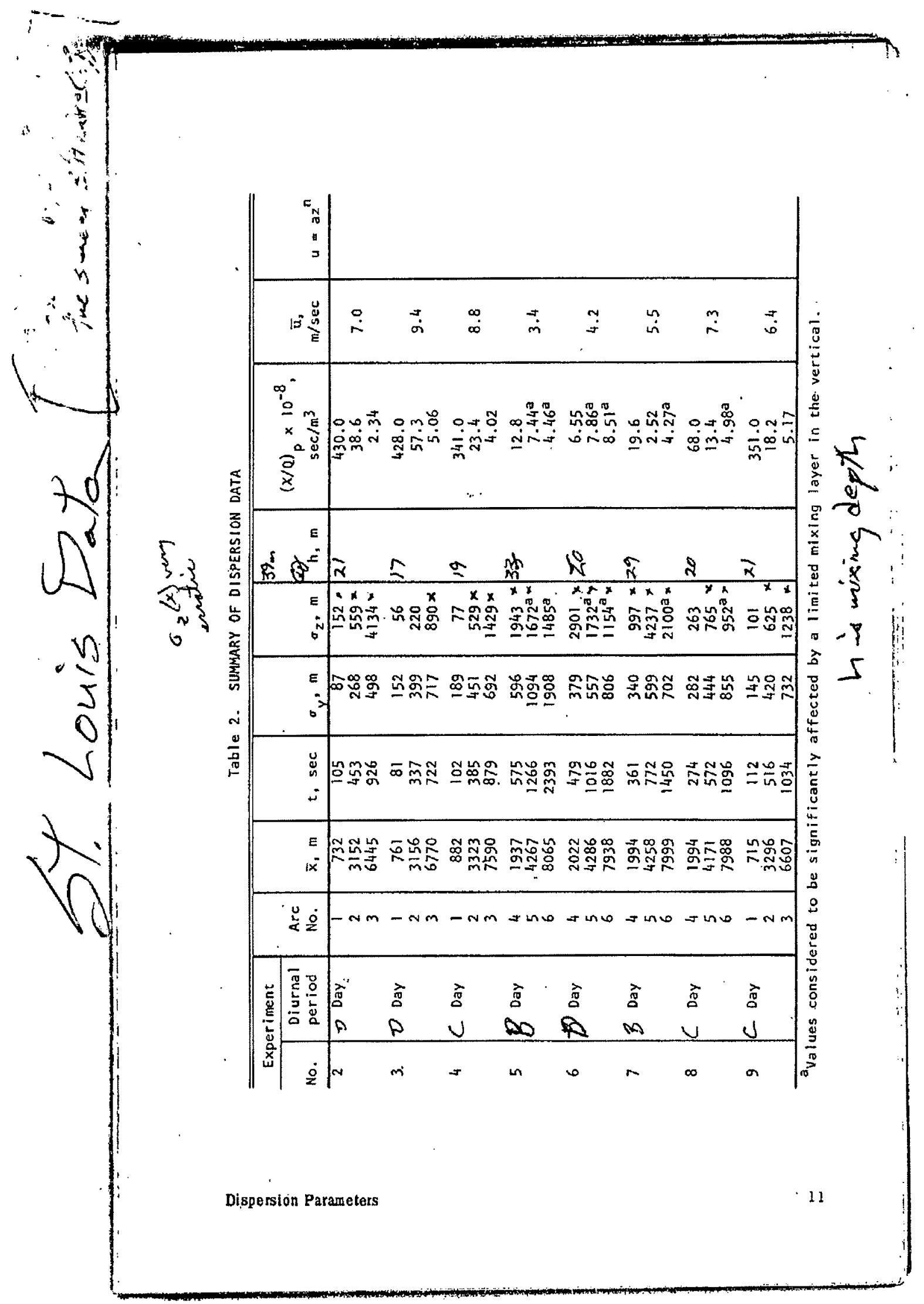




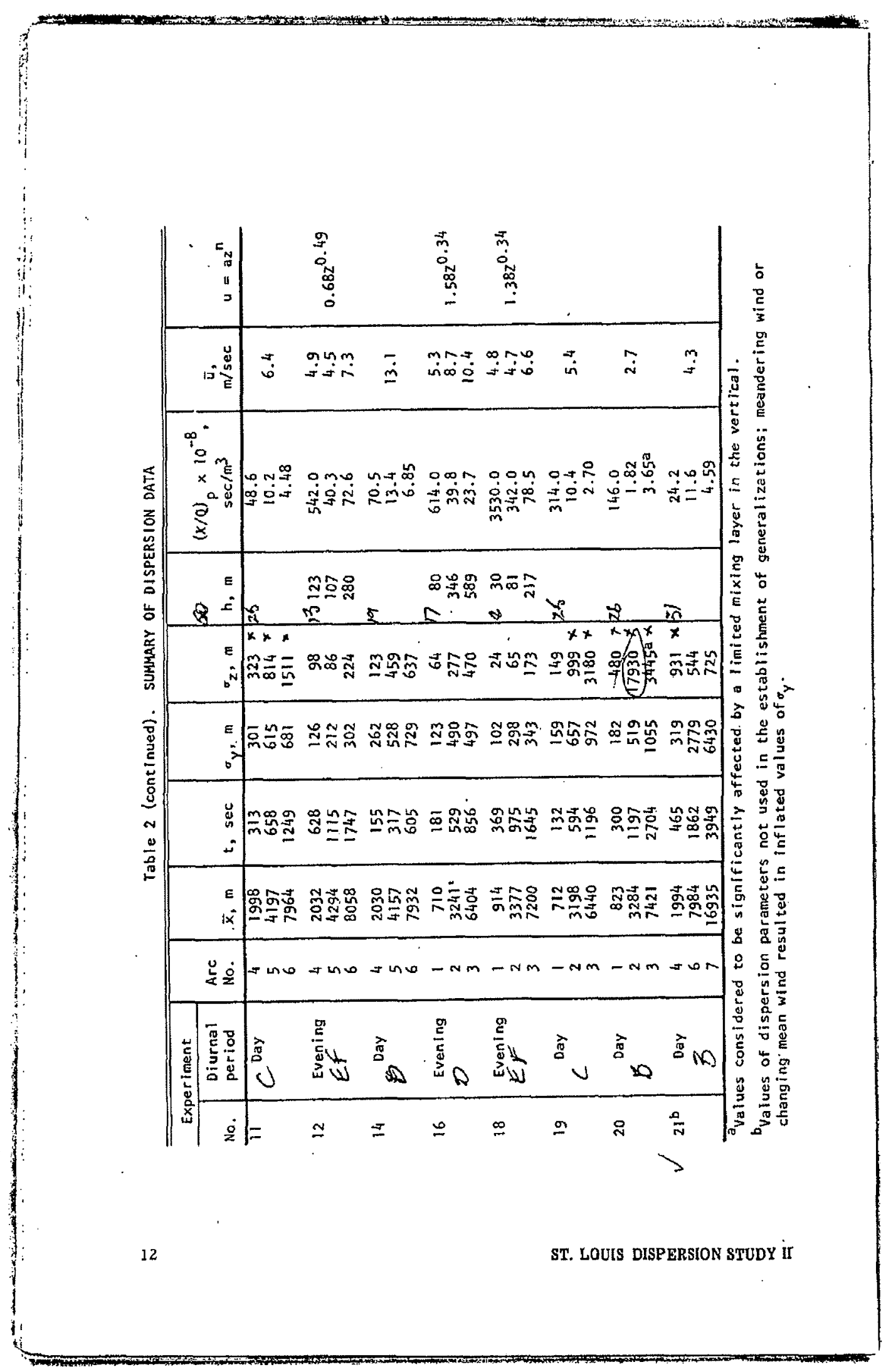




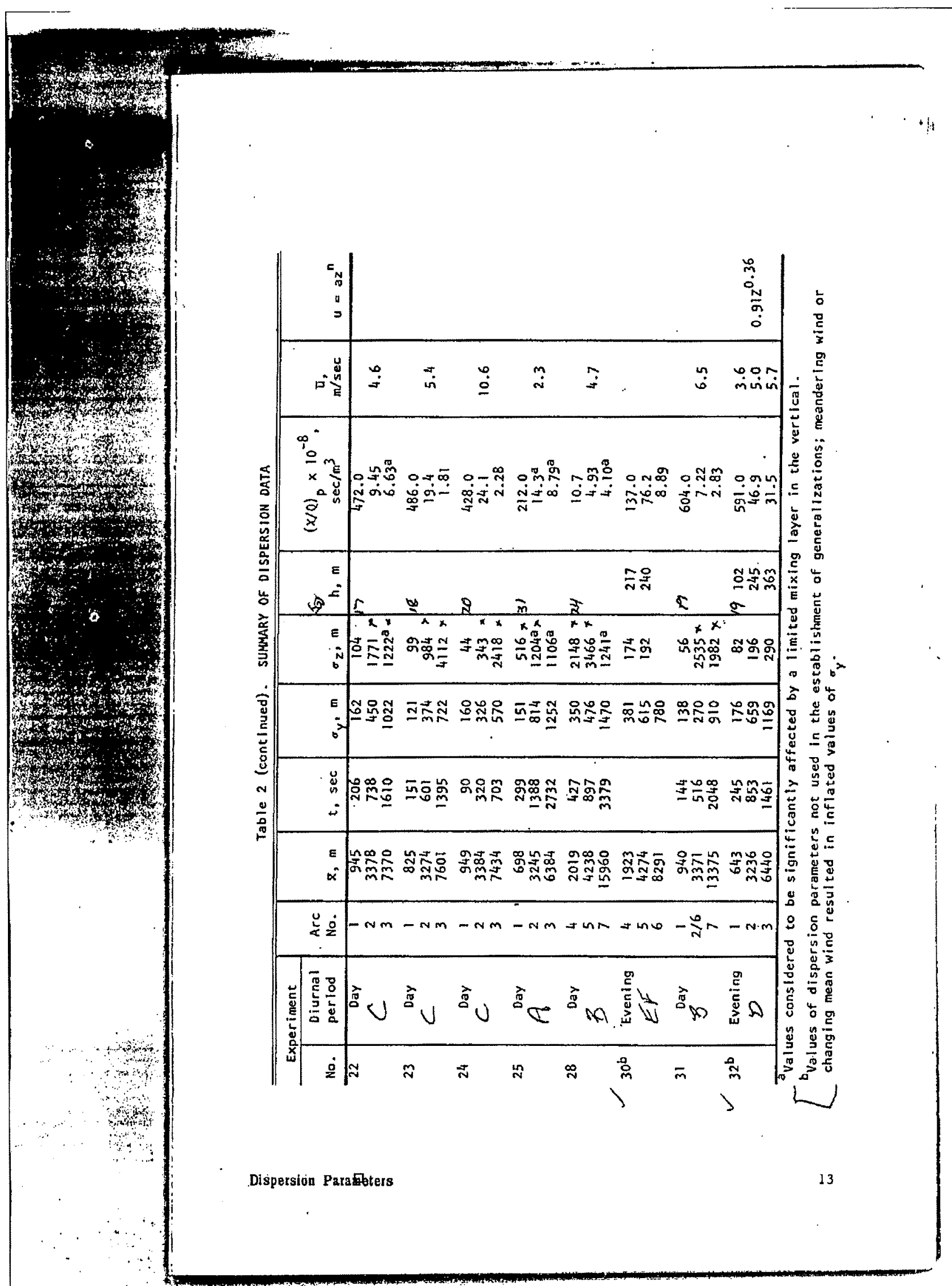




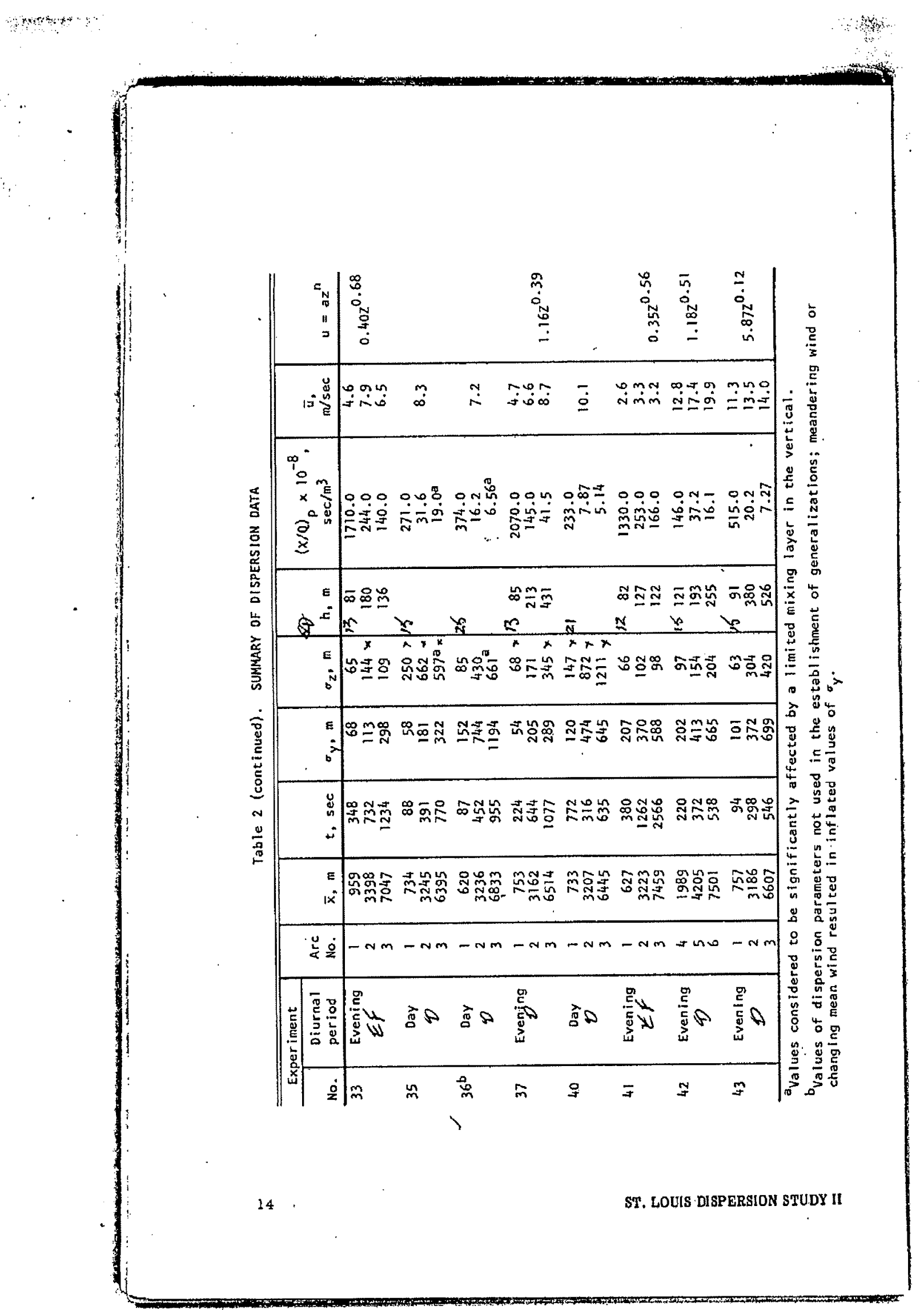




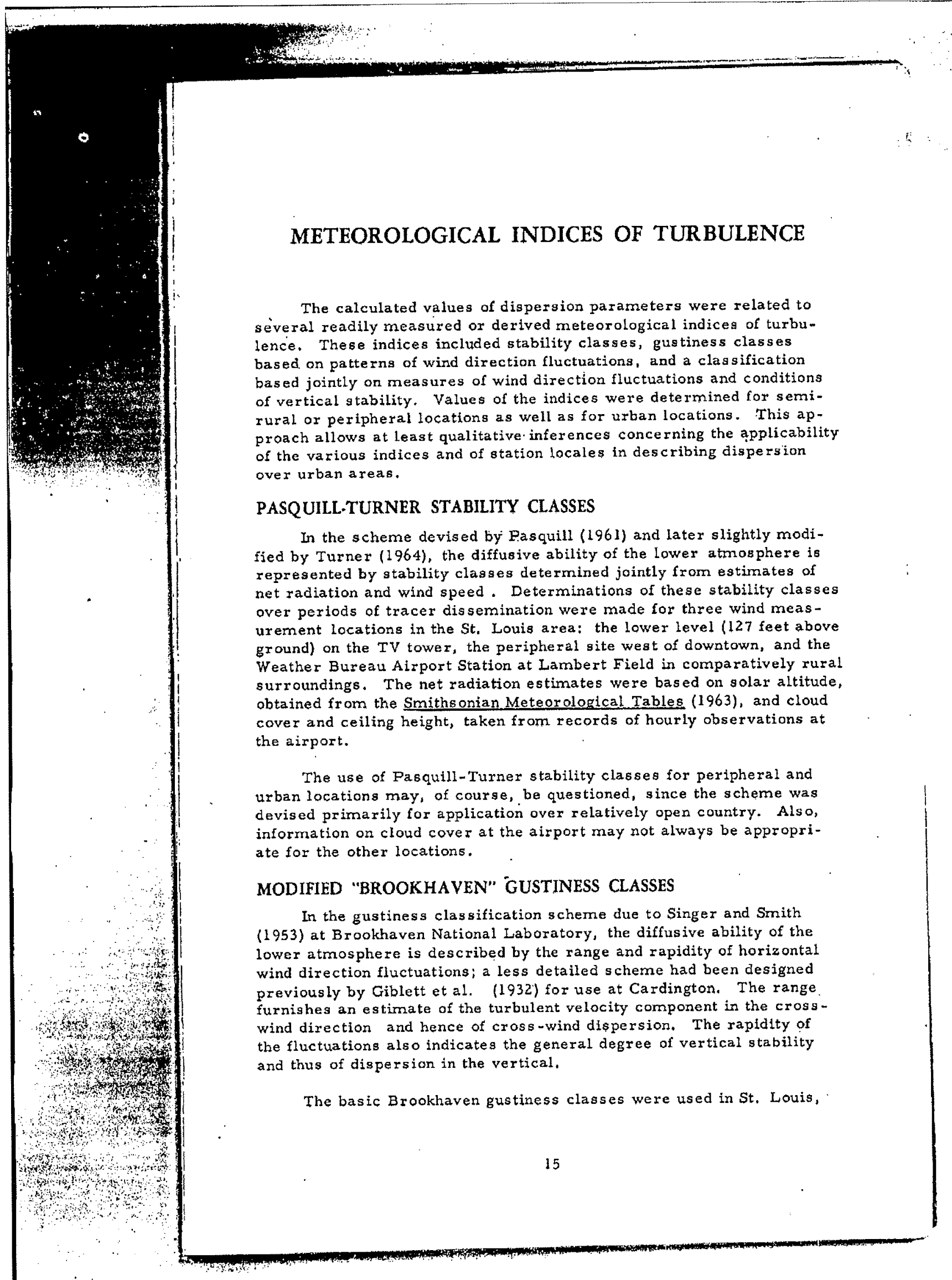


but different class limits on the ranges of wind direction fluctuations were adopted. Although the St. Louis wind sensors were the same type as those used at Brookhaven, they were located near larger roughness elements and usually nearer the ground. In addition to the urban (lower level on TV tower) and peripheral sites discussed earlier, wind data for the upper level ( 459 feet above the ground) of the TV tower were utilized also. With these additional data, comparioons can be made between wind direction fluctuations at 127 feet, slightly above nearby building tops, and those at 459 feet, well above the buildings. For each site, range limits for the specific classes wexe derived from appropriate analog traces obtained from a climatological analysis of the (analog) records and were, without exception, greater than those found by Singer and Smith (1953) at the Brookhaven site.

\section{HORIZONTAL WIND DIRECTION FLUCTUATIONS AND CONDITIONS OF VERTICAL STABILITY}

This joint meteor alogical index employs the standard deviation of horizontal wind direction fluctuations, $\sigma_{\theta}$, and a direct estimate of vertical stability expressed as a gradient Richardson number. Indices based partially or totally on these elements have been applied by such investigators as Cramer (1959), Fuquay et al. (1964), and Slade (1965) to organize dispersion data from othex experimental programs.

Eatimates of $\sigma_{\theta}$ over the tracer dissemination periods were made from frequency histograms of azimuth angle derived from records of the analog wind traces. Since the chart speed of wind recorders was a low 3 inches per hour, portions of the analog traces were occasionally "painted" (i.e., the more commonly occurring azimuth directions). Frequencies for the "painted" azimuth angles were extrapolated from those of the "non-painted" angles under the assumption that the frequency distributions of azimuth angle were Gaussian or resulted from sums of Gaussian distributions.

Comparisons of these values of $\sigma_{\theta}$ with the extreme, third highest, and fifth highest ranges of wind direction fluctuations over the tracer dissemination periods showed statistically linear relationships for each range for each meteorological site. Linear correlation coefficients varied from 0.8 to slightly over 0.9 , the higher correlations generally occurring for the peripheral and upper-level urban locations. Somewhat better correlations were attained with the third highest range than with the extreme or fifth highest ranges. Average values of the ratio of range to $\sigma_{\theta}$ for the extreme, third highest, and fifth highest range were, respectively, about $7.5,6.0$, and 5.5 . The value of 7.5 for the extreme range is slightly different from the 6.0 found by Markee (1963) and Slade (1965) for other locations and exposures.

Estimates of stability were based on wind and temperature meas urements at the downtown TV tower or temperature measurements from the downtown radios onde ascents. Lapse rates, stability ratios, and various forms of the gradient Richardson number for several layers in the lower atmosphere were considered. Thorough evaluation of these 


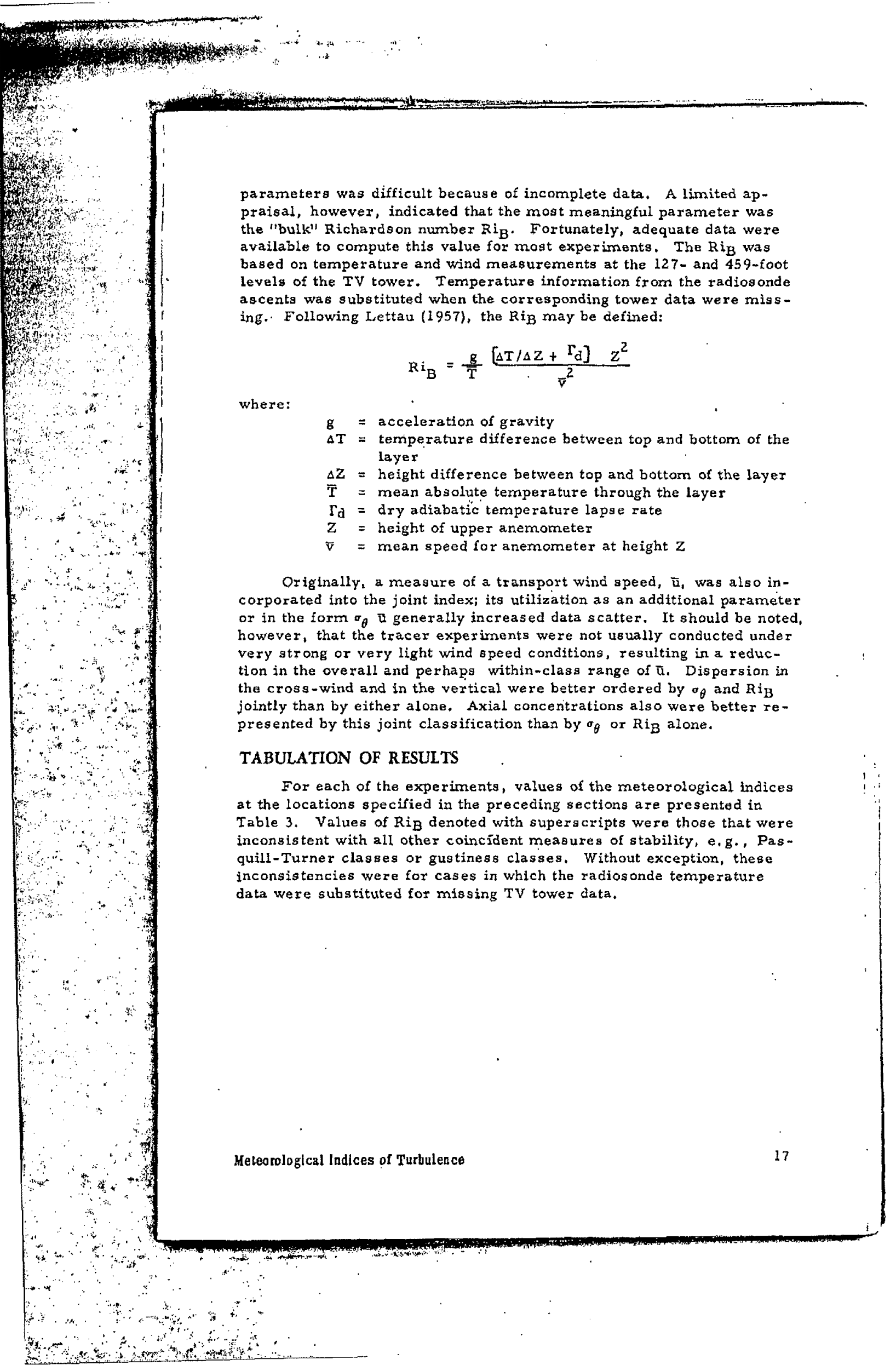




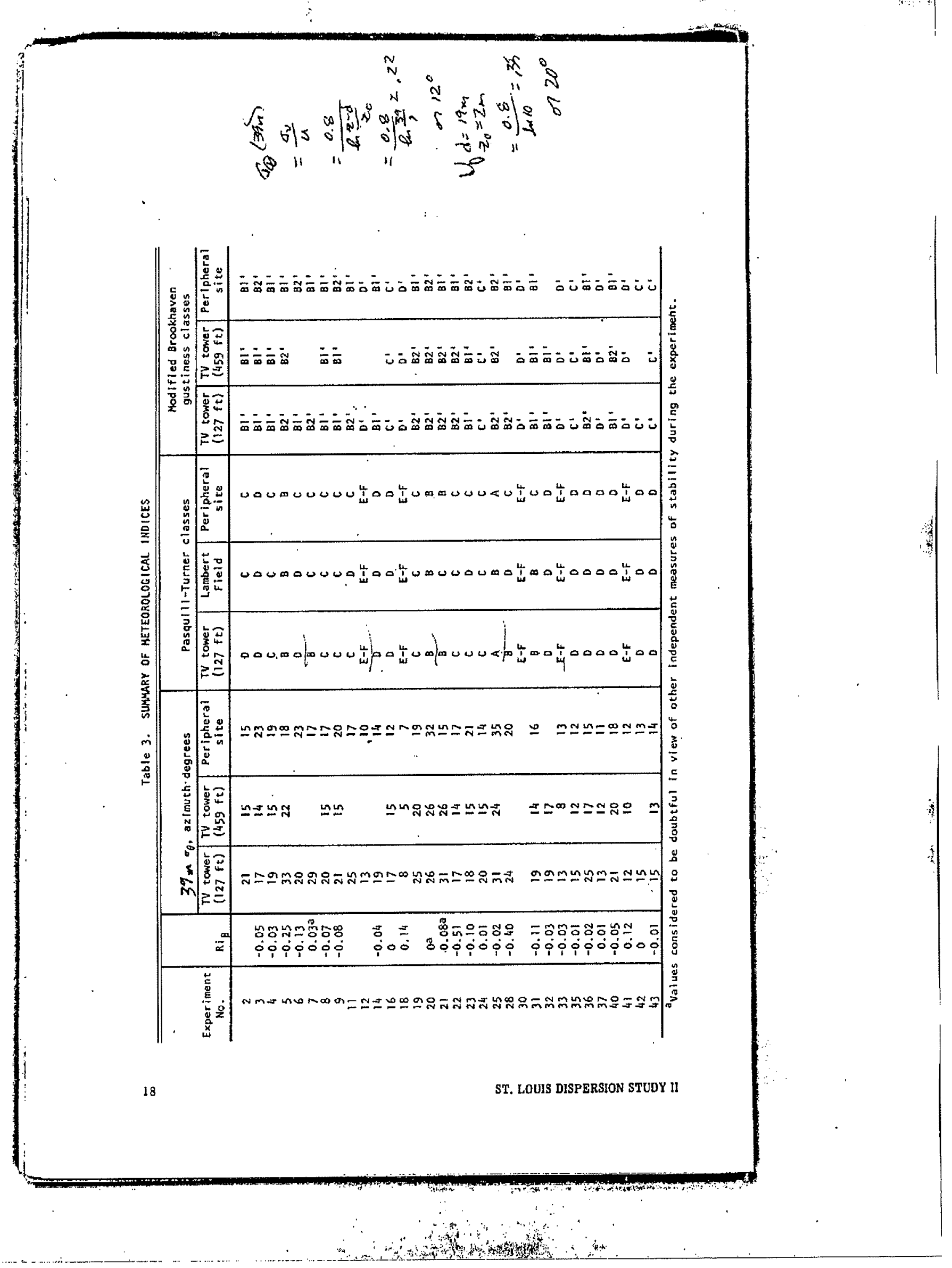




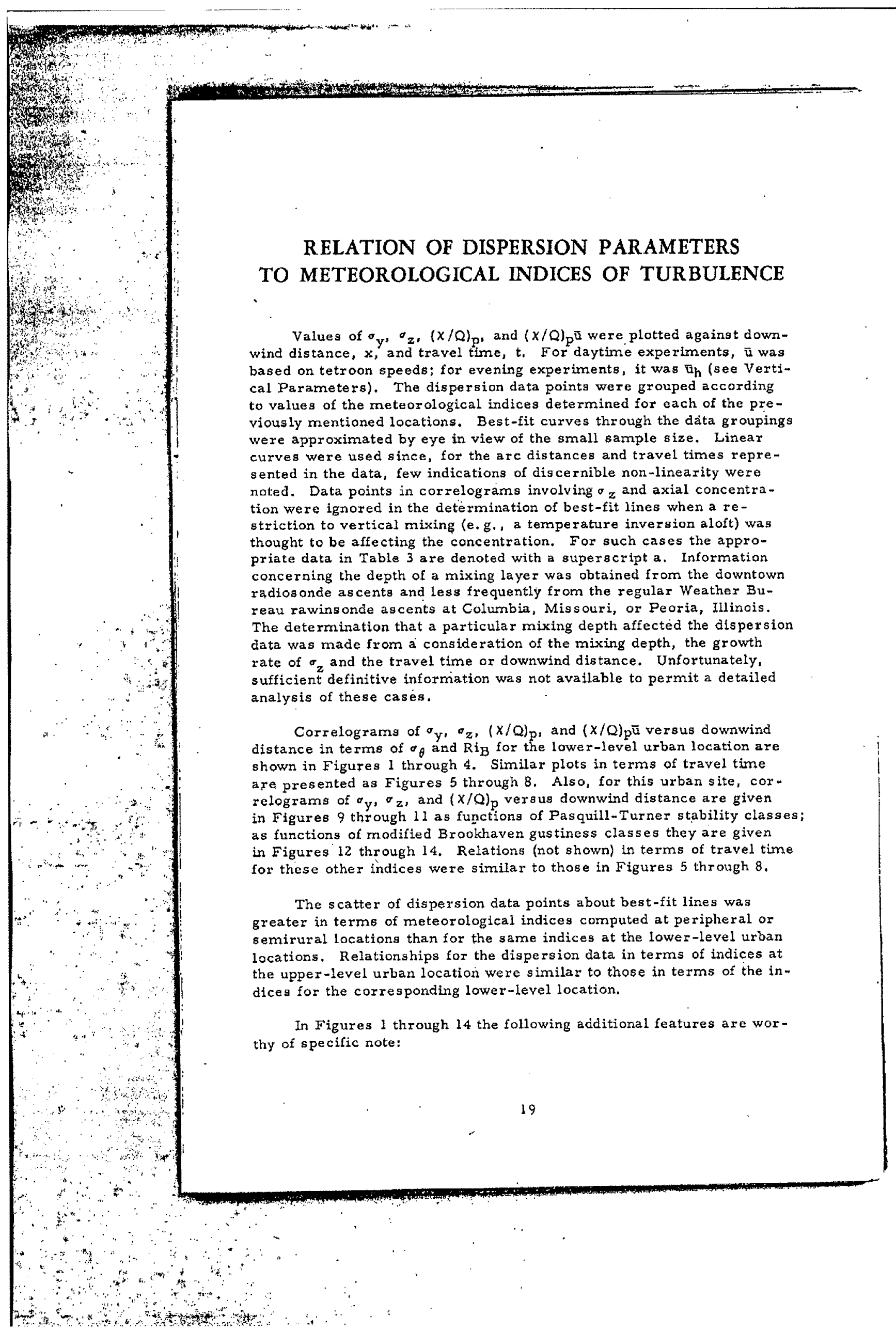


1. The ordering of data was poorest for the close-in sampling arcs at which multi-peaked or otherwise complex distributions in the cross-wind occurred in greater proportion than at more distant arca. As previously noted, channeling of the airflow due to various locally induced circulations may be largely responsible for the appearance of such distributions.

2. The scatter of data points about best-fit lines was much greater in $\sigma_{z}$ than in the other correlograms. Since the actual vertical distributions of tracer material were largely unknown, the relative magnitude of such scatter was nat altogether unexpected.

3. When plotted according to travel time, data were grouped best into only "stable" and "non-stable" regimes, except for $\sigma_{z}$, which was ordered about as well by travel time as by downwind distance.

4. In an earlier preliminary analysis of the dispersion data, Pooler (1966) found that values of ${ }^{\prime} y$, ordered only according to daytime and evening categories, were grouped about equally well in terms of downwind distance and of travel time, as shown in Figures 1 and 5 . In these figures daytime is indicated with a very few exceptions by those points for which $\mathrm{Ri}_{B} \leq 0.01$. As illustrated in Figures 2 and 6 ,

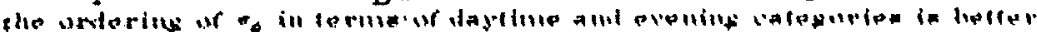
in terms of travel time than of downind distance.

5. Values of $\sigma_{2}$ and axial concentration that were considered to be significantly affected by a restrictive mixing layer were usually smaller and larger, respectively, than their non-affected counterparts under similar meteorological conditions.

6. Only a slight improvement in ordering af data points was achieved through normalizing $(x / Q)_{p}$ by $u$. Since, however, as was noted earlier, the range of likely th's is not fully represented in the data here, the generality of this result and of that involving the ordering of $\sigma_{z}$ with distance and time may requite further verification.

7. The scatte $x$ of data points about best-fit lines was considerably greater for Pasquill-Turner stability classes than for the other indices. For the modified Brookhavef gustiness clasges and the joint classes of $\sigma_{\theta}$ and $R i_{B}$, the scatter of data points about best-fit lines was quite similar. 


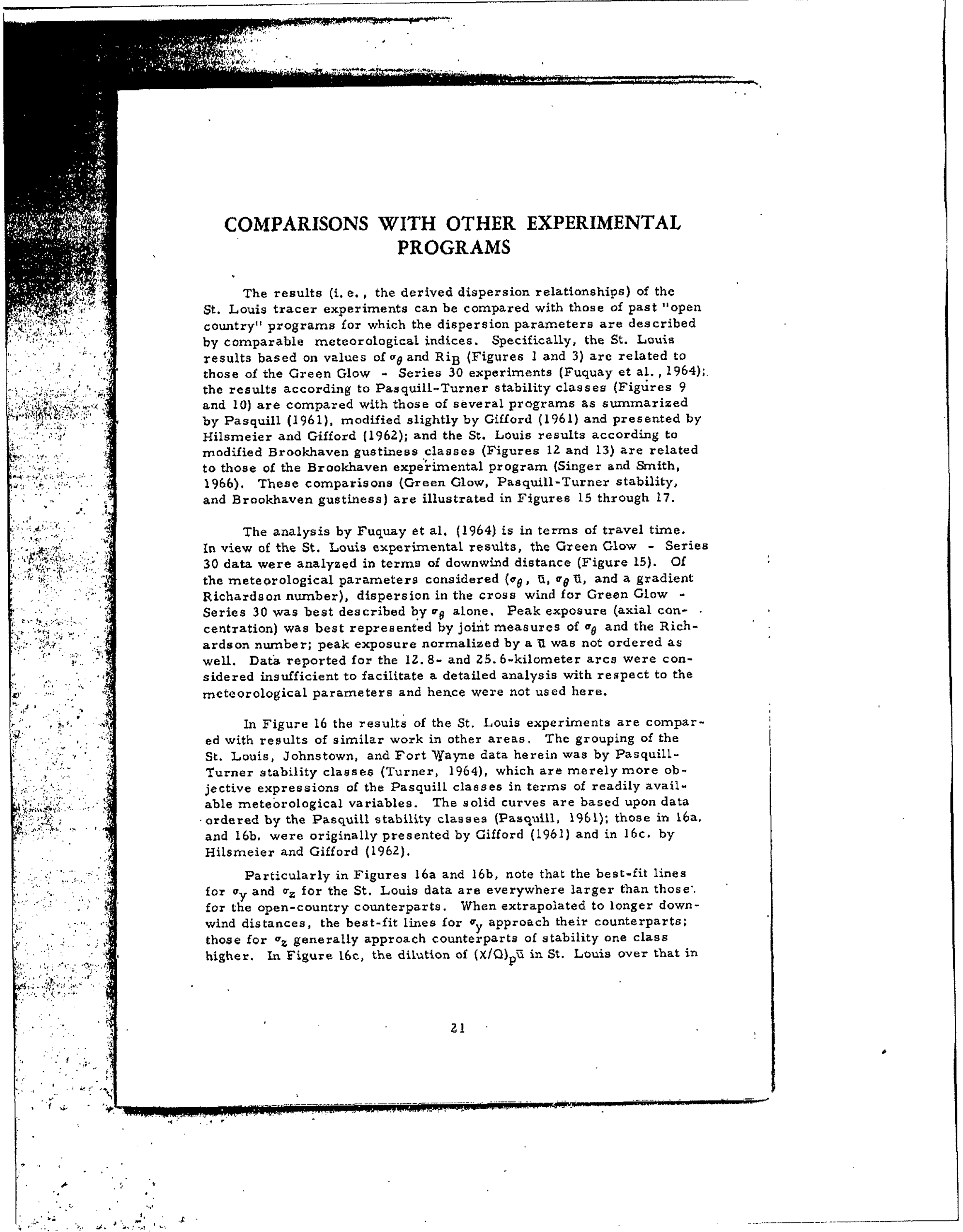




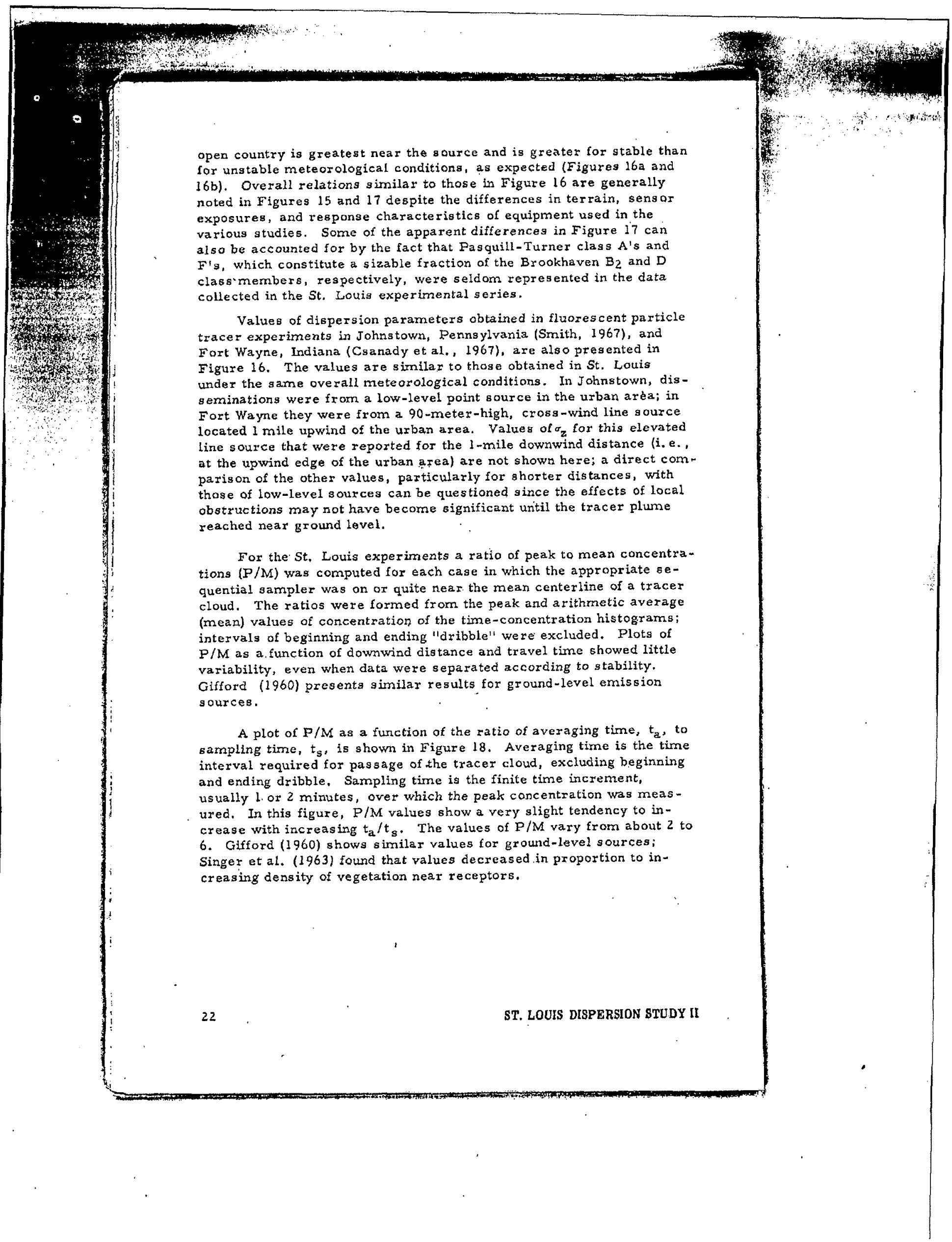




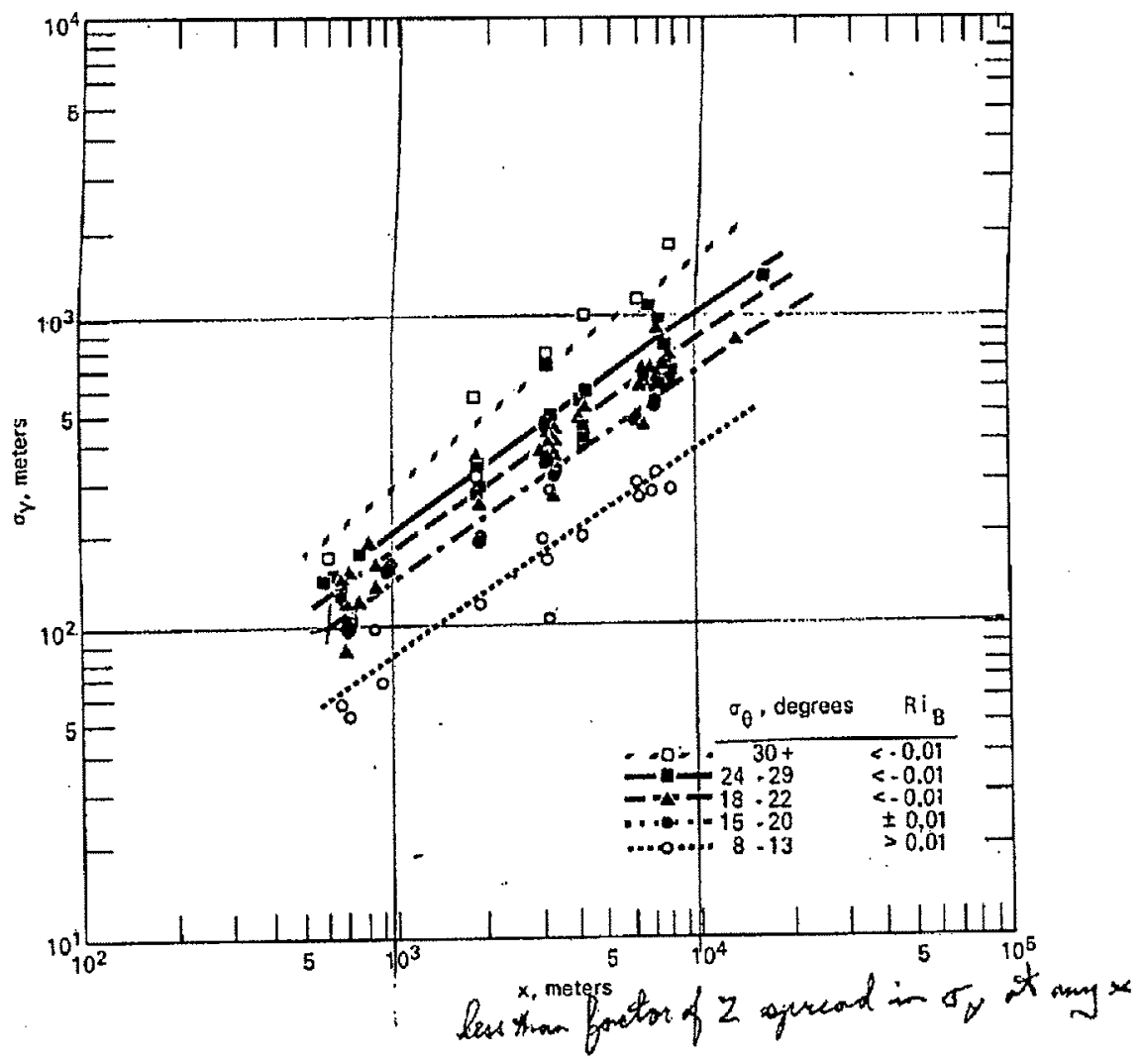

Figure 1. Cross -wind standard doviation of tracer material as a function of downwind distance in terms of standard deviation of wind direction fluctuations $\left(\mathrm{\sigma}_{\theta}\right)$ and bulk Richardson numiber $\left(\mathrm{Ri}_{\mathrm{g}}{ }\right)$. 


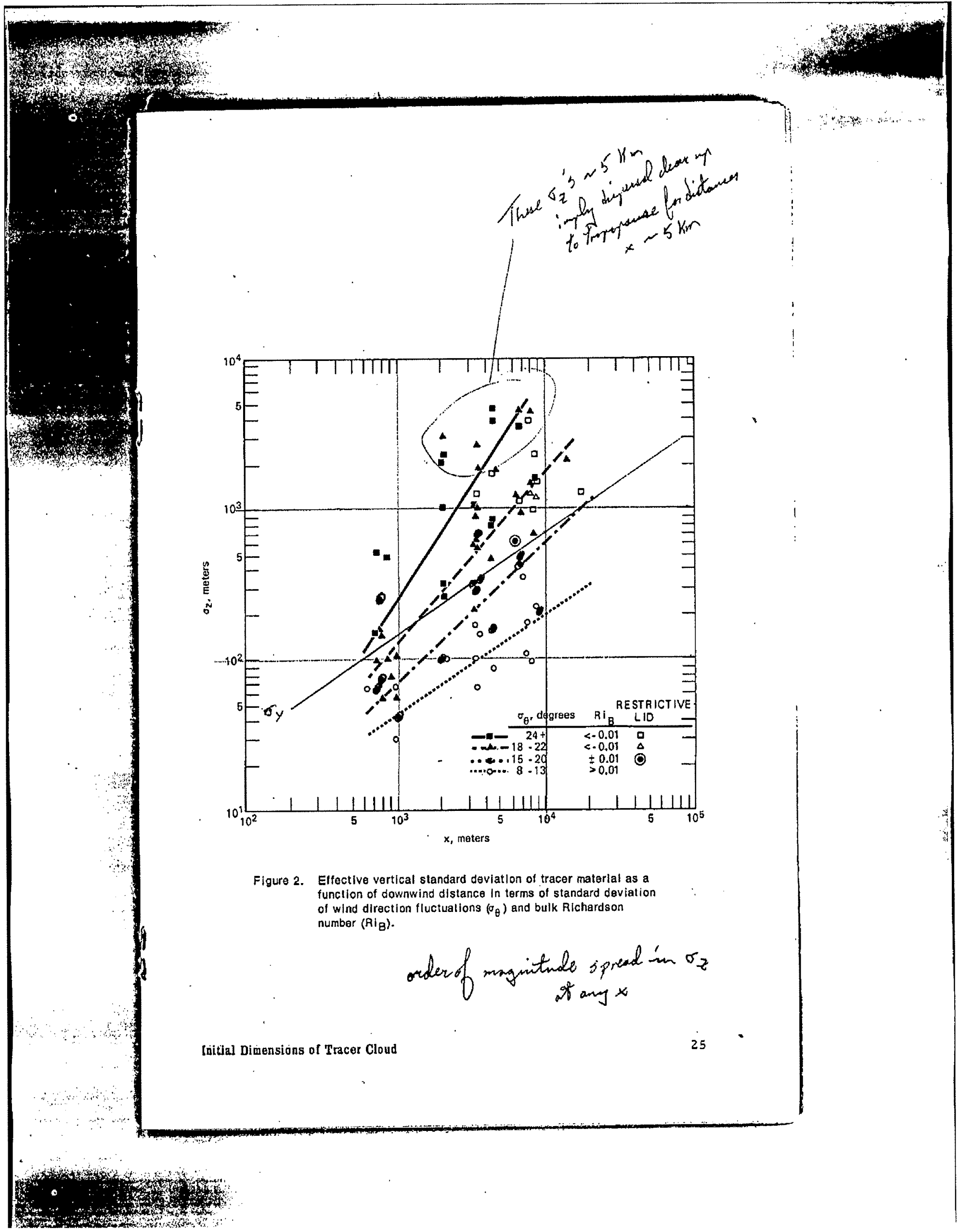




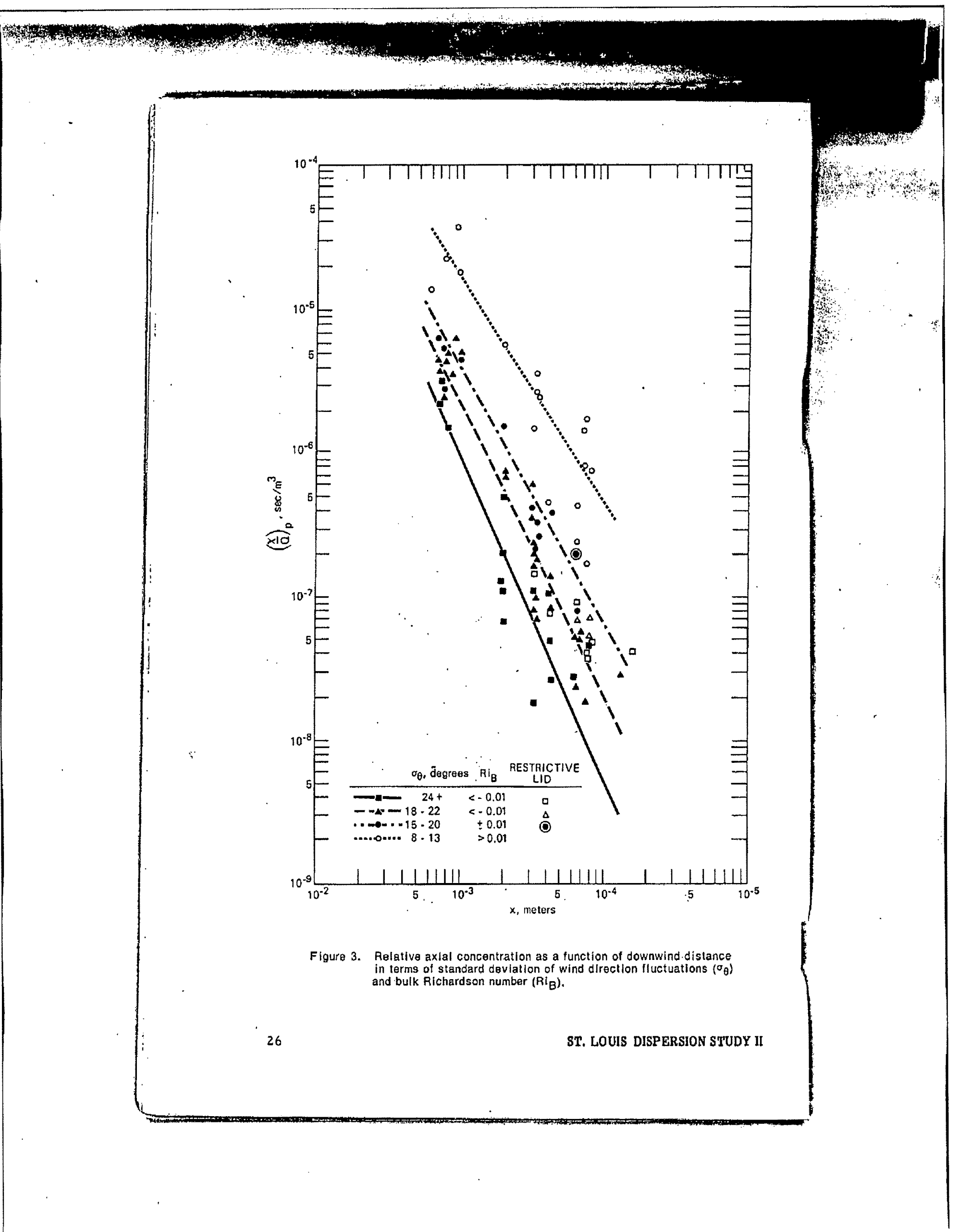




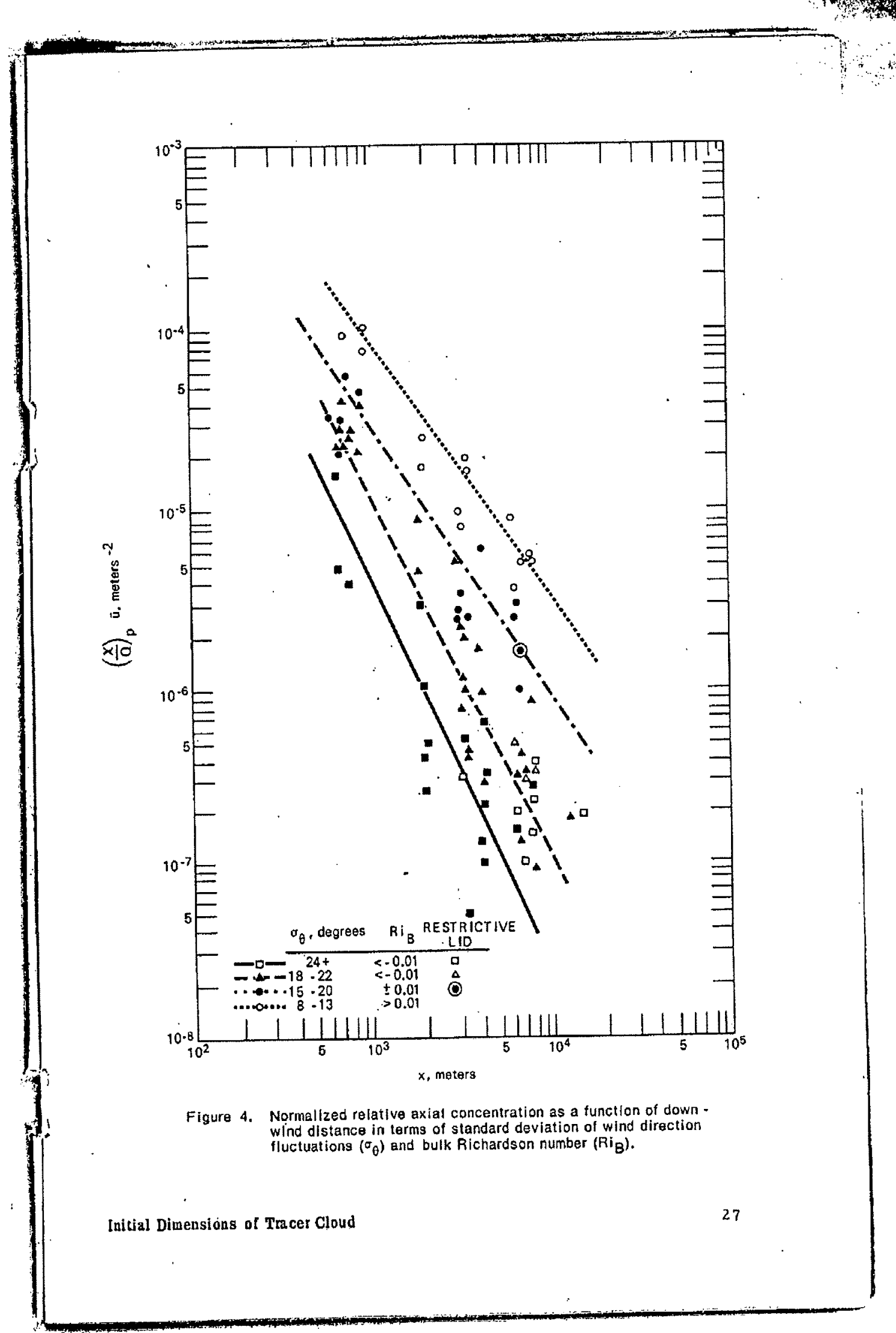




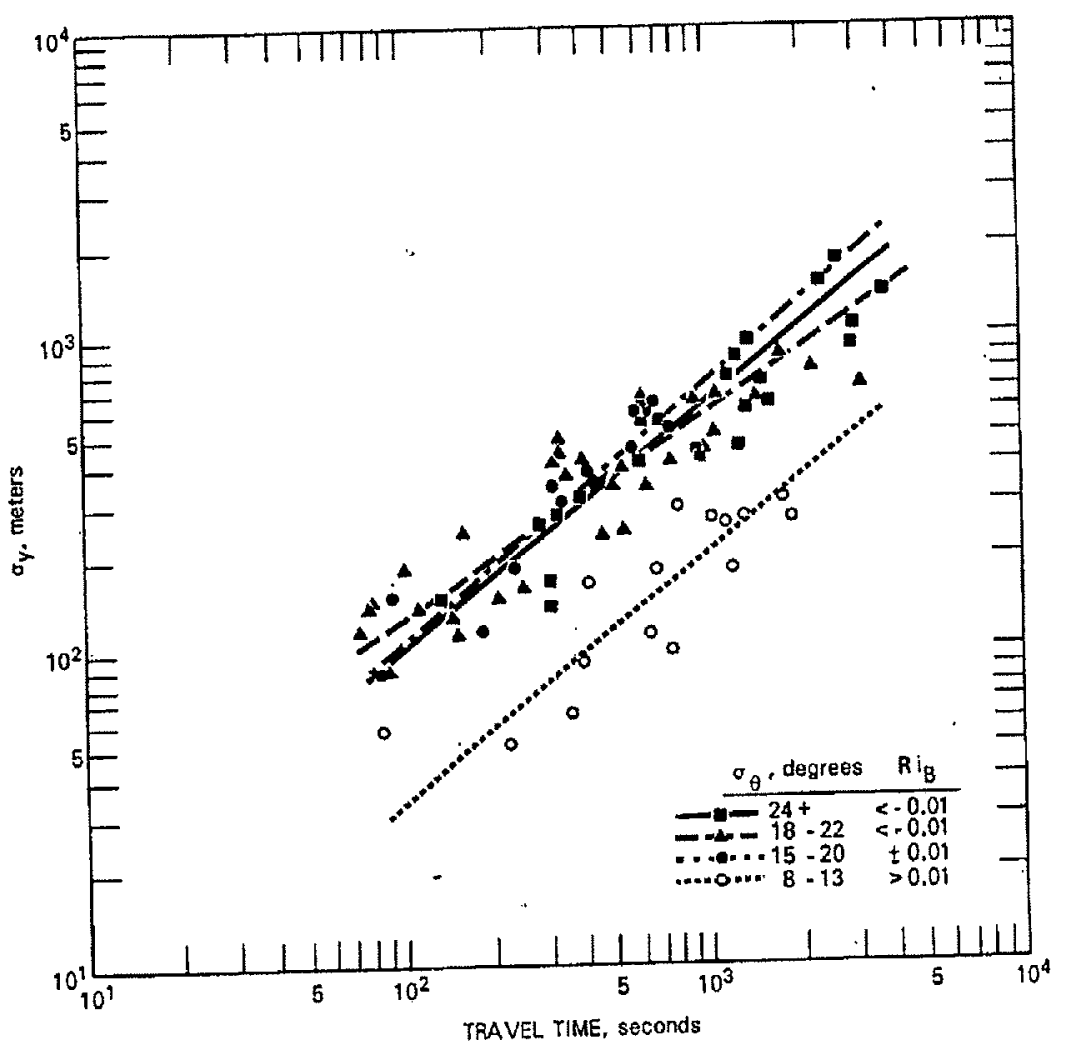

Flgure 5. Cross - wind standard daviation of tracer material as a functlon of travel $4 \mathrm{me}$ in torms of standard deviation of wind directlon fluctuations $(\sigma \theta)$ and bulk Richardson number $(R / B)$. 


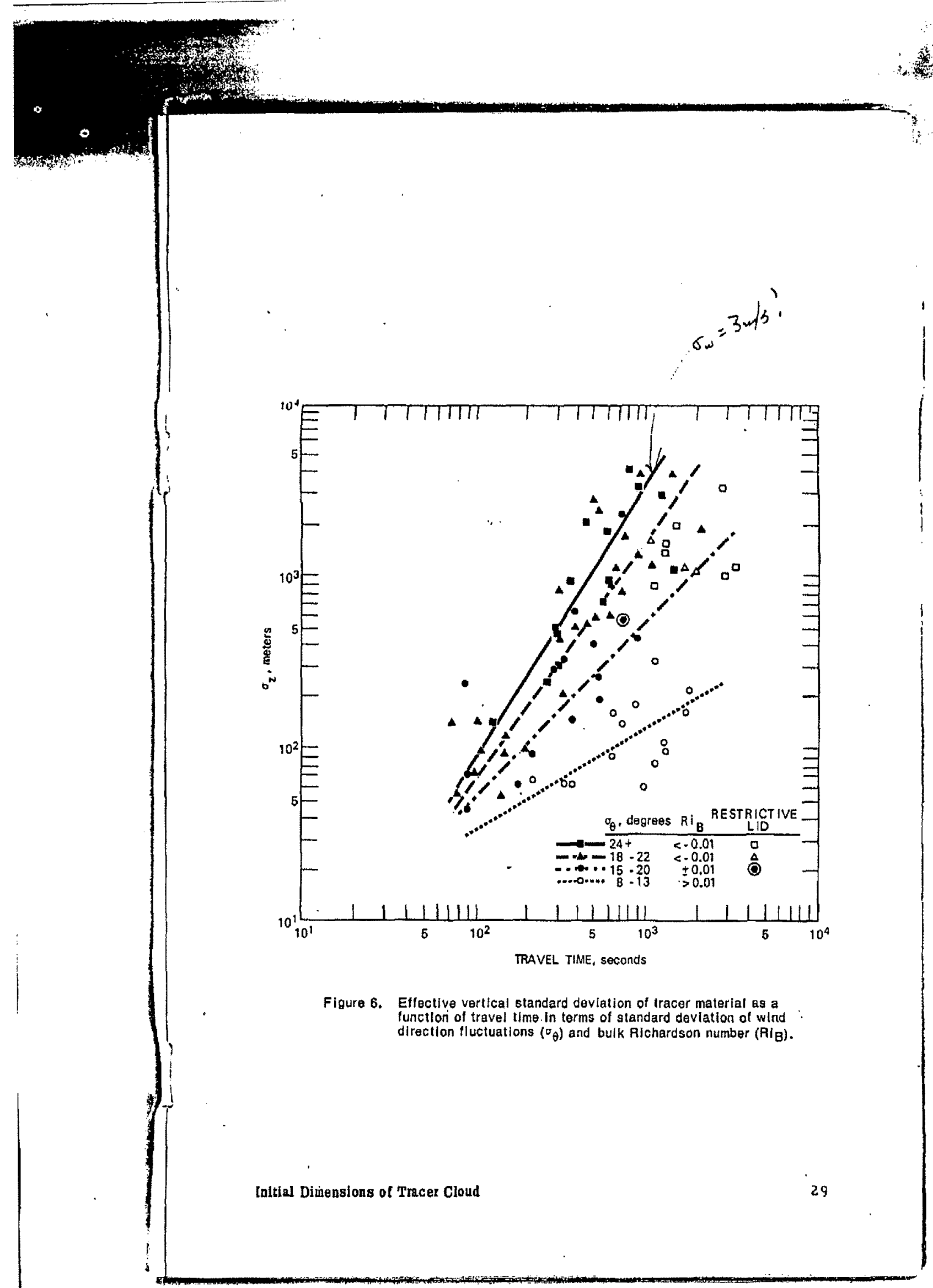




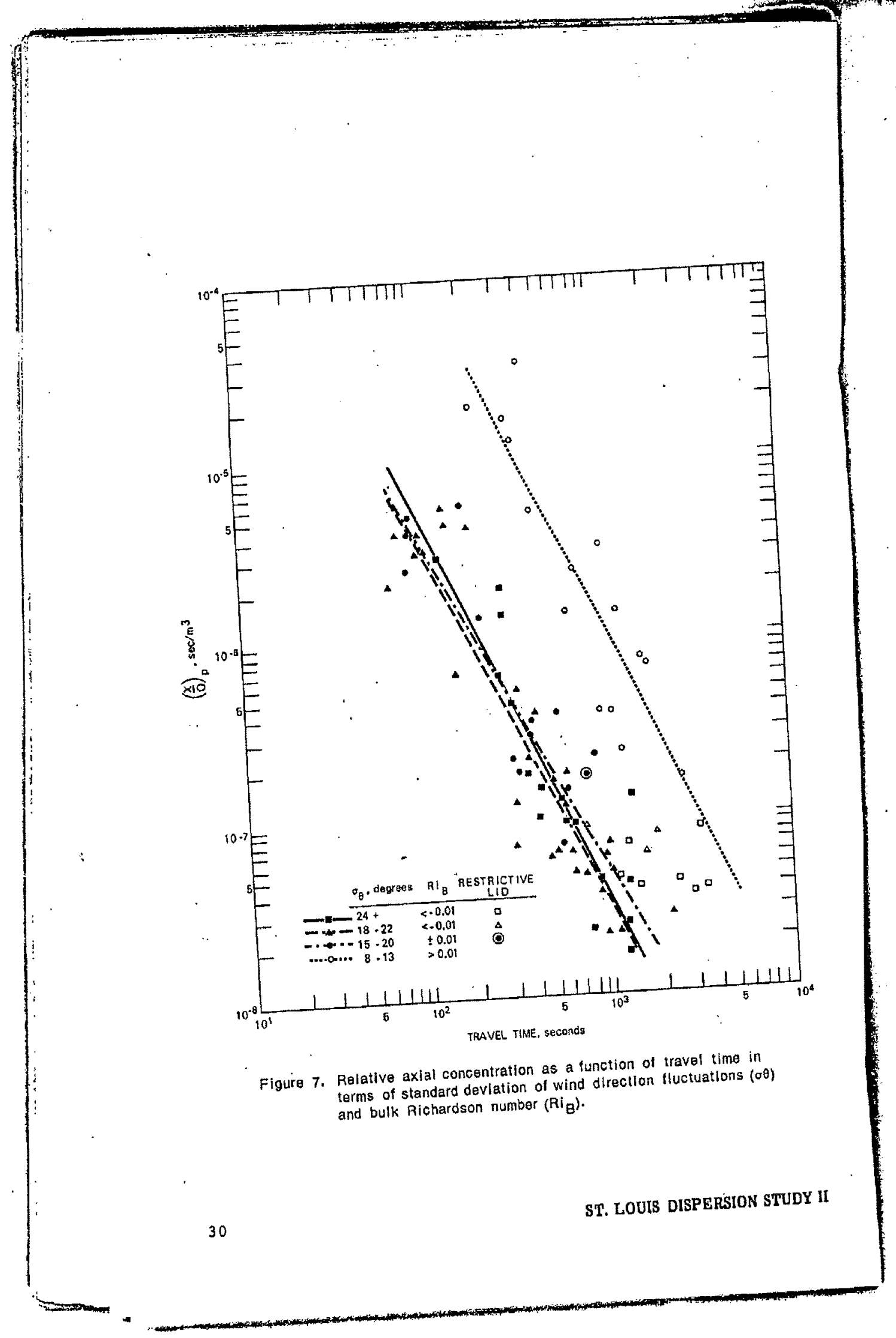




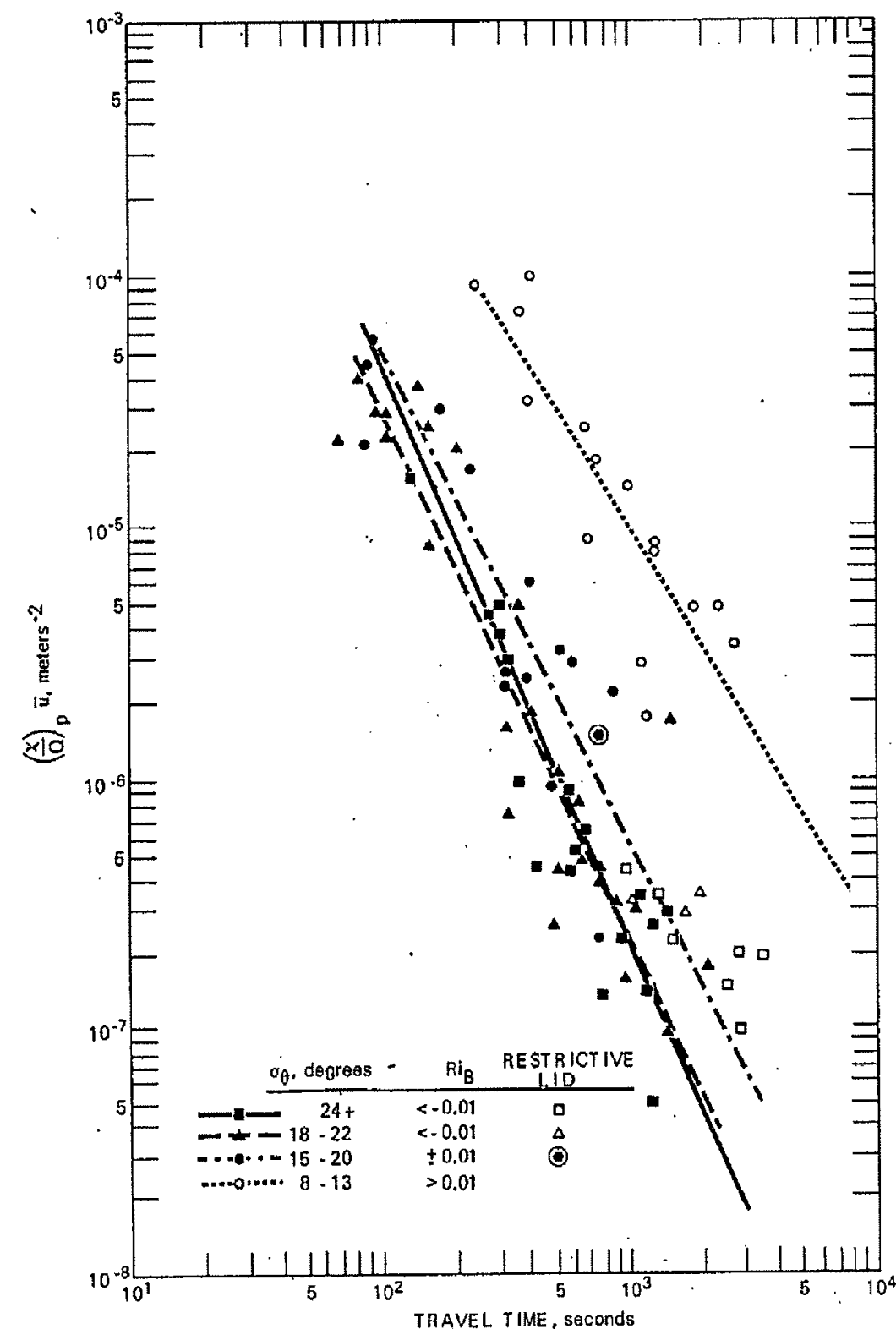

Figure 8. Normalized relatlve axial concentration as a function of travel time in terms of standard deviation of wind direction fluctuations $\left(\theta_{\theta}\right)$ and bulk Richardson number $\left(\mathrm{RI}_{B}\right)$. 


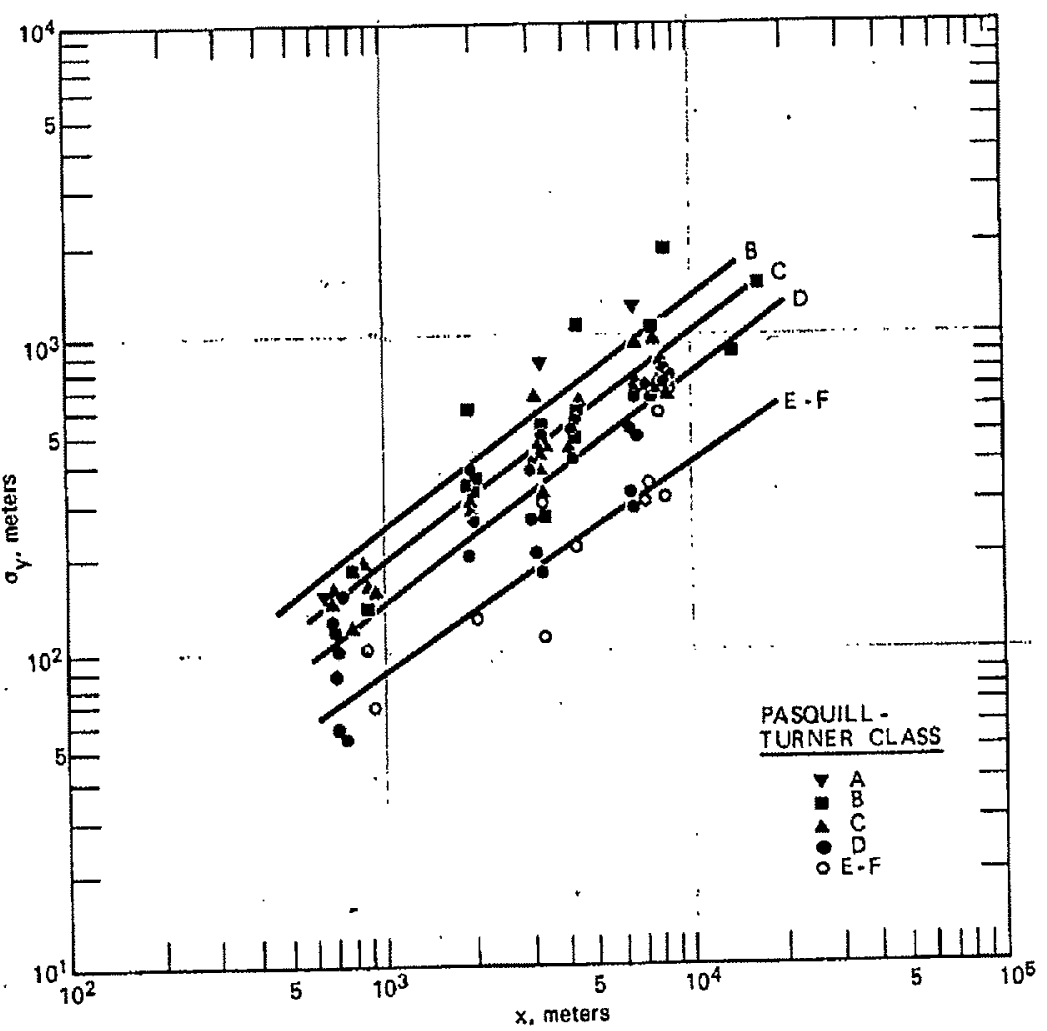

Flgure 9. Cross -wind standard deviallon of tracer materlal as a functlon of downwind distance In terms of Pasquill - Turner stabjlity classes. 


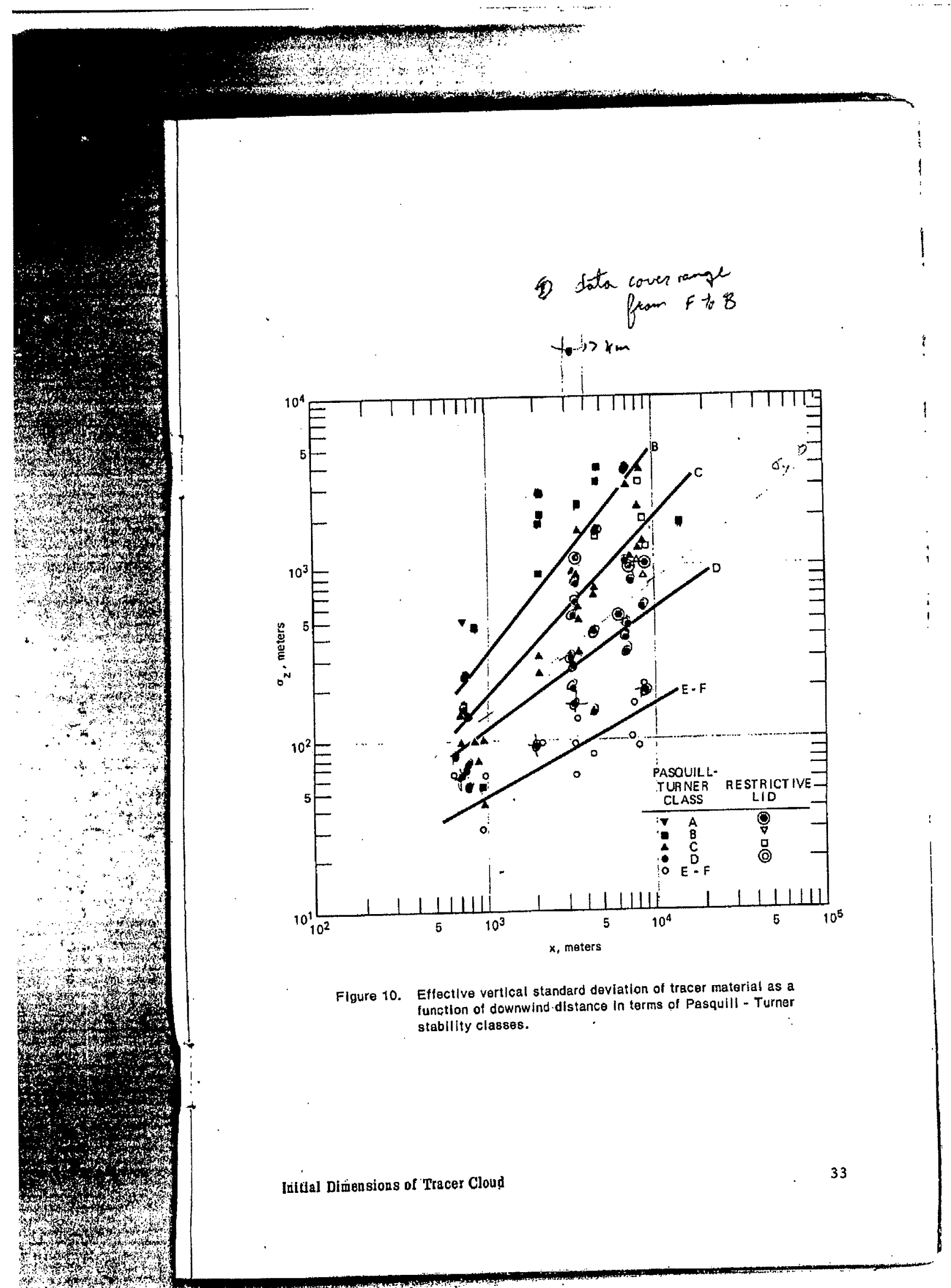




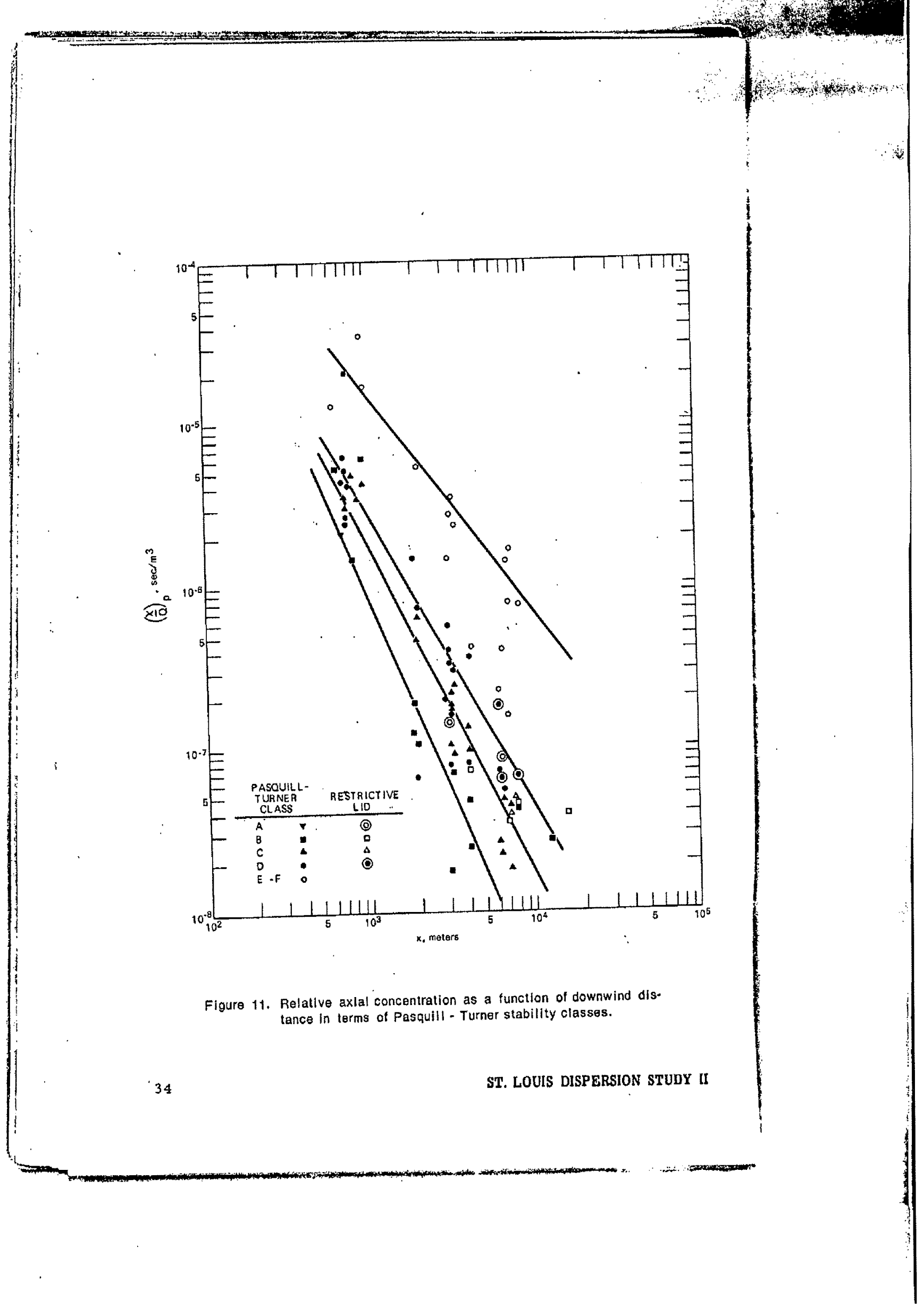




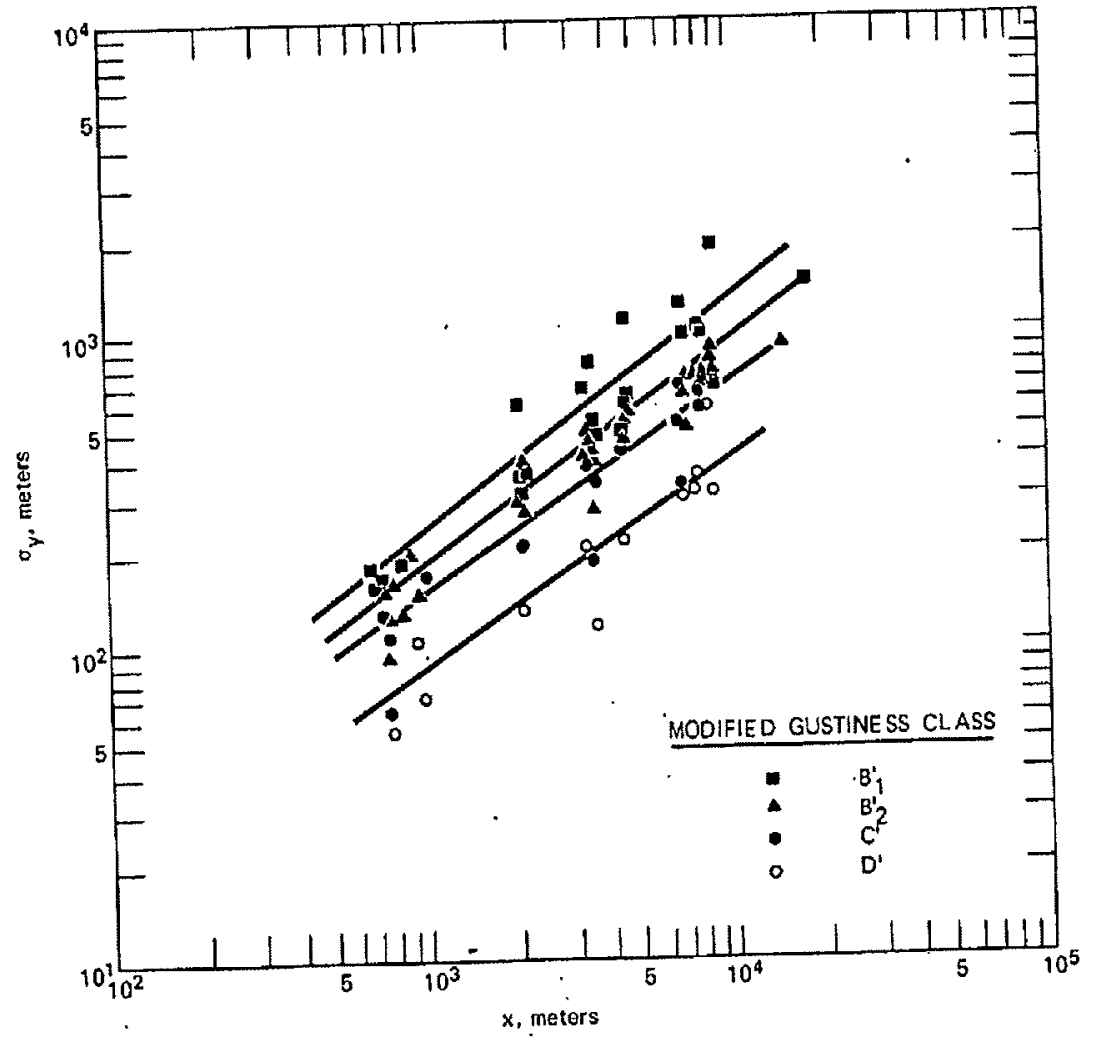

Flgure 12. Cross - wind standard deviation of tracer material as a function of downwind distance in terms of modified Brookhaven gustiness classes. 


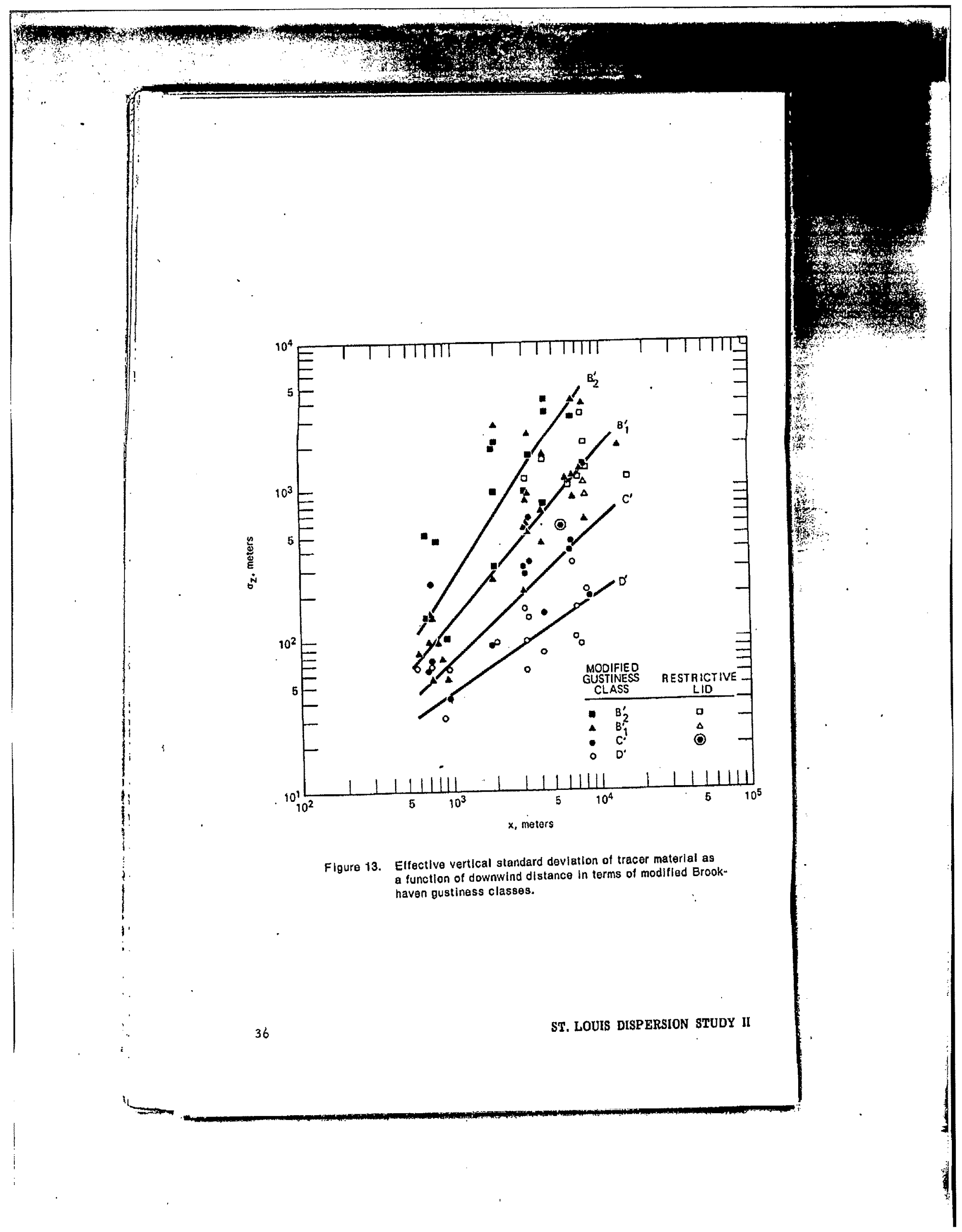




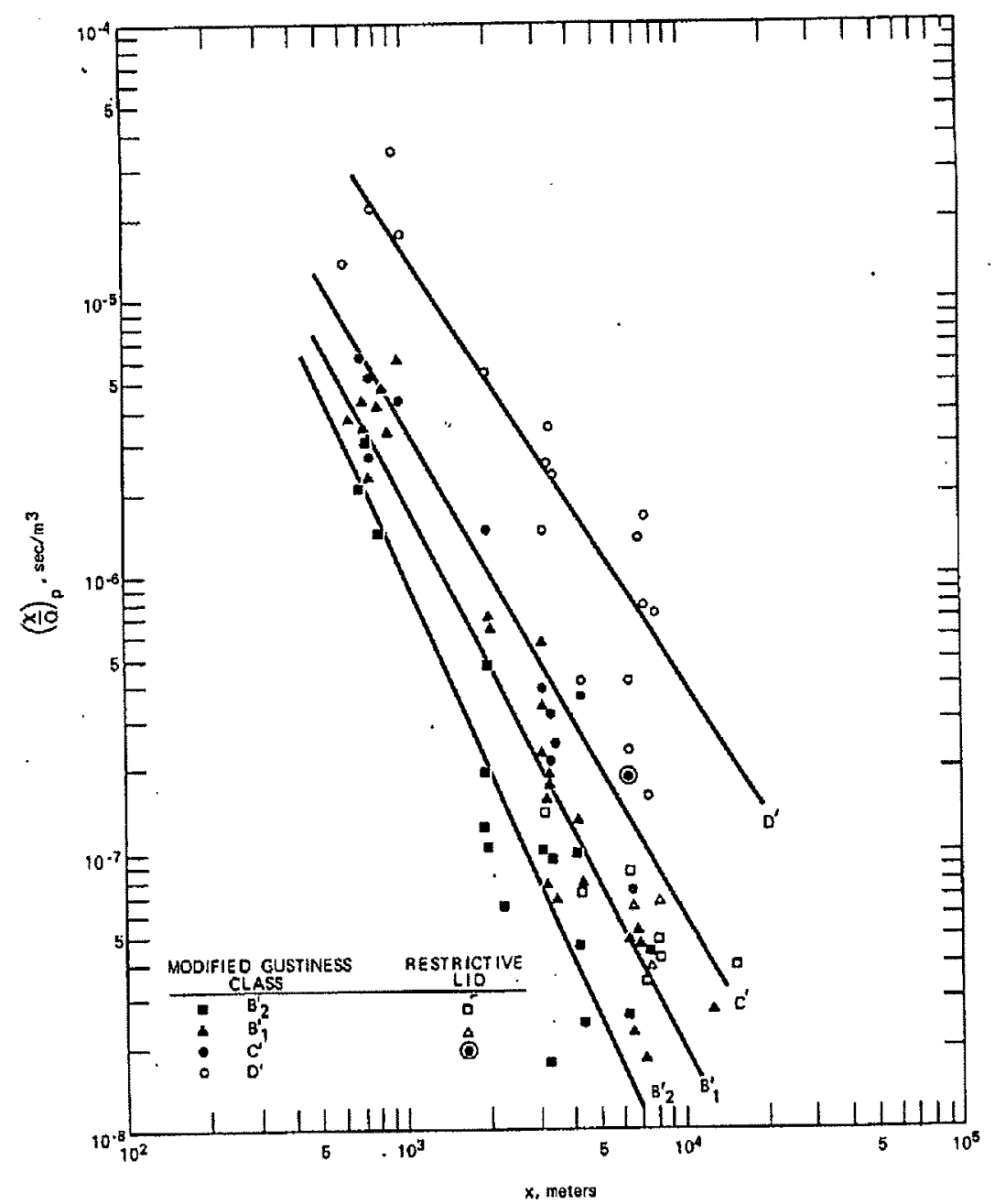

Figure 14. Relative axial concentration as a function of downwind distance in terms of modifled Brookhaven gustinass classes. 


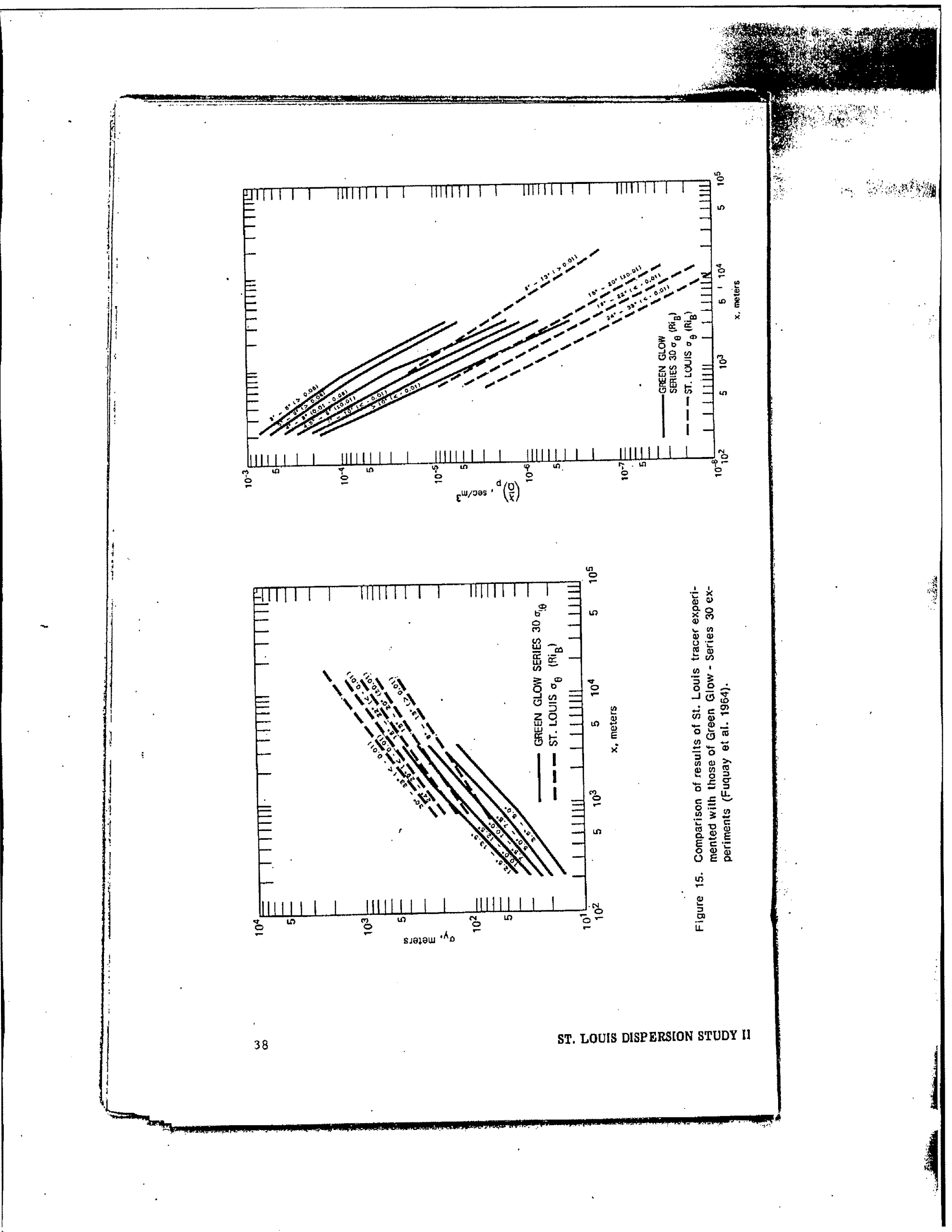




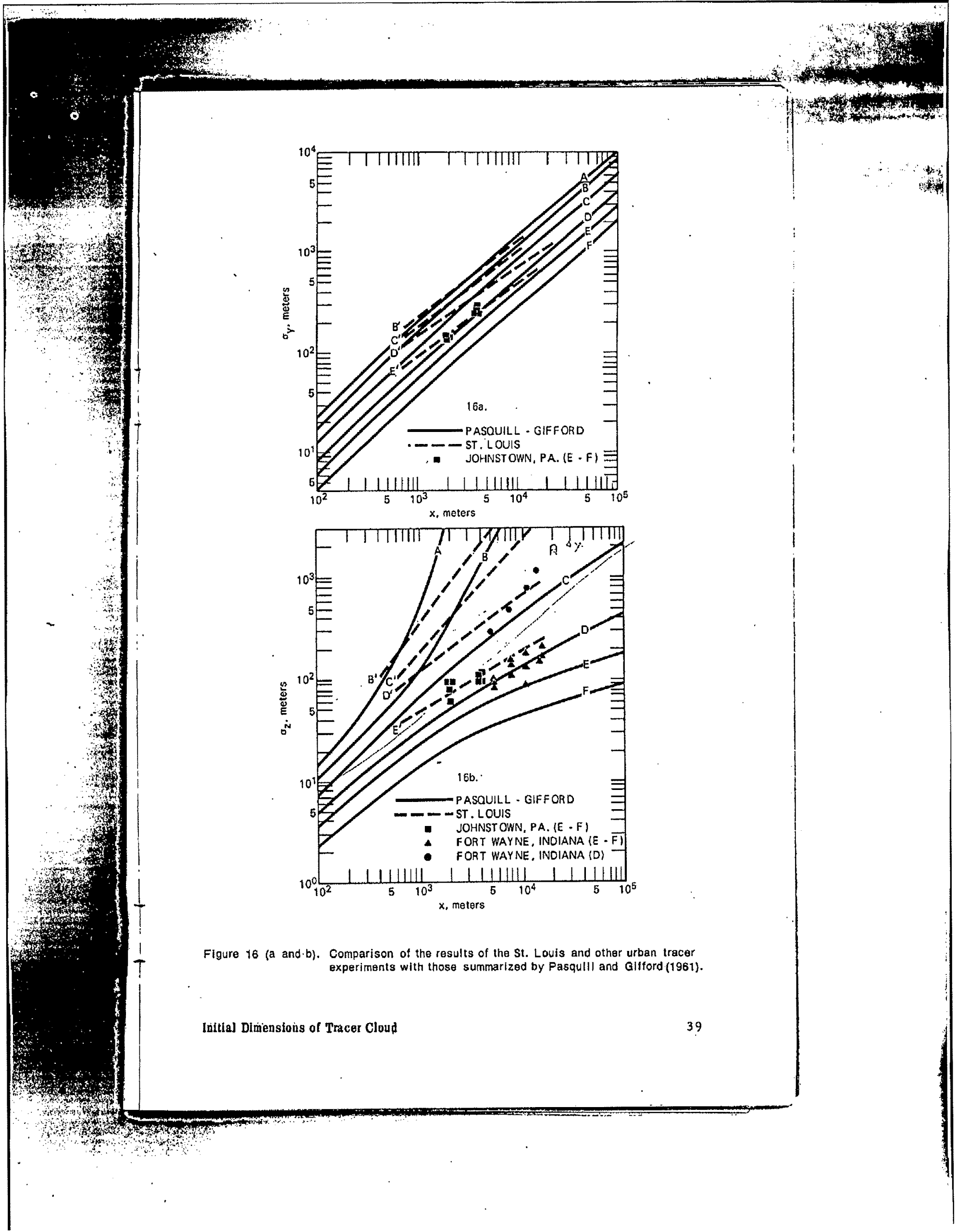


Note:

The grouping of the St. Louis, Johnstown, and Fort Wayne data in Figure 16 was by Pasquill-Turner stability classes (Turner, 1964), which are really only more objective expressions of the Pasquill stability classes (Pasquill, 1961) in terms of readily available meteorological variables. The solid curves are based upon data ordered by the Pasquill stability classes; those in Figures $16 \mathrm{a}$ and $16 \mathrm{~b}$ were originally presented by Gifford (1961), and those in Figure 16c by Hilsmeier and Gifford (1962).

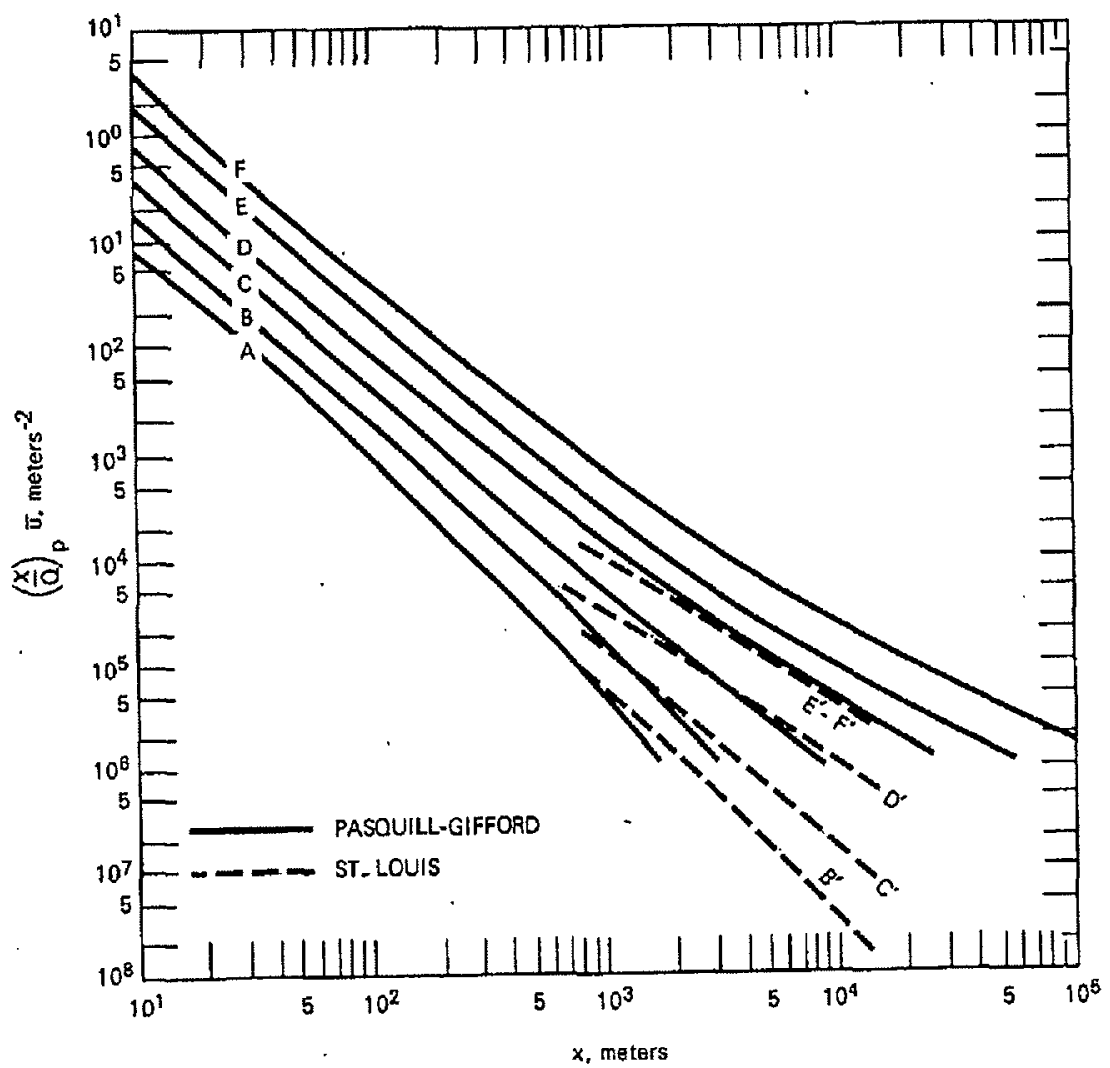

Figure 16 (c). Comparison of the results of the St. Louis tracer experiments with those summarized by Pasquill and Gifford (1961). 

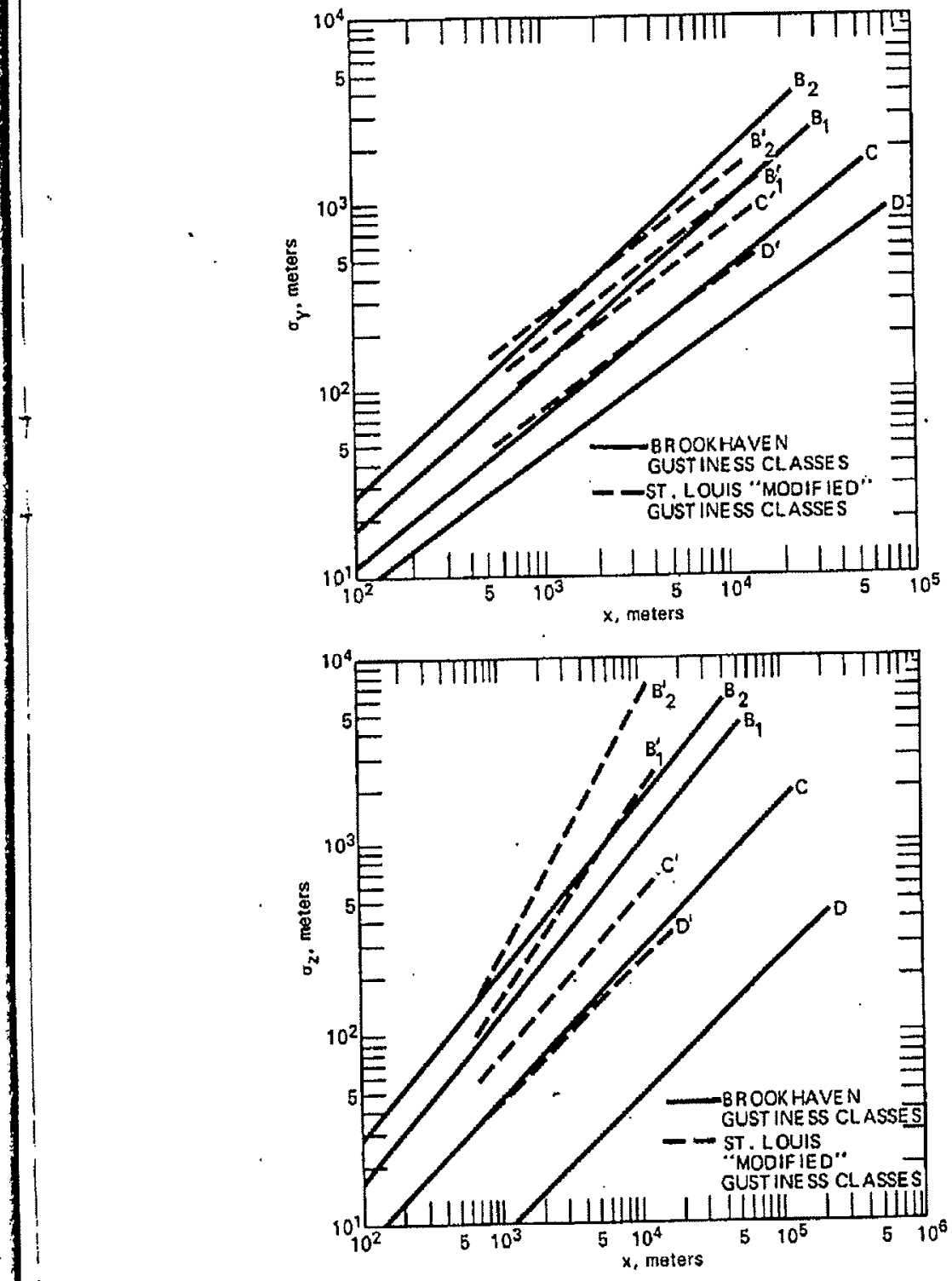

Figure 17. Comparison of results of St. Louls tracer experiments with those of Brookhaven experiments (Singer and Sm/th, 1966). 


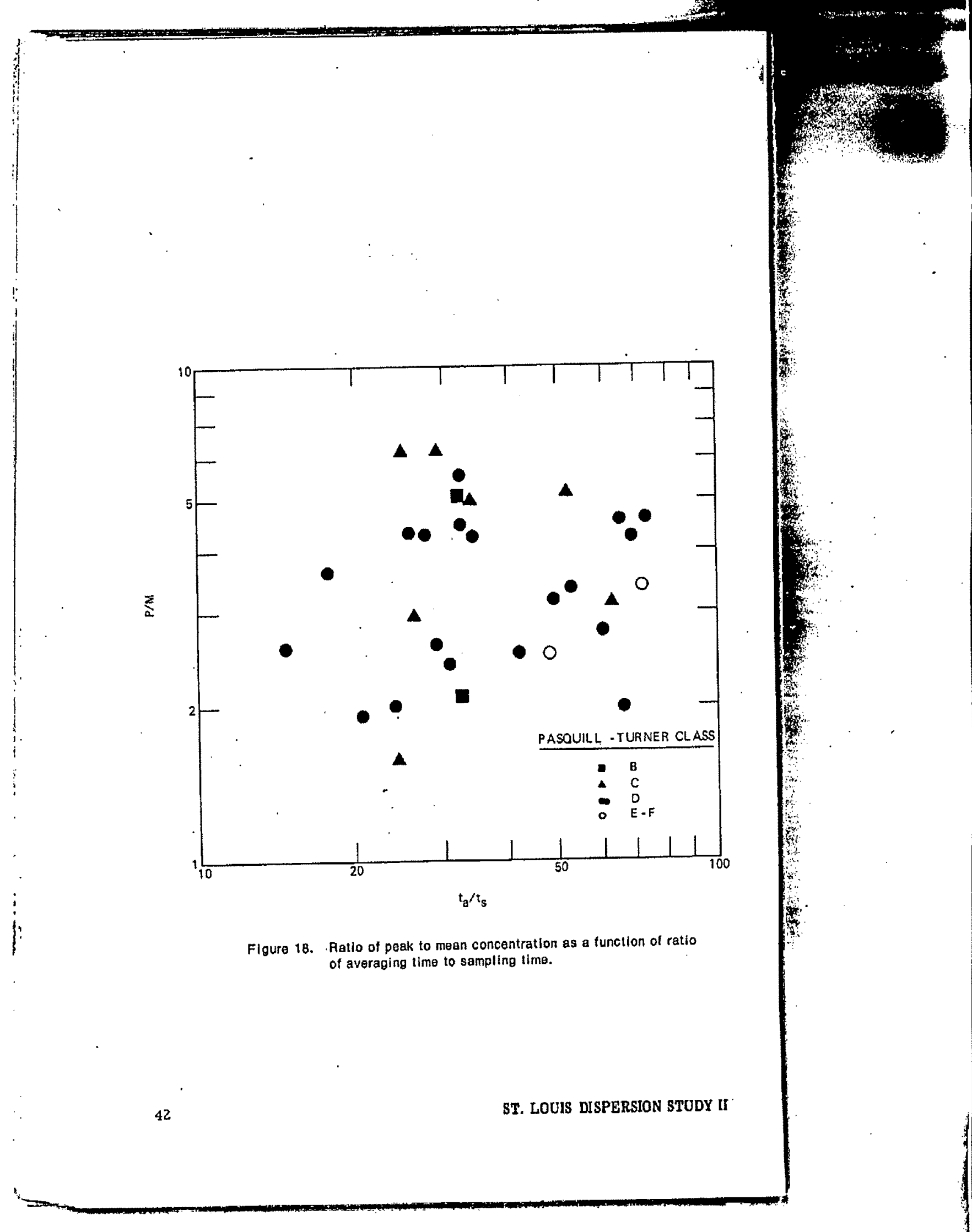




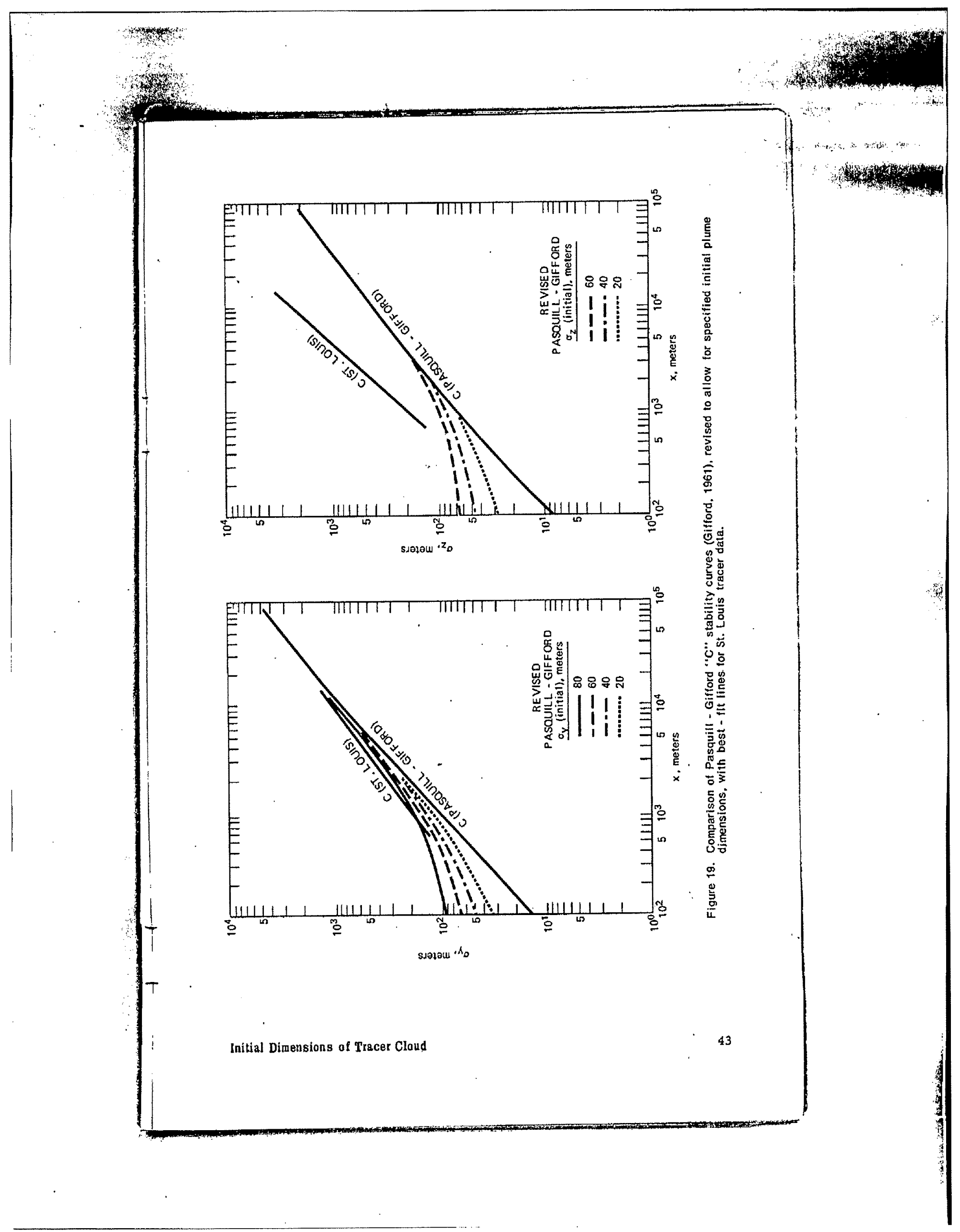


page 44 is blank 


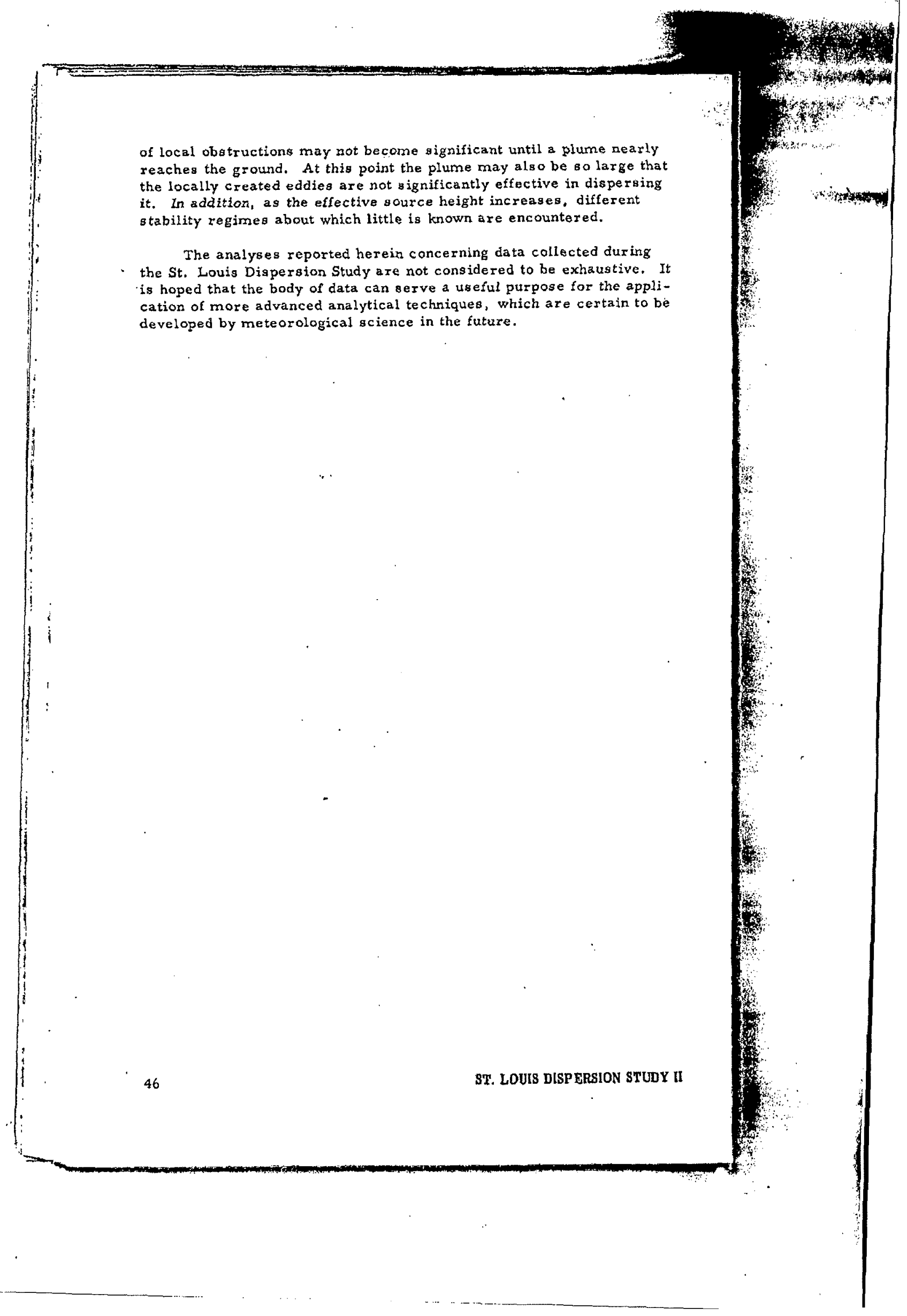




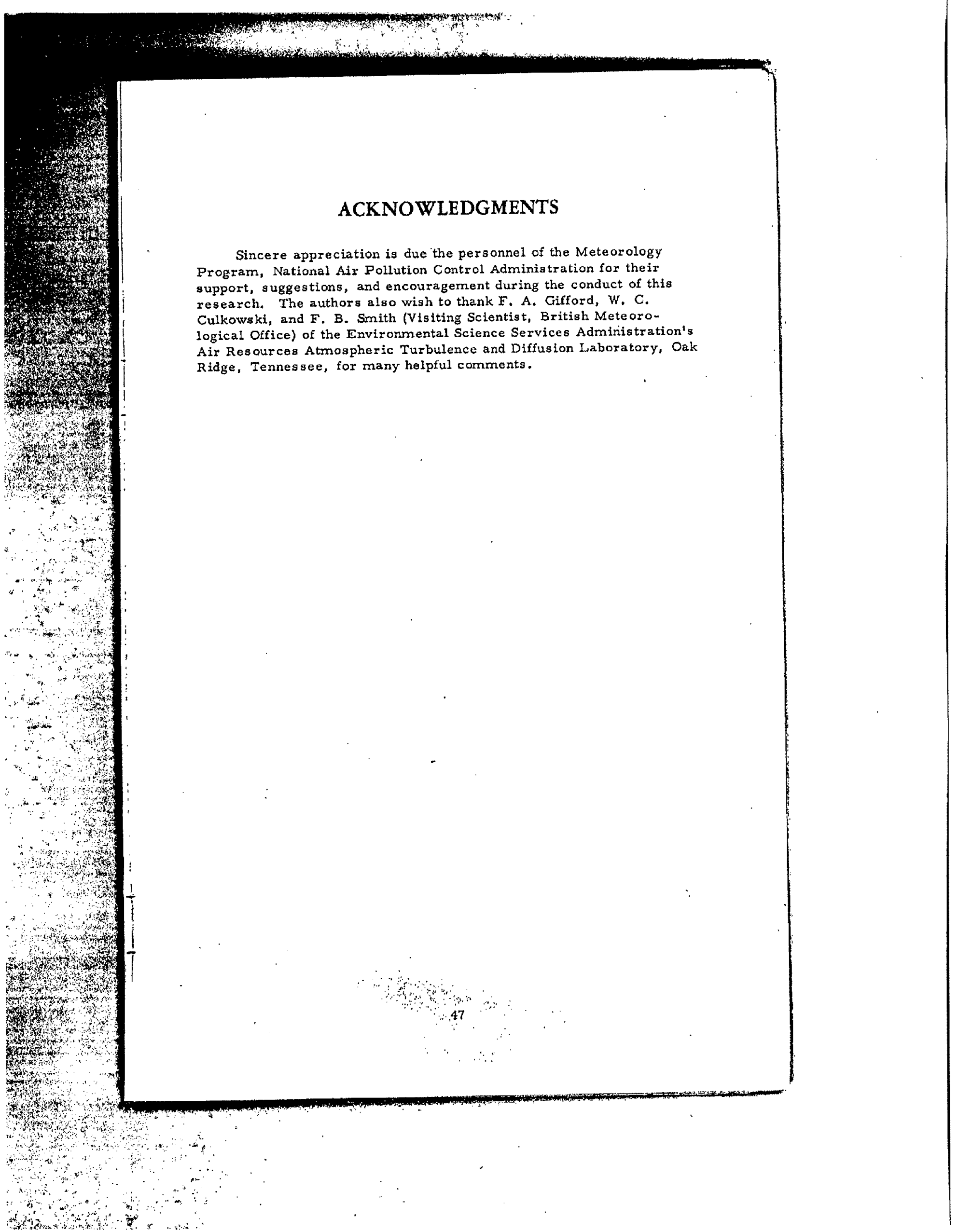


page 48 is blank 


\section{REFERENCES}

Cramer. H. E., 1959: Engineering estimates of atmospheric dispersal capacity. AlHI Journal, 20, 183-199.

Csanady, G. T., G. R. Hilst, and N. E. Bowne, 1967: The diffusion from a cross-wind line source at Fort Wayne, Indiana. Unpublished Report. Travelers Research Center, Hartford, Connecticut.

Dickson, C. R., G. E. Start, and E. H. Markee, Jr, 1967: Aerodynamic effects of ERB II containment veasel complex on effluent concentration. Paper presented at the USAEC Micrometeorological Infor mation Meeting, Chalk Rivẹr Laboratories, Ontario, Canada, September $11-14$.

Fuquay, J. J., C. L. Simpson, and W. T. Hinds, 1964: Prediction of environmental exposure from sources near the ground based on Hanford experimental data. J. Appl. Meteor., 3, 761-770.

Giblett, M. A. etal. 1932: The structure of wind over level country. Meteorological Orfice Geophysical Memoirs No. 54.

Gifford, F. A., 2960: Peak to average concentration ratios according to a fluctuating plume dispersion model. Int. J. of Air Pollution, 3 , $253-260$.

Gifford, F. A., 1961: The problem of forecasting dispersion in the lower atmosphere. AEC Division of Technical Information Extension, Oak Ridge, Tennessee, $28 \mathrm{pp}$.

Grinnel, S. W., 1965: The influence of daytime travel conditions on the detectability of fluorescent particulate material. Technical Report No. 115, Metronics Associates, Inc. Palo Alto, California, Contract. No. (DA-42-007-AMC-21 (R) ). U.S. Dugway Proving Ground.

Hilsmeier, W. F., and F. A. Gifford, 1962: Graphs for estimating atmospheric dispersion. Oak Ridge, Tennessee, AEC, Division of Technical Information, ORO-545.

Halitsky, J., 1963: Cas diffusion near buildings: theoretical concepts and wind tunnel model experiments with prismatic building shapes. Geophysical Laboratory No. 63-3. New York Univarsity, New York, N. Y. 
Lettau, H. H., 1957: Computation of Richardson Numbers, classification of wind profiles, and determination of roughness parameters. In: Exploring the Atmosphere's First Mile, Vol. 1, Instrumentation and Data Evaluation, edited by $B$. Davidson and $H$. H. Lettau, Pergarnon Press, New York, N. Y., pp. 328-332.

List, R. J., 1963: Smithsonian Meteorological Tables, Smiths onian Miscellaneous Collections, Vol. 114. Smithsonian Institution, Washington, D. C., 6th rev. ed., $527 \mathrm{pp}$.

Markee, E. H., Jr, 1963: On the relationships of range to standard deviation of wind fluctuations. Monthly, Weather Review, 91, 83-87.

Panofsky, H. A, and G. W. Brier, 1963: Some applications of Statistics to Meteor ology. College of Mineral Industries, Pennsylvania State University, University Park, $\mathrm{Pa}_{\mathrm{a}}, 223 \mathrm{pp}$.

Pasquill, F., 1961: The estimation of the dispersion of windborne material. Meteor. Mag., 90, 33-49.

Pooler, F., Jr, , 1966: A tracer study of dispersion over a city. JAPCA, 16, 677-681.

Schiermeier, F. A., 1967: A study of the urban heat island over the Saint Louis metropolitan area. MS Thesis in Meteorology. Saint Louis University, St. Louis, Mo.

Slade, D. H., 1965: Dispersion estimates from pollution releases of a few seconds to 8 hours in duration. U.S. Dept. of Commerce, ESSA, Air Resources Laboratory Report No. 1, Technical Note No. 2, Washington, D. C.

Singer, I. A., I. Kozuhiko, and R. G. Del Campo, J963: Peak to mean concentration ratios for various terrain and vegetation cover. JAPCA, $13,40-42$.

Singer, I. A, and M. E. Smith, 1953: Relation of gustinese to other meteorological parameters. J. of Meteor., 10, 121-126.

Singer, I. A. ; and M. E. Smith, 1966: Atmospheric dispersion at Brookhaven National Laboratory. J. of Air and Water Pollution, 10. $125-135$.

Smith, D. B., 1967: Tracer study in an urban valley (Johnstown, Fennsylvania). MS Thesis in Meteorology. Pennsylvania State University, University Park, $\mathrm{Pa}$.

Turner, D. B., 1964: A diffusion model for an urban area. J. Appl. Meteor., 3, 83-91.
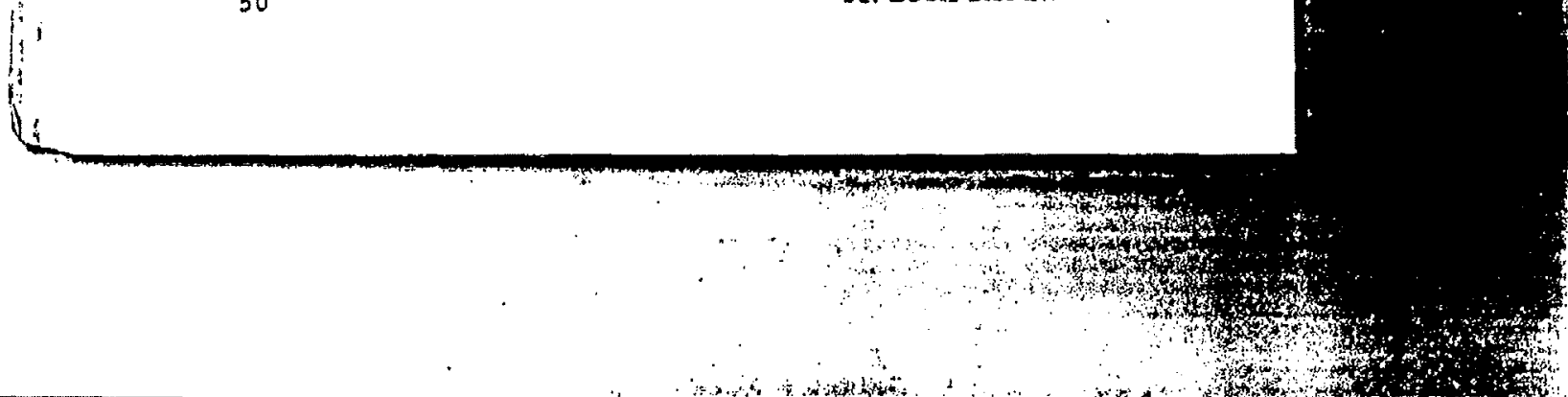
Vaughan, L. M., and R. W. McMullen, 1968: The physical analysis of particle size distributions from field samples obtained during St. Louis fluorescent particle tracer experiments. Technical Report No. 145, Metronics Associates, Inc., Palo Alto, Calif. (Performed under U.S. Dept. Commerce contract CWB-11408). 


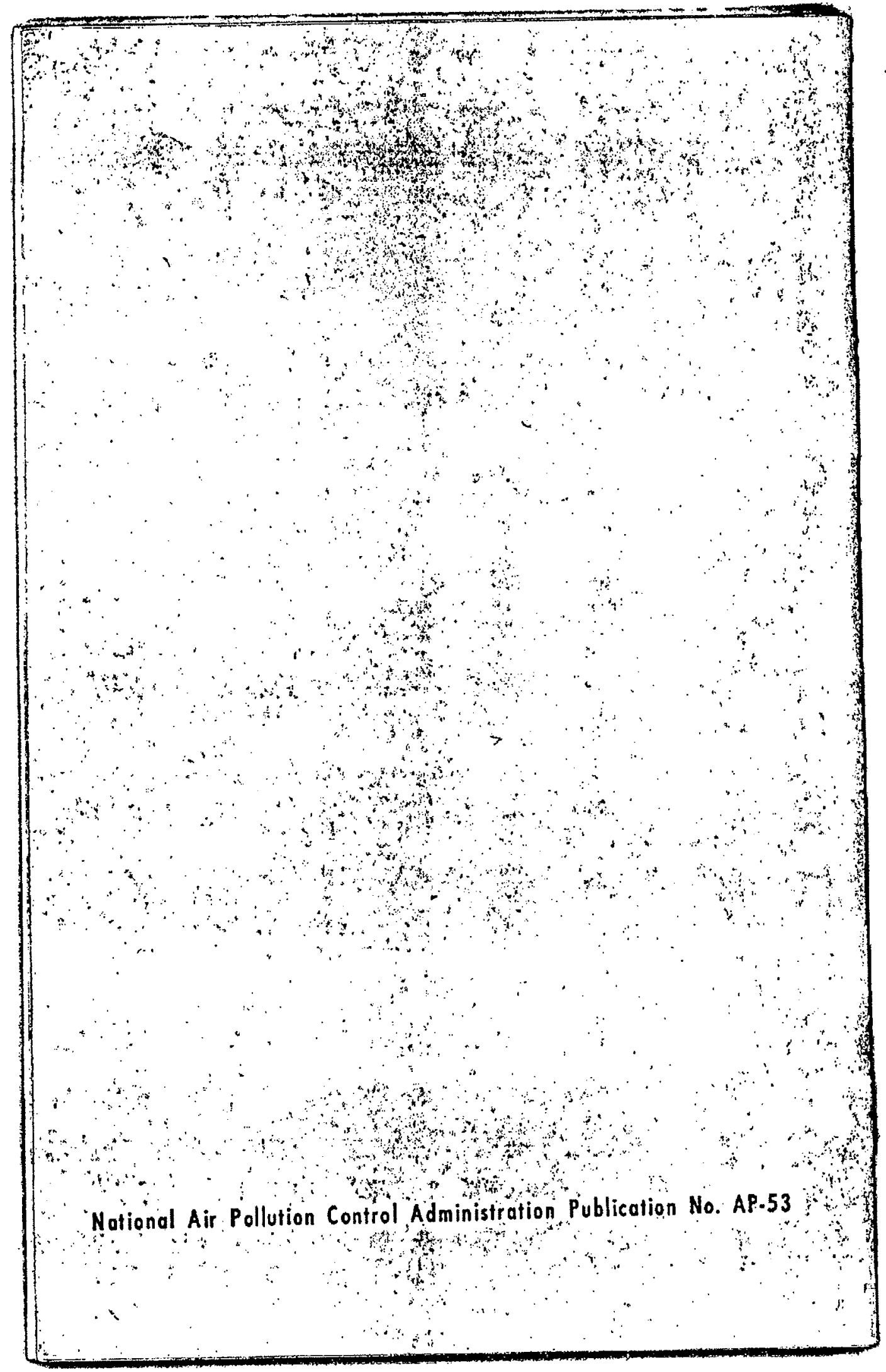




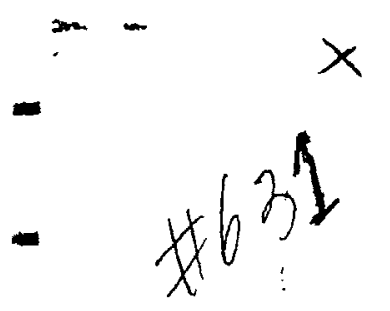

$-4$
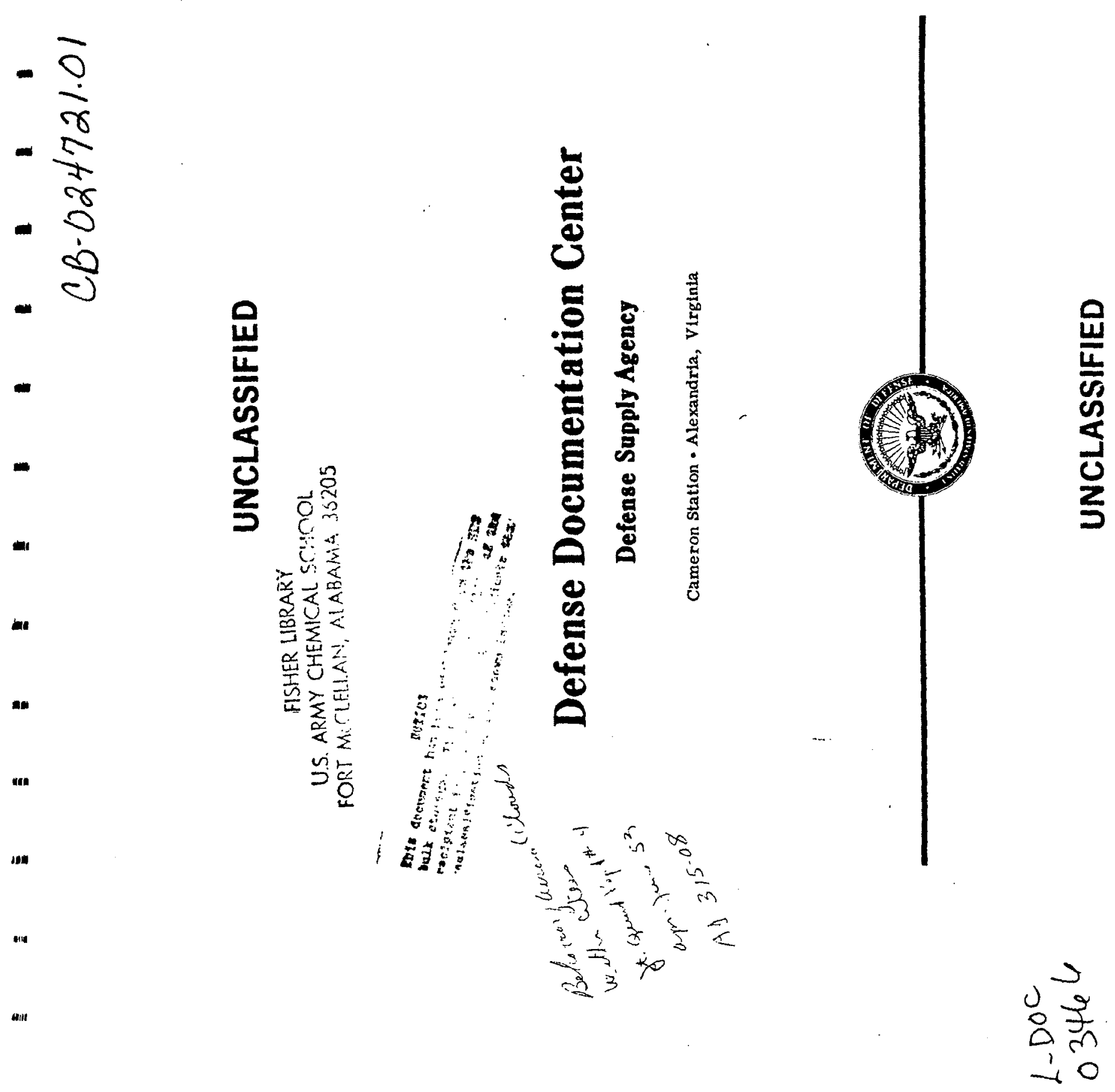


\title{
$\mathbb{U N C} \mathbb{N}$ SSIFIED
}

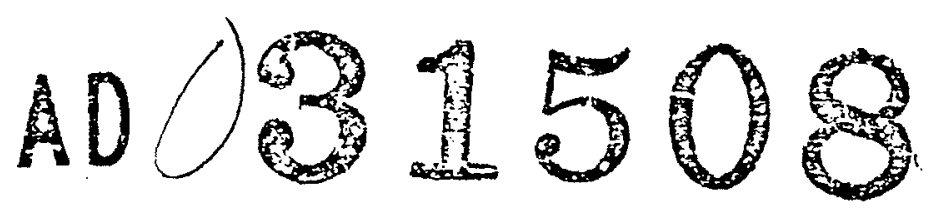

DEFENSE DOCUMENTATION CENTER

\author{
FOR \\ SCIENTIFIC ANO TECHNICAL INFORMATION
}

CAMERON STATION, ALEXANORIA. VIRGINIA

CLASSIFICATION CHANGED

TO UNCLASSIFIED

FROM SECRET

PER AUTHORITY LISTED IN

ASTIA TAB NO... $\$ 63-4-4$ -

DATE $1510 \% .63 \ldots$.

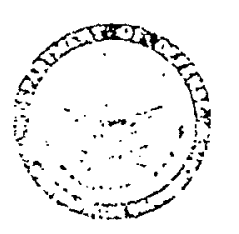

."

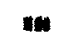

a11 
NOTICE: hen government or other dravings, spec1f1-ations or otber data are used for any furpose other than 1: connection with a definiteiy relutet. government procurement operation, the U. S. Govemment thereby incurs no responsiblilty, nor in:y cbligation whatsoever; and the inct that ine covert.ment may bave formlated, furalahed, or in any way supplied the sald drawirgs, speclficaticrs, or other iata is not to be regarded by 1nplication or otborwise as in any manner licensing the tolder or any other persor or corporation, or ccrveylng any rlghts or permission to manufacture, upe or bell any ratented invention that may in : ny way be related. thereto. 


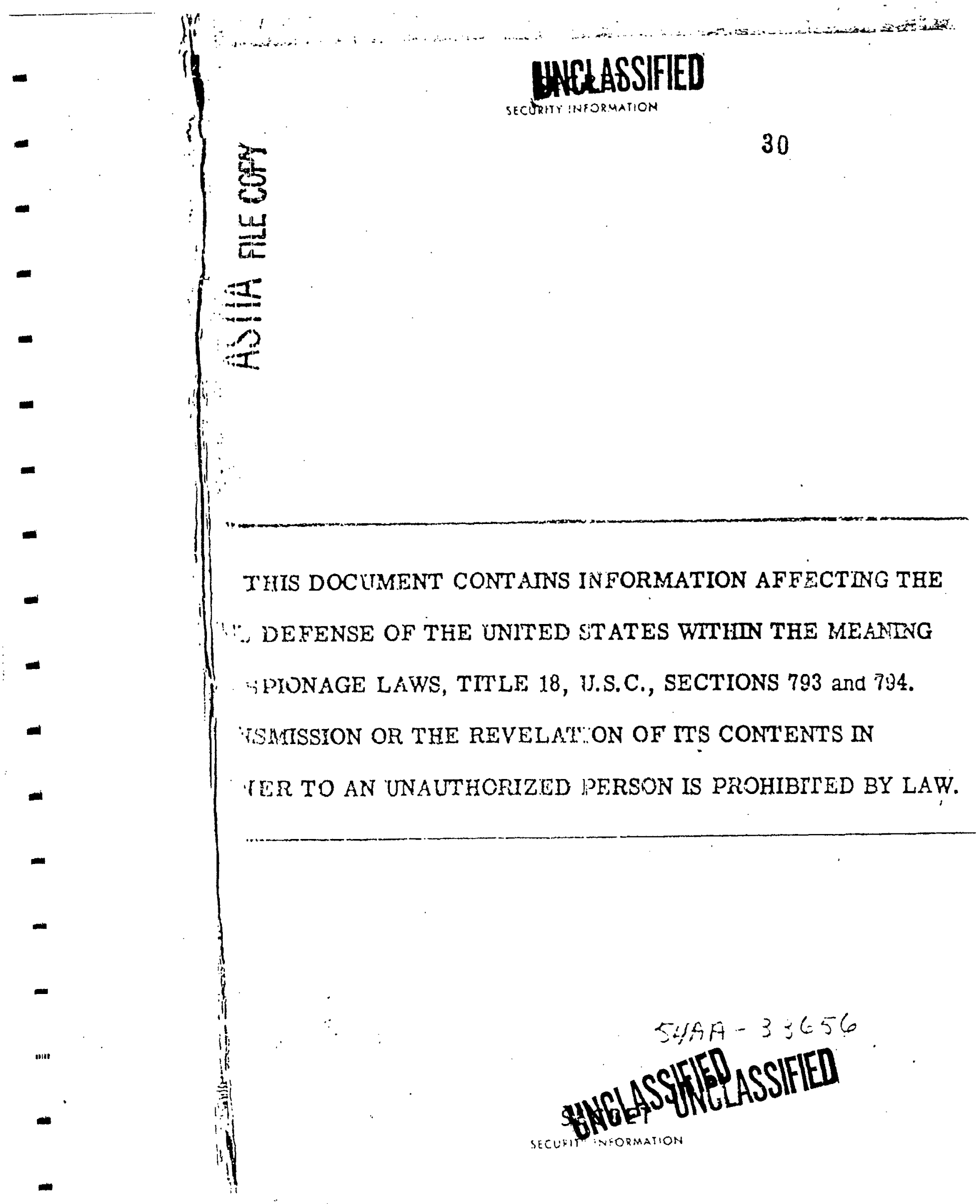




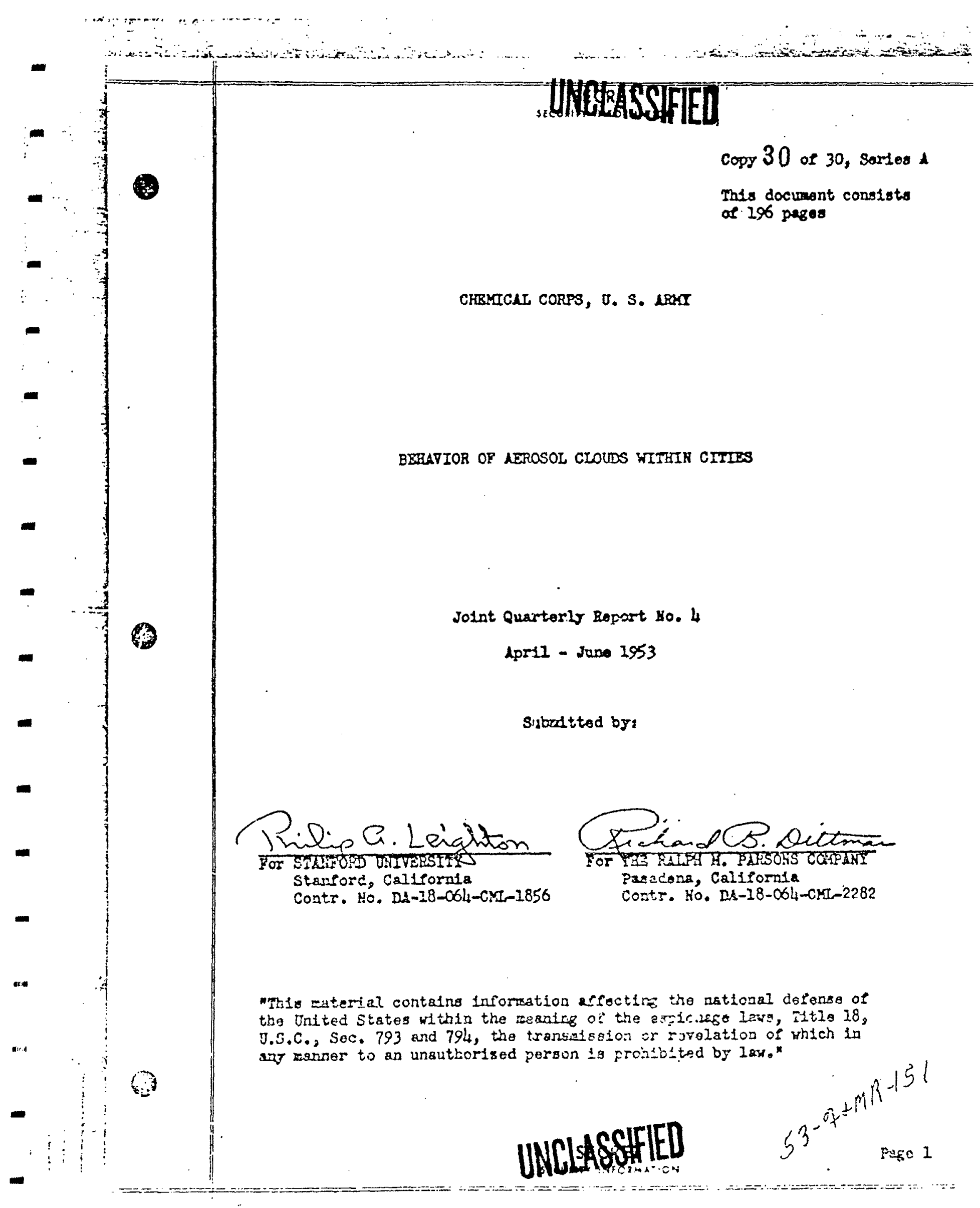




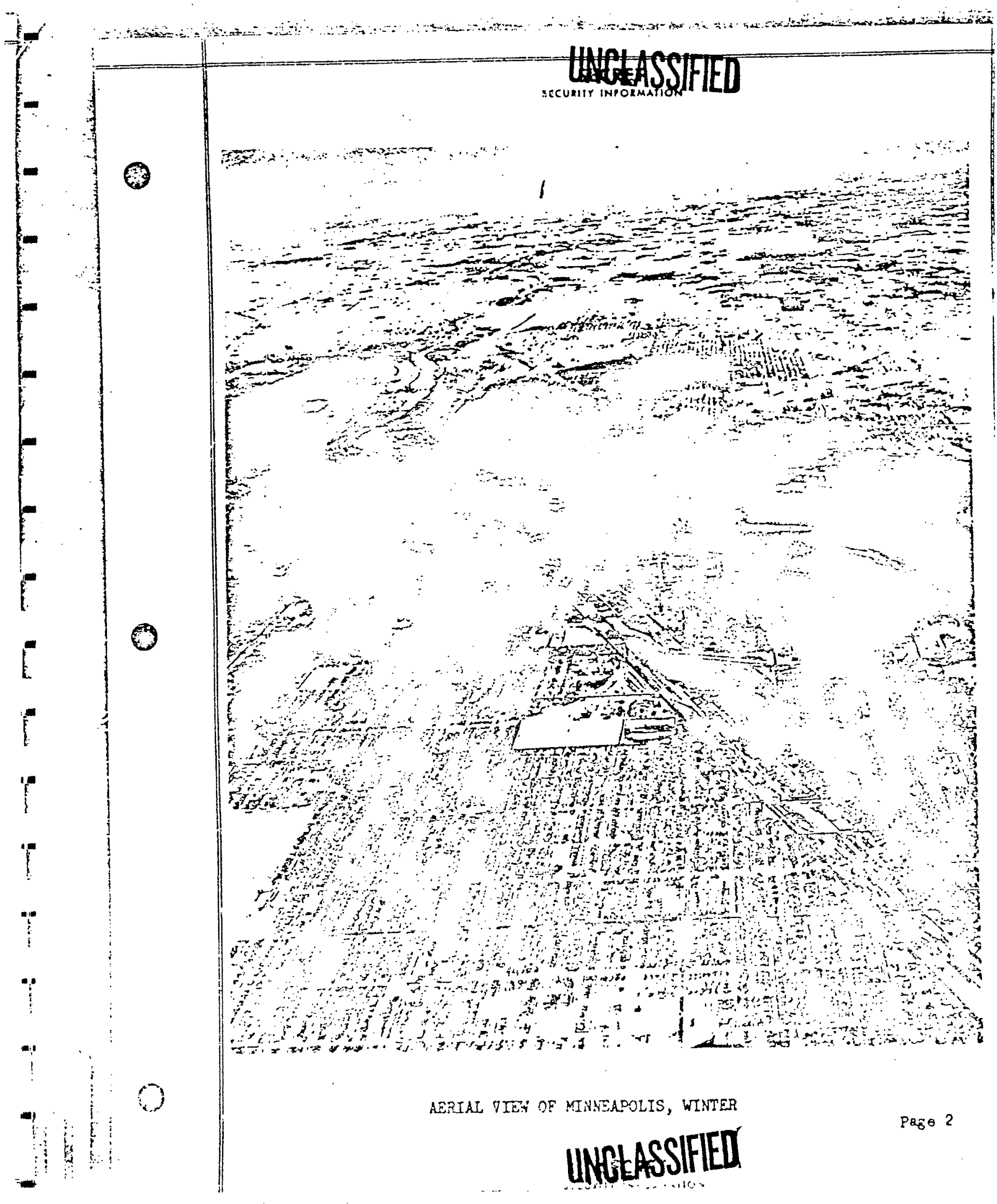




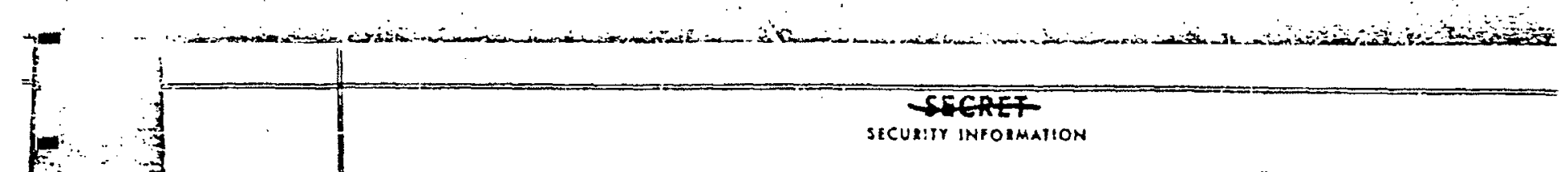

a

CO\&I8 I 5

Puge No.

TITIZ PLOS

CONTBITS

LIST OR TABLES 4

ISST OF TAXTULC TIJUSTRATIONS 5

I. SORMURT

L. Operational and Adurinlstrative Progress

B. Eralastion of Hinter Progxan in Minnespoll:

II. FIRTD OPSRUTIONS AND MUNAORGEST

A. Stadniatration

B. Hotocrological Surrogs 17

c. Field Toats

III. WIMTER LFROSOL TESTS IN MITARUPOLIS

$\begin{array}{ll}\text { 1. Sumery and Scopo of Oporations } & 33 \\ \text { B. Test Sites } & 38\end{array}$

C. Bralastion of lerosol-Cloud Bubarlor in Hineapolls 52

LPPEYDICES

A. Sblo tros, Ninnerpolts 68

Bo Dale: Lrea, Binneapolto. 90

C. Chsilio droa, kinospolss 128

D. Drg Area, Knnaspolis 140

B. Cityolio, Kinneapolis 179

6 


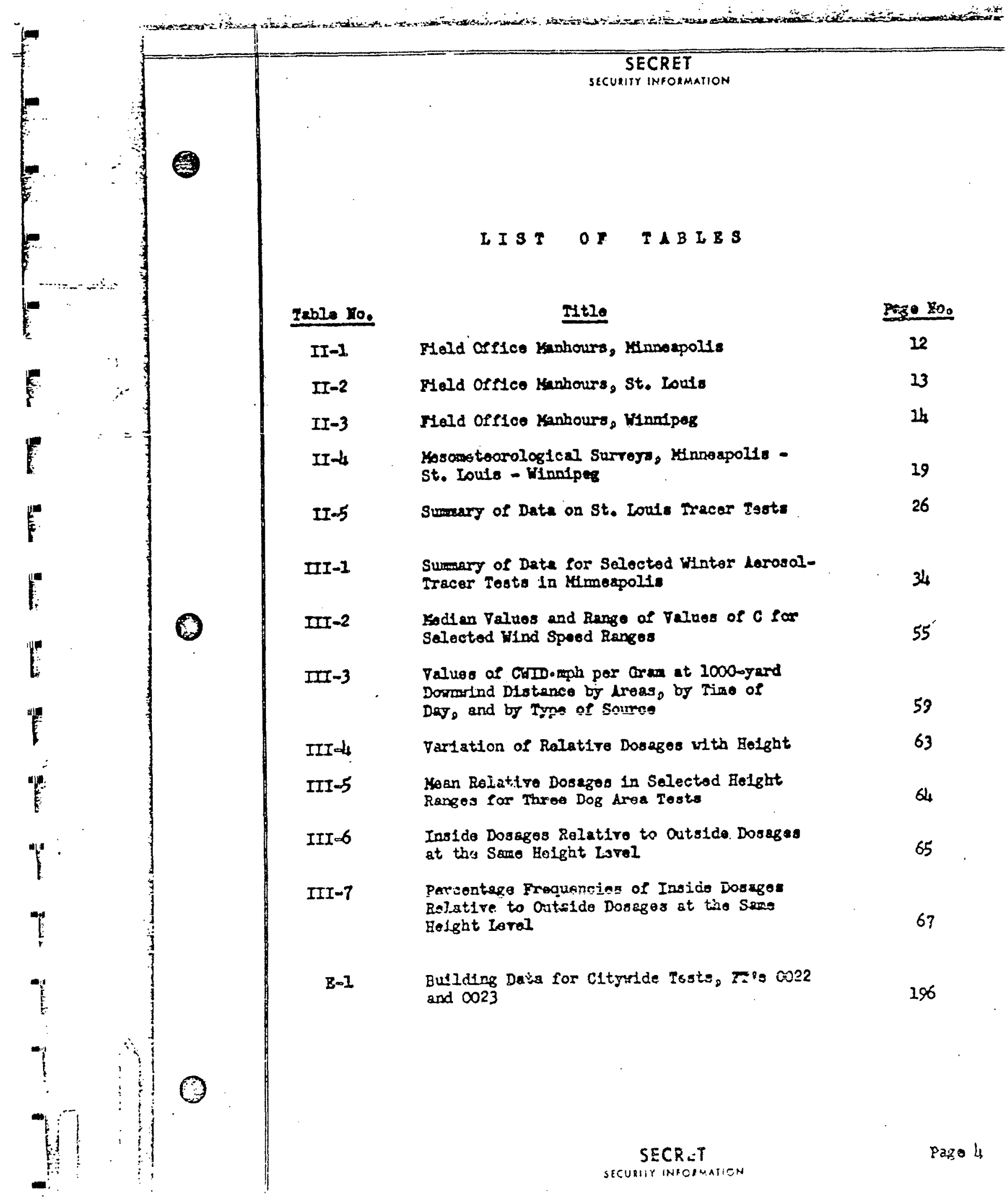




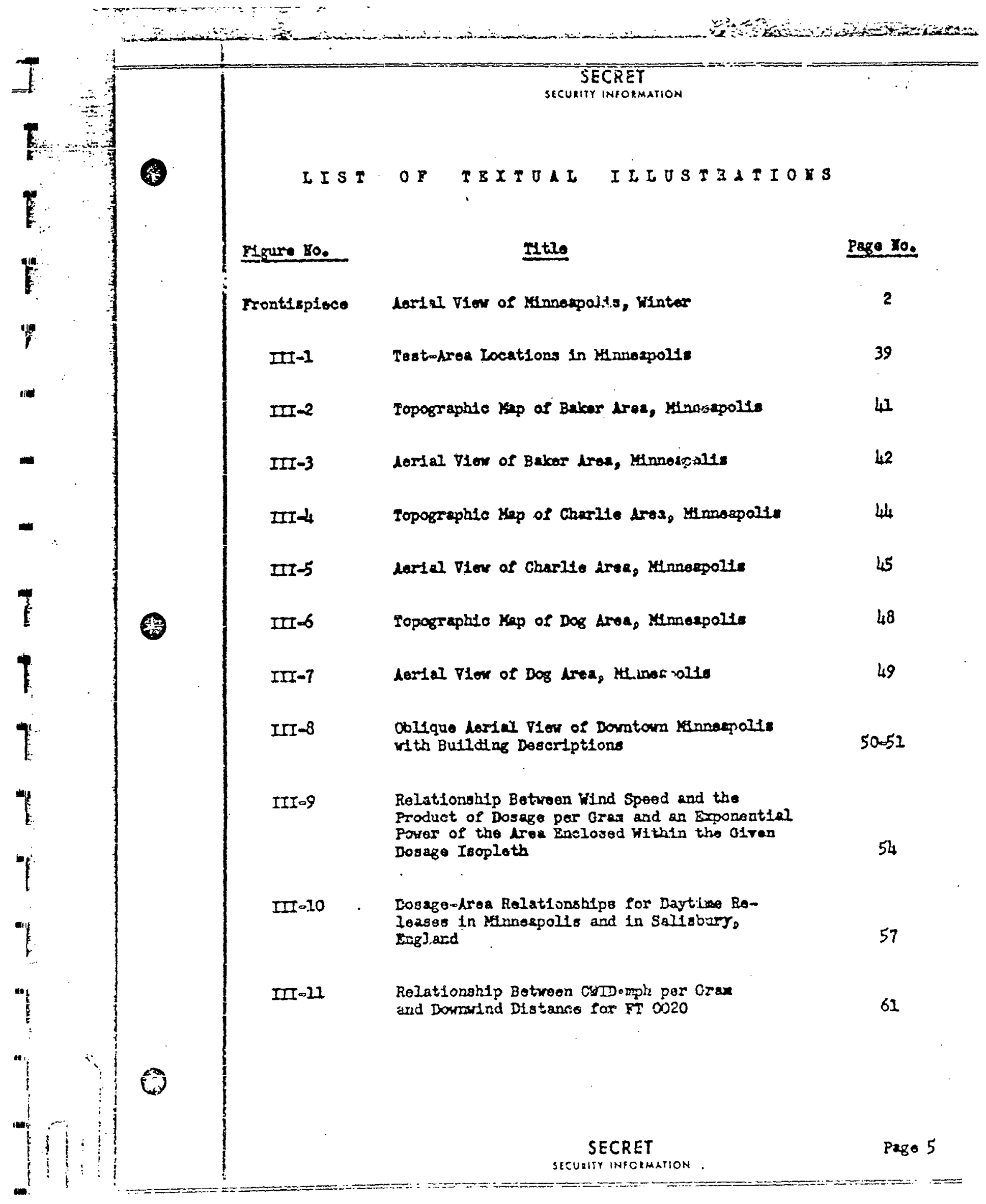




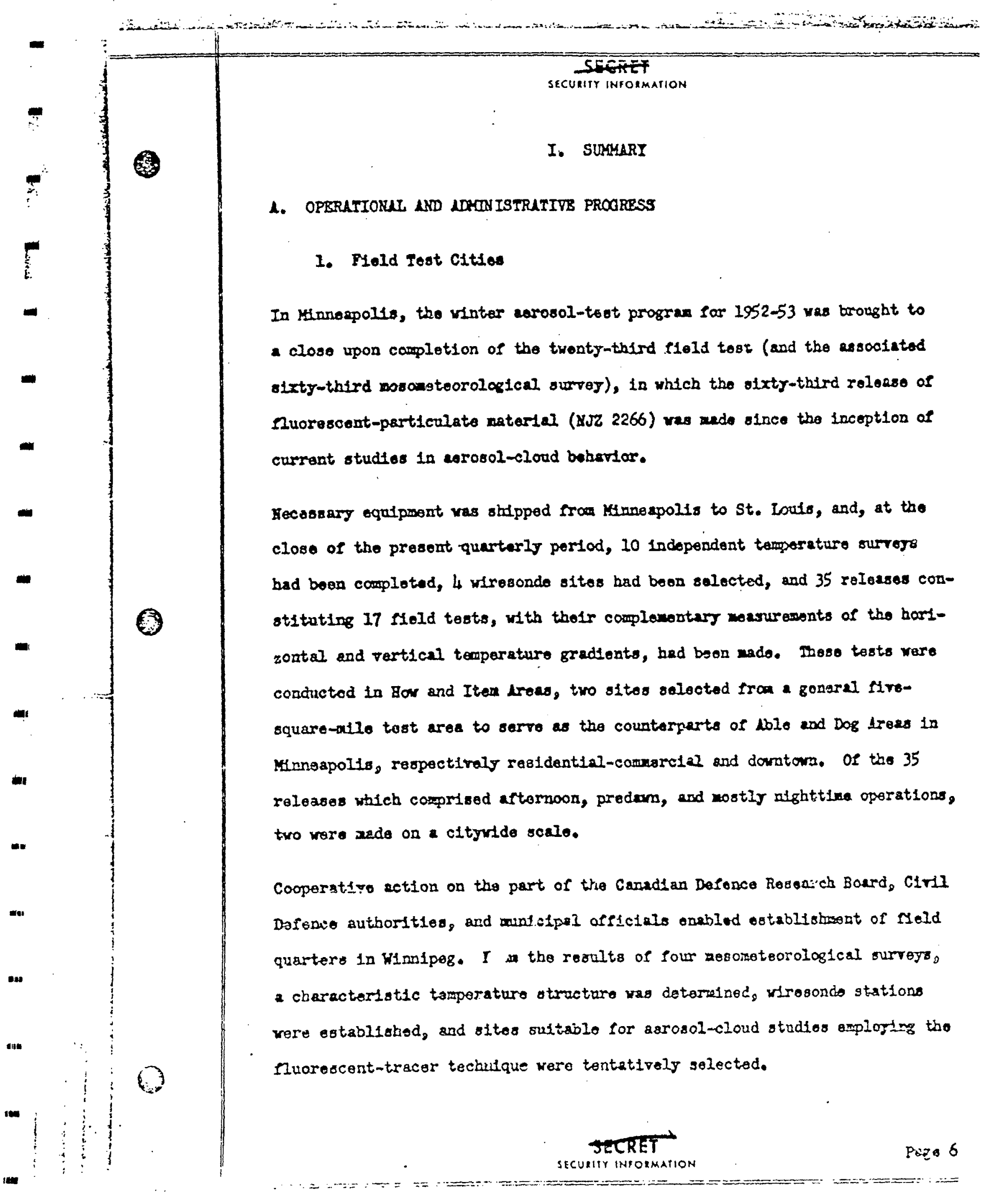




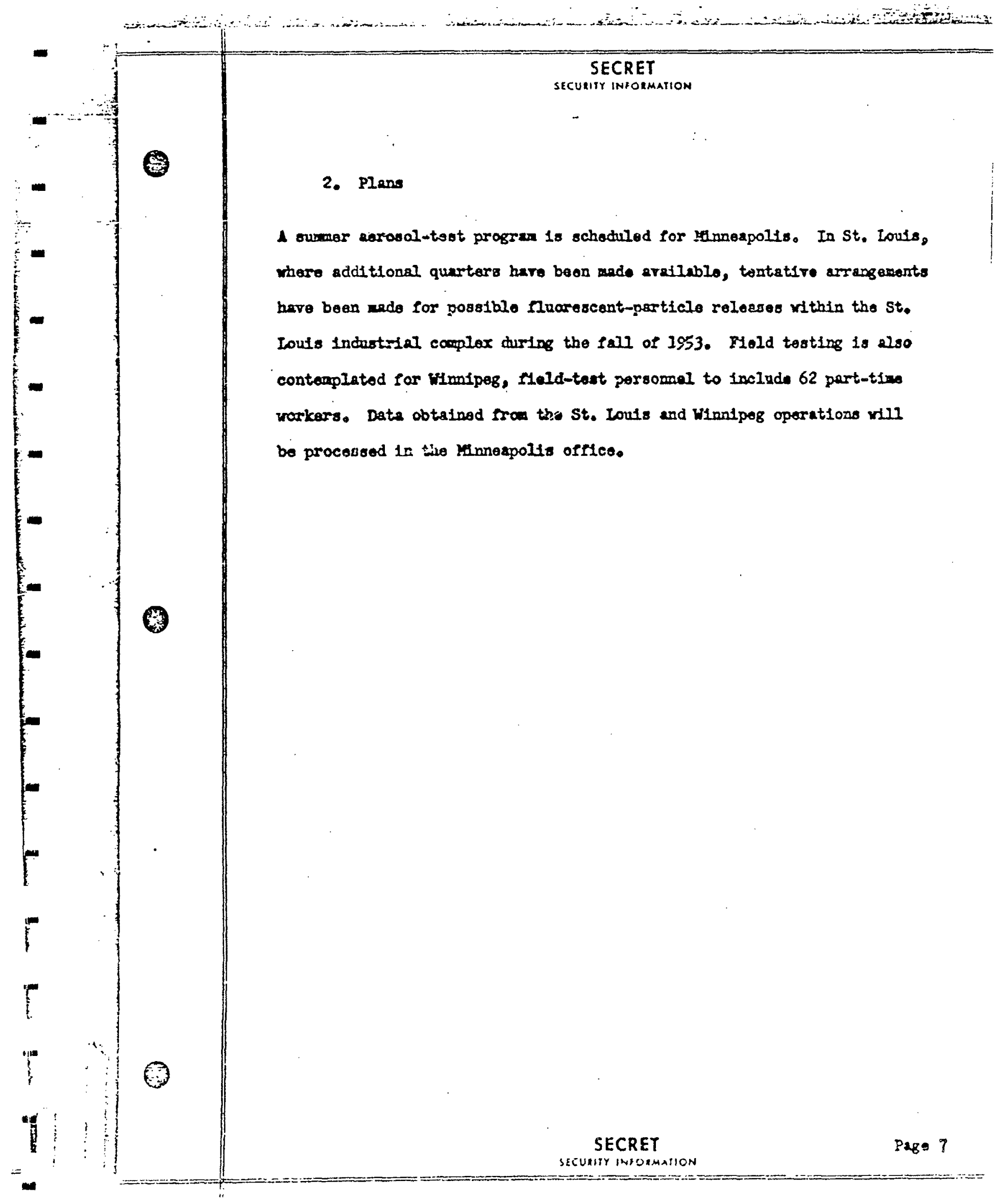




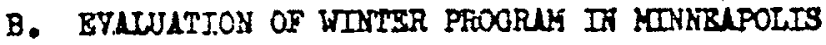

or the 63 relouses (23 field tosts) constituting the winter serosol-tost

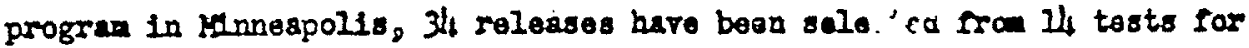
oraluation in the present report. These relosese of NJZ 2266, coopresing both point and lino-souroo disporsals tran a surfece-nountod blaver disparser, and including four reloases on a cityuldo ecelo, waro nado in foar selected areas of varging topographical and land-use charecterlstics. In the oraluation of wintertion sorosol-oloud behstior, sone consideration has been given to St. Gloud raob somitings and to associated mesurants of the borliontal and rertical temperature gradiente. Primary conolderatIon has beon given to the results obtetned fros sasplars oxposed at surrace lorel, for studying horisontat distribution of aerosol dosages; st raryling heights, for irrostigating rertical distribution of arrosol dosages at afferent locations within butlitings, for ascertaining the dagres of clood penotrationg and with fllter units axposod soquentially both inside and outsido bulldings, for verifying (along with soreral tiso-resolution semplers) that the loagth of the sampling pariods was ouffictent to ansure complate ampling of the aerosol cloud.

Posiling further confurwing date, the following obsarvations way bo made

1. Dosage patterns are gindlar for releases mado from a given point within a thrse or four-bour perlod, protlded there are no werkad changes in wind or stability conditions. then a release is ado In or uprind of a river garge, the arosol cioud is displaced laterally and the dosage pattern, therefore, is somonthat altersdo 


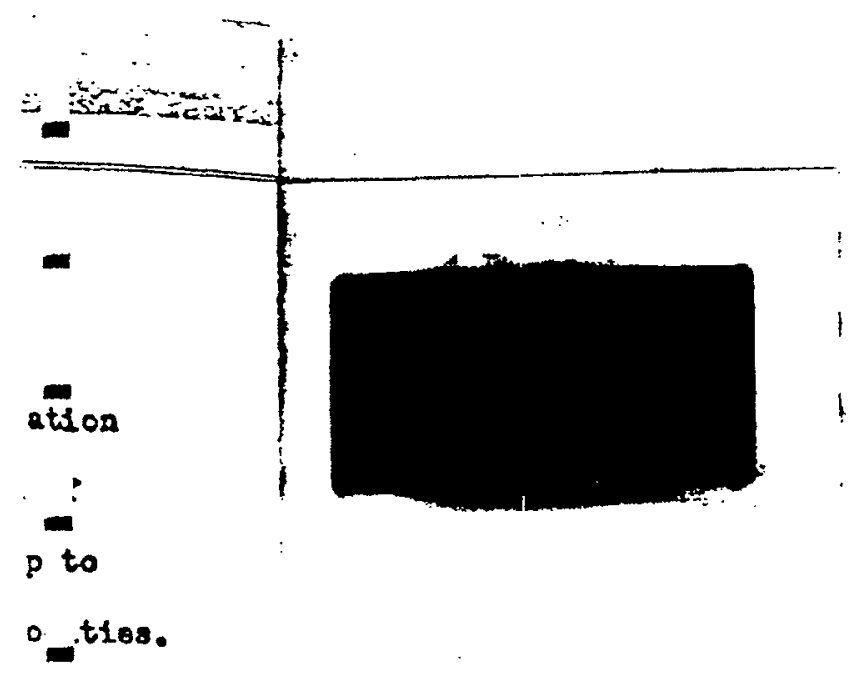

apputed

$-10$

arancea

arth

s n an

r the-

ป) -

$=$

3: 1105

bo-

i) 89

$\rightarrow$

x for

a

Iloud

$3 \mathrm{rco}_{2}$

ielght

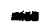

i] a con-

yencan

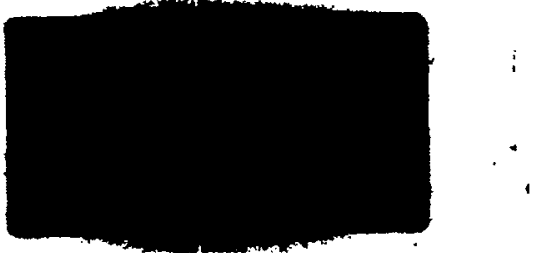

$-$

-

$108 \cdot 9$

-

- 


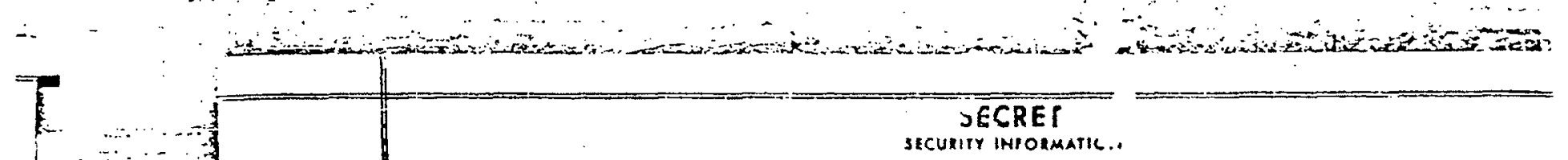

8

2. For compering the arees corarod ro utron dosages, cospensetion far the effects of wind relocity by sioplo multiplicetion of

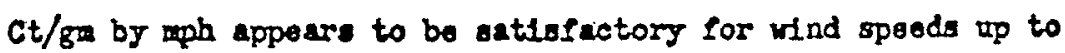
6 ph, but gites raloos wich are to large at bighor relocities.

3. Compersison of chll values (arosorind lategretod dosages conputed for relenses at regular interrals $a$ ' 'Istance domarind to tho

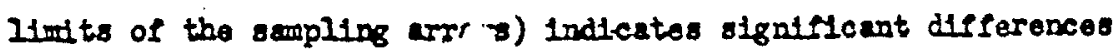
only wen dayting reloases are ando in a rosidential area (with reculting Ior values) and whon nfigttive relosses are wado in an open area (with resulting higher values). CWID ralees for rolosses from points and short lines aro moro noerly caparable than those for point and long line ralesses.

4. Here comparisons are possible for tests conducted under stedlar conditfons, there are no apparont signi: 'sent differances botween the values approsing the : olationship of area and dosago per gram for polnt-source releases of 1.5 to $13.3 \mathrm{grams}$ and $\mathrm{for}$ short line reloases of 14.3 to 2 ? 5 grass.

5. Within the helght ranges of butldinge rsed in stucties of cloud attemation and at the given dowatind distances from the source, there seems to be no significant docrease of dosage with helght In built-ap areas.

6. Besults from ono test indicato that urea generelly unstable conditions, increased inptability due to high bullding deraity can cause a repld dissipation of the serosol cloud. 


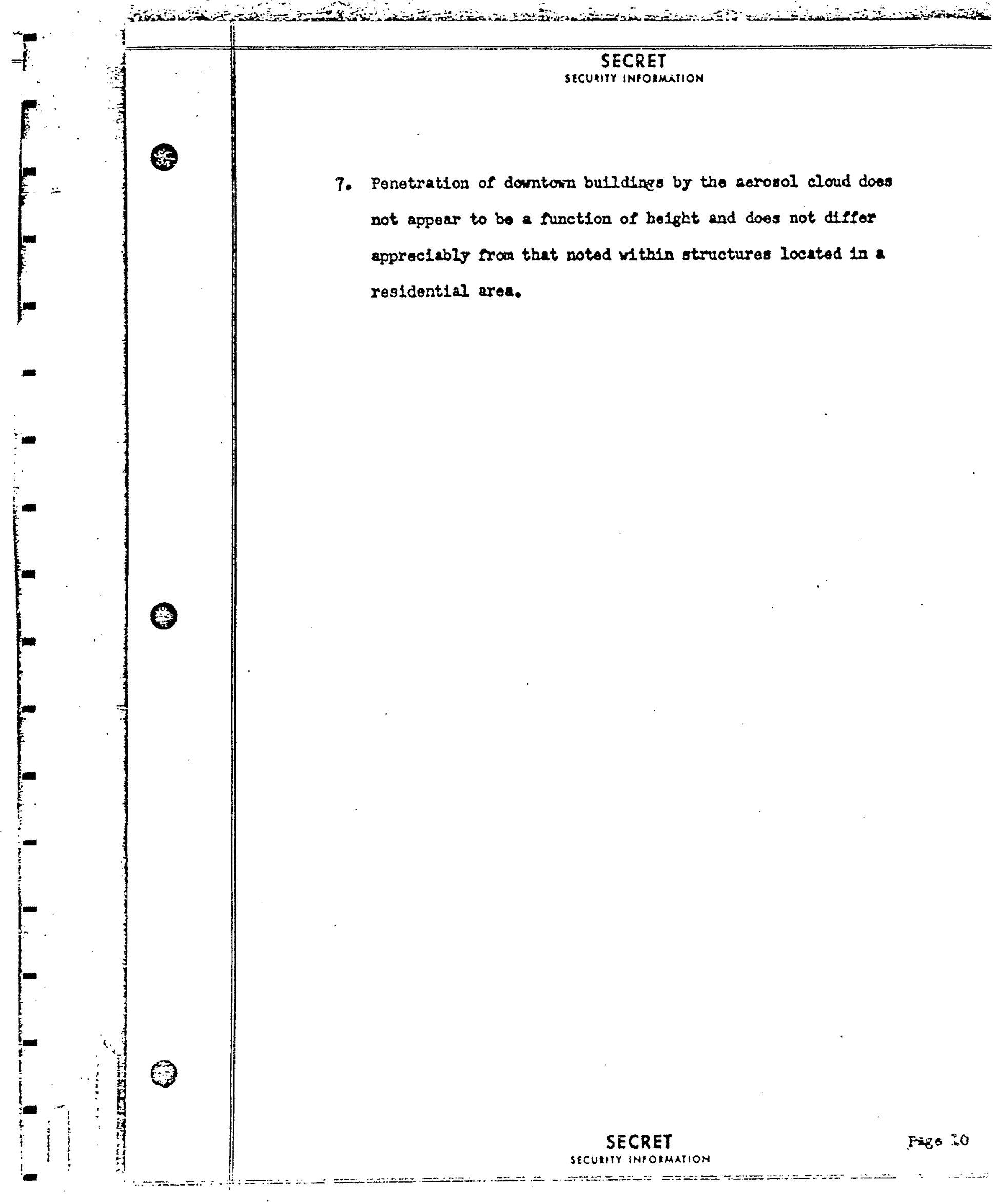




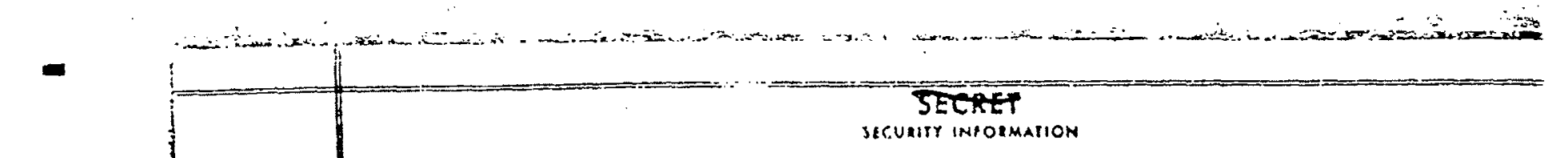

II. TIED OPBRATIOHS AND KuLCOBMAr

\section{A. ARImLSTRIION}

\section{Organdration}

There ware no additions to the rall-tive fleld of flce parsonnel during

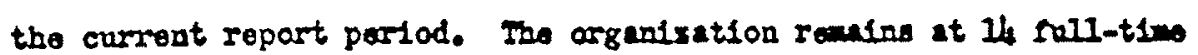

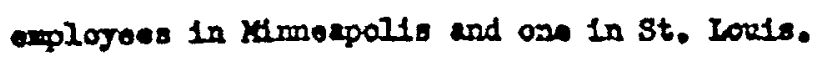

1s of 31 werch, the totel mabor of purt-tiwo eoploges in vinnespolls vas 180. During the current perlod, only tro earosol tosts and the

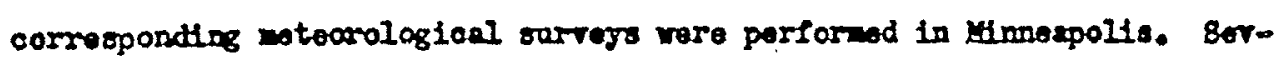
oral part-tim axplogoes norzalls assigned to parform fleld work mare tratnod for and utillsed in laboratory analyels wart. In annospollo the wajor portion of the flald fores was inactire perding rosweption of tast actirity in the sumer. Duriag the perlod, alght peoplo wore hirod and 25 were separatod, loaving a totel of 163 on recard es of 30 Jum.

At the start of the curront quarter, as roported in 2093 , the part-tios farce in St. Iouts numbered 53. Soas 257 pooplo vere bired, and 13 wore terntrated, leaving 197 enpiogess on rocord at the end of the quartar.

In Hontpeg, 62 part-tide vorkers wore hired in tho sonth of Jum, repre-

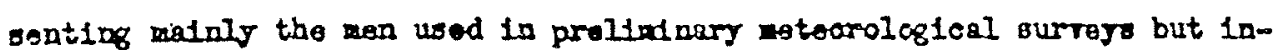
cluding those Intifily hired for the slald test crev.

Tabloy II-1, II-2, and II-3 show both rull-tixo and part-tImo manours

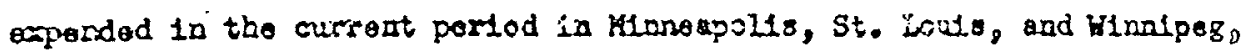
raspactirely, broken dowa by xonths and actiritias. 


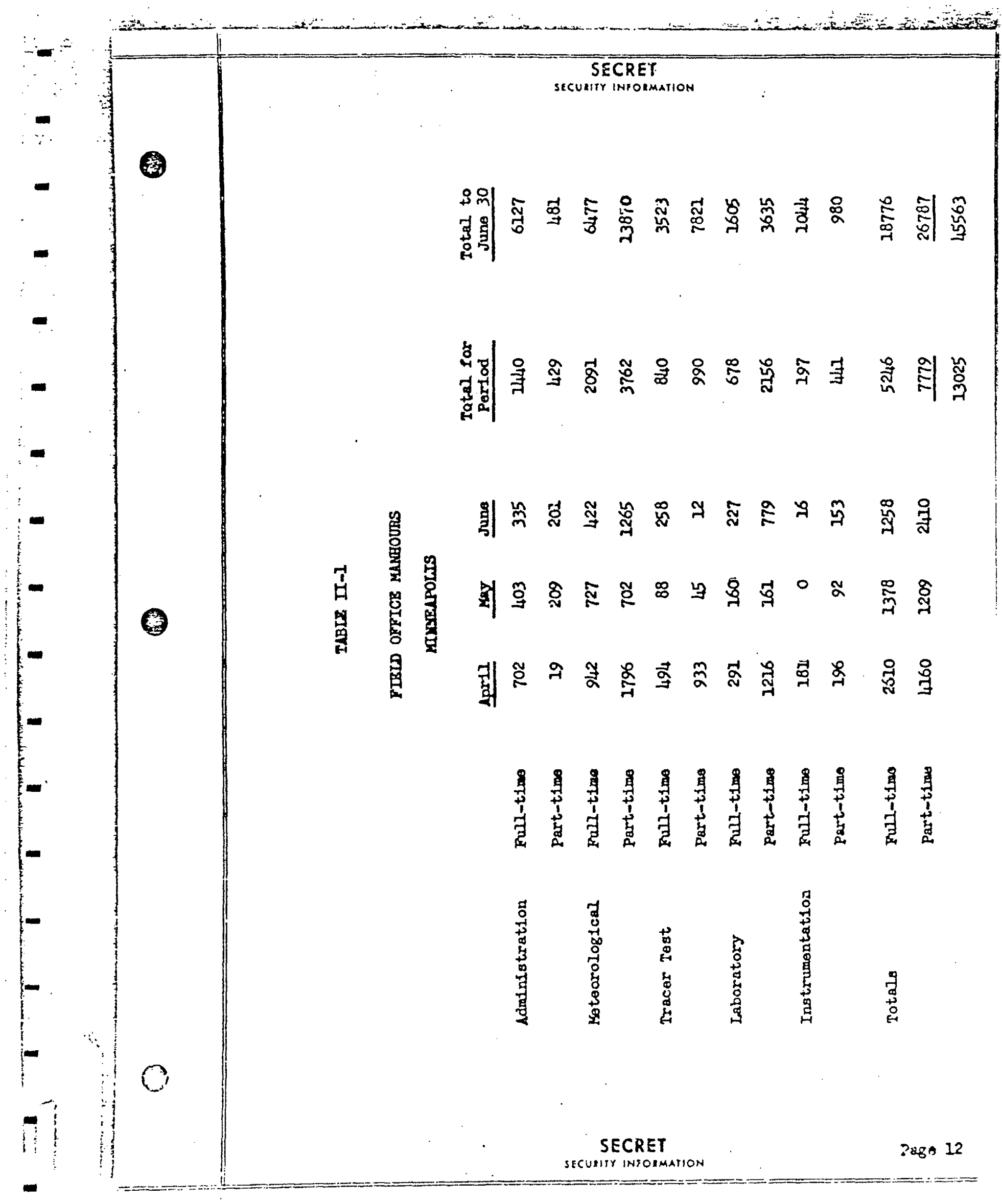




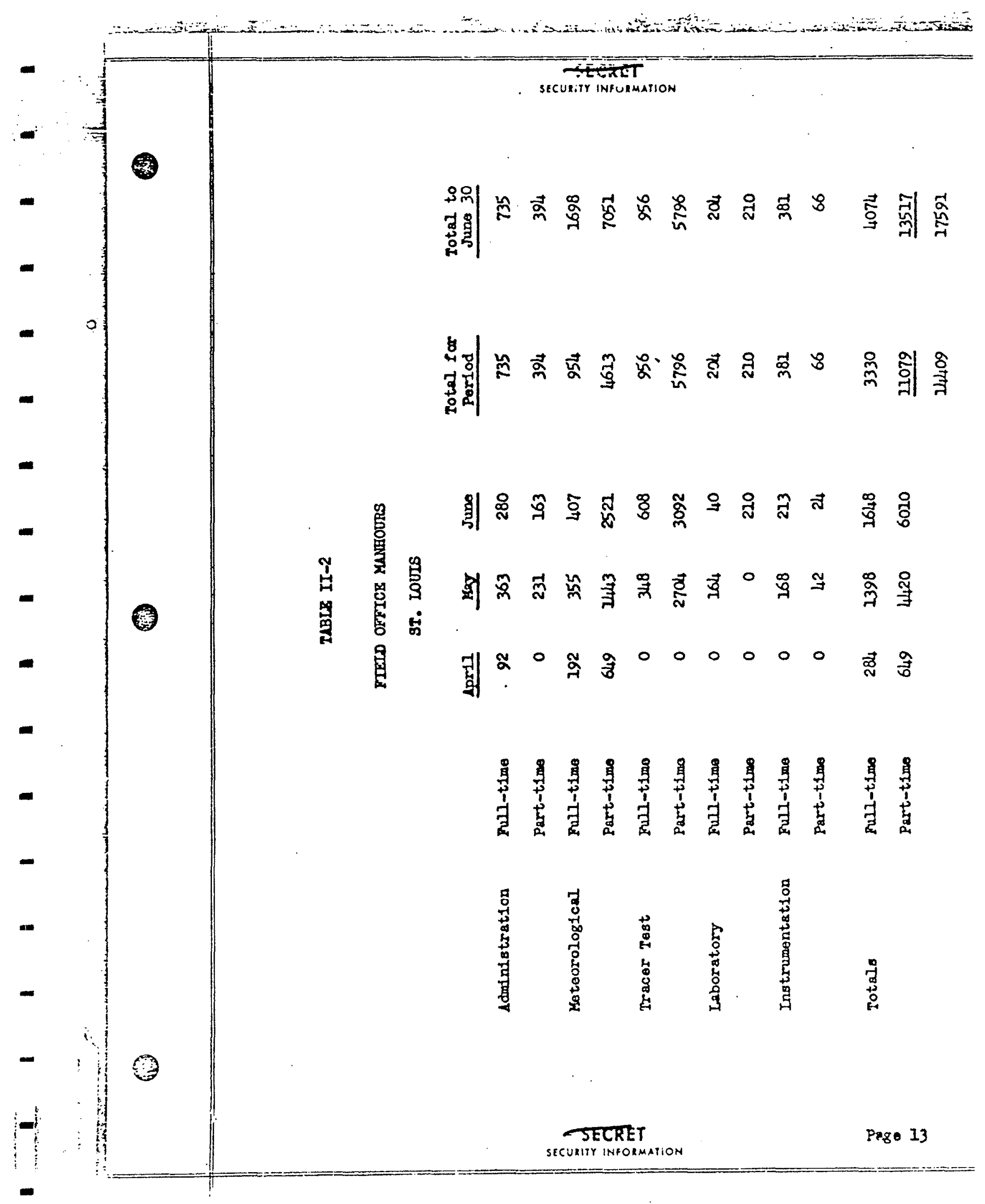




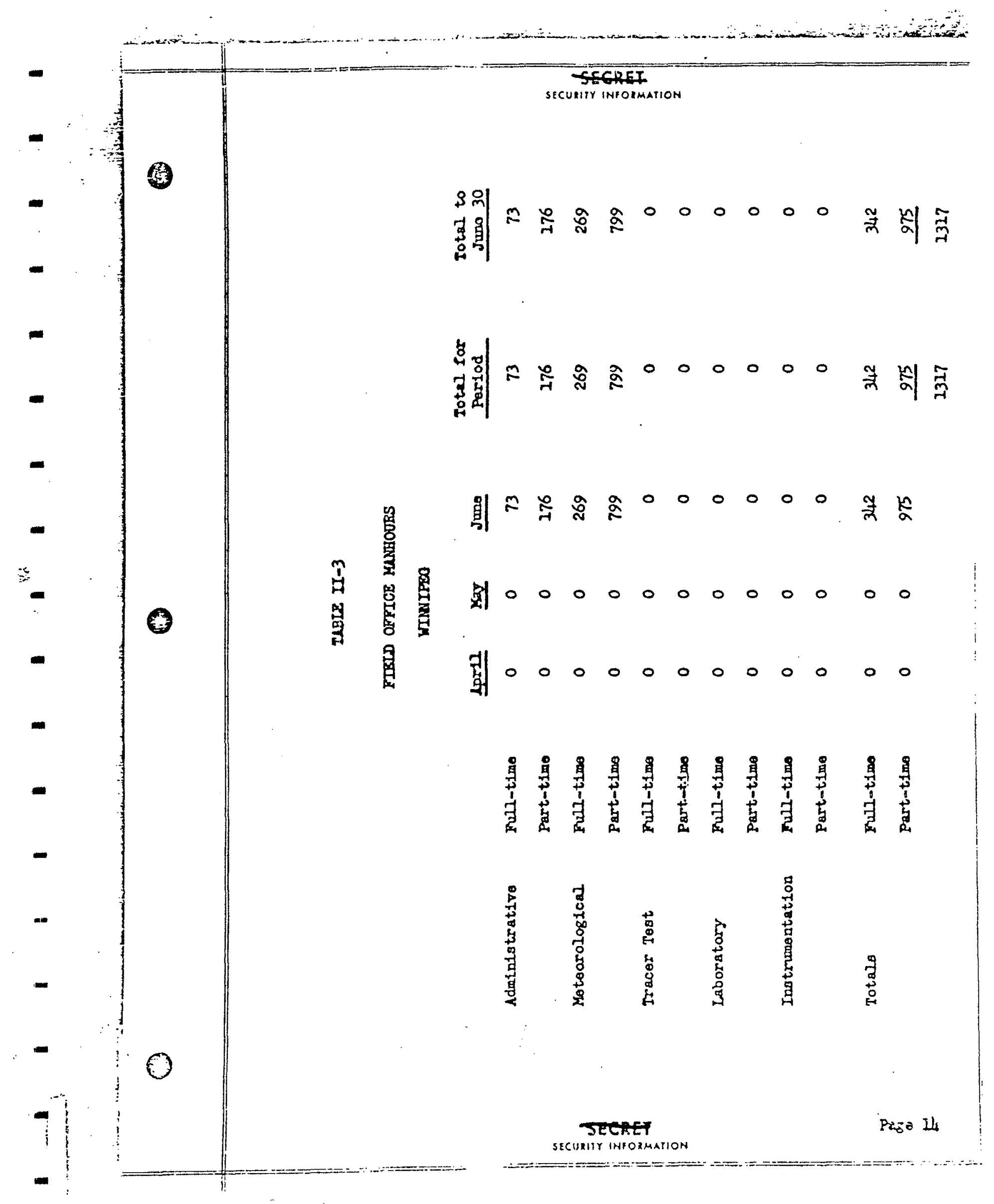




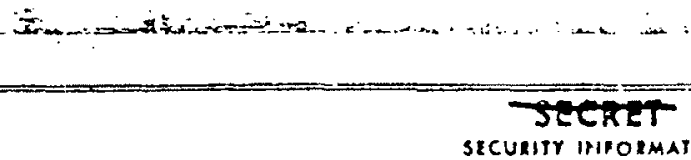

\section{Esetlitios}

For performance of aerosol tests In St. Iouls, additlonal space of epproduatoly 3500 square foot was prooured on a month-to-anoth rentel basts. Ints additional space sifoins tho arding flold offlce in the second-hoor garege at 5589 Pershing Areme, and includes 500 square fest of offloe mpace to accomodate the functions of aerosol-test achinistration. The belance of the space is Open-garage area for the equipmont assombly aroa, cros sesembly area, battory-charging room, instrwant and tool crib, and the laboratory. The latter three room are of light kack-dorm construction, with wall and colleng panols prefabricated in innoapolts. It was anticipeted that these exolosures would be utflised atifiald offices resote from Milnoapolla, and, therefore, were constractod to perredt easy assecubly, desssesbly, and trensportation. The only eddition to the St. Louls office to parate infistion of earasol tosts, other than montionad abore, was a 220-volt, 3-phase elootrical power sertice to the battery-cherging genorstors.

Sore 12,000 pounds of oquipment and factlities rere shipped by one notor ran frox kInnoapolis to Si. Louls. Includod in tho ahipsont ware all sampling untts, two battery-cherging generator, motocological 1nstrewouts, tools, supplles on hand, prefabs, end offlce equipant, The carplote noro and roBstablishent of this siseablo anmunt of equipant and facilities res accomplighed in less than a veek whout aigniflcant dasage to the trangportad goods. Lt the and of the current period, with St. Loul s tests completed, frcillties and squipont vero in the process of transfar diroctly to filantpog by a statlar type of transpartation. 


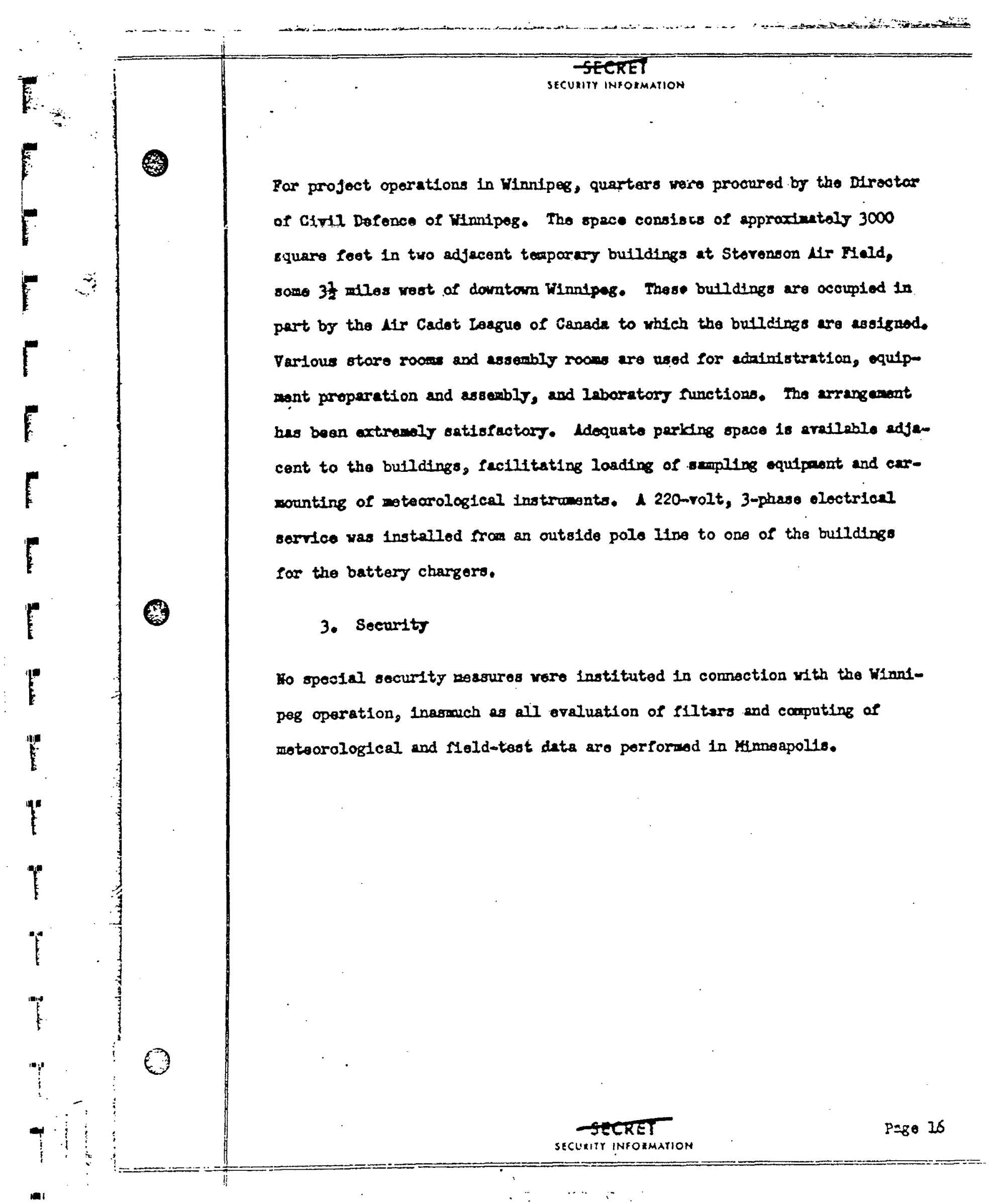




\section{SECOET}

SECURITY INIORAATION

B. METEOROLOGIGAL SURVETS

\section{Conaral}

The purpose of the mesacotocrological surreys conduetad daring the current perfod was to dotemine the horisontal and rertical texporature distributions to serre so bers for the selection of acrosoltest 8.ttes in St. Iools and Wmeng, and to obtatn data both for dotermining possible offect of thase distributions on the diffusion of aercal clouds in Mmoapolls and St. Louls and for Irrestigating the charging distributions in varlous reather situations in rimsoapolis and St. Louts.

In order to obtaln the temparature date, wrevarse routes in all throe c1tios ware destgred to include the business aree, wost of the residential area, and sufficient andoraloped area to onsble the ostablishont of the characterlstic distributions which affect aorosol diffasion. It was found that eight routes were necesary for antwan coverage in St. Louts, and the routes were redesigned accordingly priar to otarting tho

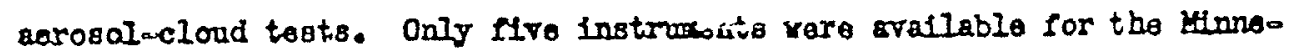
apolis tests, altbough a nintara of six routes vill be necescary for summer tasts. It was found nocessary to design six routes for Winnlpeg tests. As in the past, lour to eight circults wers mado on oach route in accordo anes with the requirements of each fleld test. Wresondo ascents vare also conchicted in both business and urdevelcped-aroa locations, ascents boing made once each hour to colnetde with traverse operations. 


\section{Tost Data}

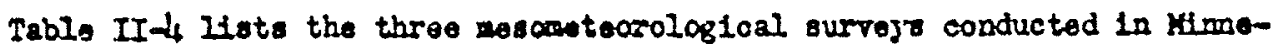
apollo in the current poriod, the four surrege concucted in wamper, and the 25 survore in St. Louls. This table shows the partinent statiotice on the number of routes, runs, wirssocde ascents, seps obtatinod, and nenhoure expessded durline the period for varlous pheses of the operetion in connection with these eurroge. The mahours expended durtig the curront parlod on surveys conducted in previous porlods are not 1ncludod.

\section{Pabric Rolations}

Heotings yere held with varlous elty offlcials of St. Louls for the purpose of comploting arramgents for wiresonde and fleld-test operations. Hinor difficulties with the Park Caradsaloner vere ironed out with the completion of the chenge in city adnintration. The St. Louts pollce dopertment was quito cooperative at all times, and the fire depertant alded In the recovory of a kotoon and thamistor wich bad become entanglod in a treo during gusty winds. The puble showed considarablo interest whon Porest; Park hat to be used for the undevelopedarea wiresonde at to. Howorer, no troidents of consequence occurred.

Civil Defence and city offictals of Winnipeg and surtounding michallties were axceptionelly cooperativo in helping to initiato merosetoorological eperations in that city. is a resilt, considerable intarest was gbosn by the press and the public. Traverse car operations oroked littio interest. Boxeror, tho f1rat wresonde asconts drow quite a largo crosd, ono teenago 


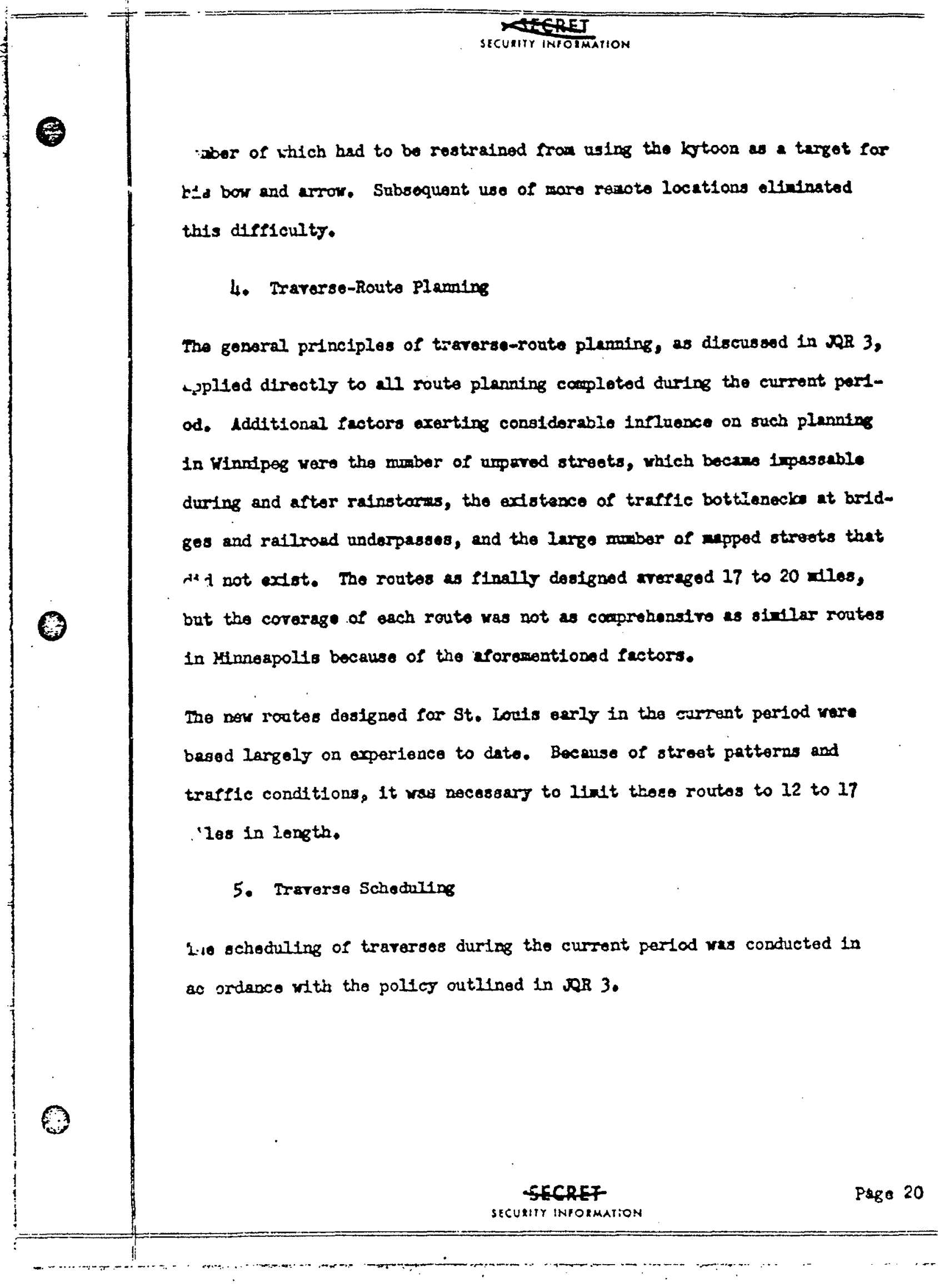




\section{Selection of wresonde Sttes}

In accardance with the prinolples dtscuseed in $Q R 3$, viresonde sites vere seleoted in both St. Lools and Winadpeg during the current periad. The St. Iouls businass-area location was established on top of a tro-otory butlding on the nortbrest carnar of stghth and Delmar, rest norr the conter of the heat 1slend. The undereloped-area location was eatrablehod in Porest Park in the lowrest sccsssiblo opot. In alternate underaloped-erea location for use on Sundays or bolldags was found at wilnore Park on the south odze of the c1t5. La additionel alto was located in the sarasoltest area on a three-story buflding on the northrest carner of Benton and Loffingrell.

the businessmeres location solected in wimlpeg wes the roat of the throsstory Dowintion Kotors Buildeng on the sortinest corner of Fart and Crahna, ibout 1000 feet froen the centar of the heat 18land and on the odge of the lafgh buslding aren, I sattsfectory wodoreloped-area location vas found in an opon fleld on the northrest corner of Watt and kelrose in East IKIIdonan, throe N168 north-northesst of the host islend. The coldegt point in the area scams to be ono-bele mile further out, but troes proclude the use of wresond equipmont there.

\section{Wresonde Schodurting}

The scheduling of wirescnde operations durtag the current perlod vas strictIf in accordance wth the policy outlined in 32. 


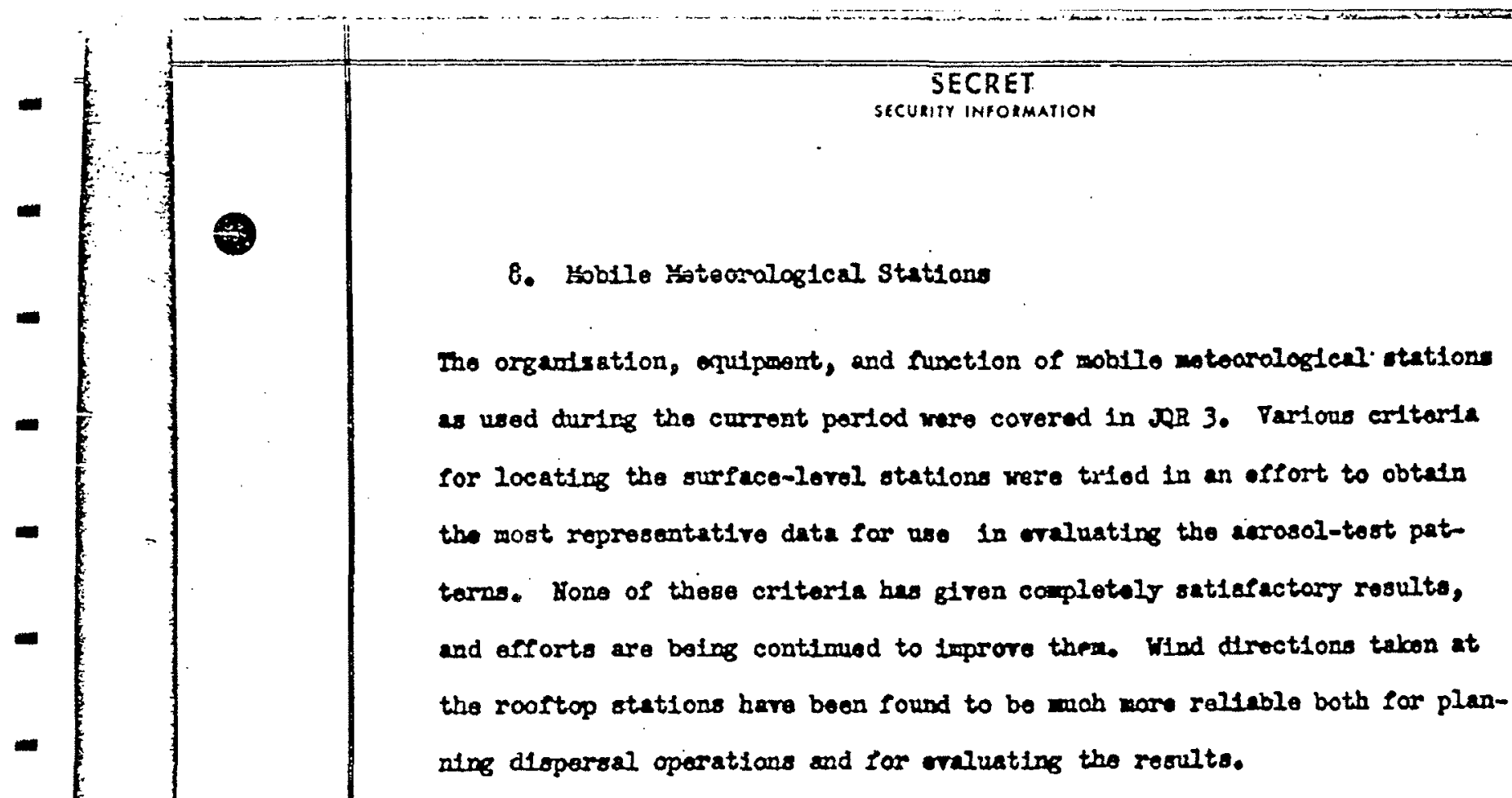

\section{Date Boduction and Analfois}

The procedares outlinod in DR 3 were followed in the current periodo Date rocuction and esp plotting ware in progrese at the end of the period. Bororer, the analysis of wany of the tests was not coupleted becanse of the 1modiate pressure of operating daties. Wh the coxplotion of nost of the argantsational work, more time will be aratlablo for analyois in coatios nonths.

10. Parsonnal

lo vas anticipated, the tight labor maricet in St. Loulo wade it dirfleult to obtatn edequate personnal, particularly reoponglblo personnal. Tho scope of sereral C? the tests yas linited by fallore of exployes to roport for duty. It was necessery to discard scme date because of obrlous poor quallty and incouplotenoss. The repid personnel turnover, coupled with the gewarally. 


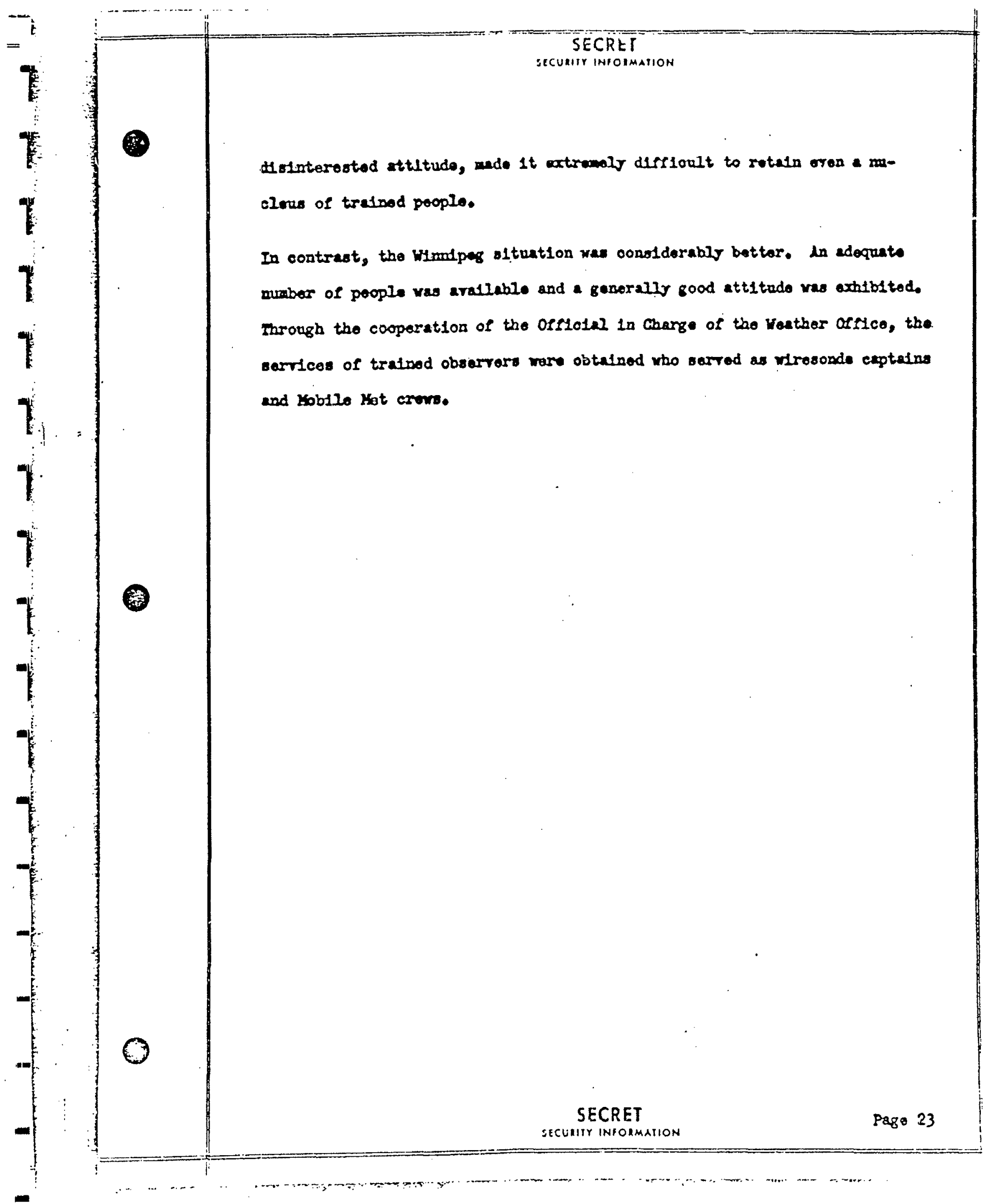




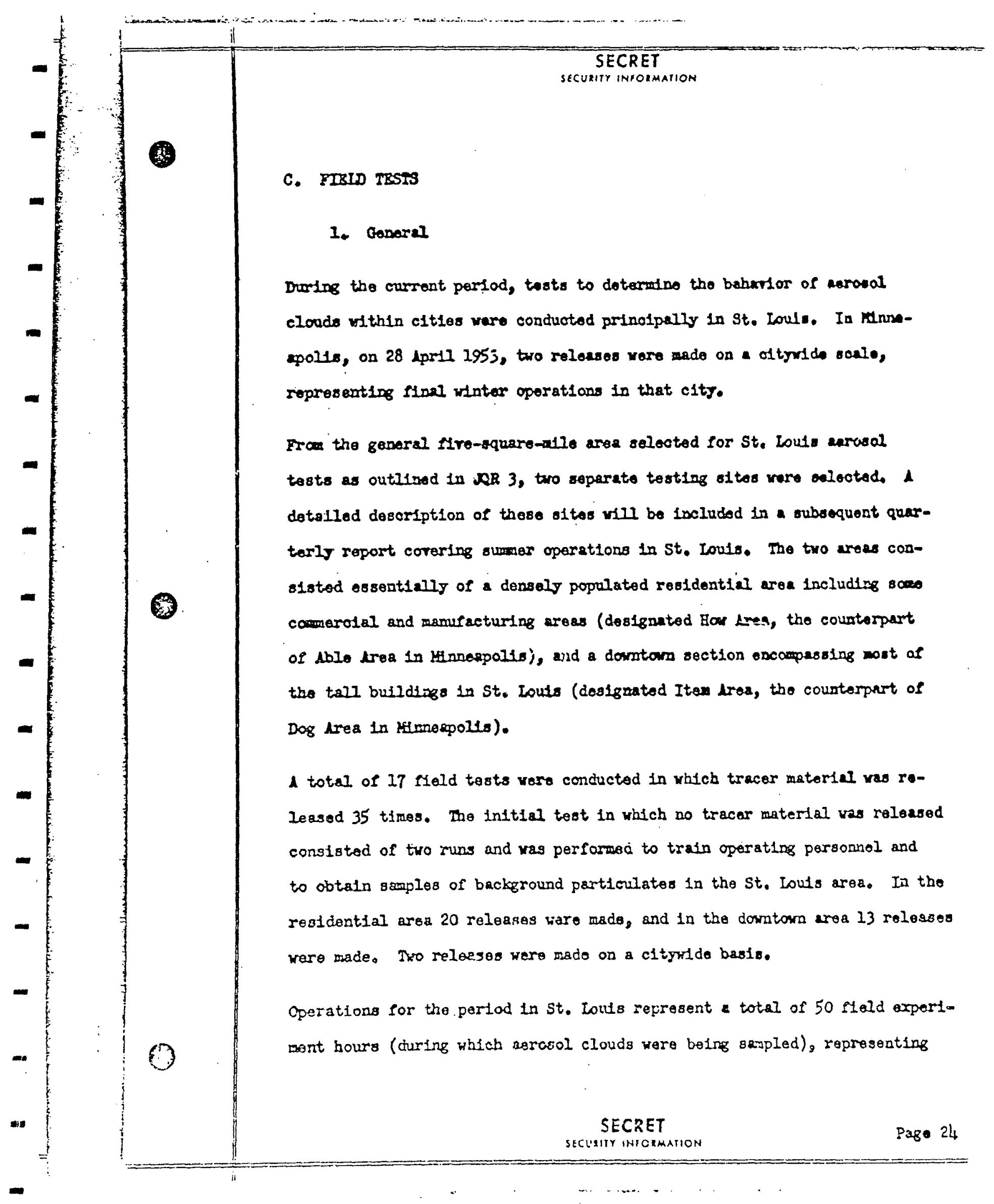


an equndture of 7511 menhours of sull-tine and part-ties persomel to accouplish the rleld and laboratory phases of the gropran. It 18 soted that the fleld work was completed in the current parlod, but the laboratory wark was only partially complate as of 30 June. Flald tosts vere conducted prodocinantly in the erening hours betwesn 2000 and 2300 CST, wth servoral supparting experinonts being concuctad in oxch arou durine the afternoon hours between 1300 and 1600 CST, and durlag the earls wroting bours between 0000 and 0500 CST.

\section{Tost Data}

Tabl. II-5 omoristos all flold toste contuctod in St. Loats during the porlod cororod of this roport. Portinant otetiotice are giren relatire to the soveral reln phases of a flold operation and the attordent analois work. Totel senhour expenditure figures in rarlous oparations and manowr

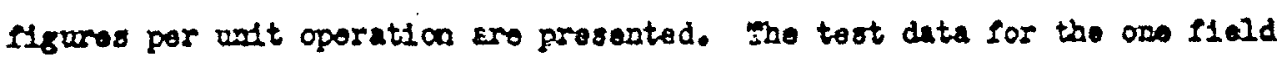
tost conducted in Hanoapolls during the currsat perlod will bo incladed In a subsequent roport with other Hineapolls tosts.

\section{Pablic Rolations}

Lo proviously outlinod in OQR 1 , advence mootings with St. Louls city offlcials wero hold in the fell of 2952 in preparation for condueting aroo sol tosts in that city. In 1pril of 1953 metings vers 2qain bold win representatires of the Karoris office, with the Chief of pollee and his representatives, and with menbers of the Park Board, during which the rarlous phases of the oumer tost program were outlined. 
In proparation for the conduct of aerosol-clood tests in industrinl compilexes in the St. Loulo ares in the fall of 1553, nootings vere hald durIns the current period rith officialo of Monsanto Chomical Company, SocongTreuum 011 Compung, Orante C1ty Steel Carp., and the Board of Mlderaen of oraal te City, Inllnats. Is a rosult of these mestings, the full cooperation of these Industrial firse was axtended to The Ralph Mo parsons Camaso In the prodecution of the tosting propress, with pencission boing grented vy all firms for use of compang proparties for fleld-test sites. Tests ure planned at a Konsento plant lacetad in St. Lould proper, representing

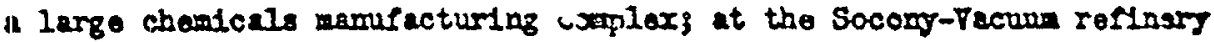
In Bast St. Louls, Dlinois, rop-osenting a largo petroloum refinirs conplox; and at tho Oranito C1ty Stoel Corporation, reprosenting a 1acre istoel wanufacturing complax, Including blast farnaces, open bearth for. naces, and bloowng and rolling facilltias.

Web lese public interest and curloaity was aroused by tho fleld-tost phase of the program in St. Louls than was experienced in Mlnnsapolls. How Arsa consists principally of a densely populated slun distriet, and Inttial operations in this area were planned with particular preceutions boing txken in the arrargenant of equfprent and schadulting of menpor to mintatze the posstbility of loss of equipment. The Pollce Dapartruent requerted that it be notiryed prior to each test in this area is order to he prepured to quell ans disturbance resulting from the presence of the tost crew in the area. While the nature of the cistrict justiffed such precautions for each operation, tho whole program was conductsd without a siagle case of randalisa or disturbanea. Those residente in the fors tros 


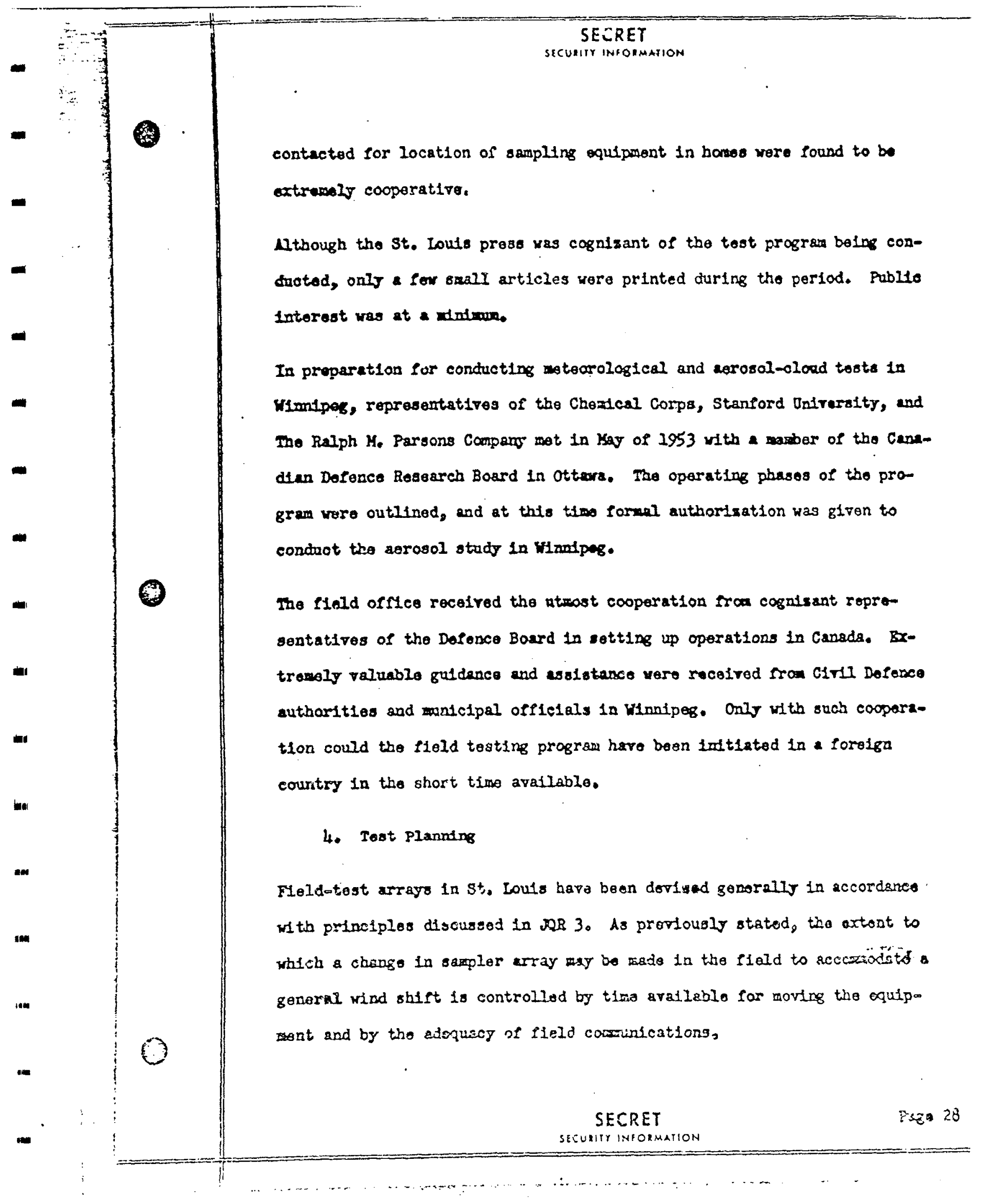


SECRET

SECURIYY INFORAAIION

\section{Sampling}

Part-tise oxplogeed hirod an sempler attondants in St. Loulo rare pre-

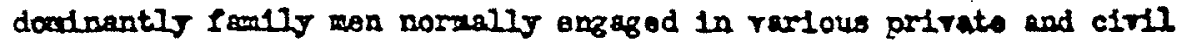
occupations, in contrest to vinnoapolls crowe which consiotod largely of 0021 oge students. Because of the greater neturity of wen aradiable for hire, it was found possible in the initial job intarrion to saloct qualtriod wo for Flald ares ceptalns to suparrise the sampler fleld crors.

Thts group of erew chless was given indtruction in operating proceduros prior to intitial assembis of the rexsining wibers of the crer, and these supervisors vere dologatod the responsibility of elsseatinating such operational inforeation to mon undar thair cogndsance at tho initsal trafning seasion. The actranteges of this procodure offset the genarally uninterested attitude proralent among St, Lowia pert-tise amploges and peraitted

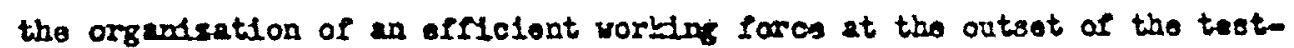
Ins progran.

Bomataing aspects of the atr-gapling operation are described in aR 3. Durtog the latter part of the St. Louis sarles of aarosol tests, in addition to the usual datalled oarpling of the atrbarmo cloud, cloan glass plates for the measuremant of fall-out wore placed at fire to stx points up to 1500 fest dowrind from tiso release point. These measureaents were degired to obtain an eatiats of the neture and nognitude of the fall-aut of FP satarlal occurring during the St. Louts norosol tests and to coapare 
these date with eif ar studies made in connection with the Stanford Fold oxparisonts ( $59 \mathrm{~g} 1856-4$ ). Results of this phase of the prograx w1ll be troated in a sabequent foint quartarly ropart on the St. Louls tosts.

6. Lerosol con iation

Organdsation of the rosol-generatar eron realned as doseribed in 208. 3.

1 proceduro caloulated to proclude the posstbility of conterination by flumest-trecar material of 11ald offloe prondses, in addition to those outlined in DQR 3, imolved the storine and charging of the genorator battery powar pack at th, location. of generator storese, remots from the flold of:lce. This procedare will be matritained during all fortbcoming test pertods.

It was firat no' $3 d$ in St. Louls that the finoly pordored bult XJ 2266 naterfal bes a tendoney to clump badly under high hualdsts conditions, thus causing the matertel to leed poorly from tho metering into the dispersar genu. "or. Unless apectal precautions ars taked when operating under high bouddity conditions, the feed rates fall bolor these calfobratod for girm opas atting roltages. To remedy this condition, the fluorescent material to heited in an oren until nflcfry and is then stored in an afr tight contalner itil reacy for use in the 1101d.

\section{Test Direction}

Tho flald tost direction pr cocureo havo remalned as Indicated in 3.

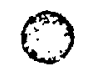




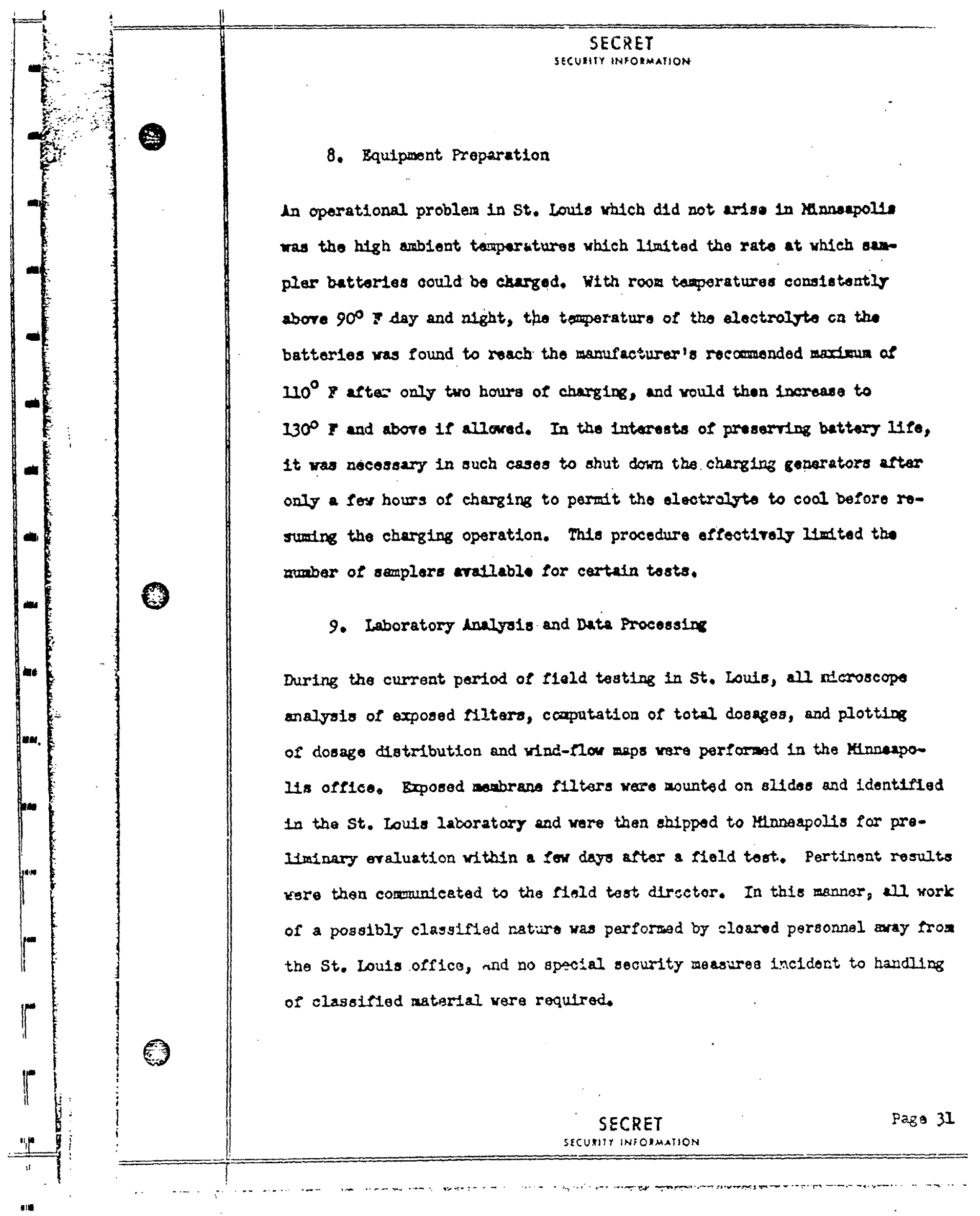




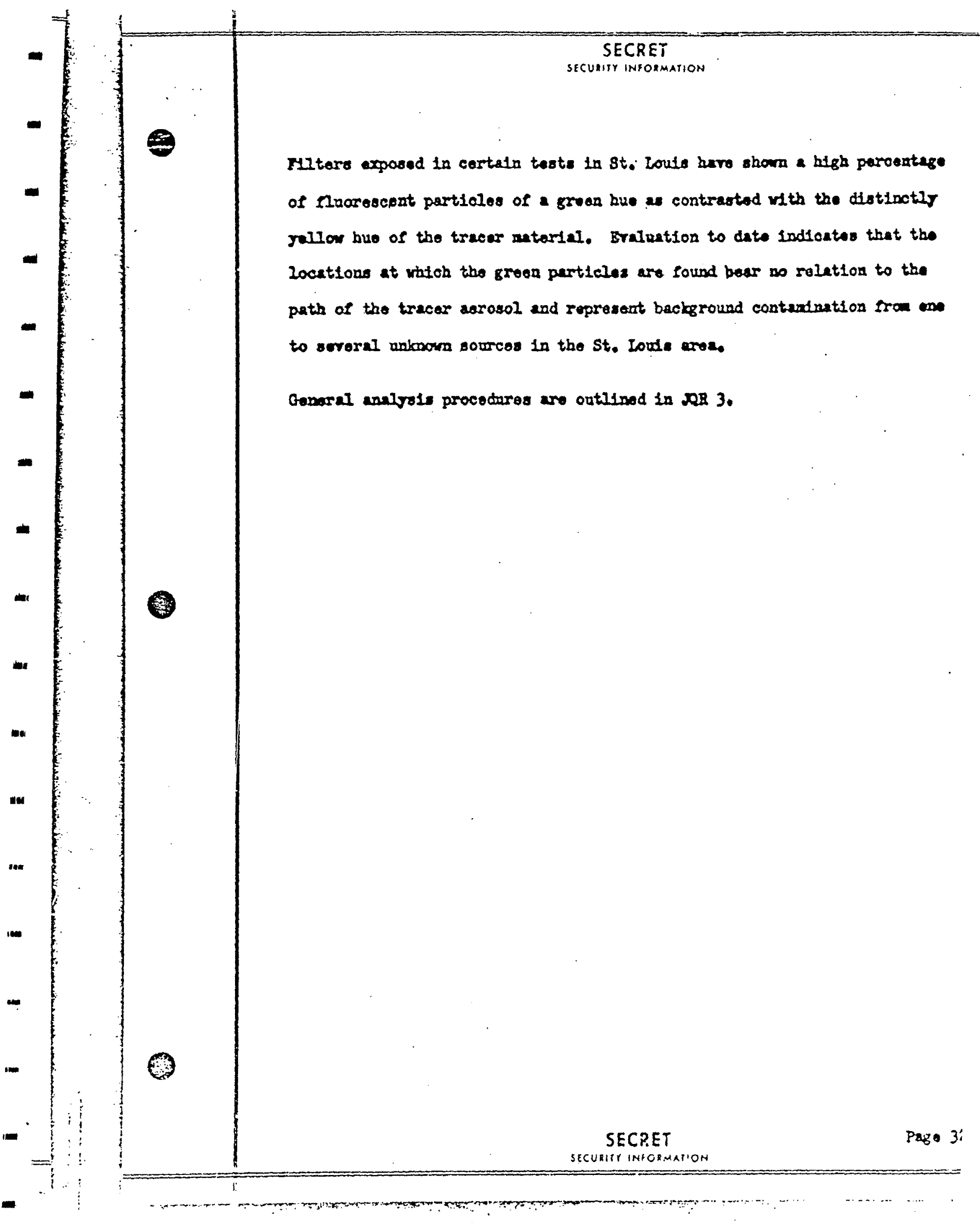



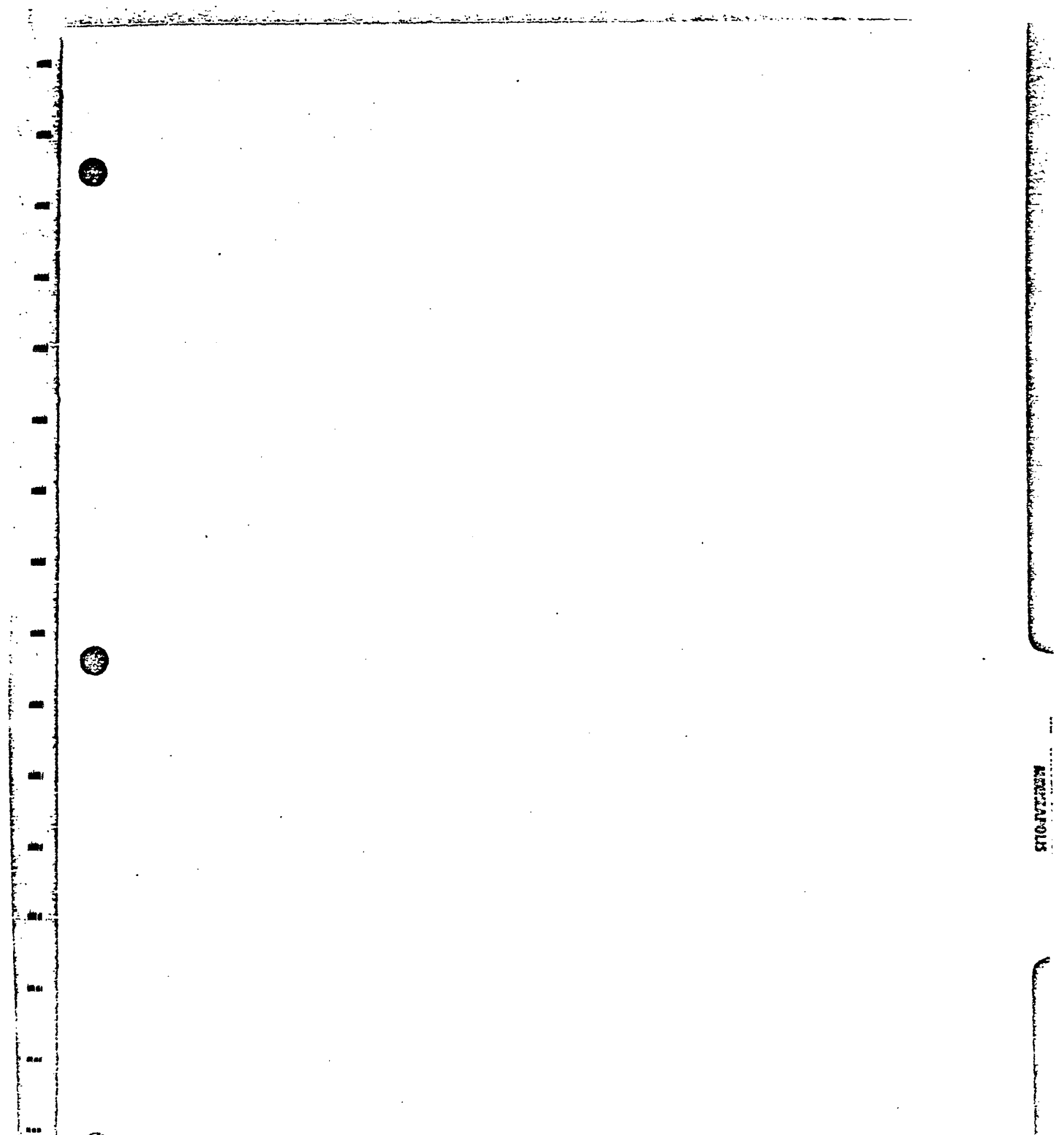

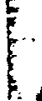

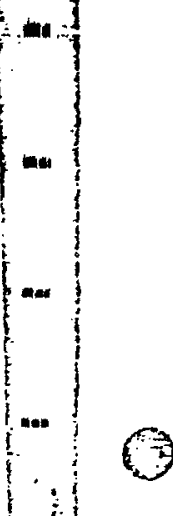

?a:

$=3$

ax 


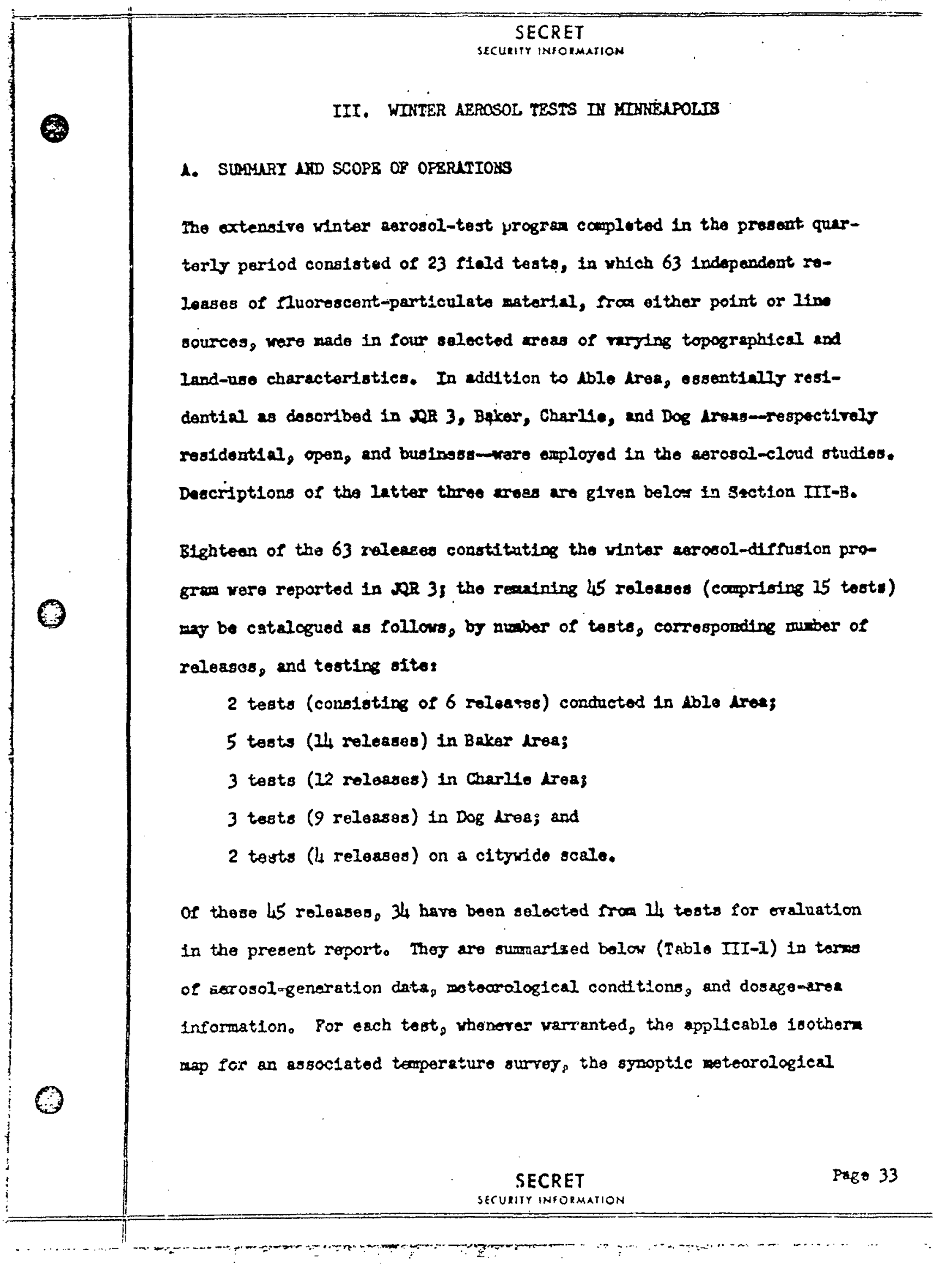


sumery, St. Cloud raob sounding, wresonde graphe, edfustod dosage-area relationships, loodosage charte, tixo-resolution graphs, and butldine suraarles are giren in the approprieto appendix dorotod to the presentetion of date for all teste conducted in a giren aron (ace Appendices l-B). Braluation of the compleantery tamarature survers, in terws of $D_{1}$,

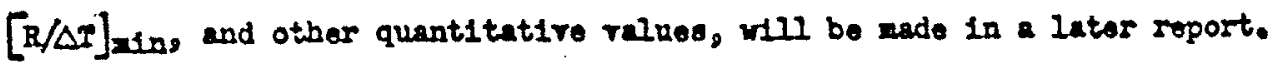
Onlike LR 3, which deccribed only polnt-sopres relesses in one aree (Lble), the present report oraluntes 11 ltoe-source roleases, as well as 23 politsource reloases from a rohiclo-mounted blower disperser." The length of

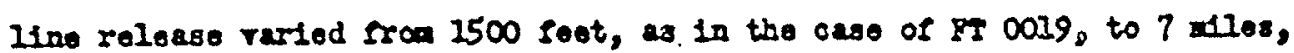
28 in the case of the c1tywlde test PT 0023. Hot orid was Cllnton School used for studiey of aerosol-clond fonotration, 28 in lble test $\mathrm{II}$ 0014, but floneer Ball, a dormitory on the campus of the Undrerolty of yinsesote

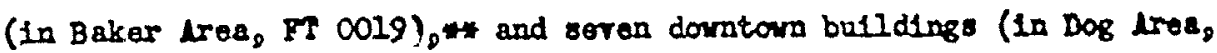

thot 1ncluded are FT: 0016 and $\infty 16 b_{n}$ which waro made frea a roofo courted disperser, as vere the four releases (FT's $0009 b_{0}$, $010 \mathrm{a}_{8}, 0011 \mathrm{a}_{\mathrm{g}}$ and CoIlb) reported in JQR 3.

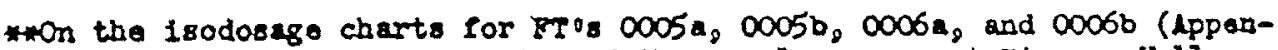
dix 3) there is no indication of the sampler array at Flonear Hall, slace the building was not in the path of the prevaling wind direction and bence of the aerosol cloud. 
FI's 0015,0016 , and 0017 ) varo 2180 anploged. In adaltion, rool-located saxplare were arrayd on 20 botildings, in the four line-souree reloases of Tris 0022 and 0023 (Table E-I).

Ilke the tosts oraluated in the lest quarterly ropart, those described in tho present vere conductod at might and included prodern reloeses (II's 0017 and .0027$)$. Samplar-array proosctures for these testo vero oseontially unchanged from those regartad in DR 3. For exweplo, smolers in oach of the downtom baildings, as in Clinton School and salocted rosidmees (NR 3), ware placod at different helghte, sowo with holders axtending beyond the windows for moasuring rertical attanation of the aerosol cloud, othere completely inside for masuring cloud penotration, and including those wth

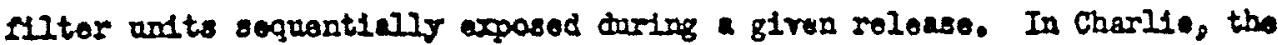
open ares used as atto for on serlos of tests, enplors wero locatod on the ground, with filter holdars generally fixed to stakes at the four-foot leval. Though soreral amplars in cortain teats had to be rolocated outgldo the stake area and honoo vare plecod at the sampling-unit lovel, all und are nonotioless conoldered whts the ural classification, as outside semplers at the one to six-foot olovation. Procedures for estinatiog the fluorescent-particle count wero likentso unaltared, though sose difflcuity in arriving at a nore definito count resulted yhen molted ice or snor ergstals on the pilters exposad in the Charlle reloases caused scare particles to more to the odges of tho pilters. Doseges precented with the ognbol $y(800 \mathrm{Figs}, \mathrm{C}-3, \mathrm{C}-10, \mathrm{C}-11$, and $280 \mathrm{~B}-28$ ) should tharerore gardad as conserpative los velues. 


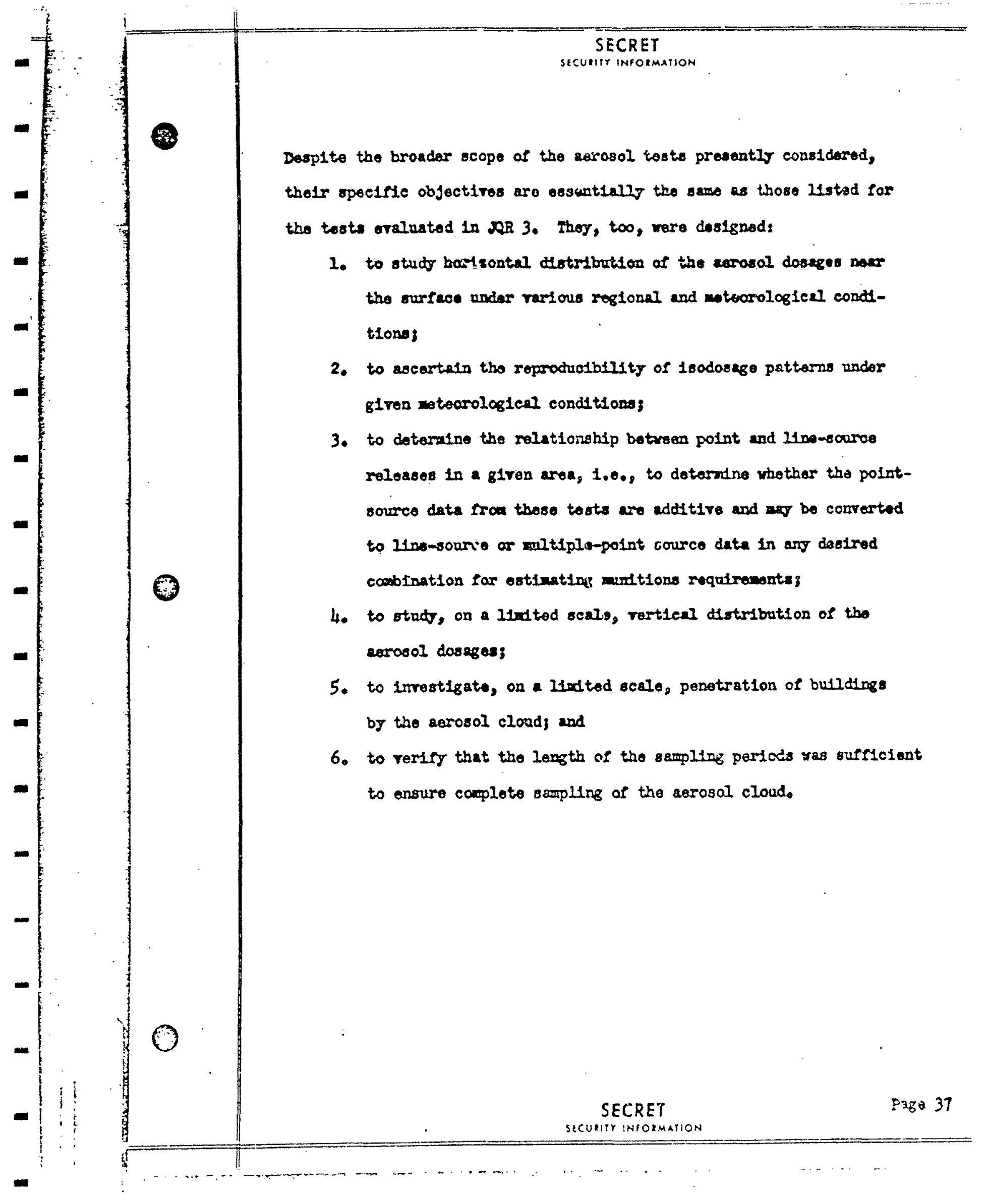




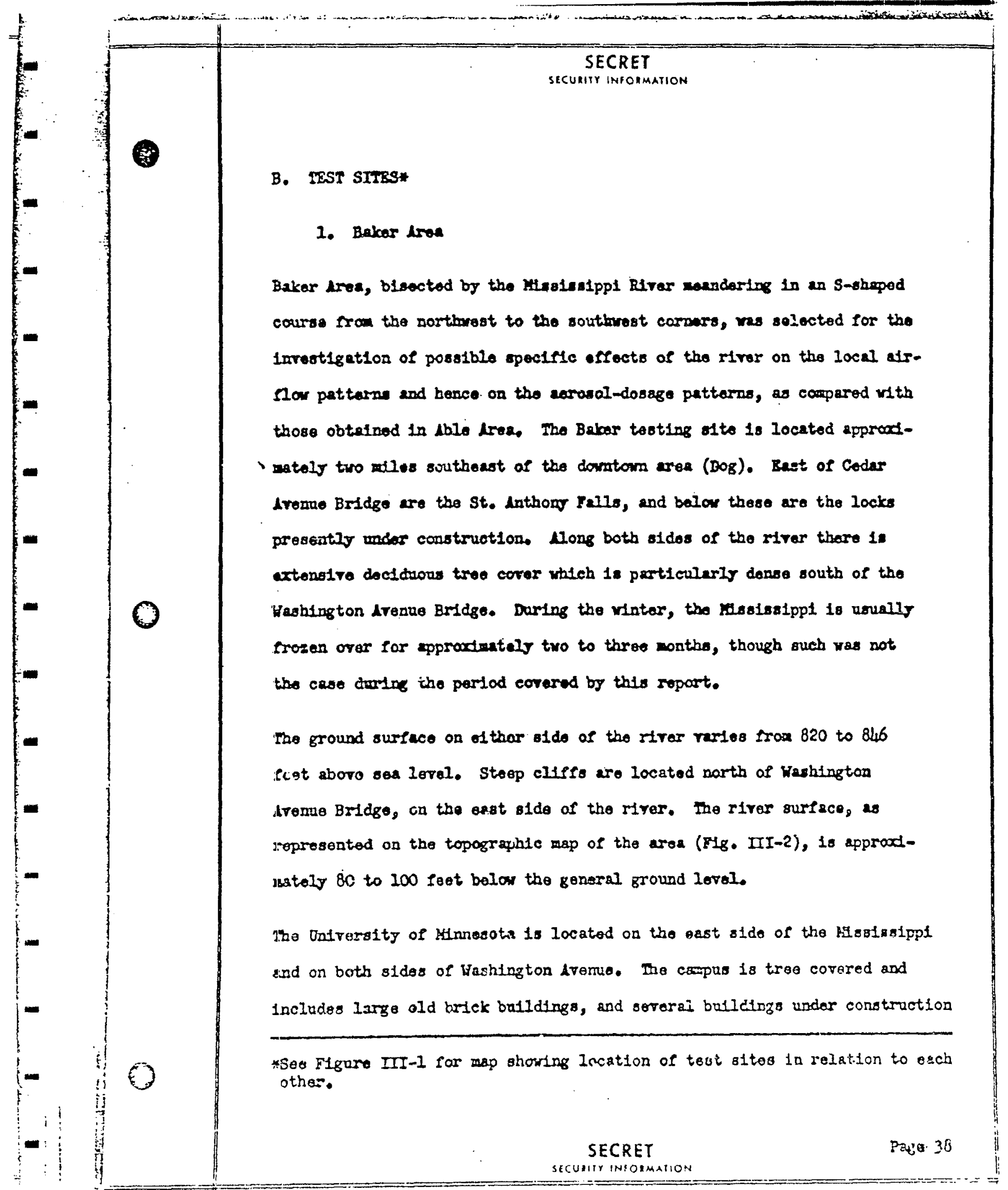




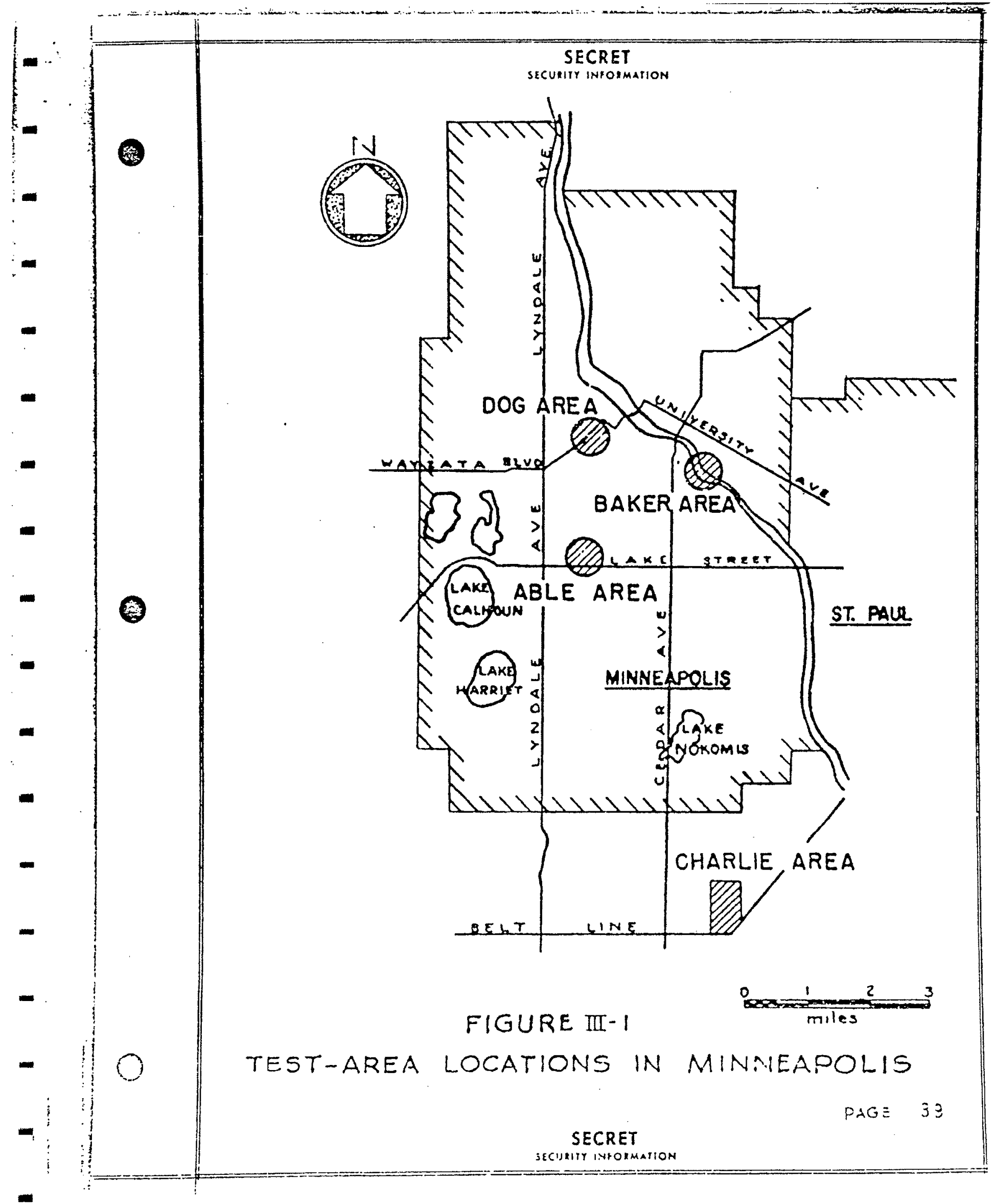




\section{SECRET}

SECUIIYY INFORMATION

In the soutbern soction. The central boating plant 18 located on the river. Onir the anror buildins ero als conditioned and equippod vith stoel-sash cascosant vindars; doublo-bung, rocden-saub windors aro gonerelly found in the ranetning butldinge.

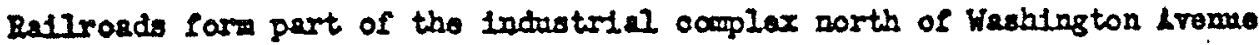
and wost of the rlrer, Only the Great Sorthera Ifro, ruming north of the Unirorsity area, is depressed benoath the street and the genoral ground surface. In addition, the Industriel complex consiste of call docks, tank farms stoel and brick warebouses, stoel will butldings, and cruin eleratar of rolinfareed conoroto (I18. III-3).

Begrond the Indastrial structures aro resfdences and comereial buildings. The latter are genorally tro storles high, of brick construction, and are located along the soln streste, prodocisantly at the intersections of poorls matntatngd sophalt rasds. The flrst neor of a comarolel building 1s typicrily loged for bueloess cotifities, while the second foor is

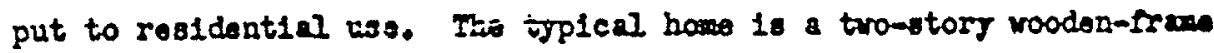
structure, epprarisately 30 rours old. Apartment boildings are usually brick structures from three to olght storles high. 


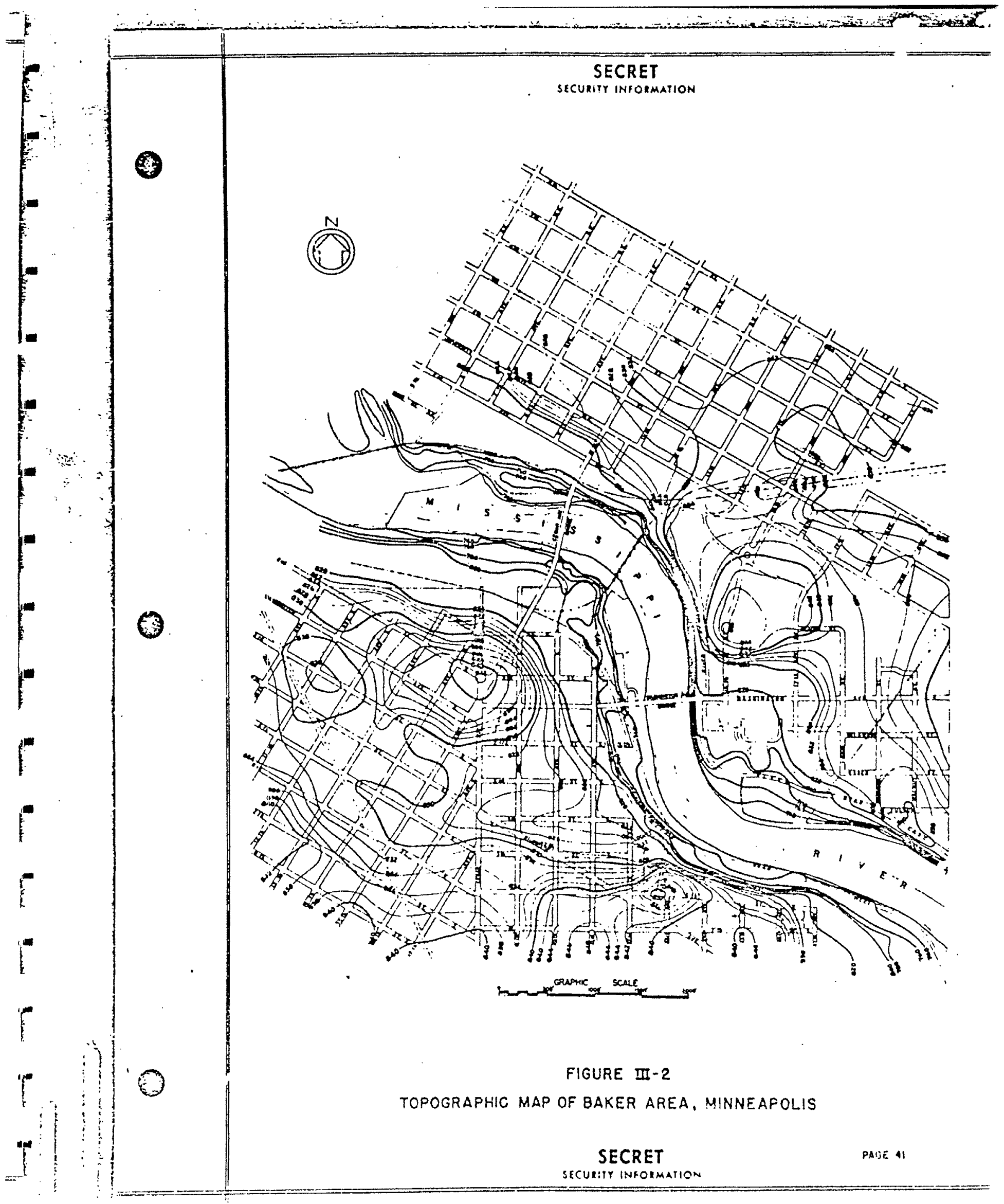




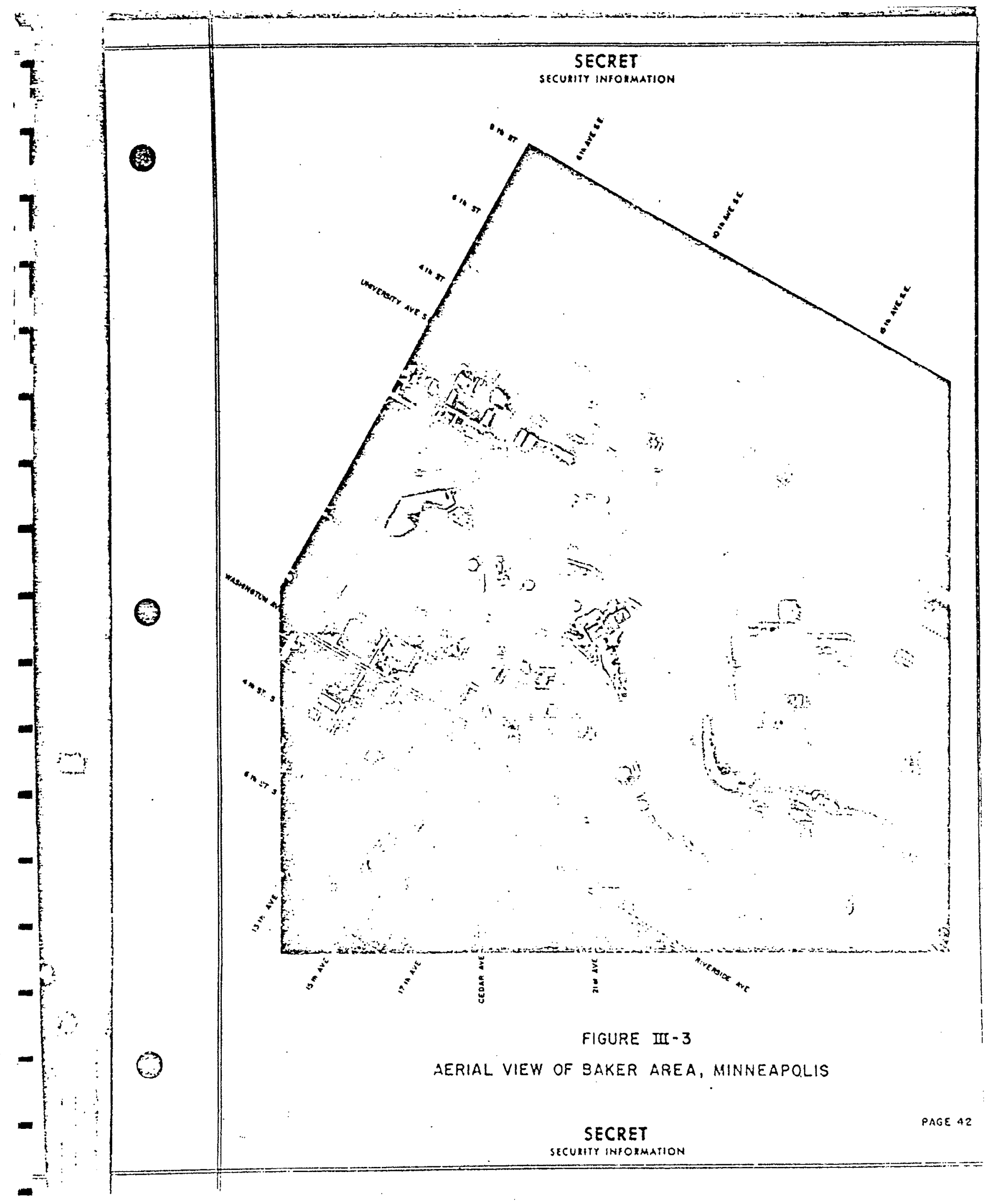


Charlis iroc was solected as a tost st to to represunt open flat torraln subfect to the save motearological influences as the adfecent batlt-up

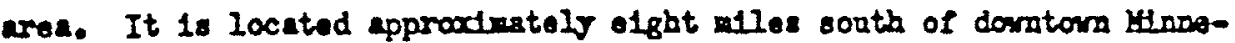
apolis, and is bounded by Eighways 5 and 100 on the south, by Thirtyfourth Arene South and Fort Snolling Mationel Comoterg on the east, by Serrentioth Stroot on the narth, and by Irenty-fourth Areme South on the west. These boundarles are the hearleat traveled raids affording access to the Wald-Chembarlate nelolpal Mrport to the northoust.

The area consists of relatively het tarrain, wh gradial rariation in ileration tron 806 to 840 saet soove sea lovel. The larest deprassions are found in the south-central partion adjointing the nowinal Belt If 1 highest elerations are found in the southroat corner. The relatiro orenmass of the torratn is further Indlatiod by the 1 crase-section line (F/8. III-4); the dorlation from the genaral lorel, olther abore or belor, is not mach greatar than two foot. Perlation in the B cross-section does not expoed 14 foot $(818-832)$.

In vintar, snor depth orer the area aroragas about one foot. The Ion spots ere scatimes filled to a depth of 10 feet or aore, whtle the rolatiroly High section in the center arerages about 10 inchos in dopth. The labe In the nortb-contral portion of the area (F/g. III-5) carmonly freeses oror during the senson. Butlding are scatterod and fex, and therofore have negligtblo offect on the afr-flos and tomporsture conditions. Grain and truck ferxiog constitutos the main astirity in Charles droa. 


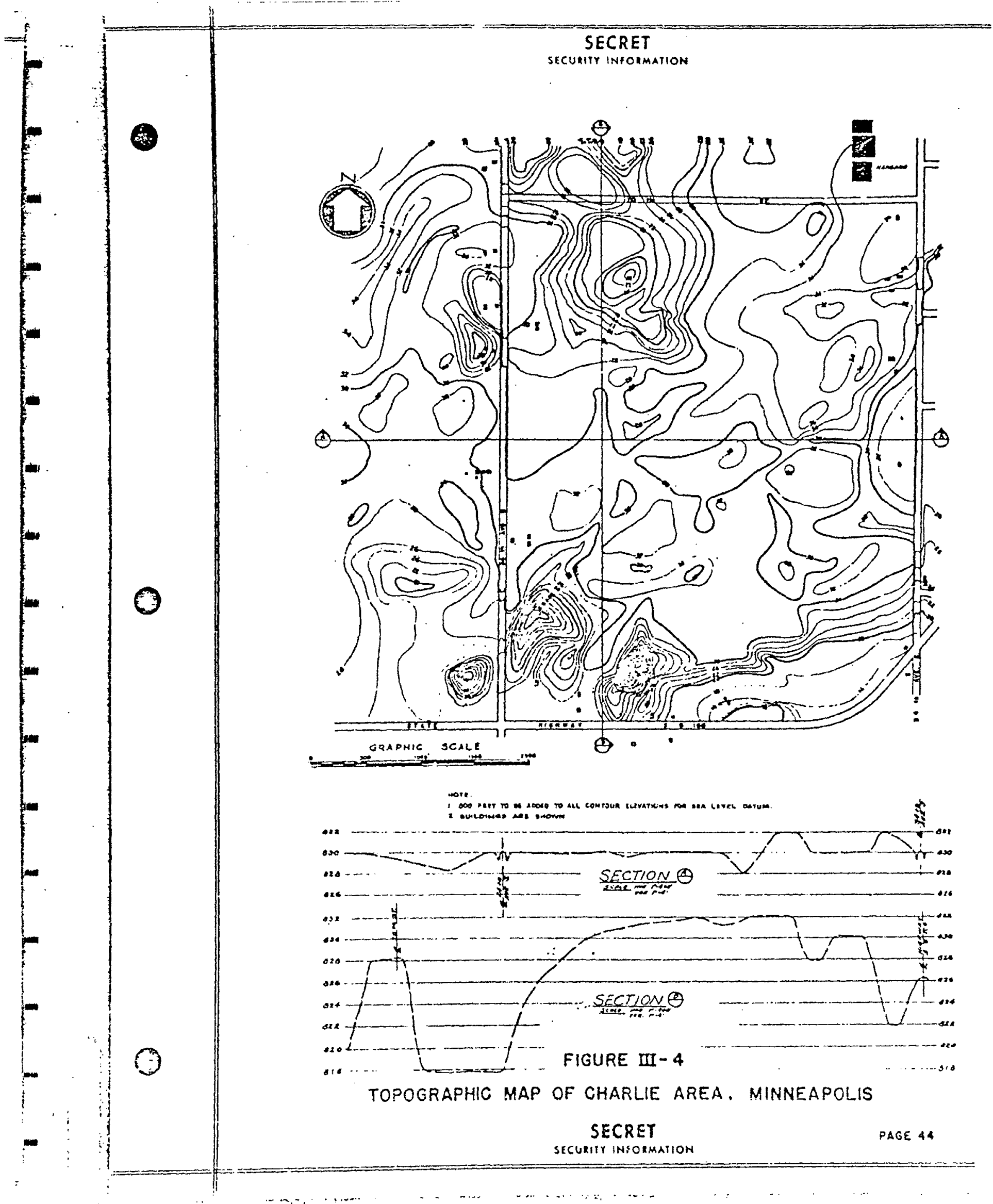




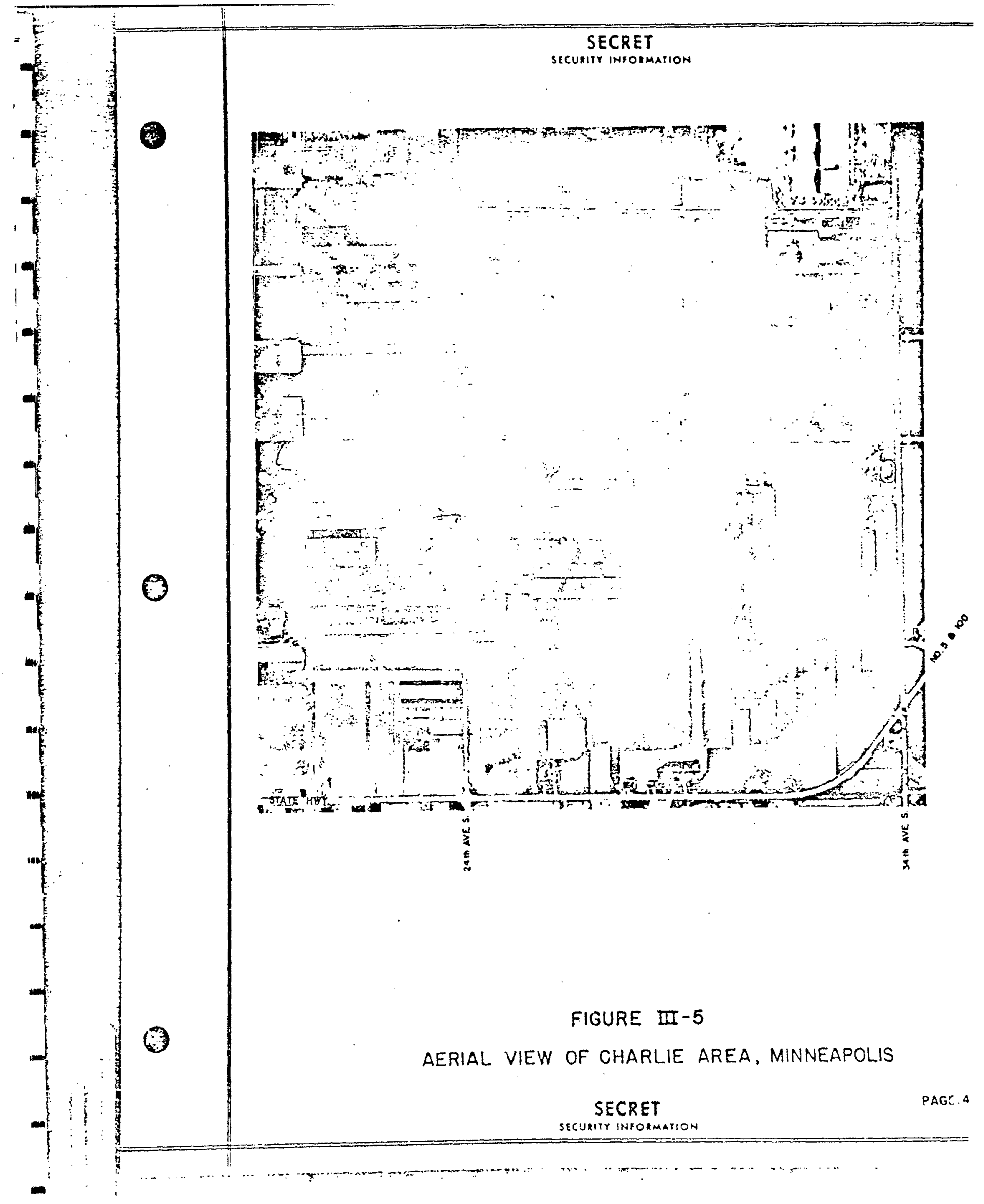




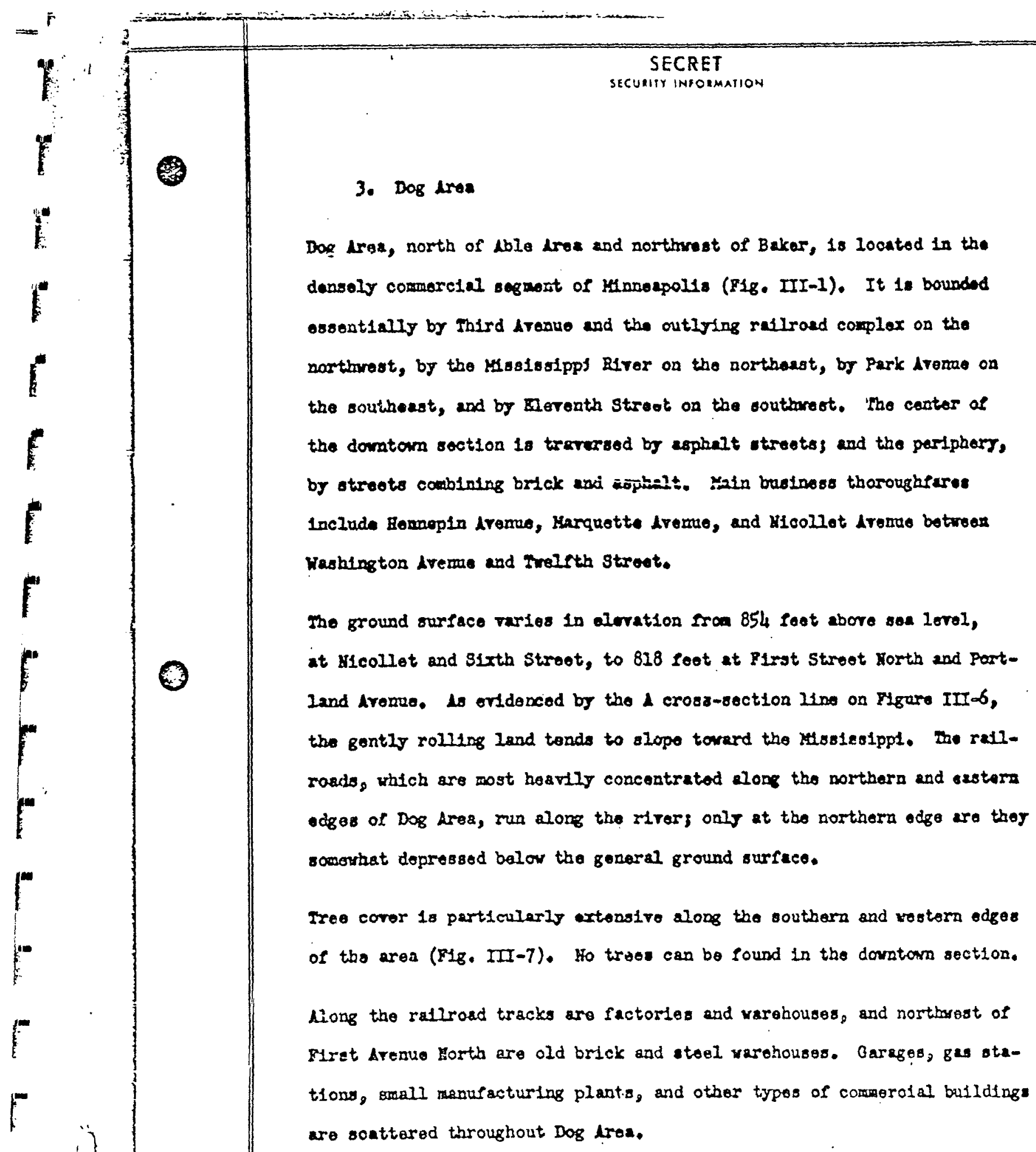




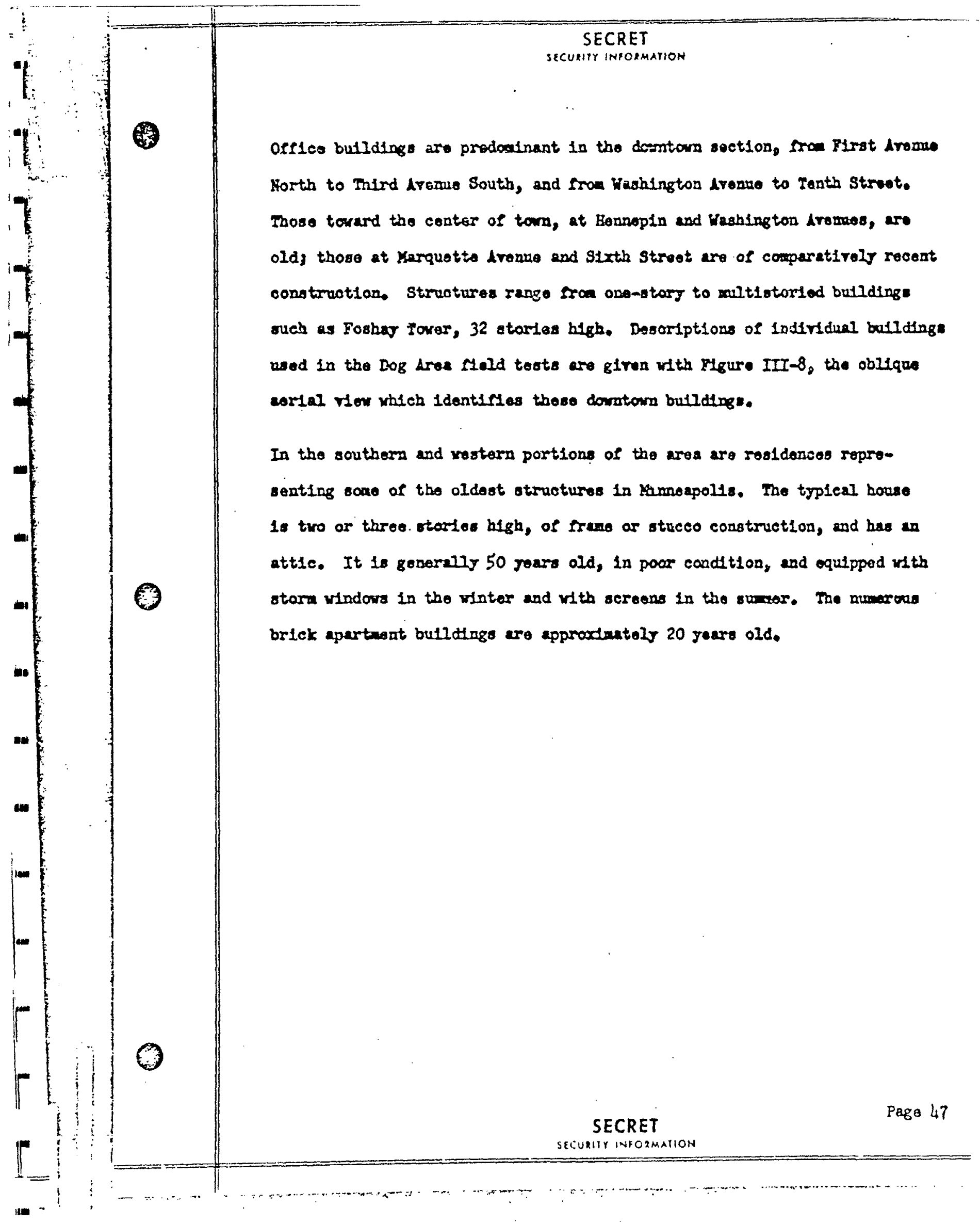




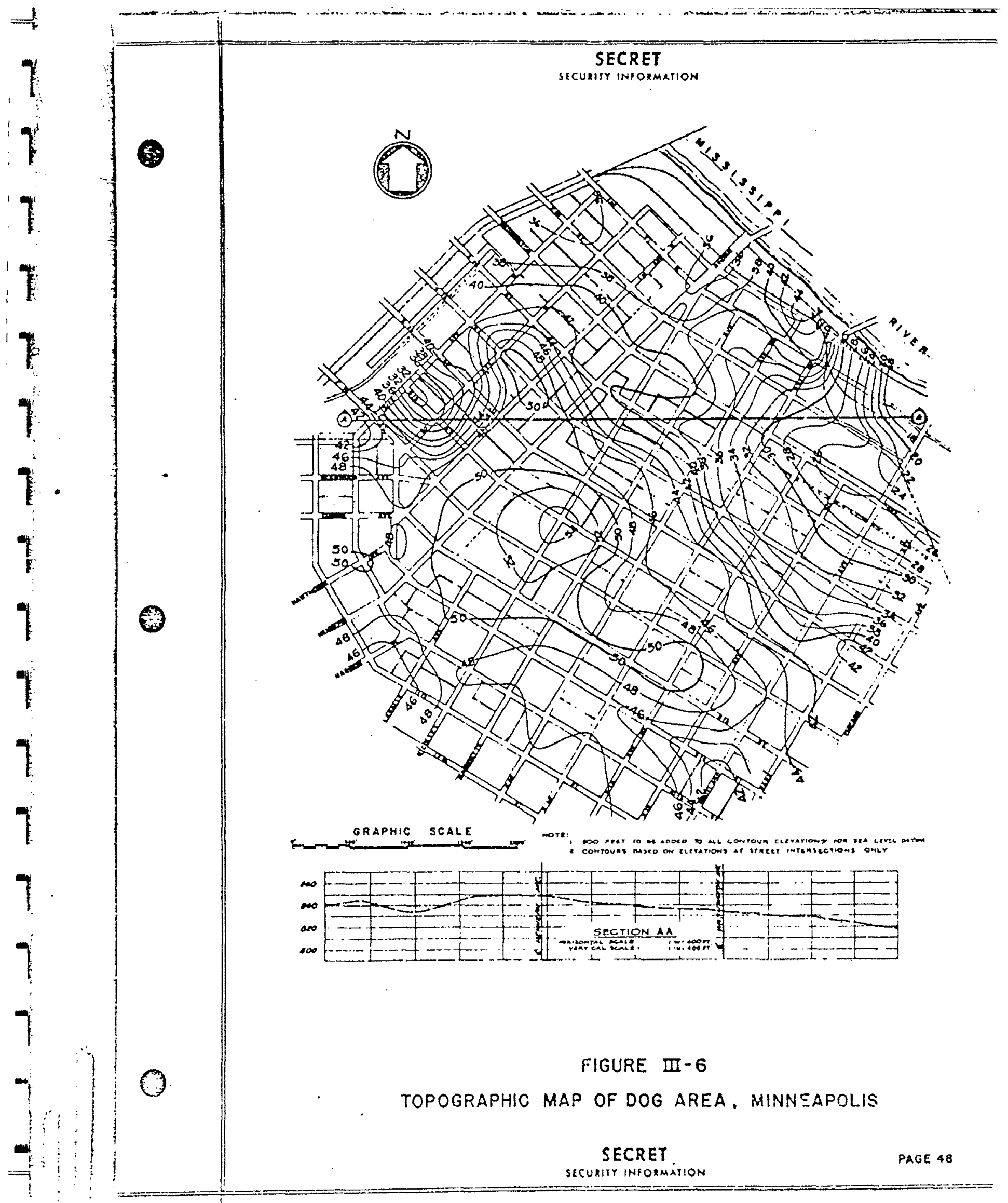




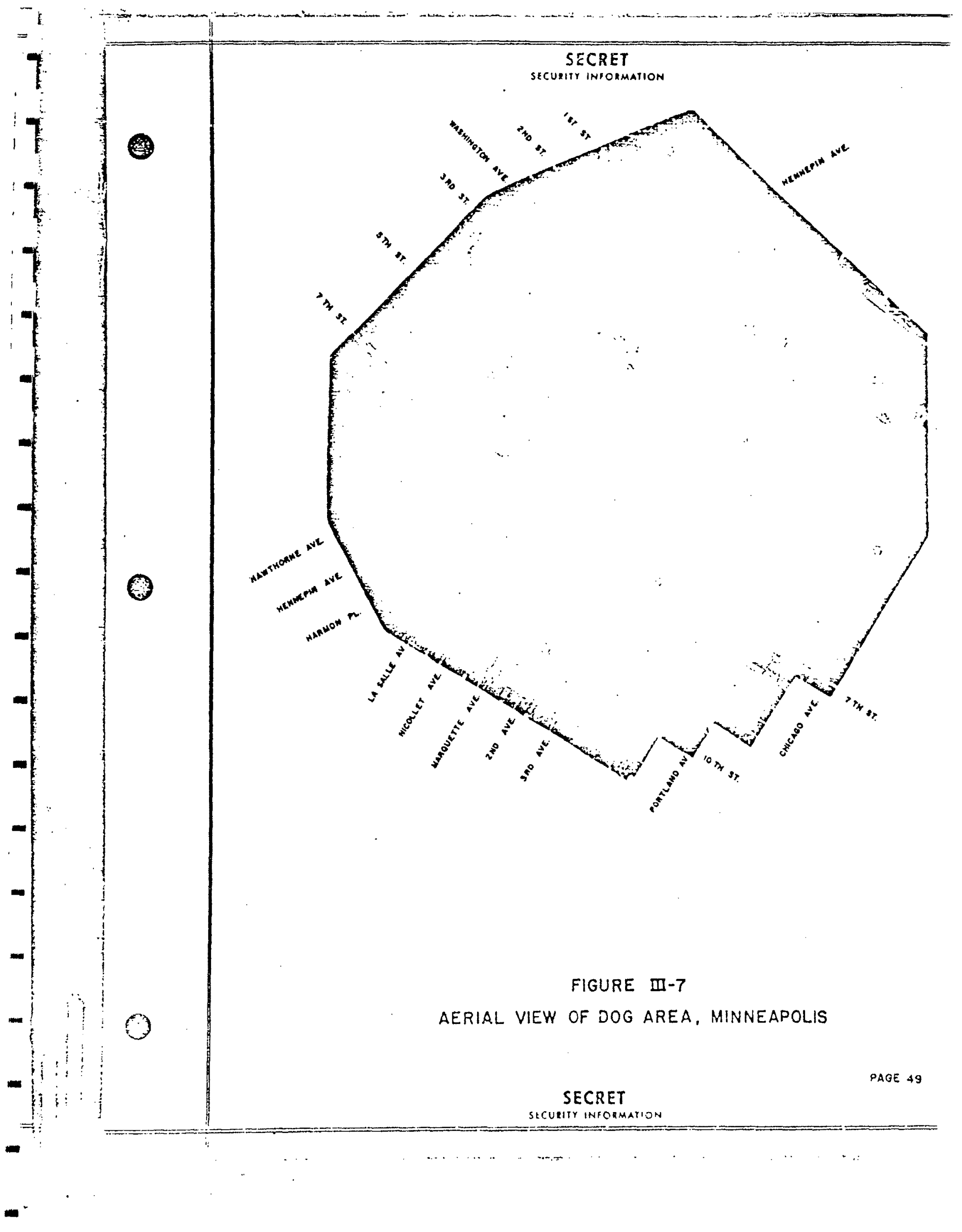




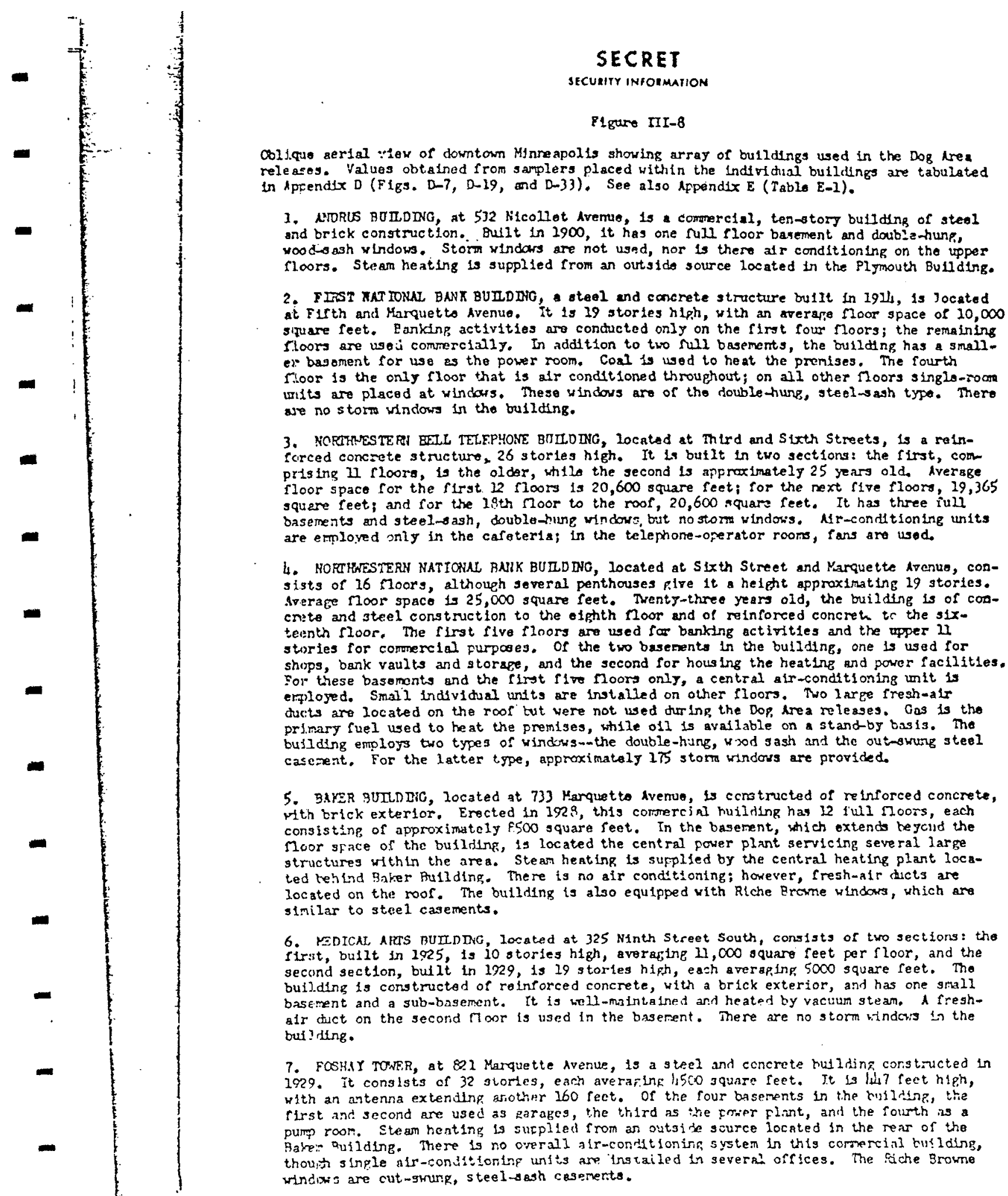

Paze 50

SECRET

SECURITY INFORMAIION 


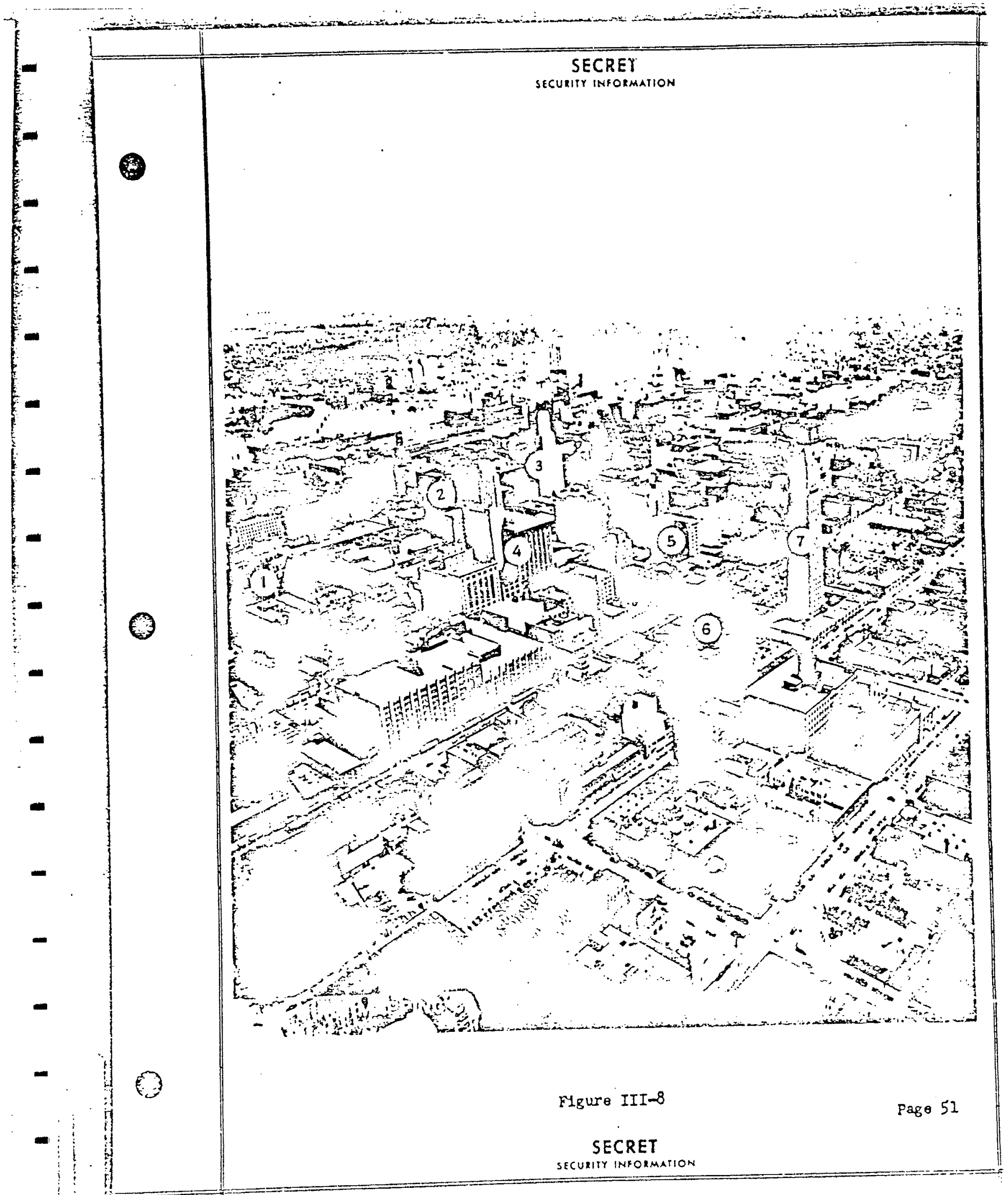




\section{SECRET}

SECURITY INFORMAIION

C. BVALJATIOK OF ABROSOL-CLOUD EBHAVIOR IN MIINBAPOLTS

\section{Dosago Lreas}

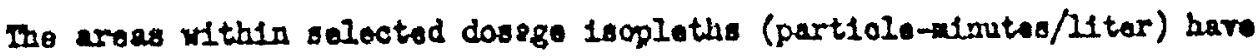
boen measured for all releuses axoopt in thase cases where the dieposition of the smplers with respoct to the cloud path ras ouch that 11 thlo confldance could be placed in the areas dorfrod from uncomplotod lsoplaths." The areas enclosed by the seleotod lapplaths here beon plottod agalnat adfusted dosege relues obtained from mitiplfeation of the dosege by uind speed and division by the muser of grams of FP watortal rolozsod. The resulting grapts of "Ldfusted Dosago-Lrea Relationships" aro prosontod in the approprlate po-tions of Appendtood $A$ through $\mathrm{Z}$.

The consiatont use of ons sot of dosage raluea in the lsoploth anelyses precludes haring the same oot of Ct.mph per gram raluos for all rolessos.

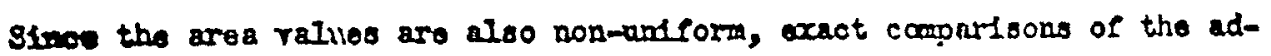
justod dosages and related areas canoot be pado botween diffarent releases. The 1eoploth ralues used are powers of 10; the aroas onclosed within these 10oplethe are 118ted in Tablo III-1, along with vind speeds, counts of FP natorial roloased, and other data portinant to the lodiflenal release. Desplt the Iack of a standard sot of Ct.aph por gram raluos, cocparison of the results of different roleases way be mado in a gonorul way. When the areas fncluded withtin the dosege 1soploths are plottad on log loz paper as runctions of the corrosponding adjusted dosages, it is found thet the

* Ralenses not included, therefore, are FTO $0012 \mathrm{a}, 0012 \mathrm{c}_{\mathrm{p}}, 012 \mathrm{~d}, 0013 \mathrm{a}$ $0013 \mathrm{~d}, 0016 \mathrm{a}, \infty 16 \mathrm{~b}, \infty 18 \mathrm{~b}$, and $0018 \mathrm{c}$. 


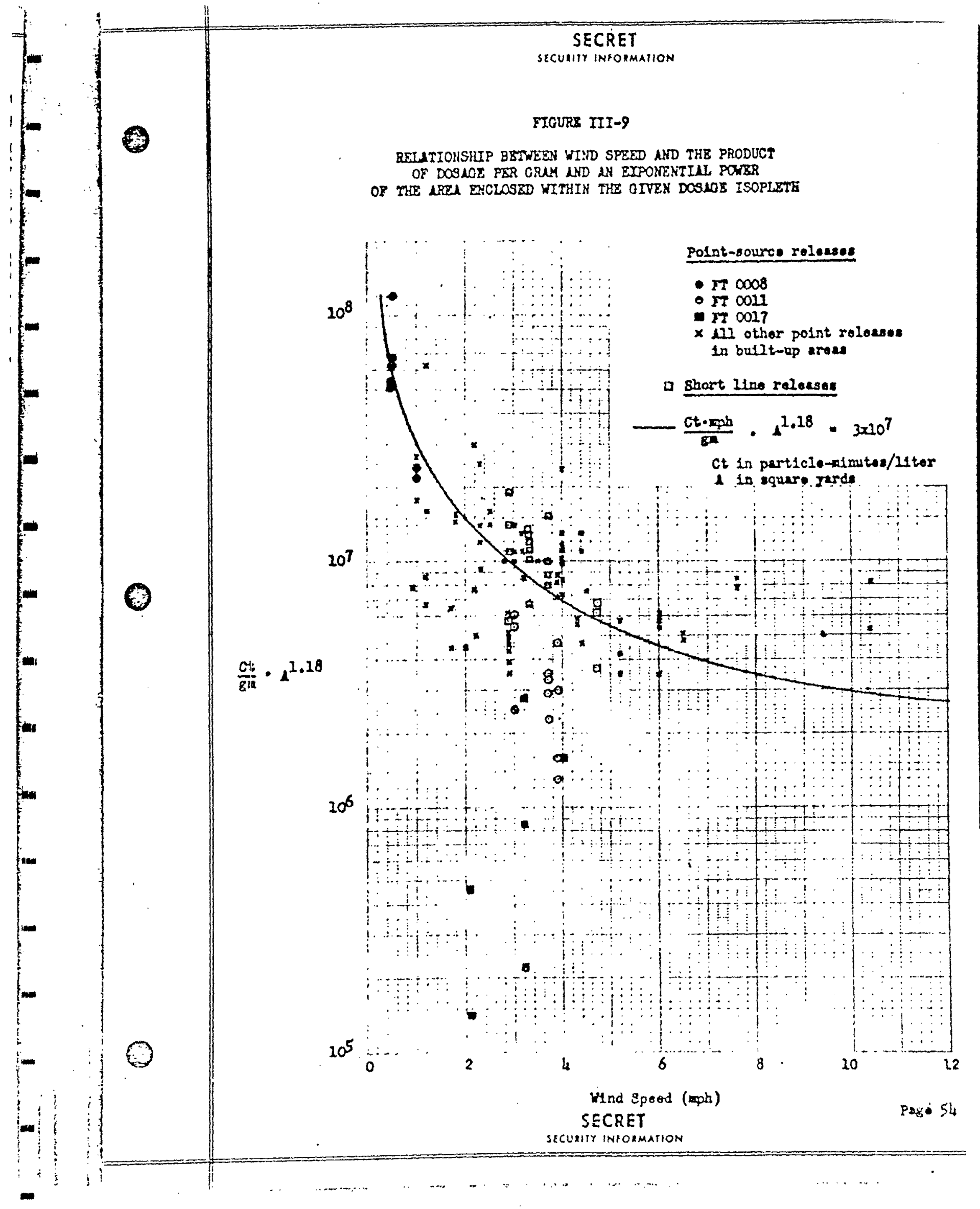




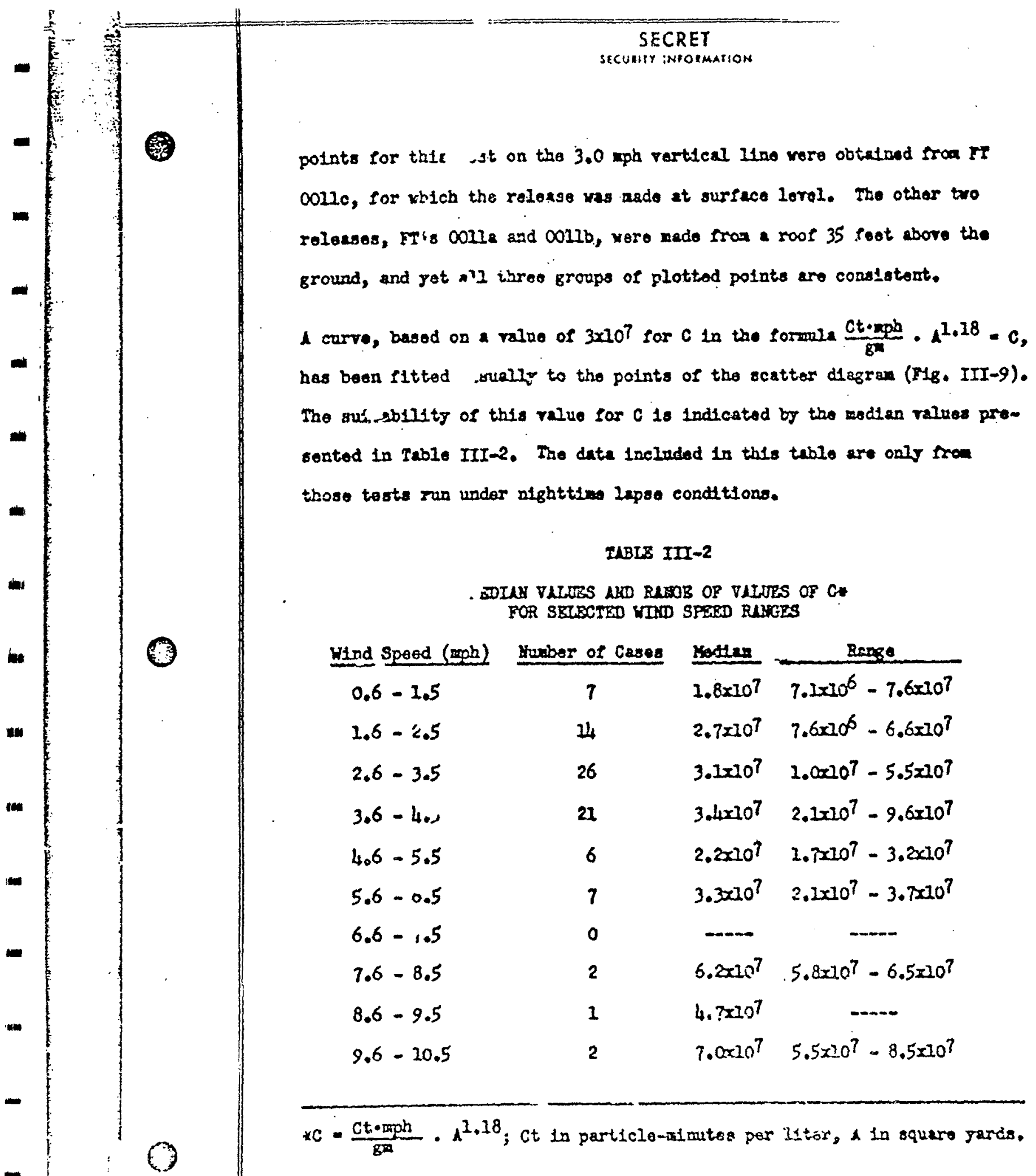


The $0.6-1.5$ mph wind speed range is the only one for which the extrame range of values of $C$ exceeds a factor of 10 . This range is also the only one below 6.5 ph for which tho modian value differs fran the rloully I1ttod value of $3 \times 107$ by more than 27 par cont.

The promise that the effects of the wind on the dosafe within a giren ares can be compensated for by multiplying the dosage par grax by the wind speed seams open to question when the wind excesda six mis. For the 1taIted number of cases in which the wind exceeded $s$ lx mph, the proportioner application of wind speed to obtain adfustod values of dosege por gran gives products which aro consistentify higher than the ererage of the products in the lower whd spoed ranges. This orldence of non-proportionalty supports the findings of tosts conducted in Sarsiburg, Bngland.* These tosts, performed with whds renging frow 5 to 10 mb, showed sam Intrease in area with an increase in wind speed.

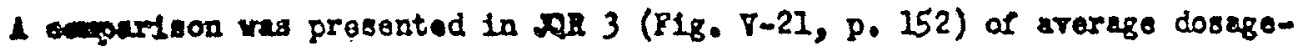
area relationshtps for daytias teats in Hinneapolis and Salfebary. A rovised presentation is given here in Figur III-10, where the Mimoapolis data have been converted to the units used in the orfolnal presentation of the Salisbury data. Recent tests show that for each grem of FP material released, $3 . c \times 10^{10}$ particles hare becane afrborne. Thus, one particlewinute per liter is equiralent to $3.3 \times 10^{-5}$ alcrogram-ainutes per litar. since the Sallobury flor rates are oxpressed in cuble auters por gute,

*C. J. M. Aarsesen, "Dlffusion of Smoke in a Bullt-up Lrez," Porton Tochnical Paper No. 193, 1950. 


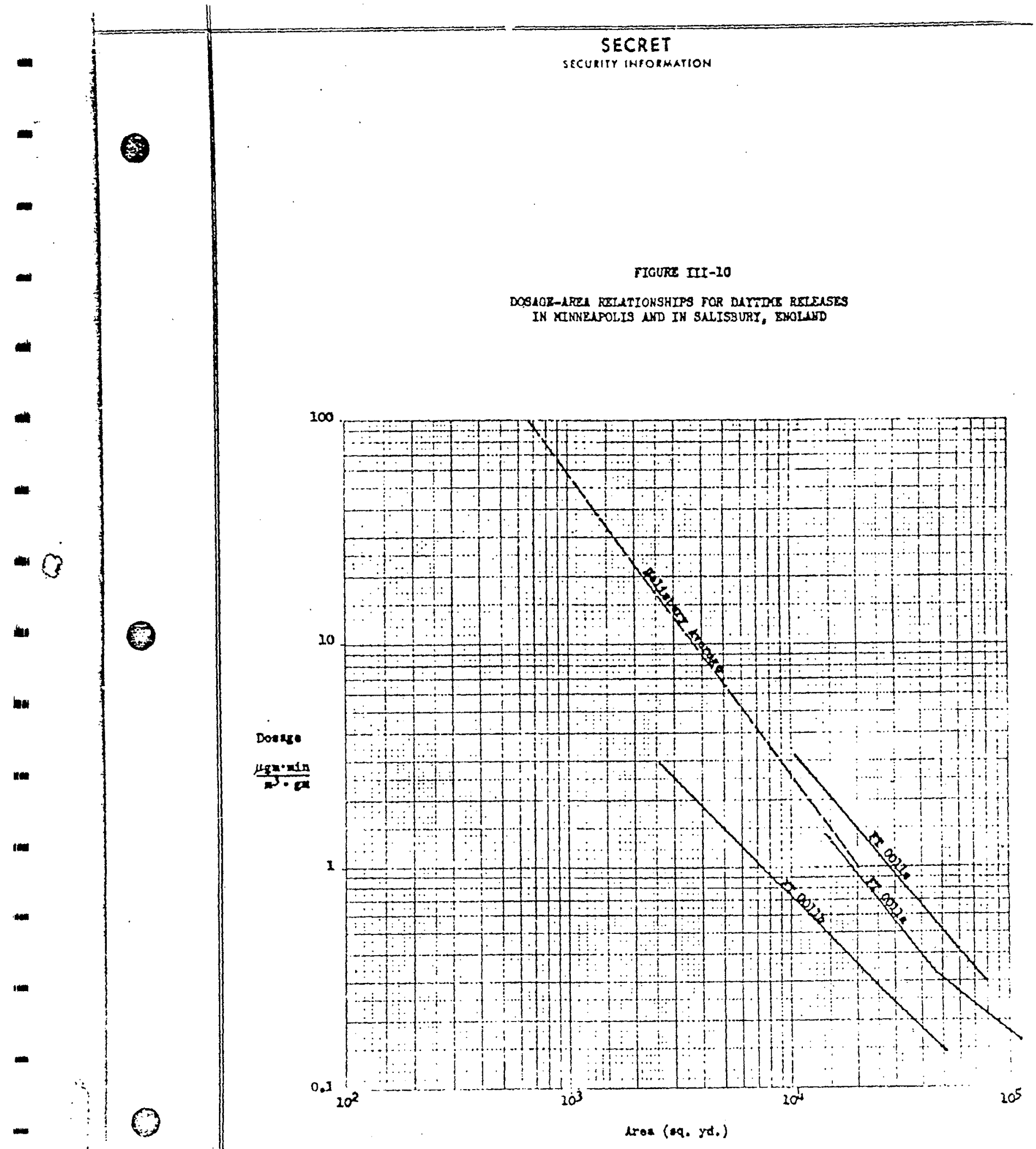

Aि 57

SECRET

SECUNITY INFORMAIION 


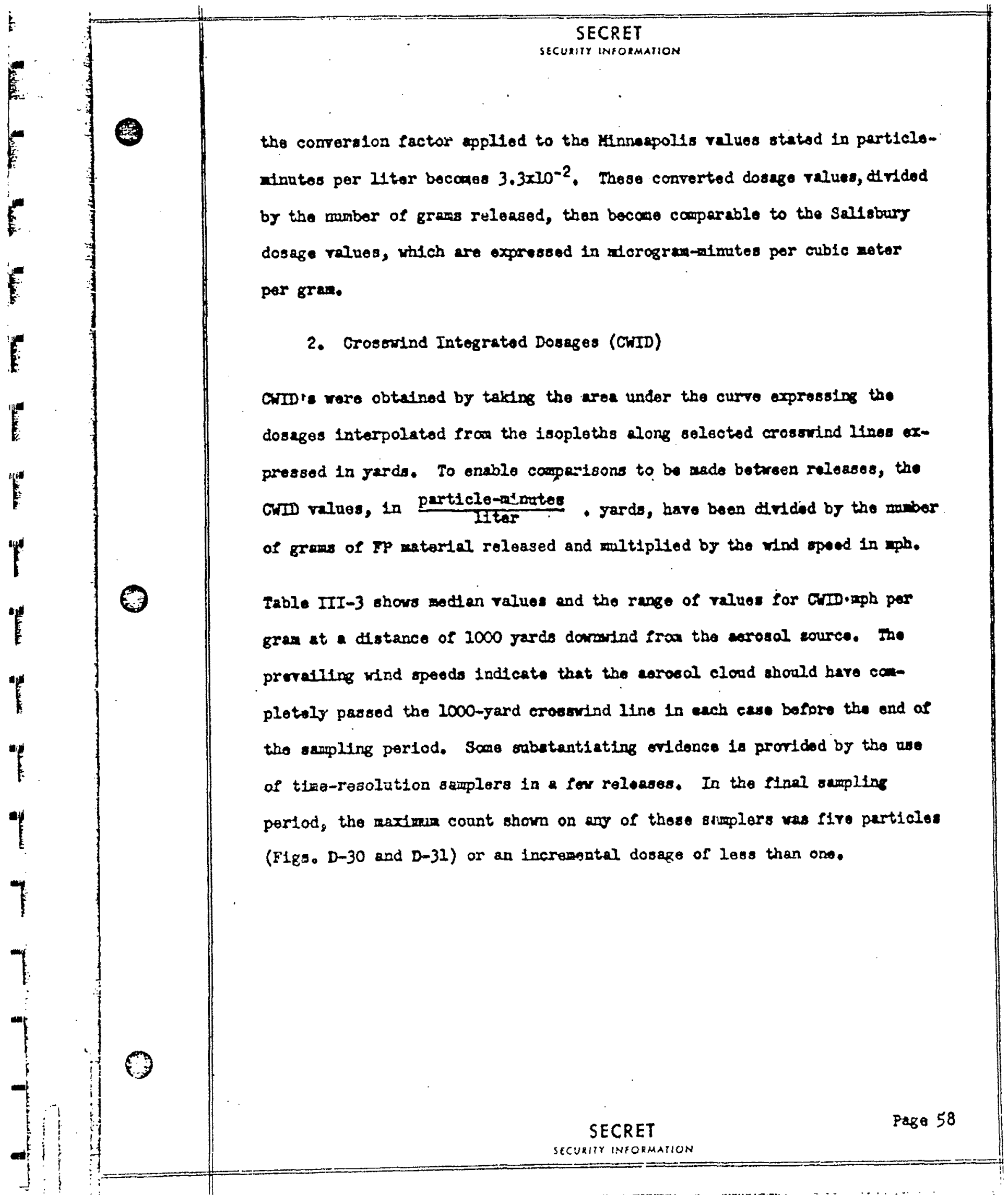




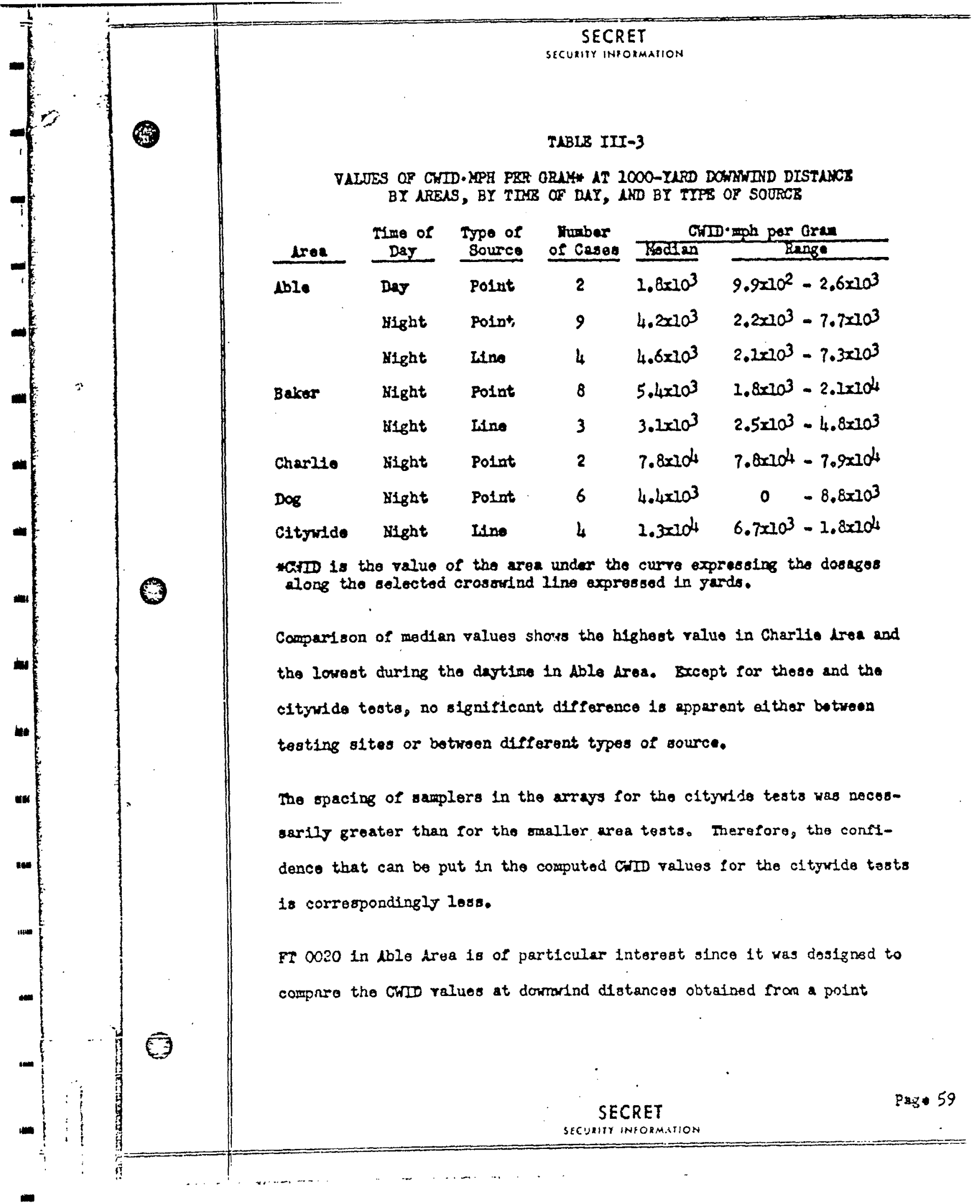


SECURIYY INFORMAYION

raloase end frow two line roloases of sufficlent lopgth to have the affect of an infinite Iins with respoct to the oxpling erray. PIgure III-il

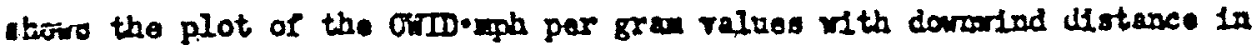
gards for the throe roleaseas. It w111 be noted that the defference belareen the ralues for the polnt roloase and ofther line reloase 10 gonarally

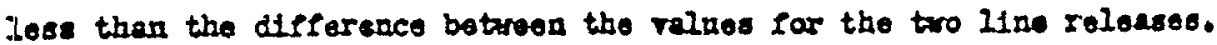

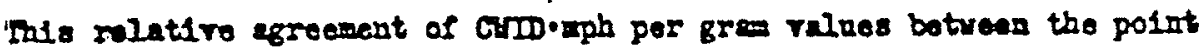

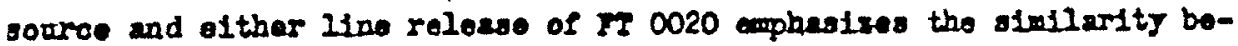
troen the results obtatiod fram the othor polat rolesses of 1.5 to 13.3 grams and the short 11 ne roloases of 14.3 to 23.5 grans. Ho signteleent diffarances were found to oxd between tho two types of releses when the erea-dosage per gran relettonshlp was inrestigatod far the short line relenses (FIs coll and 019 ). The relationebip could not be orilueted for FI 0020 since the Ins releases wore of infintto longth with respect to the saxpling array.

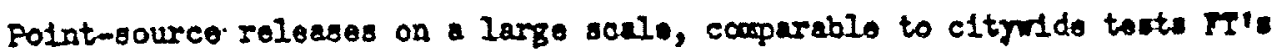
0022 and 023 , In mich 400 to 800 graws wore disporsed, way be destrablo to Inrestifate the extent of the agraaingt botareen the remalte for lino and point-source releases.

\section{Reproduciblitity of Dosage Pattern}

The genoral appearance of the dosego lsopleth pattorns is quito starler for rolesses ado from a given polnt within a period of threo or four hours, providod thero wre no arked chenges in whid or stebllity conditions. 


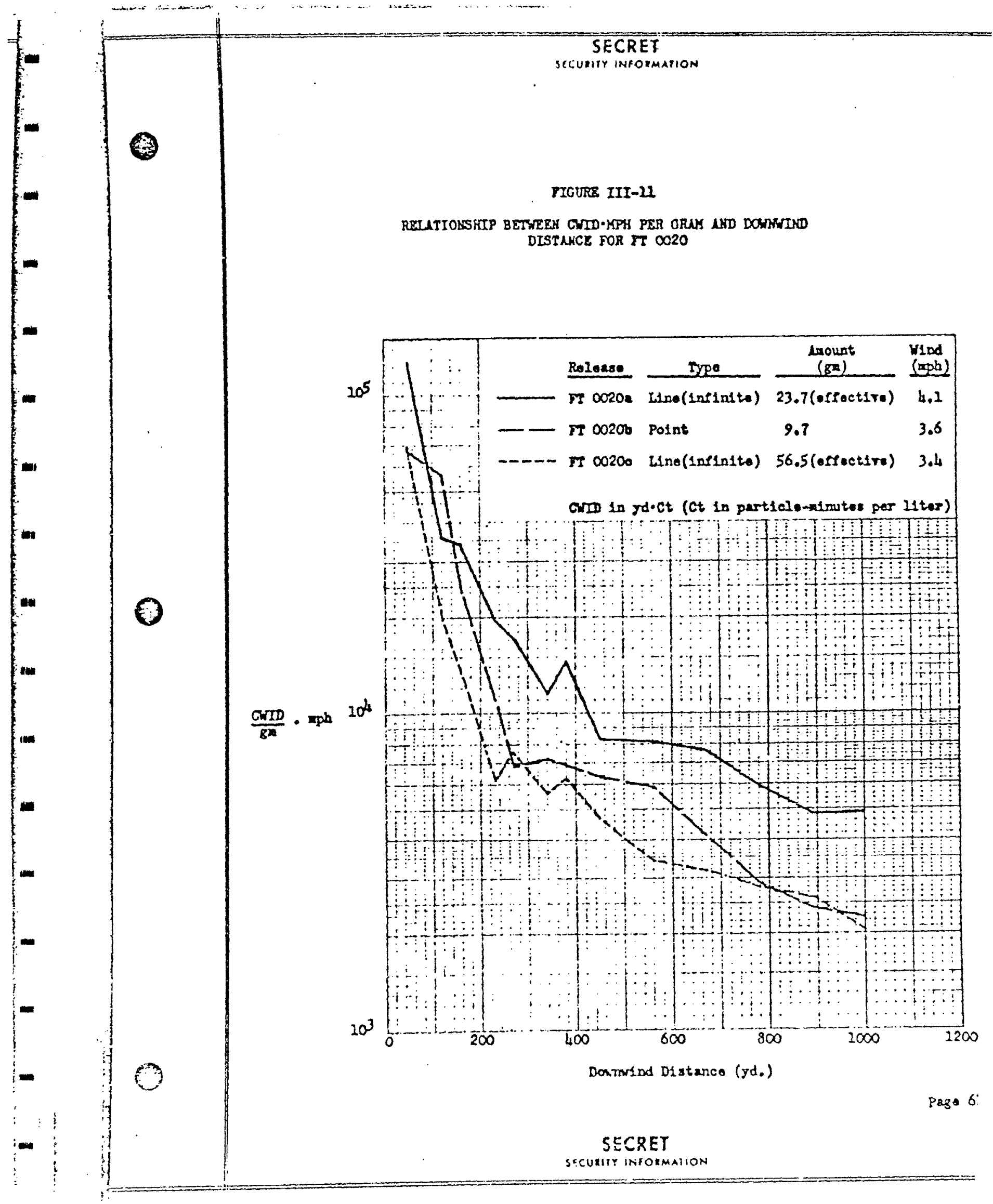




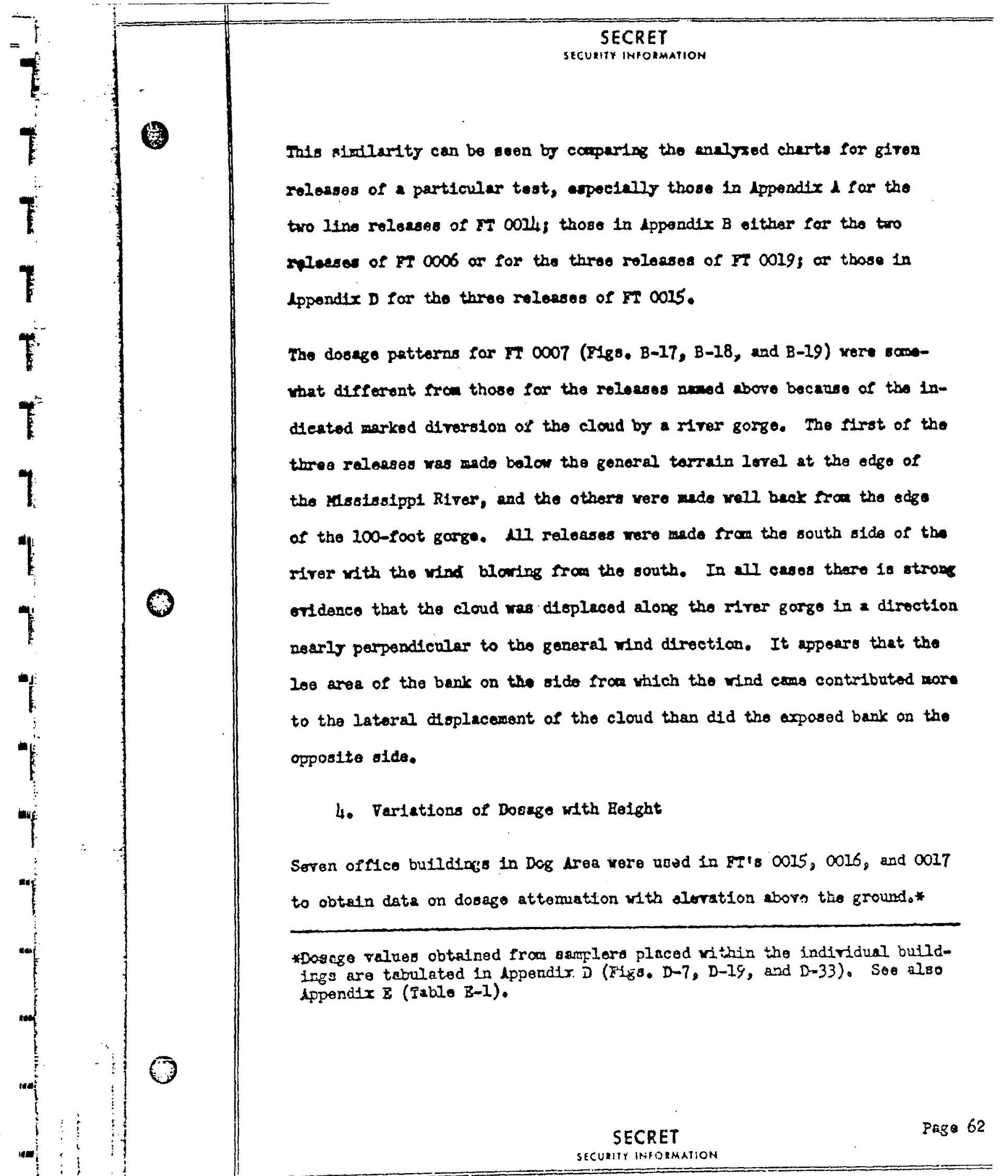




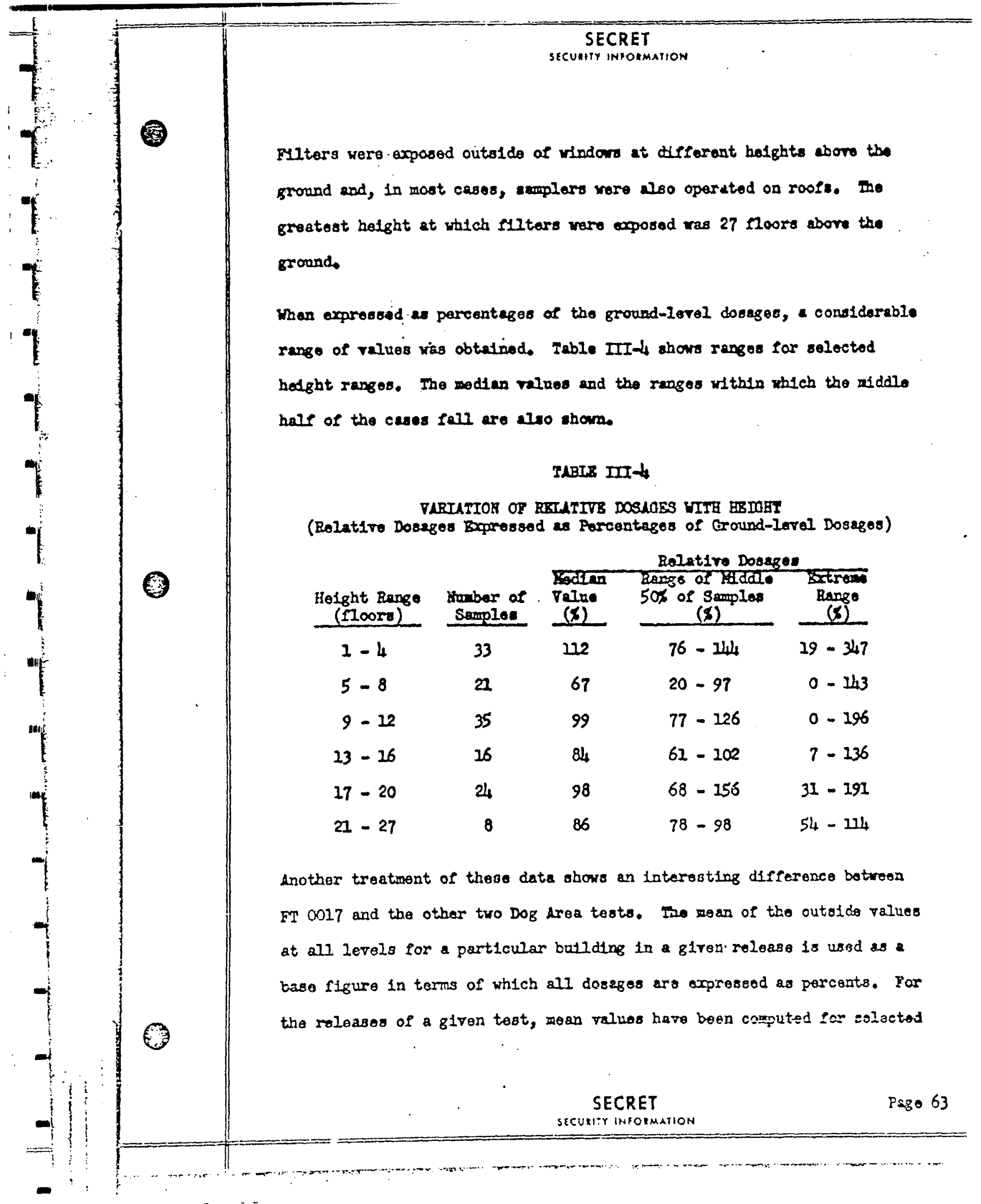




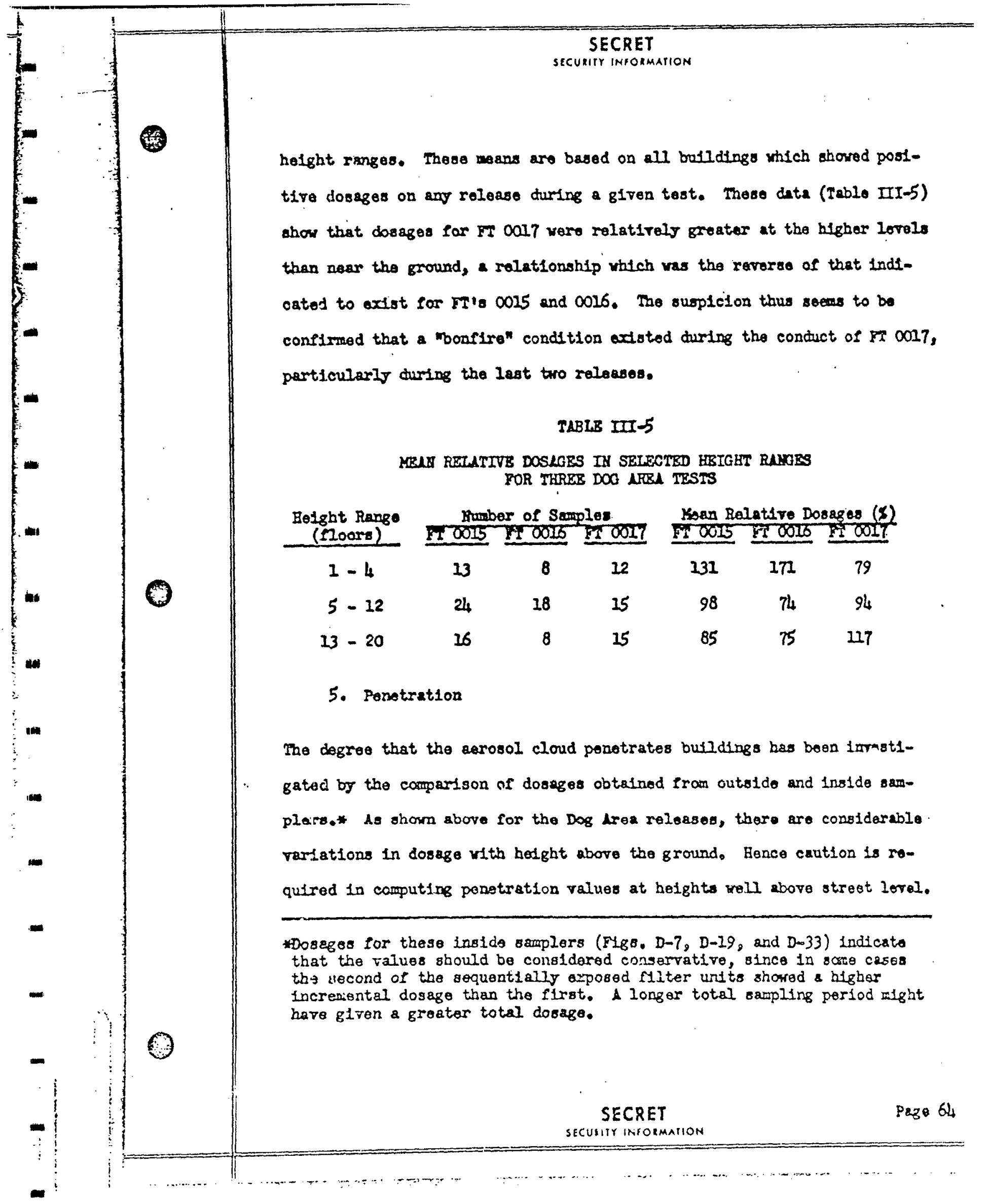




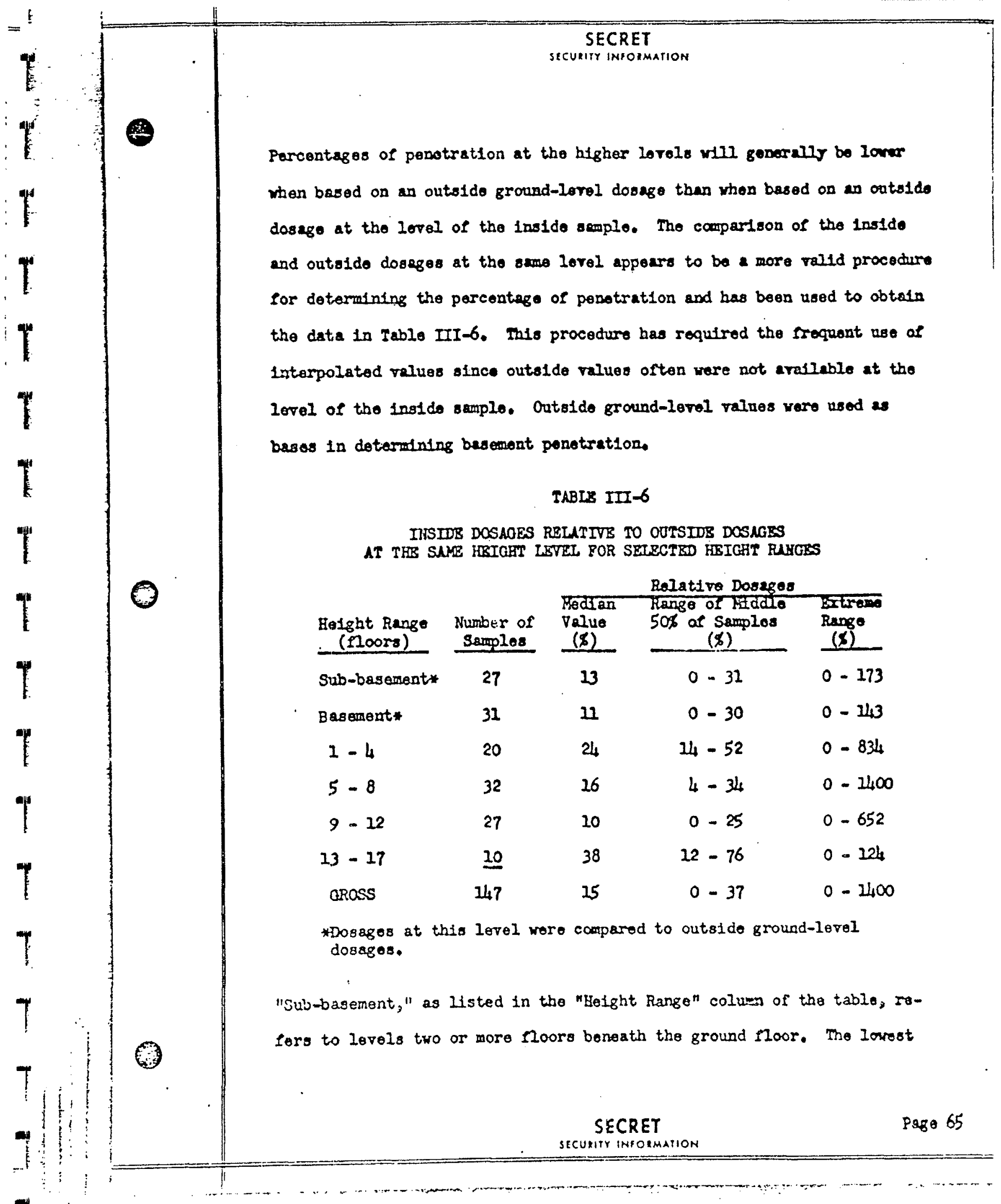




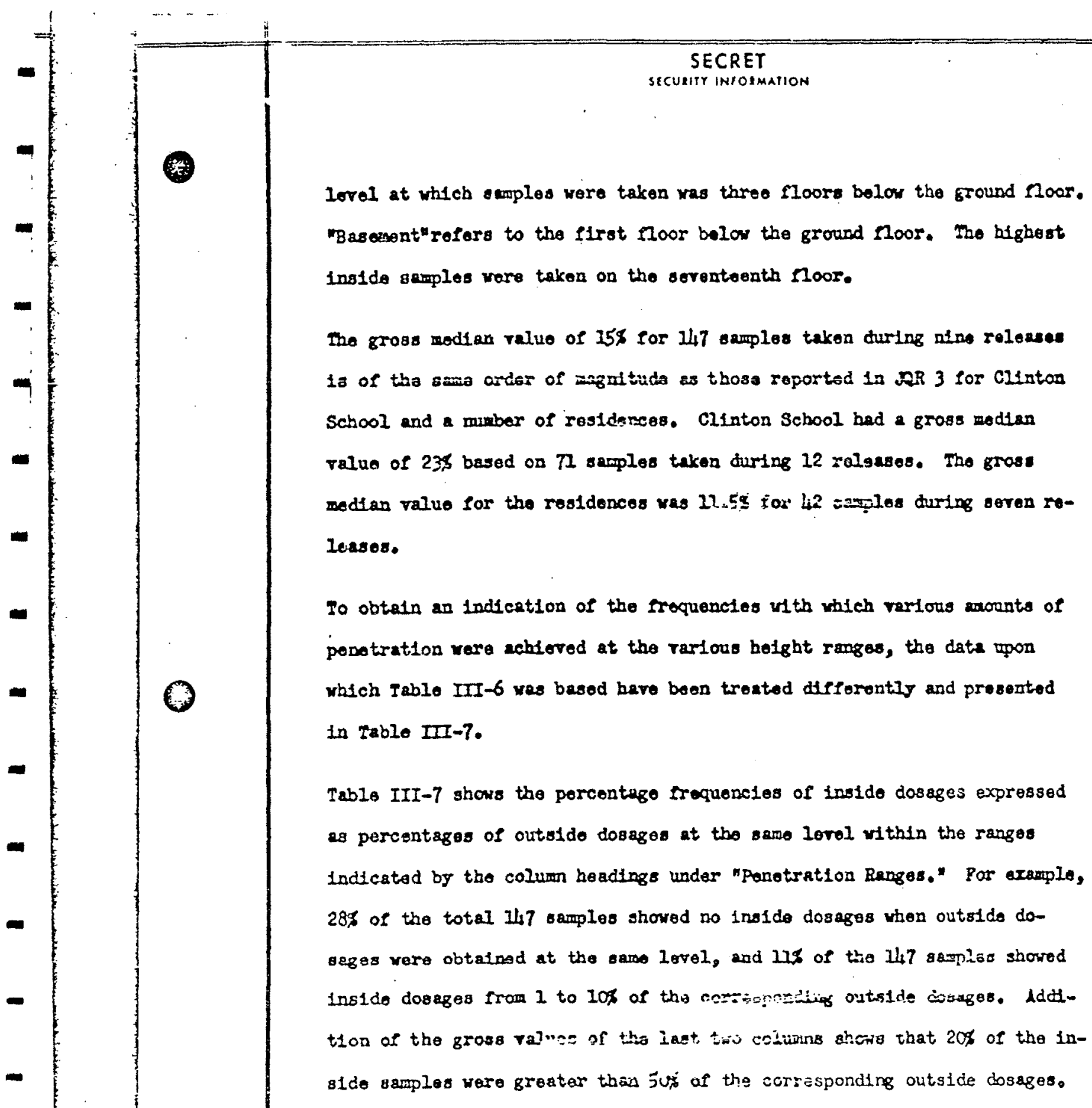




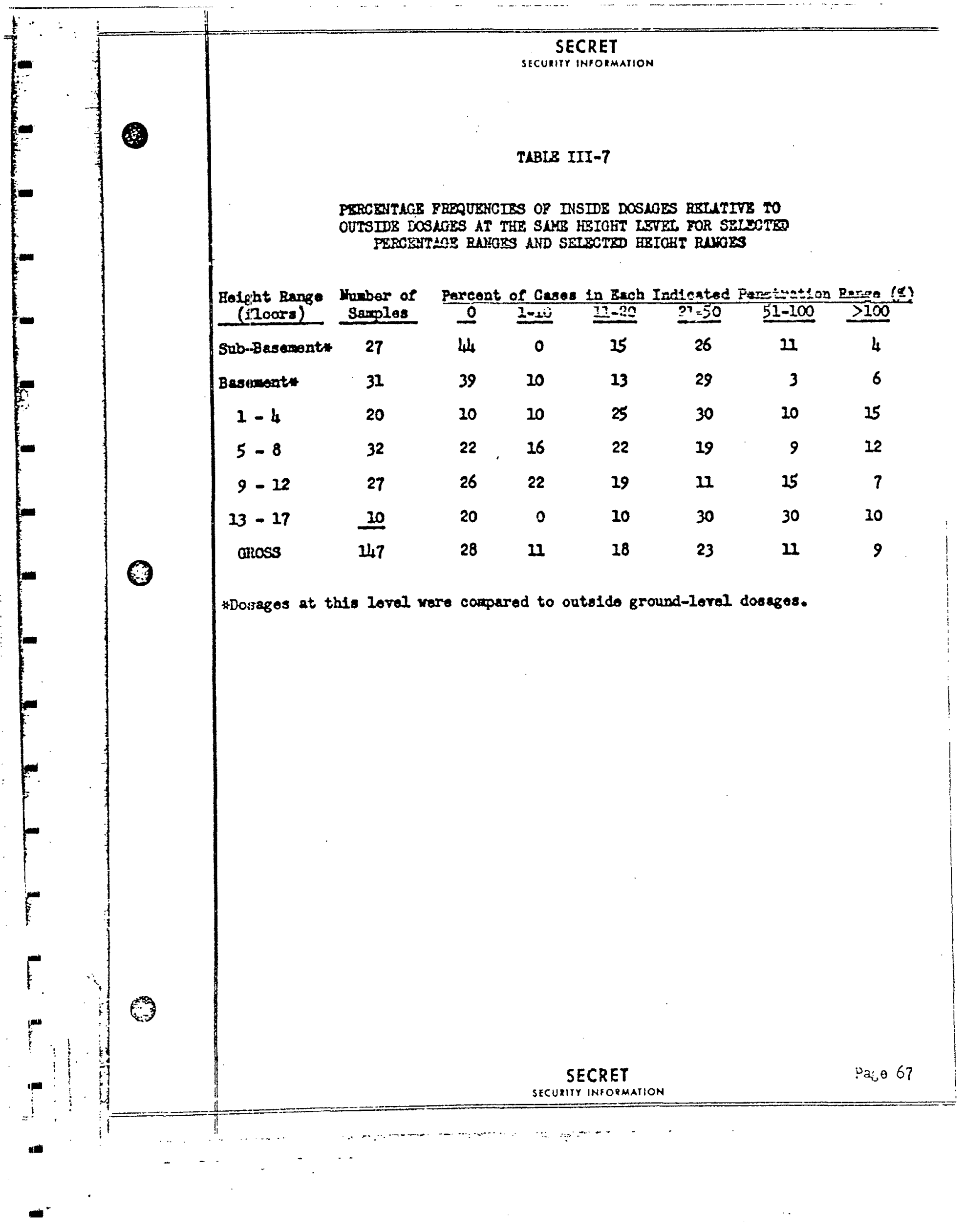




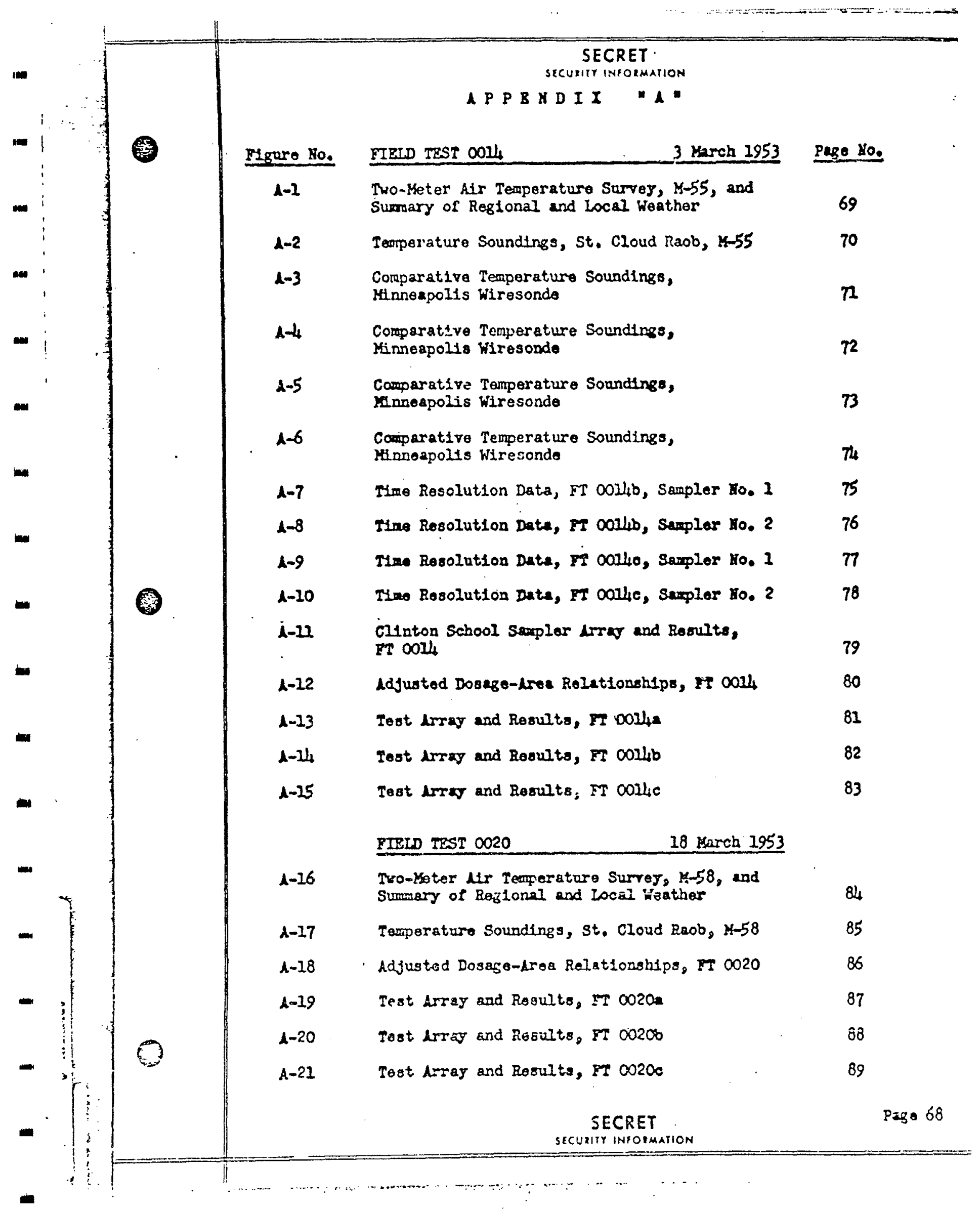


SUMHARY OF REGIONAL AND LOCAL WEATHER

3 Karch 1953

(Surrey K-55, Supplemental to it 0074)

\section{SINOPTIC SITUKTION}

A. strong ridge of high prossure extended from the Paciflc Northrestern states eastrard to the creat Lakes, bringing relatively cold air acrosa linnesota. An intenslfylng Iow centered over lake Erle serred to increase the surface gradiont. There was some evidence of a very veak cold frontal passage at Minneapolts on the evening of the test. At the jo0-mb level, a broad slow-moving trough extended from Saskatchewan southward to Texas and long-wave ridges lay just off the Atlantic and pacific coasts. The rosulting gradient wind over Hinneapolis was westurly at 35 h.

WEATHER REPORTS FROM WOLD-CHAMBERLAIN FIELD (KCNNEAPOIIS)

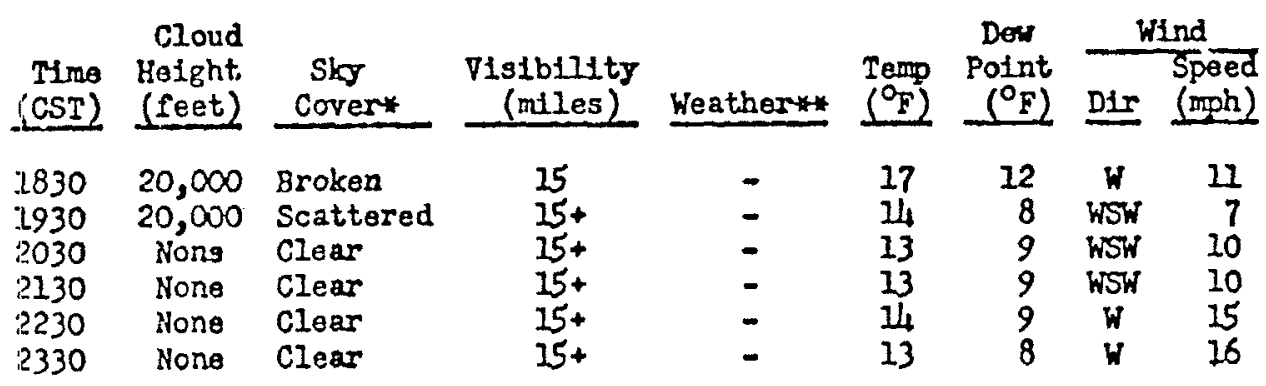

* Average cloudiness sunrise to sunset: $100 \%$

* And/or restriction to visibility

Sea-level pressure at $2130 \mathrm{CST}: 2009.5 \mathrm{mb}$

Ground condition: Trelve-inch packed snow; main streets clear; side streets clear but $50 \%$ ice from daytlite nelting; lake frozen

Tree cover: None 


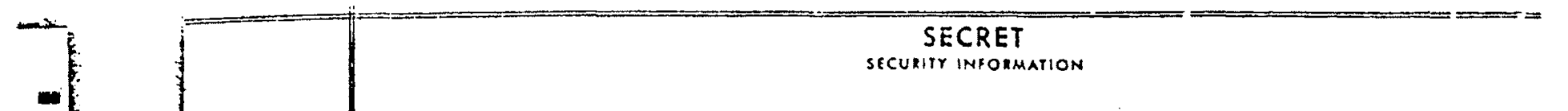

8

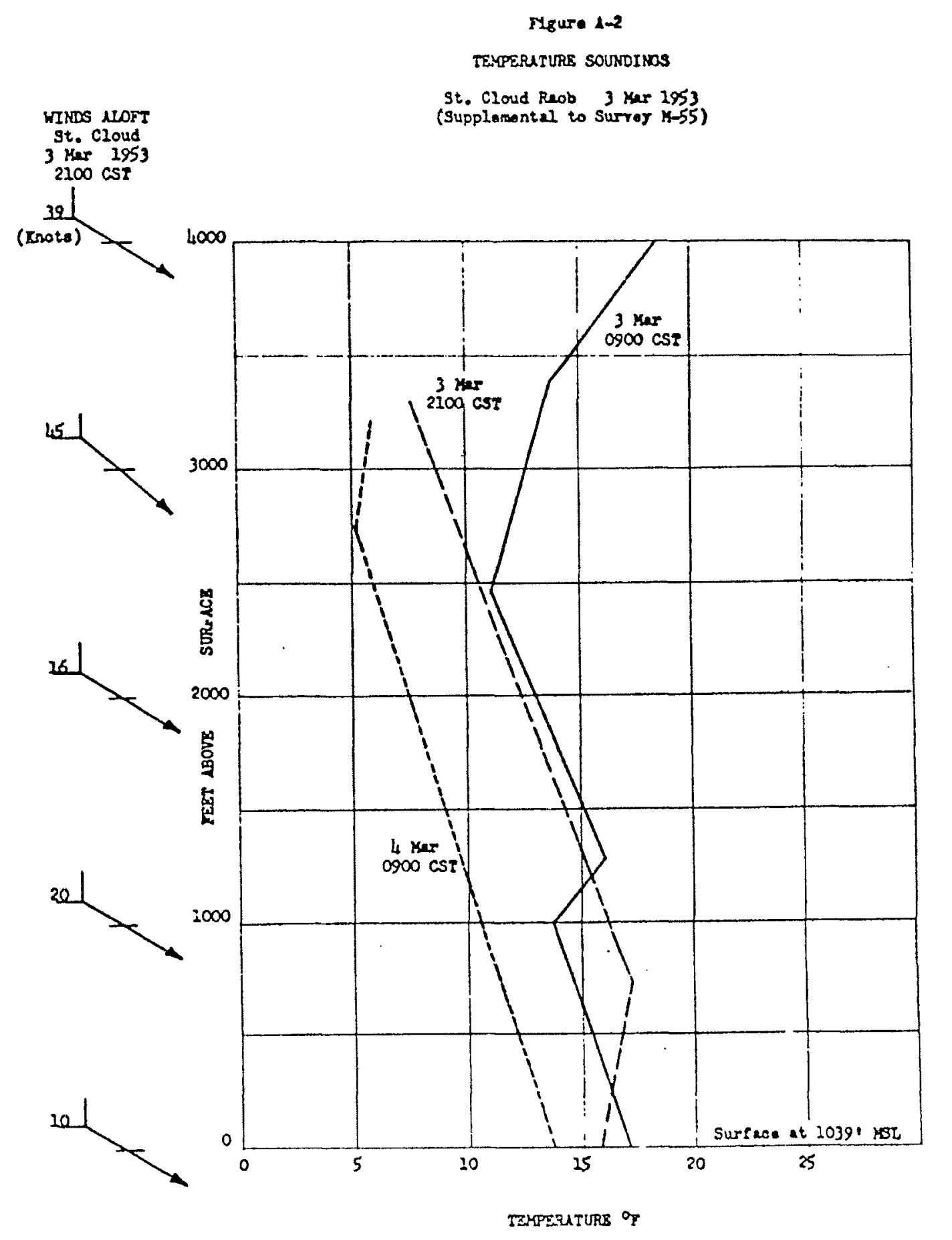




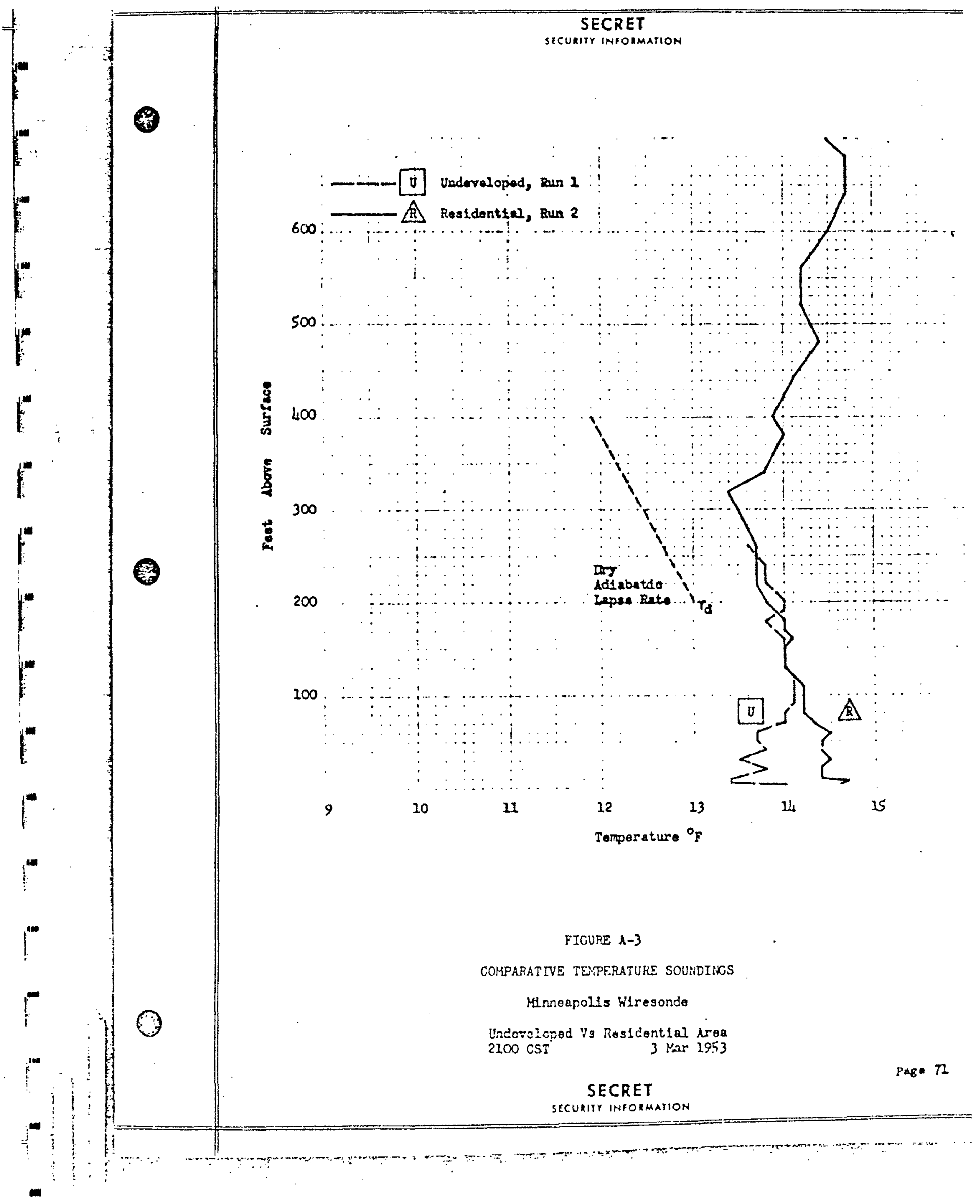




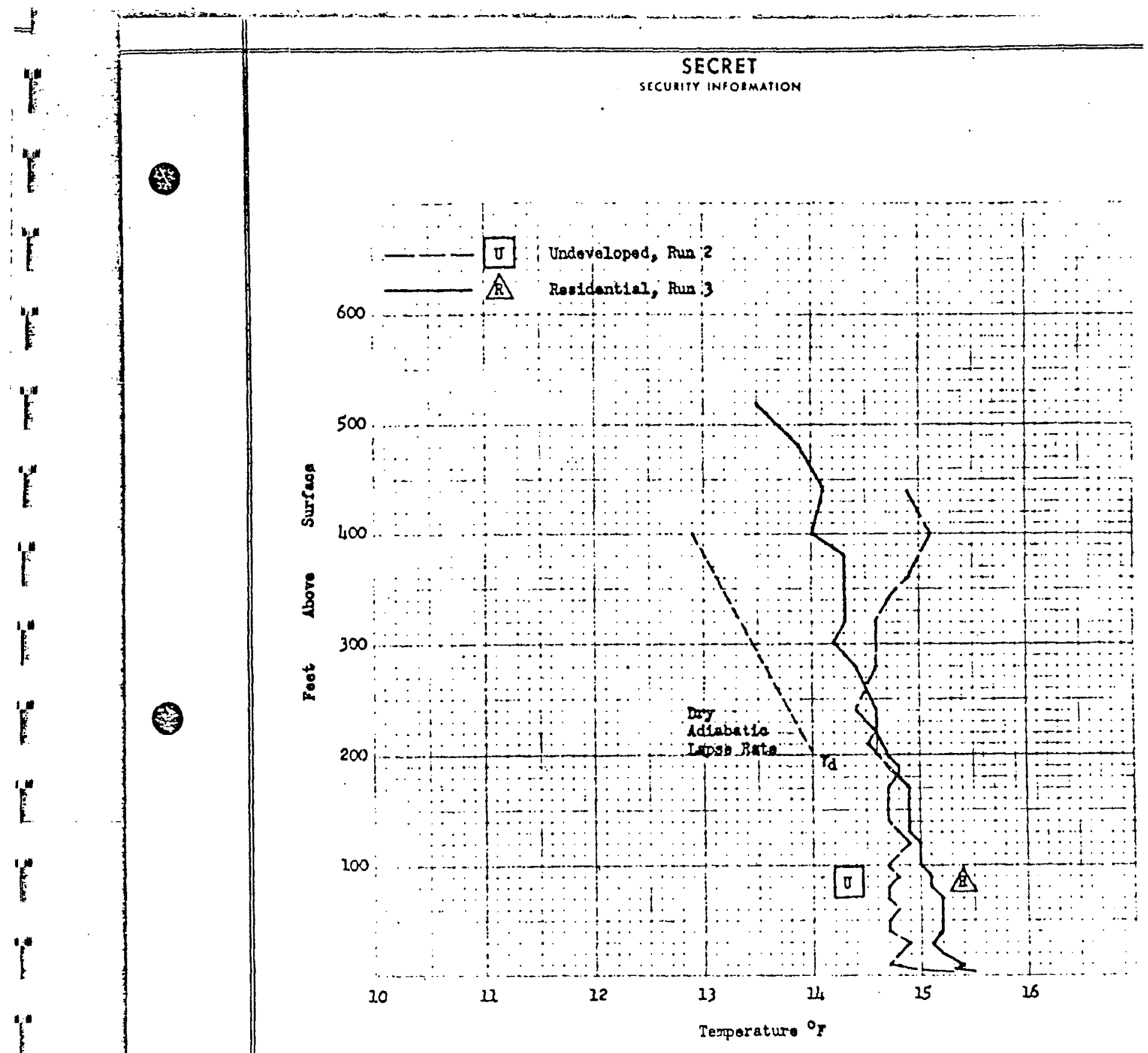

FIGURE 14

COMPARATIVE TEMFERATURE SOUNDINS

Mnnnapol1s Wirosonde

Undevelopod V Residont1el Area

$2200 \mathrm{CST}$

3 Mar 1953 


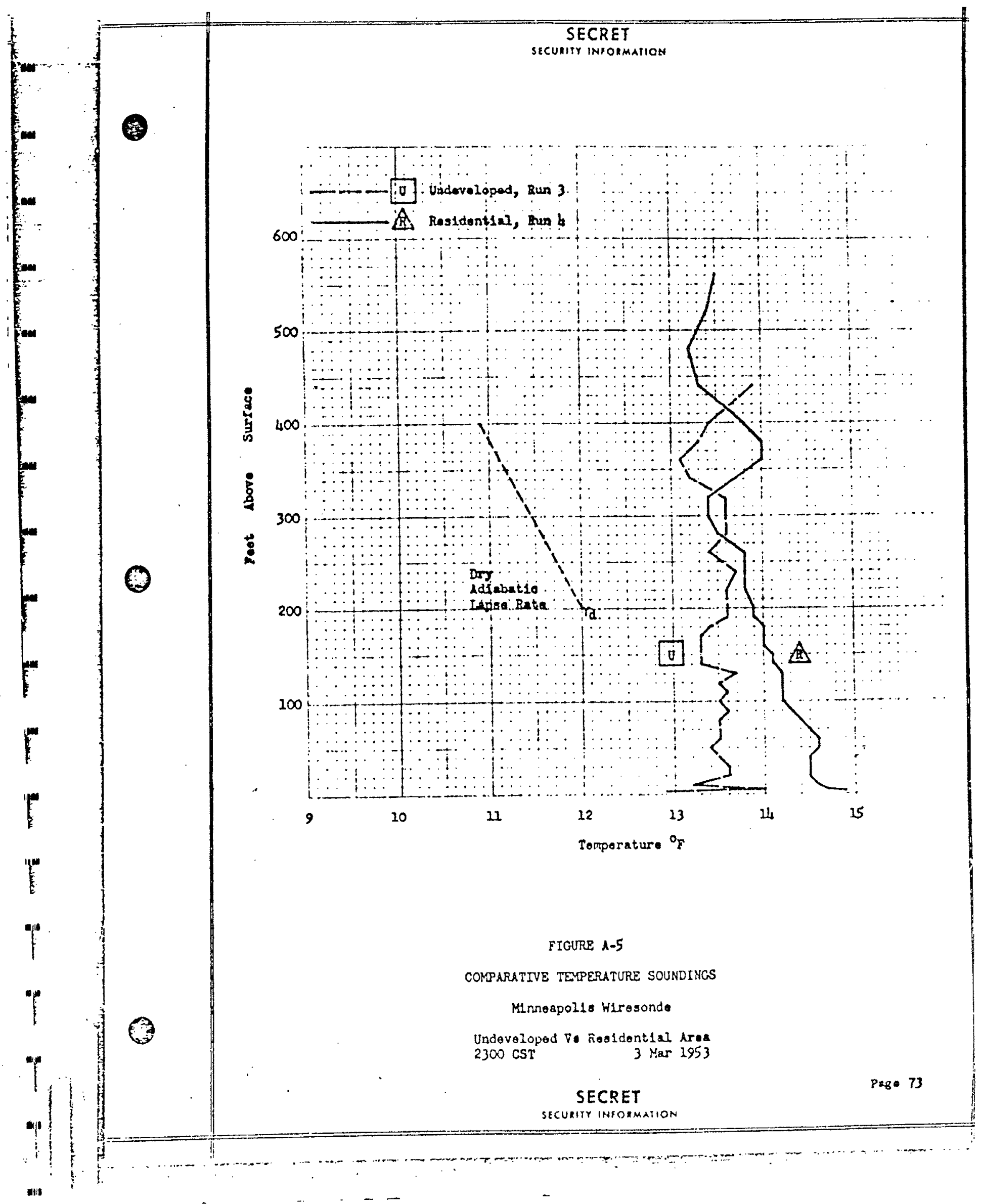




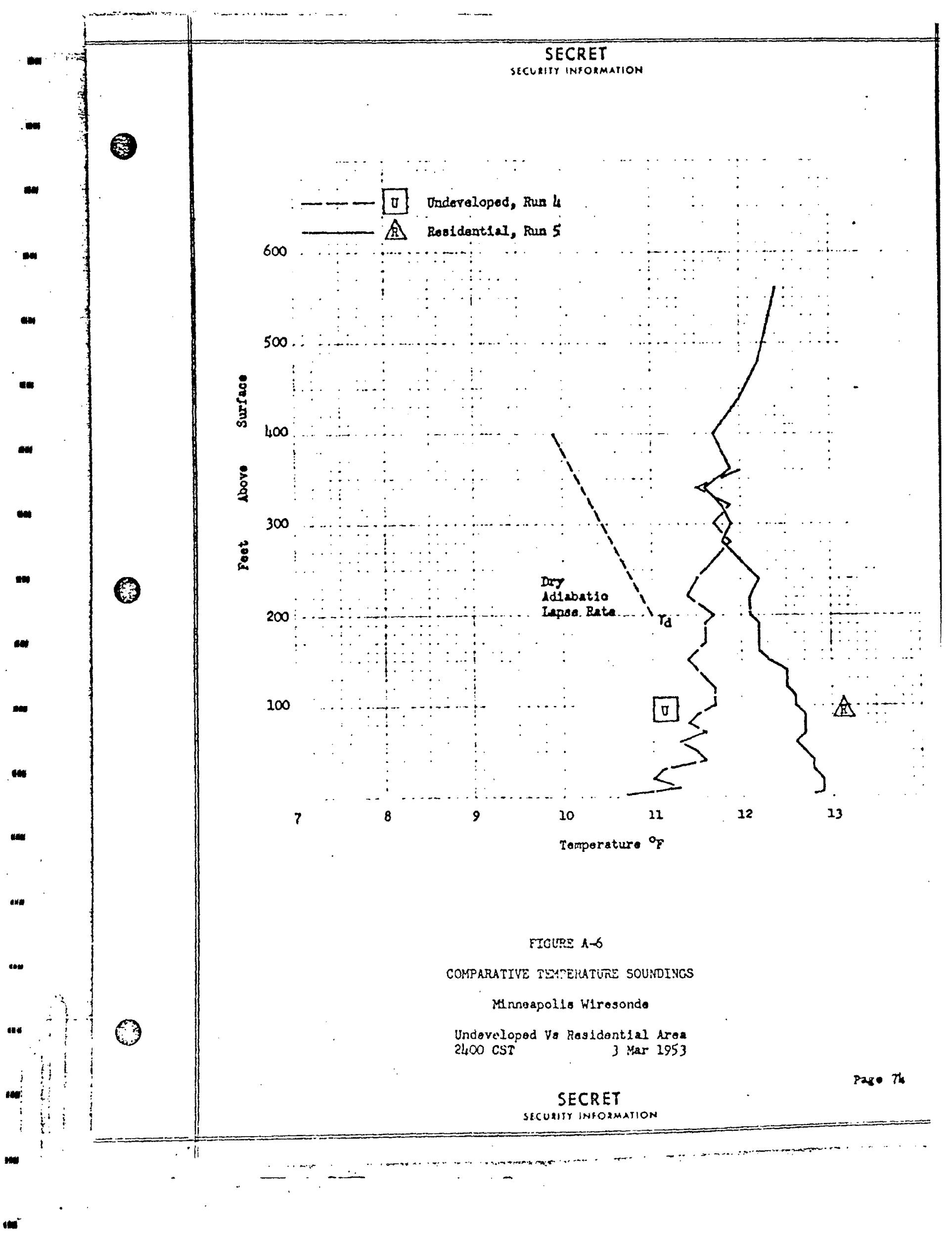




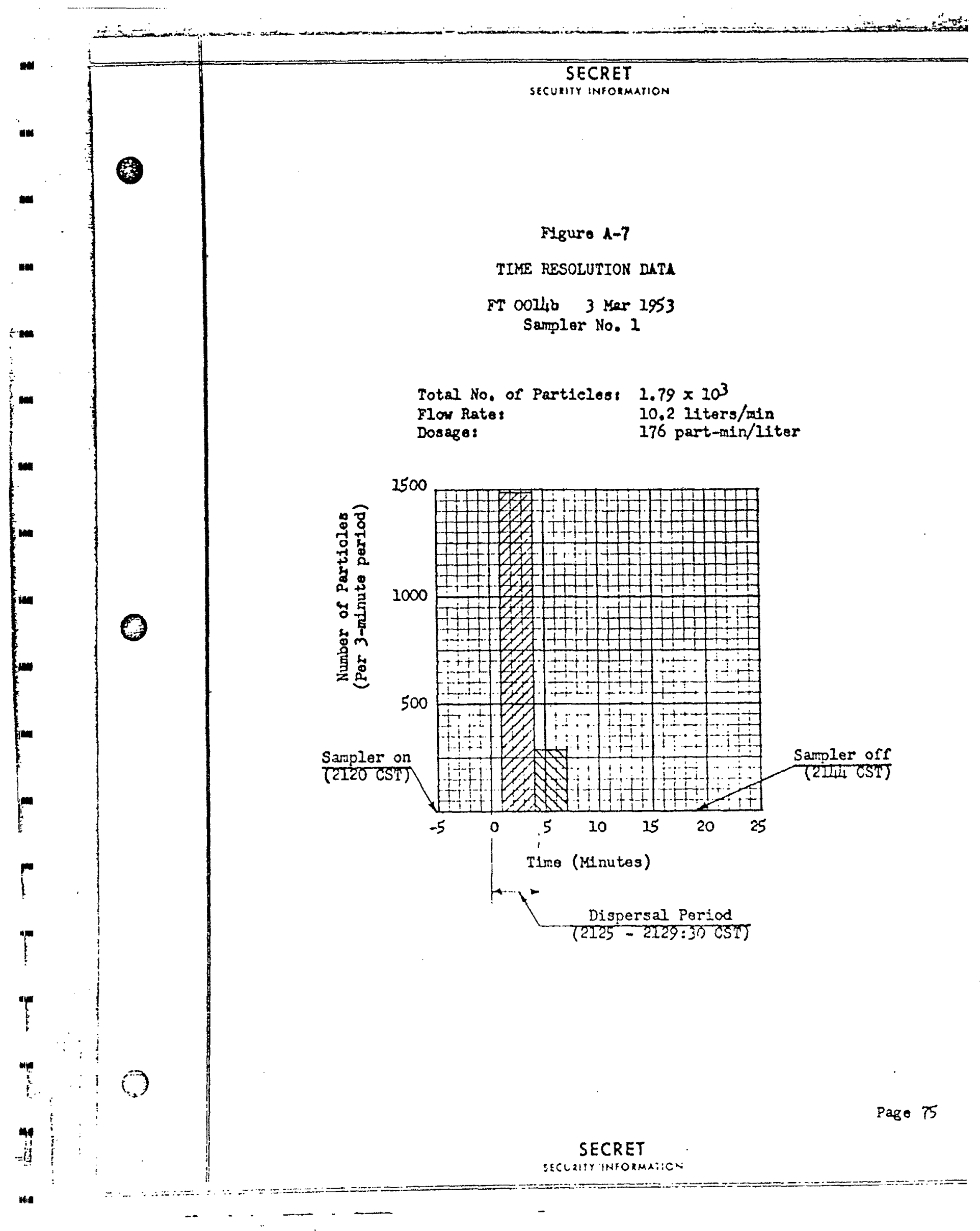




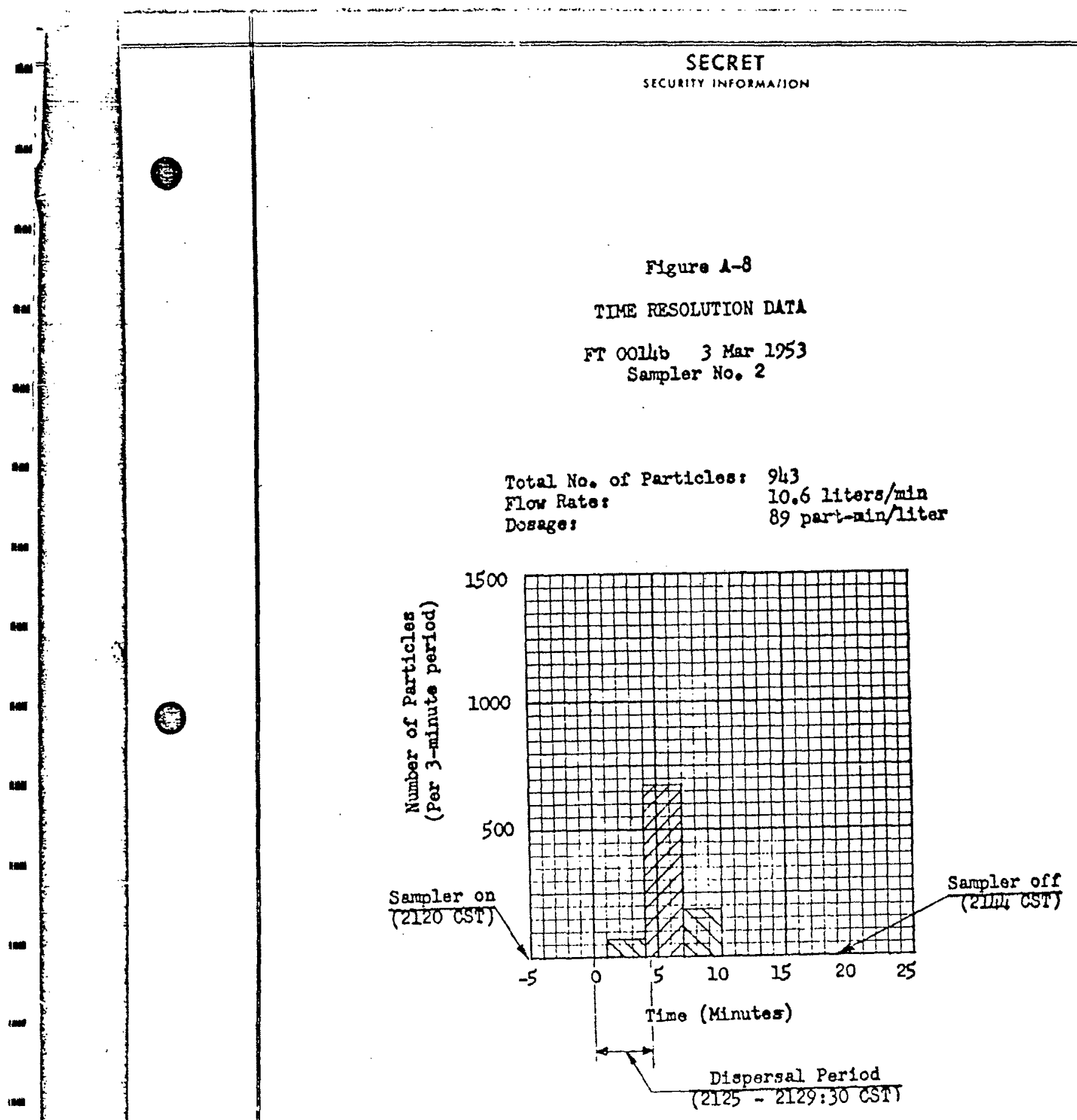

Page 76 


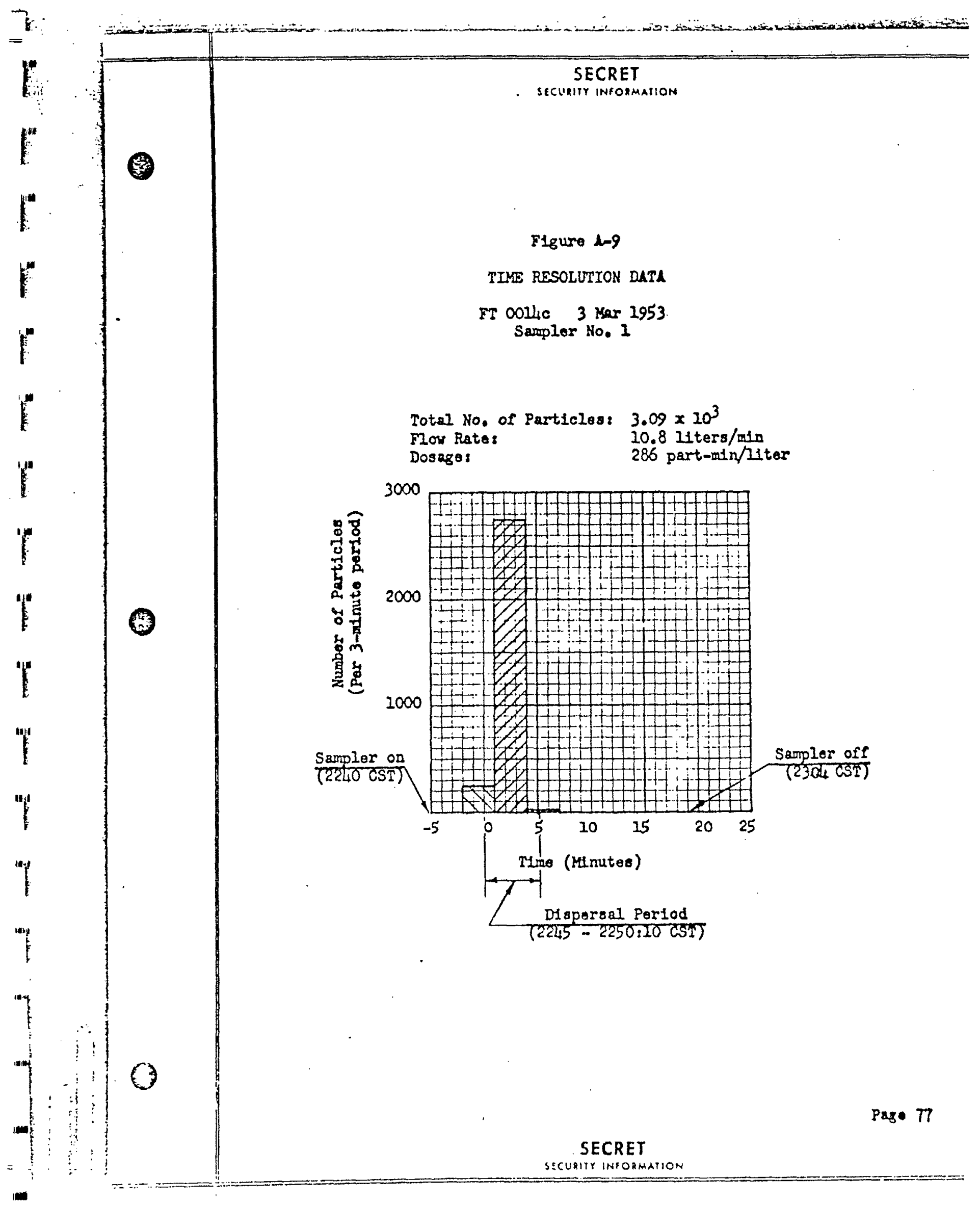




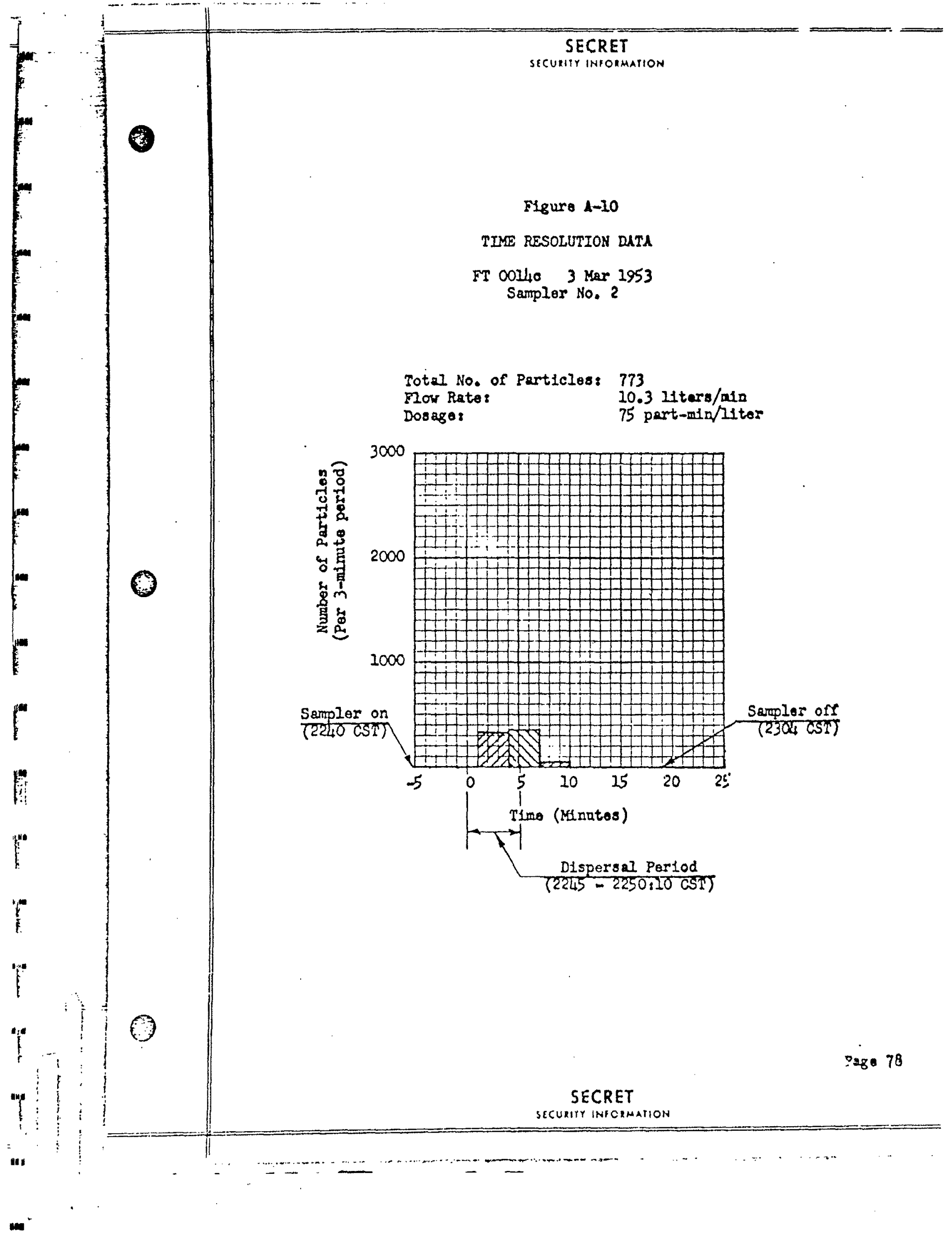


CLINTON SCHOOL DOSACES*

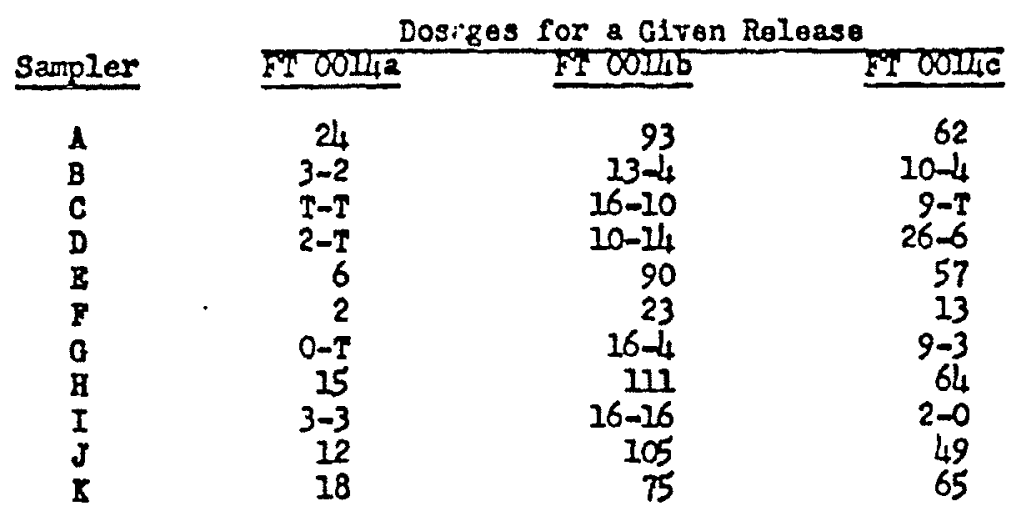

* Doseges are expressed in particle-mtnutea per 11ter; $\mathrm{T}$ represents trace dosage, $1 . e_{\text {. }}$ a count not exceeding 15 Muorescent particles. A single ontry expresses the dosago obtafned from a filter unit exposed during the entire sampline period of a particular rolease. Double ontrles for a given column represent incremental dosages obtalned with sequantially exposed filter units. Applicable incremental periods for each sampler, as well as full sampling periods for each release, are as follows:

\begin{tabular}{|c|c|c|}
\hline Release & Sarmiling Period & Incremental Perlocs \\
\hline FT OOLlua & $2000-2100$ CST & $\begin{array}{l}2000-20 L_{4} \mathrm{csT} \\
2015-2120 \mathrm{CST}\end{array}$ \\
\hline FT OOIlib & $2120-2220$ CST & $\begin{array}{l}2120-2205 \text { CST } \\
2205-2240 \text { CST }\end{array}$ \\
\hline FT OOJic & $2240-2340 \mathrm{CST}$ & $\begin{array}{l}2240-2325 \text { CST } \\
2325-2340 \mathrm{CST}\end{array}$ \\
\hline
\end{tabular}

Figures A-13, A-IL, and A-15 (Appendix A) show Bullding No. 11, clinton School, in relation to the grid complex and the dosage pattern for the indicated releases. 


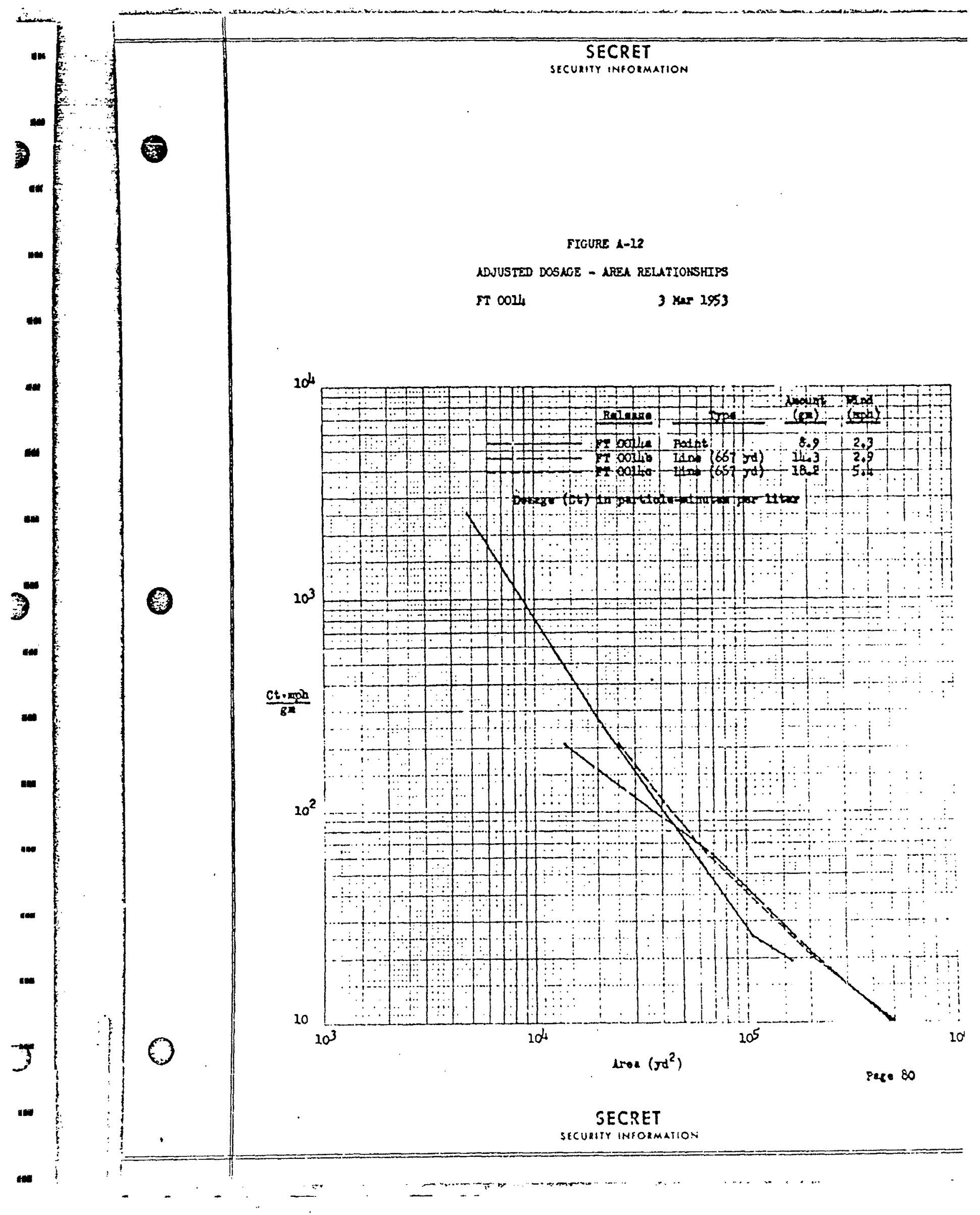




\section{NERCSOL GENERAT TOH}

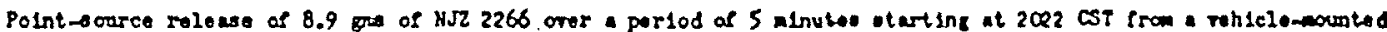
blower disporser located at point in. SLerging

Locat100 end Exposure

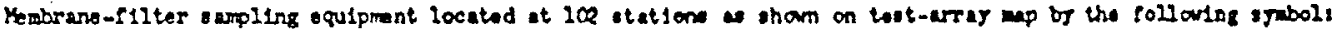
- Datboor samplor at haligit botwe I and 6 seot.

Posulta

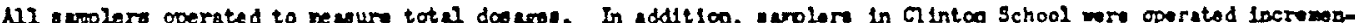

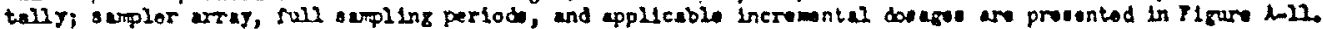
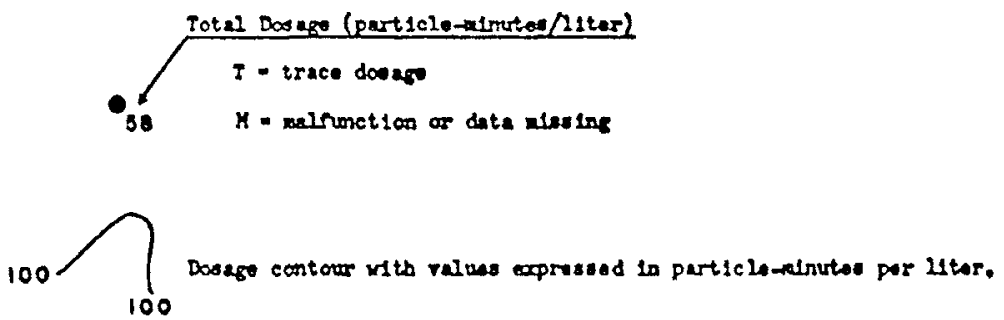

MTrEOROTOOY

Equipment and Hesuroment

At strot lerel, wind direction continuously recordod, end alr and surfuce tomperaturee, vind rolocity, wd other neteorological obourvations taken at stutions delignated 0,0 , no 0 .

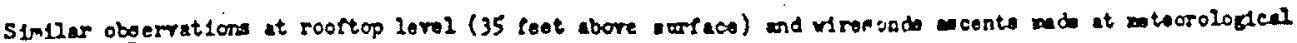
lation (9).

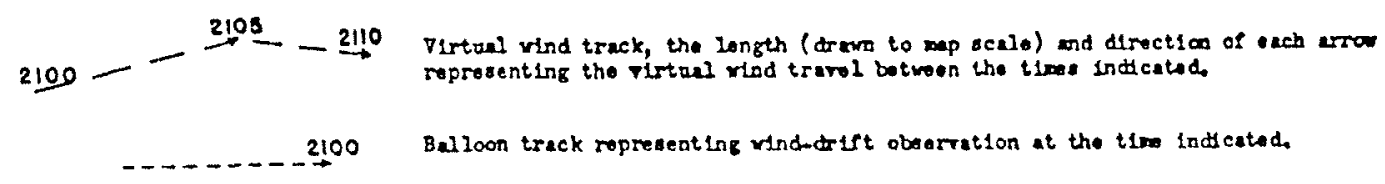

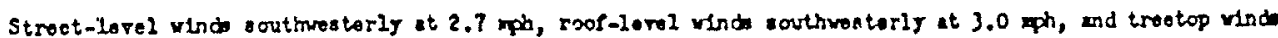
weat-nortimest to soutriveat at $8-10 \mathrm{mph}$,

\section{Stcb111ty}

$1.14 \cdot$ F lapae sron 6-300 rt.

3hy

Clocr dring test porlod,

Texperature

16-17* $p$ at 2 moters in tho test wrea.

Yolsture

Mexing ratio of $1.4 \mathrm{gr} / \mathrm{kg}$ ar 10. 


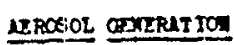

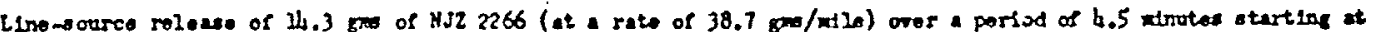

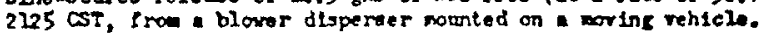

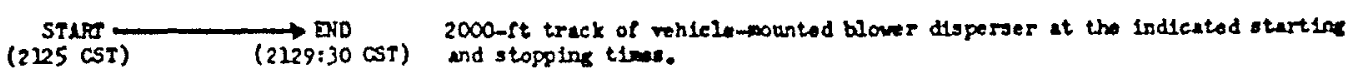

Sempt. ino

Location and Exposin

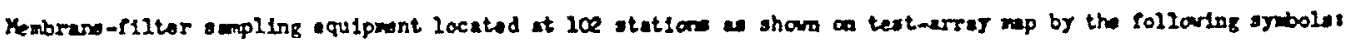

- Oatdoor ourpler at holaht betwoen 1 ind 6 loct.

A Ime-resolution swolar vith station maber.

Rosulte

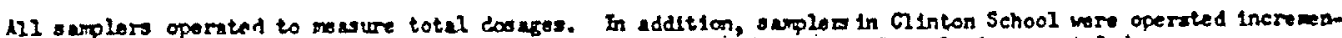

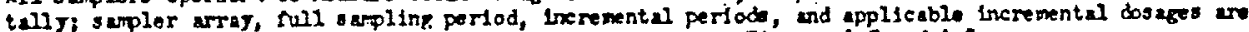

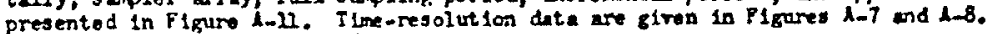

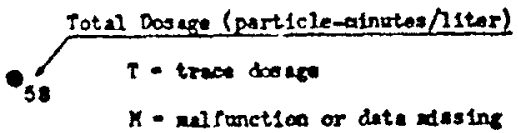

$\tan$

\section{ETEOROLOTI}

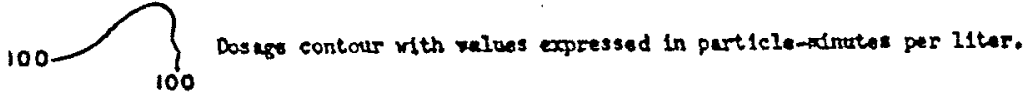

\section{Equignent gnd wosuroment}

At stret lovel, wind direction contingowaly recorded, and alr surtge tomperatges, wiod relocity, and

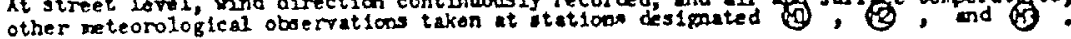

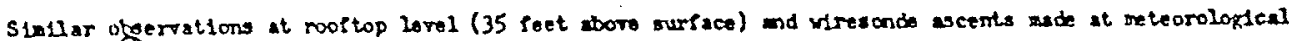
station (3)

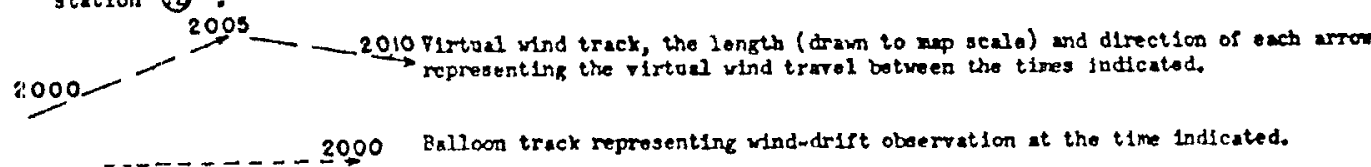

Minds

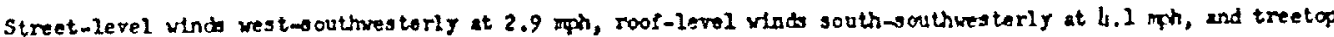

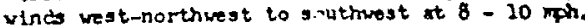

\section{Stebl1ity}

$1.2 \cdot$ I Iapse frow 6-300 tt.

Shy

Coes durling test period.

Ienre raturo

$25^{\circ}$ to $16^{\circ} \mathrm{F}$ at 2 metere in the test area.

Motsture

Muxing rat to of $1.4 \mathrm{~km} /$ yegra dry atr. 


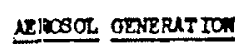

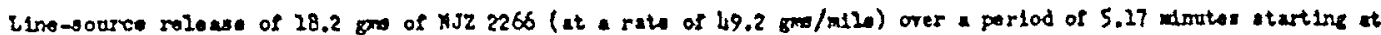
2245 CST, fron a blower disperser mouted on a nor ine vehicle.

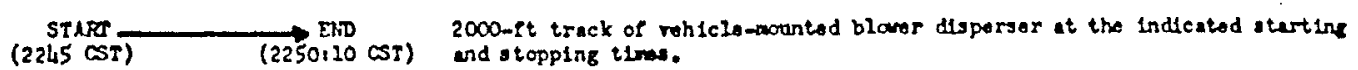
SNIF I0

Location and Exporuse

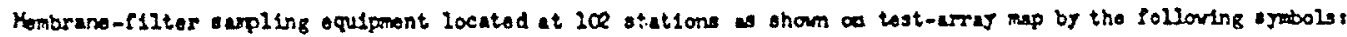

- Cutdoor sapler at helght betroen 1 and 6 foot.

$\Delta$ Tine-resolution serplor with atation nuabor.

Resurute

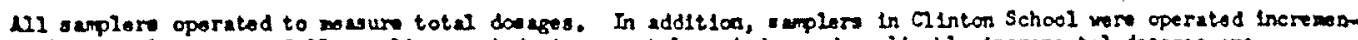

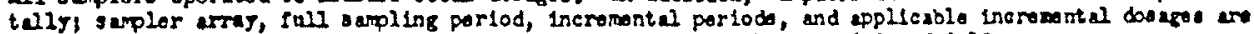
presentod in Figure L-11. Tine-resolution date aro given in Figures $1-9$ and $1-10$.

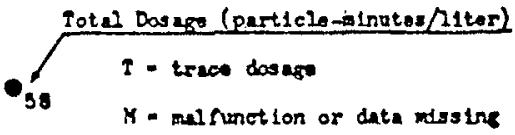

X - mal function or data mosstre

3)<smiles>O=C(O)CCO</smiles>

Doougo contour with values exprosed in particle-ralnutos por ilter.

MeTropoloor

Equiprent and keasurorent

At atreat 20vol, wind direction continuously recorded, and air and aurece tomperatures, wind rolocity, and

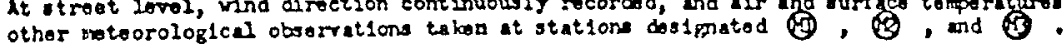

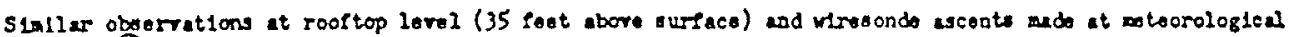
otation 9 .

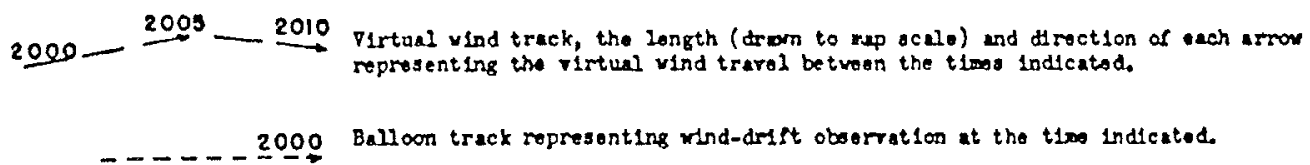

Hinde

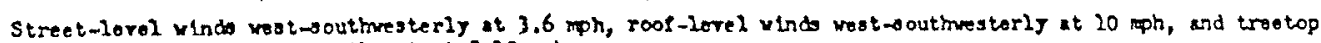
winds vest-northwest to southrost at 8-10 mph.

\section{stablititr}

1.5. F Lepes tros $6-300 \mathrm{tt}$.

$3 x y$

Clese during tost period.

Temerature

$14.7^{\circ}$ to $15.7^{\circ}$ F at 2 metore in the lest arok.

Moleture

Maxing ratlo or $3.1 \mathrm{gN} / \mathrm{kgm}$ try atr. 
SURMARY OF RECIONAL AND LOCAL WEATHER

18 March 1953

(Survey M-58, Supplemental to FT 0020)

\section{SYNOPTIC SITUATION}

Associated with a 996-mb low center 300 miles northeast of Duluth, a reak dissipating cold front passed Minneapolds the night before the test with no precipitation. If ondary cold front one hour prior to the test period. Following the becondary front, a fresh mass of cold air in a weak high roved rapilly from the northwest. At the $700-\mathrm{mb}$ level, a rapldly moving trough passed from Lake Supertor through Indiana and Arkansas to Texas, and rfdges lay over the Rockles and the Appalachians. The $700 \mathrm{mb}$ gradient ind over itinneapolis was northwesterly at $40 \mathrm{mph}$.

WEATHER REPORTS FROM WOLD-CHAMBERIAIN FTEID (MINNEAPOLIS)

\begin{tabular}{|c|c|c|c|c|c|c|c|c|}
\hline $\begin{array}{r}\text { THms } \\
(\operatorname{CST})\end{array}$ & $\begin{array}{l}\text { Cloud } \\
\text { Helght } \\
\text { (feot) }\end{array}$ & $\begin{array}{c}5 k 8 \\
\text { Cover* }\end{array}$ & $\begin{array}{c}\begin{array}{c}\text { Visibilits } \\
\text { (miles) }\end{array} \\
\end{array}$ & Weather & $\begin{array}{l}\text { Temp } \\
(0 \mathrm{~F})\end{array}$ & $\begin{array}{c}\text { Dew } \\
\text { Polnt } \\
\left({ }^{\circ} \mathrm{F}\right)\end{array}$ & $\frac{W}{D 1 r}$ & $\begin{array}{l}\frac{1 \text { ind }}{\text { Speed }} \\
\text { (mph) }\end{array}$ \\
\hline $\begin{array}{l}830 \\
930\end{array}$ & $\begin{array}{l}1900 \\
1900\end{array}$ & $\begin{array}{l}\text { Brok } \\
\text { Scat }\end{array}$ & $\begin{array}{l}15 \\
15\end{array}$ & - & $\begin{array}{l}35 \\
35\end{array}$ & $\begin{array}{l}33 \\
31\end{array}$ & $\frac{W}{W}$ & $\begin{array}{c}24 \\
20 \\
\text { (gusty) }\end{array}$ \\
\hline 2030 & 2100 & Broken & 15 & - & 35 & 31 & WNNS & $\begin{array}{c}24 \\
\text { (gusty) }\end{array}$ \\
\hline $\begin{array}{l}2130 \\
2230\end{array}$ & $\begin{array}{l}2200 \\
2500\end{array}$ & $\begin{array}{l}\text { Broken } \\
\text { Scattered }\end{array}$ & $\begin{array}{l}15+ \\
15+\end{array}$ & - & $\begin{array}{l}33 \\
32\end{array}$ & $\begin{array}{l}27 \\
25\end{array}$ & $\begin{array}{l}\text { WNW } \\
\text { WNW }\end{array}$ & $\begin{array}{c}20 \\
24 \\
\text { (gusty) }\end{array}$ \\
\hline 330 & None & Clear & $15+$ & - & 30 & 20 & WWW & 20 \\
\hline
\end{tabular}

* Average cloudiness surnise to sunset: $50 \%$

And/or restriction to visibility

Sea-level pressure at $2130 \mathrm{CST}: 1006.8 \mathrm{mb}$

Ground condition: Tro to four-inch packed snow and 1ce; $40 \%$ of snow gone;

Tree cover: None 


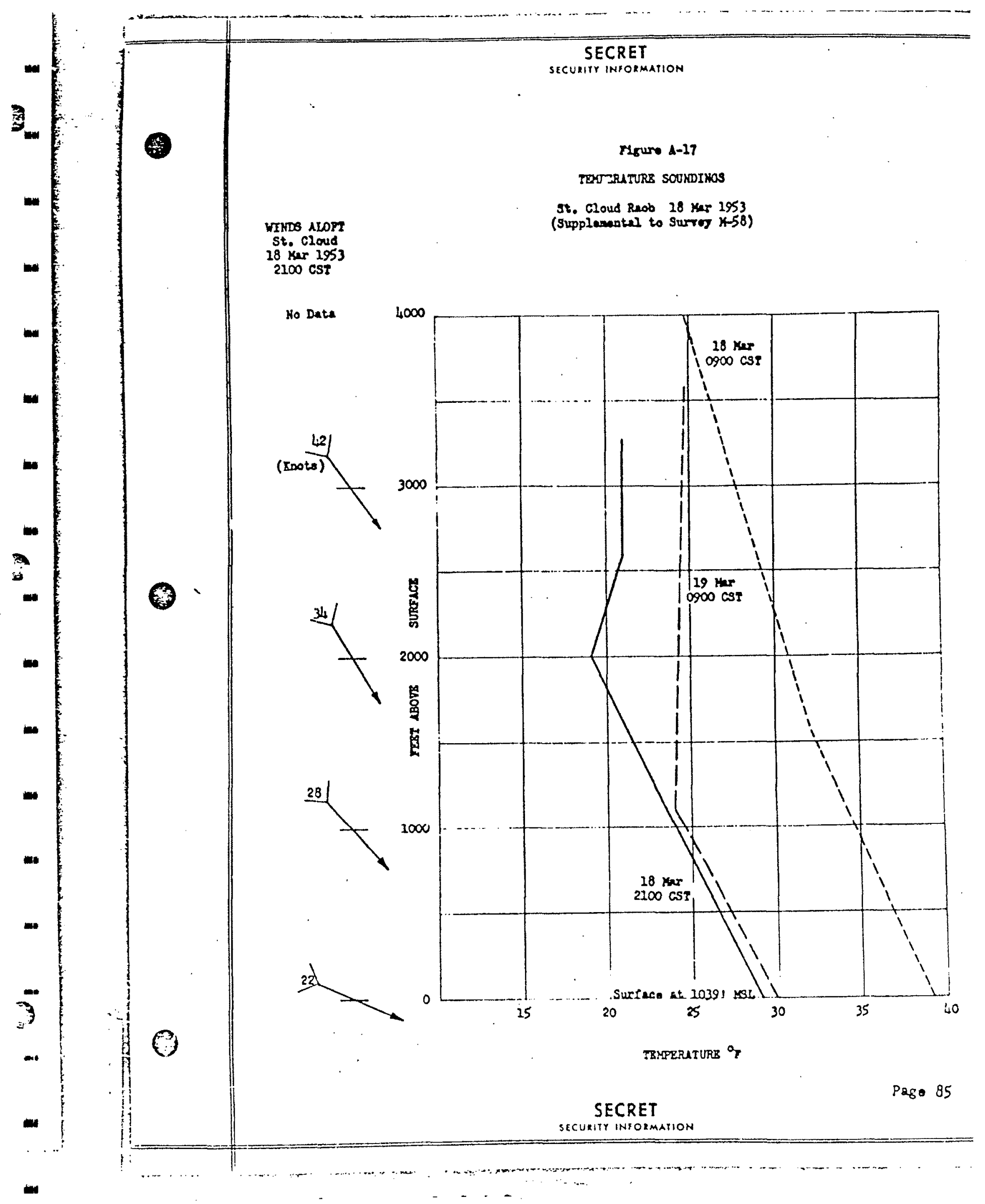




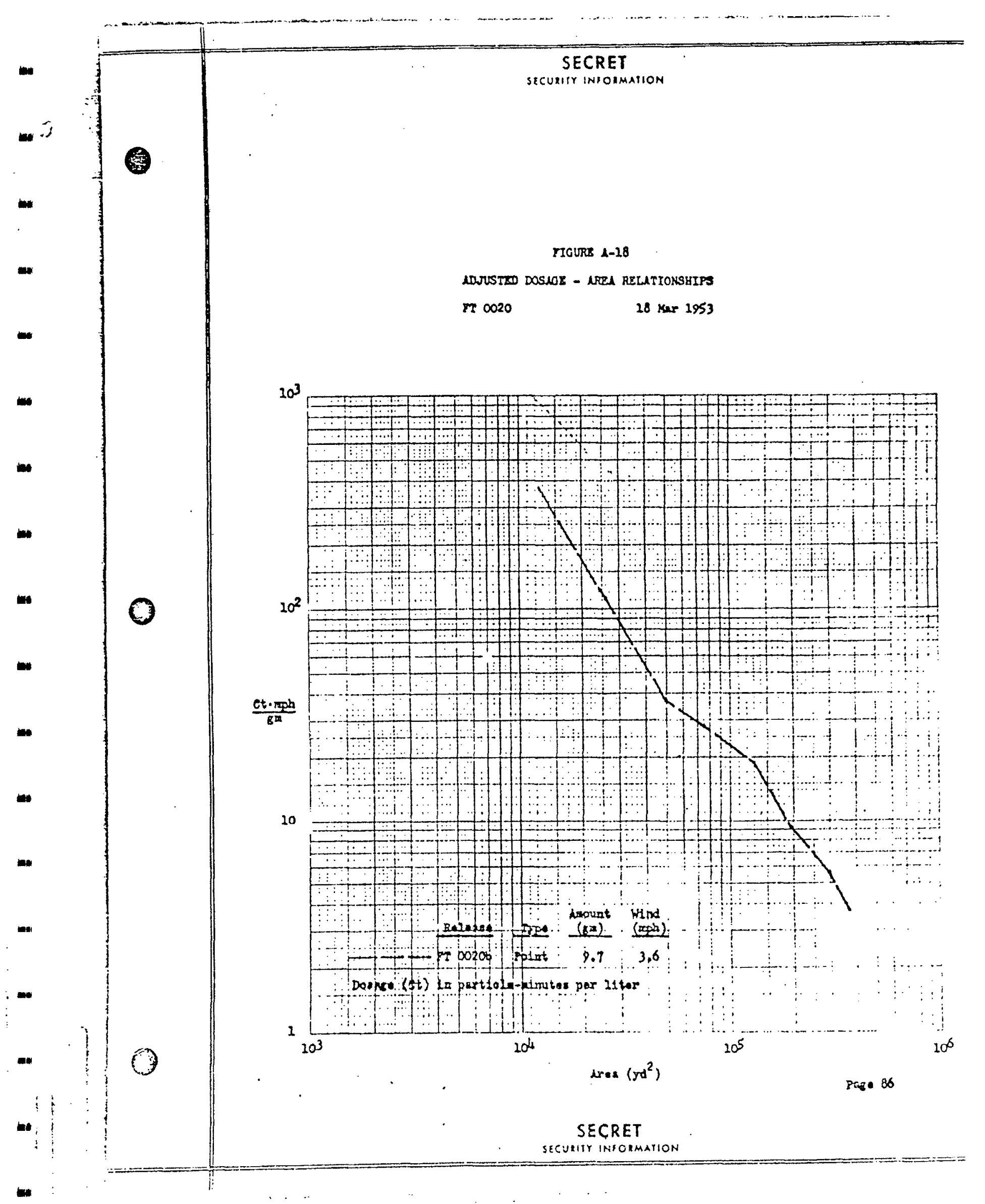




\section{Nerasor generatyon}

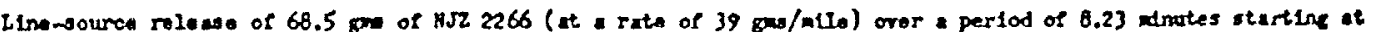
$2005 \mathrm{CT}$, from blover disperser mounted on a noring rehiela.

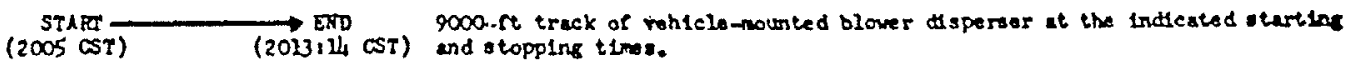
SAlpiting

Location and Expentre

Hembrans-p1ltor sumpling equipment located at 1d atation so show on test-array nep by the following aymbias - Ortdoor supler at belght botwen 1 and 6 foet.

- Outdoor asmplor at helght above or bolon general torrafn lovel a indicatod by sote.

Resulte

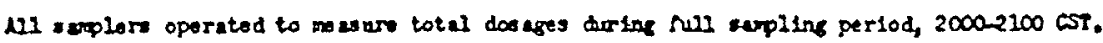
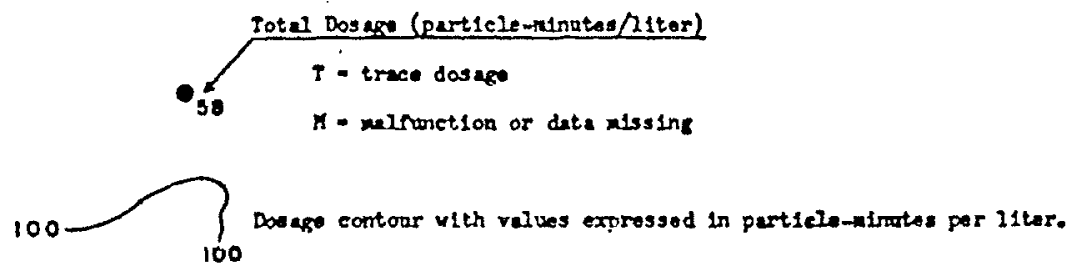

Zquipont end warenent

At atreot level, wind direction continuously recorded, and Als and surface temporatures, rind relocity, and othar te teorological obeerrations taken at stations dosizated of and

Sindlar abservationa et rooftop lovel (35 foet above surfece) made at metoorological station , where - quipment. vas sls o sot up for viresondo mosurents.

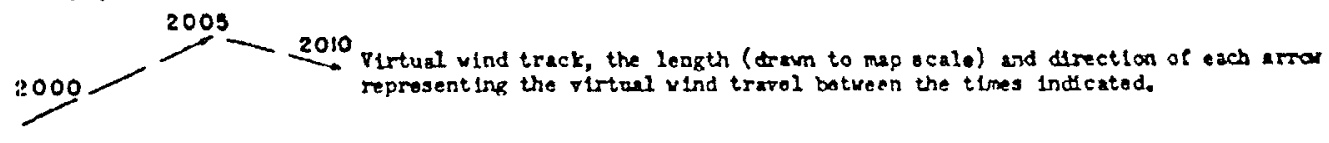

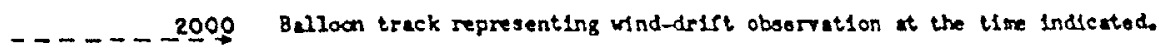

Winde

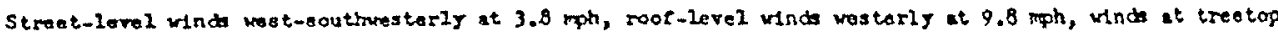
vesterly at $10.15 \mathrm{mph}$, and abovo traetop lowel yosterly at $20-30 \mathrm{mh}$.

\section{Stebiuty}

No direct measurement; Hresonde operations precluded by relatively strong wind. These wad and supporting roob date (F1B. A-17) indicate adsobatic conilitions.

sig

poben clouds with beset $2100 \mathrm{ft}$ abara the surface.

Turreralure

$35^{\circ}$ to $35.5^{\circ} \mathrm{F}$ at 2 moters in tho test area.

Koisture

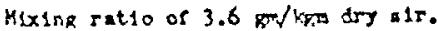


AEROSOL OENERTITIN

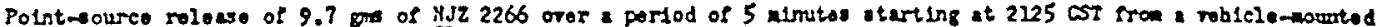
blover disperser located it point its.

SUMPL DNO

Location and Expoesure

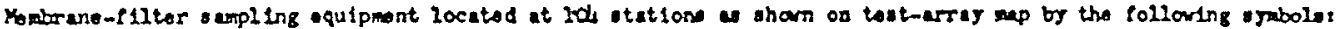
- Outdoor antoler at helpt betmeen 1 and 6 feet.

- artdoor oumpler st hal ght ebore or below general torrein lovel as indicated by note.

Roscite

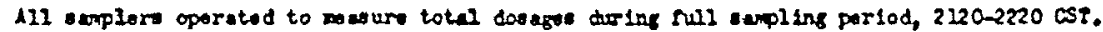
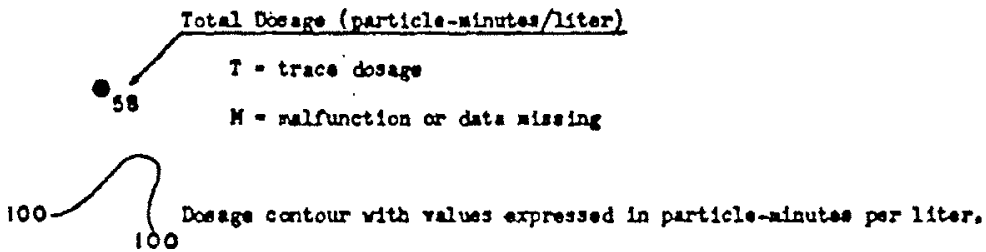

Equipent and Megureiment

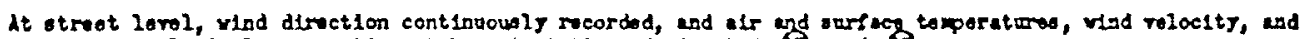
othor weorological oberration taken at atations dasiented and of

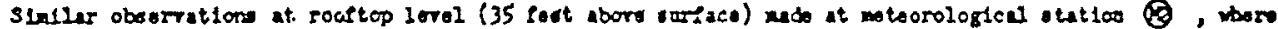
- quiposent was also ost up for virosond wasurante.

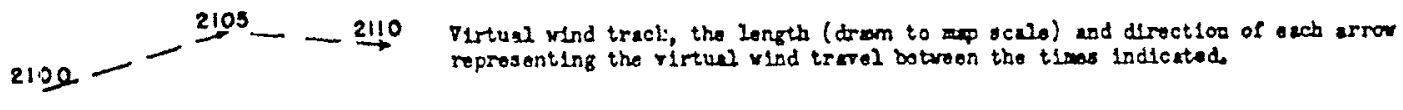
2100 Balioon track ropresenting vind-drift observation the tim indieated.

\section{Ninds}

Stroct-level vinde vest-northosterly at $3.8 \mathrm{mh}$, rool-1erel vinds yost-northwesterly at 21.2 wab, winds at treetop weaterly at $10-15 \mathrm{mph}$, and abovo troetop lovel vesterly at $20-30 \mathrm{mph}$.

\section{Steblilty}

No direct measument: wiresonde operetions precludad by relatively strong vinds. Those wind end supporting raob dat. $\left(F_{1 \mathrm{~g}} .1-17\right)$ indicate adiabatic conditions.

sky

Erokxa clouds with bases 2200 rt tbore the auriace.

Iemerature

$34.2^{\circ}$ to $34.8^{\circ} \mathrm{F}$ at 2 potera in the tost area.

Yesture

M.1xizg ratio of $3.1 \mathrm{gm} / \mathrm{kgm} \mathrm{drg}$ a1r. 


\section{LROSQ CEMERT TO}

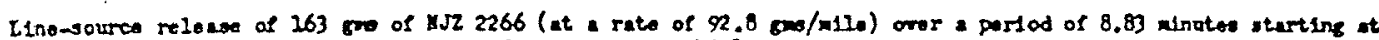

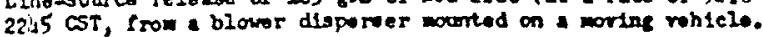

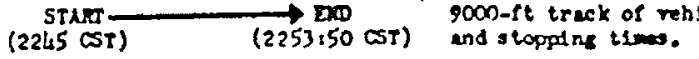

SNMLIDIS.

Location end Expoung

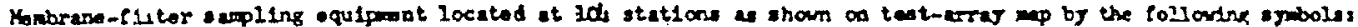

- Outbor sepler at helebt betwed 1 and 6 foet.

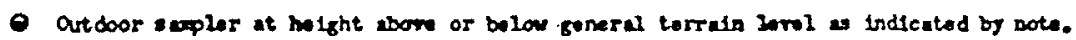

Rosult

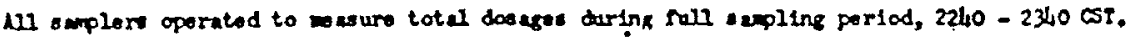

ffrtonotoor

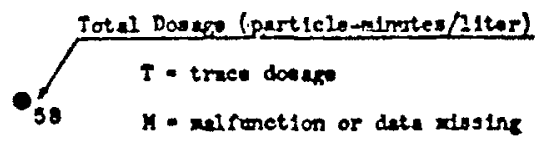

Equipmont and Keasurenont

At street level, wid direction continuously recorded, and alr and surface tarperatures, vind velocity, and other toorological aborrations taken at station destonated of and 0

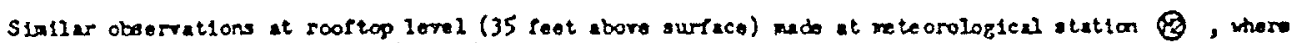
equipment vas also set op 5 ar viresonde nesurewente.

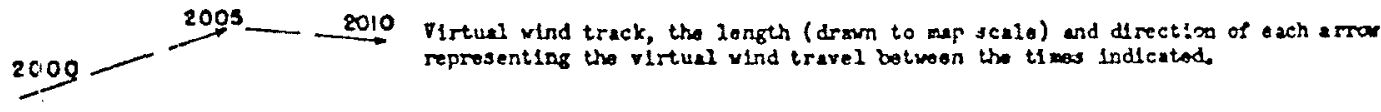

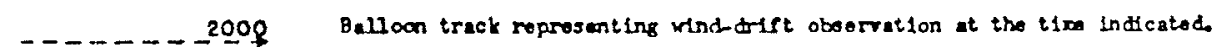

Winds

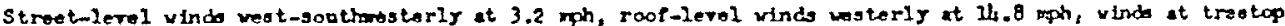
westerly at $10-15 \mathrm{kph}$, and aboro treotop levol westerly at $20-30 \mathrm{mph}$.

\section{Stability}

No direct wesurement; wresoride operations precluded by rolativoly strong winds. These wincs gnd gupporting raob data (F18. A-17) indicato diabatic conditiona.

$\underline{s k z}$

Scattorad clouds with bases 2500 ft ibore the surace.

Semperatare

$29.8^{\circ}$ to $30.5^{\circ} \mathrm{F}$ at 2 moters in the test anta.

Molsture

Muxing ratlo of $2.8 \mathrm{gm} / \mathrm{km}$ drg ais. 


\section{APPBVDII $B$}

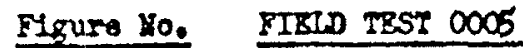

26 January 1553

Page Xo.

B-1 Trowleter L1s Teaparature Survey, K-38, and

Sumary of Reglonal and Local Woather

B-2 Temperature Soundings, St. Cloud Raob, $x-38$

B-3 Temperature Soandings, Rosidentlal-droa Wiresonde

B-4 Idfusted Dosaga-hrea Relattonohips, it 0005

95

B-5 Toot irray and Bosults, IT 0005a

Iost Array and Rosults, IT 0005b

FIRTD TEST 0006

28 Jamary 1953

B-7 Tro-kster Ner Temerature Survey, $\mathrm{K}-4 \mathrm{O}$, and Swowary of Roglonal and Local Weather

B-8 Temporature Sounding, st, Clood Enob, $\mathrm{k}-40$

Temporature Soundings, Rosidontial-iras Wiresonde

$B-10$

Ldfusted Dosage-drea Relationshlps, IT 0006

B-12 Test lrror and Resulte, IT 0006b

B-13 Trookstos Lir Temprature Surroy, $\mathrm{K}-4 \mathrm{I}$, and Swmary of Boglonal and Local Weather

B-If Tomparature Sounding, st, Cloud Raob, K-41

Temperature Soundiago Rooldential-drea Wresonda 


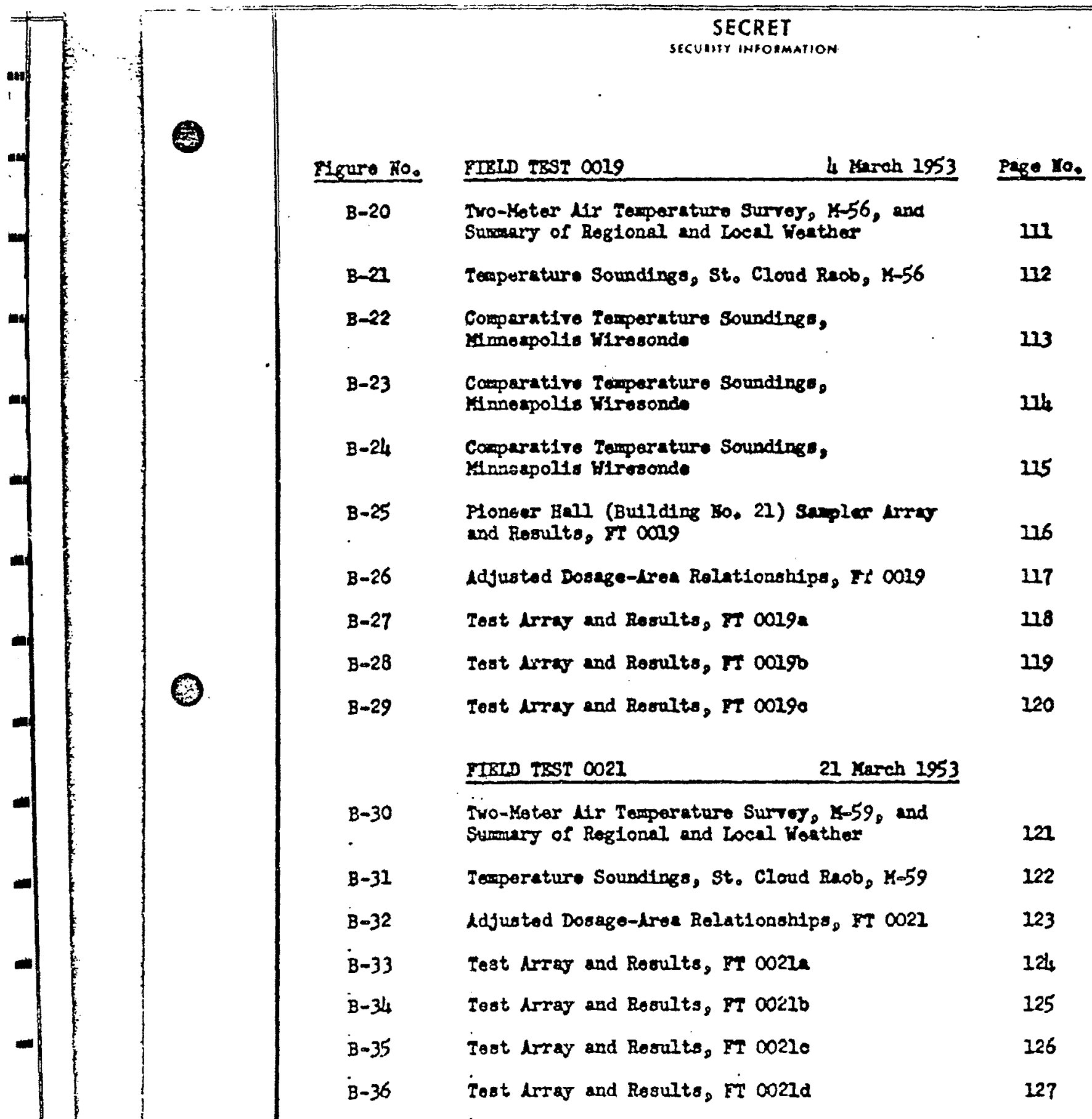


SURMARY OF REGIONAL AND LOCAL WEATHER

26 Jenuary 1953

(Survey M-38, Supplemental to FT 0005 )

\section{SYNOPTIC SITUATION}

A 1000-mb low-pressure area, centered 1400 miles north-northwest of kinneapol1s, was moring east at $20 \mathrm{mph}$. An associated warm front with scattered snow showers was just past kinneapolis at test timo. The cold front, extending northeast-southwest over northwestern Munesota, was approaching at about $30 \mathrm{mph}$. In the warm sector covering the test area, 1 ight westerly winds prevalied. At the 700-mb level, a weak low system north of Duluth produced only slight perturbation in strong westerly flow across the country. The 700 -mb gredent wind over Mnnespolis was westerly at 40 mph.

WIAATHER REPORTS FROM WOLD-CHAMBERLAIN FIELD (MINEAPOLIS)

\begin{tabular}{|c|c|c|c|c|c|c|c|c|}
\hline $\begin{array}{l}\text { Mma } \\
\text { (CST) }\end{array}$ & $\begin{array}{l}\text { Cloud } \\
\text { Helght } \\
\text { (feet) }\end{array}$ & $\begin{array}{c}\text { Skg } \\
\text { Cover* }\end{array}$ & $\begin{array}{c}\text { valbility } \\
\text { (m+1es) }\end{array}$ & Weather* & $\begin{array}{l}\text { Temp } \\
\left(O_{\mathrm{F}}\right) \\
\end{array}$ & $\begin{array}{l}\text { Dent } \\
\text { Point } \\
\left(O_{F}\right) \\
\end{array}$ & DIS & $\begin{array}{l}\text { Lnd } \\
\text { Speed } \\
\text { (\$h) }\end{array}$ \\
\hline $\begin{array}{l}1830 \\
1930 \\
2030 \\
21.30 \\
2230\end{array}$ & $\begin{array}{l}4400 \\
2000 \\
1400 \\
\text { None } \\
\text { None } \\
\text { None }\end{array}$ & $\begin{array}{l}\text { Overcest } \\
\text { Orercast } \\
\text { Broken } \\
\text { Clear } \\
\text { Clear } \\
\text { clear }\end{array}$ & $\begin{array}{l}6 \\
6 \\
6 \\
6 \\
4 \\
4\end{array}$ & $\begin{array}{l}\text { Haze } \\
\text { Haze } \\
\text { Haze } \\
\text { Haze } \\
\text { Fog } \\
\text { Fog }\end{array}$ & $\begin{array}{l}28 \\
28 \\
29 \\
27 \\
25 \\
24\end{array}$ & $\begin{array}{l}25 \\
25 \\
26 \\
25 \\
23 \\
22\end{array}$ & $\begin{array}{c}\text { SSH } \\
\text { SSW } \\
\text { SW } \\
\text { SSW } \\
S \\
E\end{array}$ & $\begin{array}{r}11 \\
9 \\
7 \\
8 \\
10 \\
3\end{array}$ \\
\hline
\end{tabular}

* Average cloudlnogs sunrelse to sunset: $100 \%$

* And/or reatrictions to viaibility

Sea-level pressure at $2130 \mathrm{CST}: 1012.5 \mathrm{mb}$

Ground condition: Frozen $s 1 x$-inch base; snow dirty; streots tio-inch packed snow and ice; river free running, open water;

Tree cover, Bare lake frozen, snow coverod 


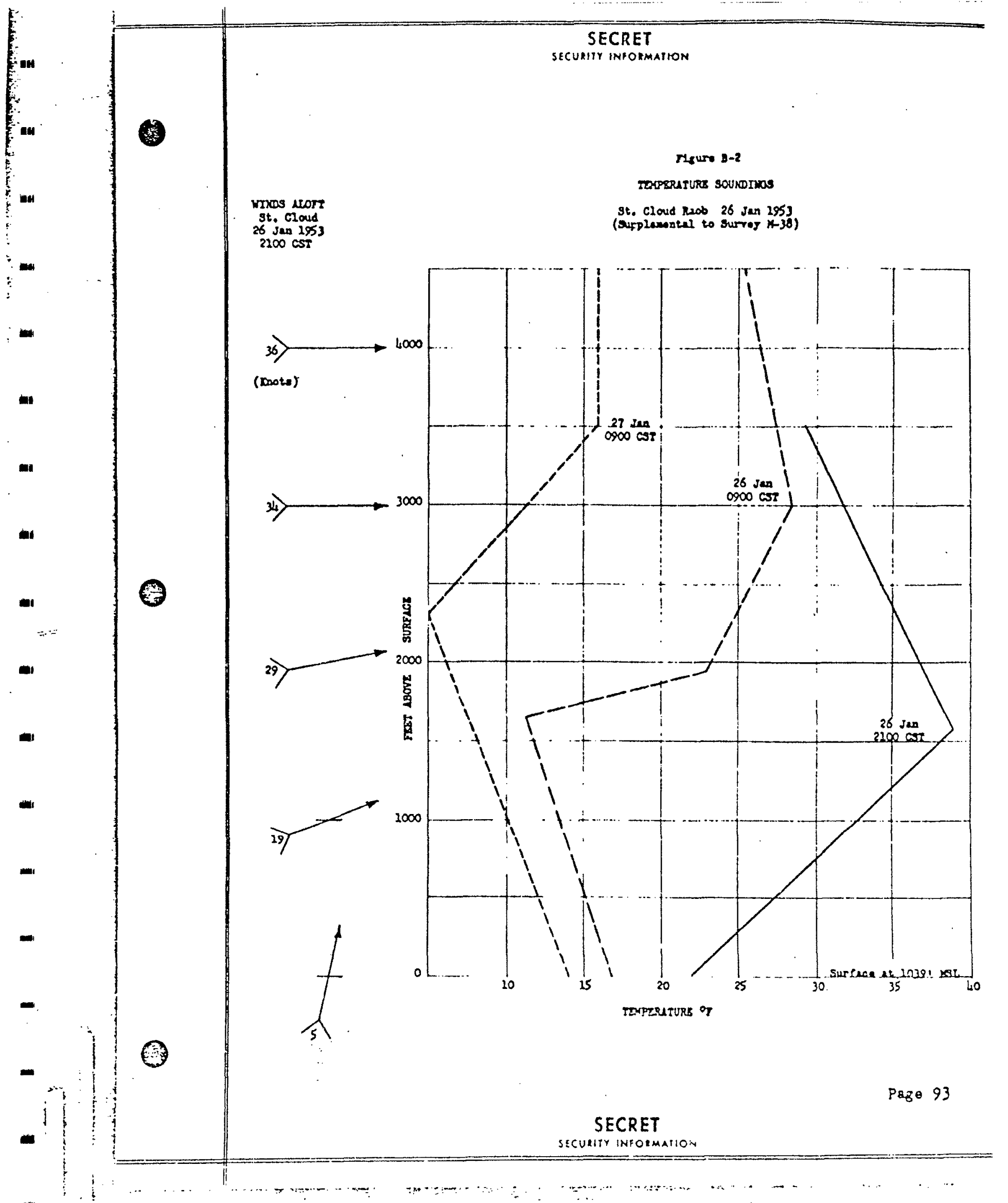




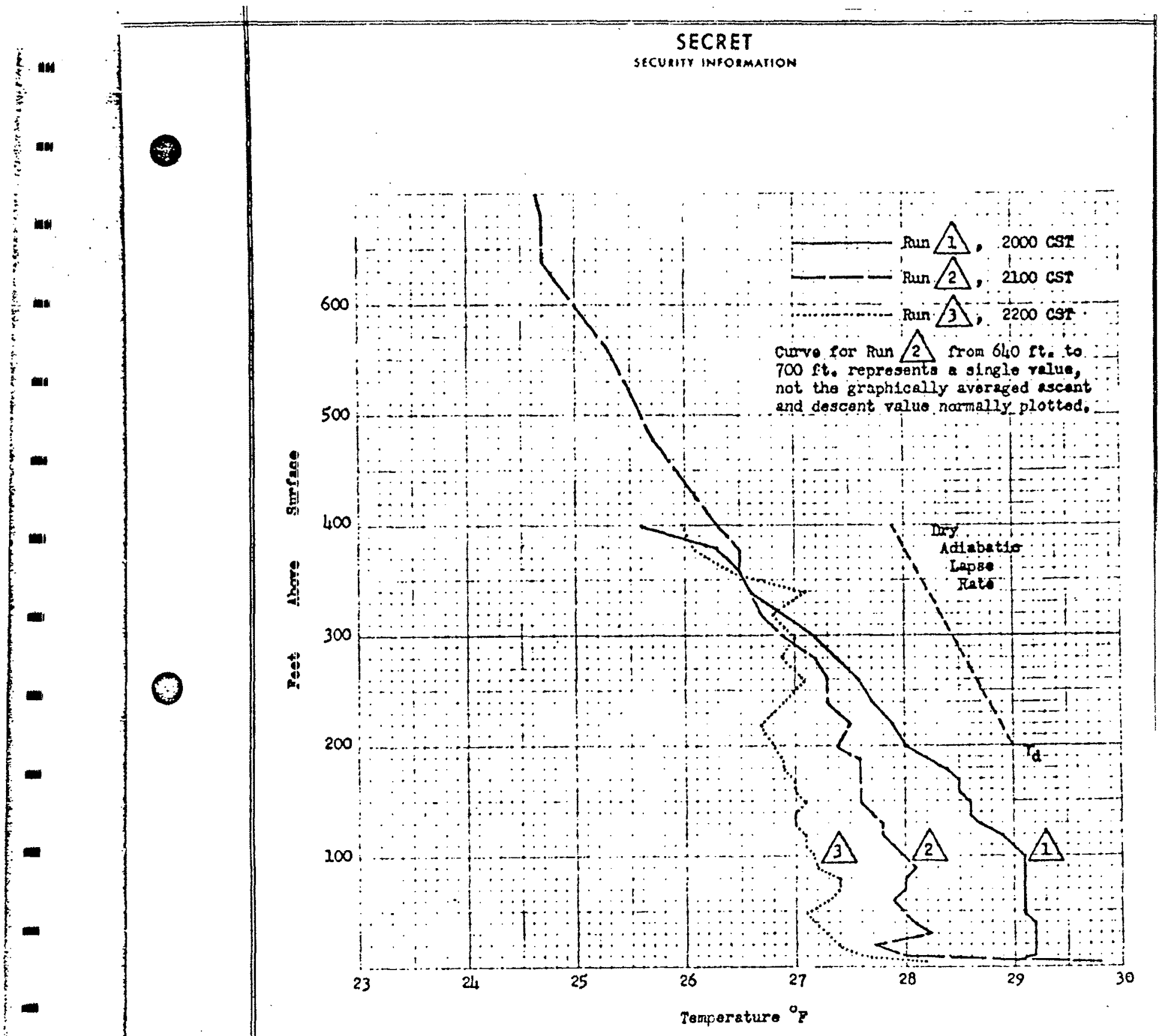

FICURE B-3

TEMPERATURE SOUNDINSS

Minnsapoll:

Rosidential-lroa Wirosondo

$4-38 \quad 26$ Jan 1953

P*8*944 


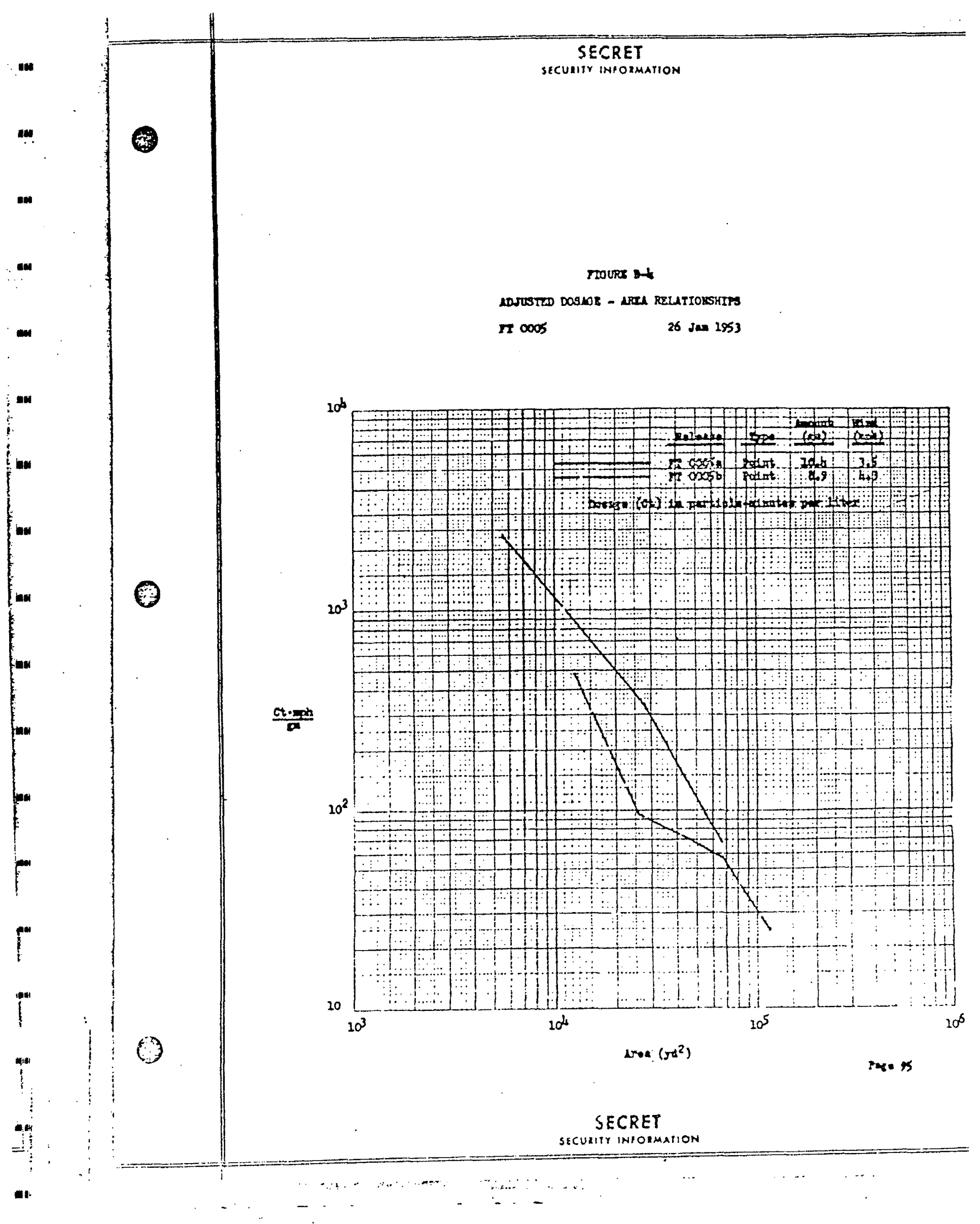




\section{LEROSOL GFHFRAT TH}

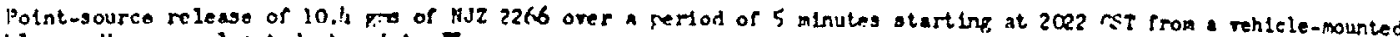
blower dispersor located at folnt is.

SAMPL IIG

location and Exposure

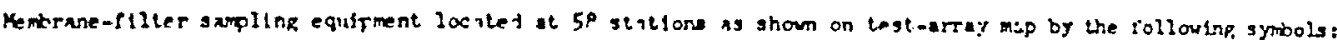

- Outbor sampler at helotic totwen 1 and 6 feet.

O Outibor sampler at helight above or belov perseral terraln level as indicated by note.

Mesulte

A11 smplers operated to reasure lotal dodnges turlip full samplinp per10d, 2000-2100 CST.

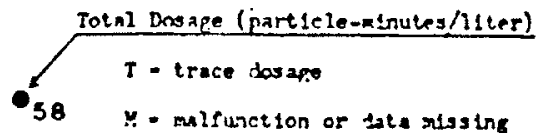

$\int_{100}$ Dosape entour with values axpresset in particle-ninutes per 11 tes.

\section{METronotont}

\section{Fquinment and Mrasurement}

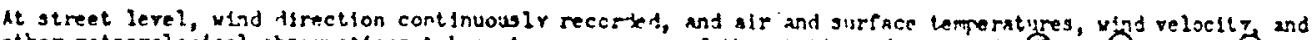

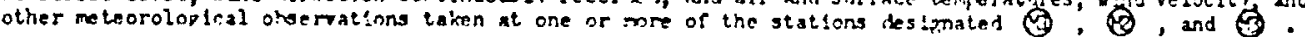

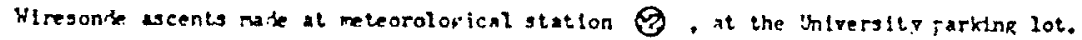

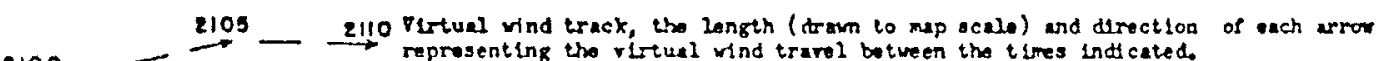

2100

-

$---(-2100$

Halloon track rerrosenting the vind-drift oberration at the time indleatod.

Ylade

Stroot-lerel y lack aodh-southwesterly at 4.9 ab.

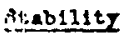

1.8* I lepe tran $6-300 \mathrm{rt}$.

sis

Broben cloud with keses li, 0 ft ebore the surface.

Tusereture

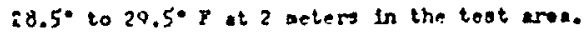

Xistare

Mixtng ratto of $2.9 \mathrm{pr}$ xgo dre alr. 


\section{AERISC, GTERATION}

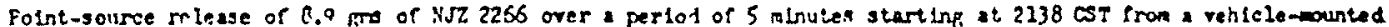
blower digperser located at point ity.

\section{SLML DiO}

Location and prosuro

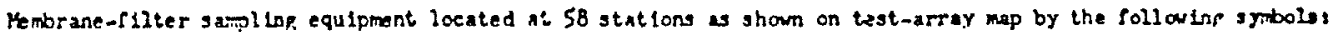

- Cutdoor sampler at heipt between 1 and 6 feet.

- nuthoor sampler at he lght above or below general terraln level ss lndieated by nota.

Results

111 amplers operated to mensure total dos ap,os durinp foll sampinp, period, 2130-2230 CSt.
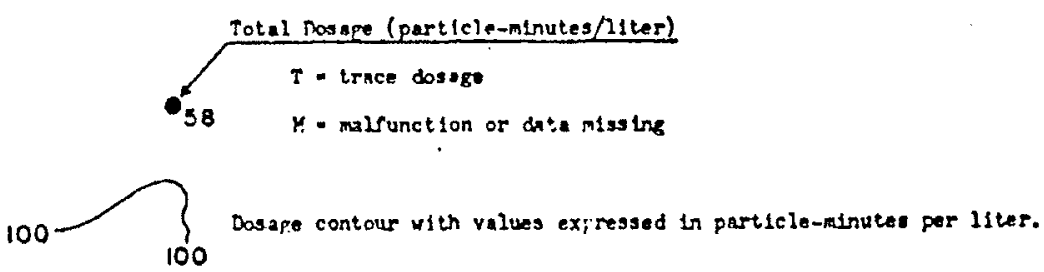

\section{YETSORCOGI}

\section{Equipment and teavurent}

at otroet level, whid direction cont lnuous iy recorided, and als ant surface temperatures, vind relocitf and other meteorologleal observations tohen at one or more of the stations desipnated (4), and

Wiresonde ascents made it meteorolorical station (2), it the Dhiversily parking lot.

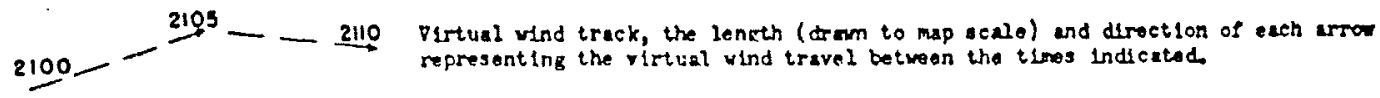

\section{NIndy}

Streat.lerel wnds southerly at $4.2 \mathrm{mph}$.

\section{Stabulity}

$2.2 \cdot \mathrm{T}$ lupse from 6-300 ft.

$3 x y$

Goar during tast period.

\section{Temperature}

$26^{\circ}-27^{\circ}$ at 2 metars in tho test aroa.

Molsture

Mixing ratio of 2.8 praikgo dry alr. 
SUMTARY OF RDOIONAL AND LOCAL WEATHEH

28 January 1953

(Survey $\mathrm{H}-40$, Supplemental to FT 0006 )

\section{SYNOPTIC SITUATION}

1 flling, stationary frontal system extended from British Columbia eastsoutheast to eastern Iora, and shbllow waves along this system were accompanfed by widespread snowfall. A weak 1020-mb hlgh-pressure area, centered 600 miles north-northwest of Minneapolis, supplied cold continental Arctic alr across Kinnesota. At the 700-mb level, a long-kave ridge over the Rockles and trough over the Appalachians resulted in a west-northwesterly gradient at 22 over onneapolis.

WEATHER REPORTS FROM WOLD-CHAMBERIAIN FIBID (MINNEAPOLIS)

\begin{tabular}{|c|c|c|c|c|c|c|c|c|}
\hline \multirow[b]{2}{*}{$\begin{array}{r}T \perp m \theta \\
(\mathrm{CST})\end{array}$} & \multirow{2}{*}{$\begin{array}{l}\text { cloud } \\
\text { Helght } \\
\text { (foot) }\end{array}$} & \multirow[b]{2}{*}{$\begin{array}{c}\text { Skg } \\
\text { Covar* }\end{array}$} & \multirow[b]{2}{*}{$\begin{array}{c}\text { Visibility } \\
\text { (miles) }\end{array}$} & \multirow[b]{2}{*}{ Heatherk } & \multirow[b]{2}{*}{$\begin{array}{l}\text { Tenp } \\
\left({ }^{\circ} \mathrm{F}\right)\end{array}$} & \multirow{2}{*}{$\begin{array}{l}\text { Derr } \\
\text { Point } \\
\text { (o } F) \\
\end{array}$} & \multicolumn{2}{|c|}{ Wind } \\
\hline & & & & & & & Dir & $\begin{array}{l}\text { Speed } \\
\text { (mph) }\end{array}$ \\
\hline $\begin{array}{l}1.830 \\
1.930 \\
2030 \\
2130 \\
2.230 \\
2330\end{array}$ & $\begin{array}{c}6,000 \\
20,000 \\
\text { None } \\
\text { None } \\
\text { None } \\
4,100\end{array}$ & $\begin{array}{l}\text { Scattered } \\
\text { Scattered } \\
\text { Clear } \\
\text { Clear } \\
\text { Clear } \\
\text { Scattered }\end{array}$ & $\begin{array}{l}15 \\
15+ \\
15+ \\
15+ \\
15+ \\
15+\end{array}$ & $\begin{array}{l}\overline{-} \\
\overline{-} \\
\overline{-}\end{array}$ & $\begin{array}{r}10 \\
8\end{array}$ & $\begin{array}{l}1 \\
0 \\
-3 \\
-3 \\
-4 \\
-4\end{array}$ & $\begin{array}{l}\text { NW } \\
\text { WWW } \\
\text { WNW } \\
\text { WWW } \\
\text { W } \\
\text { WWW }\end{array}$ & $\begin{array}{l}6 \\
8 \\
7 \\
6\end{array}$ \\
\hline
\end{tabular}

* Average cloudiness sunrise to sunset: $90 \%$

* And/or restrictions to Visibility

Sea-level. pressure at $2130 \mathrm{CST}: 1021.0 \mathrm{mb}$

Ground condition: Four-inch packed snow; main streets clear; secondary

Tree cover: None 


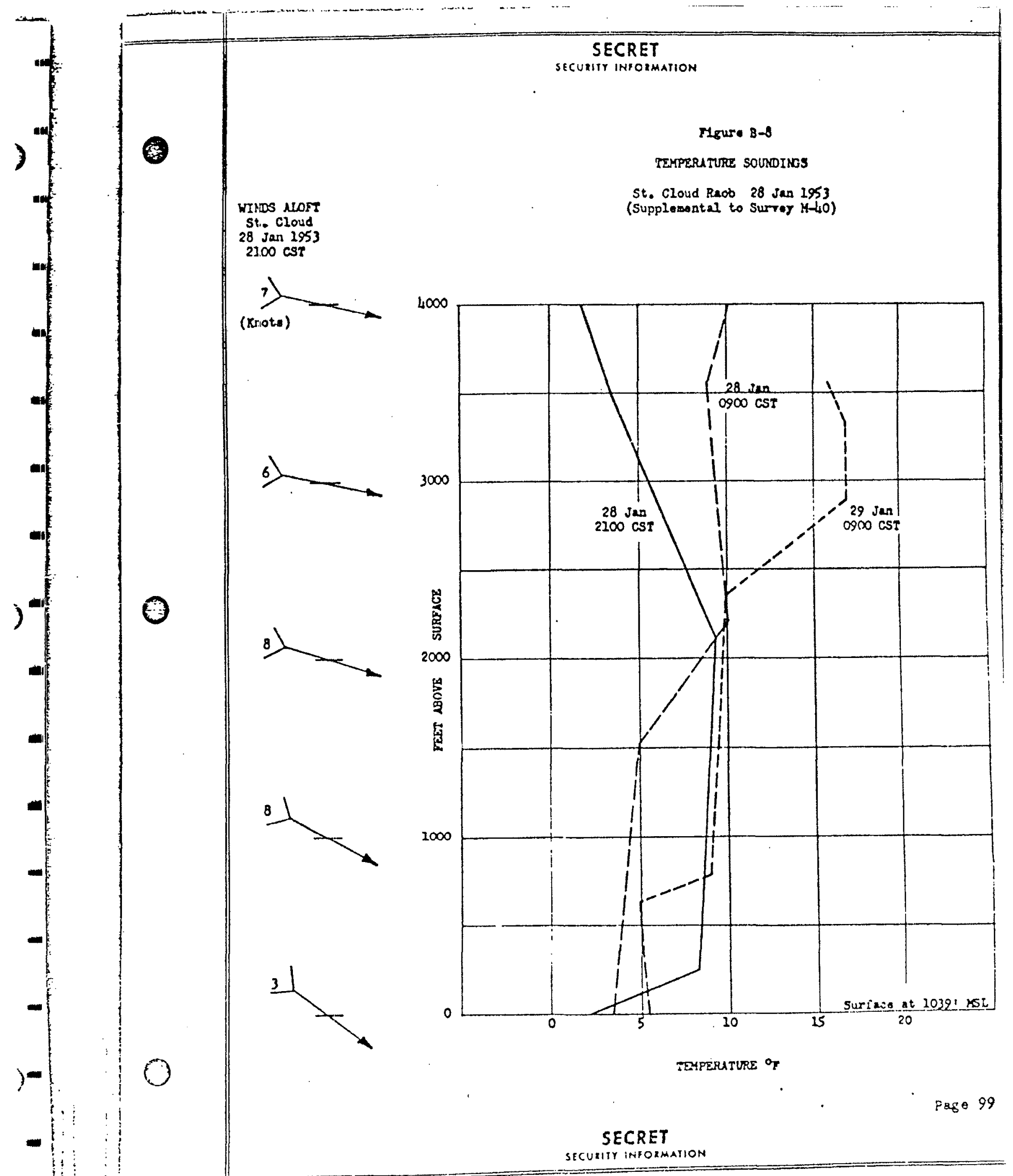




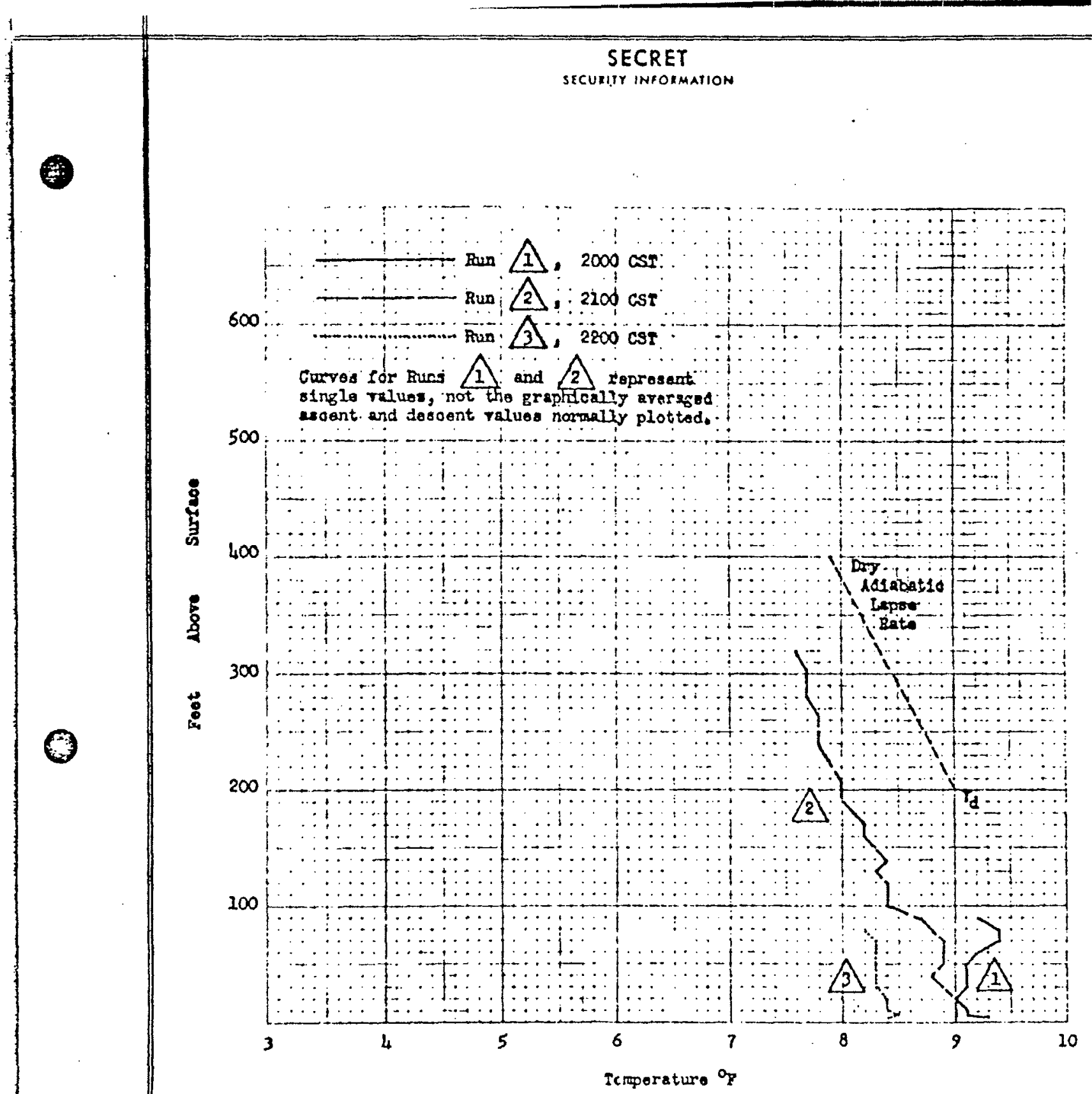

FIOURE B-9

TEMPERATURE SOURDINGS

Mnseapolla

Resldent12l-Area Wiresonde $\mathrm{M}-\mathrm{LC}$ $28 \mathrm{Jan} 1953$ 

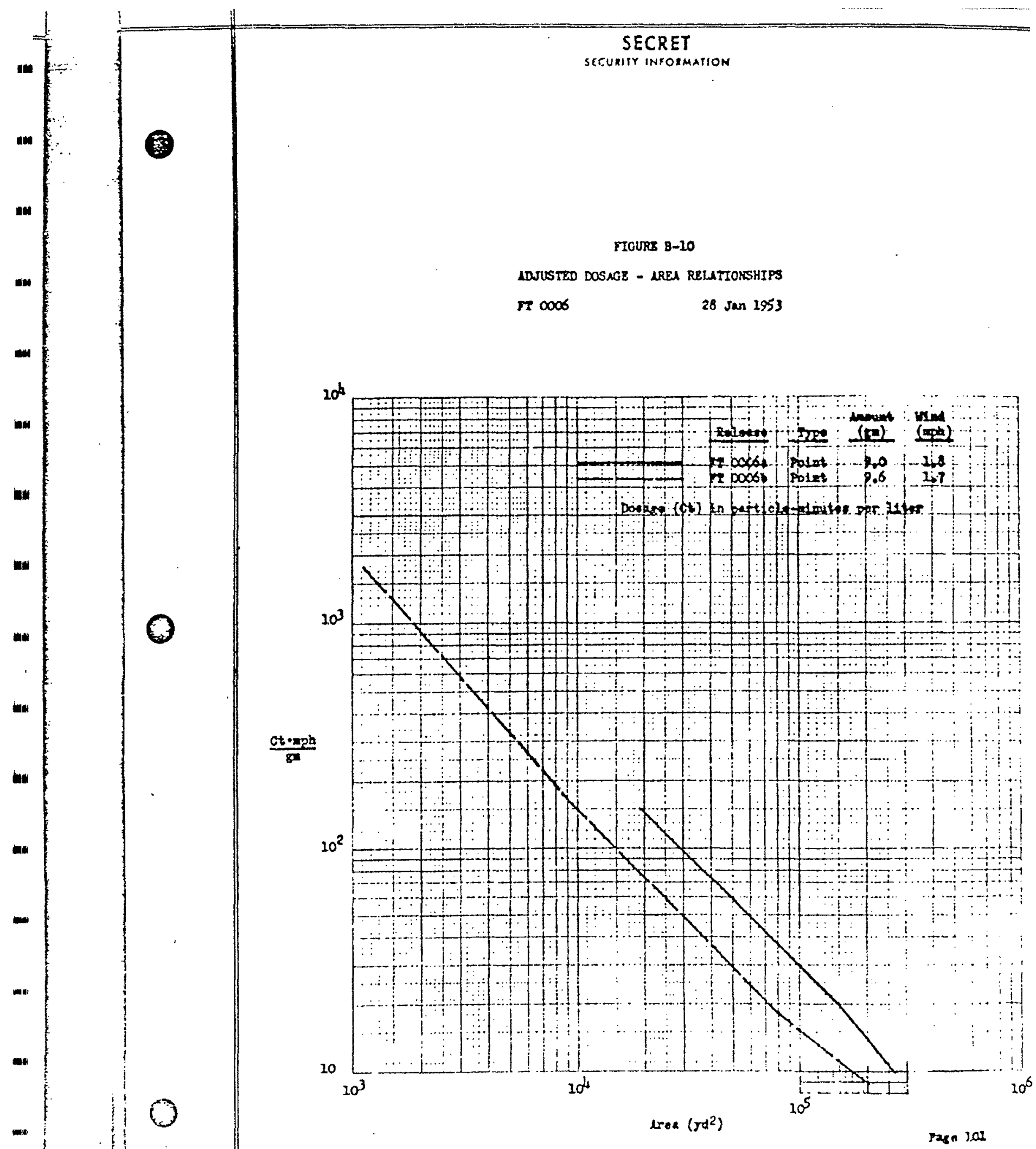

SECRET

SECURITT INFORHATION 


\subsection{0sor apreratrox}

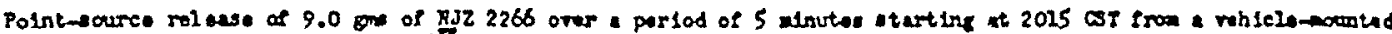
blorer dieperser located et polnt in.

sevpengo

tocation and Bposure

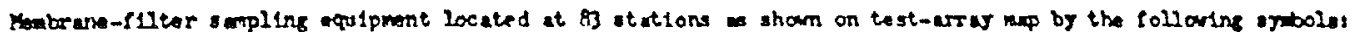

- autbor sapier at helght between 1 and 6 foet.

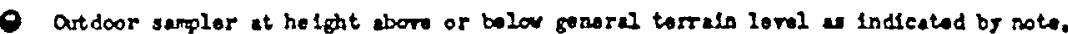

Barults

Al soplers operated to ware total doese during rull inpling per10d, $2000-2100$ CST.

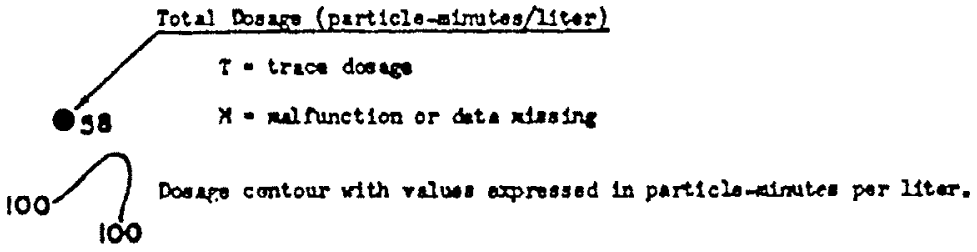

8 ETELoworor

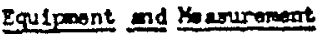

1t troet levol, wind direction continuousiy recordo, and ar axd surface tenperatyras, whd rolocitz and other meteorological obserrations taken at ase or more of the stations designated 6 , 6 , and 6

Wiresonde ascents at meteoralnglesl station (3), at the Oniversity parking lot.

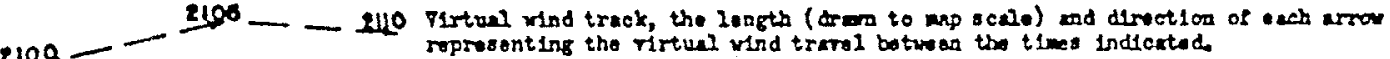

$$
\begin{aligned}
& \text { - }
\end{aligned}
$$

Hinde

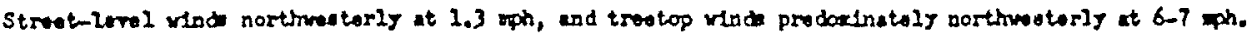
stib111tz

$1.2 \cdot 1$ Lape trom $6-300 \mathrm{rt}$.

$3 x z$

Cloar during toot perlod.

$\because$ irperntare

$8.5^{\circ}$ to $10^{\circ} \mathrm{T}$ at 2 moterd in the tort aron.

Yolsture

Mixing ratio of $0.8 \mathrm{gm} / \mathrm{kgm}$ dry atr.

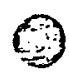




\section{NBROSOR CERERTTOK}

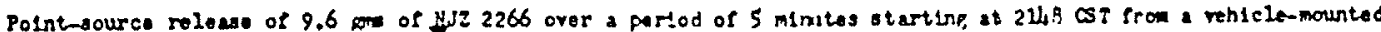
blower dioperser located at point 4 , spproximatels 5 feet obove the river level.

Location and Exposure

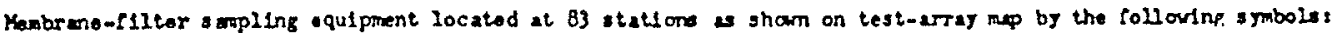

- cutdoor smpler at helght botween 1 and 6 feot.

- autdoor samplor at holght above or belou general terrain leval ss indfeated by note.

Rasulte

111 somplars oporcted to mesure total dosapes turing rull smpling reriod, 21302230 CST.

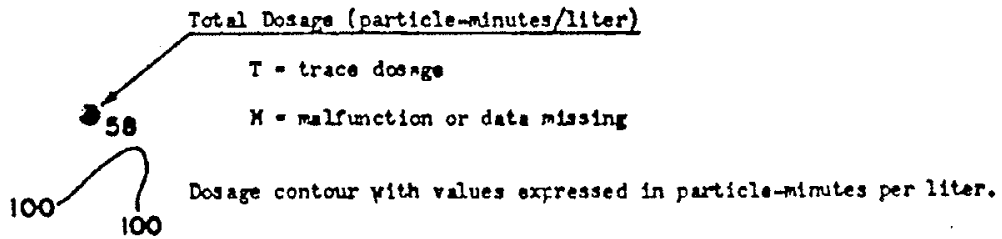

ETEOROLOOI

Equipmant and Yeasurement

at atreet level, wind direction continuousiy recorded, and $i f$ and surface terperatures, vind relocity and other mtoorological obscrvations taken at ore or nore of the stations desienated (1), (3), and 8 .

Wiresonile ascents made at reteorolopical station 8 , at the 'hiversity parking lot.

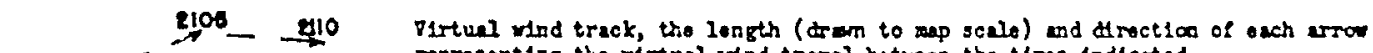
2100<smiles>[Si]#CC1CCCCC1</smiles>
reproesting the rirtual vind tratel botweed the tioes indicated.

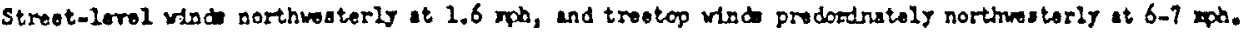
Stabilex

1.3 . T lape frat 6 to $300 \mathrm{tt}$.

sky

Cloar during tost porlod.

Tamperatiure

$7.5^{\circ}$ to $8.5^{\circ} I$ st 2 mater in the tost ares.

Kolsture

K1xing ratio of $0.8 \mathrm{gr} / \mathrm{kg}$ dry atr. 
SURPLARY OF REOIONAL AND LOCAL WEATHER

30 January 1953

(Survey M-4l, Supplemental to FT 0007)

\section{STNOPTIC SITUATION}

A deepening low-pressure system, moving rapidly castward, passed 200 miles to the north of Minneapolis during the test period. The associated warm front extended to the south-southeast, and the cold ront to the west-southwest. Nelther front. passed the station during the test period, but very light intermittent snow was observed. A strong highpressure cell, 1000 miles north-northwest of the station wes supplying cold continental Arctic air to the north side of the system. At the 700-mb level, a weak ridge along tho Atlantic coast, a stronger ridgo along the pacific coast, and a shallow trough extending from Wisconsin to Texas produced a west-northwesterly gradient wind of $38 \mathrm{mph}$ over Nunneapolis.

WEATHER REPORTS FROM WOLD-CHAMBERLAIN FIEID (MINLEAPOLIS)

\begin{tabular}{|c|c|c|c|c|c|c|c|c|}
\hline $\begin{array}{r}\text { TIme } \\
\text { (CST) }\end{array}$ & $\begin{array}{l}\text { Cloud } \\
\text { Helght } \\
\text { (reet) }\end{array}$ & $\begin{array}{l}\text { Sky } \\
\text { Cover* }\end{array}$ & $\begin{array}{c}\text { Visibility } \\
\text { (miles) }\end{array}$ & Weather** & $\begin{array}{l}\text { Temp } \\
(\mathrm{F}) \\
\end{array}$ & $\begin{array}{l}\text { Der } \\
\text { Point } \\
\text { (OF) } \\
\end{array}$ & $D \perp r$ & $\begin{array}{l}\text { Spd } \\
\text { Speed } \\
\text { (mph) }\end{array}$ \\
\hline 830 & 700 & overcast & 3 & $\begin{array}{l}\text { Snow grains } \\
\text { and fog }\end{array}$ & 25 & 22 & $s$ & 1 \\
\hline 1930 & 500 & overcast & 3 & $\begin{array}{l}\text { Snow grains } \\
\text { and } f \circ g\end{array}$ & 25 & 22 & SW & 10 \\
\hline 2030 & 300 & Overcast & $2 \frac{1}{2}$ & $\begin{array}{l}\text { Snow grains } \\
\text { and fog }\end{array}$ & 24 & 22 & SSH & 12 \\
\hline 2130 & 400 & Overcast & $2 \frac{1}{2}$ & $\begin{array}{l}\text { Snow grains } \\
\text { and fog }\end{array}$ & 25 & 23 & s & 1 \\
\hline 230 & $\begin{array}{l}7500 \\
9500\end{array}$ & $\begin{array}{l}\text { Overcast } \\
\text { Broken }\end{array}$ & $\begin{array}{l}3 \\
4\end{array}$ & $\begin{array}{l}F \circ g \\
F \circ g\end{array}$ & $\begin{array}{l}25 \\
26\end{array}$ & $\begin{array}{l}23 \\
23\end{array}$ & $\begin{array}{l}\text { SSW } \\
\text { SSW }\end{array}$ & \\
\hline
\end{tabular}

* Average cloudiness sunrise to sunset: $100 \%$

* And/or restrictions to visibility

Sea-level pressure at $2130 \mathrm{CST}: 1011.2 \mathrm{mb}$

Ground condtion: Four-inch to six-inch base snow; main roade clear; 1co in spots; residential and side sireats two-inches packed

Tree cover: None snow and 1ce; river open 


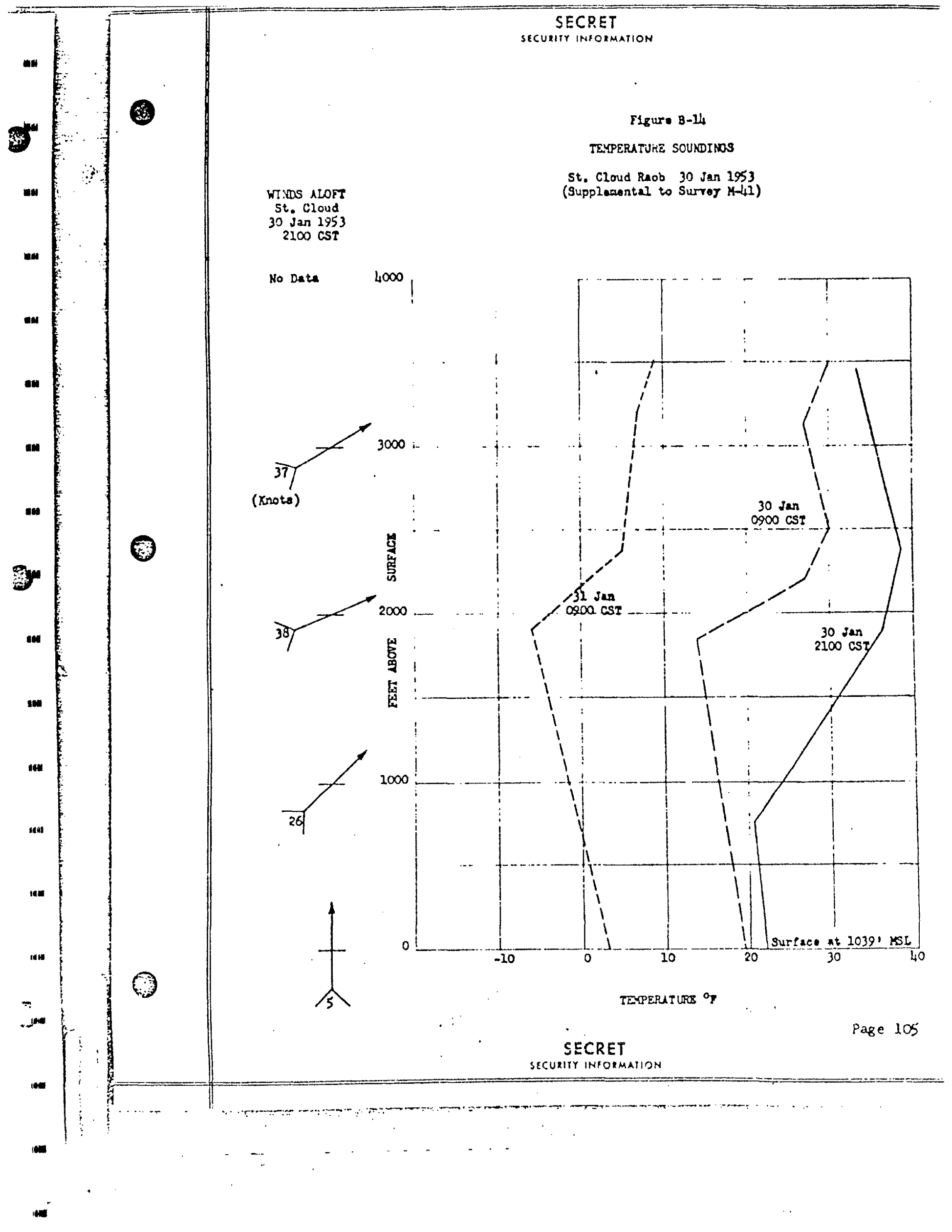




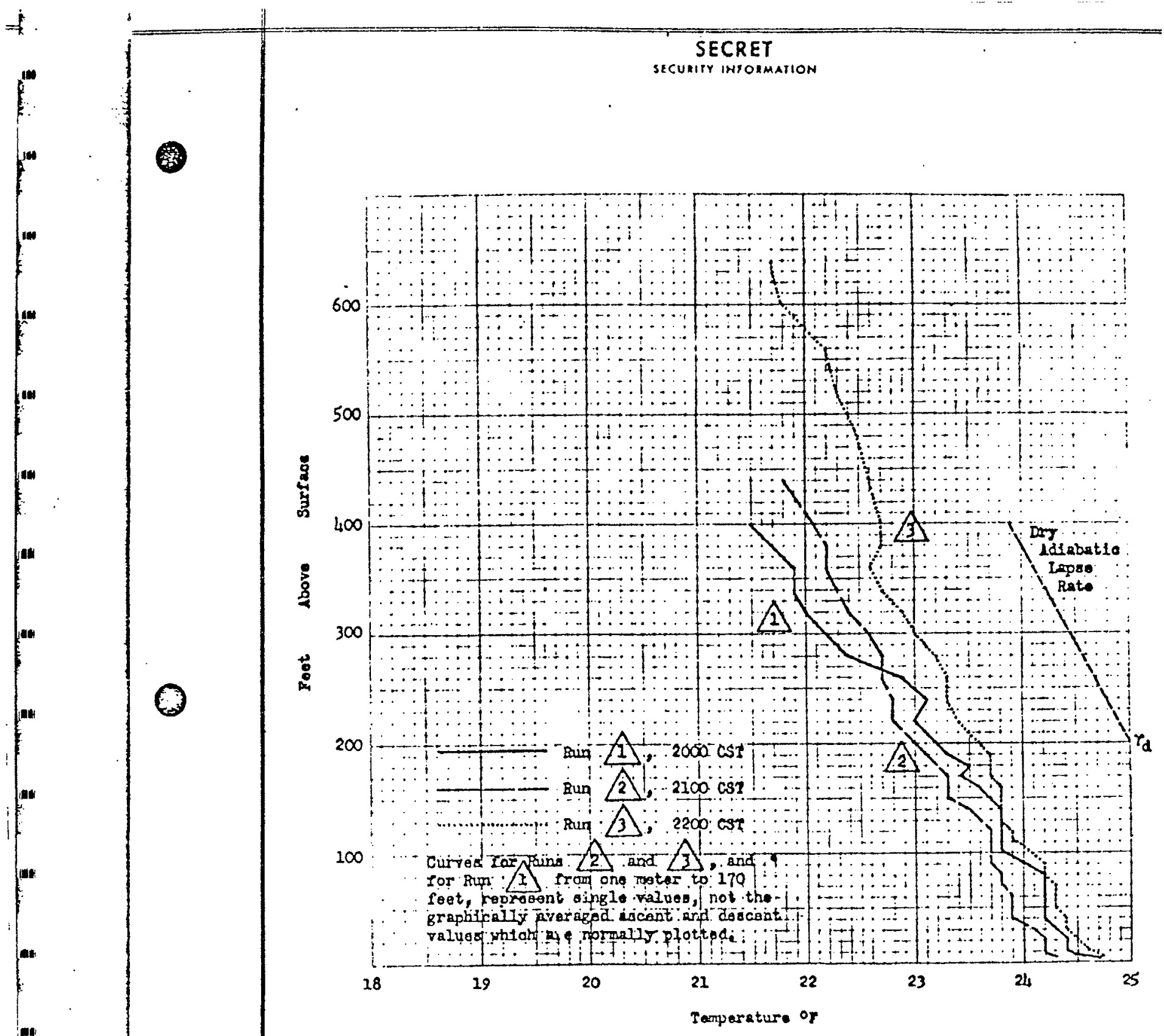

FIOURB B-15

TEAPERATIYR SOUNDINAS

Hinnospoli.

Rosident1al-Aros Wrosondo

H. 41 $30 \mathrm{Jan} 2953$

P.g 105

\section{SECRET}

SECURIYY INFORMATHON 


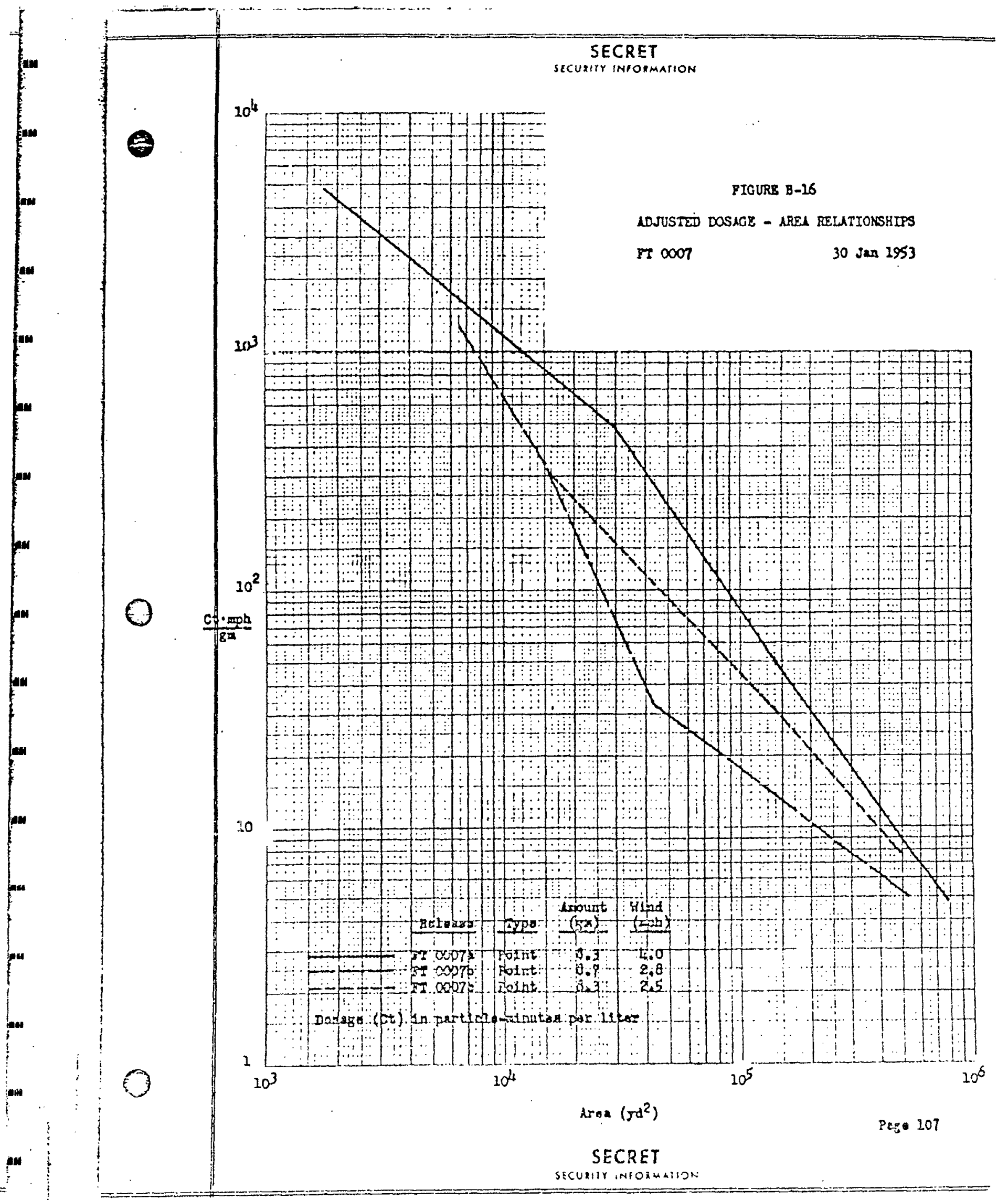




\section{AEROSOL GFEPAT TOH}

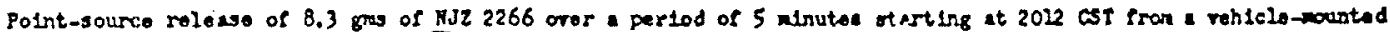
blower disperser locatod at point il.

\section{Locetion and Exposure}

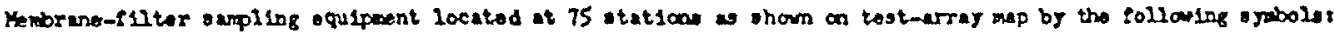

- Outdoor a ampler at haffit botwen 1 and 6 soet.

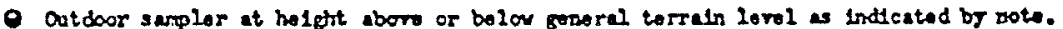

Rosulte

AlI amplers operatod to measure total dosages biring rell sampling pertod, $20002100 \mathrm{cst}$.
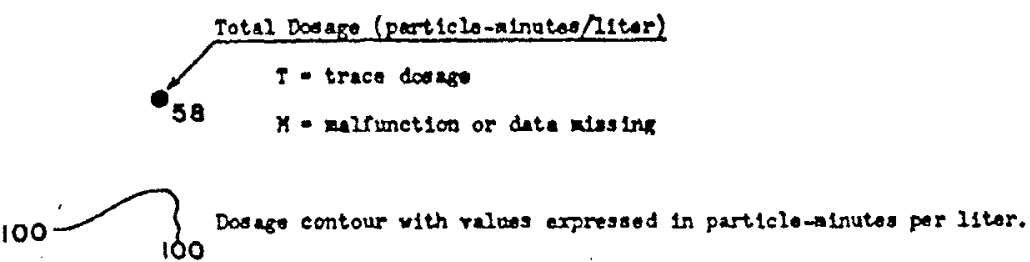

METEORO.OT

Egulpmont and Besurement

At stret level, wind diroction continnously recorded, and sir and surface tomperatures, wad relocits, and other weteorologicel oberrations takan at stations designited 8 and 8 .

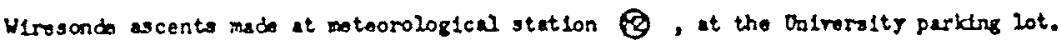

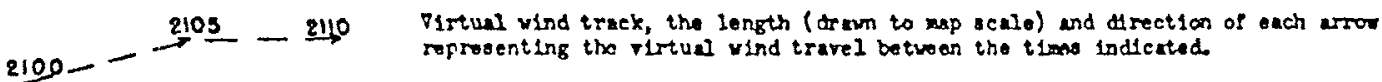

$$
\ldots \ldots+\ldots 2180
$$

Balloon track representing wind-drift obserration it the tim fodeated

Hinds

Street-level wids acotherly at $3.8 \mathrm{mph}$, and troetop winds south to southom terly at 5.6 ph.

\section{Stab111t}

$2.3^{\circ}$ E lase sran 6-300 rt.

shy

Orersest slouds with bases 300 ft abore the surtsces.

Terrerature

$23.9^{\circ}$ to $34.9^{\circ} F$ at 2 metora in the toat aro.

\section{Ko is ture}

Hixing ratio of $2.4 \mathrm{gra} / \mathrm{kg}$ dry 4. 
AEROSOL OzNERATION

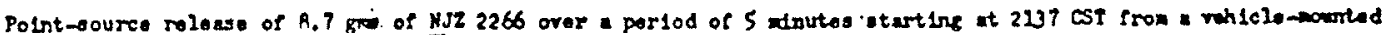
blower disporser located at point is. SAITINO

Location and Exposure

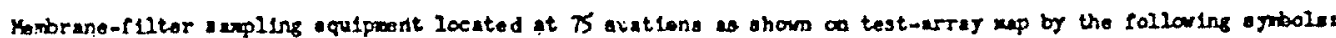

- Outdoor suplor at hologt botivean 1 and 6 foot.

- outdoor sumples at bulght abore or betow general torrala lovel w Indiceted by note.

Rosulte

NI sarplers operated to nesuro total ded ages during rull sowling period, $2130-2230$ CSt.

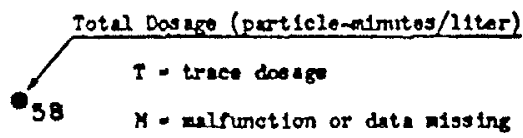

M.TFOROLOT

Equipont. and Yosaurement

At strect level, vind direction continuousit recorded, and air and aurface temeratures, wind relocity, and other meteorolopical obserrations taken at stations desipnated and of

Wiresonde ascents mate at meteorologiesl station , at the Oniversity parking lot.

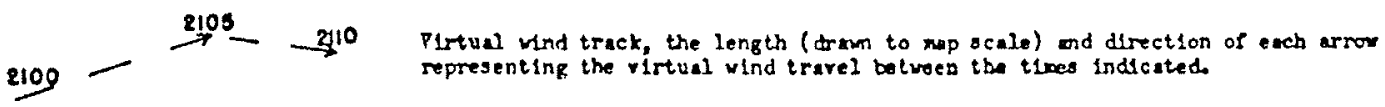

WLate

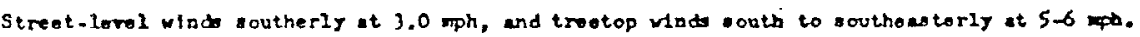
Stabll1tr

$1.6^{\circ}$ Iвpse Irom 6.300 $\mathrm{st}$.

sky

crercut eloud with beses 400 ft sbove the surface.

Temperature

$23.9^{\circ}$ to $24.3^{\circ} r$ at 2 metora in the tost aren.

Kolsture

Sixlng ratio of $2.6 \mathrm{gm} / \mathrm{kgn}$ t大 $4.1 \mathrm{r}$. 
TEST LIRAT AID RESUTS

Figure 8-19

LERCSO1: TENERATION

Point-source rolesso of $8.5 \mathrm{gmo}$ of $\mathrm{NJ2} 2266$ over a pertod of $5 \mathrm{minutes}$ atarting at 2305 CST rrow vehicle-mounted bilower dispersor loested at polint is.

SMMPL Dro

Lixation and Exparaxe

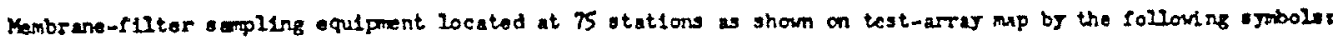

- artdoor samplor at holght beturen 1 and o feot.

- autdoor sampler at heipht above or below general tersifn letal as indicated by now.

Risoulte

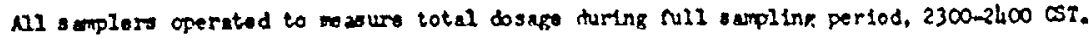

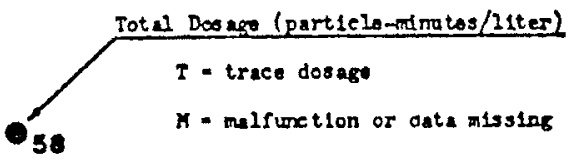

METEORILOT

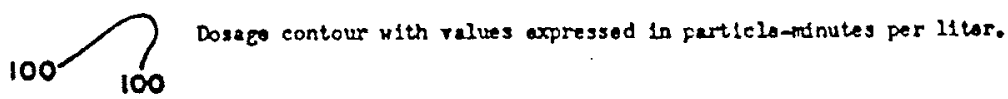

Equiprent and Monsuroment

At street lovel, wind droction continuously recorded, and Ir and surface temeratures, vind velocity and

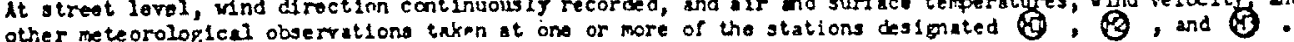

Viresonde scemts made at meteorolopical station 6 , at the iniversity parding lot.

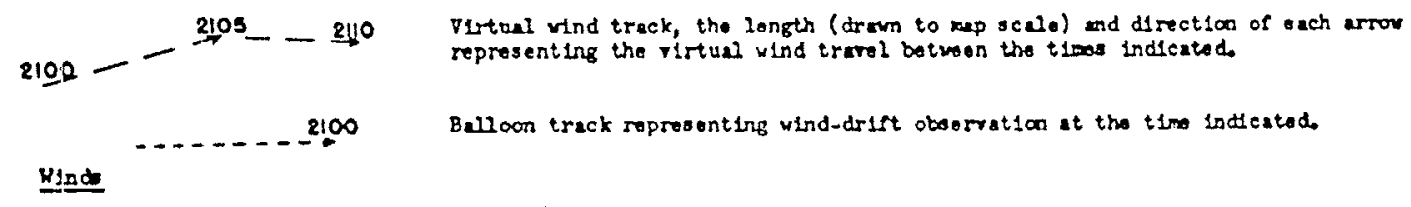

Street-20vel winds south-southosytorly at 2.4 aph, and troetop vinds south to southousterly at $5-6$ mb. Stab111ty

$1.7^{*}$ T 1 жse e troa 6-300 it.

six

Orercast clouds with beses 7500 ft abore the auf ace.

Temperature

$24.3^{*}$ to $24.9^{\circ} \mathrm{P}$ at 2 metors in the tost area.

\section{Yolature}

. Mixing rat 10 of $2.6 \mathrm{gr} / \mathrm{kga}$ drs $21 \mathrm{r}$. 
SUMARY OF REGTONAL AND LOCAL WEATHER

4 March 1953

(Survey M-56, Supplemental to FT 0019)

\section{SYNOPTIC SITUATION}

Most of Minnesota was covered by a cyclonfe stream of cold air associated with a 978-mb low-pressure center over Quebec. Rapldily variable cloudiness and infrequent light snow showers accompanied a moderate wind, which varled considerably in speed during the test perlod. At the 700-mb level, a northwesterly gradient wind of $45 \mathrm{mph}$ was due to a long wave-length pattern consisting of a broad trough extending from Quebec to Florida and of a strong ridge over the Pacific coast.

WEATHER REPORTS FROM WOLD-CHAMBERLAIN FIELD (MINEAPOLIS)

\begin{tabular}{|c|c|c|c|c|c|c|c|c|}
\hline \multirow[b]{2}{*}{$\begin{array}{l}\text { Time } \\
\text { (CST) }\end{array}$} & \multirow{2}{*}{$\begin{array}{l}\text { Cloud } \\
\text { Height } \\
\text { (reet) }\end{array}$} & \multirow[b]{2}{*}{$\begin{array}{c}\text { Sky } \\
\text { Cover* }\end{array}$} & \multirow[b]{2}{*}{$\begin{array}{l}\text { Visibility } \\
\text { (miles) }\end{array}$} & \multirow[b]{2}{*}{ Weather * } & \multirow[b]{2}{*}{$\begin{array}{l}\text { Temp } \\
\left({ }^{\circ}\right) \\
\end{array}$} & \multirow{2}{*}{$\begin{array}{c}\text { Dow } \\
\text { Point } \\
(\mathrm{F}) \\
\end{array}$} & \multicolumn{2}{|c|}{ Wind } \\
\hline & & & & & & & $\underline{D r}$ & $\begin{array}{l}\text { Speed } \\
\text { (mph) }\end{array}$ \\
\hline $\begin{array}{l}183 \\
193 \\
203 \\
213 \\
223 \\
233\end{array}$ & $\begin{array}{r}12,000 \\
11,000 \\
11,000 \\
4,200 \\
3,500 \\
4,000\end{array}$ & $\begin{array}{l}\text { Broken } \\
\text { Broken } \\
\text { Scattered } \\
\text { Scattered } \\
\text { Scattered } \\
\text { Scattered }\end{array}$ & $\begin{array}{l}15+ \\
15+ \\
15+ \\
15+ \\
15+ \\
15+\end{array}$ & $\begin{array}{l}- \\
- \\
-\end{array}$ & $\begin{array}{l}19 \\
18 \\
17 \\
17 \\
17 \\
16\end{array}$ & $\begin{array}{r}10 \\
11 \\
9 \\
11 \\
10 \\
10\end{array}$ & $\begin{array}{l}\text { WSW } \\
\text { WSH } \\
\text { WSW } \\
\text { WSW } \\
\text { WSW } \\
\text { W }\end{array}$ & $\begin{array}{l}13 \\
11 \\
12 \\
12 \\
15 \\
15\end{array}$ \\
\hline
\end{tabular}

* Average cloudiness sunrise to sunset: $60 \%$

* And/or restriction to visibility

Sea-level pressure at $2130 \mathrm{CST}$ : $1009.8 \mathrm{mb}$

Ground condition: Twelve-inch packed snow; main street clear; sije streets clear, but 1cy 50 s because of melted snow; river tempera-

Tree cover: None ture $34^{\circ} \mathrm{F}$ 


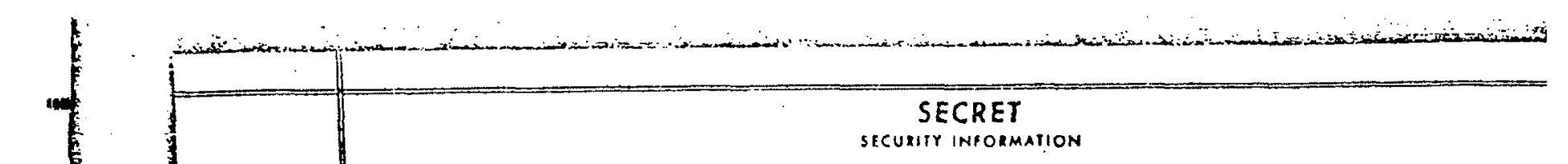

8

Fqure 8-21

TERPRUTURE SOUDINOS

WTNDS NTOFT
St. Cloud

St. Cloud Beob 4 Kar 1953

4 st. Cloud 1053

(3upplanantal to Survoy $\mathrm{B}-56$ )

2100 CST

(xnot:)

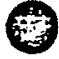

-

-

3.

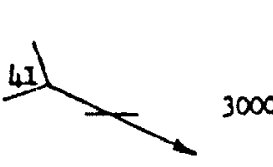

4000
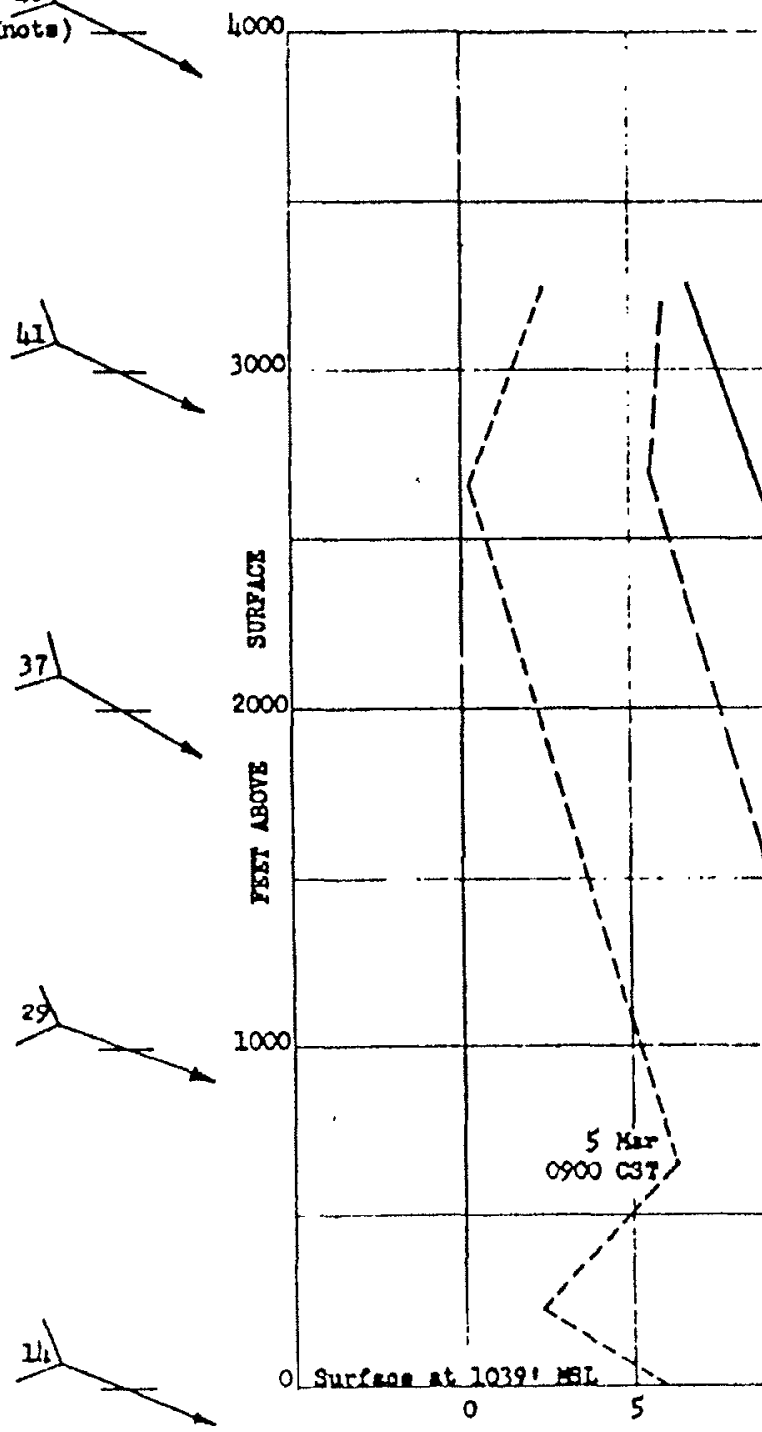

Pá $11 \hat{c}$ 


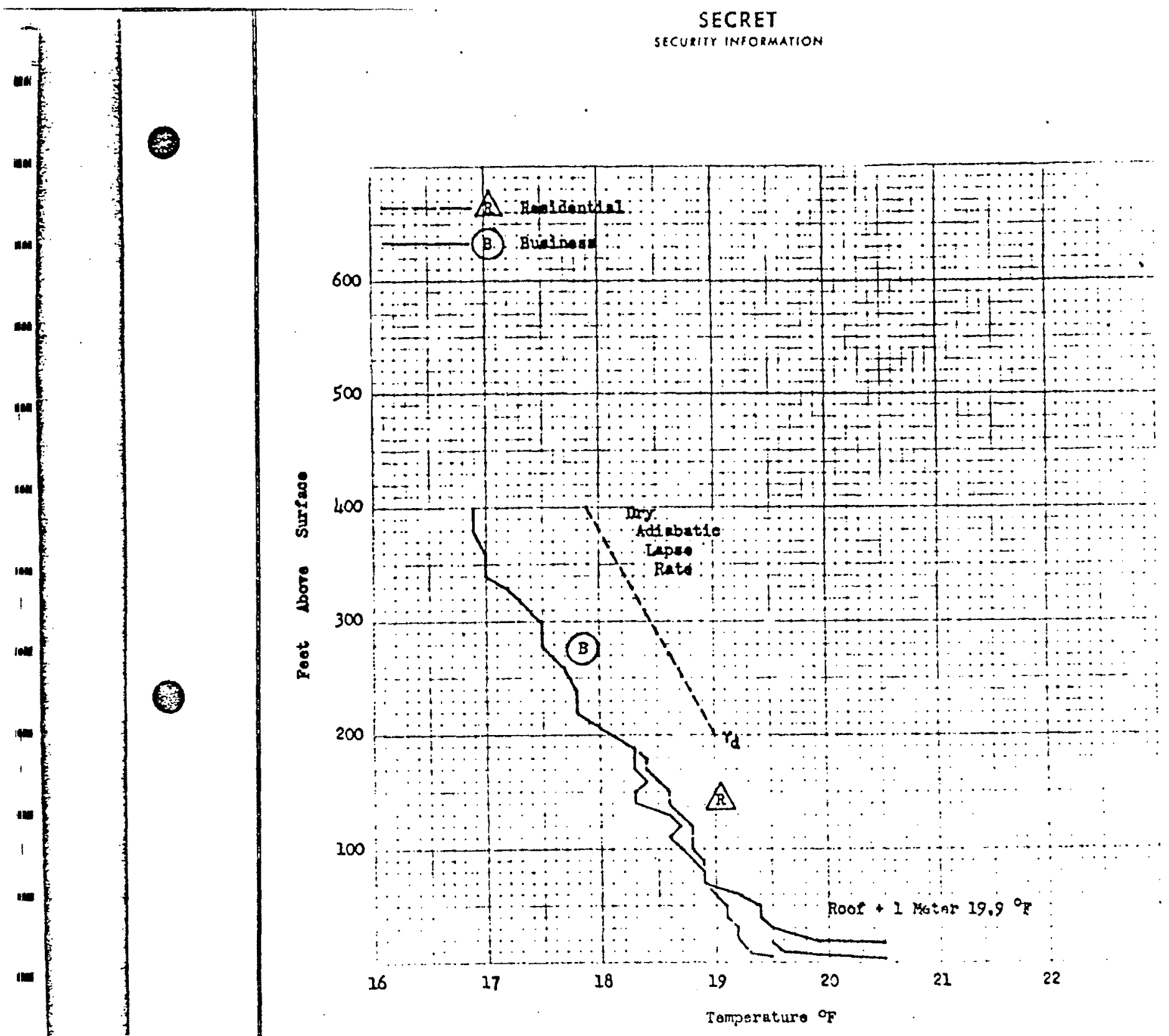

EICURE B-22

COMPARATTVE TEYPERATURE SOUNDINGS

Mrnaapolis Wiresonde

Residential yo Business Aroe

Run 1,2900 CST 4 Mar 1953

\section{SECRET}

Pazy 113

SECURIYY INFORMATION 


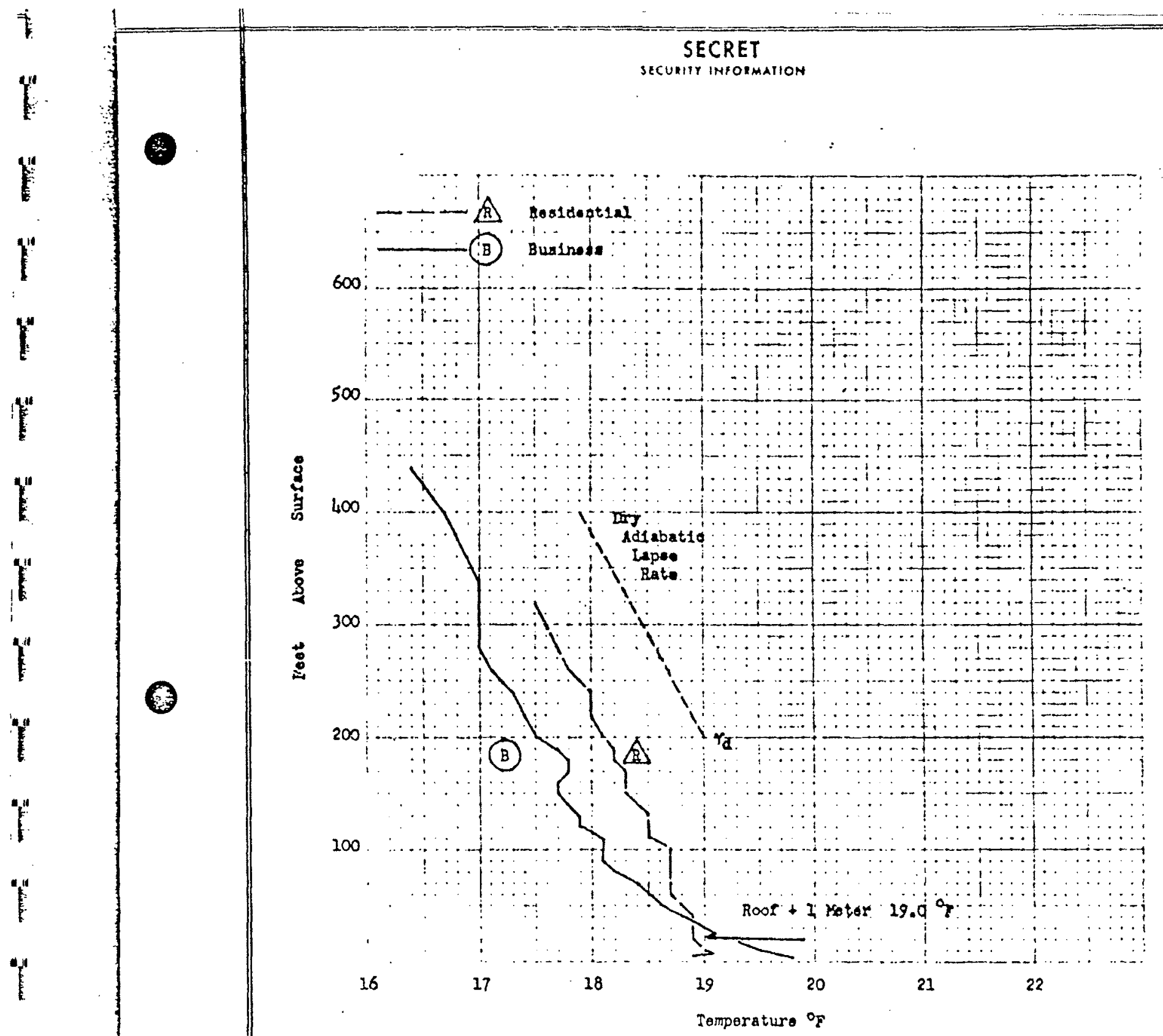

FIGURE B-23

COMPARATIE TE.PPERATURE SOUNDINGS

Hnnoapolis Hiresonde

Rosidential Va Eusiness Nros

Fun 2, 2000 CST 4 bar 1953

\section{SECRET}

Page IIt 


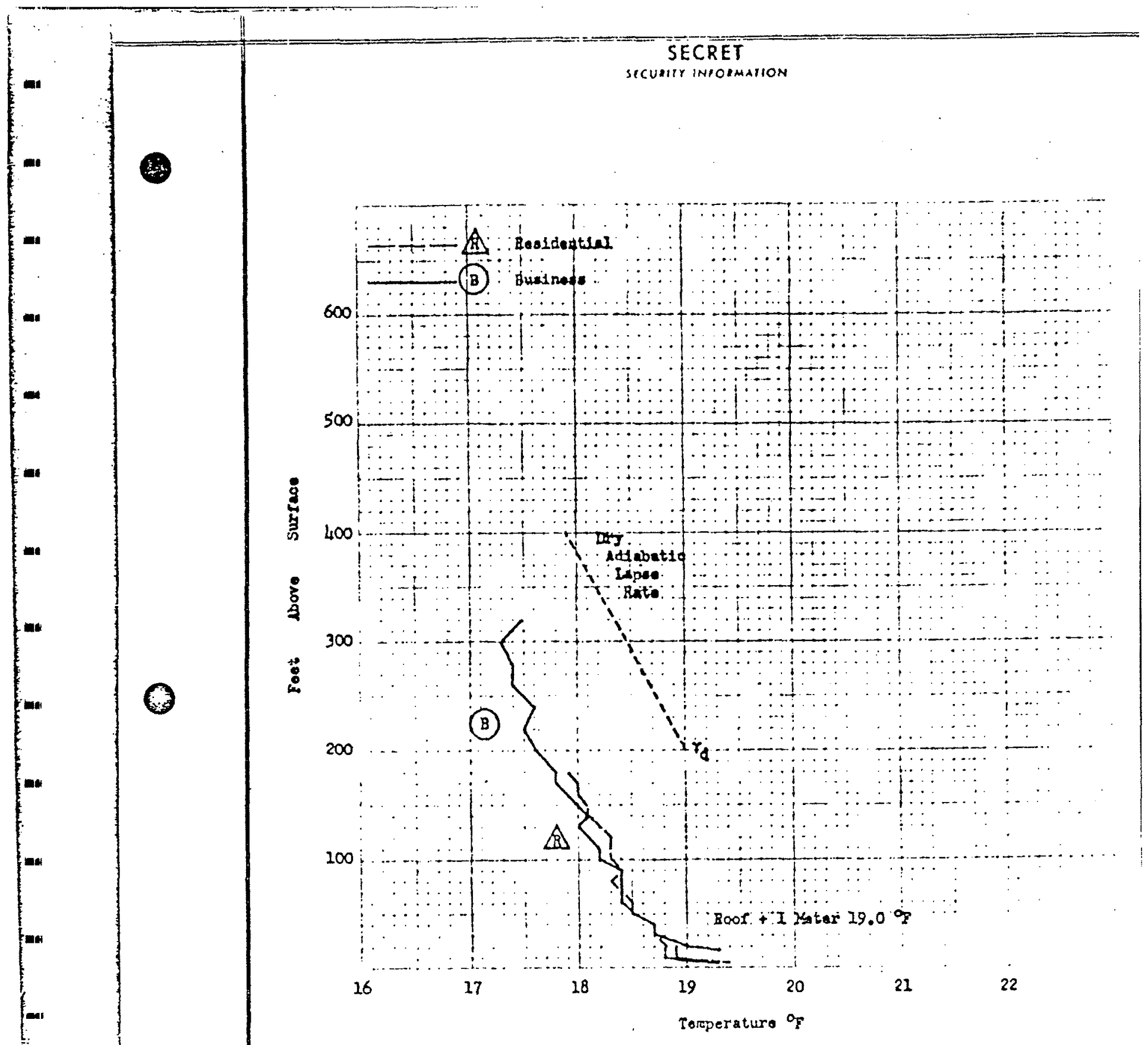

FIGURE $8-2 !$

COMPAPATIVE TEUPERATURE SOUNDINGS

Mrneapolid Wiresondo

Rasidential Va Business liea

Run 3, 2130 CST 4 Mar 1953

SECRET

SECURITY INFORMATION

$p_{50} \cdot 125$ 
PIONEER HAIL DOSAGES

Sampler

Location

Dosages for a Given Release

\section{A Surface*}

B lst Floor

C 2nd Floor

D 2nd Floor

B Basement

F

Basement

PN 001
$5-0$
$5-0$
$5-1$
$T-0$
$1-0$

5
$5-0$
$2-0$
$5-1$
$T-0$
$T-0$

FTO19b

FT 00190

$\begin{array}{rrr}5 & 13 & 23 \\ 0 & 12-0 & 0-15 \\ 0 & 6-0 & 4-0 \\ T & 0-0 & 0-T \\ 0 & T-T & T-T \\ 0 & 5-0 & 6-0\end{array}$

* Dosages are expressed in particle-minutes per l1ter $T$ represents trace dosage, 1.e., a count not exceeding 15 fuorescent particles. Double entries for a given colum represent increnental dosages obtained with sequentially exposed filter units. Appilcable incremental periods for each sampler, as well as full sampling portods for oach release, are as follows:

\begin{tabular}{|c|c|c|}
\hline Ralease & Sampling Period & Increinental Perlods \\
\hline FT $0019 a$ & $2000-2100 \mathrm{CST}$ & $\begin{array}{l}2000-2100 \mathrm{CST} \\
2100-2120 \mathrm{CST}\end{array}$ \\
\hline FT $0019 b$ & $2120-2220 \mathrm{CST}$ & $\begin{array}{l}2120-2220 \text { CST } \\
2220-2300 \text { CST }\end{array}$ \\
\hline FT $0019 \mathrm{c}$ & $2300-2400 \mathrm{CST}$ & $\begin{array}{l}2300-2345 \text { CST } \\
2345-24,00 \text { CST }\end{array}$ \\
\hline
\end{tabular}

* In the absence of an adjacent outside sampler (3), at the one to six-foot lovel, a value has been estimated, based on the analyals of the overall 13odosage pattern for a given release. The estimato has been mado in order to obtain the base value needed to establish the percentage of aerosolcloud penetration. 


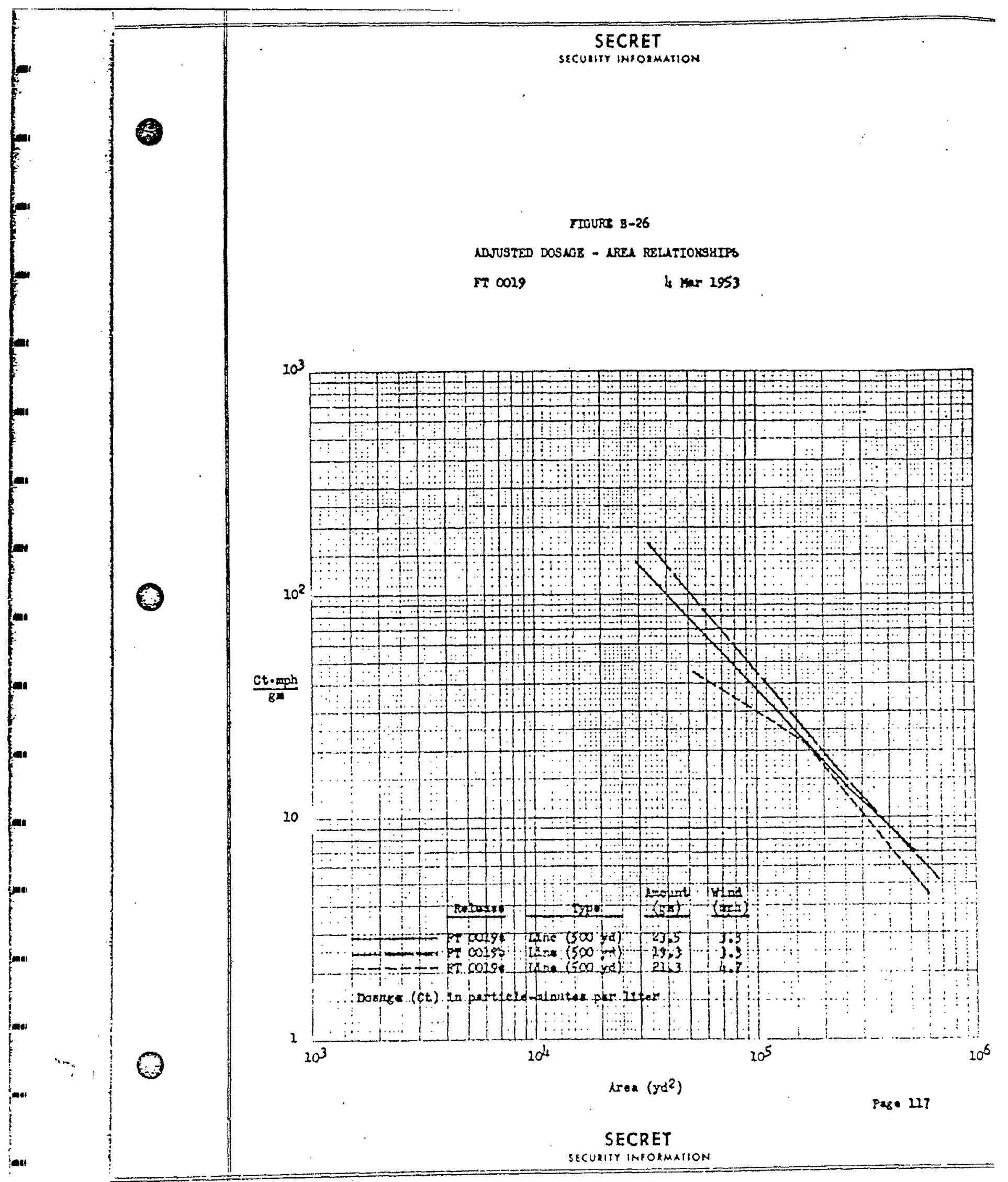




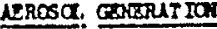

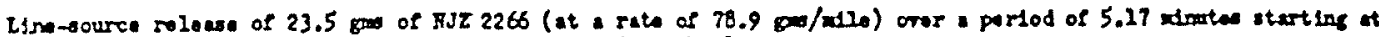
2 COS CST, tros a blower disporser nounted on a morlng rahiele.
$(2 \sin \propto S T)$
$(2010110$
1500-ift track (Lonz high-ground elorat 100) of rehicle-houted blower deperes
$(2010110 \mathrm{Cs})$
at the indleated atioting and otoppine tines.

SNIDT

Lcestion and Exposure

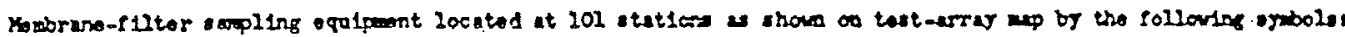

- Outdoor supler at holght botmon 2 and 6 foet.

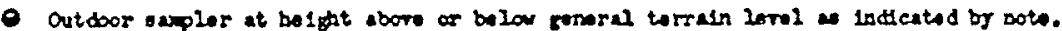

Besulte

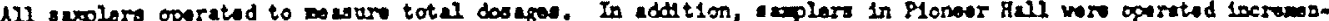

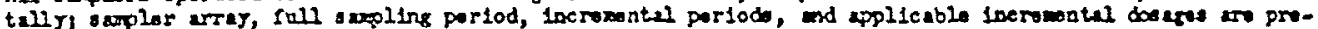
suted in rigare 8.25.

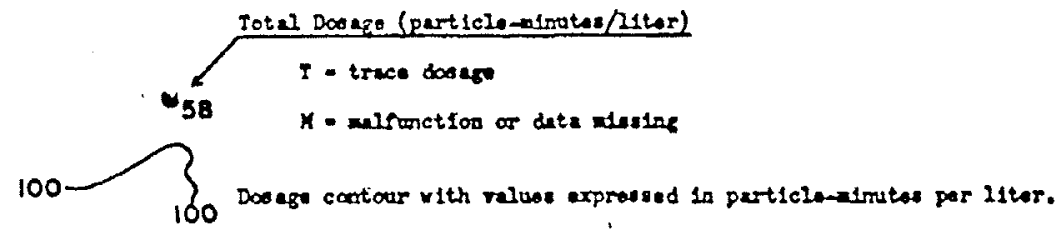

\section{ETEOROIDOT}

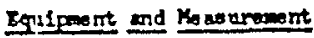

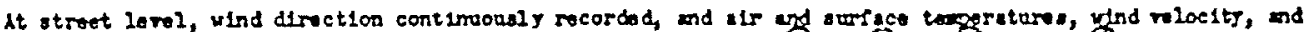
other metoorological observations taken at otations dosicated $0,0,0$

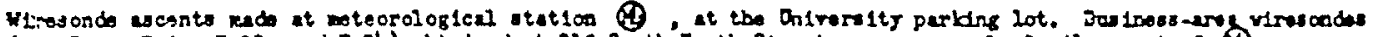

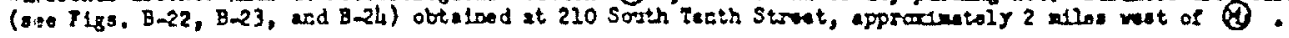

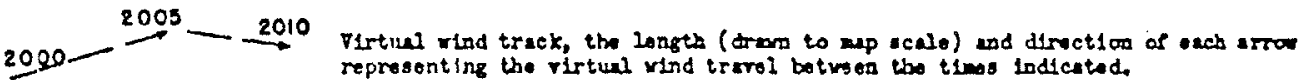

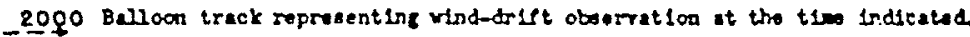

Mind

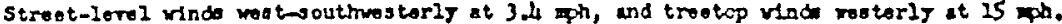

Stno11tx

$1.5^{\circ}$ Inpse tron 6-300 et.

skrt

Seattered cloud with bssos $21,000 \mathrm{ft}$ abore the surface.

Teicorature

$18.9^{\circ}$ to $19.8^{\circ} \mathrm{F}$ at 2 metors in the toot aroa.

Motstive

Mring ratio of $1.4 \mathrm{gm} / \mathrm{kga}$ try $\mathrm{alr}$. 


\section{AERISA OENERUTIOW}

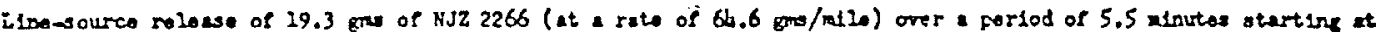
2125 CST, frow a blower disperver mounted on a moring rehlelo.

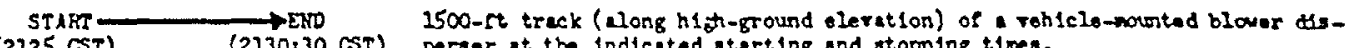
(2225 CST) (2230:30 CST) peroer at the lidicatind atarting and otoppling times.

\section{SAMTIX}

Location and Expastre

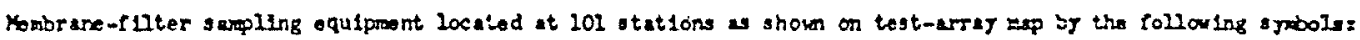

- autdoor armpler at holght botwe en 1 and 6 feet.

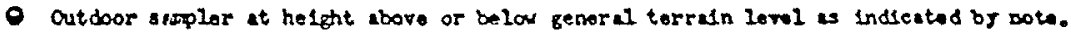

Regurts

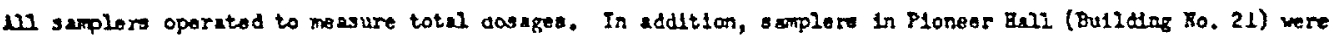
operated incrementaliy; samplor array, full.8apleng perlod, Increnental porfode, and applicablo incromental dosapes are presented in Figur B-25.

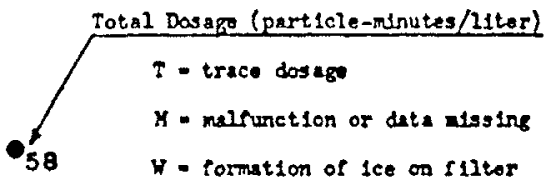

- - eribence of contmination

MTEOROLOOY

Equipment and Measurament

At street level, whd direction continuously recorded, and air and surfget temeretures, vind relocity, end other neteorolopical ohoertations thien at stations desimated 0,

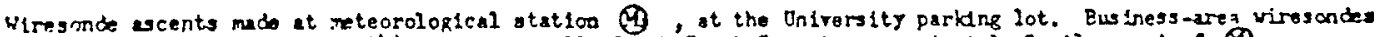
(see F1Rs, B-22, B-23, and B-24) obtained at 210 South Tenth Street, approxinately 2 wiles west of (D).

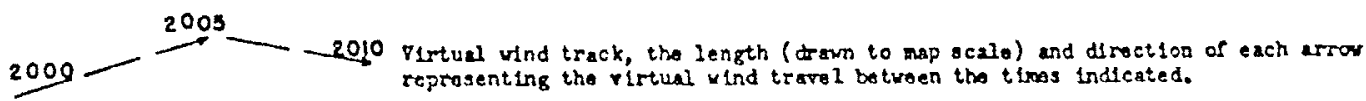
2000 Ballion treck representing vind-telt oboorration the tim intlcated. Winds

Street-level wind west-ajuthisatorly at 3.4 sph, and treetop winds westorly at 15 aph. stability

$2.1 \cdot F$ lapso from 6-300 It. $5 k$

Scaitered clouts with bnses lo200 ft aboro the surface.

\section{Terearature}

$18.7^{\circ}$ to $19.5^{\circ} \mathrm{F}$ at 2 metero in the tesi wea.

Boletaro

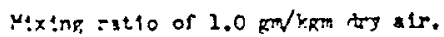




\section{EEROSOL QENERAT IOA}

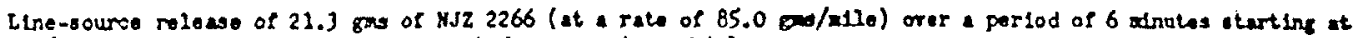
$2305 \omega \mathrm{C}$, Tron a blower disparser mounled on worting rehtele.

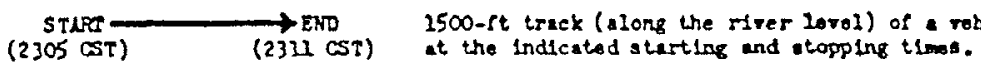

SAYPLINO

Loestion and Exposure

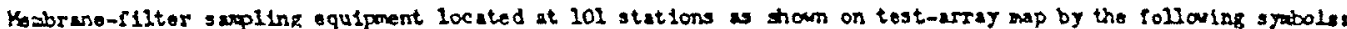

- outdoor sampler at holitht betreen 1 and 6 reet.

- Outdoor sapler at helpht atore or beloy genoral terraln lerel as indicated by nota.

\section{Results}

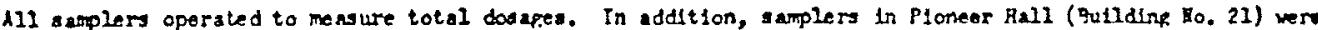
operated incrementally; sempler array, full, sopling porod, incremental periods, and app 21 eable incronental dosages are prosented in Figuro B-2S.
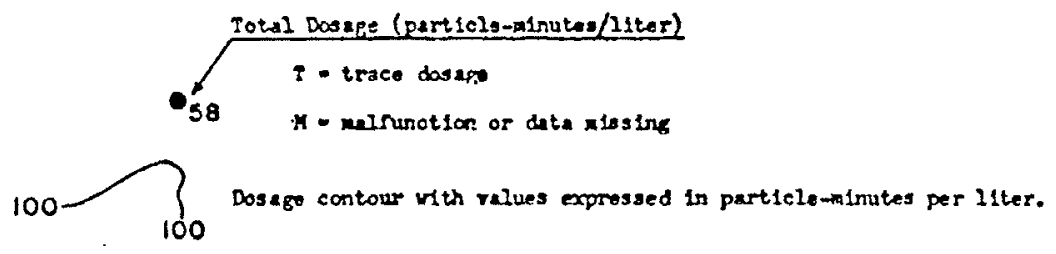

\section{Equipent and Measurenent}

At 3 tret lovel, wind drection continuously recorked, and $21 \mathrm{r}$ and surlace teracatures, vind relocity, and other meteorologlesl observations taken at stations designuted (8),

Hiresende axcanta ando at moteorological station 6 , at the Ohirersity parking lot. Bus Inessareg wresondea (see $7180.8-22,8-23$, and B-2L) obtalned at 210 South Tenth Street, acproxinately 2 niles vest of (2).

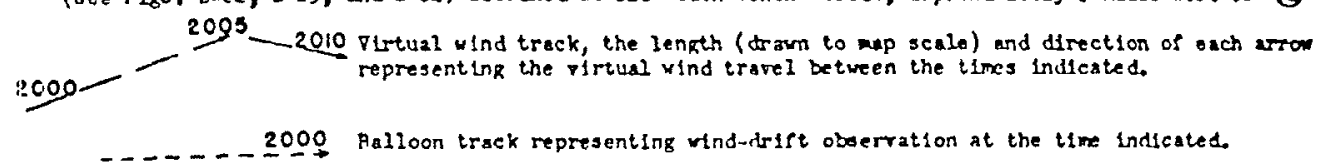
Winde

Street-lerel viads westerly at $3.9 \mathrm{mph}$, and treotop winds westerly at $15 \mathrm{mph}$. Stab121ty

1.7. F Ianso srom $6-300$ st.

sky

Scattered clonds 3500 ft sbove the surface.

\section{Terpersture}

$38.8^{\circ}$ to $19.5^{\circ} \mathrm{F}$ at 2 meters in the tast area.

Solsturs

Melreg ratio of $2.5 \mathrm{pr} / \mathrm{km}$ tre alr. 
SUMMARY OF REGIONAL AND IOCAL WEATHER

21 March 1953

(Survey M-59, Supplemental to FT D021)

\section{SINOPTIC SITUATION}

During the test period, a deepening 986-mb low center over western Nebraska, moving northeast at $20 \mathrm{mph}$, and a 1020-mb high over Quebec comblned to produce. a flow of warm alr with a southeasterly gradient of $35 \mathrm{mph}$. The low passed Minnoapolis the following day with onahalf inch of ratn. At the 700-mb level, a moderate ridge extended from Ceorgia to eastern Lake Superior and a deepening trough extended from Montana to New Mextco, producing a southerly gradient wind of 35 aph.

WEATHEH REPORTS FROM WOLD-CHAMBERLAIN FIELD (MTNGEAPOLIS)

\begin{tabular}{|c|c|c|c|c|c|c|c|c|}
\hline $\begin{array}{l}\text { Time } \\
\text { (CST) }\end{array}$ & $\begin{array}{l}\text { cloud } \\
\text { Helght } \\
\text { (feet) }\end{array}$ & $\begin{array}{l}\text { Sky } \\
\text { Cover* }\end{array}$ & $\begin{array}{c}\text { Visibility } \\
\text { (miles) }\end{array}$ & Weatherst & $\begin{array}{l}\text { Temp } \\
\text { (OF) } \\
\end{array}$ & $\begin{array}{r}\text { Dew } \\
\text { Point } \\
\text { (OF) } \\
\end{array}$ & DIr & $\begin{array}{l}\text { ind } \\
\text { Speed } \\
\text { (mph) }\end{array}$ \\
\hline $\begin{array}{l}2230 \\
2330 \\
0030 \\
0130 \\
0230 \\
0330 \\
0430 \\
0530\end{array}$ & $\begin{array}{r}6,000 \\
5,500 \\
5,500 \\
5,500 \\
20,000 \\
20,000 \\
20,000 \\
20,000 \\
5,000\end{array}$ & $\begin{array}{l}\text { Orercast } \\
\text { Overcast } \\
\text { Scattered } \\
\text { Scattered } \\
\text { Broken } \\
\text { Scattered } \\
\text { Broken } \\
\text { Overcast } \\
\text { Scattered }\end{array}$ & $\begin{array}{l}15+ \\
15+ \\
15 \\
12 \\
10 \\
10 \\
12 \\
12 \\
10\end{array}$ & $\begin{array}{l}- \\
\overline{-} \\
\overline{-} \\
\overline{-} \\
\overline{-}\end{array}$ & $\begin{array}{l}47 \\
46 \\
45 \\
41 \\
41 \\
41 \\
41 \\
41 \\
42\end{array}$ & $\begin{array}{l}33 \\
32 \\
34 \\
35 \\
34 \\
35 \\
36 \\
36 \\
37\end{array}$ & $\begin{array}{l}\text { ESE } \\
\text { Z } \\
\text { ESE } \\
\text { ESE } \\
\text { ESE } \\
\text { ESE } \\
\text { ESE } \\
\text { ESE } \\
\text { ESE }\end{array}$ & $\begin{array}{l}19 \\
15 \\
19 \\
16 \\
22 \\
23 \\
20 \\
23 \\
21\end{array}$ \\
\hline
\end{tabular}

* Average cloudiness sunrlse to sunset: $80 \%$

$*$ Andor restrictions to visibility

Sea-level pressure at $0230 \mathrm{CST}$ : $1000.3 \mathrm{mb}$

Ground condition: Two-tenths snow remaining (two to three inches); streets clear; lake frozen

Tree cover: None 


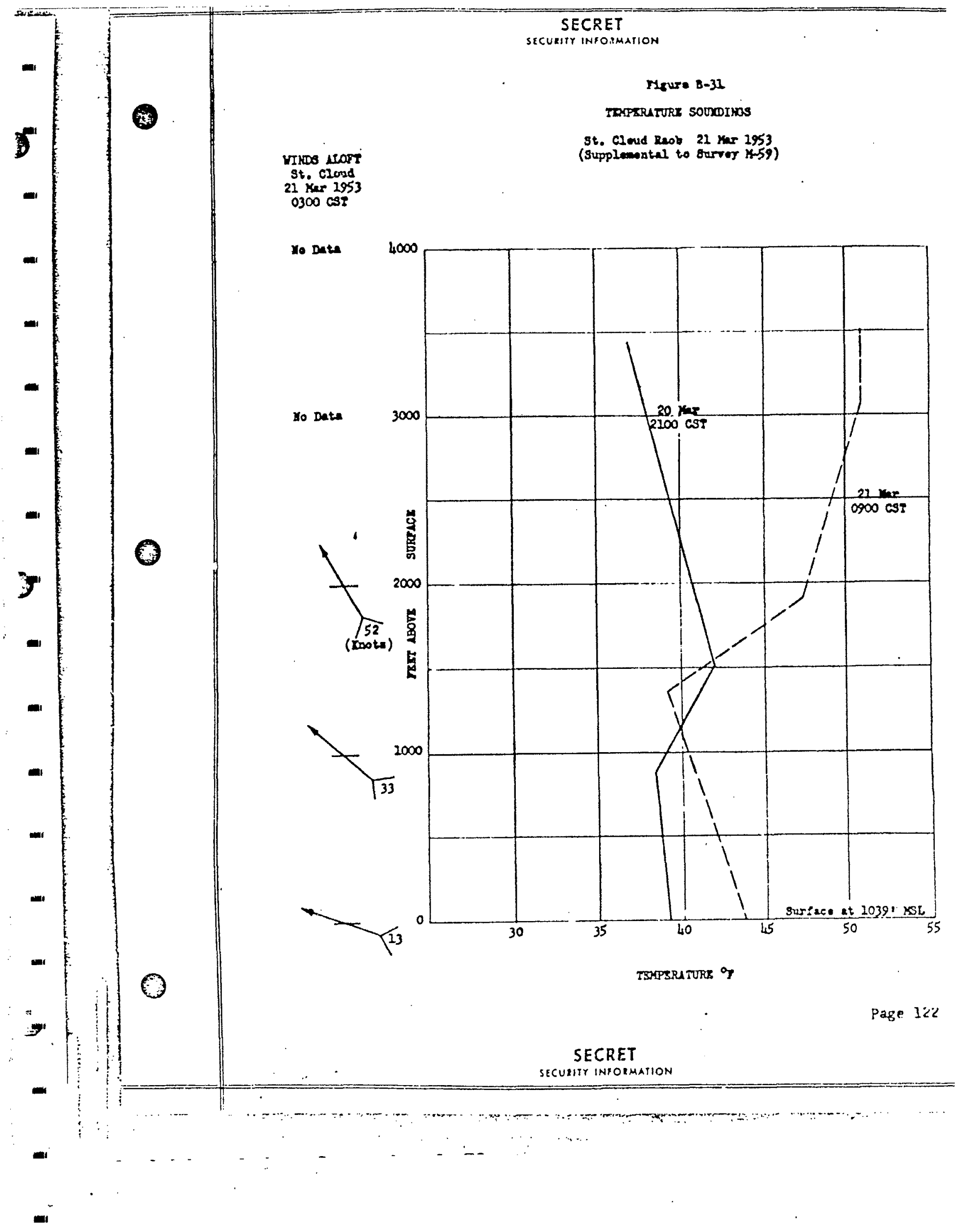




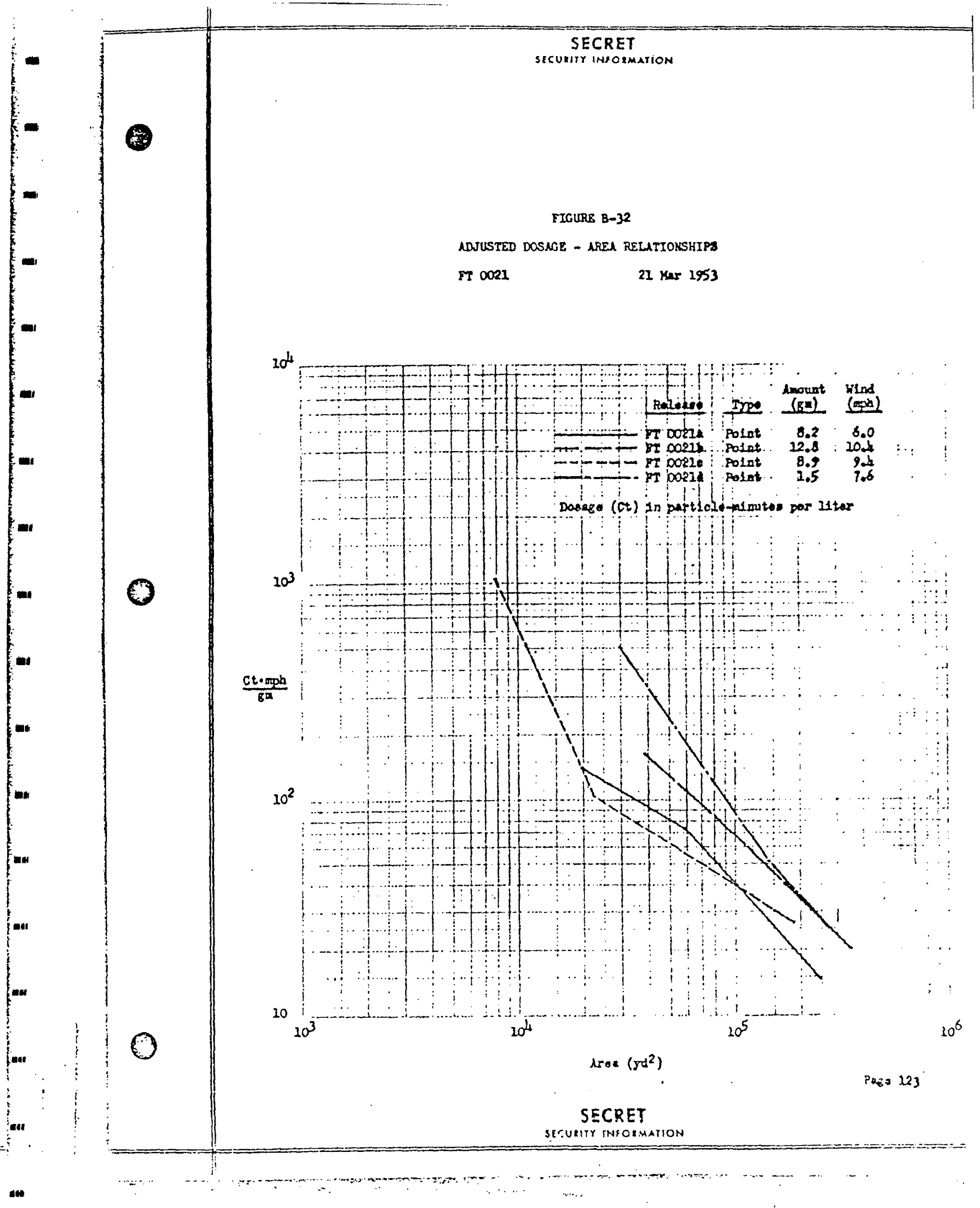




\section{ÁRCSOL Gryetrat}

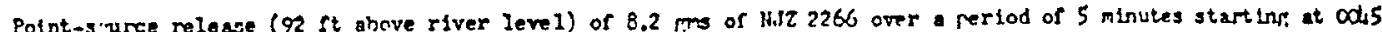
CST rras a vehlcle-mounted biover disperser located at polnt

\section{SANTLIX}

\section{Locat ion and Pxposure}

Hesbrare-fliter sapling equipment located at $1 \alpha_{1}$ stations as show on test-array map hy the following symbols s

- Outdoor sampler at heifit between 2 and 6 reet.

- audoor anpler at helfit ateve or below gencral tarrain lavel is indicated by note.

\section{Results}

AI semplers operated to measure total dosanes durisr fnil saplinp perlod, 0030-0130 CST.

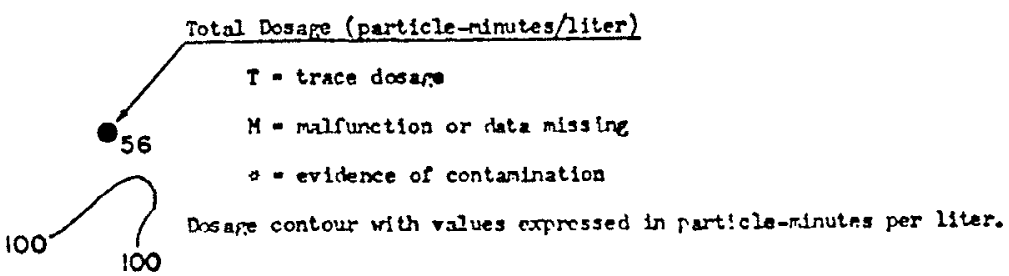

ETroxLax

Equicinent. ind Yeasurement

At strect level, wind direction continuously recorted, and itr and surface temeratures, wind velocity, and

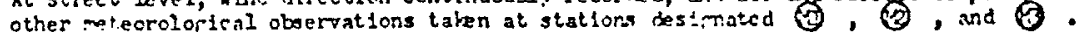

himesende equiprent located at meteorolopienl station $\Theta$, at the thiversity parking lot.

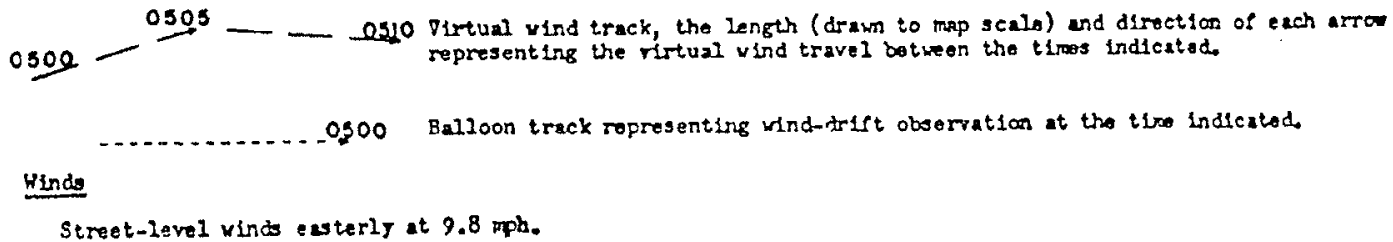

Street-level vinds essterly at $9.8 \mathrm{pph}$

\section{Steb11ity}

- No direct nesurement; wresonde oporation presluded by relatively strong vinds. Theso whin and supparting raob dats (Fig. B-31) indieste adiabatic corditions.

Skr

Scattered clouds with basea 5500 'et abovo the surfaco.

Torgerature

$41.5^{*}$ to $42.2^{*} F$ at 2 meters in the tost area.

Molsture

ysxine ratto of 4.1 ge/ker dry air. 


\section{NEFOSOL GENERATION}

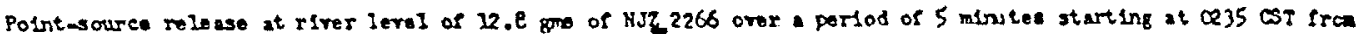
- vehlele-mounted blaver disporser located at point 29 .

\section{SNPLDNO}

Location and Frosure

Me-brane-filtar sepiline equipnent locstod at 20 stations as shom con test-erray mep by the following symols:

- Outdoor sampler at helpht betipen 1 and 6 reet.

- artdoor ampler at helght above or welow general tarraln level es indicated by note.

Result.

All semplers operated to neasure total doc ase turing full 3 appline pertod, ce00-0300 CST.

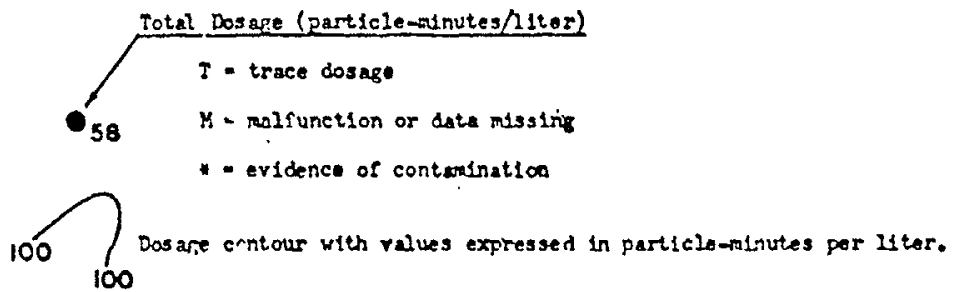

METOROLOCY

Fouipment and leasurement

At sireet level, wind direction continuously recorded, and alr ard surface terperatures, wind velocily, end other retenrolopical observations takn at stations desimated as $\mathrm{O}, 3$, and 0

Hirescnie equipment loeated at meteorolopical station 3 , at die triversity farking lot.

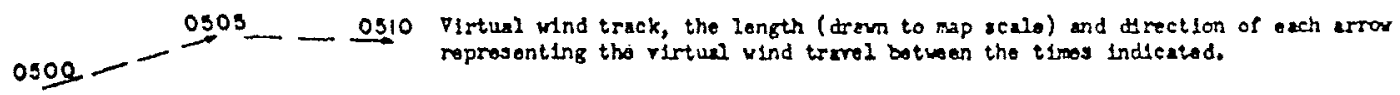

Balloon track representing wind-drift obsermition at the time indicated

Vind

Street-lovel winds esst-southosterly at $11.6 \mathrm{mh}$.

:tab114ty

Wo direct masurenent; wiregonde operations precluded by relatively strong winds. Theso vinds and supporting raob dats. (Fig. B-31) indicate adiabatic conditions.

5ikz

Broken cloudy with bases 20,000 ft above the surface.

Temperature

$40.9^{\circ}$ to $42.9^{\circ} \mathrm{F}$ at 2 moters in the test area.

Molsture

Mixing ratio of $4.3 \mathrm{gm} / \mathrm{kg}$ ir air. 


\section{AEROSOL TDERTITOR}

Point-source release ( $50 \mathrm{ft}$ above river level) of 8.9 pro of $\mathrm{kJz} 2266$ over a persod of 5 minutes starting at 0350 CST trom a vehicle-mowited biower deperser located at point kis.

\section{SAYGE DNO}

Location and פxporure

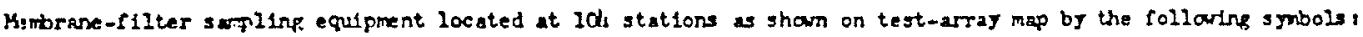

- Outdoor sarpler at helght betwoen 1 and 6 seet.

- Outdoor ampler at helght above or below peneral tersaln level as lndicatod by note.

Results

Nil samplers operated to reasure lotal dosage during, rull sampline period, 0330-du30 CST.
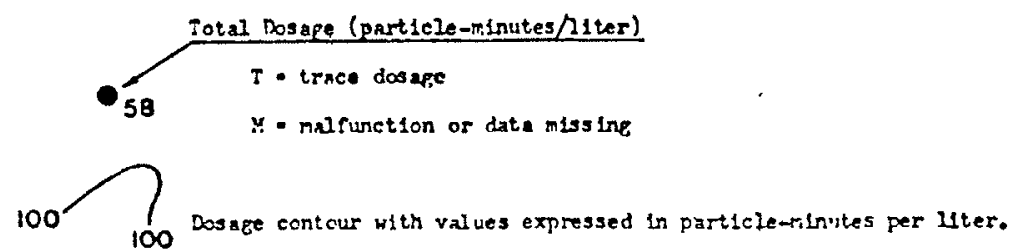

MPTOOATIMT

\section{Equijment and Yensurement}

A: street level, $x$ the direction contlnuously recorden, end als and surface te.peratures, wind velocity, and other meteorolorical otservatlons taken at stations des 1 pnated 10 , and

Wiresonde equiprent located at meteorolopical station (3), at the University parking lot.

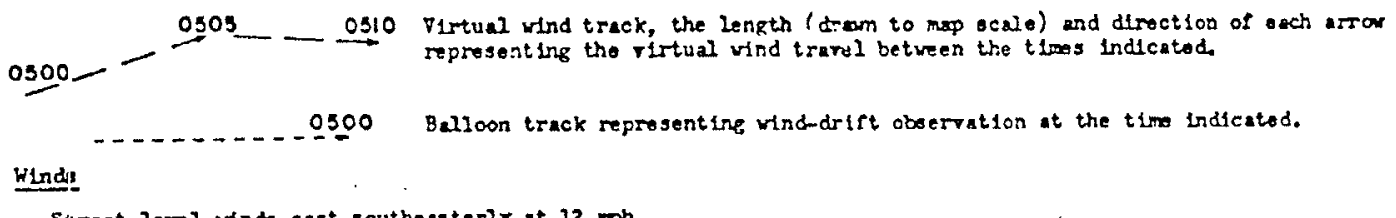

Si:ret-20rel wind east-southeasteriy at 12 moph.

$\underline{S t a b}[19 t y$

Wi direct gensurement; wi resonde operations precluded by relatively strong winds, These winds and supporting ruob dats $\left(\mathbf{T}_{n \mathrm{~B}}\right.$. B-31) Lndicste adiabatic conditions.

Sky

Soattered clouds with bares 20,000 reet above the surface.

Temourature

$4: .3^{*}$ to b1.7. $F$ at 2 beters in the teat aren.

Molsture

Hoxing retio of $4.3 \mathrm{gad}$ hom dor air. 
TTST LRTUT AND RESUTS

Piguro 8-36

FT oomld

21 Mar 1953

\section{NFROSOL GENERATIOR}

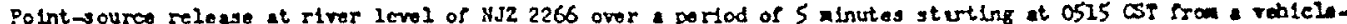

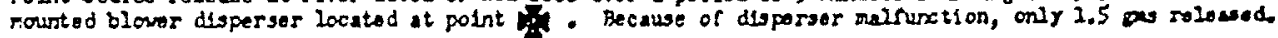
SAMPLIN

\section{Location and Exparare}

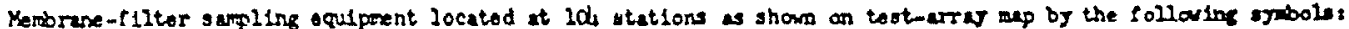

- Outdoor sarpler at heieht betwe en 1 and 6 soet.

- Cutdoor sampler at helght ebove or bolox general terrads level a ladiested by note.

Mesults

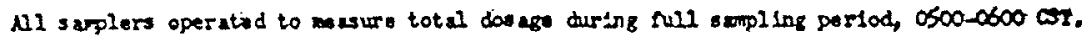

\section{MTT:OROLOOT}

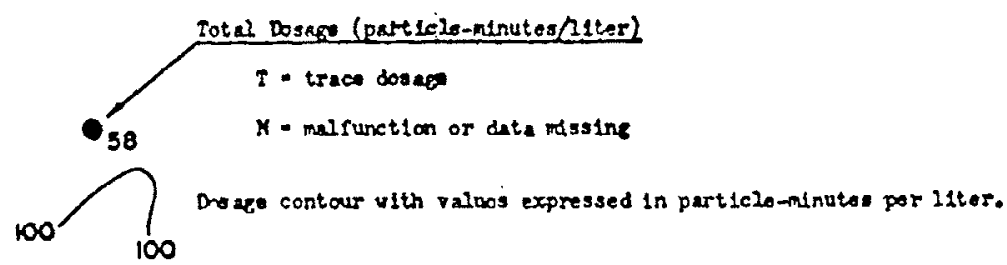

Equipment and Kessument

At stret level, wind direction continuow ly records, and alr and surface tenperatures, wind wactity, and

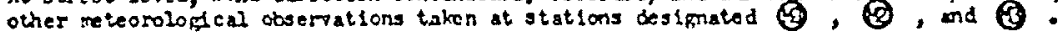

Viresonce equipment locatod at meteorological station , at the University perking lot.

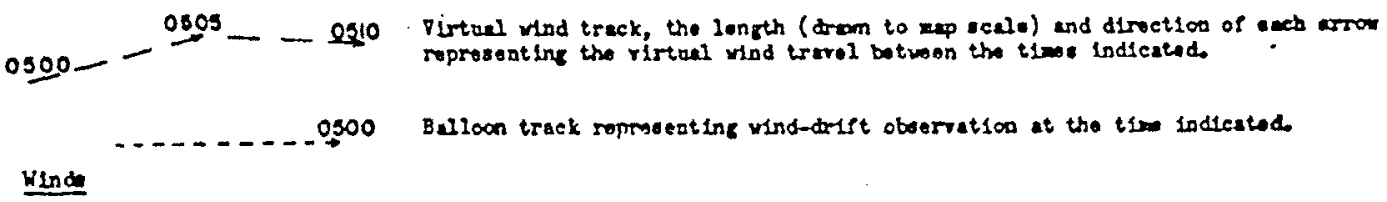

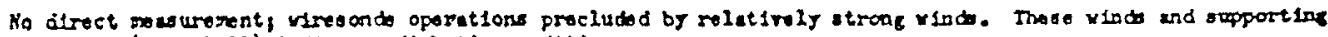
raob det. (F18. B-31) indicato silibetic conditions.

$\underline{s k}$

Orerest clouds wh beses 30,000 ft abore the sarface.

\section{Tenperature}

$41.6^{\circ}$ to $42,4^{\circ} \mathrm{P}$ at 2 meters is the lest area.

Solotare

Nuring ratio of $4.5 \mathrm{~km} / \mathrm{kgm}$ dry $1 \mathrm{ir}$. 


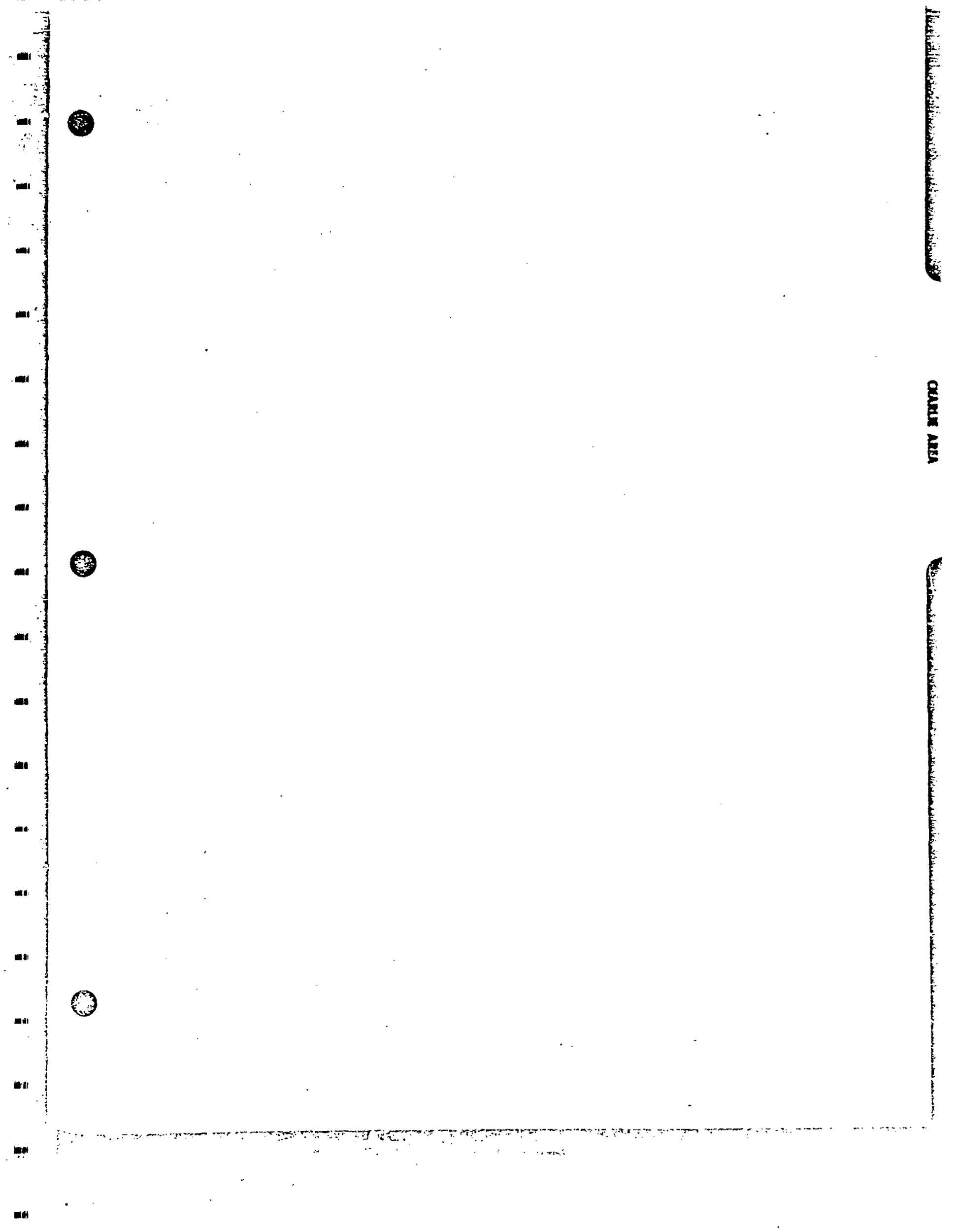




\section{A PBADIX *C*}

Figure Ho. IIEID IEST Da12 26 Pobruary 1953 Page Ho.

C-1 Temparcture Soundings, St, Clond Beob, M-SO

C-2 Teuperature Somulings, Ondoreloped-urea Mireonde

C-3 Test Lrrey and Bosults, IT 00120

C-4 Torature Soundings, St. Cloud Rnob, K-52

C-5 Comperative Temperature Soundings, Kinnoepol1: Mirosond

C-6 Comparative Texperature Soundigs, zinneapolla Wresonds

C-7 Cosparatiro Temperature Soundtigs, Hunespolls Wiresonde

C-8 Comparatiro Temperatura Soundings, Kinsepolis Wiresondo

C-9 Compratire Texperature Soundtrgo, zirnoupolls Kiresonde

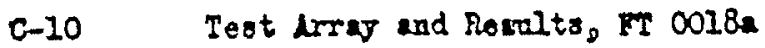

C-11 Tort Array and Rosults, FT $0018 d$ 


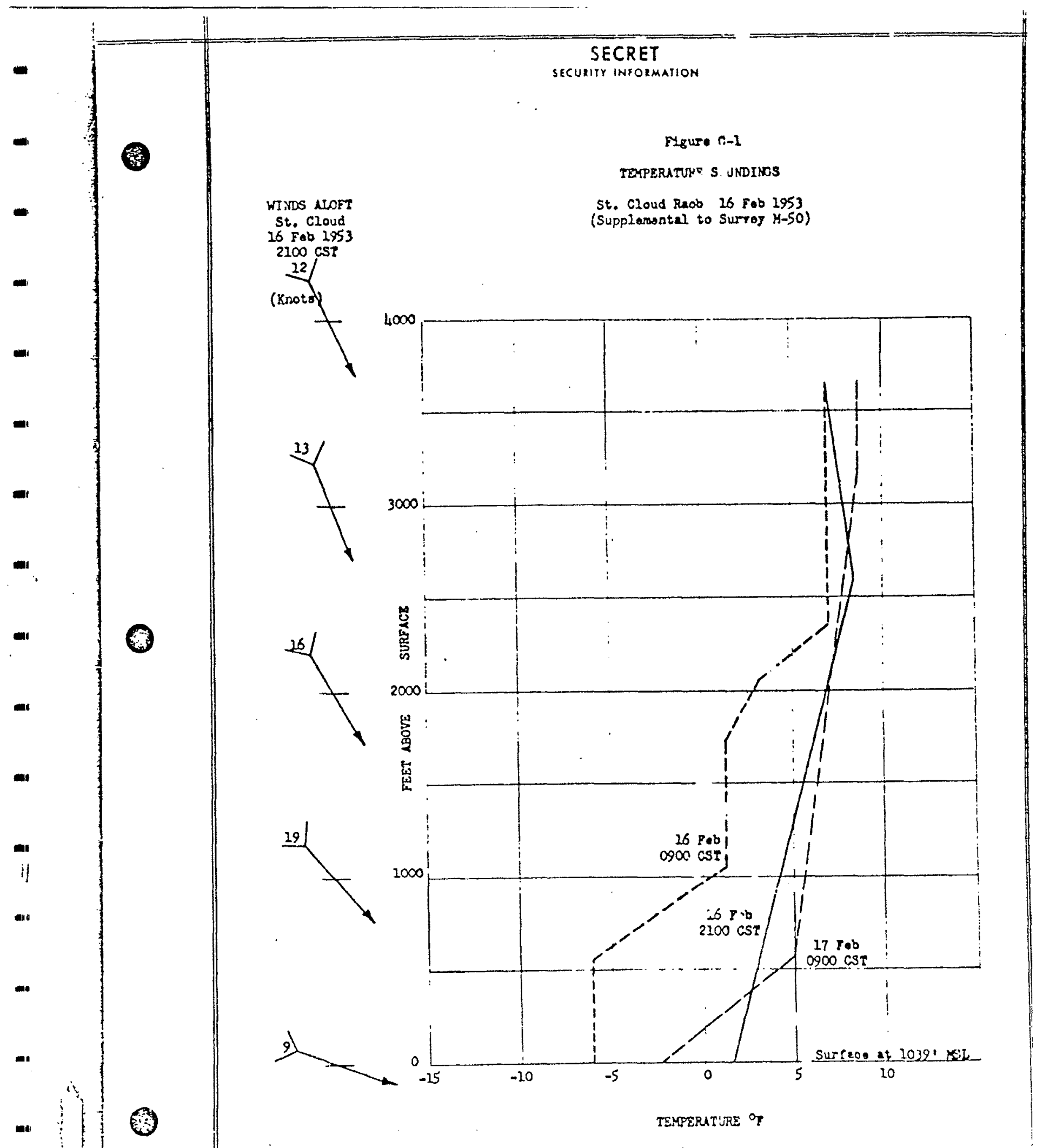

\section{SECKET}




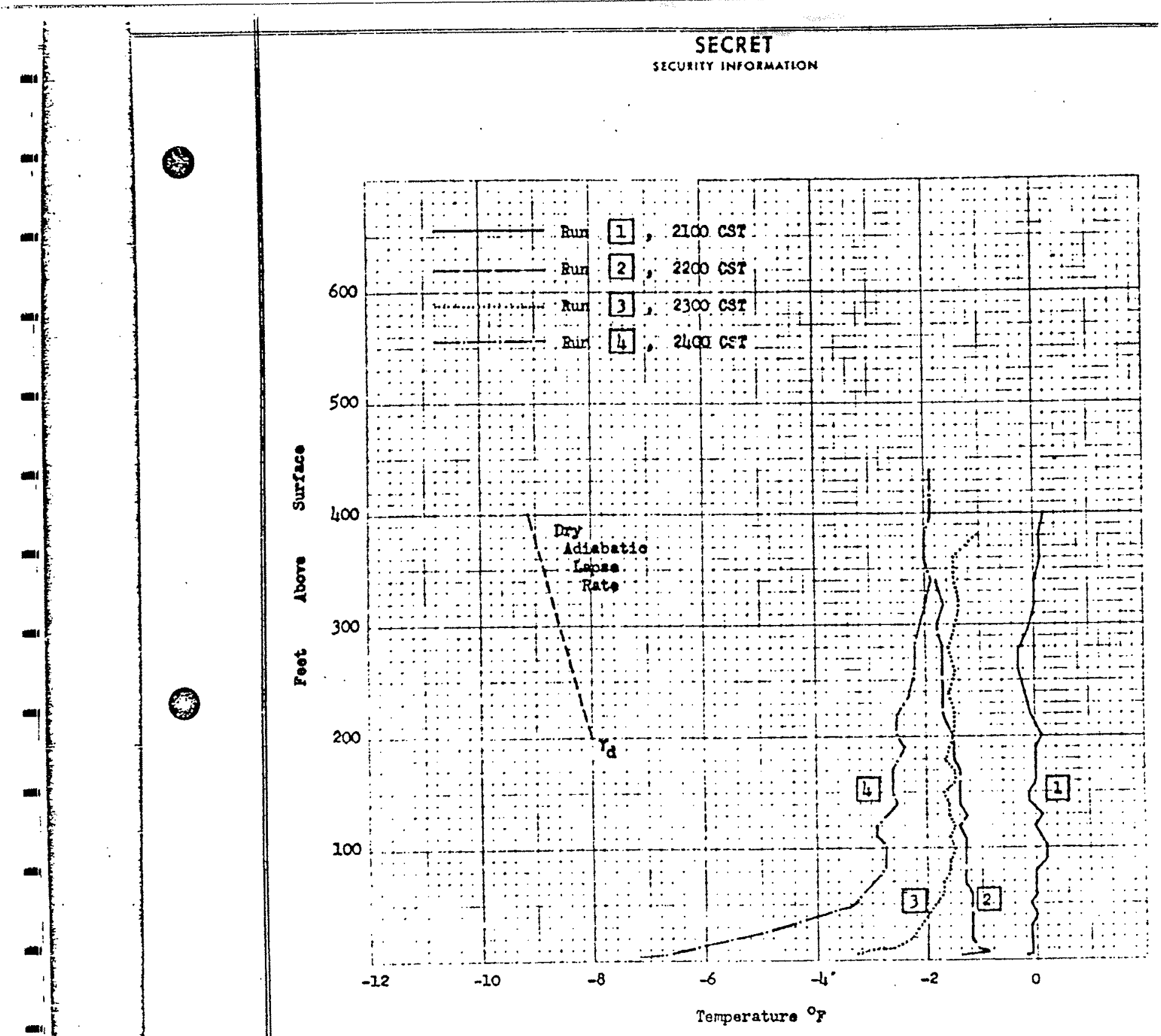

FIGUPE C-2

TEMPERATUHE SOUNDINCS

itinnespolss

Undeveloped-Aroa wiresondo

M-50 16 Feb 1953

$28 \cdot 130$

SECRET

SECIJITY INHORMATION 
TEST ARRAT AND RESULTS

18tur $0-3$

$16 \mathrm{Peb} 1953$

TI coits

APROSO: CENFRTION

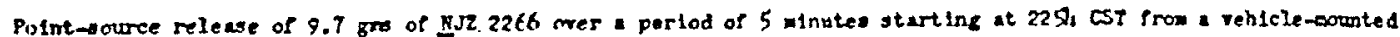
bilower dioporger located at point bis.

SARPL DN

Lecation and Prpouture

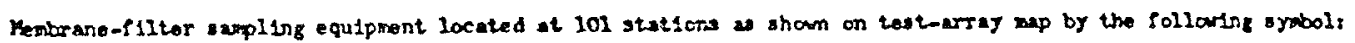
- Outdoor ampler at helght betmeen 1 and 6 Seet.

Rosurte

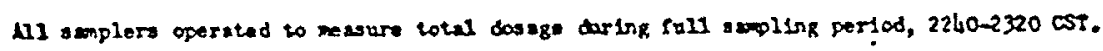
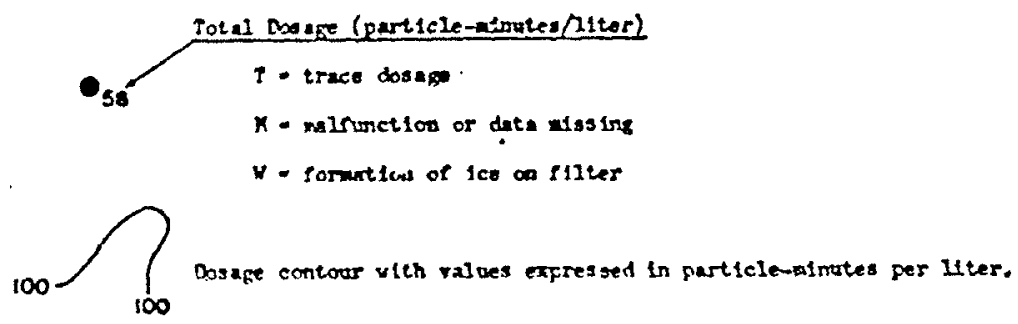

\section{IETFORAXT}

Equiprent and besurenent

It street level, wind drection continuously recorded, and atr sut surface te peratures, wind velocity, wh other netecrological cbservations iaken at alntions designated 0 and

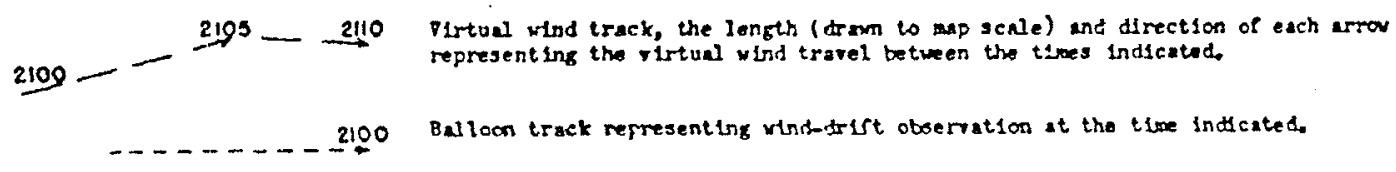

Winde

Street-leres winds gouthresteris at $1.8 \mathrm{mph}$.

Stabl11ty

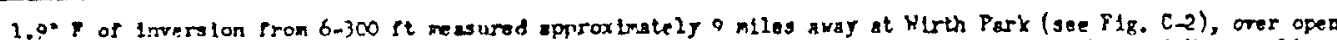
tistrain comparable to Charlie krea, at the yestem rather than at the southeastem peripinesy of pinzeapolis.

\section{Tereferture}

2. to $-7^{\circ} \mathrm{F}$ at 2 meters in the test ares.

Skg

Clear durting tost pertod.

Notsture

Mexlop, ratso of $0.6 \mathrm{gm} / \mathrm{kpm}$ dry $2 \mathrm{tr}$. 


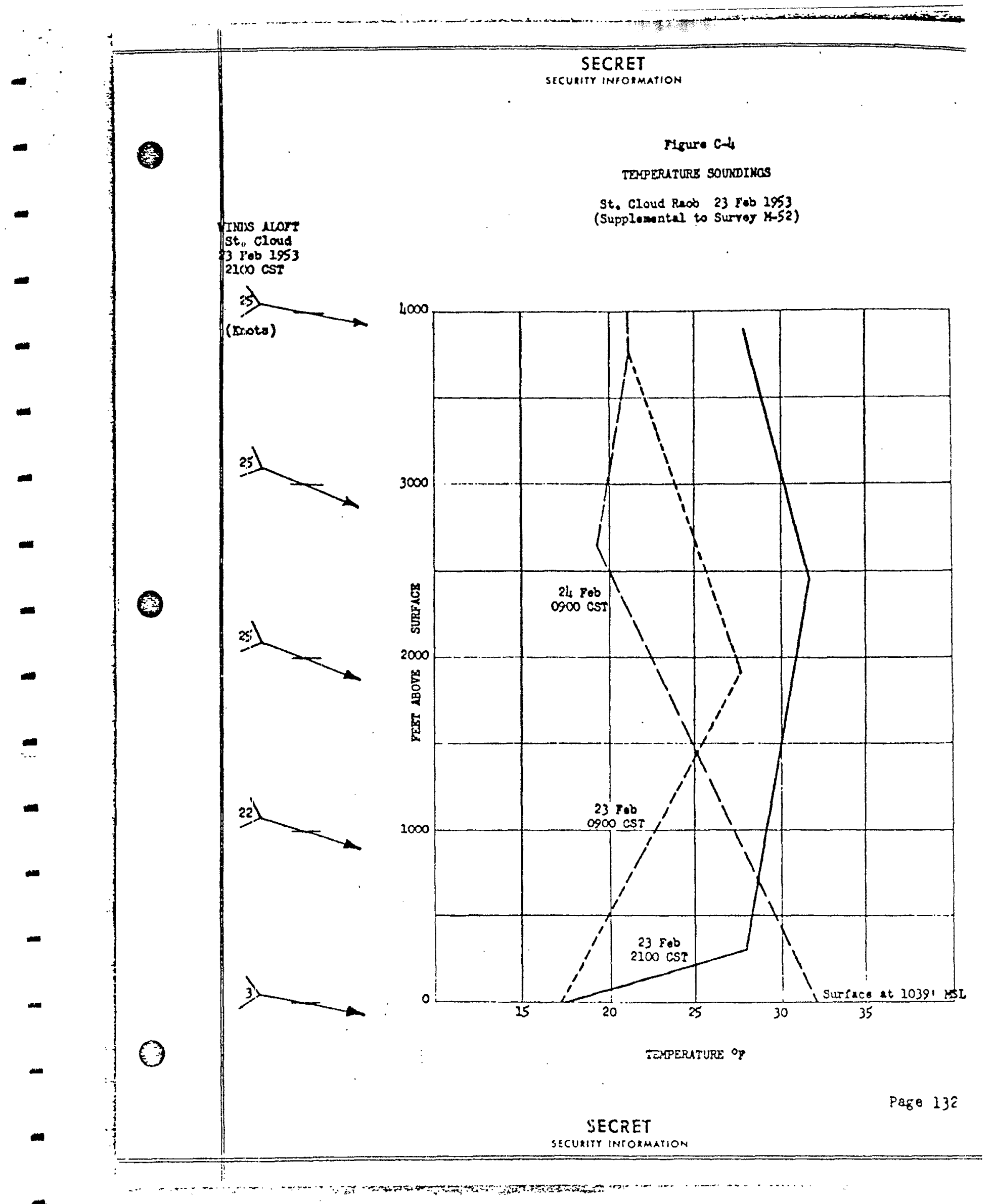




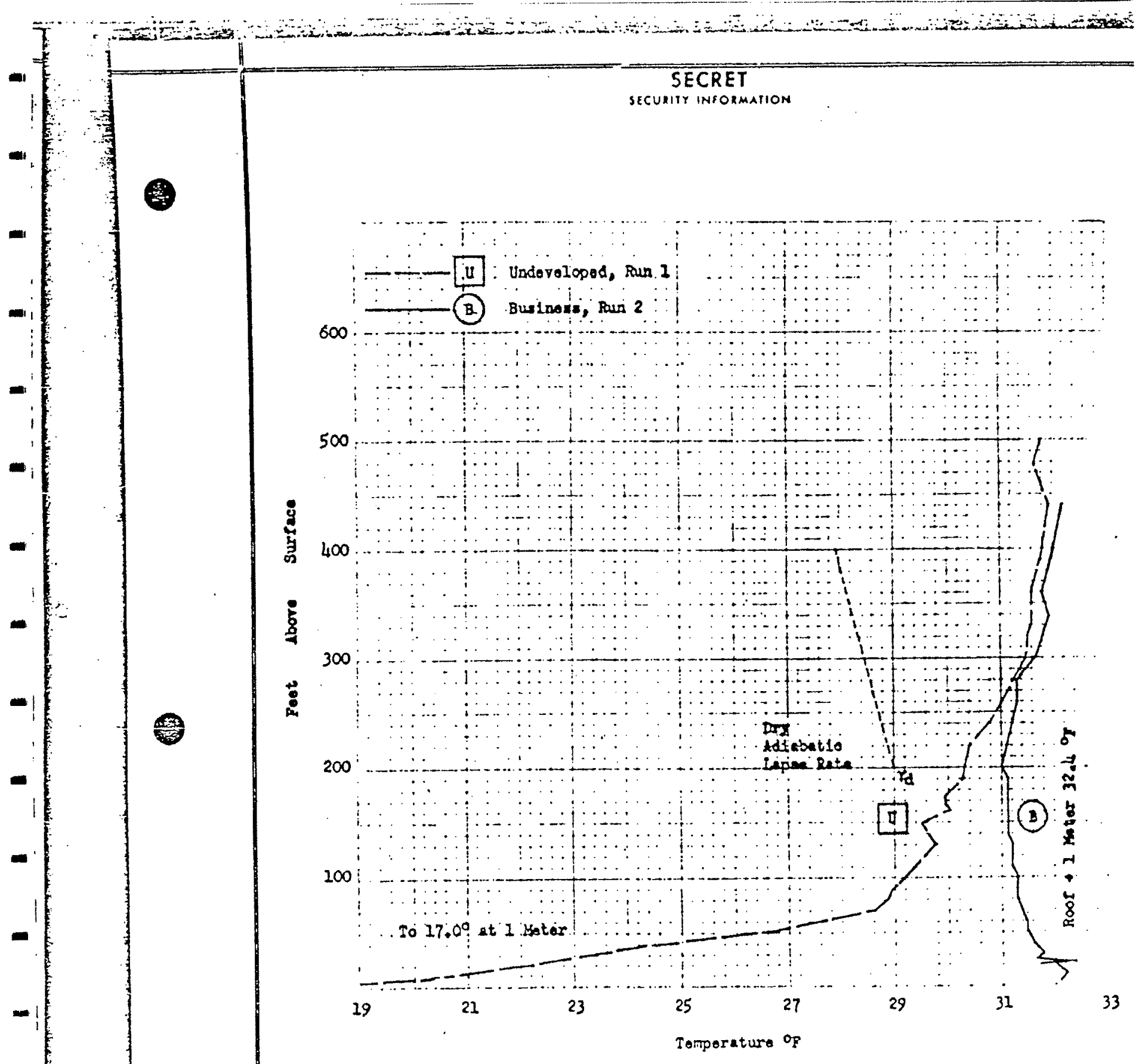

EYGURE C-5

COMPAPATIVE TEAFERATURE SOURDTMS

Mrmapolls Wirasonda

Undevoloped Vs Business Area

$2000 \mathrm{CST}$

23 Fob 1953 


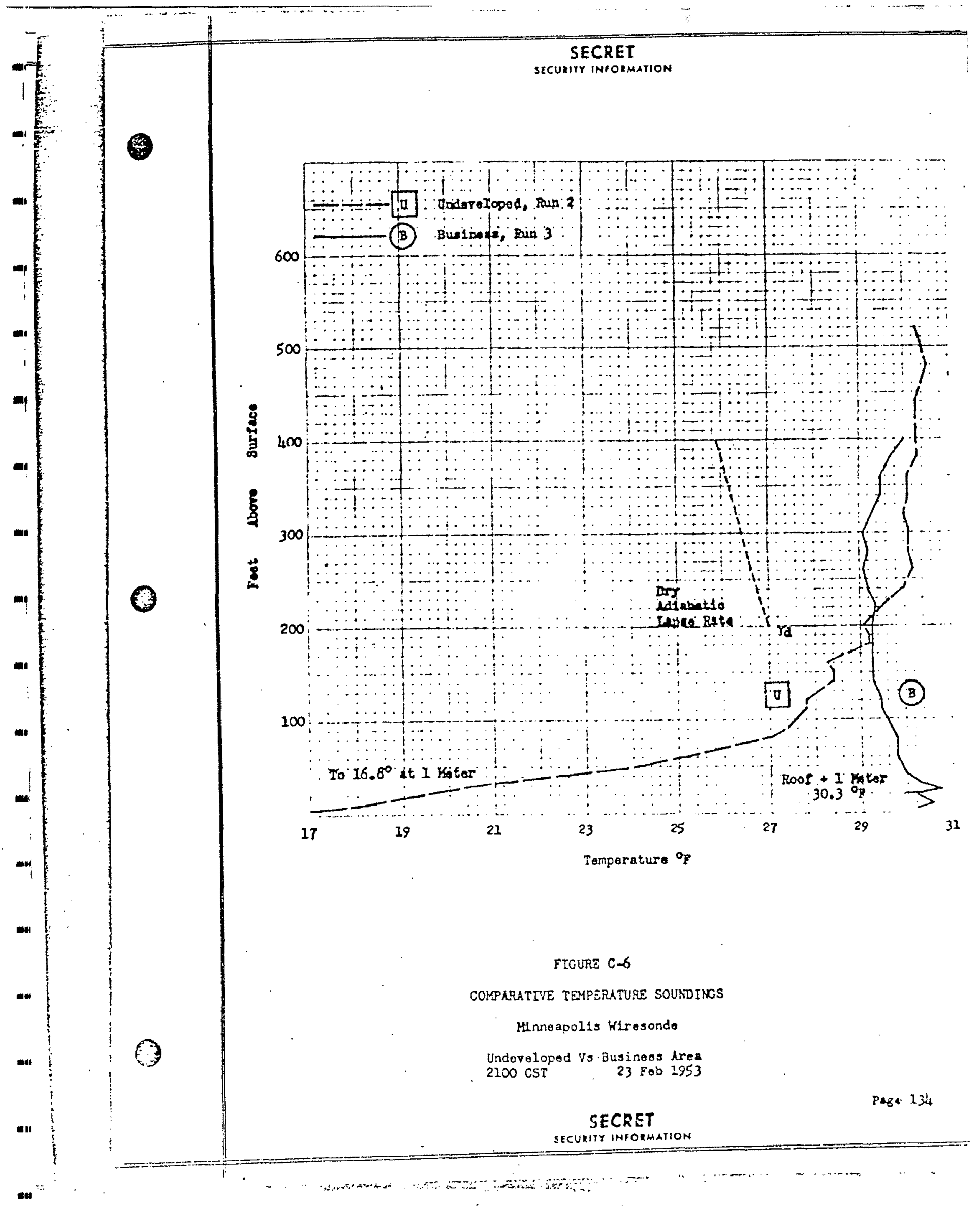




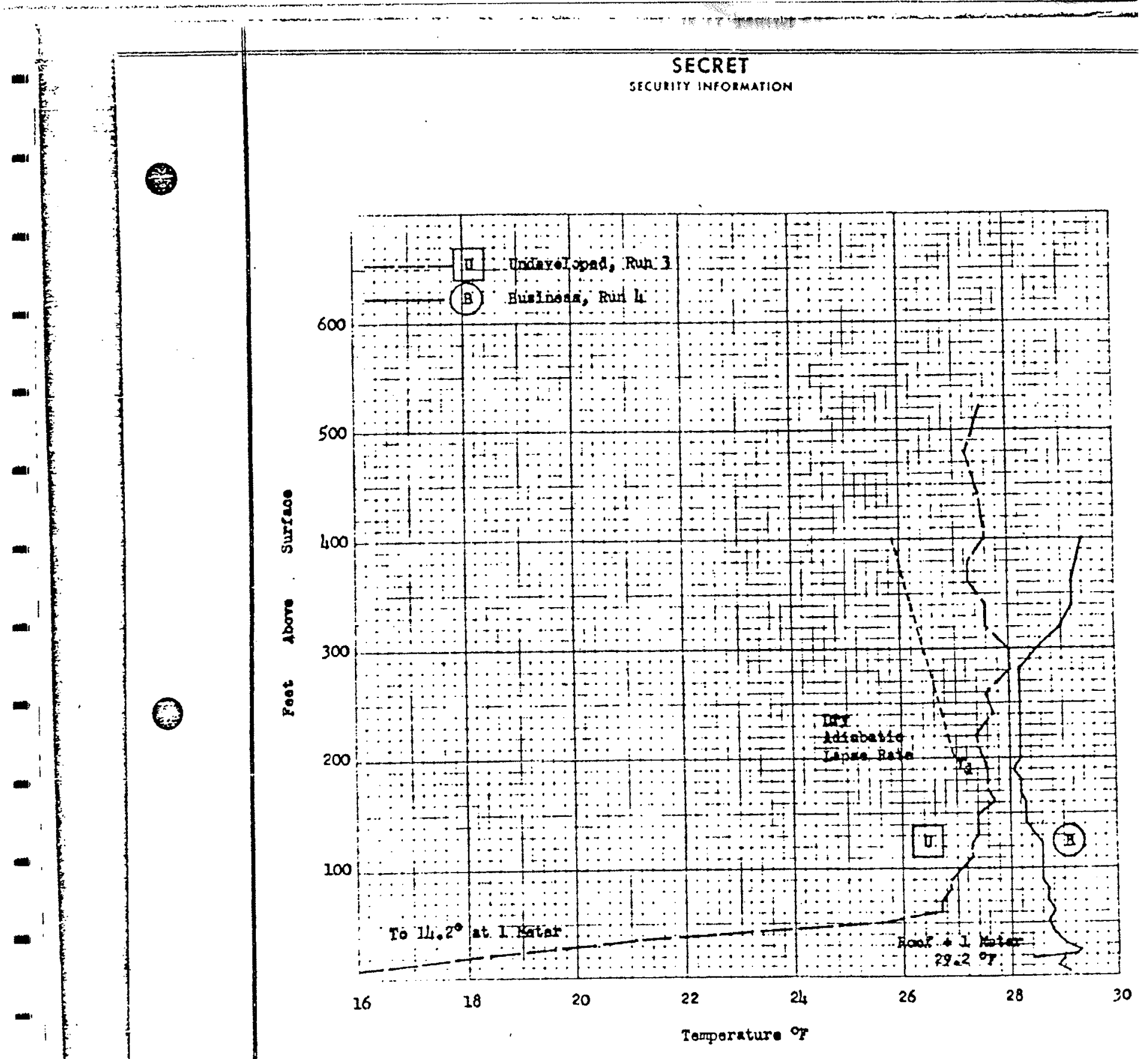

FIGUFE C-7

COMPARATIVE TEYPERATUNE SOUNDINOS

Mnnoapol1s Whosondo

Undeveloped $\nabla$ s Business Area

2200 CST 23 Fob 1953

SECRET

Pag: 135

SECURIT INFORMATION 


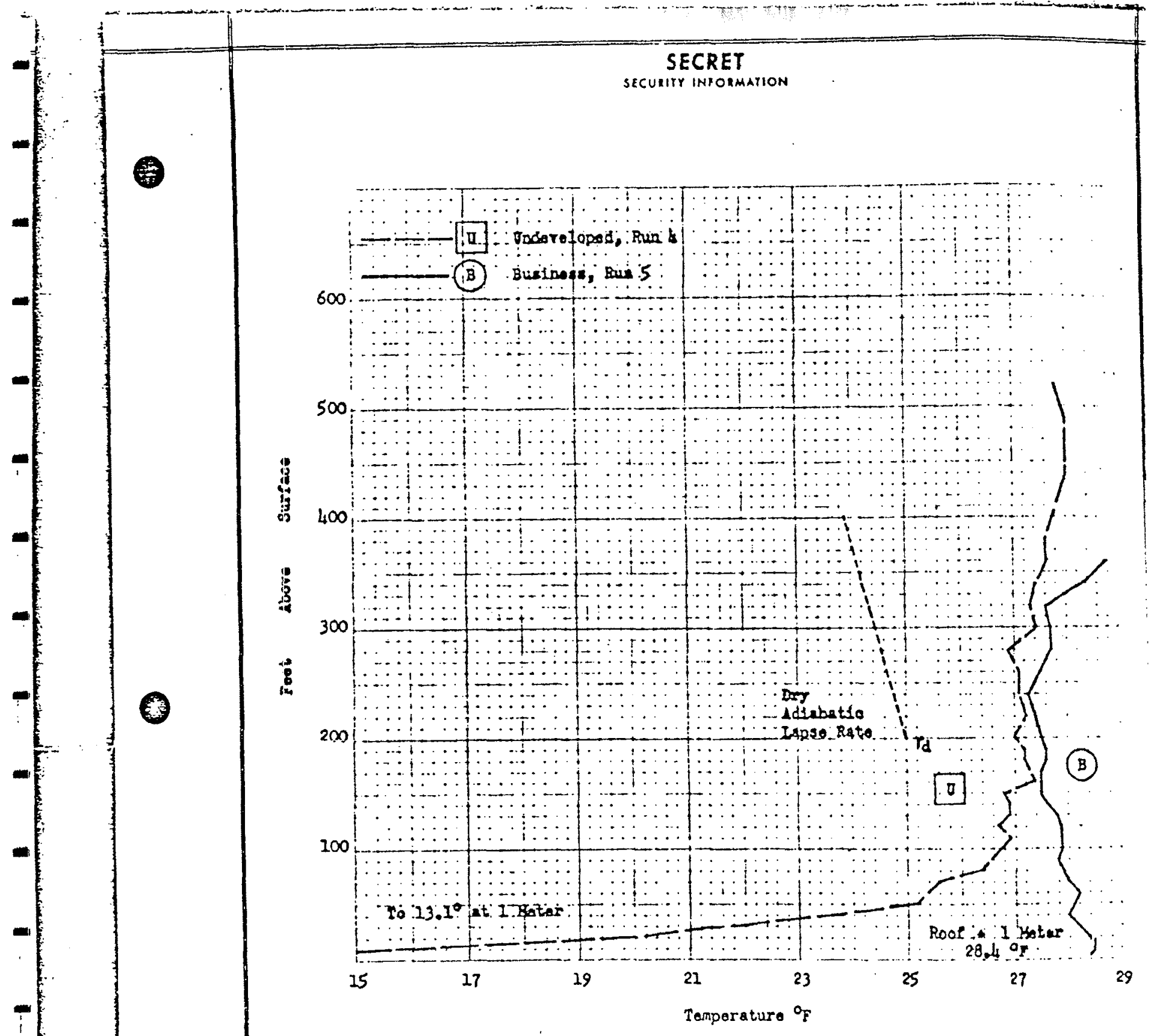

FIOURE $C-8$

COLPARATTE TEMPERATURE SOUNDINGS

Minneapolla Wiresondo

Undevoloped Va Business Arma

$2300 \mathrm{CST} \quad 23$ Fob 1953

$P \cos : 136$

SECRET

SECURITY INFOIMATION 


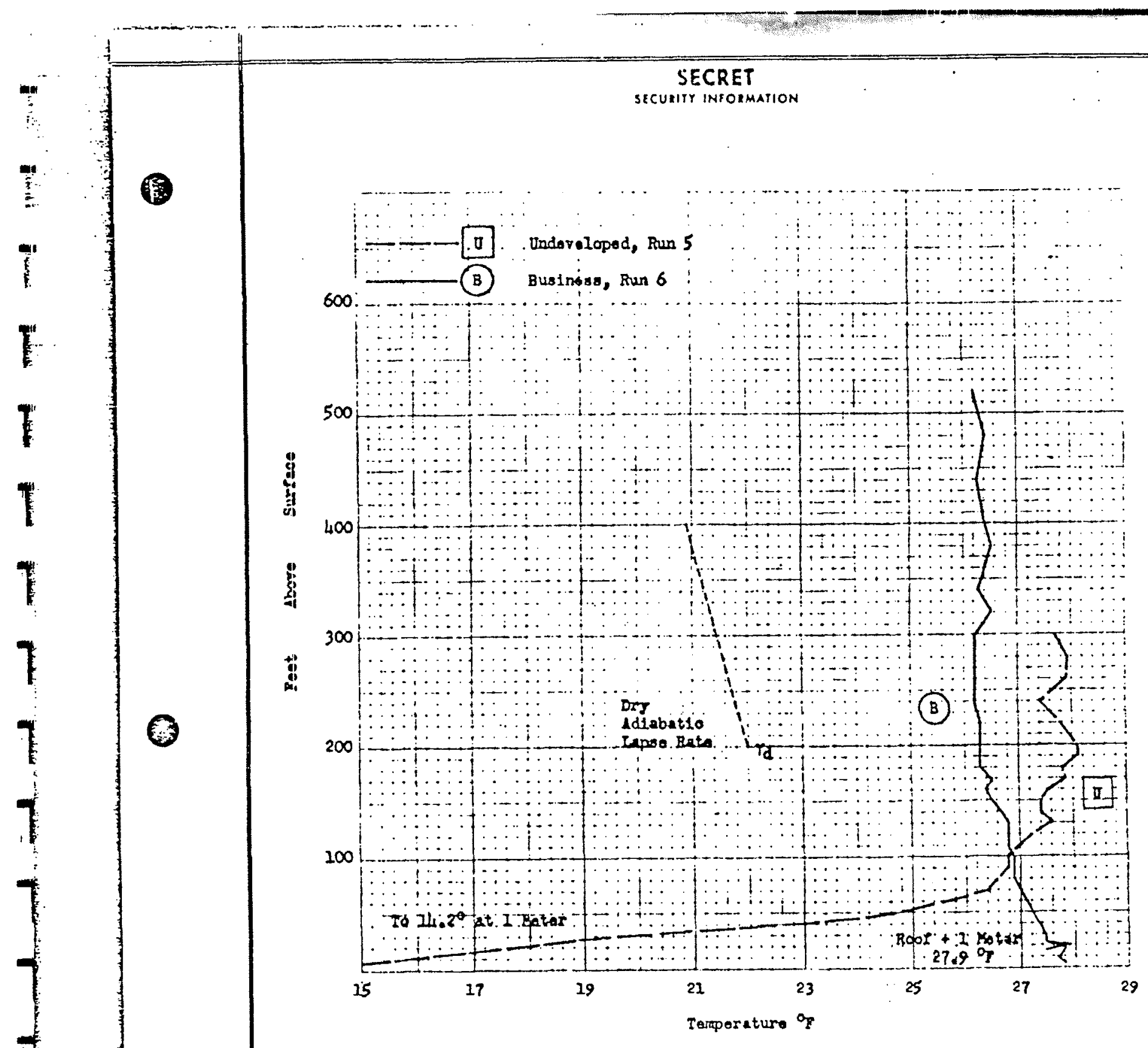

FIGUPE C-?

COMPARATIVE TEIPERAT:RE SCUNDIMGS

Hnneapolis Wiresonde

Undoveloped Vs Blisinoss Aros

2400 CST 23 Feb 1953

$P 4 \cdot 137$ 


\section{Aspoda CBSERAT TOK}

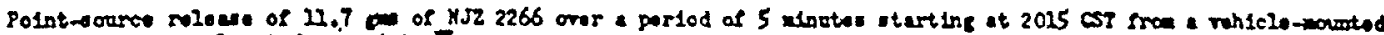
blarer disperen located at polot in.

s.pry. Do

Locstion and Expoesure

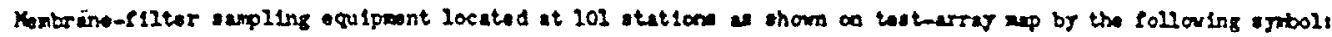

- Outdoor apler at halpt betwer 1 and 6 foet.

Bevolte

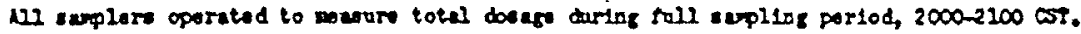
Totei Dosese (particle-einuteo/steres)

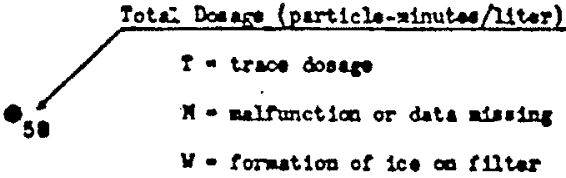

Eetrenotoor

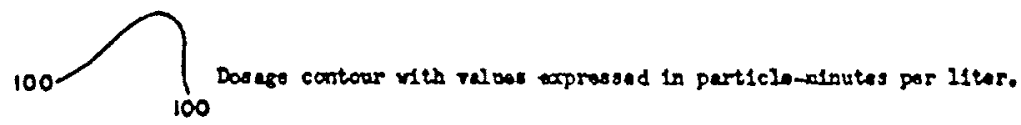

Equipment and kesurement

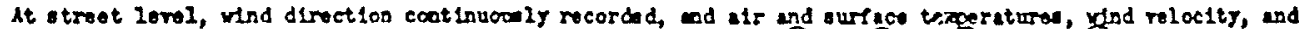

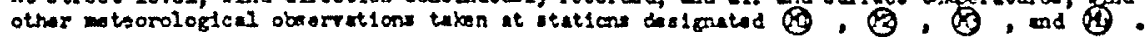

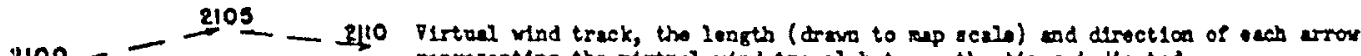
representiog the rirteil viad tievel between the times indicated.

Balloon track representing viod-dett oberration at the tins indicated.

IInd

Stret-lerel winds southarly at 1.7 ph, reering to soutbuaterly at trootop loral. Stebility

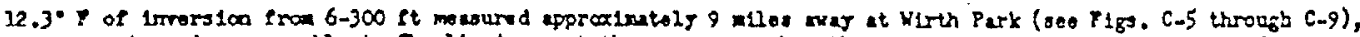
orer open terrain comorablo to Charlie Area, at the wotern rethor then at the southouterm pariphery of

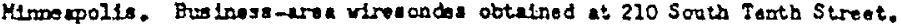

s.5

Clear during tast poriod.

Teroerature

21. to 25.7 at 2 moters in the tast area.

Yolature

KIxing rat10 of $2.7 \mathrm{gm} / \mathrm{kgn}$ dry air. 
TEST ARRAY AND EESTTTS

Tigure $6-2$

$237 \circ 62953$

$r$ coled

AEROSOE GENERAT TOM

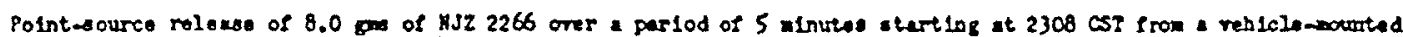
blover disporser loceted at point SAMPLE

Location and Frosum

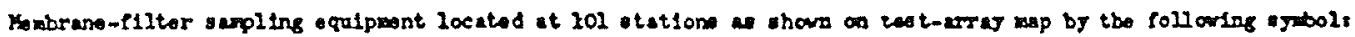
- Outioor sumpler at belight between 1 and 6 feet.

Rosules

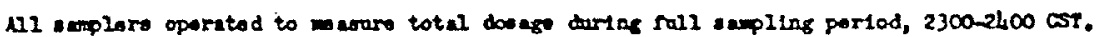

4 mirorotort

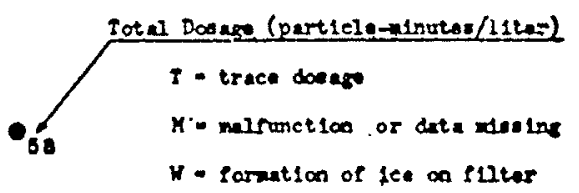

Iquifinant and Hocourenent

At atreet lovel, wid direction contimouly recorded, and alr and ourfece tonotatures, yind relocits, and

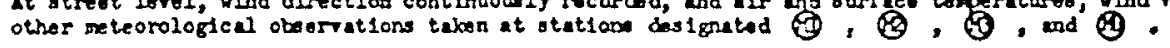

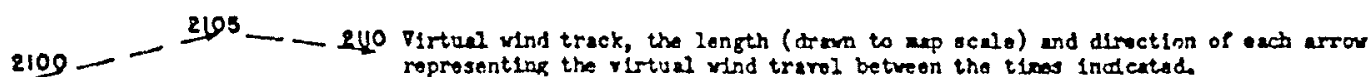
2100 Belison track reprosenting tho wind-deift obserration at the tim indleated

$\underline{y_{i}} \mathbf{z}$

Stret-level wind a outhwesterly at 1.3 phi winde at troetop level also southostorly.

stablilty

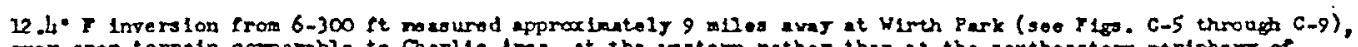
orer open terrain cosparable to Charlie Area, at the wostorn rather than at tho southeastern poripher of Minneapolis. Business-2ros wiresondo obtained at 210 South Tenth Street.

$\underline{S \underline{k}}$

Clear dering tost poriod,

Tomperature

$19^{\circ}$ to $27^{\circ}$ I st 2 moters in the test aros.

yoloture

Mixing satio of $2.6 \mathrm{~km} / \mathrm{kgx}$ dr $4 \mathrm{dr}$.

3 


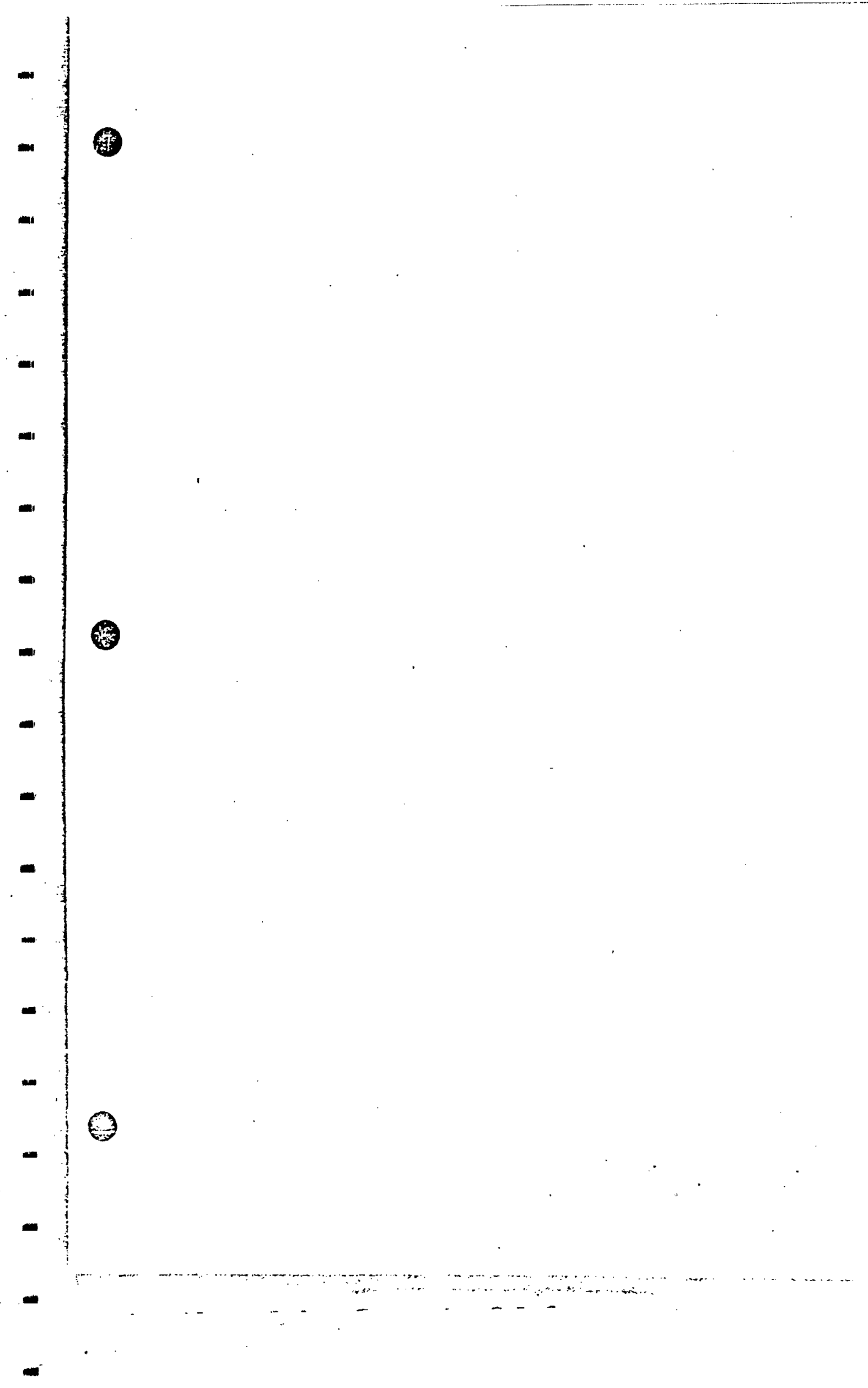

5 


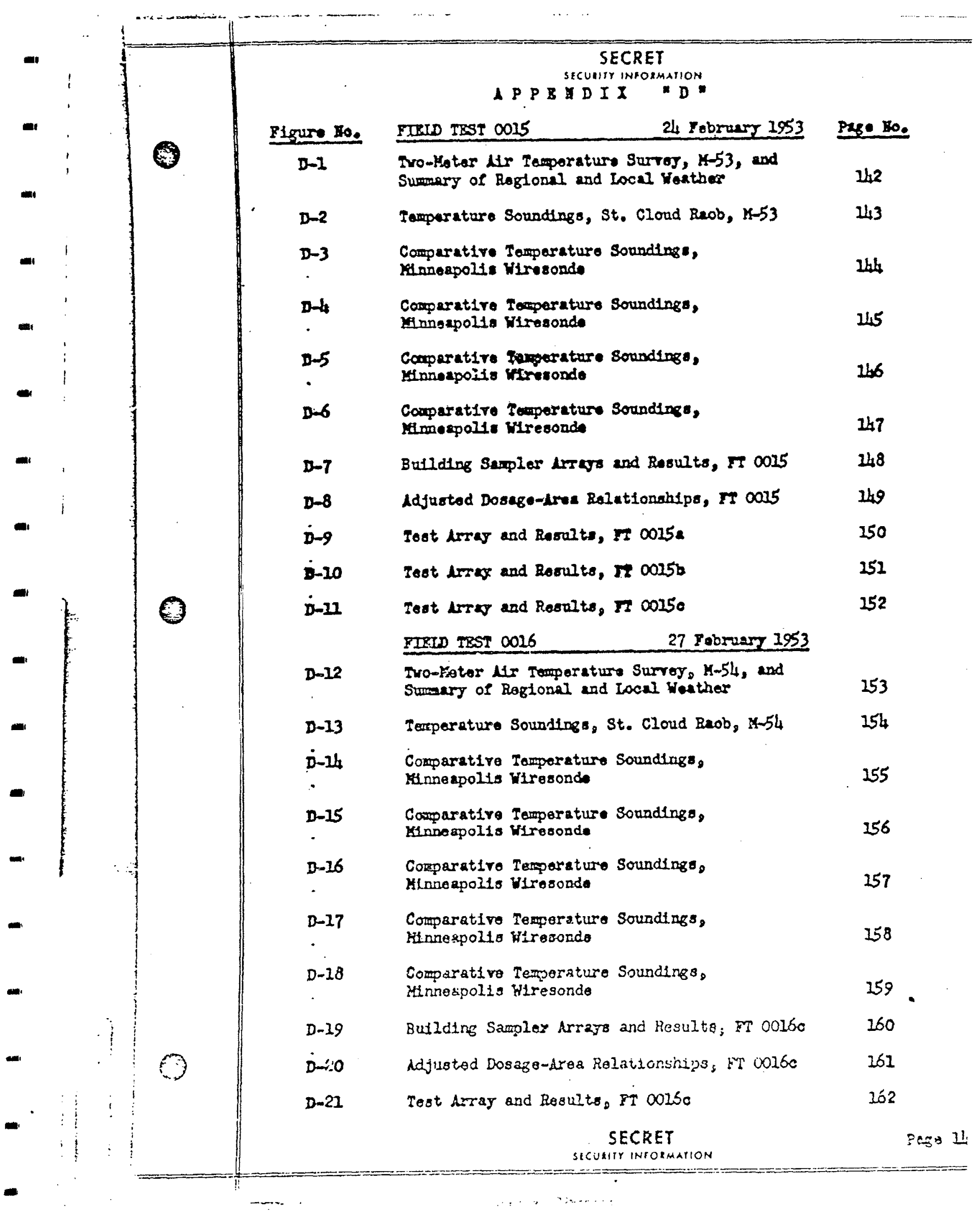




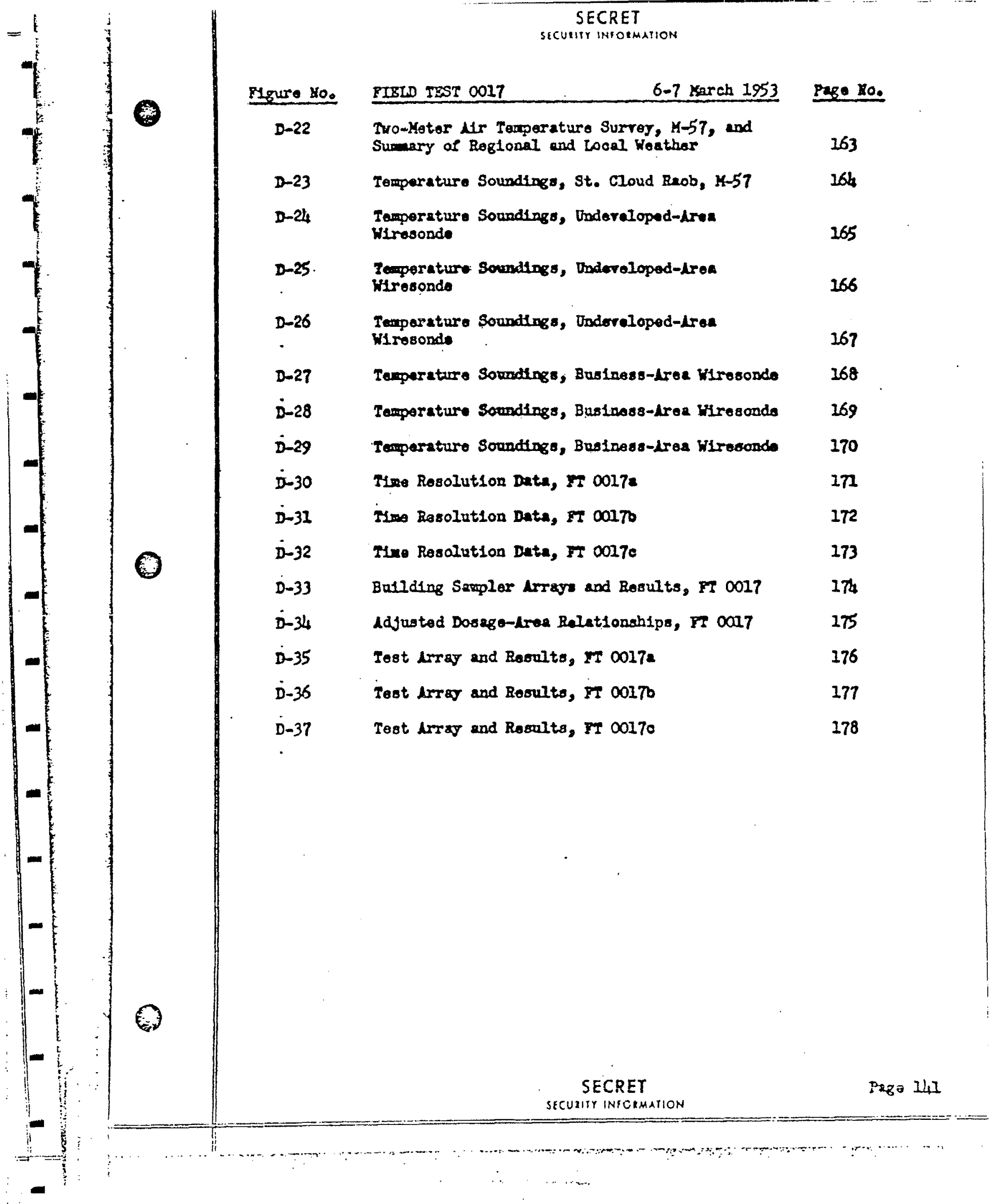


SUMARY OF REGIONAL AND LOCAL WEATHER

24 February 1953

(Survoy M-53, Supolemental to FT 0015)

\section{SYNOPTIC SITUATION}

A small 1020-mb high cell, centered in southeastern Hinnesota, carried continental polar air over Minneapolis. An occluded front at the MontansDakota border was not yet close enough to affect the test. area, although an air-mass stratus deck did appear during the period. At the 700-mb level, the northern portion of a trough was sheared off over Canada, and the balance of this trough extended from South Dakota to Arizona. $A$ strong northwesterly flow persisted over central Canada, but the gradient over Minnesota was relatively flat, resulting in a northwest 700 -mb wind of $10 \mathrm{mph}$ for Minneapolis.

WEATHER REPORTS FROM WOLD-CHAMBERLAIN FIEID (MINNEAPOLIS

\begin{tabular}{|c|c|c|c|c|c|c|c|c|}
\hline \multirow[b]{2}{*}{$\begin{array}{r}\text { Time } \\
\text { (CST) }\end{array}$} & \multirow{2}{*}{$\begin{array}{l}\text { Cloud } \\
\text { Helght } \\
\text { (feet) }\end{array}$} & \multirow[b]{2}{*}{$\begin{array}{l}\text { Sky } \\
\text { Cover: }\end{array}$} & \multirow[b]{2}{*}{$\begin{array}{c}\text { V1sikillty } \\
\text { (miles) }\end{array}$} & \multirow[b]{2}{*}{ Weather } & \multirow[b]{2}{*}{$\begin{array}{l}\text { Tamp } \\
\left({ }^{\circ} \mathrm{F}\right)\end{array}$} & \multirow{2}{*}{$\begin{array}{c}\text { Ders } \\
\text { Point } \\
(0 \%)\end{array}$} & \multicolumn{2}{|c|}{ Wind } \\
\hline & & & & & & & $\underline{D 15}$ & $\begin{array}{l}\text { Speed } \\
\text { (mph) }\end{array}$ \\
\hline 830 & None & Clea & 15 & - & 30 & 23 & NW & 8 \\
\hline 930 & None & Cles & $15+$ & - & ? & 20 & WW & 7 \\
\hline & None & Clear & $15+$ & - & 2 & 17 & WSW & 7 \\
\hline 2130 & 1700 & Broken & $15+$ & - & 20 & 16 & $\mathrm{~W}$ & 8 \\
\hline 2230 & 1500 & Overcast & $15+$ & - & 1 & 15 & WSW & 7 \\
\hline 2330 & 1700 & Overcnst & $15+$ & - & 18 & 15 & WSW & 10 \\
\hline
\end{tabular}

* Average cloudiness sunrise to sunset, $80 \%$ * And/or restriction to visibility

Sea-lovel pressure at $2130 \mathrm{CST}: 1022.0 \mathrm{mb}$

iround condition: Twelve-inch snow; main streets clear of snow but thin Ice in spots; side streets $50 \%$ clear; two-1rch packed

Tree cuver: None snow and Ice; lake frozen 


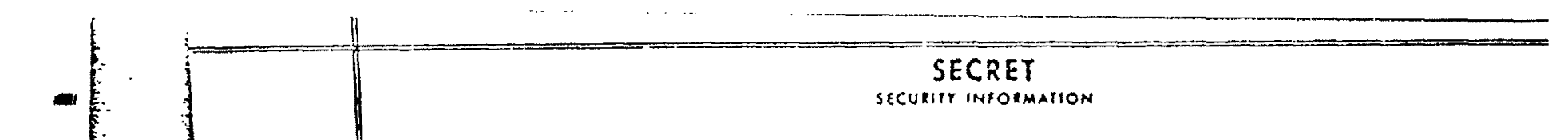

(2)

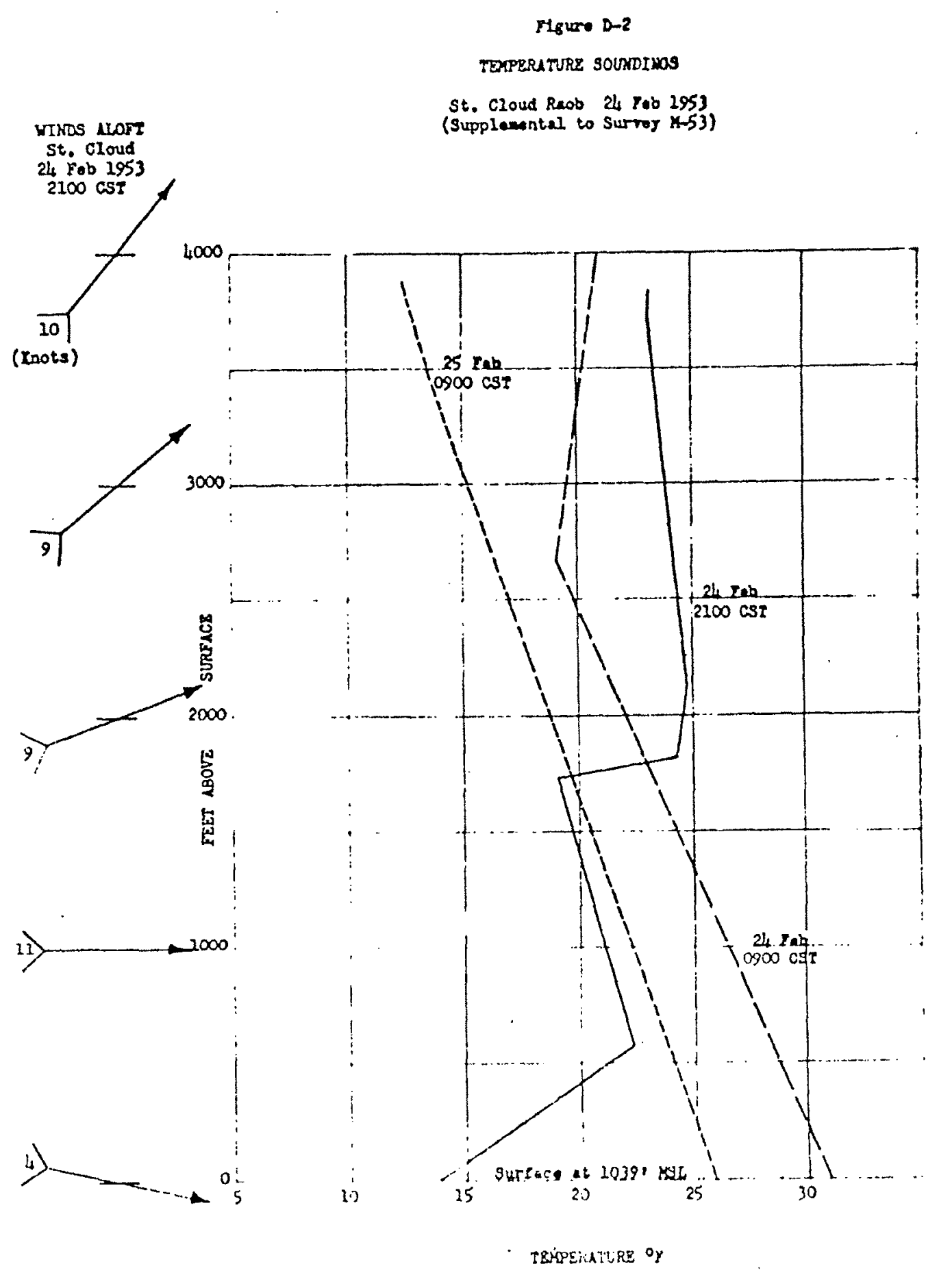




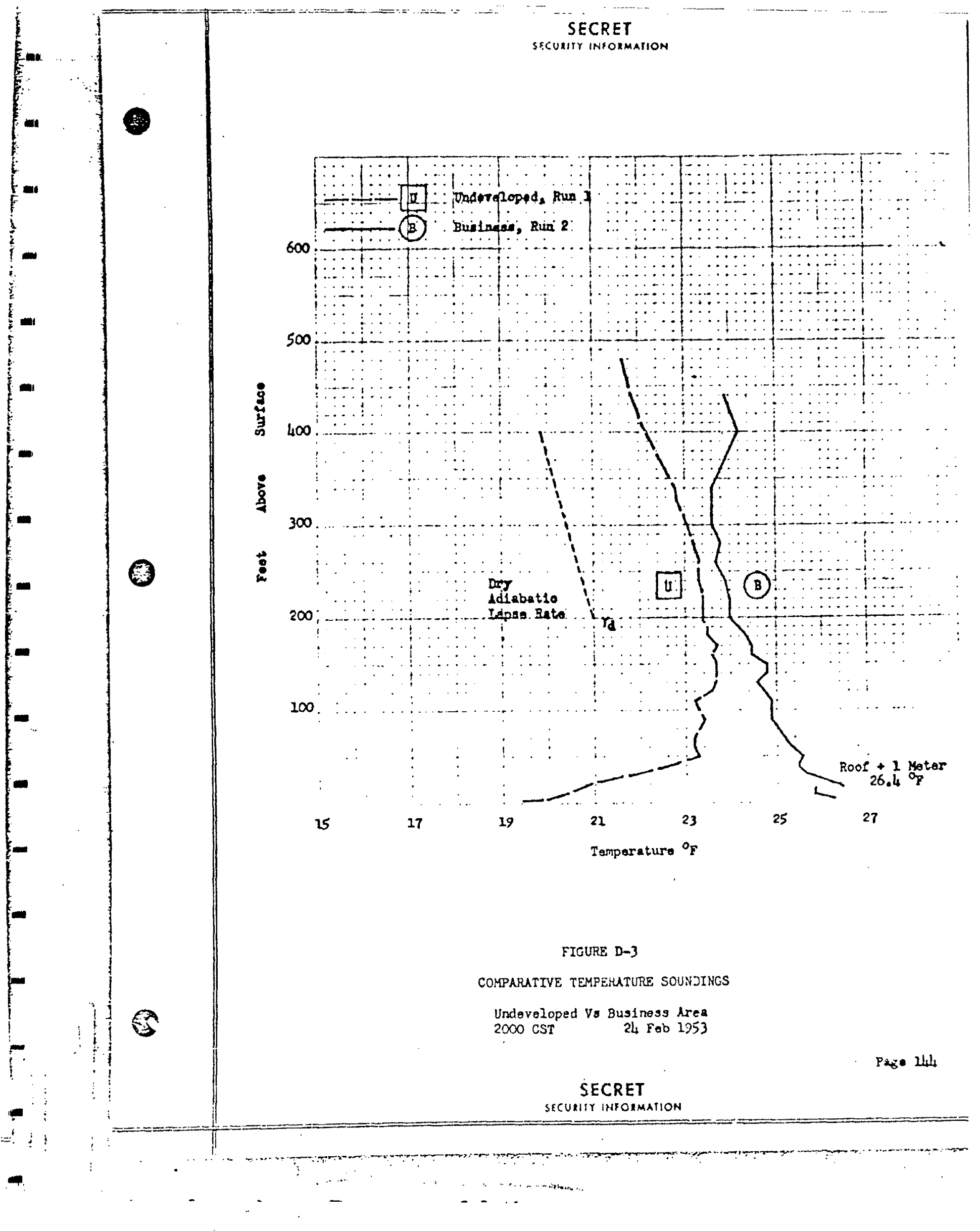




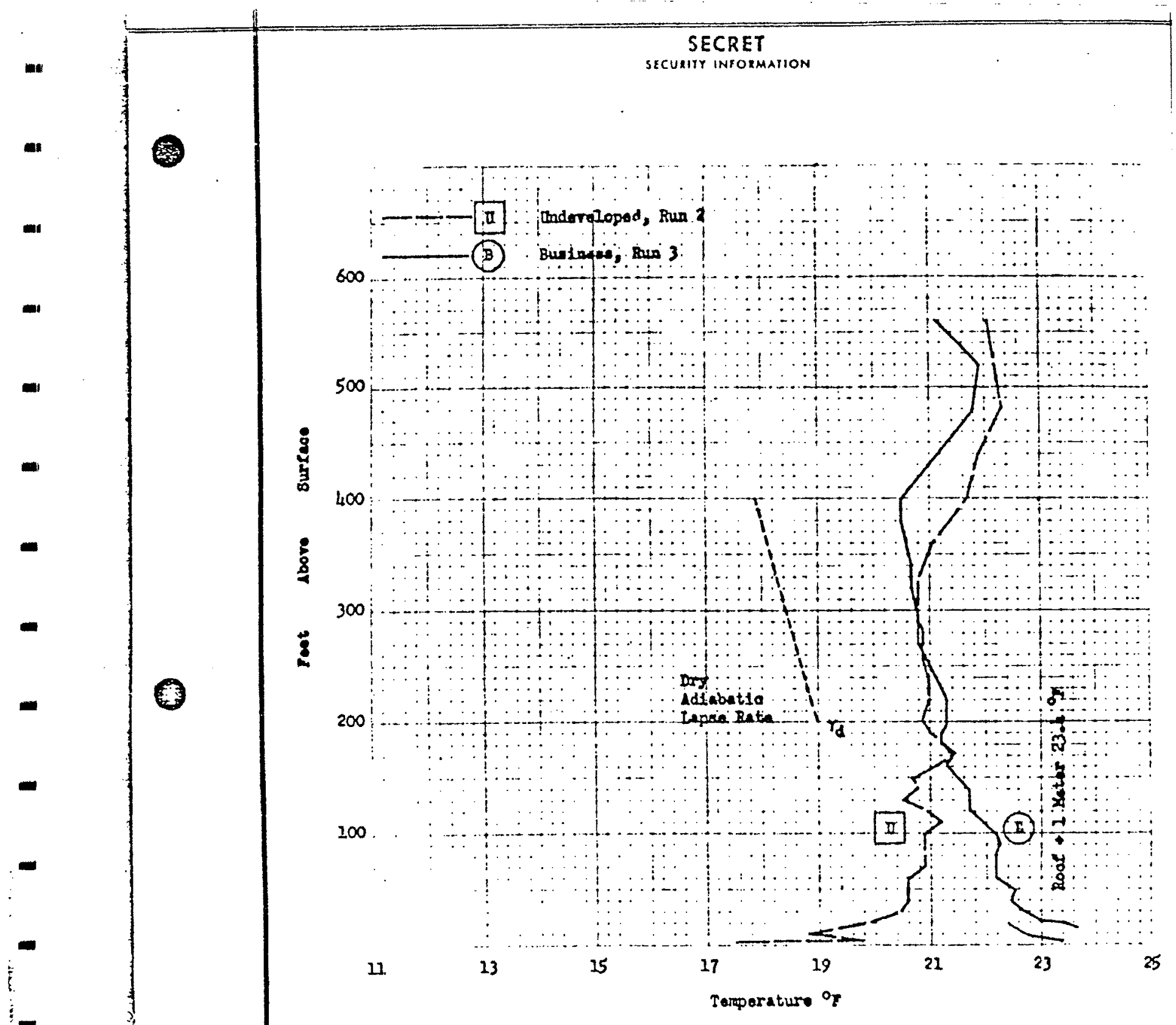

FIOURE D-4

COMPARATTVE TDMPESUTURE SOUNDINGS

M1nnezpolls W1resonda

Undoraloped 78 Busineso Nrod

2100 CST 24 Fob 1953

Page I45 


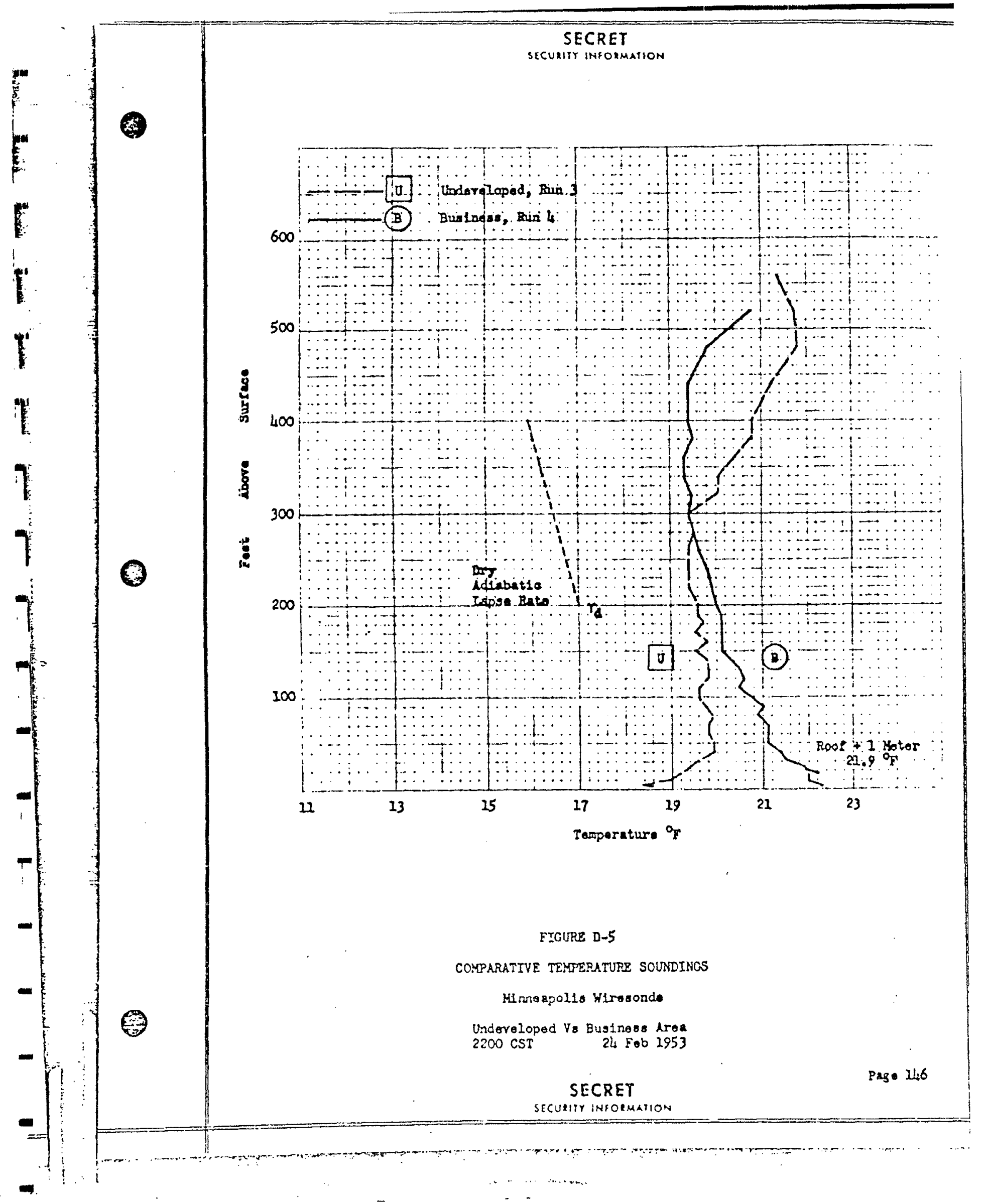




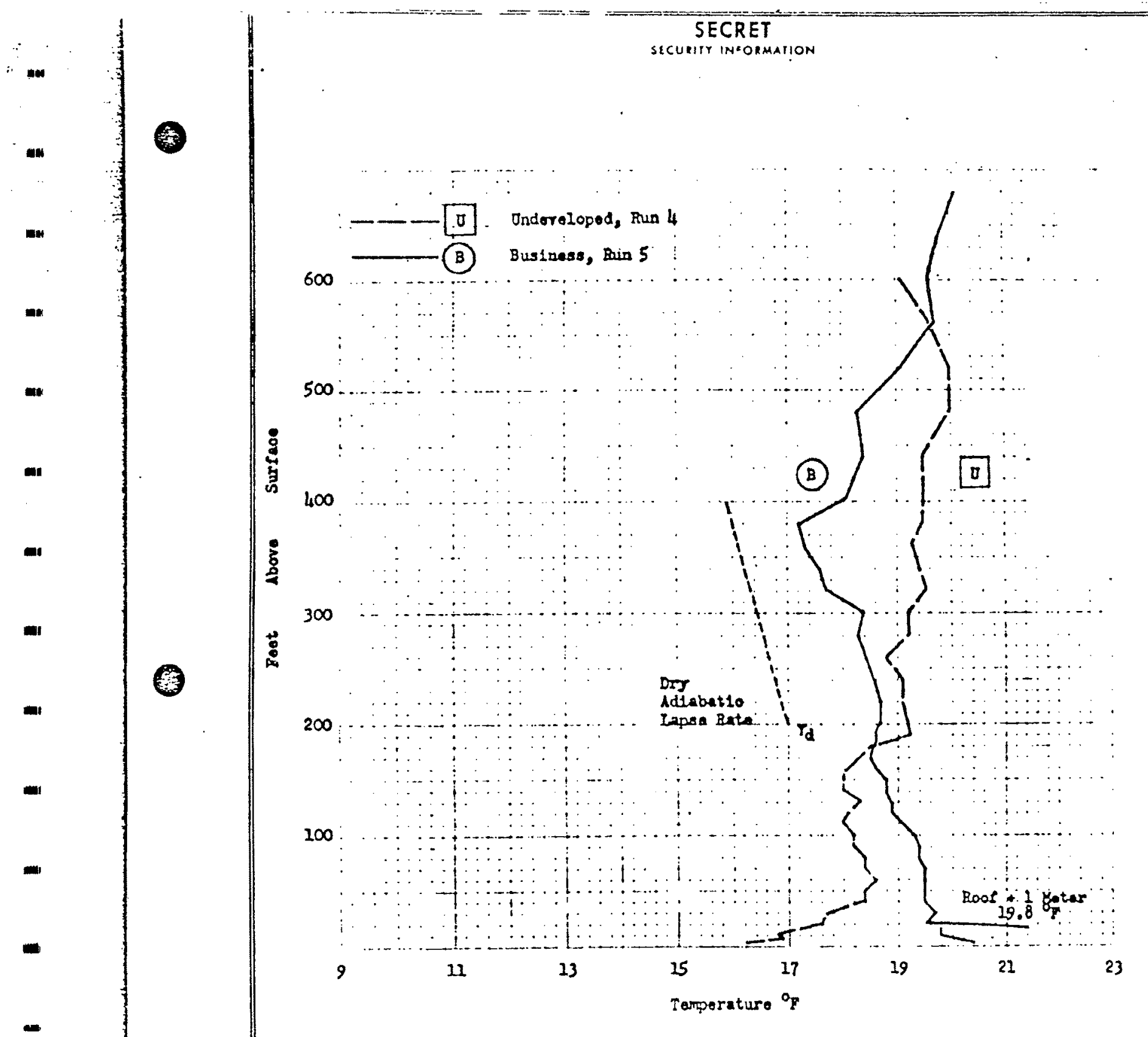

FIGURE D-S

COMPARATIVE TEYPERATURE SOUIDINGS

Minneapol ' Wiresondo

Undeveloped Ys Business Aros

23CO CST

24. Fob 1953 


\begin{tabular}{|c|c|c|c|c|c|c|c|c|c|c|c|}
\hline \multirow[b]{3}{*}{$\begin{array}{l}\text { Solplar } \\
\text { Location } \\
\left(\text { noor } f^{2}\right)\end{array}$} & \multicolumn{3}{|c|}{ 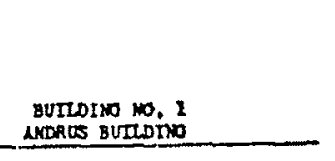 } & \multicolumn{4}{|c|}{ 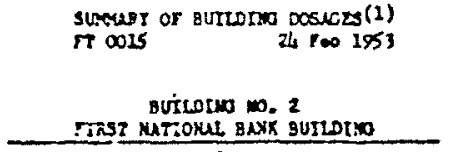 } & \multicolumn{4}{|l|}{ axturs te } \\
\hline & & \multicolumn{4}{|c|}{ outese } & \multirow[b]{2}{*}{ 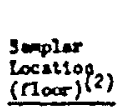 } & \multicolumn{3}{|c|}{ Ootside } \\
\hline & \multicolumn{3}{|c|}{ 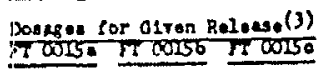 } & $\begin{array}{l}\text { Lecitiog } \\
\text { (Iloor) }(2) \\
\end{array}$ & Danger: & tren & $\frac{1+20(3)}{100150}$ & & $\begin{array}{l}\text { Dosasen } \\
\text { Foct5a }\end{array}$ & $\frac{\operatorname{ascos} x}{2 \cos s}$ & $\frac{10,00(3)}{r 200150}$ \\
\hline \multirow[t]{2}{*}{ 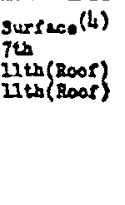 } & $\begin{array}{r}130 \\
7 \\
73 \\
39\end{array}$ & $\begin{array}{l}60 \\
92 \\
74 \\
76\end{array}$ & $\begin{array}{r}55 \\
122 \\
96\end{array}$ & Surfaco $(4)$ & 52 & \$ & $\begin{array}{l}\text { The } \\
\text { bulldins } \\
\text { yes not } \\
\text { yod in } \\
\text { this } \\
\text { roloses }\end{array}$ & 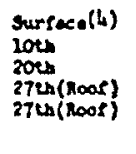 & $\begin{array}{l}21 \\
29 \\
18 \\
17\end{array}$ & $\begin{array}{l}50 \\
6 \\
28 \\
33 \\
23\end{array}$ & $\begin{array}{l}35 \\
18 \\
14 \\
16 \\
18\end{array}$ \\
\hline & \multicolumn{3}{|c|}{$\ln 16$} & \multicolumn{4}{|c|}{ Inelde } & \multicolumn{4}{|c|}{ Inte } \\
\hline 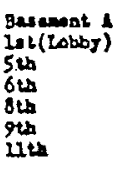 & $\begin{array}{r}28 \\
84 \\
5-3 \\
10-5 \\
5-9 \\
35-6 \\
64\end{array}$ & $\begin{array}{r}29 \\
76 \\
2-19 \\
4-10 \\
3-10 \\
8-5 \\
5-23\end{array}$ & $\begin{array}{r}51 \\
83 \\
58-9 \\
29-9 \\
25-22 \\
4-6 \\
17-6\end{array}$ & 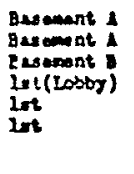 & $\begin{array}{l}6-2 \\
7-7 \\
4=3 \\
6-2 \\
7 \\
29\end{array}$ & $\begin{array}{l}1 \\
3 \\
7 \\
23 \\
53\end{array}$ & & 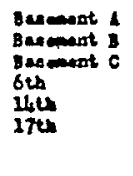 & $\begin{array}{r}0-0 \\
19-0 \\
0-0 \\
T-t \\
b-i\end{array}$ & $\begin{array}{c}x-11 \\
0-31 \\
0=0 \\
7-3 \\
13 \\
x-0\end{array}$ & $\begin{array}{r}6-2 \\
14-0 \\
0-0 \\
7-14 \\
10 \\
11\end{array}$ \\
\hline \multicolumn{4}{|c|}{ 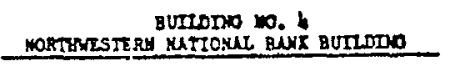 } & \multicolumn{4}{|c|}{ 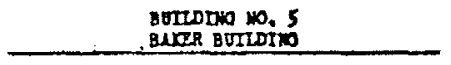 } & \multicolumn{4}{|c|}{ 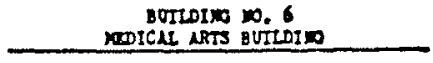 } \\
\hline \multirow[b]{2}{*}{$\begin{array}{l}\text { Saplar } \\
\text { Locallog) } \\
\text { (floor) } 2)\end{array}$} & \multicolumn{3}{|c|}{ nutalde } & \multicolumn{4}{|c|}{ Oatordes } & \multirow[b]{2}{*}{$\begin{array}{l}\text { smplar } \\
\text { Locit!an } \\
\text { (nogr) }(2)\end{array}$} & \multicolumn{3}{|c|}{ Outside } \\
\hline & 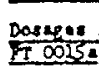 & $\frac{\text { or ofron }}{I 0015 \mathrm{~b}}$ & $\frac{\operatorname{loss}(3)}{700150}$ & $\begin{array}{l}\text { septar } \\
\text { (oxitiog } \\
(2 \operatorname{cor})^{(2)}\end{array}$ & $\frac{\text { Dosents }}{\mathrm{R} 00 \mathrm{~s}}$ & $\frac{01 \text { ren }}{00156}$ & $\frac{10200(3)}{Z 0055}$ & & $\frac{D 0 s}{I 015}$ & $\frac{01700 x}{\pi \cos 58}$ & $\frac{1.210(3)}{700150}$ \\
\hline \multirow[t]{2}{*}{$\begin{array}{l}\text { surf tace (4) } \\
11 \text { th } \\
11 \mathrm{th} \\
15 \text { th } \\
17 \text { th (Roor) } \\
17 \text { th (Roof) }\end{array}$} & $\begin{array}{l}30 \\
12 \\
20 \\
19 \\
30 \\
23\end{array}$ & $\begin{array}{l}80 \\
14 \\
31 \\
57 \\
72 \\
30\end{array}$ & $\begin{array}{l}70 \\
40 \\
44 \\
36 \\
16 \\
55\end{array}$ & 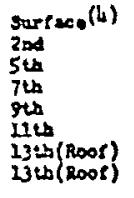 & $\begin{array}{r}1 \\
7 \\
1 \\
1 \\
0 \\
0 \\
0 \\
0 \\
3\end{array}$ & $\begin{array}{r}7 \\
13 \\
5 \\
x \\
10 \\
x \\
4 \\
6\end{array}$ & $\begin{array}{r}10 \\
11 \\
12 \\
8-0 \\
8 \\
7=0 \\
? \\
9\end{array}$ & 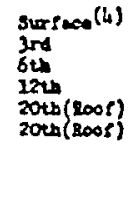 & $\begin{array}{l}0 \\
0 \\
0 \\
0 \\
0 \\
0\end{array}$ & $\begin{array}{l}1 \\
1 \\
1 \\
0 \\
0 \\
0\end{array}$ & $\begin{array}{l}1 \\
1 \\
7 \\
0 \\
0 \\
0\end{array}$ \\
\hline & & Inside & & & & naso & & & & Inet & \\
\hline $\begin{array}{l}\text { gasemant } 1 \\
\text { gesement } \\
3 \text { sd } \\
6 \mathrm{th} \\
12 \mathrm{th}\end{array}$ & $\begin{array}{l}5-7 \\
9-7 \\
5-7 \\
3-7 \\
2-0\end{array}$ & $\begin{array}{l}2-3 \\
0-12 \\
2-7 \\
7-3 \\
0-3\end{array}$ & $\begin{array}{r}6-3 \\
15-2 \\
13-3 \\
8-2 \\
1-2\end{array}$ & 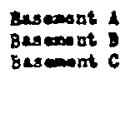 & $\begin{array}{l}3-7 \\
0=0 \\
0-0\end{array}$ & $\begin{array}{l}2-1 \\
0-1 \\
0-0\end{array}$ & $\sum_{0=0}^{3-5}$ & 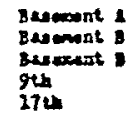 & $\begin{array}{l}0-t \\
0=0 \\
0-0 \\
0=0 \\
s-0\end{array}$ & $\begin{array}{r}100 \\
29=2 \\
00 \\
00 \\
0=0\end{array}$ & $\begin{array}{l}T=0 \\
0-0 \\
0=0 \\
0-0 \\
T-1\end{array}$ \\
\hline
\end{tabular}

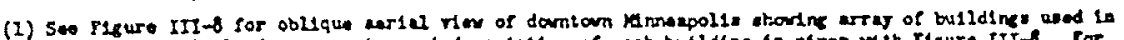

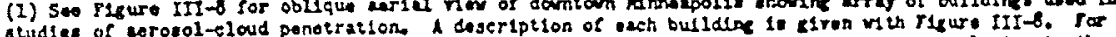

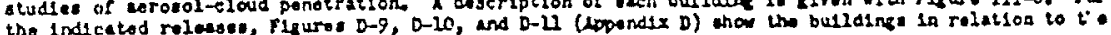
grid complex and the doese pattarn.

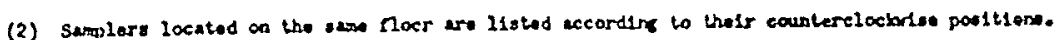

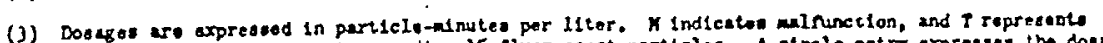

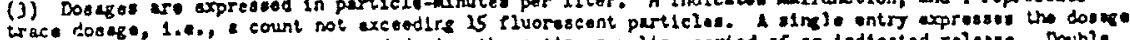

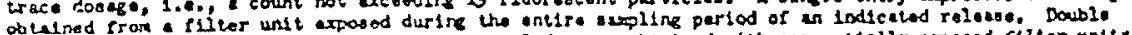

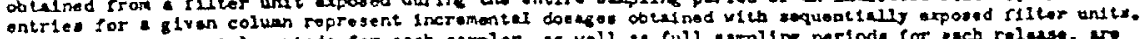

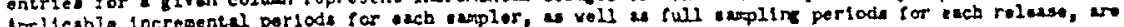
of collow:

\begin{tabular}{|c|c|c|}
\hline Relosese & Sarpl1re Portod & Inerenontel portade \\
\hline FT $\infty 15$ & $2000-2100 \operatorname{css}$ & $\begin{array}{l}2000-2 d, 5 \text { cst } \\
20,5-2115 \text { cst }\end{array}$ \\
\hline$T 20010^{\circ}$ & $2215+2215 \operatorname{cst}$ & $\begin{array}{l}2115-2200 \mathrm{cst} \\
2200-2230 \mathrm{cst}\end{array}$ \\
\hline$\pi$ ootso & $2230-24,00 \operatorname{cst}$ & $\begin{array}{l}2230-2315 \text { cst } \\
2315-2115 \text { cst }\end{array}$ \\
\hline
\end{tabular}

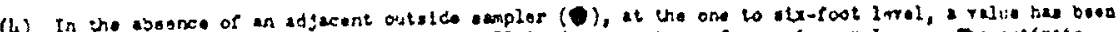

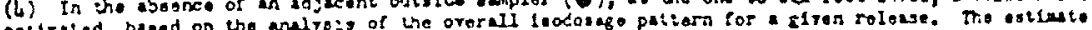

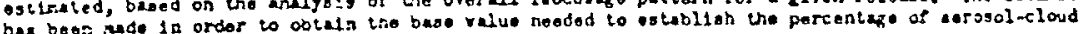
Fontration. 


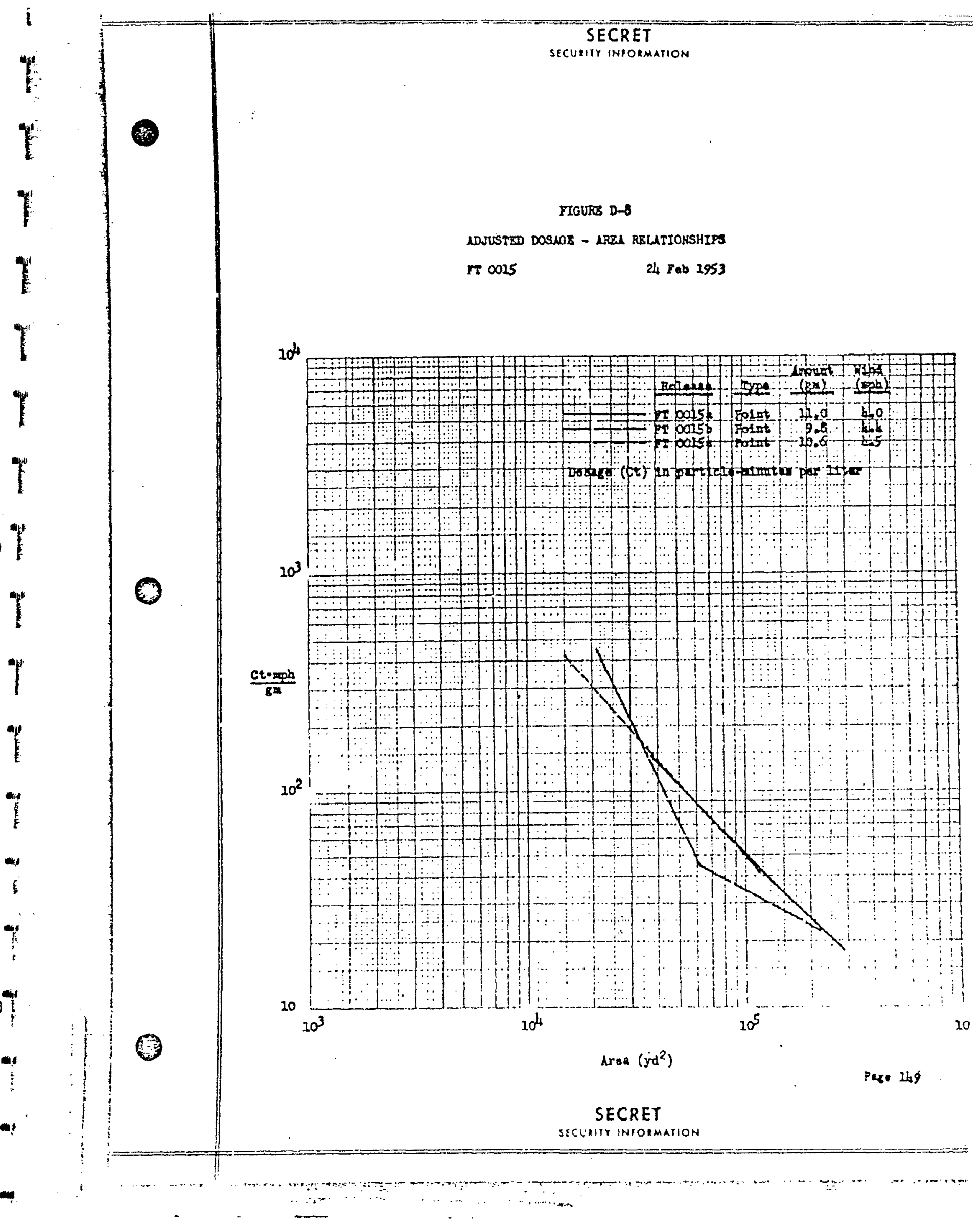




\section{AERQIOL TRRTIOA}

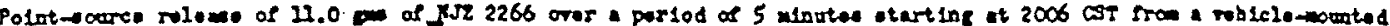
blower cuporoer locatad it polmt hy. surpt. Do

\section{Loeation and Exporurs}

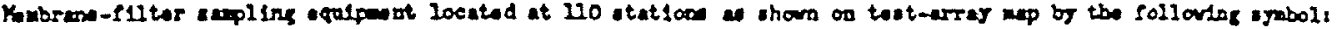

- Oatdoar appler at halet betwen 1 and 6 foet.

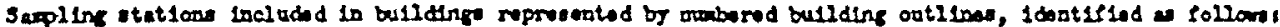

leaples

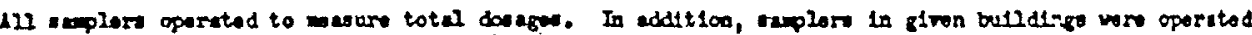

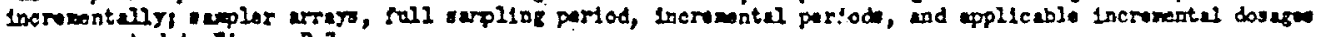
are preseated in 21 our a.7.

영

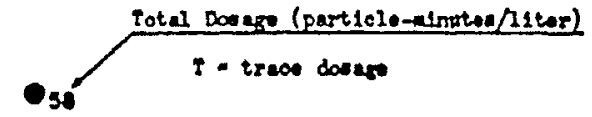

\section{vetrokacor}

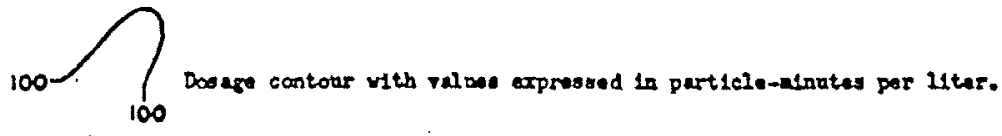

Equipont and tomement

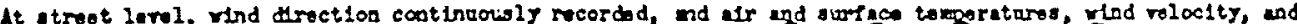

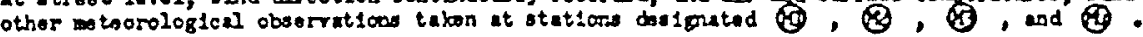

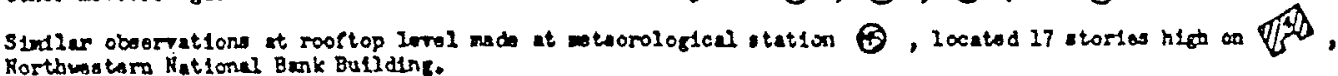

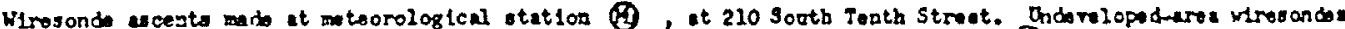

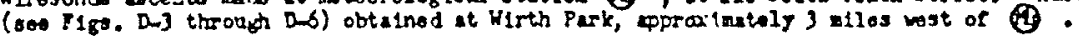

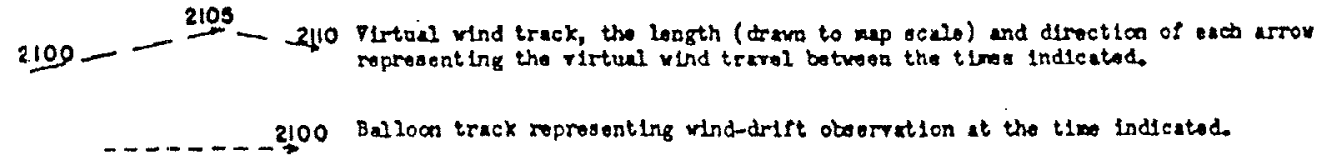

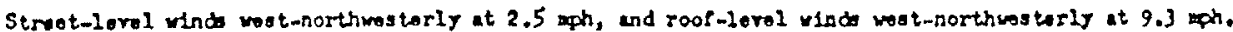

\section{St:binsty}

$3.0^{\circ}$ r lapse from 6-300 st.

six

Clear during teat perlod,

Temperature

$24.8^{\circ}$ to $26.5^{\circ} \mathrm{F}$ at 2 maters in the tost aras.

Kolsture

Mirine talio of $2.0 \mathrm{gm} / \mathrm{xga}$ dr alro 
as Rosol Gotertion

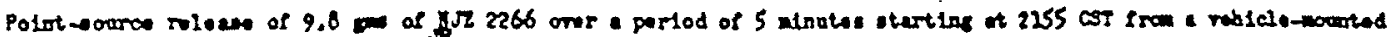
blowr dtopariour laceted it polnt

Suxp Dno

Locat1on and txposure

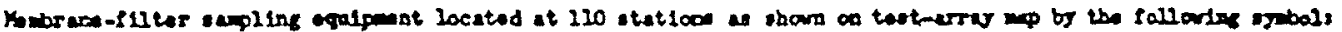
Outbor explor st balght botwen I and 6 reet.

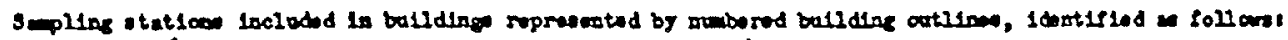

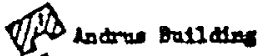
OS rint Iational Benk B2dx

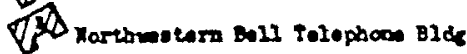

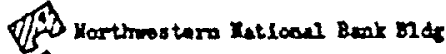
Tid Bawer Ballant

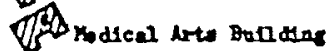

\section{Bavies}

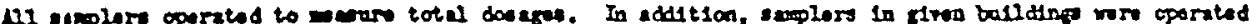

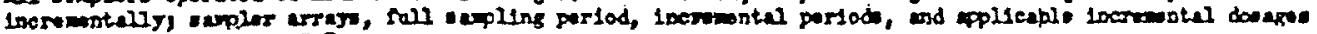
are presented in $71 \mathrm{gmen}$ D-7.
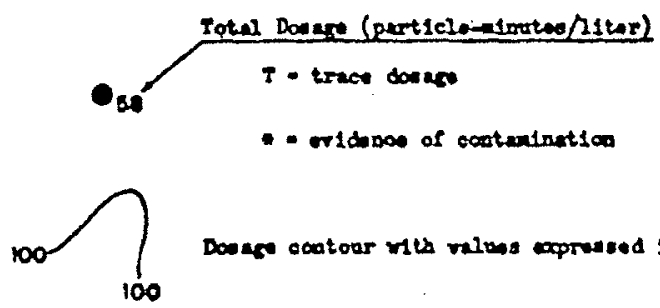

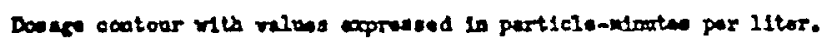

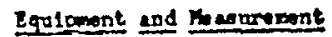

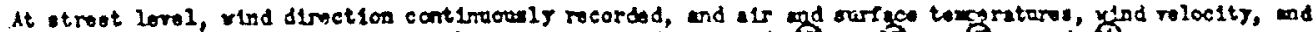

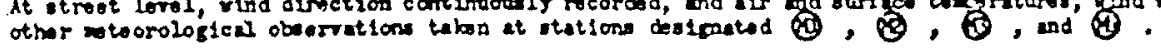

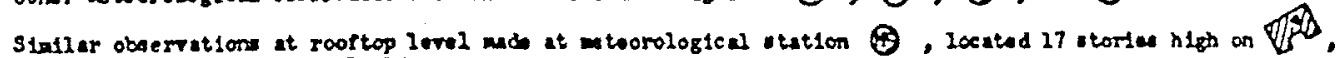
Horthestara Kational Bank Batlding.

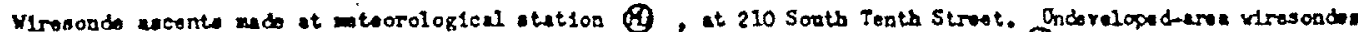

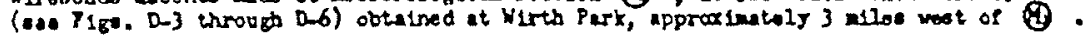

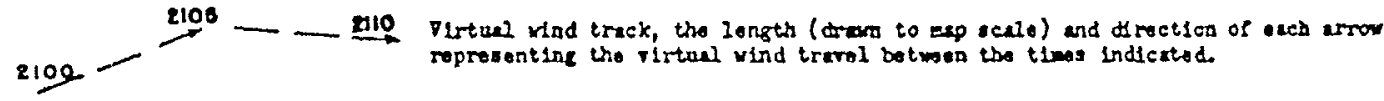
2100 Belloon track representing wind-drift obeorration at the the indeated.

\section{Nind}

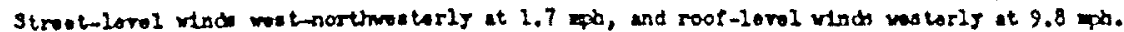

\section{St+b111t}

$2.8^{\circ} 7$ ispose eran 6-300 et.

$3 x$

Orereat cloode with bases 1500 it abore the warlace.

Tonoerature

$20^{\circ}$ to $22^{\circ}$ It 2 work in the tost area.

Holsture

Mring rut10 of 1.9 adkg dry etr. 


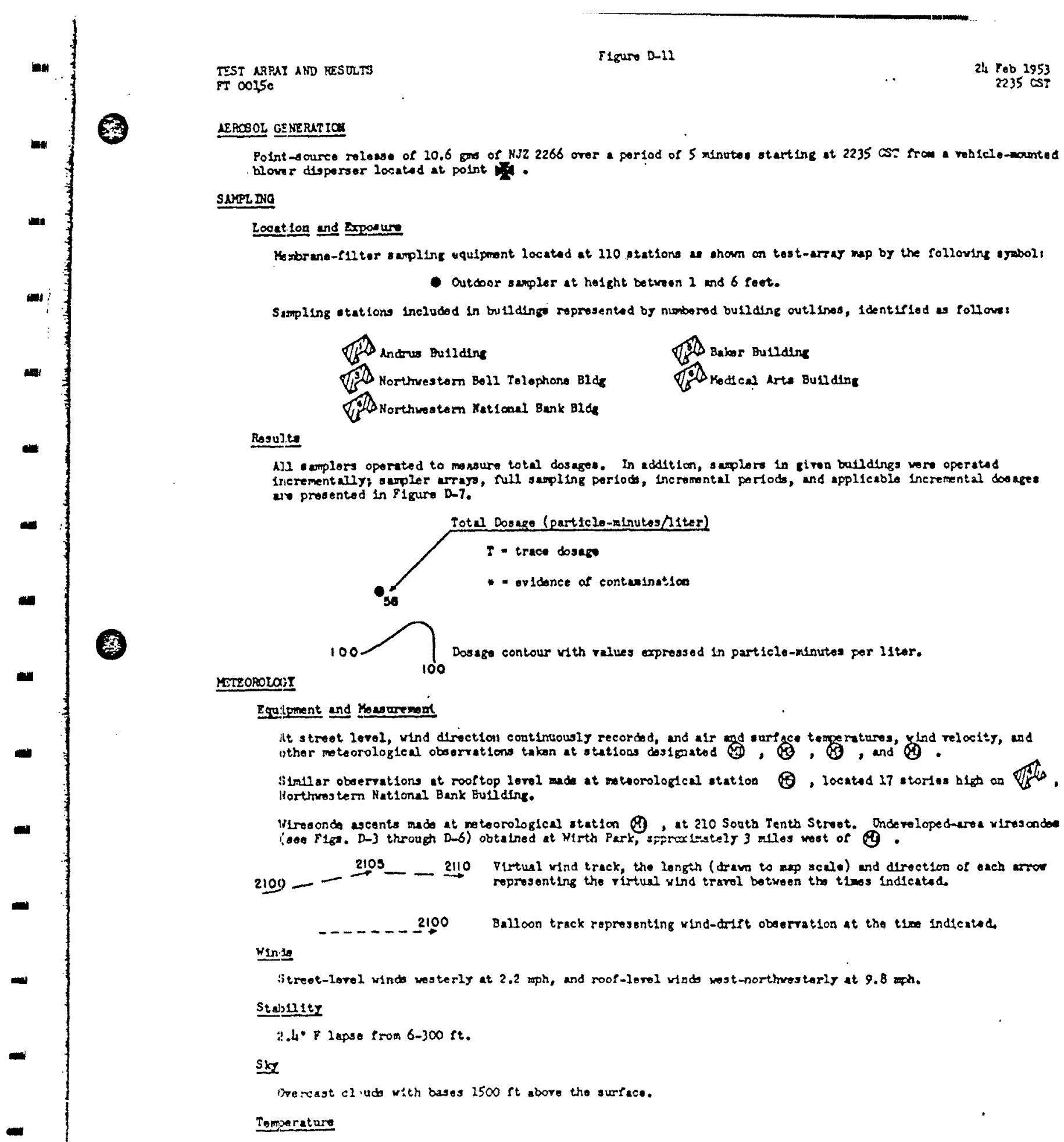


SUMMARY OF REGIONAL AND IOCAL WEATHER

27 February 1953

(Survey M-54, Supplemental to F: 0016)

\section{SHNOPTIC STTUATION}

A wearly stationary cold front trailing from the weak system that passed Mimeapolis the previous day was oriented southeast-northwest through Minnesota and western North Dakota. What appeared to be a weak stablo wave mored southeast along this front, its crest passing Minneapolis durIns the test perlod. Multiple cloud decks and occastonal snow flurries aciompented this passage and a fresh surge of colder air followed the temporary warming prior to lts passage. A weak Polar continental high cell was centered over Kansas and a moderately strong Arctic continental high wais centered over northern Saskatchewan. At the 700-mb level, a westnorthwesterly gradient wind of $45 \mathrm{mph}$ resulted from a broad trough extendins from Ontario to Flordda and from a wide weak ridge ovor the Rocky Mountailn states.

WEATHER REPORTS FROM WOLD-CHAMBERIAIN FIEID (MINNEAPOLTS)

\begin{tabular}{|c|c|c|c|c|c|c|c|c|}
\hline $\begin{array}{r}\text { Time } \\
\text { (CST) } \\
\end{array}$ & $\begin{array}{l}\text { Cloud } \\
\text { Holght } \\
\text { (feet) } \\
\end{array}$ & $\begin{array}{l}\text { Sky } \\
\text { Cover* }\end{array}$ & $\begin{array}{c}\text { Visibility } \\
\text { (miles) }\end{array}$ & Weathert-x & $\begin{array}{l}\text { Tenpp } \\
\text { (OF) }\end{array}$ & $\begin{array}{r}\text { Der } \\
\text { Polnt } \\
(\text { OF }) \\
\end{array}$ & $\underline{D I}$ & $\begin{array}{l}\text { Ind } \\
\text { speed } \\
\text { (mph) }\end{array}$ \\
\hline $\begin{array}{l}1830 \\
1930 \\
2030 \\
2130 \\
2230 \\
2330\end{array}$ & $\begin{array}{l}4400 \\
3700 \\
2900 \\
3500 \\
3600 \\
4000\end{array}$ & $\begin{array}{l}\text { Broken } \\
\text { Overcast } \\
\text { Overcast } \\
\text { Broken } \\
\text { Broken } \\
\text { Broken }\end{array}$ & $\begin{array}{l}15 \\
15+ \\
15+ \\
15+ \\
15+ \\
15+\end{array}$ & $\begin{array}{l}- \\
\overline{-} \\
\overline{-}\end{array}$ & $\begin{array}{l}24 \\
24 \\
25 \\
25 \\
25 \\
26\end{array}$ & $\begin{array}{l}13 \\
\frac{14}{18} \\
20 \\
20 \\
23\end{array}$ & $\begin{array}{l}\text { W } \\
\text { SSW } \\
\text { SSW } \\
\text { SSE } \\
\text { SSW } \\
\text { WSW }\end{array}$ & $\begin{array}{l}5 \\
5 \\
5 \\
6 \\
4 \\
8\end{array}$ \\
\hline
\end{tabular}

* Average cloudiness sunrisa to sunset: of * And/or restriction to vioibllity

Sea-level pressure at $2130 \mathrm{CST}: 1014.9 \mathrm{mb}$

Ground conditions: Twelve-inch snow; maln streets ciear of snow; thin ice In spots; side streets $50 / 50$ clear and two-inch packed

True cover: None snow and ice; lake frozen 


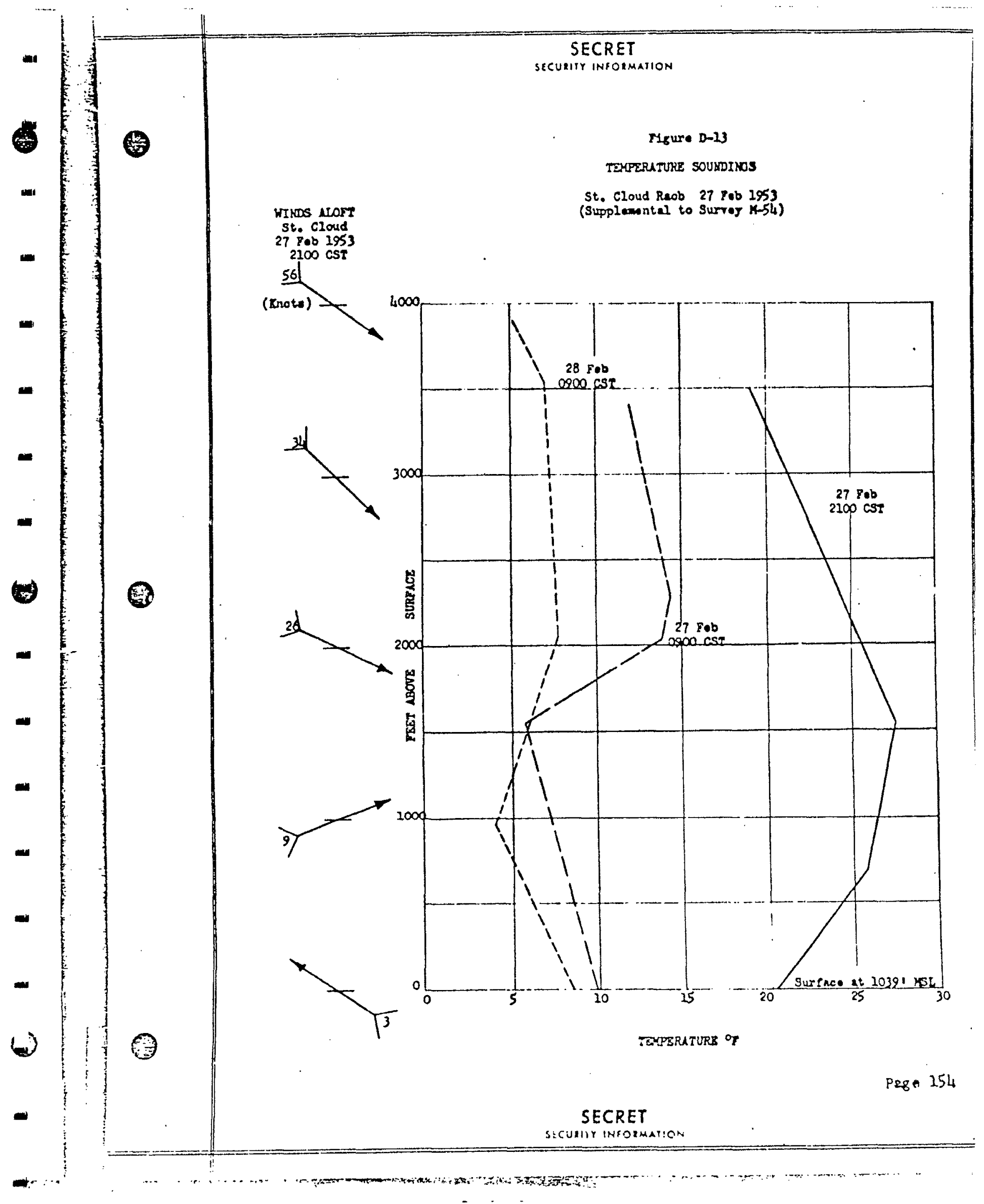




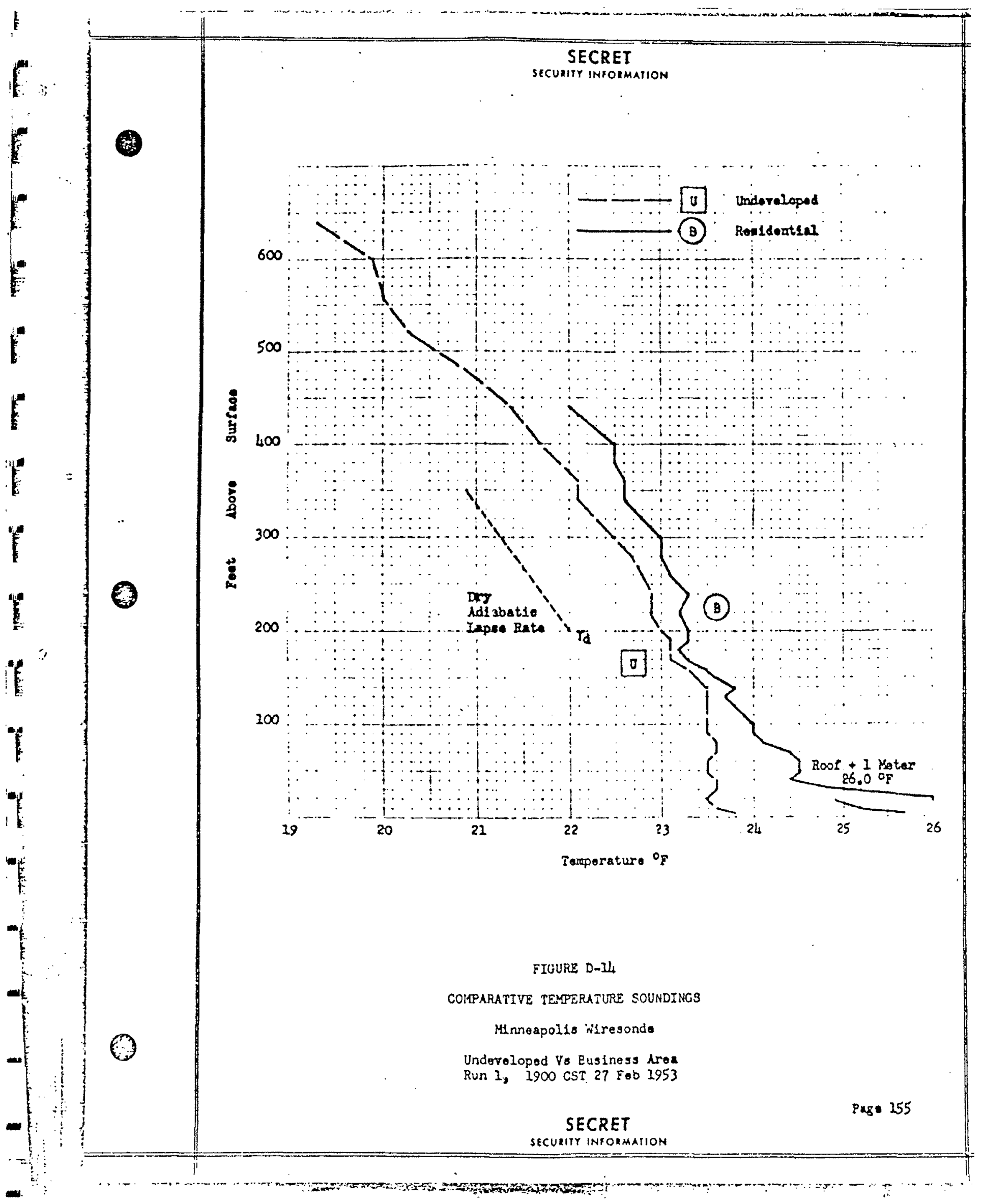




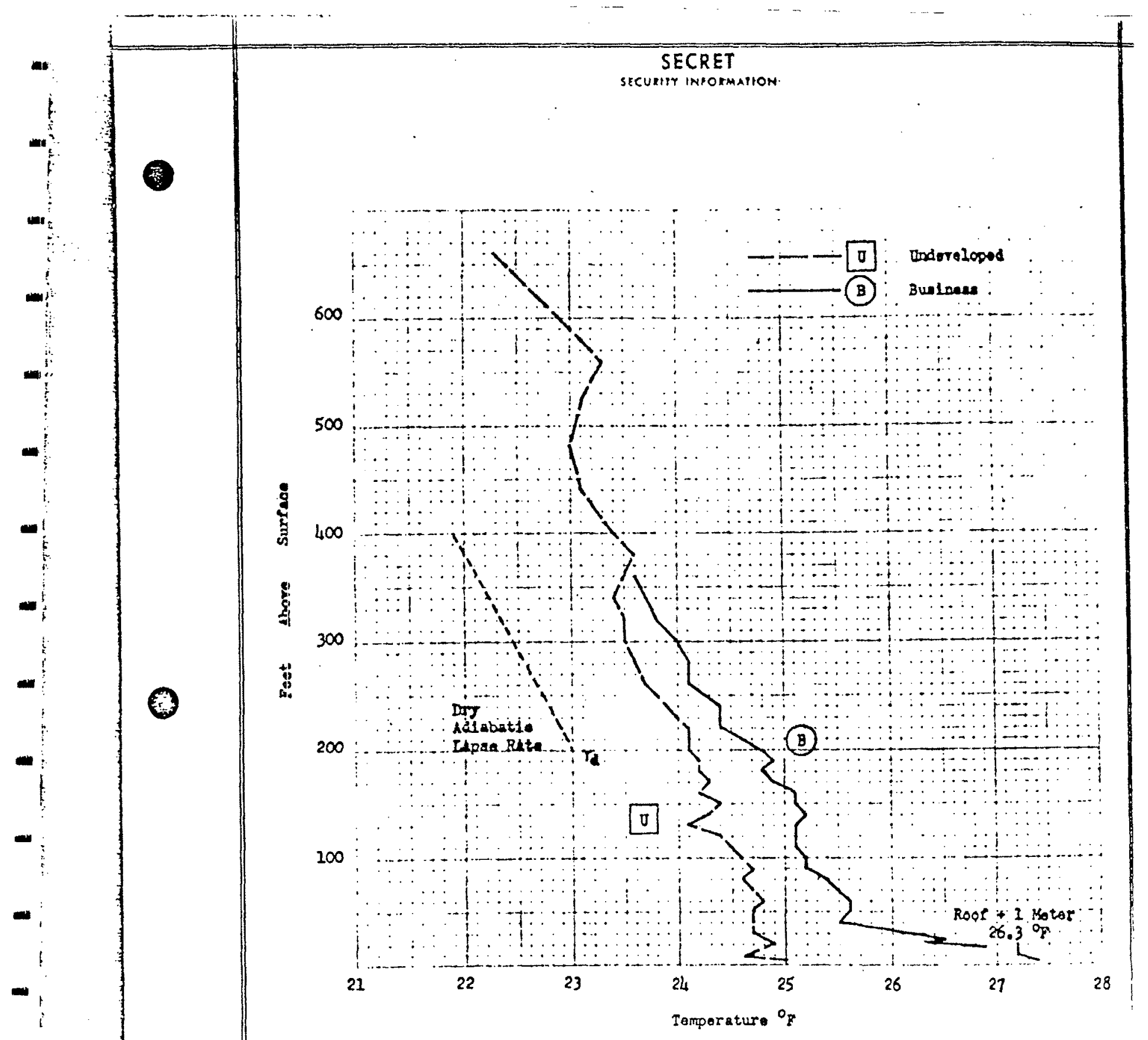

FIGURE D-15

COMPARATIVE TETPERATURE SOUNDINOS

Minigapol1s Wiresonde

Undereloped vs Business Area

Run 2, 2000 CST 27 Fab 1953

SECRET

Page 156

SECURITY HNOOMATION 


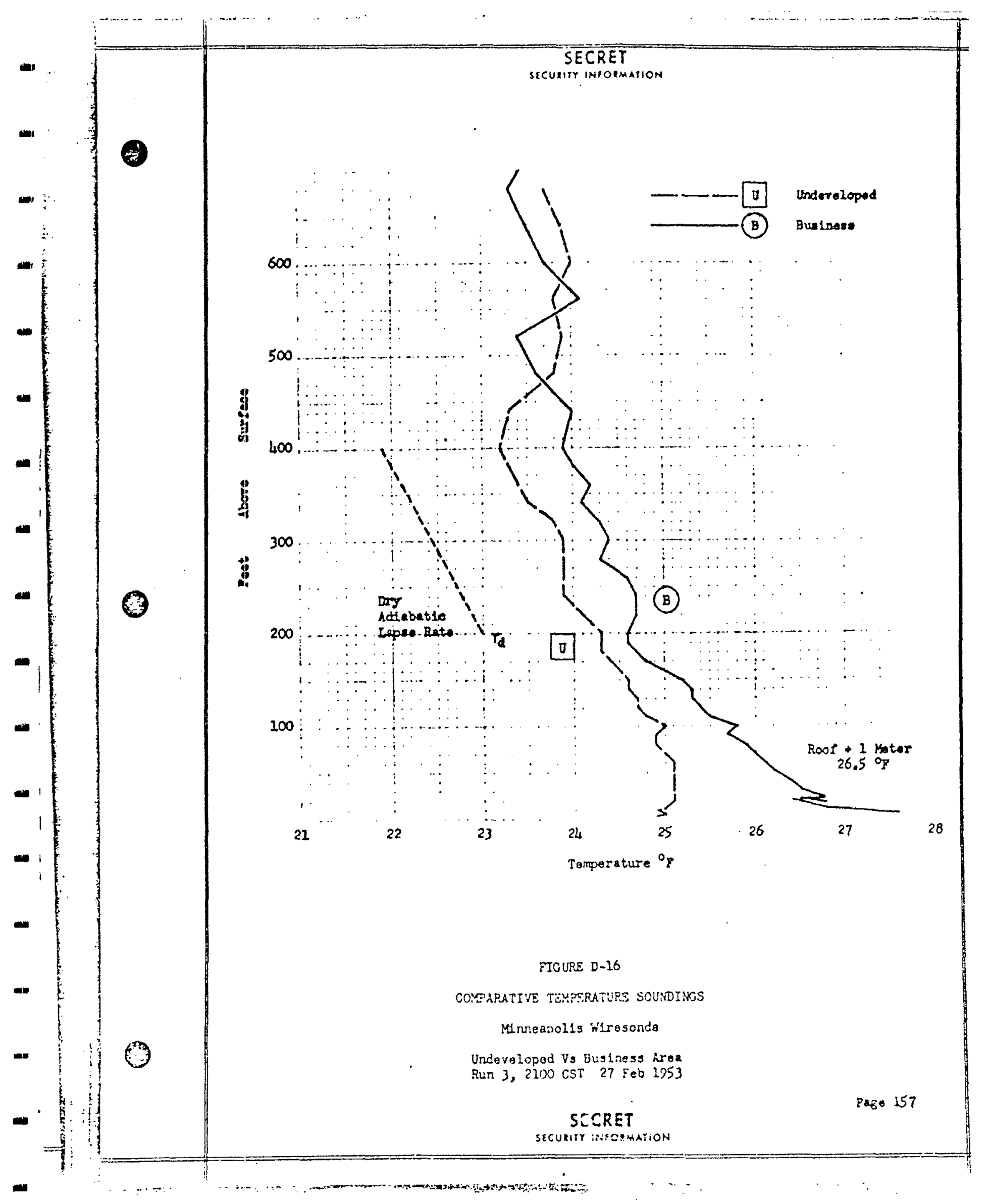




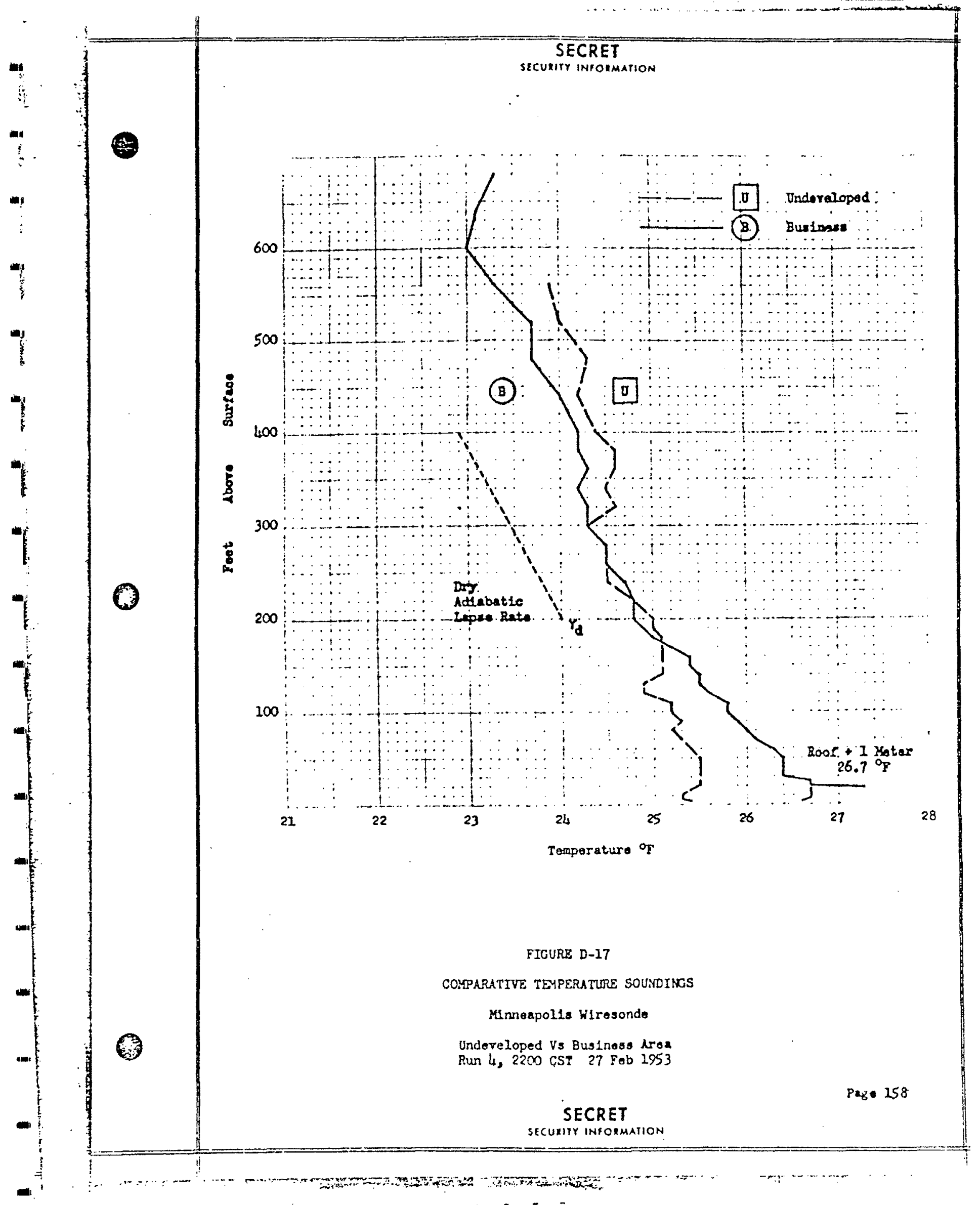




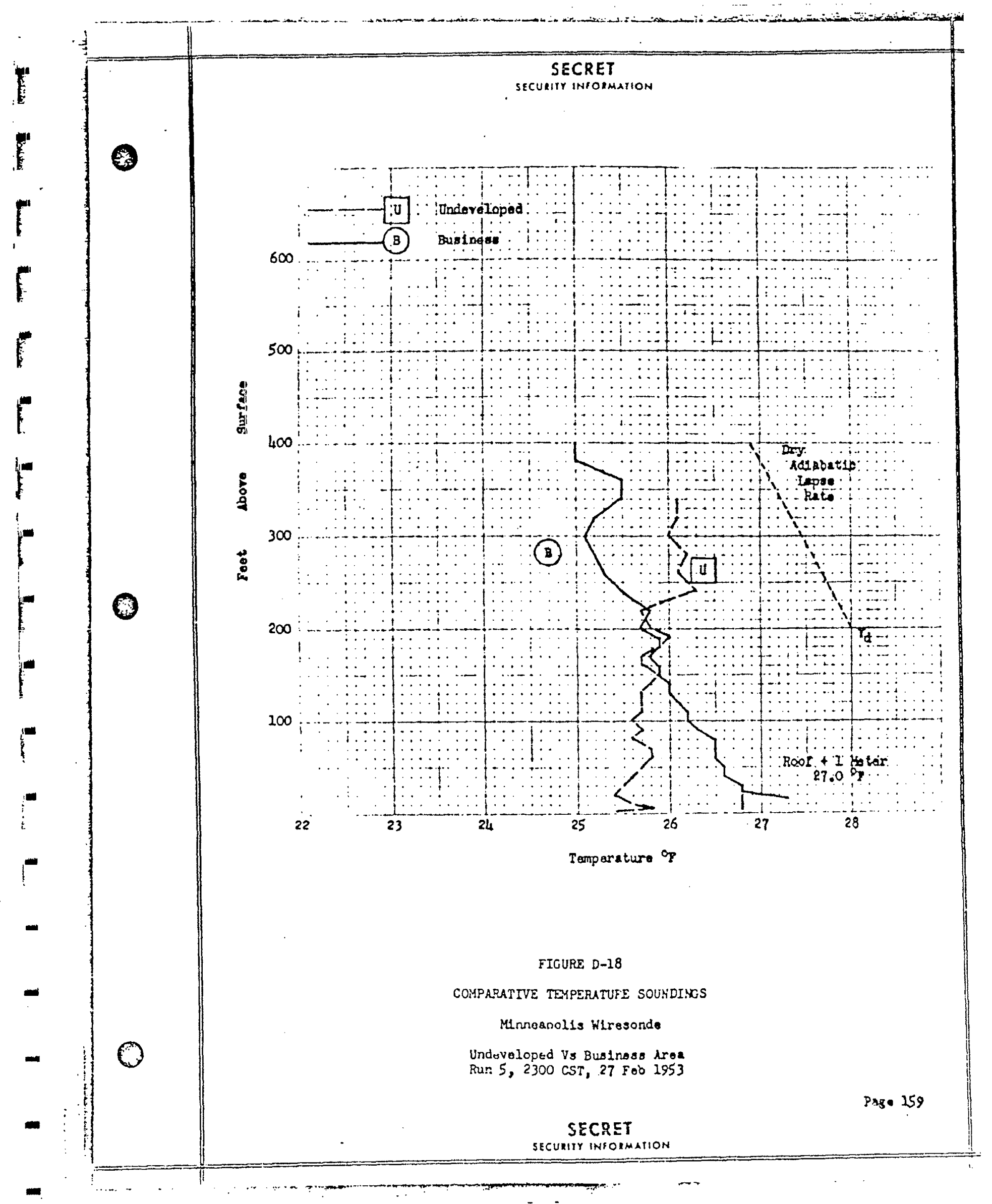




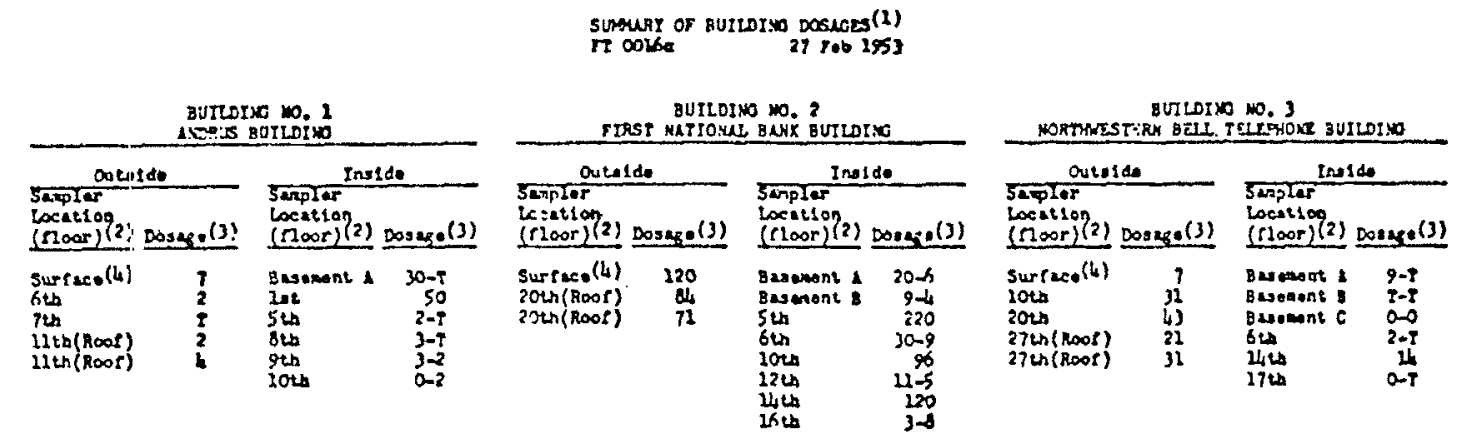

BgThinc so. 4

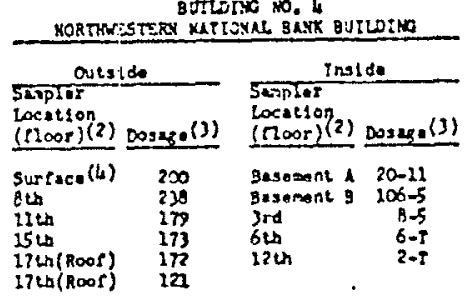

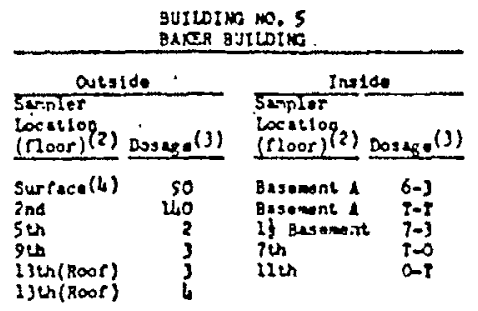

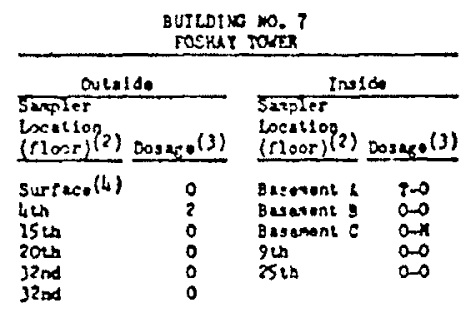

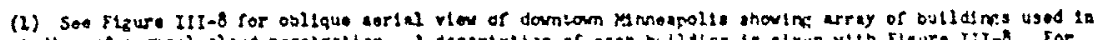

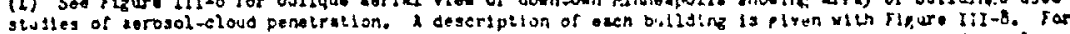

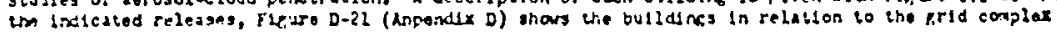
ert the dosepe pettarn

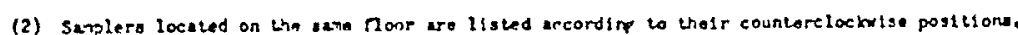

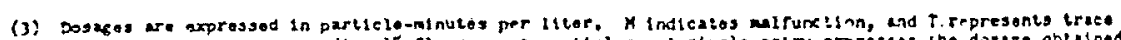

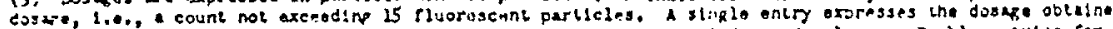

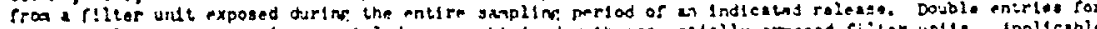

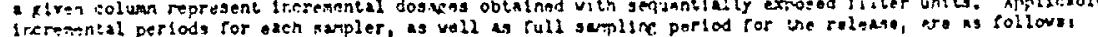

$$
\begin{aligned}
& \text { Sumplin: Perios } \\
& 2733-2330 \mathrm{csT}
\end{aligned}
$$

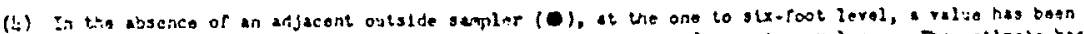

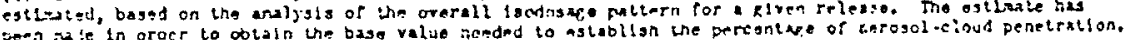




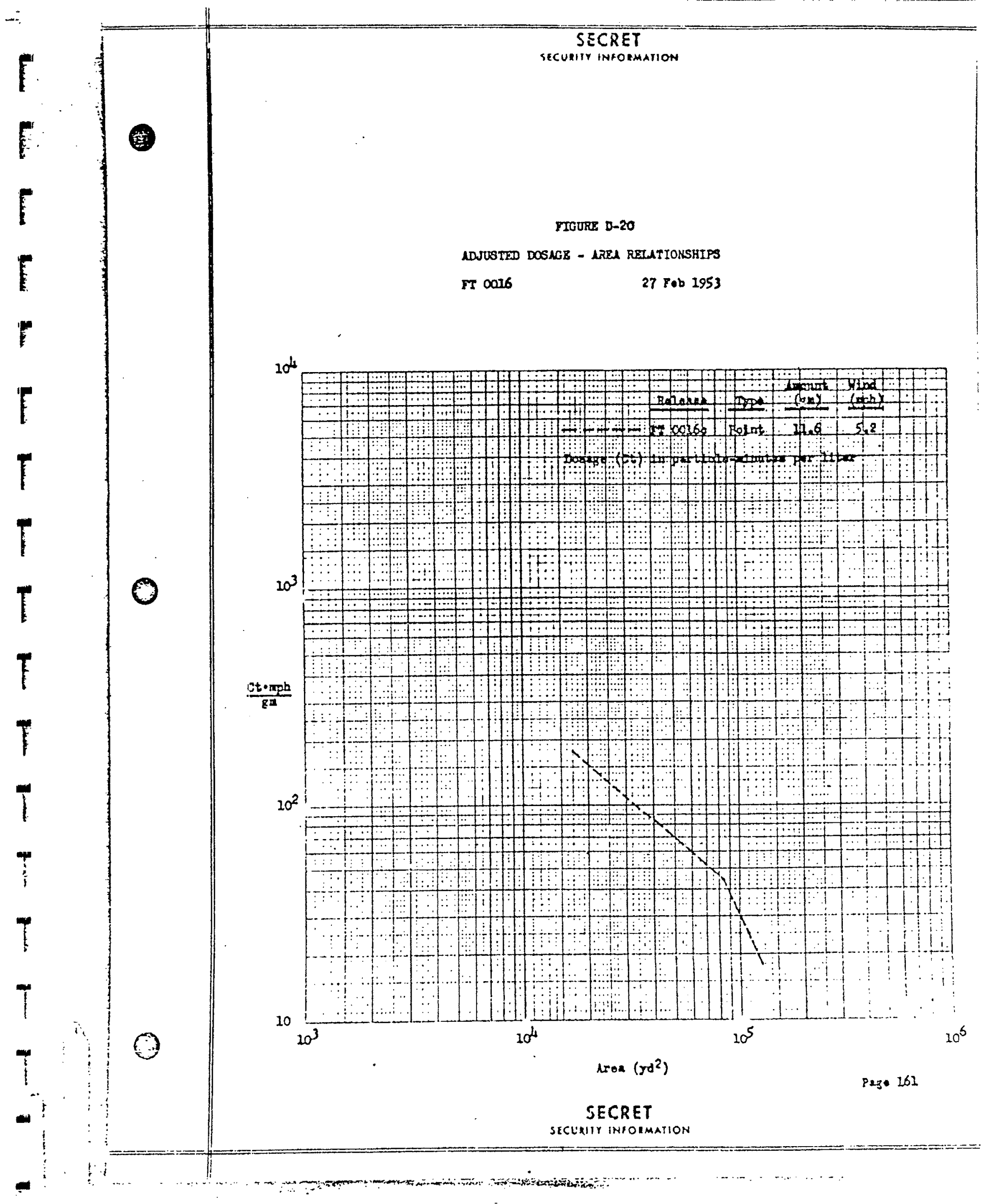




\section{AERosol ofererta}

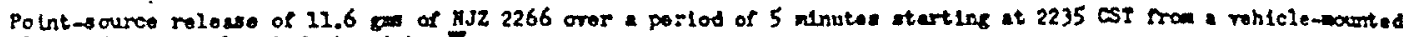
bliswer dispersor located at polnt

\section{SAXPLInI}

Loxiation and Ixposure

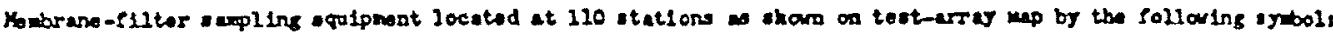

- artdoor anpler at ha 1 ght butwoen 1 and 6 reat.

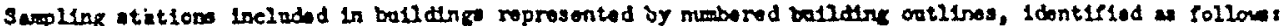

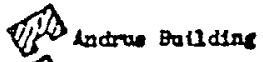
USD Firat Iatiogal Bank BId

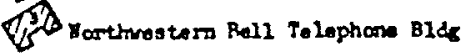
OD Mortmestera Xotional Benk Bd

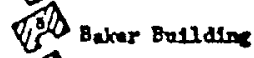
W Toah tow

Resulte

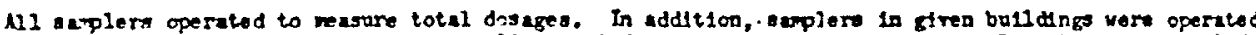

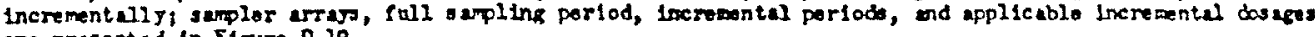
are presented in $F$ igure 0-19.
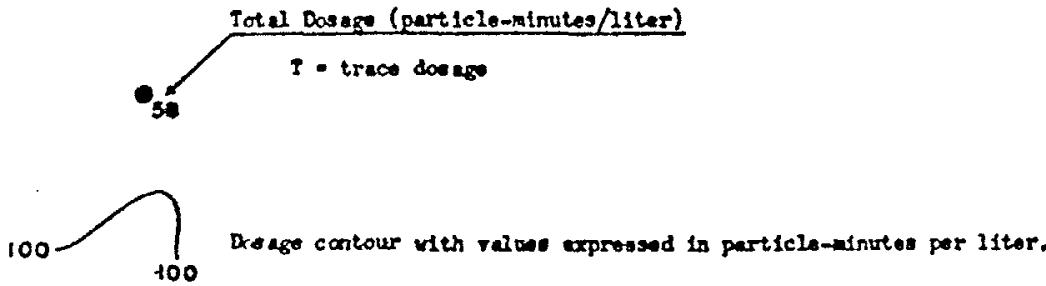

\section{PiTronotoGT}

Equipent and Younrenent

lt etreet lerel, wind direction cont inoously recorted, and afr and surface tergeratures, yind velocitr, and

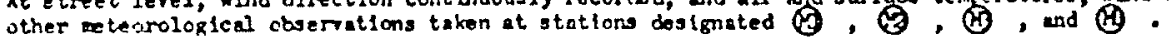

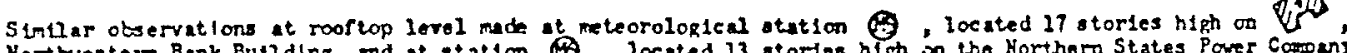

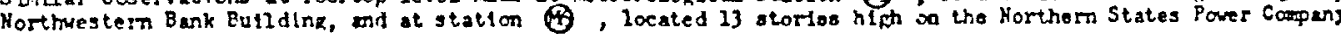
Butldink.

Hiresonde ascents made at reteorological atation $Q$, at 220 South Teneh Street. Ondeveloped-areaviresondet

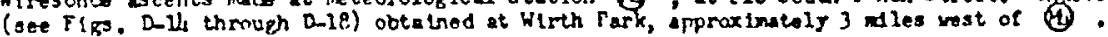

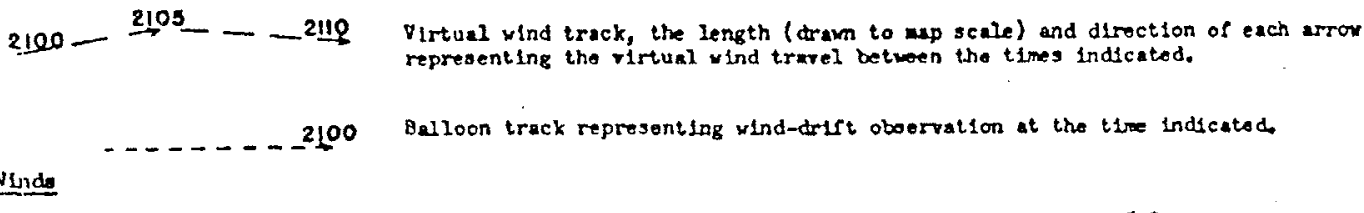




\author{
SURMARY OF REGIONAL AND LOCAL WEATHER \\ 6-7 $\operatorname{March} 1953$ \\ (Surrey M-57, Supplemental to FT 0017)
}

\title{
SMNOPTIC SITUATION
}

A $1.035-\mathrm{mb}$ high cell, orjentod northwest-8outheast and moving east-northeast at $20 \mathrm{mph}$, was centered in northwestern Minnesota, 1ts ridge IIne just west of Minneapolis at the start of the test period. The ridge Iino passed the station during the period, bringing wamer and more molst afr over the station and resultirg in low cloud cover. At the 700-mb level, a slow-moring, long wave-length pattern with a ridge off the Pacific cosst and a brciad trough off the Atlantic coast resulted in a northwesterly gradient wirid of $50 \mathrm{mph}$ over Mirneapolis.

WEATHER REPORTS FROM WOLD-CHAMBERLAIN FIELD (MIRTEAPOLIS)

\begin{tabular}{|c|c|c|c|c|c|c|c|c|}
\hline \multirow[b]{2}{*}{$\begin{array}{l}\text { Tin:e } \\
\text { (CST) }\end{array}$} & \multirow{2}{*}{$\begin{array}{l}\text { Cloud } \\
\text { Height } \\
\text { (feet) }\end{array}$} & \multirow[b]{2}{*}{$\begin{array}{c}\text { Skg } \\
\text { Cover* }\end{array}$} & \multirow[b]{2}{*}{$\begin{array}{l}\text { Visibility } \\
\text { (miles) }\end{array}$} & \multirow[b]{2}{*}{ Westher } & \multirow[b]{2}{*}{$\begin{array}{l}\text { Temo } \\
\text { (OF) }\end{array}$} & \multirow{2}{*}{$\begin{array}{l}\text { Dow } \\
\text { Point } \\
\text { (OF) }\end{array}$} & \multicolumn{2}{|c|}{ Wind } \\
\hline & & & & & & & $\underline{D 1 x}$ & $\begin{array}{l}\text { Speed } \\
\text { (mph) }\end{array}$ \\
\hline $\begin{array}{l}2330 \\
0030 \\
0130 \\
0250 \\
0350 \\
0430 \\
0530\end{array}$ & $\begin{array}{r}20,000 \\
20,000 \\
20, \infty 00 \\
20,000 \\
20, \infty 00 \\
6, \infty 00 \\
6,000\end{array}$ & $\begin{array}{l}\text { Scattered } \\
\text { Broken } \\
\text { Overcasi } \\
\text { Overcast } \\
\text { Overcast } \\
\text { Broken } \\
\text { Broken }\end{array}$ & $\begin{array}{l}15 \\
15 \\
15 \\
15 \\
15 \\
15 \\
15\end{array}$ & $\begin{array}{l}\overline{-} \\
\overline{-} \\
\overline{-}\end{array}$ & $\begin{array}{l}4 \\
4 \\
6 \\
5 \\
6 \\
6 \\
5\end{array}$ & $\begin{array}{l}-11 \\
-11 \\
-5 \\
6 \\
-6 \\
-6 \\
-8\end{array}$ & $\begin{array}{c}\text { WNW } \\
\text { NNW } \\
\text { SSE } \\
\text { SE } \\
\text { SSE } \\
\text { SE } \\
\text { E }\end{array}$ & $\begin{array}{r}6 \\
5 \\
6 \\
3 \\
5 \\
8 \\
10\end{array}$ \\
\hline
\end{tabular}

* Average cloudiness sunrisa to sinset: $O \&$

* * And/or restriction to visibility

Sea-level pressure at $0230 \mathrm{CST}: 1037.6 \mathrm{mb}$

Ground condition: Ten-1nch packed snow; main streets clear; secondary streets $50 / 50 \mathrm{clear}$ and packed 1ce and snow; lake rrozen

Trce cover: None. 


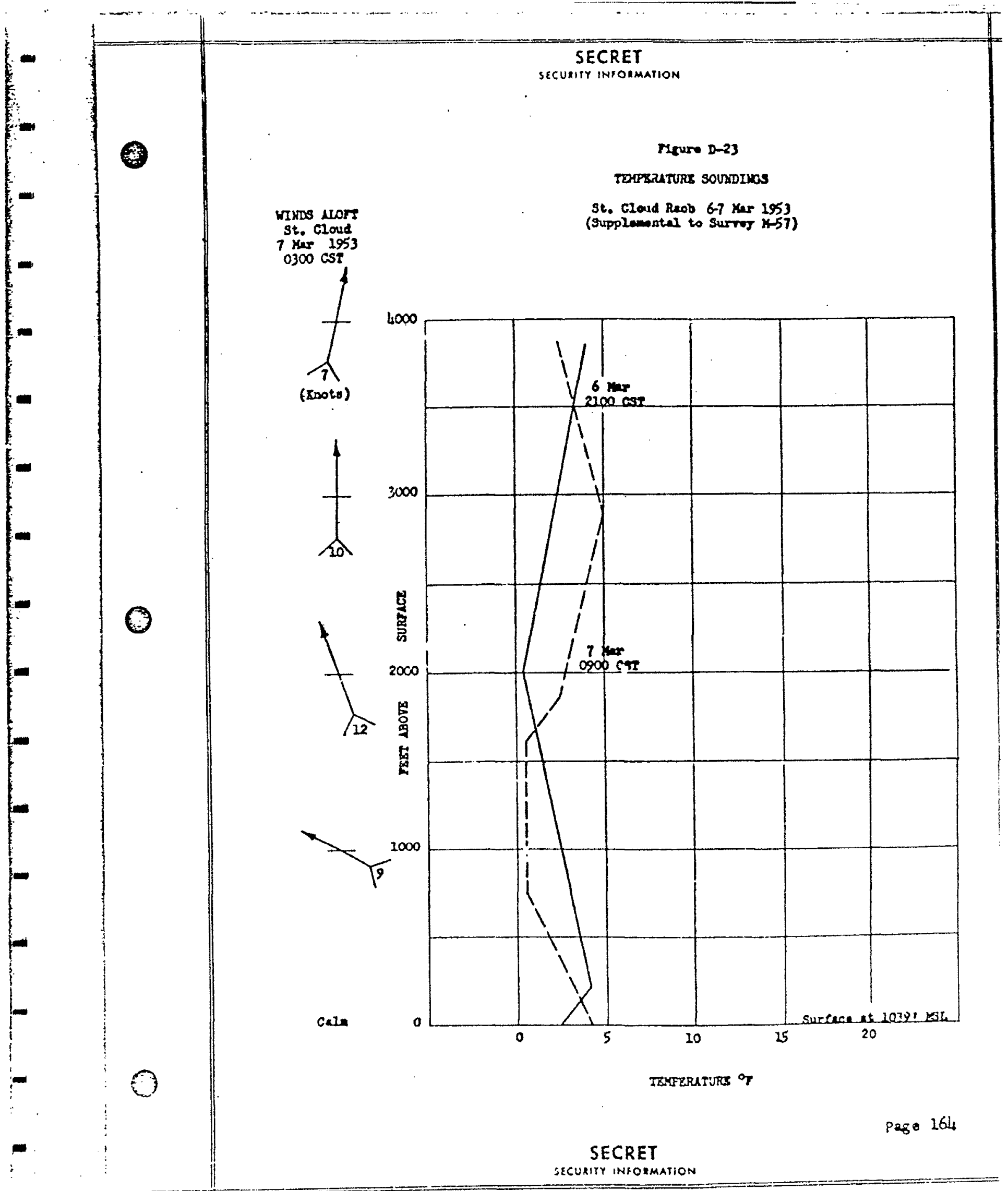




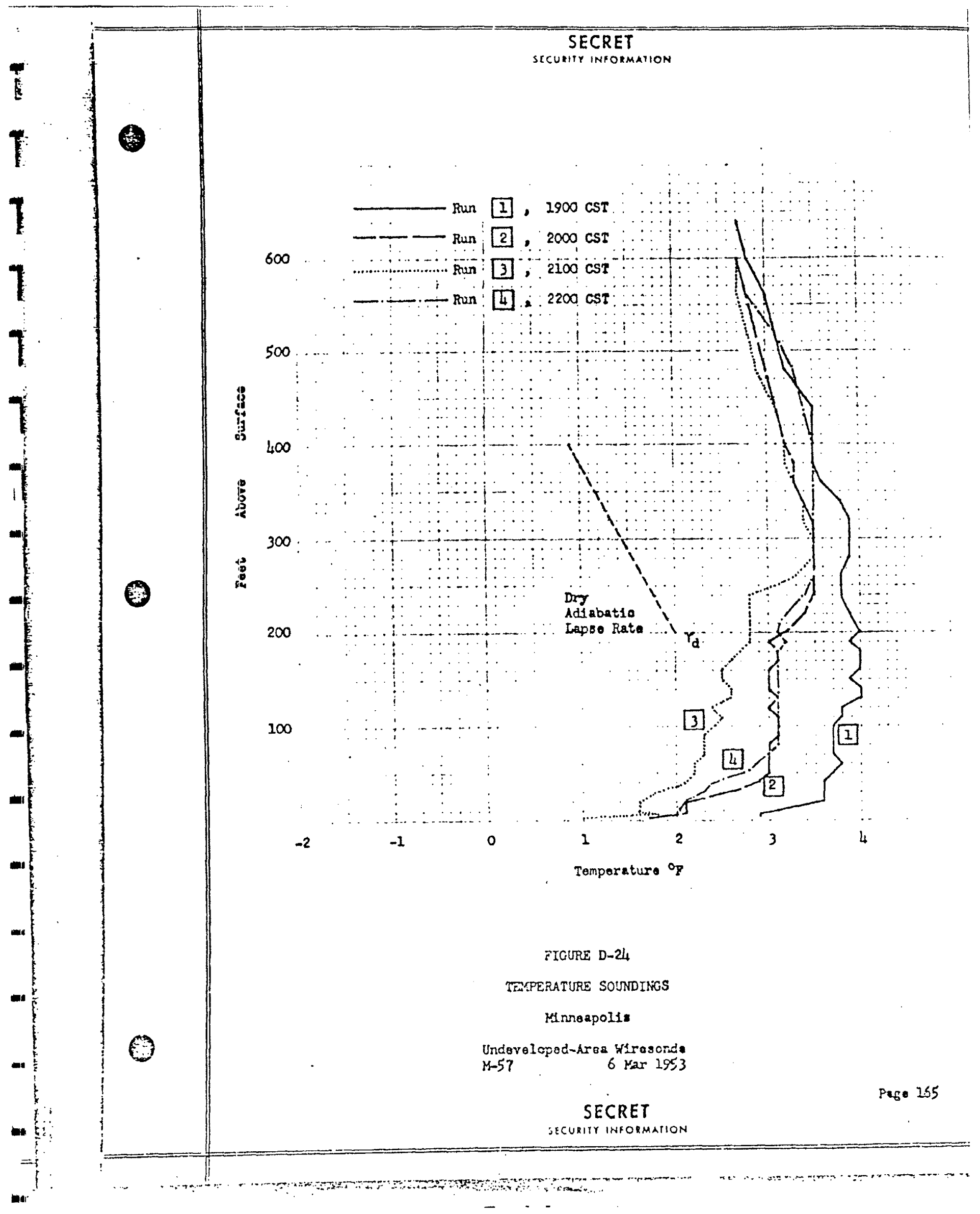




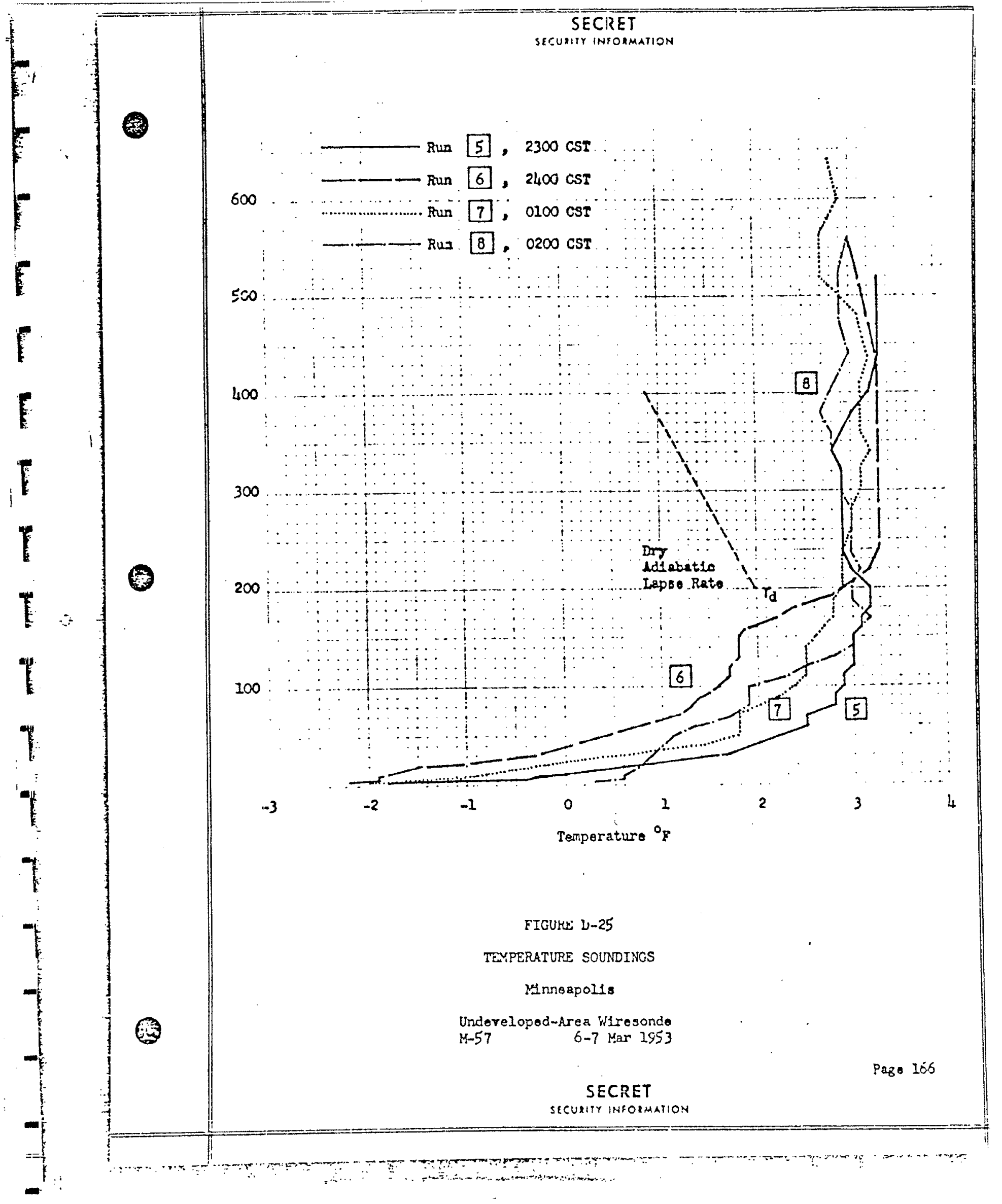




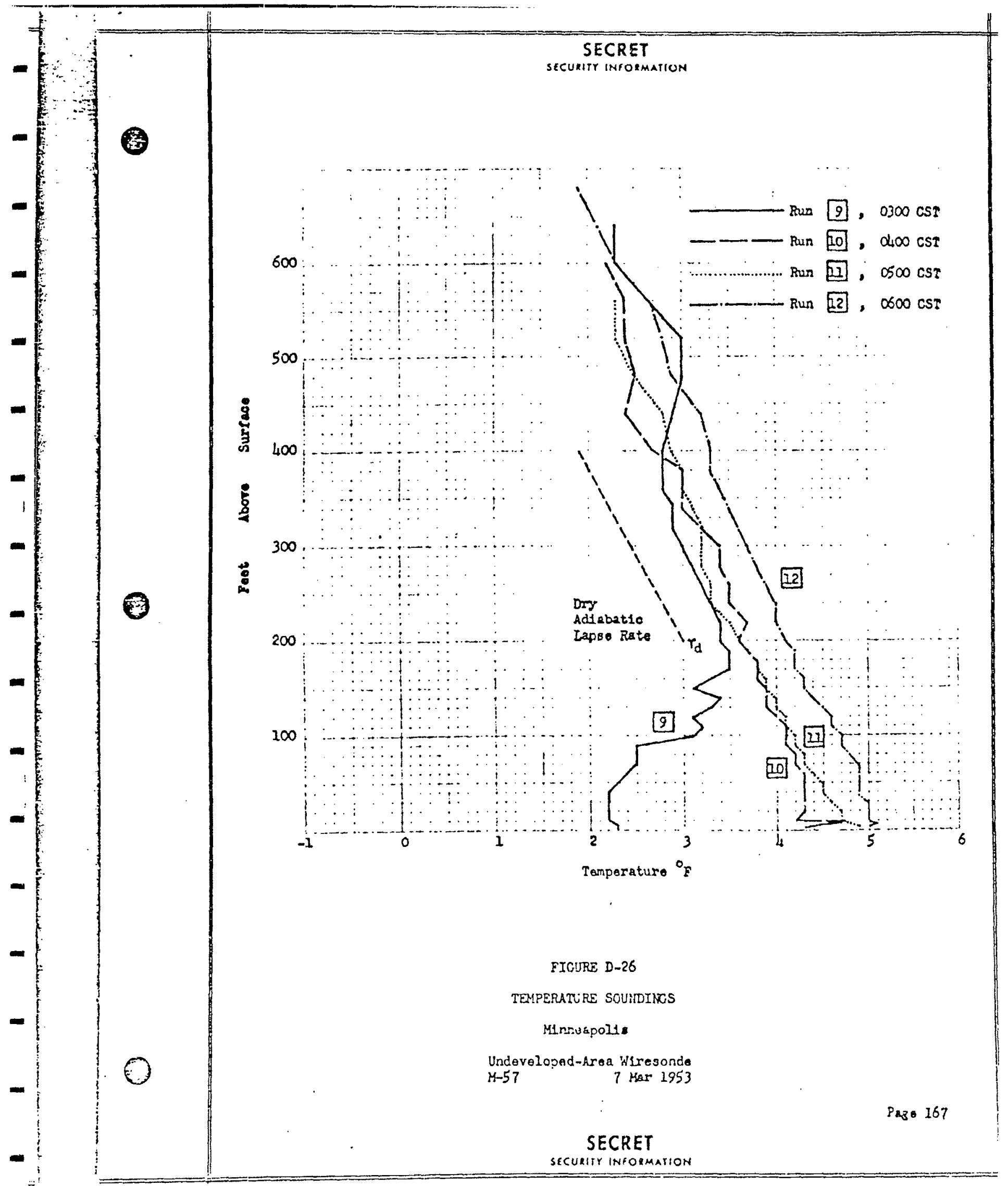




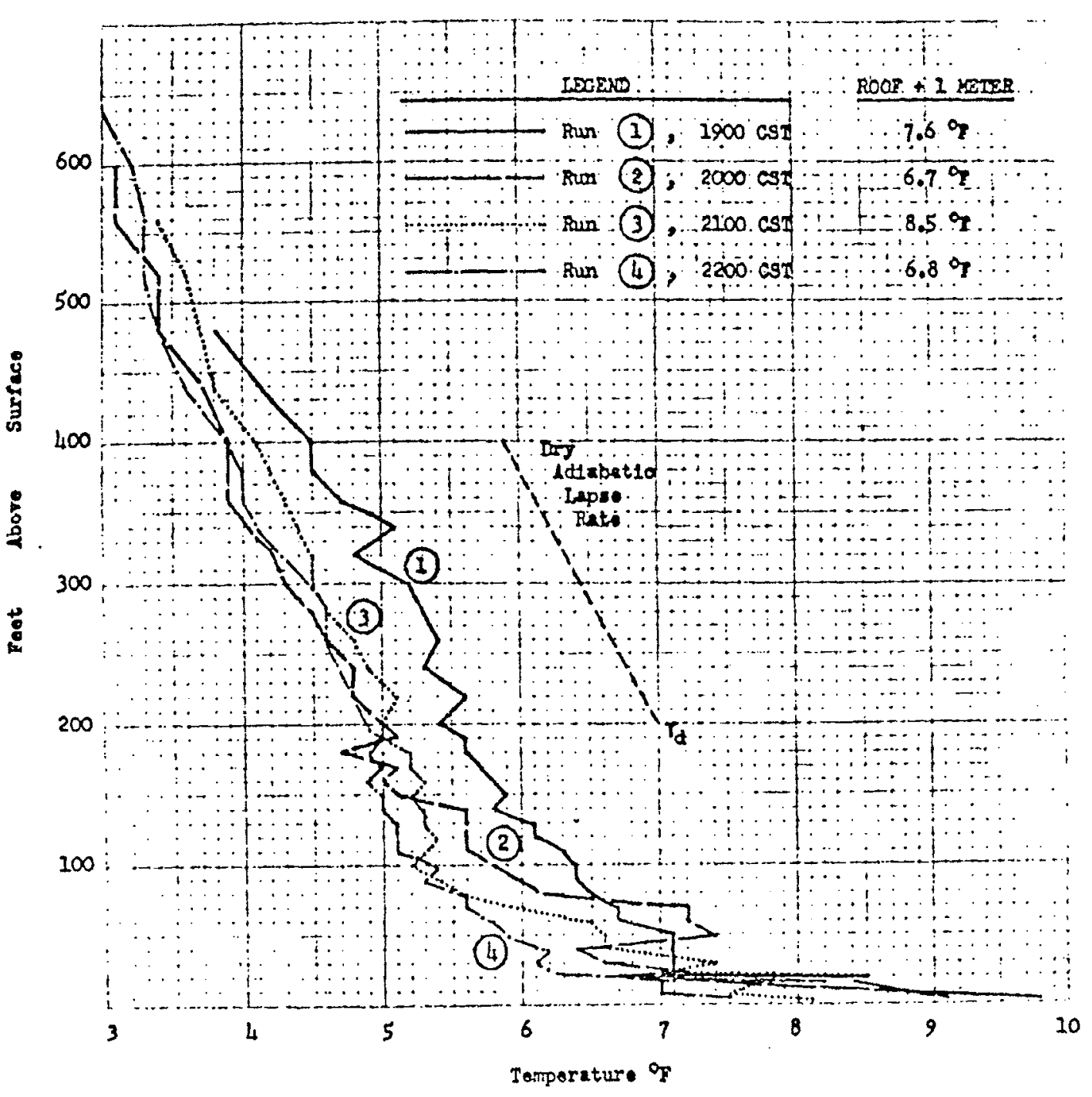

FIQURE D-27

TEMPERATURE SOUNDINOS

Minneapolis

Bus1nas-drea Wiresondo

M-57 6 Kar 1953

SECRET

P23 168 SCCURIPY INFORMATION 


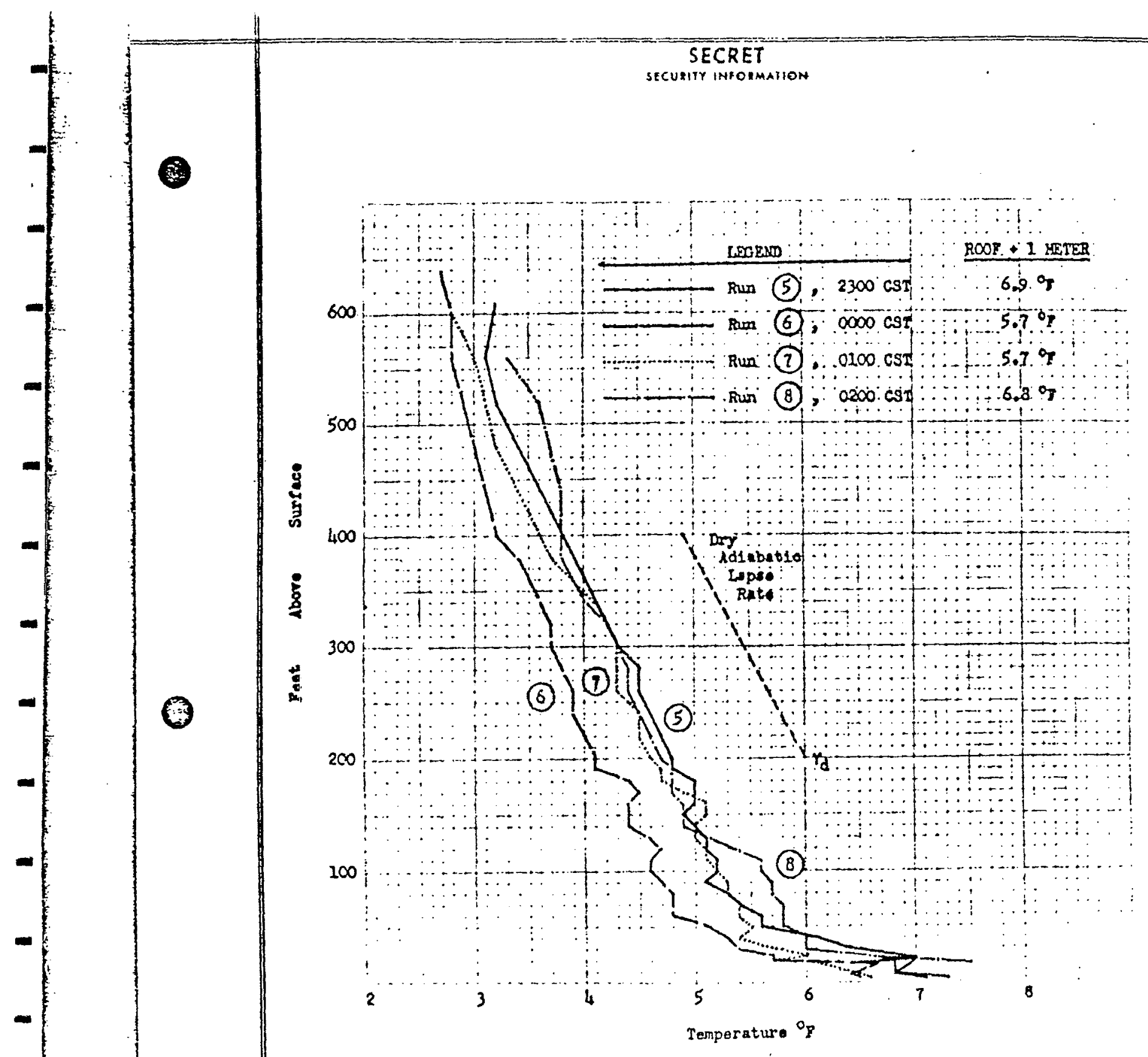

FICURE $0-28$

TEYPERATURE SOUNDIMGS

Minneapol1.

Businass-krea W..hasonido

ب. $57 \quad 6-7 \mathrm{Mer} 1953$

Pas. 169 


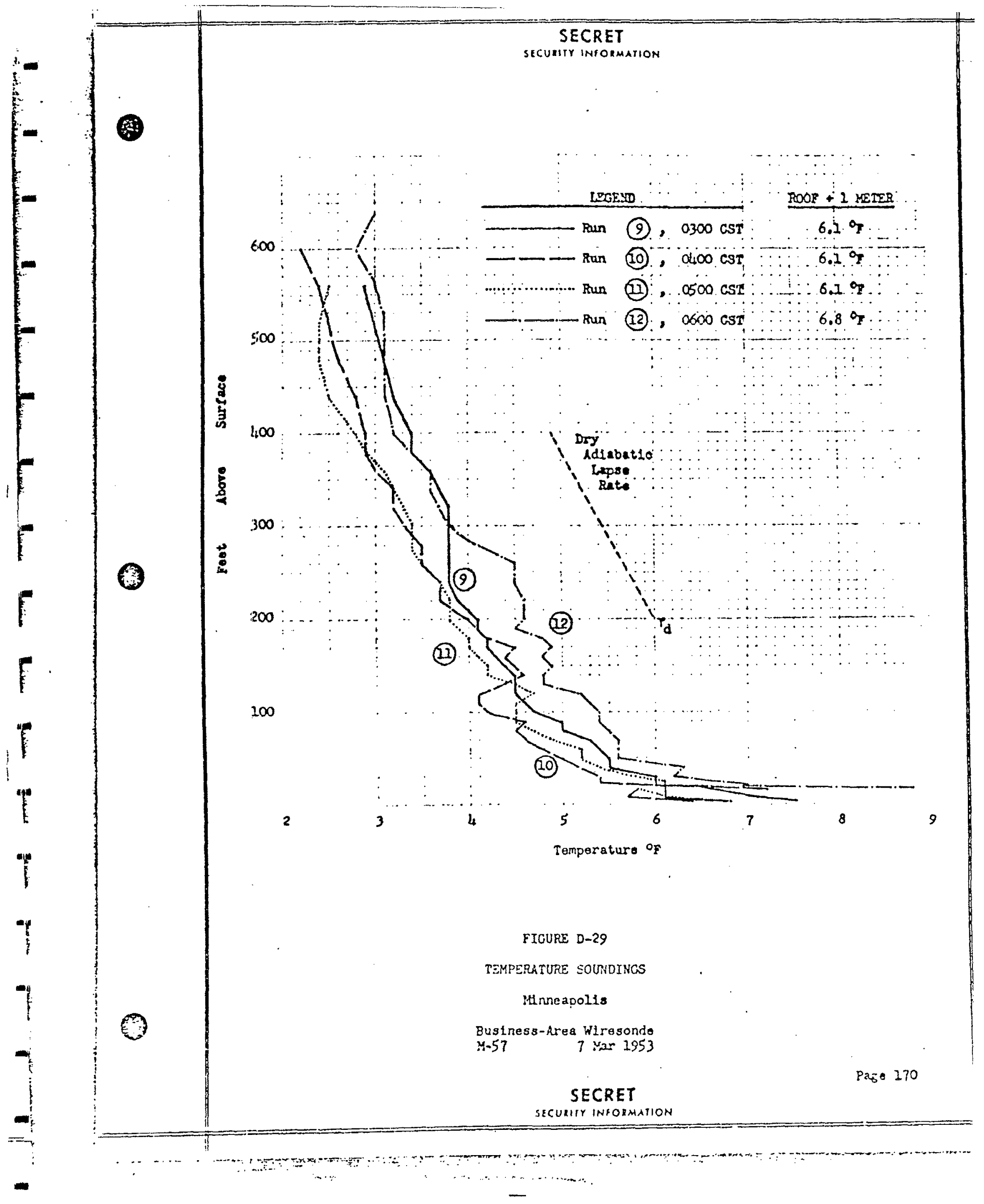




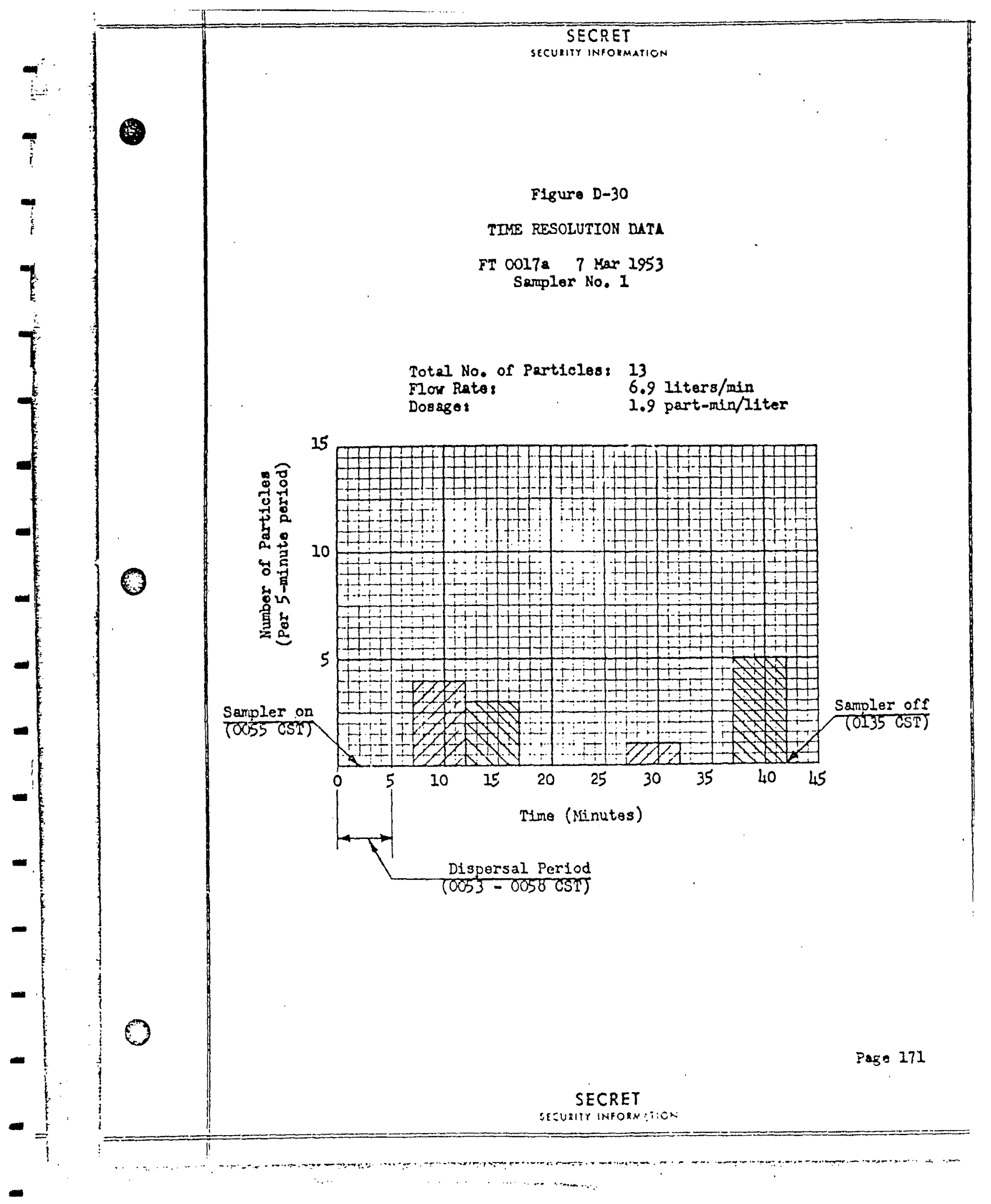




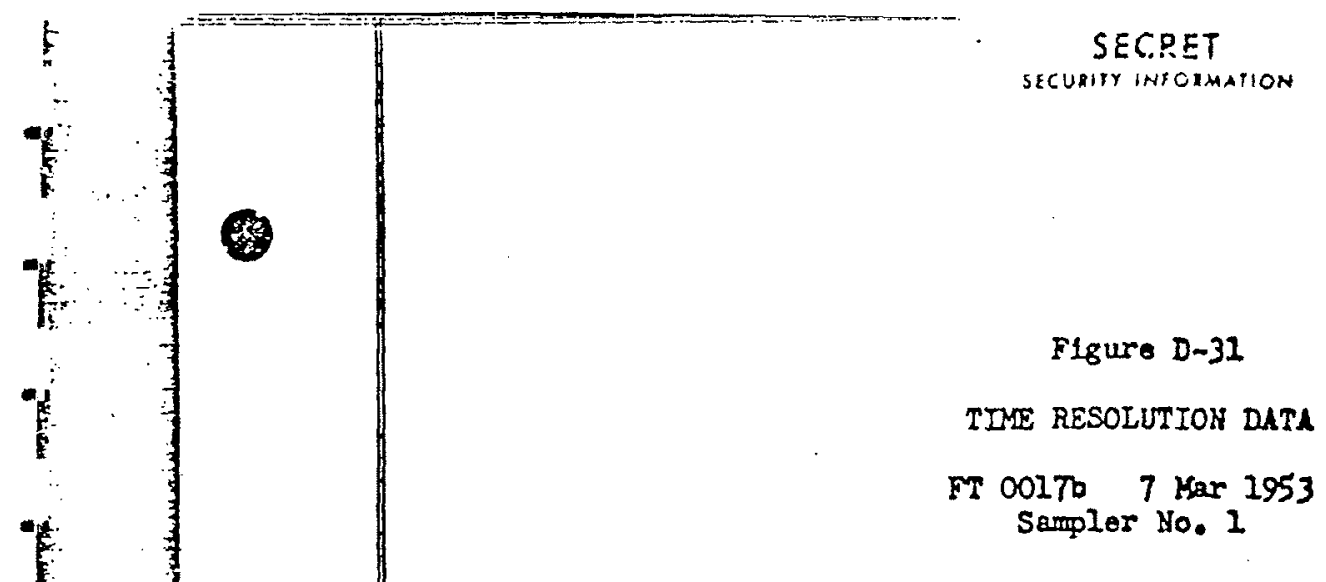

Total No, of Particless 52 Flow Rate: Dosage:

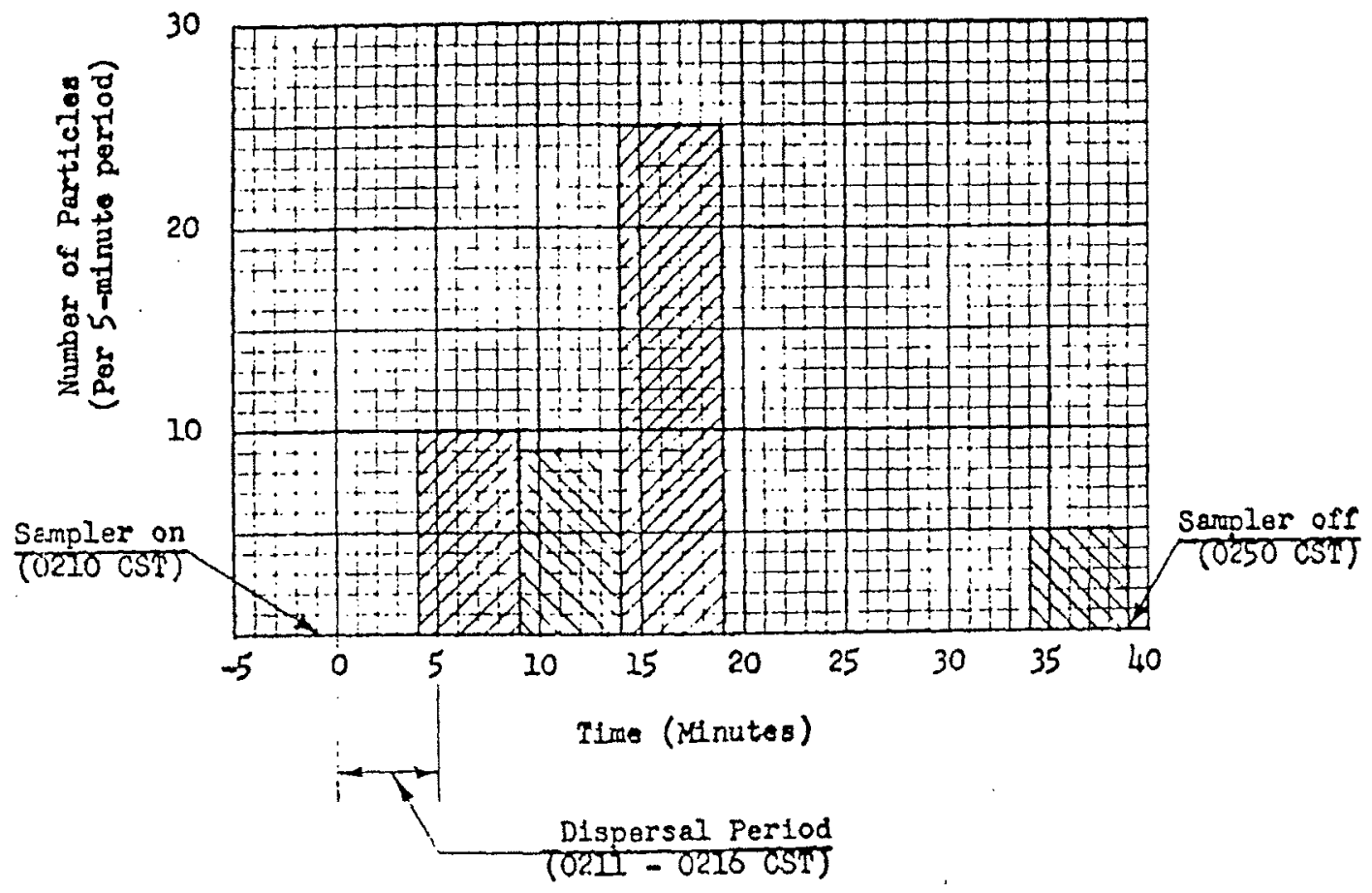

$P 2 \div 0172$

SECRET

SECUNIT INIORMATION 


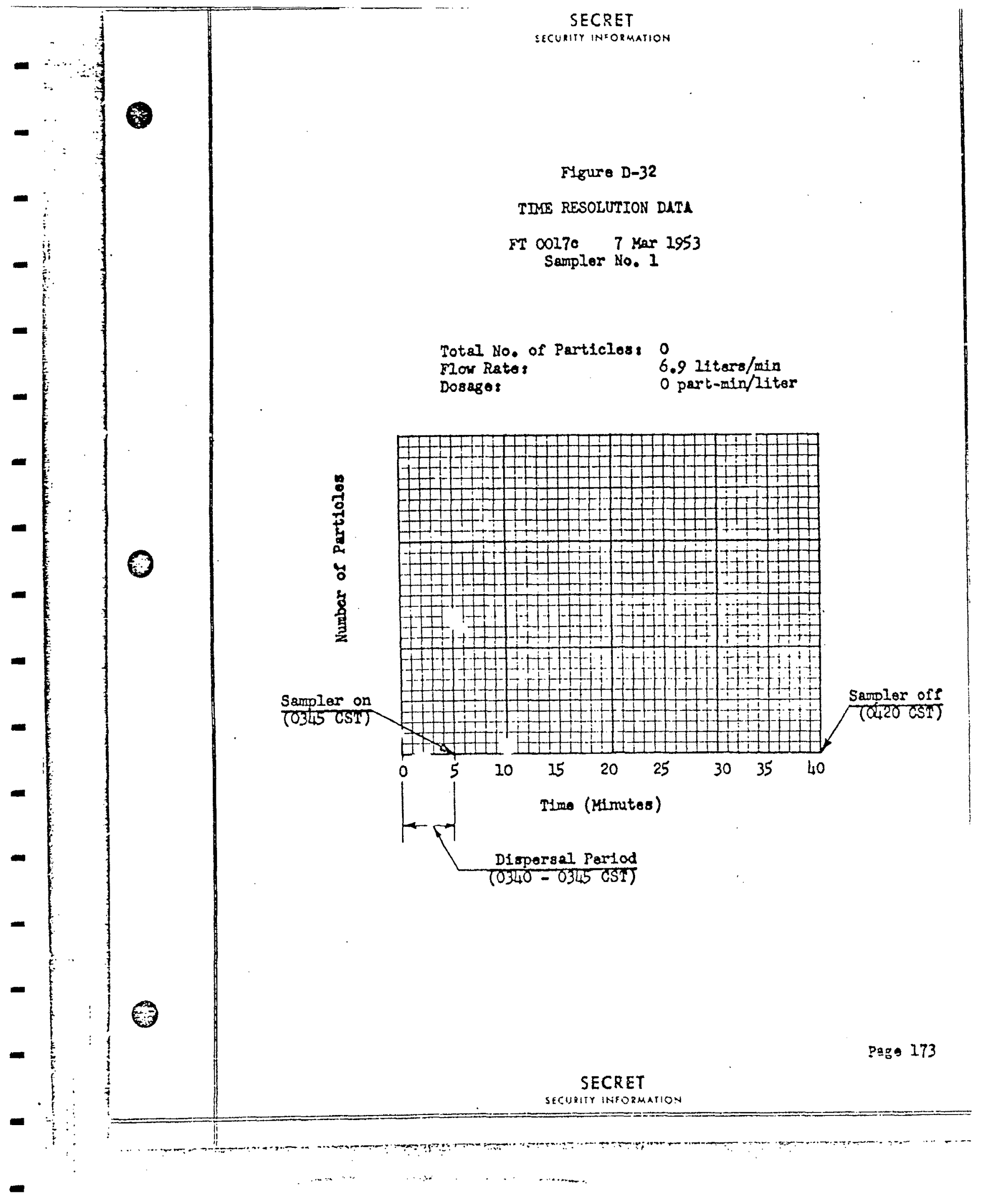




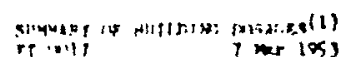

84TLINo 20. 1

AKDRIS BLTLILIM

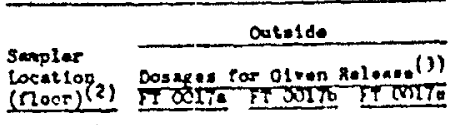

Surface (b)

sure

Ster ilthoot)

IIth ( Roor)

26
$3-3$
$0-3$
52
6.1

$\begin{array}{rr}0 & 0 \\ 0-0 & 0-0 \\ 7 & 0-7 \\ 7 & 0 \\ 7 & 0\end{array}$

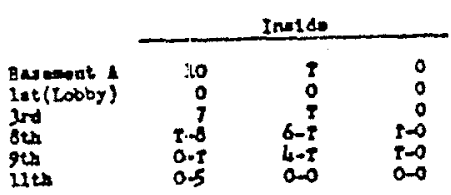

Burdorm 00.5

BACER Butrotis

\begin{tabular}{|c|c|c|c|}
\hline \multirow[b]{2}{*}{ 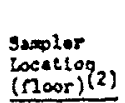 } & \multicolumn{3}{|c|}{ outsto } \\
\hline & $\begin{array}{l}\text { Dos sxos } \\
\text { Ir b0017a }\end{array}$ & $\begin{array}{l}\text { ser giren } \\
\text { moth }\end{array}$ & $\frac{\text { Reloase(3) }}{\text { Iroolte }}$ \\
\hline \multirow[t]{2}{*}{ 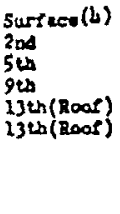 } & $\begin{array}{l}8 \\
7 \\
7 \\
9 \\
7 \\
6\end{array}$ & $\begin{array}{l}0 \\
0 \\
1 \\
9 \\
1 \\
0\end{array}$ & $\begin{array}{l}12 \\
11 \\
10 \\
15 \\
17 \\
19\end{array}$ \\
\hline & & Inulide & \\
\hline 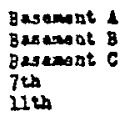 & $\begin{array}{l}x-7 \\
z-7 \\
7-2 \\
0-7 \\
0-0\end{array}$ & $\begin{array}{l}+\infty \\
0 \rightarrow 0 \\
i \rightarrow 0 \\
0 \rightarrow 0 \\
i \rightarrow 0\end{array}$ & $\begin{array}{l}t-0 \\
7-T \\
T+T \\
0-1 \\
0-0\end{array}$ \\
\hline
\end{tabular}

H:ilision mo, s

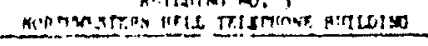
Oulinde

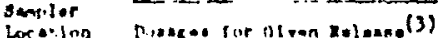

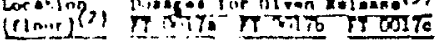
Surfere (4)

lown Lin

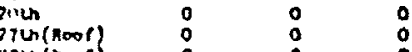

\begin{tabular}{|c|c|c|c|}
\hline \multirow[b]{2}{*}{ 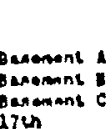 } & \multicolumn{3}{|c|}{ Inotids } \\
\hline & $\begin{array}{l}0-0 \\
0=0 \\
0-0 \\
i \rightarrow 0\end{array}$ & $\begin{array}{l}0-0 \\
0-0 \\
0-0 \\
0-1\end{array}$ & $\begin{array}{l}a-x \\
0-0 \\
0-0 \\
x-7\end{array}$ \\
\hline
\end{tabular}

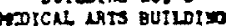

\begin{tabular}{|c|c|}
\hline & outalose \\
\hline 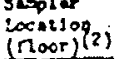 & 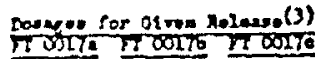 \\
\hline
\end{tabular}

sursace(4)

3rd

6in

$12 \mathrm{th}$

20th(noor)

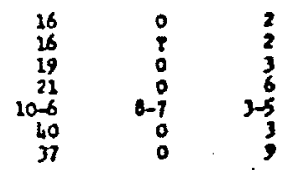

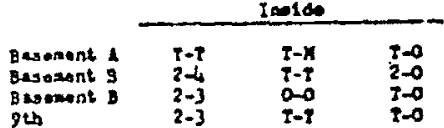

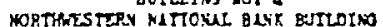

Outside

Samplar Dosses for Giren Rulese(3)

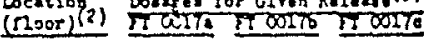

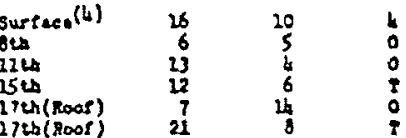

Inside

\begin{tabular}{|c|c|c|}
\hline 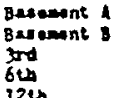 & $\begin{array}{r}0-1 \\
2-3 \\
2 \\
1=0 \\
0-0\end{array}$ & $\begin{array}{r}x-1 \\
2-1 \\
3 \\
x=0 \\
0=0\end{array}$ \\
\hline
\end{tabular}

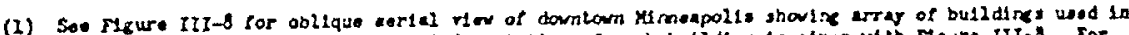

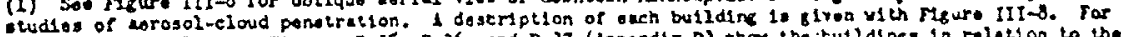

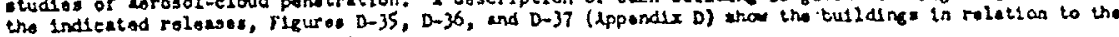
critd complax and the dosege paltara.

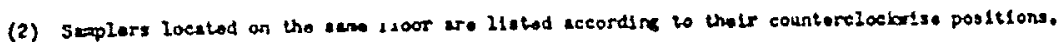

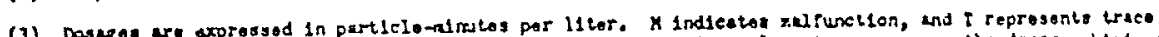

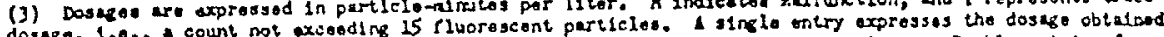

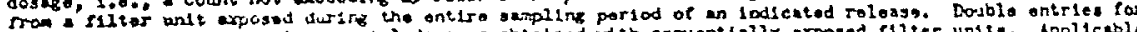

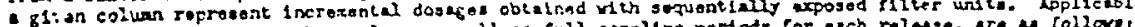

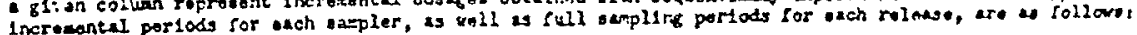

\begin{tabular}{|c|c|c|}
\hline Raloese & Szpling Pertod & Ineromintel Porlode \\
\hline FT $\infty 017$. & DO30-0145 CST & $\begin{array}{l}\text { co30-01215 cst } \\
0115-0145 \text { cst }\end{array}$ \\
\hline 700170 & 020200315 cst & $\begin{array}{l}0200-0245 \text { cot } \\
0245+0215 \text { ast }\end{array}$ \\
\hline$\pi 00170$ & $0330-1445 \operatorname{cst}$ & $\begin{array}{l}\text { c) } 300-2,15 \text { cst } \\
\text { o.15-0.,15 c5t }\end{array}$ \\
\hline
\end{tabular}

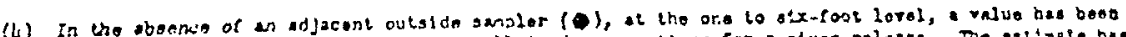

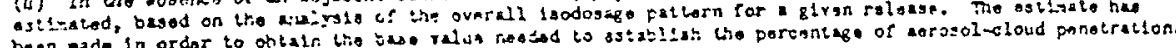




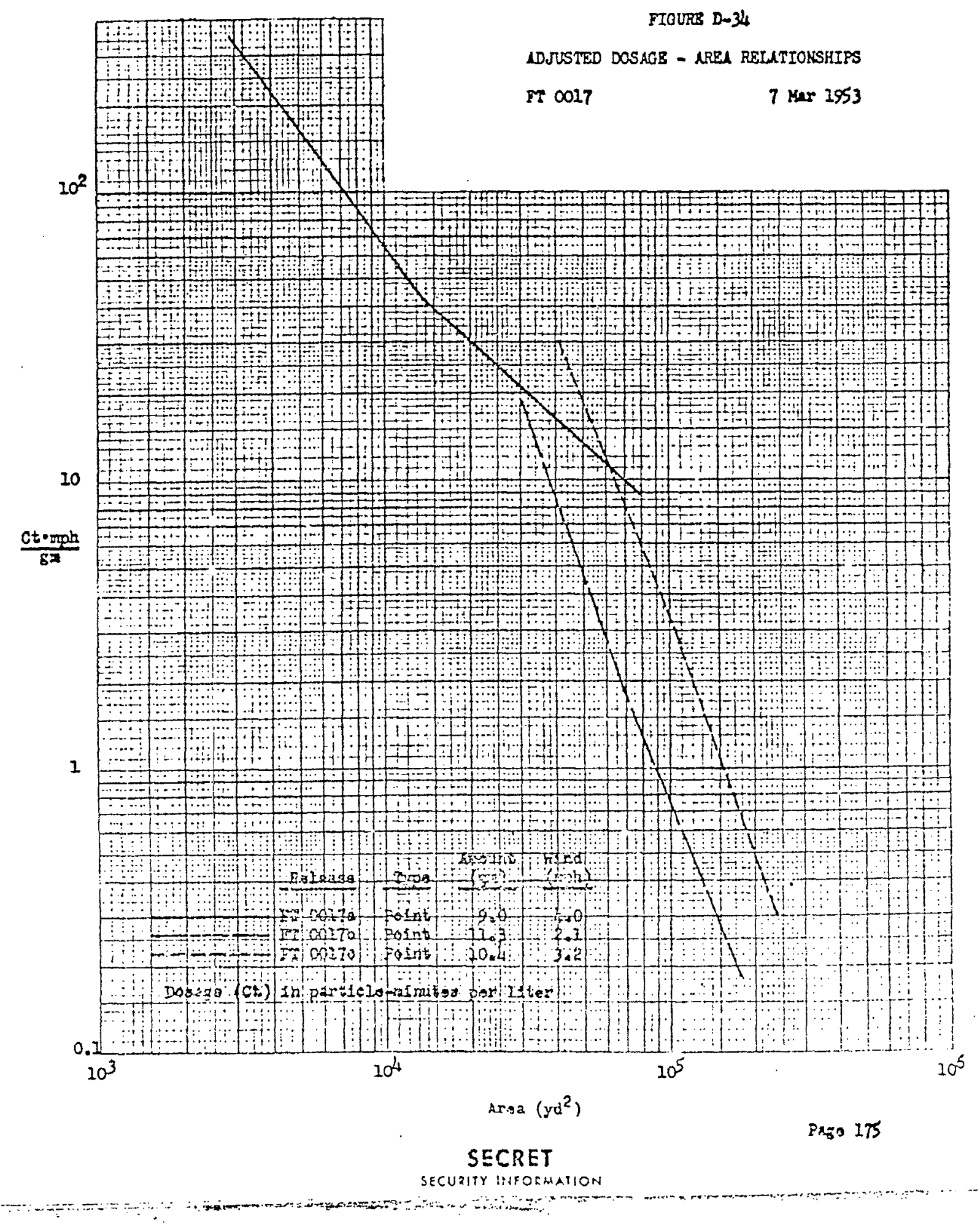




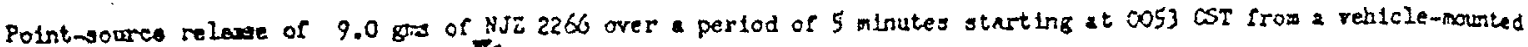

blowar disperses lacuted ab point it.

\section{sempro}

Location and Boours

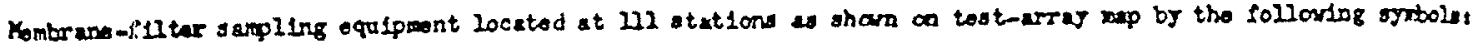

- Outdoor sampler at helght between 1 and 6 roet.

A Timeresolution sampler uth stetion maber.

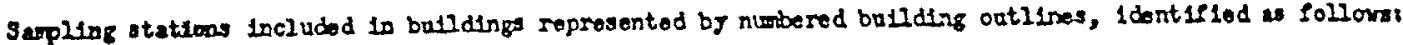

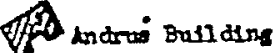

$$
\begin{aligned}
& \text { 16 nathestern Bell Telophone Bulldins } \\
& \text { Portiostom National Bank Bullelns }
\end{aligned}
$$

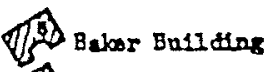

Of Hadical irta Batlare

\section{Resuits}

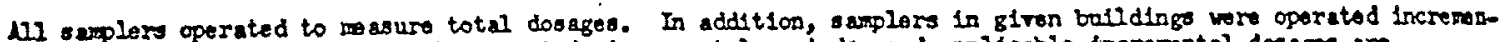

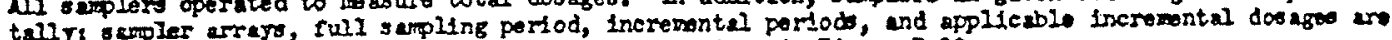
prosented in Fiforo D-33. Timorosolution dats are gtron ln F1guro D-30.
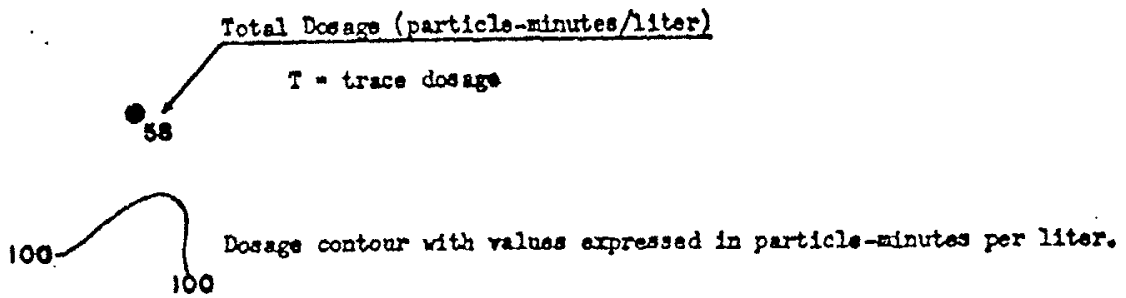

\section{Eergoroxoor}

Equiprent and Hoverement

It atreot lerel, wind direction continuosoly rocordod, and ar and arface teceratures, find relocity, and

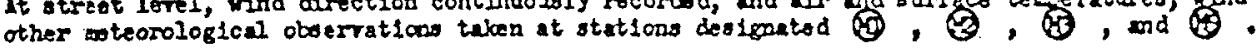

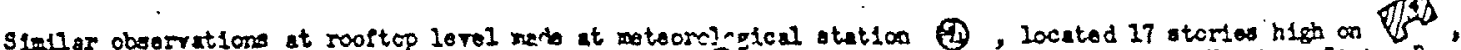

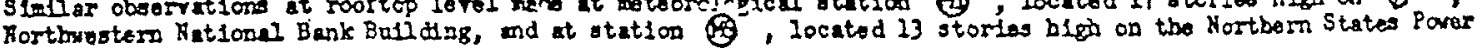
Corpary Butliteng.

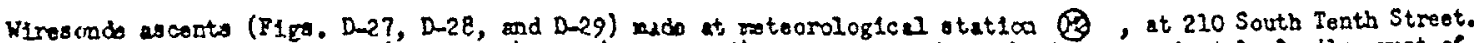

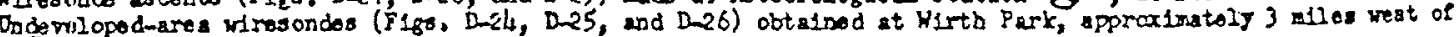
(3)
0500 - 050s - 0510 Tirtual wind track, tho longth (tran to map scalo) ond direstlon of each arrow representiag the pirtul wind trarel between the tioes indicated.

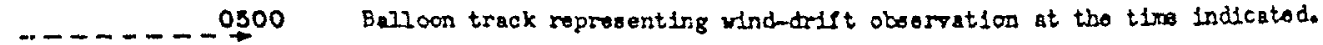

Hindes

Street-level winde rooth-northwsterly st $2.8 \mathrm{mh}$, roof-lorel wisd north-northwestorls at $5.8 \mathrm{mph}$, and (2) rool-letel wind norticeasterly at $3.8 \mathrm{mph}$.

Stabsi1:

2.2. Ikpoe from 6-300 it.

Skg

Orefrest clouds with bsses 20,000 ft sbore the surface.

Temperature

$5.1^{\circ}$ to $7.1^{\circ} F$ at 2 moters in the test area.

\section{Yoletare}

Y.ixing ratio of $0.8 \mathrm{gma} / \mathrm{kg} \times \mathrm{dry}$ air. 


\section{LEPCSOL GENERTT IOR}

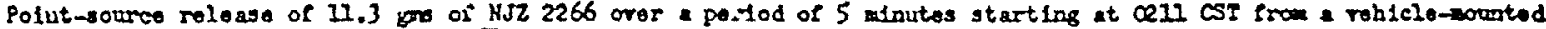
blower disperser located at polnt

\section{SAYFLIO}

\section{Location and Exposure}

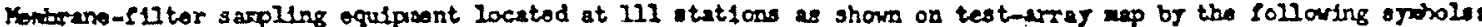

- Orddoor suplor at holght between 1 and 6 feot.

A Tino-resolotion sexpler vith station number.

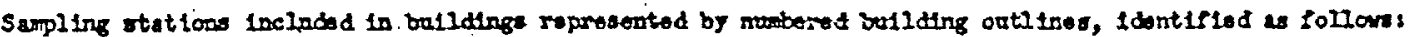

\begin{tabular}{|c|c|c|c|c|c|}
\hline & \\
\hline & & & & & 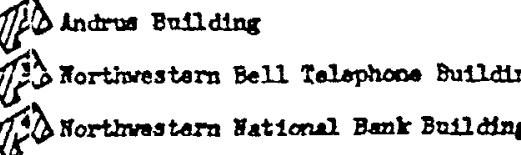 \\
\hline
\end{tabular}

160 Bakr Bolld dins

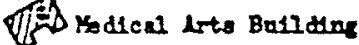

Rosults

111 samplora operated to wasure total doeages. In adition, amplars in given bullding ware operated increantally; sampler array, full saspling perlod, incresental poriod, and appliesbio locrementel doo aged are presented 10. Fifure D-33. Tine-rosolation date are given in Figure D-31.

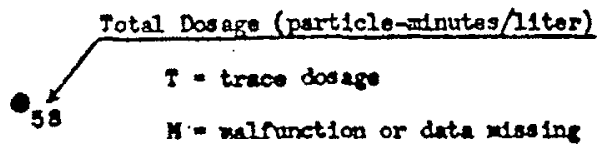

$-$

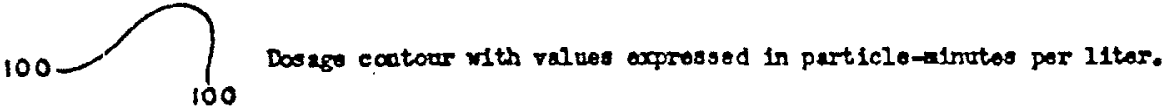

\section{KETEROCOT}

Equipment and hensurement

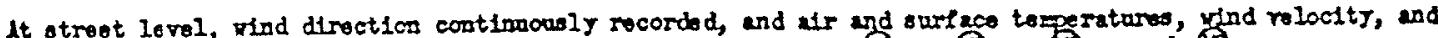

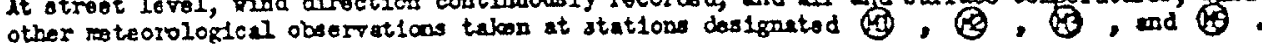

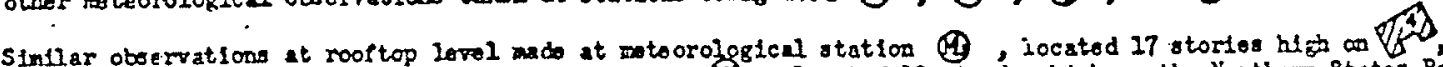

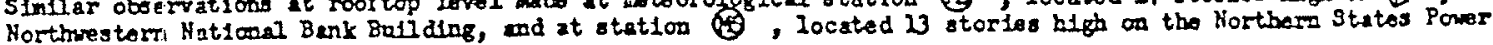
Company Butlang.

Wiresonde ascents (P1g, D-27, D-28, and D-2S) mado at motoorological station at at 210 South Ianth Streot.

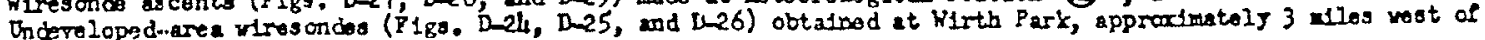
02 .

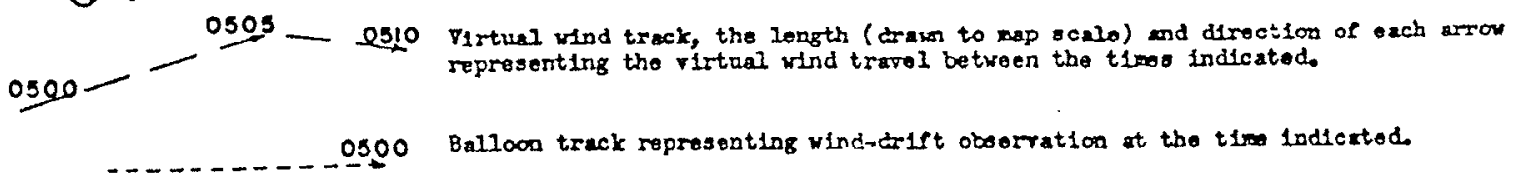

Hinds

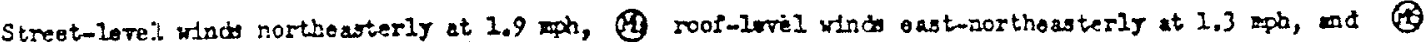
poof-lorel srinds northeasterly at $5.7 \mathrm{mph}$.

Stabilty

$2.3 * 5$ 2spen from $6-300 \mathrm{ft}$.

sy

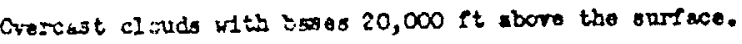

Tezergture

5.5० to $6.8^{\prime \prime} \mathrm{P}$ at, 2 wetors in tho test ares.

Yotiture

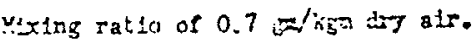




\section{LERTSOL CARERT TOM}

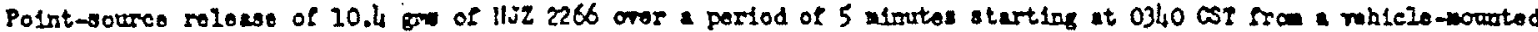
blower disperser located at polnt is.

\section{SMPPLDF}

\section{Location and axpoutro}

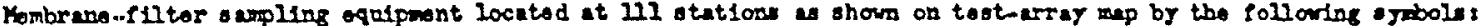

- artdoor suplor at belot botvoen 1 and 6 soet.

A I1meresolation amplar with station nuber.

Sapling stations included in bailding represented by nembered bollding outlines, 1dontiflod as followes The lodras Bulldine

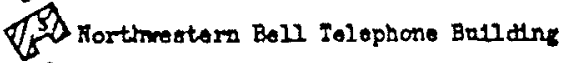
Dis Baker Eatling 14. Rorthwostorn National Bank Bullders

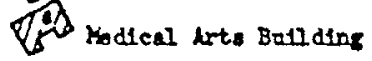

Rosulte

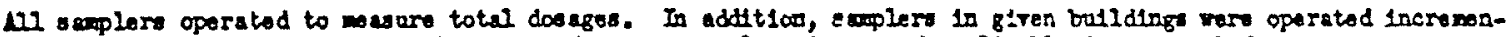

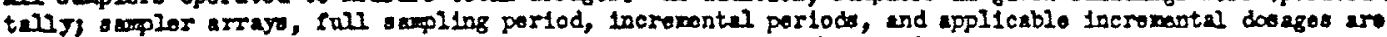
prosented in F1gure D-33. Tino-resolution date are given in Piguro D-32.

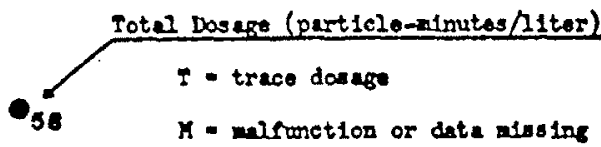

1012

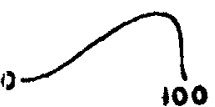

Doo age contour with relues oxpreased in particio-minutas per litor.

\section{ETEOROTOOT}

\section{Equipment und Kouswerent}

At atreat lovel, wad direction continoouly recordod, and alr and ourface temperatures, wind relocity, and

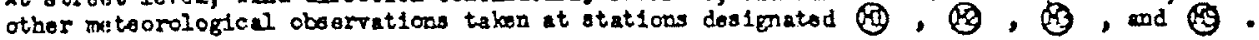

S1milar obeervations at roortop level med at meteoralogical station th, locsted 17 otorles bigh on of Northwestern National Bank Butleting, and at station , locatod 13 storias high on the Northem States Power Compeny Building.

Wiresond asconts (P1ga, D-27, D-28, and D-29) ande st meteorological atation , at 210 South Ienth Street.

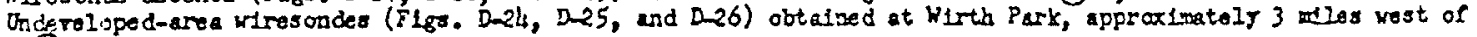

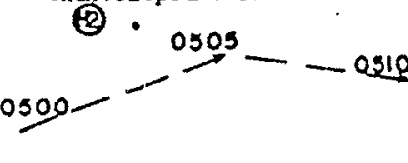

Tirtual wind track, the length (drarn to map scalo) and direction of each arrow representing the vircusal wind travel between the tises lidicatod. 0500 Balloon track representing vind-drift obserration at the tio indicatod.

Yinds

Stret-level winds ow terly at $2.4 \mathrm{mph}$, 9 rool-level whids eastorly at $5 \mathrm{mph}$, and $\theta$ root-level vinds eastnorthessterly at 8.2 wah.

\section{Stablity}

$3.4 \cdot I$ ispee srom 6-300 rt.

Skg

Overesst cloud with bases 20,000 it abere the surface.

Tarerature

$5.5^{\circ}$ to $6.4^{\circ} \mathrm{F}$ at 2 meters in the tegt area. 


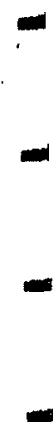

…

5

-

$-$

$-$

$\omega$

m

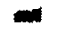

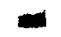

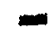

부

$\omega$ 
Plgure 110.

$\mathrm{B}-1$

z-2

B-3

B-4

B-5

$\dot{8}-6$

$\dot{\mathrm{B}}-7$

.

$\mathbf{B}-8$

B-9

$\dot{B}-10$

3.11

$\dot{\mathrm{B}} \infty 12$

is 13

E. 14

$\dot{\mathrm{E}}-15$

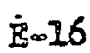

FIRTD TEST 0022

Tro-kstor lir Tomparature Sarteg, $14-60$, and Sumary of Regional and Iocal Weather

Temperature Soundinge, St. Cloud Raob, $\times-60$

Temperatare Soundinge, Dnderveloped-lree

Wirescods

Tine Resolution Data, IF CO22b

idjusted Dosage-drea Relationshlps, FI 0022

Test Irray and Rosults, FT 0022a

Test Irray and Rosults, II 0022b

FIIID TEST 0023

Tro-keter Atr Terperaturo Survey, 1063 , and Strary of Roglonal and. Iocal Weather

Temperature Soundings, St, Cloud Raov, 4-63

Tixe Resolution Data, FI 0023a, Samler BO, I

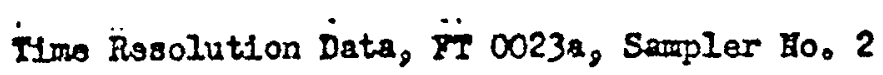

Ifre Resolution Data, $\ddot{\text { FT }}$ 00230, Ssmpler HO. I

Time Resolution Data, FT $0023 b_{2}$ Serapler HO. 2

idjustod Dosege-1rea ReIationships, FT 0023

Test lyrey and Besuitio, FT 0023a

rest Array and Results, ir $0023 b$
Table No. 301

Builcing Data Por Citgalde Tests, Fis 0022 and 0023

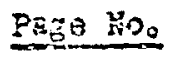




\section{SUMAARY OF REOIONAL AND LOCAI WEATHER \\ $24 \mathrm{March} 1953$ \\ (Survey $M-60$, Supplemental to FT 0022 )}

\section{SYNOPIIC SITUATION}

A secondary cold. front preceding a fresh outbroak of continental polar air passed Kinneapolis several hours before the test. A light snowfall zccompanied and followed this passage. A $1029 \mathrm{mb}$ high systen, centered over Saskatchewan, dominated the upper Midwest, and resulted in moderate north-northwesterly gradient winds over Minnesota. At the 700-mb lovel, a sharp ridge off the Atlantic coast, a deep trough from Hudson Bay south to Florida, and a narrow ridge from New Mexico to Saskatchewan, all slow-moving, gave a 50 mp northerly gradient wind over Minneapolis.

WEATHER REPORTS FROM WOLD-CHAMBERLAIN FIELD (MINNEAPOLIS)

\begin{tabular}{|c|c|c|c|c|c|c|c|c|}
\hline \multirow{2}{*}{$\begin{array}{l}\text { Time } \\
\text { (CST) }\end{array}$} & \multirow{2}{*}{$\begin{array}{l}\text { Cloud } \\
\text { Height } \\
\text { (feet) }\end{array}$} & \multirow[b]{2}{*}{$\begin{array}{l}\text { Sky } \\
\text { Cover* }\end{array}$} & \multirow[b]{2}{*}{$\begin{array}{c}\text { V1stbility } \\
\text { (miles) }\end{array}$} & \multirow[b]{2}{*}{ Heather } & \multirow[b]{2}{*}{$\begin{array}{l}\text { Tenp } \\
(E)\end{array}$} & \multirow{2}{*}{$\begin{array}{l}\text { Dew } \\
\text { Point } \\
(E)\end{array}$} & \multicolumn{2}{|c|}{ Wind } \\
\hline & & & & & & & $D \perp r$ & $\begin{array}{l}\text { Speed } \\
\text { (mph) }\end{array}$ \\
\hline 1830 & 3000 & Overcast & $15+$ & - & 34 & 27 & $\mathrm{NH}$ & 14 \\
\hline 1930 & $4000^{\circ}$ & Scattered & $15+$ & - & 32 & 27 & WTH & 20 \\
\hline 2030 & None & Clear & $15+$ & - & 31 & 25 & WNW & 17 \\
\hline 2130 & None & Clear & 15 & - & 30 & 24 & $N$ & 17 \\
\hline 223 & 1800 & Gvercast & 150 & 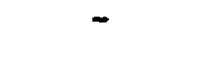 & 28 & 23 & NW & $\begin{array}{c}19 \\
\text { (gusty) }\end{array}$ \\
\hline 2330 & 1800 & Overcast & $15+$ & - & 27 & 21 & $\mathrm{NH}$ & 17 \\
\hline
\end{tabular}

* Average cloudiness sunrise to sunset: $100 \%$ * And/or restriction to visibility

Sea-level pressure at $2130 \mathrm{CST}: 1017.3 \mathrm{mb}$

Ground condition: Snow all gone; light flurries of snow during the evening; streets clear, but darm; lake frozen

Tree cover: None 


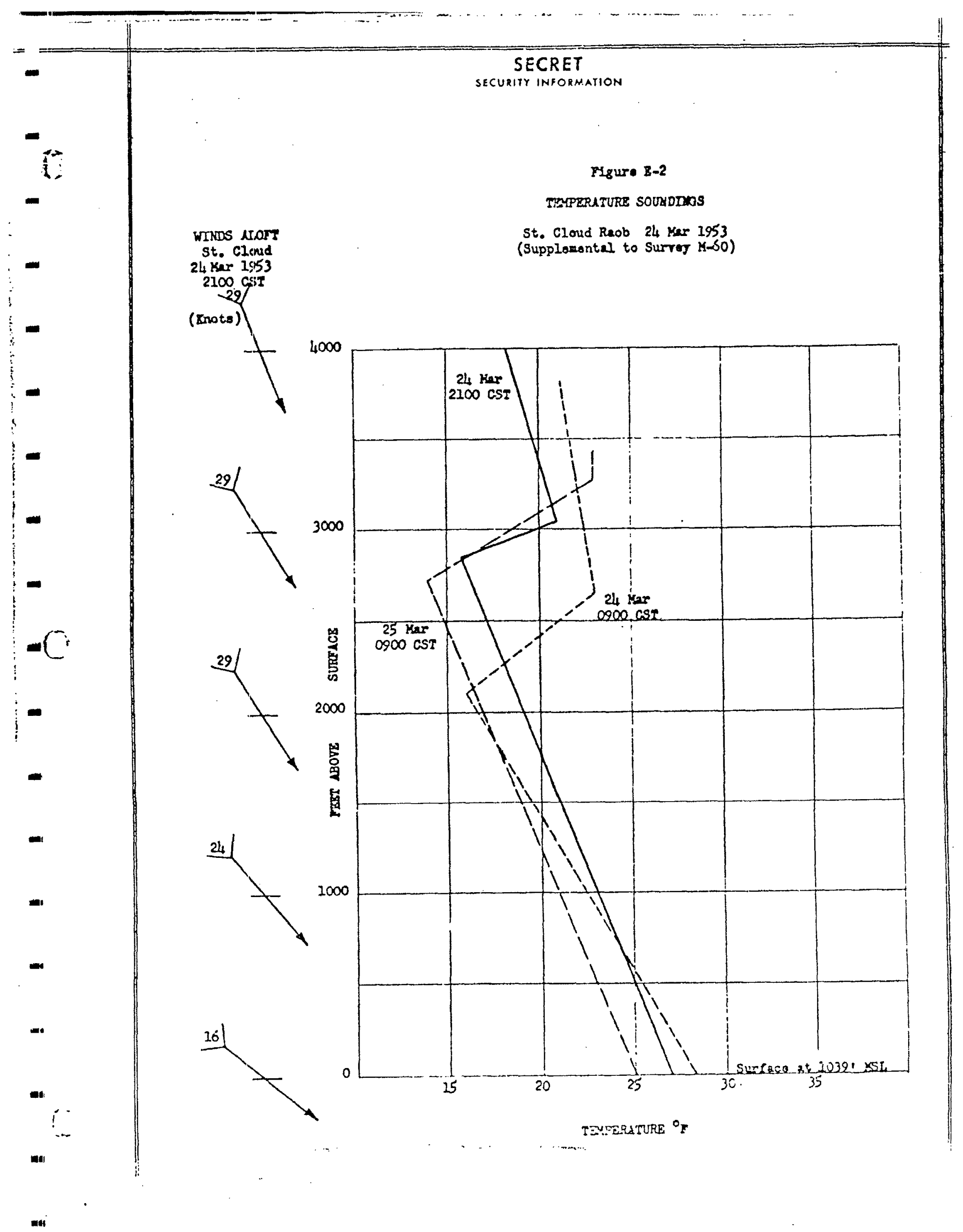




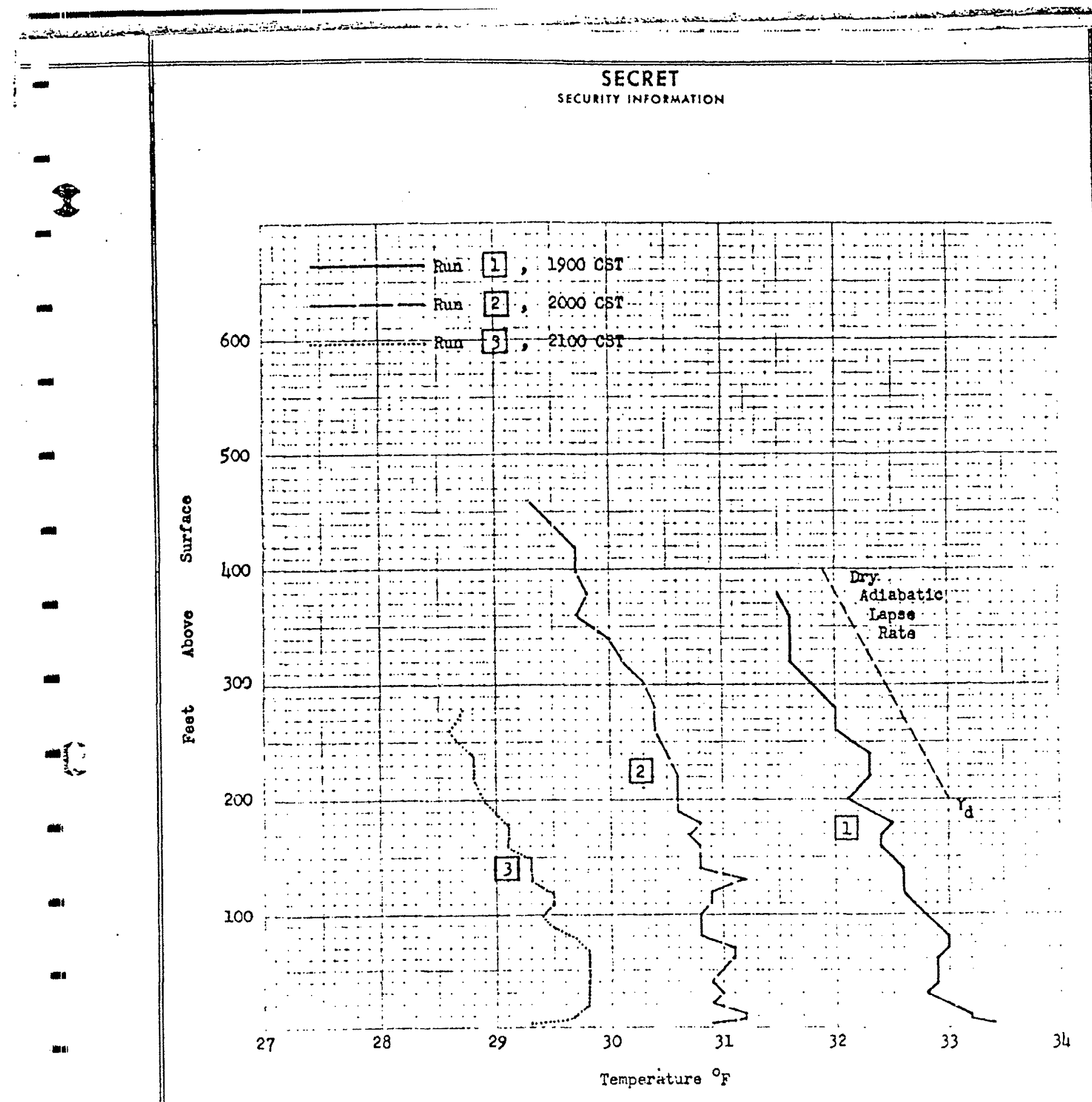

FICURE E-3

TEMFERATUKE SOUNDIES

Minneapolis

Undeveloped-Area Wiresonde

$\because x 0 \quad \therefore \ldots$ 21 Yar-1953 


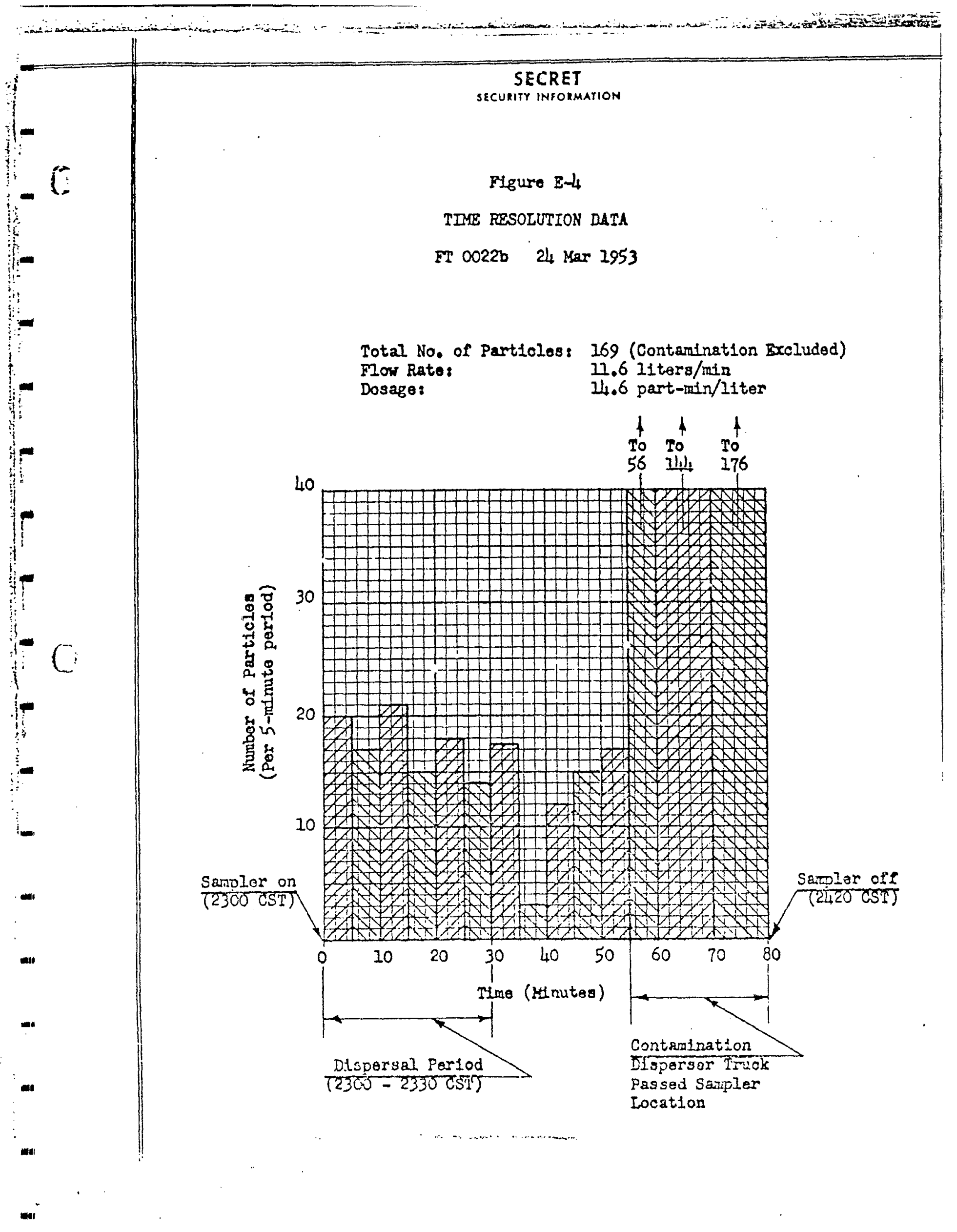




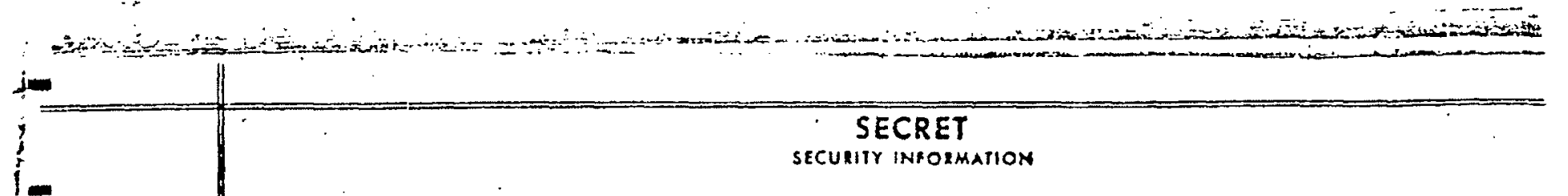

FIGURE E-S

ADJUSTED DOSAGE - NHEA REIATIONSHIPS

FT $0022 \quad 24$ Kar 1953

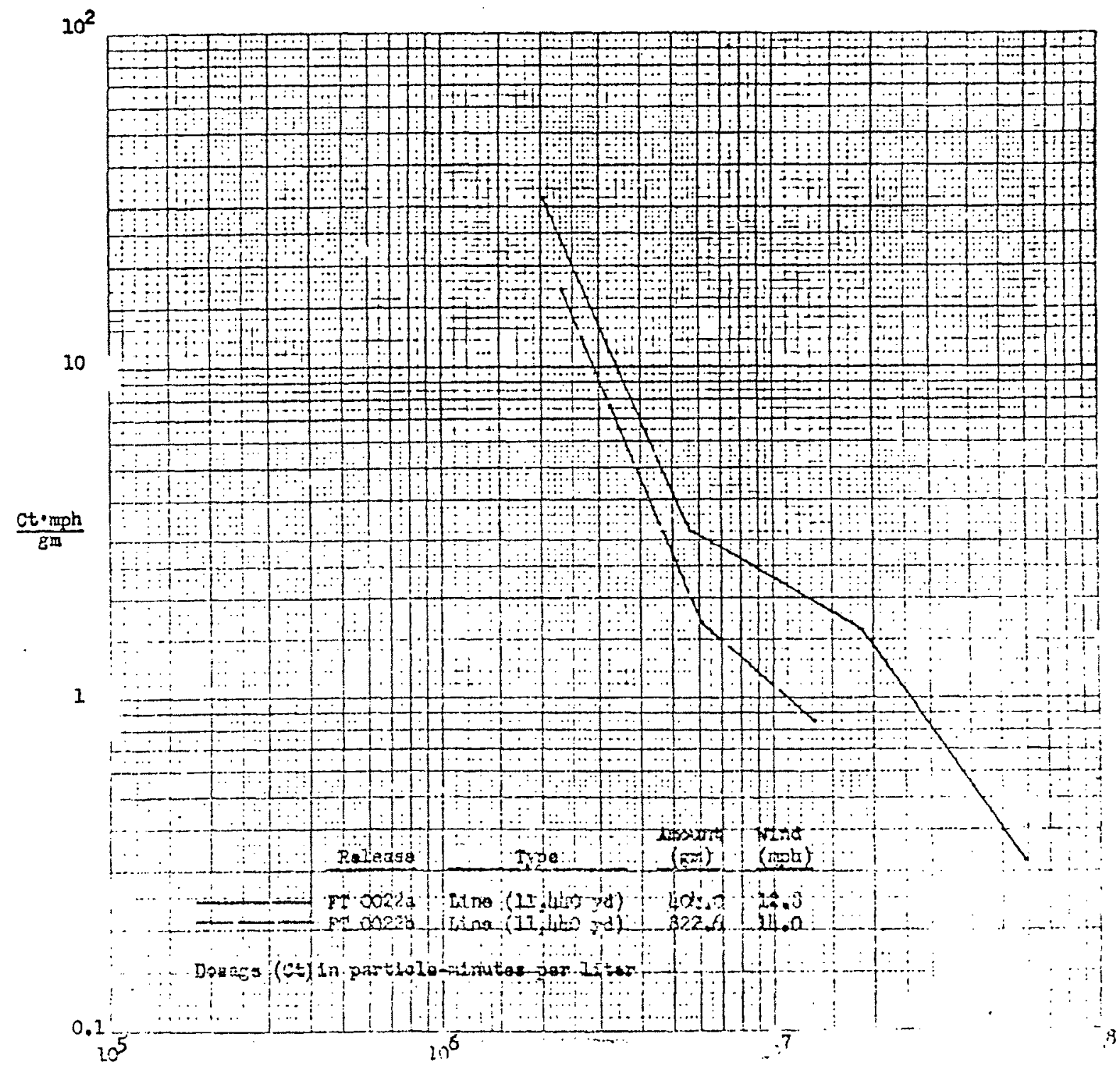




\section{LSROSOL CRERATIM}

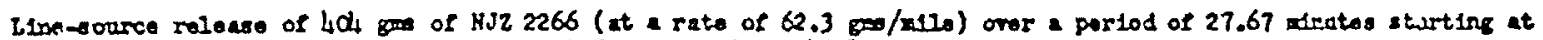
1958 sho CST $_{11}$ frou a blown disperser sounted on aring rehiele.

STLRT
(2958:40 (ST) $\quad$ (2026:20 CST)

\section{SARFL INO}

Locatlan and Exposure

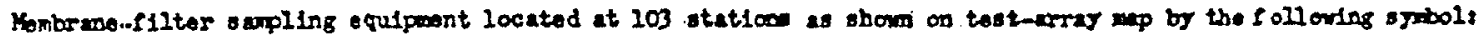

- Oatdoor sapplor at helght botwoen 1 and 6 foet.

Swopling stutions incluced on top of bedianga repsesentod es lollows

EN Fumbord butlding with axplar located an roof.

\section{Ragalts}

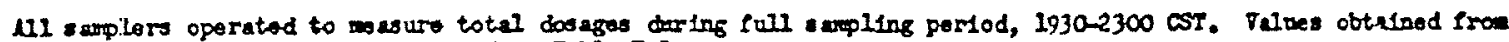

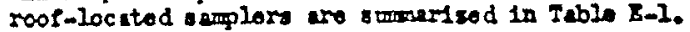

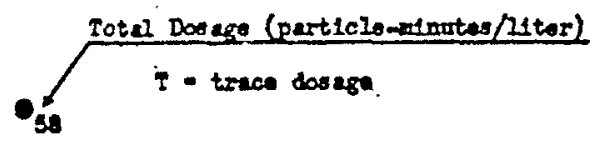

Equipont and Yosurement

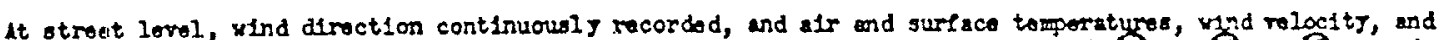

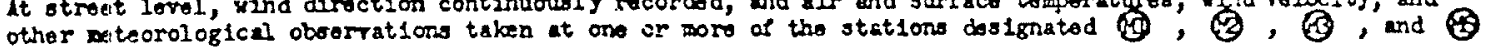

Sin1lar obserpabions at rooftop lovel made at metoorological stution (B), locatod atop the Borthuestora Nationa. Bank Eullding, and at $\overline{5}$, located atop The Rejph K. Parsons Comanj Budlding. Dadereloped-aroa uresonce (F1g, E-3) obtelned at weteorological atation

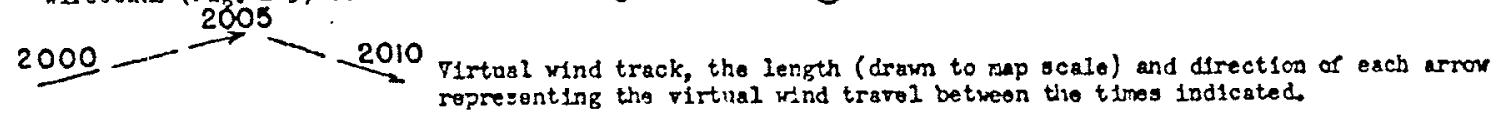

Yinds

3treet-lerel winds westerly at 13.? mph, and 3 roof.lerel vinds norchwesterly at 16.8 mb.

a.

a)
Stab111ty

$0.9^{\circ}$ Lacse from $6-300 \mathrm{ft}$.

$\underline{S K I}$

crest during teat perlod.

Itretetury!

$4^{\circ}$ to $46^{\circ} F$ at 2 meters in the test area.

Moistive

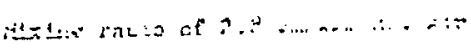




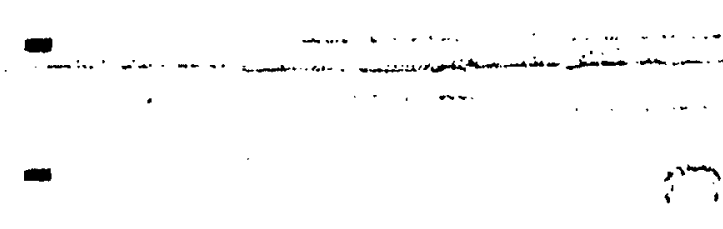

\section{PABLE E-I}

BUIIDING DATA FOR CITYWDE TESTS, FT IS 0022 AND,0023

(VaIuss Obtained from Roof-located Samplers) $(I)$

ㄴ.

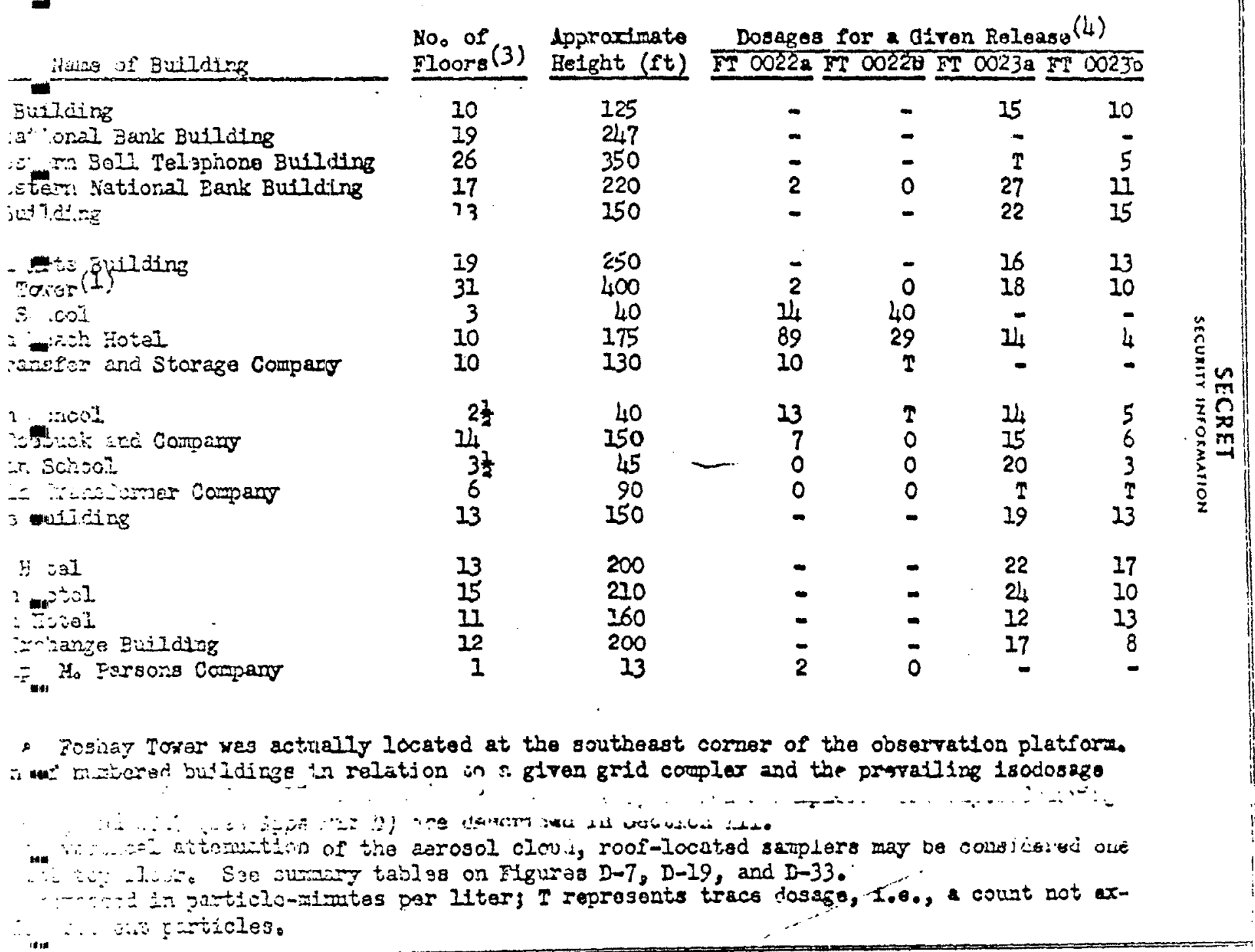

- Fogizar Toxar ves actrially located at the southeast cormer of the observation platform.

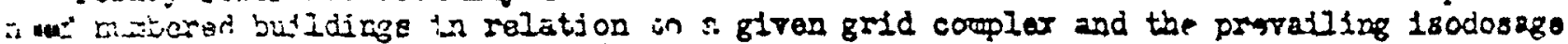




\section{ARROSOL GFNFRAT TRA}

Line-source relosse of $222.6 \mathrm{gns}$ of $N J Z 2266$ (at a sate of $126.3 \mathrm{gm} / \mathrm{mdlo}$ ) over a period of 30 xinutes oterting at $2300 \mathrm{CST}$, from a blower disporser mountod on morifg rehlele.

START $\underset{(2300 \mathrm{CS}:)}{\longrightarrow}(2330 \mathrm{ENT})$
and otopping times.

\section{SNMPLINO}

Locat1on and Bxoosure

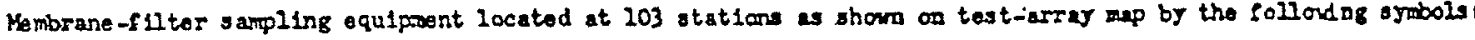

- Outdoor sampler at halght between $I$ and 6 root.

$\Delta$ Tine-resolution a arplor with station number.

Sampling stations included on top of buizdings represented as follows:

EN Muberod butlding with sampler located on rook.

Rosults

111 samplers operated to measure total dosages during full sampling period, 23\%0-Ce30 c5:. Falues obtalned frox root-located samplers ara sumprarizod in Table E-l. Time-regolution data are presented in Figure Ed.

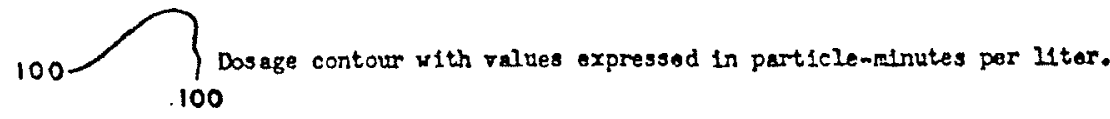

Equipment End Mosurement

lt stragt level, wind drection continuously recorded, and a1r and surface temperatures, wind relocity, and

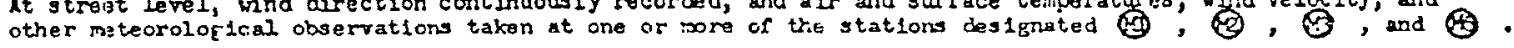

Similar obervations at rooftop level made at neteorological station , located atop the Northrestem Natlonal Bank Building, and at , located atop The Raloh $\%$. Parsons Company Butlding. Dndeveloped-area viresonte $\left(\mathrm{F}_{-3} . \mathrm{E}-3\right)$ Gotilined at meteorological siation

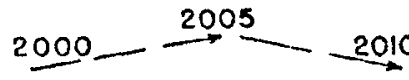
$\underline{2000}$

Hinds

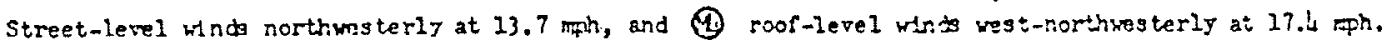
Stab1lity

4: At $2100 \mathrm{csT}, 1,1^{*} \mathrm{~F}$ lapse from $6-300 \mathrm{ft}$.

Skr

Corcagt clouts with bayez lgco ft atove the surface.

\section{Terreratur:}

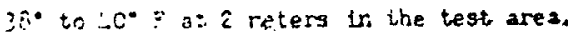

Virtual wiad track, the length (tram to map scale) and direction of each arrow representing the virtual wind tratel betwen the times indicited.

Balloon track representing wizd-drift obersation at the time indicated. 


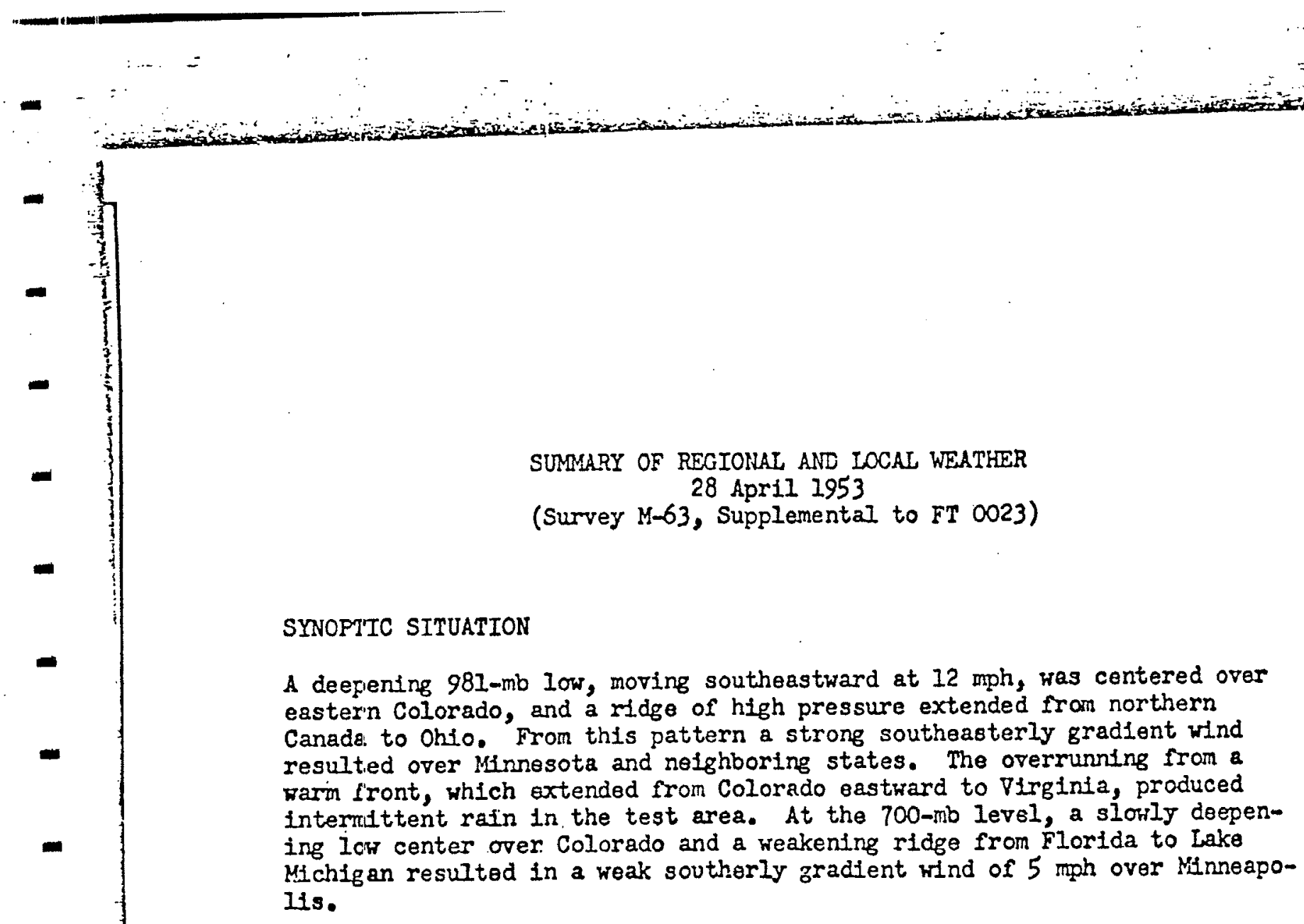

WEATHER REPORTS FROM WOID-CHAMBERTAIN FIETD (MINNEAPOLIS)

\begin{tabular}{|c|c|c|c|c|c|c|c|c|}
\hline \multirow[b]{2}{*}{$\begin{array}{l}T \lim \theta \\
(\operatorname{csT})\end{array}$} & \multirow{2}{*}{$\begin{array}{l}\text { Cloud } \\
\text { Helght } \\
\text { (feet) }\end{array}$} & \multirow[b]{2}{*}{$\begin{array}{l}\text { Skg } \\
\text { Covar* }\end{array}$} & \multirow[b]{2}{*}{$\begin{array}{c}\text { Visibiltty } \\
\text { (miles) }\end{array}$} & \multirow[b]{2}{*}{ Weather $* *$} & \multirow[b]{2}{*}{$\begin{array}{l}\text { Temp } \\
\left(O_{F}\right)\end{array}$} & \multirow{2}{*}{$\begin{array}{l}\text { Dew } \\
\text { Point } \\
\left({ }^{\circ} F\right)\end{array}$} & \multicolumn{2}{|c|}{ Wind } \\
\hline & & & & & & & $D 1 r$ & $\begin{array}{l}\text { Speed } \\
\text { (mph) }\end{array}$ \\
\hline $\begin{array}{l}1830 \\
1930 \\
2030 \\
2130 \\
2230 \\
2330\end{array}$ & $\begin{array}{l}8000 \\
7000 \\
8000 \\
7000 \\
6000 \\
5500\end{array}$ & $\begin{array}{l}\text { Overcast } \\
\text { Overcast } \\
\text { Overcast } \\
\text { Overcast } \\
\text { Overcast } \\
\text { Overcast }\end{array}$ & $\begin{array}{l}15+ \\
15+ \\
15+ \\
15+ \\
15+ \\
15+\end{array}$ & $\begin{array}{l}- \\
- \\
- \\
-\end{array}$ & $\begin{array}{l}48 \\
47 \\
47 \\
47 \\
46 \\
45\end{array}$ & $\begin{array}{l}35 \\
34 \\
32 \\
32 \\
31 \\
31\end{array}$ & $\begin{array}{c}\text { ESE } \\
\text { ESE } \\
E \\
E \\
\text { ESE } \\
\text { ESE }\end{array}$ & $\begin{array}{l}17 \\
17 \\
21 \\
21 \\
22 \\
20\end{array}$ \\
\hline
\end{tabular}

* Average cloudiness sunrise to sunset: $90 \%$

* Andor restrictions to visibility

Sea-level pressure at $2130 \mathrm{CSt}$ : i01z.2 mb

Ground condition: Grass shoring, not fully green; Wirth Lake $42^{\circ} \mathrm{F}$; Calhoun Lake $52^{\circ}$ I

Tree cover: None 


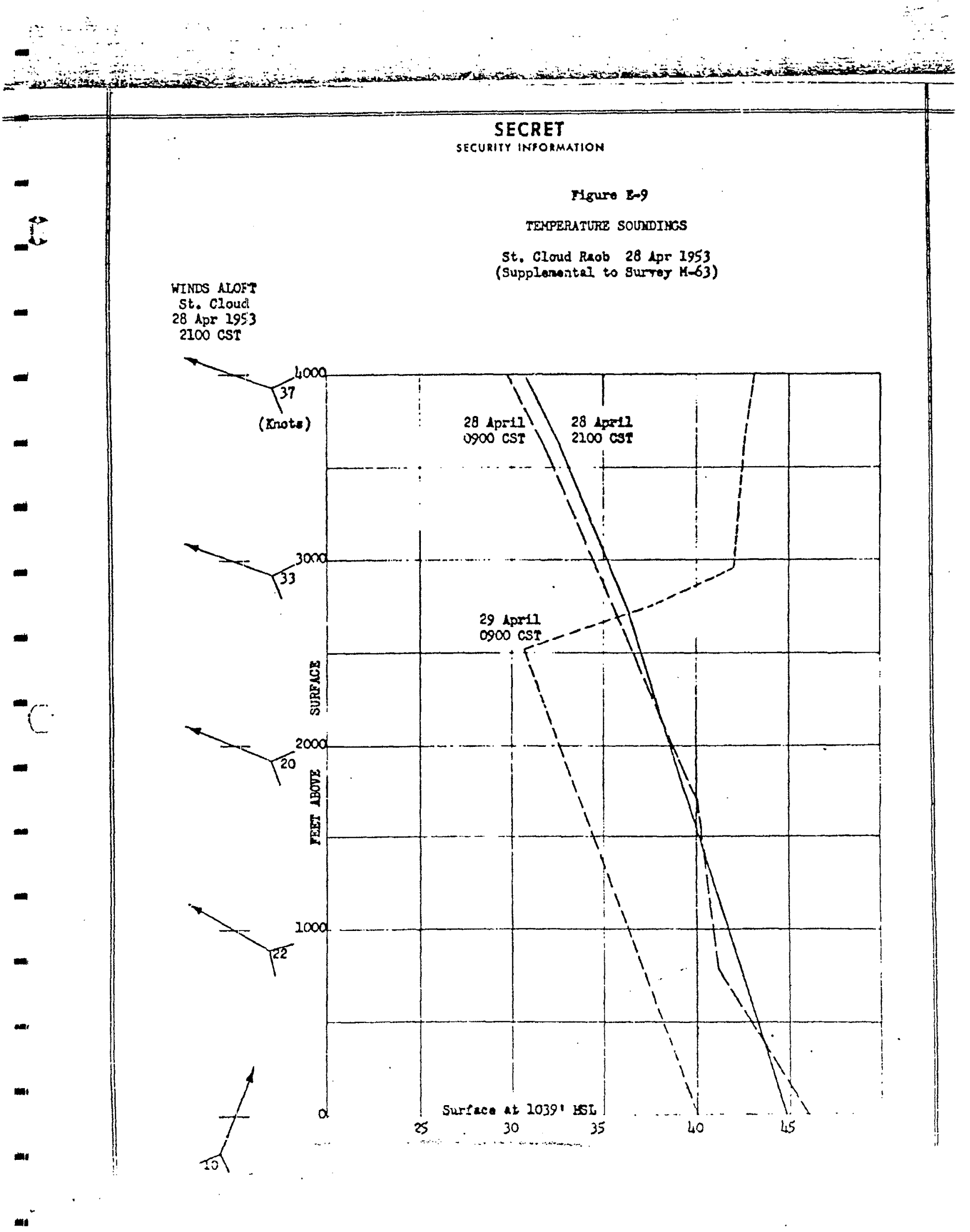




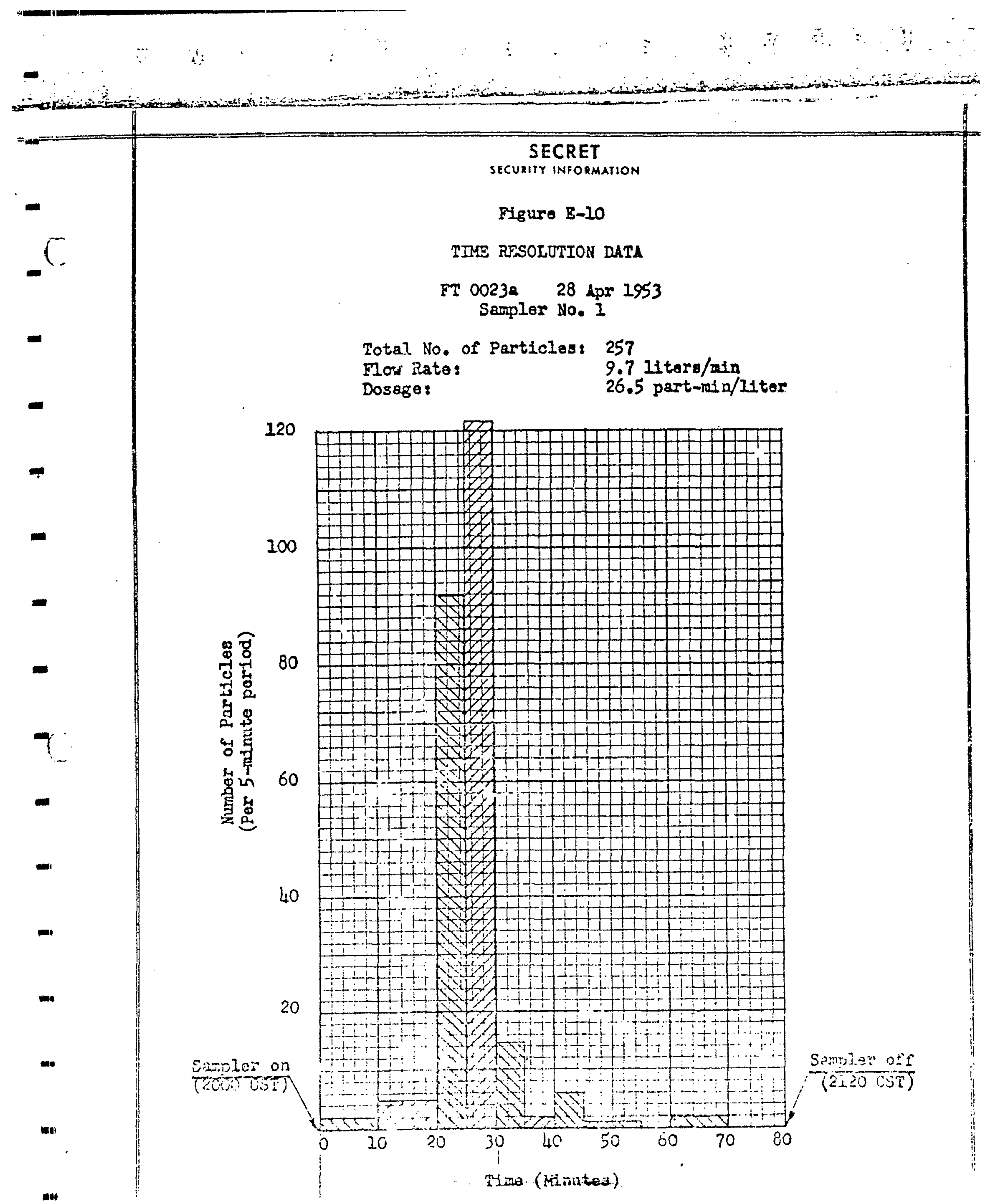




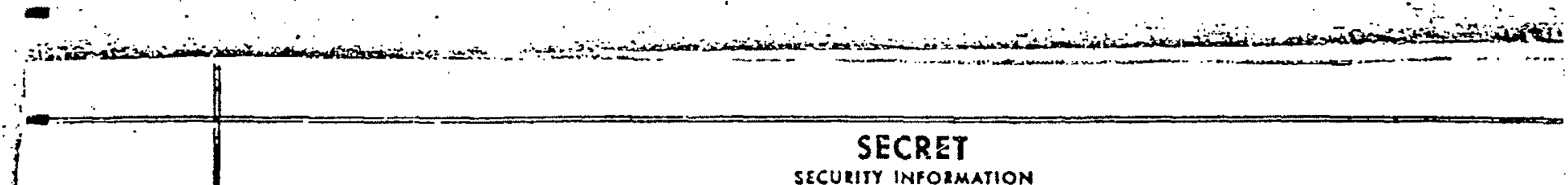

SECUEITY INFOLMATION

Figure E-11

TIRE RESOLUTION DATA

FT $0023 \mathrm{R} \quad 28$ Aps 1953

Sampler No. 2

Total No, of Particless 164

Flow Rate:

10.0 Ittars/min

Dosages

16,4 part-ring/1itar

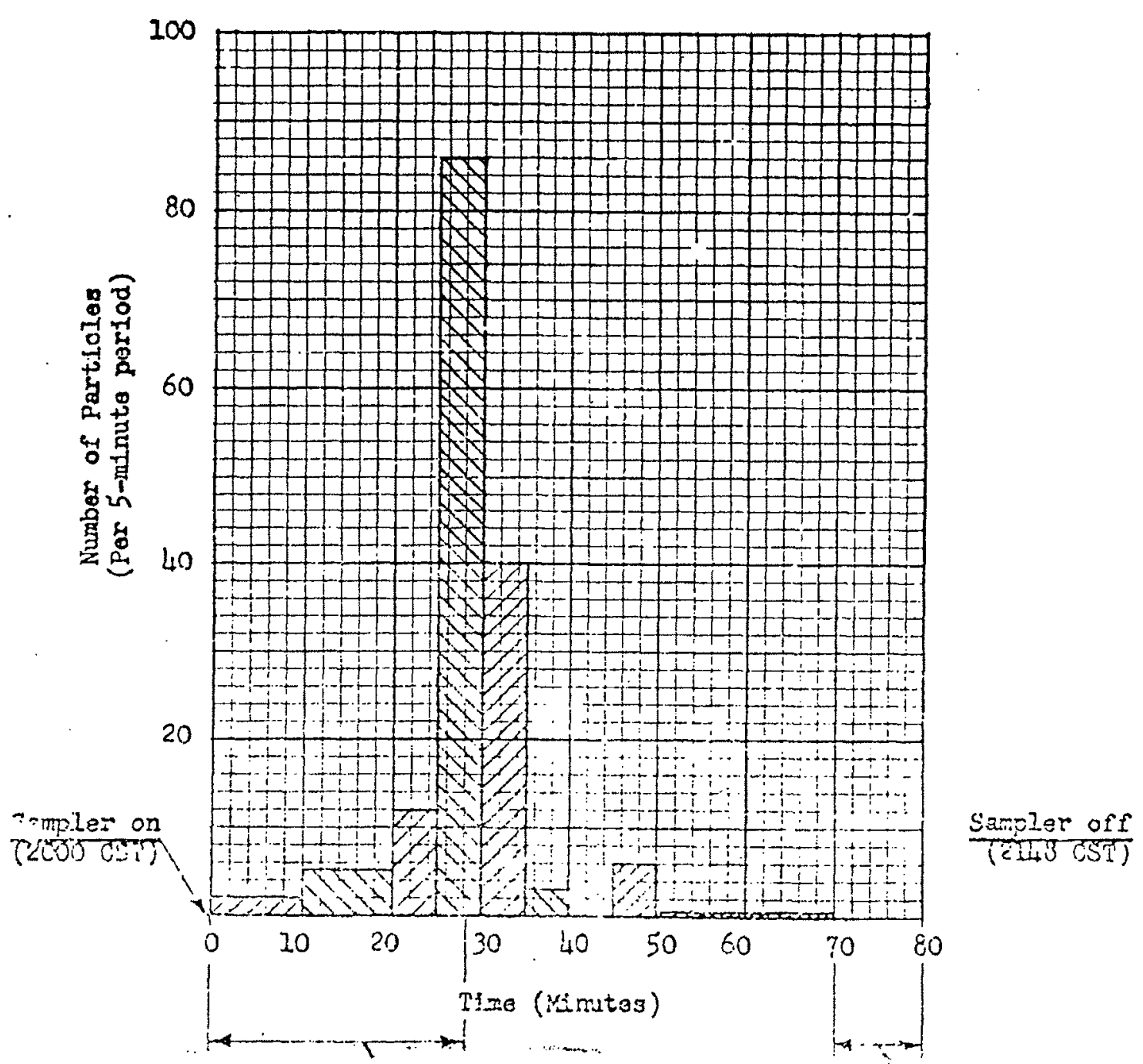




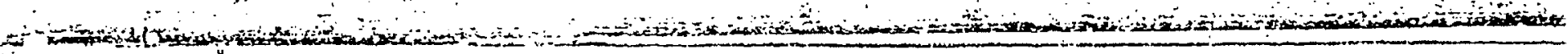

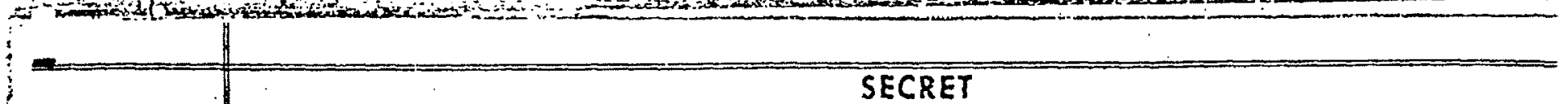

SECURITY INFORMATION

Figure $z-12$

TIMB RESOLUTION DATA

FT $0023 \mathrm{~b} \quad 28$ Apr 1953

Sampler No. 1
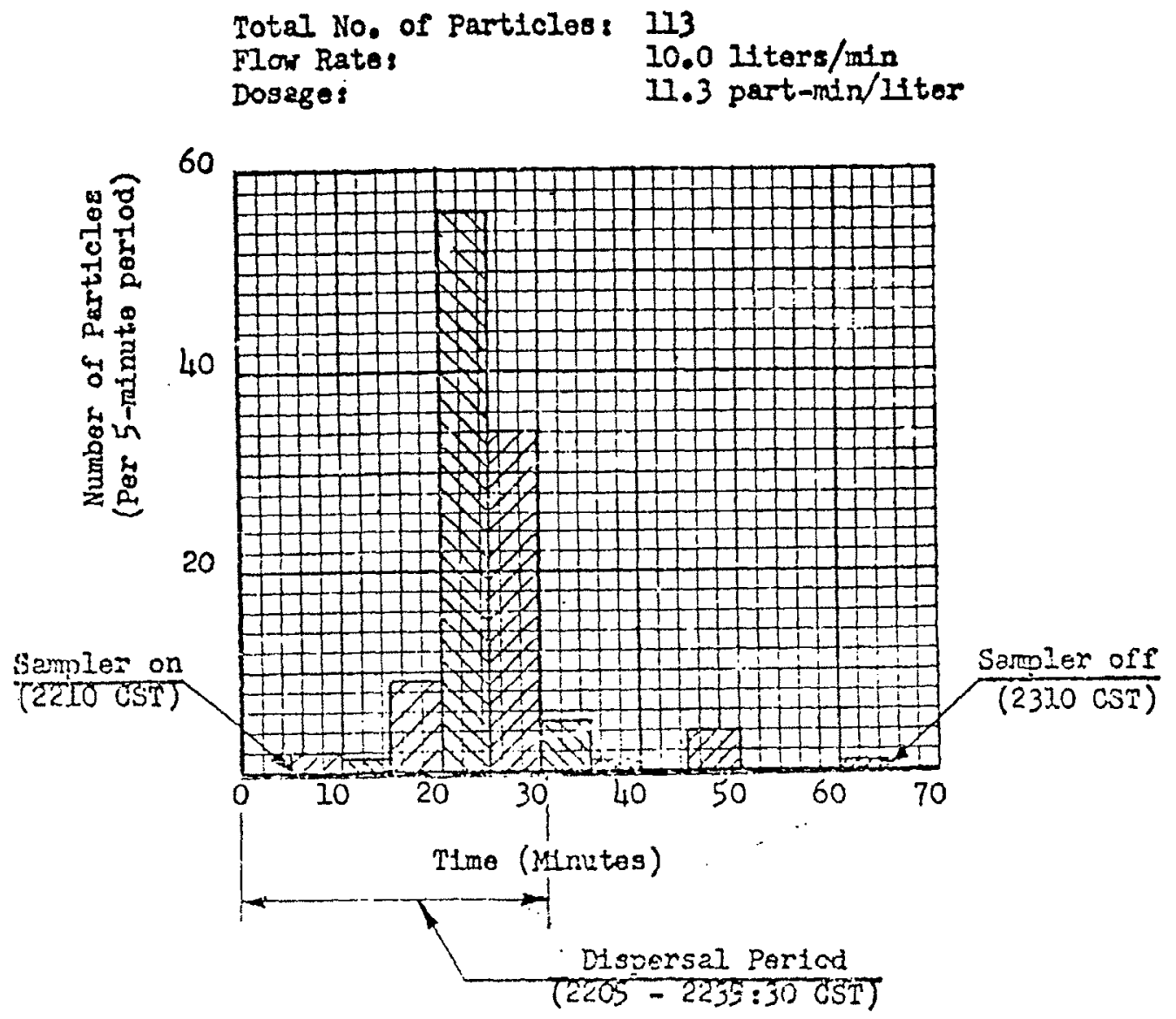

눈 


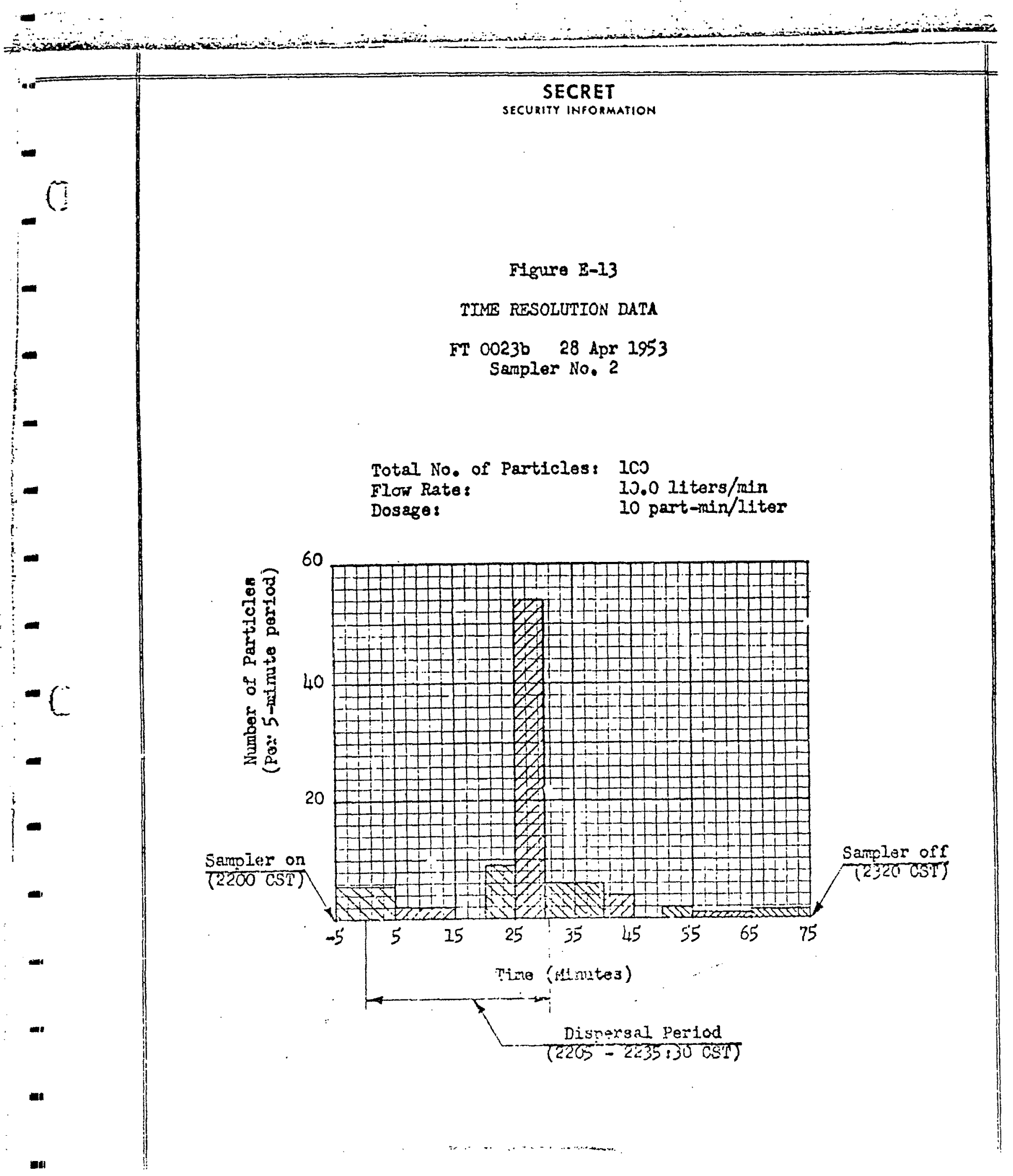




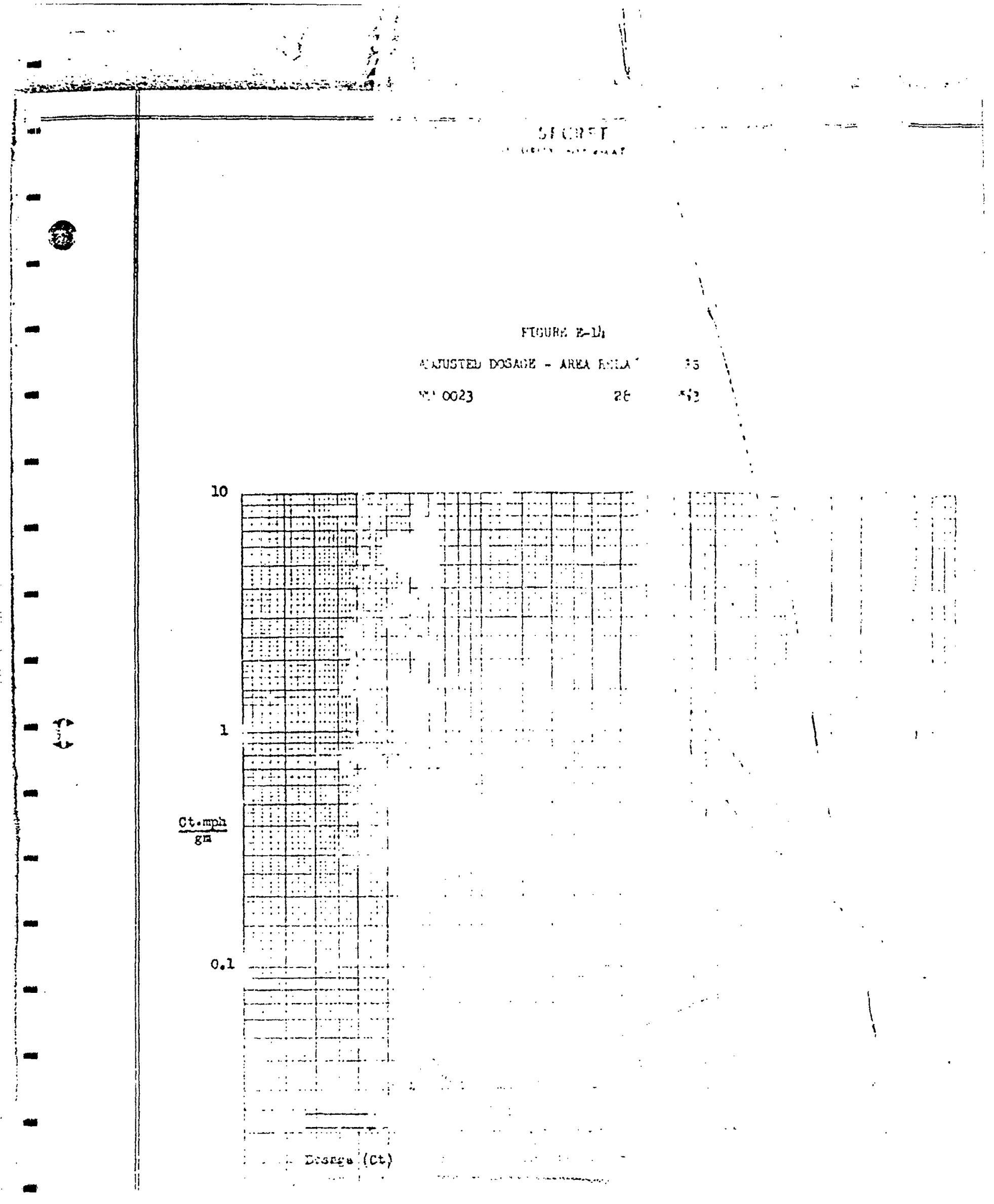




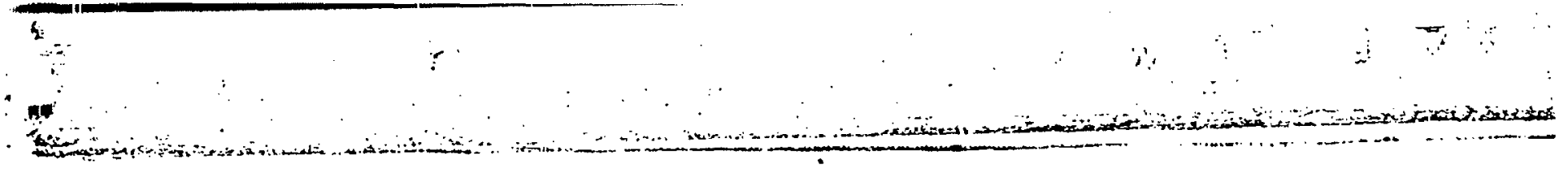

FEST ARUT AND RESILTS

I18ure $8-25$

rI $003 \mathbf{a}$

26 Lpr 1953

$2000 \mathrm{CST}$

NEROSOL GENEWUTIOH

Iine-source release of 693.3 of $N J 2266$ (at a rate of 99.0 gro/ndlo) over a period of 28.17 minutes startine at $2000 \mathrm{CST}$, tron a blower disperser monted on a moving rohicle.

(2OO) CST $\quad(208: 10$ CST $)$

7-miln track of rehicle-wounted blowar dispersor at the indicated starting and atopping tiwa.

\section{SNMLITO}

Lacation and Exposure

Habirane-pilter sampling equipment located at 99 stations as shom on tost-array mep by tbe following aymbols:

- Outbor sampler at halght between 1 and 6 loet.

A Time-resolution sarpler with otation number.

Sampling stations included on top of buildings represented as follows

NI Numberad bullding with saupler located on root.

Results

111 sarplars operated to asure total dasagea daring foll samping period, 2000-2200 CST. Faluos obtained from roof-located samplers sumarized in Tahlo E-1. Timo-resolution data are presented in F1gures B-10 and $E-11$.

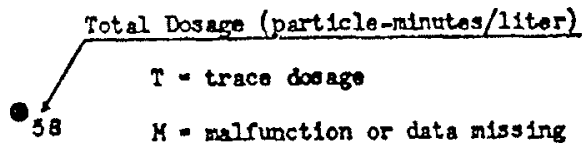

\section{METEOROLOGT}

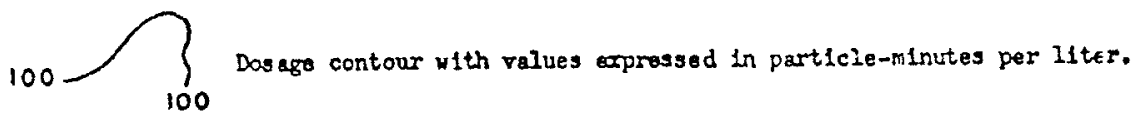

Equipment and Yasurement

At $s$ treet lavel, wind disection continuows is recorded, and air and suriaco temperatiuses, wed relgeity, and

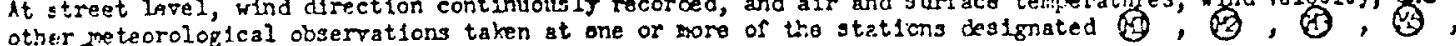
and 87

Sindlar cuseryations at rooftop lovel made at meteorological station (9), located atop the Northwestern

Nat..,nal Bant Rullding, and at $\Theta$, located atop tho Northem Statos Power Company Builing.

Wrisonde equifment locsted at rateorologleal station $\Theta$.

$$
2000 \longrightarrow-2005 \text { virual vind track, the length (dram to rap scale) and diruction of each arow }
$$

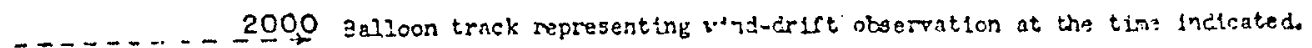

$\underline{H E} \dot{\underline{H}}$

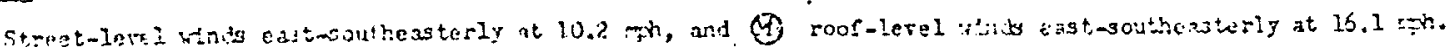

\section{Etability}

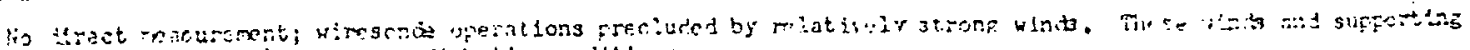

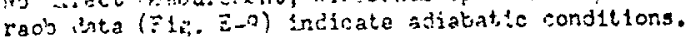




\section{LEF:SOL GENERAT TOR}

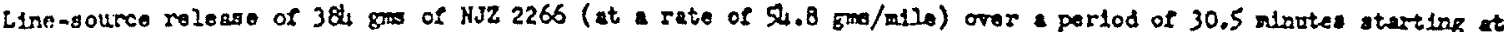
$2205 \mathrm{CST}$, from a blower dispersur mounted on a morling vehicle.
ST.IRT
$(2205$ CST $)$
$(2235 \cdot 30$
7-ndle track of rehicle-mounted blower disperser at the indteated starting
$(2205$ CST $) \quad(2235: 30 \mathrm{CST})$
and a topping times.

\section{SAvTh DiO}

\section{Location and Exposiure}

Kembrane-fliter sampling oquipment locoted at 99 stations as shom on test-array by the following spatolos

- Outdoor satpler at bolght between 1 and 6 seat.

A rise-resolution sampler with station number.

ispling stations inclided on top of bulldings ropresented es follows:

ET Numbered butllting with somplor located on roor.

Pesnlts

111 samplers operated to pesure total doseges during full sampling poriod,2200-2330 CST. Talnes obtained fram roof-located amplers aro sumerized in Table E-1. Tin-resolurion ista aro presented ir F18ures E-12 and E-13.

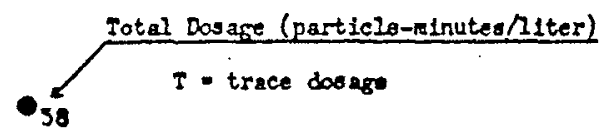

\section{VETEGROSOOT}

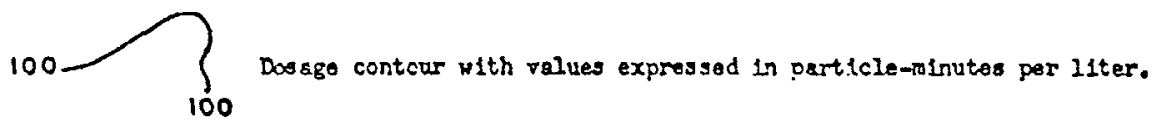

Equiprert and Measurement

At sireet level, wind direction contimously rocorded, and alr and surface temporatures, whd rolgeity, gidd othe: meteorolofical observations taken at one or more of the otations designatad , and 8 .

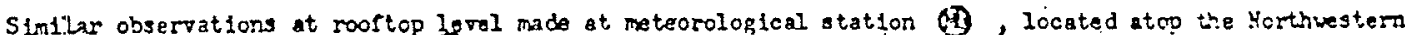
National Bank Buflding, and at 3 , locatad atop the Northam States Power Company Building.

Vilre:son to equiprent $1 \propto \infty$ ated at ateorological station 60 .

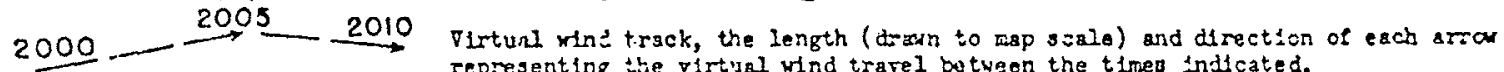
representing the virtigl wind trarel botween the timeo tndicated.

2000 Selloon track representing wind-drift observation st the tine indicated.

tinde

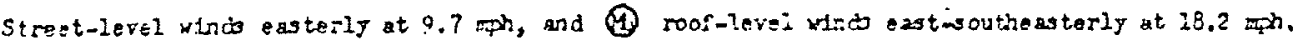

\section{Etelylty}

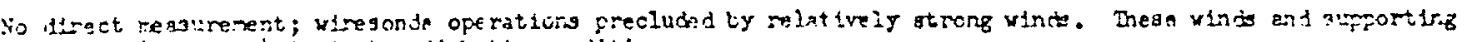

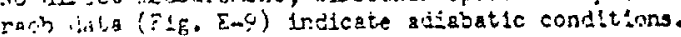

Exy

Orercast clouts inth basts $6000 \mathrm{ft}$ sbove the surface.

$=0$ tiure 